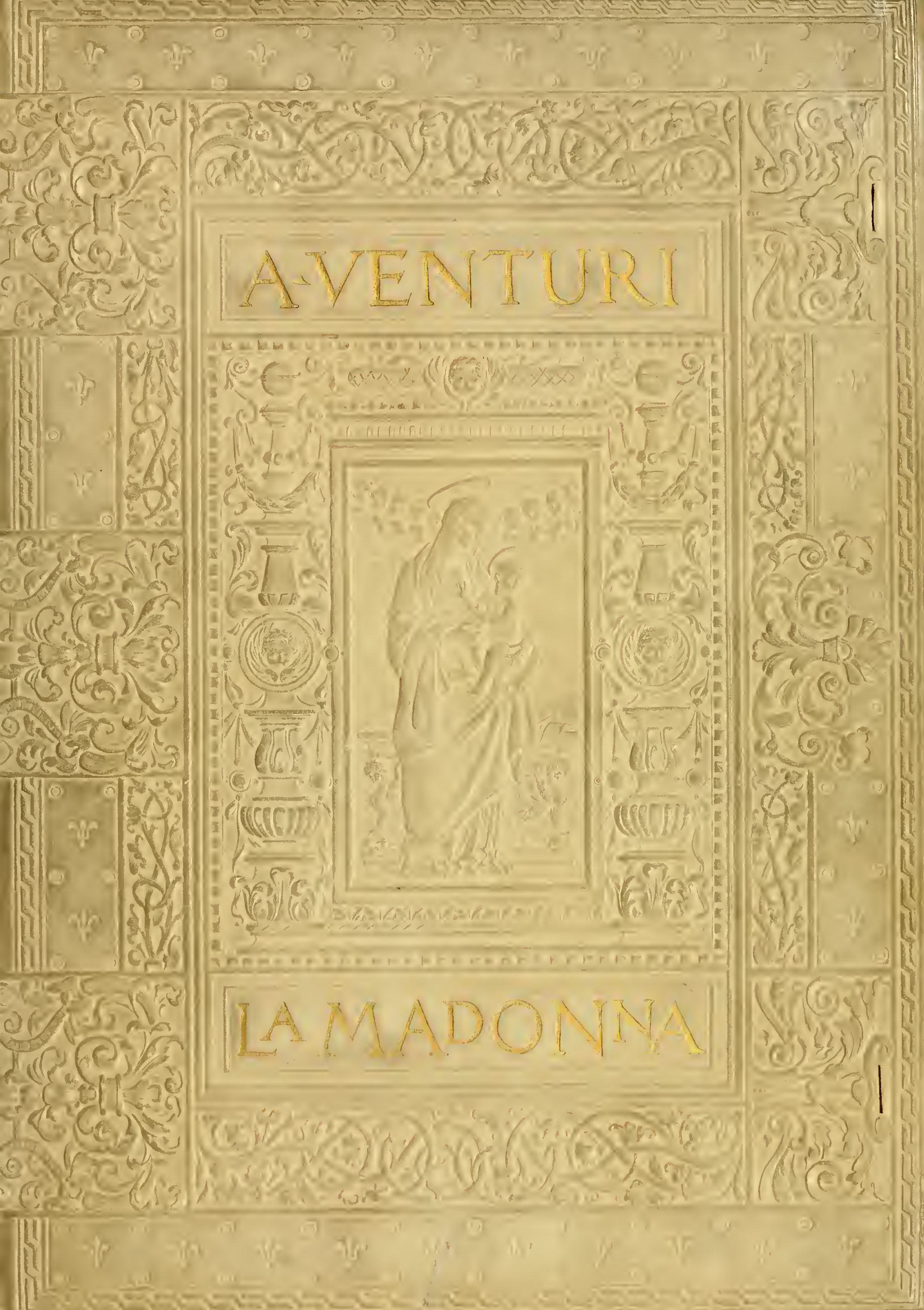








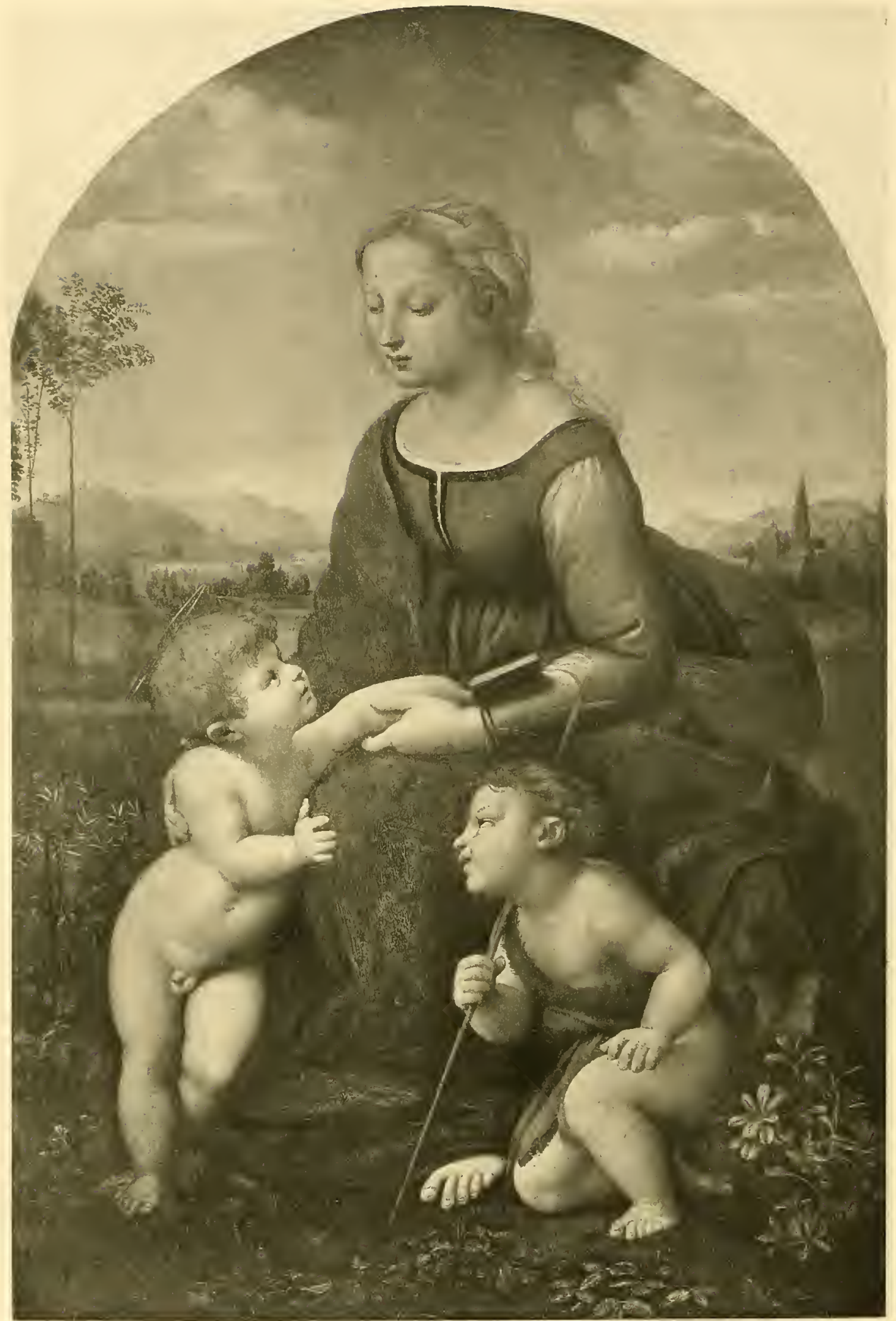

museo nazionale del Louvre

RAFFAELLO 


\section{ADOLFO VENTURI}
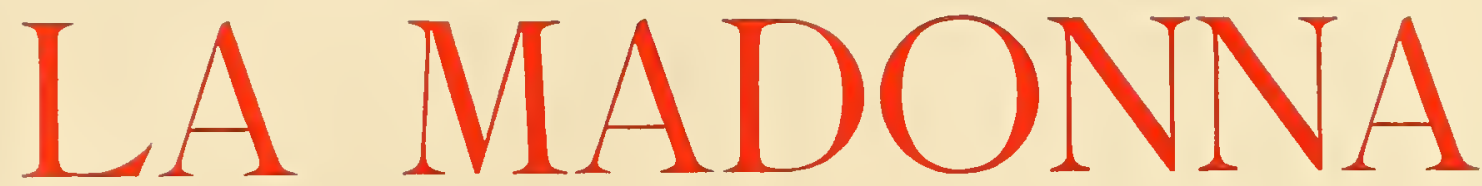

SVOLGIMENTO ARTISTICO

DELLE RAPPRESENTAZIONI DELLA VERGINE

CON 5 STAMPE IN FOTOCALCOGRAFIA E 5 I6 IN FOTOTIPOGRAFIA

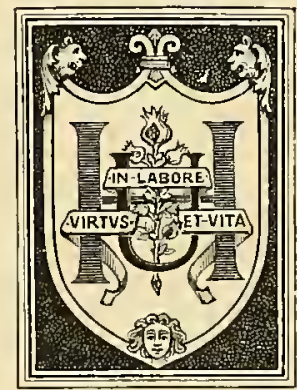

ULRICO HOEPLI

EDITORE LIBRAIO DELLA REAL CASA

MII.ANO

1900 
TUTTI I DIRITTI RISERVATI

Tipografia dell'Unione Cooperativa Editrice Roma, via di Porta Salaria, 23-A. 


\section{INDICE}

Prefaztone . . . . . . . . . . . . . . . . . . . . . . . . . Pag. y

L'Inmagine sacra. . . . . . . . . . . . . . . . . . . . . . . . . . I I

La Natività di Maria . . . . . . . . . . . . . . . . . . . . . . . . . $S_{I}$

La Presentazione di Maria al tempio . . . . . . . . . . . . . . . . . . . I05

Lo Sposalizio. . . . . . . . . . . . . . . . . . . . . . . . . . . . I I I

L'Annunciazione . . . . . . . . . . . . . . . . . . . . . . . . . . I39

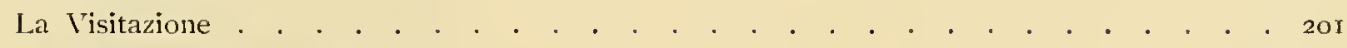

Le angosce di Giuseppe. . . . . . . . . . . . . . . . . . . . . . . . 215

Il Presepe. . . . . . . . . . . . . . . . . . . . . . . . . . . . . 219

L'Adorazione de' Magi . . . . . . . . . . . . . . . . . . . . . . . . 263

Isa Purificazione. . . . . . . . . . . . . . . . . . . . . . . . . . . . ${ }_{2} 8_{7}$

La fuga in Egitto. . . . . . . . . . . . . . . . . . . . . . . . 303

Disputa di Gesì nel tempio . . . . . . . . . . . . . . . . . . . . . . 3I7

La Passione del Cristo . . . . . . . . . . . . . . . . . . . . . . . . 32 I

La Crocifissione. . . . . . . . . . . . . . . . . . . . . . . . 325

La Deposizione dalla Croce e la «Pietì» . . . . . . . . . . . . . . . . . 359

L'Ascensione. . . . . . . . . . . . . . . . . . . . . . . . . . . . $33_{3}$

La Pentecoste . . . . . . . . . . . . . . . . . . . . . 393

L'Assunzione. . . . . . . . . . . . . . . . . . . . . . . . . . 40 I 



\section{PREFAZIONE}

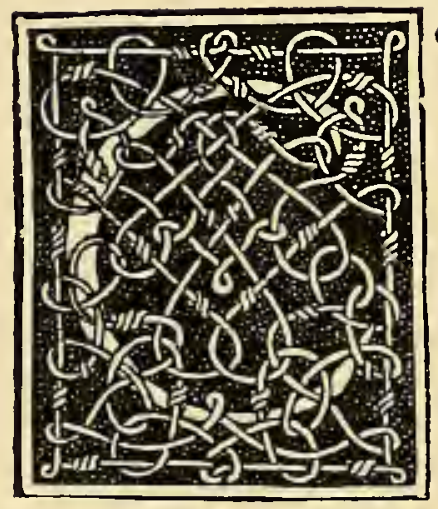

ous la pianta che s'insinua nel terreno da cui trae la vita, ogni tipo, ogni forma d'arte ha le sue radici profonde. Con l'andar del tempo, l'albero cresce, stende più rigoglioso i rami, che si vestono di frori, di foglie e portan frutta, le quali, giunta l'età più vigorosa, e non ostando la inclemenza delle stagioni, si fanno più abbondanti e belle, finché, venuto meno d'anno in anno il giovanile rigoglio, sfrondati, isteriliti, i rami si allungano al sole. Così avviene dell' arte, che, germogliata ove la natura della razza umana é terreno fecondo, prospera a gradi, e, compiuto il suo ciclo luminoso, a gradi declina.

Lo studioso, che segue passo per passo lo svolgersi di una forma d'arte, si forma della facolta umana dellinvenzione un concetto molto differente da quello che una meno organica nozionc aveva potuto dargli. Vi sono momenti in cui l'artista, rispondendo come a una parola d'ordine, stampa soltanto vecchie forme e le riproduce, quasi fossero consacrate, senza permettersi di mutar 
l'insieme d’una figura o d'una composizione, e neanche i piu minuti particolari e i movimenti più lievi. A poco a poco il talento, e pure la incapacità o la negligenza di chi rifá vecchie imagini, producono varianti artistiche, che si fanno ognora piu numerose e complesse, finché viene il momento in cui la rappresentazione d'arte si determina nelle sue linee generali, e resta solenne esempio all'avvenire. L'industre lavoro delle generazioni si è raccolto tra quei segni, che divengono i termini della tradizione. Sopravverrà l'artista d'individualitá potente, ma lavorerà sulla trama data dal tempo; e, alla fine, il genio stesso rispetterà quei limiti fatali. Quando essi andranno in pezzi, l’arte pure cadrá, e si rimetterà brancolante in cerca di vie nuove, chiedendo nuova vita al terreno, all'aria, al sole.

Non si rompono le anella delle tradizioni e non si disperde il cumulo delle esperienze secolari, se non quando l'arte ha compiuto un suo ciclo. Fenomeni esteriori possono prima sospenderne il moto progressivo; ma essa riesce a riannodarsi, dopo soste più o meno brevi, all'antico. Nell'etá carolingia, i musaicisti di Pasquale I ripetono le composizioni del $v$ e del vi secolo; nell'età romanica, l'arte, con un nuovo sforzo, indaga nelle vestigia dei bassi tempi i codici dell'arte cristiana, per eternarli nelle basiliche e nelle cattedrali; e Nicola Pisano e i suoi seguaci traggono pro, per i loro pulpiti trionfali, finanche dei dittici d'avorio, ultimi segni dell'arte antica ridotta a meglio usare la raspa che lo scalpello. Nulla si perde dell'opera delle generazioni per raggiungere le proprie idealità: il tempo la raccoglie, e la porge ai posteri come sacro tesoro. Intorno a questo sorge poi l'altare, su questo girano le volte dei templi; 
e al deposito antico si fissano sempre gli sguardi e le menti degli uomini.

Arrivata al sommo della sua orbita, l'arte sembra abbandonare alcune vecchie forme, e invece le riduce, le affina e le rinnova spogliandole dell'involucro convenzionale: Raffaello non ripete l'aureola elissoidale intorno alla Madonna di San Sisto, ma la luce s'involge come limitata ancora dall'antico segno, e le figure si dispongono intorno seguendo la traccia svanita. Altre volte si rivedono le reminiscenze dell' antico nel nuovo, rimaste come per forza d'inerzia; e così Benozzo Gozzoli e altri pittori del Rinascimento fecero girare senz'ordine schiere di cherubini azzurri e rossi intorno alla Divinità, inconsapevoli della legge artistica bizantina, per cui il rosso indicava la fiamma divina, l'ardore e il giorno, e l'azzurro invece il crepuscolo e le tenebre. Tutto resta nel fondo, nell' anima dell' arte, che il destino elegge e porta al trionfo; tutto restó nell'arte cristiana, anche i primi abbozzi tracciati alla luce delle lampade nelle Catacombe, le istorie bibliche e evangeliche degli scultori de' sarcofagi, i dittici sacri, i musaici delle basiliche della religione trionfante a' tempi costantiniani, i purpurei codici della Genesi.

L'unità dei popoli nel Cristianesimo associó le ricerche e il lavoro di tutte le regioni del mondo civile per l'arte nuova, che i Bizantini religiosamente trasportarono nel medioevo. E l'arte italiana, la piu bella delle arti romaniche, compì l'opera del mondo cristiano, e innalzó la vetta, su cui aliarono i genî di Leonardo, di Raffaello, di Michelangelo, del Giorgione e del Correggio.

Il lavoro che presento ai lettori è l'applicazione di questi principî dell'evoluzione artistica, alquanto più ampli di quelli 
seguiti sin qui dagl' iconografi. Non è soltanto il disegno delle imagini quel che mi son proposto, ma la ricerca del loro grado di bellezza, e quindi il confronto con tutte le imagini che passarono e si susseguirono, l'una dall'altra derivata, sull'aurea scala dell'arte nostra, salendo, dileguandosi prima e fulgendo poi, dalle catacombe di Priscilla alle cupole delle cattedrali del Rinascimento.

Se la ricerca iconografica non segue tutto il procedimento evolutivo dell' arte dall'alfa all' omega, rimane sterile; come il giudizio del valore d'un'opera artistica, senza la cognizione di ció che ognuno ha preso a prestito de'beni altrui e ciò che ha largito del suo, rimane soggettivo e incerto. La misura dell' individualità non si puó ottenere che per via di lunghi confronti tra il prima e il poi; onde dall' iconografia dobbiamo attenderci quello che il diapason è per le note musicali. E quando sarà possibile di ricostruire idealmente tutta l'opera dell'arte, vederla dall'alto nei secoli, si comprenderá, meglio che con le astrazioni metafisiche, l'epopea cristiana. E se sarà possibile di ricostruire l'opera dispersa delle regioni italiane, si vedrà quale contributo esse fornirono al progresso dell'arte, e come concorsero al suo trionfo; e si distingueranno le varietá, le specie degli elementi iconografici che elaborarono rispecchiandovi la natura de' luoghi, i caratteri etnici, le reminiscenze atavistiche, i sentimenti diversi, le istorie e le leggende particolarmente ricordate o raccolte $\mathrm{c}$ variamente sviluppatesi.

Gl'iconografi hanno sdegnato sempre le forme piu belle, che per ultimo chiudono il ciclo dell'arte, perché, per via d'una lenta selezione, esse più si allontanarono dalle consacrate; e ragiona- 
rono come monaci bizantini, pe' quali non si poteva dipingere un capello torto alle loro stereotipate figure. Ma l'arte ha una vita propria, e non ripete solo imagini, anzi vi riflette l'anima del popolo da cui scaturisce. Quando si adornó nel Rinascimento di vesti regali, e guardó con occhi limpidi al vero dal suo trono fiorito, l'arte rispecchió la civiltá italiana. Certe apparenti dimenticanze dell'antico furono colpi d'ala verso la bellezza, certe supposte negligenze di leggi iconografiche furono poesia nuova; ché l'arte nostra penetró nel venerando cumulo delle tradizioni ne trasse gli elementi più belli, le gemme più preziose e ne formó la corona del genio.

Chi pure guarda all'evoluzione dell'arte italiana come a una serie di tentativi per avvicinarsi alla bellezza classica, non comprende che quella non parló nel latino di Cicerone, bensì nell'idioma di Dante e di Petrarca, e ragiona da archeologo, avvezzo a tutto misurare col suo stadio e il suo cubito, dimentico della trasfigurazione avvenuta nella coscienza umana, della vita nuova de' popoli e della gloria della nazione, che nell'arte stampó gagliarde e moderne idealitá, il sentimento cristiano, la passione. 



\section{LA MADONNA}





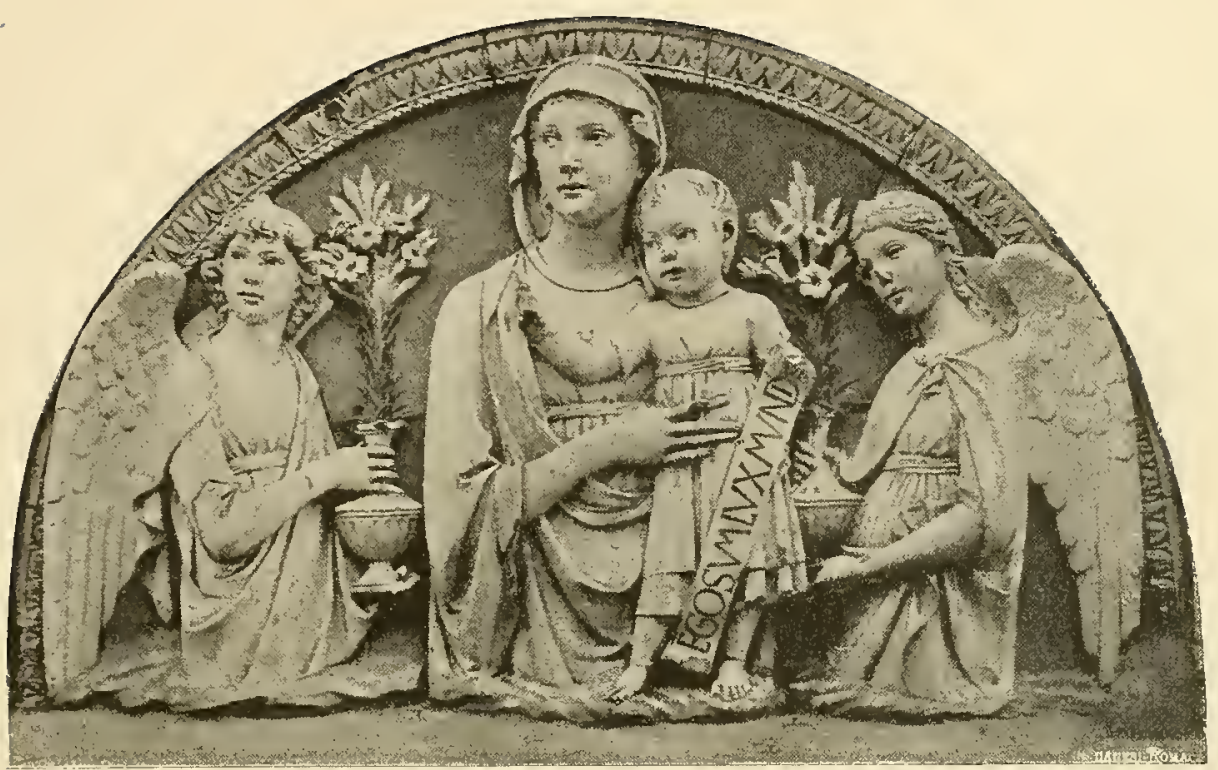

Madonna di Via dell'Agnolo in Firenze

(I,UCA Della Rosbia)

\section{L'Immagine sacra.}

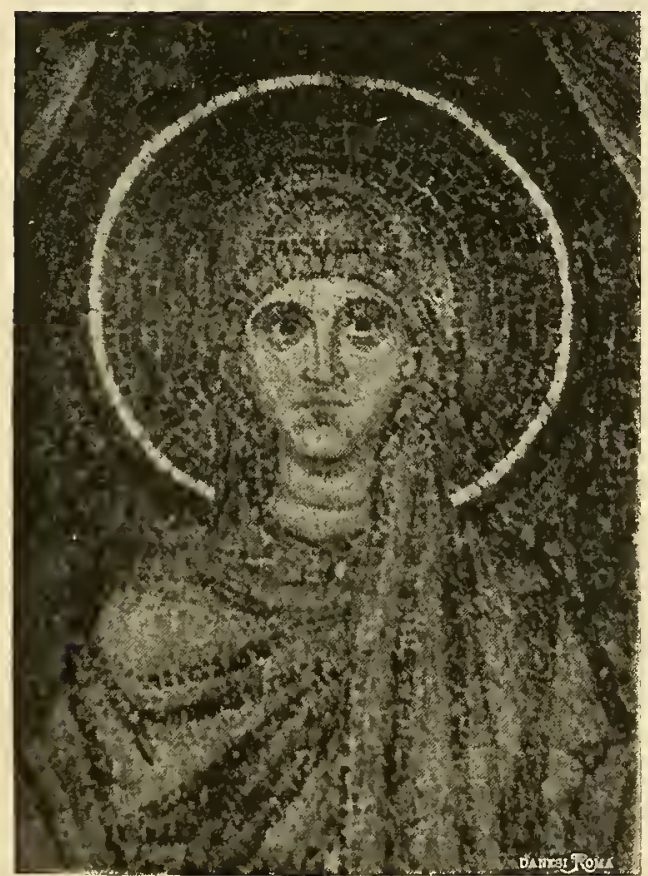

Particolare di un musaico del sec. XII Ravenna-Palazzo Arcivescovile
Trenici secoli prima che Raffaello rappresentasse la Madonna della Seggiola come una bella nutrice tutta amore per il pargolo che gira attorno gli occhi di falco, un pittore cristiano nelle catacombe di Priscilla rappresentava in simil modo una matrona con la creaturina ignuda che le si aggrappa al seno e volgesi ratta, guardando coi grandi occhi dietro a sè, quasi per mettersi a difesa del nutrimento; e la madre ripiega soave il capo, e circonda il nato suo con le braccia protettrici. Qui, come altrove, l'arte cristiana delle catacombe prelude al Rinascimento, segna le forme che più tardi splenderanno in piena luce, determina tipi e rappresentazioni che poi il Medio Evo ora nasconde, ora traveste, e che l'età moderna discopre e ravviva. 
Non sembrano essere scorsi i secoli tra il principio e la fine, poichè il Rinascimento rivide traverso alla materia bruta o alle agglomerate forme medioevali la forma prima, e la trasse fuori lentamente, e la spogliò d'ogni cosa che ne

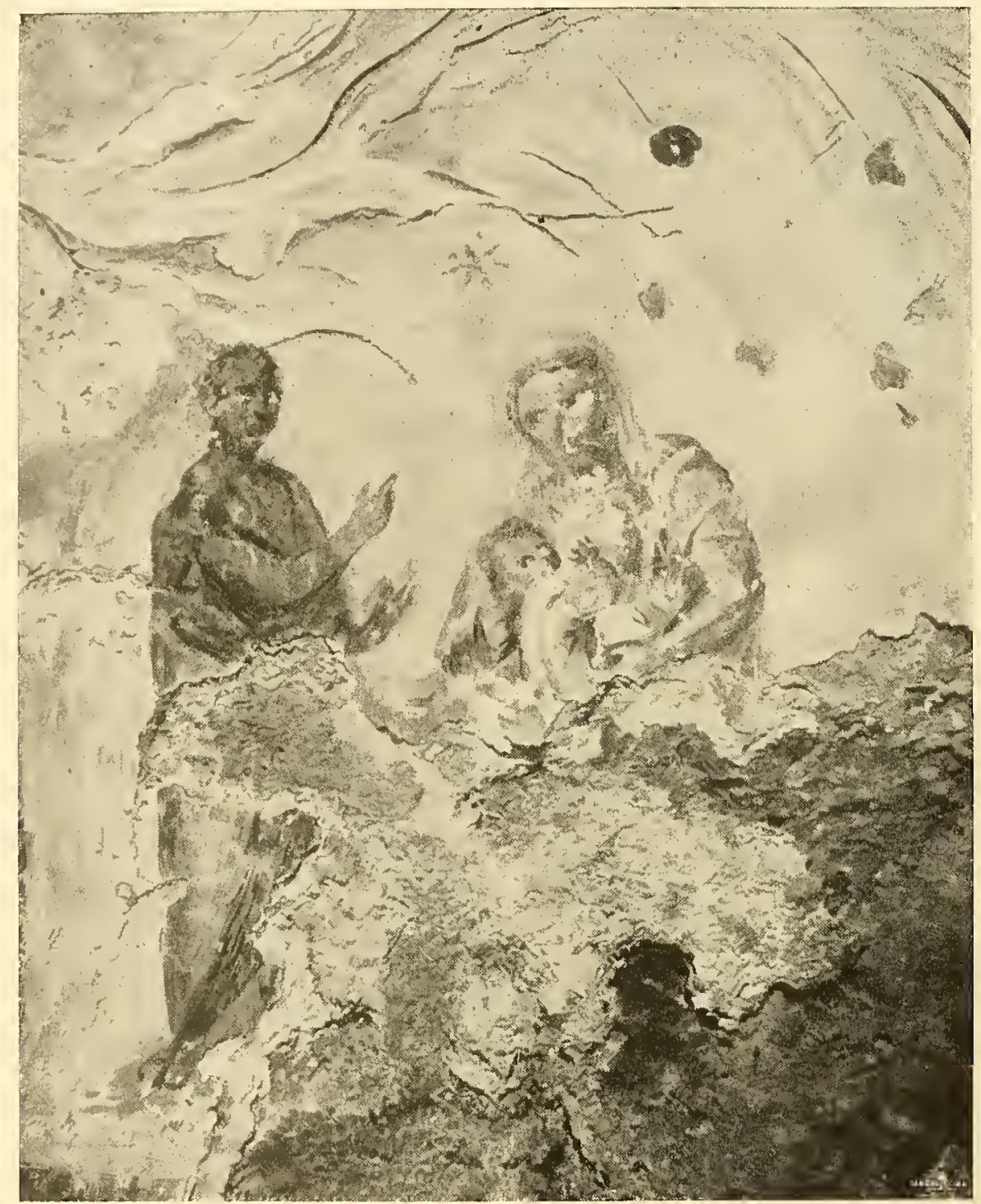

Affresco delle Catacombe di Priscilla. Sec. III

alterava l'augusta semplicità. Nel Nedio Evo è tutto un procedere dal semplice al complesso, tutto un accavallarsi di elementi nuovi sul fondo antico, un frangersi di quegli elementi in mille parti; nel Rinascimento si procedette in modo inverso, dal complesso al semplice, nella ricerca della forma equilibrata e serena. Come una campagna già verdeggiante, poi divenuta 
aspra forra, che ad un tratto si sgombri dei rovi e, rifiorita, stenda nello azzurro le braccia non più schiantate degli alberi, così l'arte, dopo lunghi tormenti e lunghe prove, riprese il suo aspetto di giovinezza. E avvenne che tanto il neofito raffigurante la Vergine nelle catacombe di Santa Priscilla, alla fine del secondo secolo, quanto Raffaello d'Urbino nelle Madonne della Seggiola e di San Sisto, videro, quasi con gli occhi stessi, Maria con l'opulenza di forme della donna feconda e con la tenerezza della madre. Ma il tipo, prima che ne' tempi nuovi riprendesse l'antica espressione naturale ed umana, variò di continuo, si offuscò e si schiarì, parve spegnersi e si riaccese, come ora vedremo.

La naturalezza della descritta figura della Vergine di Santa Priscilla non spira più dalle altre posteriori composizioni delle catacombe, sia negli affreschi, sia nei marmi coi Magi recanti a Gesù le offerte. Maria siede in cattedra,

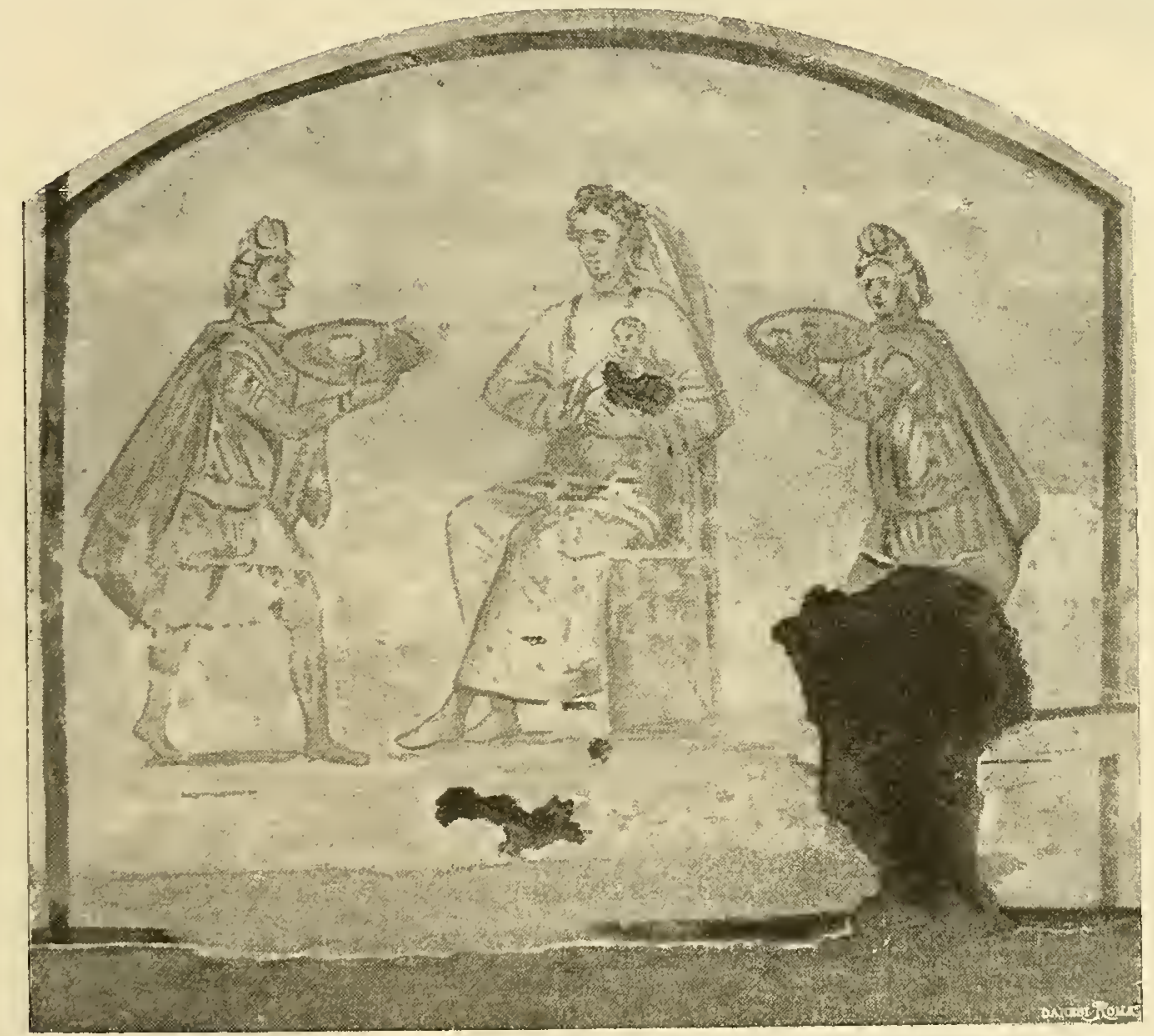

Affresco delle Catacombe dei Santi Pietro e Marcellino

onorata come nobile matrona, ma ha perduto la materna espressione gentile. Velata, ammantata, prende piccola parte alle scene che si rappresentano 


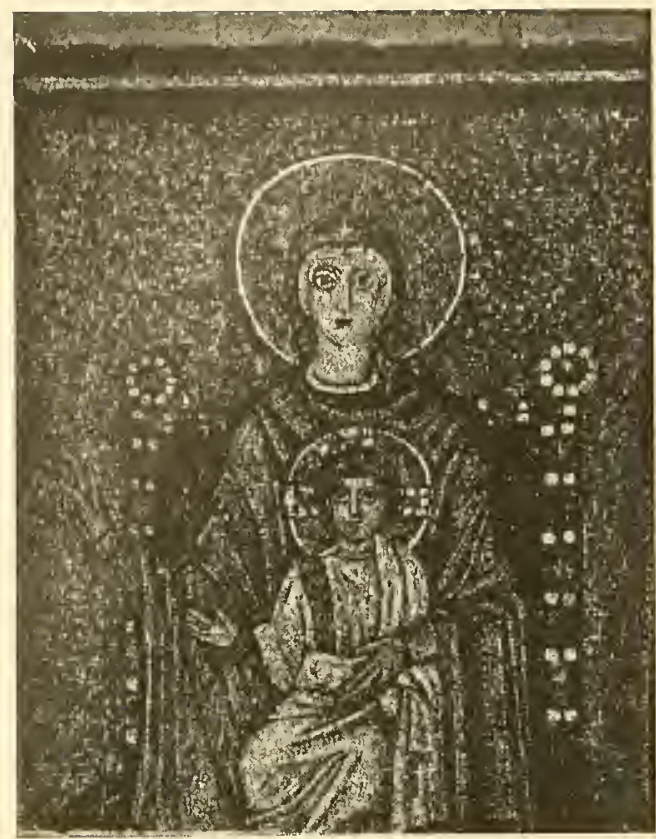

Da un musaico del sec. vi

Ravenna - Basilica di S. Apollinare Nuovo intorno a lei e quasi avvolgesi nel $\mathrm{mi}$ stero; anzi, per il decadere dell'arte sempre più inetta con l'andare dei tempi ad esprimere idee, e soprattutto idee nuove, la figura di Maria resta senza lineamenti proprî, senza anima, simbolo convenzionale della Vergine presagita da Isaia, segno di una concezione tutta spirituale. Non un ritratto di lei, vissuta in Giudea, ove la religione severamente proibiva di riprodurre le umane sembianze. $\mathrm{E}$ d'altronde, come i personaggi operanti nel gran dramma evangelico, Maria svanisce quasi ombra innanzi alla grandezza dell'Emanuele.

Data pace ai cristiani, l'arte nelle

basiliche e ne' battisteri tolse $i$ veli e plasmò un corpo alle immagini nate nei silenzî sotterra, per render chiaro alle moltitudini il senso arcano delle antiche allegorie. Allora, nella gioia del trionfo, la Chiesa riandò tutti i particolari del passato, raccontò esaltata la sua storia; e il racconto volò di bocca in bocca, si tradusse nel semplice linguaggio popolare, che ai codici sacri aggiunse, elemento meraviglioso, la poesia delle anime. Cominciarono ad accogliersi le fantasie gnostiche, gli evangeli apocrifi, e a ingrandire nelle menti dei cristiani le sacre immagini. Gli uomini, già abituati alla pluralità degli dèi, dovevano esser proclivi a inventar leggende. santi e miracoli, a comporre il Paradiso cristiano coi frusti materiali dell'Olimpo, a popolarlo con le riverse statue rimesse a nuovo; l'umanesimo pagano, che aveva concepito come uomini gli dèi, si risvegliava nelle menti e le eccitava

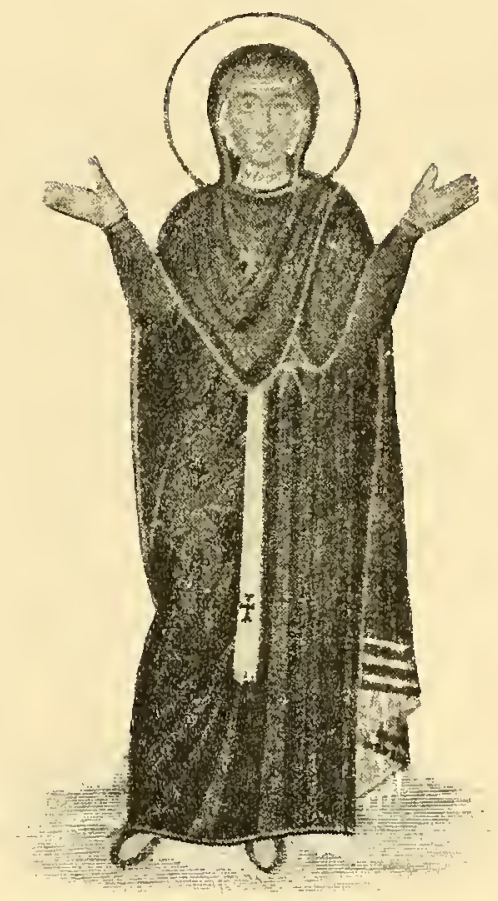

Musaico del sec. vi. Roma - Oratorio di San Vincenzo presso il Battistero Lateranense 
a dare una personalità alle sacre figure, togliendole dalla loro indeterminatezza.

Sant'Agostino aveva affermato che non si conosceva un ritratto della Vergine, e Sant'Ambrogio non seppe descriverla se non vestita di virtù, quale figura probitatis. Ma alla fine del $r$ e al principio del $r$ secolo in Oriente si vennero formando tradizioni che alcune immagini della Madonna,

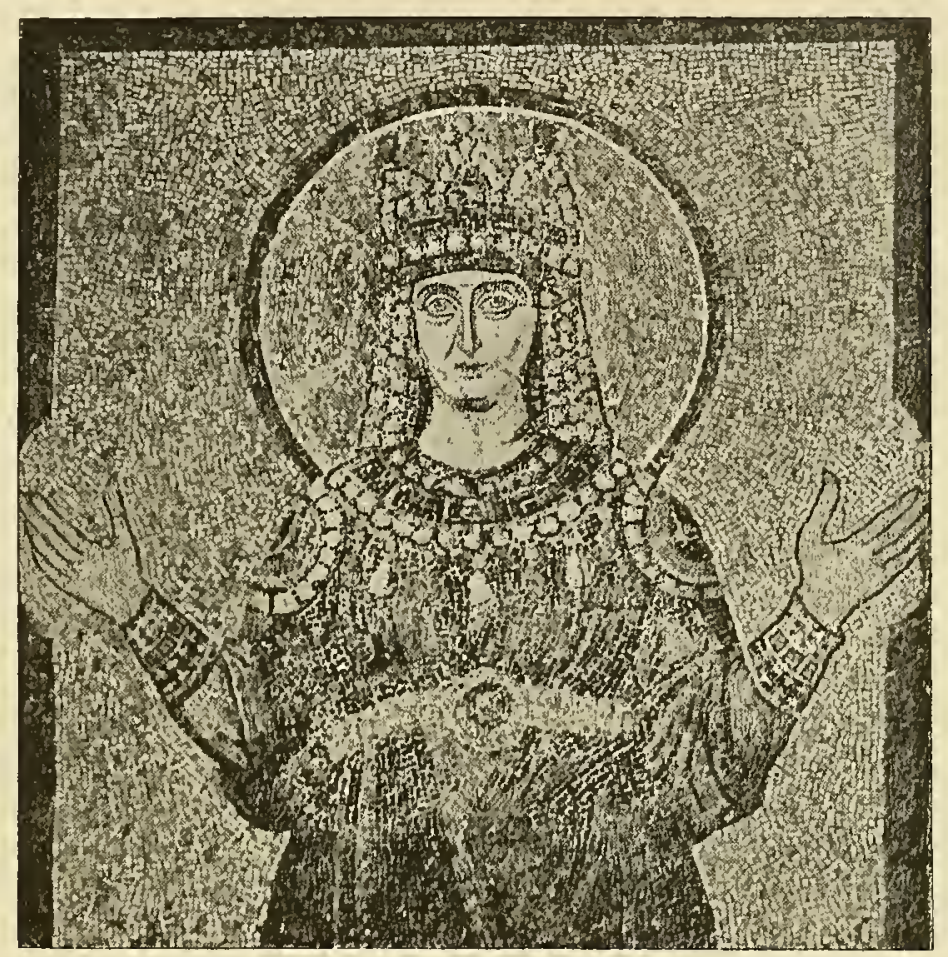

Da un musaico del sec. vili. Firenze - Chiesa di San Marco

Frammento del musaico dell' Oratorio di Giovanni VII nel Vaticano

serbate in Gerusalemme, fossero veri ritratti di Maria o acherotipi; si attribuirono poi a San Luca, per la necessità di accrescerne l'importanza col suggello di un nome storico, il nome dell'Evangelista che in ispecial modo si compiacque di tratteggiar Maria come donna sovrumana, sublime nell'umiltì che Dio volle esaltata. Anche la devozione dei fedeli concorreva a nobilitare storicamente le immagini di Maria, perchè alla venerata effigie la fede popolare si avvinceva come alla divinità stessa, e le assegnava sempre maggior valore. Quindi i lineamenti di quelle Madonne divenute sacre reliquie sono indicati come proprî della Vergine dai Padri del Sinodo orientale, 


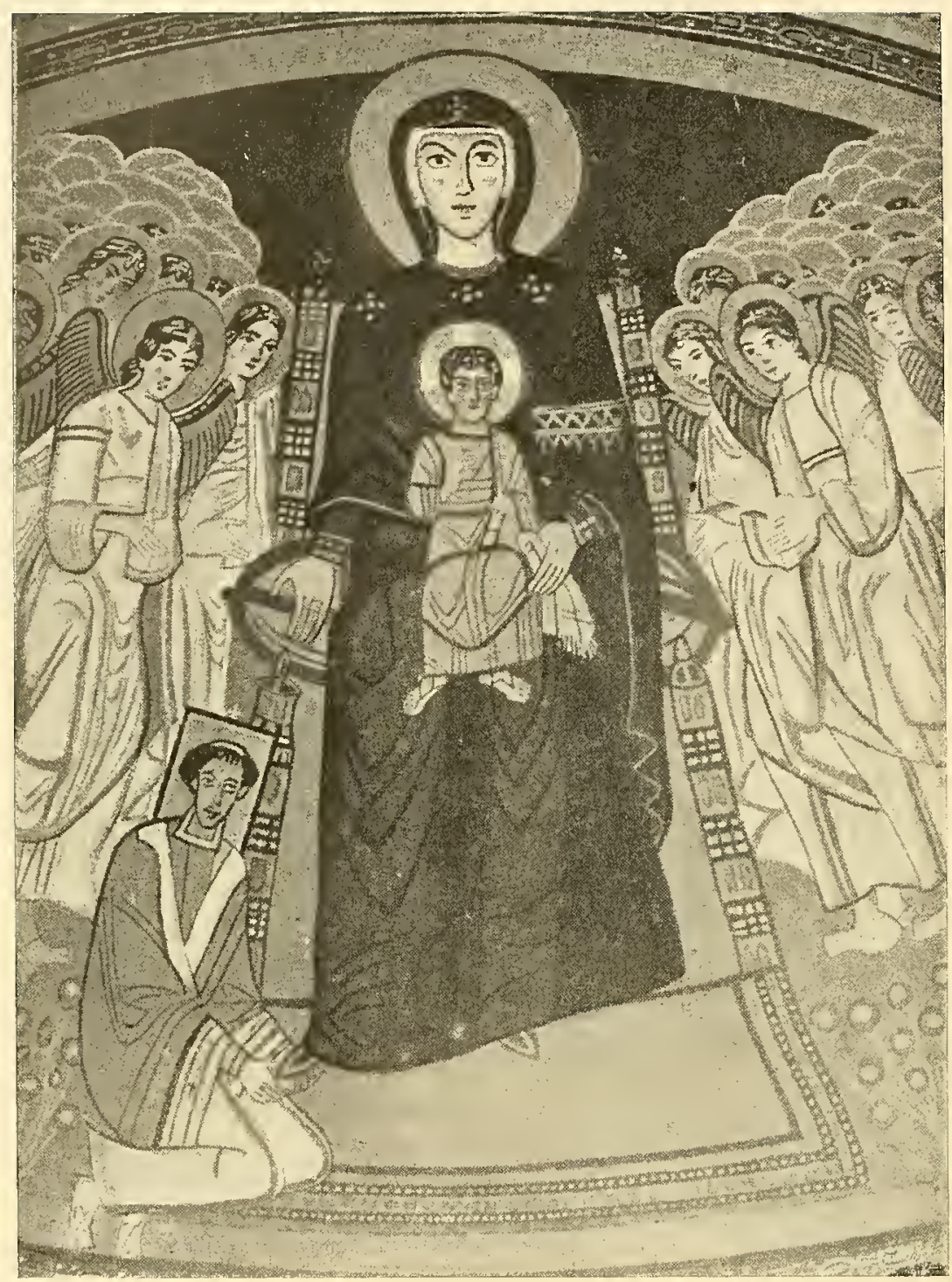

Musaico del sec. Ix. Roma - Santa Maria in Domnica o della Navicella 
che ne descrissero il colore del volto tendente al bruno, come quello del grano.

Alcune delle immagini dette di San Luca ricordano quelle della Vergine nei bassorilievi e negli affreschi rappresentanti l'adorazione dei Magi: velate

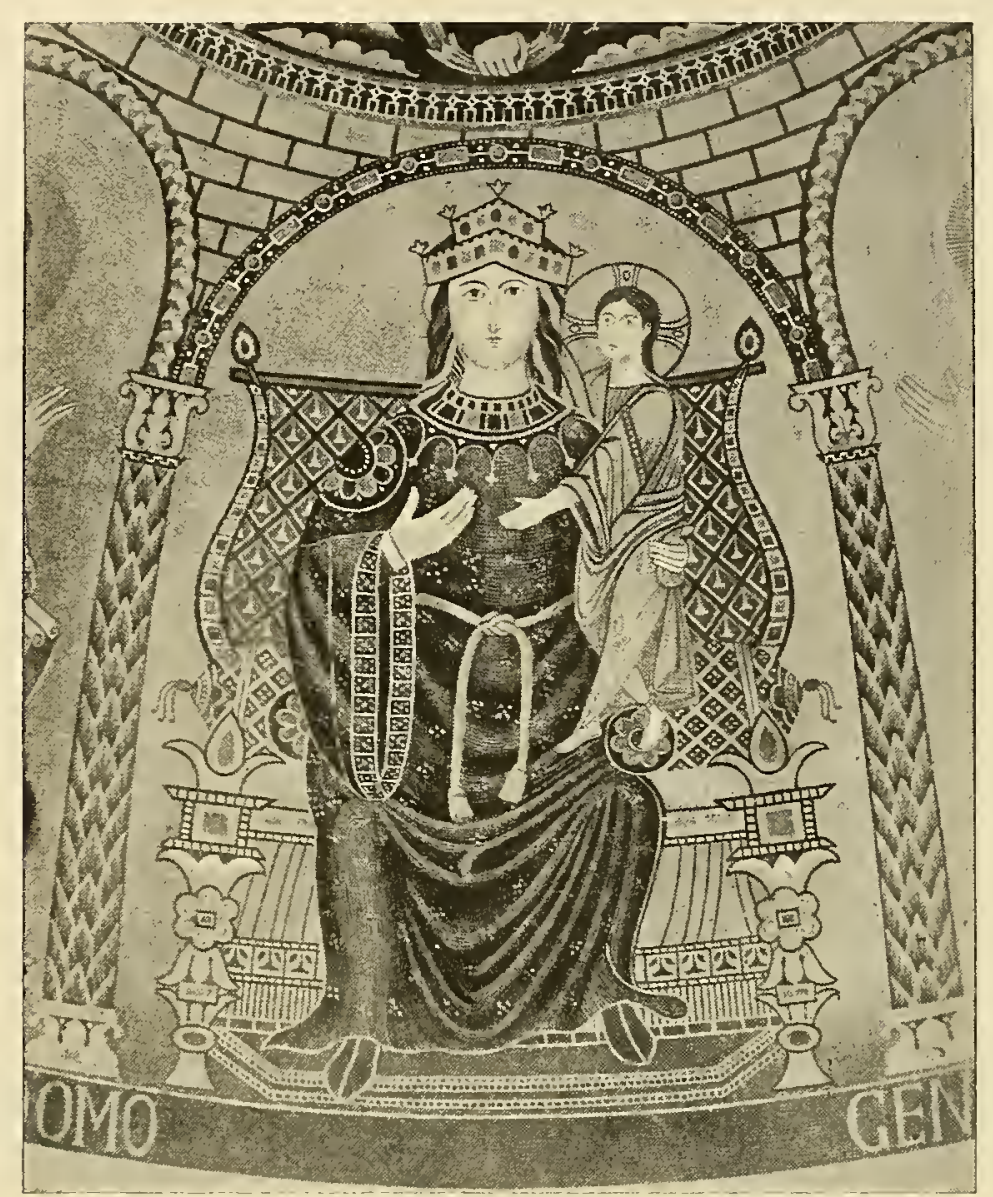

Particolare del musaico di Santa Francesca Romana

come spose cristiane e sedenti talora in cattedra, tengono il Bambino al seno o sulle ginocchia; altre, come le pie anime oranti delle catacombe, innalzano le braccia; altre infine tengono la mano sinistra sul petto e sollevano la destra quasi in atto d'intercedere grazie. Tali modi di rappresentazione sono derivati in parte dagli altri precedenti delle necropoli cristiane $\mathrm{e}$ in parte dalla fede che andava aumentando sulla potenza della Deipara, aiuto ai mortali. Evidentemente però queste immagini non si sarebbero così definite nei tempi apostolici, quando nessun personaggio storico spuntava tra 


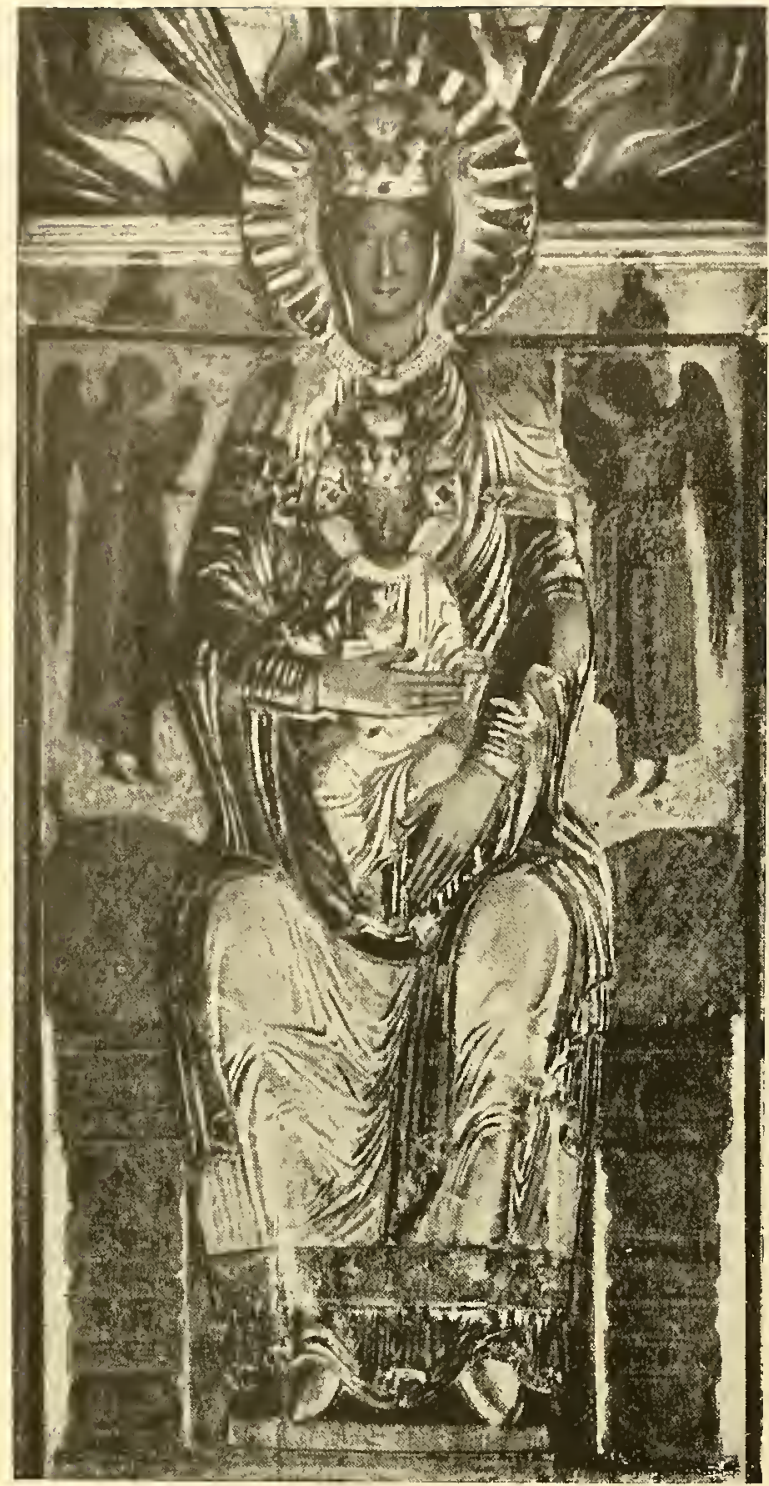

Arte bizantina

Firenze - Chiesa di Santa Maria Maggiore

i simboli, le umane forme erano soltanto i segni delle aspirazioni e della fede, e tra Dio e l'umanità non volavano intermediarî.

Le Madonne dette di San Luca presero la forma dell'arte greco-romana imitando il tipo giunonio regolare e dignitoso delle pitture e sculture pagane, con grandi occhi, il naso affilato, il mento ateniese. Insieme con l'idea della eletta da Dio sorse l'altra della sua bellezza, che per quanto era possibile a que' tempi si andò conformando al tipo classico della bellezza muliebre; onde il fulgore della venustà bionda di Afrodite mandò riflessi sulle trecce bionde della Vergine delle vergini, Madre delle madri, bellissina fra tutte le donne. Non conviene dimenticare che l'ideale della bellezza muliebre mal poteva determinarsi in quel tempo in cui l'arte, illanguidita la sua potenza creatrice, ripeteva quasi per forza d'inerzia, sempre men giustamente, le immagini tradizionali dell'arte greca. Queste avevano attinto le loro forme direttamente dalla natura; mentre le immagini cristiane, nei giorni della religione trionfante, dovevano esser cavate, diciamo così, di maniera, e da traduzioni nelle quali era svisato l'elettissimo originale antico, come da una vecchia stampa i cui pezzi, sciupati e guasti per il lungo uso, non stessero più insieme. Le Madonne dette di San Luca ebbero il volto ovale, gli occhi callo sguardo dolce assai grandi, il naso diritto, piccole e floride le labbra, 
rotondo il mento. Così furono, a giuldicare dalle immagini, l'Odegetria, venerata nel convento degli Odegi e, secondo lo storico Teodoro citato dal Niceforo, già inviata dall' augusta Eudossia, verso la fine del Iv secolo, a Santa Pulcheria imperatrice; e la $\mathrm{Ni}$ copea, alla quale i Romani del basso impero attribuirono la vittoria sopra gli Avari e la sconfitta di Foca, sì che nuova Athena promachos, fu chiamata nell'inno Acathisto coi titoli di capitana, di propugnatrice, di antesignana, di inespugnabile. Si venerava nel palazzo imperiale delle Blacherne, luogo presso il golfo Cerazio. "Se cerchi in terra", scrisse Giorgio Piside, amico di Eraclio che portò l'immagine dall'Africa, «il trono tremendo di Dio, guarda e am-

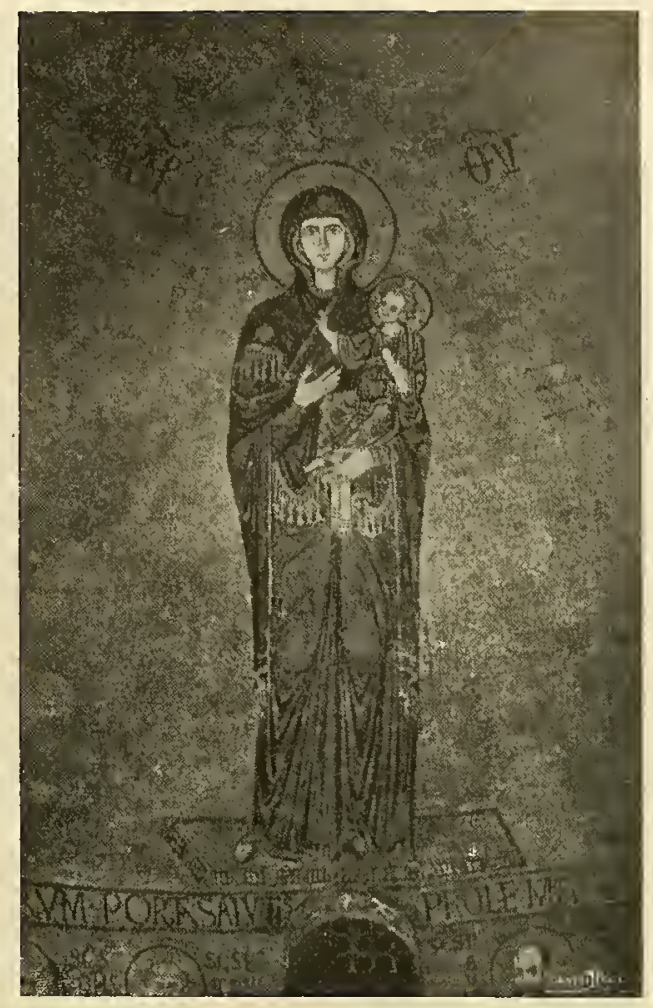

Musaico del sec. xı. Isola di Torcello-Duomo Particolare della decorazione dell'abside mira il tempio blacherniano dedicato alla Vergine; che portando Dio fra le braccia, lo porta in luogo maestoso. Qui gli scettrati dominatori della

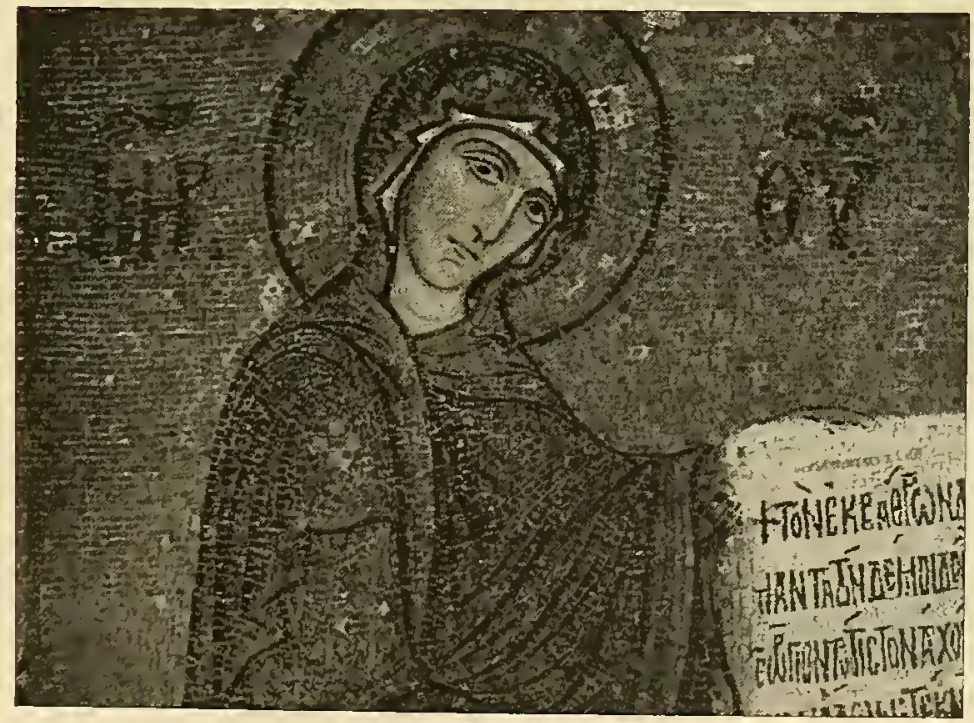

1)a un musaico del sec. xı. Palerno - Chiesa della Martorana terra confidano di ottenere la vittoria; qui, per le preci notturne del Patriarca, si rimuovono i molti mali dal mondo. E i barbari, se soprassalgano alla città, solo che veggano lei condurre l'esercito, curvano tosto le dure cervici" .

L'Odegetria e la Nicopea erano due 


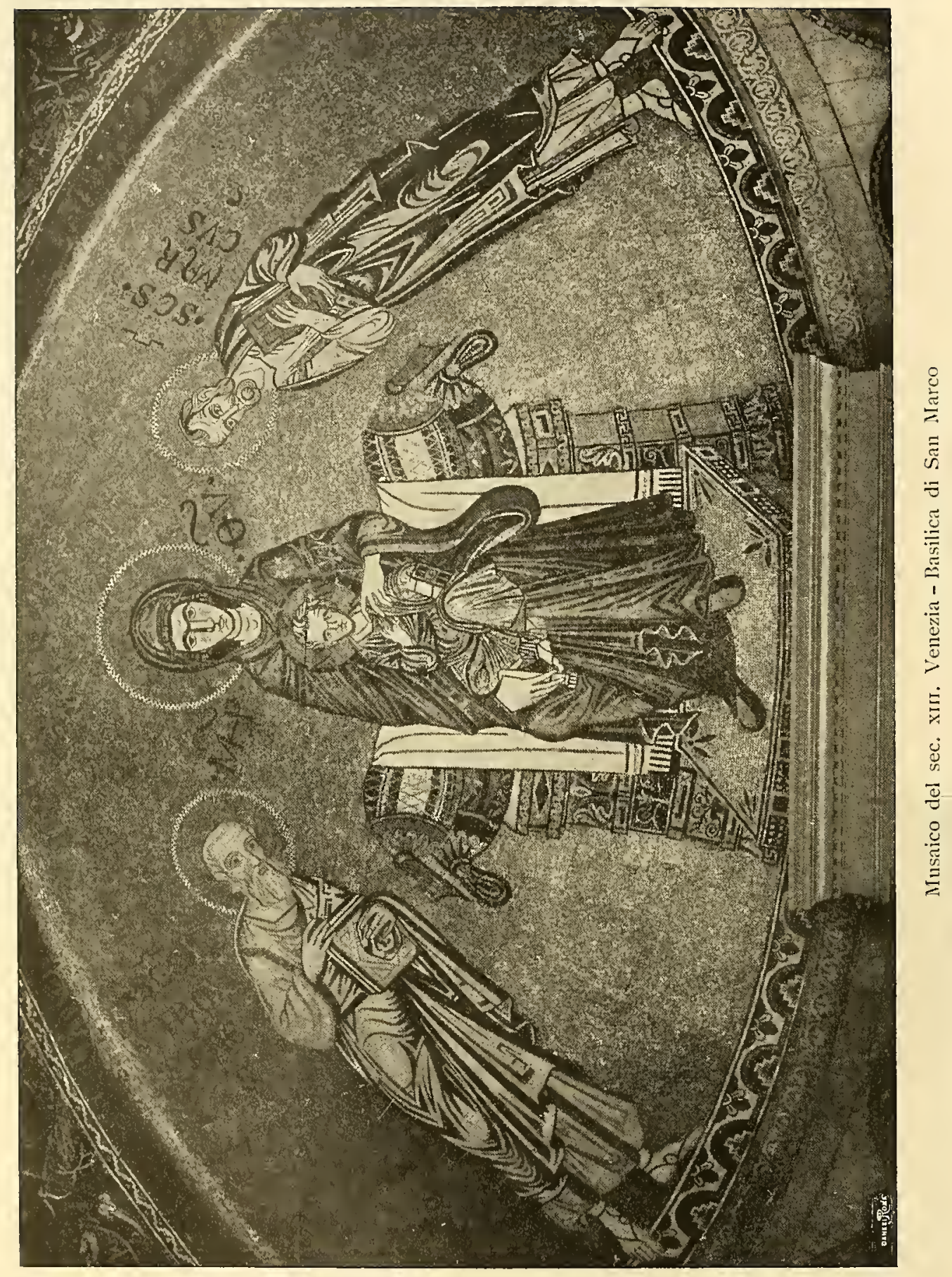




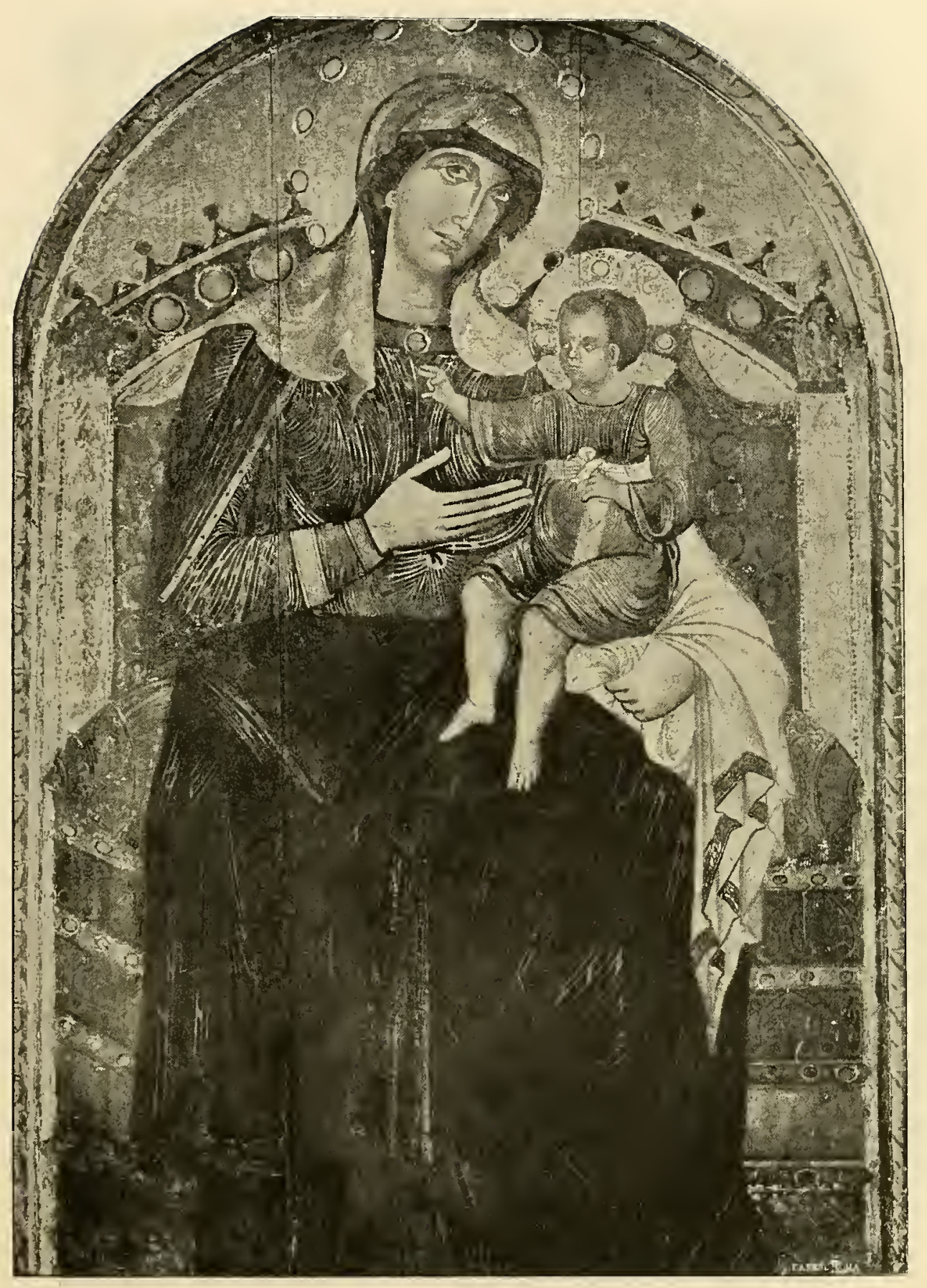

Pinacoteca d'Arezzo

(IIRGARITONE D'AREZZO) 


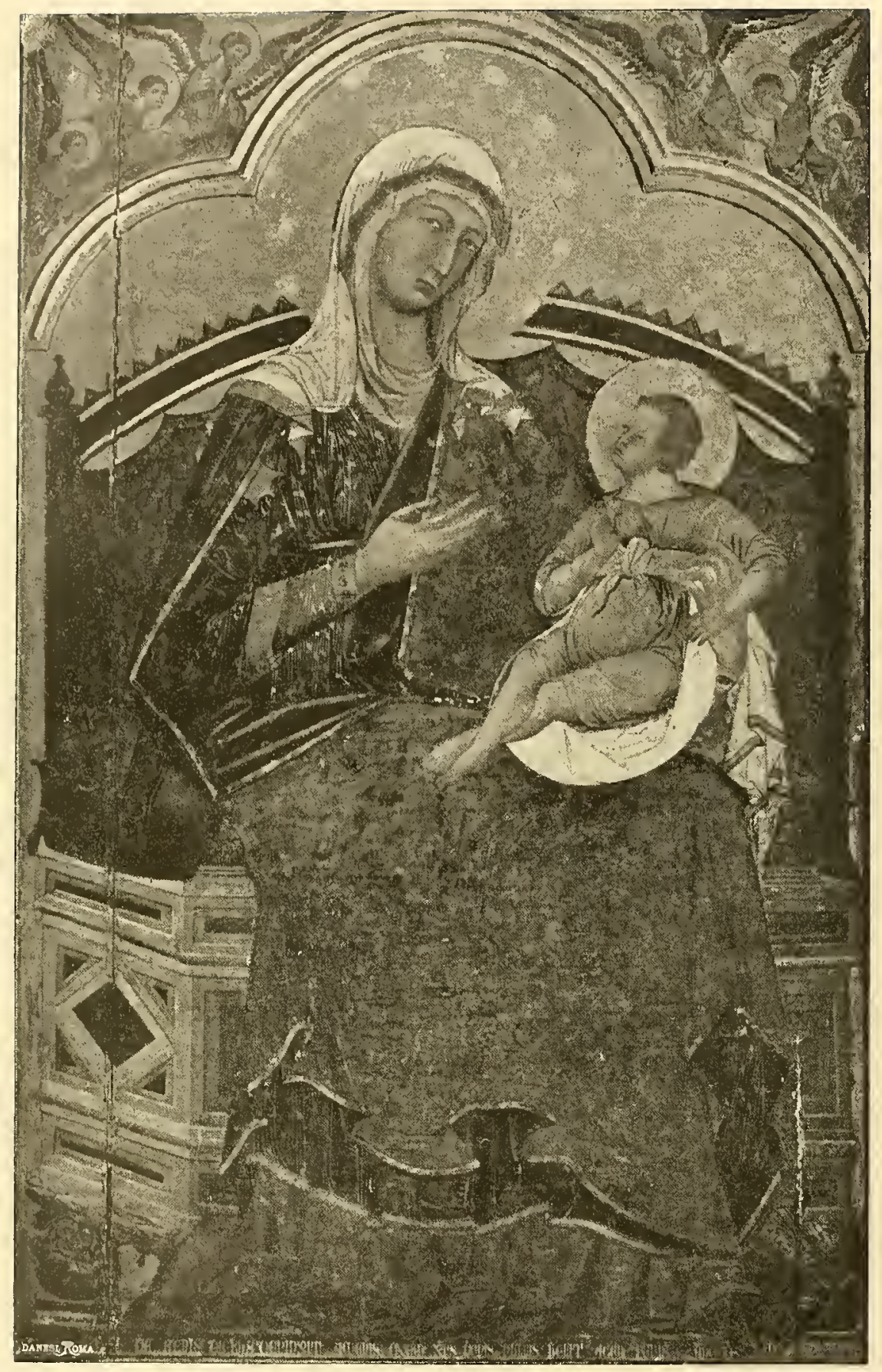

Siena - Palazzo della Signoria

(Guido Da Siena) 


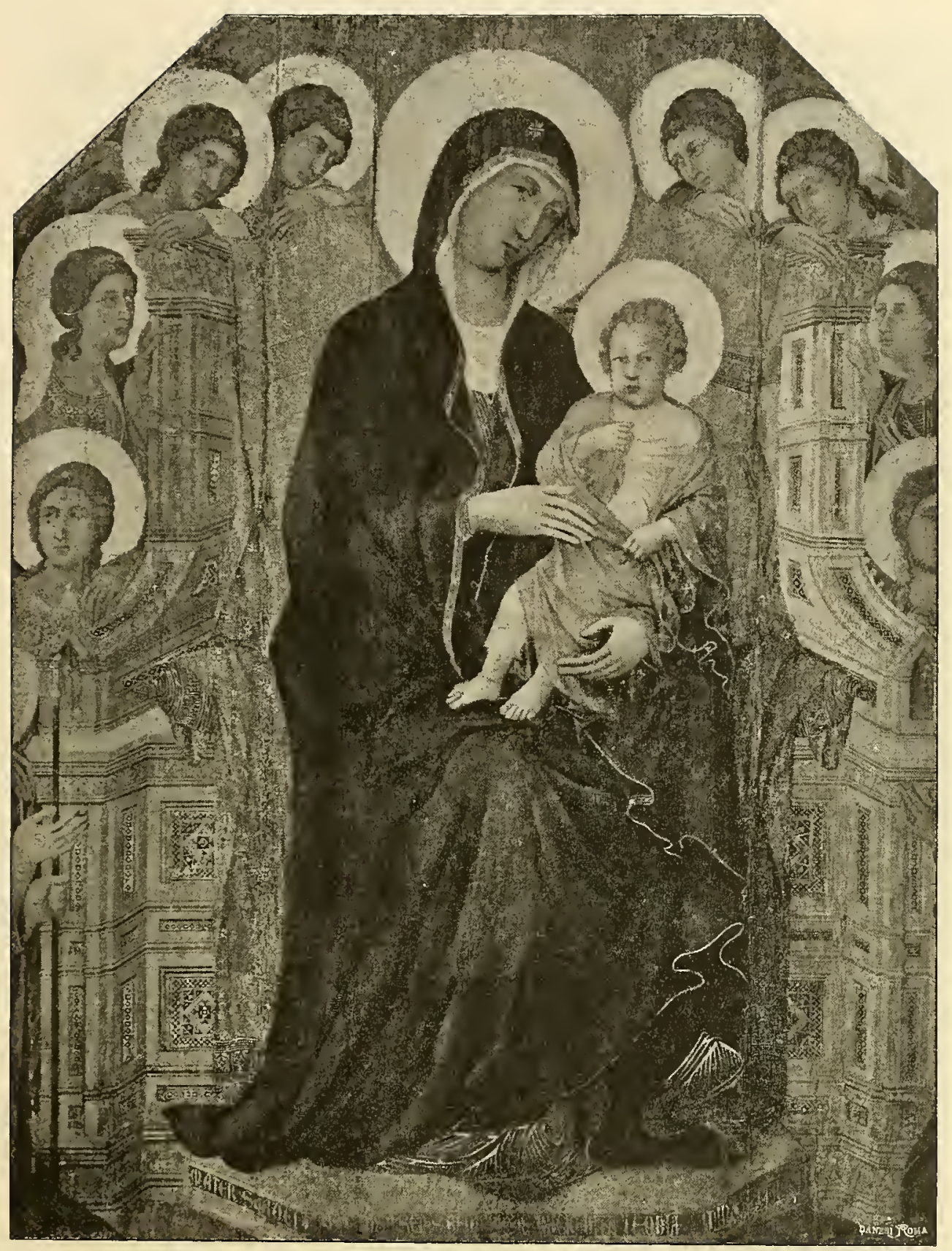

Siena - Museo dell' Opera della Cattedrale (Duccio di Bloninsegna) 


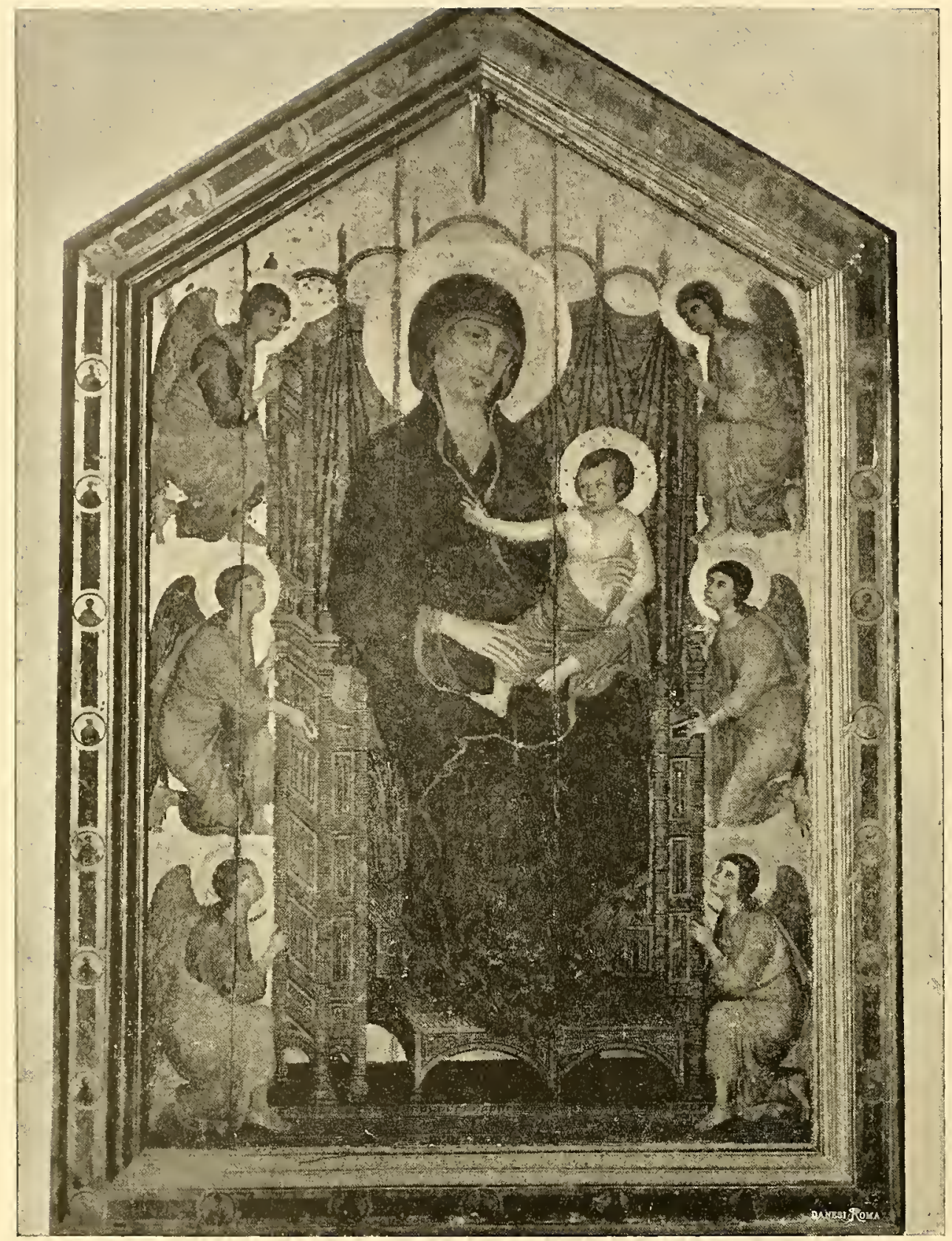

Firenze - Chiesa di Santa Maria Novella (Crmabue) 


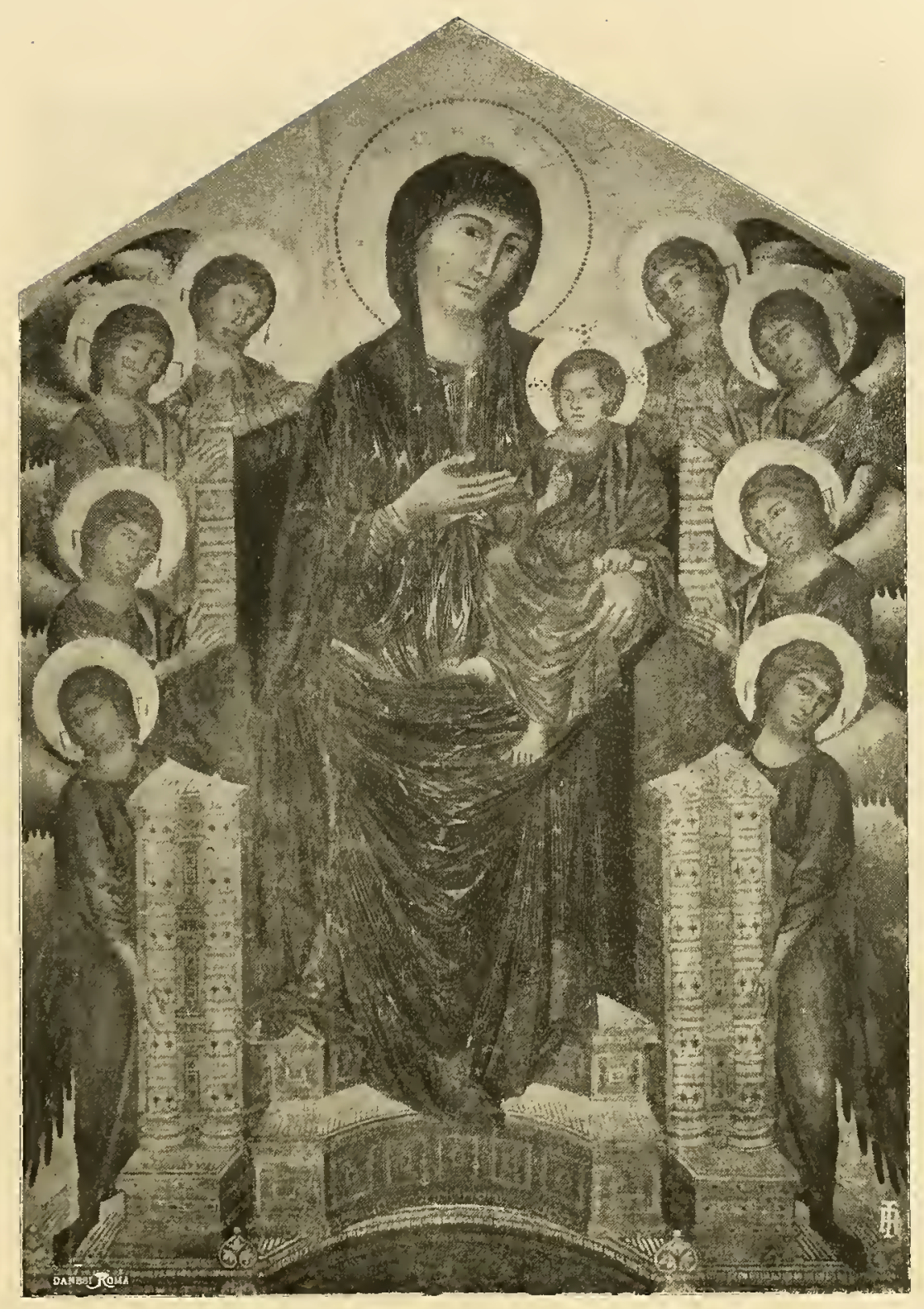

Firenze-R. Galleria antica e moderna

(Crmabue) 
tra le molte immagini che si veneravano a Costantinopoli, nelle cappelle del palazzo imperiale e nelle basiliche dell'Oriente. Venute in onore col diffondersi del culto a Maria sin dal tempo di Costantino, si vedevano già fin

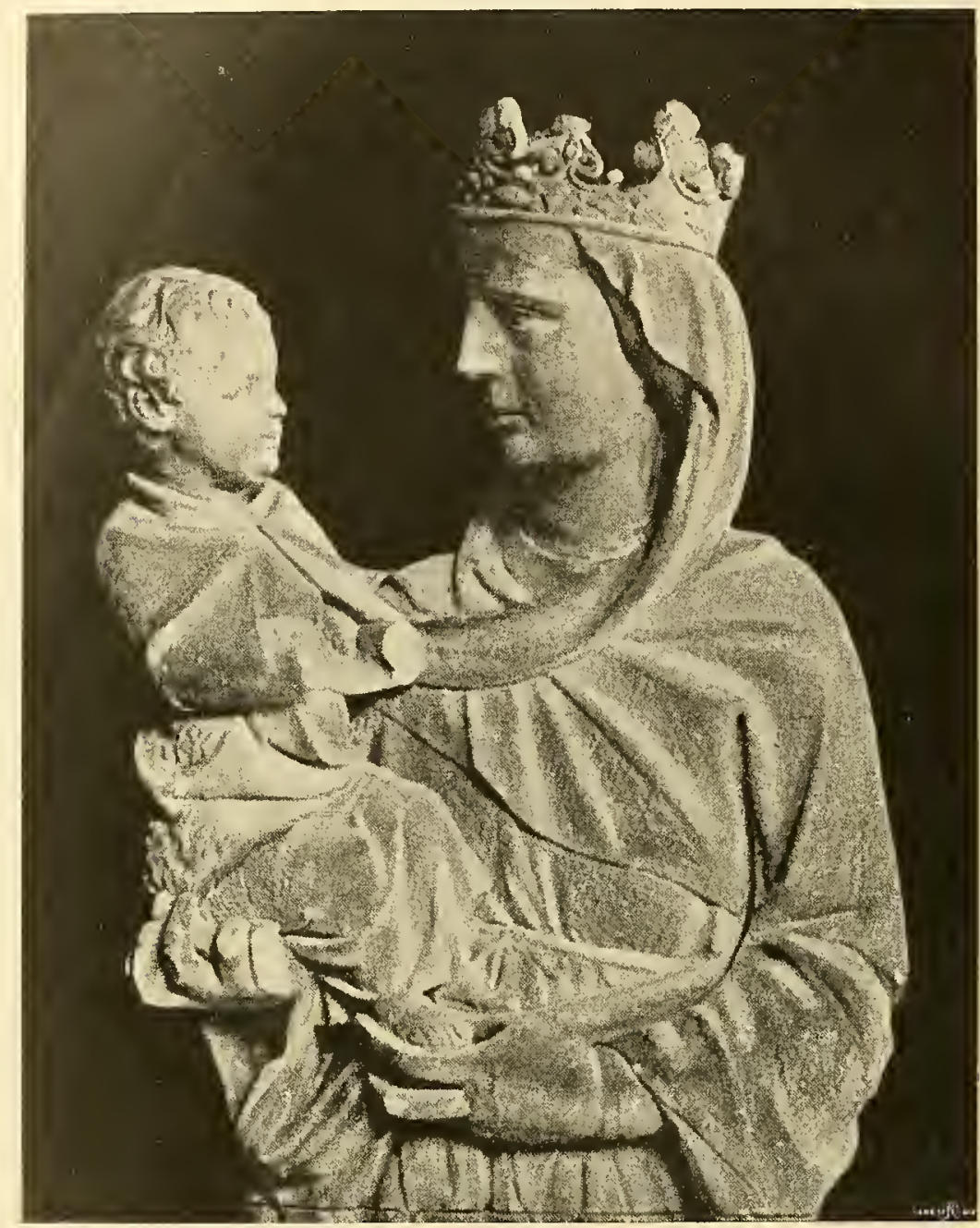

Camposanto di Pisa

(GIOVANI PISANO)

dal secolo v e vi nelle grotte degli anacoreti della Siria e dell'Egitto, sugli alberi de' navigli che solcavano i mari, nei campi di battaglia e sulle mura strette d'assedio sfidanti le orde barbariche, sotto la porta aurea di Bisanzio recate in trionfo. E l'Occidente, che sempre elabora e raffina le creazioni dell'Oriente, accolse il ritratto della Vergine, non come modello sacro dal quale fosse proibito staccarsi, bensì come effigie di un essere celeste ch'ebbe 
esistenza sulla terra e che della terra fu il fiore di grazia. La varietà delle immagini dette di San Luca, o gloriose del Figlio divino, o supplici verso il cielo, doveva permettere poi all'artista di non esser ligio ad un tipo, di

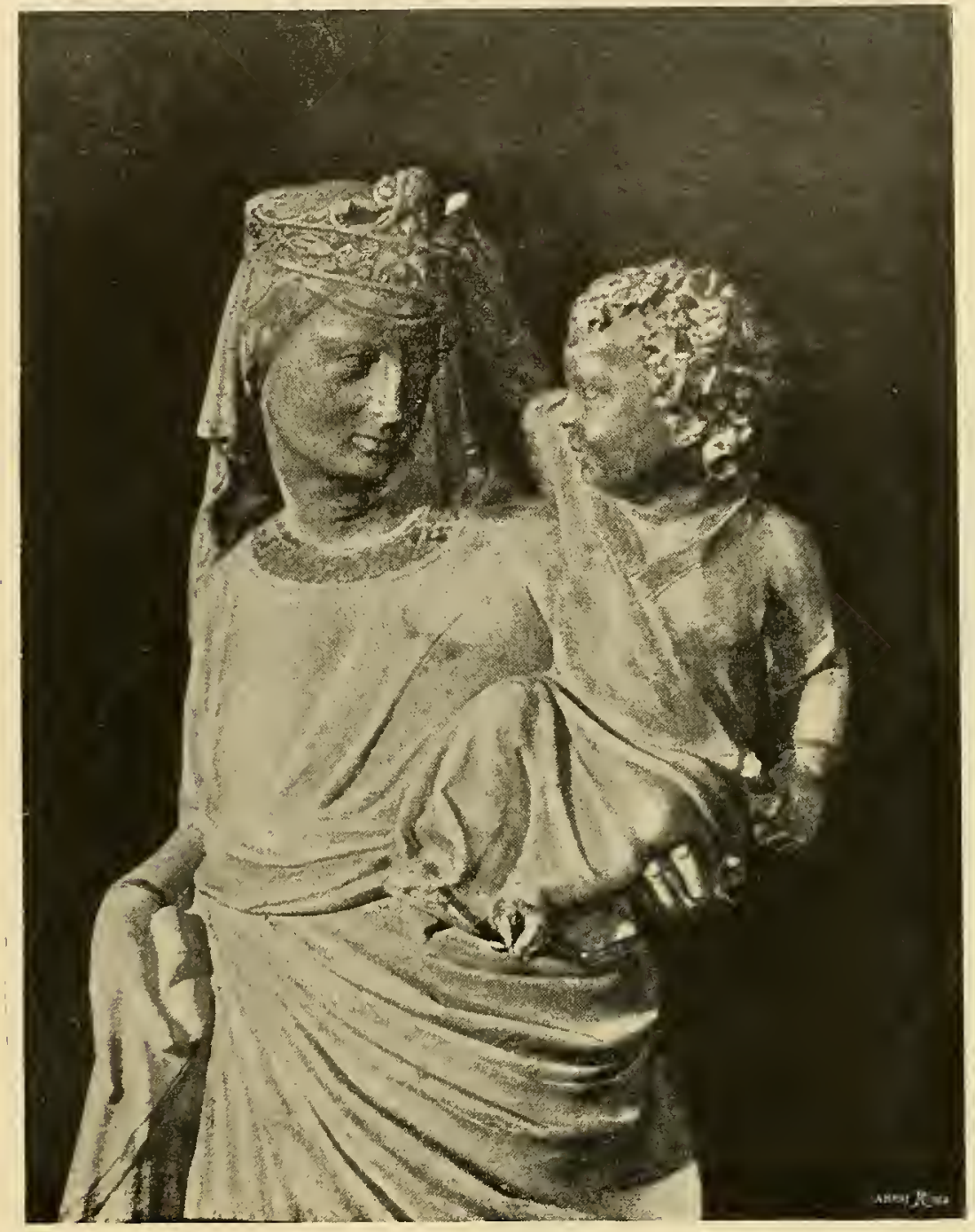

Prato - Cattedrale

(GIOVANI PISANO)

mutarlo anzi in modo che esprimesse or l'uno, or l'altro dei tanti attributi proprî della Vergine, or l'uno, or l'altro dei tanti sentimenti ch'ella destava nel cuore ai derelitti. Ciò doveva avvenire però solo quando l'arte cristiana giunse verso il meriggio suo, perchè, lungo il Medio Evo, col decadere dell'arte greco-romana da cui avevano preso la forma, quelle Madonne 
divennero sempre men belle, smunte, con gli occhi dilatati e fissi nel vuoto, senza piì altro che una certa maestà derivata dall' antico loro atteggiarsi secondo immagini pagane. Nè l'ideale di Maria, ancora troppo alto e confuso,

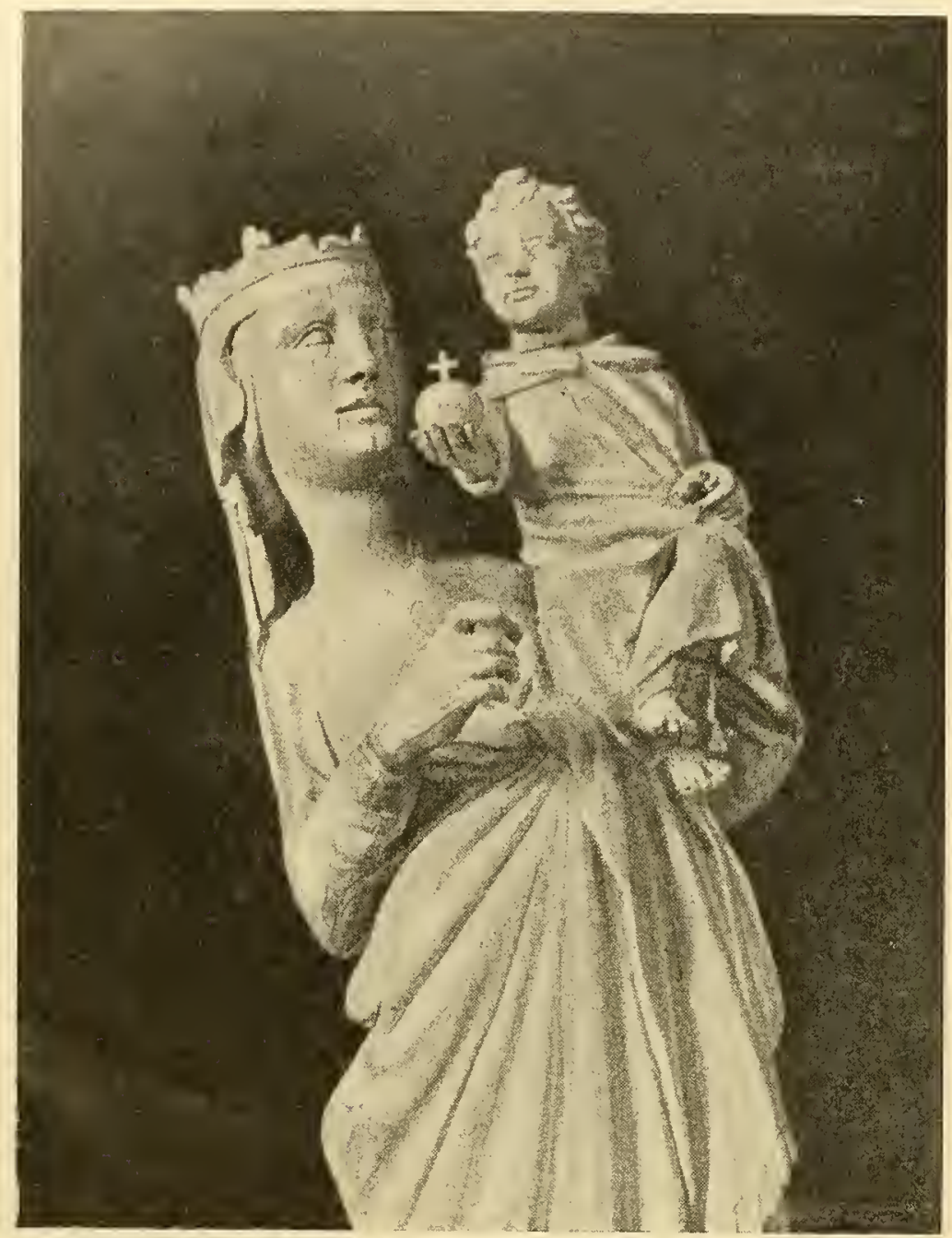

Pisa - Sagrestia della Cattedrale (Giovanni Pisano)

poteva ispirar l'artista ad animare di sentimenti ed affetti umani le sue immagini, che mantennero quindi il loro carattere ieratico. Nessuna passione scuote la soprannatural figura della Vergine delle vergini, composta e abbigliata dalla teologia.

Nella prima metà del secolo $v$ la Madonna trova in Occidente, a Santa Maria Maggiore in Roma, il suo arco trionfale nell'opera di Sisto III (XYSTVS 
EPISCOPVS PLEBI DEl), che vinta l'eresia di Nestorio al Concilio di Efeso e proclamata Maria quale madre di Dio, la volle raffigurata a illustrazione del dogma. Ella indossa veste ricamata e il pallio; ha una lamina di gioie a guisa di corona o stefane intorno ai capelli raccolti a sommo del capo, sulla fronte e agli orecchi una gemma; sta assisa sopra una sedia con cuscino e predella. Gli angioli, regali assistenti, circondano la Sovrana del cielo, la novella Giunone, che più volte si rivede nelle varie composizioni sui pennacchi dell'arcata trionfale, alla cui sommità si scorgono segni apocalittici e al cui impostarsi si disegnano i simboli dei Gentili e de Giudei chiamati alla nuova religione, cioè gli agnelli uscenti da Betlemme e da Sionne. Maria non ha il nimbo sul capo, come il divin Figlio e come gli angioli. Quantunque la sua grandezza già trascenda ogni limite, essa è lì a dimostrare un concetto mistico sulla redenzione umana. Ad ognimodo, l'ideale della perfezione di Maria si era elevato tanto da rendere impossibile il tradurlo se non in forma convenzionale. "Tu sei troppo di sopra degli uomini », dice Metodio, "perchè umana lingua dica degnamente le tue lodi ». E qual voce, osserva Basilio, "sarà tanto eloquente da cantare inni degni di lei, quali fiori di lodi potranno intrecciarle una corona? \$ Non era dato quindi all'artista di rappresentare la divina figura che $\mathrm{i}$ poeti vestivano di luce più fulgida del sole e ricoprivano del manto della immortalità; egli non poteva fissar gli occhi nell' immagine sacra senza rimanerne accecato per

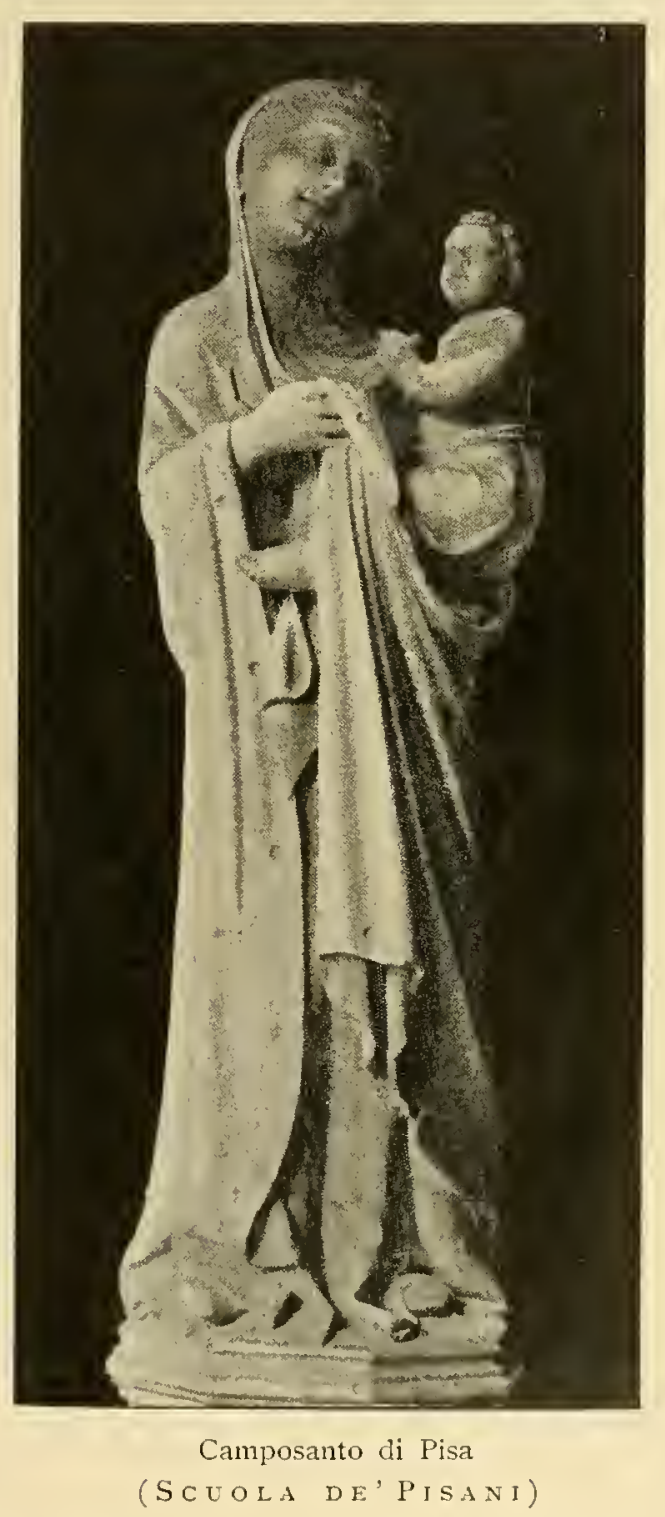




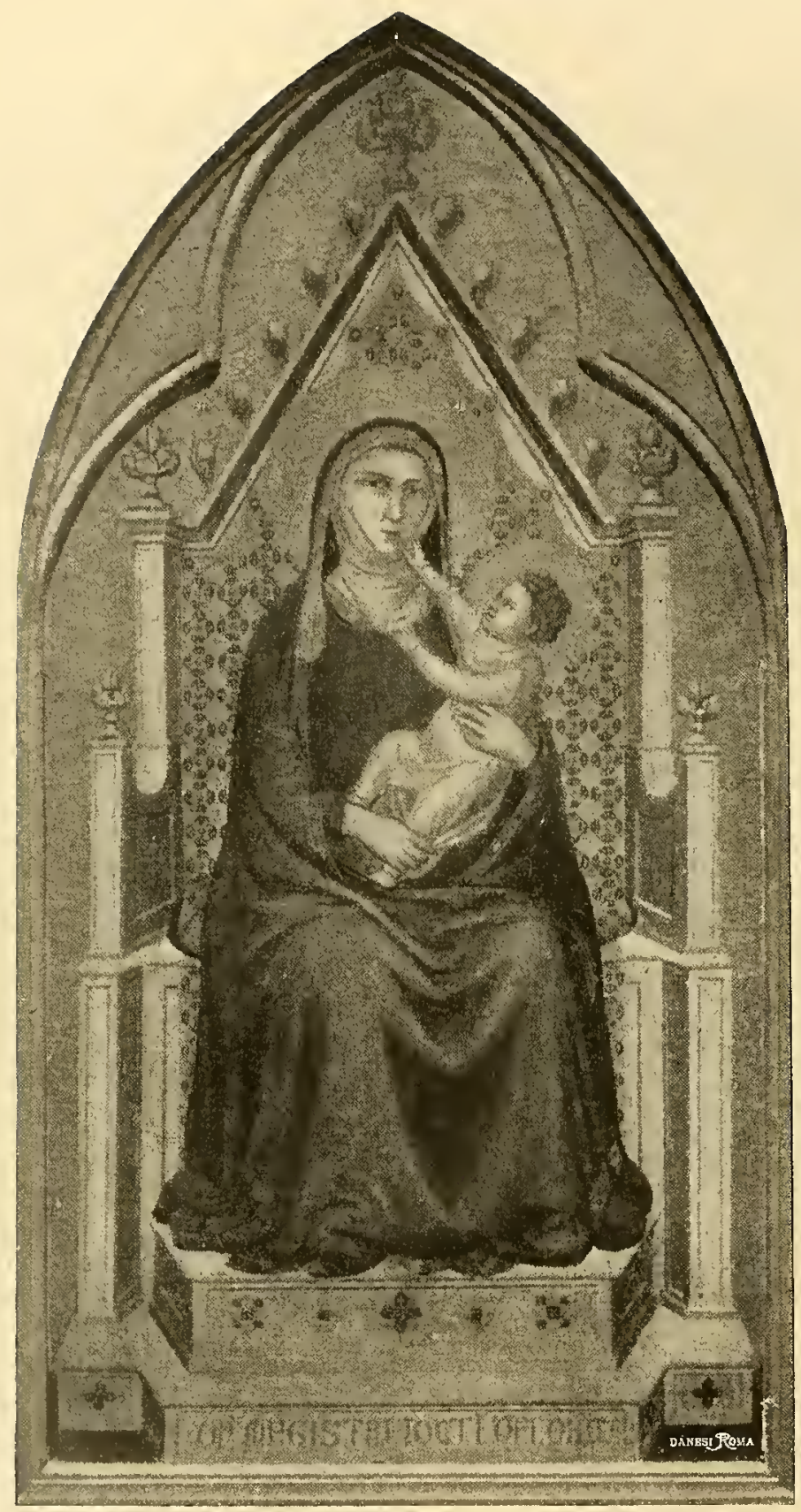

Bologna - R. Pinacoteca

(GiotTo) 


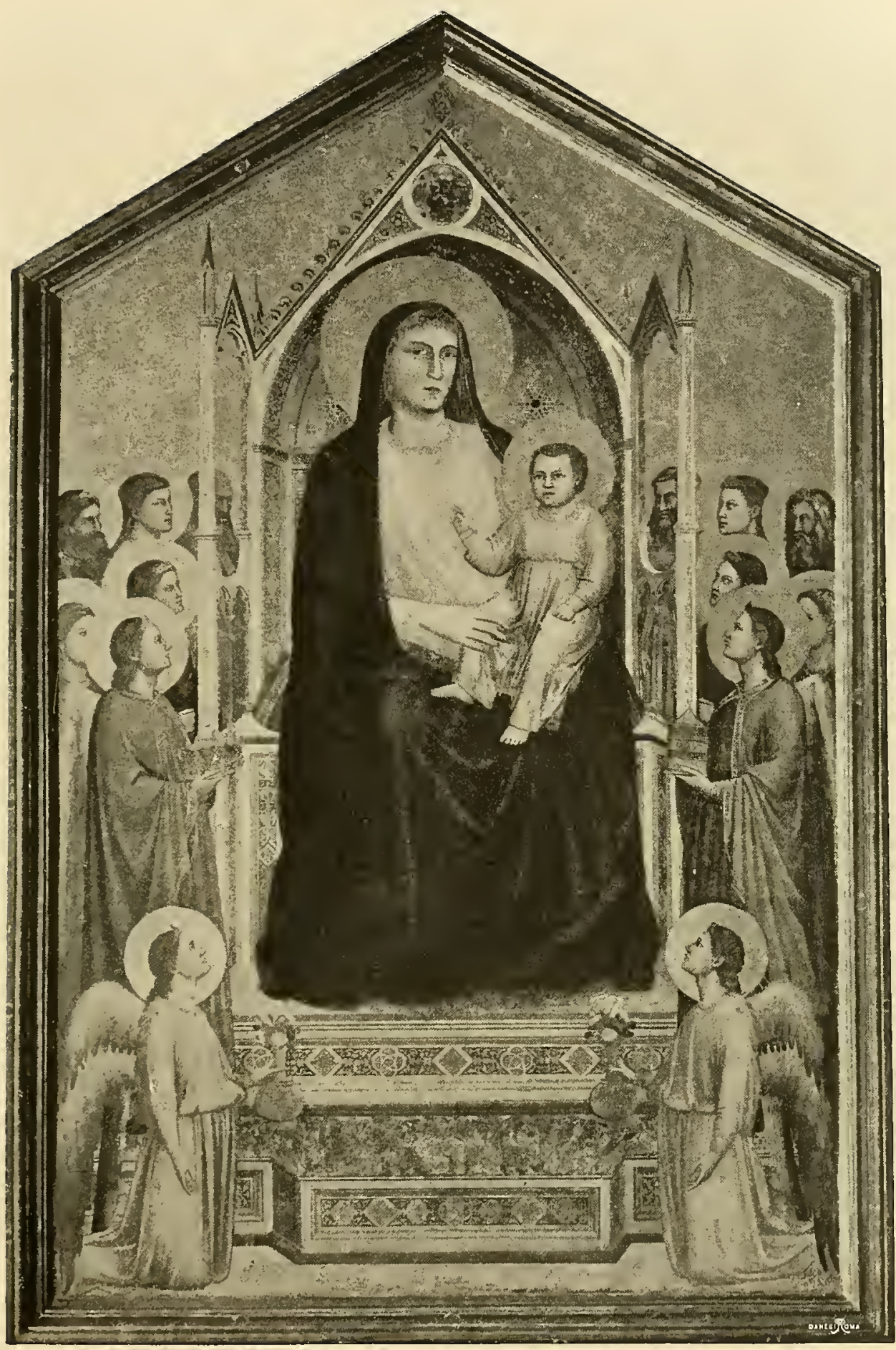

Firenze - Accademia di Belle Arti

(Giotтo) 


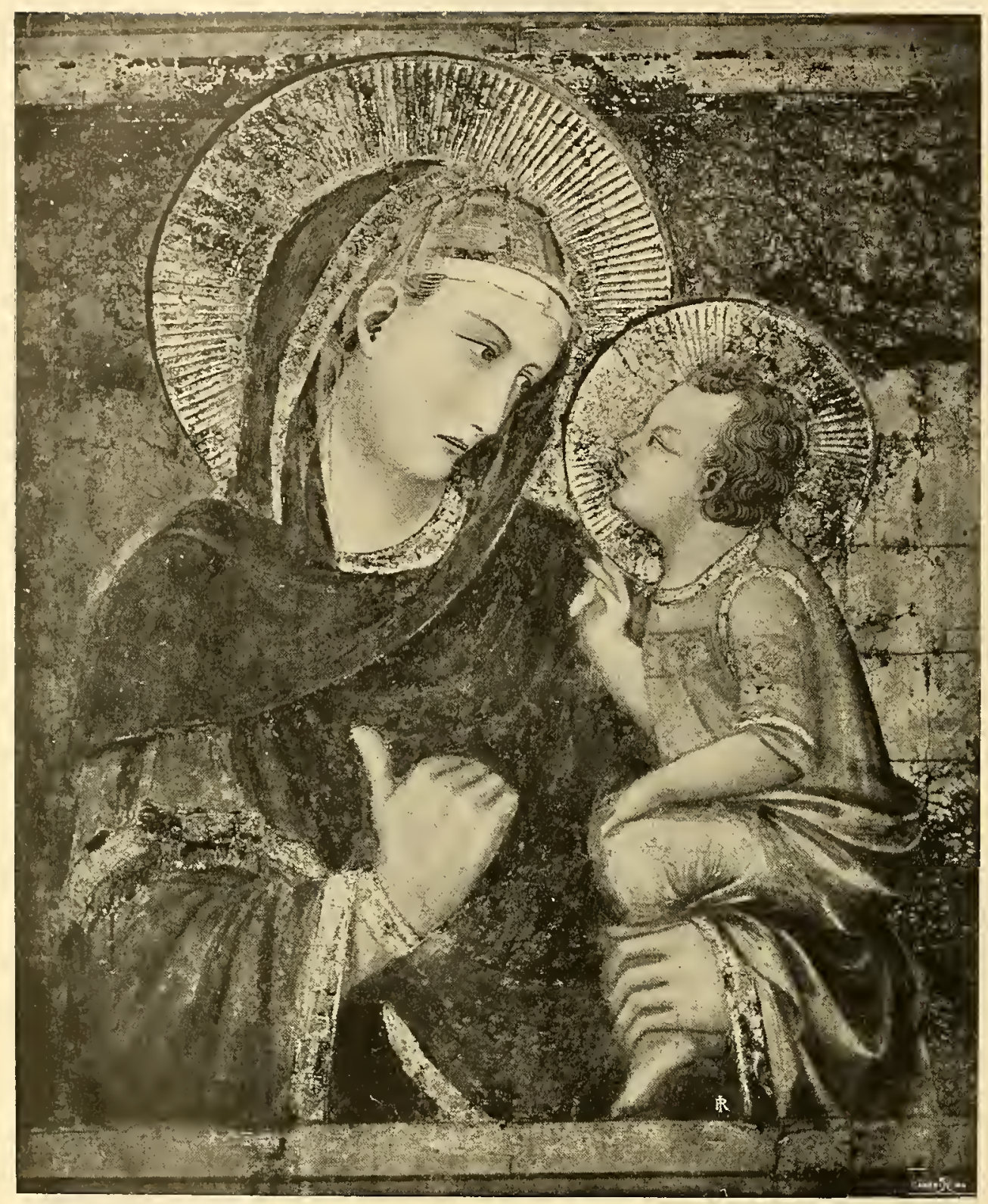

Assisi - Pittura attribuita al Cavaltini 


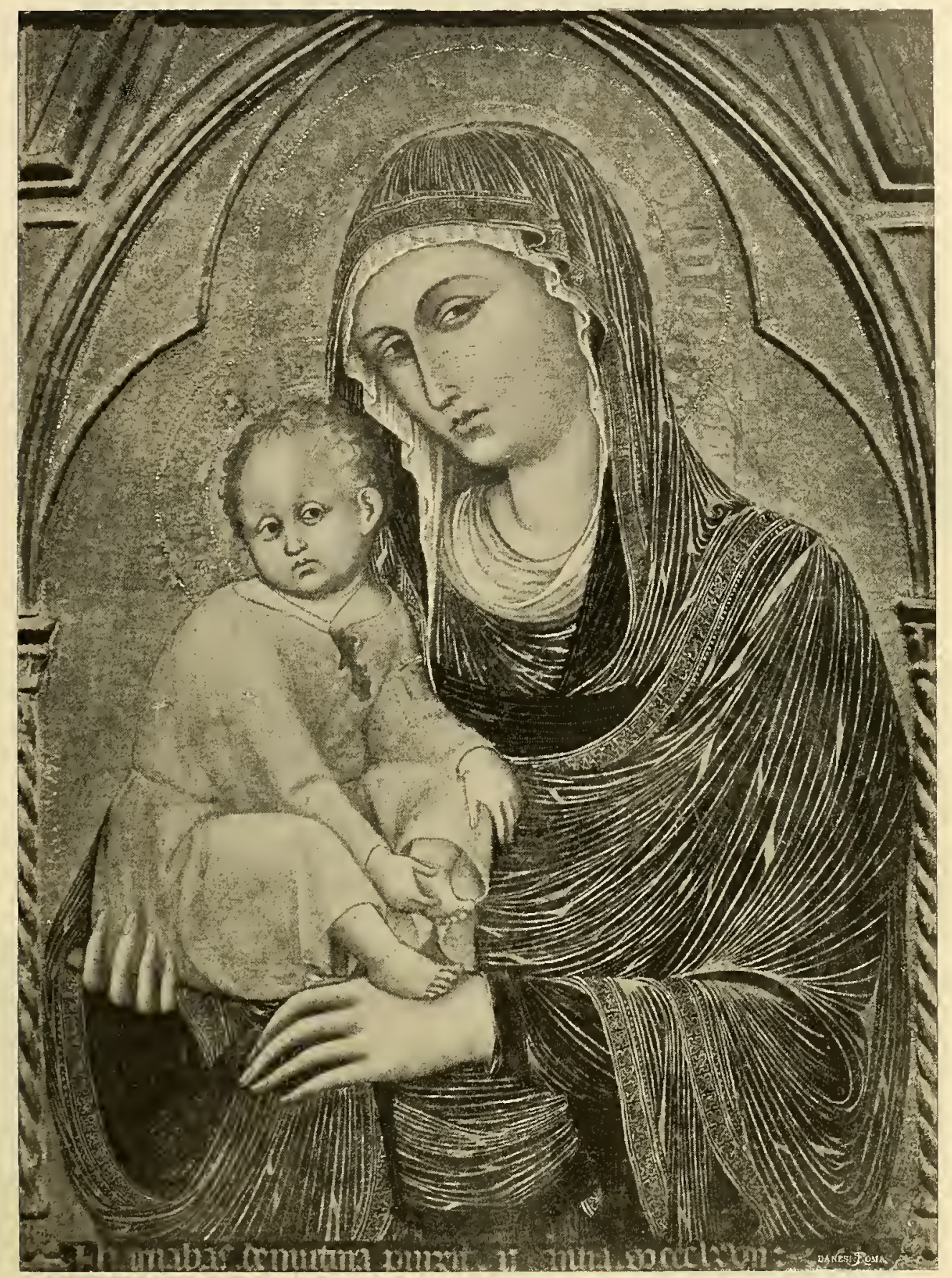

Francoforte sul Meno-Pinacoteca Städel

(Fra Barnaba da Modena) 
lo splendore. Sull'arco trionfale di Santa Maria Maggiore gli elementi pagani dell'arte accennavano a compenetrarsi coi nuovi: allora e poi la realtà tenderà

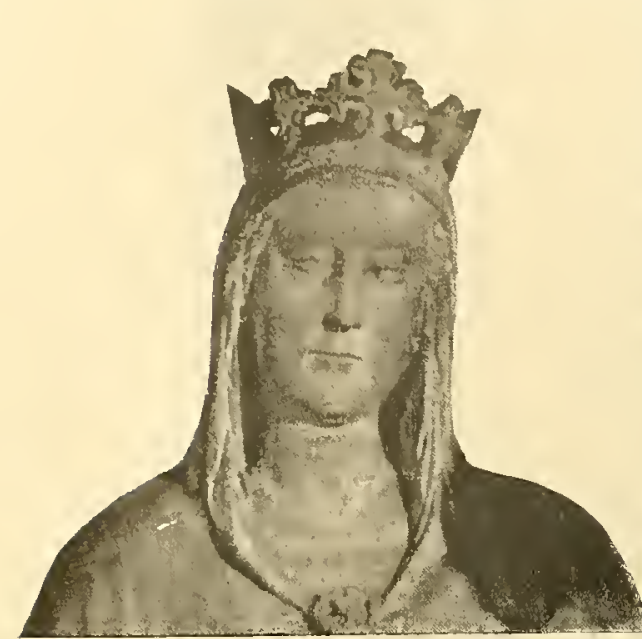

Firenze

Chiesa d'Or San Mlichele

(Sec. Xiv) a compenetrarsi con l'ideale, l'umanesimo a diradare le mistiche nebbie, la vita a scorrere entro le rigide forme dell'idolo. Sembra che due linfe sieno scorse attraverso la società medioevale, e che l'una, cone febbre malarica, si svolga dalle rovine della bassa età imperiale, e s'insinui corrompitrice nel clero, nei ginecei, nelle corti degl'imperatori d'Oriente; l'altra, come ardente di fiamma mistica, accenda moltitudini impaurite e stanche. Ma con l'andare de'secoli le due linfe mutarono: si purificò la prima, si temperò la seconda, e solo allora cessò il dissidio tra il corpo e l'anima, la ragione e il sentimento, la vita e la religione: così che l'arte potè esprimere l'armonia dell'essere e svolgere dall'ideale divino l'ideale umano. Il culto della Vergine dal secolo $\mathrm{v}$ in giù acquistò un'inportanza sempre maggiore anche nell' Occidente, e, prima che altrove, nei luoghi congiunti da stretti vincoli con l'Oriente, a Ravenna, á Parenzo nell'Istria e a Venezia. Nei musaici del secolo vi, a Sant'Apollinare Nuovo in Ravenna, si vedono le vergini recar corone a Maria, che sempre con lo sguardo fisso, come impietrita, siede sul trono circondata da celesti guardie. Così l'arte bizantina, per indicare la sublimità di Maria, le dava vesti a ricami, gemme, nimbi, lussureggianti troni e satelliti regali; ma la figura della Vergine rimaneva senz' anima in tutto quel fulgore, e $\mathrm{i}$ particolari seducenti dissimulavano

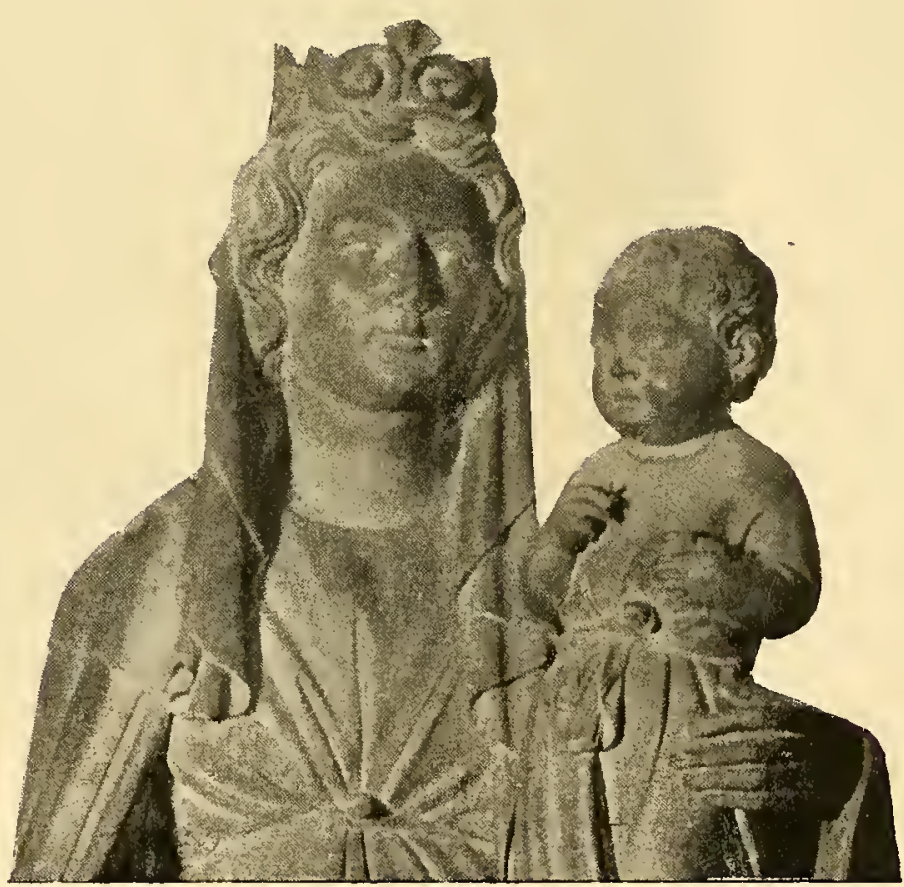

Sagrestia della Cattedrale di Ferrara (JACOPO DELLA QUercia) 


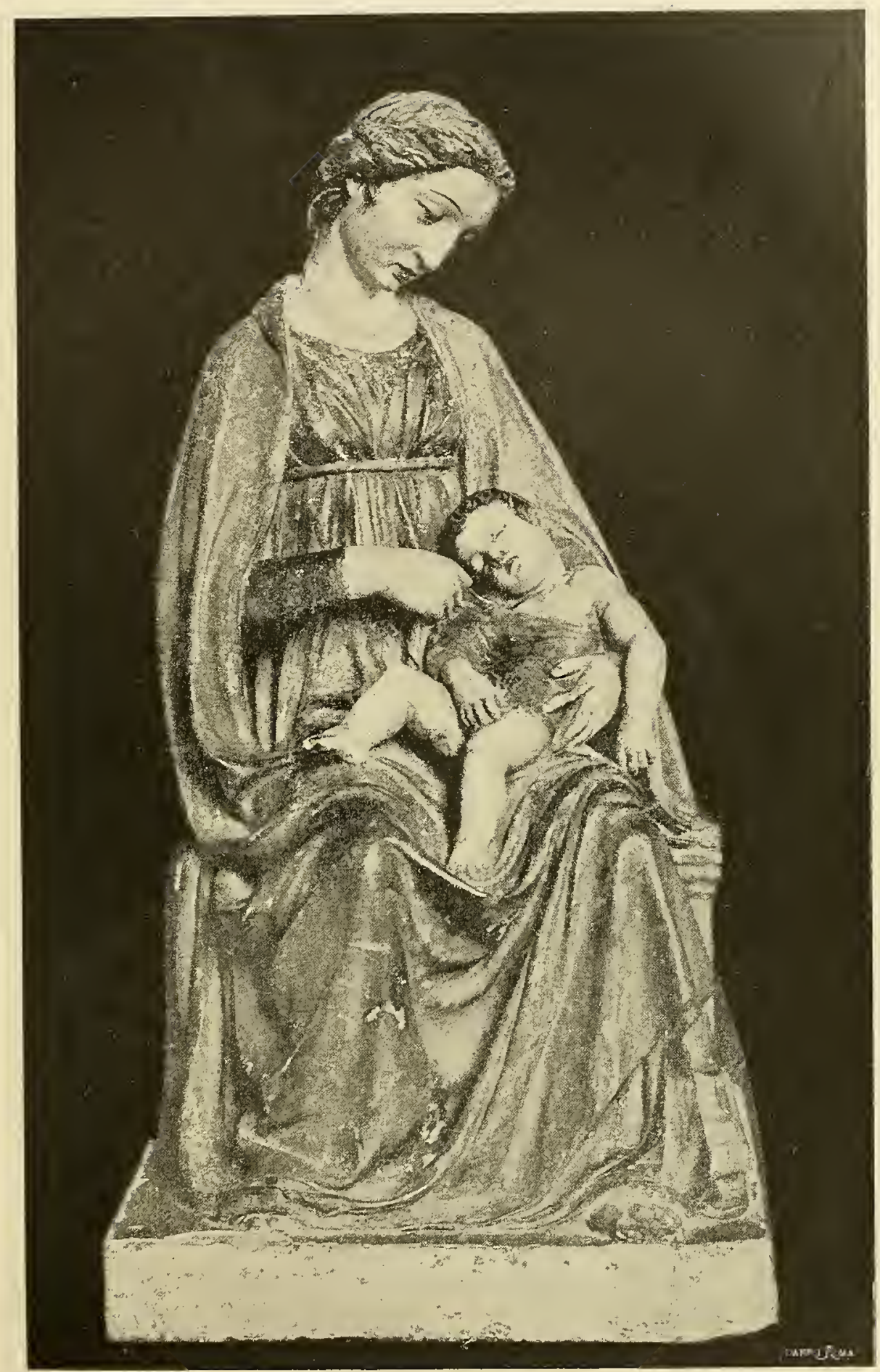

Parigi - Louvre

(Maestro della Cappella Pellegrini) 


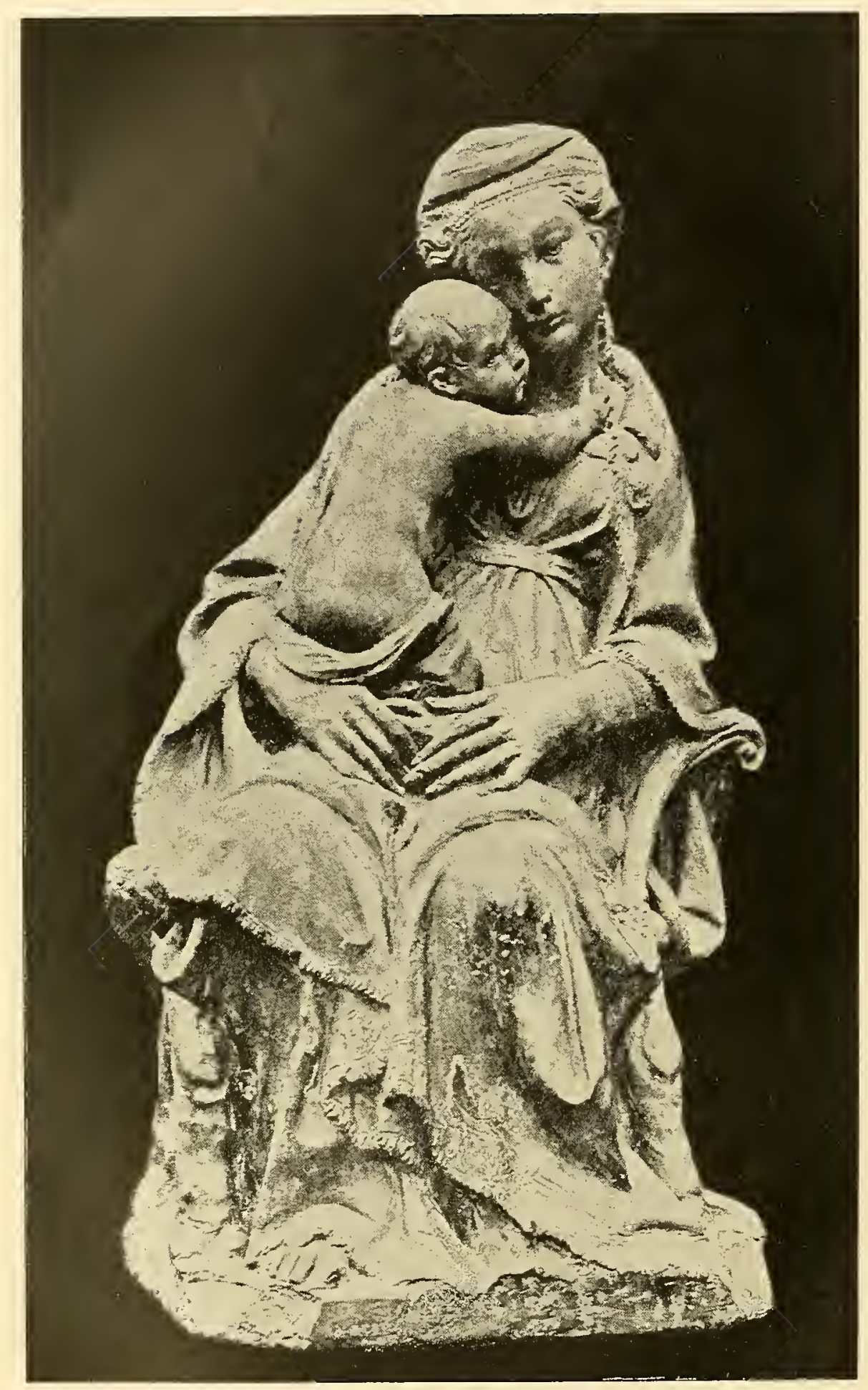

Londra - South Kensington Museum

(Maestro della Cappella Pellegrini) 


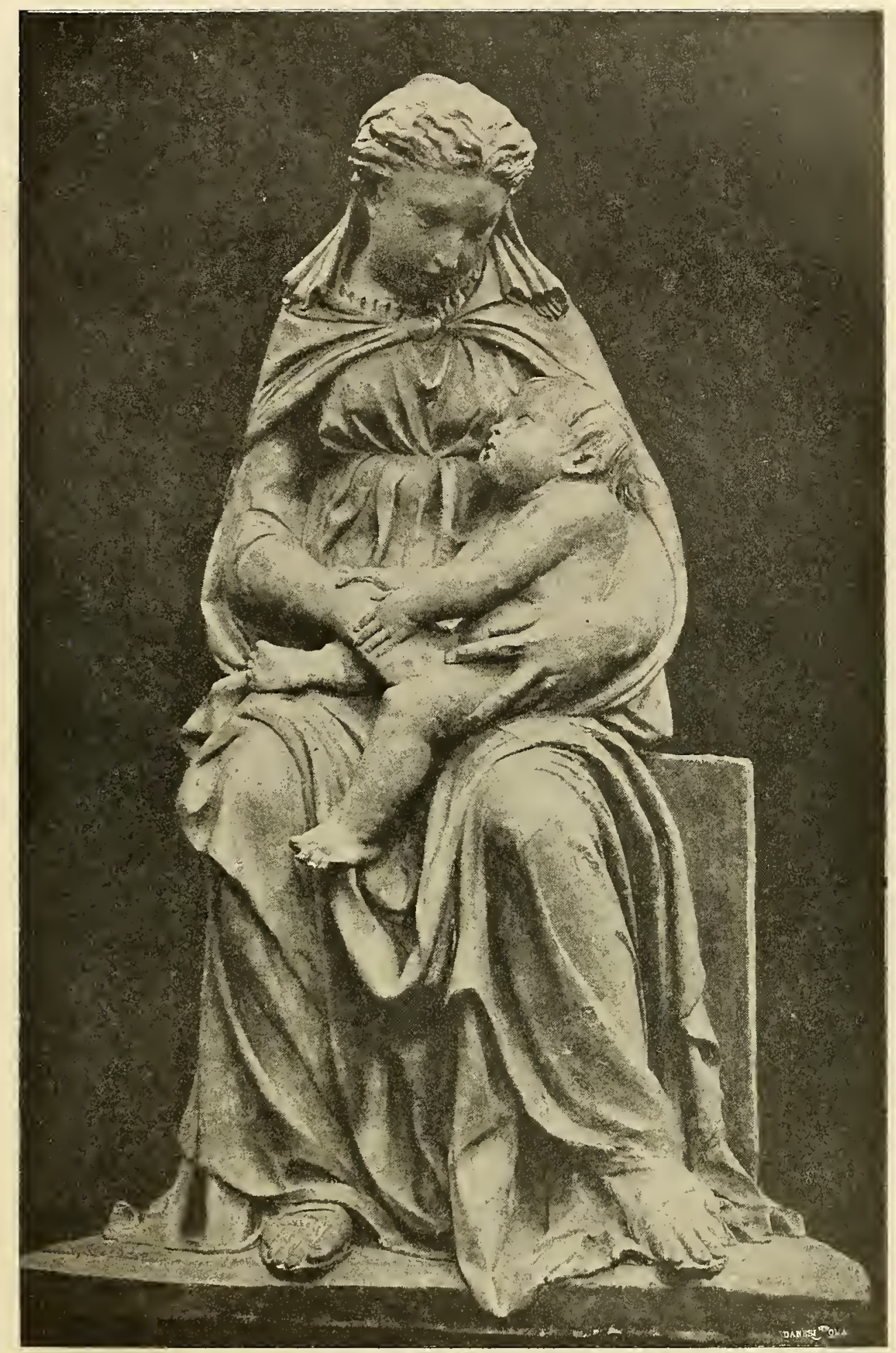

Londra - South Kensington Museum

(LUCA DELLA Robeia) 
l'aberrazione del disegno, benchè in essi pure si racchiudessero germi dell'arte avvenire, la quale conserverà per le sue Madonne la maestà dei troni e le corone d'angioli.

Di tempo prossimo a' musaici di Sant'A pollinare Nuovo è quello dell'abside della cattedrale di Parenzo, in cui la Vergine, fuori dal ciclo delle composizioni evangeliche, siede gloriosamente nel centro della conca absidale,

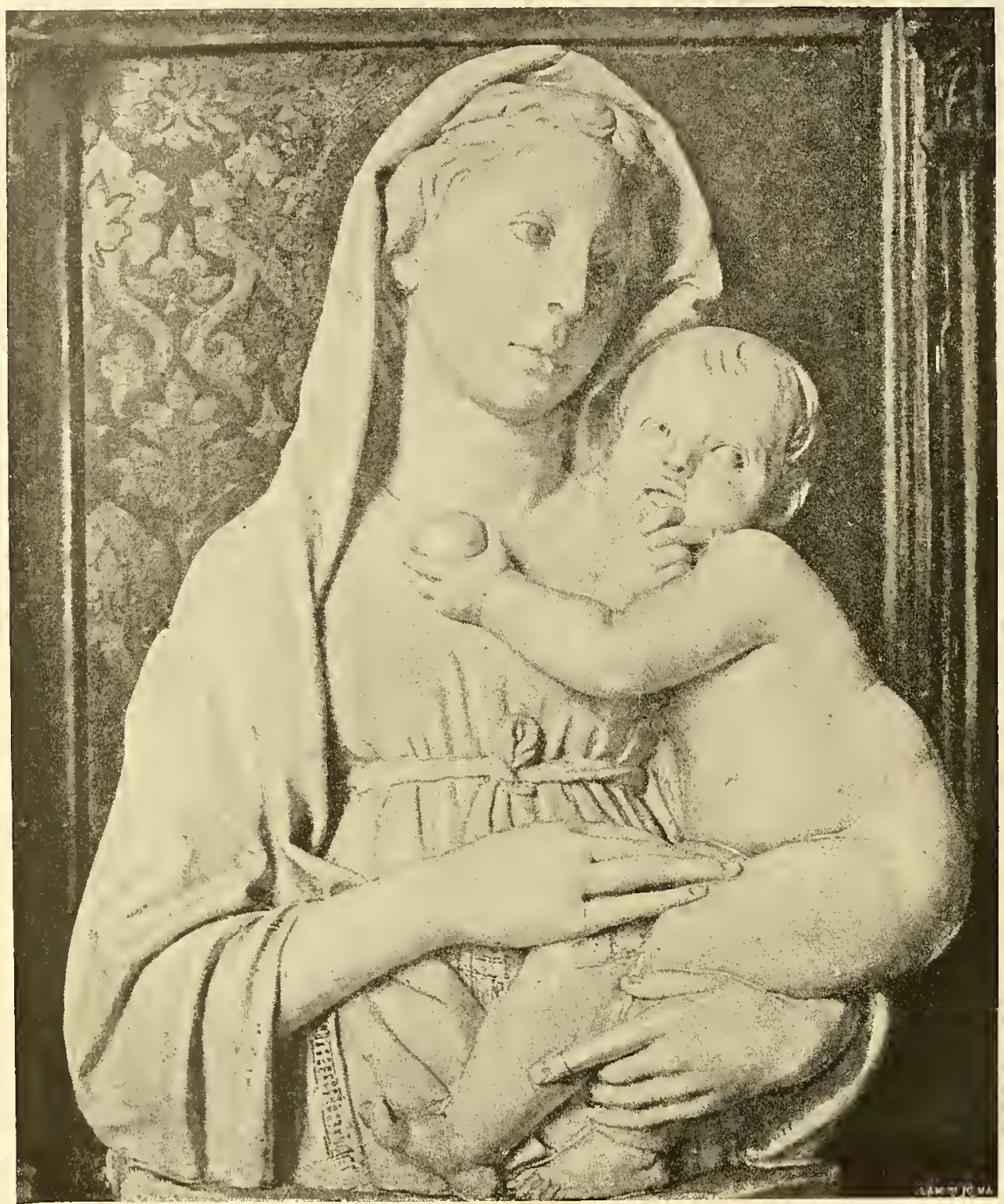

Imperiale Museo di Berlino

(LUCA della Rombia) 
cinta di nimbo il capo, con veste bianca ricamata d'oro e col manto oscuro. Il suo tipo rassomiglia a quello della Nicopea, solo che l'angolo degli

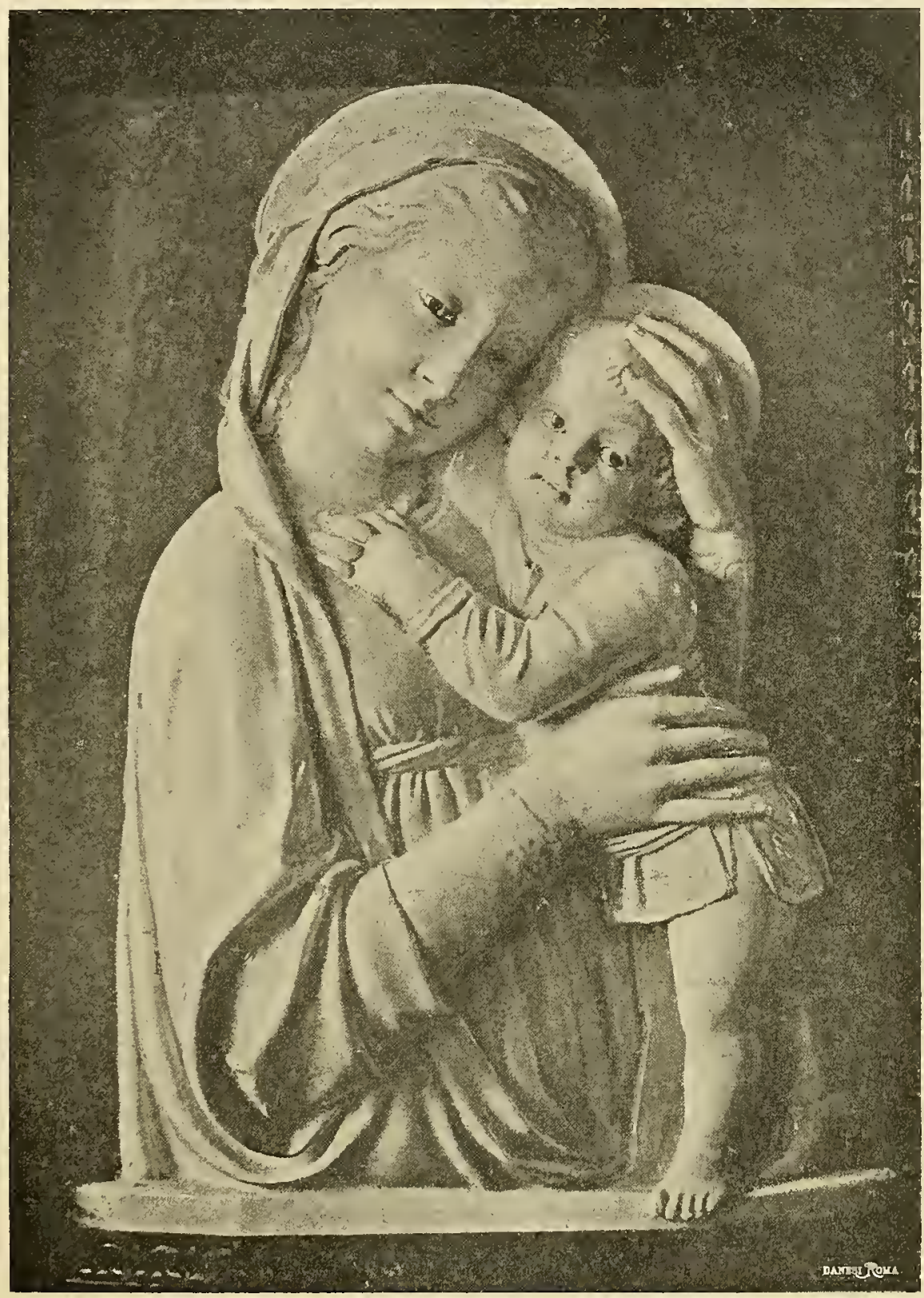

Museo Nazionale di Firenze

(LuCA DELLA ROBEIA)

occhi, aperti in modo strano, diviene più tagliente, e sotto le pupille alzate scorgesi il bianco della sclerotica. Tiene sulle ginocchia il Bambino, che ha un rotolo nella sinistra e benedice con la destra; due angioli con lunghe 
aste le si drizzano ai lati: appresso alcuni santi, un vescovo, un arcidiacono col figlio le tributano onori e le porgono voti. Non più dunque i soli angeli

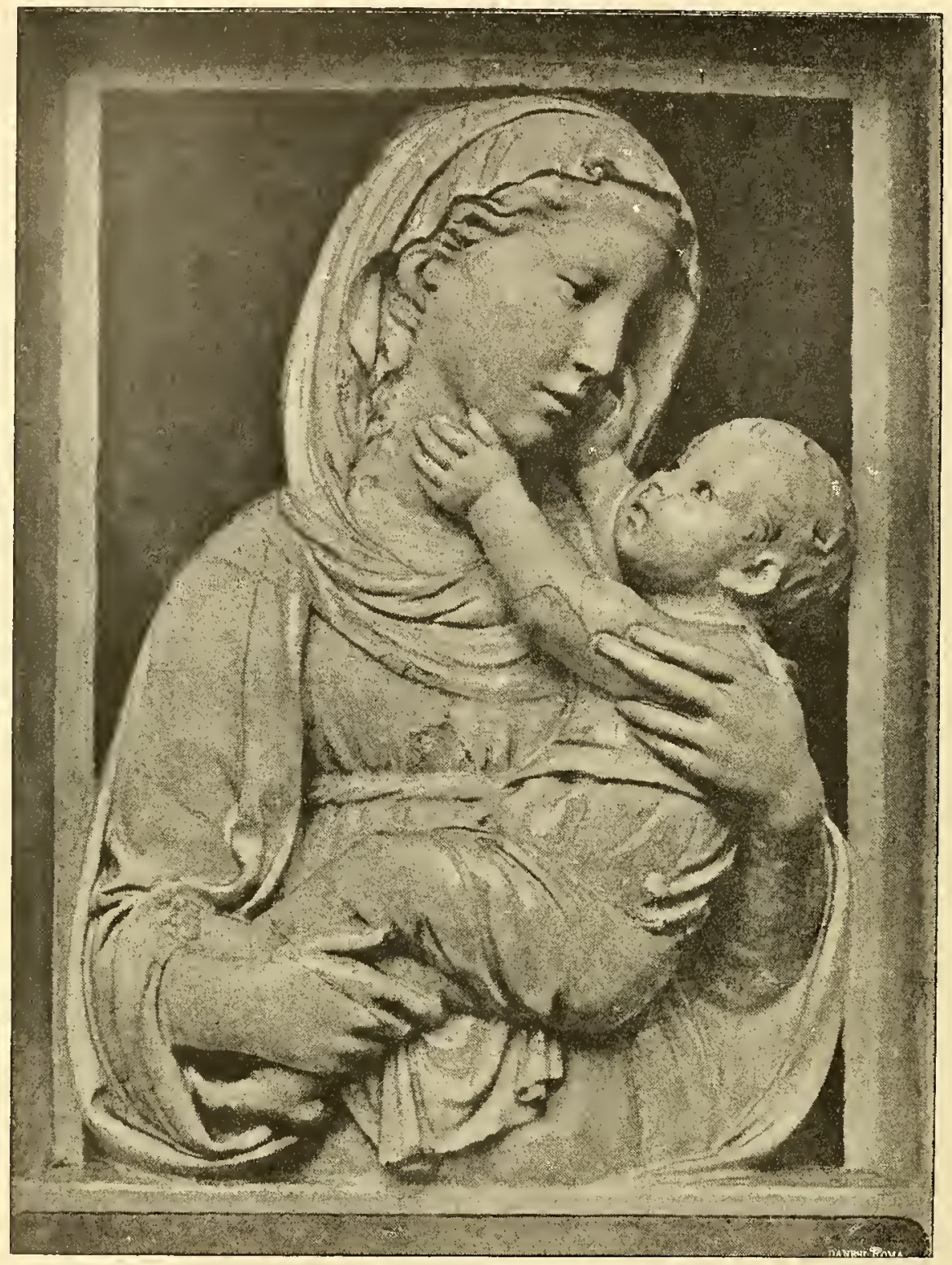

Museo di Berlino

(LUCA Della Robia)

fanno corteo d'onore a Maria; li accompagnano santi e mortali. Già Elladio, nello scrivere la vita di San Basilio, aveva fatto menzione di un quadro rappresentante la Vergine e San Mercurio, onde può ritenersi che in tempi 
prossimi a Costantino si cominciassero a raggruppare i santi ai lati della Vergine. Come intorno al Redentore santi e mortali si erano schierati sulle absidi delle basiliche, così si schierano nel firmamento figurato intorno alla Regina del cielo e della terra. I canti del popolo si uniscono a quelli degli angeli, alle acclamazioni degli apostoli e dei martiri, agli osanna dei sacerdoti; e la figura di Maria, partecipe nell'eternità dell'impero e dell'onore col divin Figlio e col Padre, ingigantisce nella mente dei fedeli, così come la proporzione della sua immagine va sorpassando, al pari dell'altra del Cristo, la grandezza d'ogni essere. Nel grandeggiare, il suo tipo decade ognor più, e, quantunque arrivino e si diffondano nell'Occidente le antiche Madonne dette di San Luca, modelli dov'era pure un fievole raggio dell'arte antica, la Vergine attribuita ad artefice greco, già nella cappella vaticana, fatta eseguire da Giovanni VII al tempo dell'inizio delle persecuzioni iconoclaste,

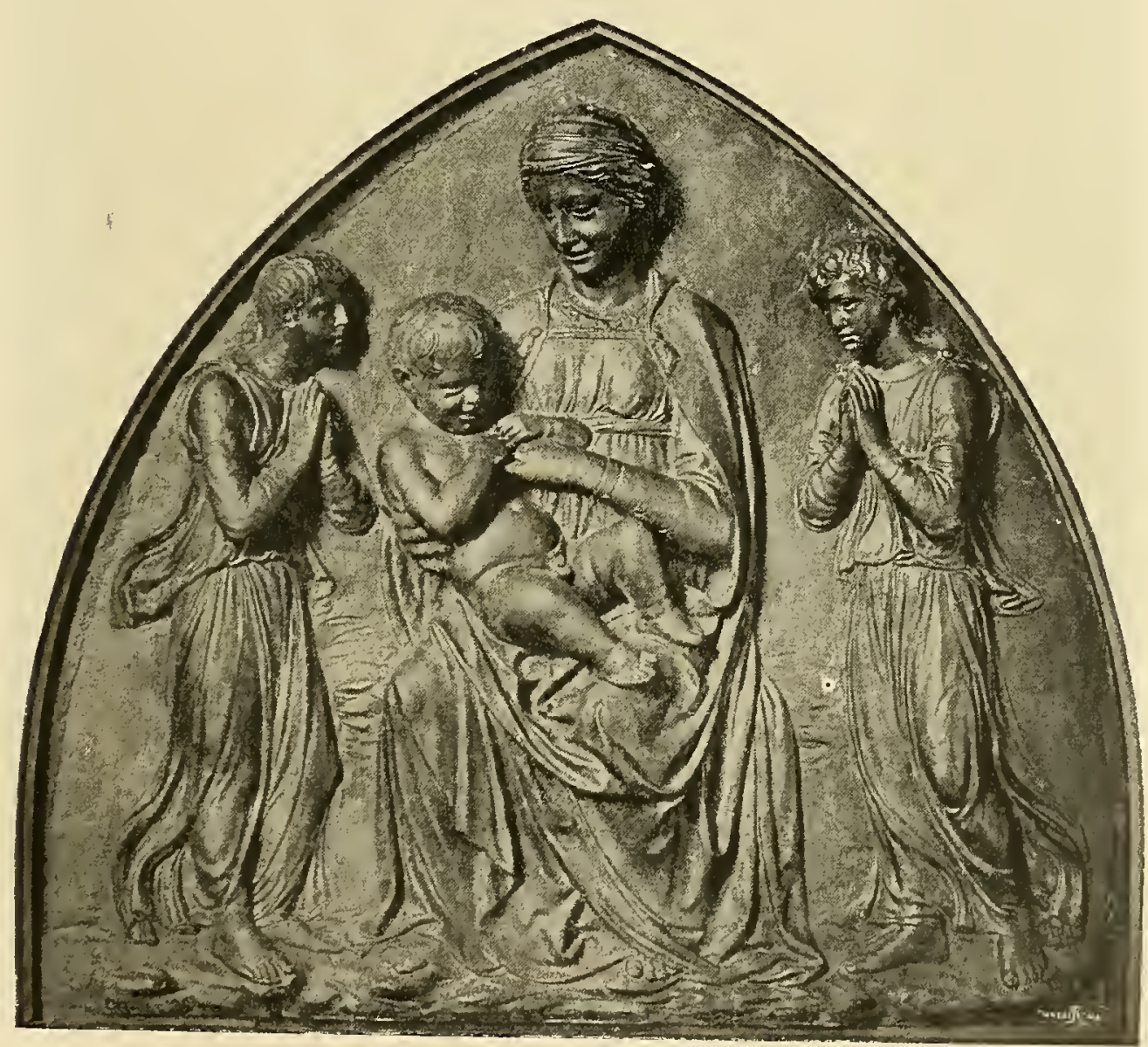

Museo di Berlino

(L UCA DELLA ROBBIA) 


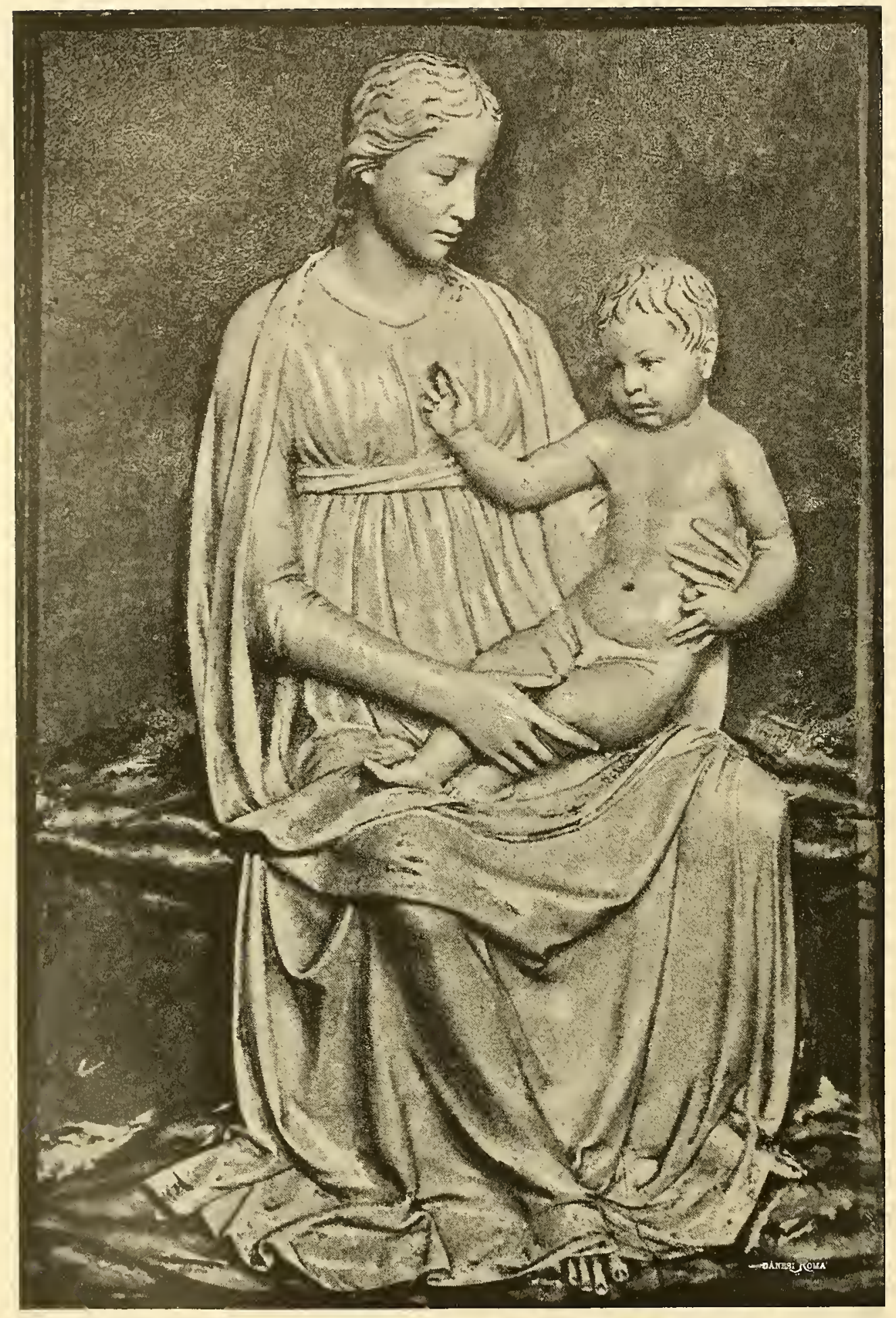

Madonna Frescobaldi

(LUCA DELLA ROBPiA) 


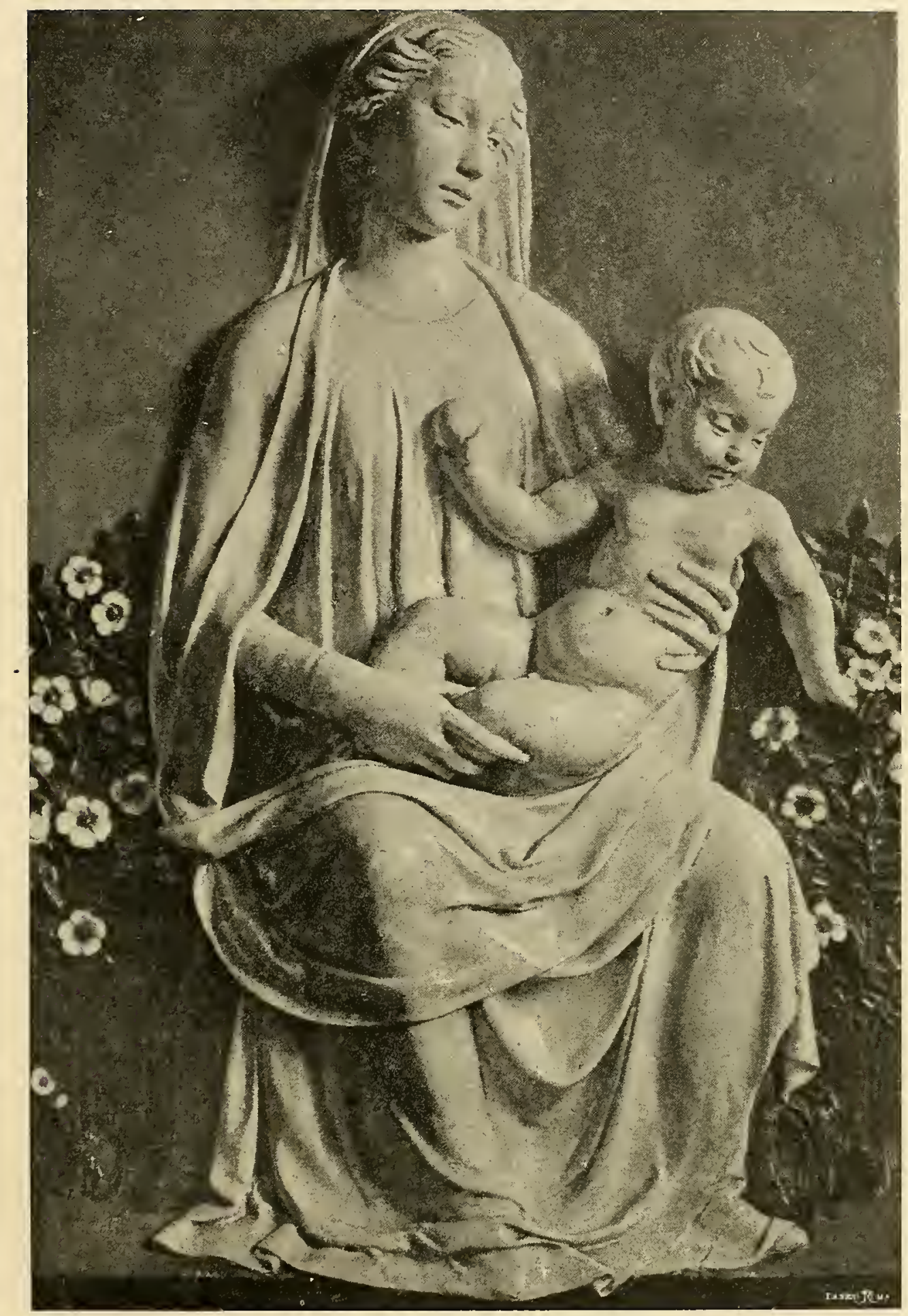

Museo Nazionale di Firenze

(LuCa DElla Robia) 
sembra un idolo con corona radiata, sopraccarico di perle, di gemme e di monili, una mummia d'imperatrice bizantina, adorata dalla nana figura del papa, che sembra una locusta ai piedi di un colosso.

Nè la decadenza ristà, chè al tempo di Pasquale I, ne musaici dell'abside della chiesa di Santa Maria della Navicella, mentre la Vergine sempre

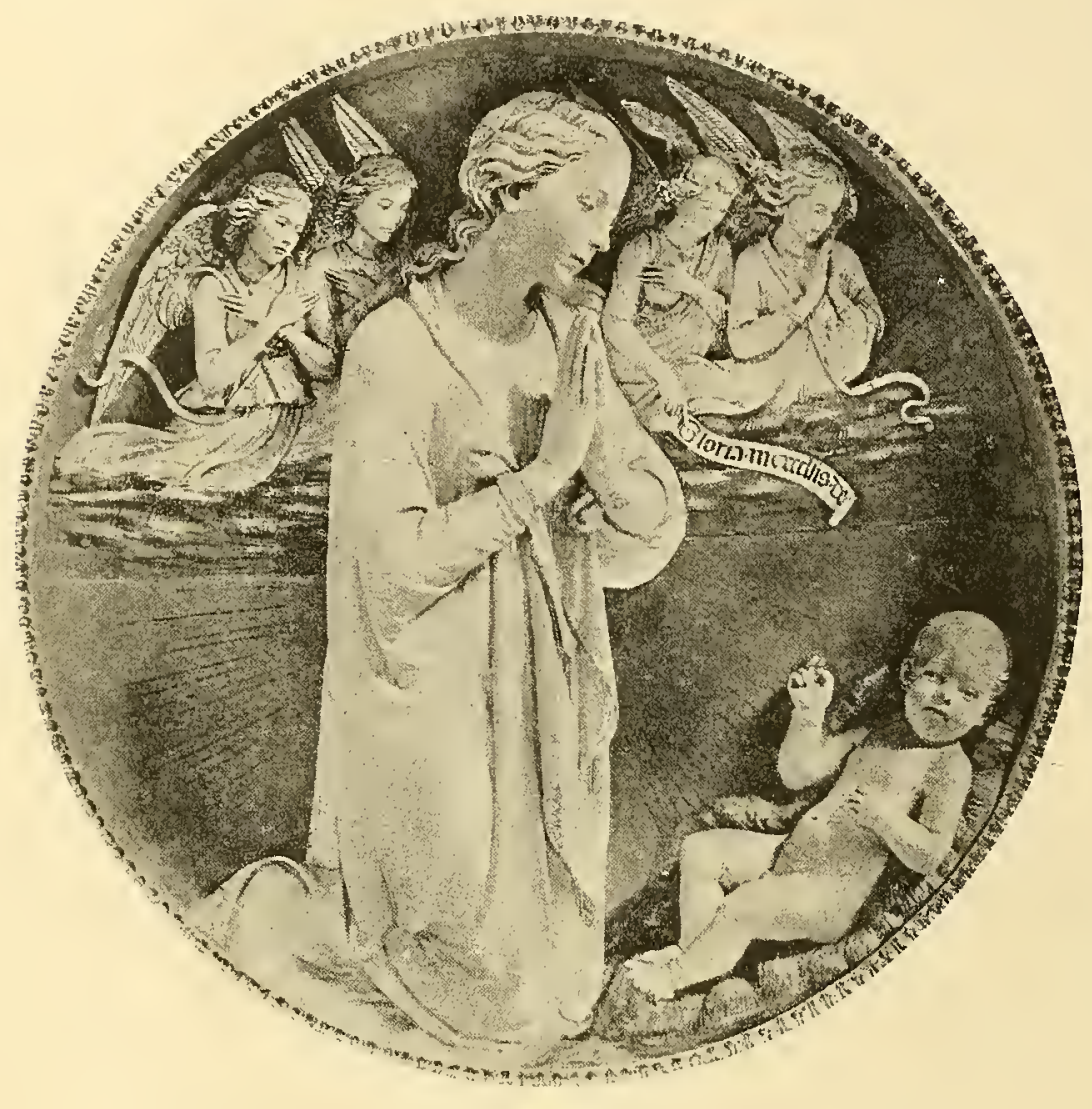

Parigi - Collezione Foulc

( L U CA DEL L A ROBBI )

più si sublima, l'arte sempre più si sprofonda nella barbarie. Nella glorificazione però, nota il Vitet, "la Vergine è triste, i suoi lineamenti sono senza espressione: tutto è severo, rigido, compassato; gli angioli raggruppati intorno al trono sono sottili come cavallette; il fanciullo Gesù è di bruttezza ripugnante». Come la pittura e la scultura, così la poesia ormai non trova accenti naturali, paragona la Vergine alla montagna sublime di Dio sulla quale risplende la purità qual neve eterna, la disegna fulgida luna che ha dato alla terra un sole, la canta come nardo, giglio, rosa, calice di profumi. Per tale 


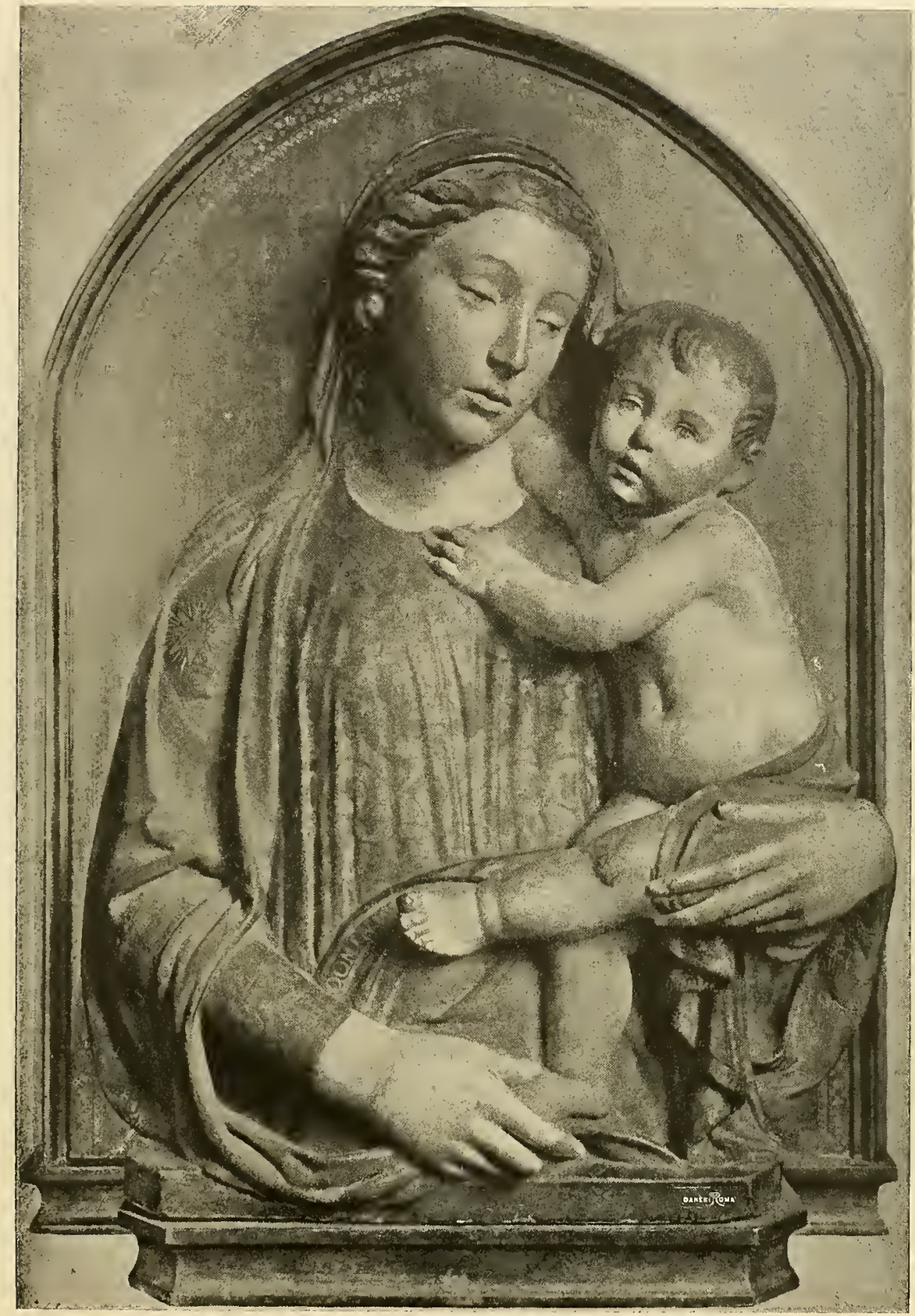

Museo Imperiale di Berlino

(Luca della Robisa) 


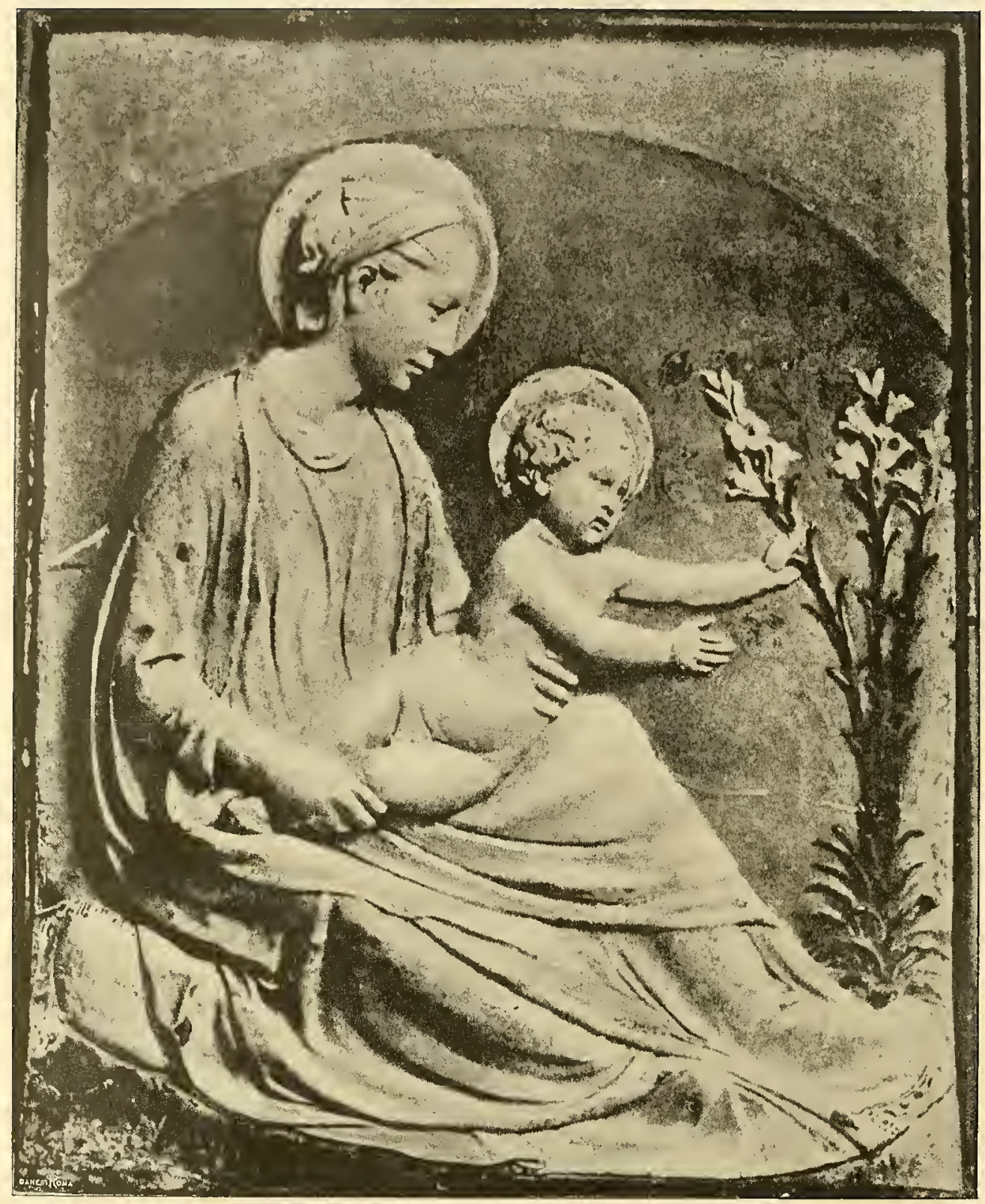

Vienna - Collezione Lichtenstein

(Luca della RobBia) 
indeterminatezza di pensieri e sorreccitazione delle menti Maria, perduto ogni contorno, diviene come un'ombra gigante sul broccato d'oro dei cieli. Ma il concetto della sua apoteosi permarrà nell'arte, e vivrà poi nelle Assunzioni e nelle Incoronazioni.

Dagli abissi del ix e del $x$ secolo l'arte comincia lentamente a ritrarsi,

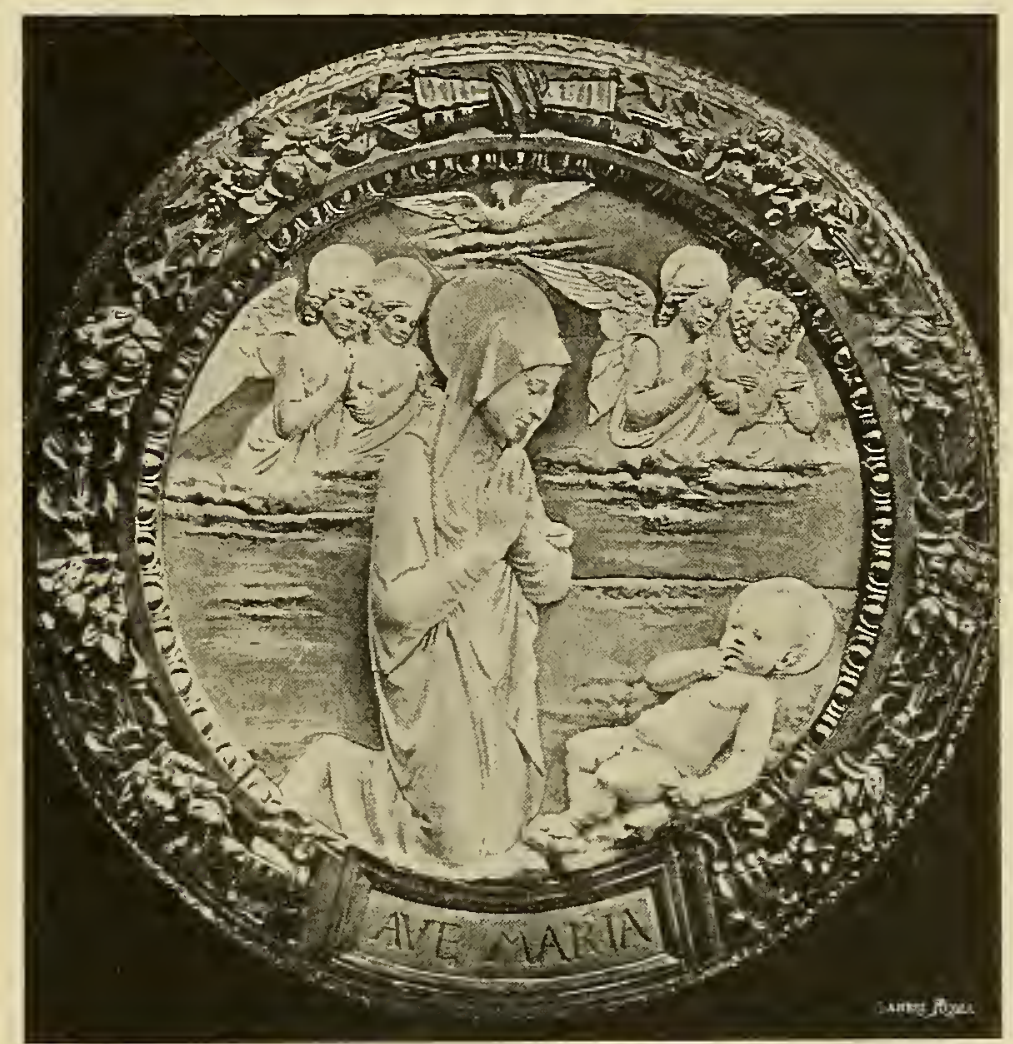

Firenze - Collezione privata

( A NDREA DELLA ROBBIA)

rimaneggiando le forme venute in luce nelle prime basiliche cristiane, ispirandosi alle nuove leggende, che spuntano come palme nel deserto. Rifiorisce l'arte a Bisanzio entrata nella sua seconda età d'oro; e i manoscritti ridono di miniature da cui raggia di nuovo la classica bellezza. Ma il tipo di Maria si colora appena di venustà umana, appena si scalda la rigida sacerdotessa. Solo a' piedi delia Croce ella comincia alquanto a riflettere l'affanno della vita che punge gli uomini del Medio Evo, e sembra presa da contrazioni dolorose o gemere come nello Stabat Mater. Fuori dal ciclo delle composizioni evan geliche ella rimane invece nello splendore della gloria, con gli astri che 


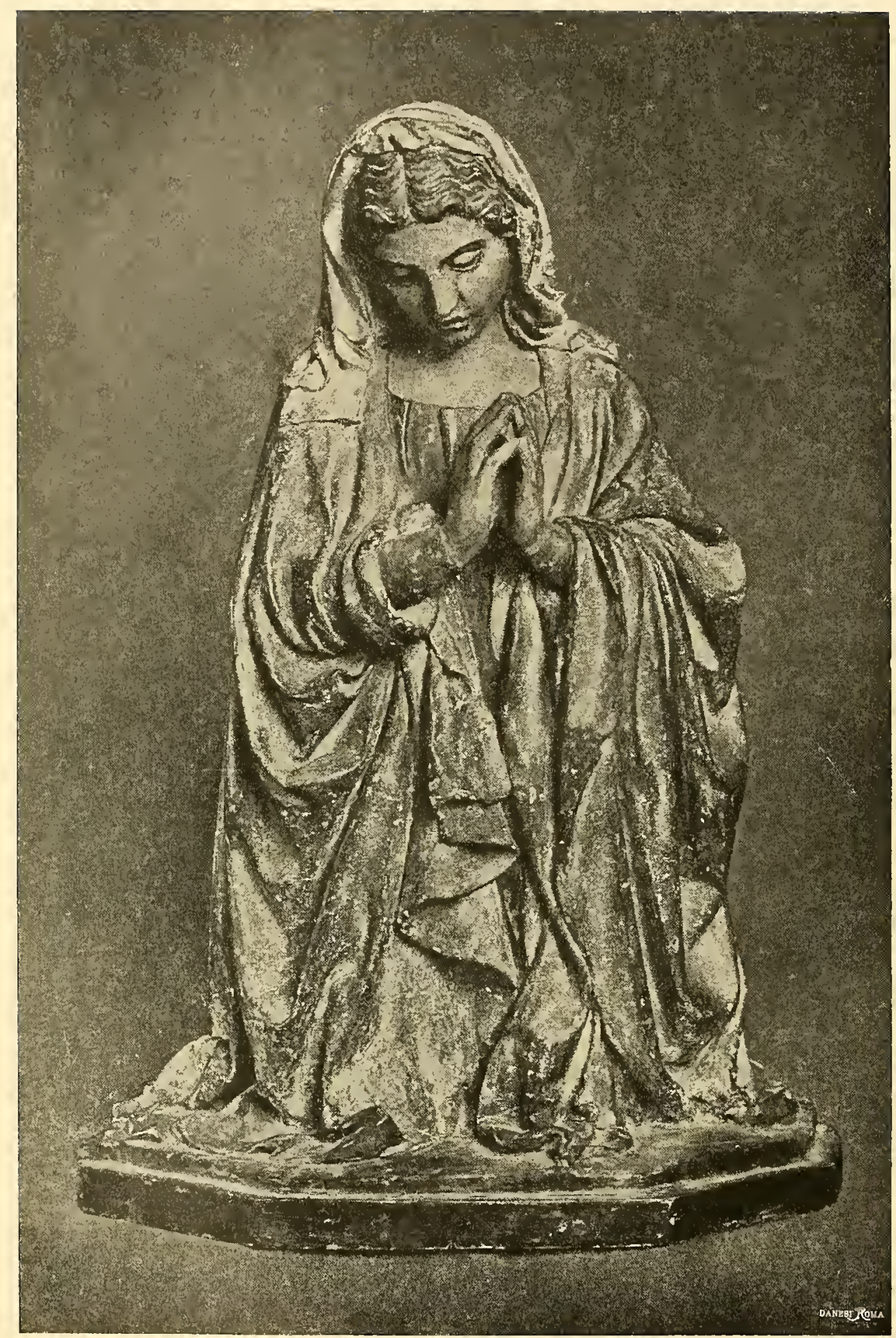

Berlino - Museo

(LUCA DELLA ROBBIA, ARTE DI) 


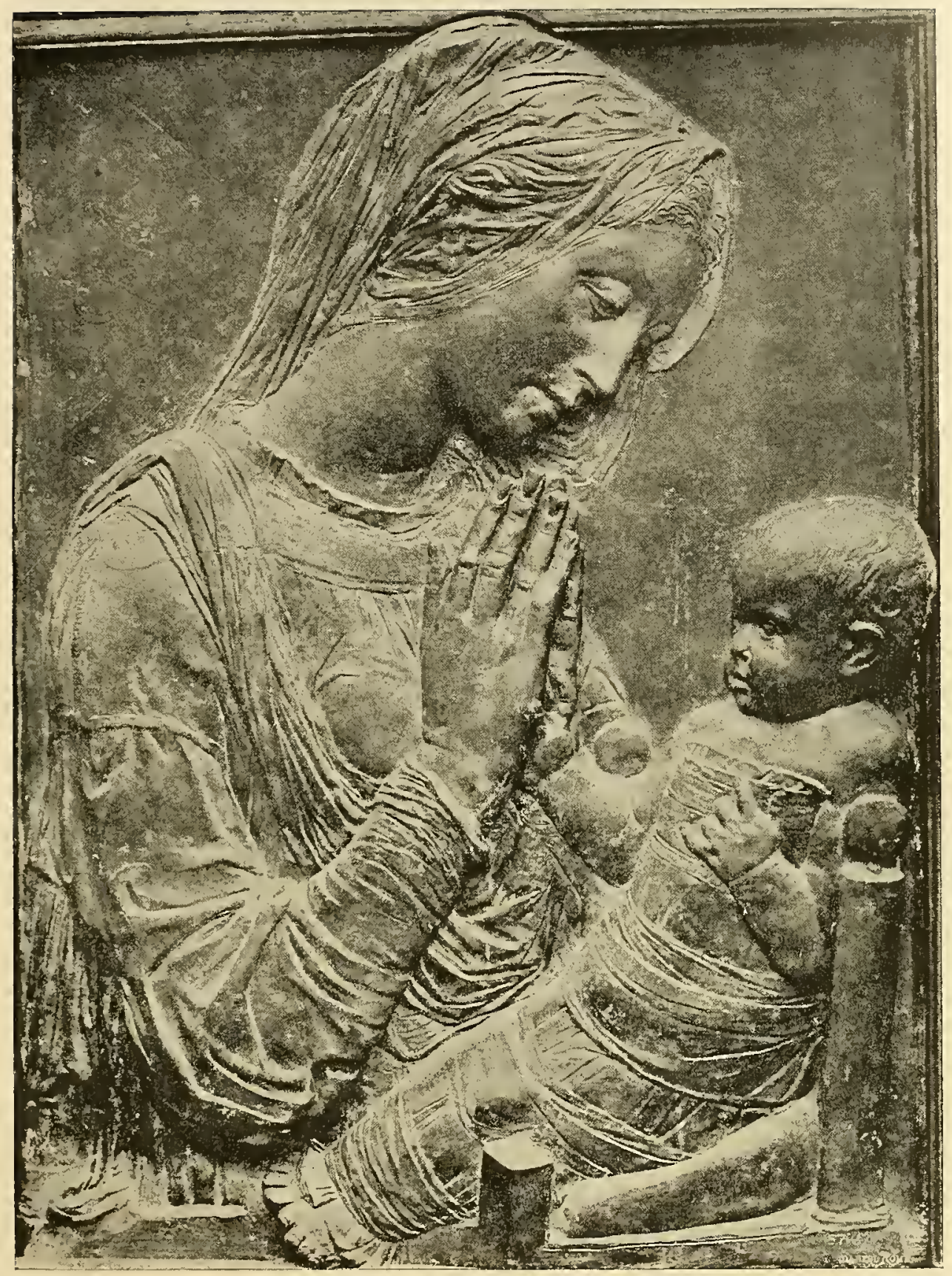

Londra - South Kensington Museum

(Donatello) 


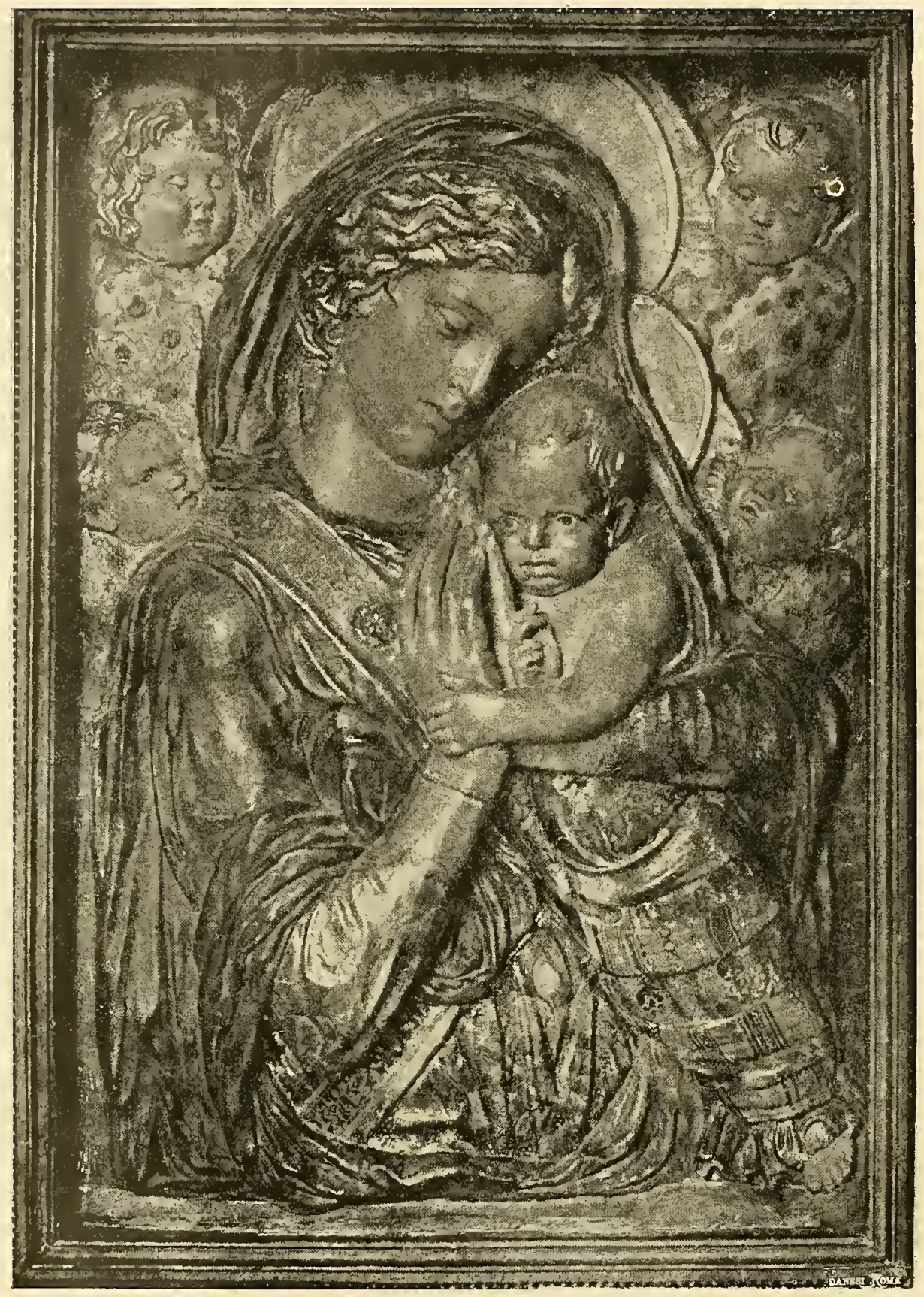

Berlino-Museo

(Doxatello) 
roteano sotto di lei, $\mathrm{i}$ patriarchi e $\mathrm{i}$ profeti che ricordano le speranze e $\mathrm{i}$ vaticini, $\mathrm{i}$ personaggi del nuovo Testamento che la benedicono, $\mathrm{i}$ santi che le porgono omaggio e le coorti degli angioli che s'infiammano alla sua luce.

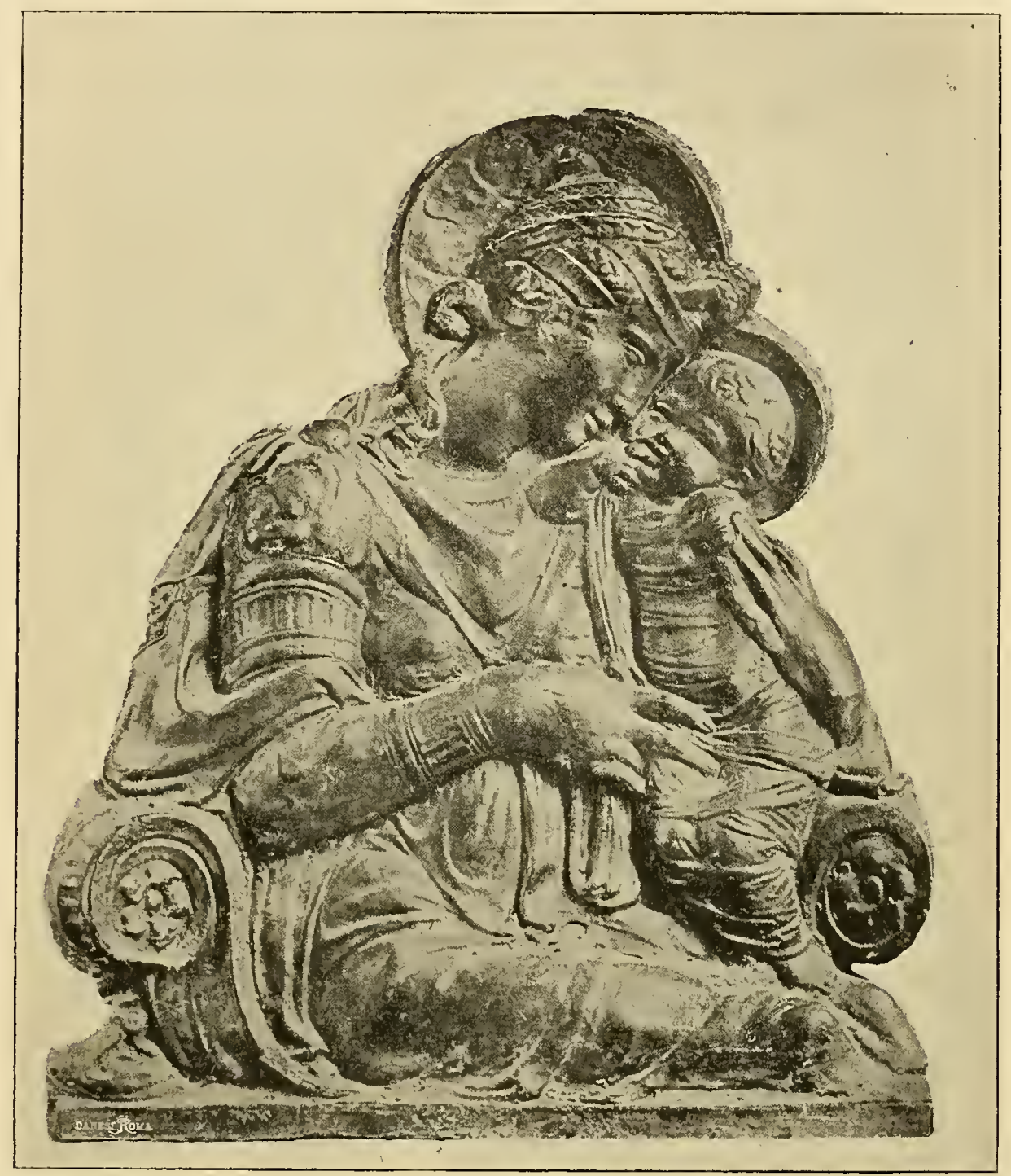

Parigi - Louvre

(DONATELLO)

I modelli delle opere romane, dal iv al vi secolo, e la scuola di musaico ch' ebbe la sua culla nel chiostro di Montecassino contribuirono però a togliere alle figure della Vergine la immobilità di cariatide assira o di sfinge egiziana dalla impronta ieratica, dall'aspetto ascetico esterrefatto. E vi contribui pure lo sforzo per isvolgere gli episodì della vita della Vergine in 
composizioni ove essa doveva prendere un atteggiamento o fare alcun gesto; dalle composizioni poi il tipo potrà balzar fuori animato da sentimenti umani.

Mentre intorno al secolo $\mathrm{x}$, in Roma, nella larghezza d'esecuzione delle opere d'arte trapela qualche reminiscenza del sentimento antico della realtà, sobrio e chiaro, l'arte bizantina si espande da per tutto trionfante e si contrappone in Italia alla rude ma ardente arte romanica. Gli artisti greci eleganti e fastosi, con le tessere musive, le agemine d'oro e d'argento, i codici miniati, si trovarono di fronte $\mathrm{i}$ tagliapietra, $\mathrm{i}$ marmorari ricercanti entro ai macigni l'anima dell'arte; le opere bizantine tutte ordinate, piane, monacali, pazienti, sottili, si trovarono a riscontro con le opere occidentali irrequiete, libere, scabre, con luci ed ombre in contrasto. Allora l'arte bizantina, senza più patria, mandava gli ultimi respiri sulla nostra terra, mentre nei comuni d'Italia la nostra cercava la propria idealità con foga audacissima.

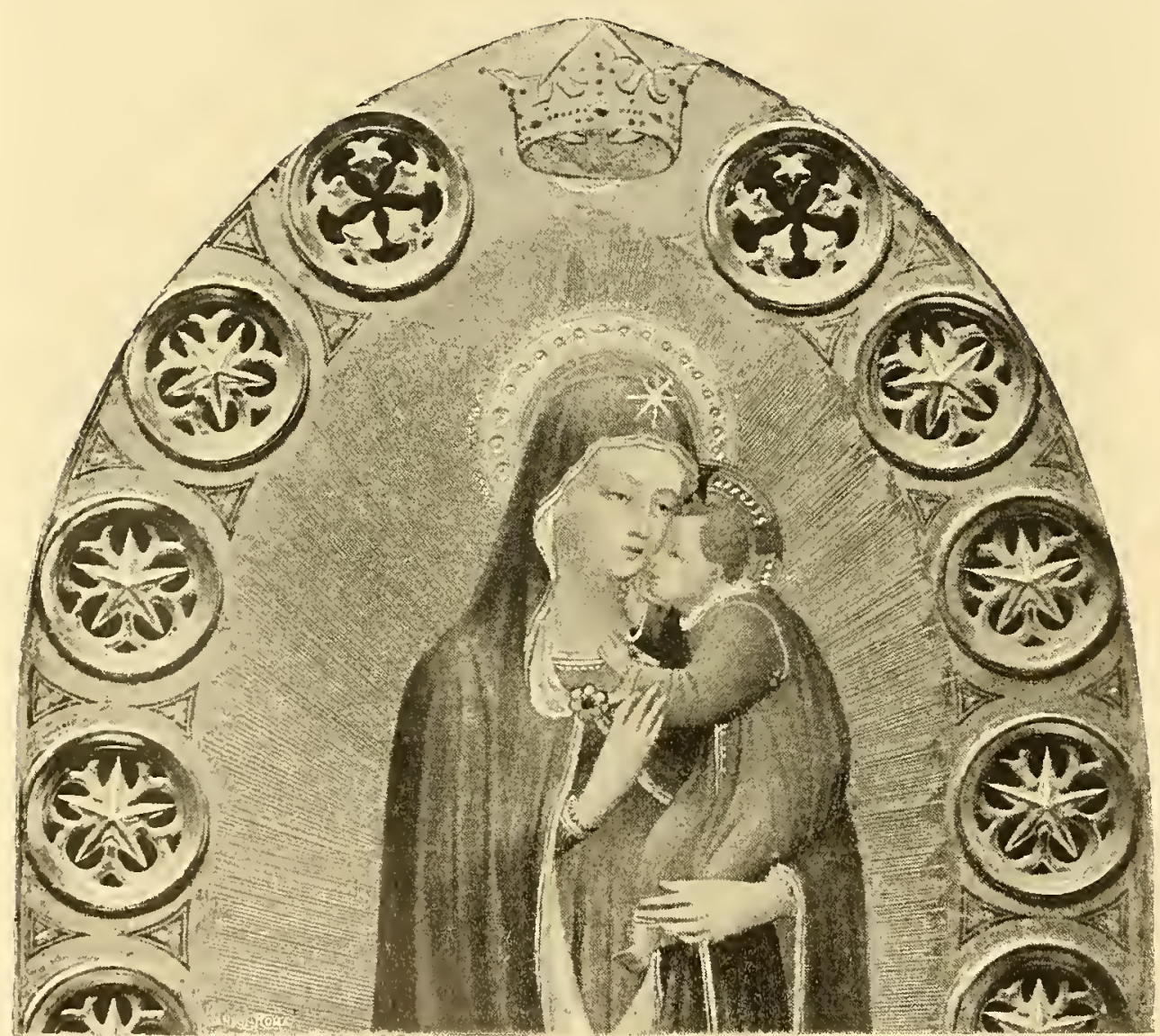

Firenze - Museo di San Marco

(Beato Angelico) 


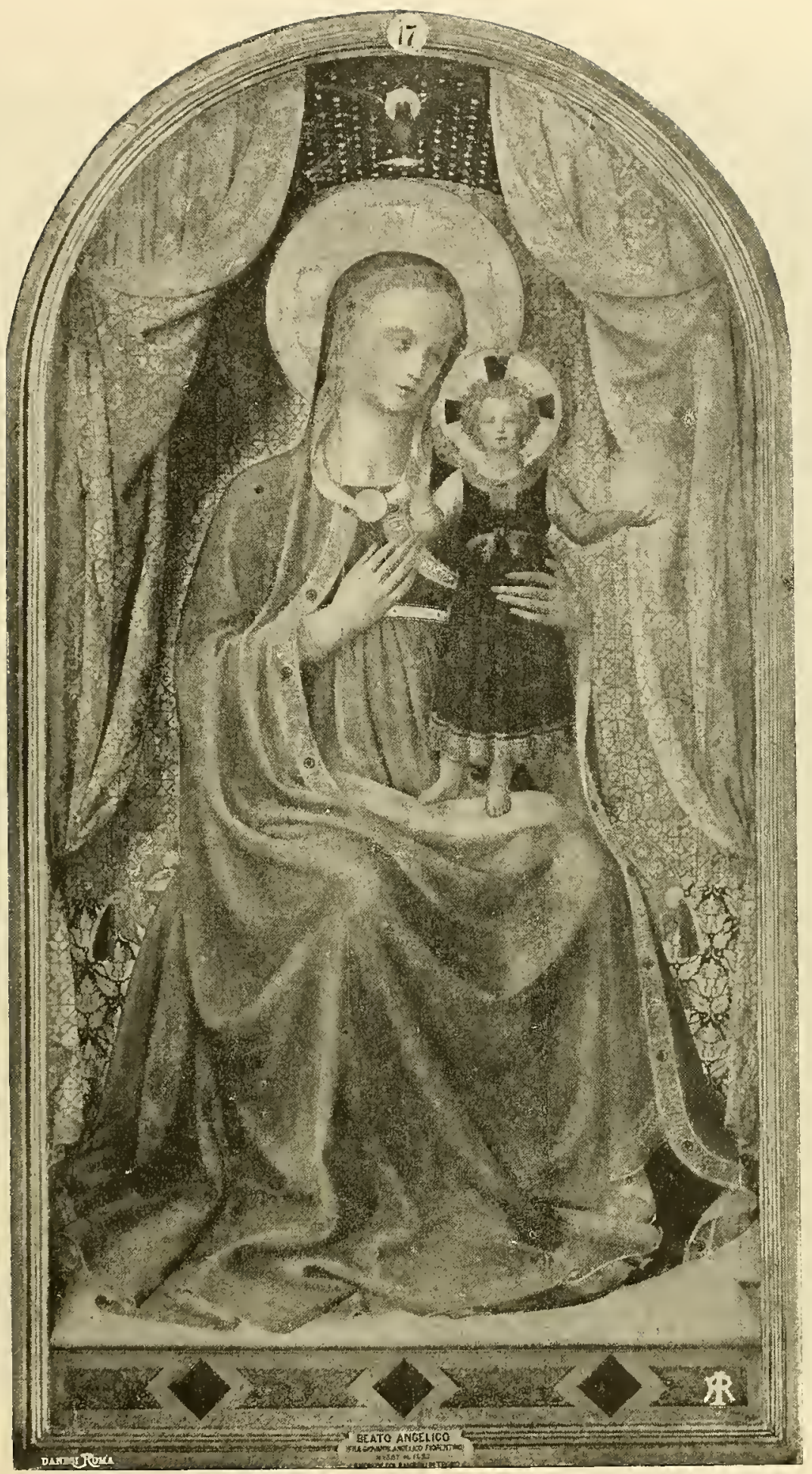

Firenze - Galleria degli Uffizi

(Beato Angelico) 


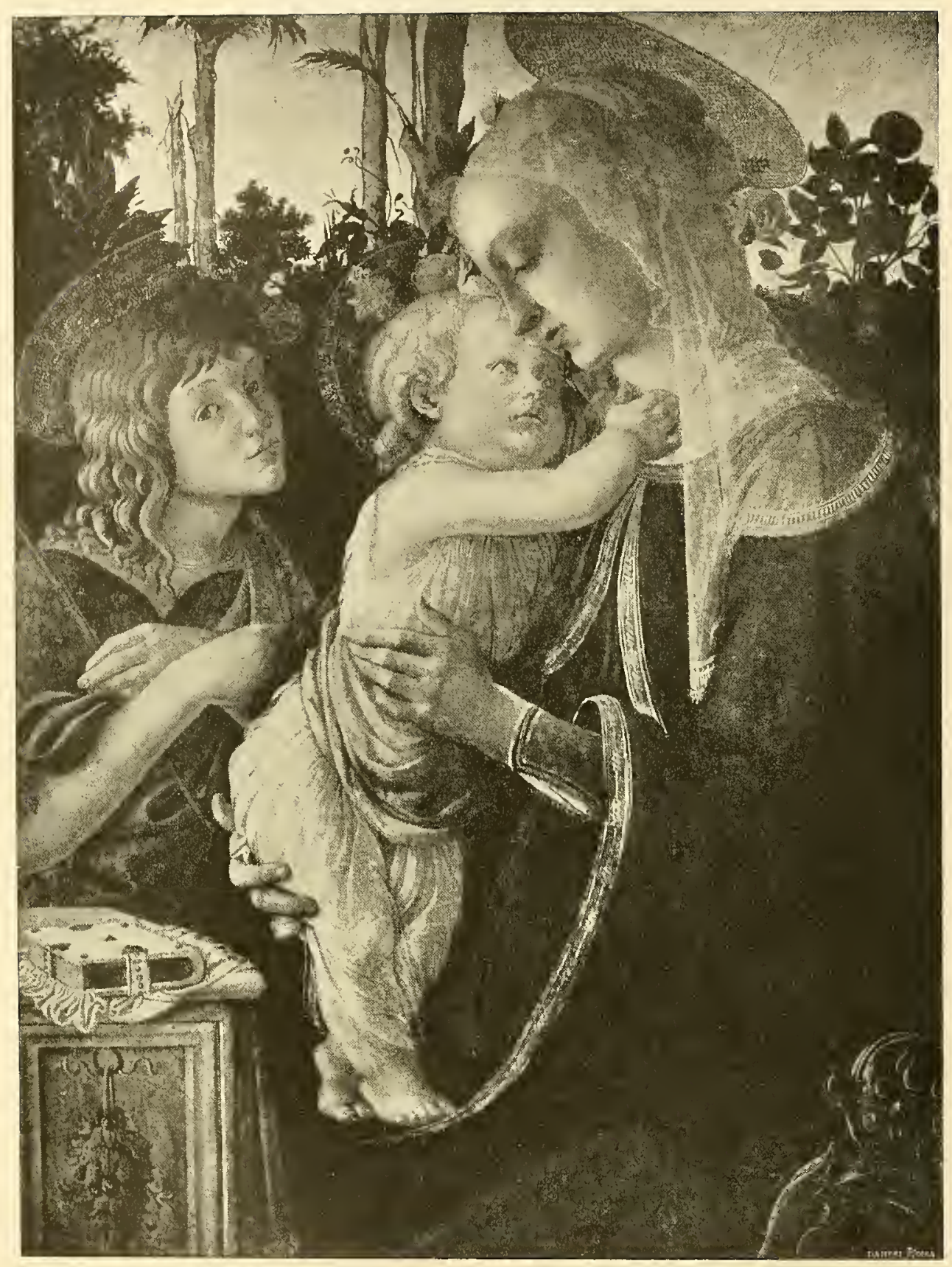

Parigi - Museo del Louvre

(BotTiCelli) 


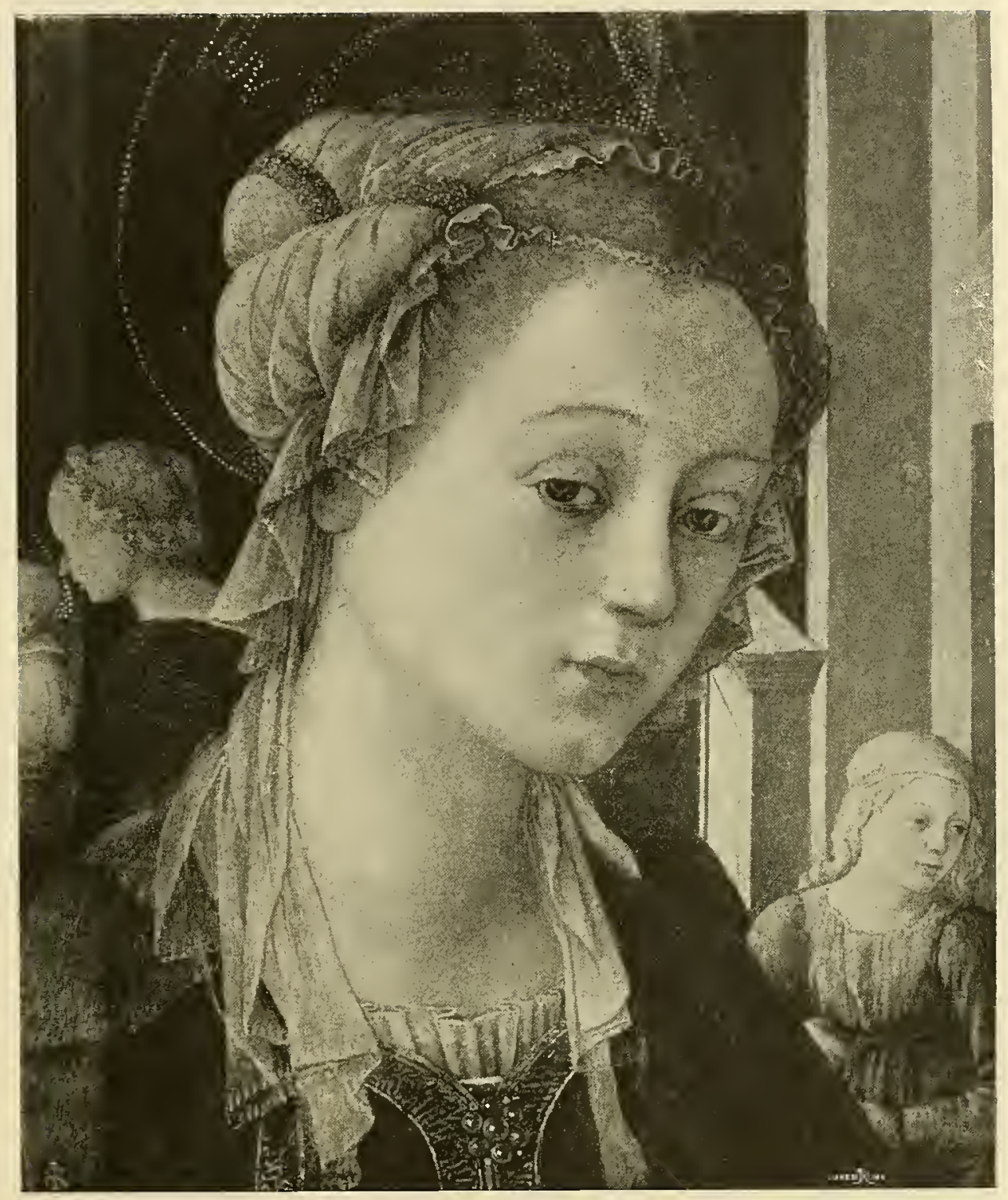

Particolare di un tondo. Firenze - Galleria Pitti (Filippo LipPI) 


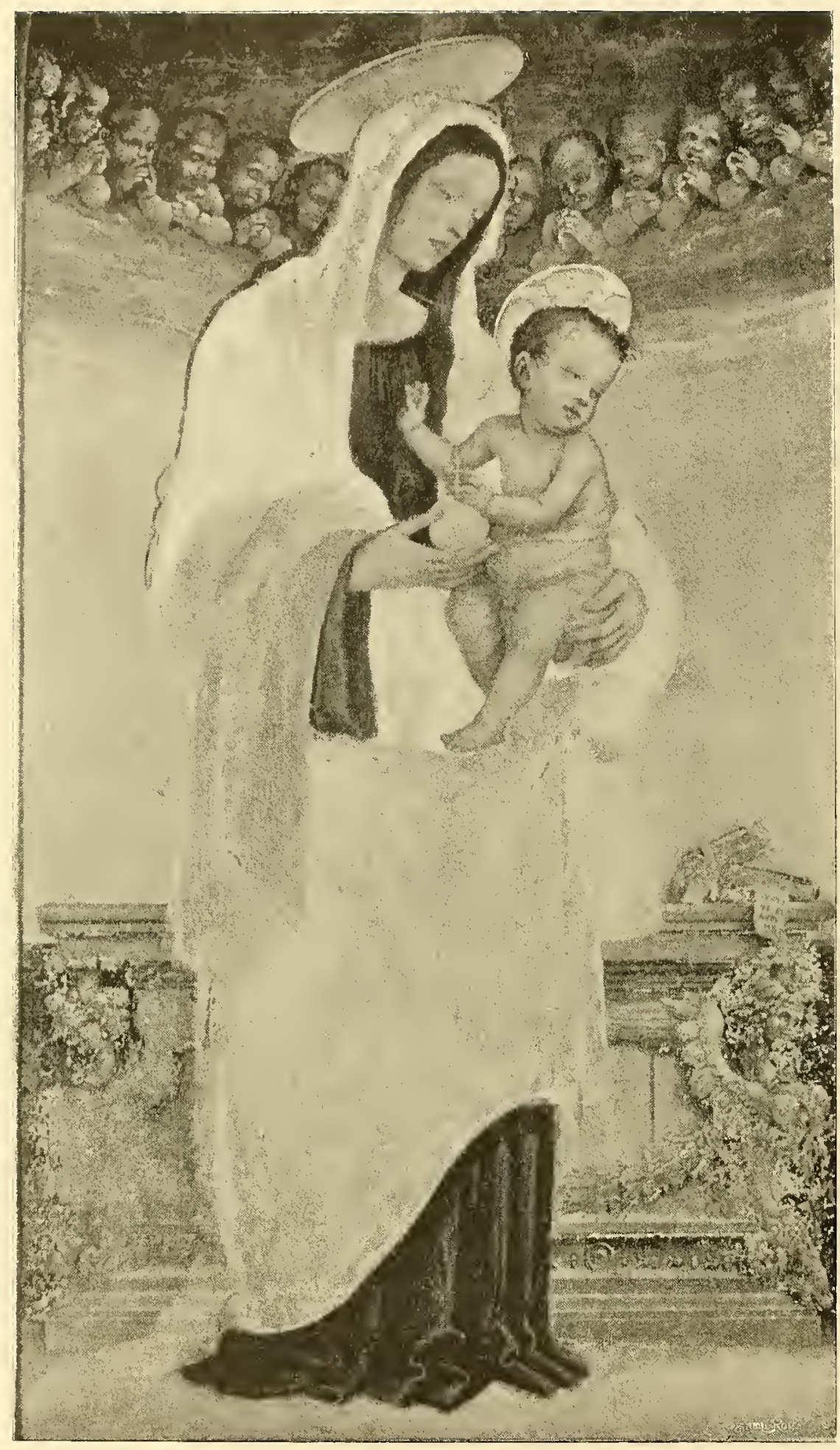

Prato - Tabernacolo sul Canto al Mercatale

(FILIPPINo Lippi) 


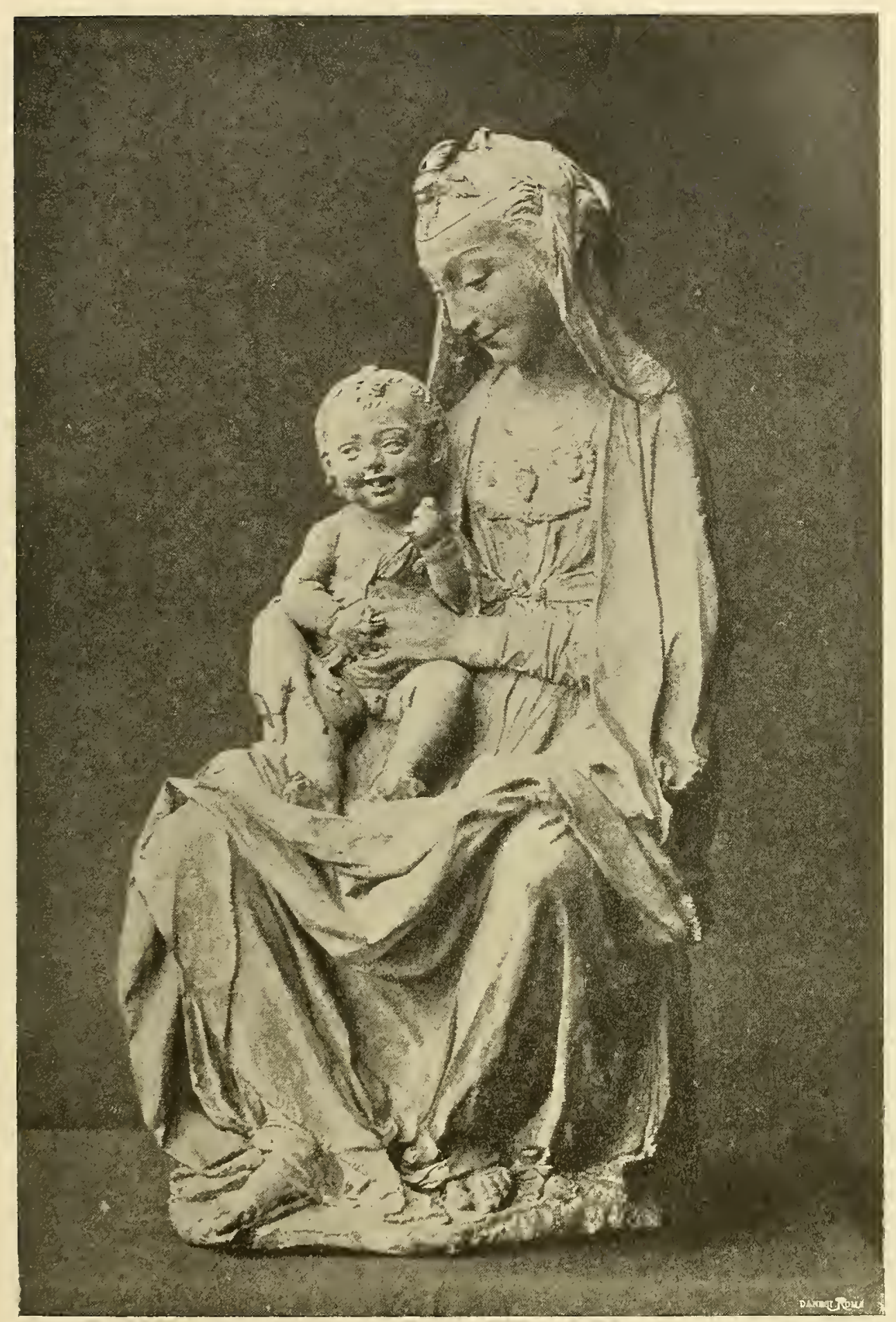

Londra - South Kensington Museum (Rossellino) 


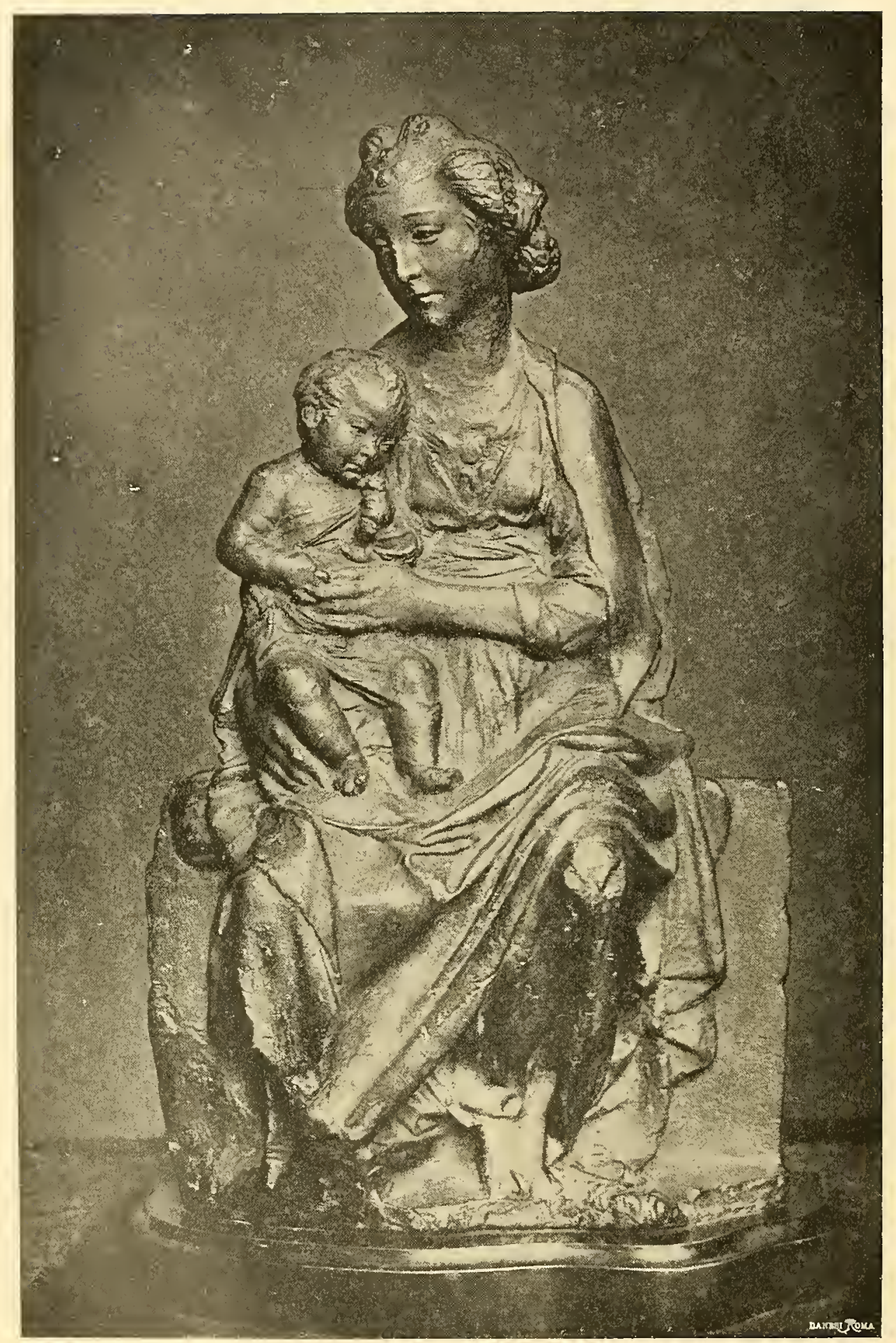

Parigi - Collezione Gustave Dreyfuss

(Rossellino) 


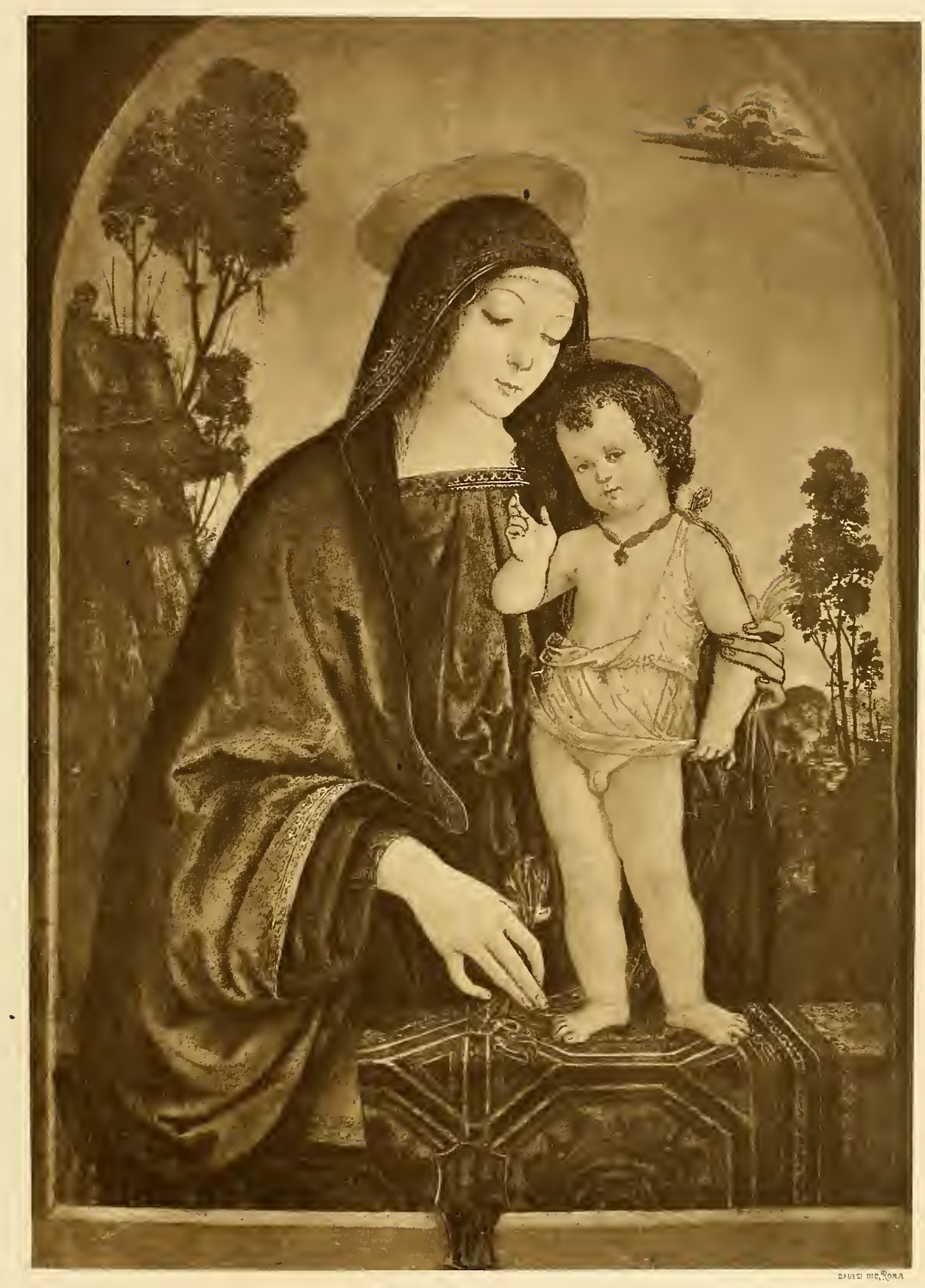

GALLERIA NAZIONALE DI LONORA

PINTURICCHIO 


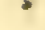


Per qualche tempo ancora il misticismo, che aveva annientato la ragione e sostituito i sogni, le allucinazioni, le paure alla realtà, non permise che le inmagini sacre riprendessero le loro proporzioni; pure si schiariva negli uomini il concetto della vita e la coscienza della propria forza, la città celeste si avvicinava alla terra per diventare a poco a poco la sede della bellezza. Quel sentimento della giusta misura tra l'ideale e il reale, la fantasia e la ragione, che in Grecia aveva respinto o trasformato anche $\mathrm{i}$ miti più mostruosi, portava nelle leggende cristiane un soffio di vita nuova. L'arte romanica si provava intanto ad abbandonare l'apparato imperiale bizantino; ma le figure della Vergine rimanevano lunghe, con occhi non più di moribondi, bensì schizzanti fuor dalle orbite, quasi volessero ammaliare la folla supplice innanzi gli altari; e il

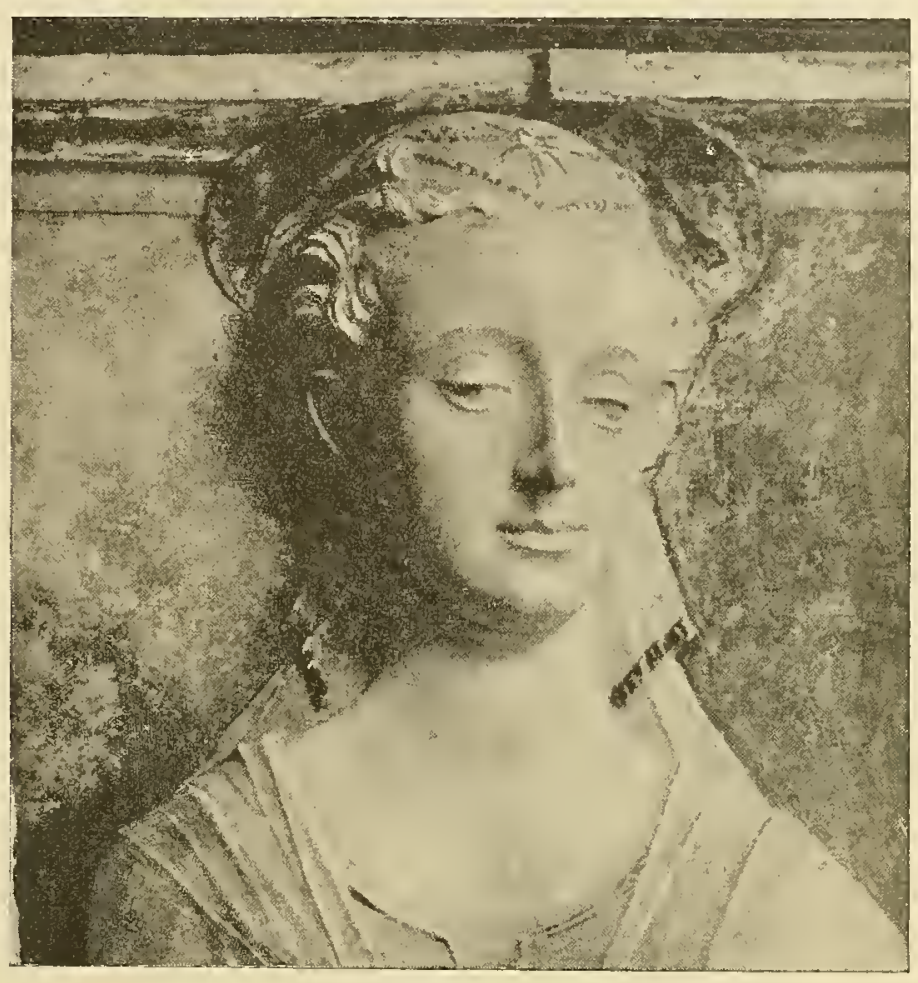

Particolare della Madonna col Bambino. Firenze - Museo Nazionale (MiNo DA Fiesole) volto loro è senile, con forti occipiti, stranamente allungato. L'artista era come un fanciullo che, tentando di rivelar sensi confusi nel cuore, riesca a pronunciare consonanti, non la parola significatrice; come un fanciullo il quale si provi a rendere la forma degli oggetti che gli passano innanzi, e per certe tendenze rimaste nel fondo dell'essere nella sua razza le renda, è vero, martoriate dalle inesperte mani, grossolane, barbare, ma con vivezza e spontaneità tutta sua.

Mentre nei castelli feudali di Provenza, di Francia e di Germania, innanzi alla dama cortese volava la strofe della canzona trovadorica, nelle grandi cattedrali dedicate ovunque a Maria si tenta disegnare l'idealità della donna 
nella figura di lei. Negl' inni sacri la immagine di Maria esce tra le lodi e le preghiere, come figura che si manifesti alla luce col dissiparsi delle nubi d'incenso: Idelberto, rescovo di Tours, ne rede la casta immagine col nitore

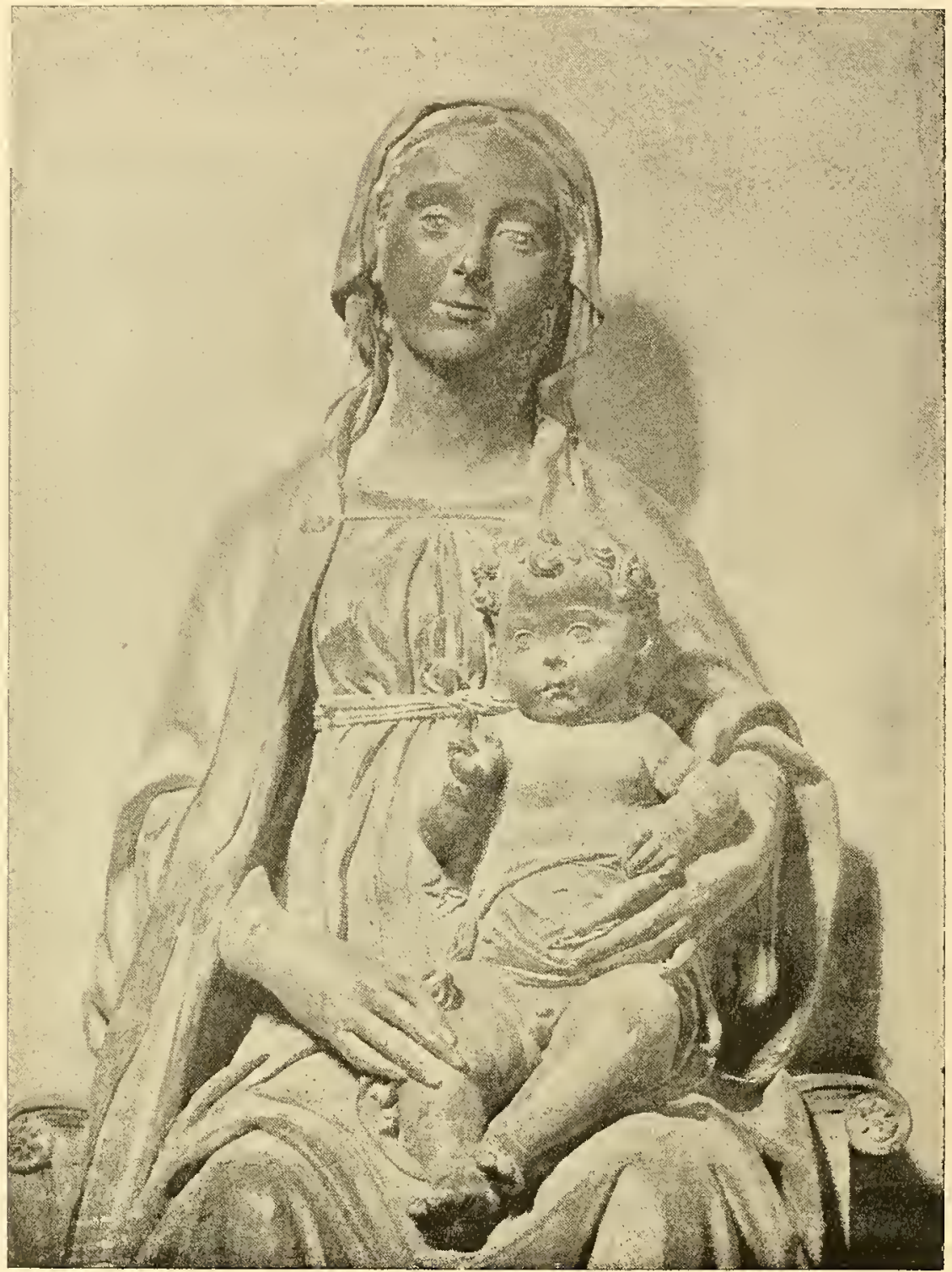

Cattedrale di Prato

(BENEDETTO DA MAIANO)

dell'avorio; it suo fodel Bernardo la rappresenta nell' atto di premere Iddio contro il seno, allorchè egli piangeva per avere il latte, e la proclama bella come l'aurora, e la vede incorruttibilmente fresca, che rallegra per la grazia splendente più dei fiori primaverili, per la dolcezza superiore al timo e al 
balsamo; infine, il trovatore provenzale Foulques de Lunel invoca Maria come la dama del suo cuore. E tuttavia l'ideale clella donna presso le genti trasvola di là da ogni confine della terra o cade nel fango. Solo quando i due concetti della donna, rispetto ed amore, potranno congiungersi, allora l'ideale muliebre troverà l'espressione giusta e bella, lieta di pace, di affetti buoni e miti, di domestiche gioie. Il Medio Evo aveva considerato la bellezza fisica come opera del demonio, la verginità sacrata a Dio come la perfezione della donna; l'Evo Moderno doveva ridare alla bellezza delle figlie d'Eva

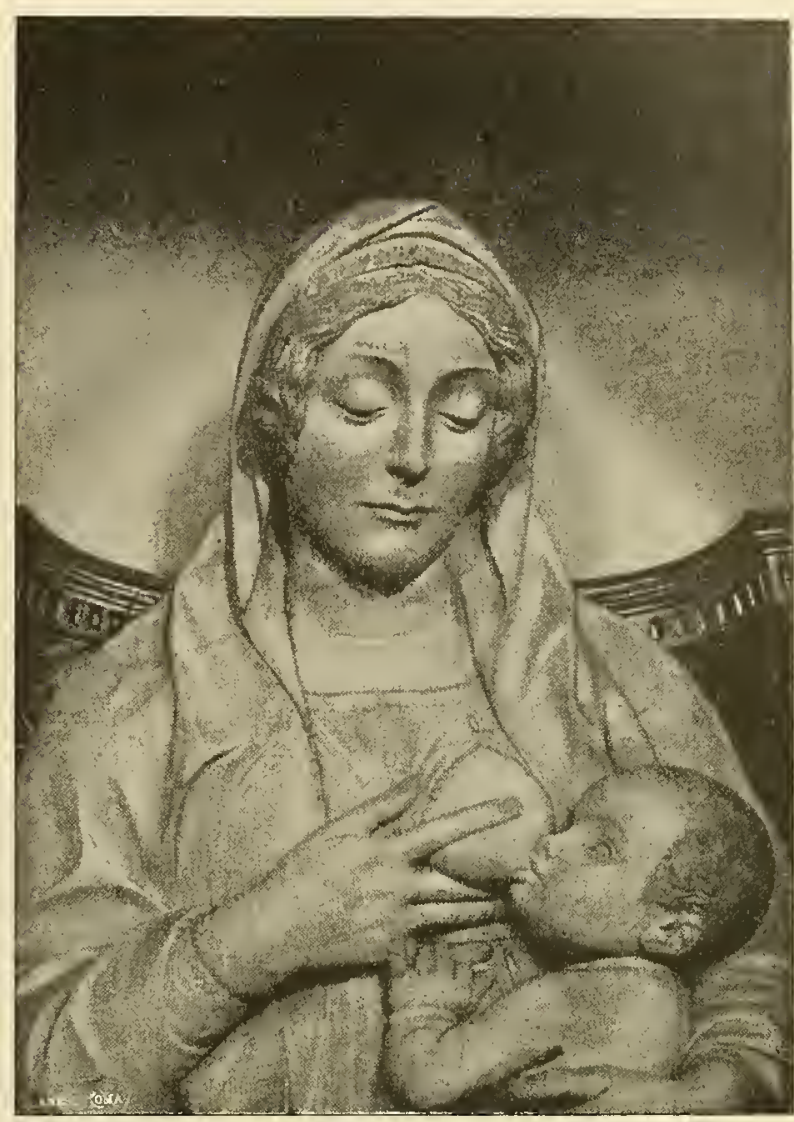

Lucca - Chiesa della Santissima Trinità (Mlatteo Civitali) una luce tranquilla, alla maternità l'omaggio. Entrata nel secolo xir l'arte

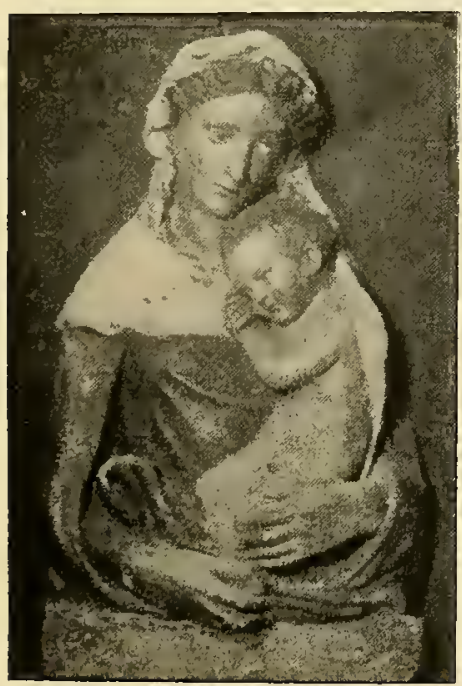

Stucco fiorentino deJ sec. $x \mathrm{v}$ Jerlino - Nuseo fa passi giganti nelle sacre rappresentazioni. Quantunque vestita di teologali virtù, Maria sorricle nel cielo.

Vidi quivi ai lor giuochi ed a' lor canti ridere una bellezza, che letizia era negli occhi a tutti gli altri Santi.

Così cantava il divino poeta, quando Nicola Pi. sano aveva già accoppiato la naturalezza e la grazia dei movimenti della Vergine con la tradizione classica. Il tipo giunonio, che troviamo nel pulpito di Pisa, si anima di nuova vita in altre opere del maestro e in quelle de' seguaci: le teste 
delle Madonne che guardano fissamente il divin Figlio a poco a poco si piegano in dolce atto d'amore, e, come vinte da tenerezza, si chinano sulla testina del Pargolo. Così Giotto aveva vestito di semplicità e d'umiltà profonda

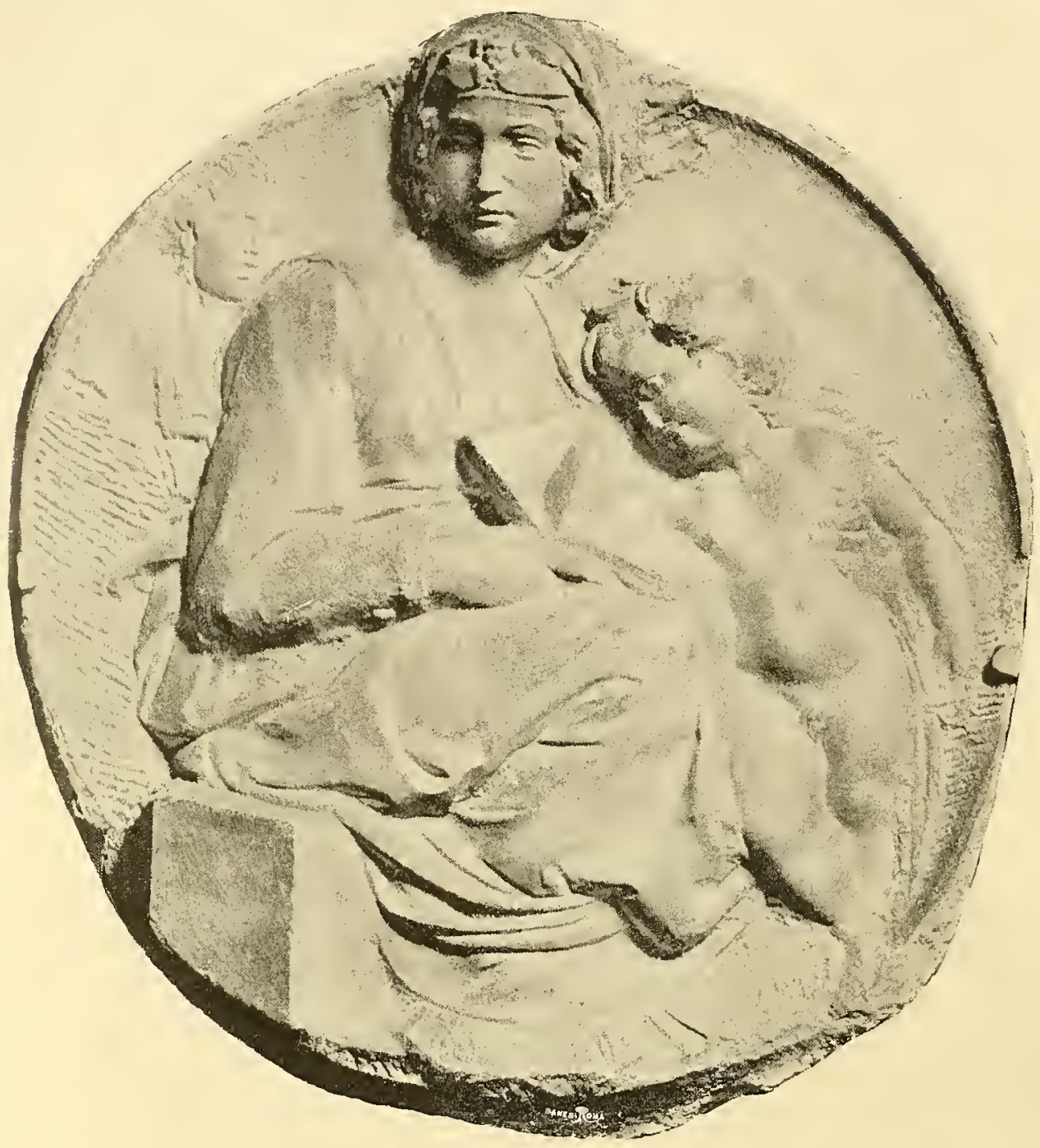

Museo Nazionale di Firenze

(MICHELANGELO)

la Vergine del cielo, cui dedicò un monumento eterno nella cappella degli Scrovegni a Padova. Ivi nelle sue Madonne abbandonò la solennità delle sacerdotesse dei tempi passati; Maria divenne una modesta popolana, che il destino trasporta attraverso le turbe nei gaudî divini e ne' dolori atroci: avvolta nel manto, pensosa, passa obbediente alla voce degli angioli e di 
Dio, finchè purificata nelle prove della vita, commossa, beata, vede il Figlio assurgere alla gloria dei cieli. Giotto però, quand' ebbe a rappresentare Maria fuori dal ciclo delle composizioni, in Padova stessa, ricorre a un tipo ideale pieno di forza, in cui spira la grandiosità medioevale nelle proporzioni e

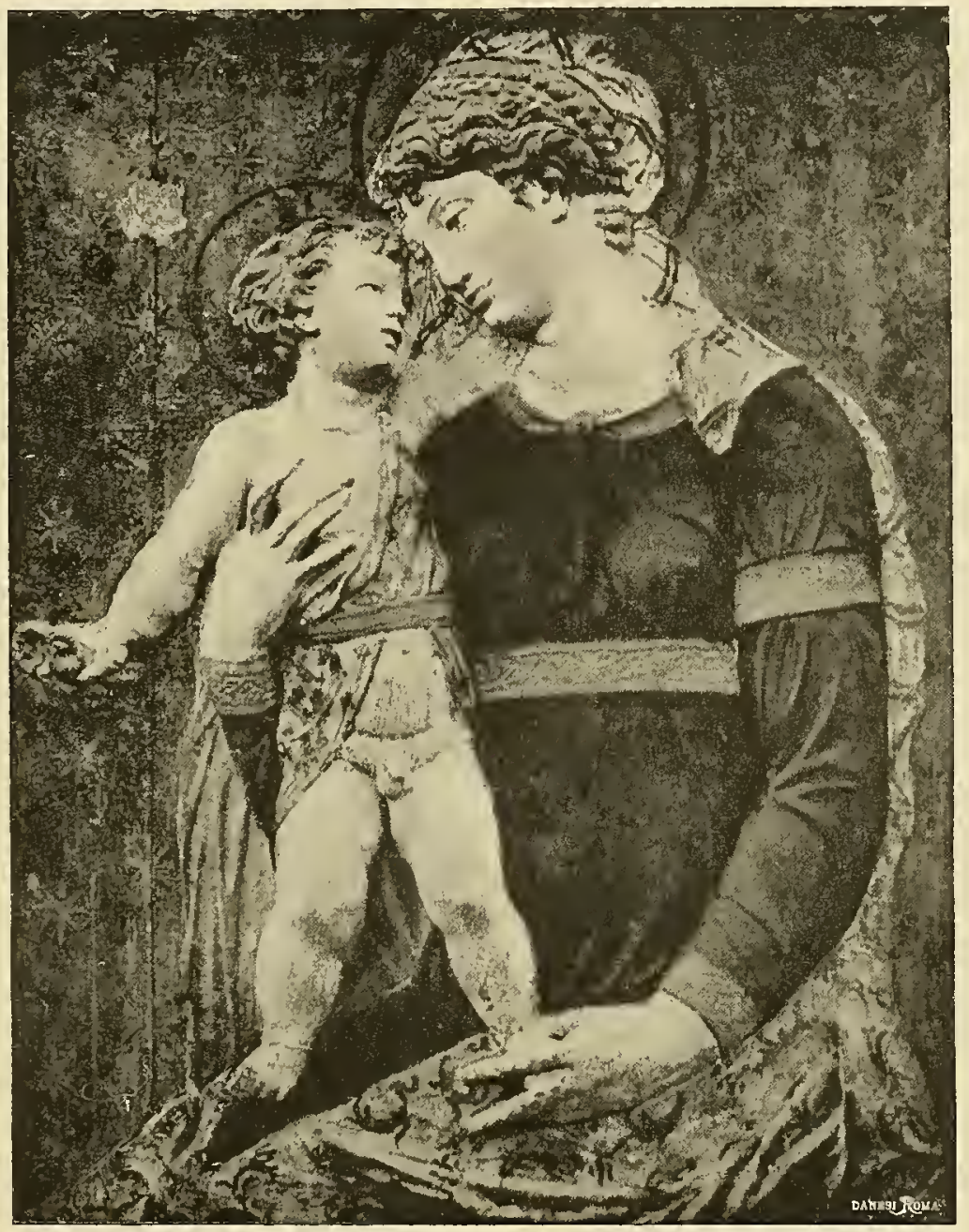

Berlino

(Andrea Sansovino)

nelle ampie orbite, e che è tuttavia il tipo muliebre della fecondità: simmetricamente disposta come un antica Madonna ma con imperial maestà, porta un diadema sul velo del capo, che il radiato nimbo celeste illumina gloriosamente. L'arte gotica si proverà a trasformare e alterare alquanto quel tipo umanamente forte, sovraccaricando di magnificenza e dando alla Vergine 


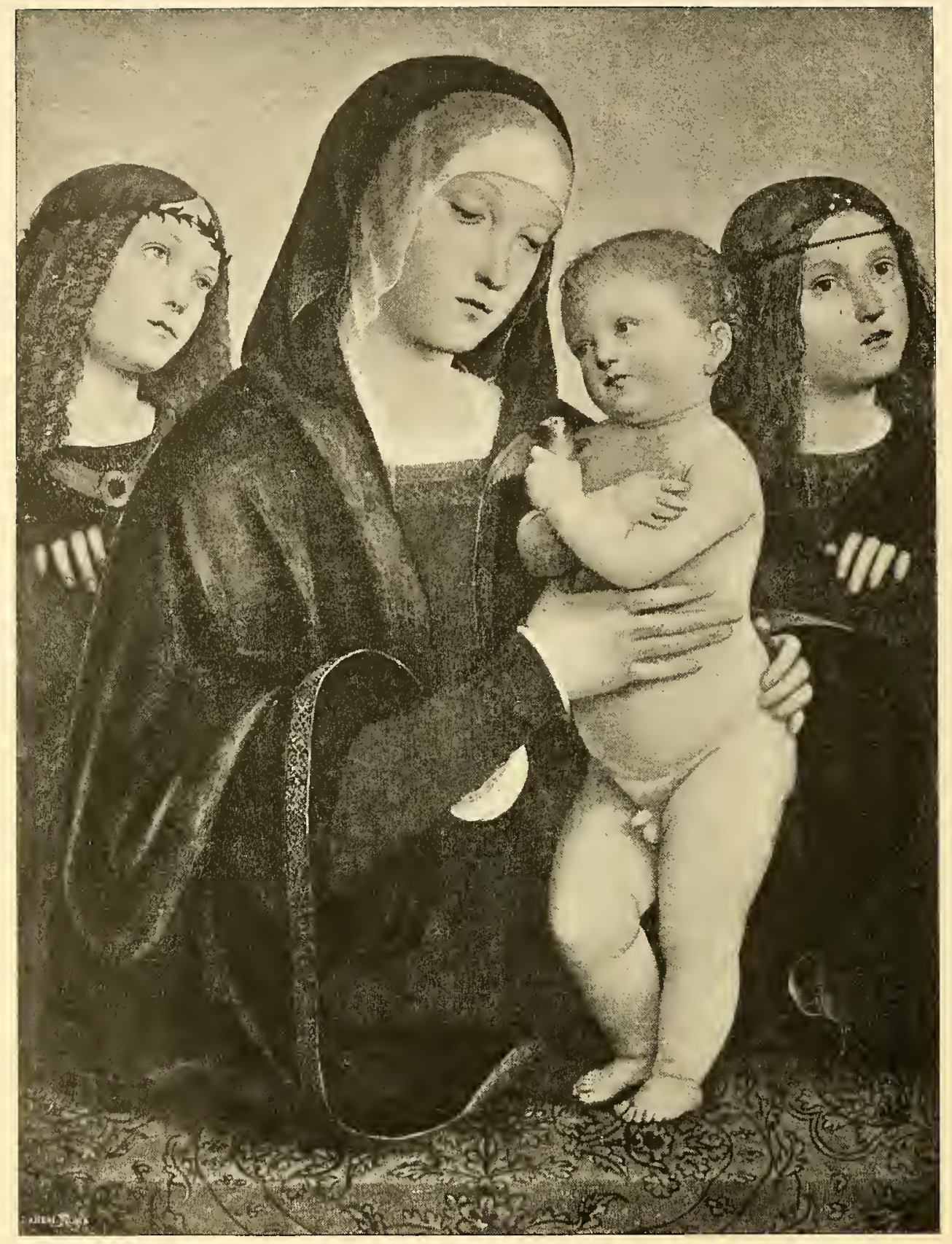

Galleria di Monaco

(FrANCIA) 


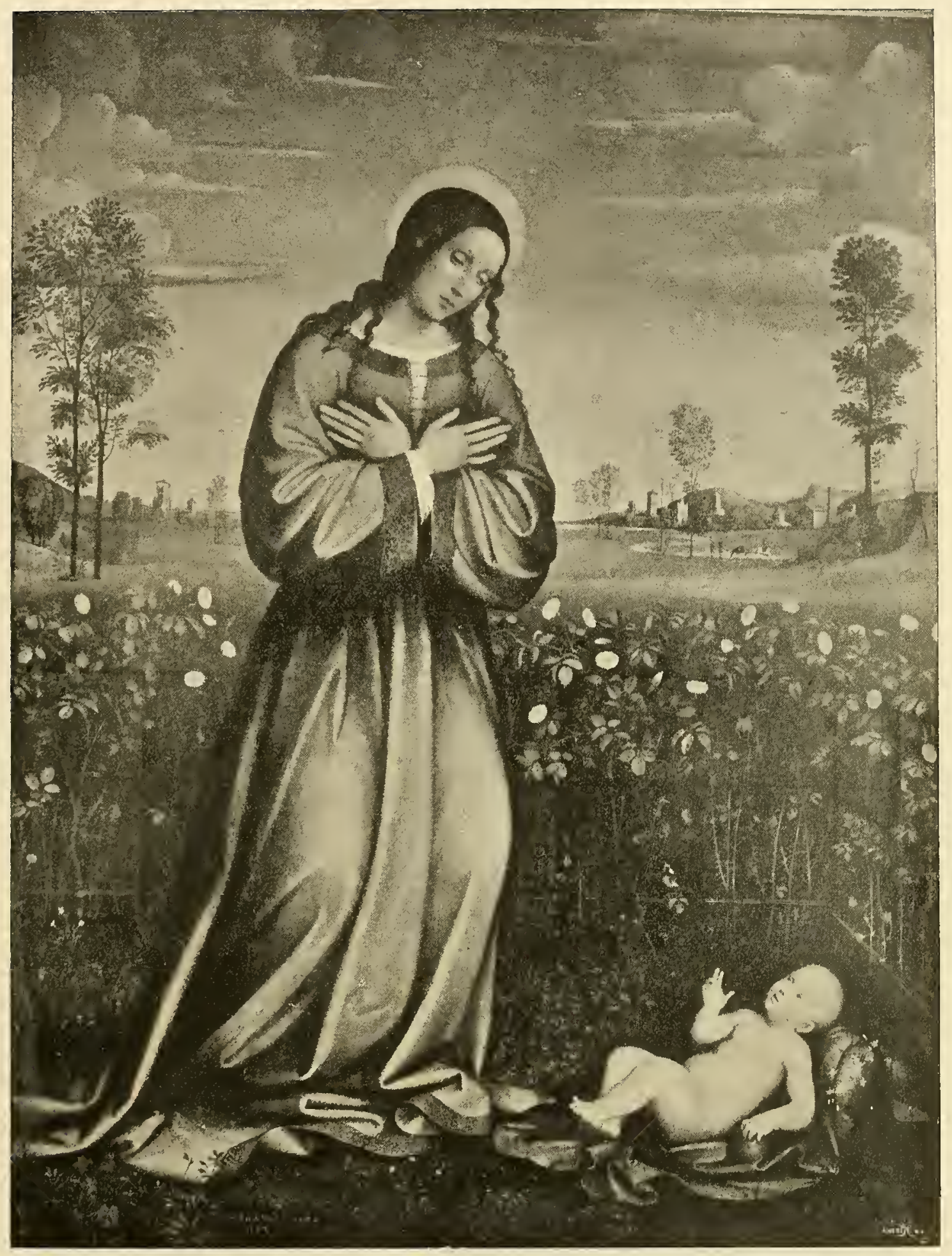

Pinacoteca di Monaco

(Francesco Raibolini, detto il Francia) 
corone gigliate e mitre e tiare; ma la castellana o la regina sorride agli uomini da sugli altari.

L'elemento ideale già si mesce al reale, così come nel Petrarca la Vergine diviene " cosa gentile", confidente de' suoi segreti d'amore, pietosa de' suoi affanni. La vita umana si comunica ai beati del Paradiso, che nel secolo Xv si muovono, vivono con l'artista, seggono allo stesso suo desco. La Madonna, ecco, è la madre che scherza col figlio, la buona massaia intenta a cucirne i pannilini. Nell'arte toscana si vedono le Vergini di Luca della

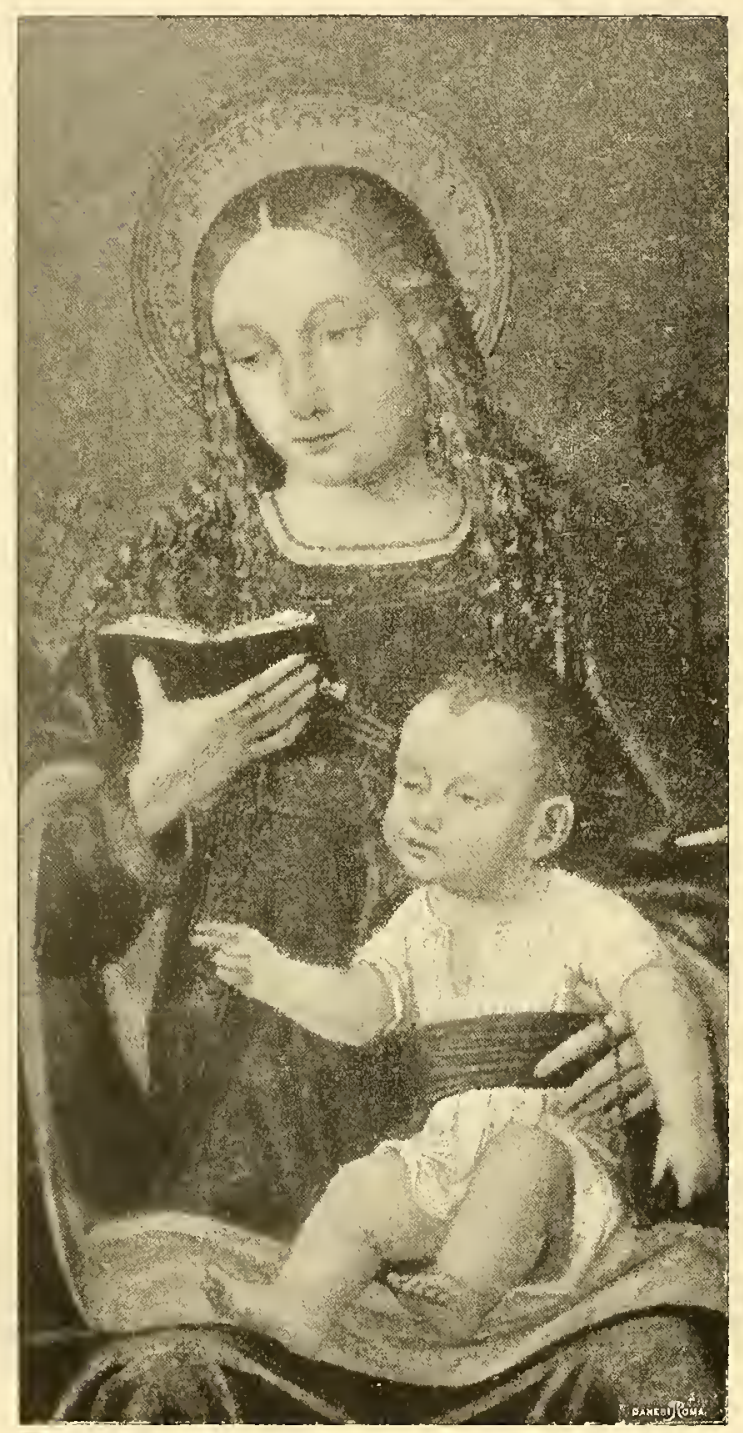

Collezione privata dell'estero

(Bergognone)
Robbia solleticare il Bambino e ridere con lui, avvicinare le labbra ai baci, stringere guancia a guancia, petto a petto, allacciarsi con le braccia carezzose; e le Madonne di Donatello e della sua scuola recano il fantolino in fasce, o che discopre lieto il seno materno o, senza lasciarlo, si volge indietro un istante. $\mathrm{Vi}$ è una tenerezza, una vivacità che rallegra, e rallegrava le vie toscane del Quattrocento dai tabernacoli delle case della città e della campagna, mentre le fanciulle che andavano spose recavano nel corredo le immagini della Vergine, o maestati, tutta leggiadria e gentilezza, sia del Beato Angelico, che vestiva la Donna del cielo di un manto di stelle, di un manto di purità e d'innocenza, sia del Botticelli, che la spargeva di grazie e di rose.

Dal Beato Angelico al Botticelli sembra che trascorra un secolo, non pochi lustri. Il primo 
compone con grande ingenuità. con semplicità che talora sembra infantile, con l'anima sua candida; veste di gotica tonacella le Madonne umilissime, dagli occhi chiari, dalle pupille che si affisano sotto leggiere sopracciglia, dagli esili corpi difanciulline. Il secondo raffigura la donna piena di grazie, in una dolce festa di colori, tra gigli e gelsomini, tra gli angioli esprimenti in coro soave le sue laudi; veli trasparenti le ador-

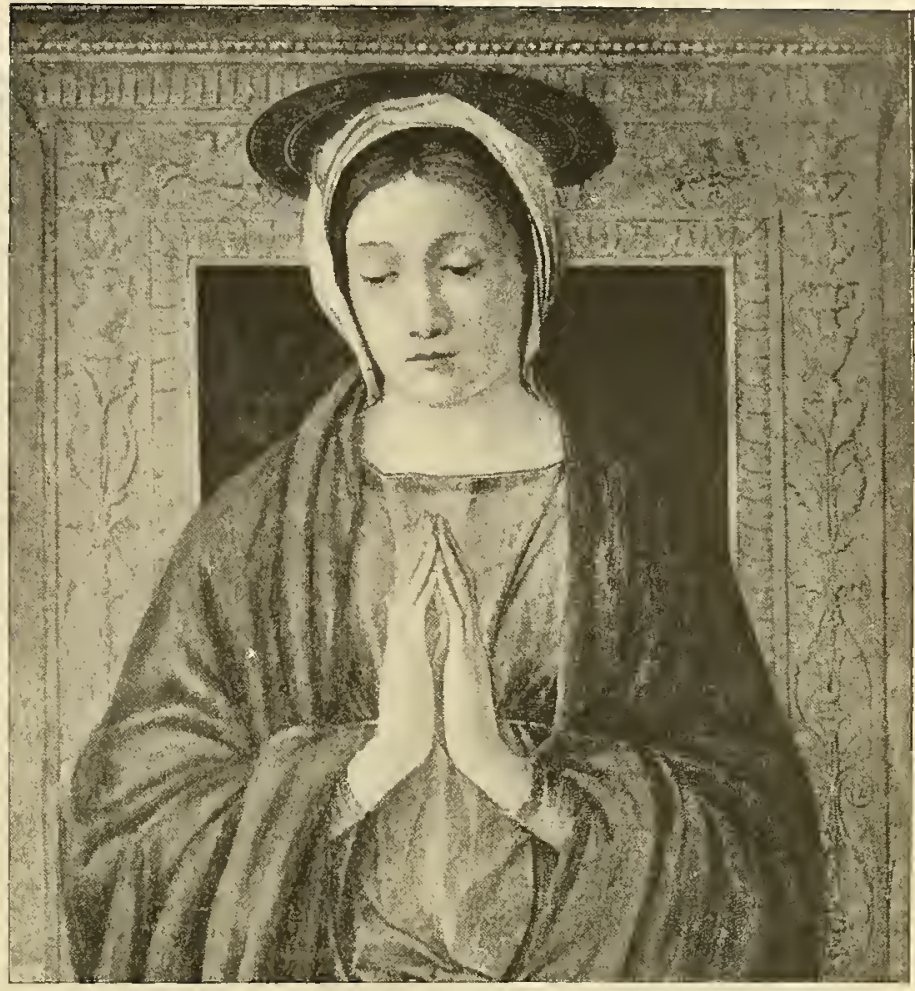

Venezia - Regia Accademia di Belle Arti (Giovanni Bellini) nano il capo, monogrammi e raggi e stelle le illuminano il manto orlato d'oro. La Madonna mistica scompare col Beato Angelico, mentre una Simonetta gentile s'asside sui troni fioriti del Botticelli e de' suoi contemporanei. Ma la scultura toscana precede la pittura nel rendere con ogni varietà e con umanissimo sentimento la figura della Vergine. In uno stucco del Museo di Berlino Donatello rappresenta ancora la Madre in atto di guardare con occhi amorosi il Bambino, ch' ella tien sollevato nelle mani, avvolto nelle fasce, e con la testa china, con le labbra semiaperte, con gli occhi presi da incanto, lo adora. Ma poi Donatello preferì un tipo meno semplice, più serio e venerabile, e volle confondere in uno il corpo della Madre e del Figlio, nello stucco del Museo di Berlino, ove Maria abbraccia e adora la sua creatura. e in quello conservato da Von Beckerath, pure a Berlino, ove le mani di Maria ricoprono il suo nato, che appoggia la guancia alla guancia di lei, e le braccia al collo, e il corpicciuolo al seno materno. La Madonna coi capelli increspati, giunonica, non è ancora la matrona opulenta che Donatello raffigurò nel bronzo del Louvre, con clamide 


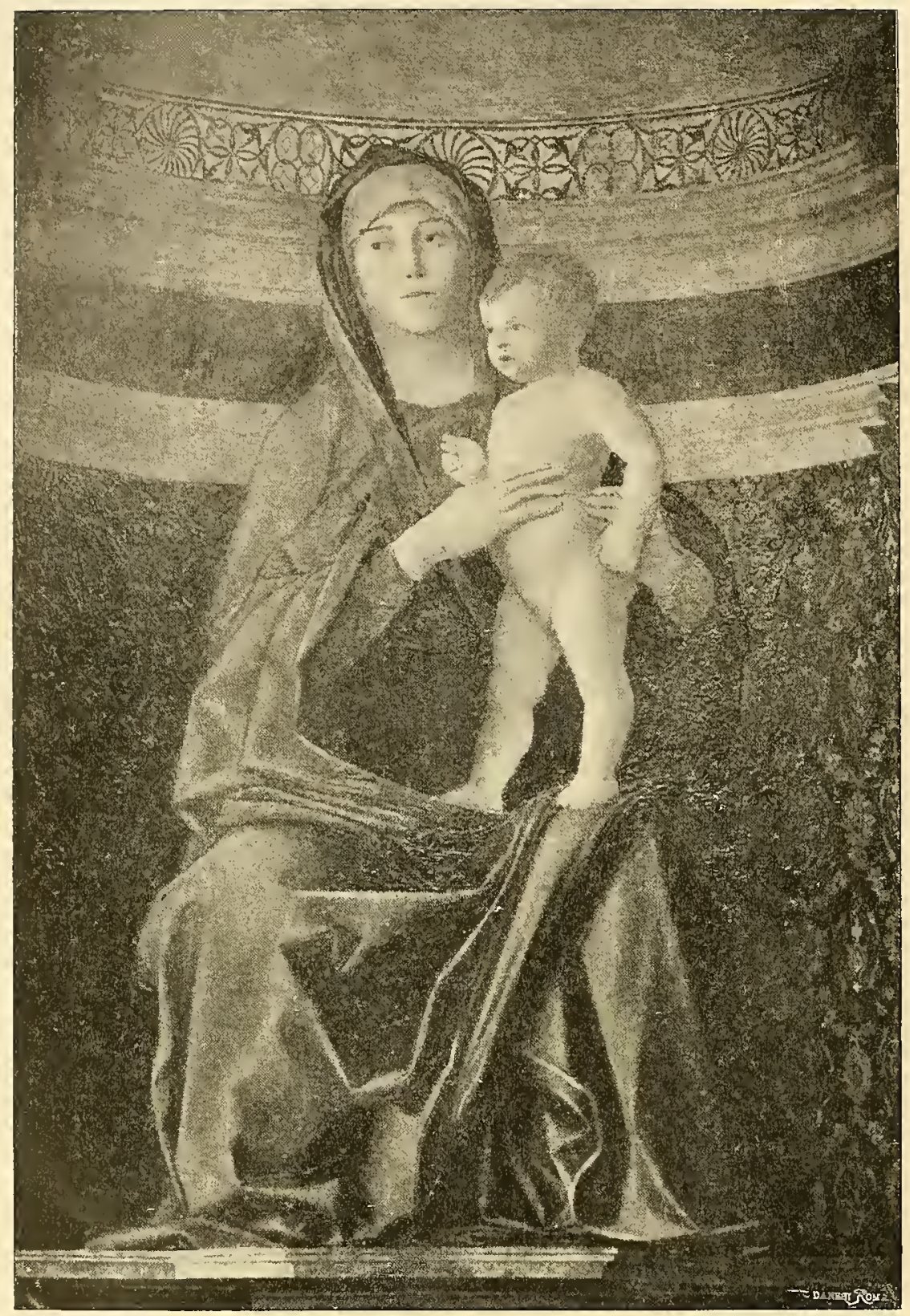

Venezia - Frari

(Giovanni Bellini) 


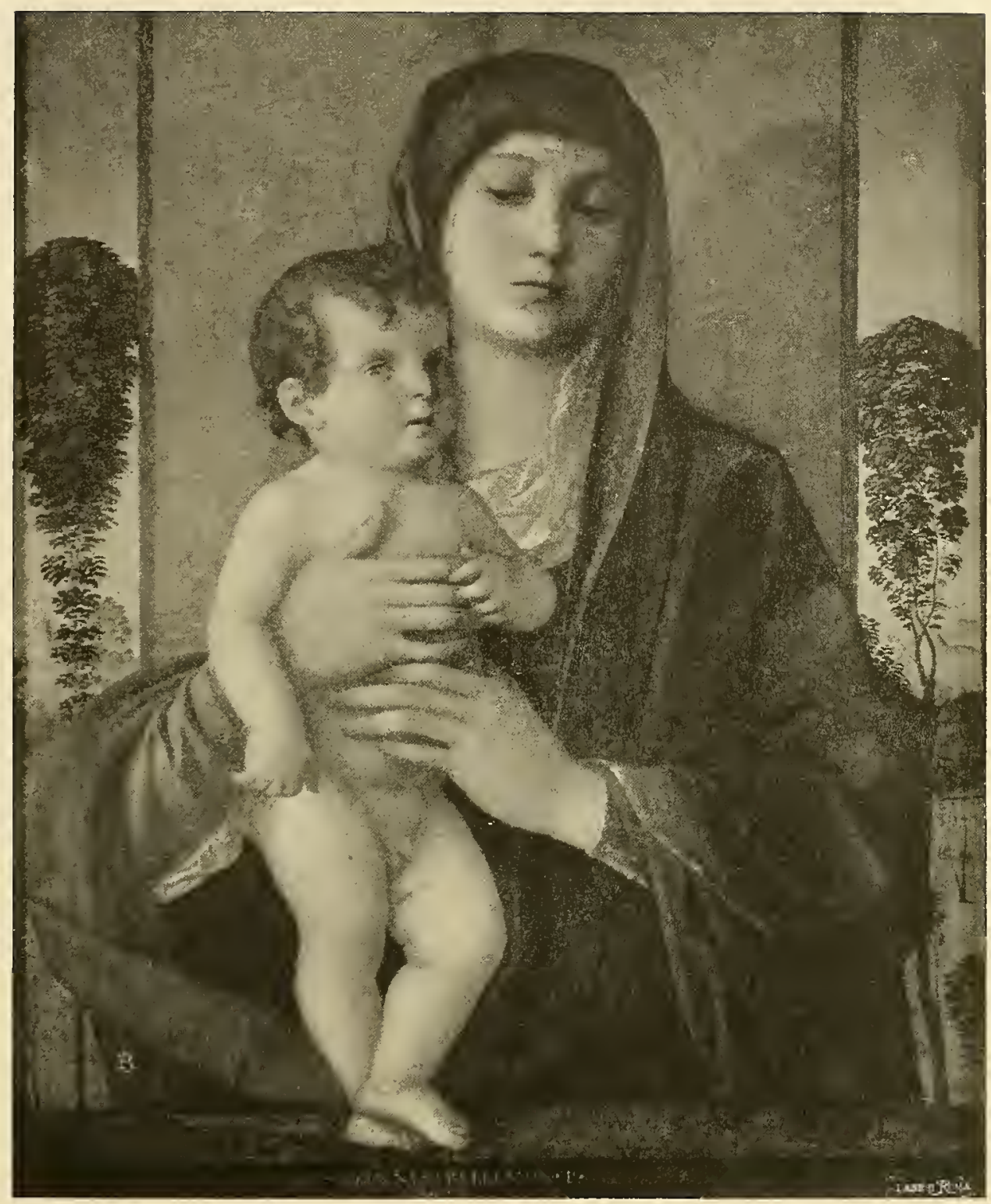

Venezia - Regia Accademia

(Giovanni Bellini) 
fimbriata, con nastri ondeggianti nelle trecce de' capelli, come corazzata e nimbata dagli amorini, seduta in nobile.cattedra. Il suo profilo diviene greco, ma la sua pupilla ha fiamme d'amore; e il Bambino si torce nelle fasce per rispondere all abbraccio della Madre, e tiene un dito in bocca, come nello

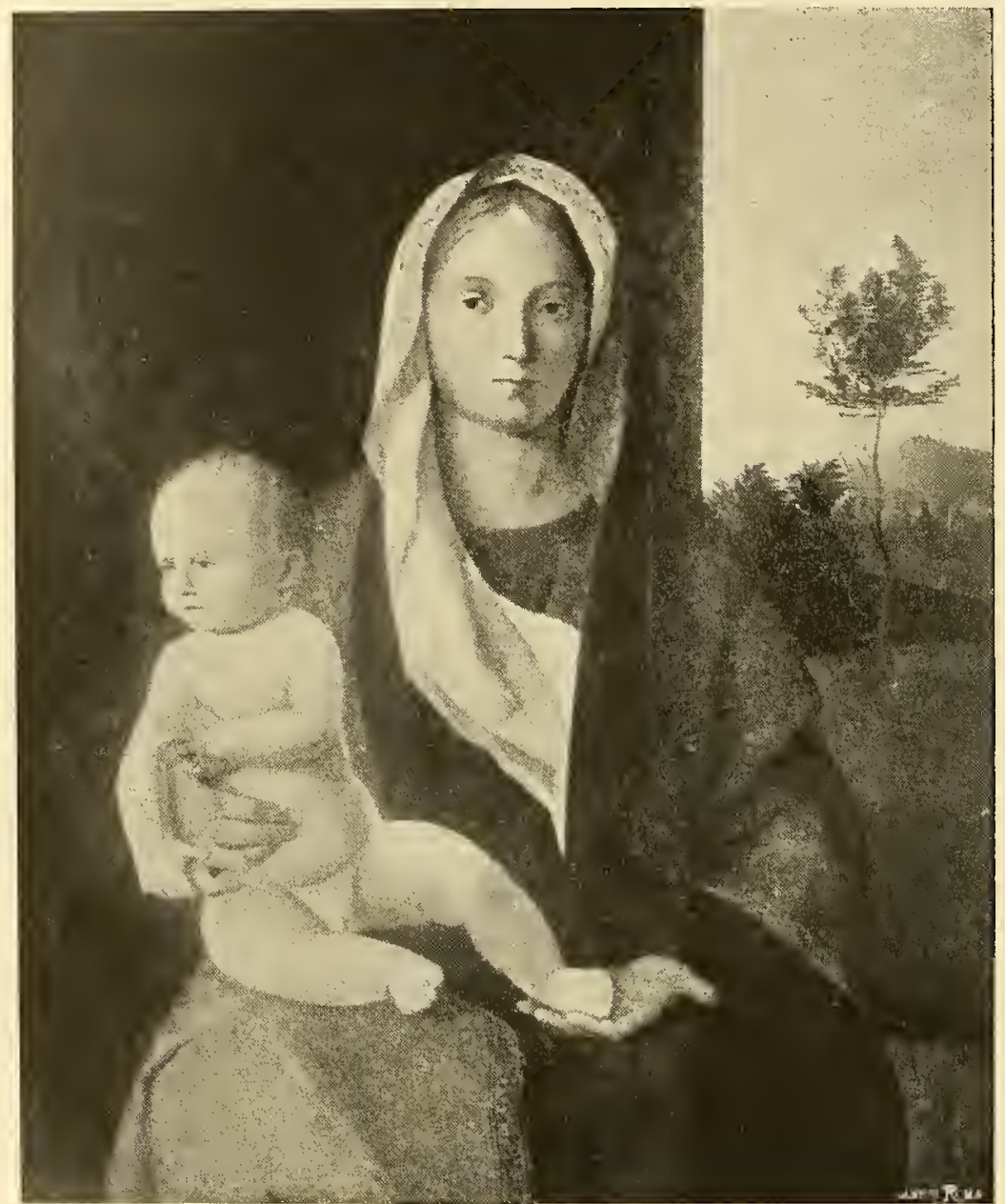

Galleria dell' Universitȧ di Strasburgo

(Rocco Marconi)

stucco di Von Beckerath, mentre gli occhi si stringono ridenti e sembrano illuminare i pomelli delle gote. Tutti gli aspetti della tenerezza materna si riflettono nell'arte toscana, e tutte ad un tempo le forme della venerazione per l'Augusta, tutti i motivi artistici che poi l'arte svolgerà pienamente. In uno stucco del Museo di Berlino s'intravvede sul graffito d'oro la Madonna a cui il Correggio darà fiori di dolcezza. Tra i vasi di gigli di Luca della 
Robbia già è spuntata Maria, il pì̀ bel giglio della terra; tra i cespi di rose, come poi la dipinsero il Francia nel quadro di Monaco e il seguace di Filippino nel tondo della Galleria Pitti, siede la Vergine nell'opera di Luca della Robbia del Museo Nazionale in Firenze; Rossellino e Desiderio da Setti-

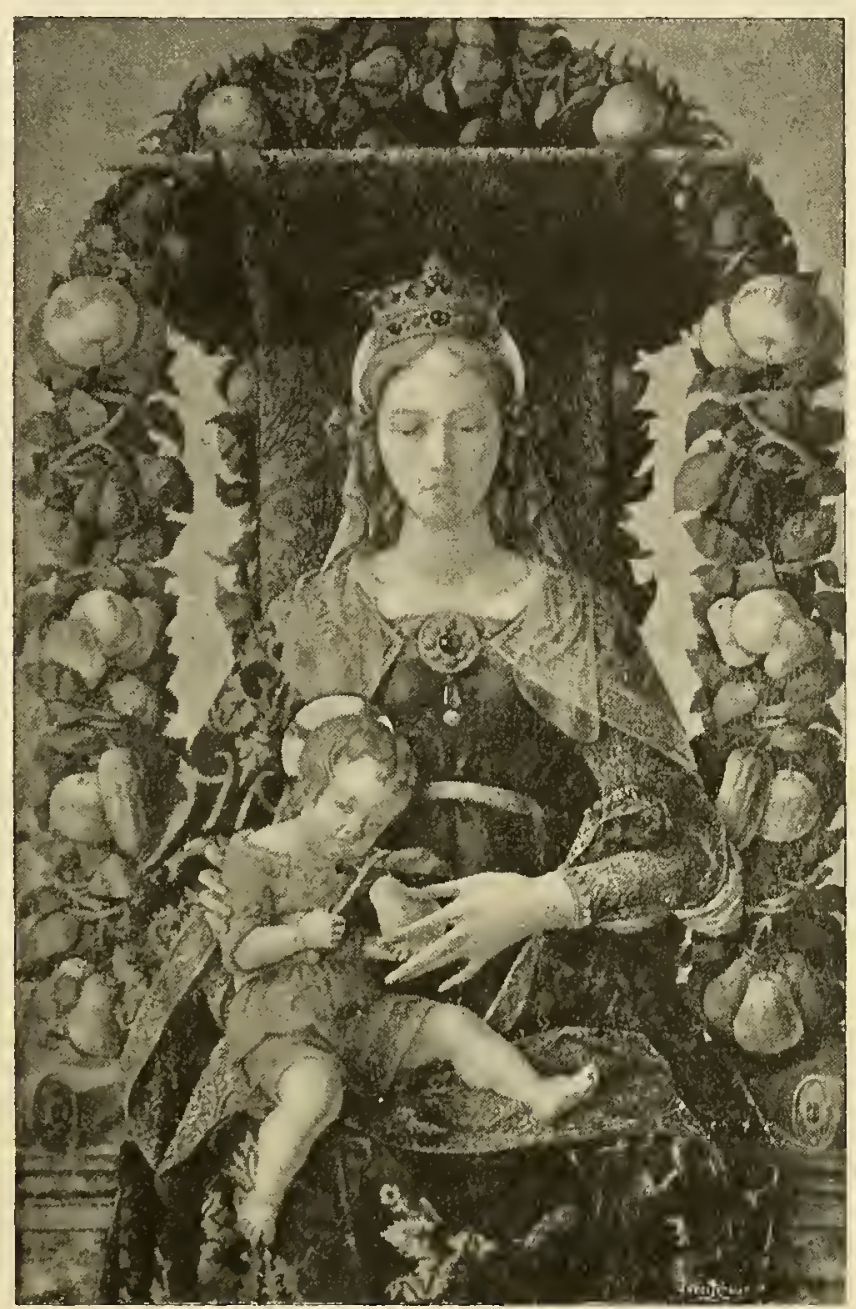

Particolare d'una pala d'altare. Milano-R. Pinacoteca

(CArlo Crivelli)

gnano, Benedetto da Maiano e Mino da Fiesole idealizzano, nobilitano quei tipi fiorentini pieni di salute, belli di tenerezza materna. Ma le eleganti fanciulle di Mino, le graziose donzelle del Rossellino e di Desiderio, le nobildonne di Benedetto da Maiano si svigoriscono: gentili, accarezzate, sentimentali, soavissime. escono dalla casa signorile, non più dal popolo, a cui si presentavano dispensatrici di grazie e di sorrisi. Restano però sempre nell'arte 


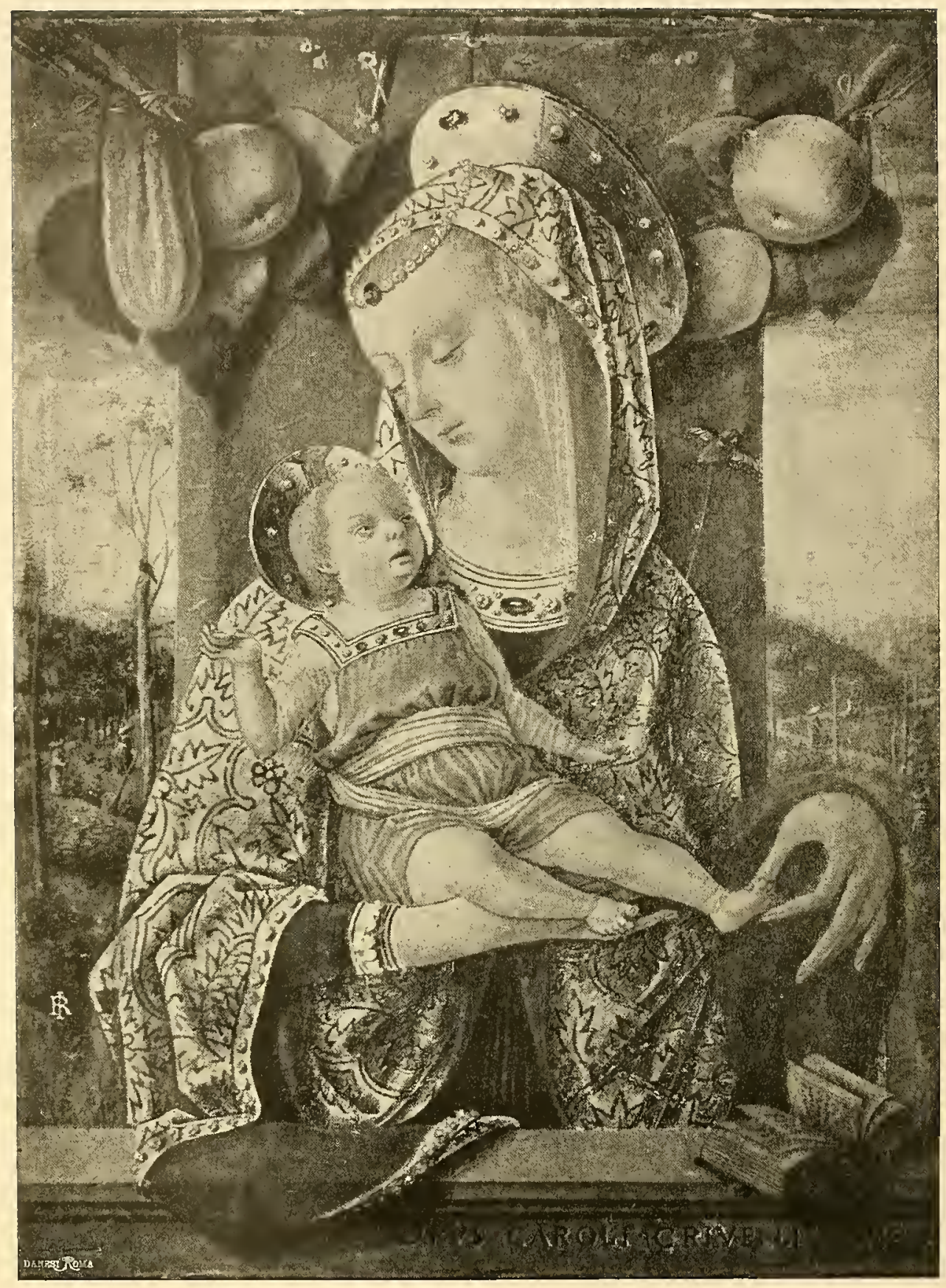

Ancona - Pinacoteca Podesti

(Carlo Crivelli) 


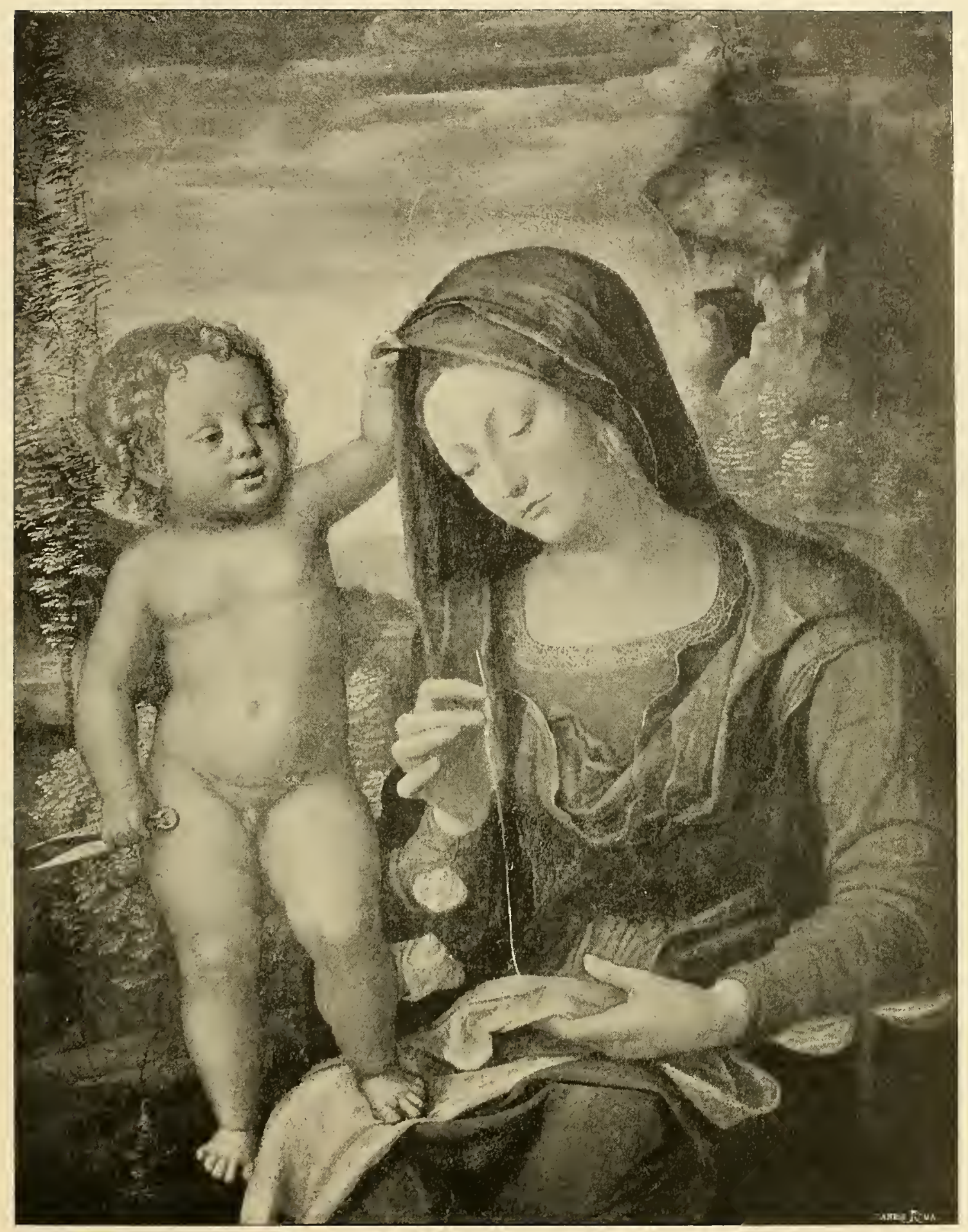

Venezia - R. Accademia

(CAROTO) 


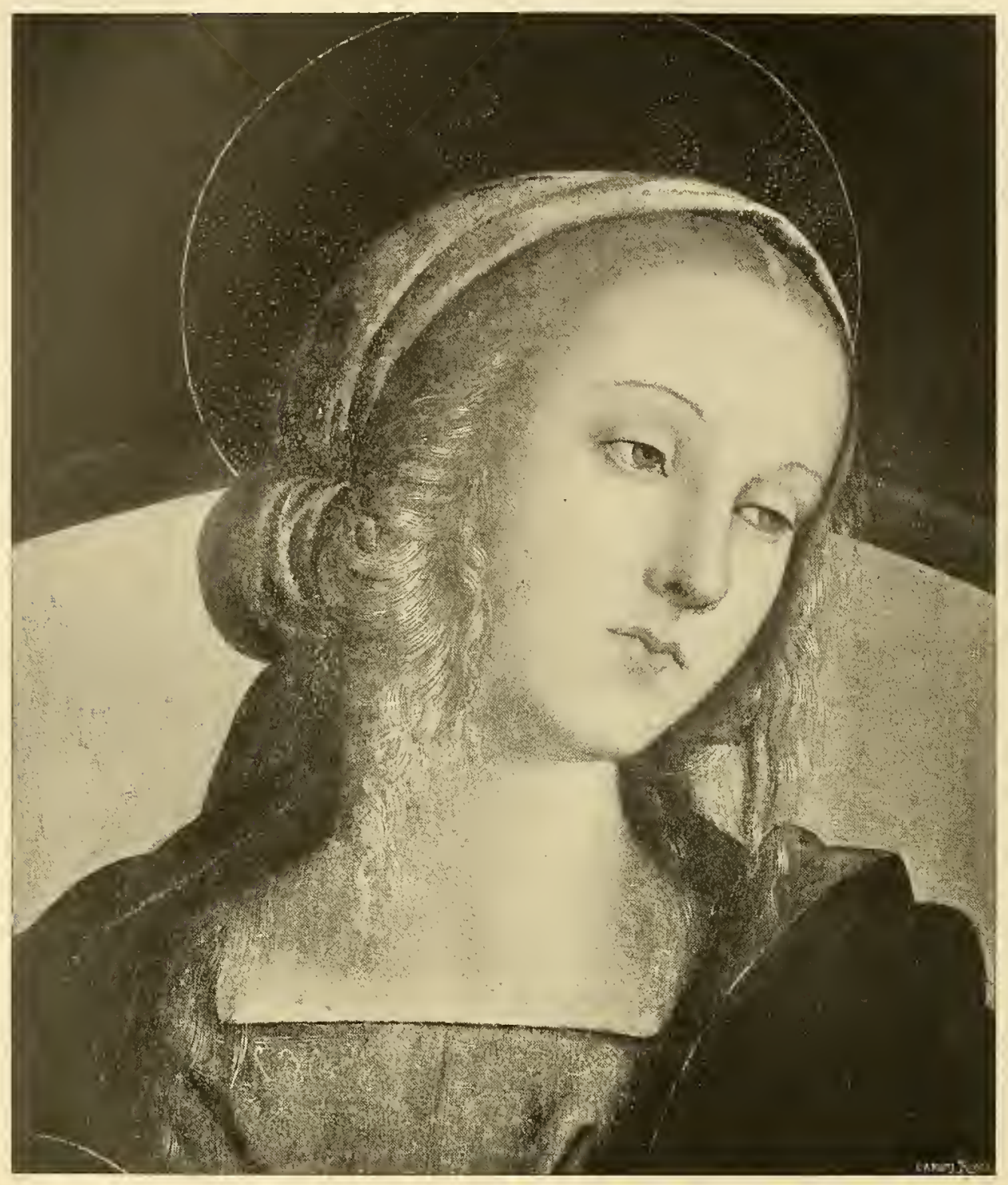

Particolare di un quadro. Firenze - Galleria degli Uffizi (Pietro Perugino) 


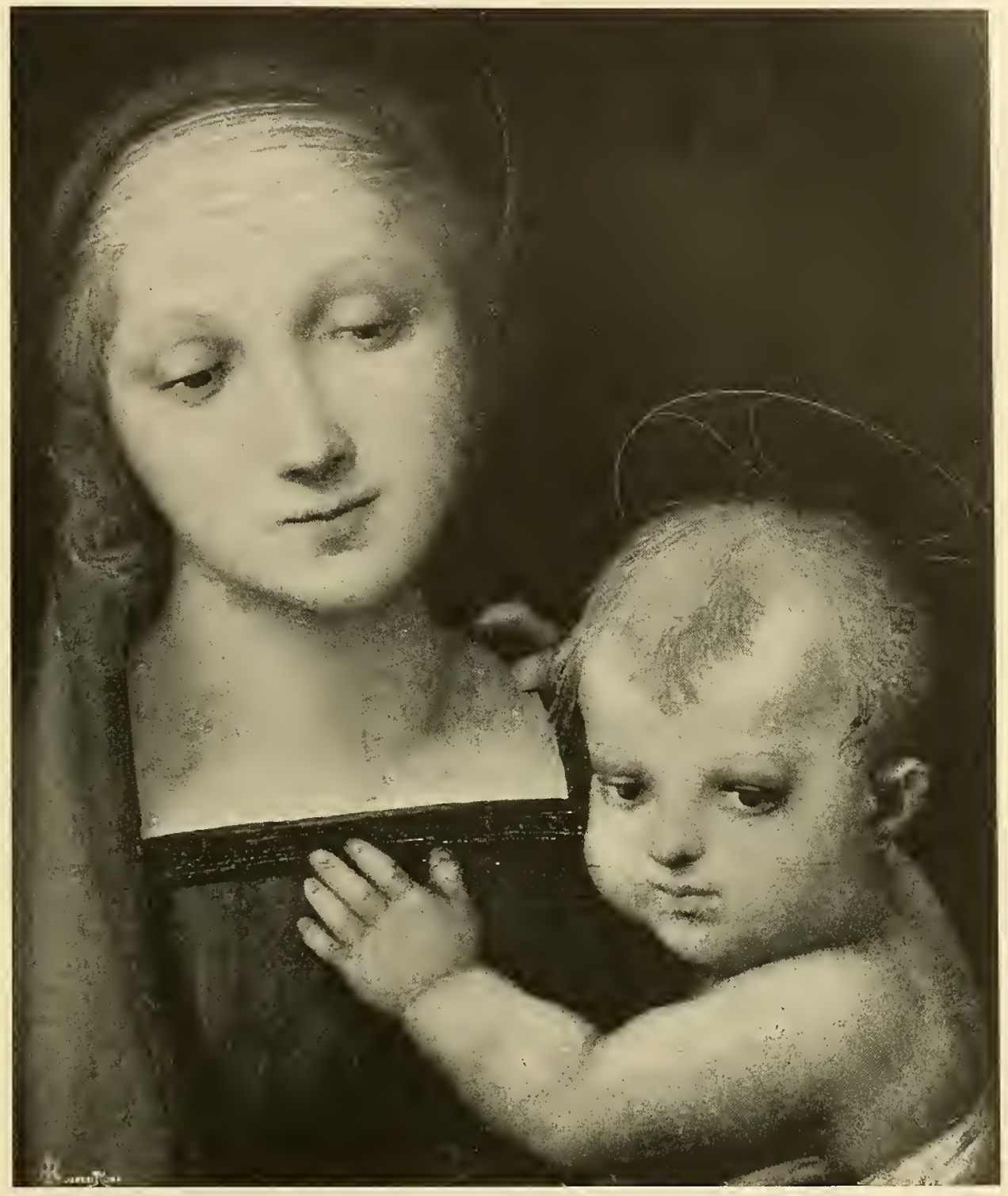

Particolare della « Madonna del Granduca ». Firenze - Galleria Pitti (Raffaello Sanzio) 
toscana le due forme di rappresentazione della Vergine segnate dal Donatello e da Luca: ora la Madonna venerata, solenne, in atteggiamento composto, pensosa; ora la Madre, che in una scenetta di genere graziosissima scherza e ride col Bambino. Ma Filippino Lippi, nella gentil figura del tabernacolo di Prato, piena d'intimità di sentimento, par che riassuma i più

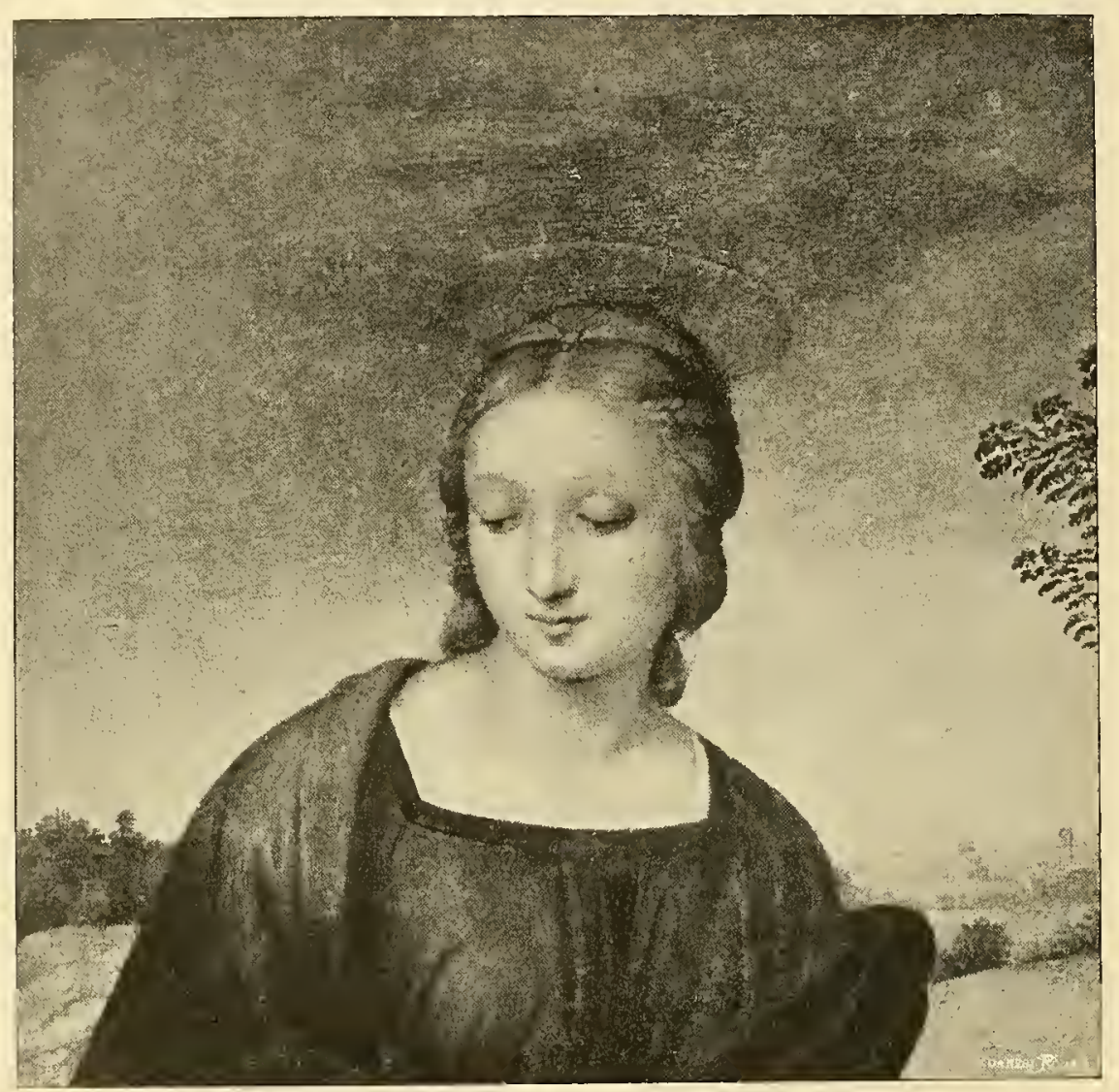

Particolare. Firenze - Galleria degli Uffizi (RafFaello Sanzio)

belli e più cari attributi dati alla Donna celeste dall'arte toscana; e Michelangelo, nel tondo del Museo Nazionale di Firenze, compie solennemente l'opera donatelliana.

Verso la fine del Quattrocento, mentre la Vergine sembrava attingere troppo la sua forma dalla realtà, corre la terra il vento di un misticismo nuovo, e lo spirito di Savonarola attraversa il campo dell'arte; onde il Perugino nell' Umbria, Lorenzo di Credi in Toscana, il Francia a Bologna, il Bergognone in Lombardia, Giambellino a Venezia dànno alle loro Vergini 


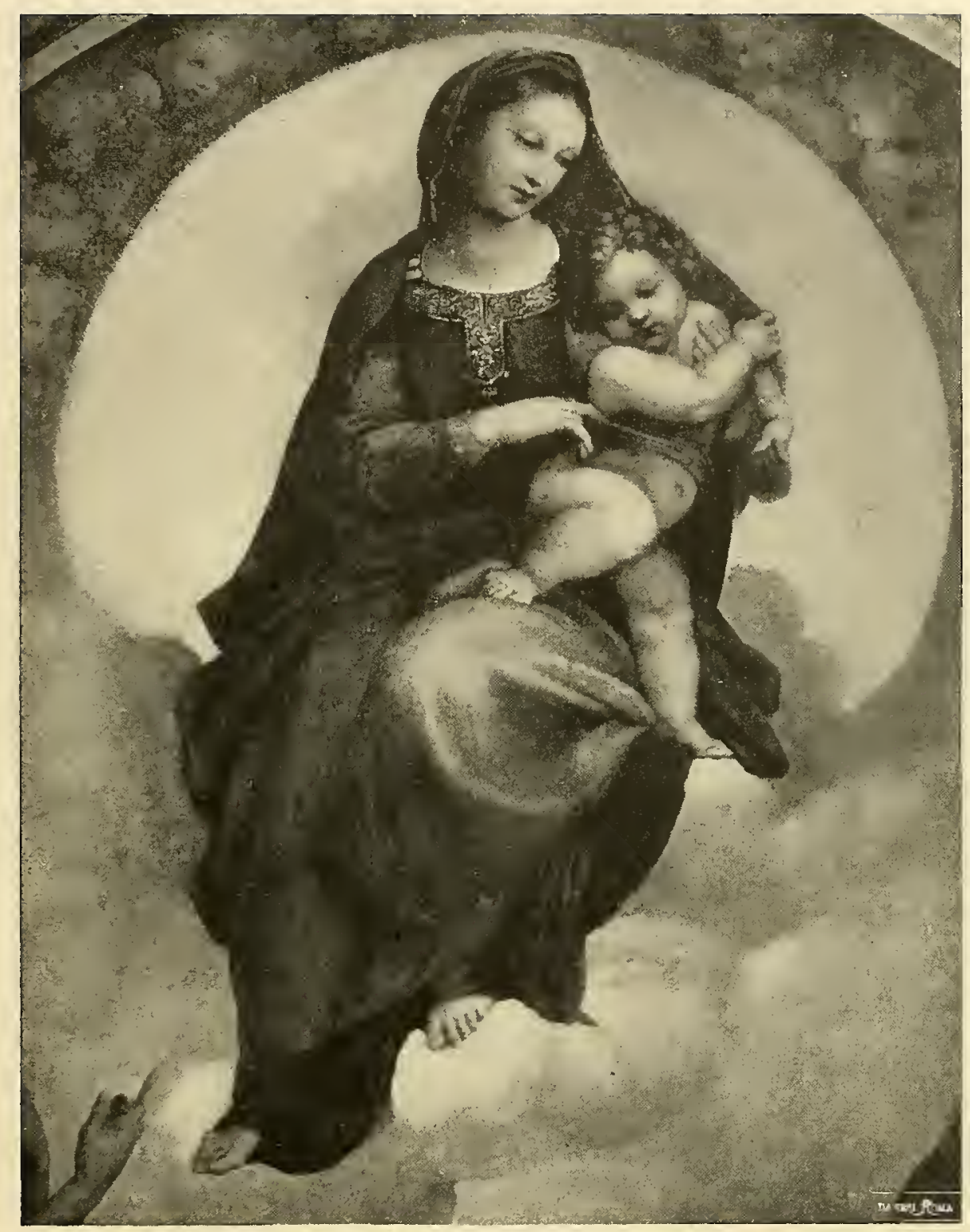

Particolare della «Madonna di Foligno» nella Galleria Vaticana (RAFFaello Sanzio) 


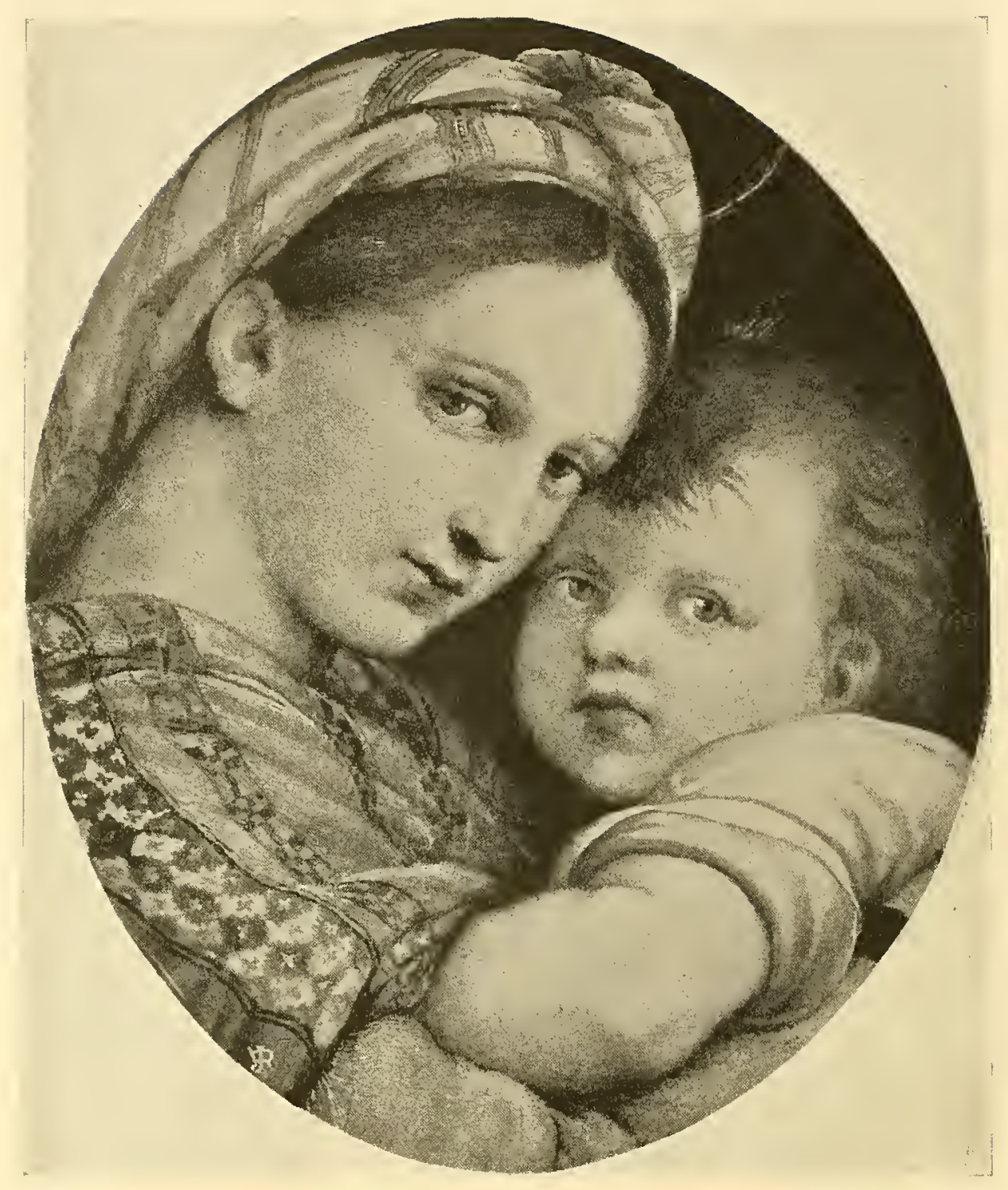

Particolare della «Madonna della Seggiola»nella Galleria Pitti in Firenze (Raffaello Sanzio) 


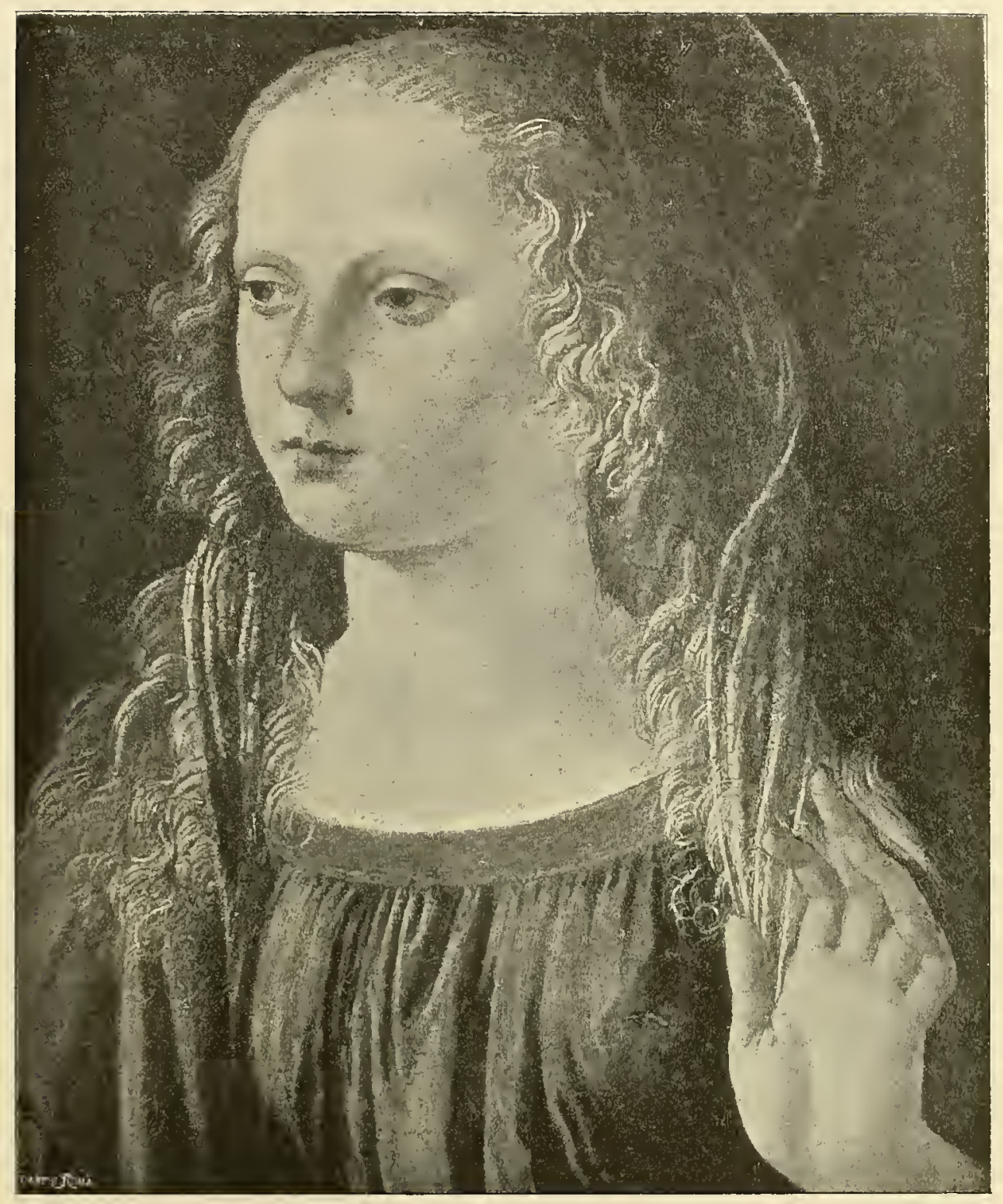

Particolare della «Annunciazione» nella Galleria degli Uffizi in Firenze (LeONardo DA Vinci) 
un'aria divota, monacale, pensosa, talora quasi sonnolenta. Ma sotto i candidi veli delle loro testine la bellezza trionfa, la grazia ne soffonde di rosa le guance, la bontà e la pietà per gli umani le illumina.

Giambellino vinse tutti nella nobiltà delle sue Madonne, dal bel drappo

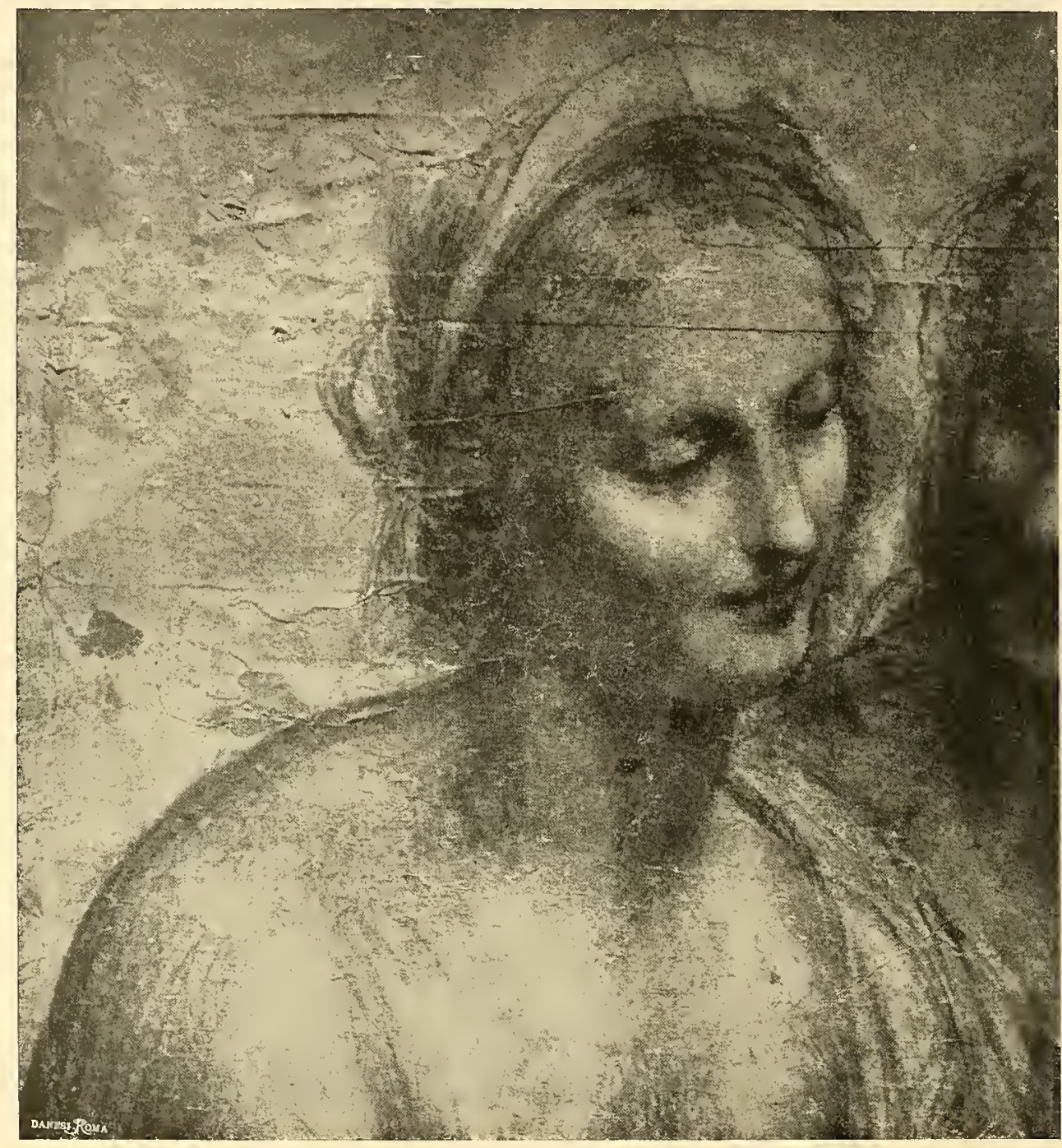

Londra - Cartone nell'Accademia di Belle Arti (LEONARDO DA VINCI)

bianco d'argento sul capo, dalle carni opaline, dolcissime. Dapprima il grande maestro rappresentò con le sue Madonne il Bambino in piedi, su un parapetto, benedicente; poi lo fece godere dell'affetto della Madre, sulle cui mani poggia le sue, per rispondere alle carezze e stringersi a lei. Prima la 
maestà della Vergine secondo la tradizione, con gli appellativi bizantini inscritti accanto alla sua immagine; poi l'idillio materno.

Per comprendere l'elevatezza dello spirito di Giambellino lo si confronti con Bartolomeo Vivarini, suo contemporaneo, che accanto a lui sembra un

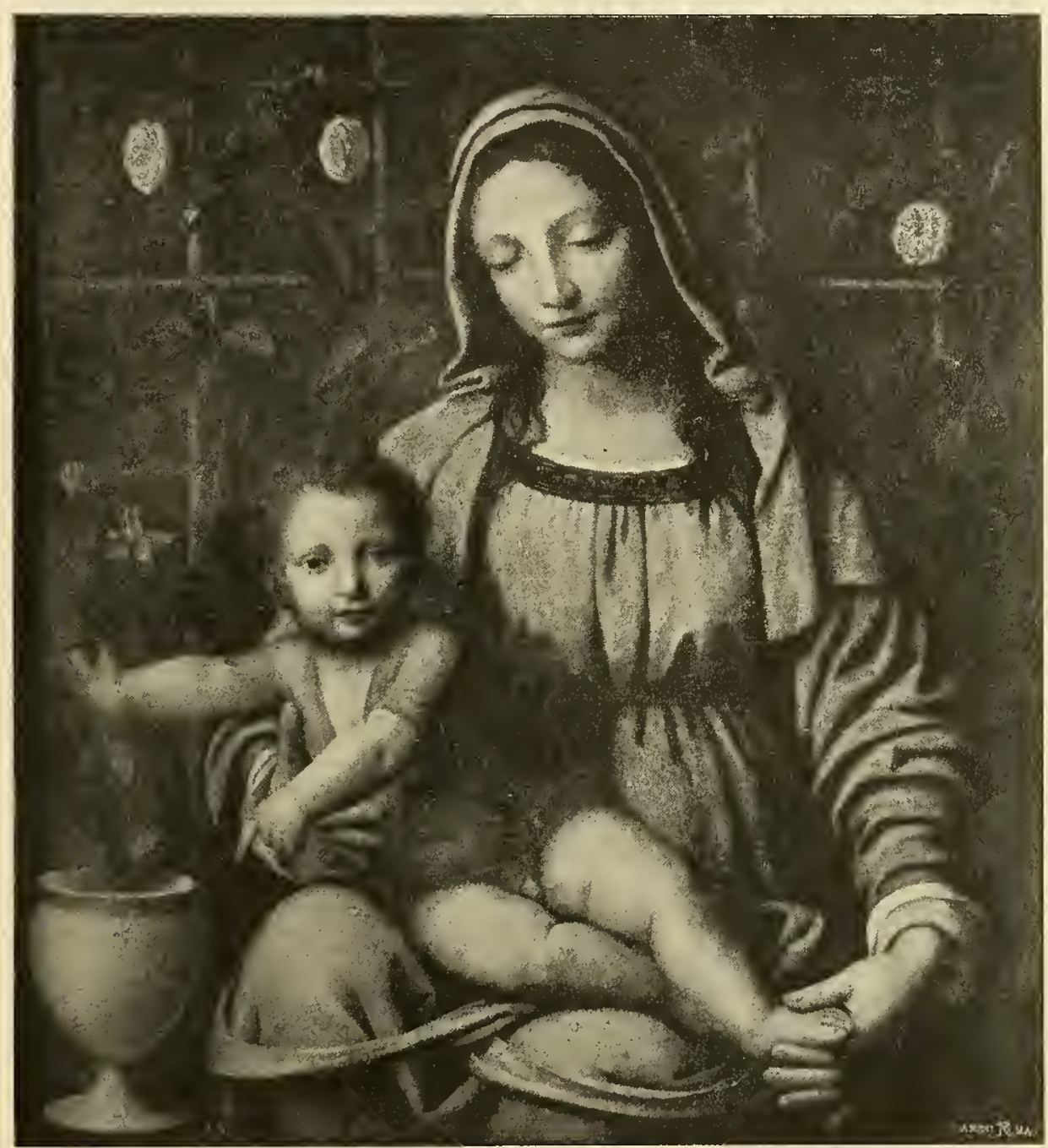

Milano - Pinacoteca di Brera

(Bernardino Luint)

barcainolo dell'isolotto di Murano presso un doge. Questi copre di serpentino gli altari della Vergine, vi profonde ornati che sembrano intagliati da Tullo Lombardo, e li aderge sul fondo d'alabastro, sotto la cupola a musaici d'oro; quegli si contenta di porre sullo scanno di legno della Madonna due vasetti di terra cotta invetriata con alcune pianticelle. Bartolomeo Vivarini 
eseguì più volte la Madonna con le mani giunte, in atto di adorare il divin Figlio dormiente sulle ginocchia di lei; Giambellino dipinse lo stesso soggetto nella forma stessa (n. 59 I della Galleria di Venezia), ma il suo Bambino

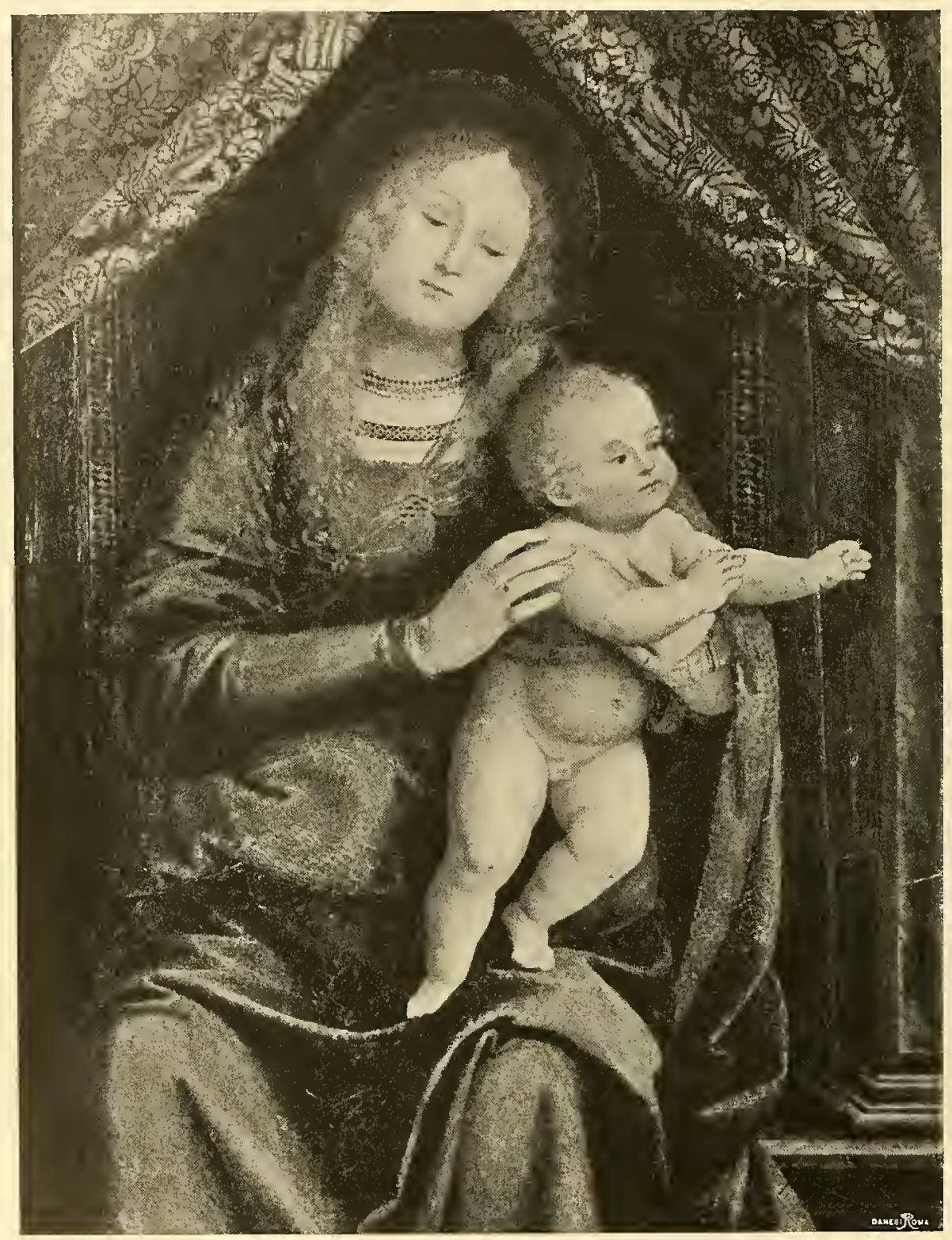

Milano - Pinacoteca di Brera

(GAUDENZiO FERRARI)

è abbandonato al sonno, col braccio destro cadente lungo le ginocchia della Madre, ha la testa piegata, i labbruzzi stretti, gli occhi velati da una lieve ombra trasparente, rosee le guance. Il barcaiuolo muranese si contentava di 
rendere l'immagine sacta rispettosamente: il nobiluomo veneziano la innalzava nel regno dei cieli e della bellezza.

Come nell'antica Grecia le immagini degli dèi e degli eroi avevano

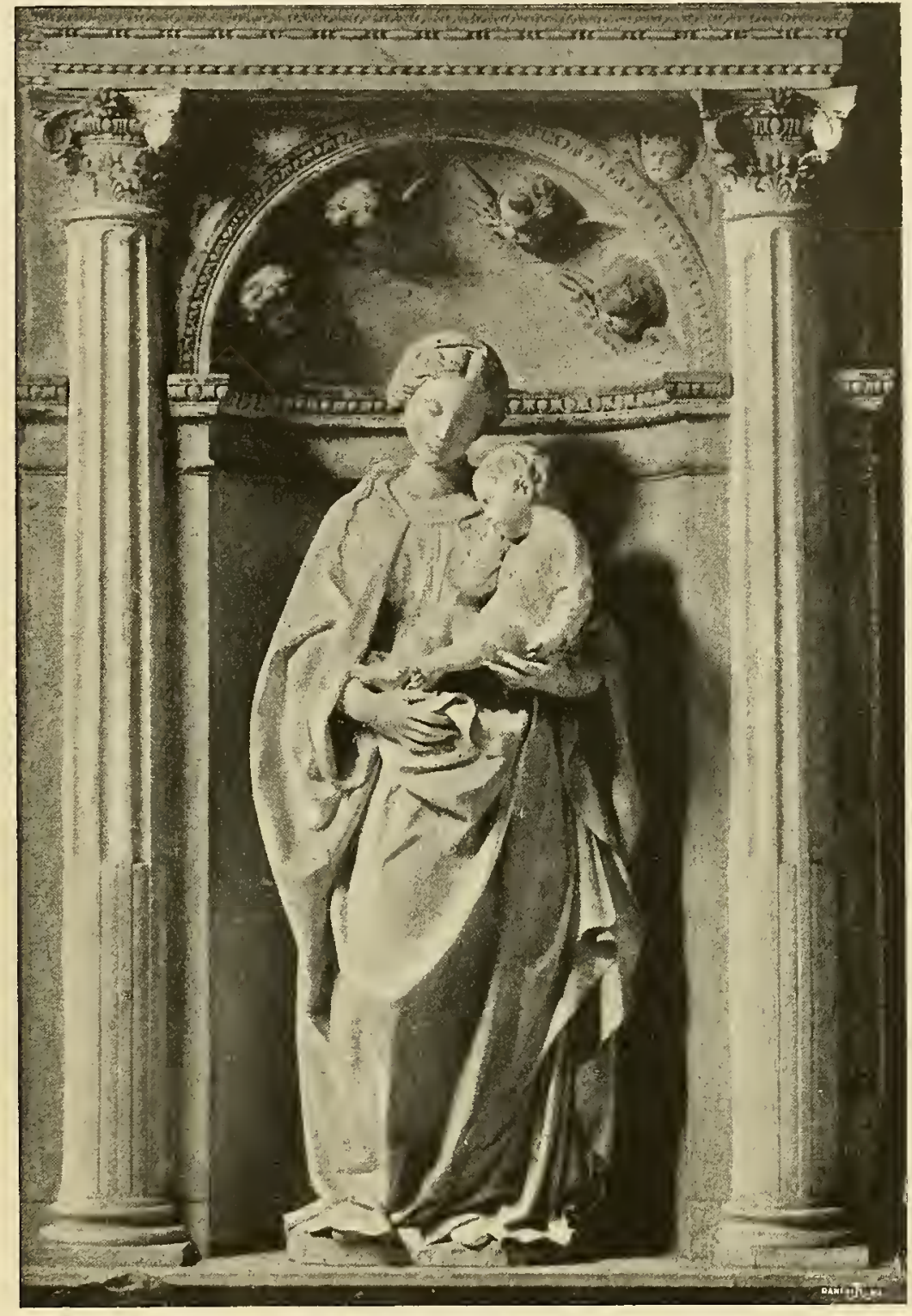

Palermo - Museo Civico

A NTONELLO GAGINI)

trovata la loro forma direttamente dalla natura, così nell'Occidente, presso popoli non inclini ad astrazioni lontane dalla realtà, dopo lunghe lotte e lunghe prove, le immagini del Paradiso cristiano si animarono delle gioie e dei dolori 
degli uomini. Le beate figure mutano fisonomia ed espressione, secondo l'ondeggiare de'sentimenti individuali e il variare etnico delle popolazioni. Ma giunta all'apice l'arte riassume le ricerche, fa una sintesi delle produzioni individuali, liba sui fiori il miele; onde si ricostruisce il tipo eterno della

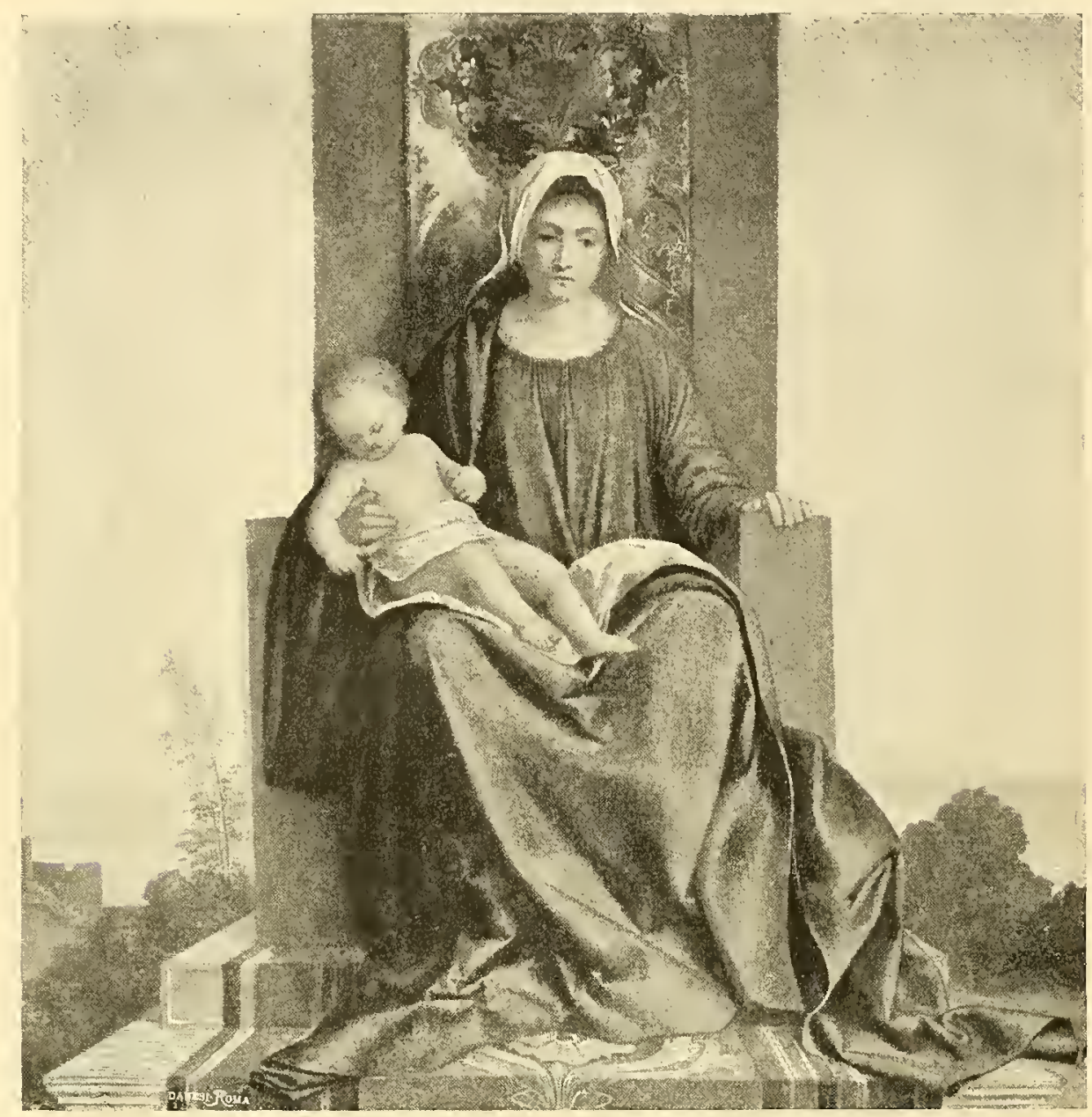

Particolare della pala d'altare nella Chiesa di Castelfranco

(GIORgrone)

bellezza col lavoro e coi materiali dei secoli, e rifulge l'idealità delle nazioni nellopera del genio immortale. E sul limitare o nel vestibolo del secolo xvi l'arte trovò nella Vergine il tipo italico clella venustà muliebre con Raffaello, Leonardo, Giorgione, Correggio e Tiziano.

Raffaello chiede dapprina al Perugino il candore delle umbre Vergini divote, all'arte fiorentina la maggior maturità femminile per le sue Madonne, 
che poi a Roma trasforma in un tipo vigoroso, idealizzando le forme delle donne della campagna romana, sì che i loro occhi grandi con nere soprac-

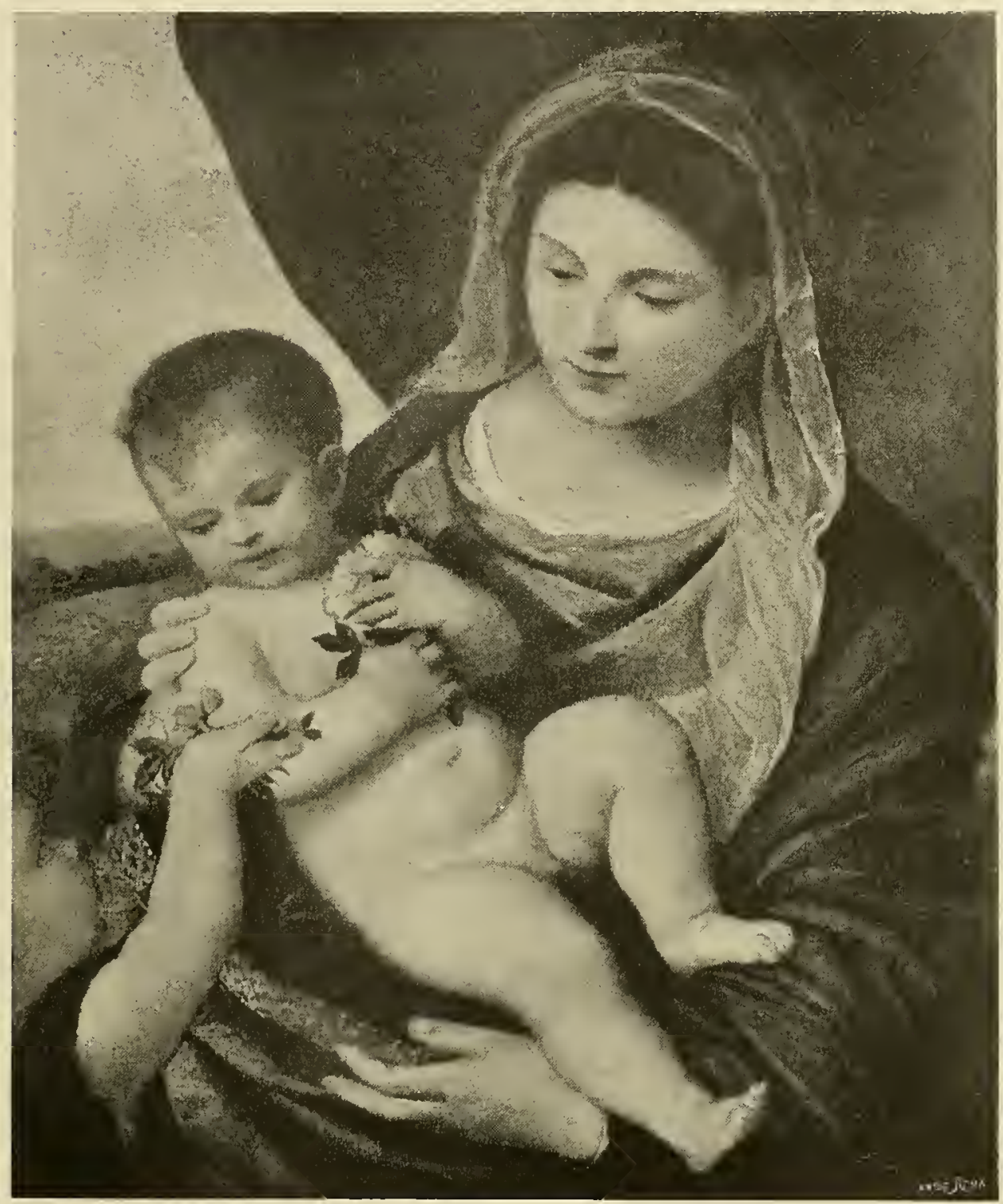

Firenze - Galleria degli Uffizi

('T1ZIANO)

ciglia arcuate, le loro carni soleggiate si rivedono nella Madonna di Dresda; ma il naso grosso all'estremità, le labbra tumide trovano correzioni sapienti dal maestro immortale. Leonardo lascia il tipo ereditato dai precursori e dai maestri e dà alle sue Madonne quella bellezza la quale può dirsi col Manzoni 


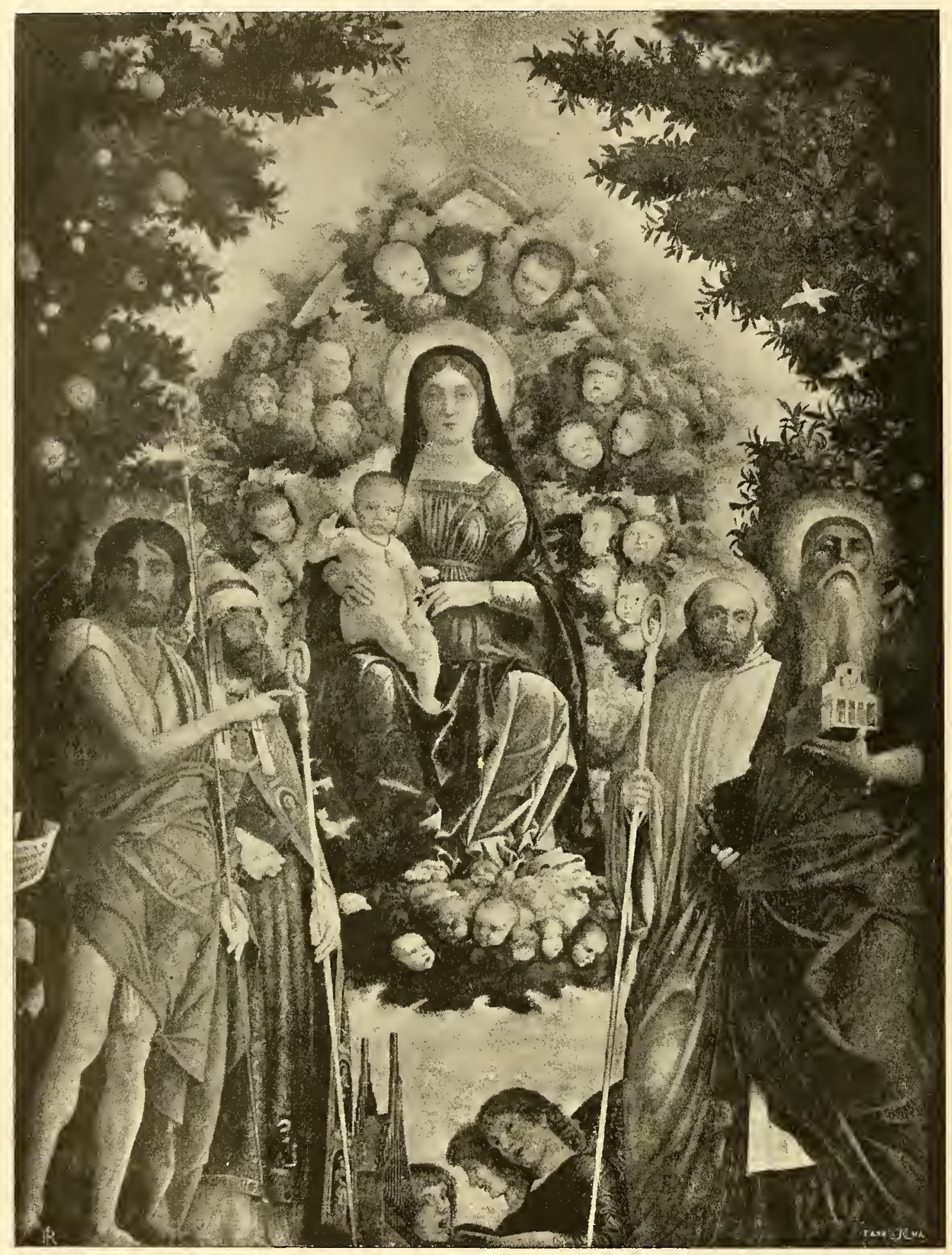

Milano - Palazzo Trivulzio

(MANTEGNA) 


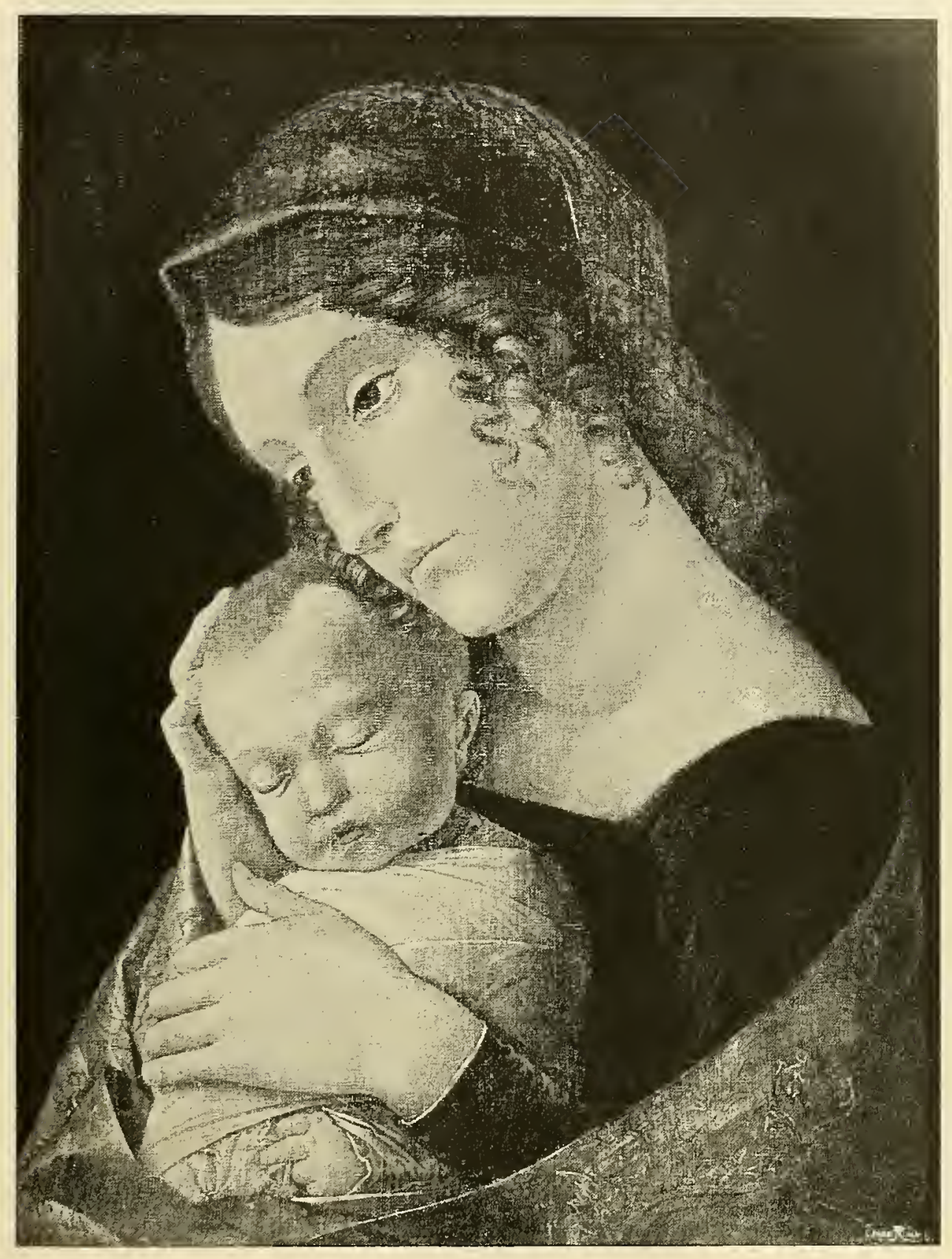

Berlino - Collezione Simon

(MANTEGNA) 


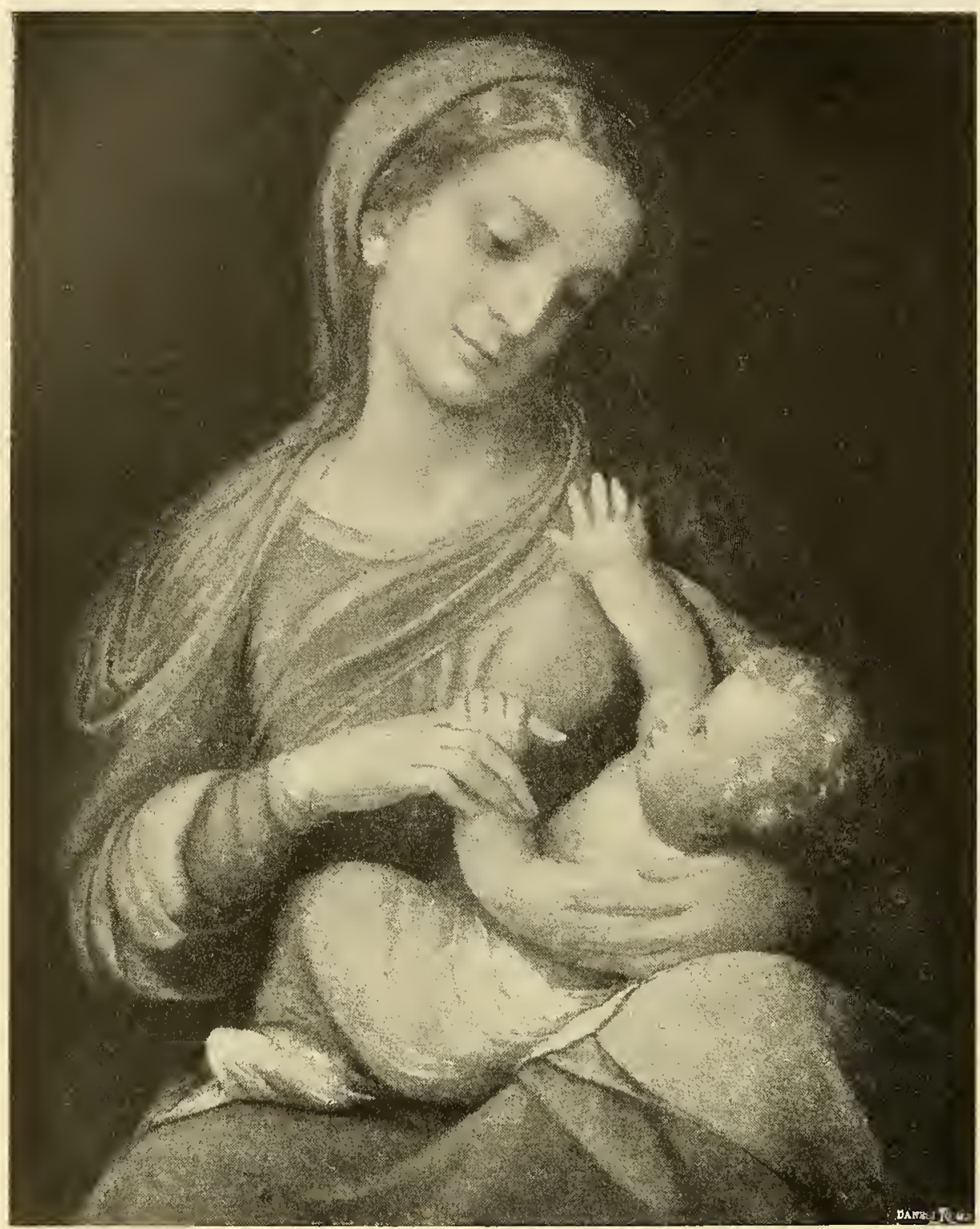

Modena - Galleria Estense

(Correggio) 


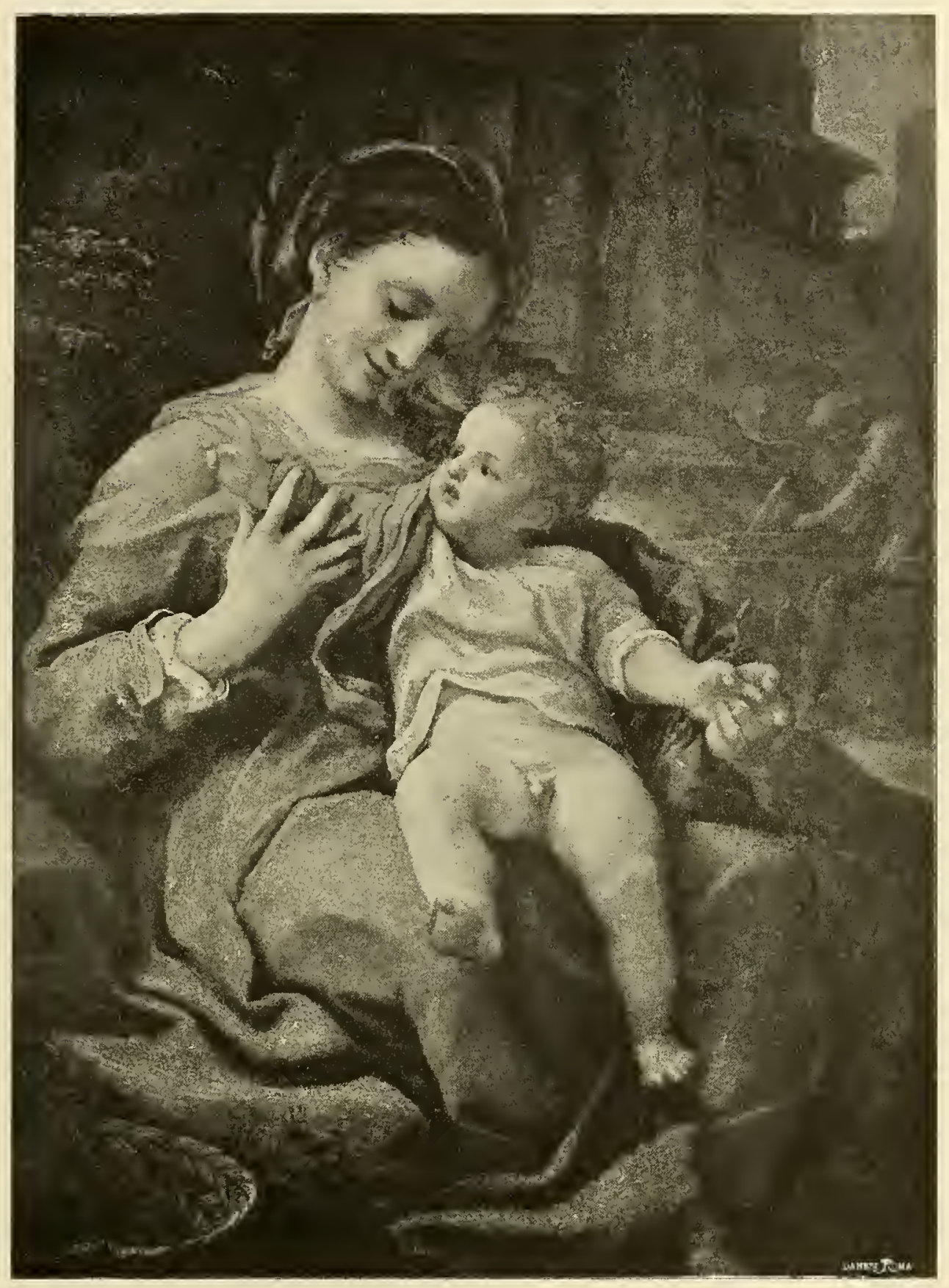

Londra - Galleria Nazionale

(CORREGgIO) 
"molle a un tempo e maestosa, che brilla nel sangue lombardo». Giorgione e Tiziano rappresentano, quello, nel dolce ovale dei volti, la fine femminilità, questo il calore delle forme muliebri splendenti di salute e di sole nella laguna; e Correggio trova nella grazia emiliana, nelle donne dalle carni candide soffuse di rosa, un tipo di voluttuosa bellezza. Come Raffaello svolse le forme derivate dal Perugino, da Bartolomeo e da altri, Giorgione scaldò quelle di Giambellino, Correggio illeggiadrì quelle studiate dal Mantegna.

Le gentildonne delle corti italiane, le madri belle di casalinghe virtù, le fanciulle sorridenti d'amore, tutte ritratte nel secolo xv, recarono la venustà di cui erano adorne, come una collana di gemme, alle Madonne loro ideali eredi.

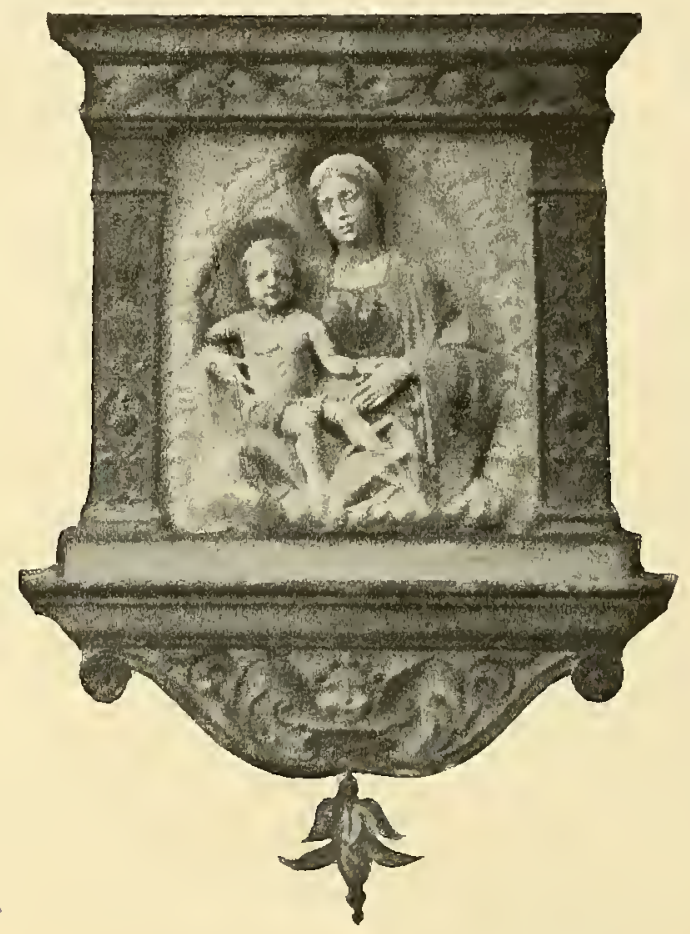

Comiso (provincia di Siracusa) - Chiesa di San Francesco (Antonello Gagini) 


\section{La Natività di Maria.}

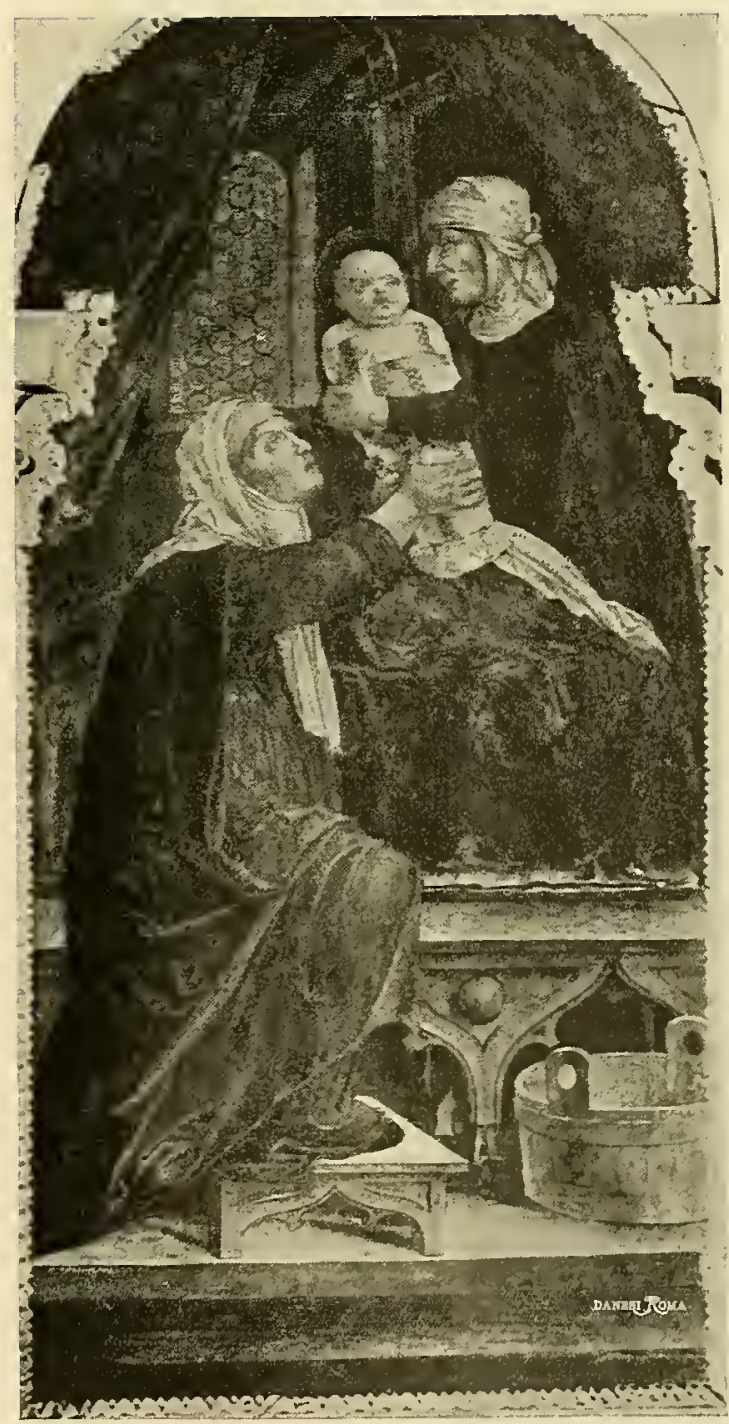

Santa Maria Formosa in Venezia

(BARTOLOMFo VIVARini)
Per anni parecchi, nella notte dell'otto di settembre, il canto degli angioli risonava nella cella di un monaco, che alla fine ebbe la rivelazione del mistico gaudio: si commemorava, si festeggiava così la natività della Vergine dagli esseri del cielo. Allora papa Sergio volle commemorarla insieme con quegli angioli istituendo nel 695 la nuova solenne festa della Chiesa. "Date fiato alle trombe", diceva Sergio, vescovo di Eriapoli, "perchè in quel giorno sacro è nata nella regale stirpe di Davide colei che fu madre della vita, che come splendente aurora dissipò le unane tenebre». Più tardi San Giovanni Damasceno faceva appello alle nazioni del mondo, perchè tutti, di qualunque età, lingua, condizione, si raccogliessero a celebrare il genetliaco di Lei. "Oggi», diceva, "dall'albero di Jesse si stende nel mondo un ramo su cui sboccia un fiore divino; da Anna si diparte 
una vite feconda che ha prodotto l'uva, nettare della vita eterna agli uomini » . Mentre tali inni sonavano nelle chiese, si diffondeva l'apocrifo evangelo o protoevangelo di Giacomo Minore, ove si legge che Gioacchino, ricchissimo, offriva grandi doni a Dio, ma che nella ricorrenza d'una delle maggiori feste religiose, mentre insieme con lui i figli d'Israele recavano offerte al tempio, Ruben rifutò quelli di Gioacchino, dicendogli: "Tu non devi far presenti a Dio, tu che non hai discendenti in Israele». Gioacchino fu percosso da gran dolore, tanto più quando si fu convinto che ogni giusto delle tribù aveva lasciato successori, e non volle comparire più innanzi alla sua donna. Andò nel deserto e vi stette digiunando quaranta giorni e quaranta notti; intanto la moglie Anna deplorava la propria vedovanza e la sterilità.

Tornò la solennità sacra, e Giuditta, ancella di Anna, voleva acconciarla a festa. Rifiutava ella, ma infine si spogliò delle vestimenta di lutto, si ornò il capo, si rivestì di abiti nuziali. Verso l'ora nona discese nel giardino per passeggiare, sedè sotto un lauro e pregò. Volti gli occhi al cielo, scorse sul lauro un nido di passeri, e pianse la sua sventura vedendo la fecondità degli uccelli, e pensando che di pesci è pure popolato il mare e d'ogni sorta di animali la terra.

Allora l'angelo del Signore volò ad annunciarle la felicità di madre; altri

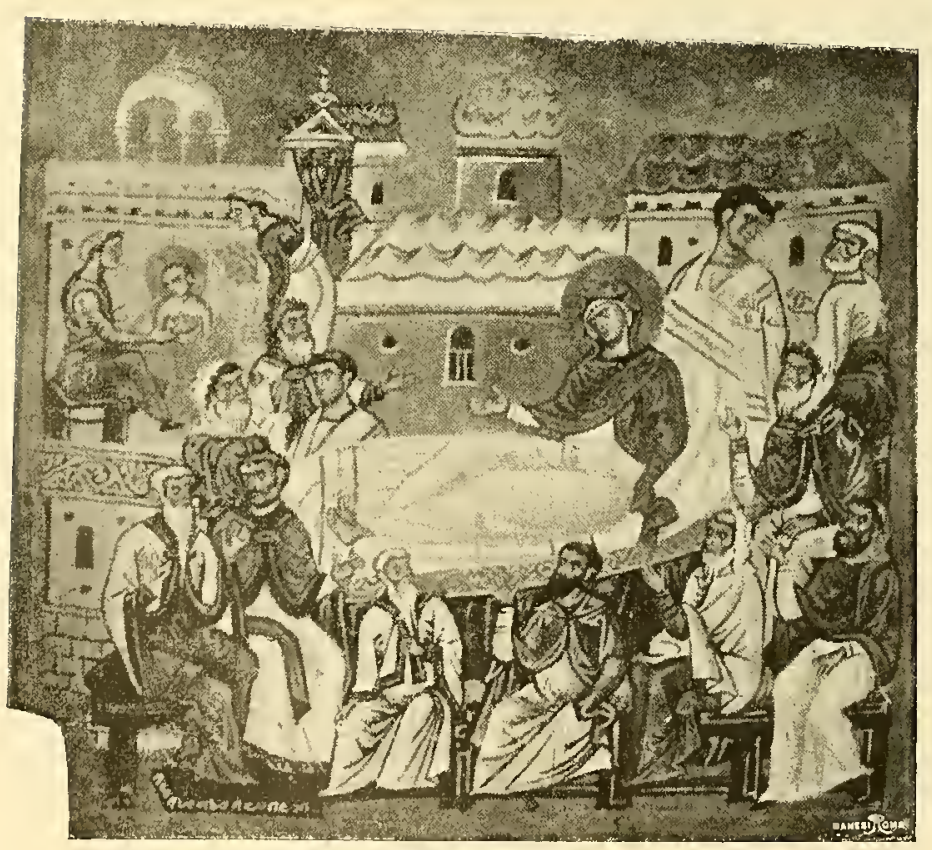

Natività di Maria. Biblioteca Nazionale di Parigi Omelie del Monaco Giacomo due angioli sopravvennero e le dissero che faceva ritorno a lei Gioacchino, il quale difatti, ricevuto l' annunzio celeste, lasciò il monte colle sue mandre. Anna era alla porta della casa; gli corse incontro e gli gettò tutta festante le braccia al collo. Il domani Gioacchino presentò le sue offerte, che più non furono respinte, e tornò benedetto alla casa, ove, dopo nove 
mesi, nacque Maria. Questo racconto del protoevangelo di Griacomo fu ripetuto con varianti nell' istoria della natività di Maria e dell' infanzia del Redentore.

Mentre nel protoevangelo Anna sfoga nel giardino il suo dolore, nell' istoria gnostica ella piange amaramente in casa e prega Dio ginocchioni; mentre in quello Gioacchino riceve semplicemente l'angelico annuncio, in questa è invitato dall'angelo a offrire a Dio in olocausto ciò che a lui avrebbe voluto dare.

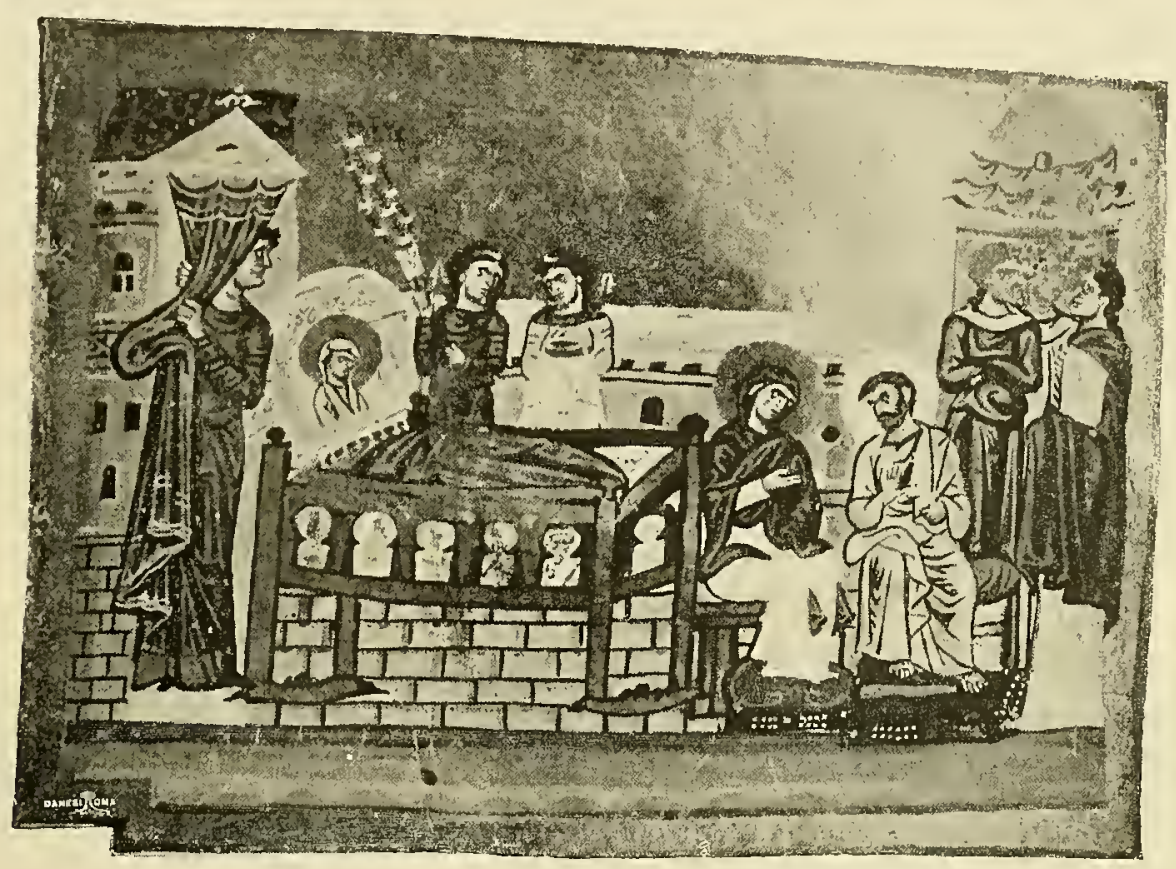

Maria nella culla d'oro. Biblioteca Nazionale di Parigi

(Omelie del monaco Giacomo)

Groacchino prese allora un candido agnello e l'offerse a Dio, e l'angelo risali ai cieli tra il fumo del sacrificio. Ciò veduto, Gioacchino cadde con la faccia a terra, e così stette dalla sesta ora fino a sera. I servi lo rialzarono spaventati, e sentendo il racconto della sua visione lo esortarono a ritornare presso la moglie. Intanto Gioacchino, incerto a qual partito appigliarsi, fu vinto dal sonno, e gli apparve l'angelo a fargli animo e invitarlo al ritorno. Destatosi, raccontò il suo sogno ai mandriani, e quelli adorarono il Signore e incitarono lui a non frapporre indugio nell'obbedire. Dopo trenta giorni di cammino, col gregge che sostava ne' pascoli, Gioacchino s'appressò alla porta dorata di Gerusalemme e v'incontrò Anna, che là si era condotta con le ancelle, secondo l'avviso dell'angelo, in attesa del marito. Così gli evangeli 

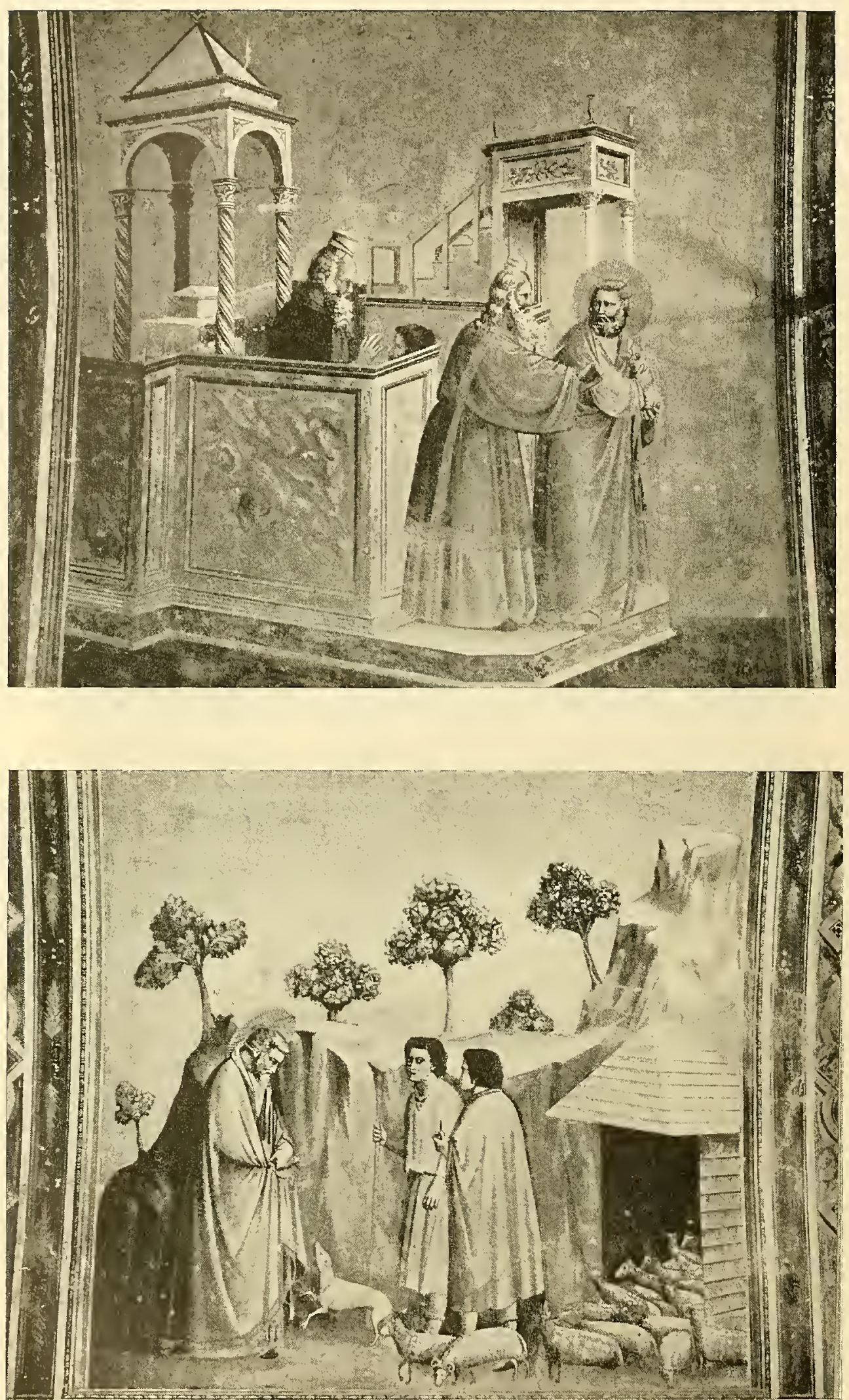

Chiesa dell'Arena in Padova

(Giotto) 

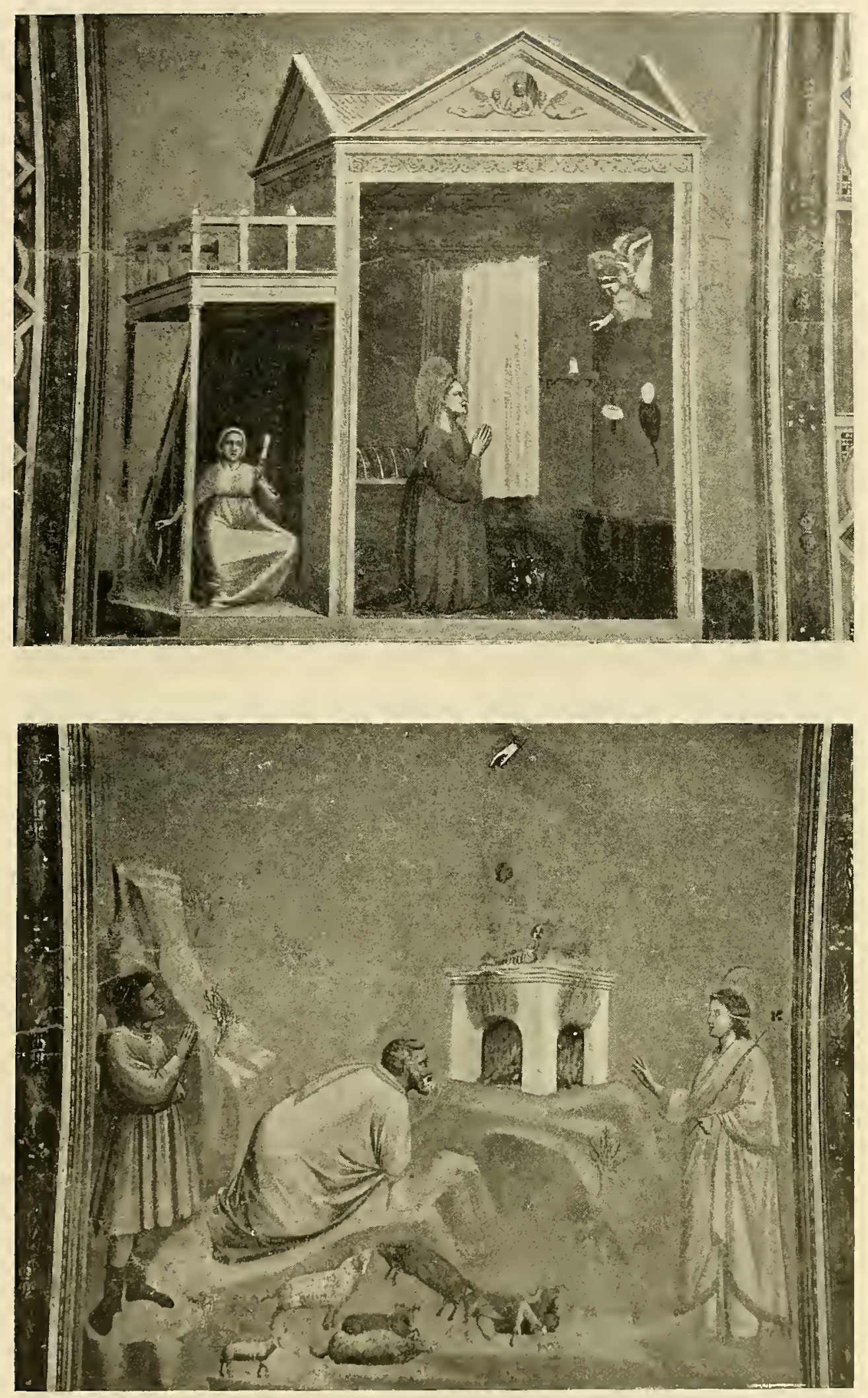

Chiesa dell'Arena in l'adova

(GiotTo) 

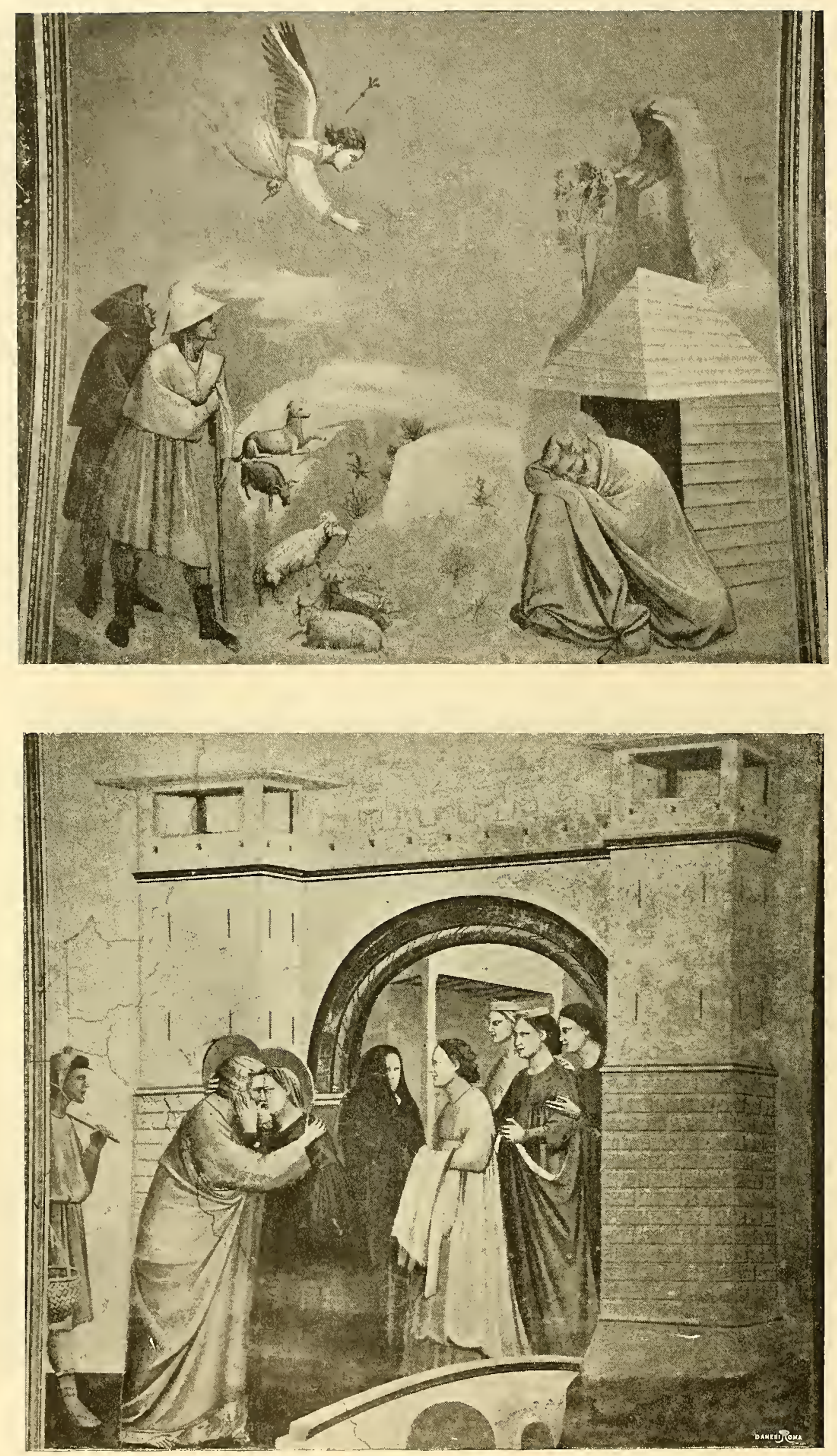

Chiesa dell'Arena in Padova

(Grotto) 
apocrifi, che l'arte interpretò. Nel menologio greco dell'anno 1025 , esistente nella Biblioteca Vaticana (vat. graec. I6 I3), vedesi Anna coricata sul letto, all'aperto; tre donne le apportano cibi, un'altra si prepara a lavare la bambina e immerge la mano in un catino per assicurarsi della giusta temperatura dell'acqua. Questo quadro ha la distribuzione e la bellezza di una pittura antica.

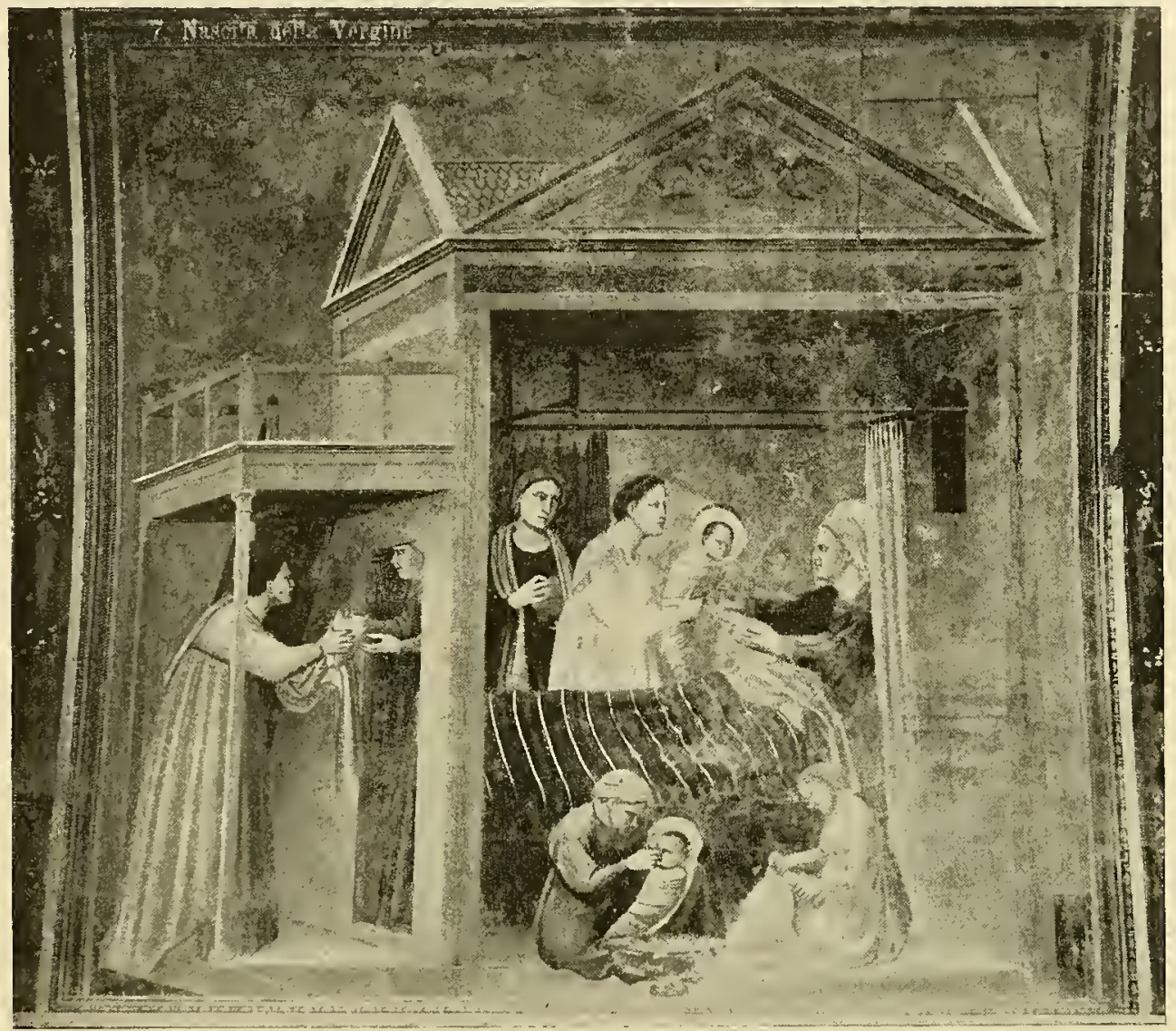

Chiesa dell'Arena in Padova

(GIOTTO)

Crediamo infatti derivi dallo studio di un bassorilievo antico rappresentante l'oroscopo o le Parche assistenti alla nascita d'un fanciullo, forse di Achille. Le tre donne che recano doni in un vassoio ad Anna sono probabilmente una reminiscenza delle tre Parche, presenti sempre allorchè un bambino schiude gli occhi alla vita; e la donna che sta per lavare il fanciullo nel catino è probabilmente un ricordo della schiava che nei bassorilievi classici della nascita d'Achille, o in generale della nascita dei bambini, si vede in atto d' immergerli appunto in un catino di acqua. 

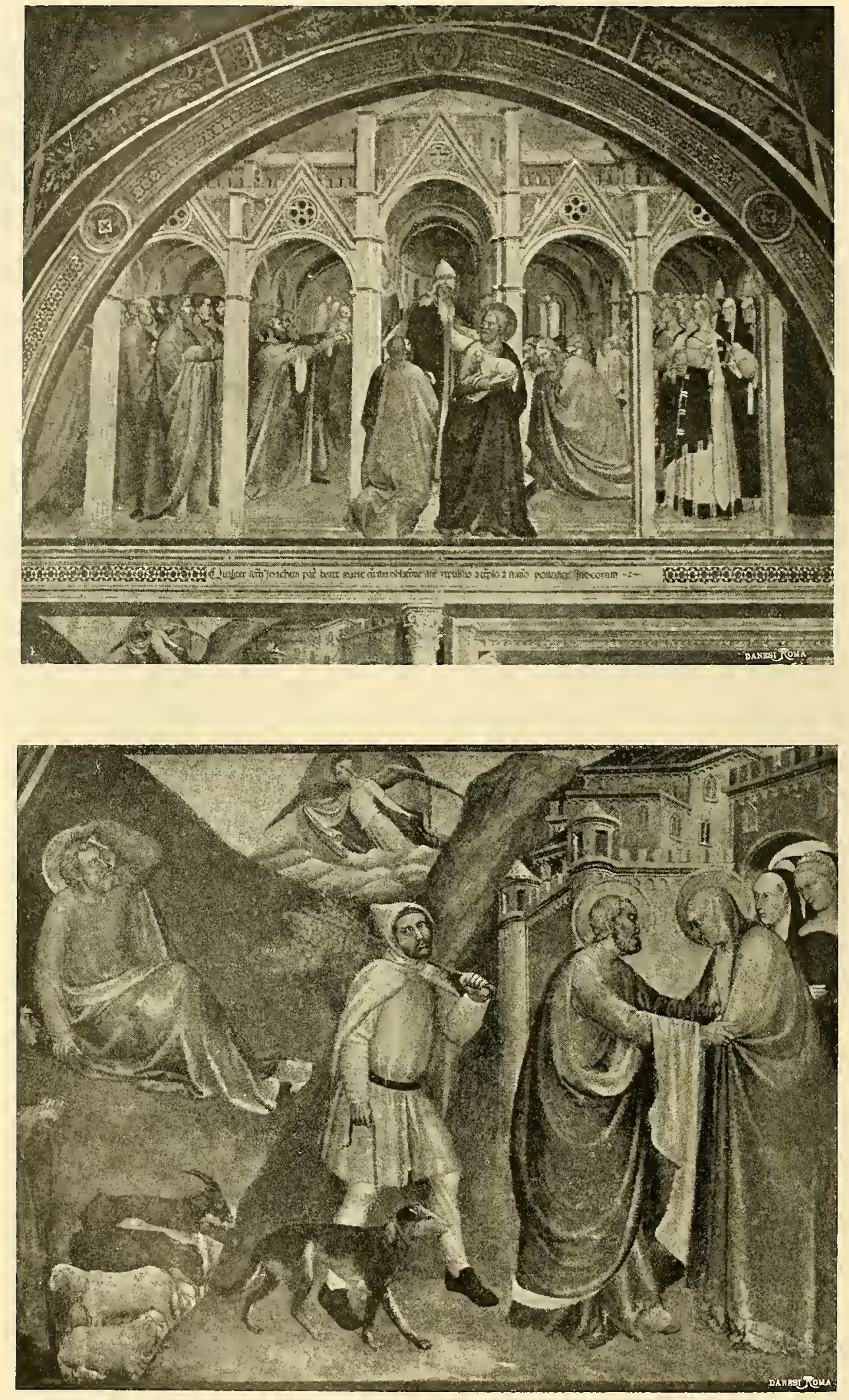

Santa Croce in Firenze

(GIOVANI DA MILANO) 
Nell'Amphitryon di Plauto la schiava Bormia si occupa a lavare un fanciulletto, e d'ordinario una schiava rendeva tale servizio all'infanzia. In

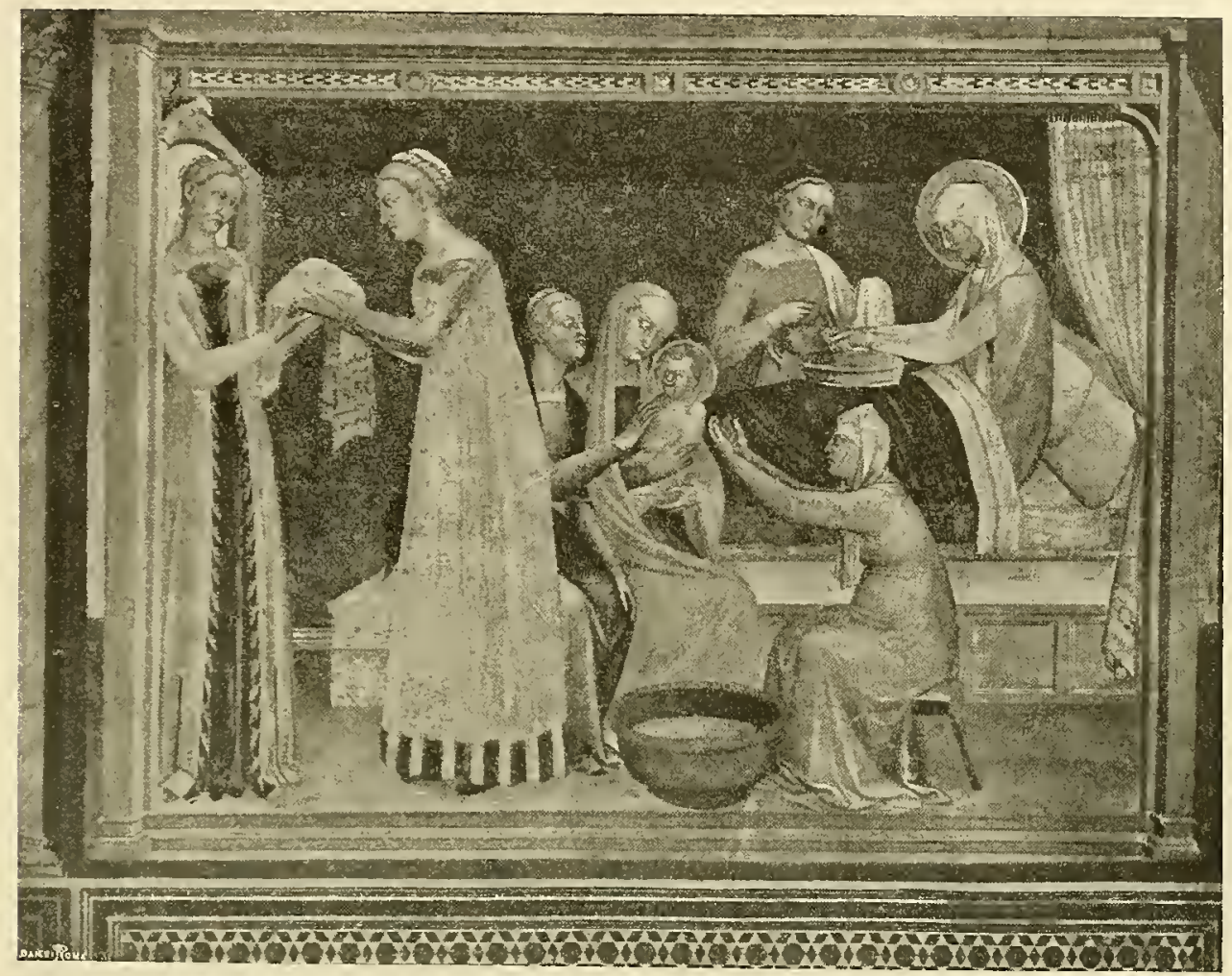

Santa Croce in Firenze

(GIOVANNIDA MIL $\Lambda N O)$

un frammento di sarcofago illustrato da Raoul Rochette una schiava è intenta a lavare un pargolo in un largo bacino, mentre un'altra si appresta a riceverlo in un lintcolum o lenzuolo, che tiene spiegato nelle mani; e le tre Parche assistono alla nascita, la prima con 11 globo, la seconda con tavolette, la terza con la conocchia e il fuso.

Più complicata è la rappresentazione nelle omelie del monaco Giacomo, pure alla Vaticana. Ivi si celebrano i genitori di Maria di stirpe regale osservante delle leggi, e si ricorda che sorpassavano nell'amore della giustizia tutti della loro tribù, e che donavano il superfluo ai poveri. Il frutto più giusto fu prodotto da esseri giusti: così esclama il monaco bizantino del principio del secolo xir, e si compiace di rappresentare Gioacchino ed Anna in atto di offrir doni nel tempio a Zaccaria, il quale li rifuta. "Non è permesso 
a te , dicevasi a Gioacchino, "di presentare offerte prima di ogni altro (leggesi cosi nel testo greco), perchè tu non hai discendenti in Israele». Profondamente addolorato Gioacchino sopportò i rimproveri e si ritirò nella solitudine; Anna, intanto, nel suo giardino, sospirava dicendo che gli animali i quali camminano sulla terra e quelli che nuotano nel mare conoscono i beneficî a lei negati, e che mentre la terra si copre di frutta e di fiori, ella era priva d'ogni favore. Un angelo le apparve dall'alto di una fonte annunciandole il gaudio materno, e cosi altri angeli annunziarono a Gioacchino che la sua stirpe sarebbe stata celebrata nell' universo. Il monaco Giacomo arriva poi a rappresentare la nascita di Maria. Anna, col nimbo intorno al capo, sta in letto, mentre nel fondo due donne lavano la neonata. Intorno al letto si vedono Gioacchino e i dodici capi delle tribù d'Israele,

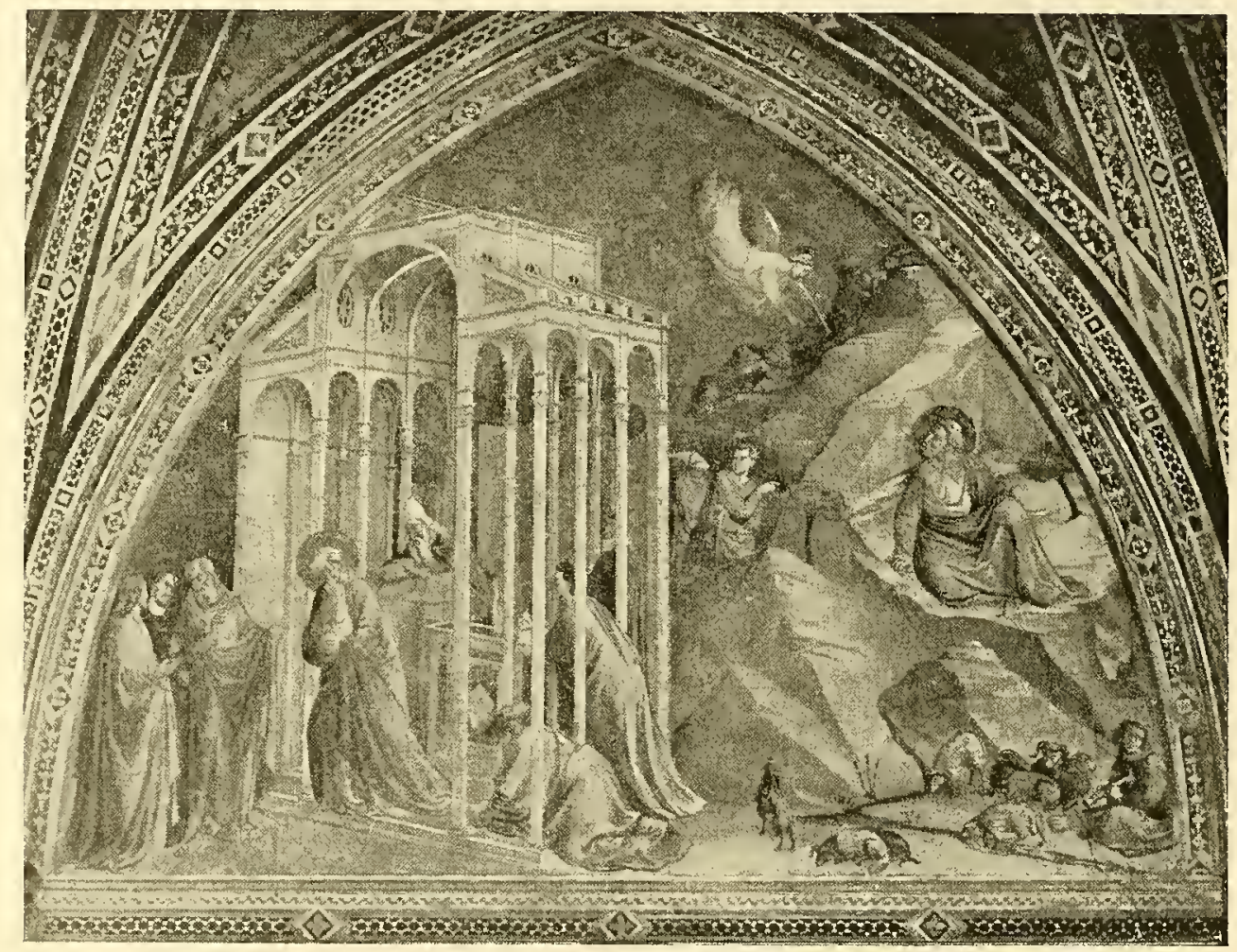

Santa Croce in Firenze

(TADDEO GADDI)

a cui Anna dice, secondo il testo: Godete della mia maternità! Accorrete al tempio, apparate gli altari, illuminate il cammino, cantate un epitalamio, 
e guidate al tempio la fanciulla come una sposa! - 11 monaco seguita a rappresentare con le miniature e con le parole la vita di Maria nella casa dei genitori, in una culla d'oro, e sulle ginocchia di Anna, mentre Davide la contempla, o i sacerdoti radunati da Gioacchino a convito la benedicono,

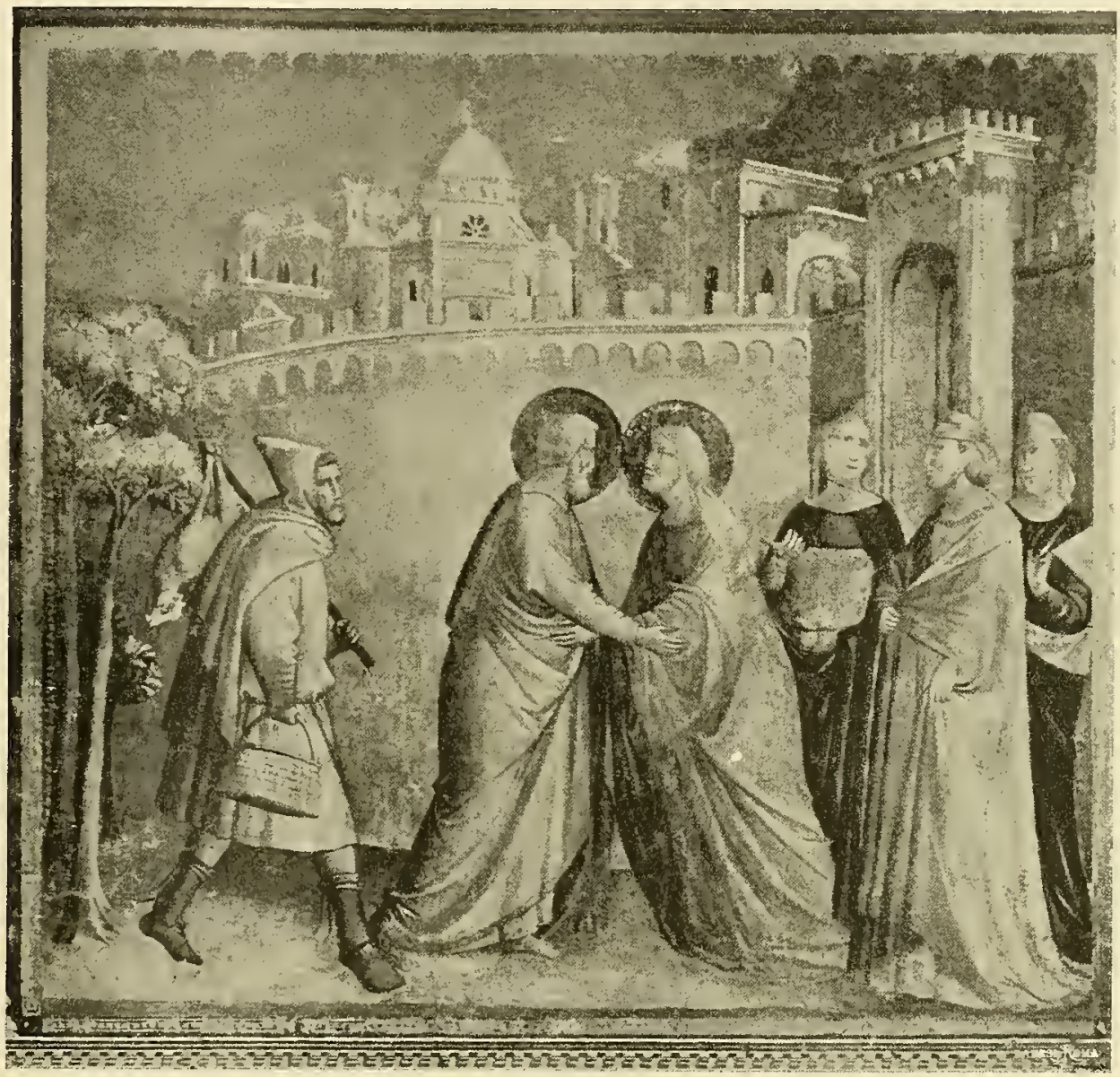

Santa Croce in Firenze

(TADDEO GADDI)

- la madre la accarezza. L'arte non seguì sempre il monaco bizantino nella sua analisi, in quello sforzo di scindere la rappresentazione della natività, che pure nell'xı secolo può considerarsi pienamente determinata.

La leggenda trova in Giotto un interprete drammatico. Accostandoci alle sue composizioni di Padova sentiamo come egli purificasse ed elevasse la leggenda, quanto Fidia ed Eschilo e Sofocle innalzarono i miti ariani. Dapprima ci troviamo innanzi a una specie di cancello di presbiterio, dietro 
cui sta un sacerdote mitrato, in atto di assolvere un fedele ginocchioni; presso al cancello s'innalza un pulpito semplicissimo; dietro al sacerdote, un ciborio sostenuto da quattro colonne ritorte. Ma innanzi al cancello è Ruben pure mitrato, con lunga barba candida, coi capelli pioventi sugli

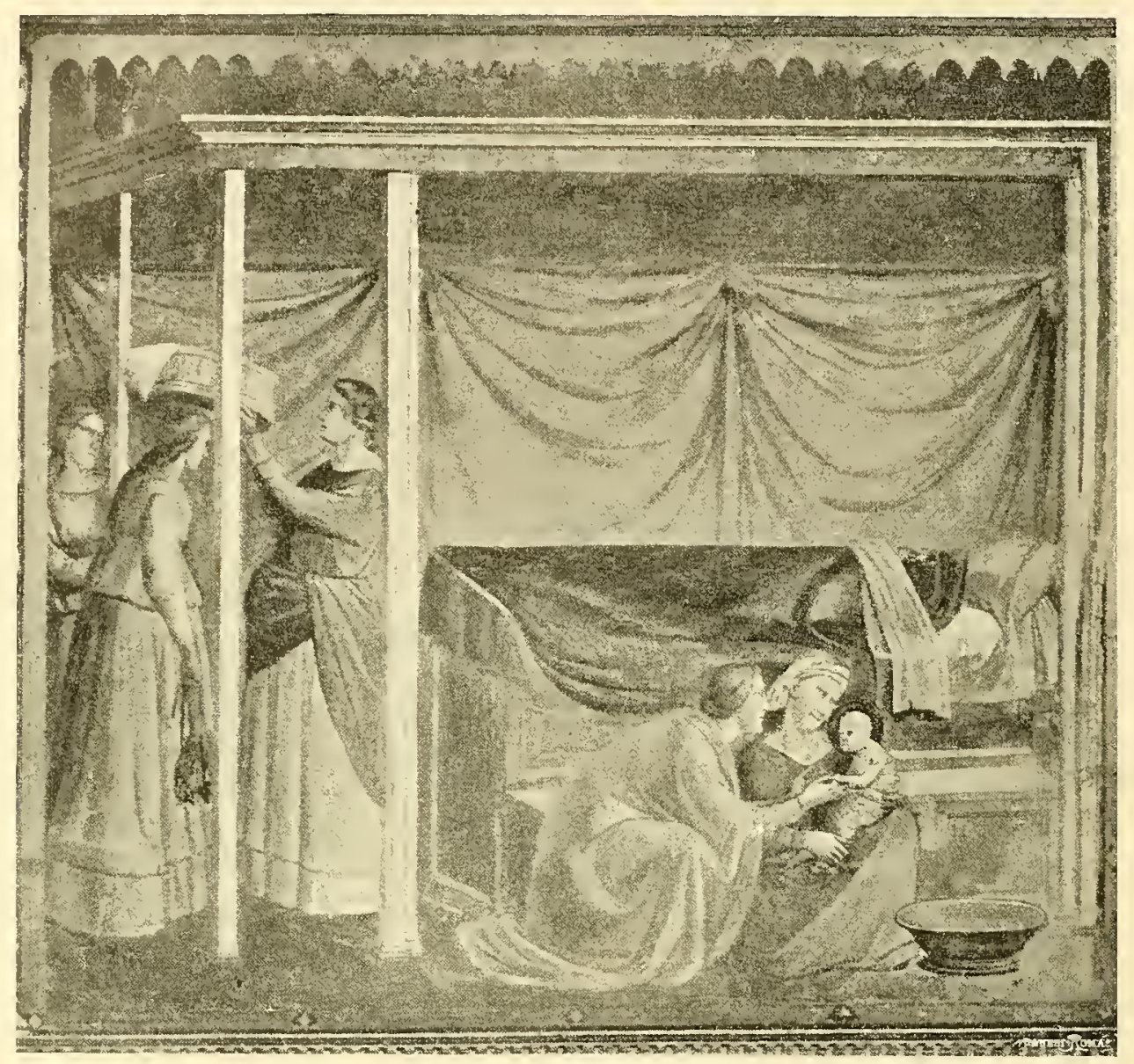

Santa Croce in Firenze

(TADDEO GADDI)

omeri, spirante ira dagli occhi come il michelangiolesco Mosè: pare che la persona, curva dagli anni, trovi nell'atto del rifiuto una giovanile energia; e Gioacchino, stretta nelle mani la pia offerta, se ne va, e si volge impaurito dalla maledizione sacerdotale, con occhi che sembrano dilatarsi sotto le sopracciglia. Ed eccolo abbattuto, chino il capo, fisso lo sguardo a terra, tutto avvolto nel manto, passare tra le rupi, incamminarsi verso l'ovile delle sue pecore, senza guardare al cane che gli è mosso incontro a festa, ma 


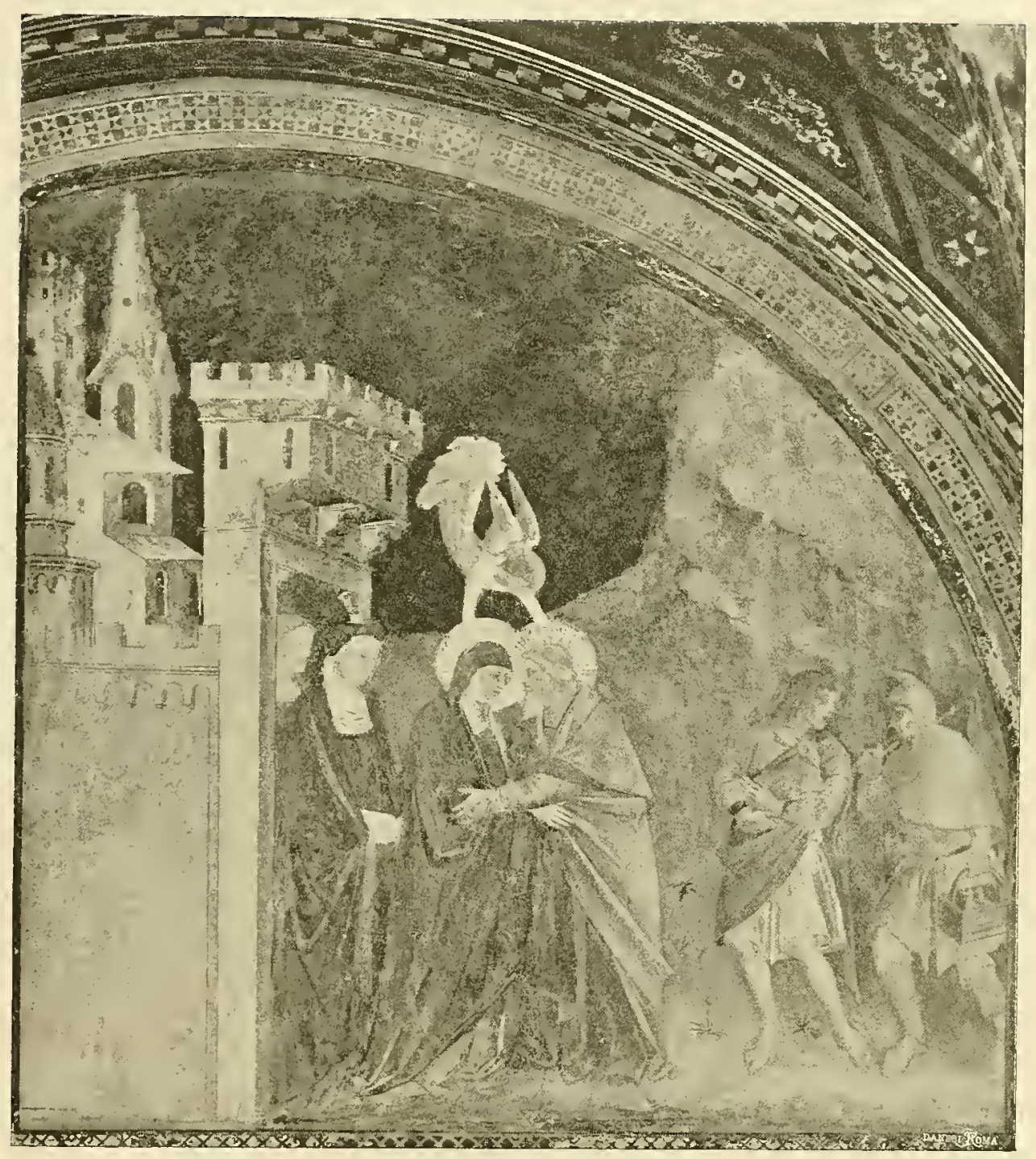

Chiostro di Santa Maria Novella

(Scuola di Giotto) 
che trattiene lo slancio innanzi alla statuaria impassibilità del padrone: due pastori, nel vederlo avanzare meditabondo, si guardano come di sfuggita,

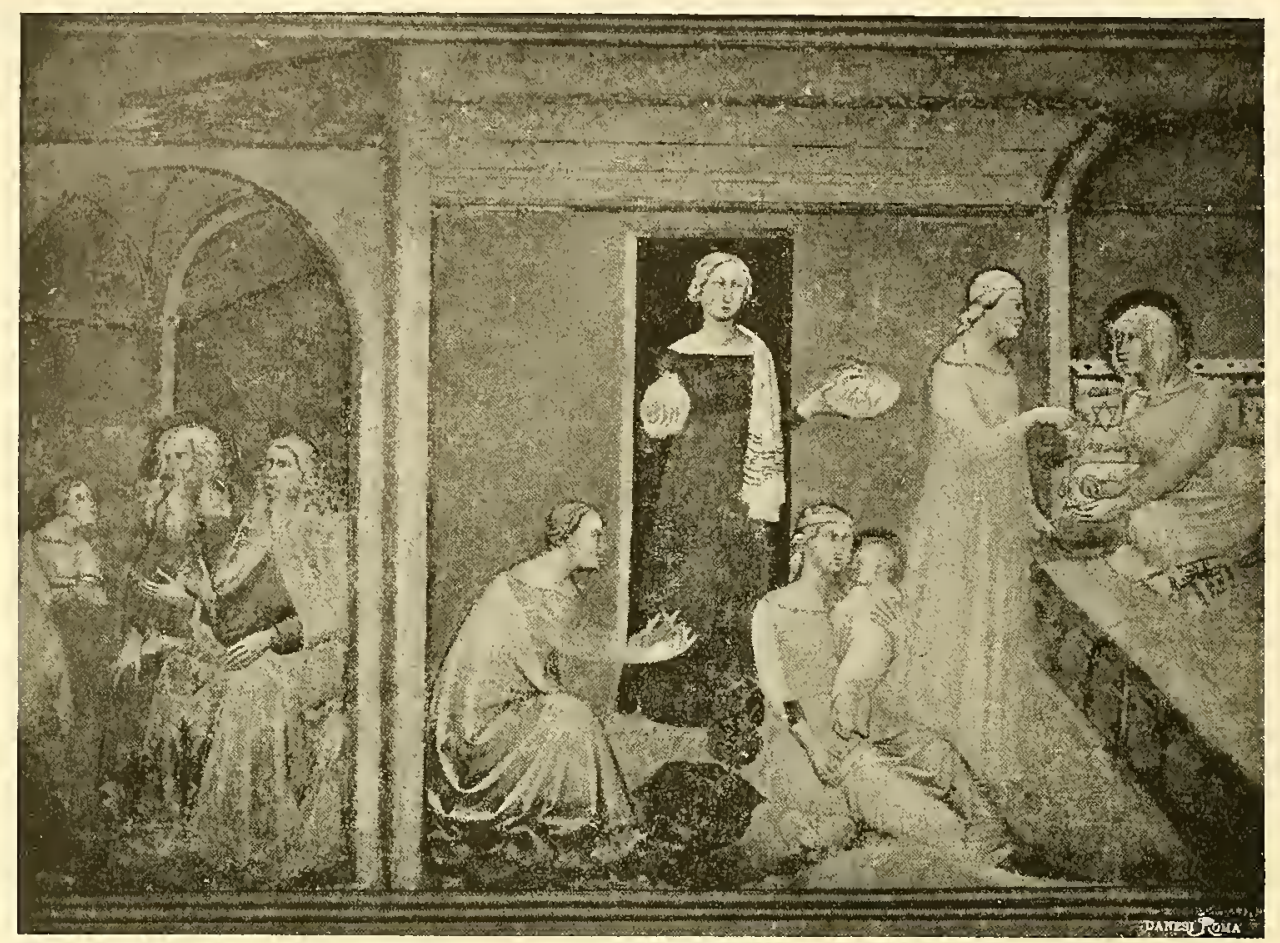

Sant'Agostino in San Gimigliano

(Bartolo Di M. Fredi)

per interrogarsi sull'accaduto; intanto le pecore escono, si sospingono fuor dal chiuso. Ed ecco poi l'angelo appare ad Anna supplice, presso il letto, coi segni dell'affanno e del pianto in volto; egli entra come rondinella del cielo, e alla derelitta tutta sorpresa stende la manina annunciante la grazia del Signore. Mentre ciò avviene, la fantesca di Anna, in una cameretta appresso, sembra sostar dal filare e porgere orecchio, come se avesse udito rumore. Ad un tempo, ecco Gioacchino sulla montagna presso un'ara, ove egli ha offerto in olocausto a Dio un candido agnello, secondo la volontà suprema espressa dall'angiolo, che come nraestoso levita sta di fronte a lui chino a terra, in atto di farsi puntello con le mani. Le fiamme escono dall'ara, il fumo s'innalza dall'ostia; l'araldo del cielo s'invola tra i vapori verso l'alto, ove la mano di Dio sporge, come nelle opere cristiane primitive, tra le nuvole, invitando il pastore, che sta dietro a Gioacchino, a soccorrere il padrone cadente con la faccia a terra. Nel vicino campo dell'affresco 
Gioacchino dorme sul braccio ripiegato sopra il ginocchio destro, come se il sonno lo avesse sorpreso mentre stava tutto agitato da opposti pensieri. Pare che niuno osi disturbare quel sonno; un pastore appoggiato al bastone guarda il dormiente, il cagnolino fedele è steso a terra, un agnello allunga

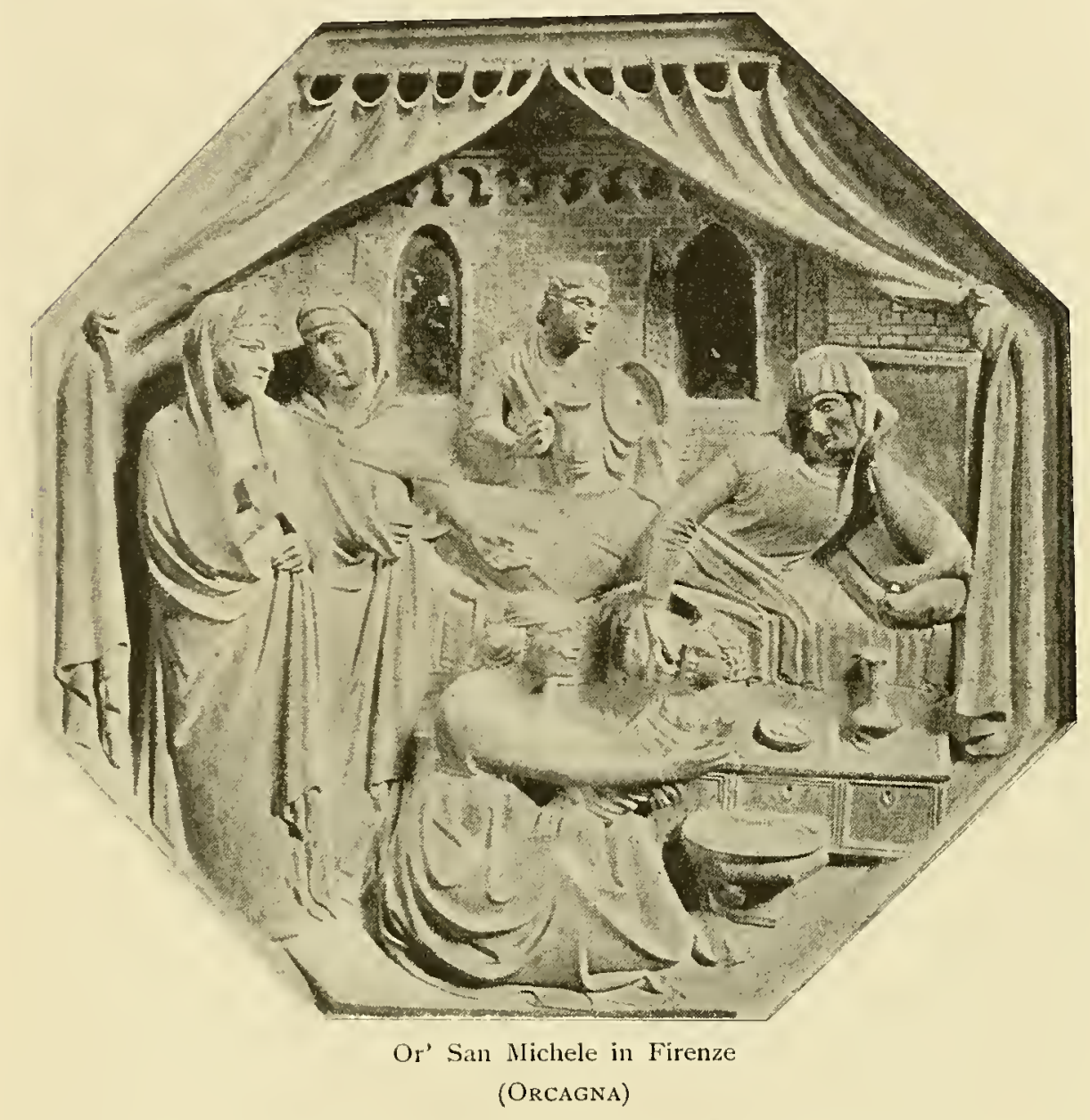

il muso verso lui, e l'angelo, riapparso nell'alto, gli stende la mano comunicandogli nel sonno la promessa di Dio. Segue l'incontro di Anna e Gioacchino innanzi alla porta di Gerusalemme, divenuta nell'opera di Giotto una porta di città toscana, merlata, fiancheggiata da due torri con feritoie, e a cui si accede per un ponte. L'abbraccio è tenerissimo: Anna prende il capo di Gioacchino con la destra e mette la sinistra tra la folta barba di lui, per appressar labbra a labbra; entrambi si fissano negli occhi languenti. Dietro, le ancelle di Anna godono dell'incontro: una innanzi alle altre esulta, una 

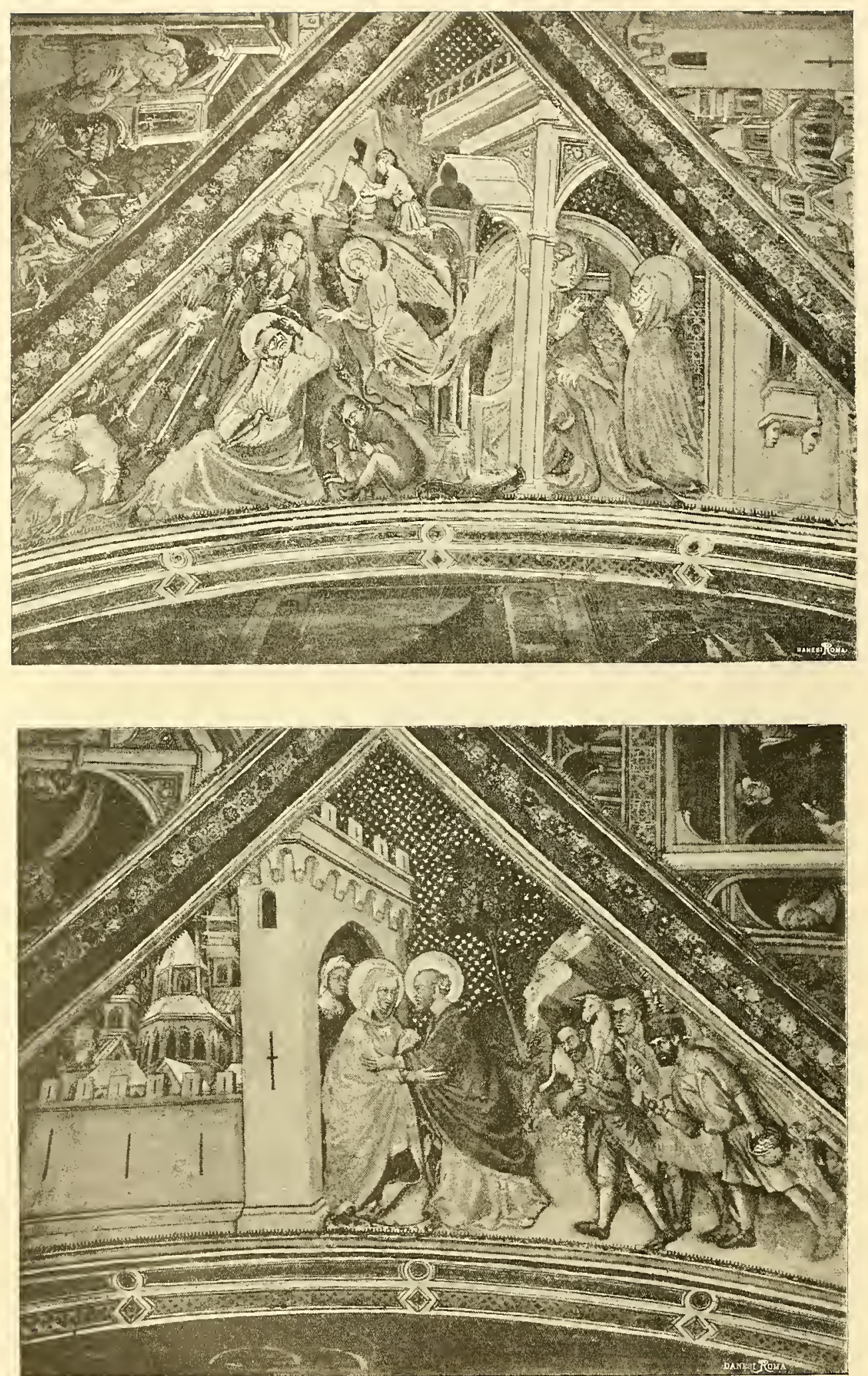

Palazzo de' Trinci in Foligno

(Ottaviano Nelli) 

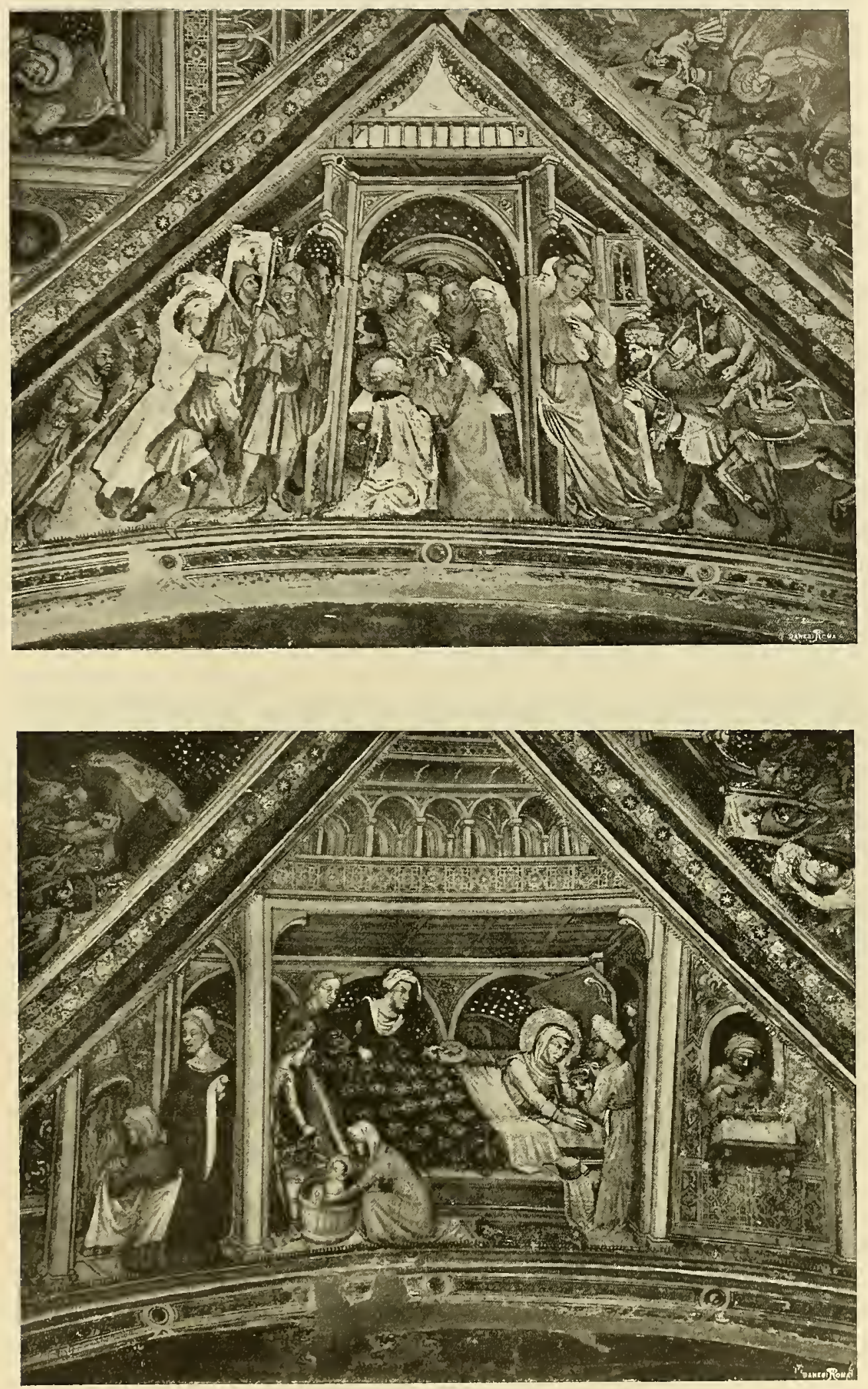

Palazzo de' Trinci in Foligno

(Ottaviano Nelli) 

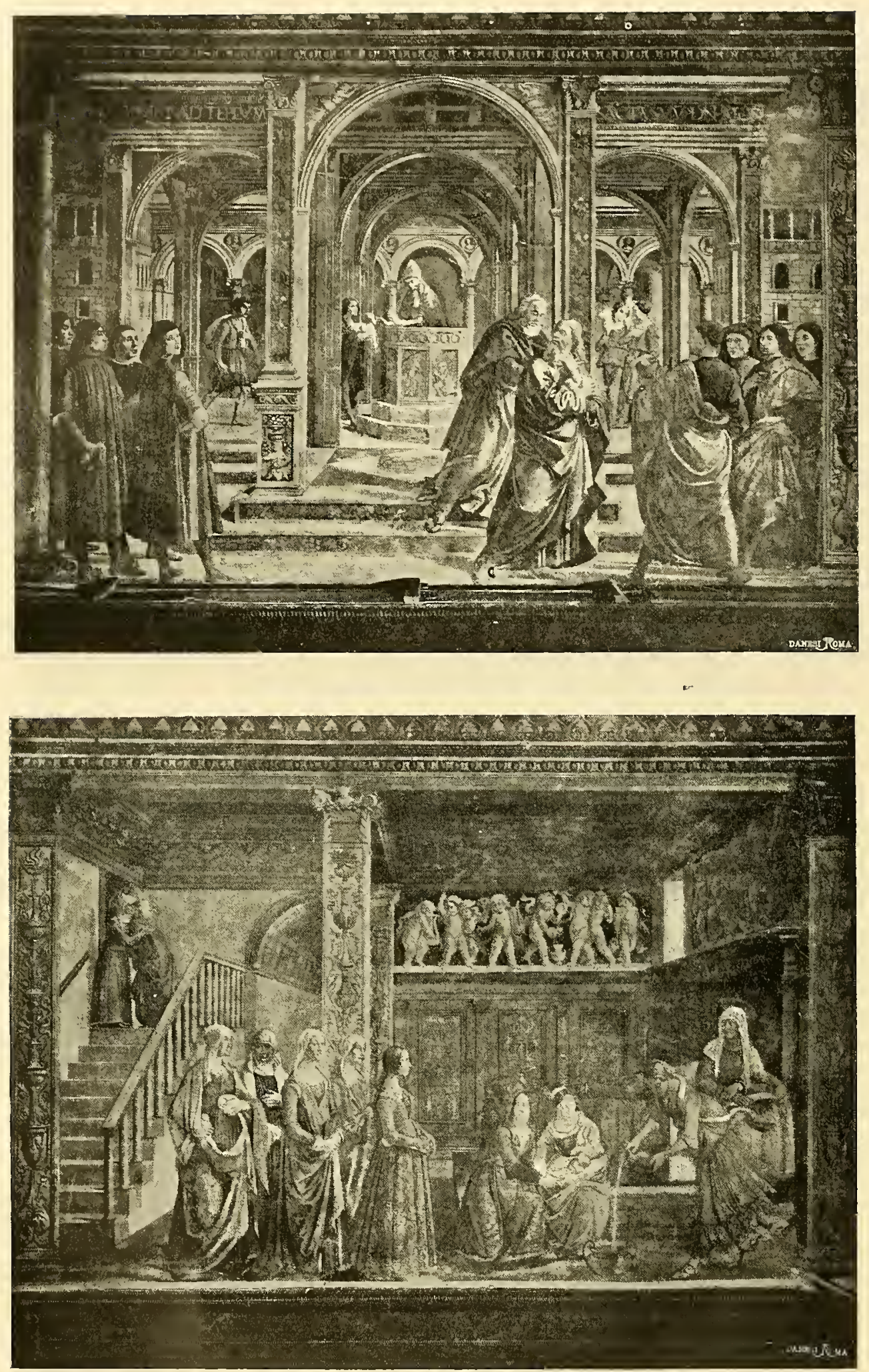

Santa Maria Novella in Firenze

(Domenico Ghirlandajo) 
dietro a tutte sporge la testa lietamente. Ed ecco un ancella mostra tutta avvolta in fasce alla vecchia madre la neonata Maria, mentre altre donne si affaccendano intorno o curano innanzi al letto la fanciullina.

I seguaci di Giotto furono ligi alle forme da lui determinate, prescritte. Giovanni da Milano, nella chiesa di Santa Croce a Firenze, rappresentò dapprima Gioacchino scacciato dal tempio, mentre fra le arcate uomini e donne s'affollano presentando gli agnelli al sacerdote. Poi Gioacchino, che vergognoso delle rampogne avute, sta ritiratosur un montetra le mandre, quando l'angelo gli appare, e gli ordina di ritornare a Gerusalemme. Gioacchino ancora che, innanzi alla porta dorata della città, incontra ed abbraccia la moglie, avvisata pure da un angelo del ritorno di lui. Infine Giovanni da Milano rappresentò la Natività di Maria, ove è graziosissimo il gruppo delle

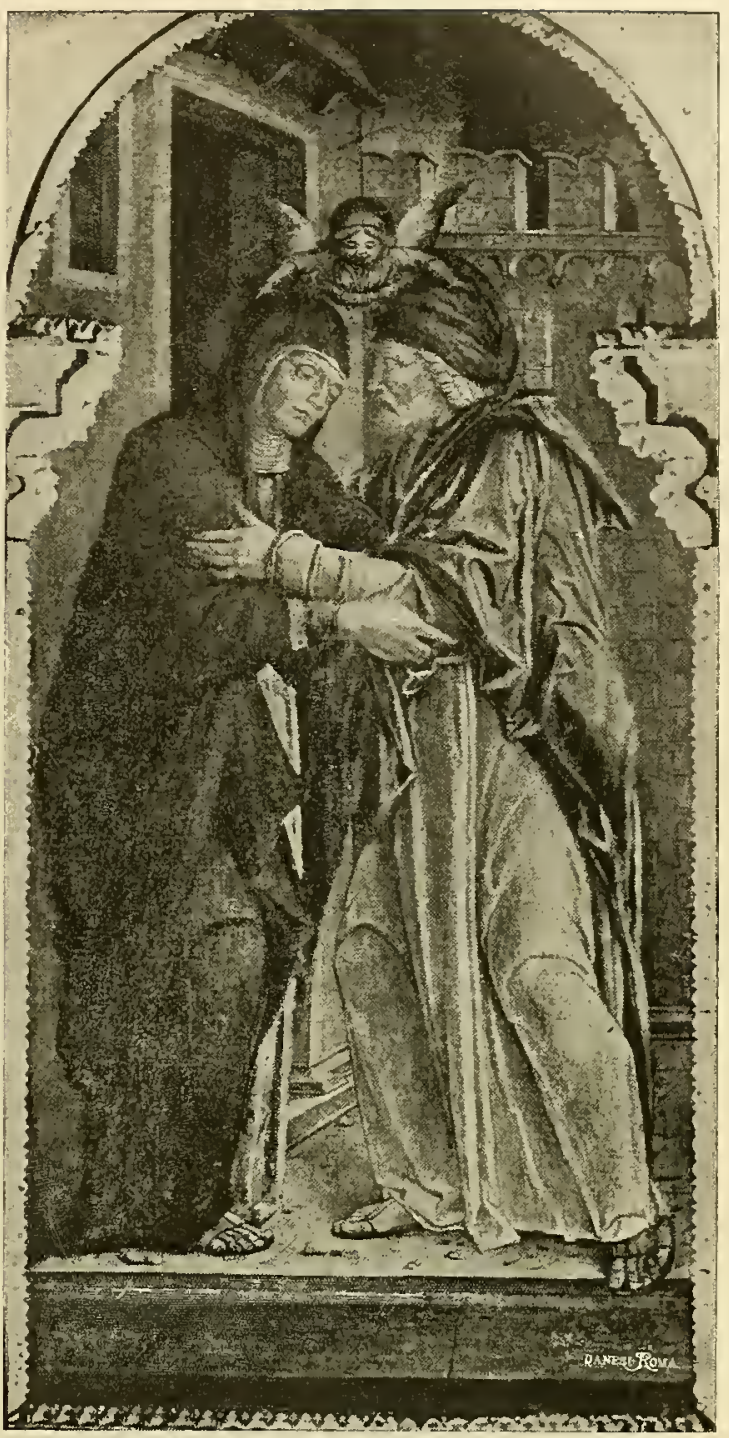

Chiesa di Santa Maria Formosa in Venezia

(BARTolomeo ViVarini) tre donne intorno alla neonata in fasce, e l'una la stringe e la guarda amorosamente, un'altra tende le braccia e fa conca con le mani come per ricevere il piccolo corpicino, la terza si protende ad accarezzare la creaturina. Nella stessa chiesa di Santa Croce, Taddeo Gaddi rappresentò, ma con più veemenza, la cacciata di Gioacchino, indi l'annuncio della paternità, l' incontro con Anna innanzi alla porta dorata di Gerusalemme, infine la Natività della Vergine: e anche qui il gruppo delle due donne intorno alla Bambina amorose, sorridenti, carezzevoli, è la parte più bella, più viva della composizione, la quale 
non muta in altri affreschi trecentistici, in quelli, ad esempio, di Agnolo Gaddi nella Cattedrale di Prato, negli altri della scuola di Giotto a Santa Maria Novella, di Bartolo di Fredi a San Gimignano, ecc. L'Orcagna in Or'San Michele rappresentò soltanto la Natività di Maria. Anna è coricata sul letto con la testa appoggiata sulla sinistra, in atteggiamento simile a quello in cui si vede rappresentato il defunto sulle urne etrusche. E forse qui, come in tante altre forme dell'arte toscana e umbra, abbiamo una riminiscenza dell'arte etrusca rimasta nel fondo della razza, nelle sue tendenze, ne' suoi ricordi. Il viso di Anna, benchè di vecchia, è illuminato da un sorriso di amore materno.

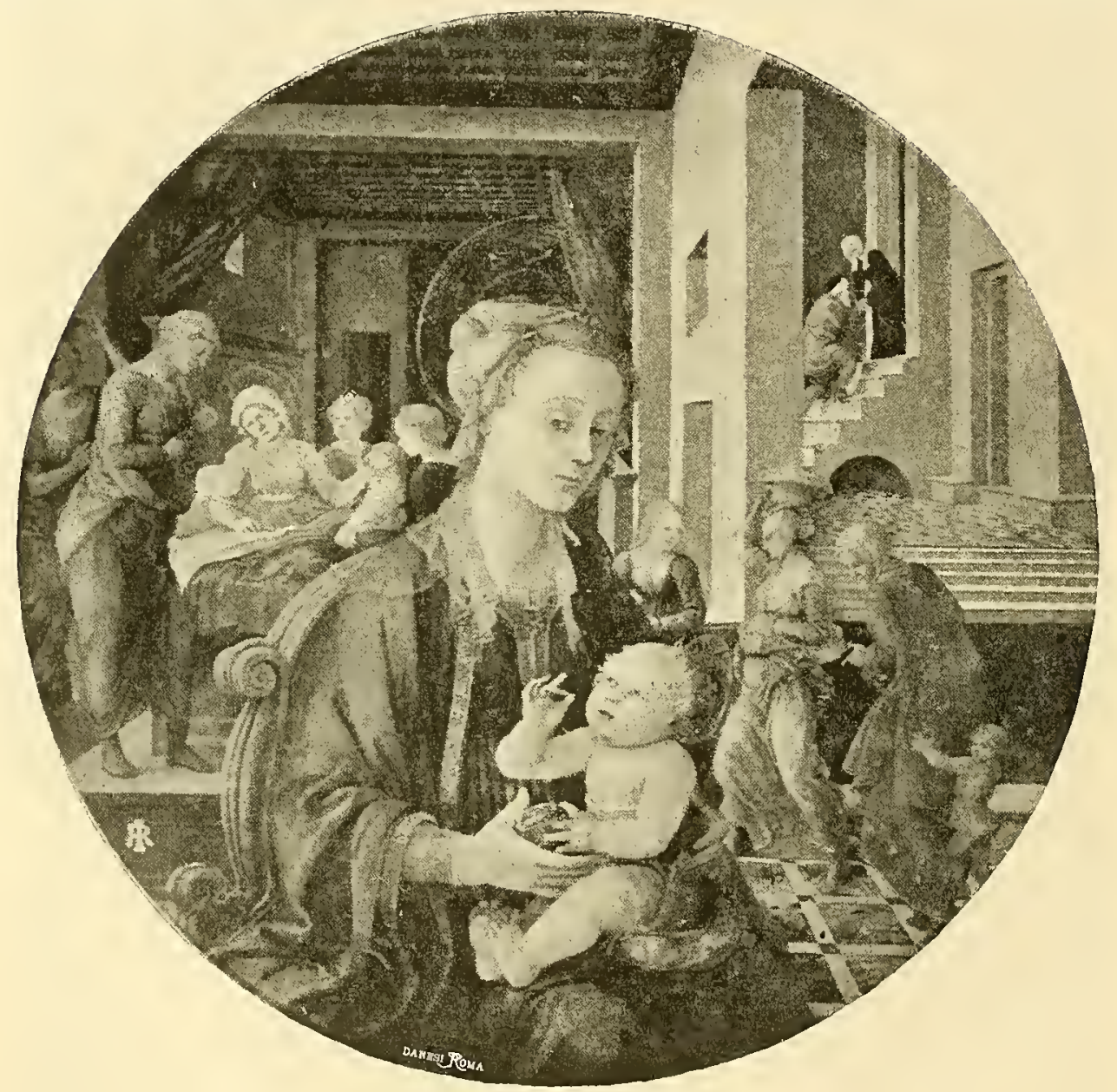

La natività di Maria, Galleria Pitti in Firenze

(Fra Filippo Lippi)

Ella stende la destra per carezzare la guancia della piccina, che una fante seduta sul pavimento tiene nelle braccia e contempla. Accanto al letto tre 
donne, come le tre Parche che assistevano alla nascita dei fanciulli nei bassorilievi classici. Una delle donne, secondo il concetto dell'artista, doveva

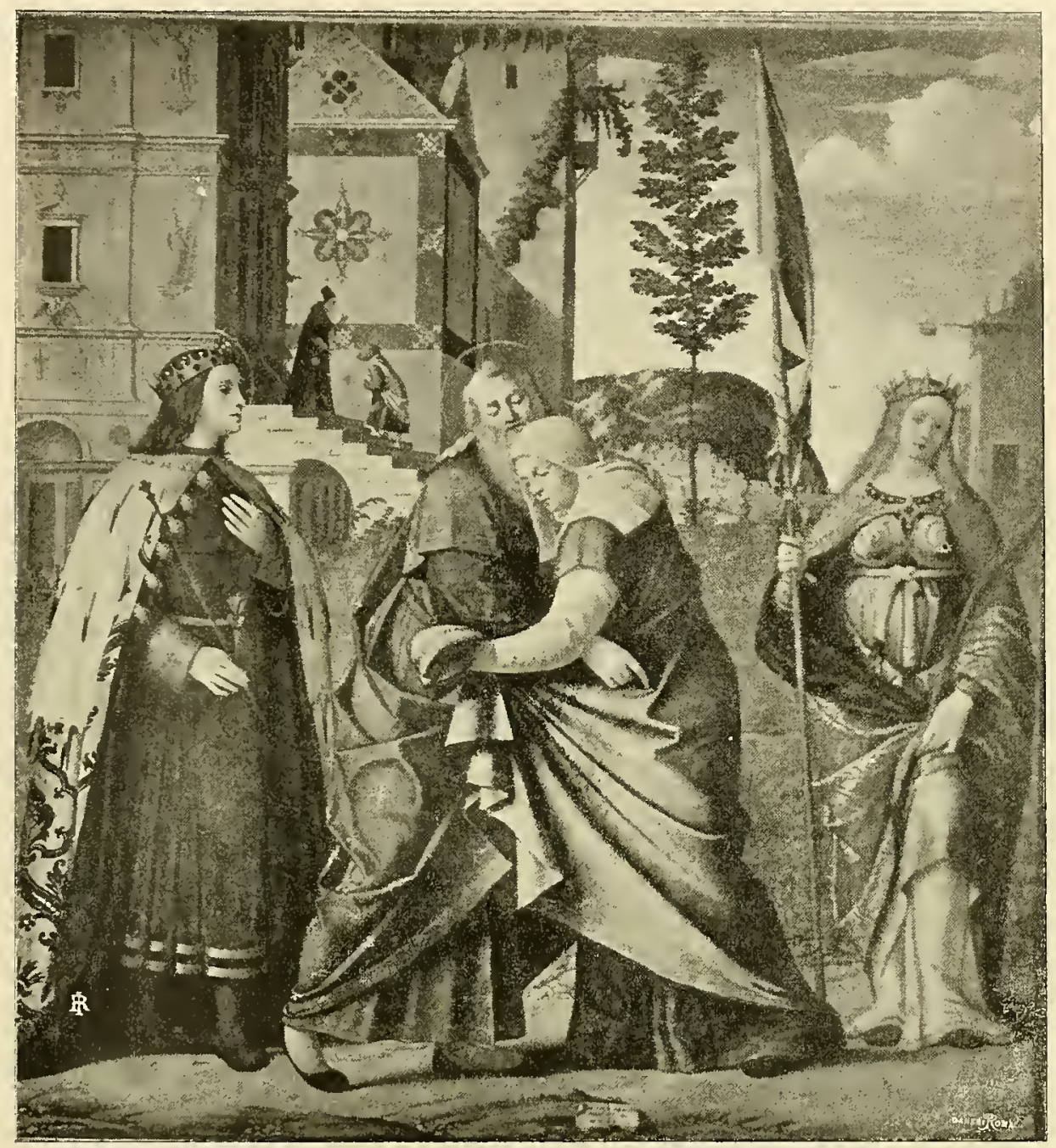

Galleria della R. Accademia in Venezia

(VitTor Carpaccio)

rappresentare Giuditta, la fida ancella che faceva animo ad Anna, quand'ella si struggeva in lagrime, disperata per la sua sterilità, e le diceva di confidare in Dio, di non piangere, di vestirsi de' suoi abiti più belli per il ritorno di Gioacchino, soggiungendo: "Sicut sum ancilla tua, formam regiam habes. Cosi come io sono tua ancella, tu sei bella come una regina! »

Il Quattrocento poco o nulla aggiunse allo schema della composizione. Filippo Lippi collocò sul fondo di una sua Madonna la scena della Natività, 
con la madre che accarezzava una guancia della bimbolina in fasce; e la scena dell'incontro di Gioacchino ed Anna, non più innanzi alla porta dorata di Gerusalemme, ma sull'uscio della casa, verso cui sale per una gradinata a

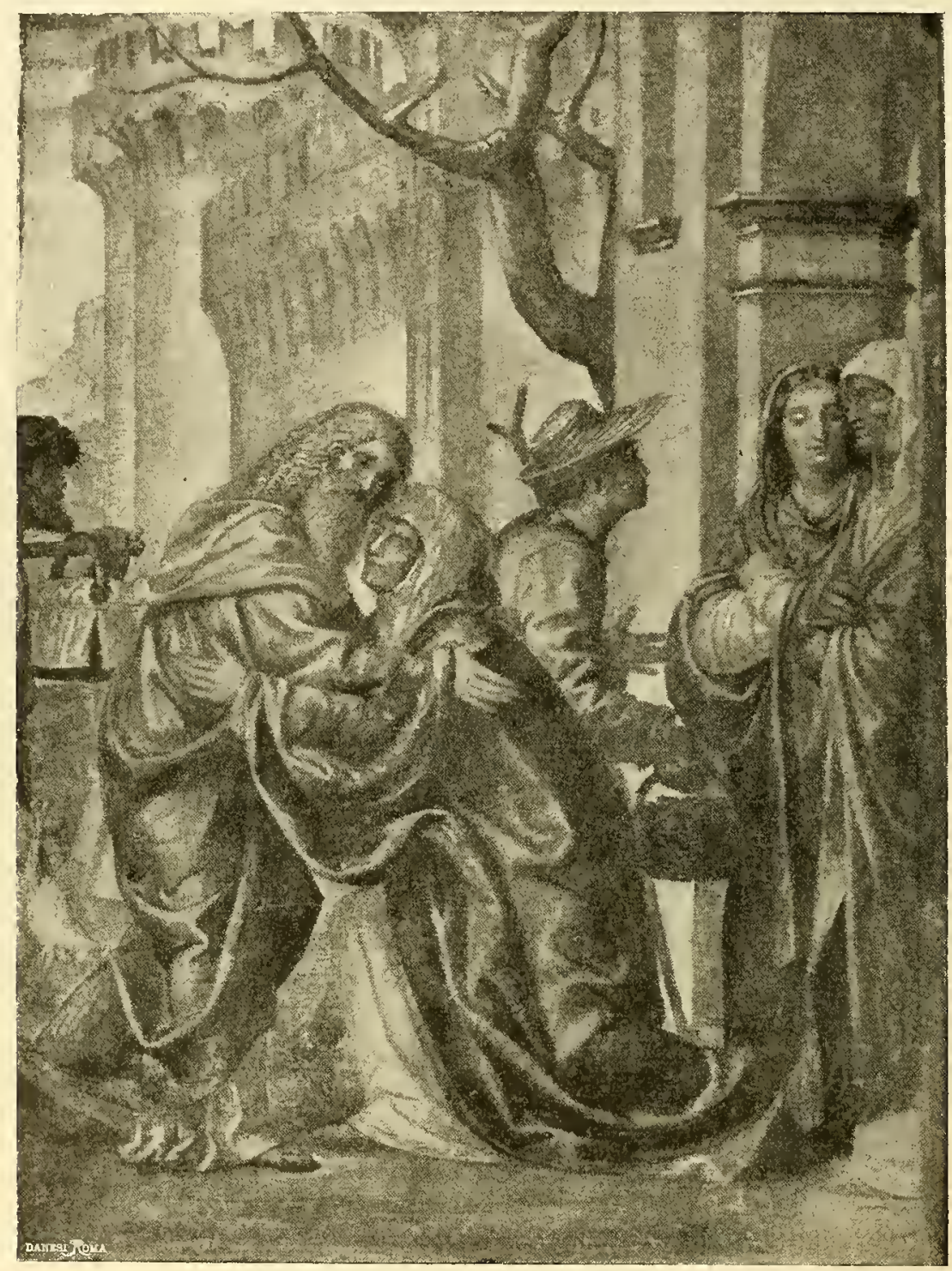

R. Pinacoteca di Brera in Milano

(Bernardo Luini)

fatica il vecchietto, mentre Anna, affacciatasi, gli prencle le mani e l'aiuta. A Santa Maria Novella il Ghirlandaio diede l'ultima e più completa forma della rappresentazione. Nella cacciata di Gioacchino dal tempio sembra che il pittore avesse presente la composizione dei trecentisti, specialmente di Gio- 
vanni da Milano: ma egli vi aggiunse la grandiosità dell'effetto, nel dipingere la scena come avvenuta innanzi a spettatori fiorentini. La nascita della Vergine avviene in una bella stanza ornata di tarsie e di bassorilievi con fanciulli musi-

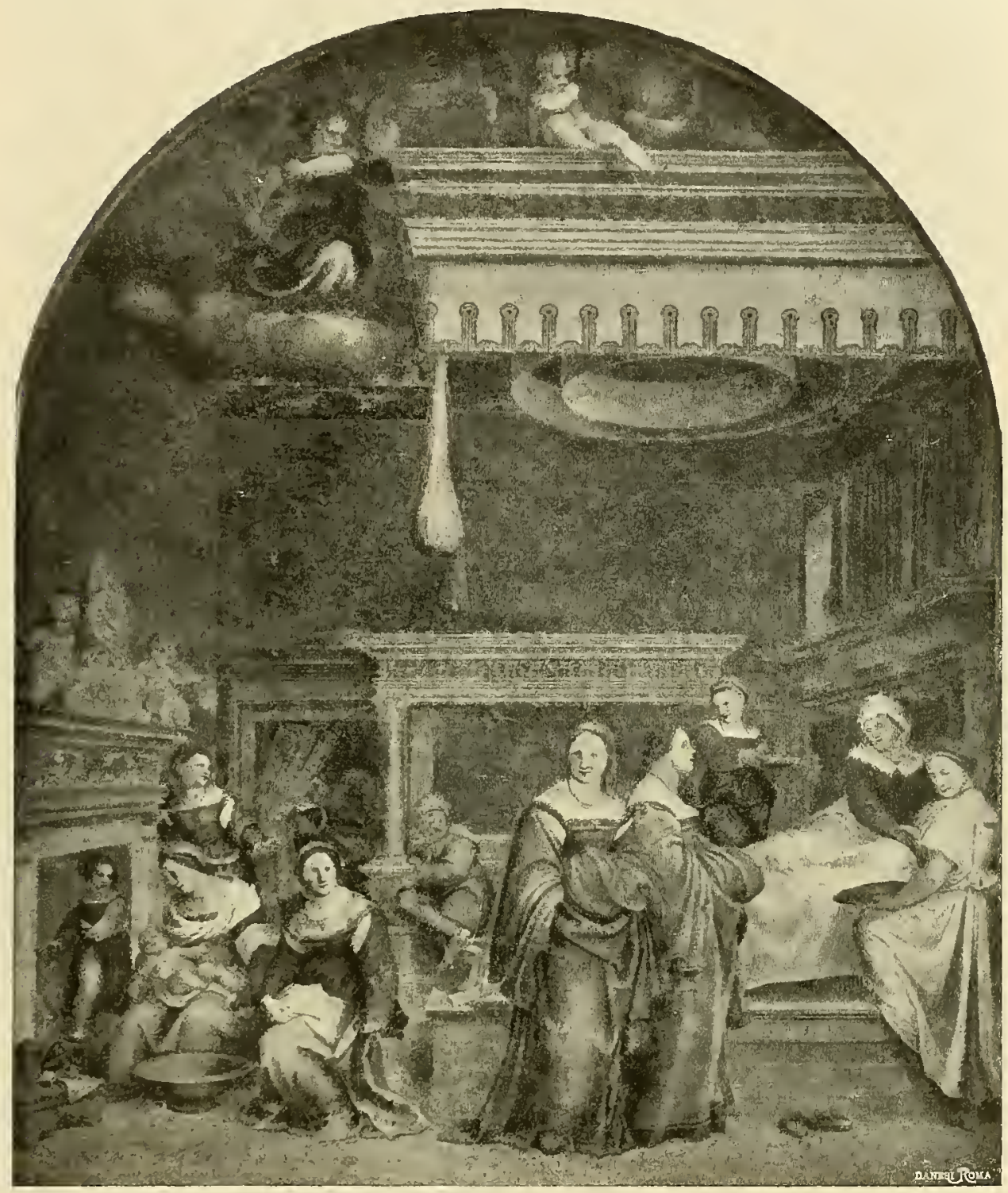

Santissima Annunziata in Firenze

(ANDREA DEL SARTO)

canti; una fante culla la neonata nelle braccia e le sorride, mentre la bambina si porta un dito alla bocca. Un altra fante ed Anna stessa seduta sul letto si volgono verso una giovinetta fiorentina vestita di broccato, seguita da quattro donne, spettatrici della nascita di Maria. 
Il Cinquecento sembrò dimenticare il soggetto. Carpaccio a Venezia rappresentò solo Gioacchino e Anna che si abbracciano; ma invece delle ancelle che seguono Anna e dei pastori che seguono Gioacchino coi doni e le vittime da offrire in olocausto, fece assistere alla scena due Santi. Al contrario, Bernardino Luini a Milano serbò le ancelle e i pastori ai lati del quadro, ove Gioacchino ed Anna si abbracciano; ma intanto questa scena diviene meno comune e meno sincera. Per questo dicevamo i cinquecentisti parere immemori del soggetto, cui i trecentisti prodigarono carezze e nel quale profusero i gentili, affettuosi sentimenti verso l' infanzia. La nutrice dei bassorilievi romani nelle rappresentazioni della Natività di Maria diviene la comare che si allegra e ride e scherza con la creaturina; le Parche divengono altre buone premurose comari che recano cibi e biancherie alla madre. Come vedesi, il realismo del Quattrocento alterò di troppo la scena, e il Cinquecento trascurò di darvi un particolare sviluppo, forse per la tendenza propria a quel secolo di nobilitare, d'igrandire le composizioni magnificamente, equilibrandone le figure. E il soggetto della Natività di Maria, tanto semplice e casalingo, dovette sembrare poco eroico e anche poco equilibrabile. La composizione, che noi moderni potremmo dire di genere, fu sacrificata dalla magniloquenza cinquecentistica. 


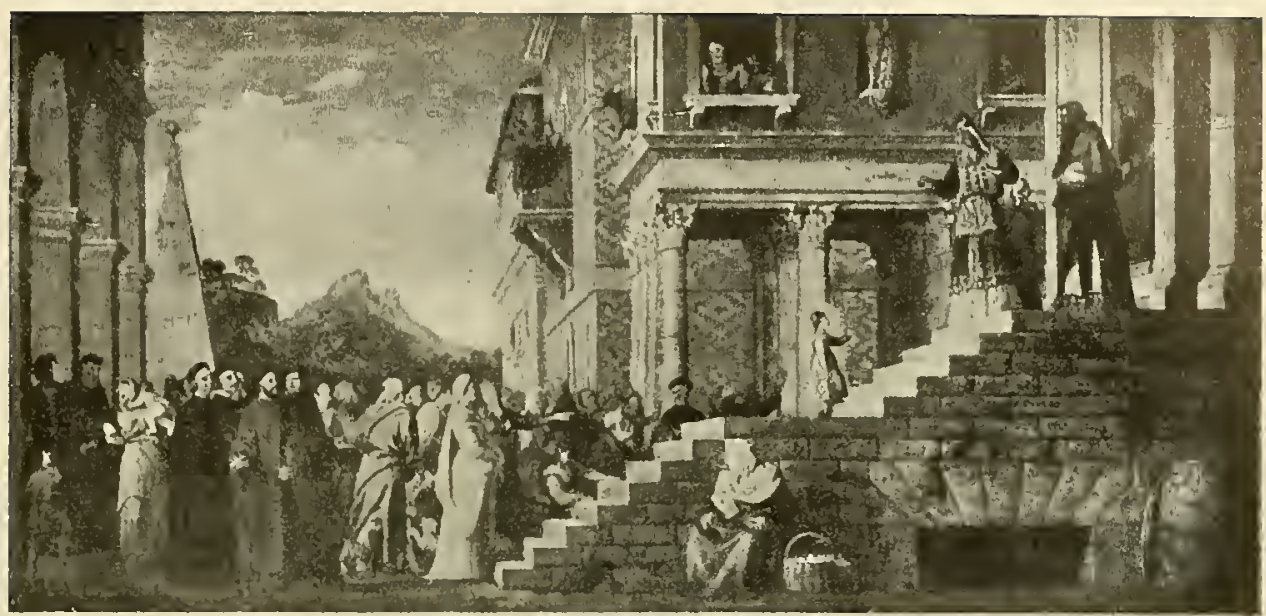

Galleria della R. Accademia di Venezia

(TIZIANO)

\section{La Presentazione di Maria al tempio.}

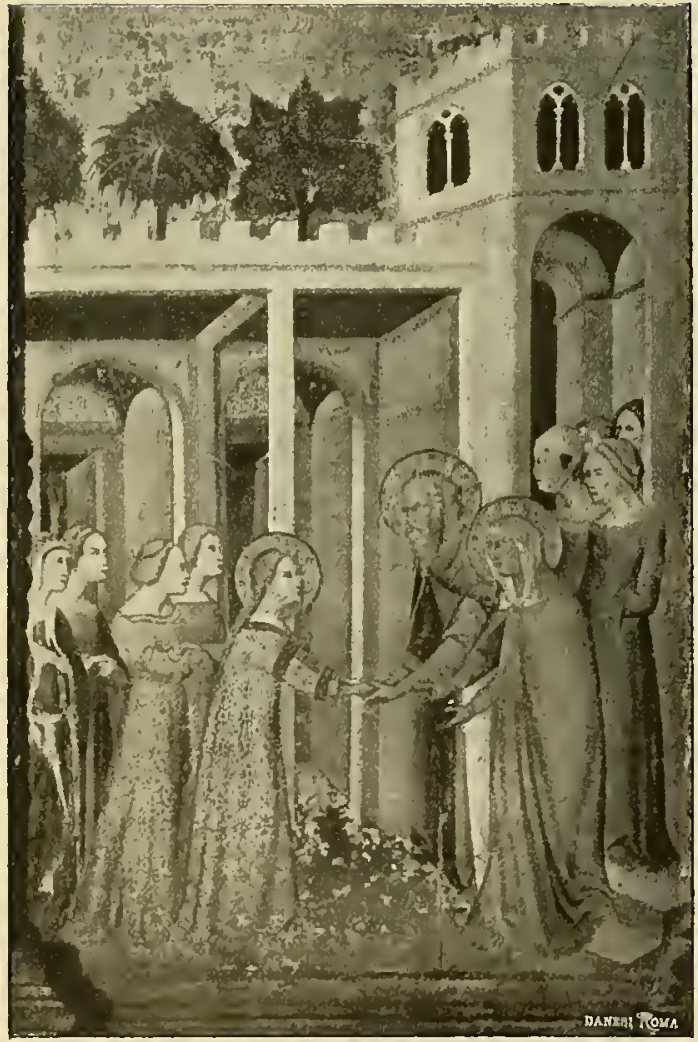

Parte di una tavola con le islorie della Vergine Galleria di Siena

(BARTOLO DI FREDI)
Quando Anna ebbe divezzata la figlia (così racconta l'apocrifo evangelo della Natività), si recò con Gioacchino al tempio del Signore a porgere offerte, e vi lasciò Maria, affinchè fosse ammessa tra le Vergini che giorno e notte lì dimoravano, lodando Dio. Allorchè la fanciulla fu dinanzi al tempio, salì correndo i quindici gradini senza volgersi indietro e senza chiedere $i$ genitori, così come sogliono i fanciulli. Tutti furono pieni di meraviglia... Maria non pareva una bambinetta, tanto era assorta e perseverante nella preghiera. La sua figura era candida come la neve.... tutti i suoi discorsi erano pieni di grazia, la verità era sulle sue labbra. 
Un'altra leggenda, raccolta dal Darras, dice che Maria a tre anni fu condotta al tempio, quantunque le fanciulle non vi fossero ammesse prima dei cinque. Gioacchino e Anna riunirono tutte le giovinette della tribù, e date loro lampade accese, si diressero verso il tempio del Signore. Così la divina fanciulla è rappresentata nelle Omelie del monaco Giacomo, mentre le giovinette della tribù, una delle quali coperta come da un velo nuziale, la

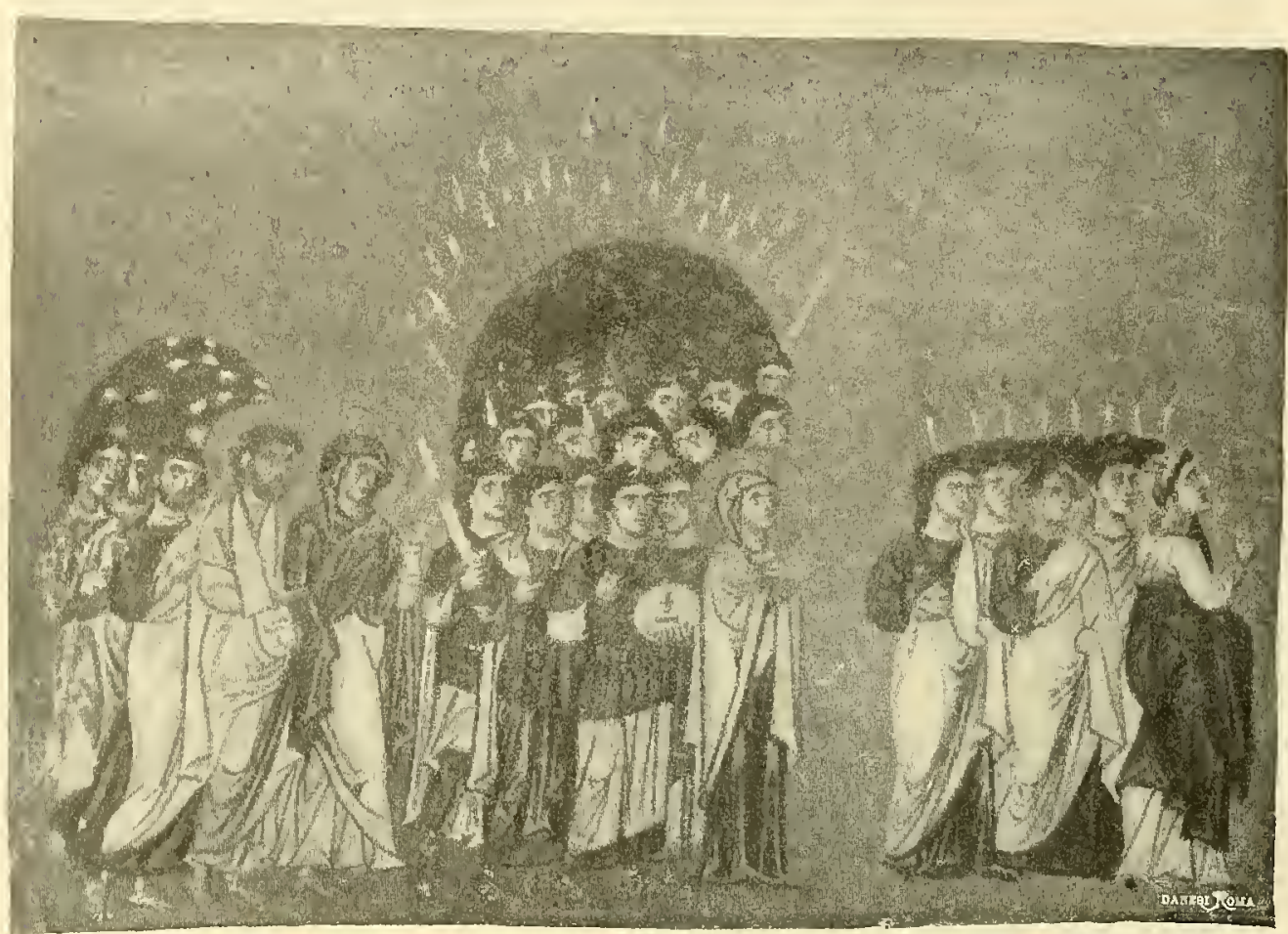

La Vergine condotta al Tempio. Biblioteca Nazionale di Parigi

(Omelie del Monaco Giacomo)

precedono con fiaccole. I sessanta forti della visione di Salomone le fanno corteo. Ella cammina, dice il monaco Giacomo, purificando la terra tocca da' suoi piedi; non isplende d'ornamenti, bensì per il manto che l'avvolge di purità, e supera in bellezza le vergini che l'accompagnano in coro, come il sole vince per fulgore le stelle.

L'arte bizantina della seconda età d'oro richiamava i ricordi delle antiche rappresentazioni degli sponsali: le fiaccole, attributo caratteristico del Dio d'Imeneo, erano portate sempre innanzi alla sposa nei matrimonî romani. Chi non ricorda l'ode di Catullo invocante Imene ad agitar la fiaccola resinosa e stimolante le vergini caste a cantare in coro: - O Dio d'Imeneo, o 


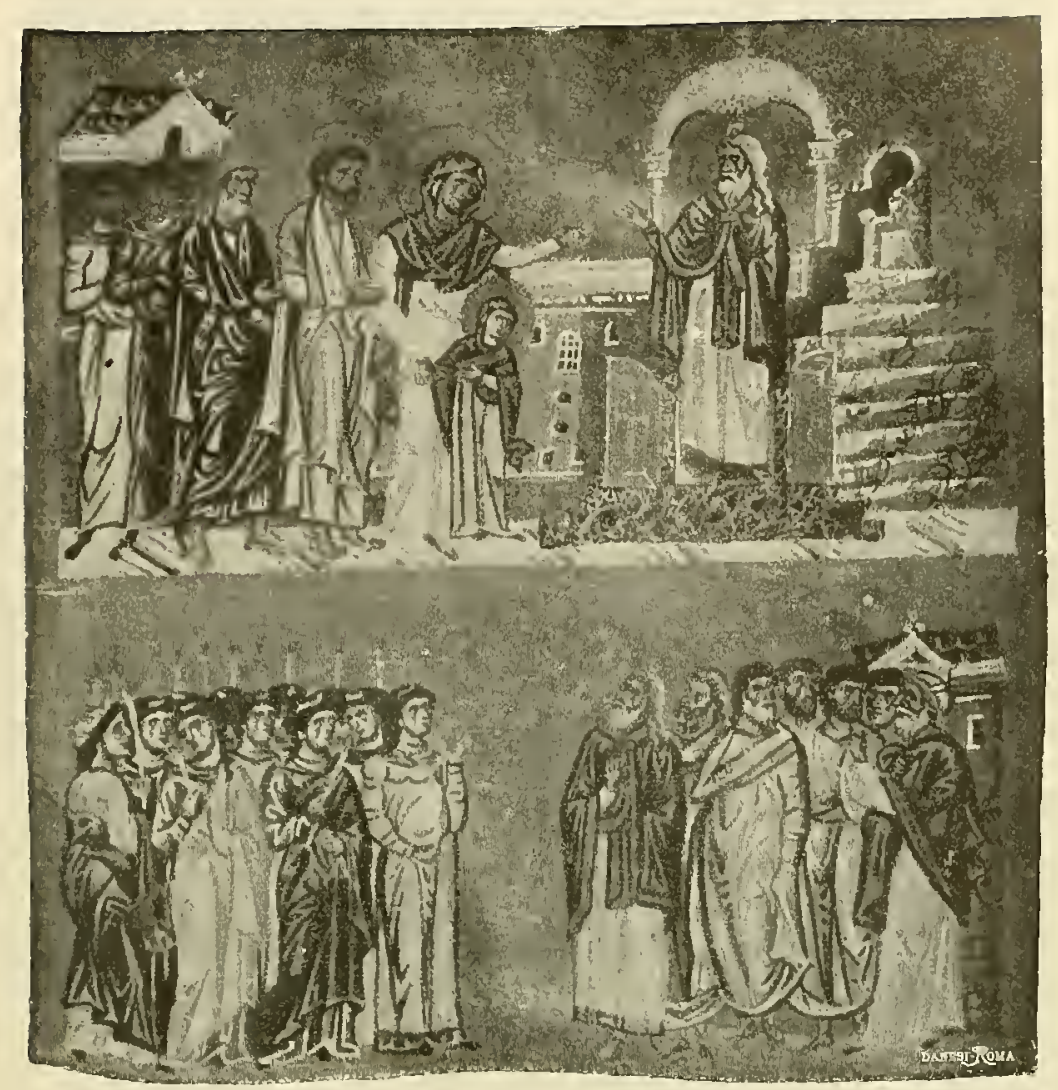

La Vergine presentata al Tempio

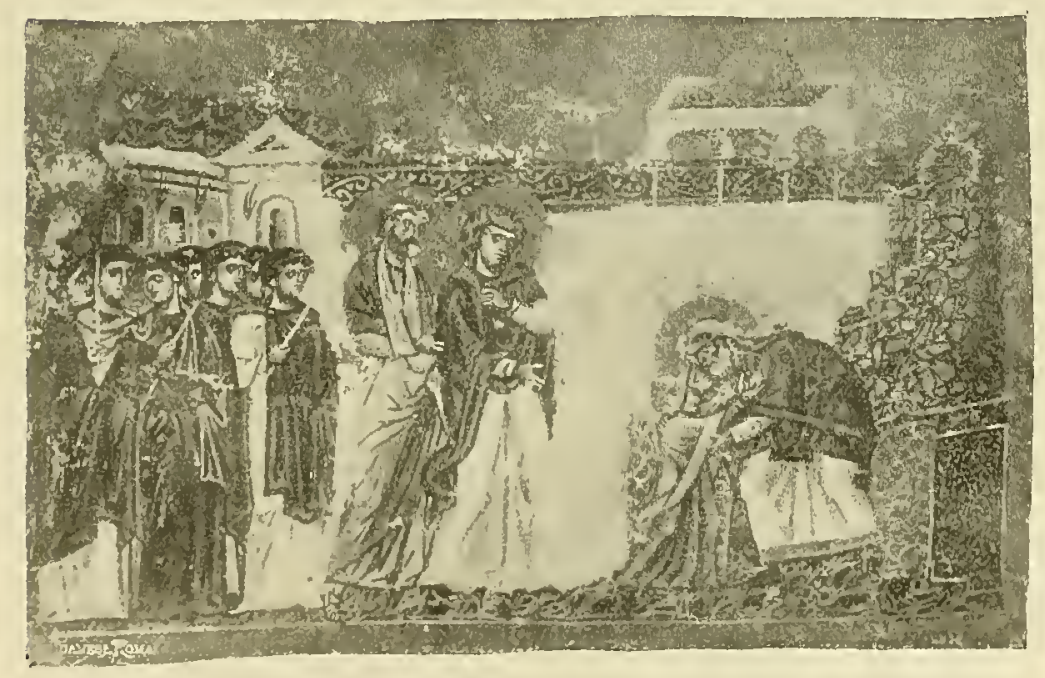

Zaccheria abbraccia la Vergine. Biblioteca Nazionale di Parigi

(Omelie del Monaco Giacomo) 


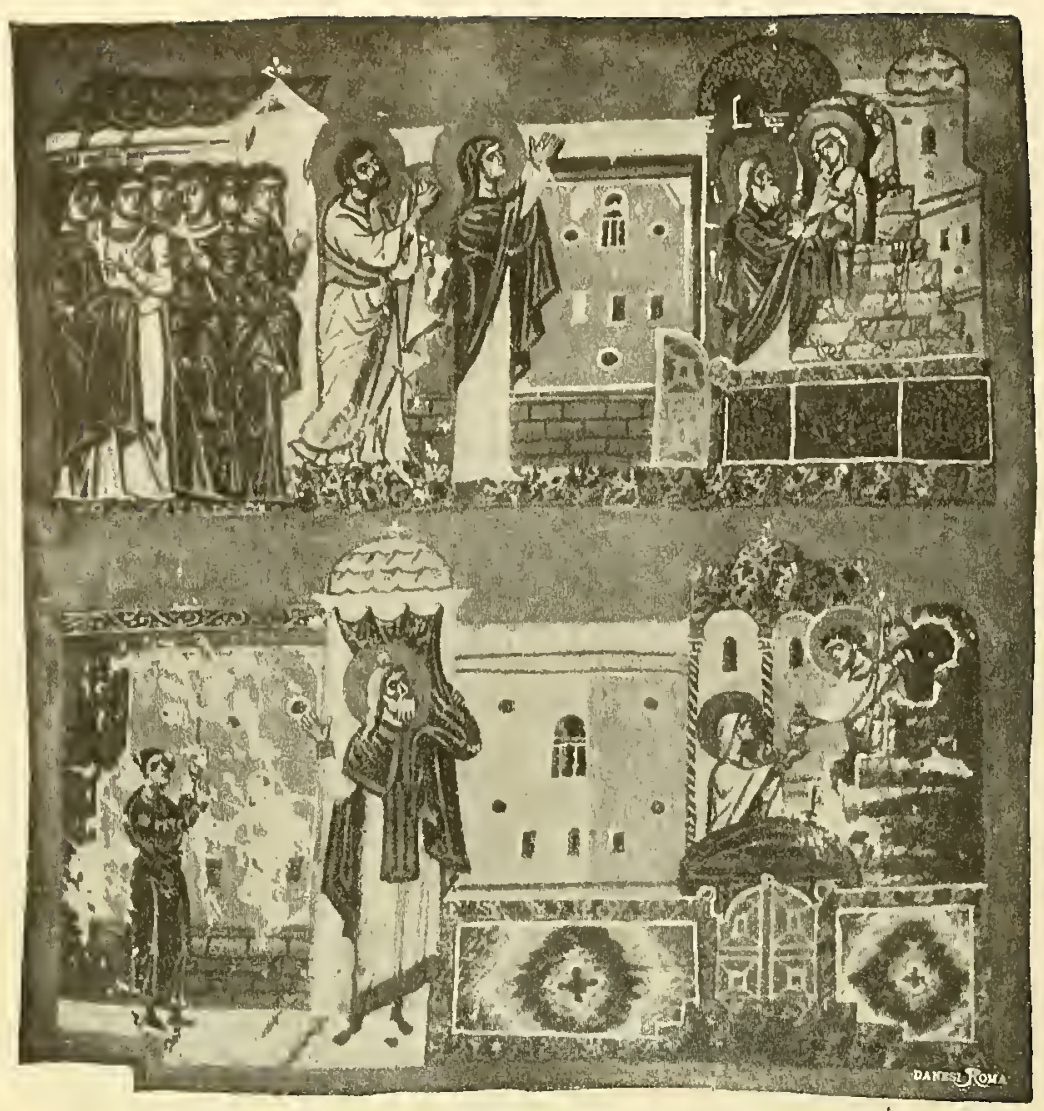

La Vergine nel Tempio nutrita dall'Angelo

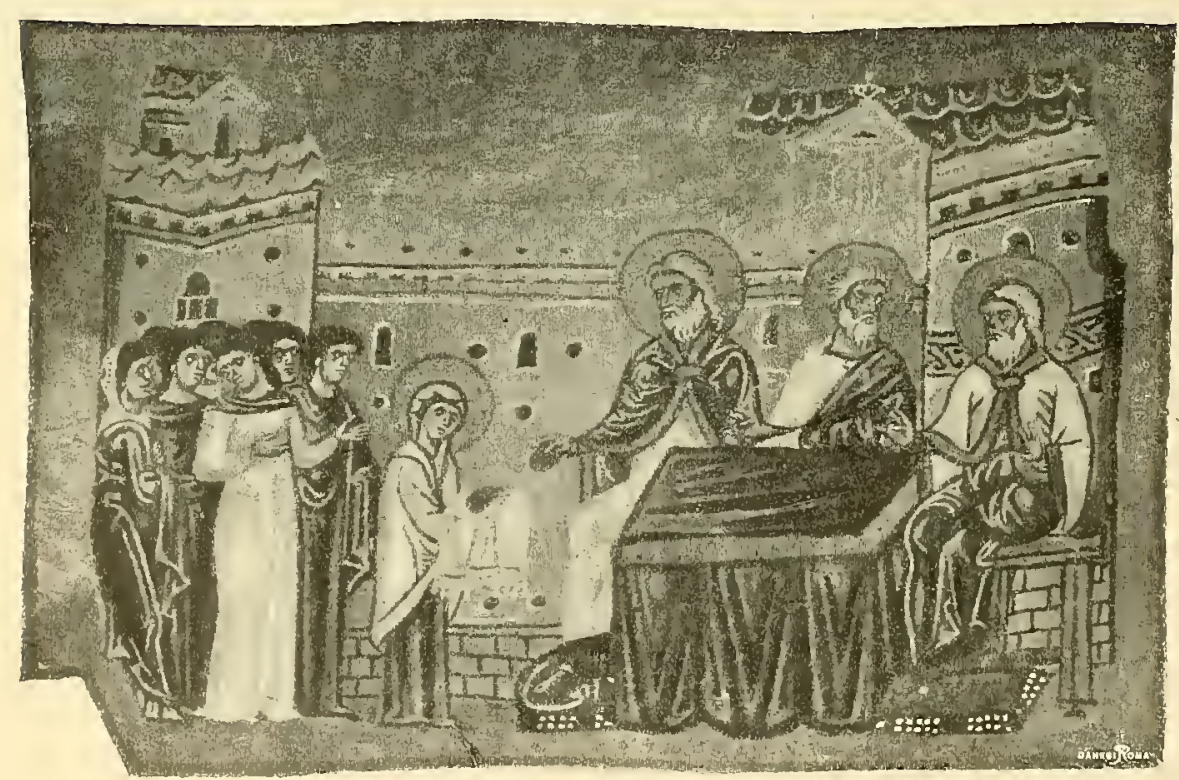

La Vergine riceve la porpora. Biblioteca Nazionale di Parigi (Omele del Monaco Giacomo) 
Imene; o Imene, Dio d'Imeneo - ? Il poeta invita le vergini ad aprire le porte della casa, chè la sposa avanza e dice: Vedete come le faci agitano la loro chioma ardente! Anche nel Menologio della Vaticana, la Vergine che si avvicina all'edicola sacra, donde Zaccaria le tende le braccia, è seguita dai genitori e da fanciulle con fiaccole; ma questa reminiscenza di antiche

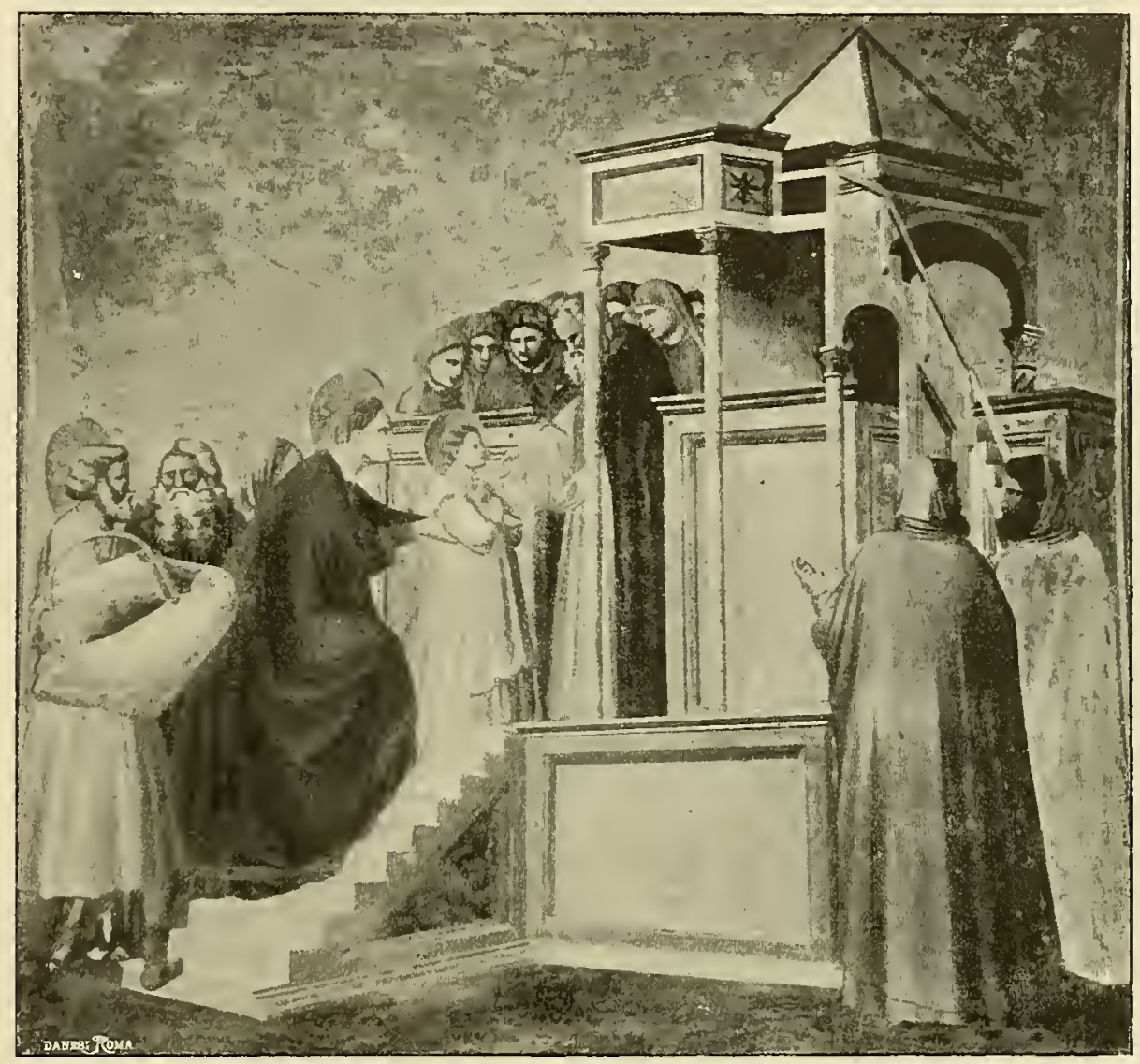

Oratorio dell'Arena in Padova

(GiotTo)

costumanze venne meno ben presto nell'arte, al pari delle figure simboliche dei sessanta forti della visione di Salomone.

L'arte occidentale lasciò alla rappresentazione il carattere festoso, pur senza farne, alla maniera bizantina, una festa matrimoniale, e ne ridusse i particolari simbolici. Giotto raffigurò la fanciullina con le mani conserte, già al sommo della gradinata, e la madre, che la tiene teneramente per le braccia, curva, ansiosa, dietro a lei. Il vecchio Zaccaria grave e lento stende le mani alla bambina, mentre s'affollano a vedere la nuova compagna curiose 
alcune giovani, come uscite dal chiostro, in abito monacale. Gioacchino ai piedi della gradinata mira la scena; un facchino gli porta appresso un cesto

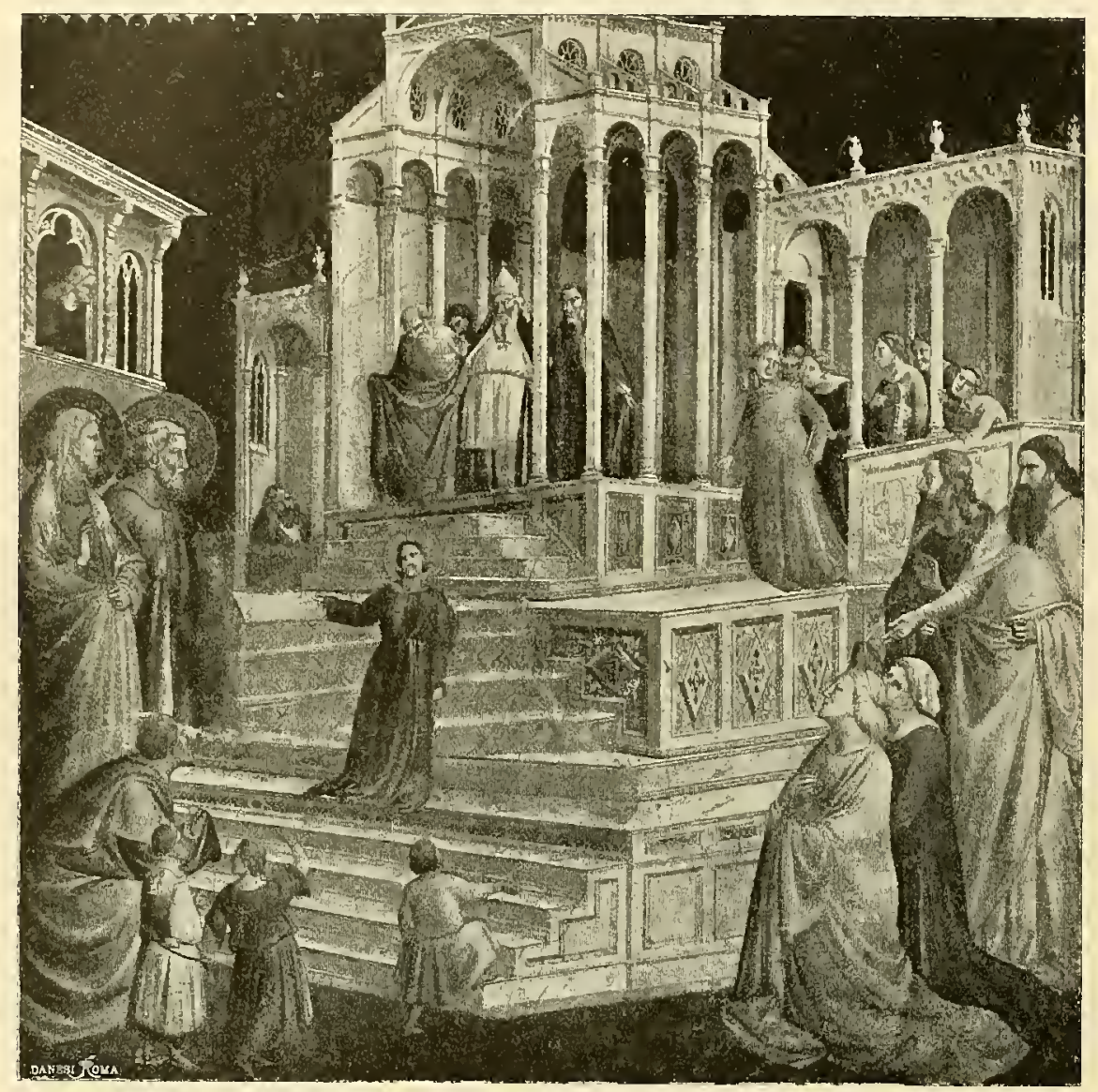

Santa Croce in Firenze

(TADDEO GADDI)

coperto da una tovaglia coi doni per il tempio; altri guardano, discorrono, commentano l'avvenimento. A questo modo il genio di Giotto trasferì la scena dal meraviglioso tempio d'Israele alla porta di un chiostro italiano; e i suoi seguaci anche distinsero il chiostro dalla chiesa, consapevoli di quanto scrisse il monaco Epifanio nel xit secolo circa alla dimora delle vergini in un ritiro, presso al portico, nella prossinnità dell'altare. La chiesa a cui si ascende per quindici gradini, - ed erano tanti secondo i Bizantini, perchè tanti $\mathrm{i}$ salni, - si vede tutta aperta; a destra si stende un porticato, ove le Vergini appaiono curiose con gli strumenti musicali su cui cantavano le cantiche di David, e coi libri di preghiera. Così vedesi nelle 
rappresentazioni di Taddeo Gaddi e di Giovanni da Milano, in Santa Croce. Zaccaria co' suoi assistenti, sul limitare della chiesa, vestito de' paludamenti sacri, sembra attendere l'arrivo di un principe. Dalle finestre, dalle terrazze guardano la solennità religiosa uomini e donne, i padri e le madri delle principali famiglie di Gerusalemme; a' piedi della gradinata stanno i genitori di Maria, mesti dell'abbandono, due sacerdoti, come nell'affresco di Giotto, e bambini stupefatti, e donne in ginocchio comprese di devozione. La scena

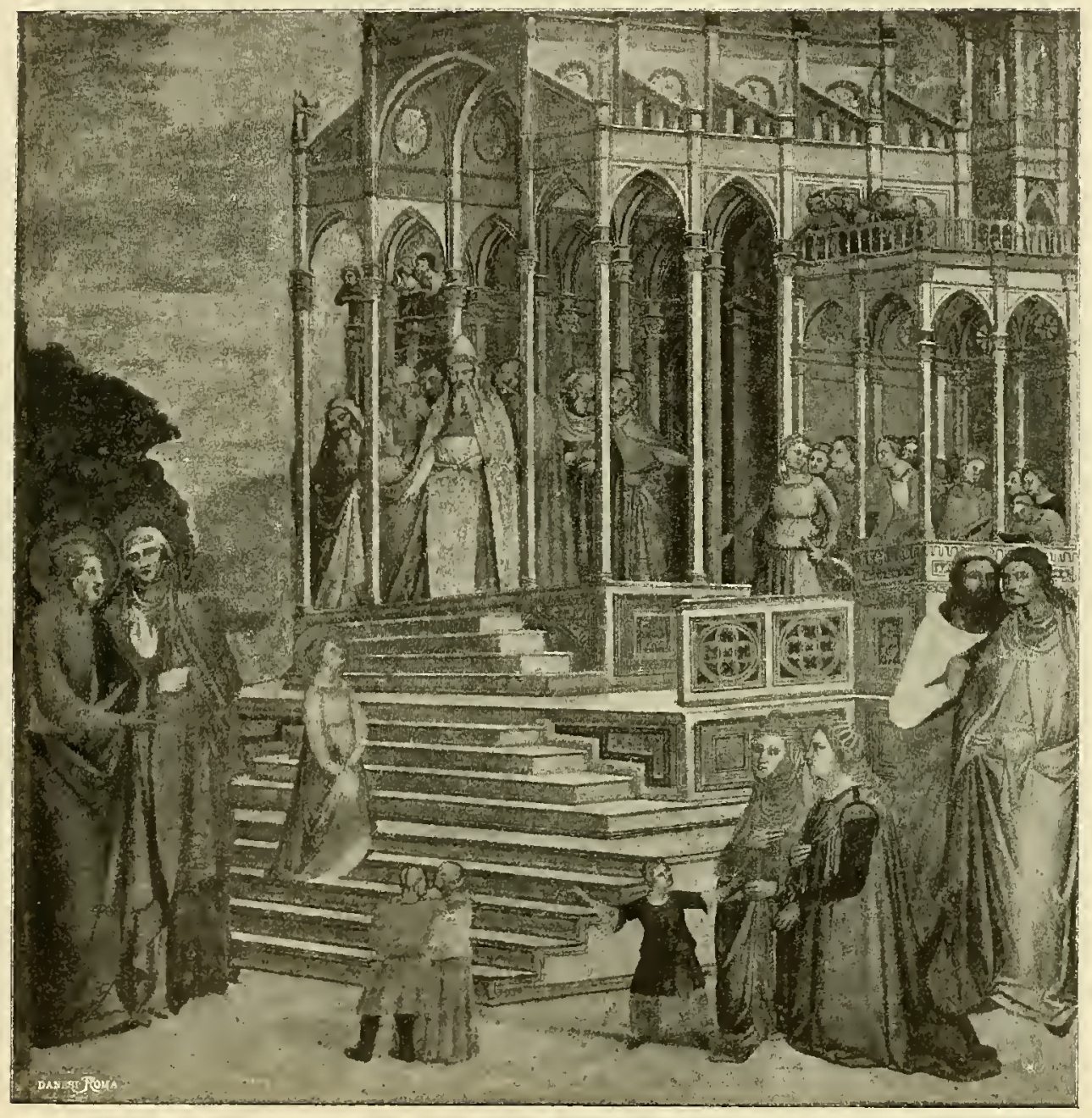

Chiesa di Santa Croce in Firenze

(Giovanini da Milano)

ne' seguaci di Giotto ha guadagnato di solennità, ma ha perduto l'aspetto familiare semplice del maestro, la grande unità della sua composizione. Gli 
elementi della scena, tanto in Taddeo Gaddi che in Giovanni da Milano, sembrano disgregarsi; e più in questo che in quello, ove tutti gli occhi e i cuori e le gotiche curve delle figure convergono verso Maria, che, saliti cinque gradi, si volge ai genitori, come per dir loro che si sarebbe dedi-

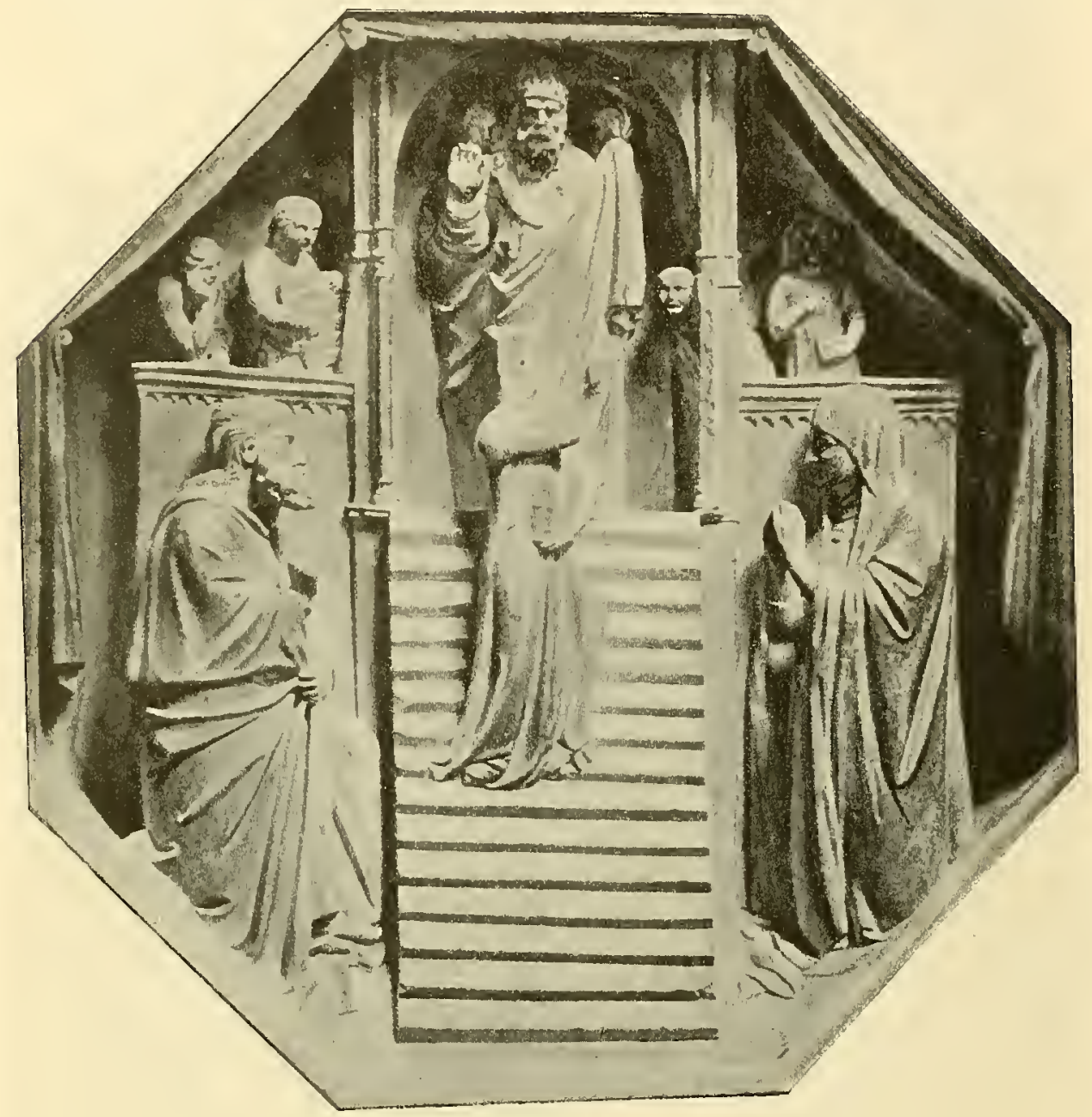

Tabernacolo in Or' San Michele a Firenze

(ORCAGNA)

cata a Dio. Giovanni da Milano si studia, invece di raccogliere insieme le parti della composizione a disegnarne il carattere particolare e il costume; Maria che sale i gradi del tempio, sollevandosi la tunica, è già una forma tipica della rappresentazione.

La scultura trovò difficoltà maggiori. L' Orcagna stesso fu minore di sè, perchè dovette riuscirgli ardıo figurare quindici gradini. 


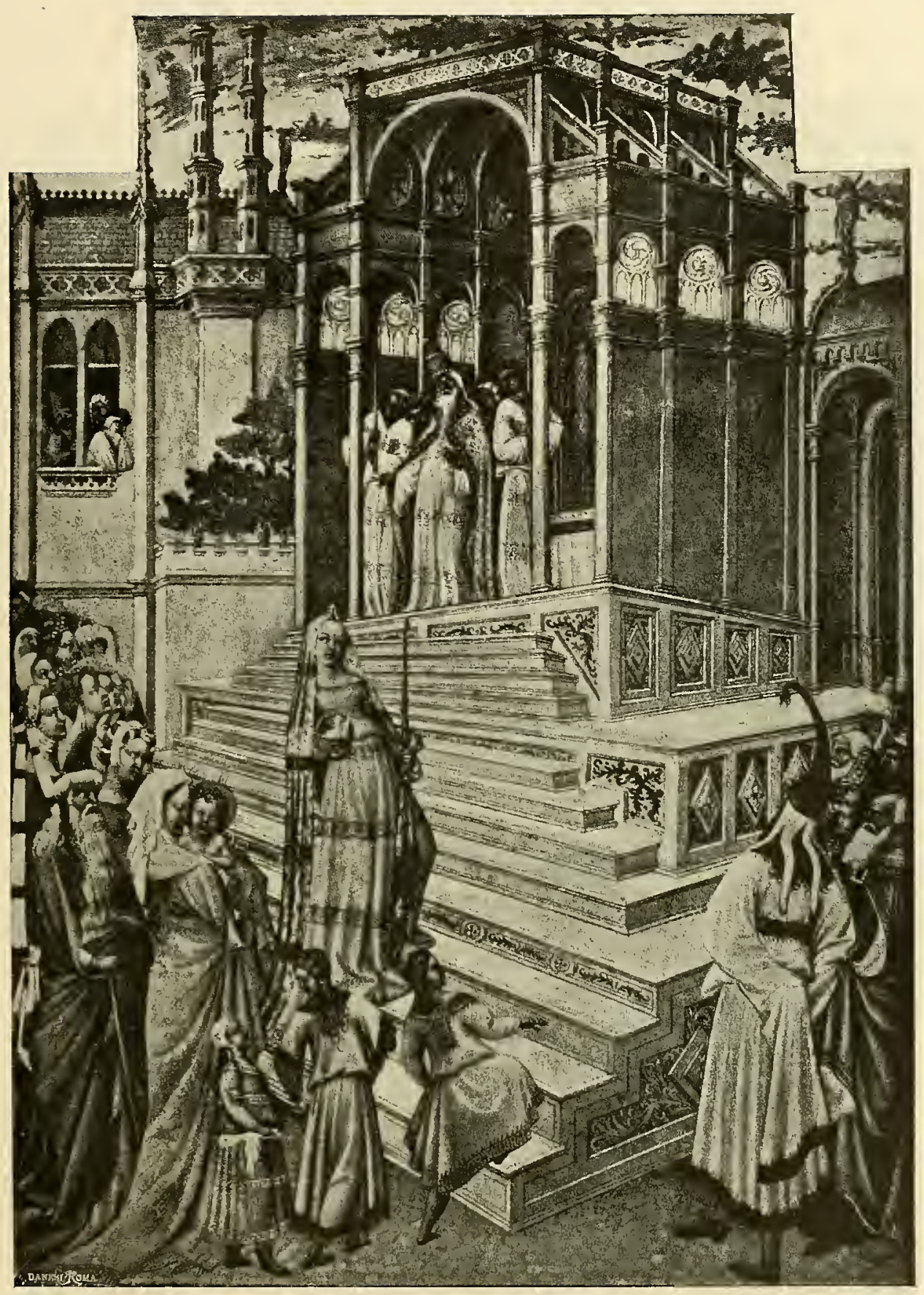

Libro d'Ore de! Duca di Berry. Biblioteca del Duca d'Aumale a Chantilly 
Collocati questi nel mezzo di un ottagono ad Or' San Michele, ei fu costretto a dare una rigorosa simmetria alle parti del bassorilievo. Maria sale gli scalini del tempio, mentre il gran sacerdote l'attende innanzi alla soglia accompagnato da due leviti; di qua e di là della porta si vedono le giovani compagne, une delle quali tiene un psalterion. Maria, col libro della divina dottrina in una mano, si volge a mezzo la gradinata, mostrando ai genitori, che stanno divoti ai lati della scala, il tempio ove si tratterrà: " et non regressa cst puella». Questo atto della Vergine, contrario ai testi, dovette essere dapprima una forma necessaria per le linee della composizione, affinchè la divina fanciulla non si vedesse di tergo; ma l'arte si giovò di quella necessità materiale anche per tradurre sentimenti gentili e umani.

Nel libro d'ore del duca di Berry, ora nella biblioteca del duca d'Aumale, la Vergine, rivolgendosi, sembra cercare con gli occhi smarriti i genitori tra la folla. Più tardi, nel secolo xv, il Ghirlandaio, in Santa Maria Novella, mostra la Vergine che sembra guardare con la coda dell'occhio i

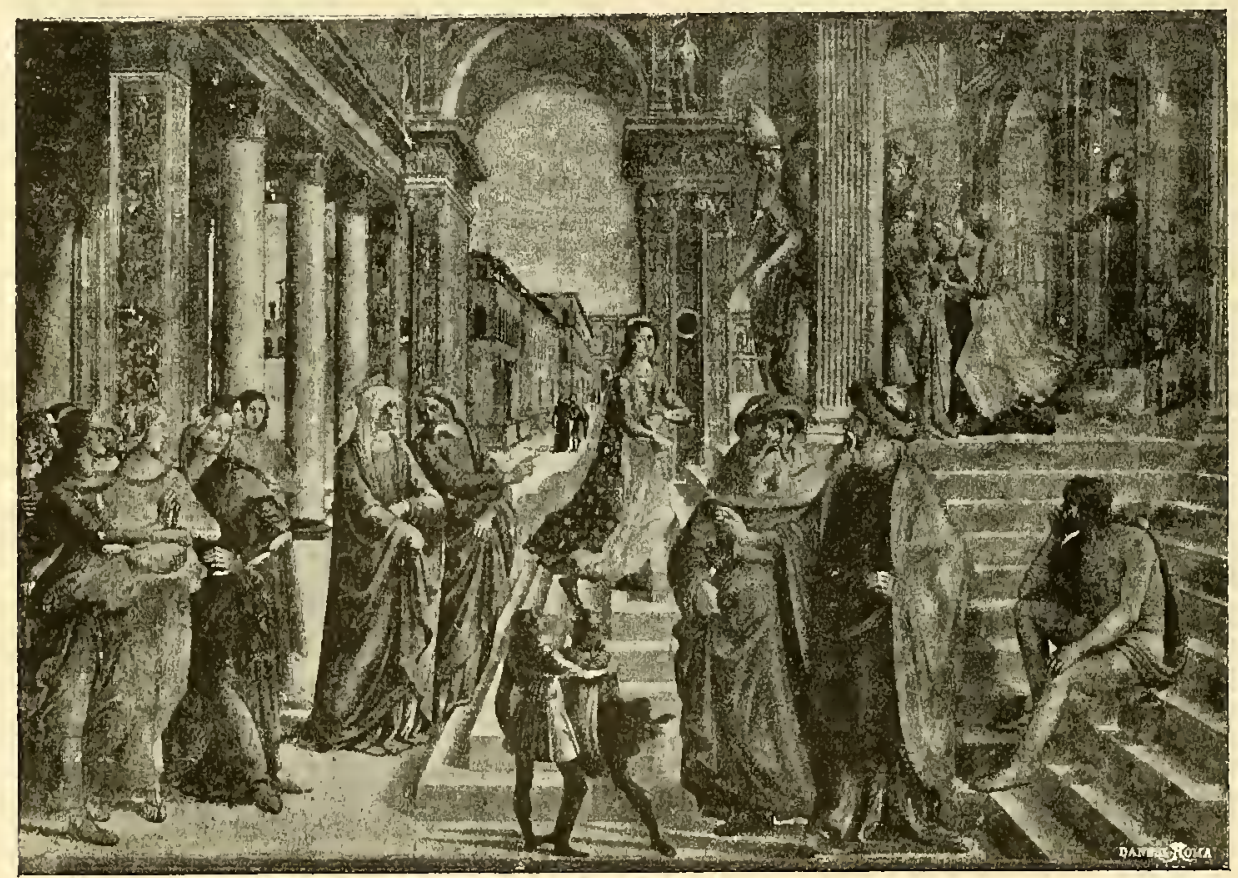

Santa Maria Novella in Firenze

(Domenico Gitirlandio)

genitori lasciati, quasi per esprimere il sacrificio del suo cuore. Quivi Maria è giovinetta, nell'età in cui secondo i Bizantini potevasi significare la precoce 
intelligenza della fanciulla, lo sviluppo rapido della donna predestinata a grandi cose. Ma ecco l'arte italiana correggere la forma simbolica per mezzo del Bazzi,

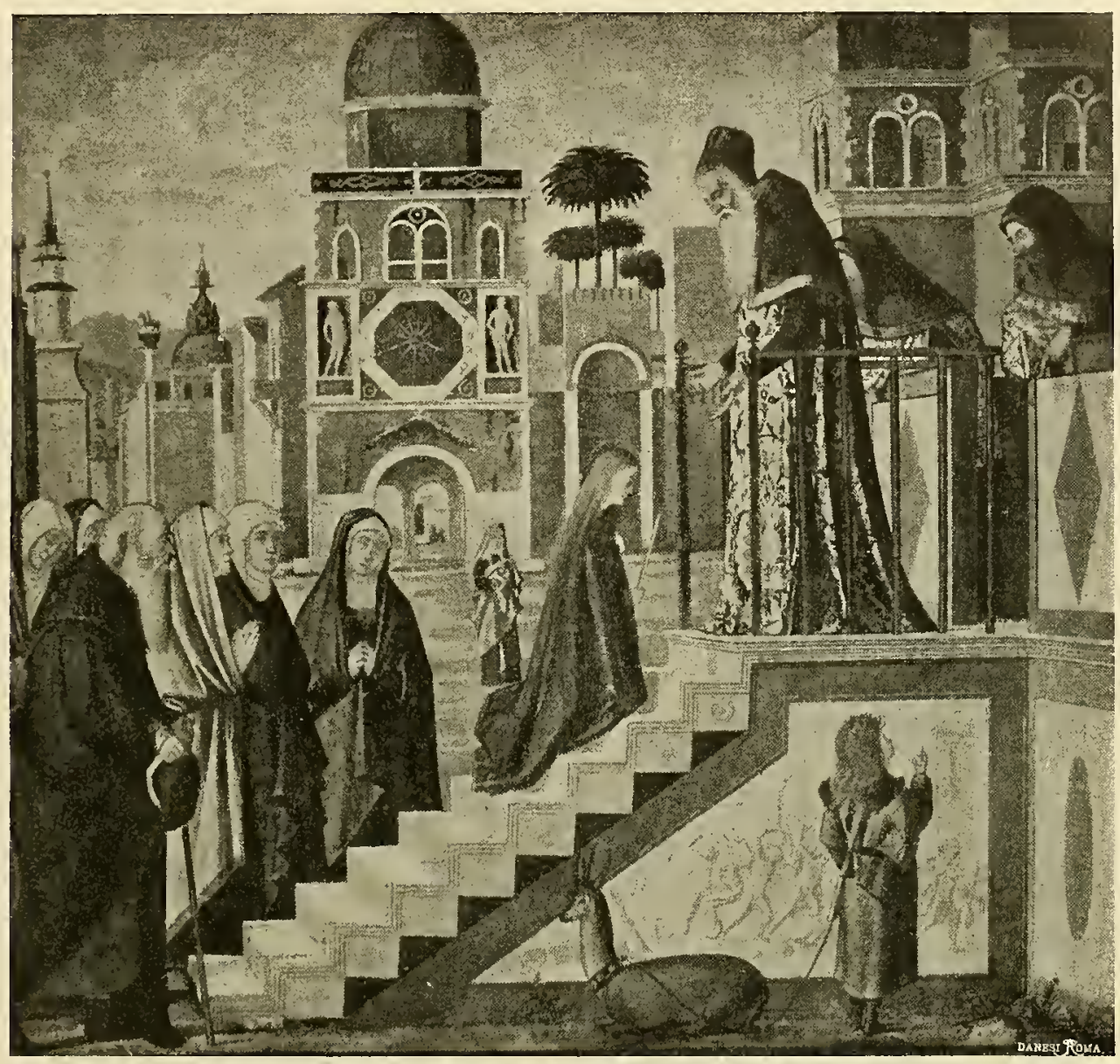

Regia Pinacoteca di Brera

(CARPaCcio)

detto il Sodoma, che, secondo gli antichi testi, rappresenta proprio una fanciuilina di tre anni, e accosta la madre e il sacerdote alla bambina, mentre le donne più formose, con occhi pieni di luce, illuminate di leonardesca bellezza, assistono, di contro a poderosi uomini. Le due file di spettatori sembrano schierarsi innanzi ai colonnati di un portico in attesa di uno spettacolo. Perciò la composizione del Sodoma non bastò al compimento della sacra scena e la perfezionò solo in parte. Tutti gli altri elementi rimasero anzi trascurati. Non così avvenne della rappresentazione a Venezia, ove il Carpaccio e Cima da Conegliano prepararono il capolavoro del Vecellio. Il Cima, 
rappresentando nel quadro di Dresda la scena tra orientali e popolani, fin anche mise seduta, nel basso della gradinata, la vecchierella, tipo di quella che Tiziano dipinse nell'opera sua e che si suppose fantasticamente esser la madre o la balia del pittore.

Tiziano concepi la composizione sacra come avvenuta innanzi a grandi cancellieri e senatori della Repubblica, sullo sfondo delle Alpi dolomitiche del Cadore, che s'innalzano dietro a edifici con porticati a pilastri corinzî, coperti di pietre a varî colori, con balconi a cui si affaccia la gente curiosa e festante. Maria, in lunga vesticciuola azzurrina, con la capigliatura annodata in treccia, circonfusa di luce, sollevando il vestitino ascende la gradi-

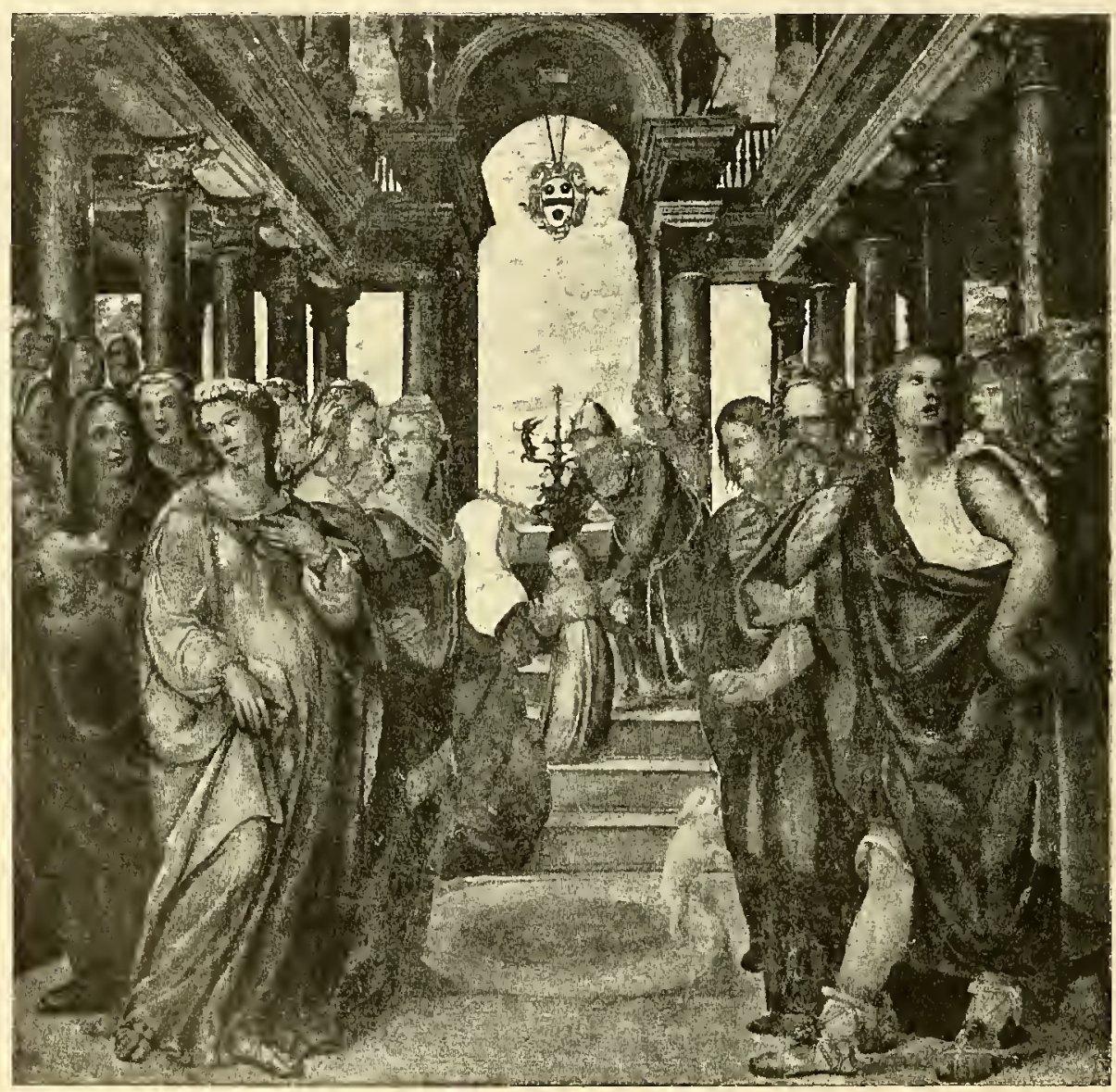

Oratorio di San Bernardino in Siena

(SODOMA)

nata del tempio, a capo della quale il Gran Sacerdote le tende le braccia. In basso una folla di popolo tutta intenta la mira, ragiona, s'allegra. Anna, la 
madre, trionfa in mezzo alla moltitudine che s'avanza e fa ressa a pie' della scala; mentre un fanciullo adesca un cane con una ciambella, un senatore porge l'elemosina ad una povera donna che stringe nelle braccia un bambino

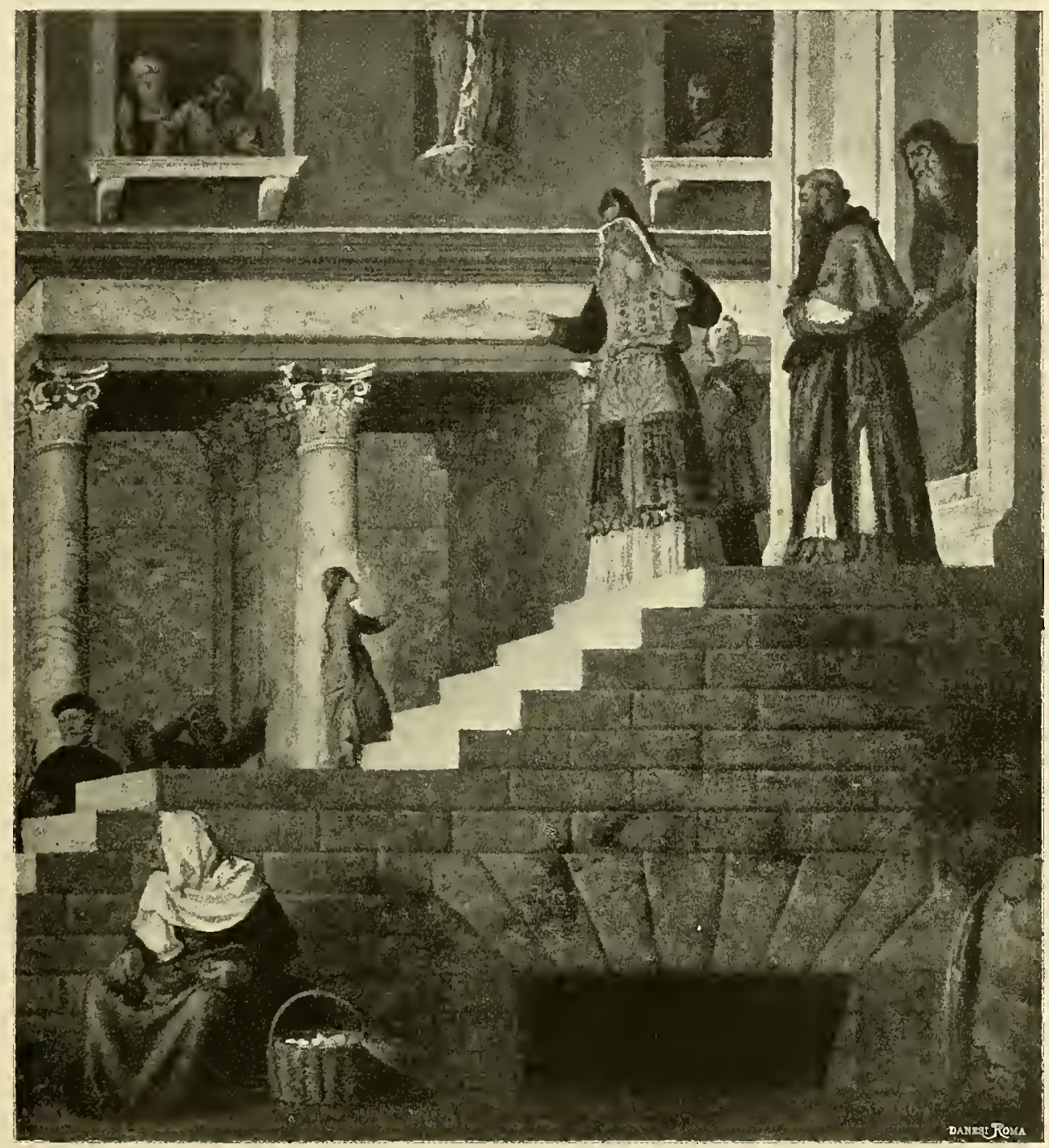

Galleria di Venezia

(Tiziano)

ignudo; e di fronte alla gradinata una vecchia siede sospendendo di contar le monete guadagnate al mercato e guarda stupita la processione che s'avvia al tempio. Così dunque Tiziano diede alla rappresentazione sacra il carattere di una festa accaduta a Venezia, invece che a Gerusalemme, e tra i senatori della Serenissima, invece che tra i Farisei. 

Per noi moderni che vorremmo tutto secondo i più scrupolosi canoni dell'archeologia, la verità ci perdette; l'arte no, lo spirito della leggenda no. L'arte non voleva più fare astrazione dal suo ambiente, dalla società contemporanea; e dimentica dei particolari iconografici non essenziali, stringeva in connubio l'antico e il nuovo, la religione e la patria, il cielo e la terra, gli uomini e la Divinità.

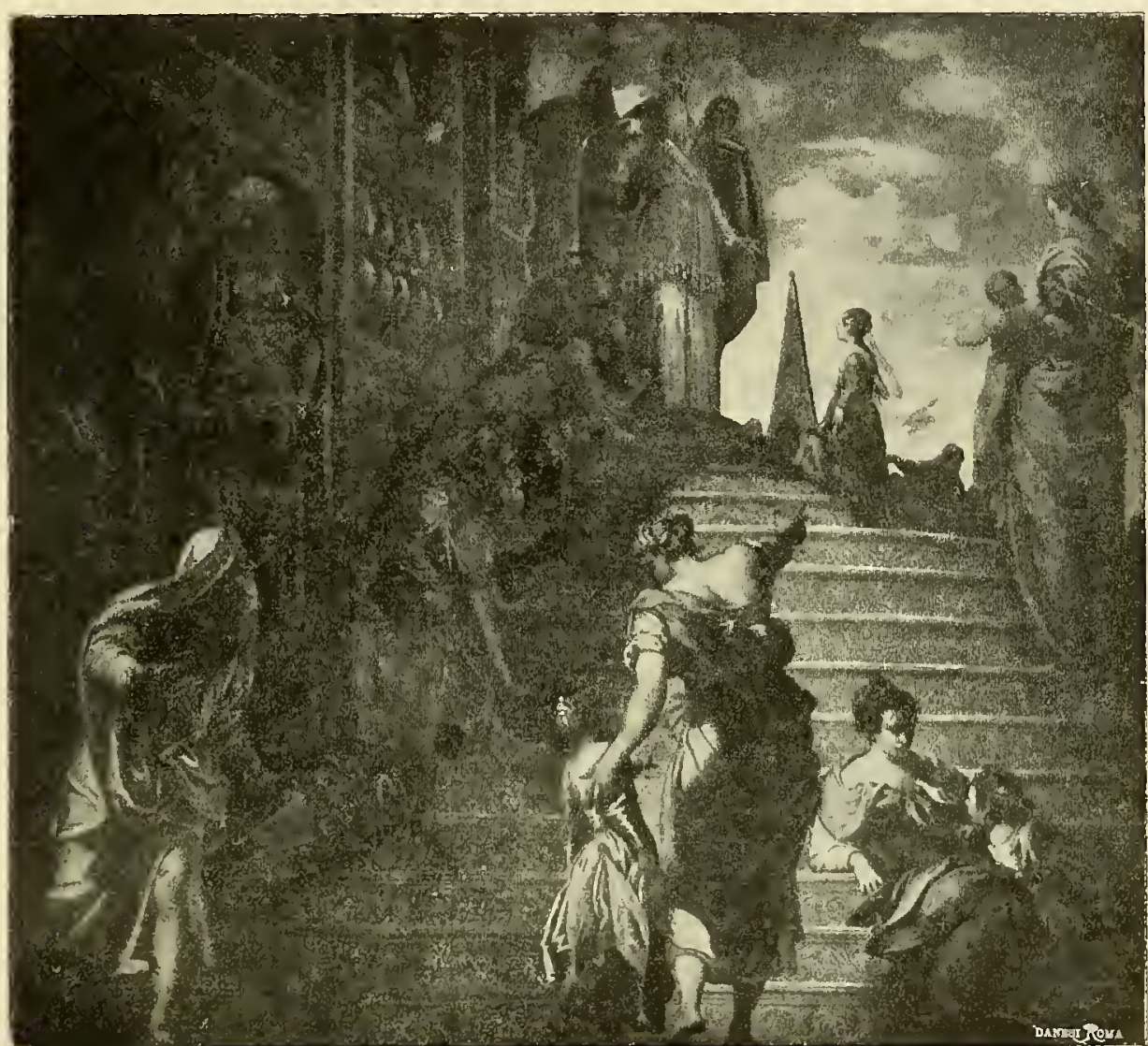

Santa Maria dell'Orto in Venezia (Tintoretto) 



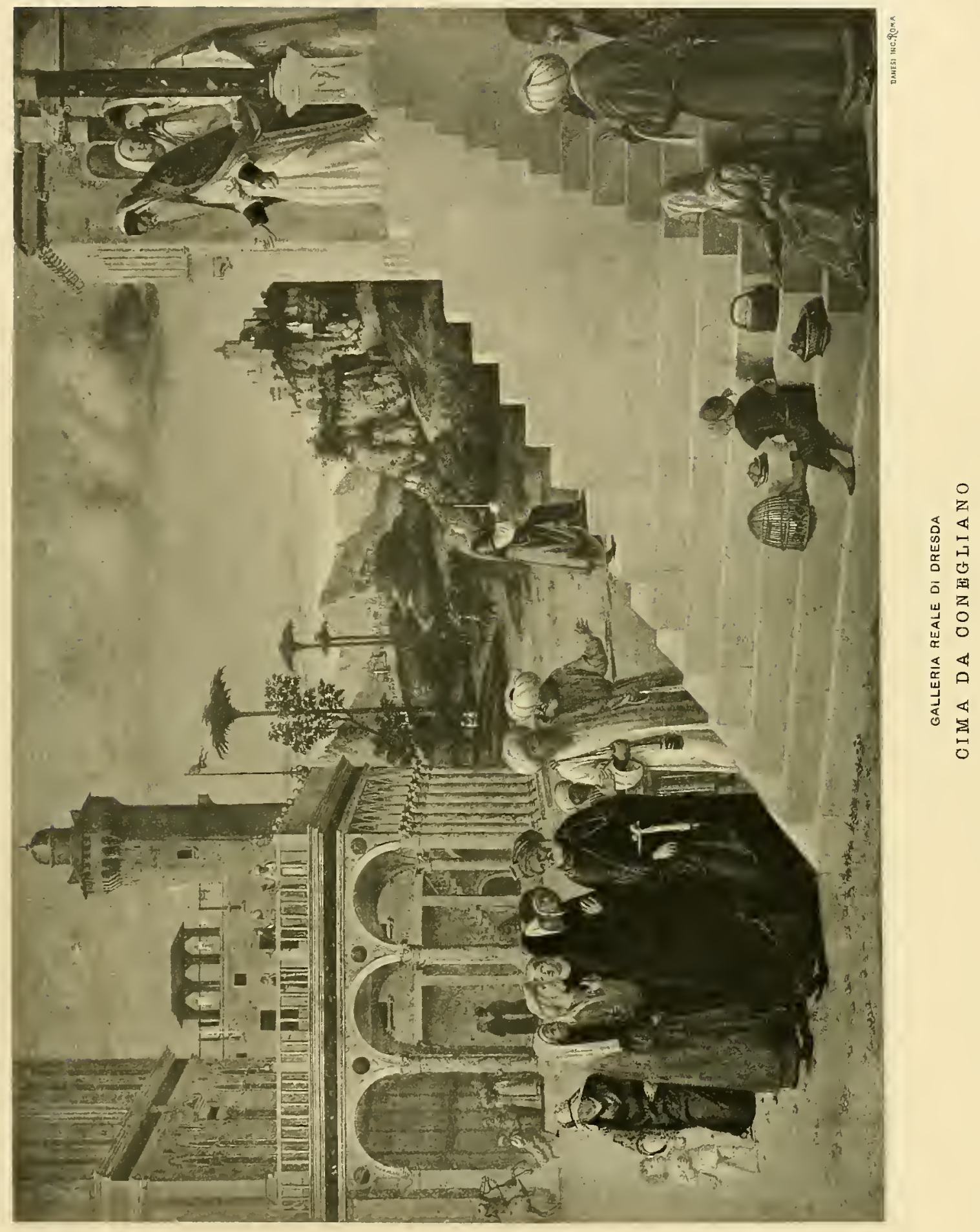





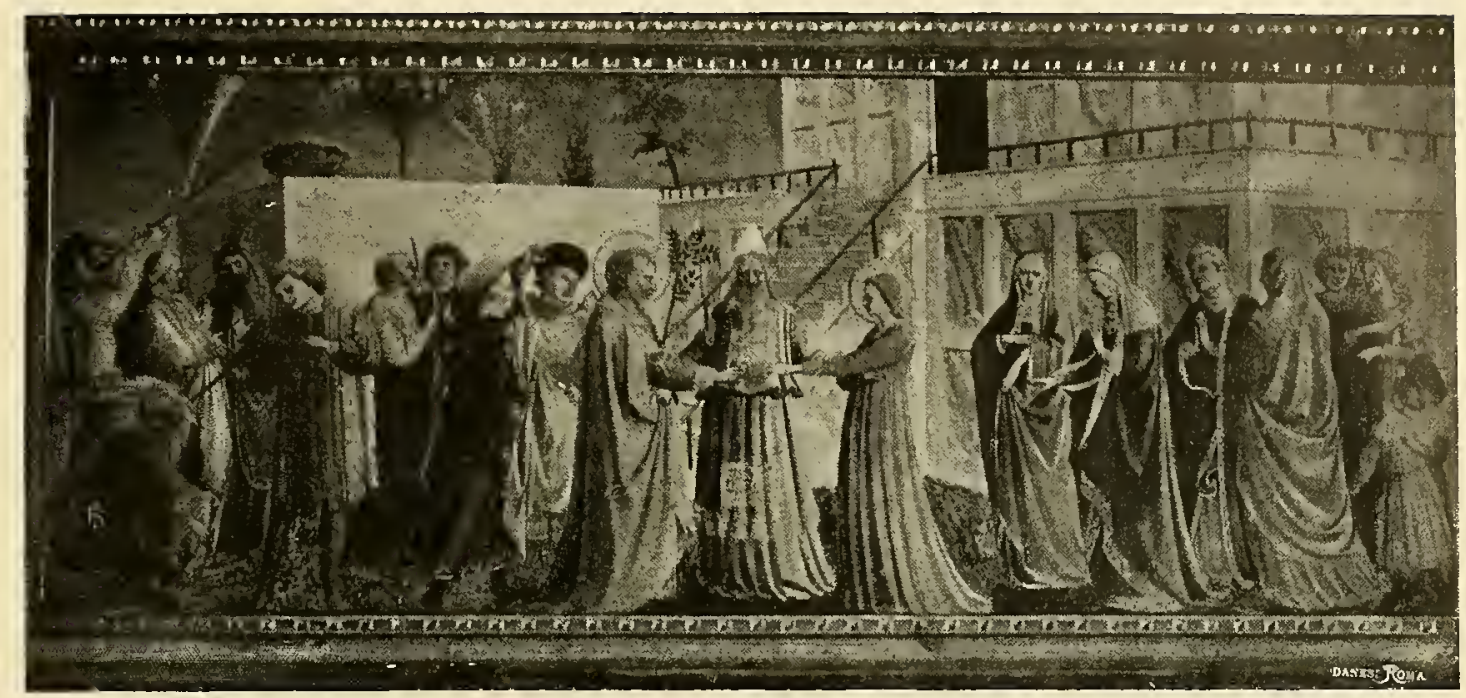

Accademia di Belle Arti in Firenze

(Beato Angelico)

\section{Lo Sposalizio.}

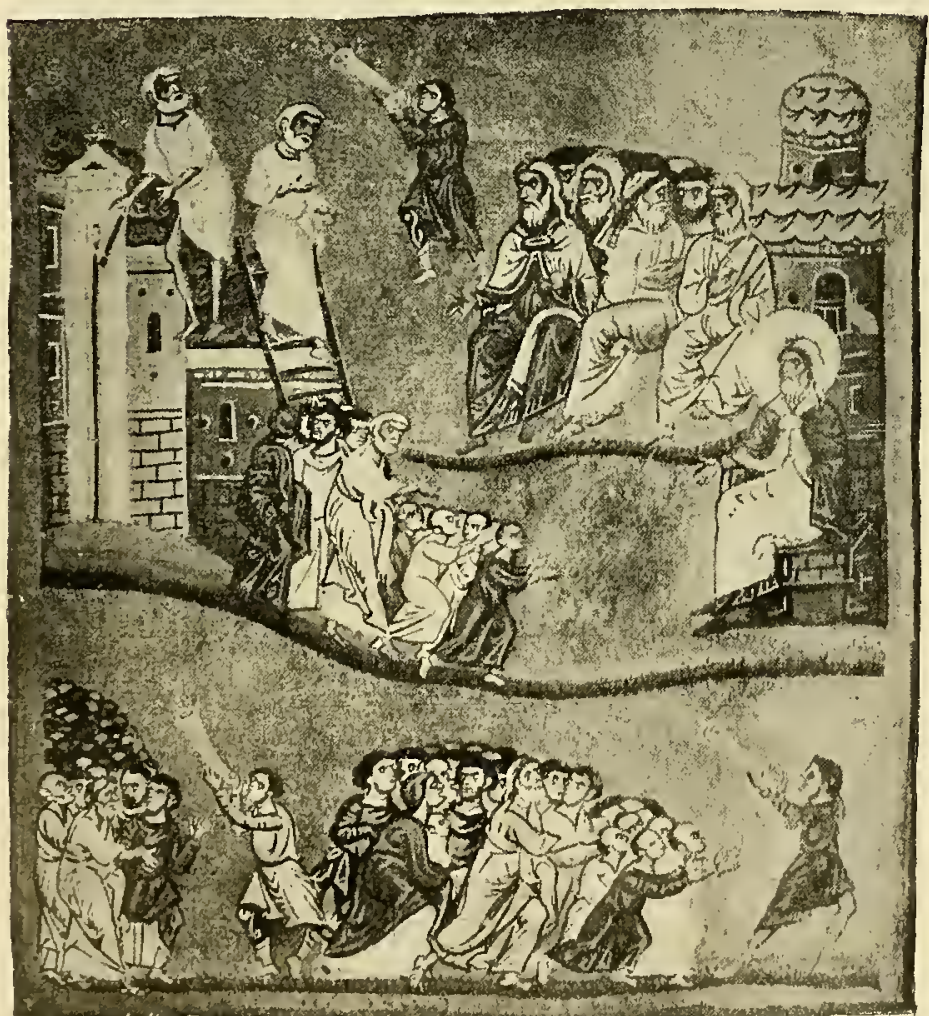

L'appello ai Celibi. Biblioteca Nazionale di Parigi (Codice delle Omelie del Monaco Gincomo)
La rappresentazione del matrimonio della Vergine si svolse compiutamente assai tardi. Il Protoevangelo di San Giovanni, dopo aver raccontato della nascita di Maria e del suo soggiorno nel tempio, arriva agli sponsali. Zaccaria, seguendo l' ordine dell'angelo, convoca tutti i celibi e dice loro di portar ciascuno una verga, chè Dio avrebbe mostrato per mezzo di un segno su chi sarebbe caduta la sua scelta. Giuseppe, deposti i 
propri utensili, si uni a coloro che s' incamminavano verso Abiathar, tutti recanti la verga. Il Sommo Sacerdote, prese le verghe, entrò nel tempio, e dopo aver pregato ne usci e le rese a chi gliele aveva rimesse, senza che alcun segno della divina predilezione si manifestasse. Giuseppe riprese per ultimo la sua verga, e tosto una colomba gli si posò sul capo. Zaccaria allora gli disse: "Dio ti ha eletto perchè tu prenda la sua Vergine, e tu serbala . Giuseppe rifiutò dicendo: "Io ho figli e sono vecchio, mentre che ella è giova-

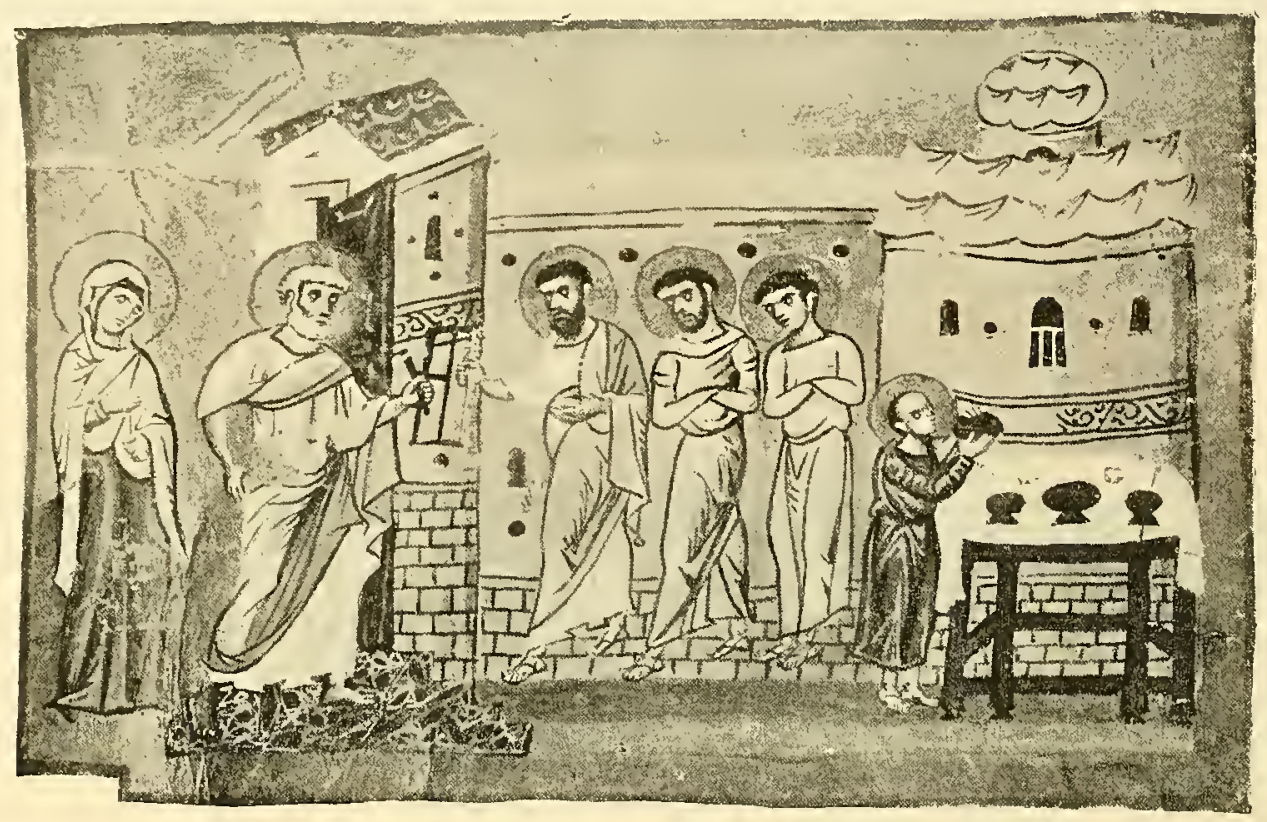

La Vergine con Giuseppe a Nazareth. Biblioteca Nazionale di Parigi (Codice delle Omelie del Monaco Giacomo)

nissima; non voglio farmi ridicolo agli occhi dei figli d'Israele ". Ma il Sacerdote lo spaventò, ricordandogli le punizioni che Dio infligge a chi non obbedisce alla sua legge. E Giuseppe prese la Vergine Maria e le disse: "Io ti condurrò nella mia casa, andrò al lavoro e torneri a te ". Intanto i sacerdoti si adunarono, dicendo: "Facciamo un velo per il tempio del Signore". E soggiunse il principe dei sacerdoti : Chiamatemi le pure vergini della tribù di Davide" Sette ne furono a lui condotte, e allora si ricordò che la purissima Maria era della tribù di Davide. Fece trarre a sorte il nome di coloro che dovevano filar l'oro, il bisso, lo scarlatto e la vera porpora; Maria si ebbe la porpora e la portò con sè per filarla. 
Tale è la leggenda che l'arte doveva raffigurare. Giuseppe era stato rappresentato giovane nei sarcofagi di Sant'Ambrogio di Milano, del Laterano, di Arles. L'antichità cristiana, sino ai Carolingi, non ha cessato di rappresentarlo in tutto il vigore dell'età. Nei musaici di Santa Maria Maggiore,

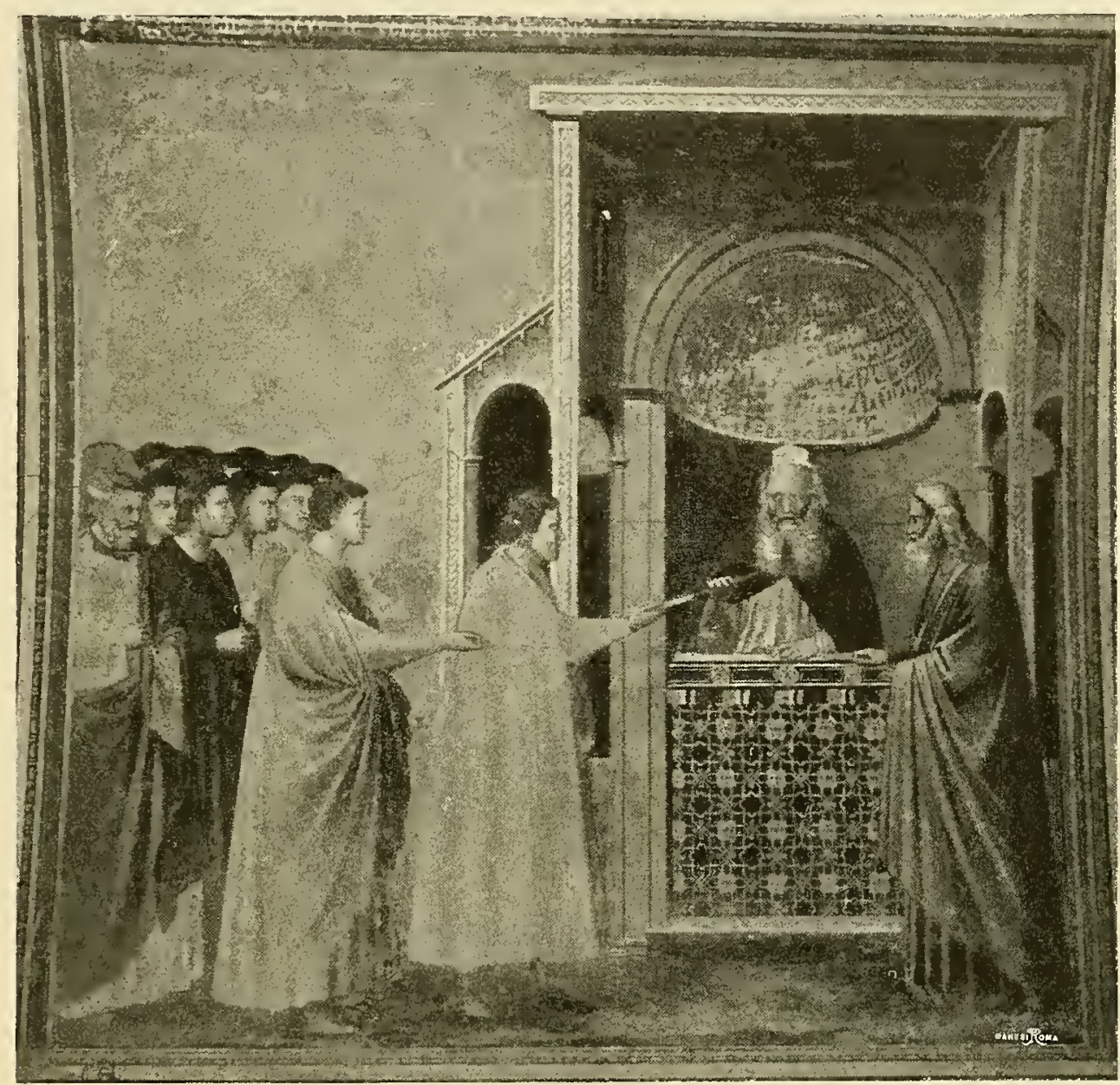

Chiesa dell'Arena in Padova

(Giotro)

ove più volte si ripete l'immagine. San Giuseppe ci appare nella forza degli anni, coi lineamenti d'un uomo maturo, coperta la testa da capelli abbondanti, vestito di tunica con lunghe striscie verticali azzurre. Ma più tardi l'arte ispirata agli apocrifi rappresentò Giuseppe decrepito. Nei giorni della barbarie pareva convenir meglio il tipo della vecchiaia allo sposo della Vergine; e inoltre la figura del Santo sembrò tornare d'imbarazzo agli uomini e ai pittori d'immagini nel medio evo, che gli diede gesti ridicoli, attitudini goffe, 
e spesso lo mise in disparte accasciato dal dolore, dagli anni, dagli acciacchi, forzato ad appoggiare alla mano la testa vacillante.

Un altro apocrifo, quello conosciuto come Evangelo apocrifo della Natività, rappresentava pure San Giuseppe in età senile. Ne ricordiamo alcuni tratti, perchè contiene alcune varianti dal citato Protoevangelo di Giacomo. Disse il Grande Sacerdote: "Chiunque è senza sposa, venga e rechi una verga nelle mani». Arrivò Giuseppe coi giovani, e tutti rimisero la verga al sacerdote, che il domani le restituì loro, ed erano circa tremila. Nessun segno però avvisò del volere divino; e allora il Gran Sacerdote Abiathar si rivestì dell'abito sacerdotale coi dodici tintinnabuli, ed entrato nella sacra

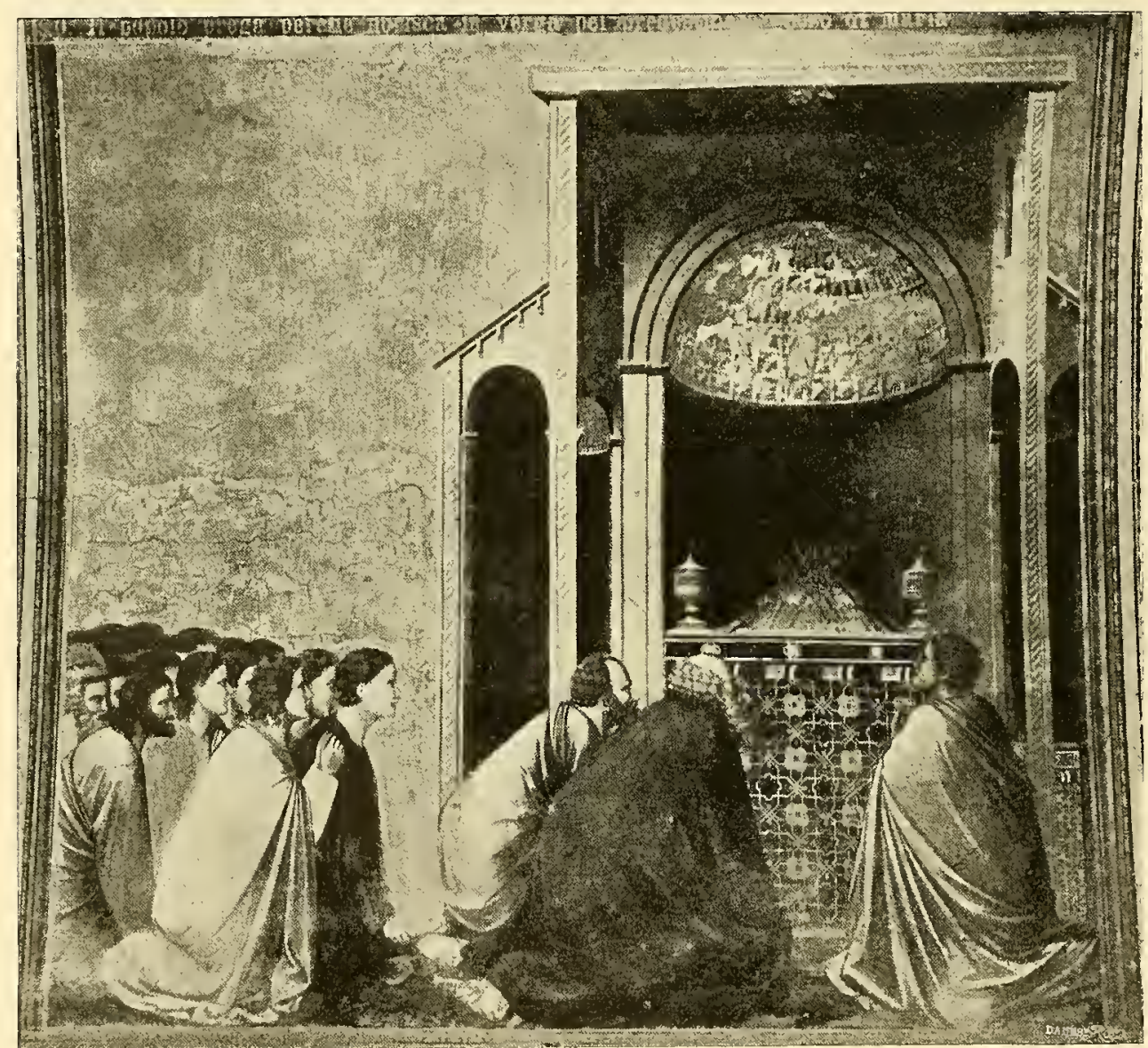

Chiesa dell'Arena in Padova

(GiotTo)

cella offrì il sacrificio. Mentre egli era assorto nella preghiera, l'angelo gli apparve e disse: "Eccoti questa verga piccolissima che tu hai trascurata; 
quando l'avrai presa e consegnata, si manifesterà il segno di cui ti ho dato l'annuncio * La verghetta era quella di Giuseppe, che se ne stava umilmente

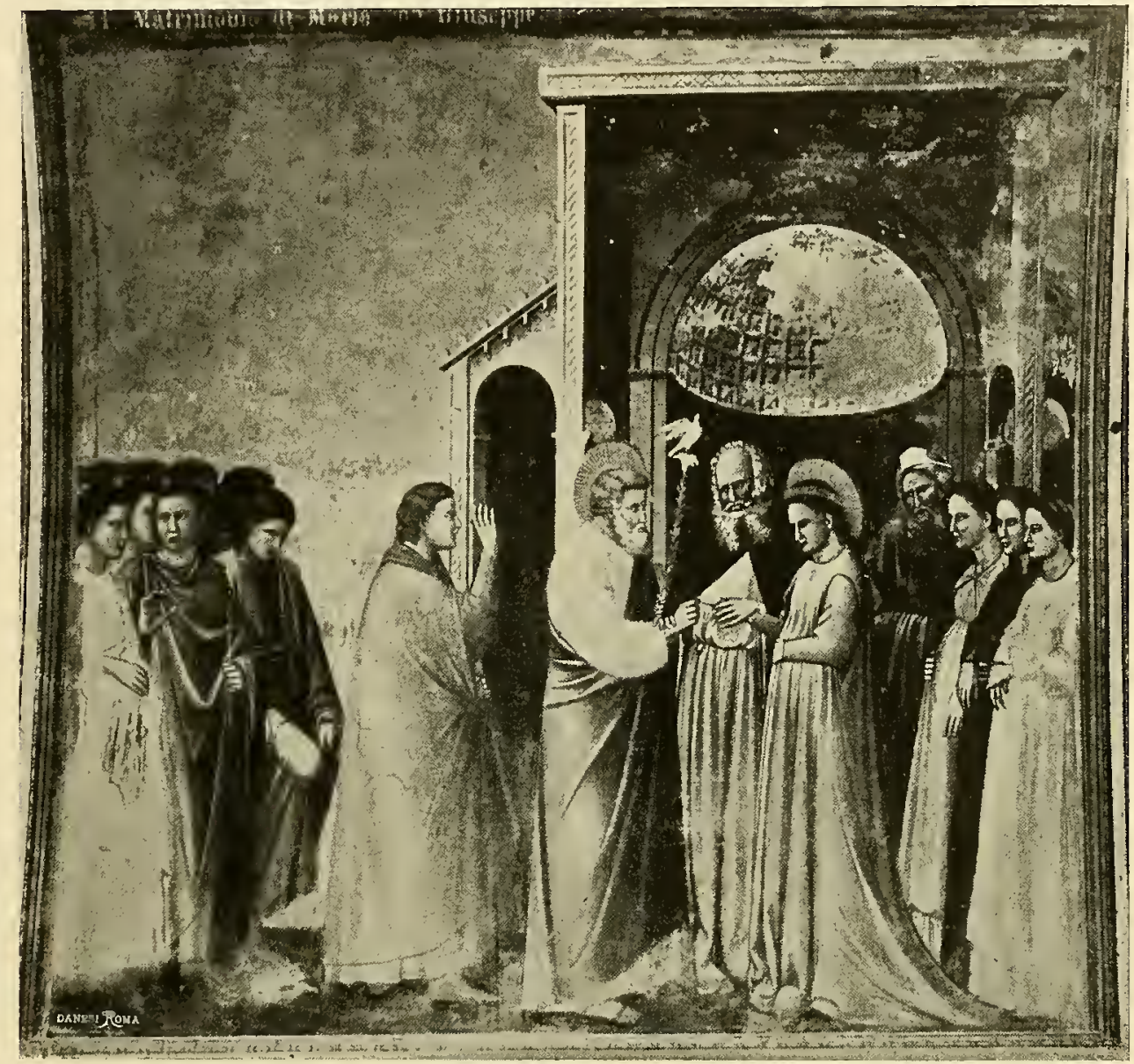

Chiesa dell'Arena in Padova

(GiotTo)

ultimo fra tutti; e Abiathar lo chiamò a voce alta: "Vieni e ricevi la tua verga, chè tu sei atteso". Giuseppe si avvicinò, pieno di spavento all'udire il tuono della voce del Sacerdote; e, quando egli stese la mano per ricevere la verga, uscì dall'estremità di essa una colomba bellissima, più candida della neve, che, dopo aver lungamente volato sotto le volte del tempio, si diresse verso $\mathrm{i}$ cieli. Tutto il popolo si congratulò col vegliardo dicendo: "Tu sei felice nella tua tarda età, chè Dio ti ha scelto perchè ti sia affidata Maria " . E i sacerdoti gli dissero: "Ricevila, perchè Dio ha eletto te". Col maggiore rispetto, ma tutto confuso, Giuseppe rispose: "Io sono vecchio, ed ho parecchi 
figli; perchè mi date questa giovinetta?». Allora il Grande Sacerdote Abiathar gli ricordò come Dathan e Abirone, per avere spregiata la volontà di Dio, perissero ; $\mathrm{e}$ " ti accadrà altrettanto, gli disse, se ti ribelli a ciò che Dio prescrive". Giuseppe rispose: "Non mi oppongo alla volontà di Dio; vorrei sapere quale de' figli miei dovrà averla in isposa. Datele a compagne alcune

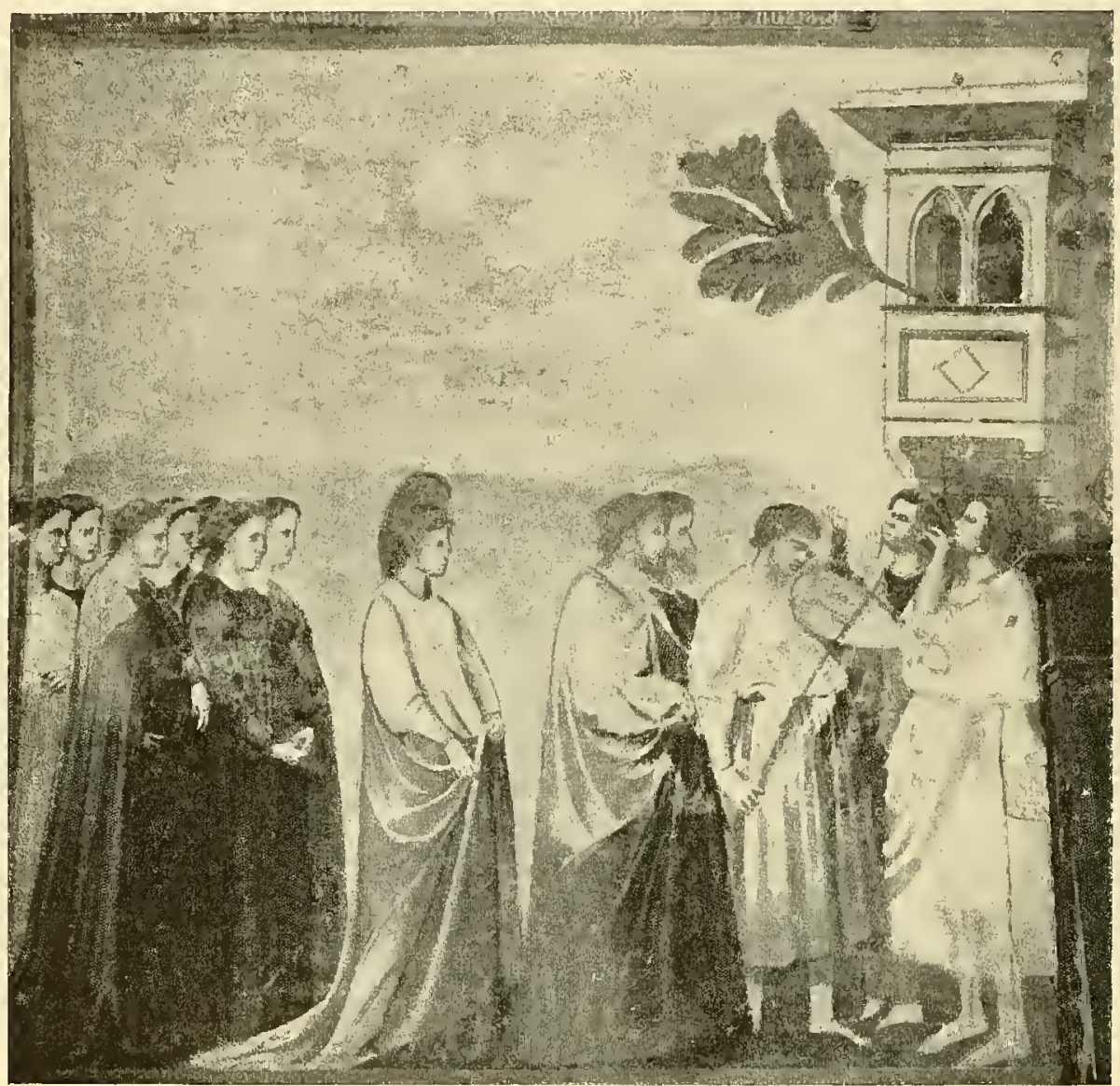

Chiesa dell'Arena in Padova

(GrotTo)

vergini, con le quali intanto dimori ». Abiathar disse allora: "Le sarà accordata la compagnia di alcune vergini, acciocchè le sieno di conforto fino a che tu non sarai suo sposo, e niun altro potrà esserlo». Allora Giuseppe prese Maria con altre cinque vergini, affinchè stessero con lei nella sua casa; e quelle vergini si chiamavano Rebecca, Safora, Susanna, Abigea e Zaele. I sacerdoti diedero loro seta, lino e porpora; elleno trassero a sorte per dividersi il lavoro; e la sorte designò Maria a tessere la porpora per il velo del tempio. 
In questa leggenda resta come un eco della vita romana. La lana data a filare a Maria dai sacerdoti, si dava pure avvolta ad una conocchia alle fanciulle romane, prima che si dipartissero dalla loro famiglia per recarsi nella casa dello sposo, e allora tutte le donne presenti gridavano la parola talassio (nome di un paniere per la lana, che doveva ricordare alla sposa i suoi doveri

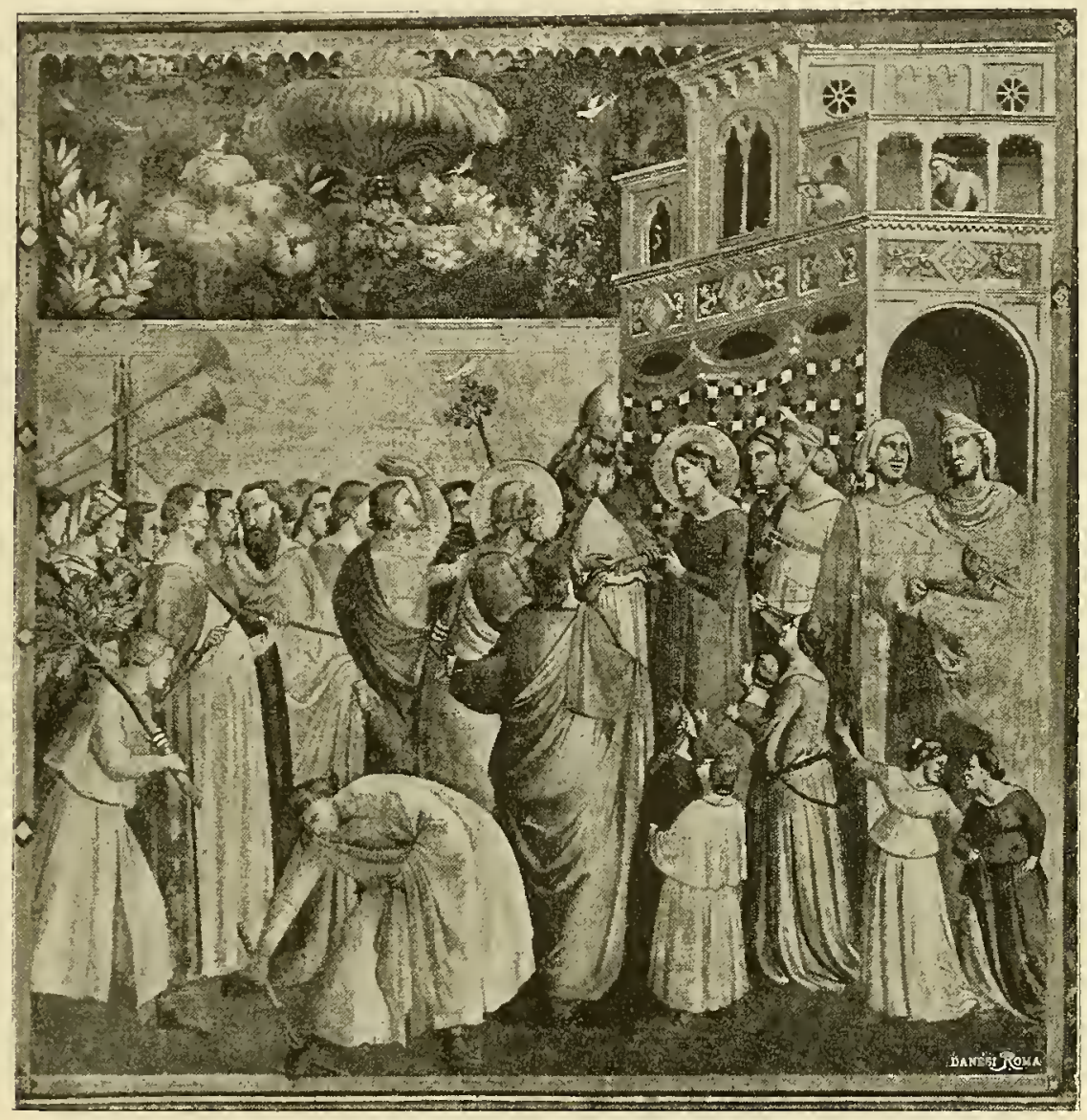

Santa Croce in Firenze

(TATTEO GAdDi)

di filatrice), e accompagnavano il grido con un cadenzato batter di mano. Il Museo archeologico della città di Puy possiede un curioso monumento del IV o v secolo, nel quale si vuol riconoscere il matrimonio della Vergine. $\grave{E}$ un frammento di sarcofago che prima del 1825 era incastrato nel Battistero di Puy. Nel mezzo si vede scolpita una cerimonia nuziale: Io sposo prende la mano della giovane, la quale reca un velo sulla testa; nel fondo un terzo personaggio assiste alla scena e sembra ascoltare i voti degli 
sposi; è un giovane imberbe con la testa circondata da un nimbo. A sinistra un angelo appare a un nomo addormentato; e si è voluto veder qui rap-

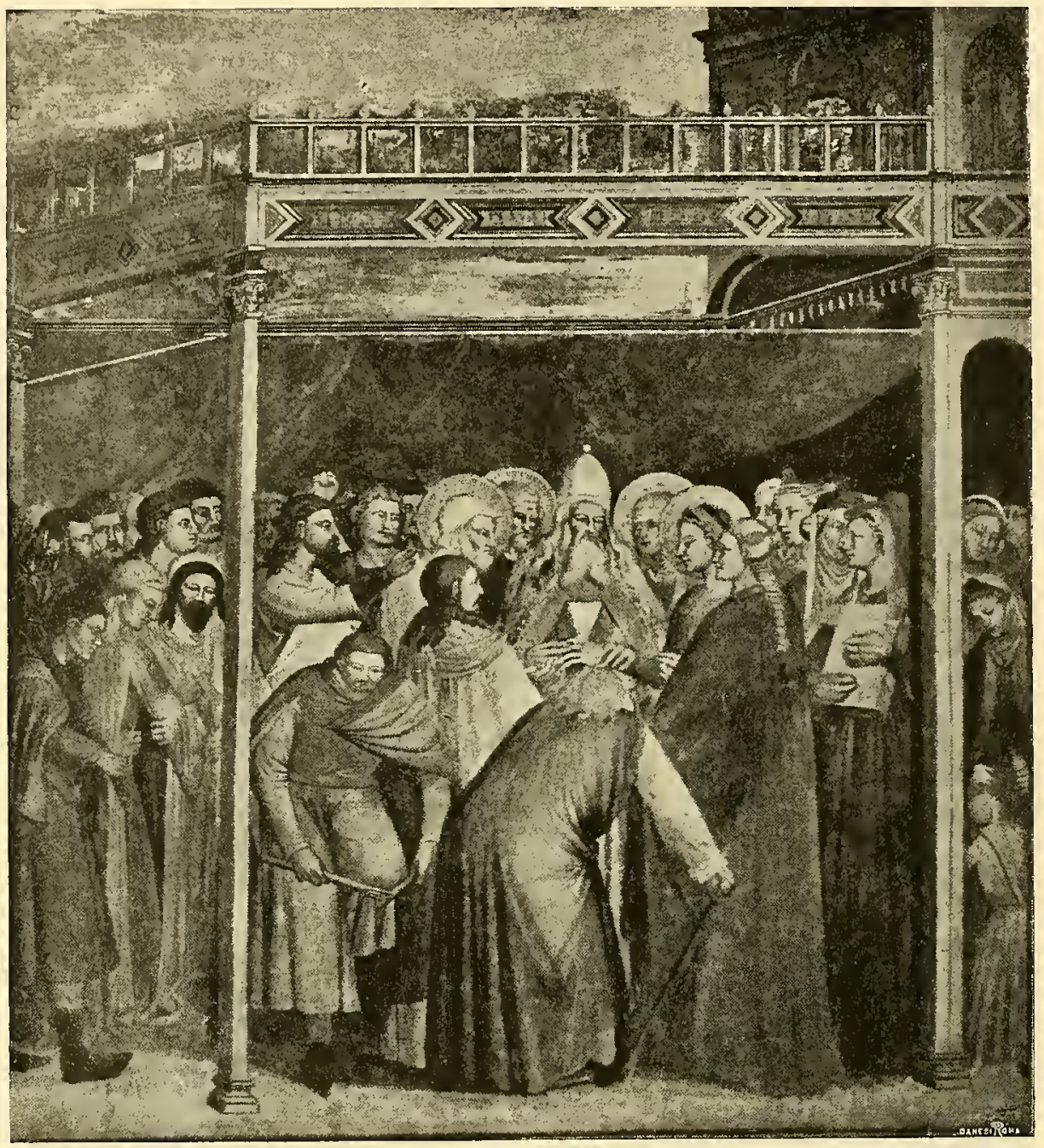

Santa Croce in Firenze

(GIOVAN N DA MILANO)

presentato il sogno di San Giuseppe, cui l'angelo rivela il mistero della Incarnazione. La corta tunica, la quale lascia scoperta una spalla del dormiente, in genere è propria dei pastori e degli schiavi; ma nei sarcofagi si vede anche data a Giuseppe e ad Abramo. Le due scene, secondo il Le Blant, si completano così: San Giuseppe, avuta la rivelazione dall' angelo e abbandonato il disegno di divorziare, è condotto alla Vergine dall'angelo stesso, e si stendono le mani riconciliati. La spiegazione è giudiziosa: ma allora 
la scena non rappresenterebbe lo sposalizio della Vergine, mentre pur sembra di dover qui riconoscere la forma embrionale dell' iconografia di questa rappresentazione. E se noi spieghiamo i due soggetti da destra a sinistra (nei sarcofagi troviamo qualche volta $\mathrm{i}$ soggetti rappresentati in quest'ordine), possiamo ritenere che la scena figuri lo sposalizio con a sinistra la successiva del sogno di Giuseppe. La scena dello sposalizio è nella forma che troveremo più tardi, nella forma veramente classica degli sposi che congiungono le destre, mentre fra loro appare la Pronuba Yzuno. I Bizantini non

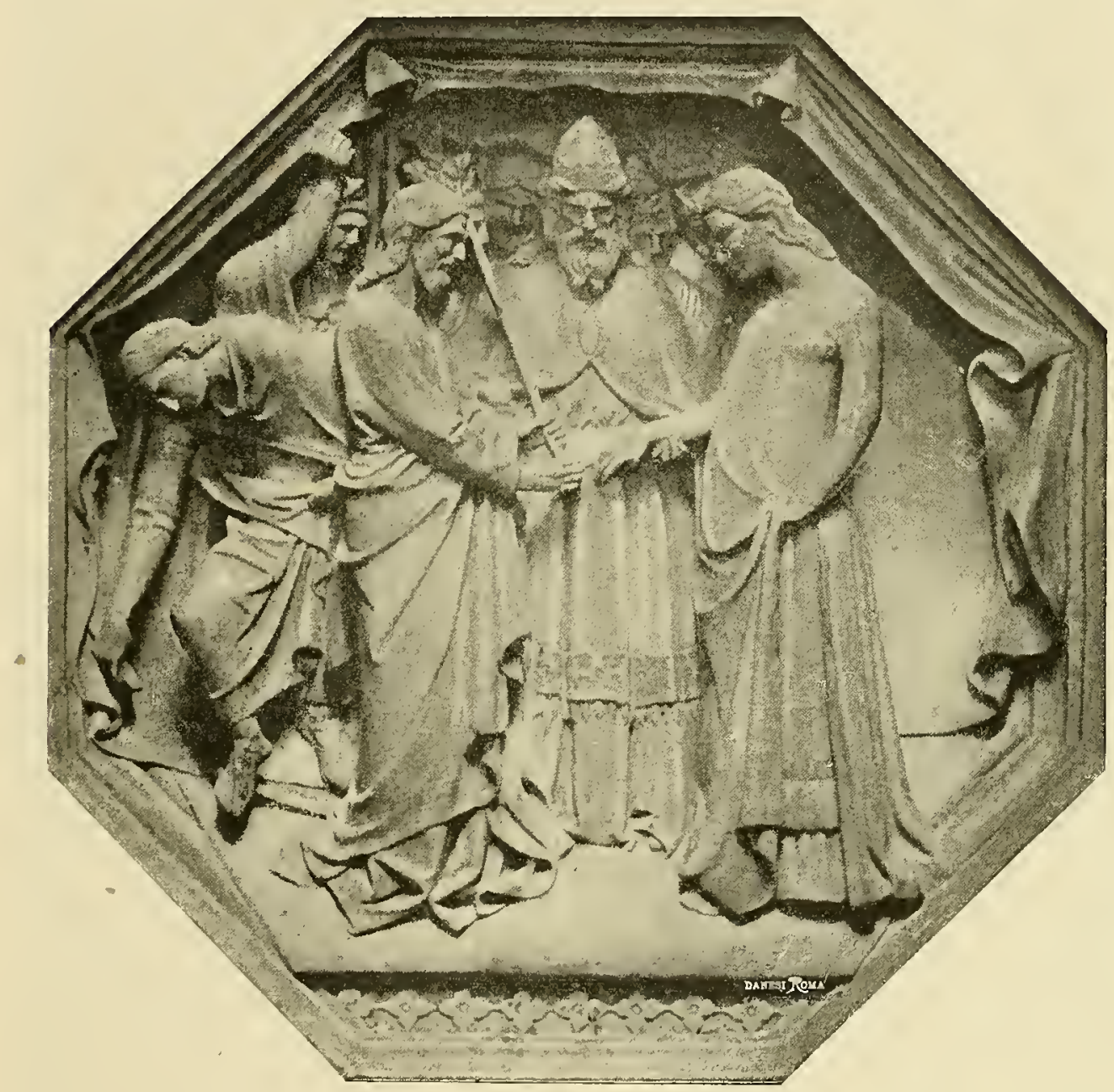

Or' San Michele in Firenze

(OrCaGna)

si attennero a questo tipo; e, per citare l'esempio richiamato nelle altre rappresentazioni leggendarie della Vergine, nelle Omelie del monaco Giacomo, 


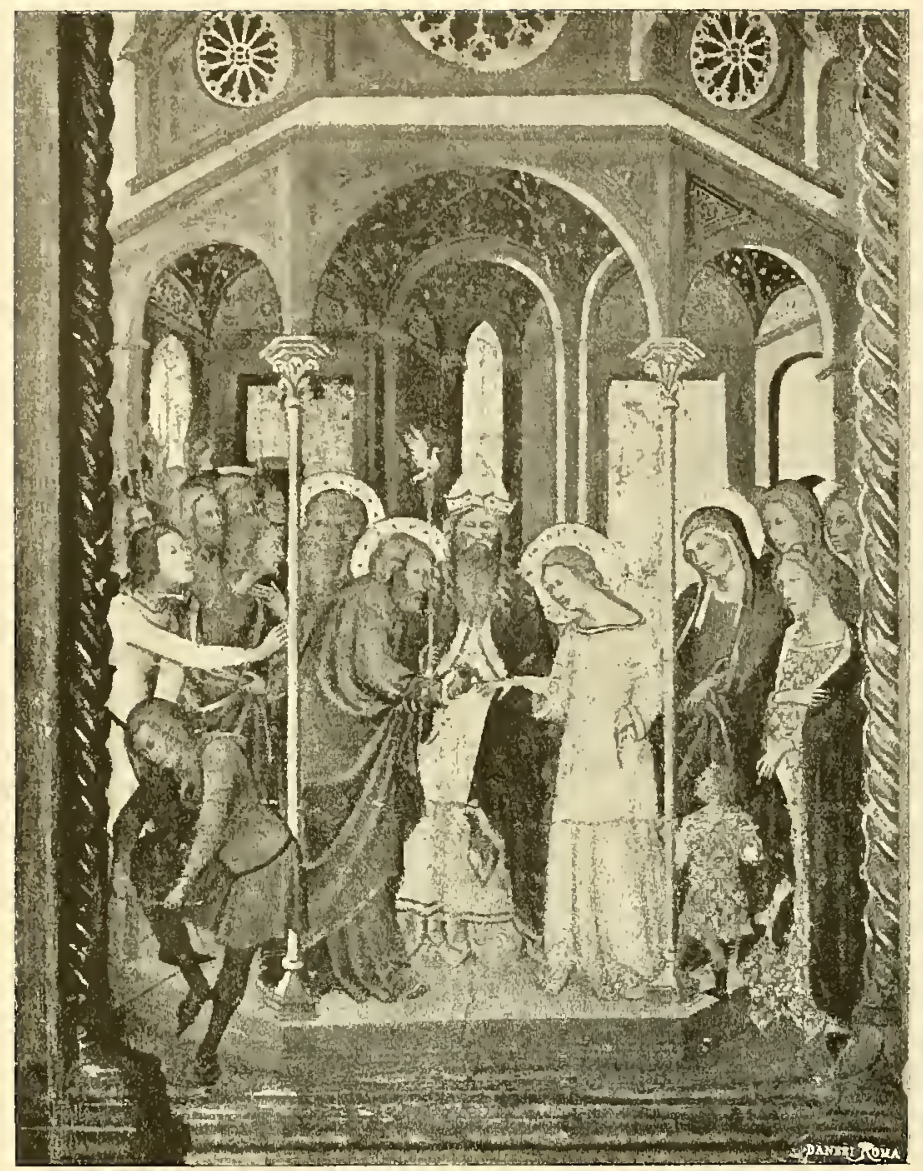

Accademia di Siena

(Bartolo di maestro Fredi)

della Biblioteca Vaticana, non è rappresentato il matrimonio, bensì il Gran Sacerdote che consegna la Vergine a Giuseppe, i quali partono verso la loro casa: Giuseppe cammina innanzi caricato degli strumenti di falegname. e la Vergine lo segue. Gli apocrifi e i Padri greci affidano a Giuseppe soltanto la custodia della verginità di Maria. La guida della pittura al monte Athos tacque circa la rappresentazione dello sposalizio; i Latini invece ammisero una vera cerimonia matrimoniale.

Così almeno s'intese generalmente il passo di San Luca : "Virginem desponsatam Joseph". Presso i Latini la verga fiori ad initazione di quella di Aronne; presso i Greci la colomba si libra su un bastone o sulla testa di Giuseppe. Presso Latini e Greci, almeno una delle verghe che non fiorirono è rotta da un assistente agli sponsali; e così pure rappresentasi il figlio del Gran Sacerdote Abiathar, che era stato fra i concorrenti alla mano della Vergine, in atto di dare un pugno a Giuseppe per vendicarsi della sorte contraria.

Giotto, nella cappella degli Scrovegni, rappresentò in un campo i celibi della stirpe di Davide recanti le verghe al Sommo Sacerdote, avanzantisi timidamente verso il leonino vegliardo; e più timido di tutti, ultimo della giovanile schiera, è Giuseppe, col nimbo intorno alla testa bianca. Segue a questa scena la rappresentazione dell'attesa dei pretendenti alla mano della 

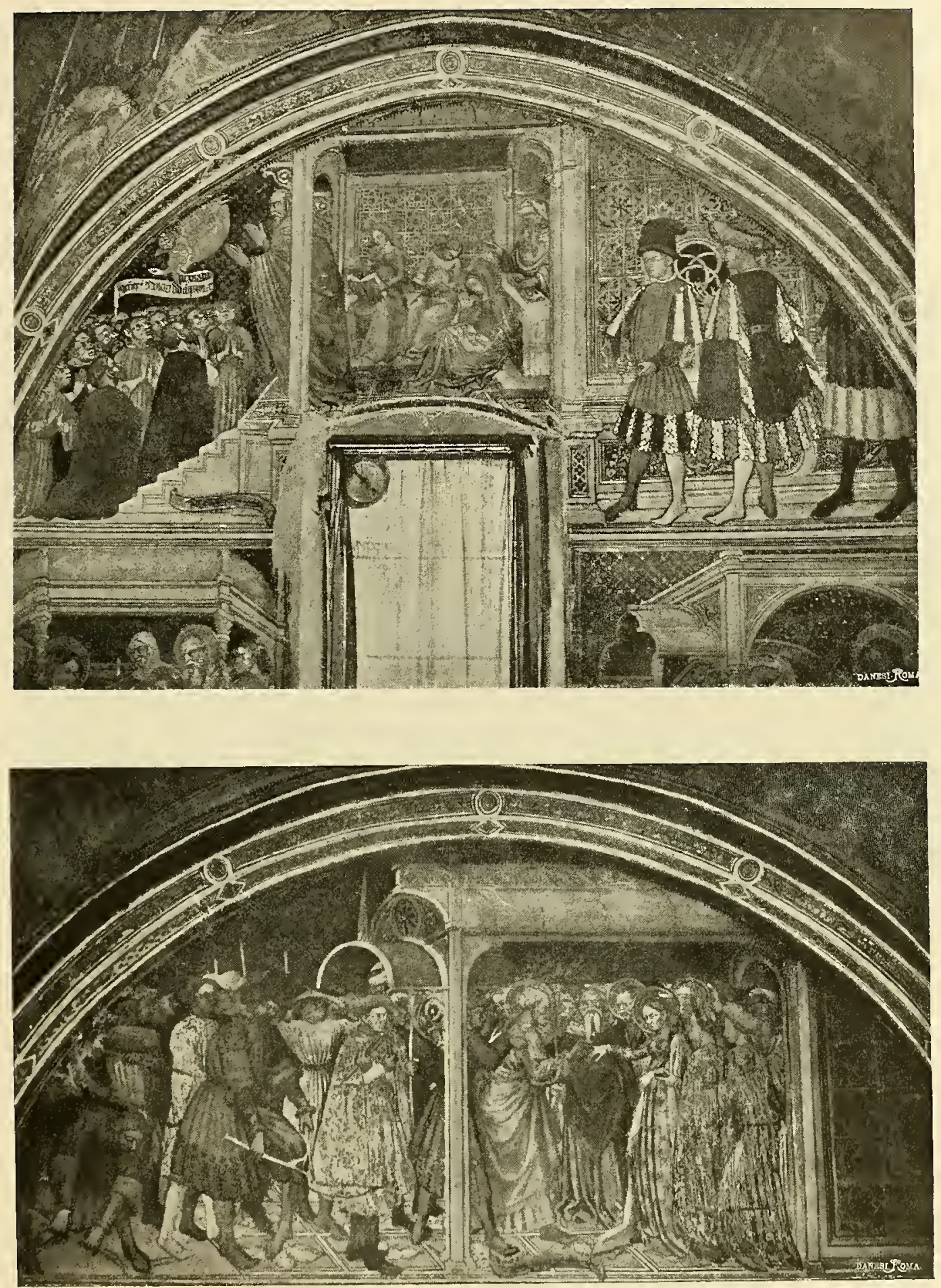

Palazzo de' Trinci in Foligno

(Ottaviano Nelli) 


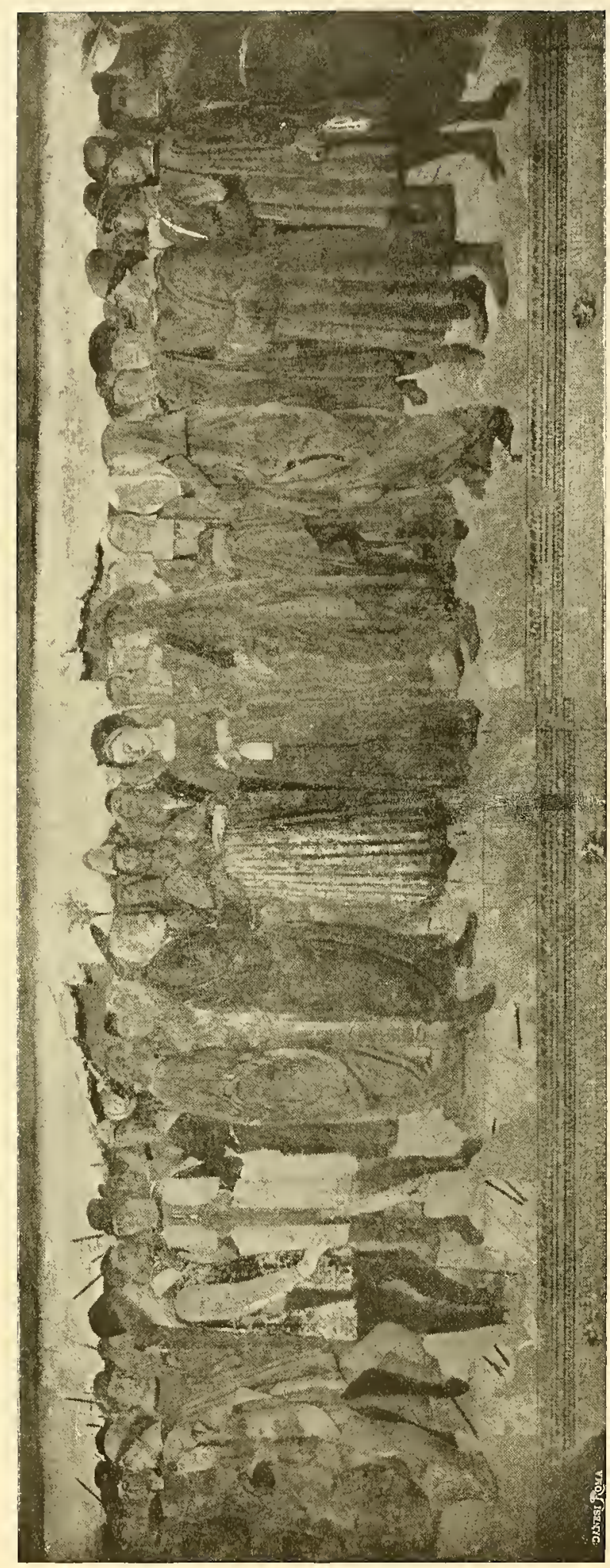

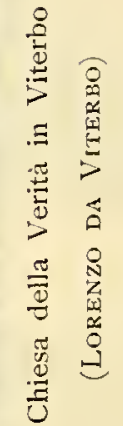


Vergine: sull'altare stanno le verghe in fascio, e ginocchioni, supplici, ansiosi tutti, aspettano la scelta celeste, il prodigio: le donne con le labbra semiaperte e con le graziose teste innanzi protese, curvi il Sacerdote e i Leviti, con gli sguardi fissi intensamente sul fascio di verghe. Tutti i cuori battono nel quadro di Giotto. Il prodigio è avvenuto; e Giuseppe, con la verga fiorita a mo' di giglio, si rivede innanzi a Maria, mentre sta per porle l'anello

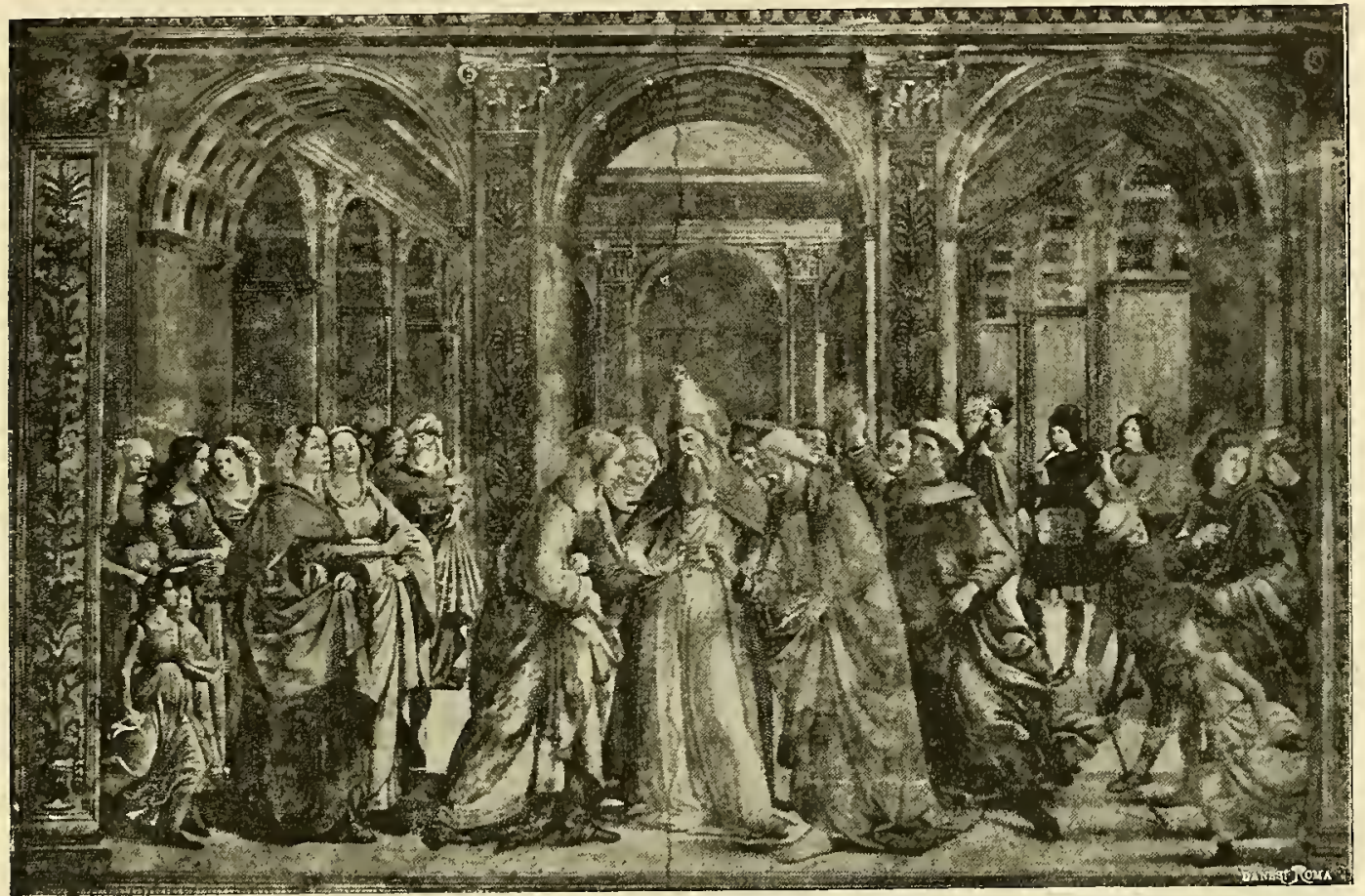

Santa Maria Novella in Firenze

(Domenico Ghirlandaio)

nella destra che il sacerdote gli avvicina. Sul giglio vola la colomba; dietro a Giuseppe, col braccio solievato come in atto di colpirlo, s'avanza il figlio del Sacerdote Abiathar. Altri celibi in gruppo seguono il vendicativo, ed uno dalla bella testa giovanile, coi capelli sparsi sugli omeri, rompe per dispetto la verga contro il ginocchio piegato. Compiuta la cerimonia nuziale, Maria, seguita dalle compagne come una regina dal suo corteo, procede verso la casa, innanzi a cui giovani inghirlandati suonano i loro strumenti verso la casetta con due gotiche finestrine, donde esce una palma, e che sembra il nido della pace campato in aria. L'augusta semplicità di Giotto sparisce ne' suoi seguaci; e la cappellina, quasi potrebbe dirsi la nicchia, ove 
si svolgono le tre prime rappresentazioni di Giotto: la raccolta delle verghe, l'attesa del prodigio, gli sponsali, - diviene l'interno di un chiostro nell' affresco di Taddeo Gaddi, e una gran sala nell'altro di Giovanni da Milano, in Santa Croce. Entrambi questi maestri affollano intorno agli sposi gli spettatori; anzi il Gaddi vi fa accorrere funanche dei fanciulli che sembrano nani. L'austerità di Taddeo cessa in Giovanni, che raddolcisce i volti. aggrazia le figure muliebri; ma gli sdegnati giovani alzano pur sempre le mani a percuotere Giuseppe, o rompono le verghe mentre si compie la cerimonia.

Similmente si vede la scena nelle opere del Trecento, anche nel bassorilievo dell' Orcagna in Or'San Michele, ove Maria, coronata da una rama

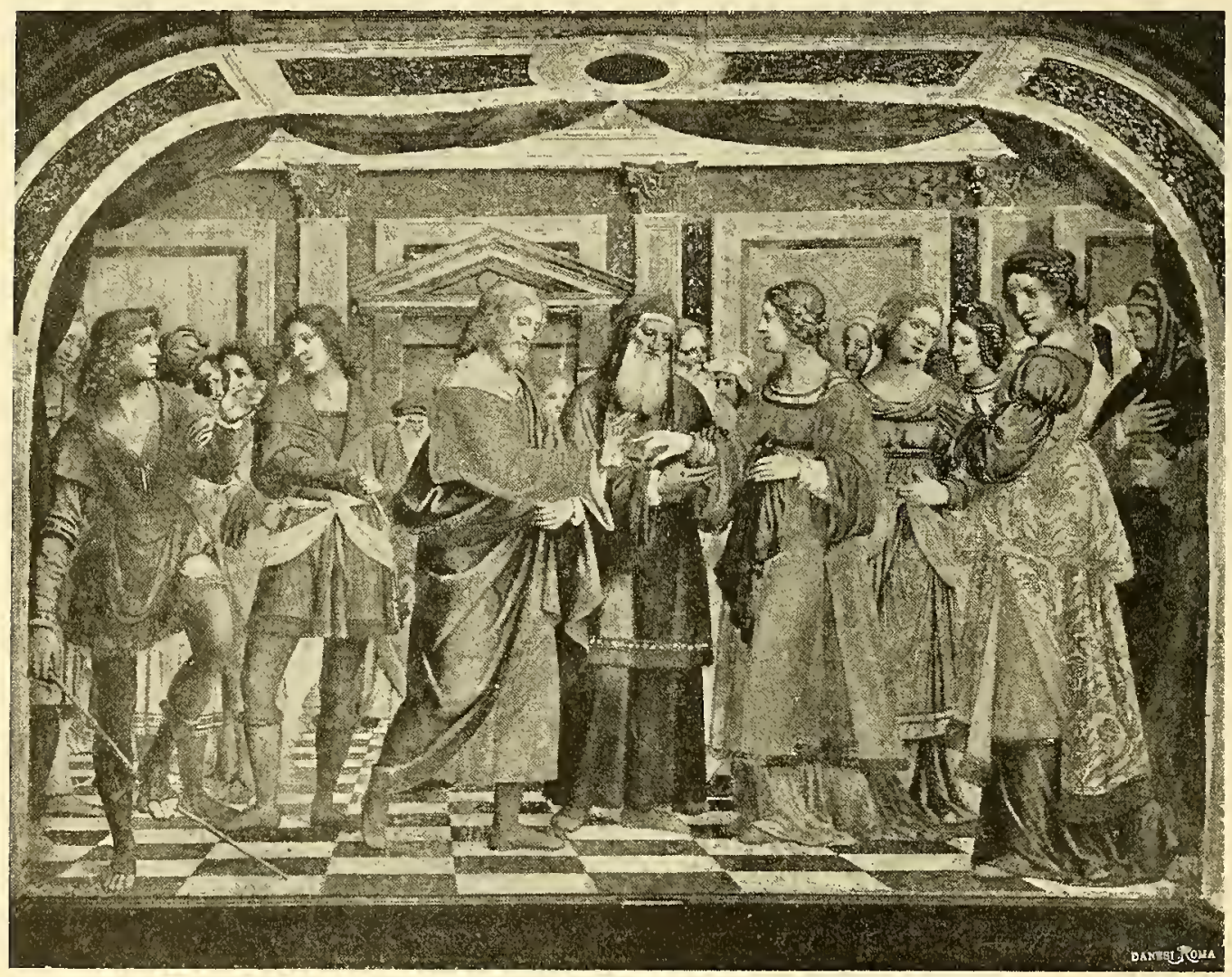

Santuario di Saronno

(BERNARDINO L UINI)

fiorita, abbandona la destra sulla mano del Sacerdote, che la porge a Giuseppe. La composizione rimase sempre la stessa sino al periodo naturalistico 
dell'arte italiana, nel Quattrocento. Il Beato Angelico, nel quadro della Galleria degli Uffizî, ancora fa che il figlio di Abiathar ed altri colpiscano sulle

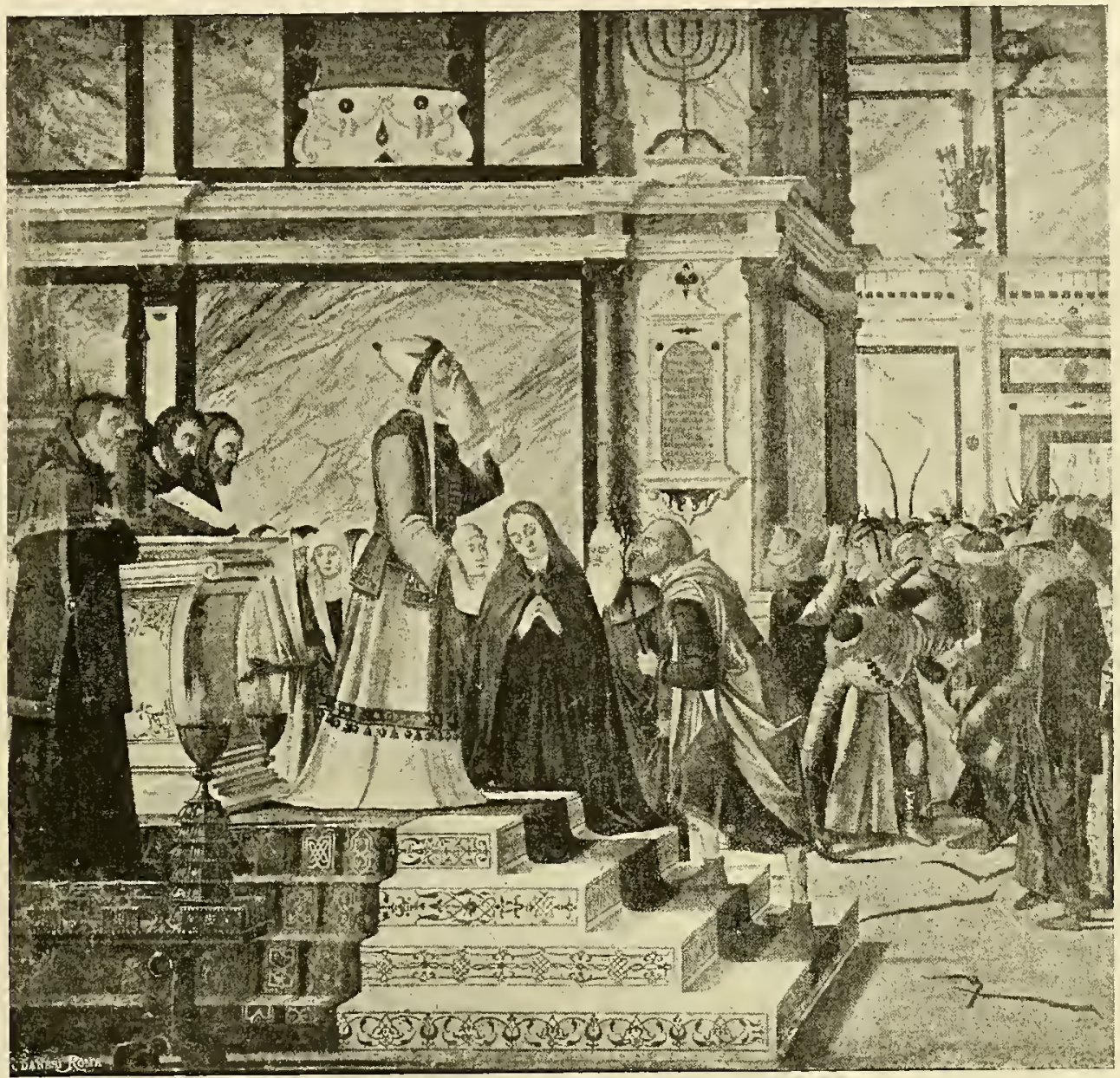

Reyia Pinacoteca di Brera in Milano

(VITTOR CARPACCiO)

spalle Giuseppe, benchè d'ira e di sdegno non potessero accendersi i corpi da lui dipinti, e tutti i volti spirassero la mitezza dell'artista, e i pugni chiusi sembrassero quelli di fanciulli che non percuotono, ma accarezzano.

I quattrocentisti succedenti resero naturalistica la scena; e Lorenzo da Viterbo espresse con vigore l'ira, l'ironia, il dispetto degli uomini che seguono Giuseppe. Perdendo il carattere religioso la scena diventa storica. Gli assistenti alla cerimonia sono gentiluomini e cavalieri del secolo xv, "cavati di naturale", come afferma Nicola della Tuccia, cronista viterbese; e si vede il cronista stesso in un "omo antico d'età, d’anni settanta otto, 
vestito di paonazzo col mantello addosso e una berretta tonda e calze nere ». In simil modo, ma con più chiara distribuzione dei gruppi, Domenico Ghirlandaio a Santa Maria Novella fece beffeggiare e colpire Giuseppe dagli

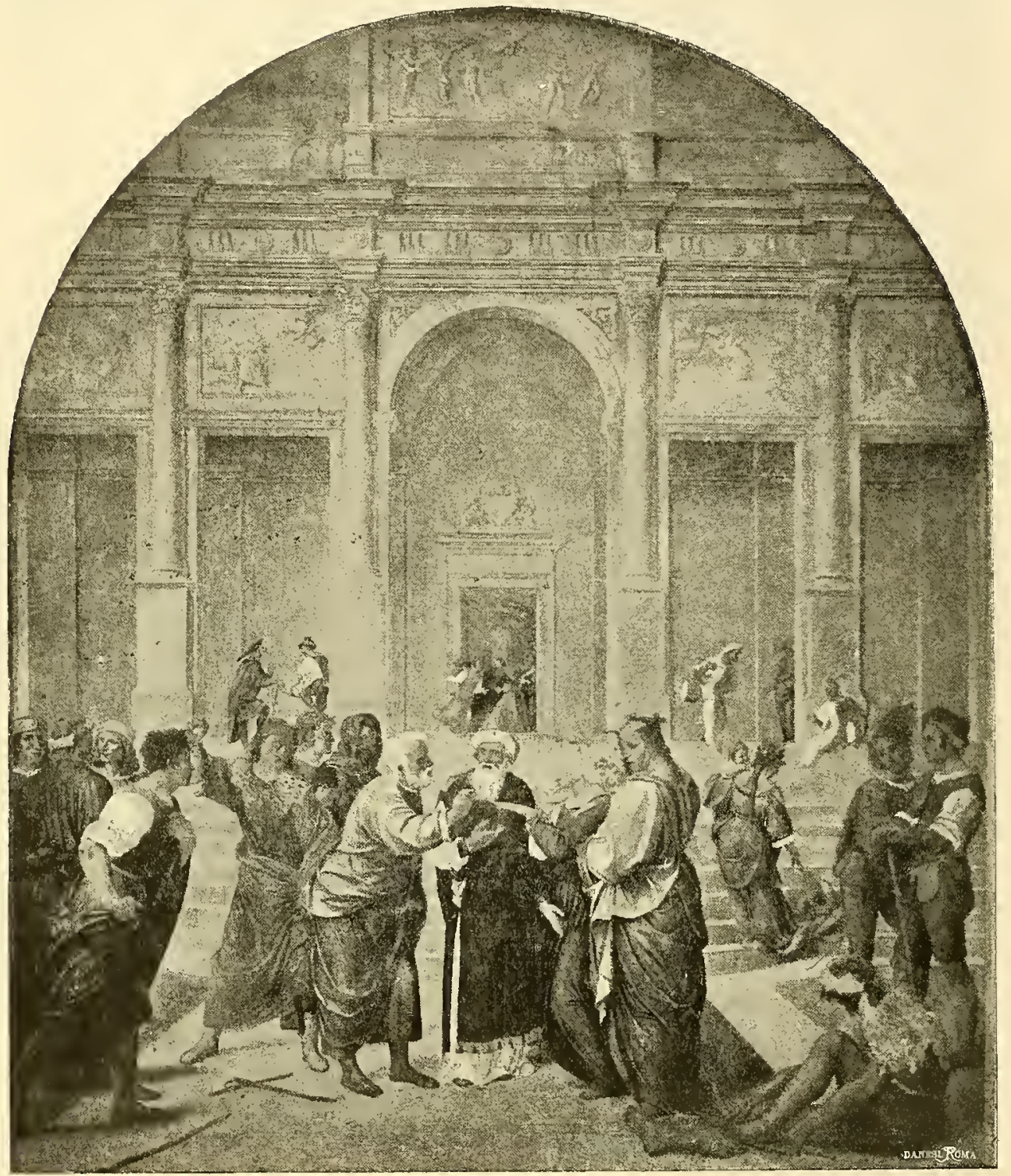

Santissima Annunziata in Firenze

(Franciabigio)

invidi; ma la colomba sulla verga vien meno, e con essa tutto ciò che era artificiale reminiscenza simbolica o forma inverosimile. Vien meno anche, nell'opera del Luini, bella d'ogni grazia lombarda, nel santuario di Saronno, la vibrata espressione dell' invidia dei concorrenti di Giuseppe. Appena un 


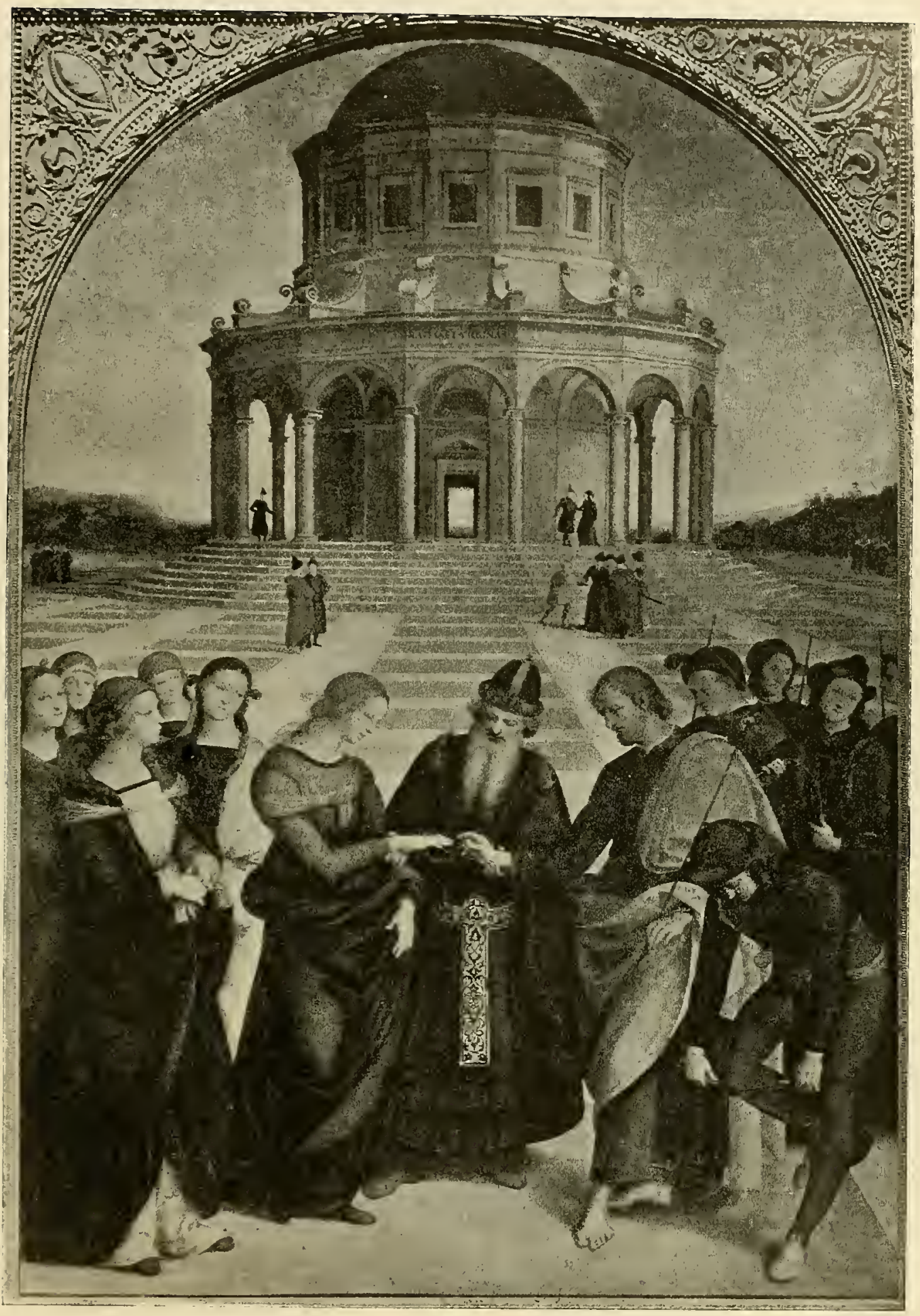

Sposalizio, Brera

(RAFFAELLO) 
sorriso sfiora le labbra d'un giovane che rompe la verga, e appena un senso d’inquietudine si dimostra nel suo vicino. Frattanto la turba intorno agli sposi si è diradata nello Sposalizio del Perugino a Fano e nell'altro di Raffaello nella Galleria di Brera in Milano, che imitò quello fedelmente. San Giuseppe mutò la fisonomia senile in quella giovane, soavissima, fresca di Raffaello, assumendo con la soavità di questo maestro la sua dolce melanconia, una grande quiete e timidezza nei moti lenti. Una purissima armonia d'ogni parte della rappresentazione si sostituisce all'antico contrasto; anzi, quantunque il contrasto sia indicato, non sembra tale. Il racconto semplificato, addolcito, nobilitato, nella rappresentazione di Raffaello prende la sua forma definitiva. Così l'arte italiana aveva riveduta e corretta la leggenda, togliendone ogni asprezza, l'opposizione della giovinezza alla vecchiaia, i sarcasmi, le beffe, le percosse; ed aveva rifatto il racconto in una forma semplice, decorosa, gentile. Il sentimento divoto degli Umbri trionfò con Raffaello sulla tradizione; e l'arte, come gemma preziosa sprigionata con grande sforzo dal sasso che la racchiudeva, divenuta purissima, brillava al sole nel Rinascimento. 


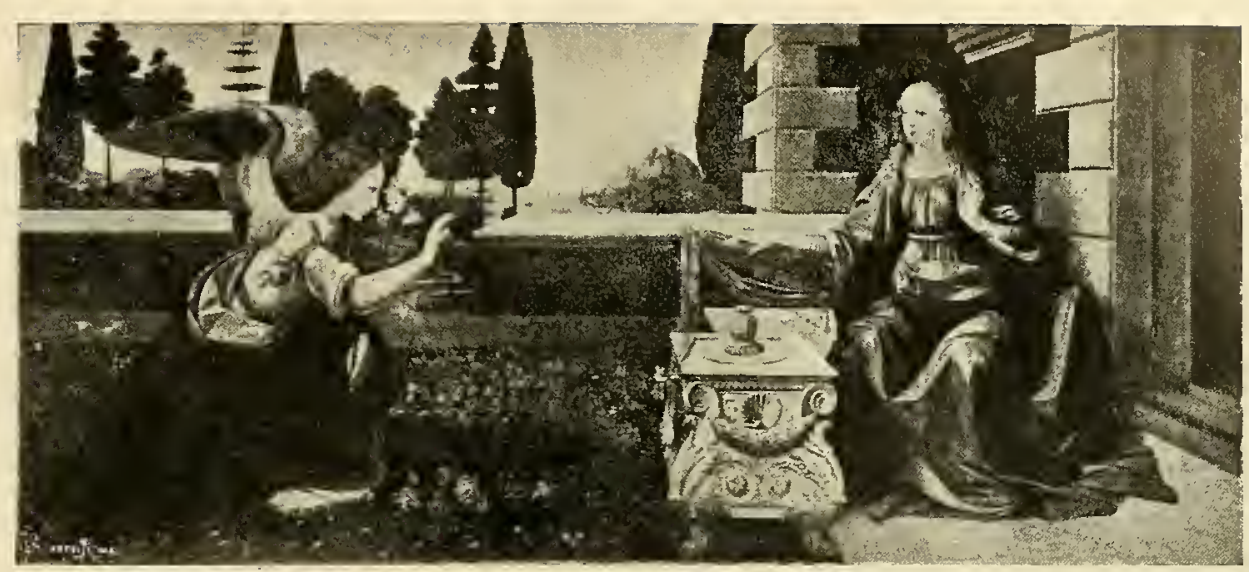

Galleria degli Uffizi in Firenze

(LEONARDO DA VINCI)

\section{L’Annunciazione.}

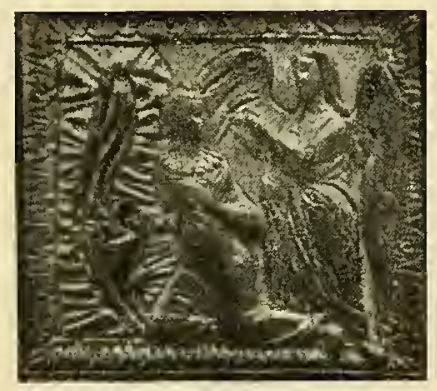

Particolare d'un avorio della Cattedrale di Milano
Negli oscuri scomparti della volta del cubicolo quarto del cimitero di Priscilla, sugl' intonachi anneriti e guasti, si discerne una figura di donna seduta su rozza cattedra, in atto di stupore, mentre un giovane con la destra stesa le porge un annuncio. È questa la prima forma della rappresentazione che di poco mutò nel giro dei secoli, e che noi seguiremo passo per passo nel suo svolgimento, nelle lievi varianti che lasciano intravedere il moto delle idee e dei sentimenti popolari, nei progressi dell'arte che conciliò la tradizione e la libertà del genio italiano. La modesta figura di Maria, l'umile ancella delle catacombe, diverrà la regina glorificata, la sacerdotessa bizantina e infine la donna nel gaudio materno; l'arcangelo oratore del cimitero di Priscilla prenderà l'aspetto eroico delle Vittorie, ripiegherà le ali splendenti di luce innanzi alla Vergine, e il satellite del cielo si trasformerà nel fanciullo innocente, coronato di fiori, dolce nel sorriso gentile. Ma la linea della composizione riman sempre quasi la stessa e inalterata si tramanda dal medio evo all'età moderna, con gl' insegnamenti dei Padri della Chiesa, con le leggende dei neofiti cristiani, con le candide tradizioni. 


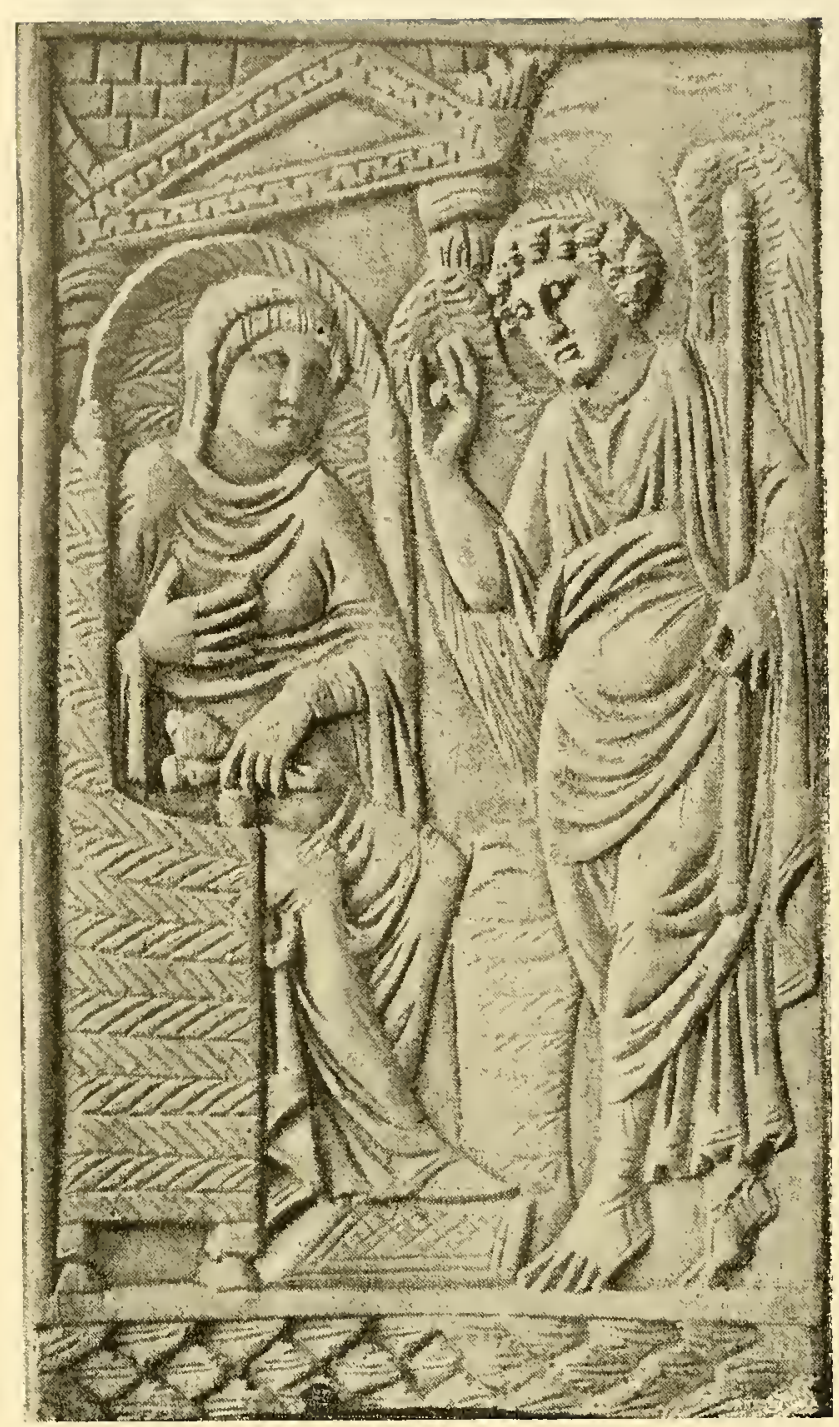

Avorio della cattedra di Massimiano in Ravenna Secolo vi

Nel cimitero di Priscilla, verso il in secolo dell'era nostra, non si poteva rappresentar meglio che in cattedra la Madre del Cristo, per simboleggiarne la dignità; e Gabriele ha figura umana, senza ali, senza il bastone viatorio - lo scettro. I prini pittori cristiani non avrebbero saputo farsi una convenzione per designare gli esseri invisibili, puri spiriti del cielo. Essi dovettero volgere intorno gli occhi per attingere dall'arte pagana il partito artistico della scena tutta nuova, che i posteri dovevano raccogliere come sacro deposito. Forse videro o ricordarono la rappresentazione di Telemaco innanzi a Penelope, o forse quella di Paride che si presenta ad Elena, come si è supposto per una certa somiglianza di forme tra una pittura pompeiana e questa delle catacombe di Priscilla. Elena, al pari della Vergine, si vede seduta, mentre Paride le dichiara l'amore. Ma qui è l'eleganza muliebre, il piacere della vita; mentre l'artista cristiano, che teneva di mira anche gli evangeli, doveva togliere ai tipi dell'arte classica quell'espressione di serenità, di vigore, di gaiezza non rispondente al sentire di poveri e di schiavi perseguitati, adoranti nel silenzio e nell'ombra il loro Dio. Quindi dalle citate rappresentazioni o dalle altre classiche raffiguranti due persone, una delle quali esprima all'altra il suo pensiero o le apporti un messaggio, si trasse la distribuzione della scena, la linea del quadro. Perciò nella disadorna cattedra del 
cimitero di Priscilla siede l'ancella del Signore, secondo l'evangelo di San Luca, non la dea, non la imperatrice, non la matrona delle antiche stele, che con tutta grazia lievemente allontana dalle spalle e dal seno la sopravveste onde ha velato il capo e racchiusa la elegante persona. Maria siede modesta e muove appena la sinistra mano, mentre l'angiolo le dice ch' ella ha trovato grazia dinanzi a Dio, e che la virtù dell'altissimo l'adombrerà, ed ella ne avrà un figlio che regnerà sopra la casa di Giacobbe in eterno. La benedetta fra le donne si era turbata per le parole dell'Arcangelo; alla Vergine ne tornava arcano il senso. Ma il celeste messaggero, scrive l'evangelista Luca, le dissipò ogni dubbio, dicendole che nulla era impossibile a Dio; e Maria rispose: "Ecco l'ancella del Signore, facciasi di me secondo la tua parola”. La interpretazione dell' evangelo

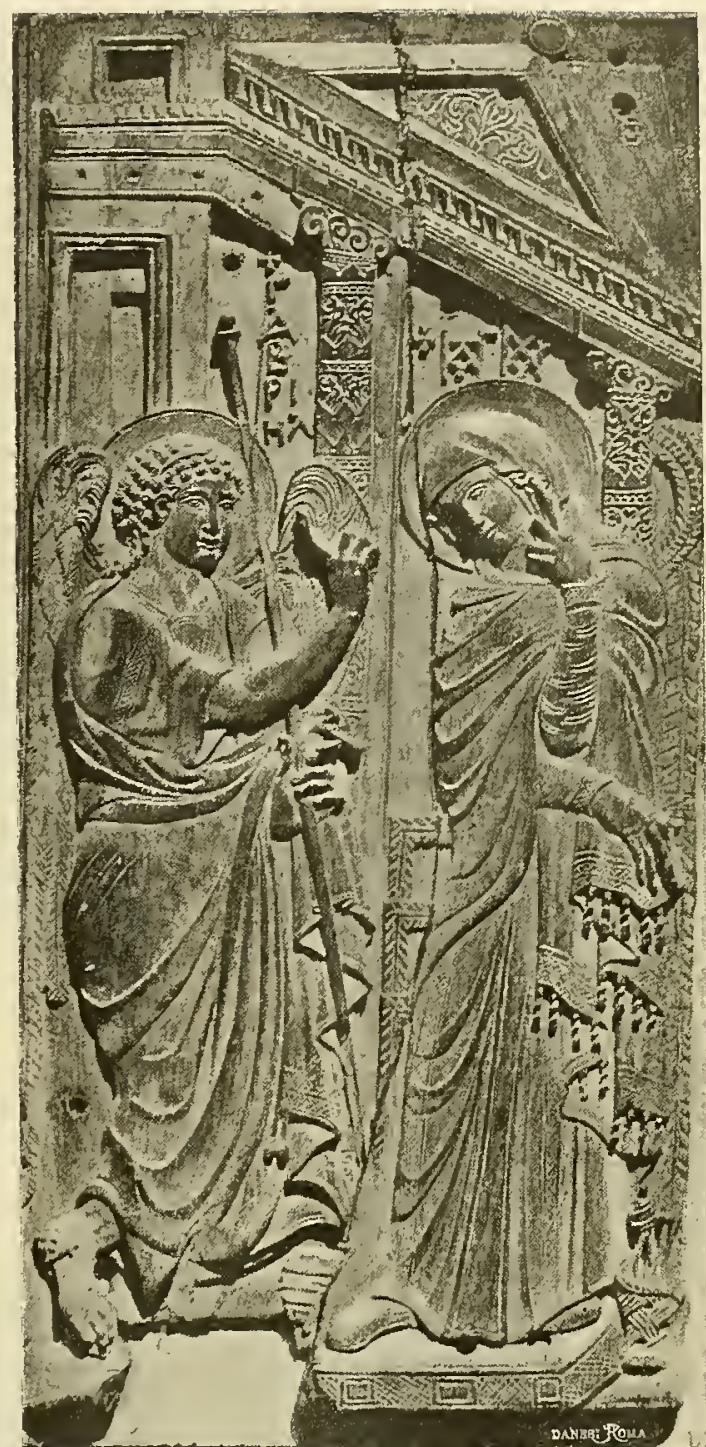

Avorio della collezione Trivulzio in Milano di San Luca nell'umile forma dell' "Annunciazione " del cimitero di Priscilla si conservò attraverso $\mathrm{i}$ secoli, benchè gli audaci gnostici ne turbassero la semplicità primitiva. I loro racconti cantati in Oriente, sotto $i$ palmizî, al popolo avido di udir meraviglie, conferirono una forma più animata ai sacri avvenimenti, prestando all'arte la traccia per uscire dagli angusti contorni degli evangeli sinottici. Così il protoevangelo di San Giacomo, della fine del IIr secolo, rappresenta Maria che attinge acqua, mentre una voce le dice: Salve, o Maria, piena di grazia, il Signore è teco, e tu sei benedetta fra tutte le donne. Maria allora guardò a destra e a sinistra, e non vide chi le 


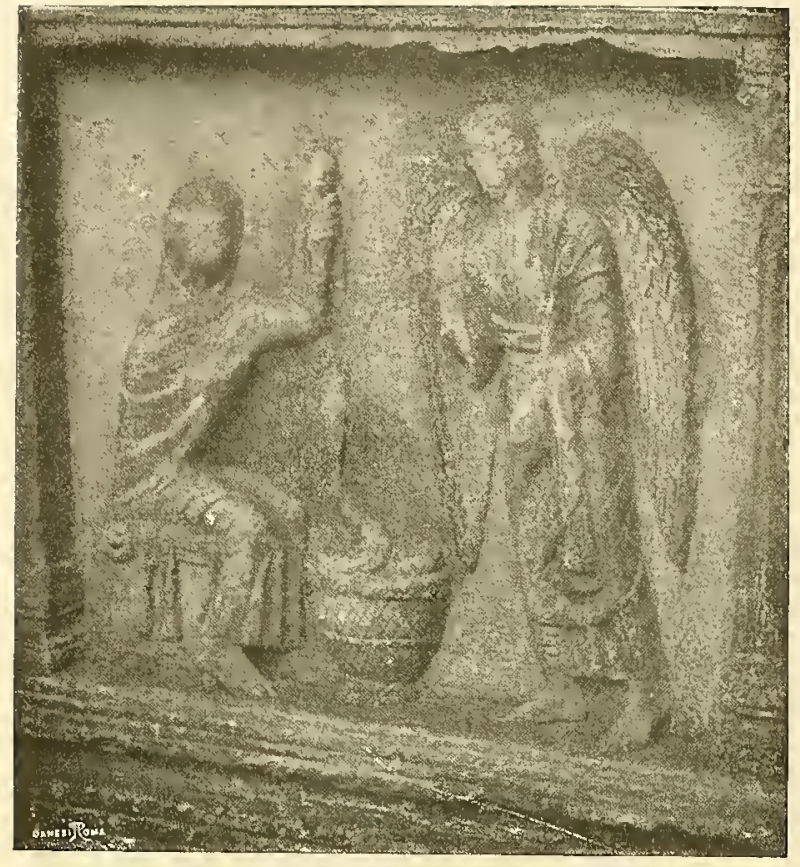

Sarcofago presso il monumento di Dante a Ravenna

parlava. Presa da spavento, entrò nella casa, depose l'idria, sedette e si mise a filare la porpora. Ed ecco che l'angelo riapparve e le disse: Non temere, Maria; tu hai trovato grazia appo Dio. E Maria pensava tra sè: Concepirò io e darò alla luce il Signore, come ogni altra madre? Non così, soggiunse l'angelo, chè la virtù dell'Eterno ti coprirà dell'ombra sua, e il Santo che nascerà da te sarà chiamato figlio di Dio. Una particolarità di questo racconto apocrifo rimase nell'arte del medio evo sino al secolo xuı, cioè la rappresentazione di Maria. in atto di filare la porpora per il velo del tempio. Evidentemente, come abbiamo già detto, nel racconto si rifletteva un'eco della vita antica. Intenta al lavoro fu rappresentata Maria nel v secolo, con accanto un paniere ripieno di fili di porpora, sull'arco trionfale di Santa Maria Maggiore, che Sisto III eresse in segno di vittoria sugli eretici Nestoriani. Nel musaico della basilica non appare l'ancella di Dio, ma la sovrana dei cittadini del cielo e degli angioli, sublime più di tutte le creature. La stefane, corona di gemme, le cinge la fronte; indossa una ricca veste a ricami, e si asside sur uno scanno munito di guanciali e predella ; le fanno corteggio tre angioli, ufficiali divini che circondano il trono della Divinità. La Vergine ha sospeso

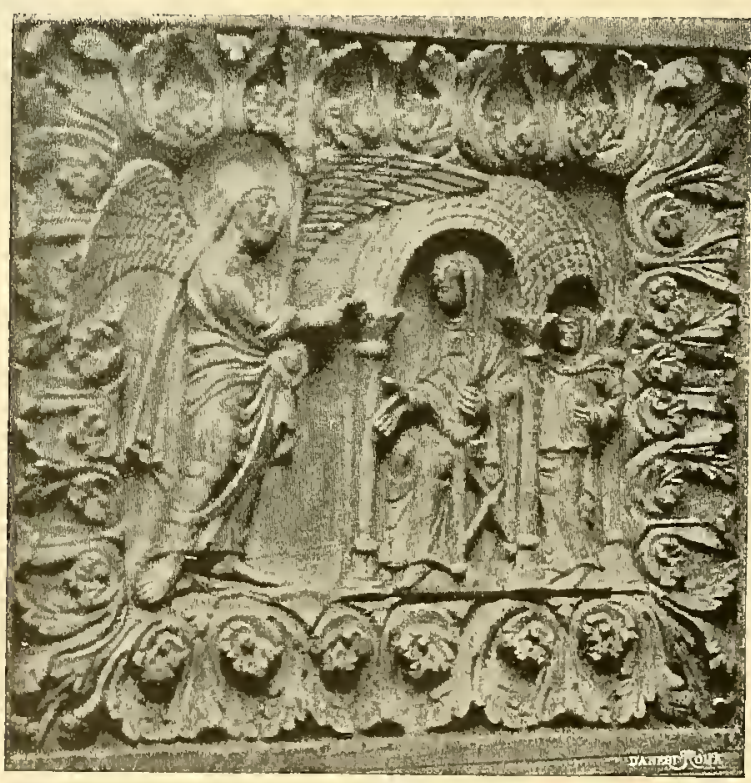

Cassettina del x secolo. Museo del Louvre 
di filare, mentre il nunzio sceso dall'alto, ove si rivede in atto di additare la colomba, simbolo dello Spirito Santo, la saluta con venerazione. Gli

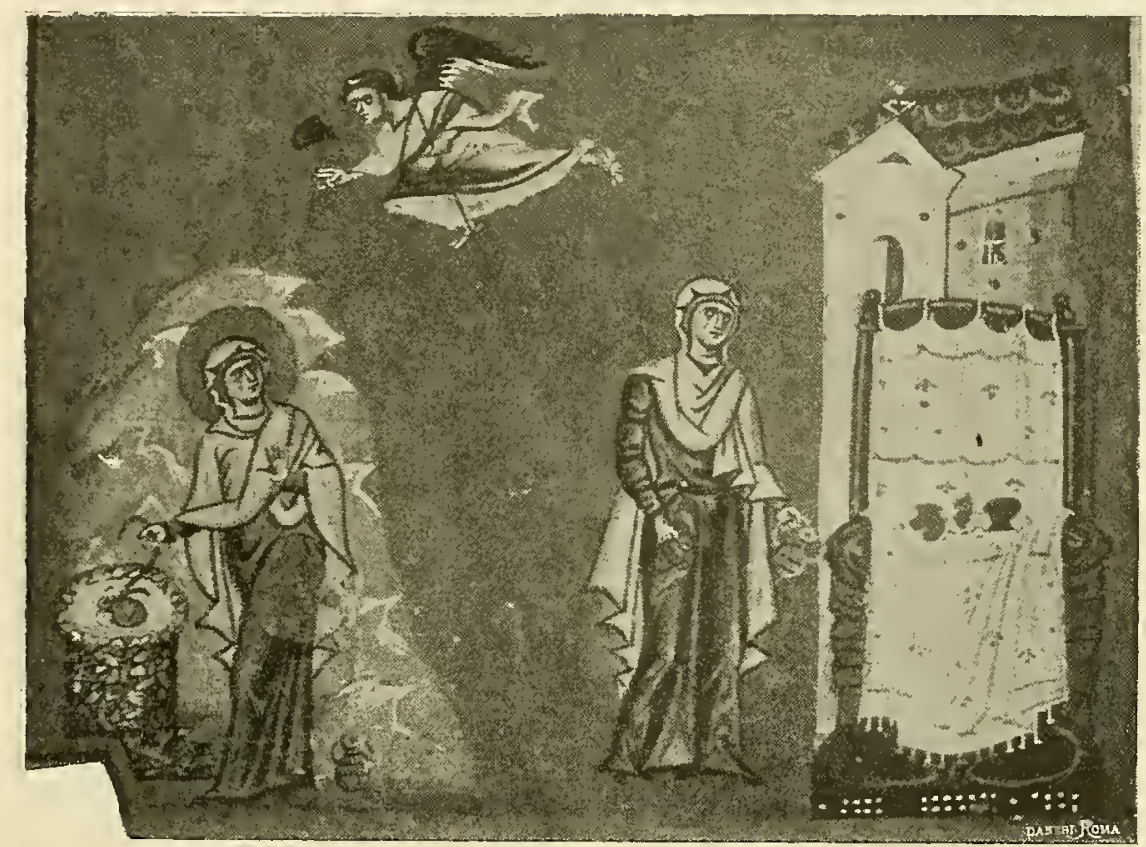

La Vergine alla Fonte. Biblioteca nazionale di Parigi

(Omelie del monaco Gracomo)

angioli, perduto ora l'aspetto di filosofi, sono i satelliti del Re del cielo, hanno le ali in segno della costante loro mobilità, e il nimbo, che già si era

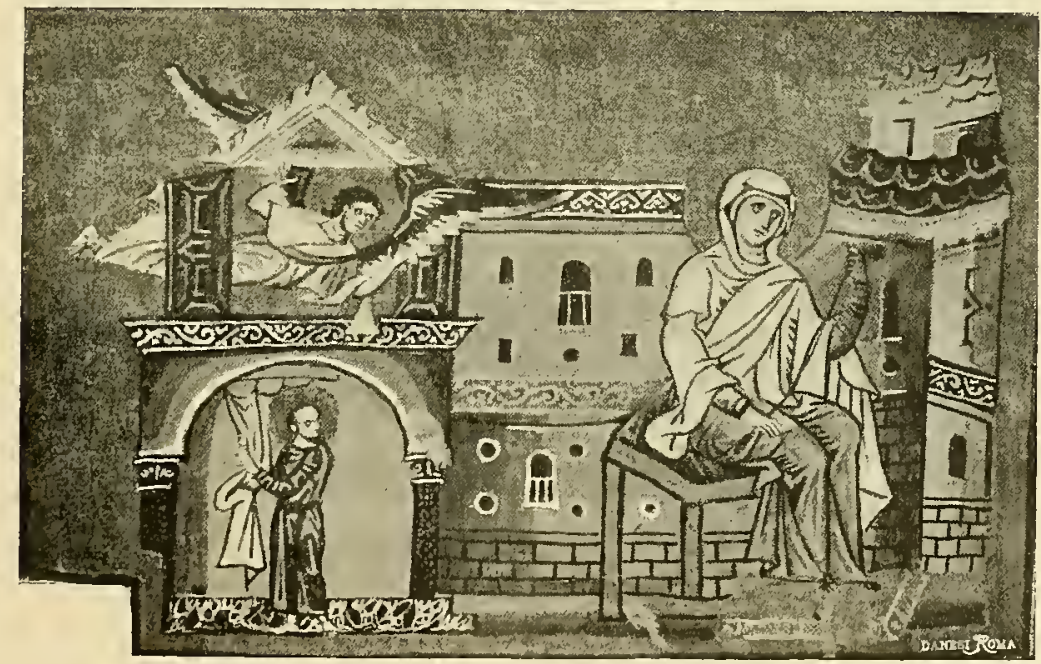

Arrivo dell'Angelo. Biblioteca nazionale di Parigi

(Omelie del monaco Giacono) 


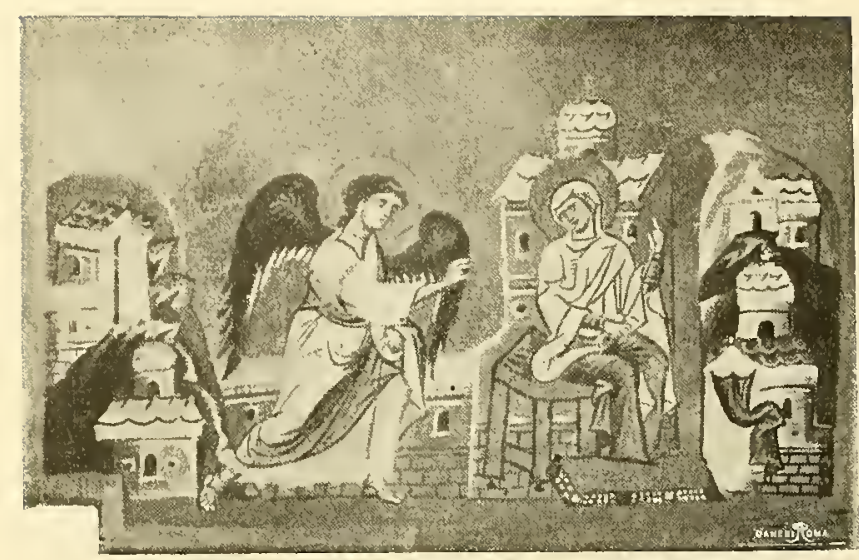

Annunciazione. Biblioteca nazionale di Parigi (Omelie del monaco Giacomo)

volto sul capo delle divinità cristiane, è come un cerchio, come l'iride, come la corona di luce apollinea che circonfuse, secondo le favole, la testa di Augusto allorchè entrò in Roma trionfatore. Un altro evangelo apocrifo, quello della natività della Vergine, rappresenta Gabriele che entrando empie di luce la stanza di Maria, e descrive questa come abituata ai volti degli angioli e al loro abbagliante splendore.

Così tra gli angioli luminosi appare la Penelope cristiana sull'arco trionfale della basilica romana, con gli ornamenti proprî di Giunone, in magnifica veste all'orientale. Le sue forme sono illuminate dalle ultime faville dell'arte

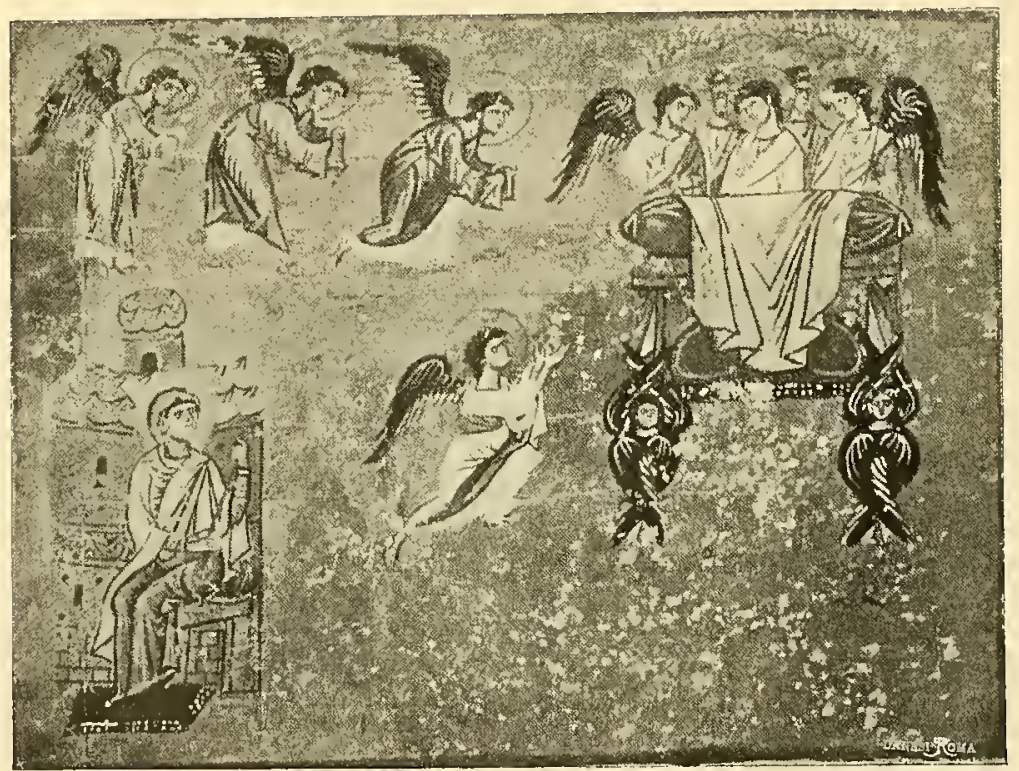

Ritorno dell'Arcangelo in cielo. Biblioteca nazionale di Parigi (Omelie del monaco Gracono)

crepitanti fuor delle ceneri, come sono anche quelle del bassorilievo d'un sarcofago presso la tomba di Dante a Ravenna, e di un avorio del secolo xl, 
certamente imitato da un originale antico, della collezione Trivulzio in Milano, pure rappresentanti l" "Annunciazione 》. Nel bassorilievo si palesa uno scultore che ancora sa cavar fuori dal marmo le figure umane, secondo le reminiscenze dell'antichità classica e secondo le tradizioni dell'arte cristiana. Maria, come una Penelope nei sarcofagi romani della Decadenza, è in atto di filare, col paniere di vimini accanto; e l'angelo alato, chino verso lei, le porge il saluto. Nessun moto però sembra animare le figure di Maria. Invece, nell'avorio della collezione Trivulzio, bellissimo anche per il disegnarsi delle forme sotto gli

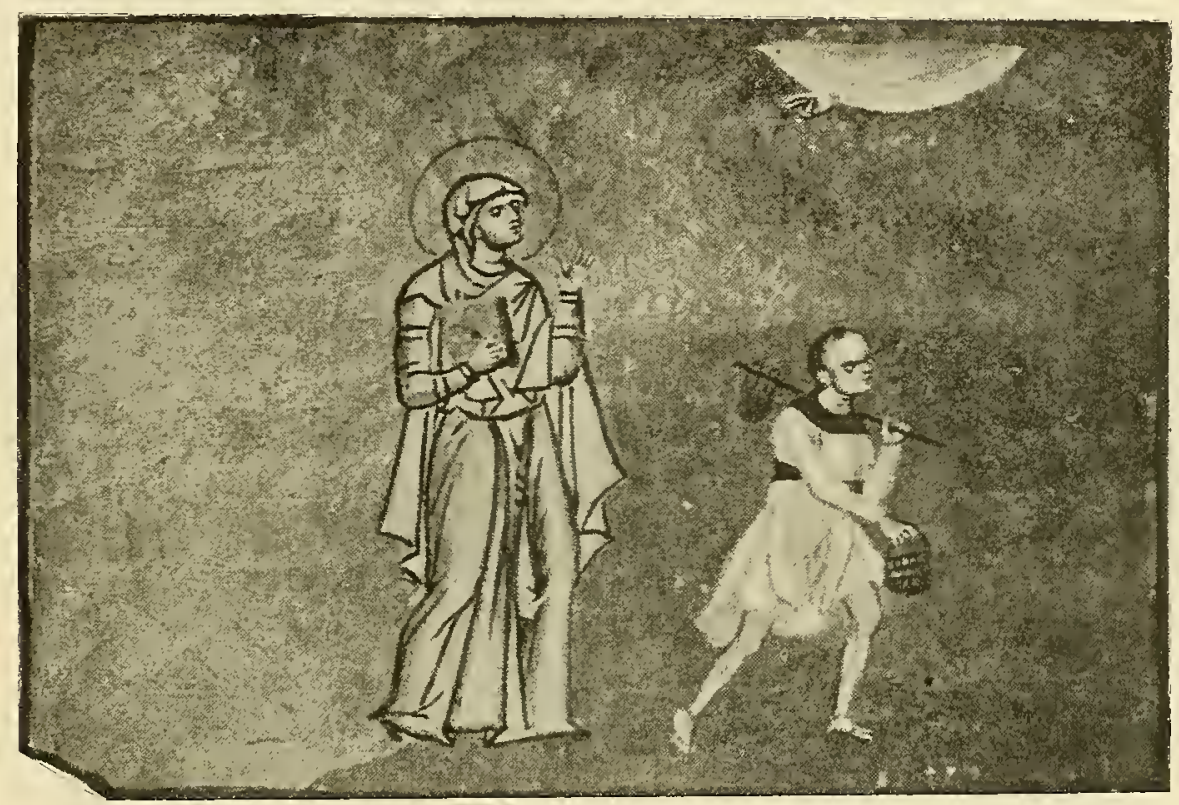

La Vergine porta la porpora al Tempio. Biblioteca nazionale di Parigi

(Omelie del monaco Giacono)

ampli drappeggiamenti, Maria sta con la testa china verso l'angelo, mentre volge il corpo a sinistra, per allontanarsi tremante dal nunzio divino. Ella si è alzata sulla predella dello scanno sostando di filare, come se le cose udite di subito l'abbiano commossa e turbata, e pudica si ritragga ravvolta nel manto. Il ministro celeste, forte e vigoroso giovane, è vestito di tunica e di un ampio pallio; con la sinistra tiene il bastone viatorio come un guerriero che stringa la lancia, e con la destra sollevata accenna all'alto; ha le ali e il nimbo, segno di gloria e d'impero. Il frammento d'avorio è di classica bellezza, a cui si è già innestata la dovizia orientale, nei fusti ornati delle colonne del fondo, nella veste della Vergine con orli ricamati e frange a spira. Ed è superiore di 
gran lunga, per lo studio dei grandi artisti dell'antica Grecia, agli avorî della cattedra di Massimiano a Ravenna del tempo di Giustiniano, ove le figure dell'Annunciazione sembrano tagliate dai solchi dei drappeggiamenti, e perdere la loro proporzione le forme che si disegnano angolose, sottili contro la massa largheggiante delle vesti. Gli occhi aperti e grandi disegnati nelle figure dell'avorio Trivulzio s'infossano nelle altre della cattedra episcopale, e nel cavo si rileva il bulbo; in quelle. un ovale delicato di volto, in queste, grossolani profili, sporgente il grosso mento sul largo collo cilindrico. Come forma, vediamo qui smarrirsi le leggi dell'arte classica, guastarsi il tipo eroico dell'angelo e il giunonico della Vergine; come espressione, l' Annun-
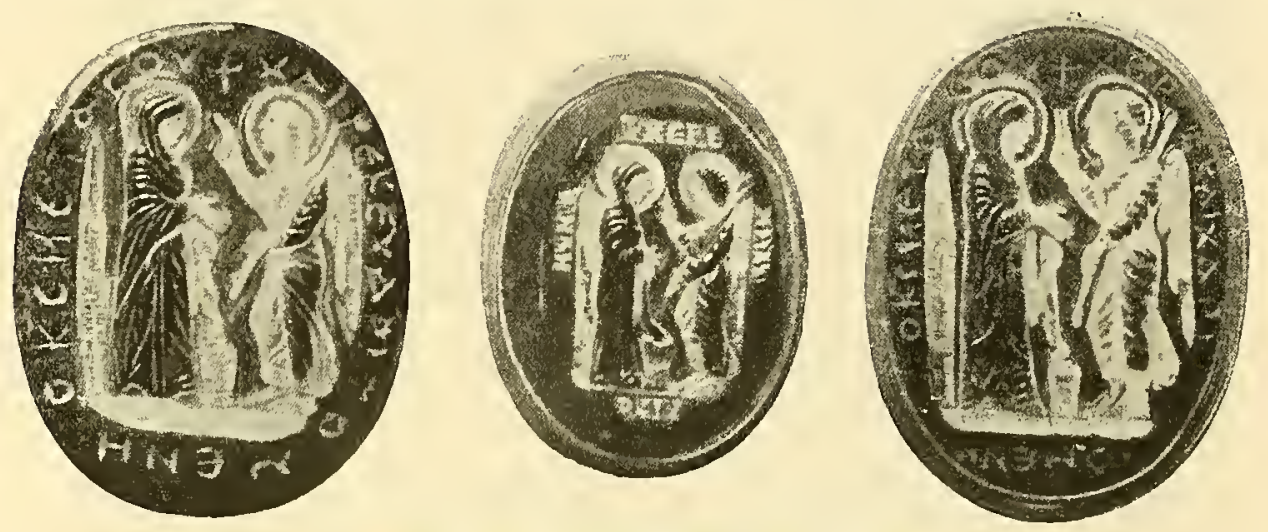

Gemme della Biblioteca nazionale di Parigi

ciazione" della Cattedra è ben lontana da quella della raccolta Trivulzio: l'Annunciata siede in cattedra, reca una mano al petto, con l'altra tiene il pennecchio e il fuso; l'angiolo benedice al modo greco. Abbiamo il segno del movimento, non la traduzione degli affetti. Ad ogni modo i due avorî rappresentano i tipi già determinati appieno dell" "Annunciazione •. Dacchè la Chiesa vittoriosa prese a raccontare fuori delle catacombe la sua storia, l'arte segnò i termini delle composizioni cristiane. La turbata Vergine dell'avorio Trivulzio la rivedremo in un simile atteggiamento scolpita da Donatello in Santa Croce; la sommessa Madre dell'Emanuele della cattedra di Massimiano la ritroveremo eternata dai pittori italiani del Risorgimento. L'arte bizantina conservò quei tipi come sacre reliquie, trasportandoli a traverso il medio evo come in una carovana a traverso il deserto. Soltanto le forme umane sembrano guastarsi sempre più, non bene difese dall'imperversare del tempo e della barbarie, ridursi in istato di mummie, pietrificarsi. Maria diviene un 
idolo inespressivo, lungo, rigido, di taglio secco e angoloso, con occhi spalancati, guance scarne, senza giovinezza. Eppure la scena non muta, tutti i

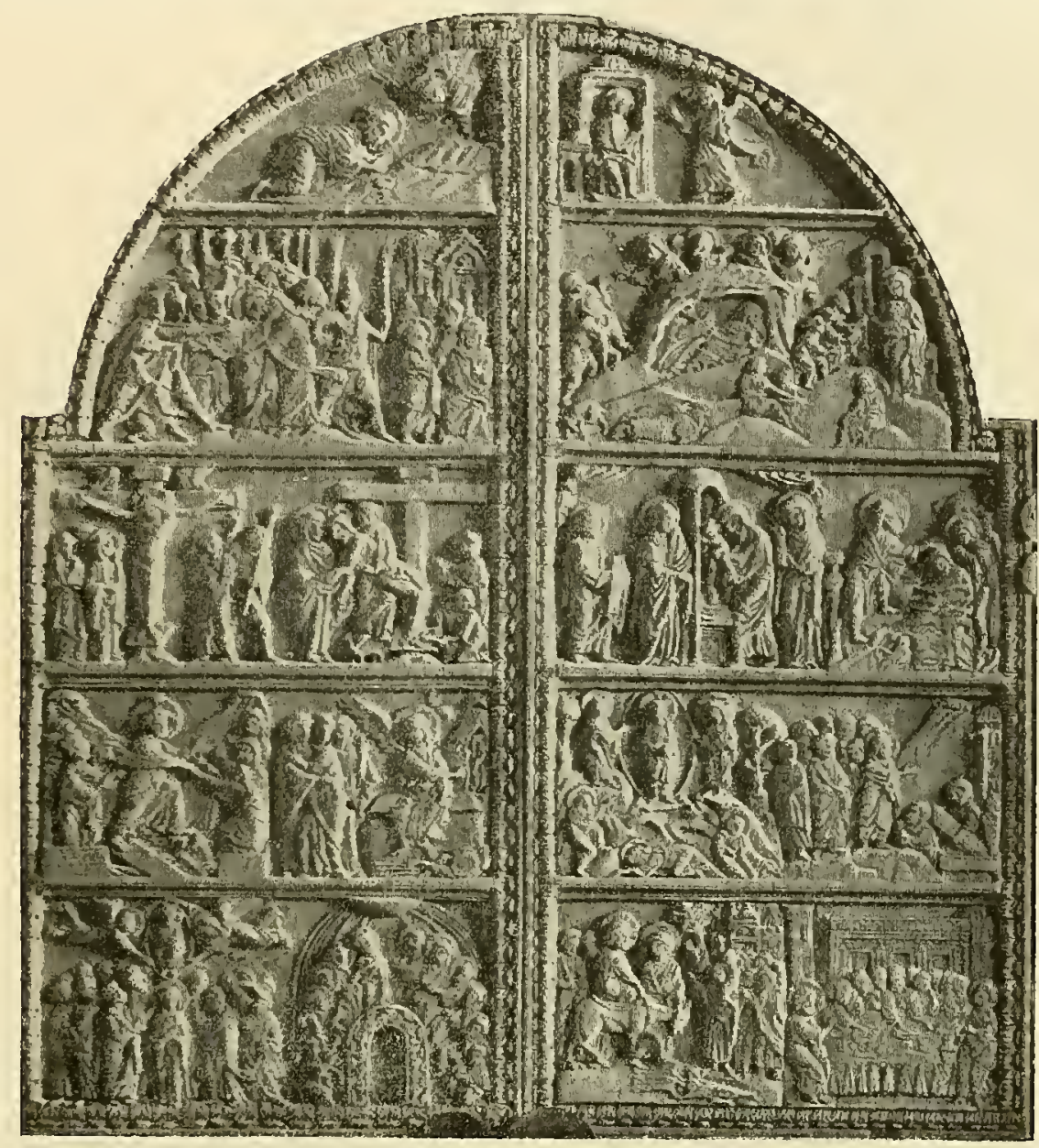

Avorio del Medagliere estense in Modena

menomi elementi si mantengono perennemente. Finanche l'apparizione di una fantesca o di una compagna di Maria, che tira la tenda della porta della casa per ascoltare il messaggero divino, la quale si vede in un avorio del vi secolo della Biblioteca Nazionale di Parigi, permane nell'arte, e si rivede origliare alla porta in opere del secolo xıv, a Siena e altrove. E l'angelo conserva la stefane ad ornamento della chioma, o una lingua di fuoco, ricordo delle fiamme che $\mathrm{i}$ pagani accendevano sulla fronte dei genî ; talora anche si drappeggia nel pallio e calza i coturni. Cosi nelle larve dell'arte. medioevale la forma antica si evolveva, per poter poi assumere ai primi tepori di civiltà nuovi, dolcissimi aspetti. 


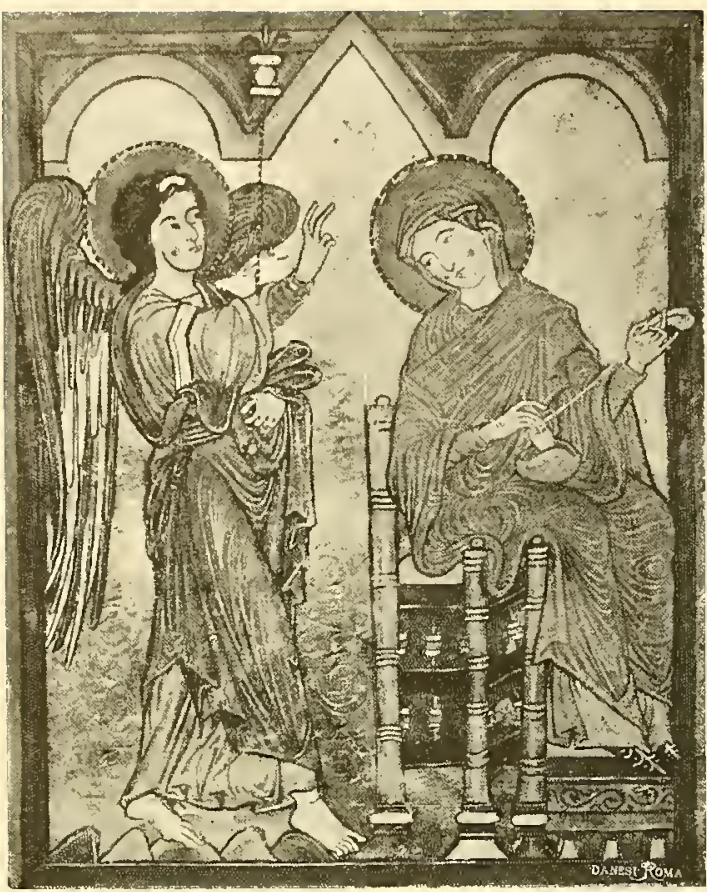

Dal Codice della Bibl. granducale in Carlsruhe

Fino al secolo ix l'arte ripete per forza d'inerzia le forme ereditate, dando loro un aspetto spettrale, come intraveduto sotto un incubo notturno. Anche nel Ix secolo in Roma, nell" Annunciazione del musaico dei Santi Nereo ed Achilleo, tutto è triste nella forma disseccata, rigida, meschina. Alla fine di quel secolo pare di riconoscere un leggero movimento nella forma della rappresentazione, uno sforzo d'inquadrar le figure organandole con l'architettura. Mentre nelle antiche opere l'avvenimento si svolge all'aperto e innanzi alla casa regale della Vergine, nel paliotto d'oro dell'altare di Sant'Ambrogio a Milano (a. 835 ) esso ha luogo sotto un portico; nel benedizionario di Sant Ethelwold (del 9\$4), conservato nella biblioteca del duca di Devonshire, l'Annunciata siede in un tempio rotondo; in un cofano d'avorio nel Museo del Louvre, opera del x secolo, Maria sta sotto un ciborio emisferico, come quello del trono degli

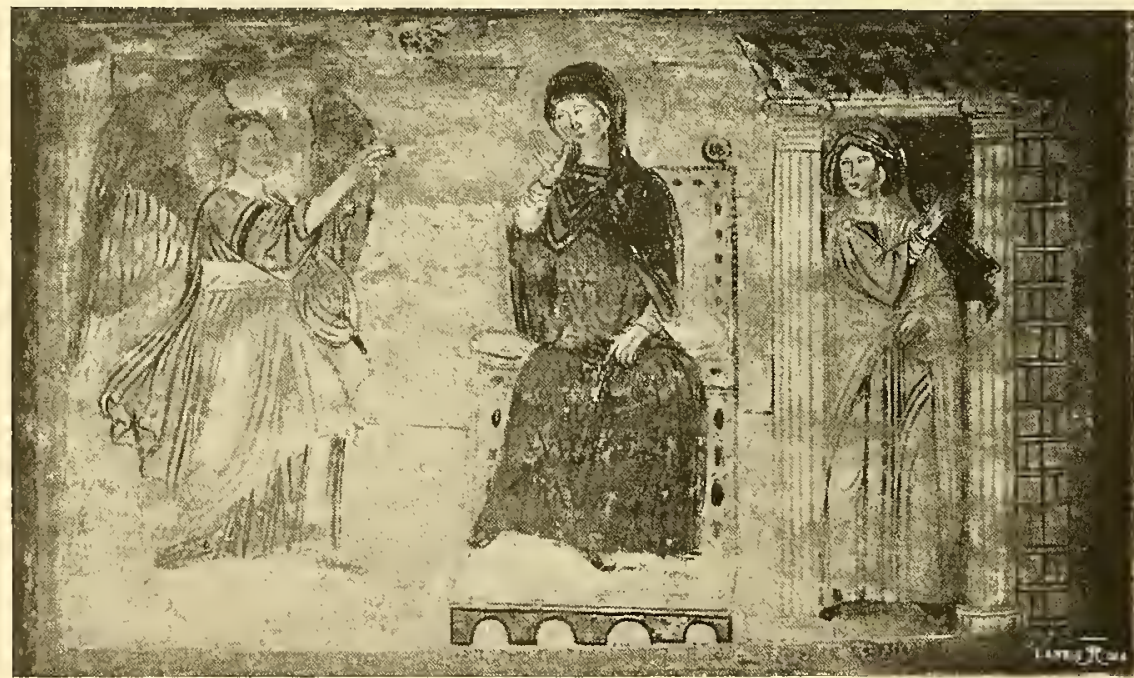

Affresco della chiesa di Sant' Urbano alla Caffarella 
imperatori bizantini. In Oriente intanto l'arte rifioriva, faceva tesoro delle poetiche leggende amate dal popolo, e rifletteva ancora una volta il raggio, benchè illanguidito, della greca bellezza. Lo vediamo nelle Omelie del monaco Giacomo della Biblioteca Vaticana, manoscritto greco che ride di miniature, consacrato alla gloria della Vergine. In esso si tentò di rendere coi colori i diversi momenti delle leggende antiche e dei testi apo-

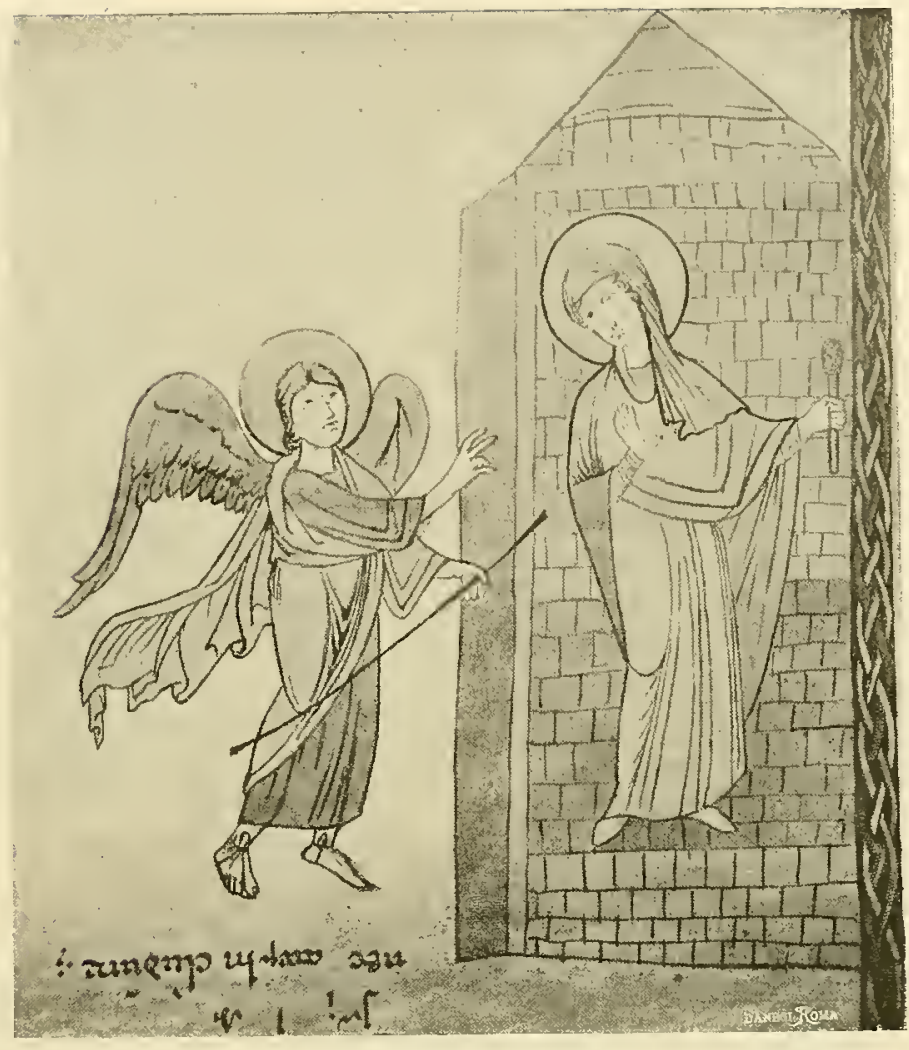

«Exultet» di Capua crifi. La Vergine attinge acqua, e volge il capo all'udire la voce dell'angiolo

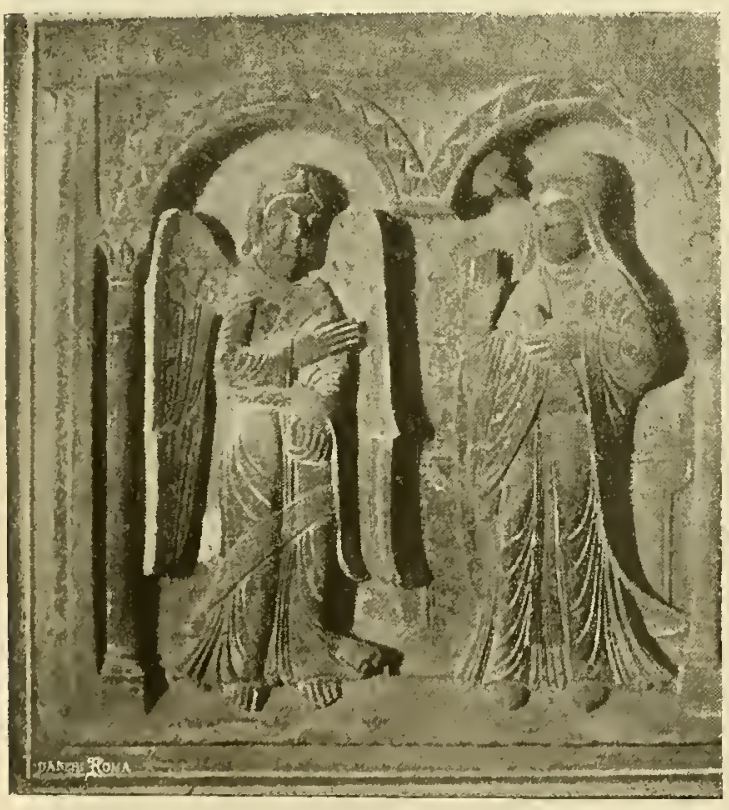

Arte romanica, sec. xir. Palazzo arcivesc. di Fano che dal cielo le parla; poi ella rientra in casa, e va per assidersi sur una sedia coperta di bianco con ornati azzurri e rossi; in seguito fila la porpora, mentre l'angelo piega un ginocchio innanzi a lei; indi la stessa rappresentazione con l'angelo che, secondo il testo, dovrebbe rivelare alla Vergine le profezie, ed altre simili, raffiguranti l' imbarazzo della Vergine, la soluzione de' suoi dubbi e la sua sommessione al volere divino. Il miniatore però, trovandosi impreparato all'analisi del 


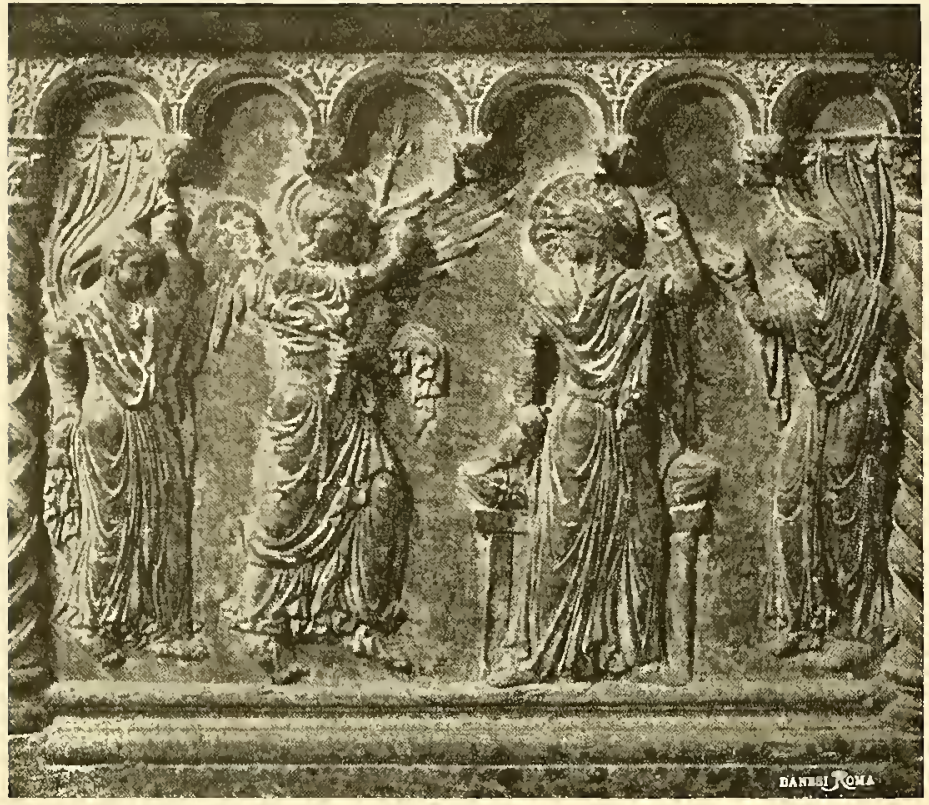

Fonte battesimale. San Giovanni in Fonte a Verona soggetto, cadde a stereotiparne le forme. Anche per indicare diversi momenti della scena ripete le immagini o con leggère varianti, la stessa figura di Vergine, lo stesso angelo benedicente al modo greco. Non potendo o non sapendo uscire dai limiti prescritti, egli insiste, reitera uniformemente la sua composizione, senza cercare corrispondenze con le leggende raccontate nel testo.

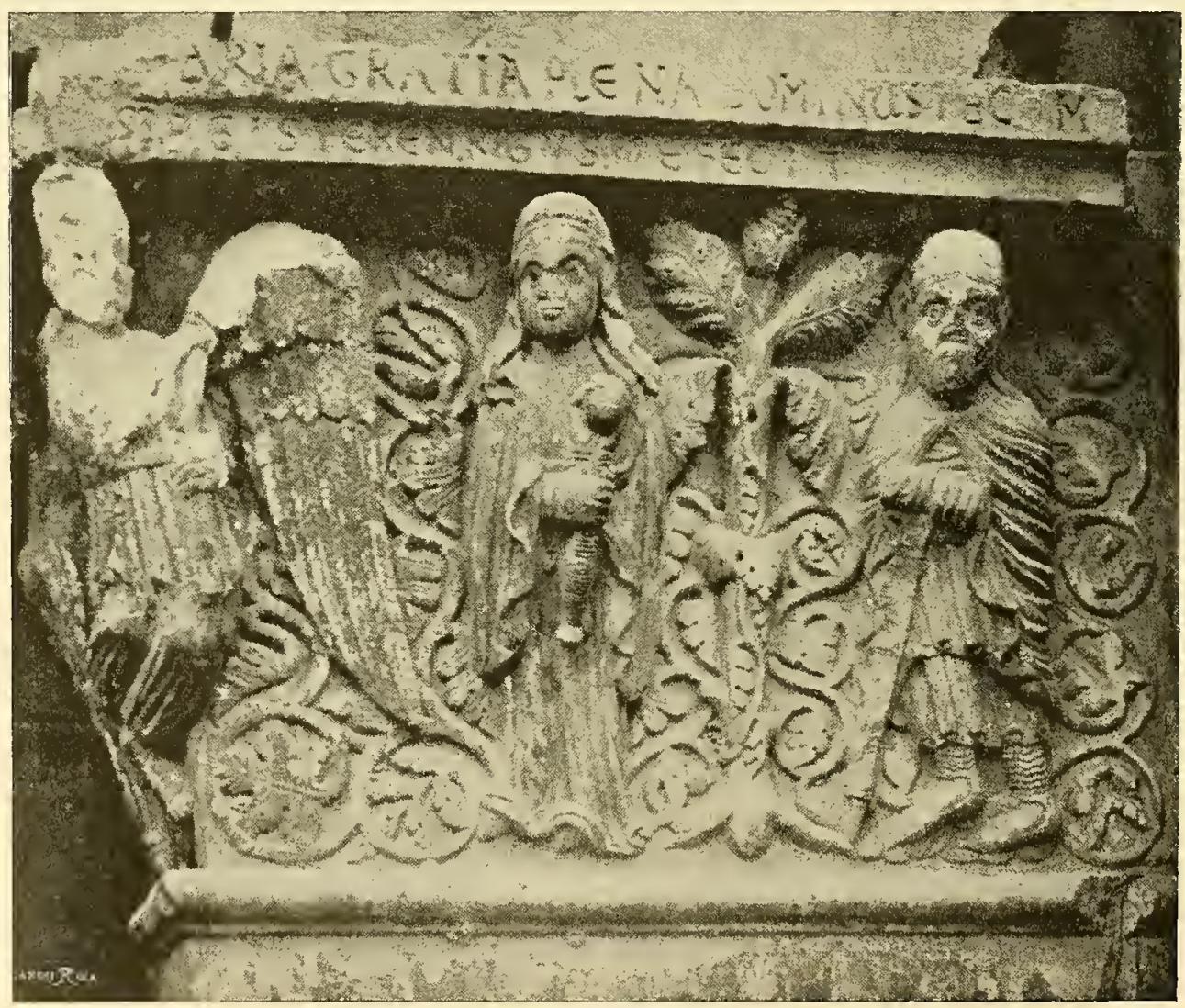

Capitello della porte di Sant'Andrea a Pistoia

(Magister Enricus) 
Ma l'angelo di tipo eroico, quale fu raffigurato al tempo di Giustiniano, e in generale la classica nobiltà, il variare dei tipi, l'animazione dei movimenti, la delicata esecuzione dimostrano che, nella seconda età d'oro, l'arte bizantina era risalita ad insperate altezze. Il tentativo di scomporre in parti la composizione non ebbe sèguito; ma gli artisti, tra $\mathrm{i}$ diversi momenti dell" Annunciazione ", quali risultano dall'evangelo di San Luca, preferirono or questo, or quello. Chi volle rappresentare la Vergine nel primo turbarsi all'arrivo e alla voce dell' angelo, chi esprimerne il dubbio

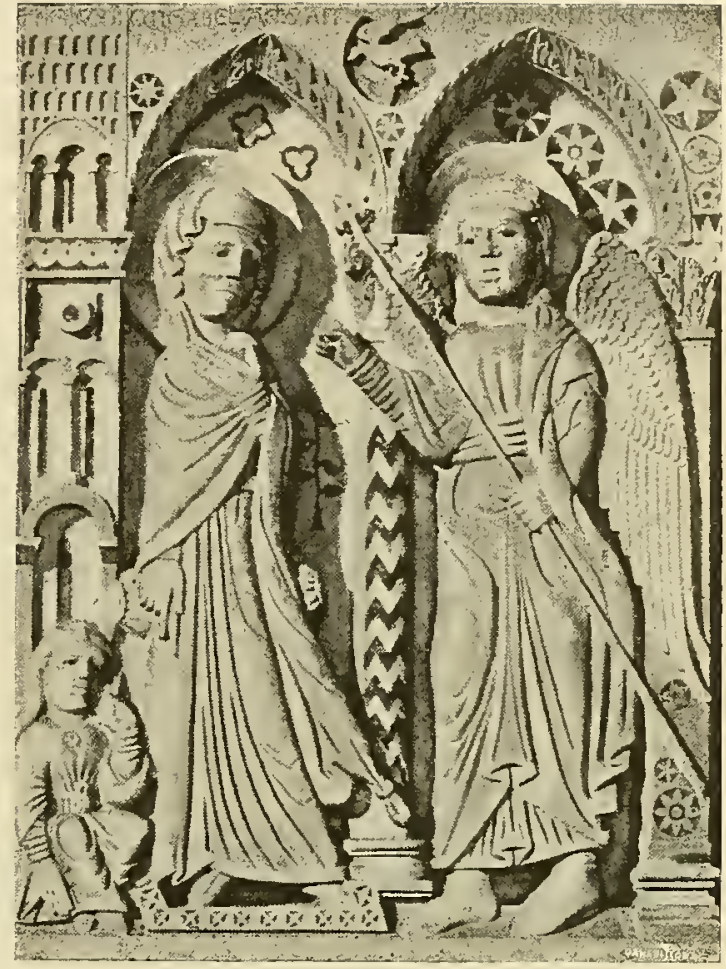

Pulpito di Barga, sec. XIII che le agitò il cuore, chi l'atto di rassegnazione al divino volere. Gli artisti medioevali tuttavia resero in modo incerto l'espressione che doveva animare la figura di Maria; e in generale si attennero al terzo momento dell'episodio, meno drammatico e meno arduo a rendere con la materia ancora indocile. Anche i Bizantini, secondo i canoni determinati nella guida greca della pittura pubblicata dal Didron, dovevano studiarsi di rappresentare la fine

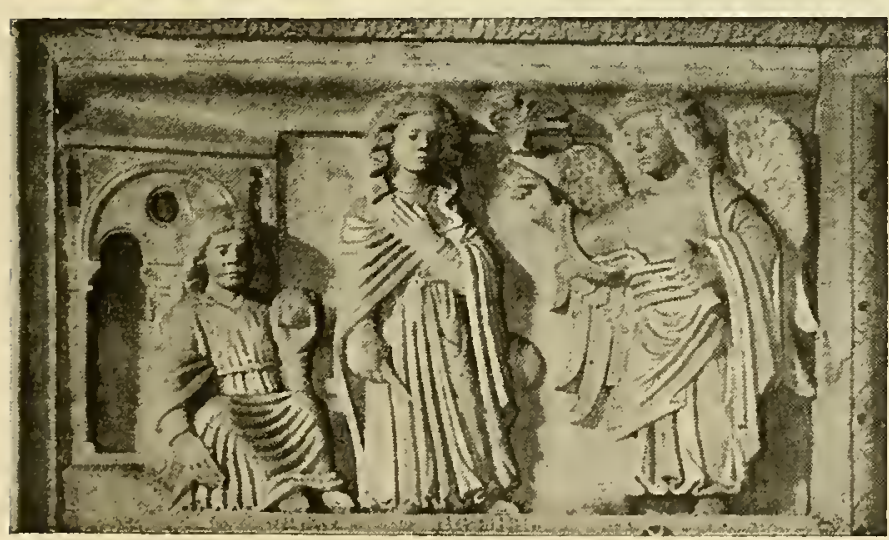

Dal pulpito di San Bartolomeo in Pantano (GUIDO DA CoMo) del racconto evangelico. Fa eccezione però lo scultore grecizzante del fonte battesimale di San Giovanni in Fonte a Verona (sec. xir), che in modo drammatico esprime il turbamento della Vergine. L'angiolo si avanza verso di lei, che, sorta in piedi, stringe 
con la destra il fuso e solleva il braccio sinistro come in atto di difesa, volgendo il piede sinistro dalla parte opposta all'angiolo, così che sembra allontanarsene. L'animatissima scena è rappresentata sotto gli archetti giranti sotto i labbri della fonte, tra le cortine tirate da due donne, che si appoggiano alle ritorte colonne, limiti della faccia del fonte stesso. Quando

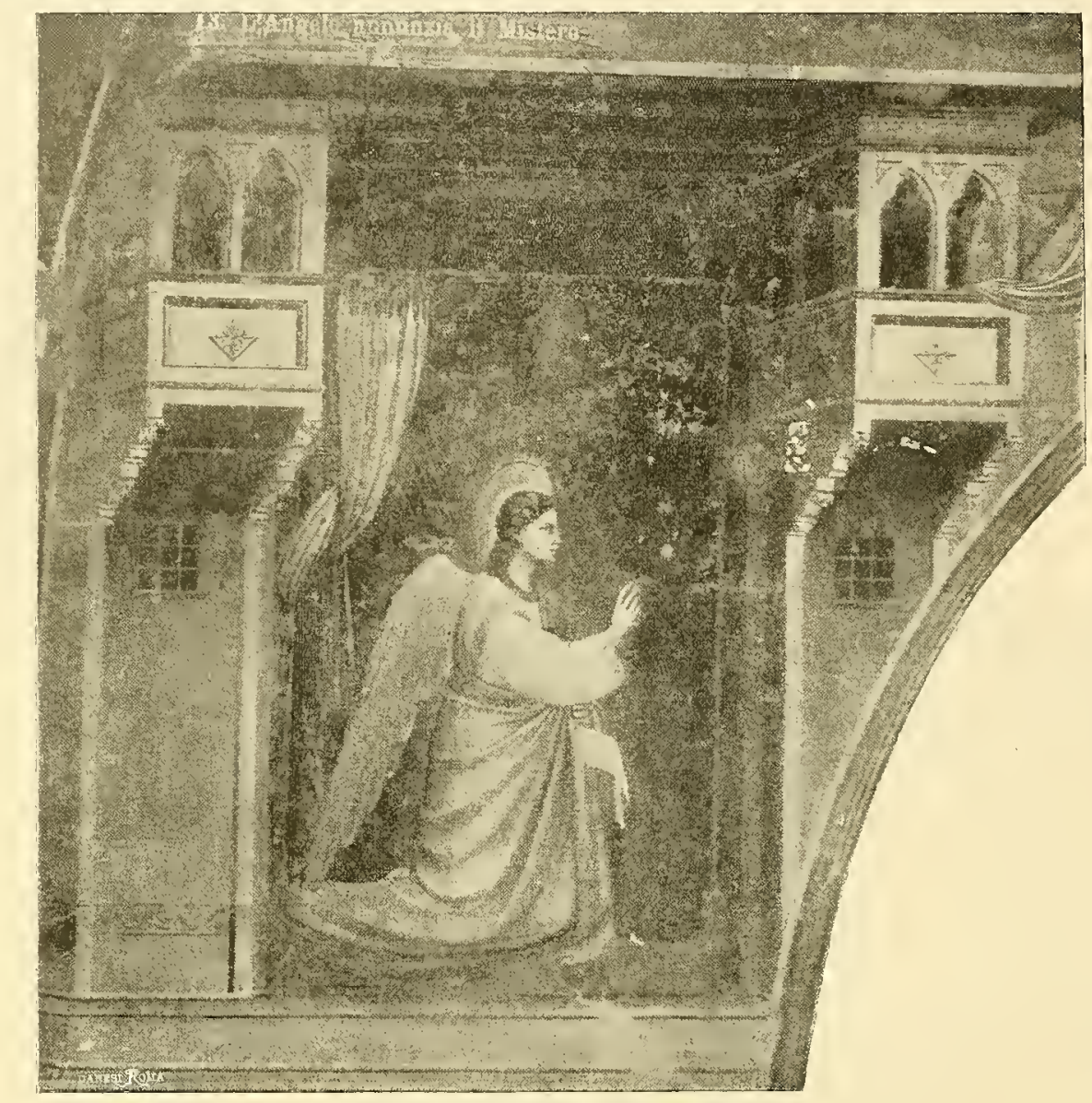

Oratorio dell'Arena in Padova

(GIOTTO)

l'arte bizantina in fiore rappresentava così l' evangelico racconto, l'arte romanica, nella chiesa di Sant'Andrea a Pistoia, tra i meandri d'un capitello della porta, dava forme selvagge alle figure; e a Fano, in un bassorilievo della cattedrale, ora all'arcivescovado, le scolpiva rozzamente fasciate dalle vesti. Ancora rudi, tagliate come a colpi d'accetta, si vedono nel pulpito di Barga presso Lucca, del xir secolo: l'Arcangelo con lungo scettro e con l'Annunciata, a' piedi l'ancella curiosa. Invece nel pulpito di Guido da Como a 
San Bartolomeo in Pantano, pure del xin secolo, la Vergine prende forme modeste e gentili; e l'angiolo, modesto anche lui, porta nella sinistra un rotolo: antico simbolo che riappare nel monumento, in cui sembra dolce risuonare la nuova favella italiana.

L'arte nostra rifiorita sulla soglia del secolo xiv si provò a indicare il

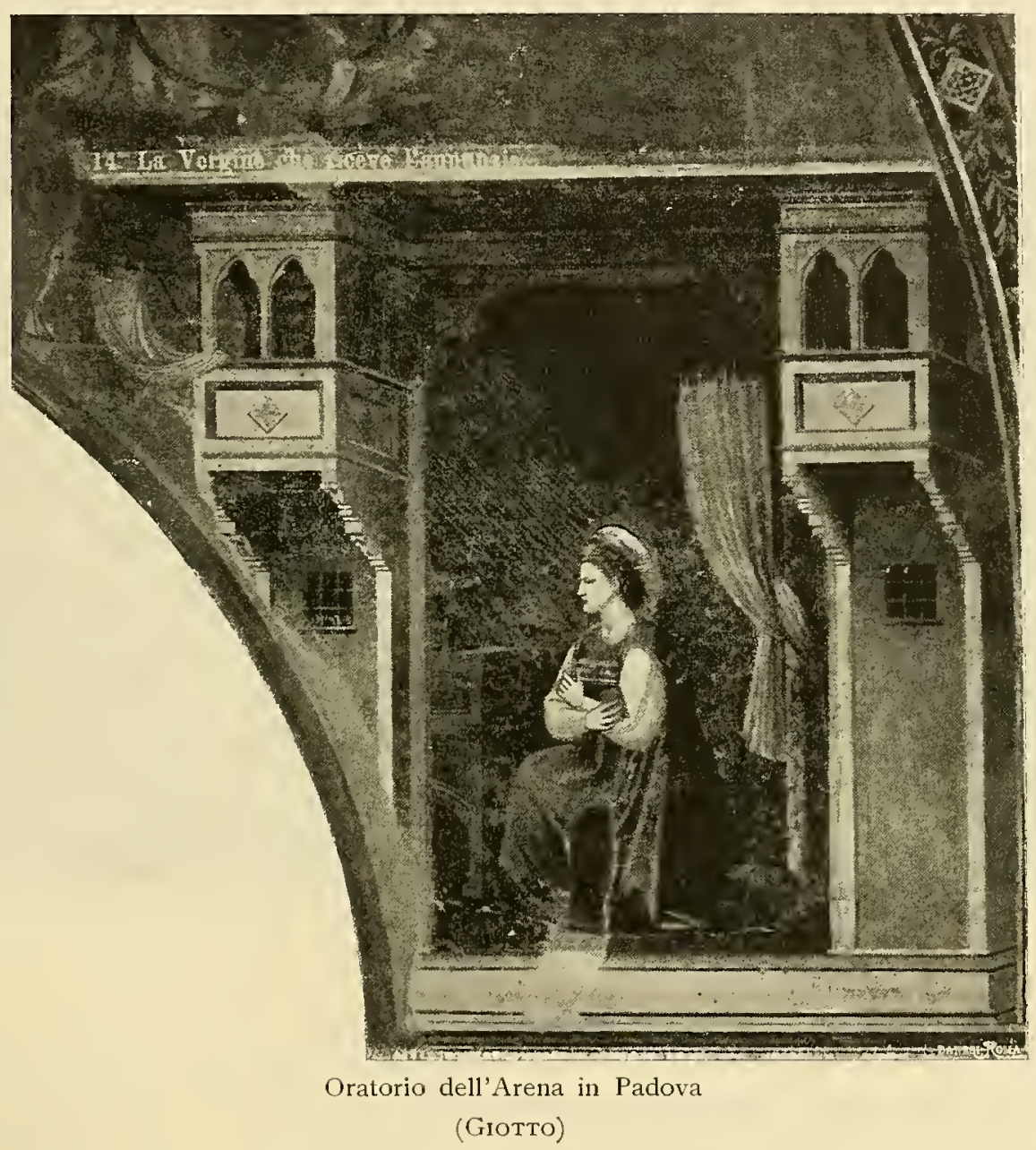

sacro mistero senza forme simboliche, senza i particolari desunti dal protoevangelo di San Giacomo, e quasi s'accorgesse di non rendere ad evidenza l'espressione delle figure, vi stampò le parole dell'angiolo alla Vergine e la risposta di lei, si come Dante descrisse l'angiolo venuto in terra col decreto di pace intagliato sulla ripa del primo cerchio del Purgatorio, dolce nell'atto, come dicesse Ave, e Maria col motto impresso: Ecce. Ancilla Dei. L'Alighieri a quelle figure d'intaglio spira la favella: l'angiolo non 
gli sembra immagine che tace, e la Vergine reca l'impronta della sommessa risposta:

$$
\text { S come figura in cera si suggella. }
$$

E Lippo Memmi nell" Annunciazione» della Galleria degli Uffizi, e Taddeo Bartoli a Siena nell'Accademia di belle arti, quasi la materia fosse sorda, fecero che dalle labbra dell'angiolo si dipartissero in un soffio verso

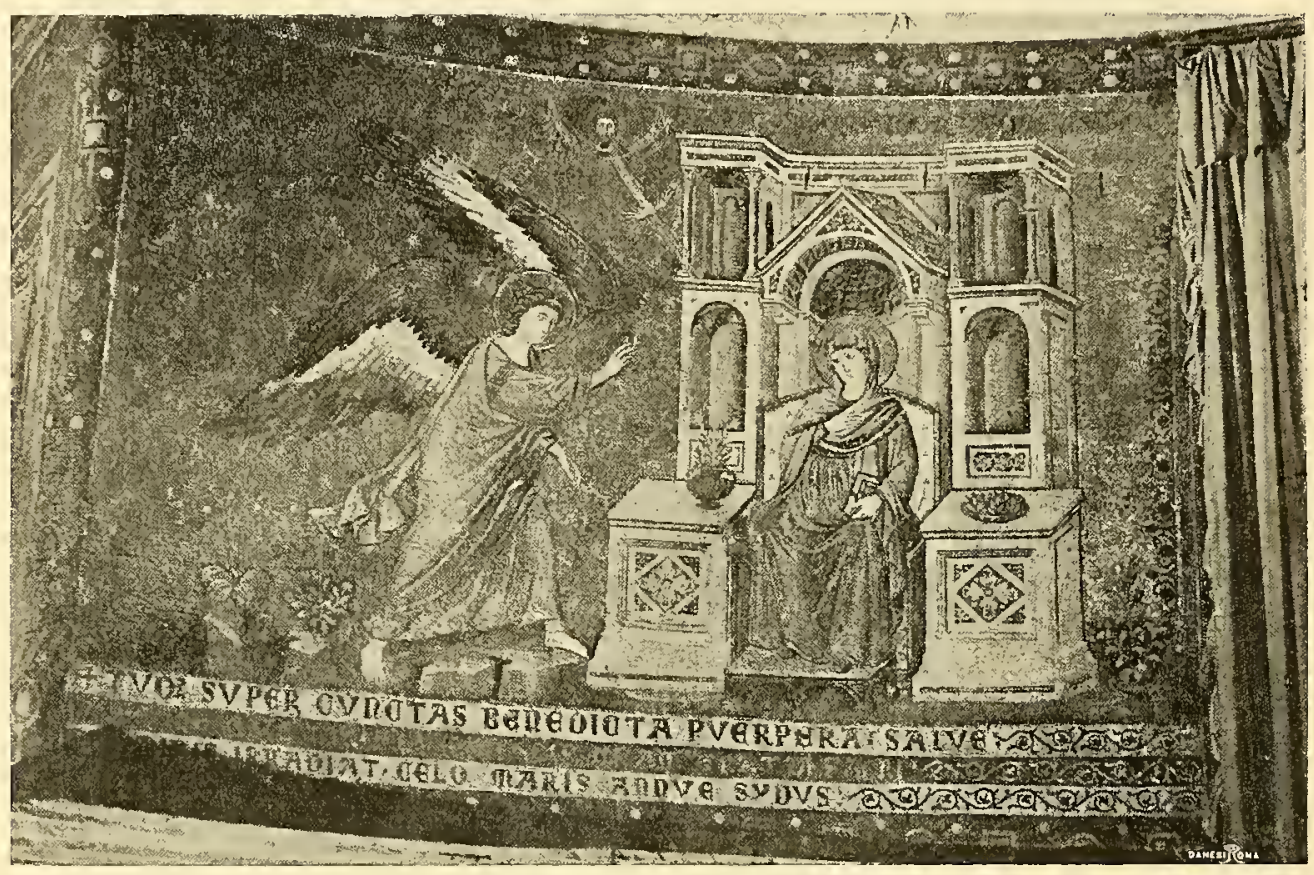

Musaico. Santa Maria in Trastevere a Roma

l'orecchio destro della Vergine le parole della salutazione; l'Orcagna incise nel libro aperto sulle ginocchia di Maria l'unile risposta: Andrea Pisano, in Santa Croce, spiegò nelle mani dell'angiolo il rotolo con le parole del divino decreto, e nella sinistra di Maria un libro con la risposta; Agnolo Gaddi allineò innanzi a Gabriele benedicente le lettere dell' iscrizione dell'annuncio, mentre la Vergine risponde con una mano sul petto e con la scritta del libro aperto nell'altra; Giovanni Balducci diede all'angiolo il cartello col saluto in parole gotiche, e nel libro sul leggì presso la Vergine scrisse: Ecce Ancilla Donimi, ecc.; infine il pittore dell" "Annunciazione " in Sant'Alessandro di Brescia, innanzi alle semiaperte labbra dell'angiolo segnò inversamente le 
parole dette da lui, cosi che tue è la più lontana, secondo la successione dei suoni.

Dante, in altri luoghi del divino poema, accenna all'Annunciazione e ne completa l'immagine, sì quando ode nel paradiso, nella luce del minor cerchio, una voce modesta forse qual fu dall'angelo a Maria;

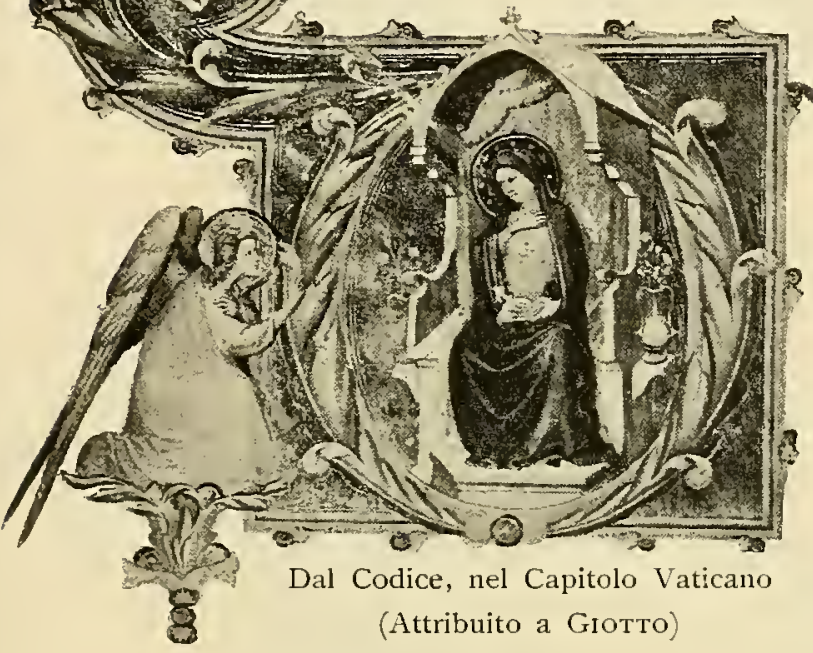

briele nell'empireo, che,

sì quando, nel giardino del Paradiso, vide la rosa in che il Verbo divino si fece carne, memore forse del poeta latino del secolo xir, che cantava: "L'aurea rosa, caduta dal prato del Paradiso nel grembo della Vergine, vi si posò: nel decoro virginale e nel chiostro del pudore la stanza della Vergine accoglie l'angelica rosa . Ancora Dante fa cantare l'Ave Maria a Piccarda Donati e all' angiolo Gadinanzi a Lei le sue ali distese.

Tutta la corte beata risponde alla divina cantilena; e Dante domanda a San Bernardo qual sia quell'angiolo che guardava negli occhi la Regina del cielo, innamorato così da parere di fuoco. E Bernardo a Dante:

..... Baldezza e leggiadria

quanta esser può in angelo ed in alma,

tutta è in lui, e sì volem che sia,

perchè egli è quegli che portò la palma giù a Maria quando il figliuol di Dio carcar si volle della nostra salma.

Invece del bastone viatorio e dello scettro regale dei Bizantini, Dante dà all'arcangelo la palma, segno della vittoria sulla morte e della vita immortale. E la palma si ritrova in qualche rappresentazione, ad esempio in quella di San Domenico di Arezzo, alla cappella Dragomanni, o nell'altra della chiesa di Sant'Alessandro in Brescia. Lippo Memmi e Taddeo Bartoli 


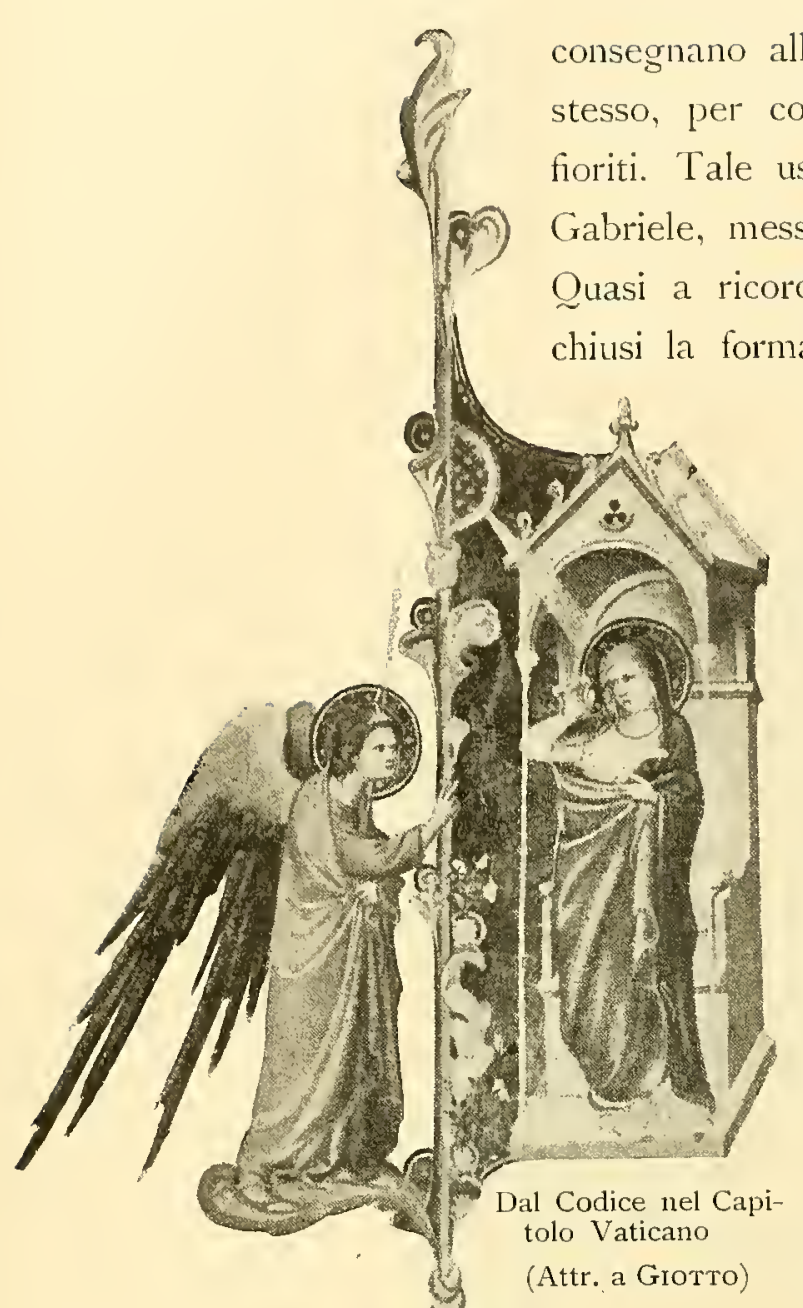

consegnano all'angelo un ramo d'olivo: ma ben presto nel Trecento stesso, per convenzione generale, gli è offerto uno stelo di gigli Tale uso derivò, a nostro parere, dallo scettro gigliato, che Gabriele, messaggero di Dio, teneva in segno di potenza imperiale. Quasi a ricordarne l'origine, l'Orcagna diede allo stelo coi gigli forma prossima a quella dello scettro regale; ma ecco che i gigli aprono le corolle, e gli arcangeli protendono il candido fiore innanzi alla Vergine salutata da Davide e dai Padri "giglio delle valli ». La poesia dell'arte cristiana balza dalle materialità medioevali, e prodiga fiori alla vaga immagine di Maria. Accanto a lei, quasi a dar forma rappresentativa alle laudi de' poeti che s'inchinano deponendole ai piedi i fiori della primavera e la paragonano agli aromi e alle piante odorose, l'arte colloca con le mani dei maestri del Trecento vasi di gigli e le piante più belle dei campi; e più tardi, nel Quattrocento, stende talora un prato di fiori innanzi alla Vergine, che $\mathrm{i}$ poeti dicevano giardino e prato di delizie.

La figura di Maria stessa, trasformata a quell'ardore del Trecento, in vece del filo di porpora, del fuso e anche dell'idria, prende un libro, e siede presso un inginocchiatoio divotamente. Questo motivo artistico derivava pure dai lontani apocriff, dal racconto della vita di Maria nel tempio, ov'ella si dedicava all'orazione dal mattino sino all'ora terza, al lavoro manuale dalla terza alla nona, e dopo la nona continuava le preghiere, meditava la legge di Dio, intonava le cantiche di Davide. All'arrivo di Gabriele, in abito sacerdotale, che piegato un ginocchio a terra le porge il saluto, ella abbandona il libro sulle ginocchia tenendolo socchiuso nella sinistra, o con le mani conserte, o con la destra sul petto esprime la sua sommessione ai voleri di Dio. E Dio Padre appare nell'alto benedicente in un'aureola attorniata da angioli: dalla sua bocca si diparte un raggio di luce d'oro, su cui si libra la colomba dello Spirito Santo, e va diritta all'orecchio destro della Vergine. Già Tertulliano aveva detto che il Verbo uscì da Dio come un raggio di sole; gli innologi cristiani chiamarono Maria porta fulgida della luce, 
cantarono la sua concezione per virtù dell'ombra di Dio, di un soffio; e Peire de Corbiac, ispirandosi agl'inni latini, nella sua canzone alla Donna regina

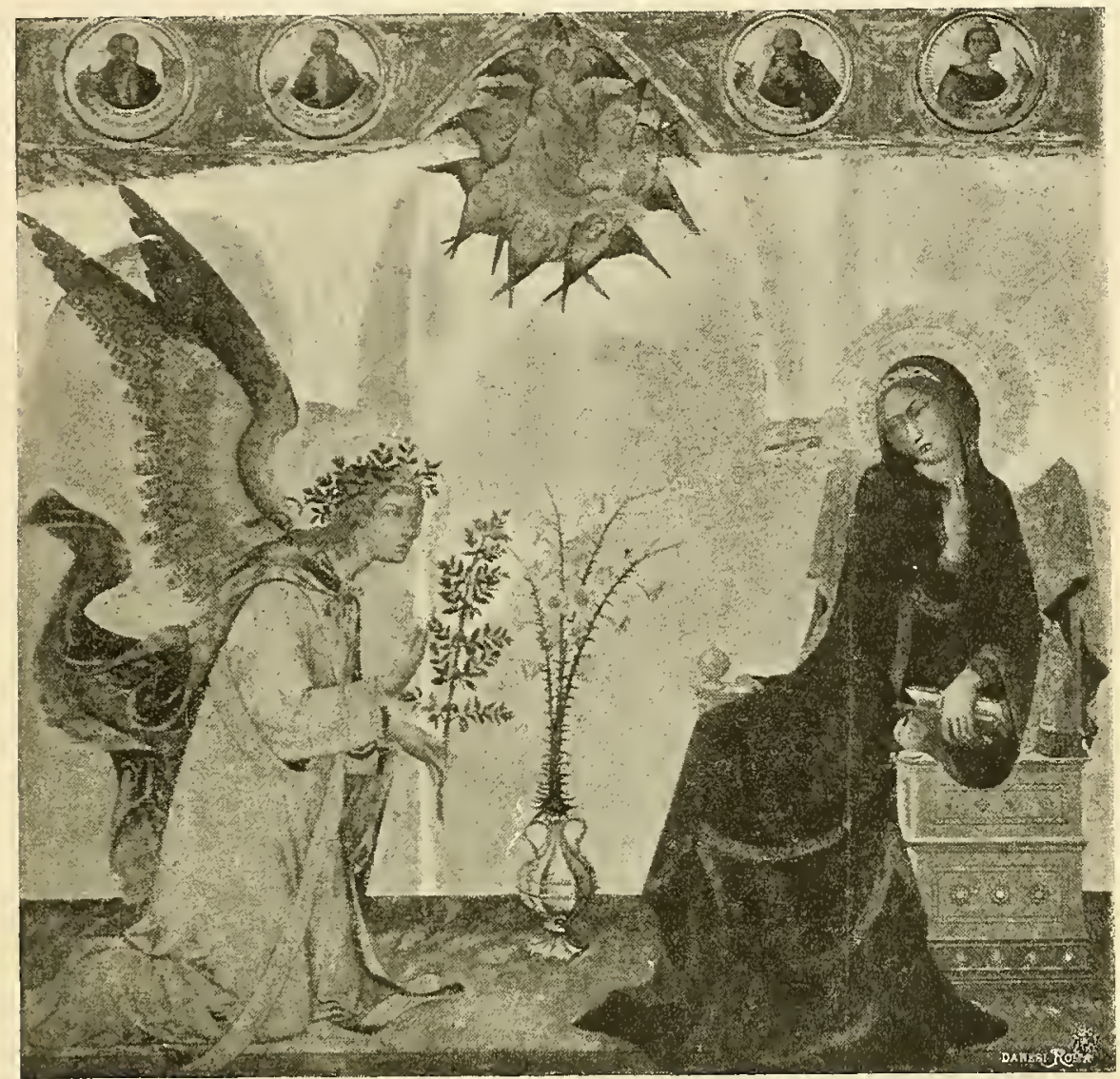

Galleria degli Uffizi in Firenze

(Simone di Martino)

degli angeli dice come "intra bels rais quan solelha per la fenestra veirina " (entra il bel raggio quando splende il sole per la finestra a vetri). Gli artisti del Trecento, per dar ragione del mistero e spiegarne lo sviluppo, raffigurarono all' incirca il Padre Eterno così come si vede nelle scene della Creazione, dentro un cerchio donde partono lingue di fuoco, mentre la colomba aleggia negli abissi, come rondine sul mare. L'Eterno, che sostituì in antico la figura di Prometeo in atto di formar l'uomo, ora surrogava la mano sporgente dalle nubi o fuori da un'aureola, simbolo dell' intervento divino. Intanto meglio si determinavano i moti dell'animo nell'espressione delle figure: serena e modesta accoglie il messo divino la Vergine dipinta da Giotto, nella cappella degli Scrovegni a Padova; pensosa l'altra di Taddeo Bartoli, nel 
trittico dell'Accademia di Siena; come in atto di ritrarsi sgomenta all'annuncio, nei bassorilievi della cattedrale d'Orvieto; e più turbata ci appare Maria nel quadro di Lippo Memmi, nella Galleria degli Uffizi, dove, nobilissima

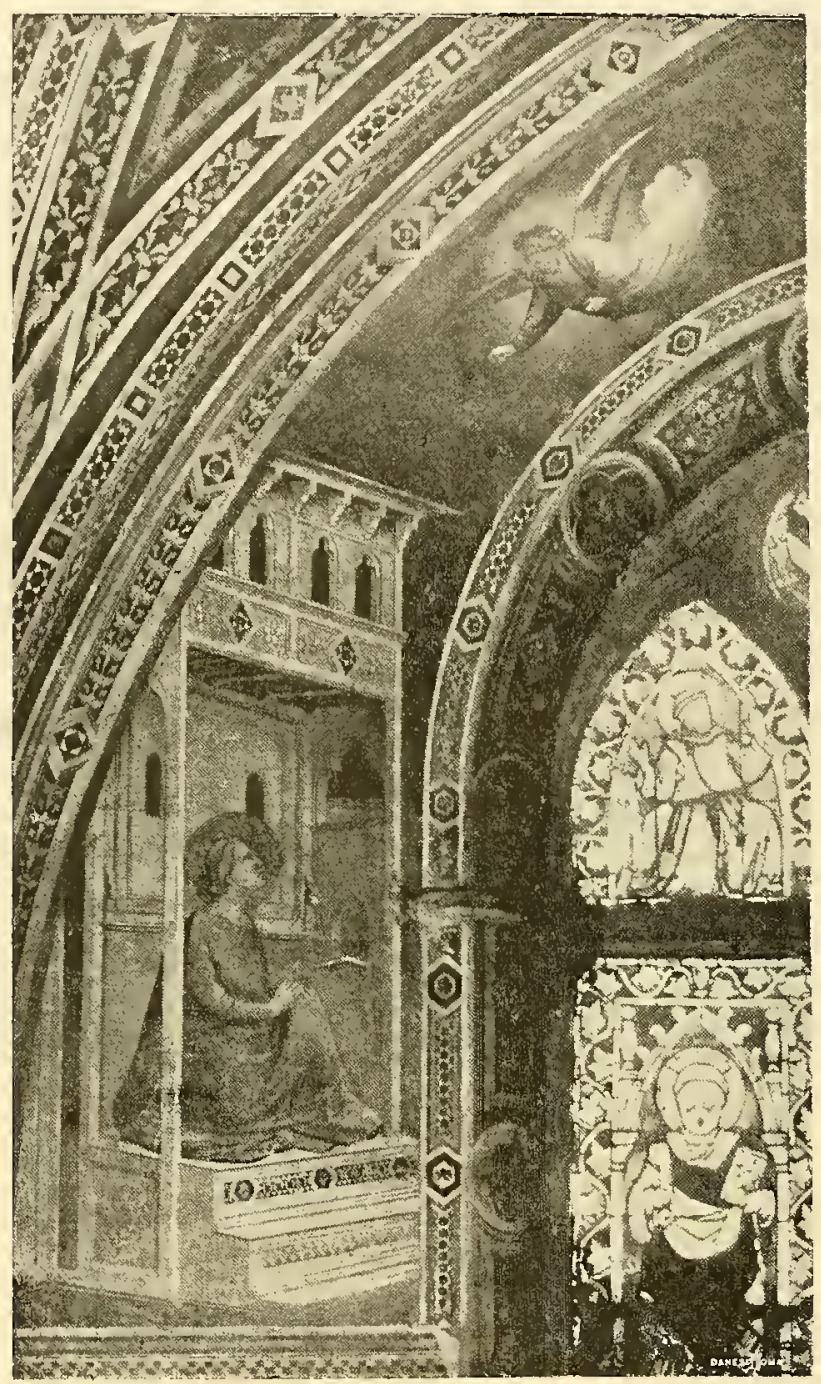

Chiesa in Santa Croce in Firenze

(TADDEO GADDI)

immagine della Pudicizia, segue come impaurita il suono delle parole dell'Arcangelo, stringe la piccola bocca e si volge a sinistra, mentre con una mano solleva il manto quasi per farsene schermo. Invece che sulla cattedra bizantina con cuscini, Maria si asside in un scanno intarsiato con spalliera adorna di panni d'oro, o entro gotiche edicolette ornate di stelle, presso un leggio, innanzi alla porta di una cameretta, le cui tende raccolte 
mostrano nell' interno il letto della Vergine. La stanza dell'Annunciata ritiene l'antico aspetto regale: marmorei i pavinenti o coperti da tappeti orientali, ricamate d'oro le cortine del gineceo, gli arredi intagliati, intarsiati,

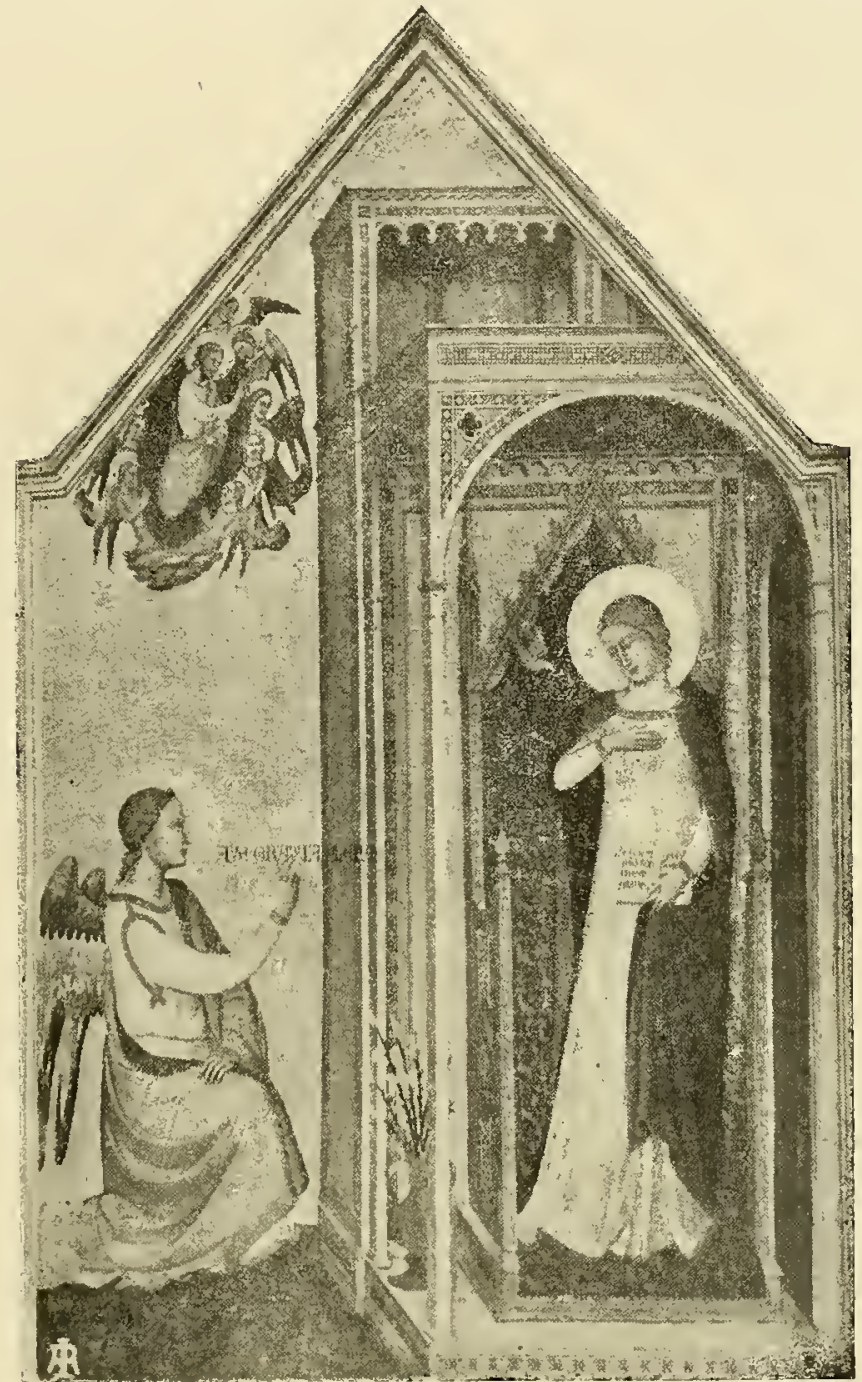

Galleria degli Uffizi a Firenze

(Agnolo Gadd)

suntuosi. In quell'albergo Ella ci appare talora con una stefane di gemme nella bionda chioma, con veste ornata, il manto fregiato d'oro, un nimbo radioso intorno al capo. In tal modo, nel secolo xiv, si onorava la Vergine; e quantunque il desiderio di rendere razionale la rappresentazione conferisse un carattere realistico, la realtà era nobile e pura. Dell'antica rappresentazione si serba in qualche caso il gesto oratorio dell'Arcangelo, che però 
in generale è meno baldo e vibrato, anzi proprio di chi timidamente esponga un messaggio, o curvi il braccio in atto di benedire. Alcune volte si vede Gabriele con le braccia conserte al seno, mentre si genuflette innanzi a Maria; la quale, umile ed alta più che creatura, come Dante la proclamò, ascolta con un ginocchio a terra. In tal guisa l'arte addolciva le sacre figure, le rivestiva di pietà e di semplicità umana.

Nel secolo xv la rappresentazione volle farsi più vera, e solo il Beato Angelico con le sue Annunciate della chiesa del Gesù ad Arezzo, del convento di

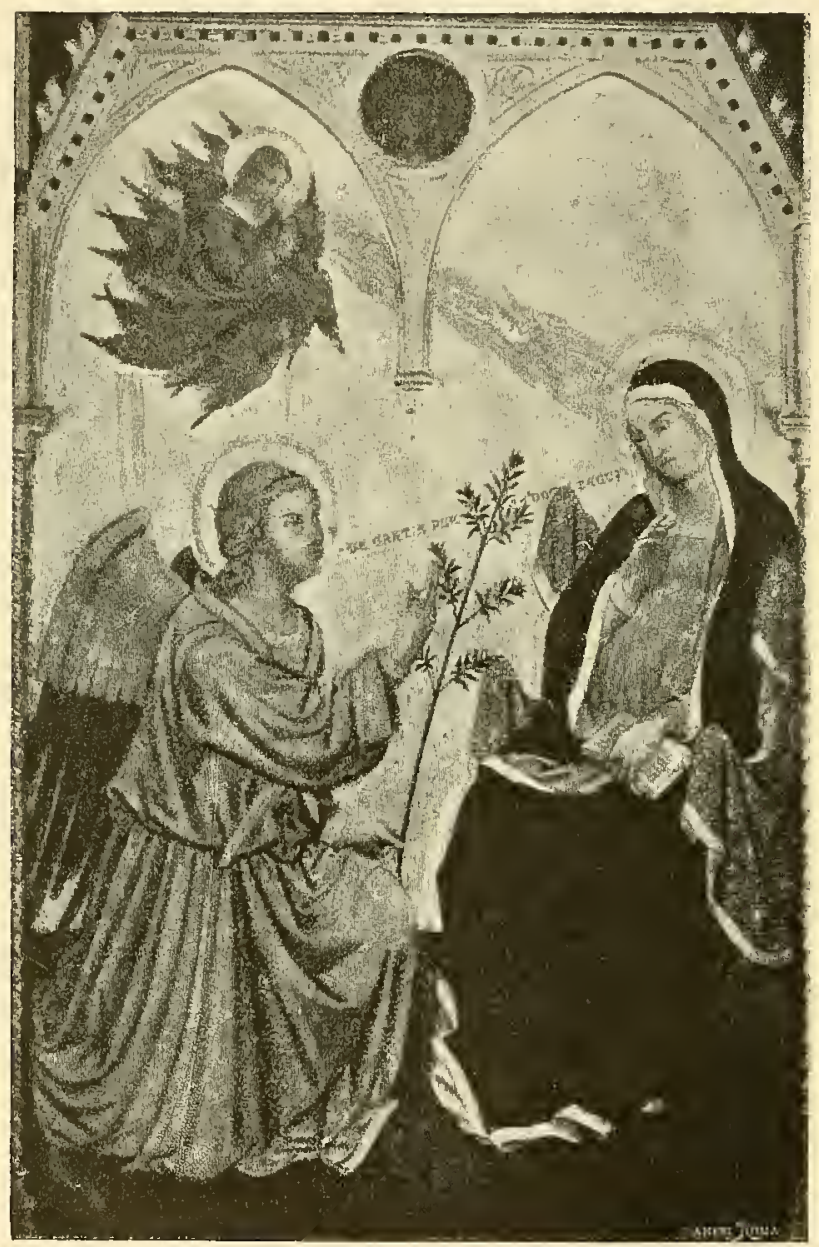

Accademia di Belle Arti in Siena

(TADDEO di Bartolo)

San Marco a Firenze, ecc., parve contrastare all'arte che lasciava in abbandono ogni mistica semenza. Il pio frate, col suo ridurre al minimo gli elementi della composizione, non riuscì a far scomparire l'ambiente ove si svolse 


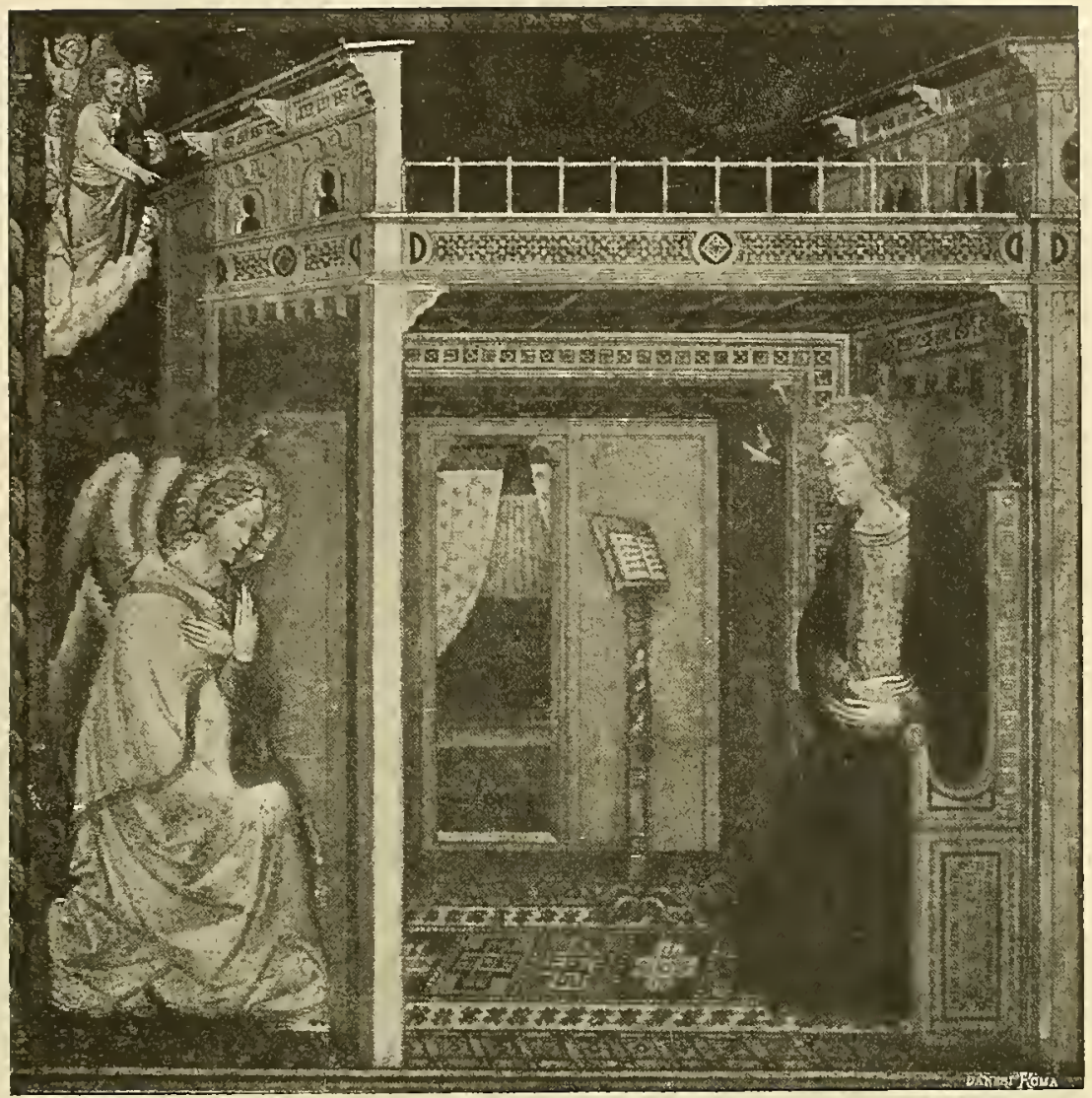

Affresco in Santa Maria Novella a Firenze, sec. XIV

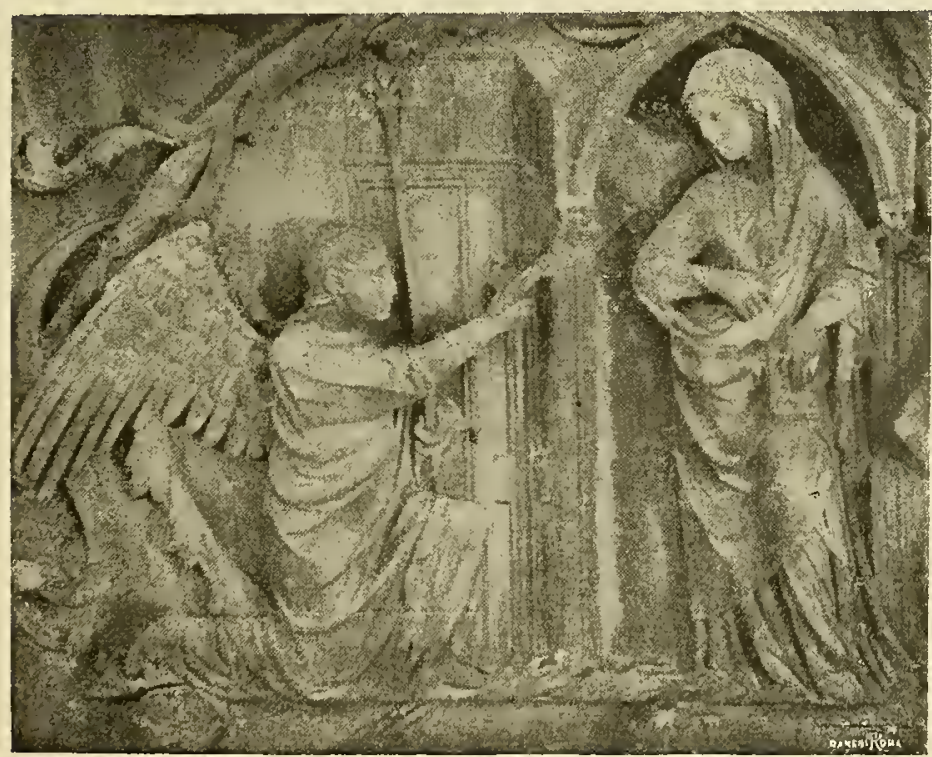

Bassorilievo della facciata della Cattedrale di Orvieto, sec. XIV 
la scena, sostituendovi un fondo d'oro a graffito, oppure rappresentandola sotto il portico d'un chiostro, nudo d'ornamenti, innanzi a una celletta avente un finestrino con un'inferriata. In questo ultimo dipinto la . Madonna siede

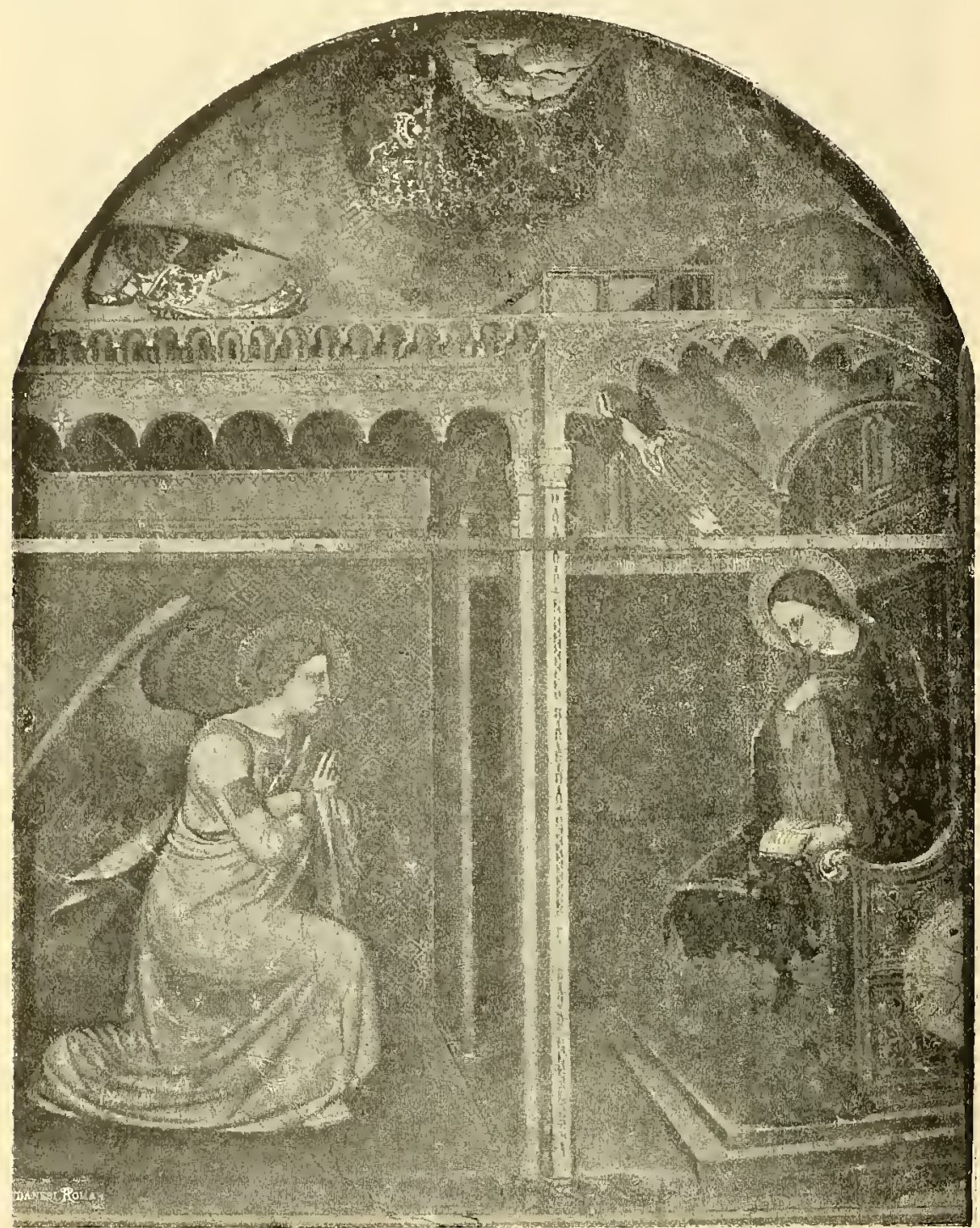

Santissima Annunziata in Arezzo

(Spinello Aretino)

su un trespolo di legno, spinge innanzi la testa e sta come incantata, con le braccia conserte sul petto, mentre in uguale atteggiamento, rimpetto a lei, piega un ginocchio, senza il giglio simbolico, l'arcangelo, che sembra un giovane novizio del convento. Nell'altro dipinto di San Marco, cioè nella parte superiore del tabernacolo di quel Museo, l'Annunciata dagli sguardi in alto 


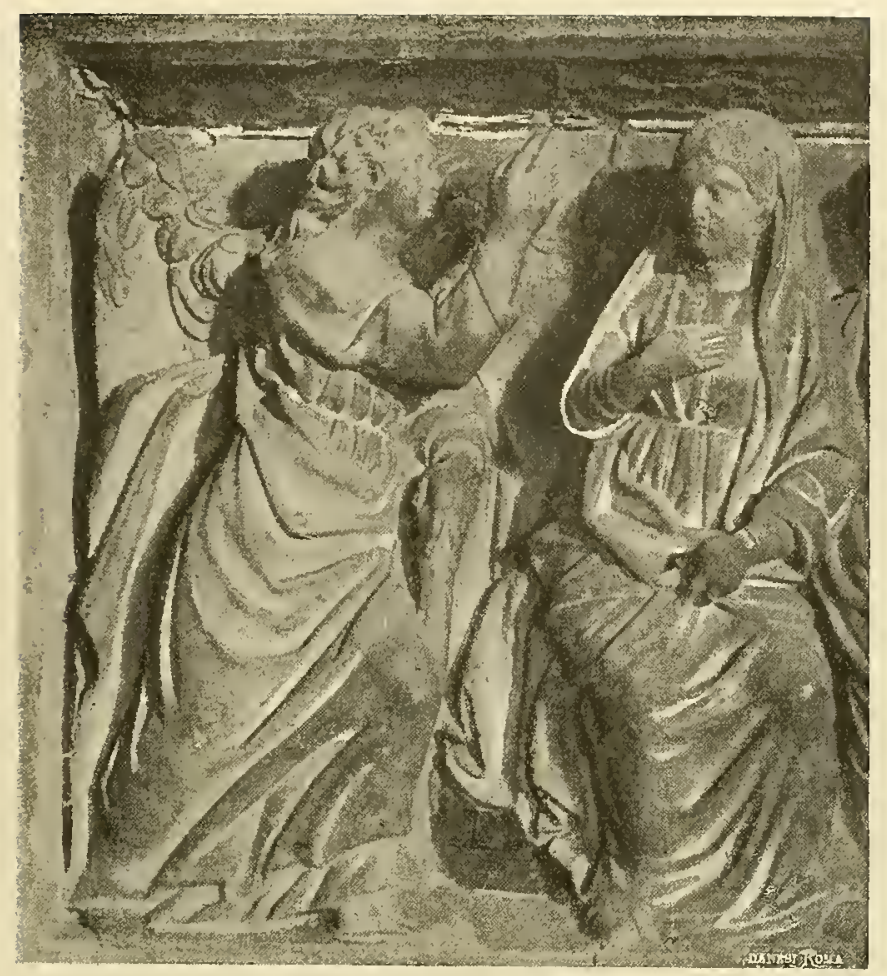

Pulpito di Pistoia

(Fra Guglielmo da Pisa)

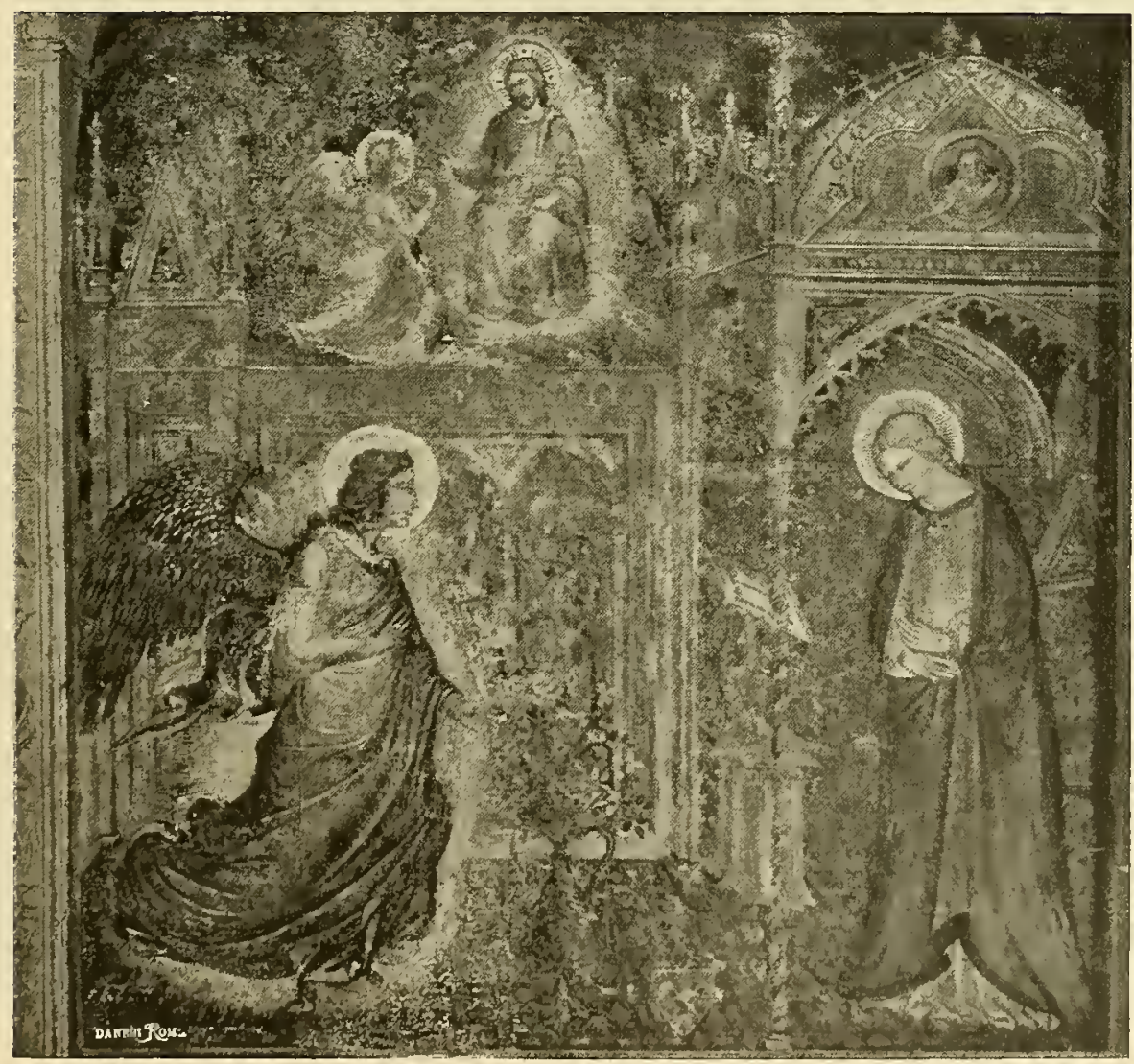

Chiesa di San Francesco in Arezzo

(SPinello Aretino) 
potrebbe confondersi con la figura della Vergine nell' Incoronazione. Il misticismo che curva le figure umane, le cosparge di unguenti, le inebbria di luce,

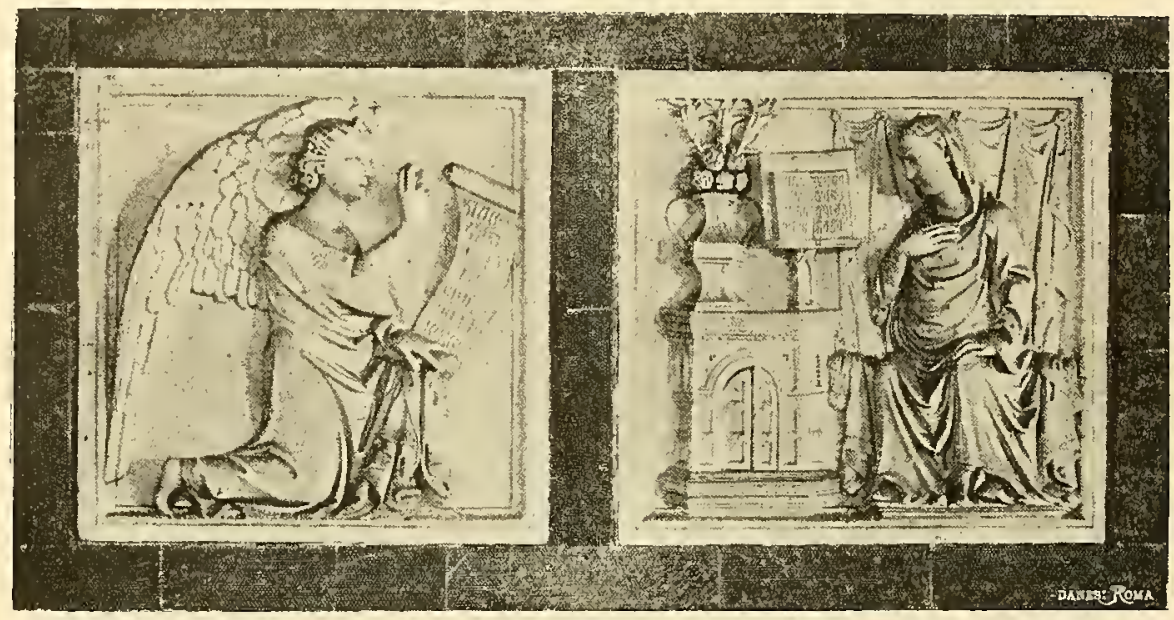

Pulpito in Santa Maria in Prato in San Casciano (Gro. Balducci)

non può muoverle sulla scena della terra; perciò l'Angelico con le sue

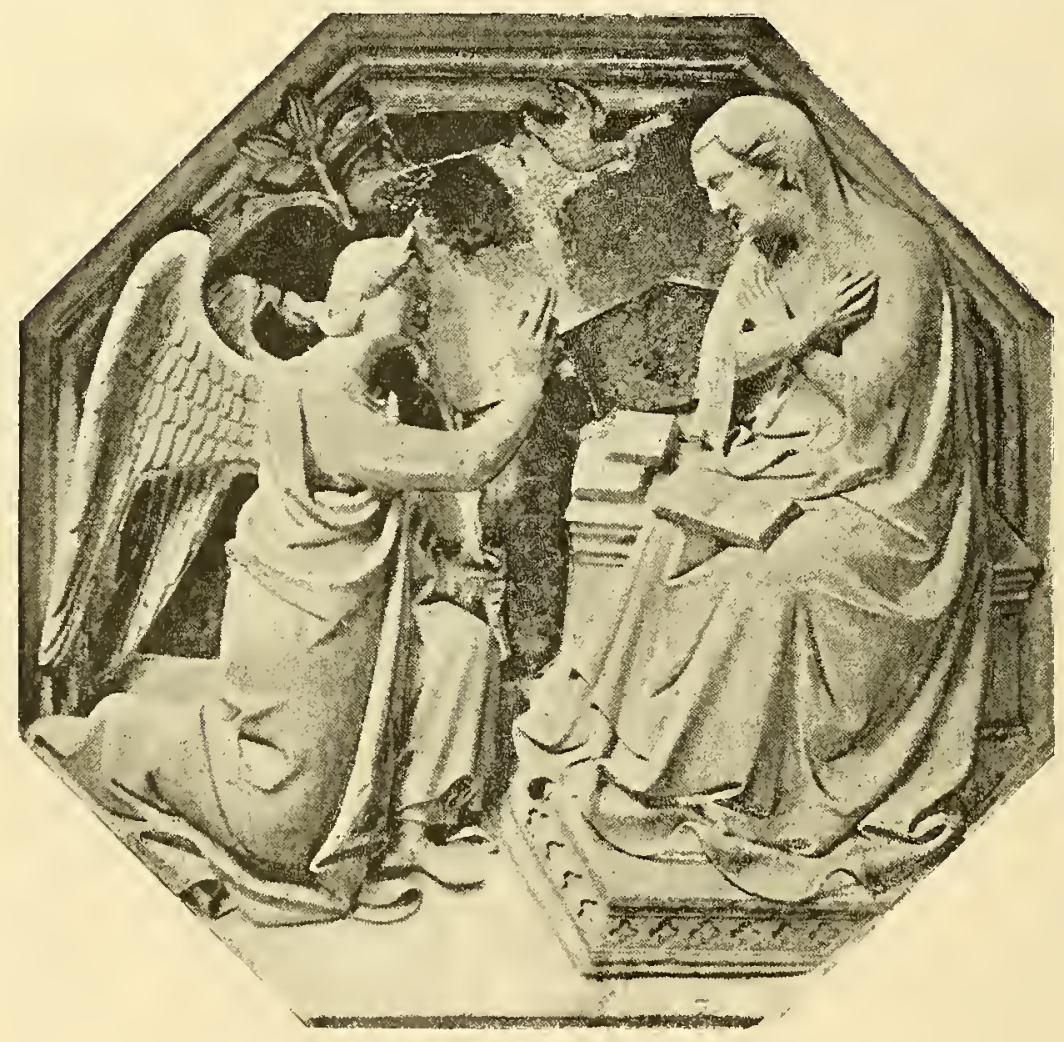

Tabernacolo in Or'San Michele

(ORCAGNA) 

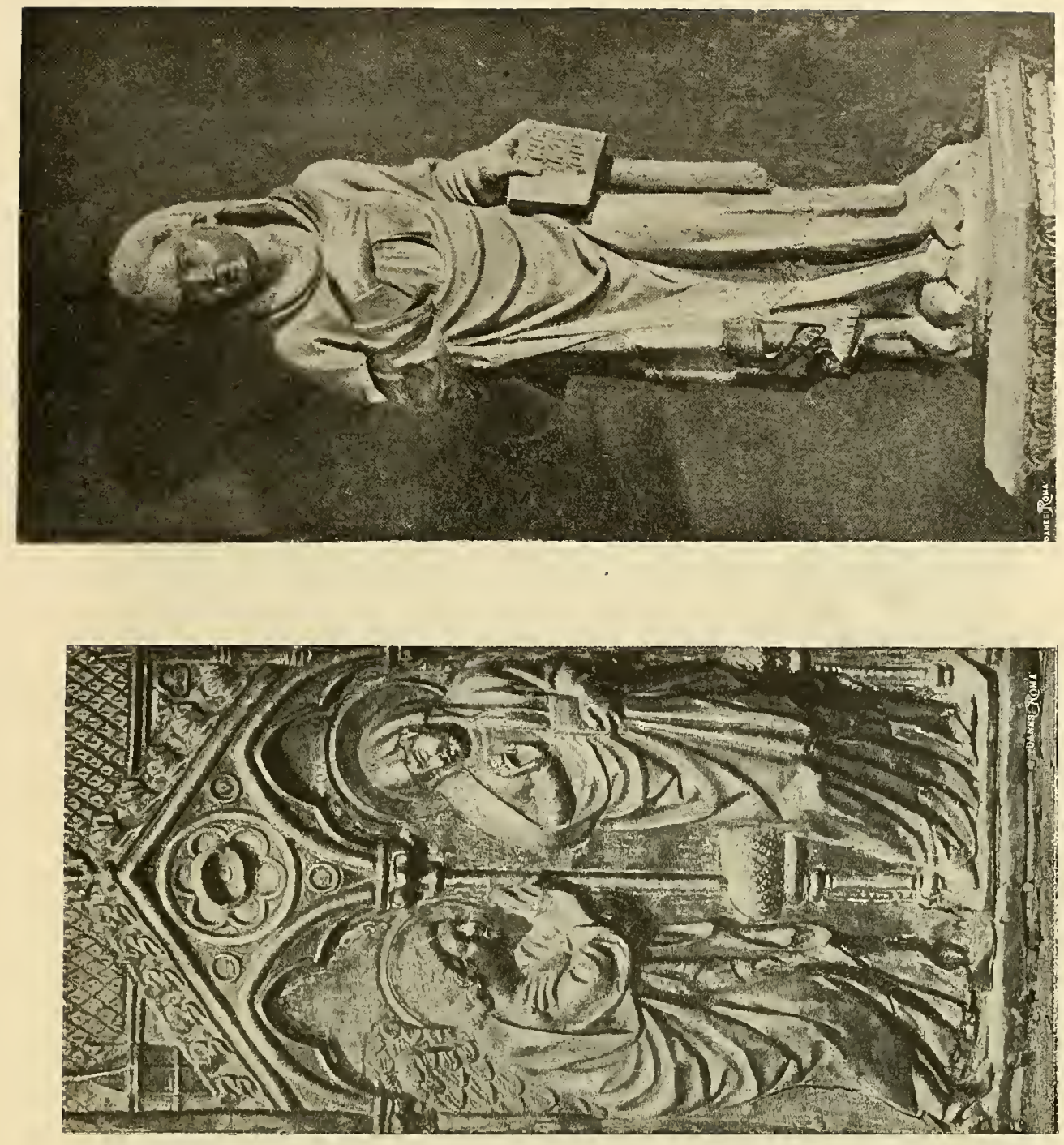

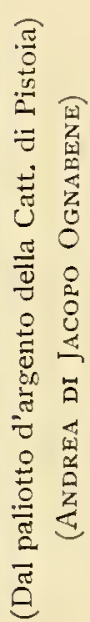

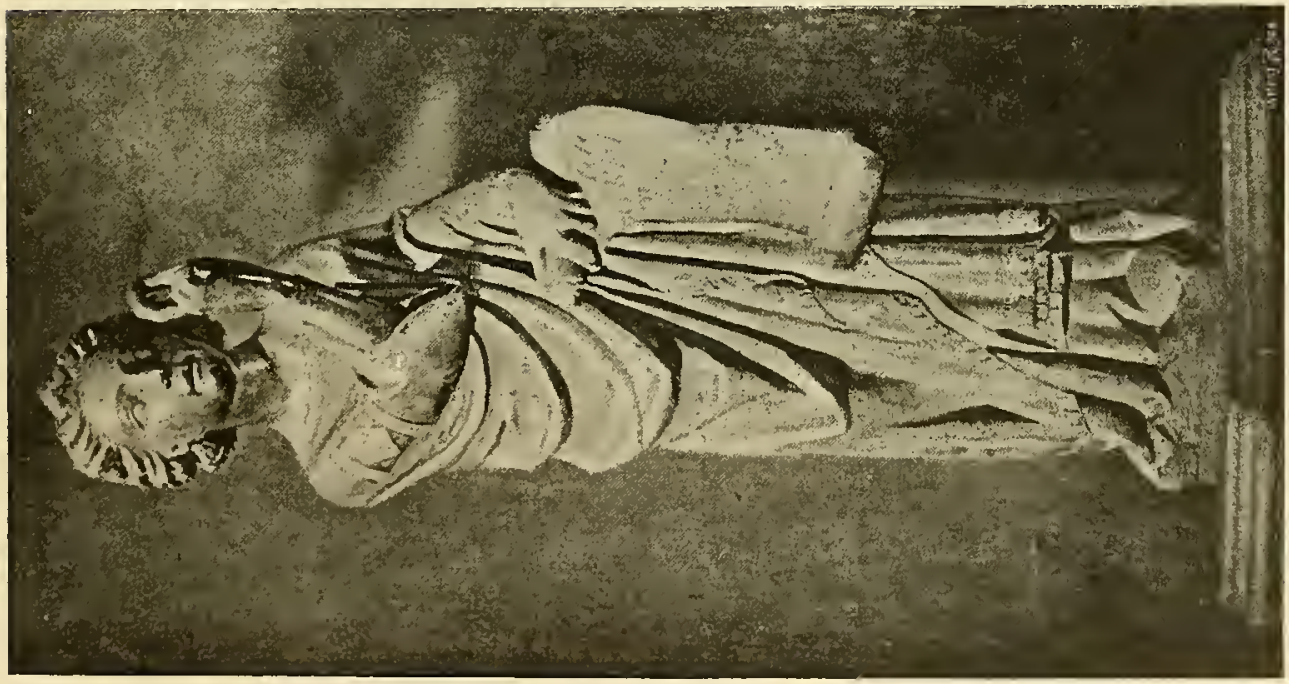




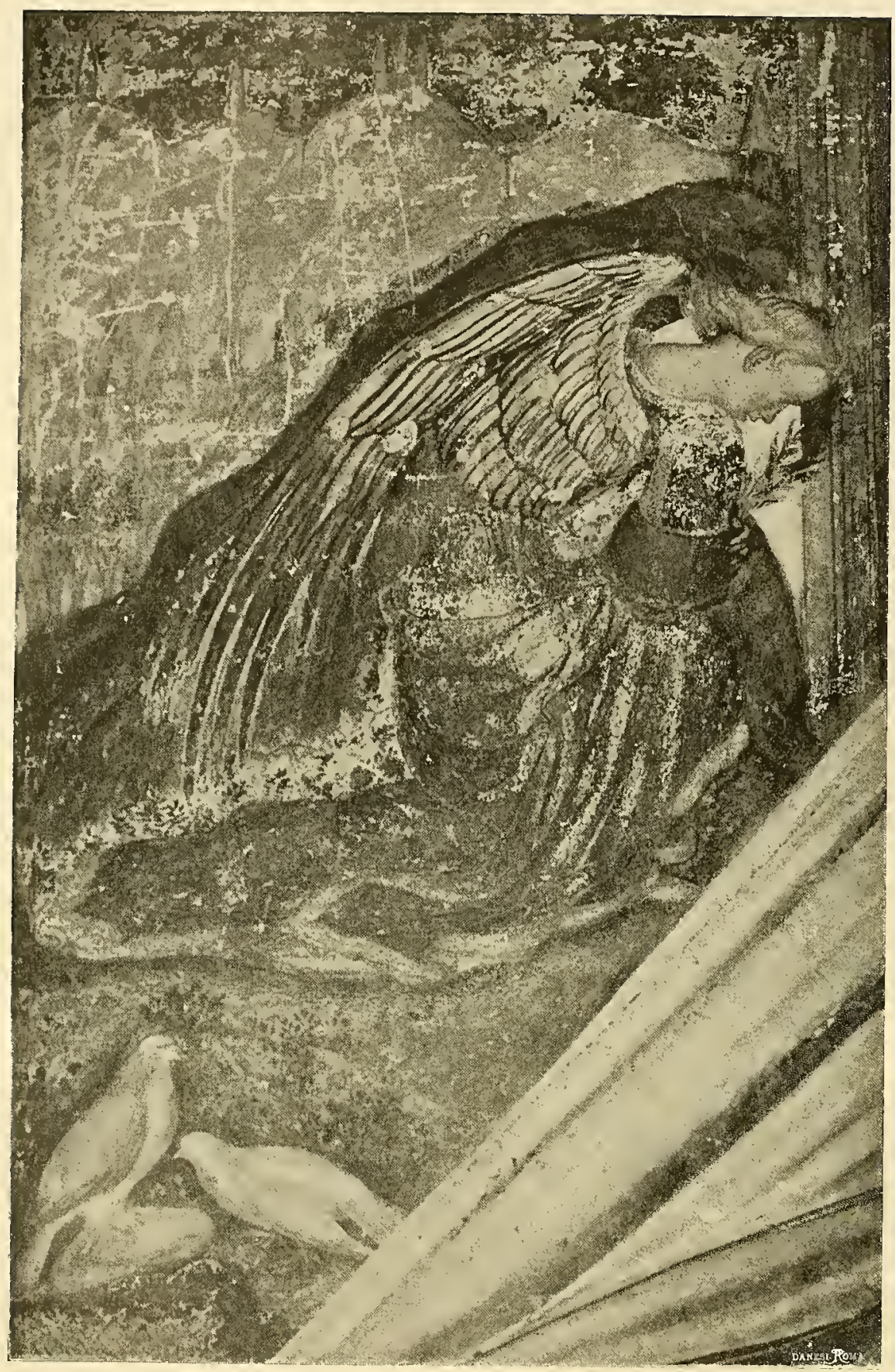

San Fermo Maggiore in Verona

(Pisanello) 


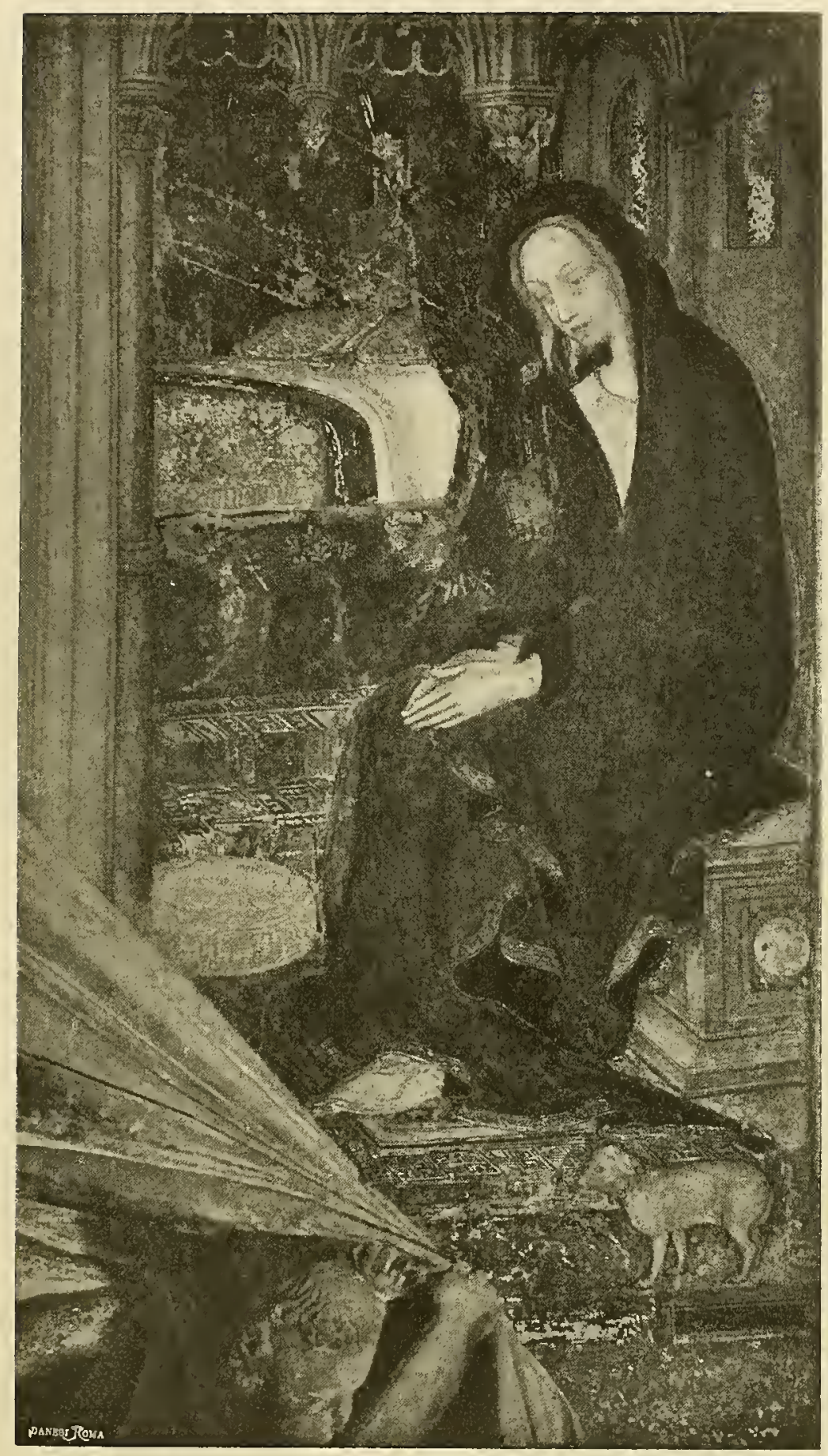

San Fermo Naggiore in Verona

(Pisanello) 


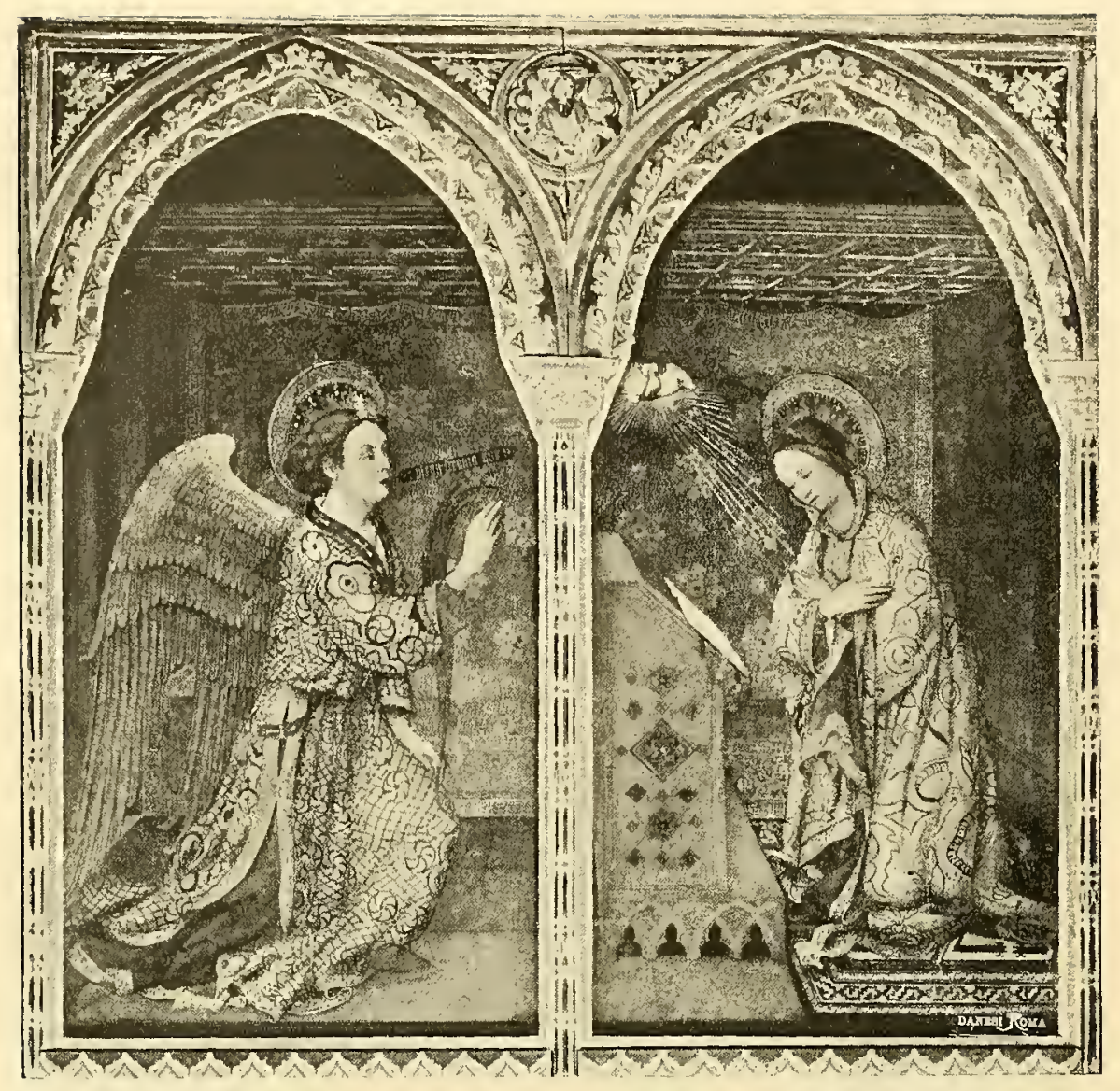

Chiesa di Sant'Alessandro in Brescia

(Pittore bResclano Della PRIMA MEtA Del SEC, XV)
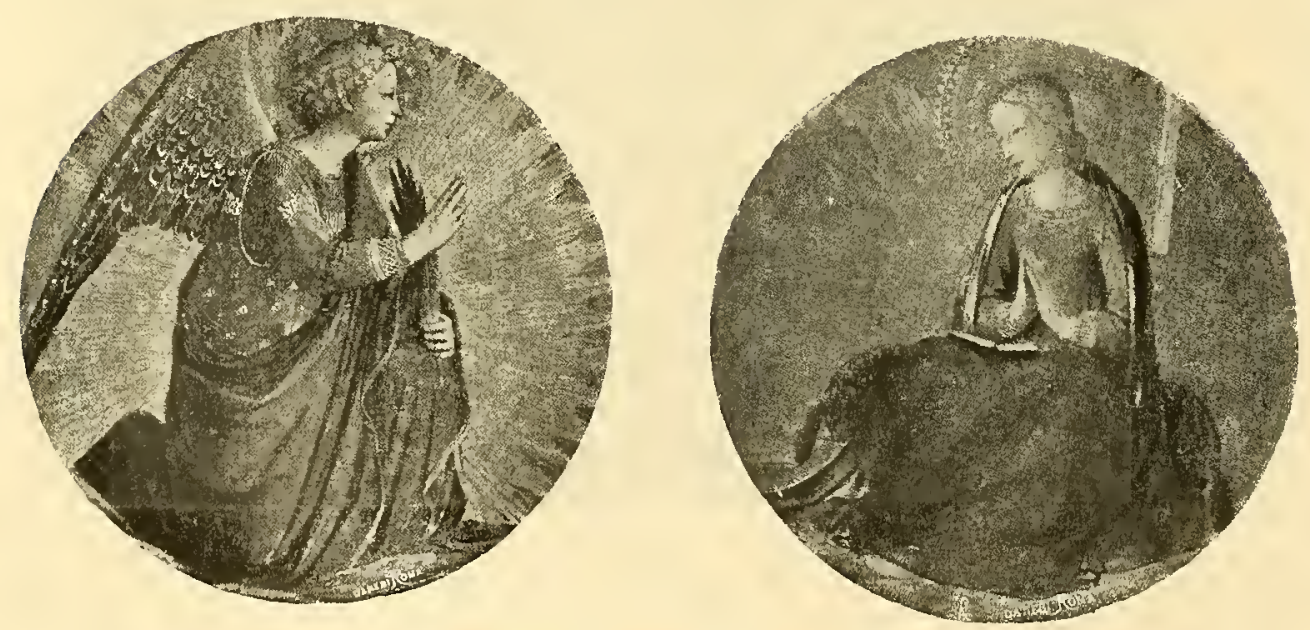

Pinacoteca Vannucci a Perngia

(Beato Angelico) 

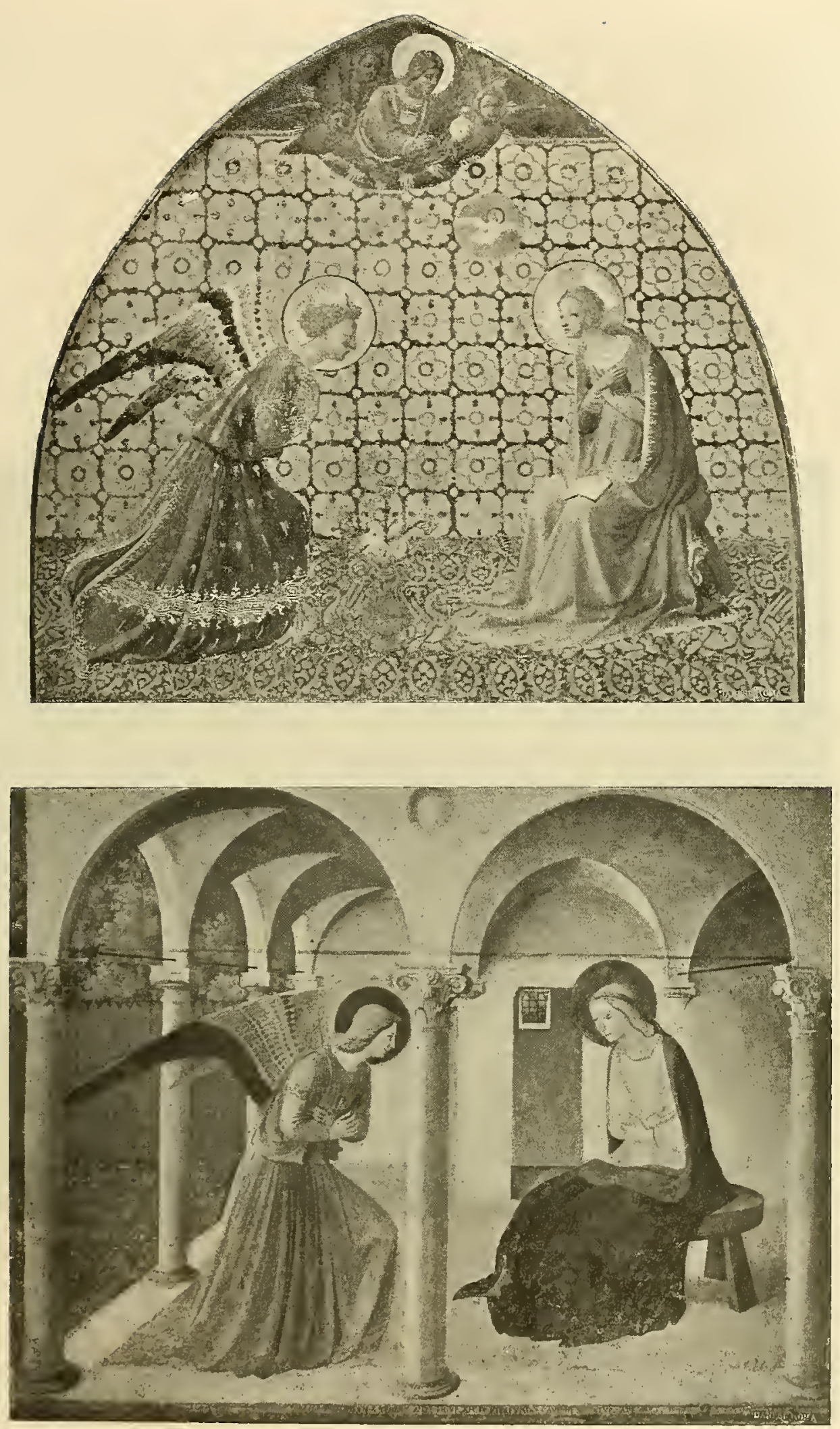

Museo di San Marco in Firenze

(Beato Angelico) 
monache estasiate andò ben lontano dal tipo umile ed alto designato dall'Alighieri. L'Angelico rivestì Maria solo di umiltà, quando la rappresentò in ginocchio innanzi all'angelo, sul pavimento di un chiostro; ma intanto Donatello in Santa Croce, senza abbandonarsi ad astrazioni, dava alla Vergine la eccelsa bellezza e, con la sua scultura di pietra serena, affinava la rappresentazione secondo la forma già usata nei rilievi della cattedrale di Orvieto. Maria si ritrae verso destra, mentre il busto è di prospetto e la testa s'inchina verso l'angelo, come se, attratta dalle parole soavi e dominato il primo turbamento, gli porga ascolto; e Gabriele in atto di omaggio, carezzevole, commosso, le esprime il volere divino. 亡̀ questa la forma dram-

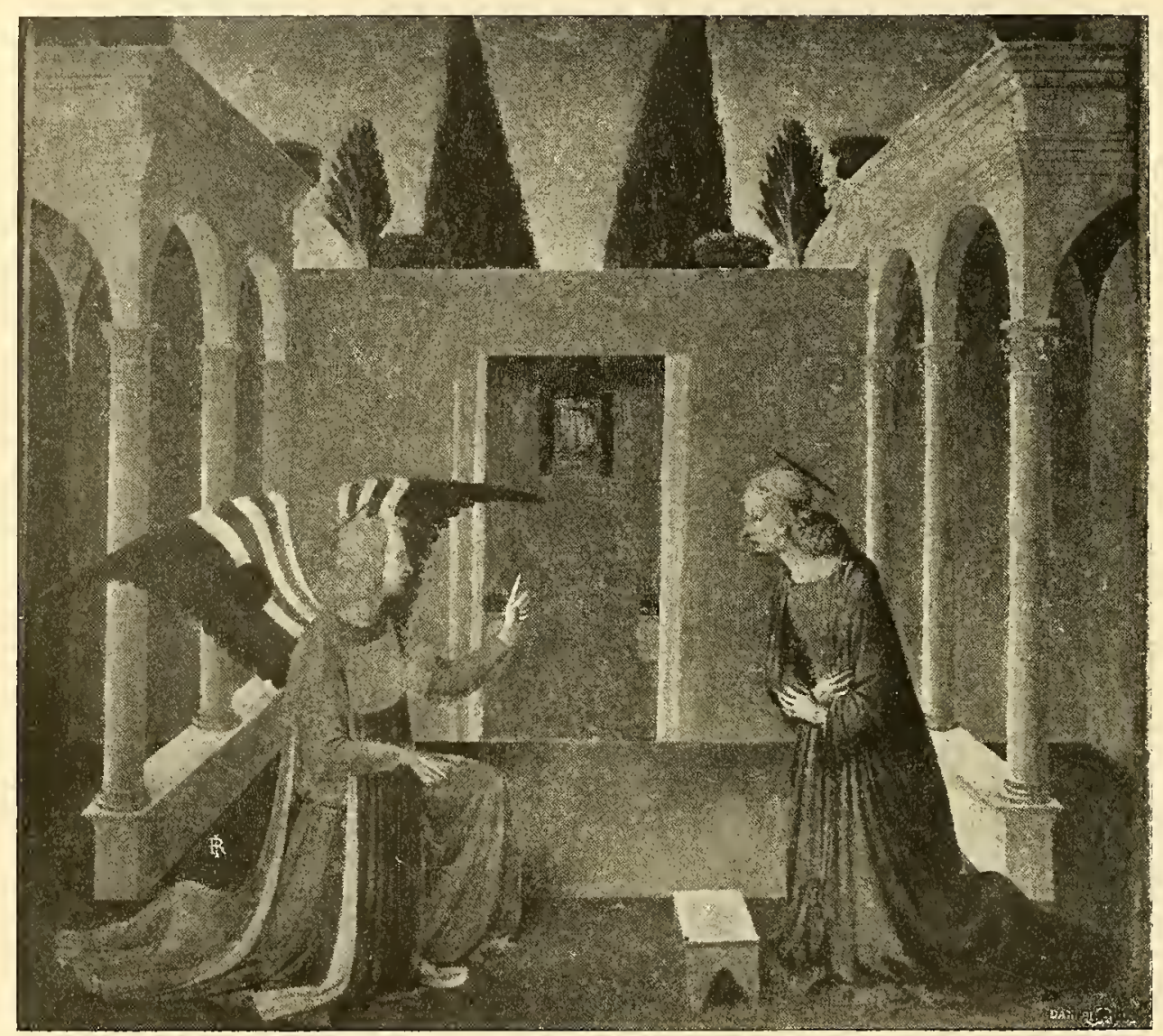

Galleria antica e moderna in Firenze

(Bento Angelico)

matica a cui si attennero poi Sandro Botticelli e Lorenzo di Credi nei quadri della Galleria degli Uffizî, il Ghirlandaio nell'affresco di Santa Maria 
Novella, il Francia nel dipinto della Pinacoteca di Brera. Il Botticelli e il Ghirlandaio avvicinarono l'angelo a Maria per esprimere il colloquio tra

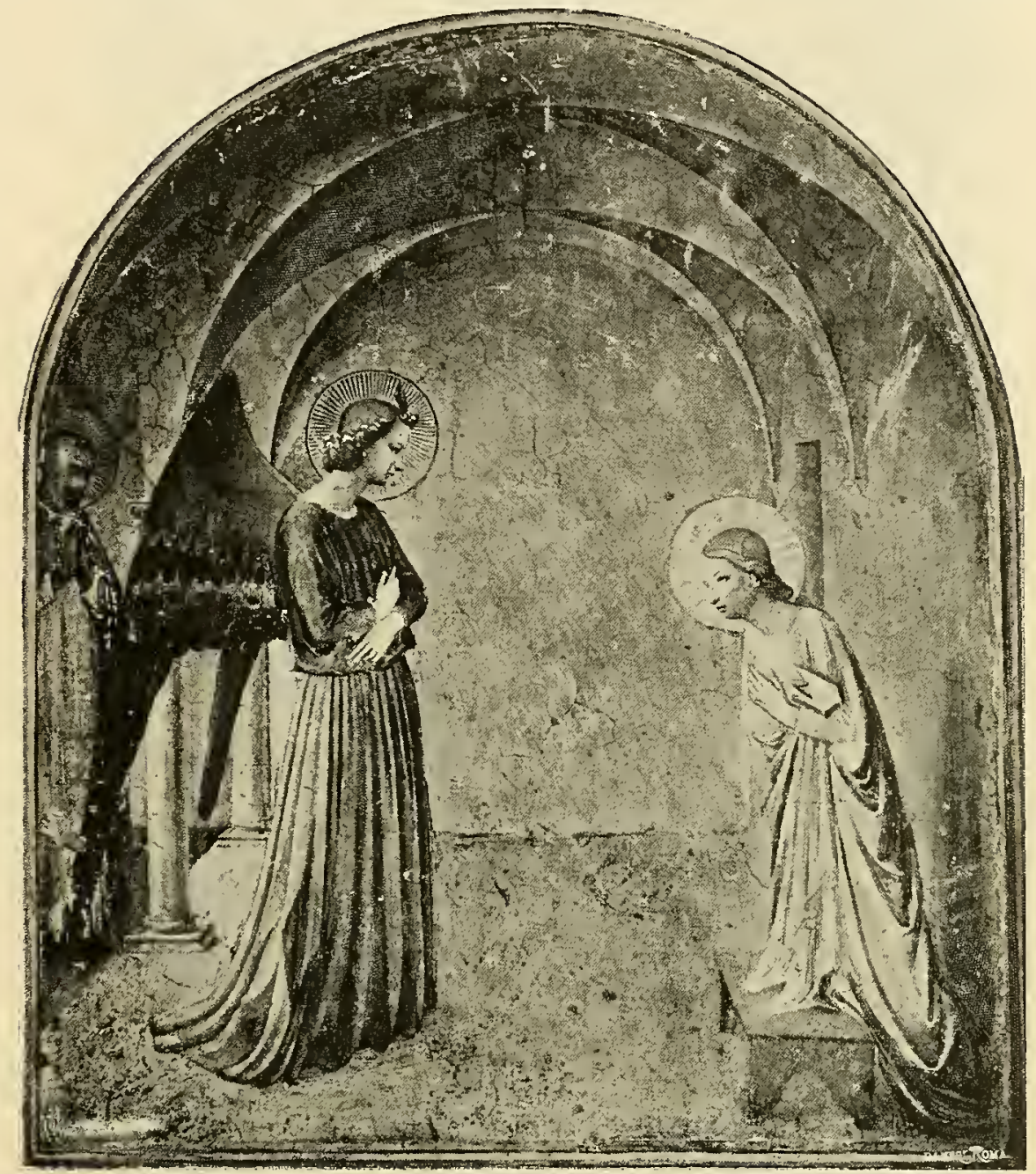

Museo di San Marco

(Beato Angelico)

loro e per ravvivare maggiormente la scena, sì che all'angiolo del Botticelli, che arriva concitato innanzi a Maria, ella risponde, interrotta di soprassalto nell'orazione, con l'atteggiamento turbato, con la testa china, gli occhi mestamente socchiusi e le mani stese aperte dinnanzi, come per meraviglia. Più tranquillo, il fanciullo coronato di rose benedice la Vergine nel dipinto del Ghirlandaio a Santa Maria Novella, e Maria più compostamente lo ascolta e s'inchina. 
Fílippo Lippi, che tante Annunciazioni dipinse, s'ispirò a motivi meno drammatici nella rappresentazione, cui diede gran gentilezza, e fresca grazia. Fra le tante ricordiamo quella già a Bagno a Ripoli, ora presso Henriette Hertz in Roma, nella quale si vede l'angiolo fanciulletto coronato di rose, in atto di porgere il ramo di gigli fioriti alla Vergine, che lo riceve confusa.

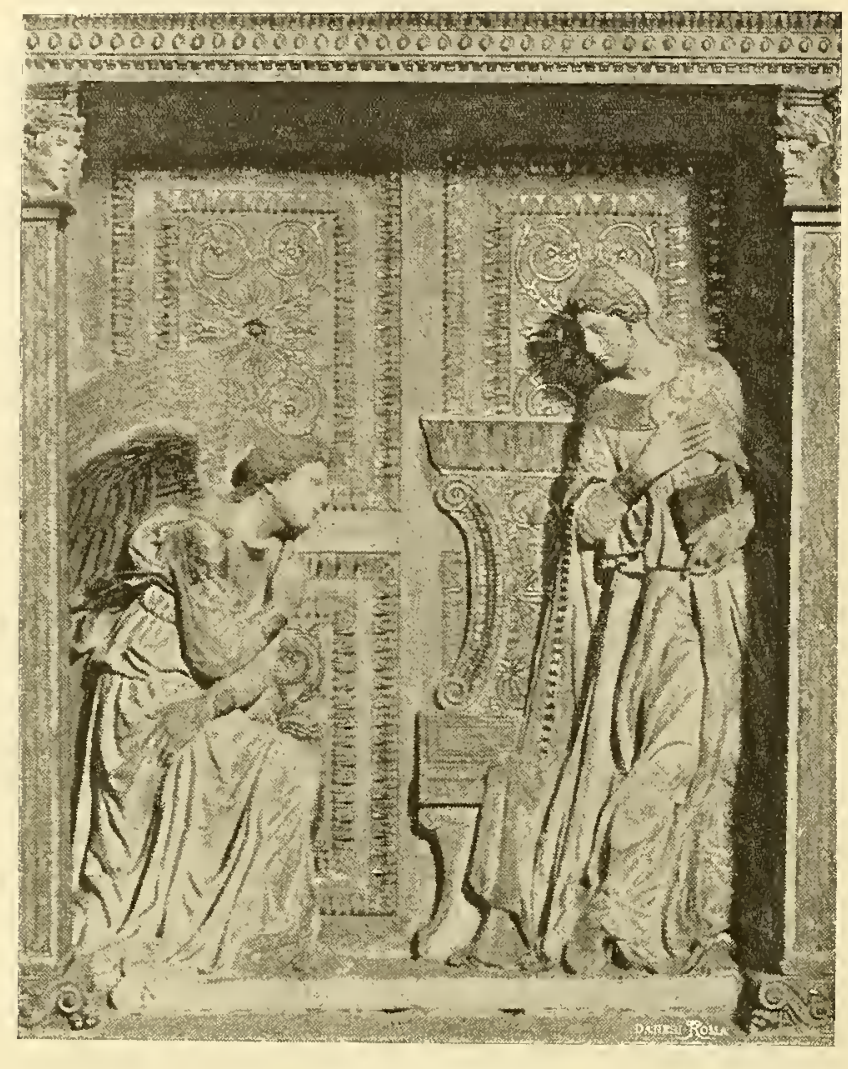

Santa Croce in Firenze

(Donatello)

E come in tutte le scene religiose gli uomini del secolo $\mathrm{xv}$ si univano ai celesti in una stessa famiglia, così anche nell'Annunciazione di Filippo Lippi i committenti contemplano il mistero divino. Quel penetrare della vita sociale entro le orbite delle leggende dei santi, del Testamento Antico e Nuovo, tra le schiere luminose dei celesti, innanzi al trono della Divinità, fa distinguere l'arte del Quattrocento, in ispecie la fiorentina. Anche fuor di Toscana, in qualche caso si trova l'intervento degli umani nelle sacre scene. Antoniazzo Romano, ad esempio, nella chiesa di Santa Maria sopra Minerva in Roma, interrompe la rappresentazione con le fanciullette presentate da un monaco 


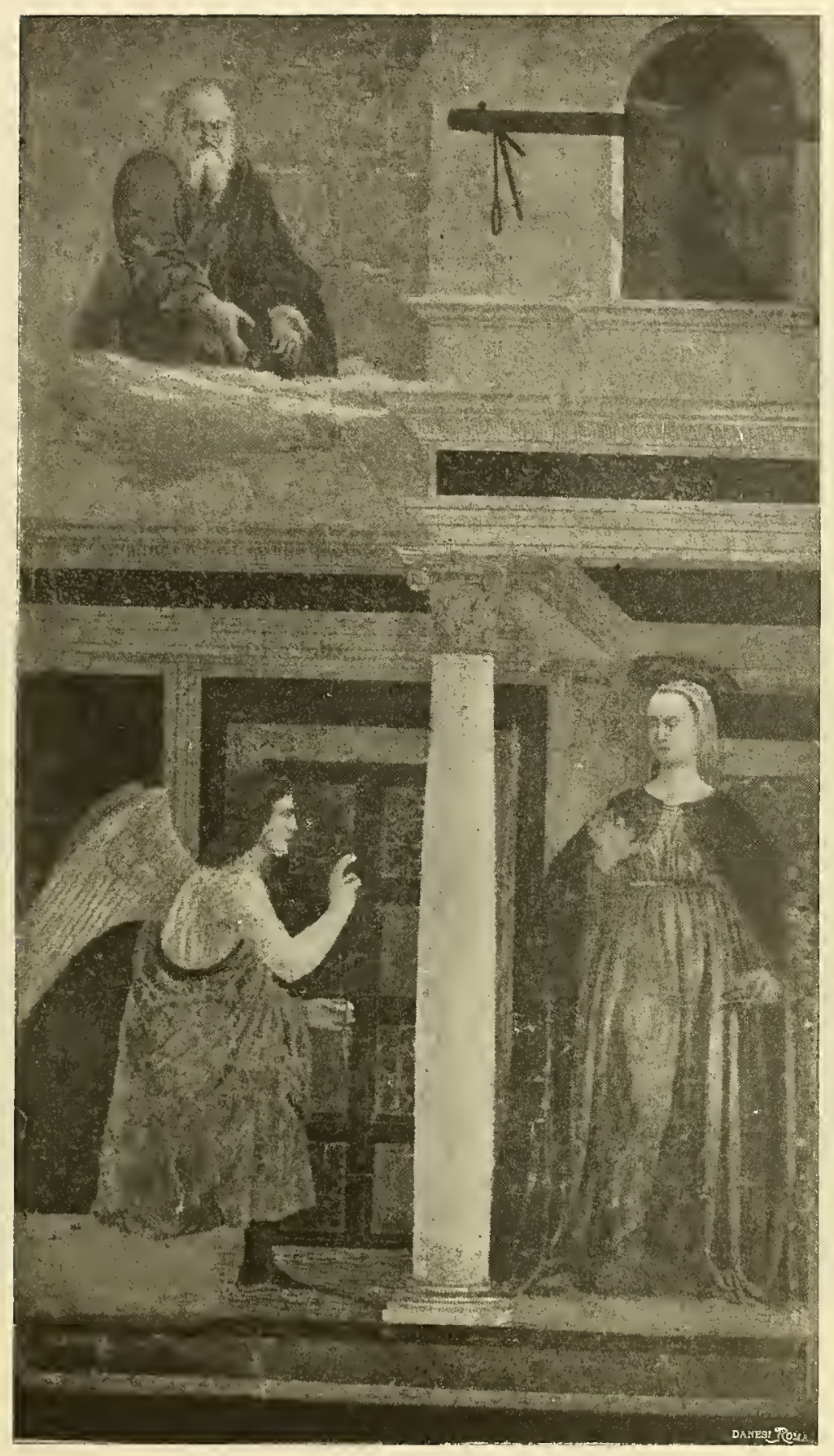

Chiesa di San Francesco di Arezzo

(Pier della Francesca) 
alla Vergine, che stende loro benigna le borse di dotazione; l'angiolo discorre; Dio Padre benedice; la colomba vola verso la Vergine, che porta la sinistra sul petto, come l'azione richiede, oppure ella si distrae per beneficare le fan-

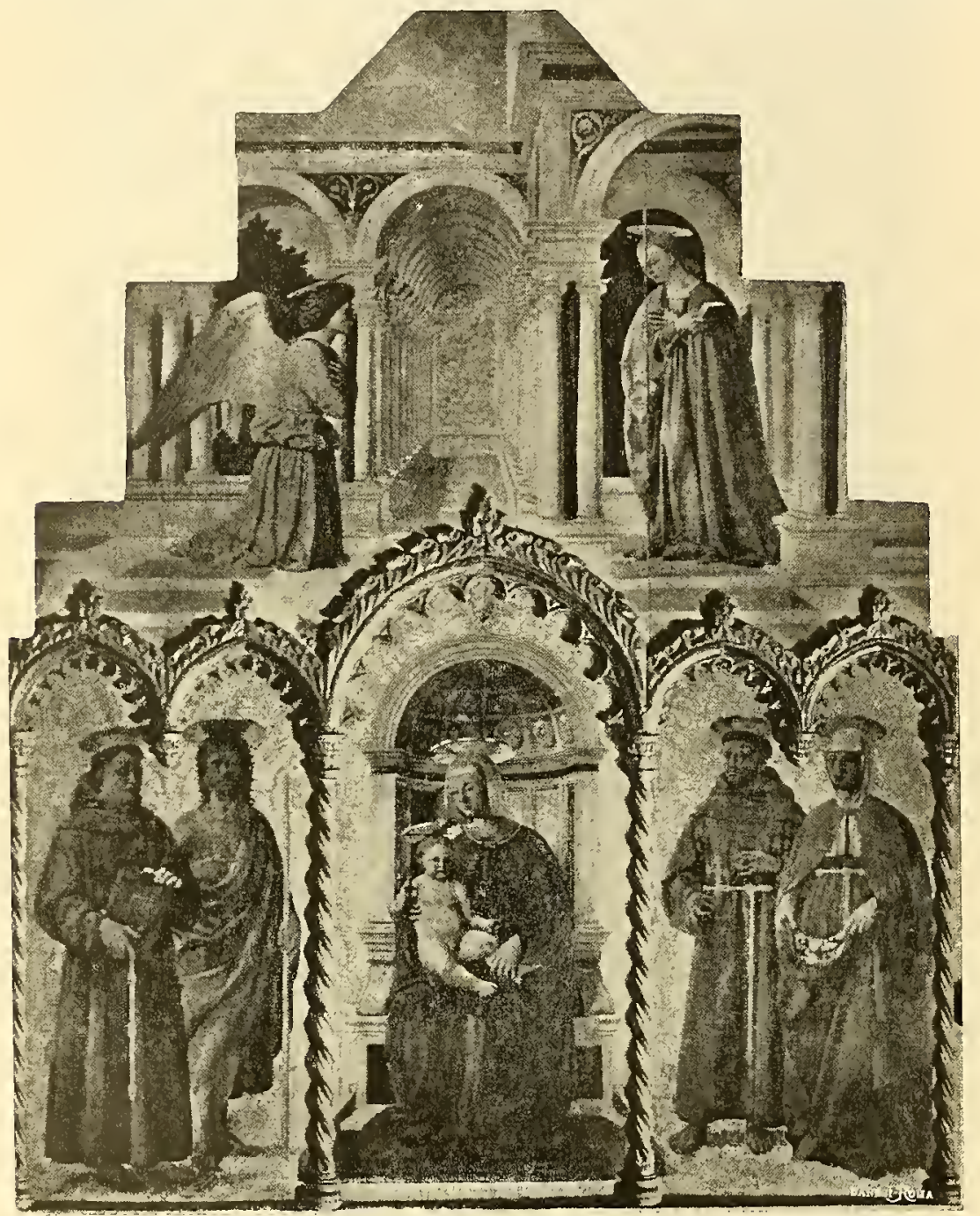

Pinacoteca Vannucci a Perugia

(Pier della Francesca)

ciulle. Sopra tutti intanto il sommo Leonardo, giovane ancora, nell' "Annunciazione " della Galleria degli Uffizi riassume le forme artistiche via via progredite. L'Annunciata, come una gentildonna fiorentina, ascolta in un giardino fiorito le sideree prime parole d'amore d'un soave giovinetto, che piega il ginocchio innanzi a lei, tra il silenzio dei cipressi e degli abeti, e la mira con occhi pieni di dolcezza. Così il motivo chiaro, semplice, naturale 
dell'Annunciazione, qual fu trasmesso dall'arte antica, non aveva mutato nelle linee generali, bensì intimamente nell'espressione; e l'imperatrice del musaico primitivo di Santa Maria Maggiore, la sacerdotessa bizantina, la mistica

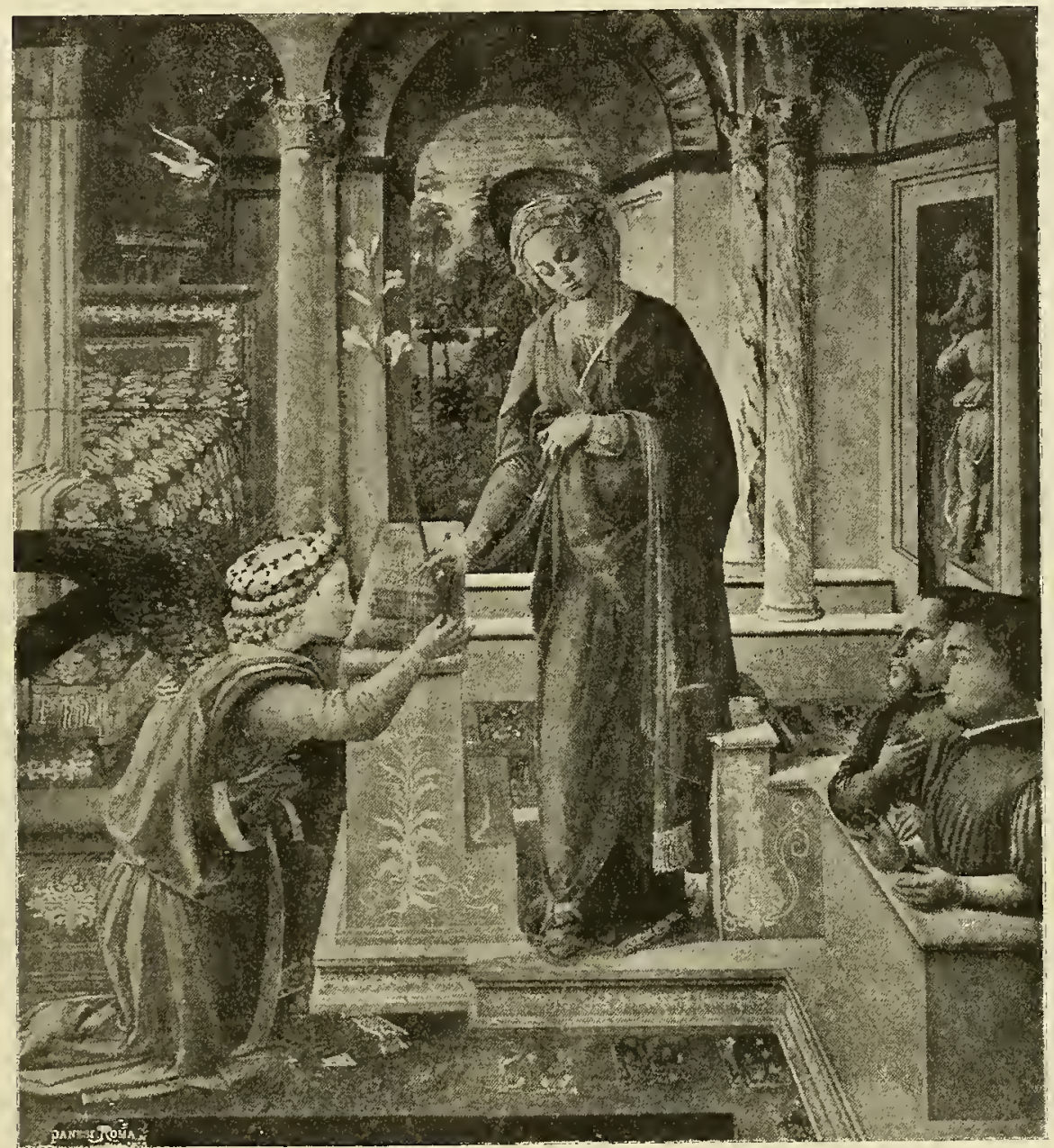

Collezione di Henriette Hertz in Roma

(FILIPPo LipPI)

Verginella medioevale assume nobili forme rigogliose di donna, prende i vezzi graziosi e la signorile eleganza delle donzelle fiorentine.

Nelle altre regioni d' Italia la rappresentazione non ebbe altrettanto sviluppo, nè lo spirito giovanile dei toscani, la tenerezza loro, il loro commovimento per il bello. A Perugia il Bonfigli, tra la Vergine e l'angiolo, fece sedere San Luca in atto di scrivere sopra liste di carta, per indicare la fonte prima del tema; uno scolaro di Cosmè, in un quadro della collezione Lombardi a Ferrara, 
dipinse dietro all'Annunciata il pozzo, da cui ella, secondo gli apocrifi Evangeli, attingeva l'acqua quando la prima volta udì la voce dell'arcangelo. Senza abbondare di esempî, può dirsi che, ove l'arte non ebbe il rapido moto e il fulgore fiorentino, le reminiscenze antiche riapparvero tra parti-

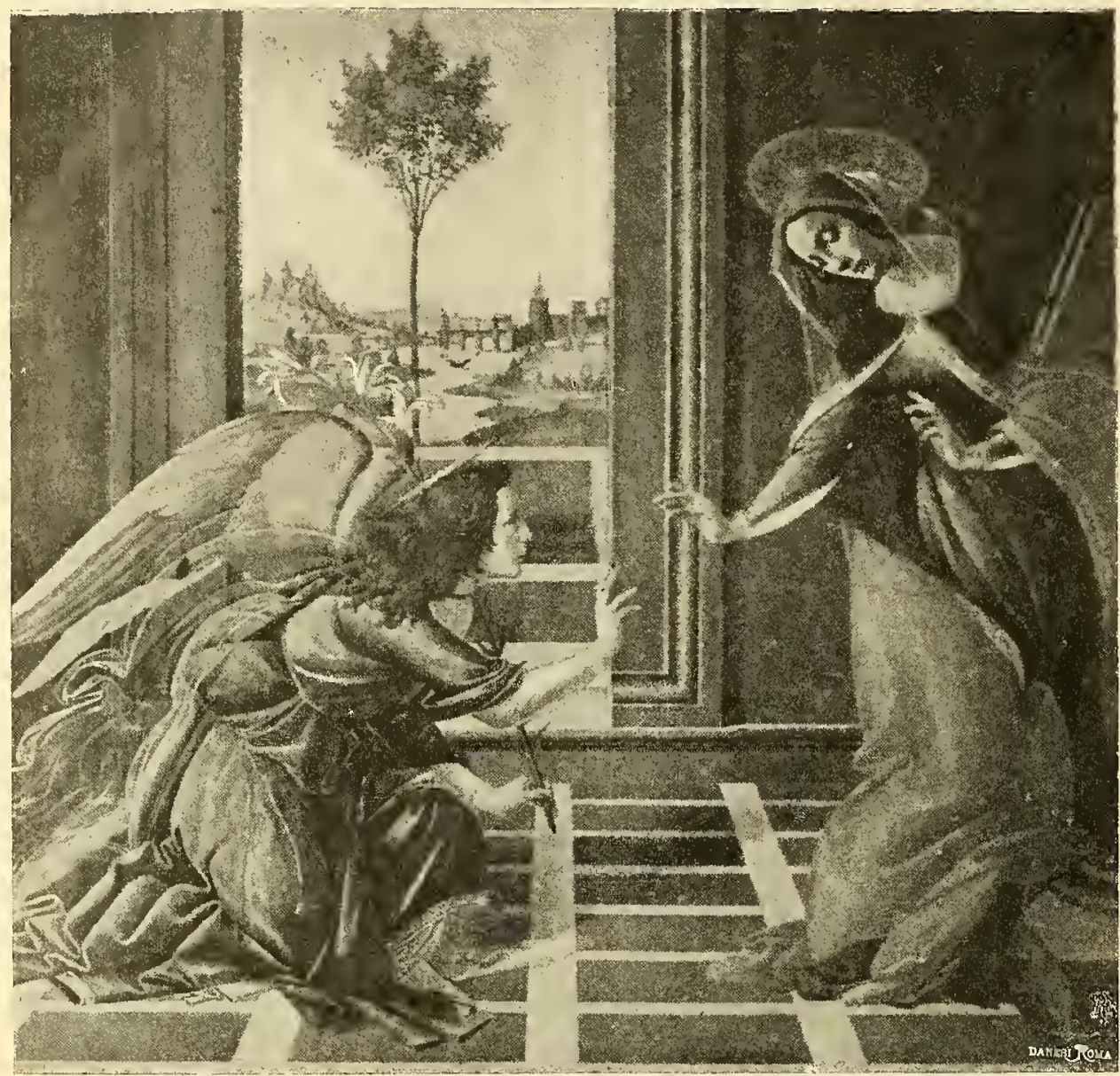

Galleria degli Uffizi in Firenze

(BOTTICELLI)

colari naturalistici e nuovi, ma indeterminate, come i ricordi dell'infanzia in un uomo nel vigore degli anni si affacciano alla mente offuscati dal tempo. Nei centri minori dell'arte si conservarono anche più tenacemente le tradizioni trecentistiche, chè, ove l'aria non si rinnova e si purifica per il succedersi dei venti, galleggiano, si aggirano in una gora i resti delle defunte cose. Avvenne che, mentre a Firenze Leonardo ed altri soppressero la figura dell'Eterno nell'aureola, e la candida colomba, e tanti altri apparati dello scenario 


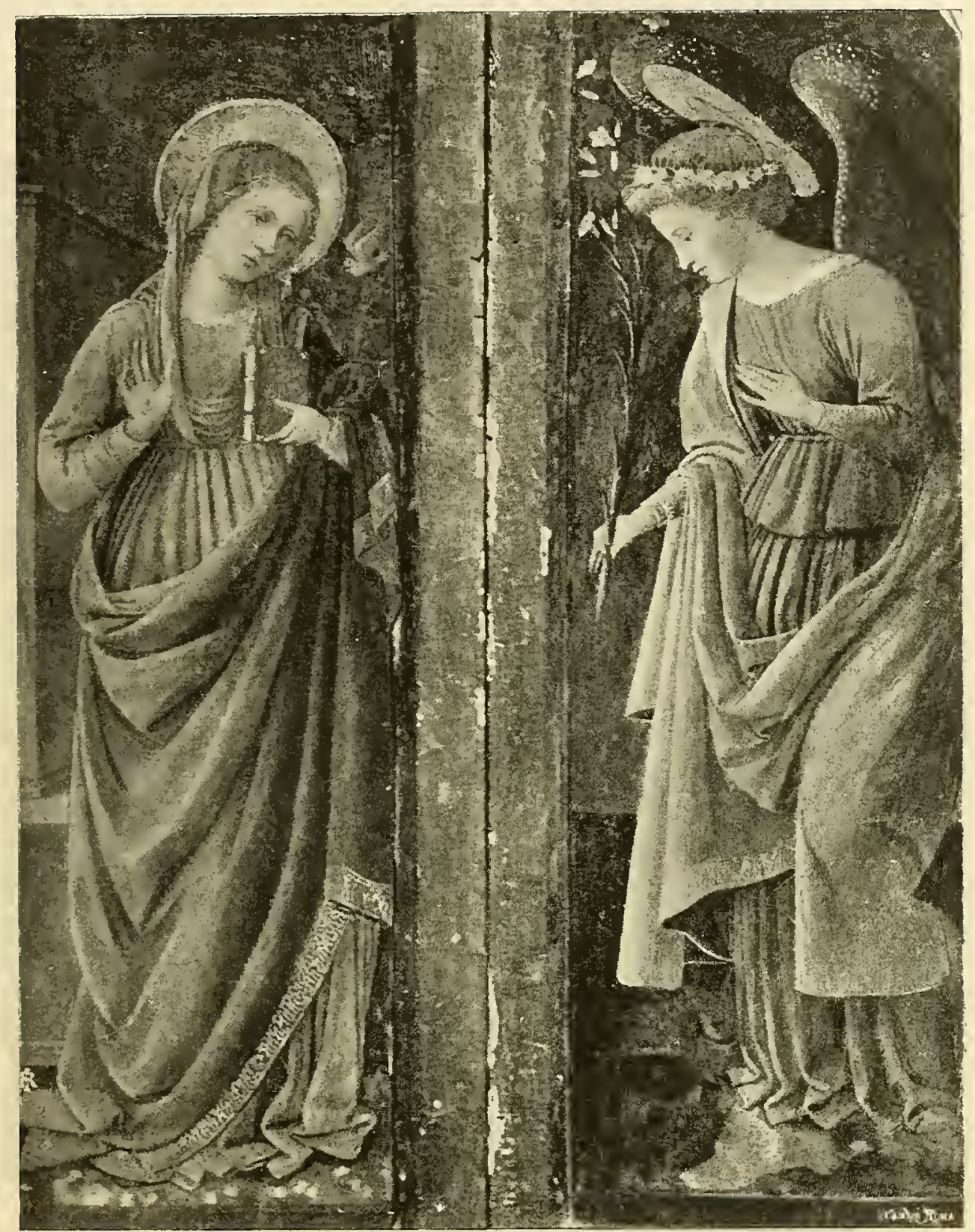

Galleria antica e moderna in Firenze

(Filimpo LtipPI) 
trecentistico, nei centri minori non solo si conservarono, ma, quasi che non dimostrassero abbastanza chiaro lo svolgimento del mistero dell'Incarnazione, e il raggio dorato che feriva l'orecchio della Vergine non indicasse bene l'avvenimento, si aggiunse pei campi dell'etra a Dio Padre e alla colomba anche il

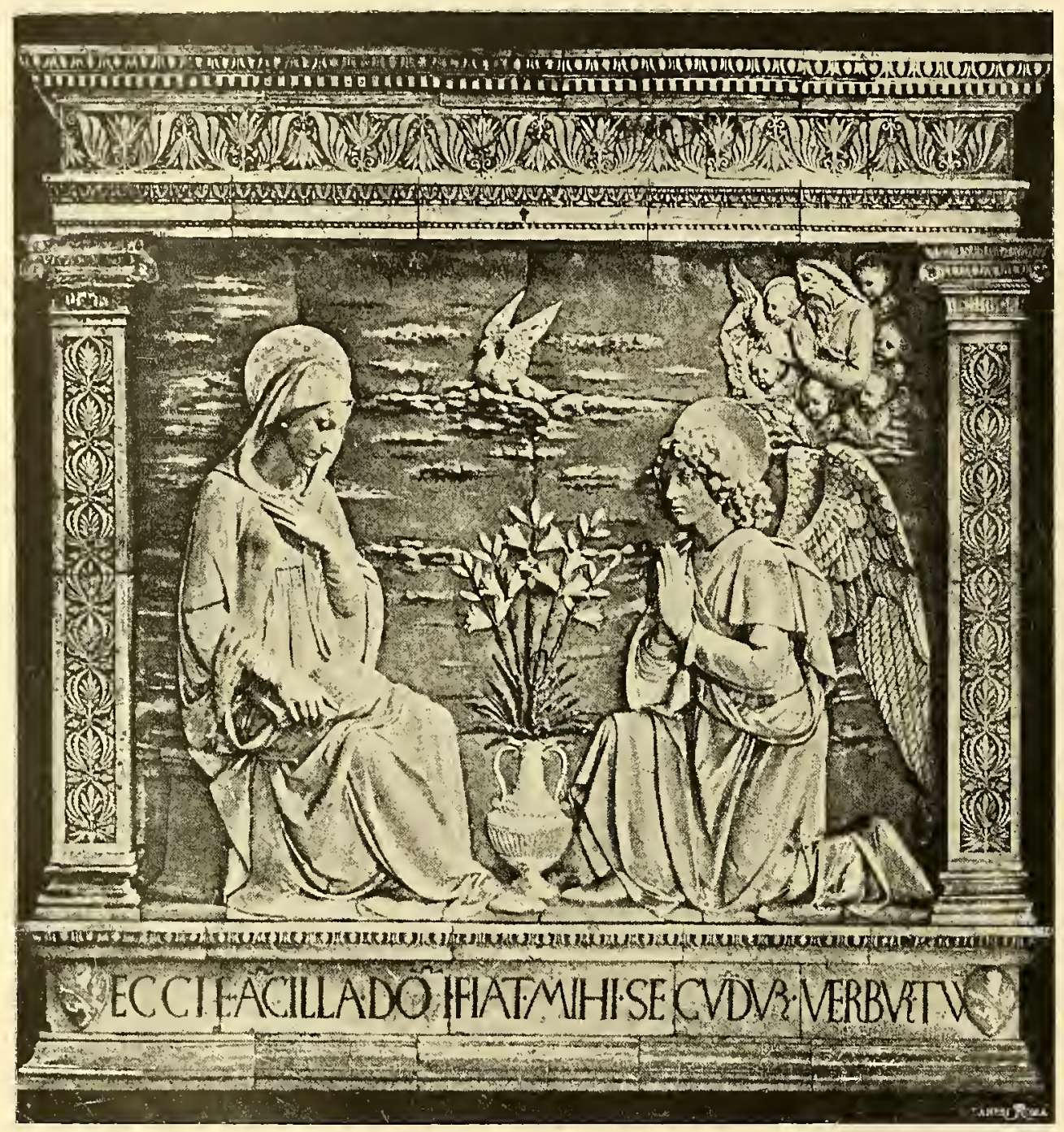

Chiesa della Verna nel Casentino

(ANDREA DELLA ROBBIA)

bambinello Gesù ignudo, con la croce sulle spalle, incamminato verso la Vergine sui fili d'oro di un raggio luminoso. Generalmente si vede in alto l'Eterno tra le nubi o in un' iride, poi la colomba nimbata, e più innanzi, nella stessa diagonale verso la Vergine, il Fanciullino con la croce. Cosi nel quadro di Giovanni Santi nella Galleria di Brera e in quelli di Domenico Panetti nell'Ateneo 


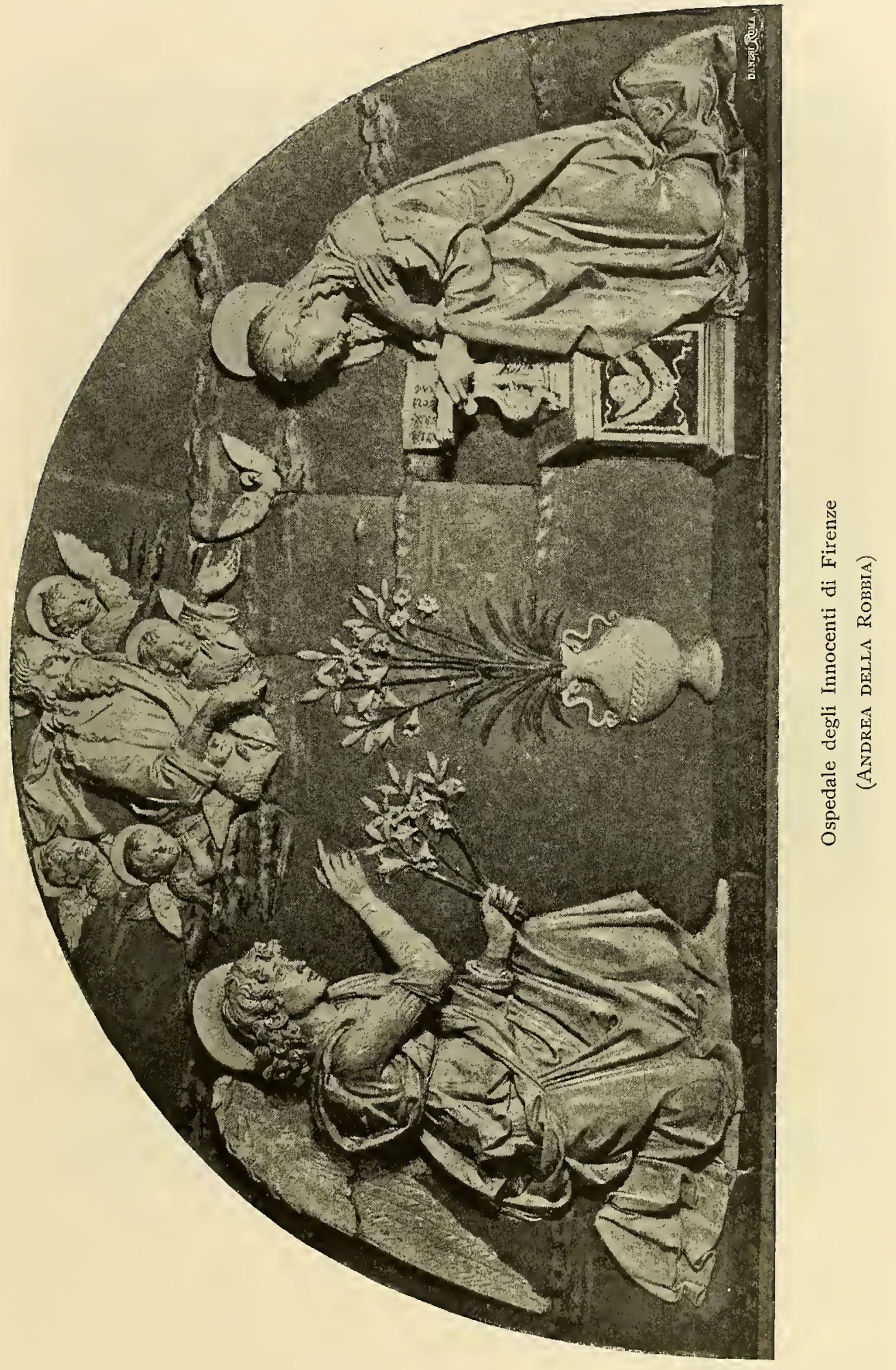


di Ferrara, del Loschi in una chiesa di Carpi, di Francesco Bianchi Ferrari nella Galleria Estense in Modena, ecc. Fu supposto che la rappresentazione fosse

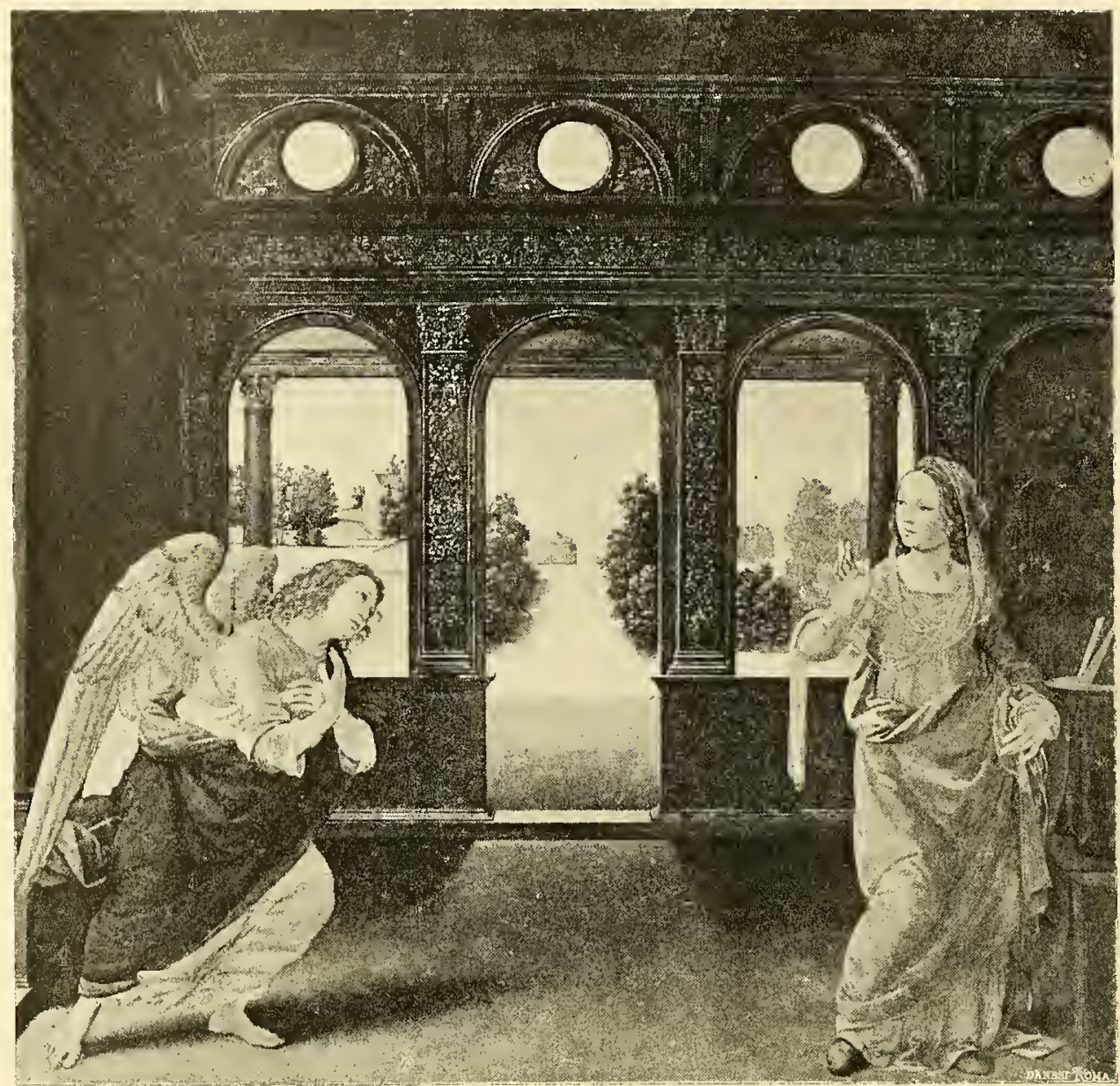

Galleria degli Uffizi in Firenze

(LoRenzo di CRedi)

una reminiscenza dell'eresia dei Valentiniani, i quali facevano prender corpo a Gesù nel cielo; ma forse era semplicemente un'aggiunta derivata dal bisogno di spiegare alle menti dei fedeli con segni sempre più manifesti il mistero religioso. Ottaviano Nelli, nel palazzo dei Trinci a Foligno, giunse sino a deviare il raggio dorato dalla via auricolare della Vergine per farle incendiare il seno. E tutti i particolari della rappresentazione si fanno realistici, e l'ambiente stesso lascia la regal forma antica per trasformarsi secondo gli usi popolari e la vita elegante del Quattrocento. Francesco del Cossa nell' "Annunciazione " della Galleria di Dresda dipinse una finestrina ad occhi di vetro, 
case con aperti loggiati e coi soffitti a formelle, un torrione in rovina, un cane e sino una lumaca che striscia sul pavimento. E Carlo Crivelli, nello splendido quadro della National Gallery, rappresentò la Vergine nell' interno di una casa signorile, con l'occhiuto pavone sul cornicione, con un loggiato superiore da cui pendono tappeti, con vasi di fiori sul parapetto e colombe posate sui bastoni messi orizzontalmente su ganci infissi ai muri. La Vergine è all' inginocchiatoio, e dietro son le cortine del letto ornate a fiorami,

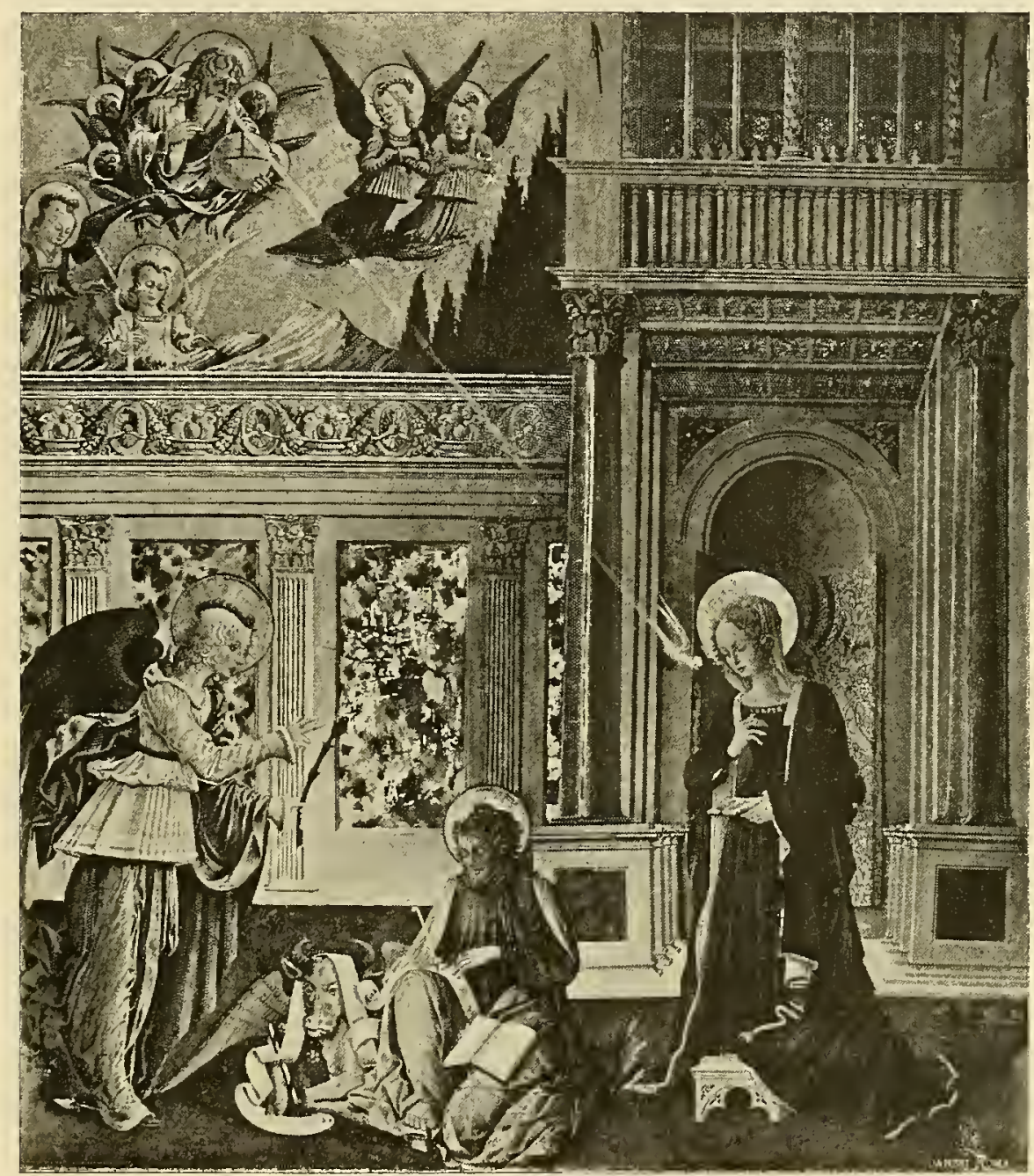

Pinacoteca Vannucci in Perugia

(BenedetTo Bonfigli)

sul quale si stendono una coperta ricamata, la bianca coltre rimboccata, i soffici cuscini all'origliere, secondo il modo tradizionale, come in una camera 


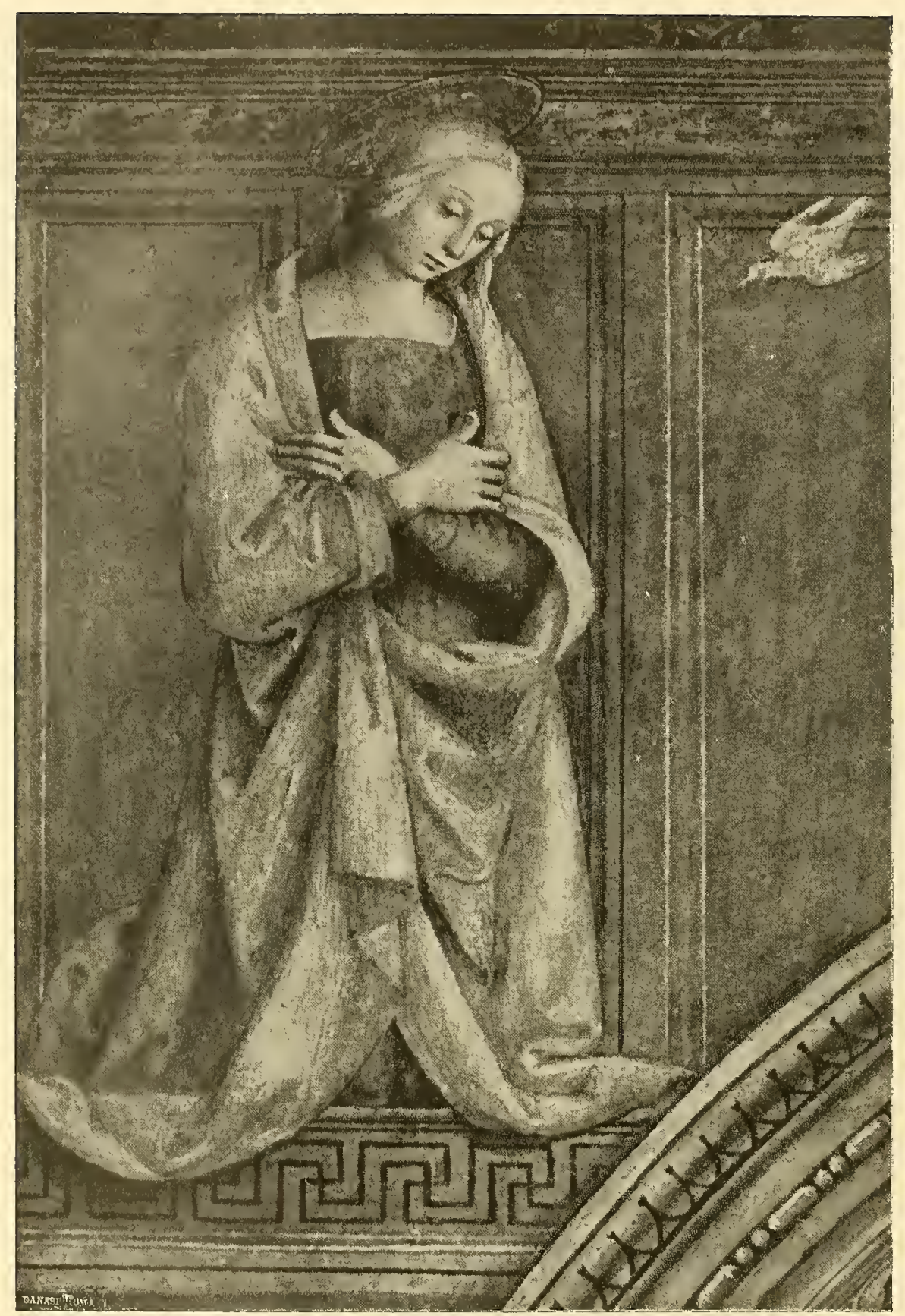

San Francesco in Montefalce

(Perugino) 


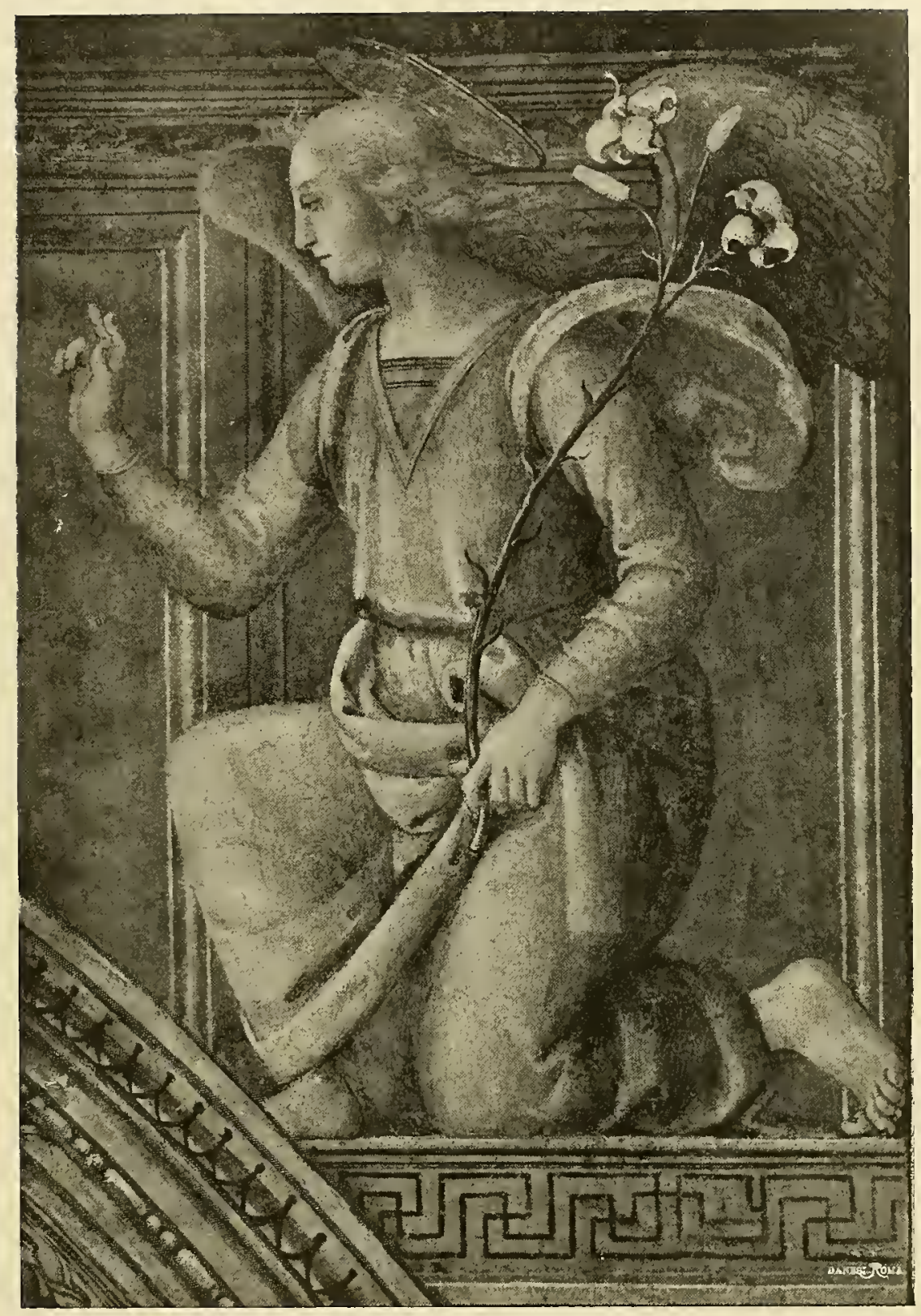

San Francesco in Montefalco

(Perugino) 
da bambole; su due modiglioni di legno poggia una tavola con vasi, barattoli, libri, una bottiglia di vetro, un candeliere, una scatola e piatti di maiolica. Una finestra, con inferriata e vasi di piante sul parapetto, illumina la stanza deco-

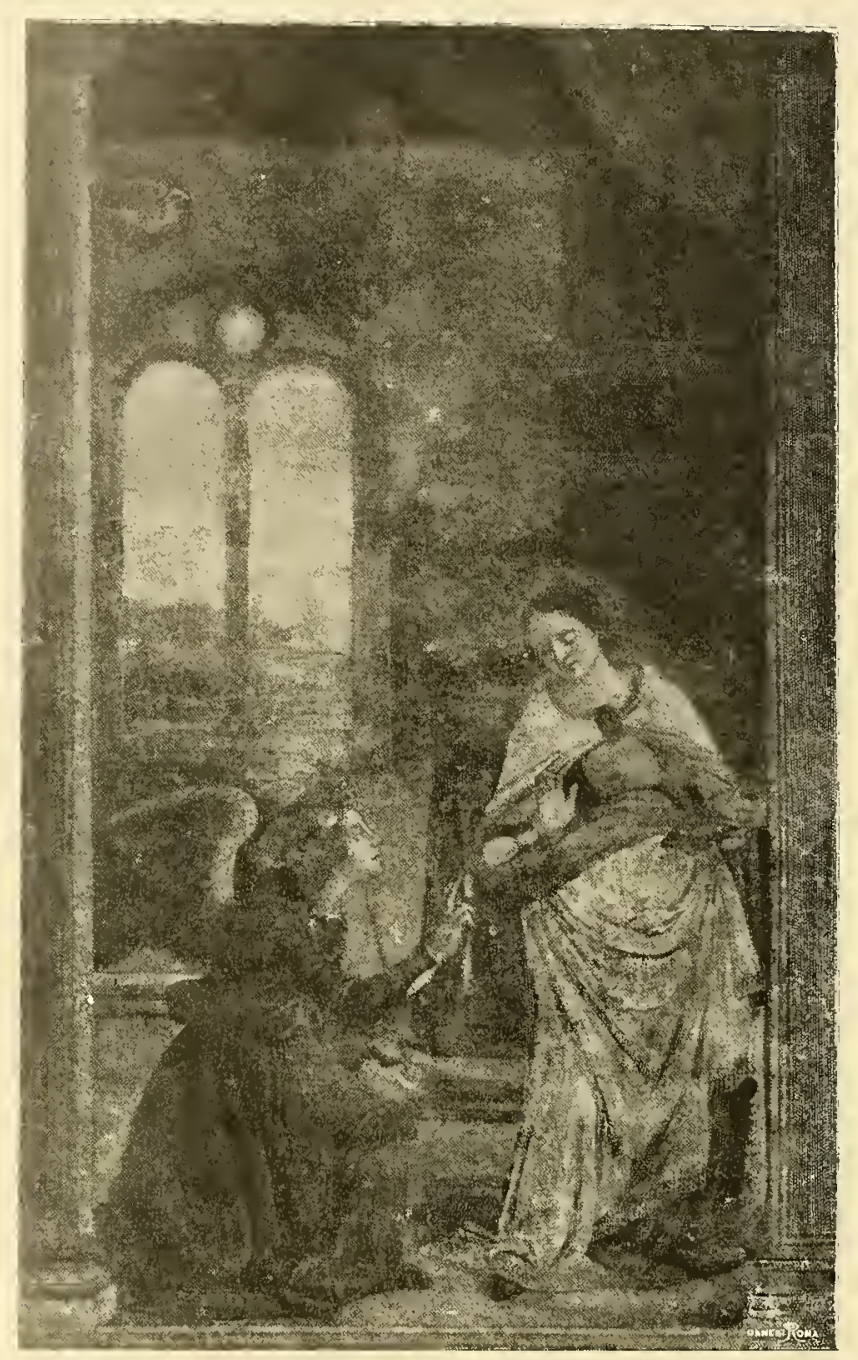

Santa Maria Novella in Firenze

(Domenico Ghirlandaio)

rosa di Maria. Innanzi alla casa corre una via che mette ad un arco, dietro cui gira una cinta merlata. Nel prino piano della via s'inginocchia l'araldo del cielo; ha una ritorta penna fissa alla gemma che ne adorna la chioma, una collana d'oro, piume sparse sull'omero destro e foglie d'acanto e svolazzanti fettucce; egli alza la destra per benedire, mentre il giovane Emidio, vescovo e patrono di Ascoli, sembra interrompere l'arcangelo per raccomandargli la 


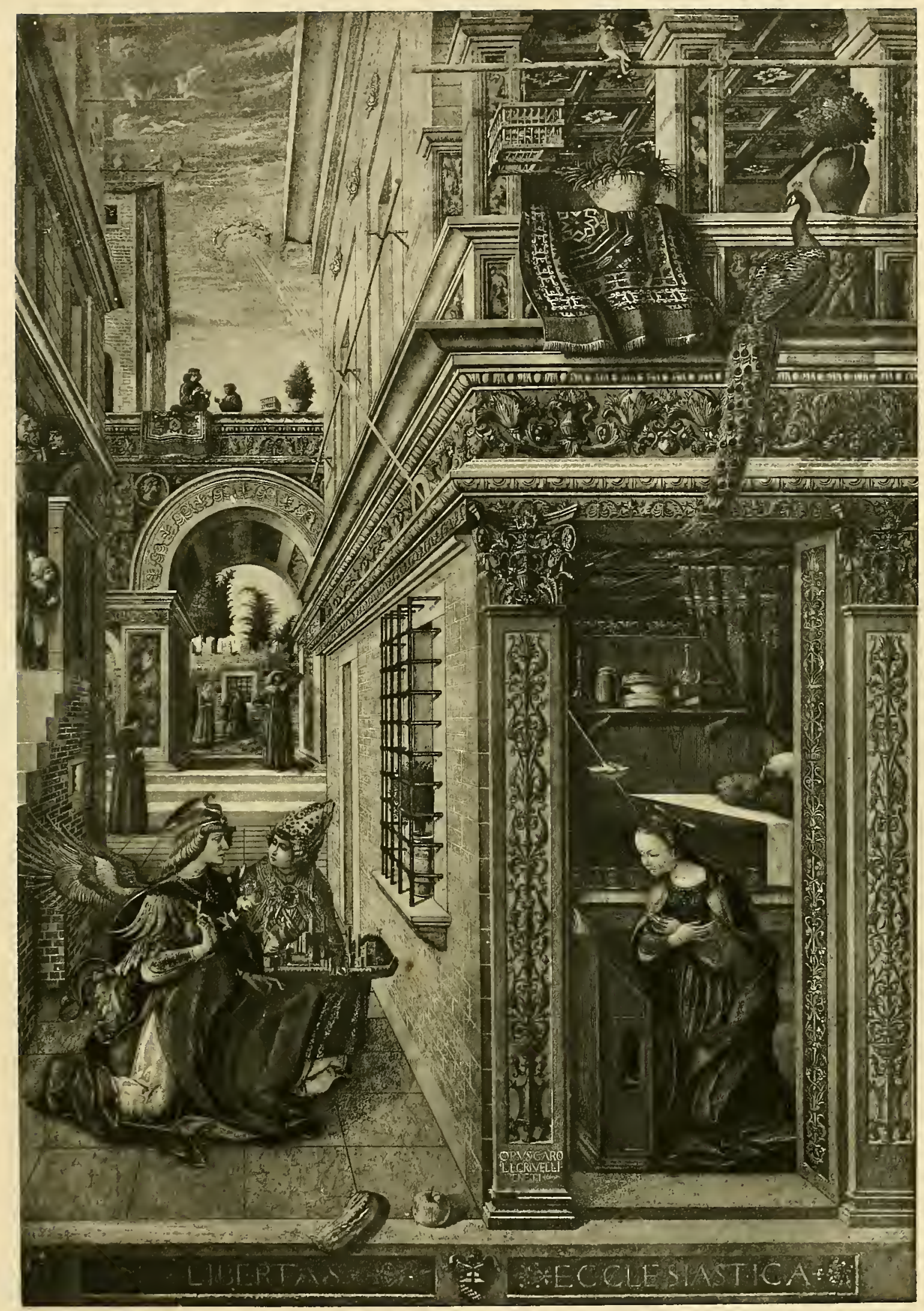

Dinse 


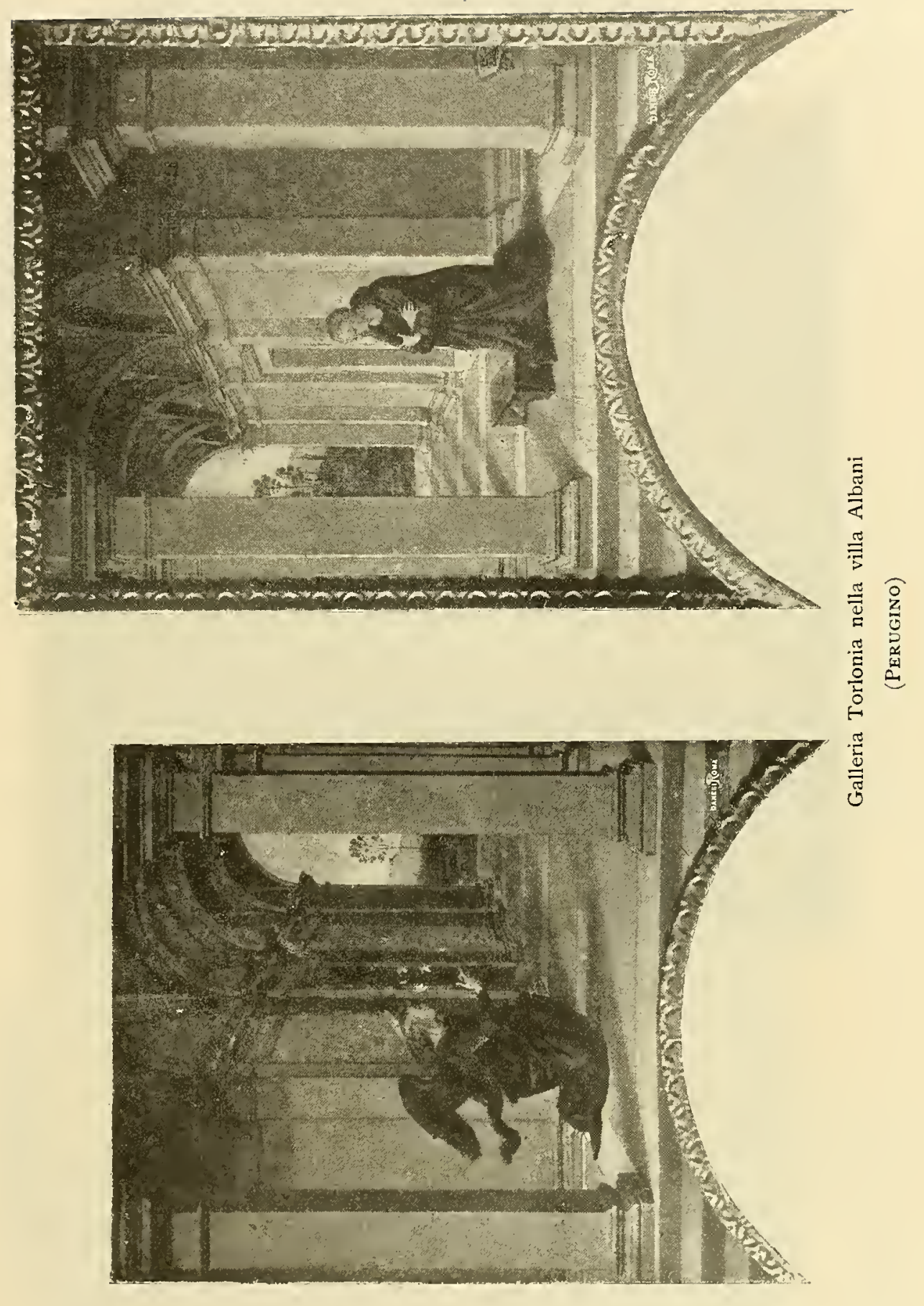


turrita città che tiene nelle mani. Dietro, uomini e donne passano per la via e si fermano a colloquio; sulla terrazza dell'arco un uomo legge un foglio ad un altro; nella casa di fronte a quella di Maria un bambino con cuffietta sporge la testina curiosa dall'alto di una scalinata, e dietro due monaci discor-

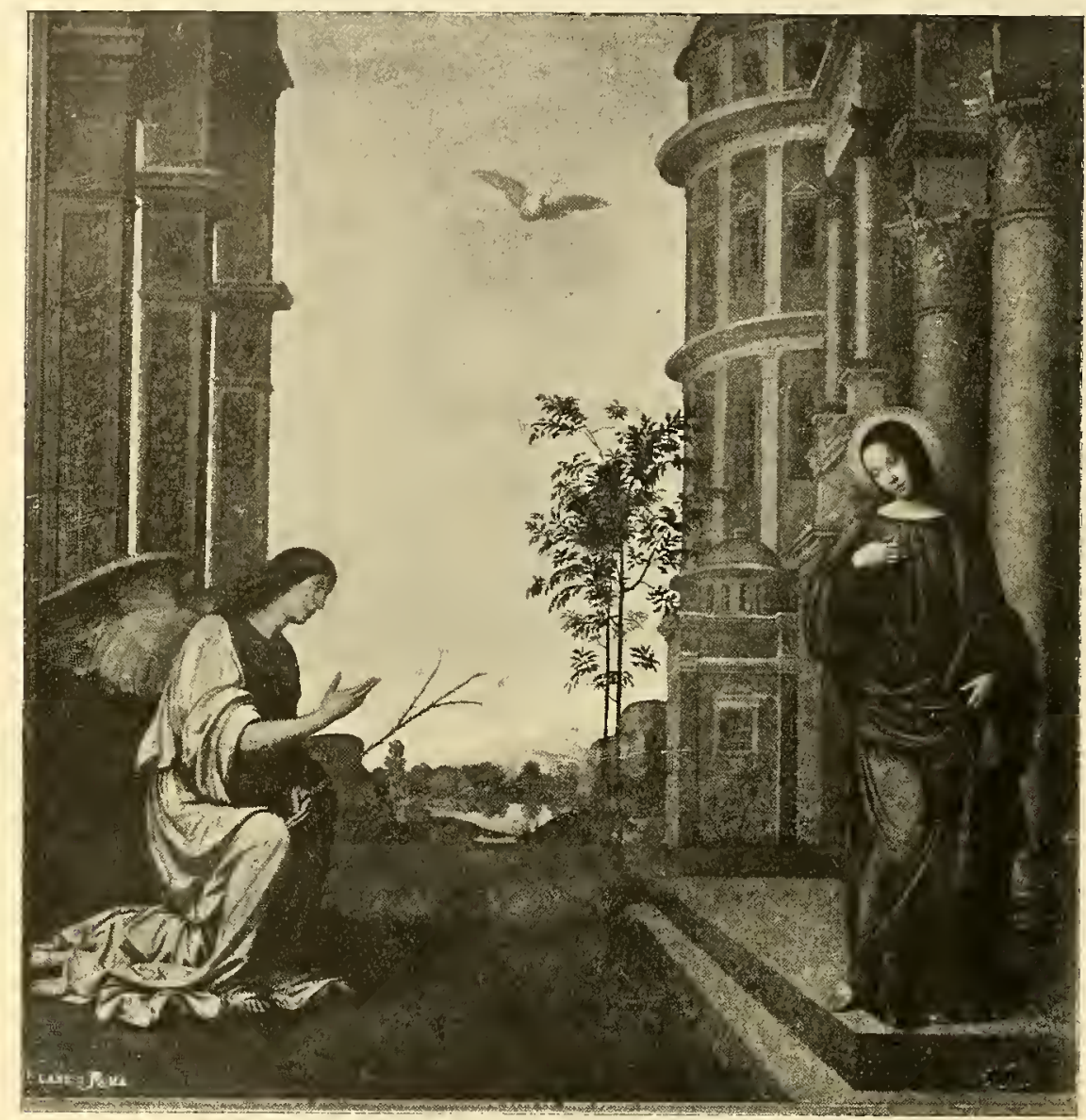

Pinacoteca di Brera in Milano

(Francesco Francia)

rono con un gentiluomo. Intanto nel mezzo di due corone d'angioli esce dal cielo e fende l'aria, come uno strale, un raggio dorato che passa per un occhio di vetro nel fregio della casa della Vergine e penetra nella stanza trasportando la colomba con ali aperte verso Maria. Carlo Crivelli così raccontava il mistero religioso al popolo ascolano, che i proprî costumi, il suo patrono, la sua vita vedeva in quel riso di colori chiesti al cedro e al melagrano. La casa della Vergine è nel più splendido stile del Rinascimento, con ornati lungo i pilastri, nei capitelli, nei fregi, ispirati all'arte romana. İn tal modo nel Cossa l'edificio 


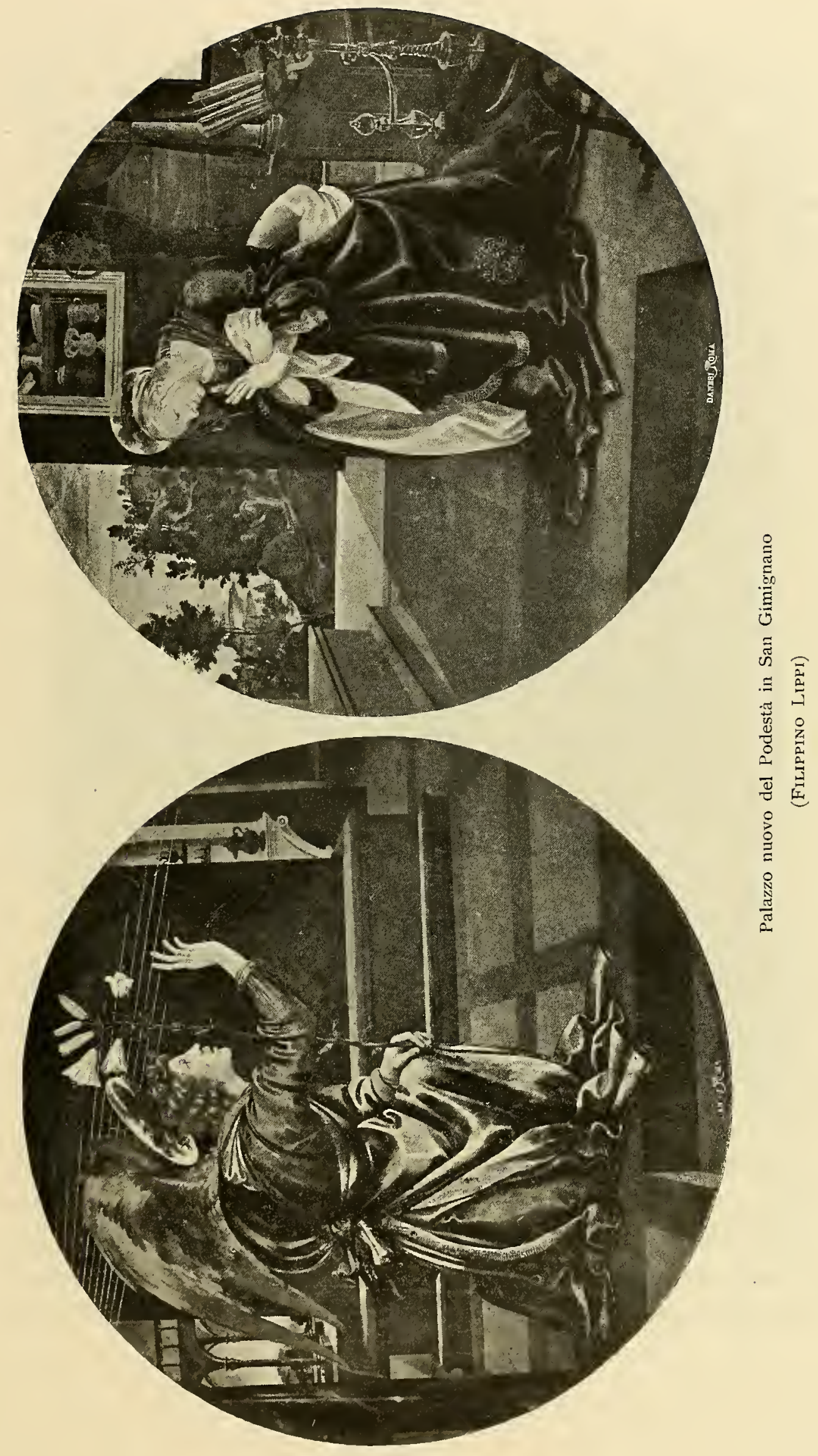


marmoreo solenne e la pila d'acqua santa presso alla Vergine, mostrano lo studio del classico stile. È evidente il contrasto fra l'espressione semplice della vita della Vergine con la magnifica architettura. Più tardi, nel Cinquecento, quel contrasto cessò, allorchè la Vergine apparve maestosa entro maestoso palazzo. Solo Lorenzo Lotto a Recanati rappresentò umile in umile luogo Naria, e dipinse un vero interno di casa, entro cui arriva di gran furia

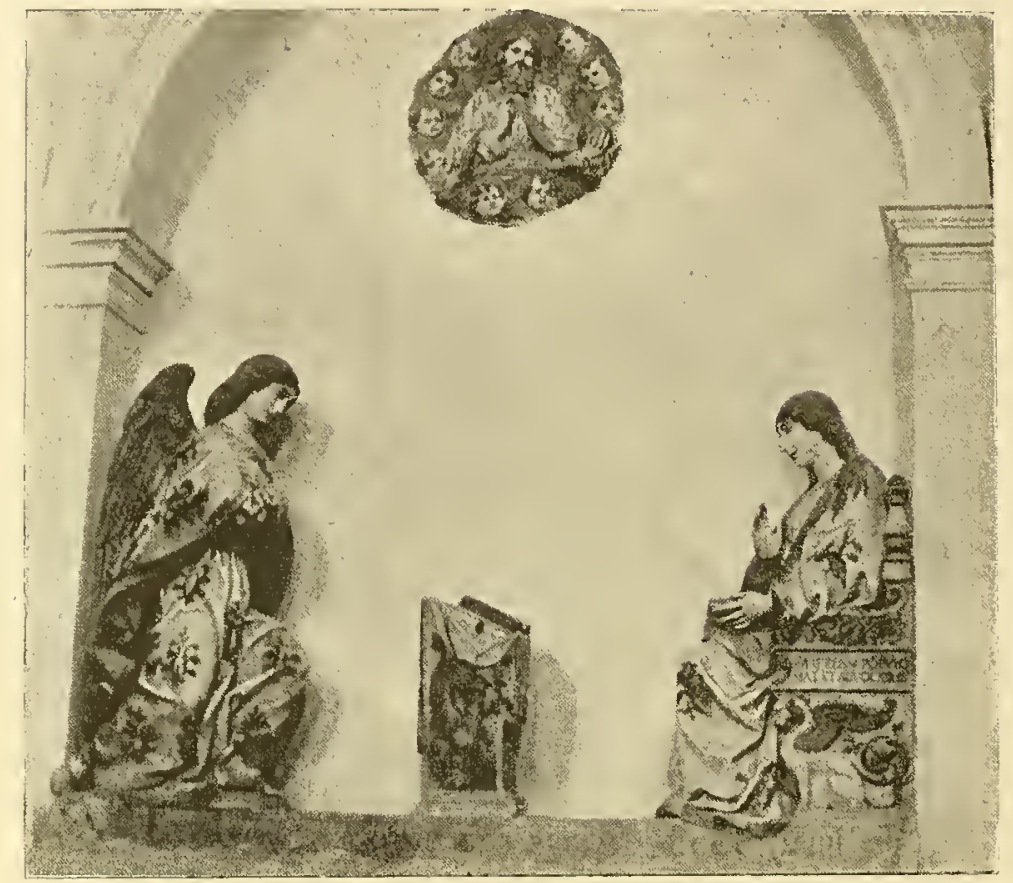

Sant'Agata a Castroreale

(Antonello Gagini)

l'arcangelo, che gesticola in modo animato, mentre l'Eterno tende le mani giunte all'Eletta; ed ella sta ginocchioni, con gli occhi fissi nel lontano, rannicchiata, con le mani aperte innanzi a sè, come se il cuore le sussulti nel petto tremebondo al sentire il rombo delle ali e il saluto dell'arcangelo, alla cui voce un piccolo micio fugge. Sul camino stanno un libro, una candela ed altre cose; dalla cornice della cappa pende un drappo, e sulla parete s'apre una finestrina con scudetti di vetro. La scena religiosa era divenuta così una scena di genere, non del tutto però, chè gli elementi soprannaturali ed umani cozzano ancora nel quadro. Vi è il contrasto della vita umana col miracolo, l'interruzione delle forme schiette della natura, il sopravvento della realtà sull'ideale. 


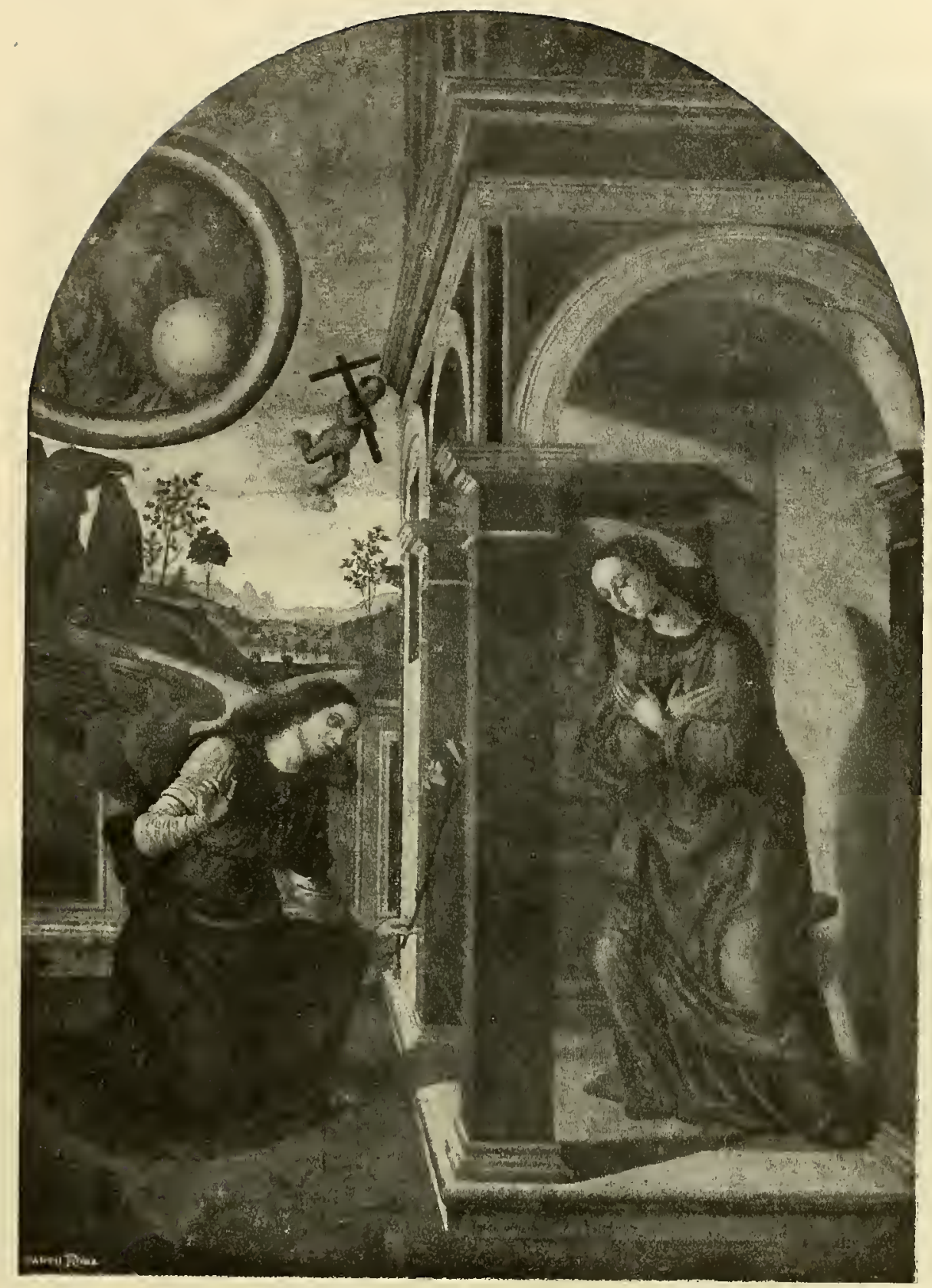

Pinacoteca di Brera in Milano

(Giovanni Santi) 
Il Cinquecento accolse dalle mani dei quattrocentisti la composizione loro prediletta, ma non l'amò, perchè quei caratteri di semplicità e di chia-

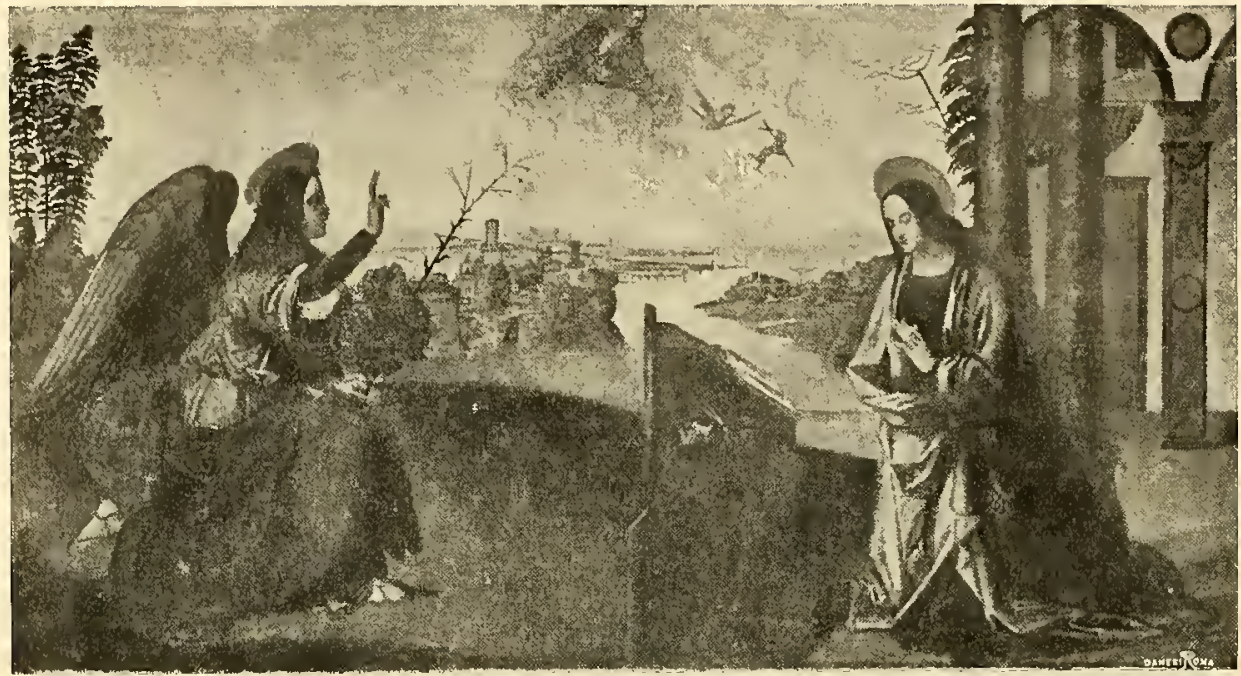

Galleria dell'Ateneo in Ferrara

(PANeTtI)

rezza, proprî della mistica scena, non potevano attrarre l'arte, che ormai cercava il meraviglioso, i grandiosi effetti monumentali. I quattrocentisti, come

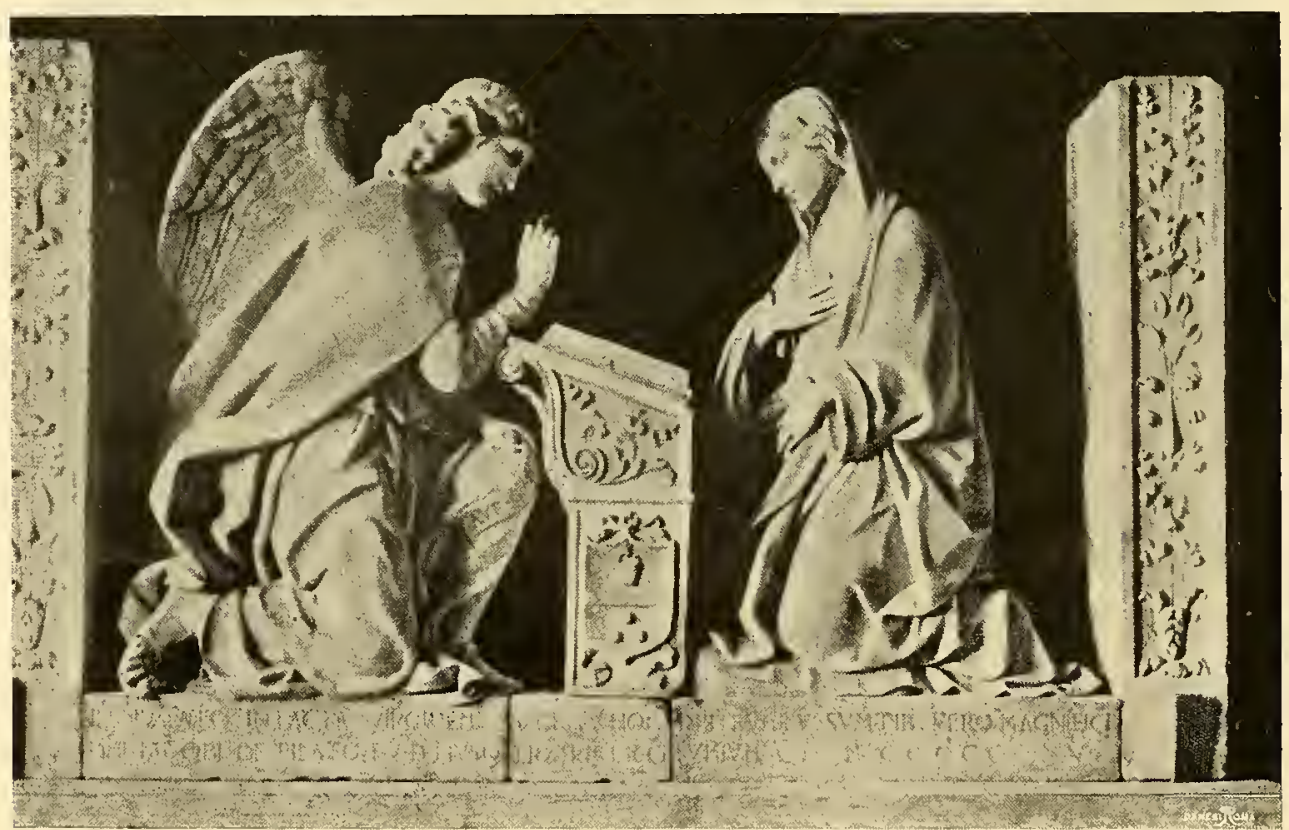

Museo Municipale a Monte San Giuliano

(Antonello GaGini) 


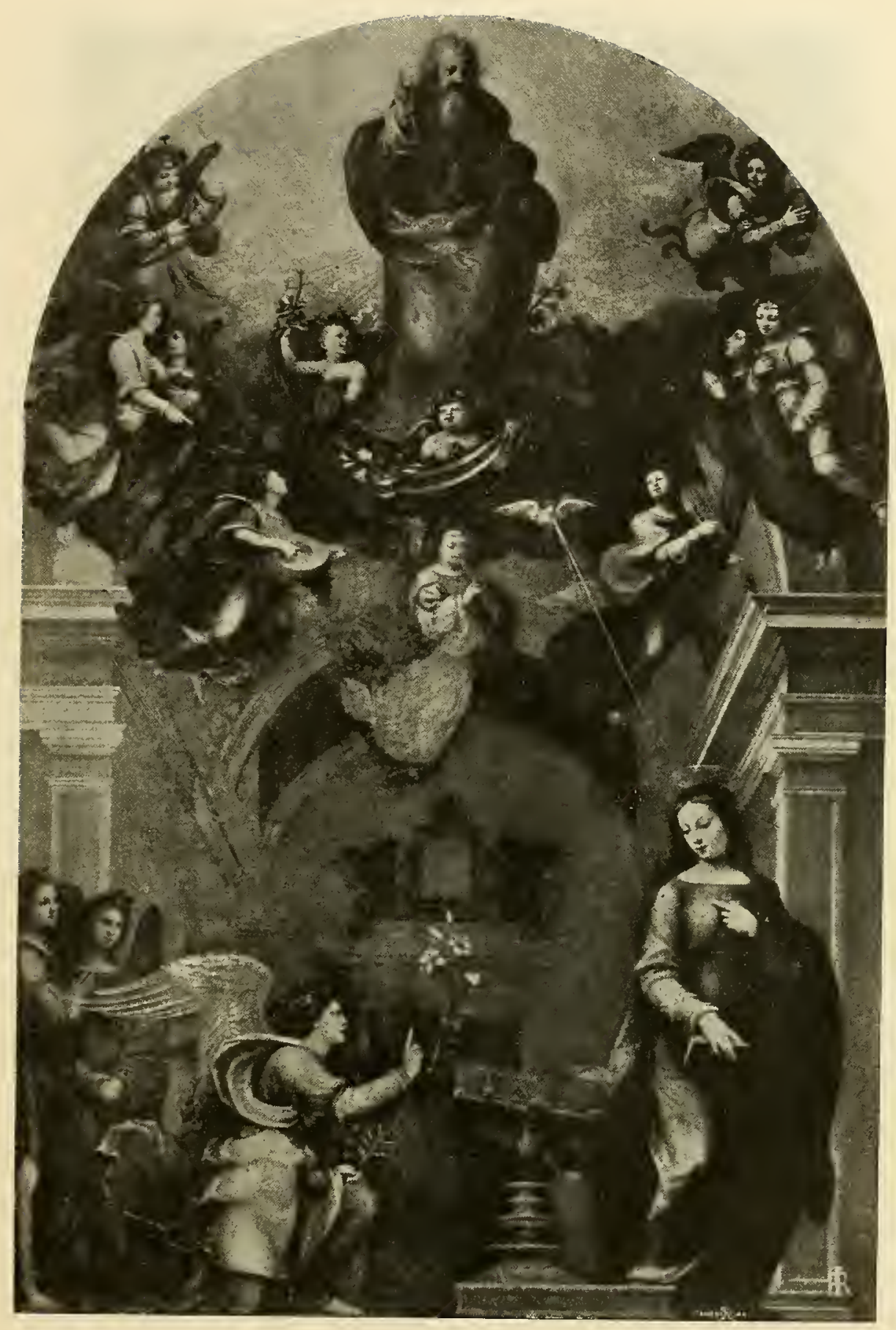

Galleria antica e moderna in Firenze

(Mariotto Albertinelli) 


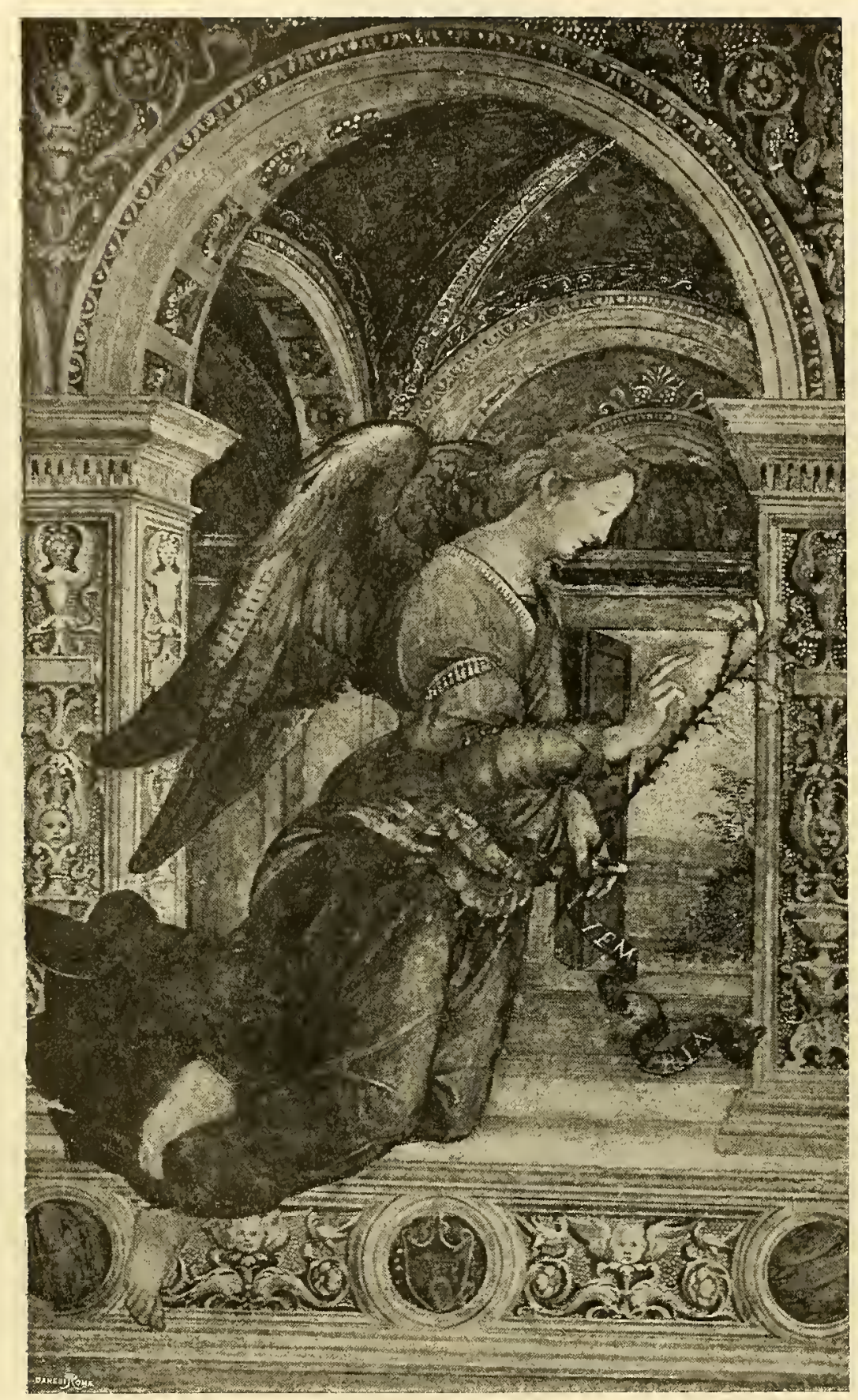

Oratorio di San Bernardino a Siena

(Girolamo del Pacchia) 


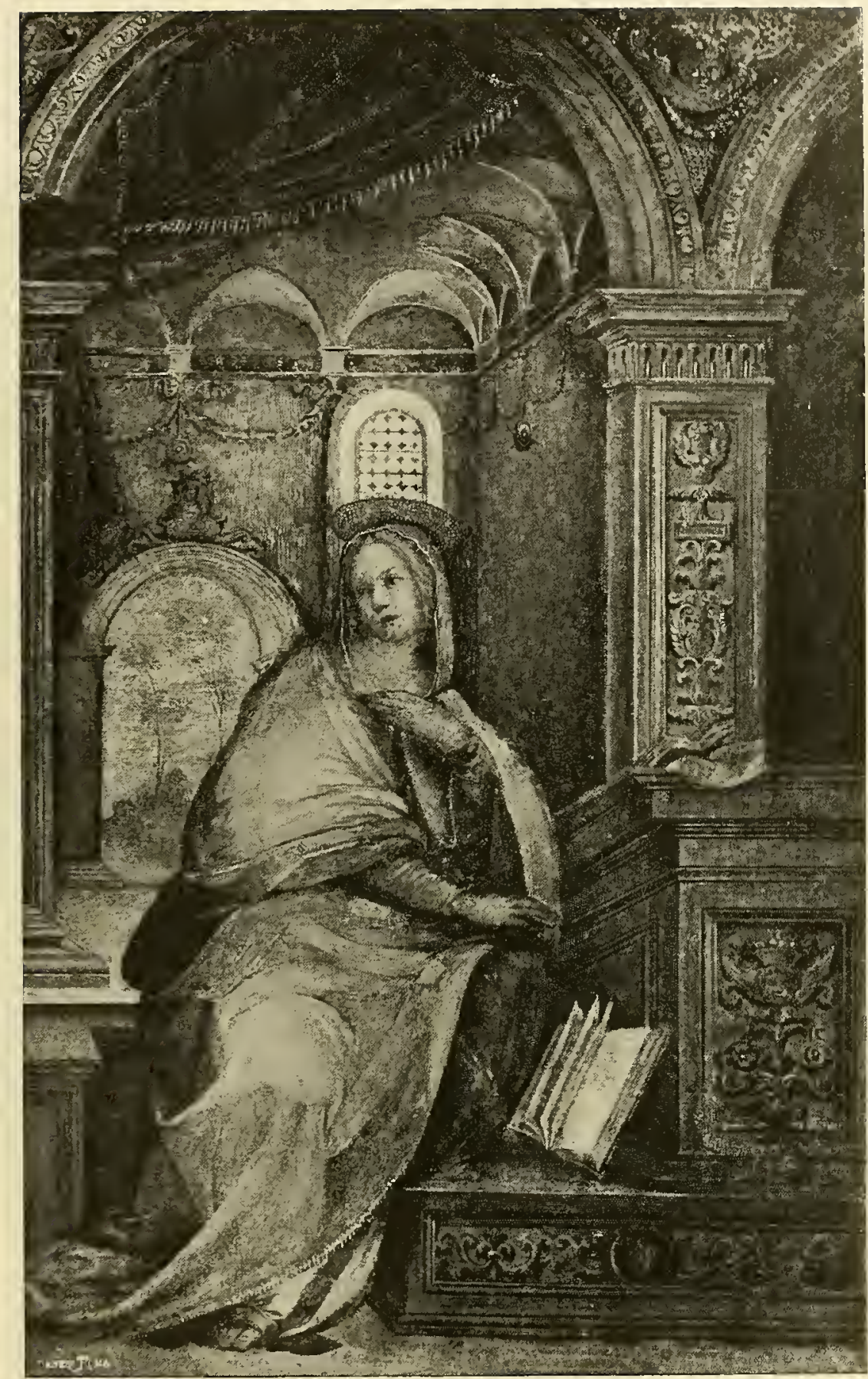

Oratorio di San Bernardino a Siena

(Girolamo del Pacchia) 
gli ultimi trecentisti, posero da per tutto le figure dell'Annunciata e dell'angiolo sui pinacoli degli altari, nei tondetti supremi dei polittici gotici, sulle arcate; e iscrissero nei nimbi d'oro degli angeli: Ave Maria, come sugli

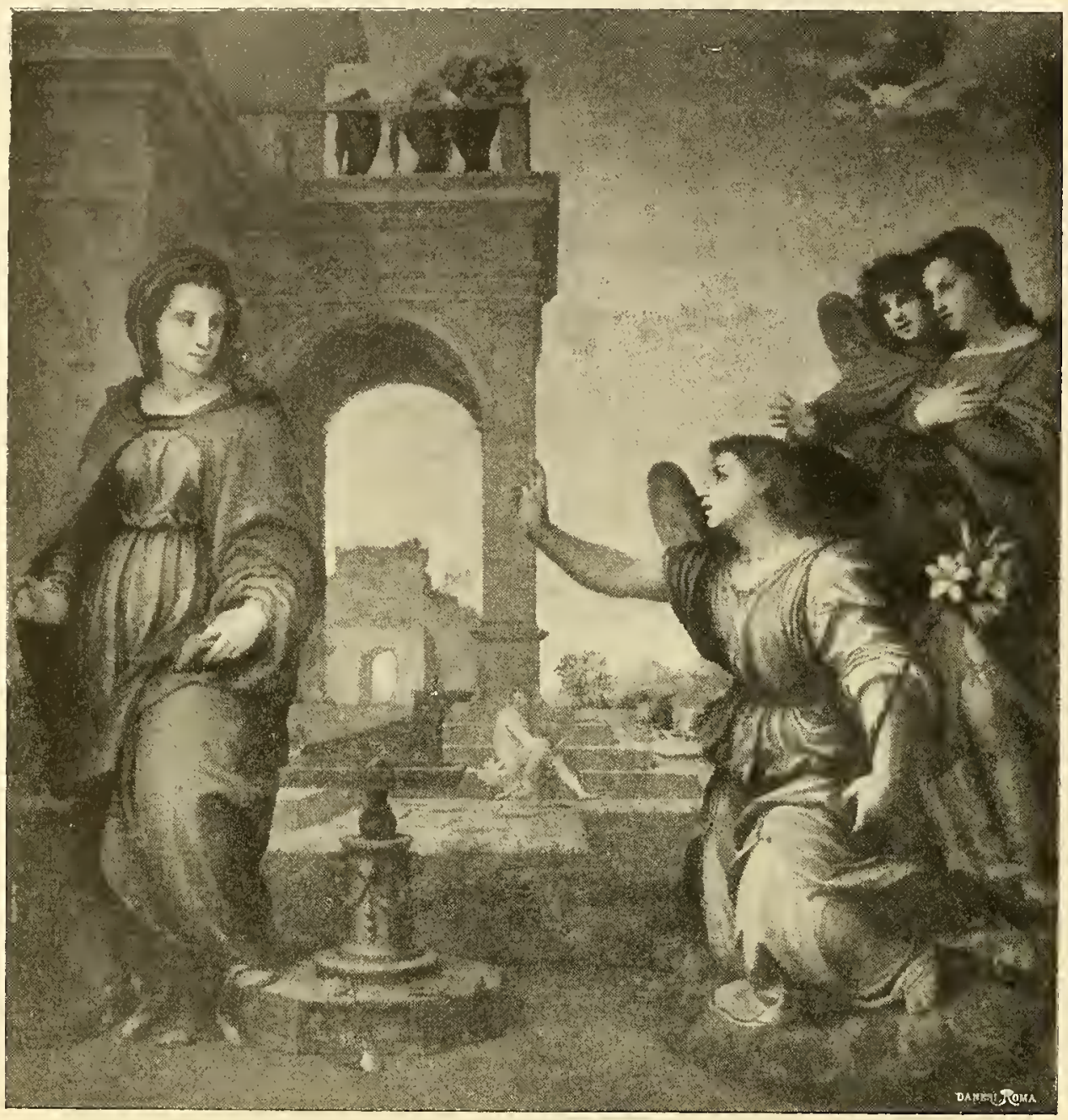

Galleria Pitti in Firenze

(ANDREA DEL SARTO)

orli dorati della veste e del manto della Vergine. Allora il popolo nel sacro mistero vedeva l'inizio della redenzione umana, e lo ricordava di frequente nelle preghiere quotidiane, nell' Angelus stabilito dalla Chiesa al tempo di Calisto III. Quindi la scena era divenuta il primo capitolo d'ogni racconto sacro o l'introduzione d'ogni opera d'arte religiosa. Ma il Cinquecento abbandonò le due ritmiche figure, troppo pure e semplici; e quando volle raffigurarle, non ne intese la modestia. Come se in una chiesa, ove si diffondeva la 


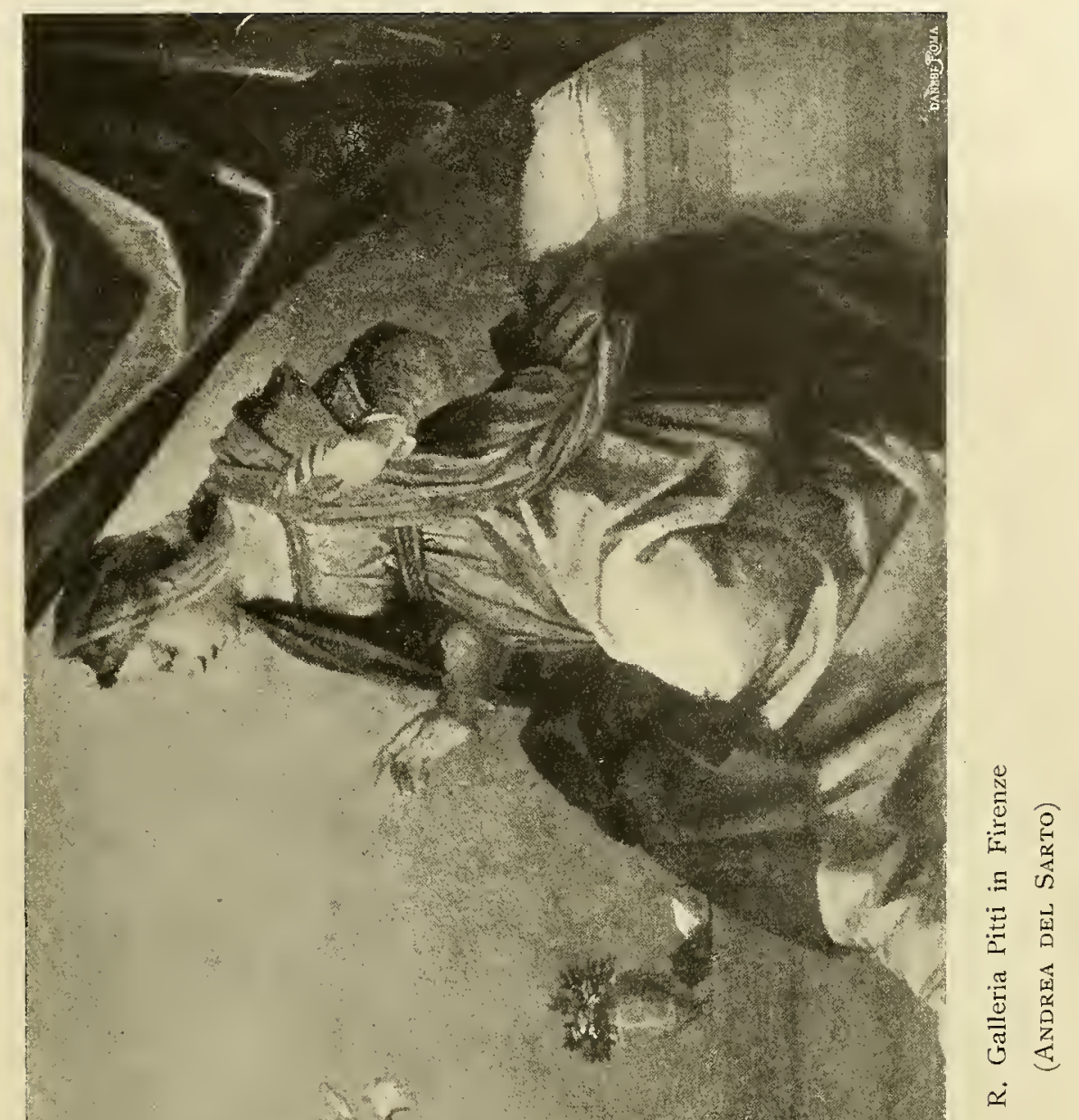


grave voce dell'organo lungo le silenziose navate, rimbombassero variati strumenti e rimbalzassero gli echi delle vôlte, e nubi d'incenso velassero la luce degli altari, già tranquilla e mite, divenuta d'un tratto tutta fuoco e faville.

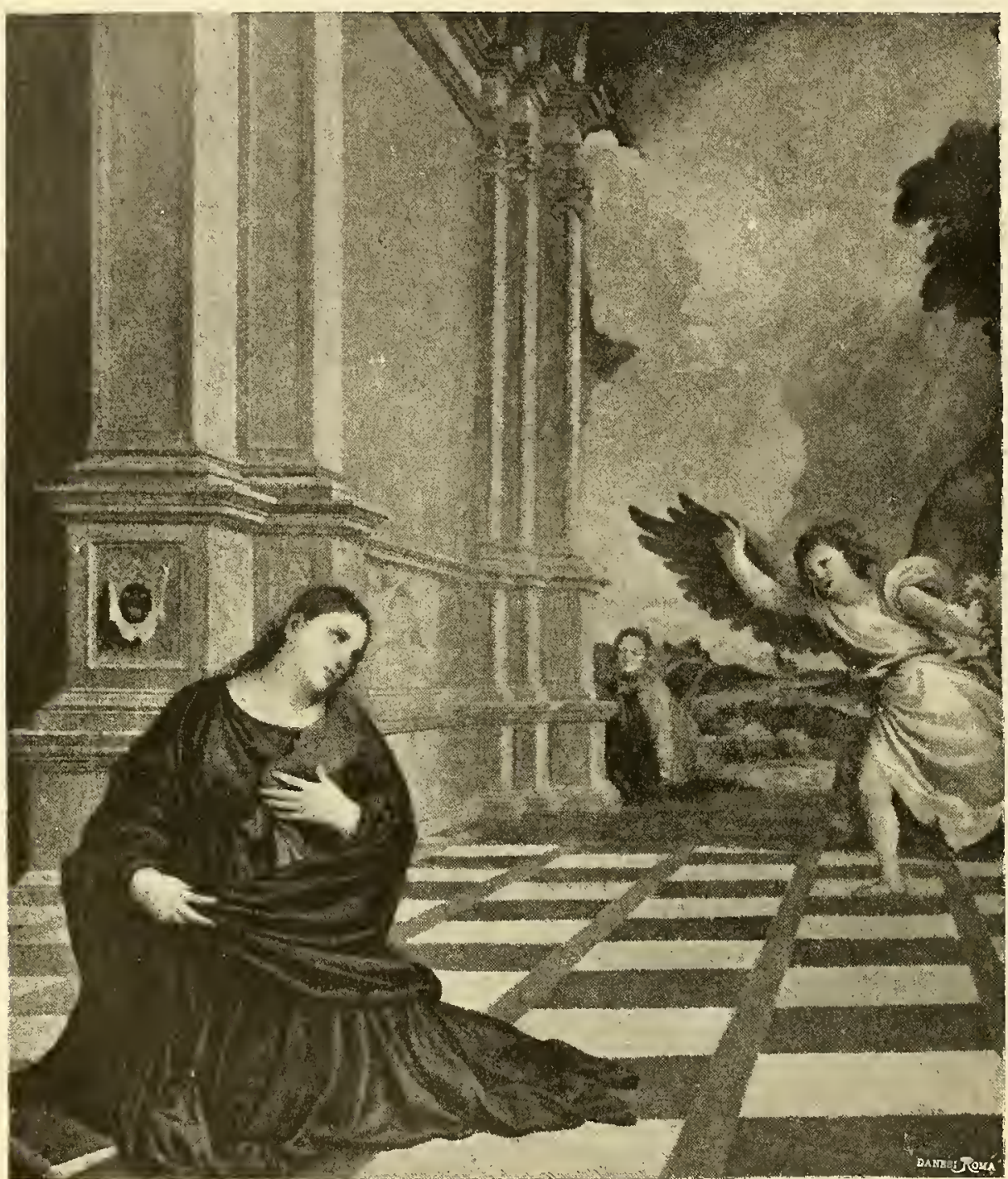

Cattedrale di Treviso

(TIZIANO)

così nell'arte si cercò la solennità col teatrale, l'effetto coi clamori e gl'inni dell'apoteosi. Nel dipinto dell'Accademia di Belle Arti, a Firenze, Mariotto Albertinelli si attiene ancora al tipo donatelliano della Vergine, ed anzi ne mitiga la vivacità della mossa; ma mette altri angioli a corteo di Gabriele e nel cielo una schiera d'angioli oranti, musicanti, che penetra a volo nelle 


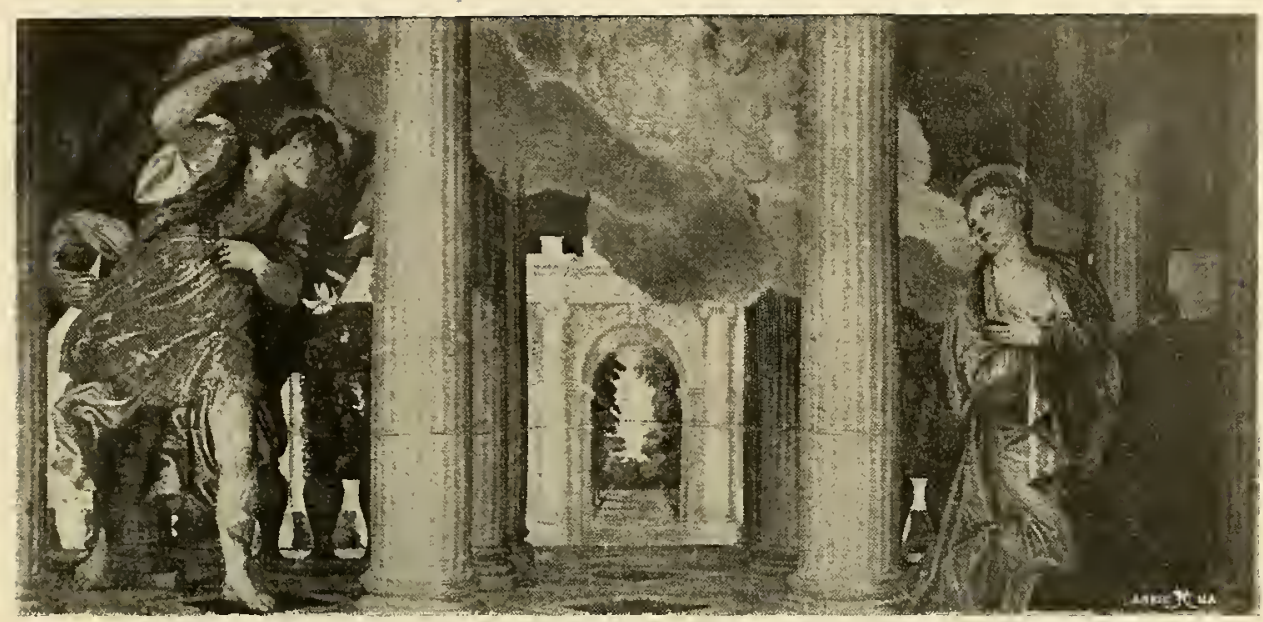

Galleria degli Uffizi a Firenze

(Paolo Veronese)

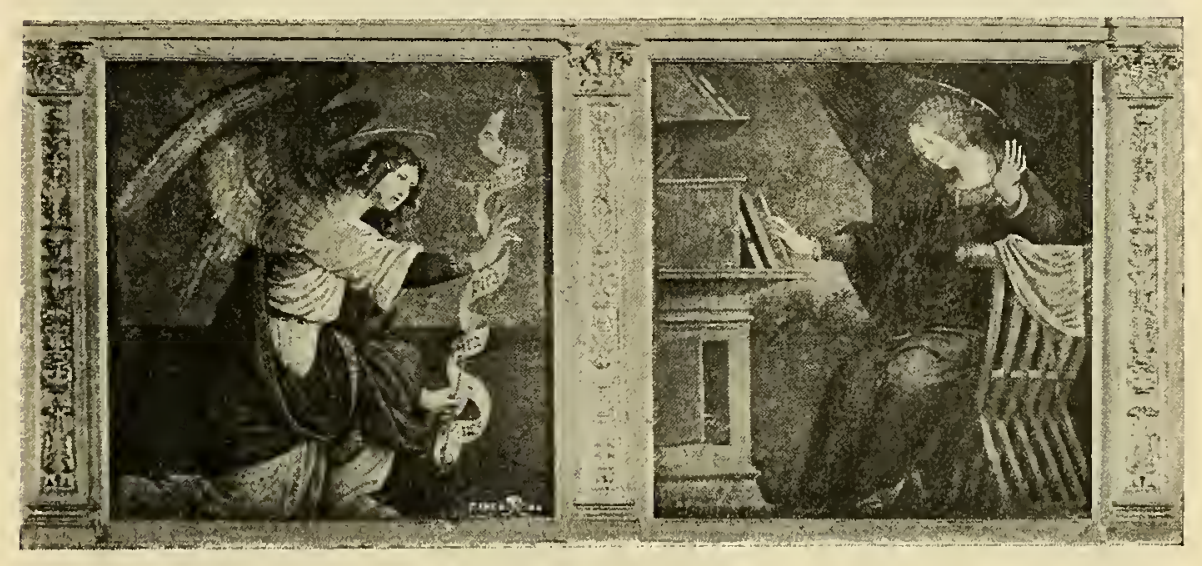

Galleria Layard in Venezia

(Gaudenzio Ferrari)

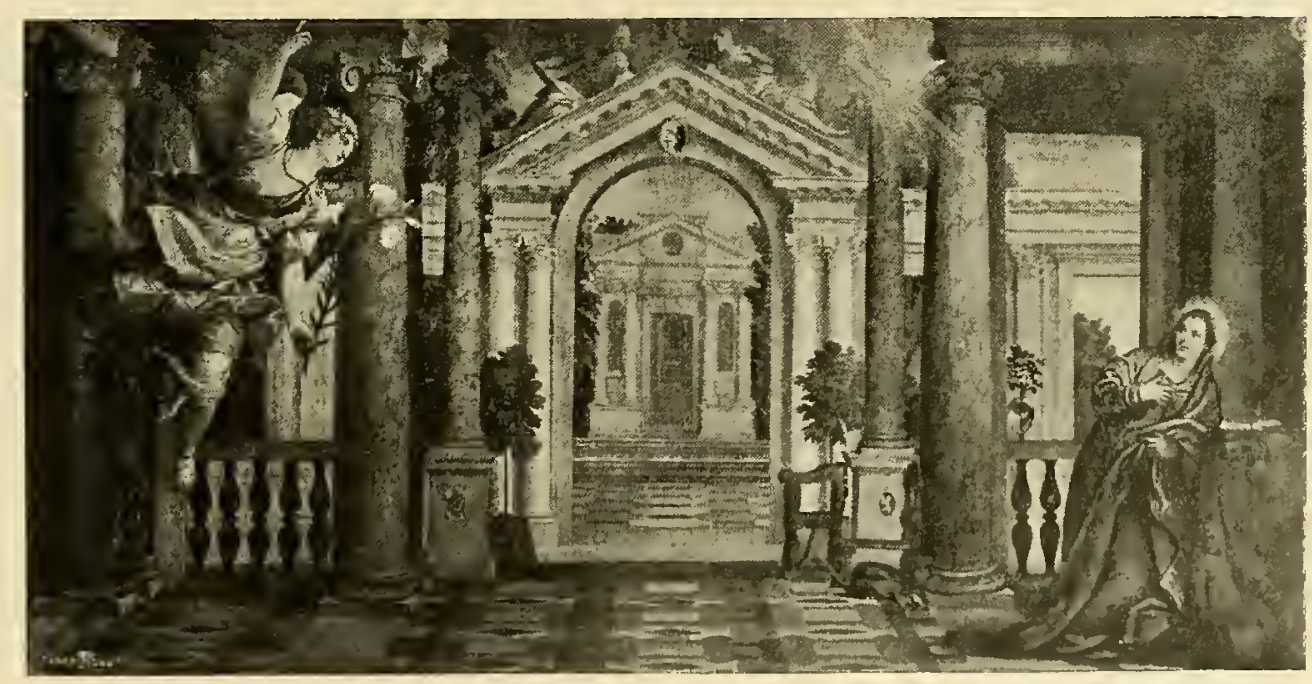

Galleria della Accademia di Belle Arti a Venezia (Pholo Veronese) 
arcate del luogo, e s'aggira a mo' di corona intorno a Dio Padre, che sta in piedi sulle nubi, tra raggi diritti e serpentini, benedicente. È l'apoteosi della Vergine, quale i quattrocentisti si erano riserbati di colorire nella "Assunzione ", rappresentandola Madre sollevata alla gloria, tra i cori degli angioli e dei beati. Più semplice nella composizione è il Sodoma a Siena; ma la Vergine, per l'opulenza delle forme matronali, non sembra tale, come non

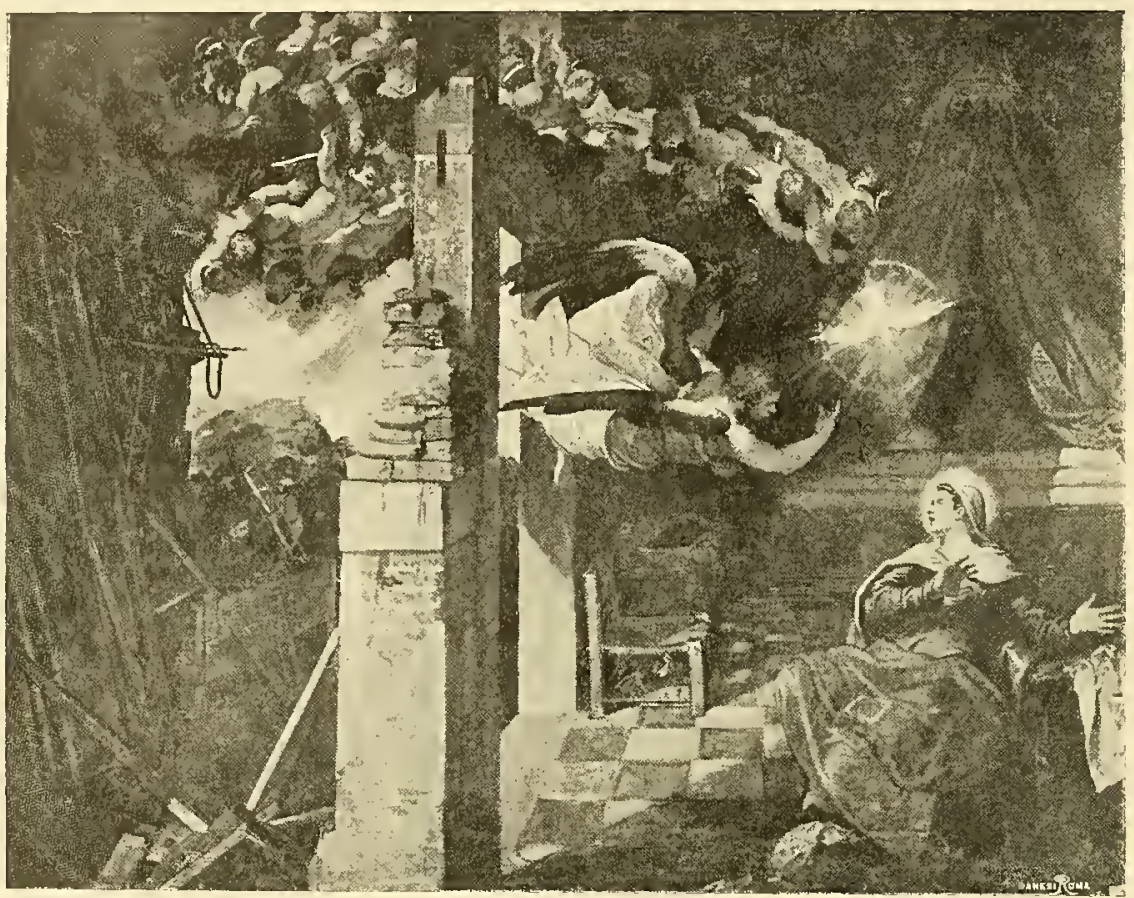

L'Annunciazione della Vergine

(TINTORETTO)

sembra nei quadri di Paolo Veronese a Venezia, esuberanti di vita, di luce, di carne. Gli angioli piombano dal cielo nei fastosi vestiboli, sulle terrazze marmoree, tra i colonnati superbi; e la colomba simbolica, che già scendeva sur un filo d'oro o sur una nuvoletta, sembra scoppiettare luce tutto intorno; e scendono le nubi, entro cui nuotano miriadi di esseri, a coprir d'ombra Maria.

Più semplicemente espresse Tiziano il sacro mistero, nella cattedrale di Treviso. Maria, bellissima matrona, inginocchiata sul pavimento mormoreo, si volge con languida espressione a Gabriele, che corre a lei cantando, corre come figlio alla madre. L'arcangelo è divenuto un fanciullo, inconscio 
apportatore dell'annuncio. Sembra che il pensiero della maternità faccia trasalire il cuore a Maria, e la dolcezza della speranza le avvolga abbandonatamente il bellissimo corpo. Maria non è la rosa mistica, ma rende l'ideale femminino del Vecellio senza ieratici contorni; e il raggio divino non cade su lei a guisa di strali d'oro, ma come luce che si sprigioni dalle nubi e ne inondi l'immagine, specchio di bontà. L'arte italiana, nello spirare bellezza dolcissima alla Vergine, nel rendere umana la celestiale figura, pareva intendere come nel mistero s'ascondesse la speranza dei secoli per il ritorno della giustizia sulla terra, della verità, della pace. 



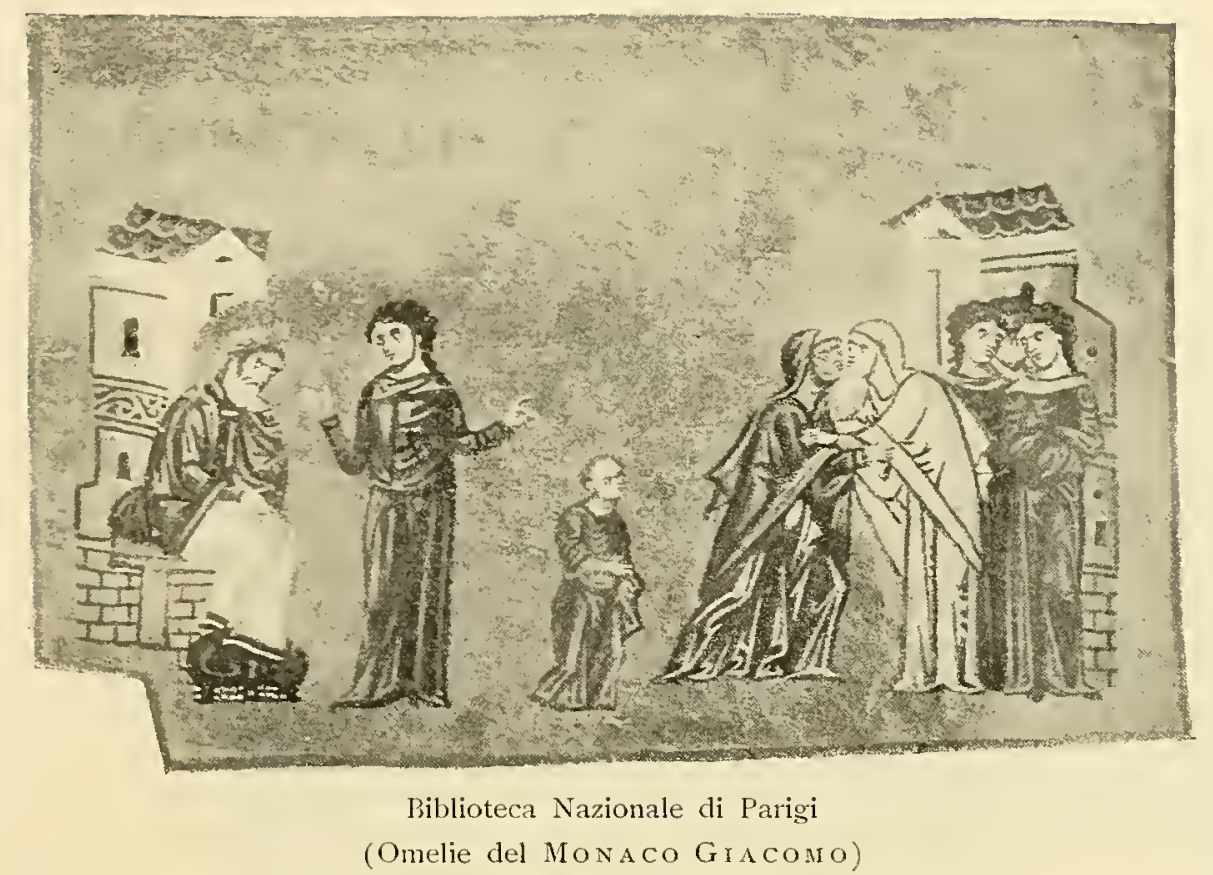

\section{La Visitazione.}

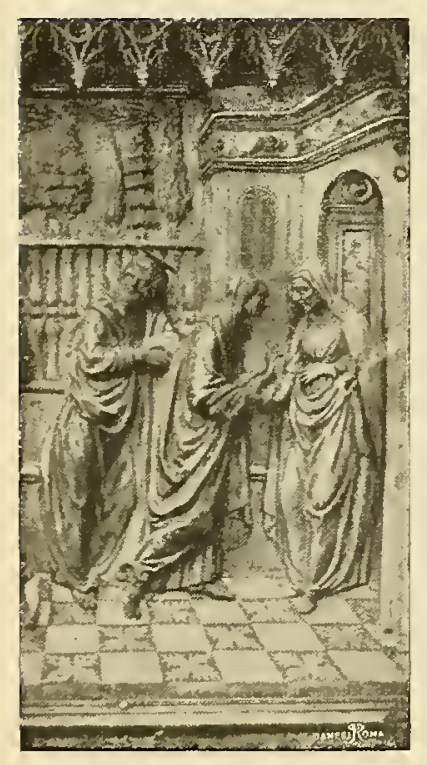

Dal dossale d'altare in Santa Maria del Fiore (Bernardo Cennini)

La Visitazione della Vergine a Sant'Elisabetta segue immediatamente all'Annunciazione nel racconto degli Evangeli, che è questo: Pochi giorni dopo l'Annunciazione, Maria si alzò e si mosse in gran fretta verso la montagna per giungere a una città di Giuda : entrò nella casa di Zaccaria e salutò Elisabetta, che ne provò grande commozione entro di sè, e gridò: Voi siete benedetta fra le donne. Qual felice occasione conduce a me la madre del Redentore? Appena ho udito la vostra voce, il mio seno ha trasalito di gioia. E Maria ad Elisabetta: La mia anima glorifica il Signore; il mio spirito è compreso di gioia, perchè Lui ha abbassato gli occhi sull' umile sua serva, ed ecco che già tutte le generazioni mi chiameranno felice. Colui che è potente ha prodotto grandi cose in me, e il suo nome è santo, e la sua misericordia si spande di età in età sui fedeli : egli ha spiegata la forza del suo braccio 
e ha annientato gli orgogliosi, rovesciato dai troni i potenti e sollevato gli umili, colmato di beni gli affamati e allontanato i ricchi con le mani vuote. Così come

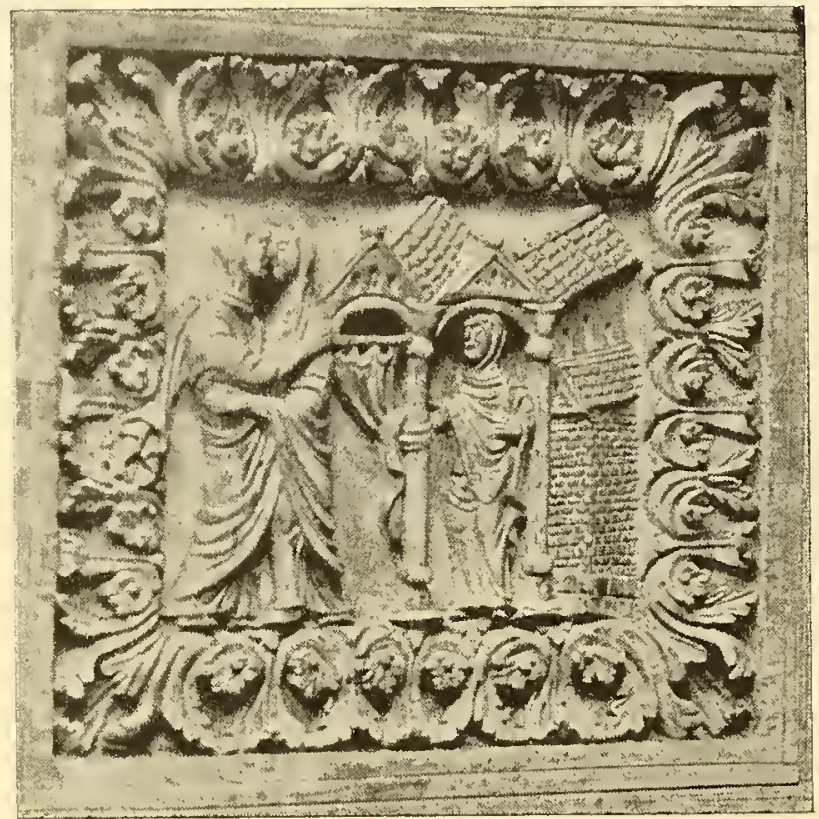

Cofano d'avorio attribuito al $x$ sec. Museo del Louvre

egli aveva promesso ad Abramo e alla sua posterità per sempre. Maria dimorò con Elisabetta tre mesi, poi ritornò nella sua casa. A complemento di questa

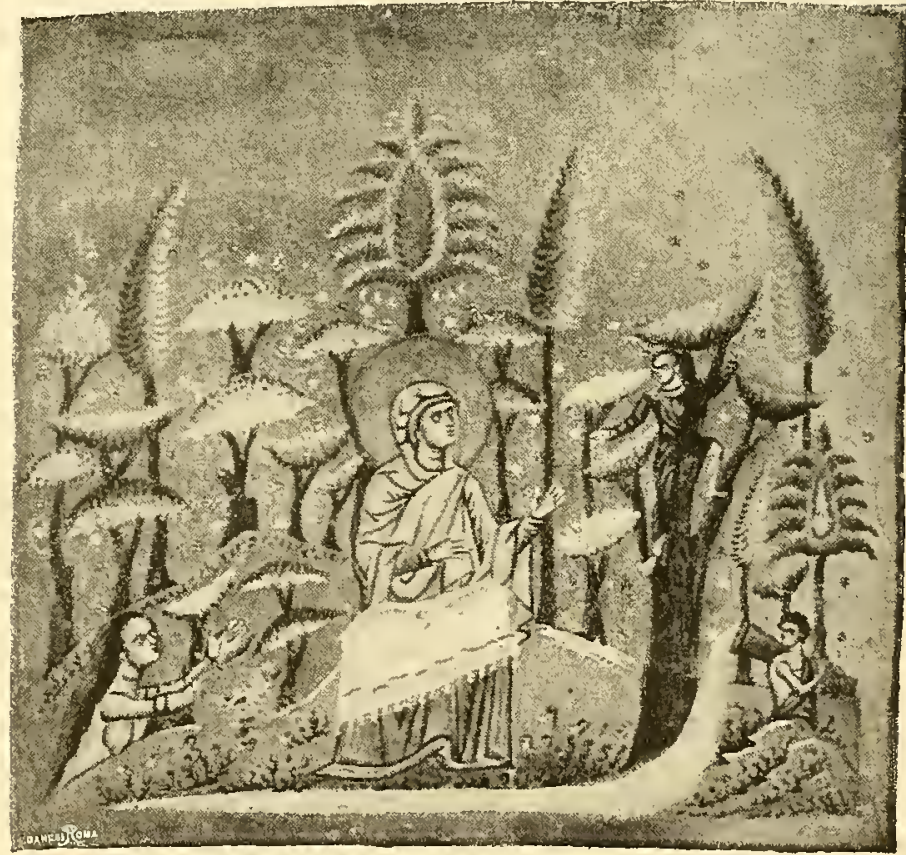

La Vergine recandosi a Elisabetta si riposa nel cammino (Omelie del MONACO Gicomo) 
narrazione dell' Evangelo, detto di San Luca, l'arte rappresentò la Vergine che, staccatasi dall'abbraccio, come invasa da spirito profetico, intuona la cantica del Magnificat, e vede nell' avvenire le generazioni chine innanzi a lei che la proclamano felice tra le genti. Ciò presso i Bizantini, che giunsero sino a rappresentare la Vergine con l'anima sua in forma di fanciulletta tra le mani, in atto di offrirla estatica a Dio: Magnificat anima mea Dominum; e l'anima volge le braccia a Dio, che si protende fra le nubi per riceverla. Nell'Occidente invece si è rappresentato semplicemente l'incontro delle due donne. Sin dal vir secolo la cristianità festeggiava la visita di Maria, ma già nel vi secolo troviamo rappresentata nella cattedra di Massimiano a Ravenna la scena dell' incontro, scena

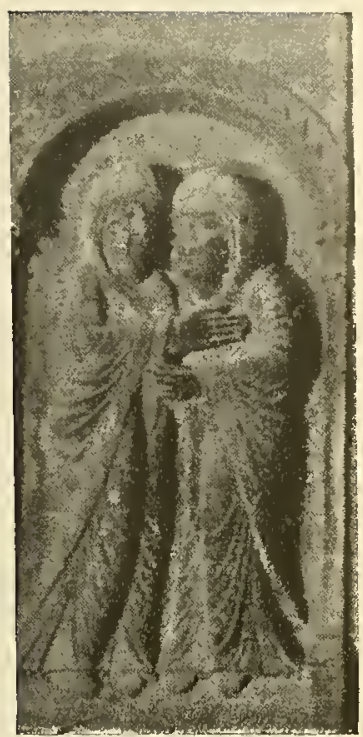

Arte romanica, secolo xu Palazzo arciv, di Fano che si ripete costantemente nell'arte. Soltanto nel medio evo si vede una fantesca che solleva la tenda del portico o d'altro luogo ove avviene l'abbraccio.

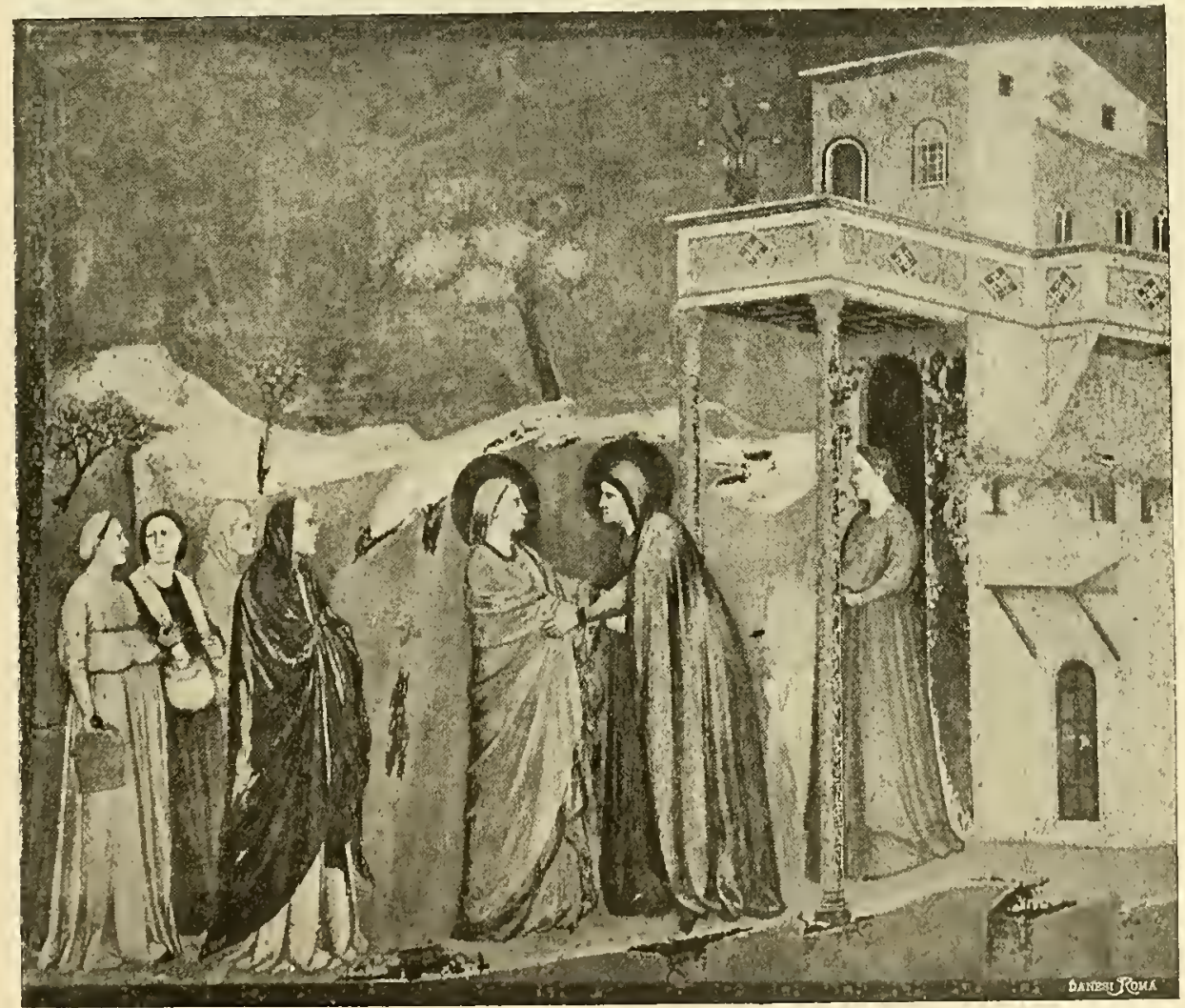

Chiesa inferiore di San Francesco in Assisi (Giotтo) 
Nelle Omelie del monaco Giacomo dell'xi secolo, citate già a proposito di precedenti rappresentazioni delle leggende della Vergine, sono raffigurati diversi momenti della scena: la partenza di Maria, il suo riposo sulla strada in un giardino sparso di alberetti rossi e azzurri, quindi il saluto e l'abbraccio d'Elisabetta e di Maria e finalmente l'addio. L'Occidente, meno analitico

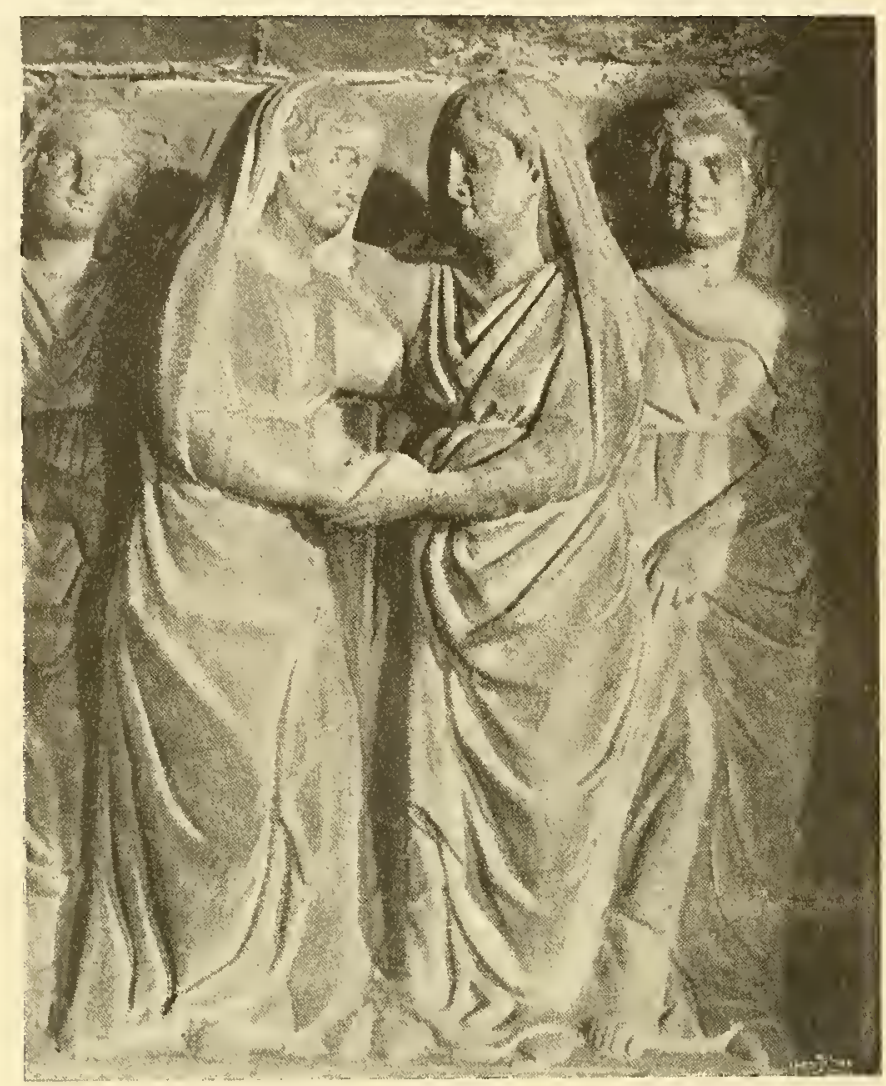

Pulpito di Pistoia

(GUGLIELMO DA PISA)

sempre, non ridusse a pezzi la scena, anzi non ne scompose l'augusta semplicità. Giotto la rese monumentale, figurando nella chiesa inferiore d'Assisi, tra rocce sparse d'alberelli, la Vergine seguita da due nobili donne e da due ancelle apportatrici di bisacce e di corbe, la Vergine che maestosa, ispirata come una profetessa, si avanza, quasi stesse per intonare il $M a$ gnificat, verso Elisabetta che reclinata le stende le braccia; e dietro alle donne coronate di nimbo, una fantesca sorride e sembra rallegrarsi della visitatrice, dell'ospite al limitare della casa gotica, adorna di un balconcino con una pianticella, da cui partono, come raggi da un vaso, gli steli 


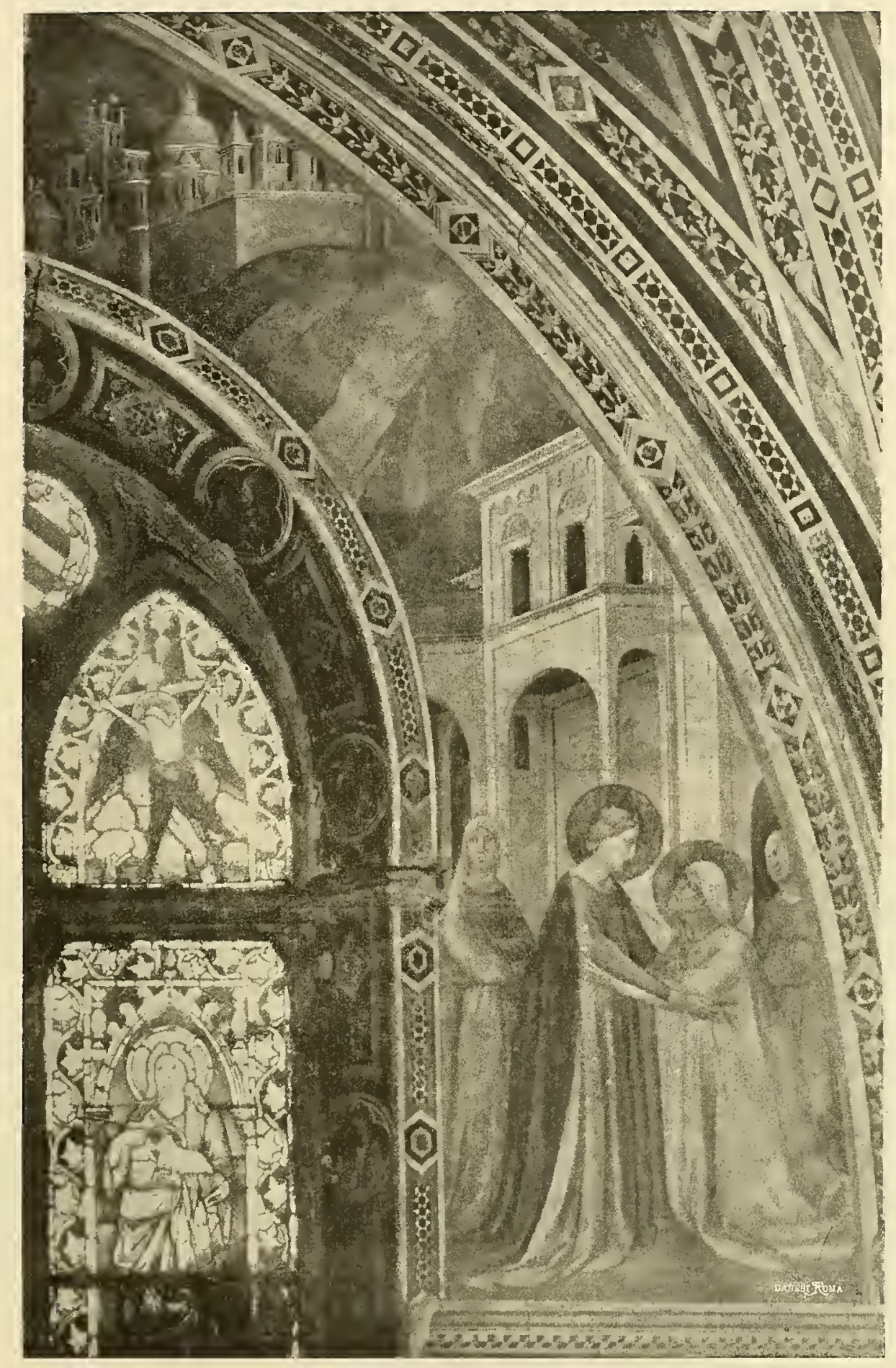

Santa Croce in Firenze

(TADDEO GADDI) 


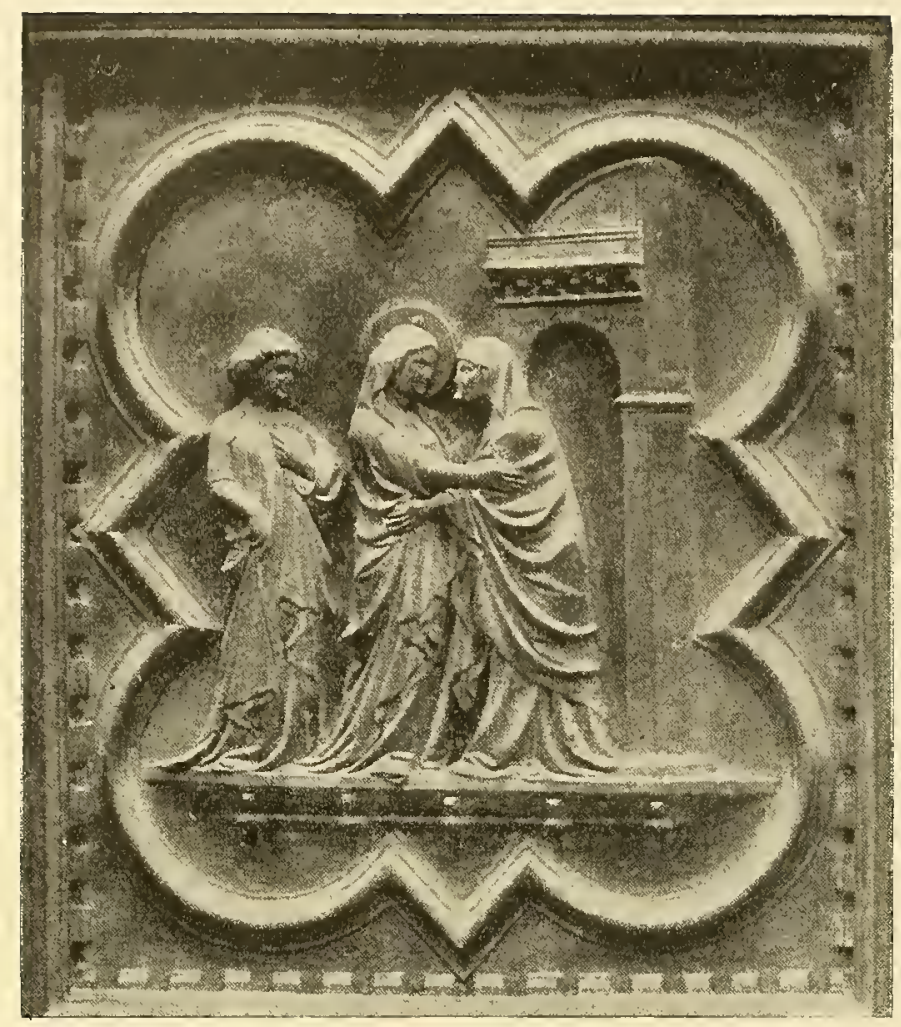

Porta del Battistero di Firenze

(Andrea Pisano)

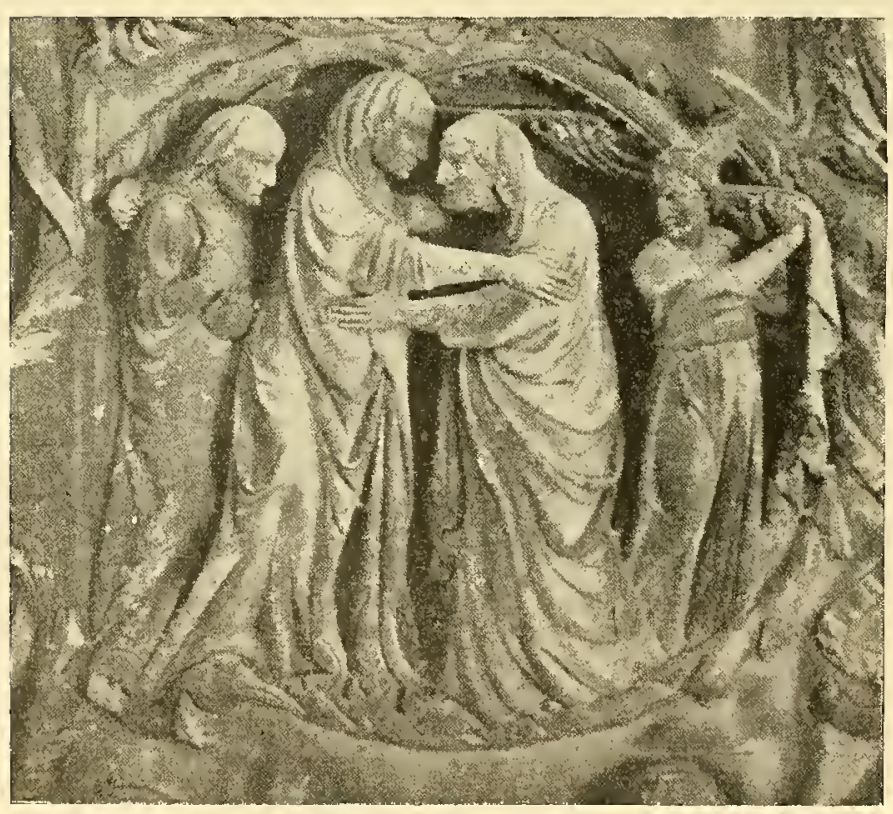

Bassorilievo nella facciata della Cattedrale di Orvieto 


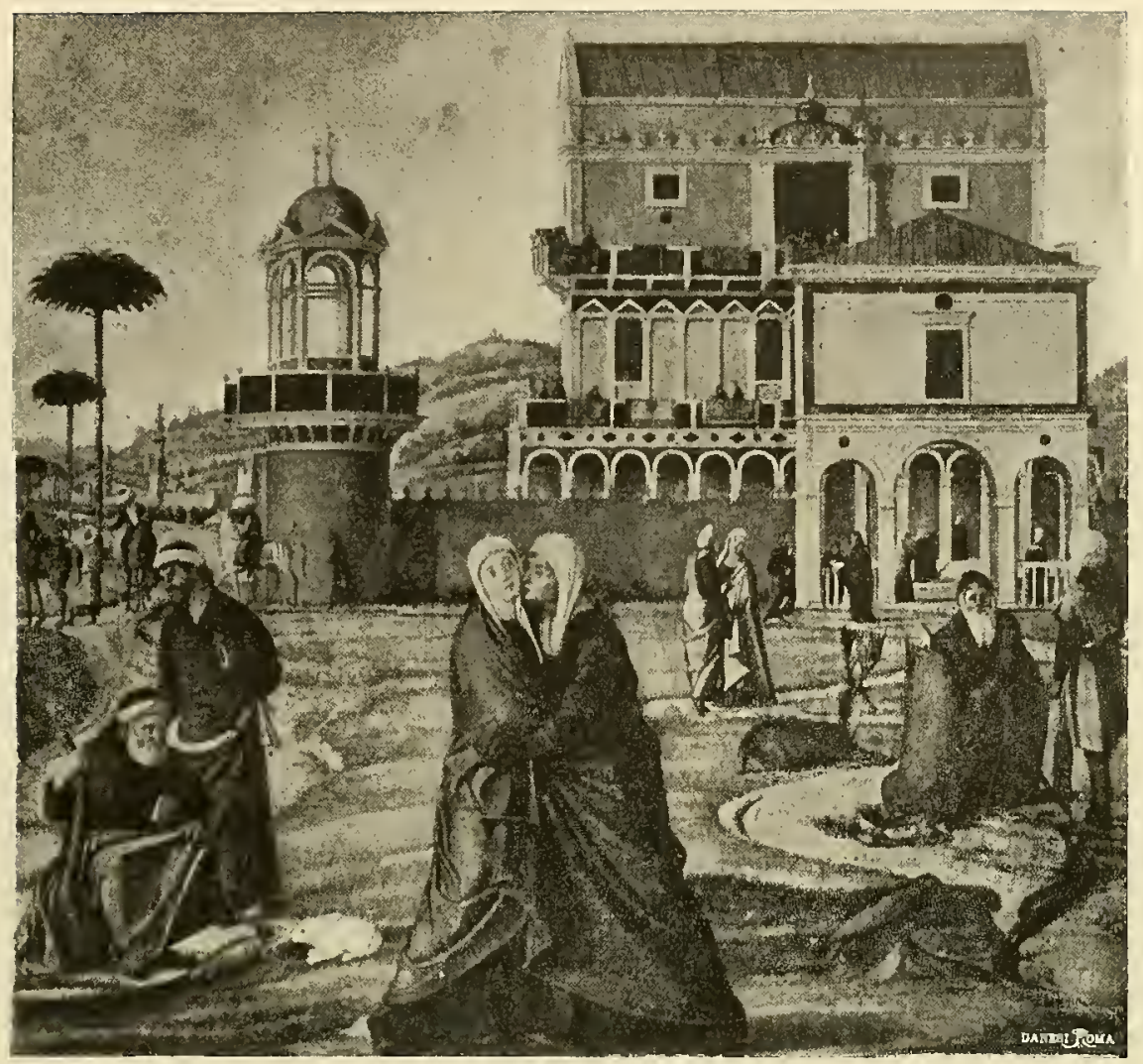

Museo Correr in Venezia

(VitTore Carpaccio)

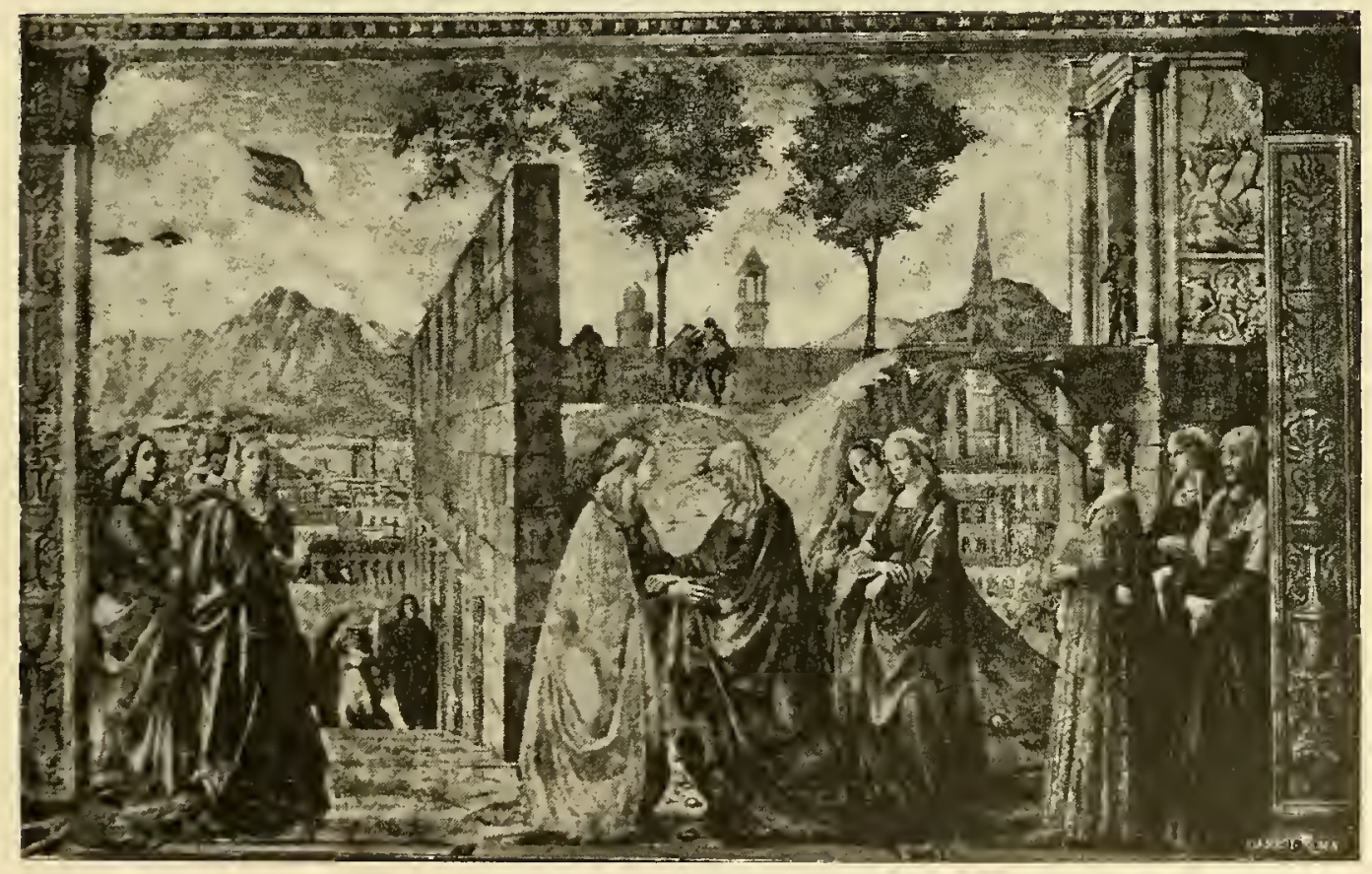

Santa Maria Novella di Firenze

(Domenico Ghirlandayo) 
biancofioriti. Similmente a Padova, benchè la scena sia meno festosa. la Vergine e le ancelle sembrino impensierite ed Elisabetta guardi a Maria negli occhi, cone se ne scrutasse i pensieri. La scena è più familiare ad Assisi, piì religiosa a Padova, ove sembra che le due beate si abbraccino in silenzio, in attesa di confidarsi i secreti dell'anima. Ma ad Assisi Maria ha

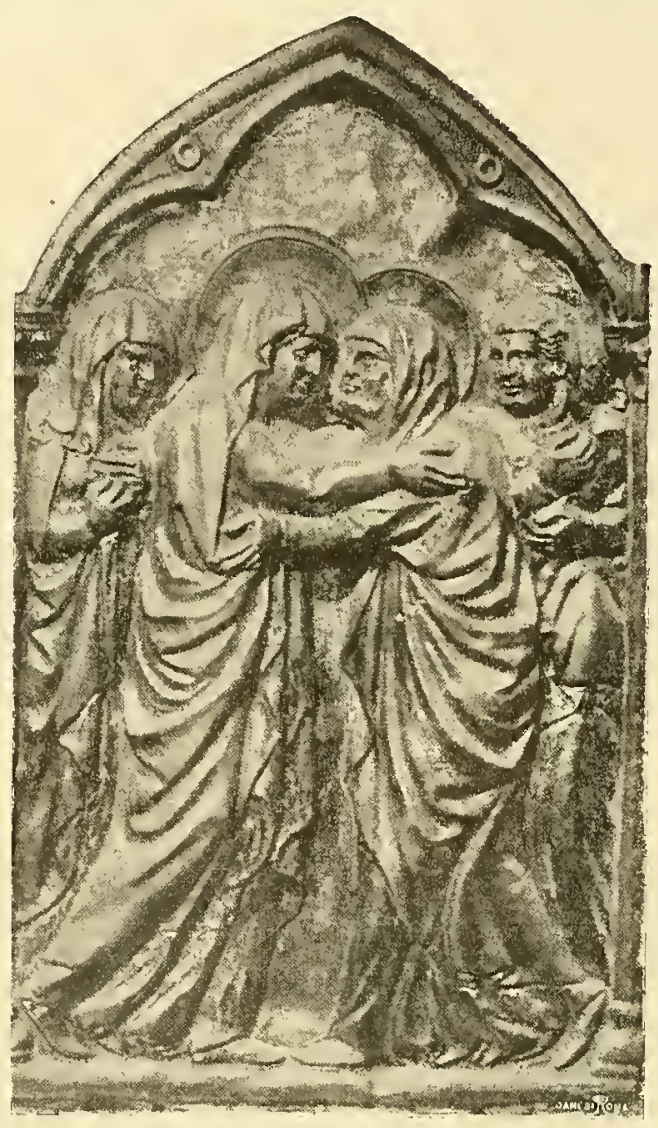

Paliotto d'argento della Cattedrale di Pistoia

(ANDREA Di JaCOPO D' OGNABENE)

l'attitudine della donna che col pensiero vede le generazioni prostrate chiamarla felice. Il medio evo l'aveva rappresentata in forma di orante, oppure in atto di porgere la sua anima a Dio, sostenuta dai profeti. Giotto invece lasciò i simboli e aderse in mezzo al quadro la figura di lei come di sibilla.

Uno scolaro dei Pisani, a Orvieto, dietro alla Vergine figurò una vecchia servente con le bisacce del viaggio, dietro a Elisabetta una giovane fantesca in atto di tirare una tenda. Fra' Guglielmo da Pisa, a Pistoia, colloca due donne ai lati del gruppo delle sante abbracciate. Mentre dapprima nella rappresentazione le protagoniste figurano sole e poi seguite da ancelle, nel 


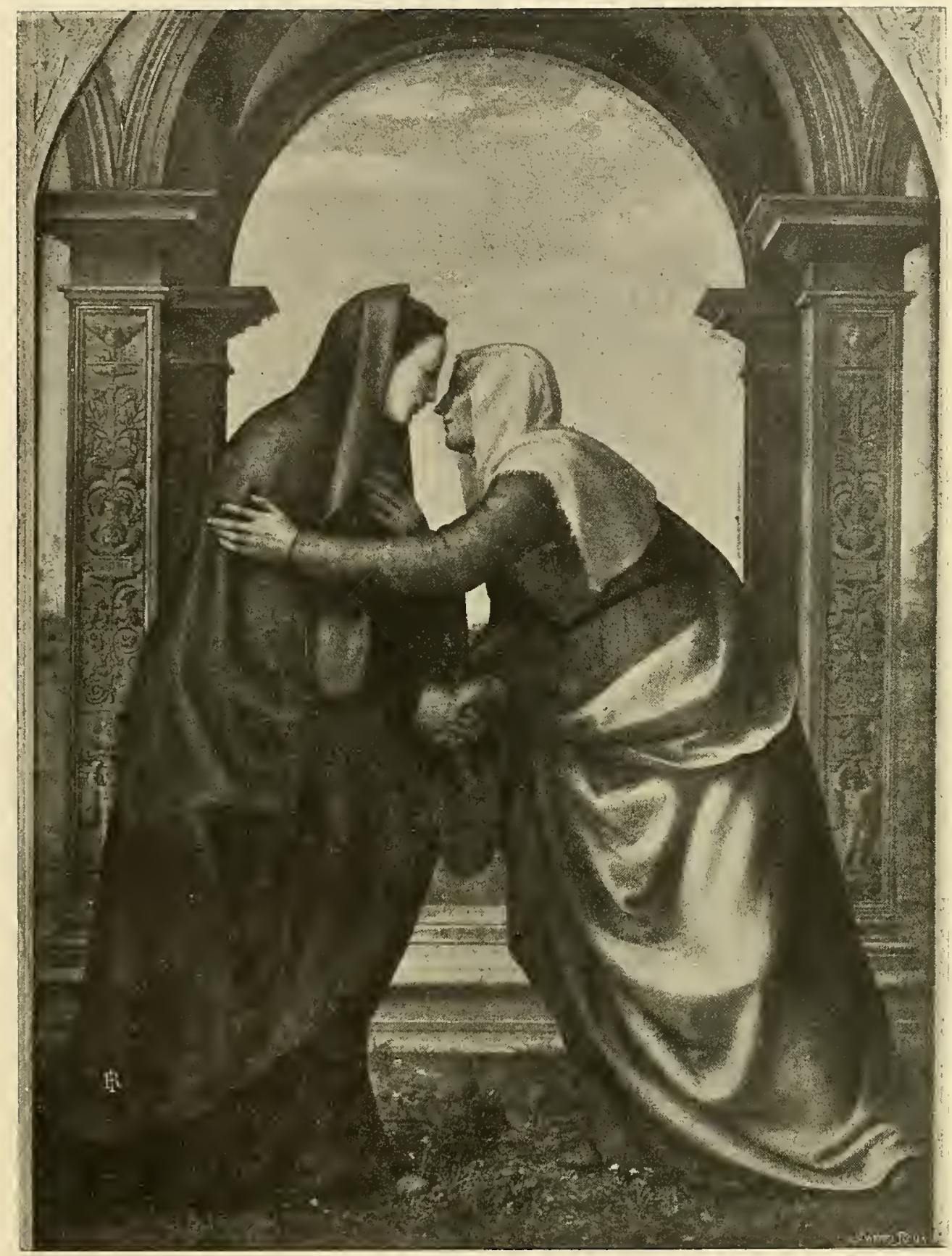

Galleria degli Uffizi in Firenze

(MnRiotto Albertinelli) 
secolo $\mathrm{xv}$ avanzato, anche Zaccaria accompagna Elisabetta, e Giuseppe segue Maria; e l'abbraccio delle due donne è pieno di tenera effusione. I quattrocentisti si contentarono di rëndere nella scena dell'incontro l'imma-

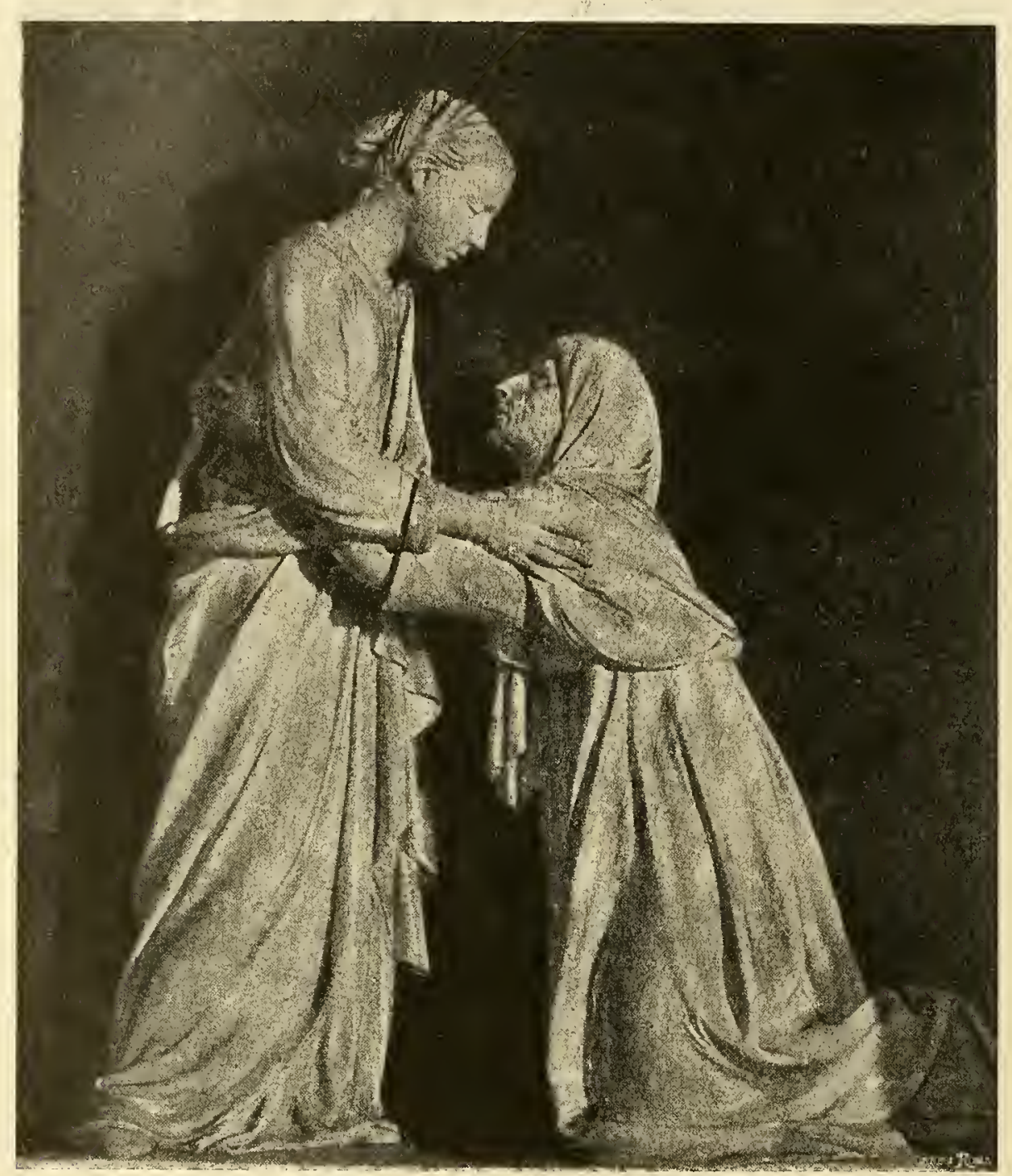

Pistoia - San Giovanni fuori civitas

(ANDREa DElla Robita)

gine dell'amicizia, della maternità. Il Cinquecento tentò di esprimere col Sodoma ancora di più, e cioè la devozione, la venerazione di Elisabetta verso la giovane Maria, che amorosamente rialza la cugina la quale ha posto un ginocchio a terra. La scena è sotto l'abside d'un tempio, tra due gruppi di spettatori, cosi che prende un aspetto solenne, aspetto che 


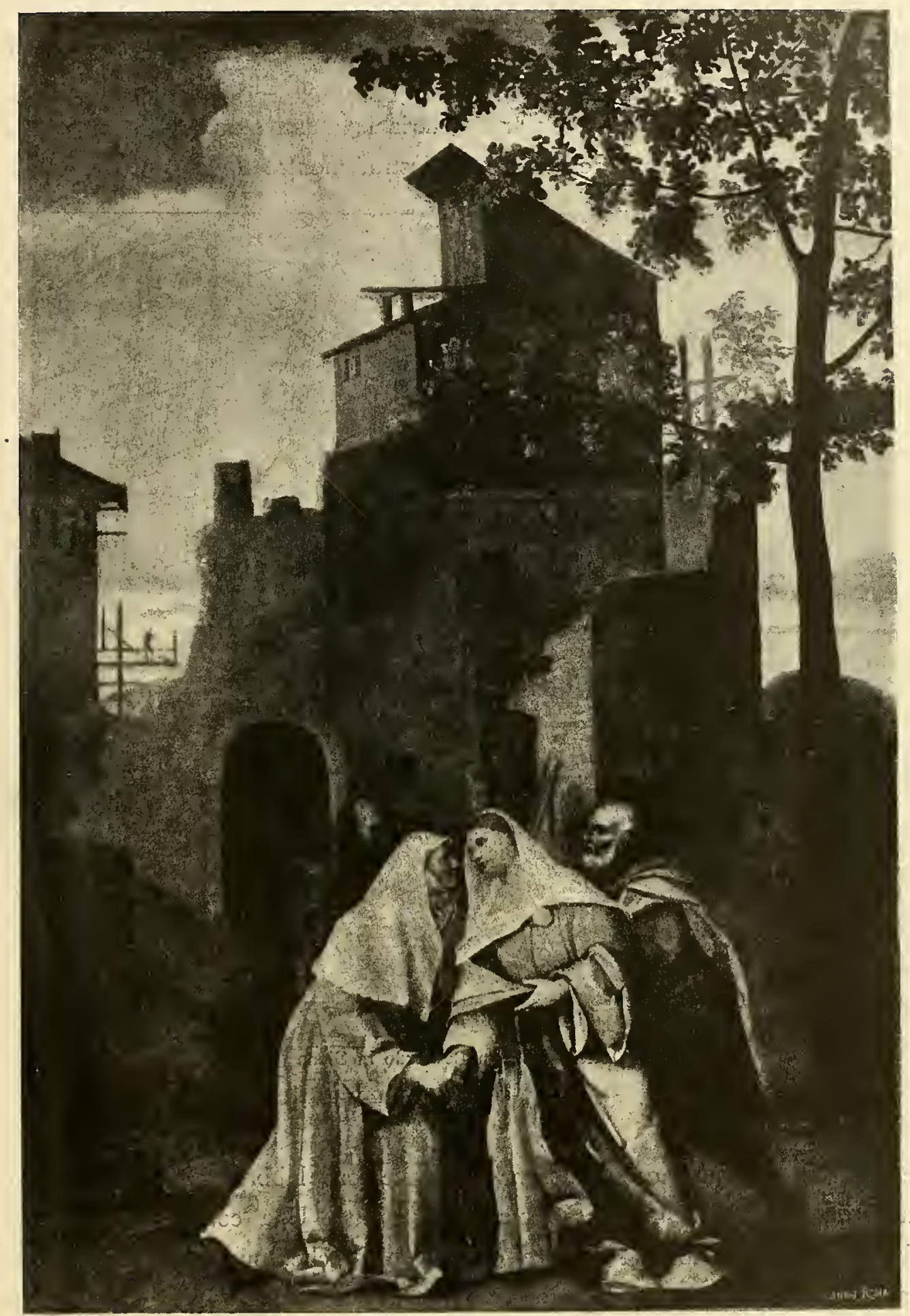

Galleria di Venezia

(Scuola di Sebastiano del Piombo) 
Mariotto Albertinelli, con tranquillità non propria del Sodoma ma propria del compagno di frate Bartolomeo, diede alle figure di Elisabetta e di Maria, sole, che si abbracciano sotto un arco. Maria con una mano sul petto saluta Elisabetta e con la destra le stringe la destra, mentre il volto di Elisabetta

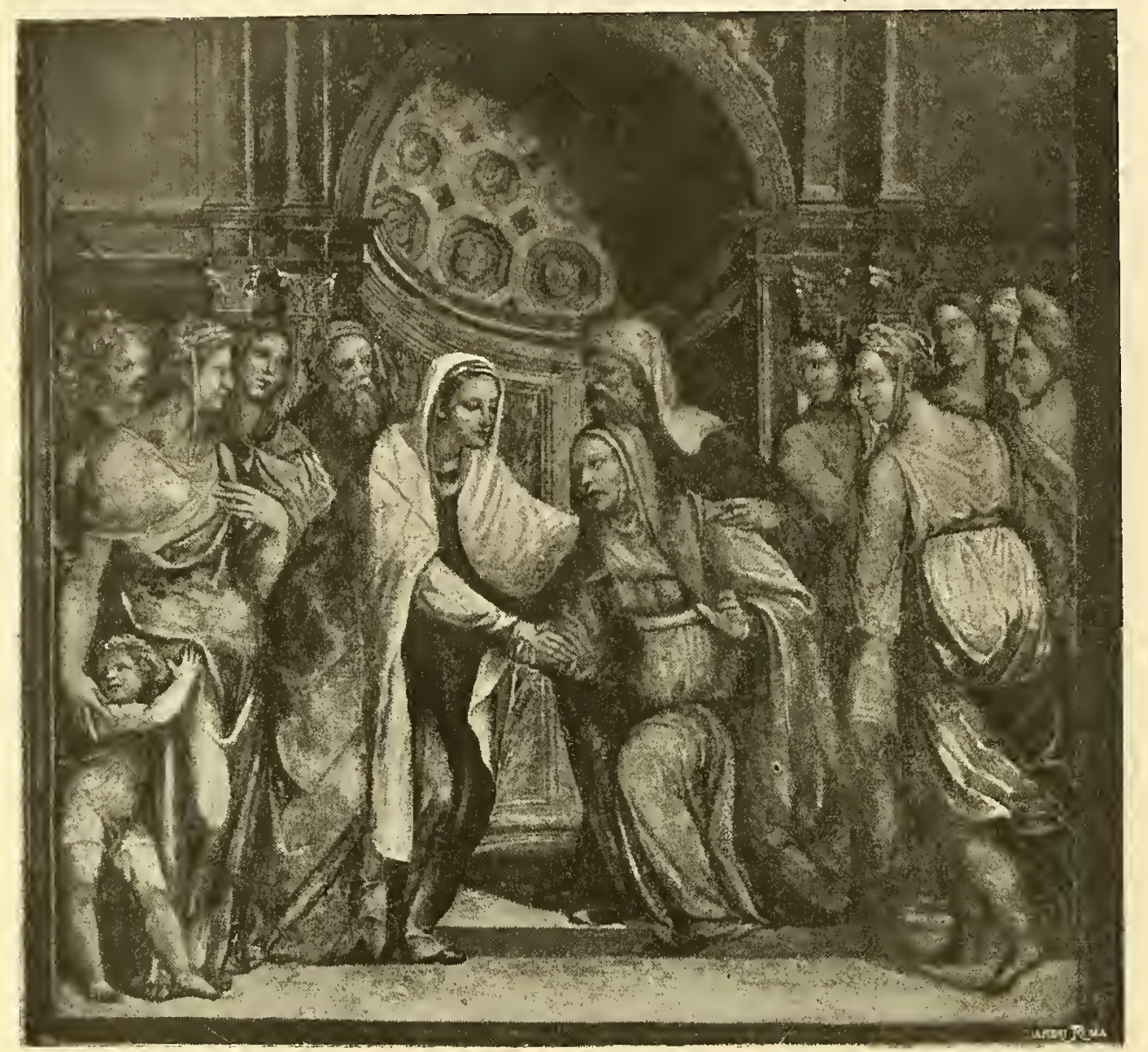

Oratorio di San Bernardo in Siena

(SoDoma)

e gli occhi s'illuminano di purissima gioia; le loro labbra stanno per incontrarsi e mormorano commosse parole di affetto. Una composizione simile fu eseguita in Pistoia da Andrea della Robbia, che, pur serbando a Maria la giovanile soavità e in Elisabetta l'ardente devozione, rappresentò questa ginocchioni e meglio equilibrò il gruppo delle due donne. Elisabetta cinge i fianchi a Maria e fissa intensamente la cugina, che soavemente si curva in atto di rialzarla. Tanto il Sodoma, quanto Andrea della Robbia, per 
dimostrare i sentimenti di venerazione concepiti da Elisabetta per la presentita madre del suo Signore, la rappresentarono genuflessa innanzi a lei. E così la rappresentazione trovò il suo compimento: non è più, come nel medio evo, l'incontro affettuoso di due cugine, ma l'evento sacro. Elisabetta esalta la parente benedetta tra tutte le donne, e Maria le si avvicina pensosa del destino annunciato dall'angelo. I due cuori materni battono uniti; un arcana gioia sospinge l'una nelle braccia dell'altra; entrambe glorificano Dio. 



\section{Le angosce di Giuseppe.}

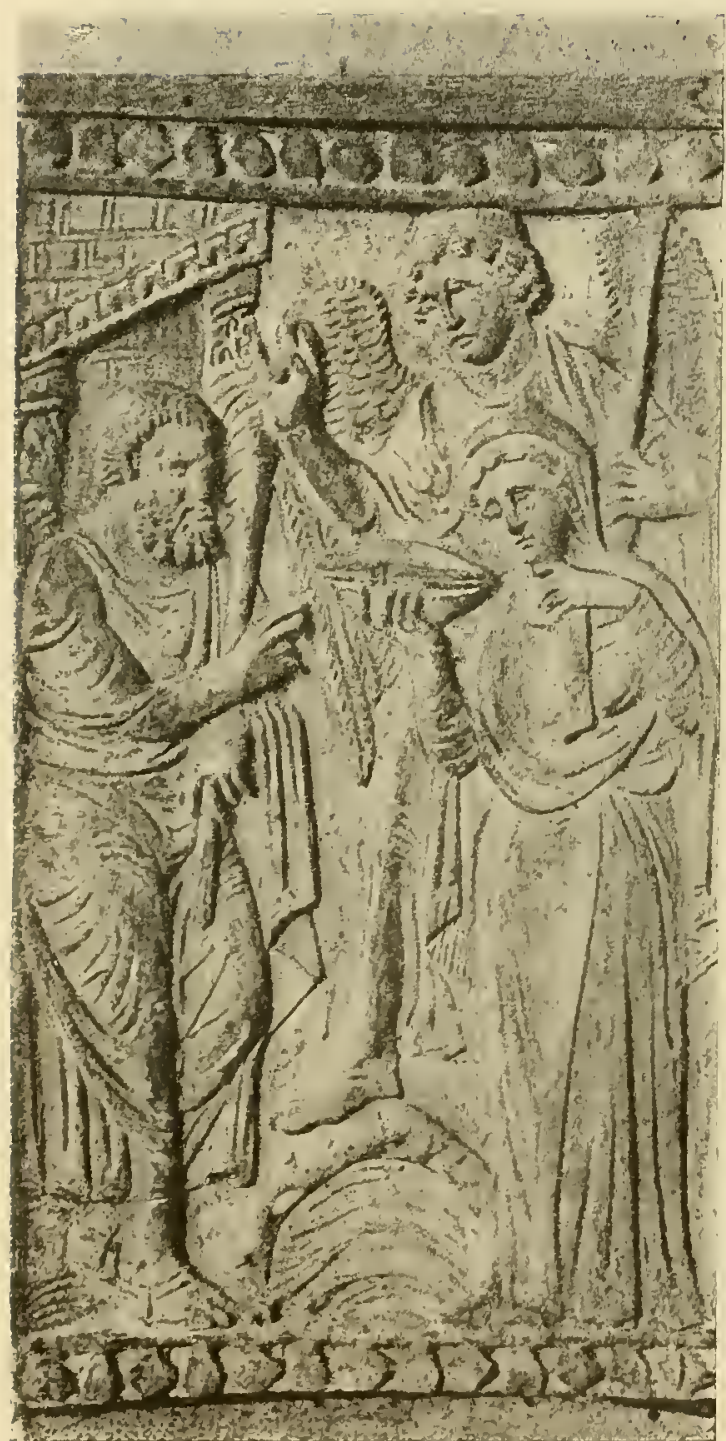

Avorio della Cattedra di Massimiano in Raventua
Alla scena della Visitazione fa seguito, specialmente nelle rappresentazioni bizantine, quella o quelle delle angosce di Giuseppe, che, al vedere Maria prossima a divenir madre, pensò d'allontanarsi segretamente da lei. L'Evangelo dice che gli apparve nel sogno un angiolo e gli disse: Non temere, poichè da Maria nascerà, per volere di Dio, un fanciullo, cui darai il nome di Gesù, perchè redimerà il suo popolo. E il protoevangelo di San Giacomo descrive prima Giuseppe che piange e si dispera, poi consolato dall'angiolo e infine accusato da uno scriba al sommo sacerdote il quale fa bere a lui e a Maria l'acqua della prova, l'acqua amara prescritta dalla legislazione mosaica: Giuseppe e Maria rimasero sani e salvi; il sommo sacerdote li assolse. Un altro Evangelo apocrifo, quello della Natitività, rappresenta 


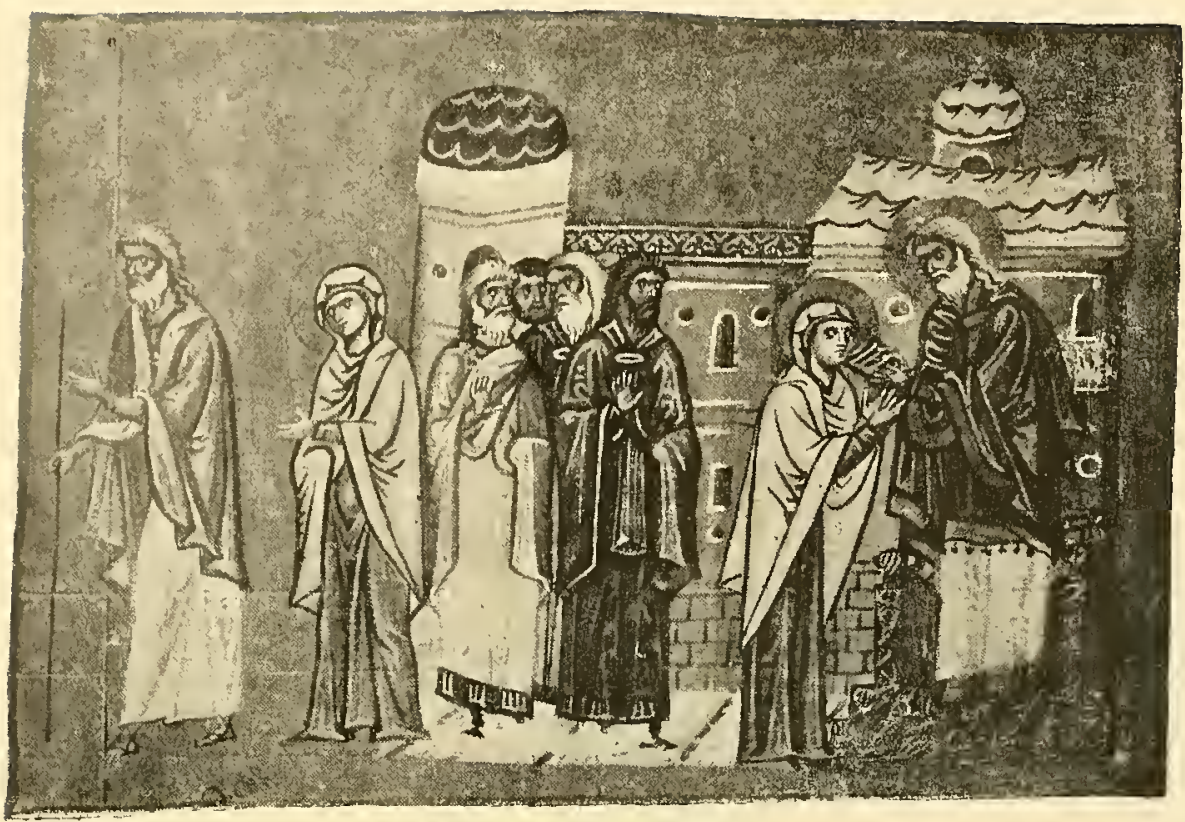

La Vergine prova l'acqua

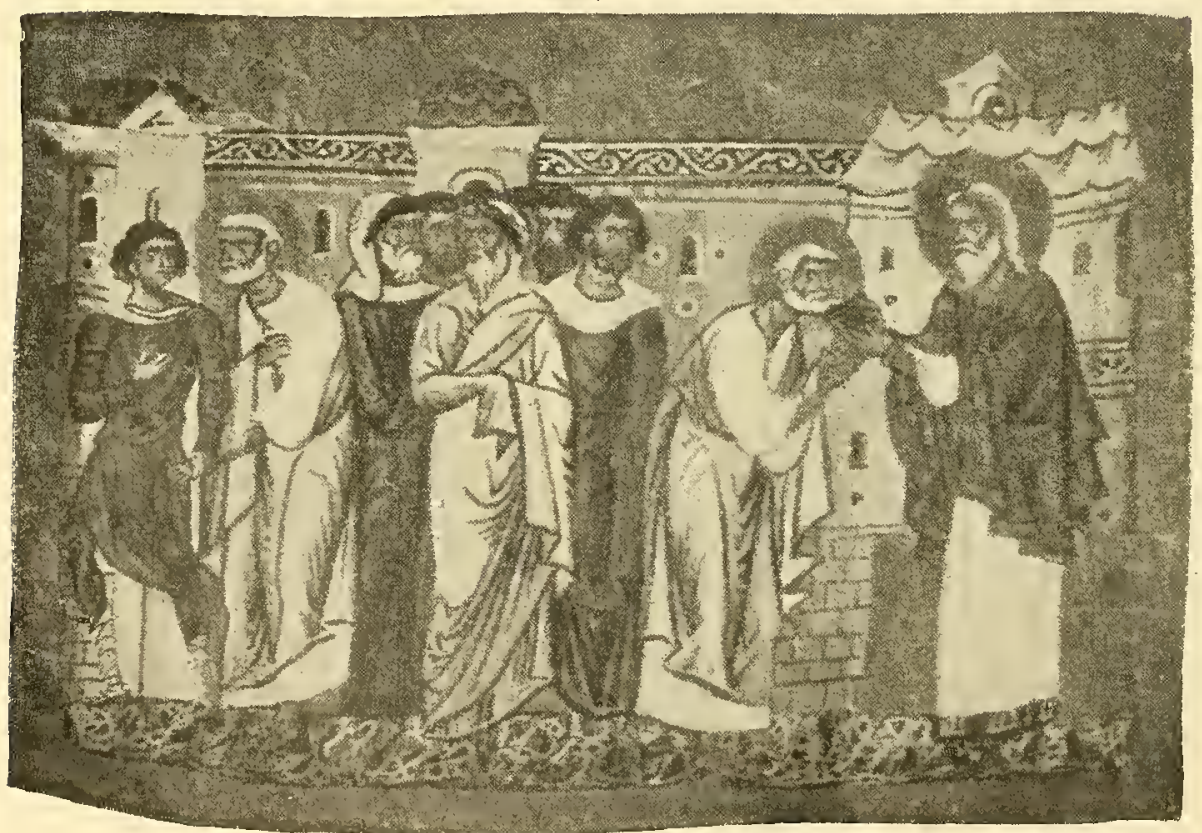

San Giuseppe prova l'acqua

- Omelie del Monaco Gincomo. Biblioteca Nazionale di Parigi) 
Giuseppe e Maria che, bevuta l'acqua della prova e aggiratisi sette volte intorno all'altare del Signore, rimasero senza macchia sul volto; onde tutto il popolo stupito riconobbe la santità della Vergine. Nella cattedra episcopale di Ravenna (vi secolo) si vede rappresentata la prova dell'acqua; nel x secolo, il menologio greco della Vaticana raffigura San Giuseppe avvisato in sogno dall'angelo, e le Omelie del monaco Giacomo forniscono i maggiori particolari della rappresentazione. Nei musaici di San Marco di Venezia l'artista fa intervenire anche i figli del Santo in atto di deriderlo. Nel paliotto di Salerno, Giuseppe siede pensoso innanzi alla Ver-

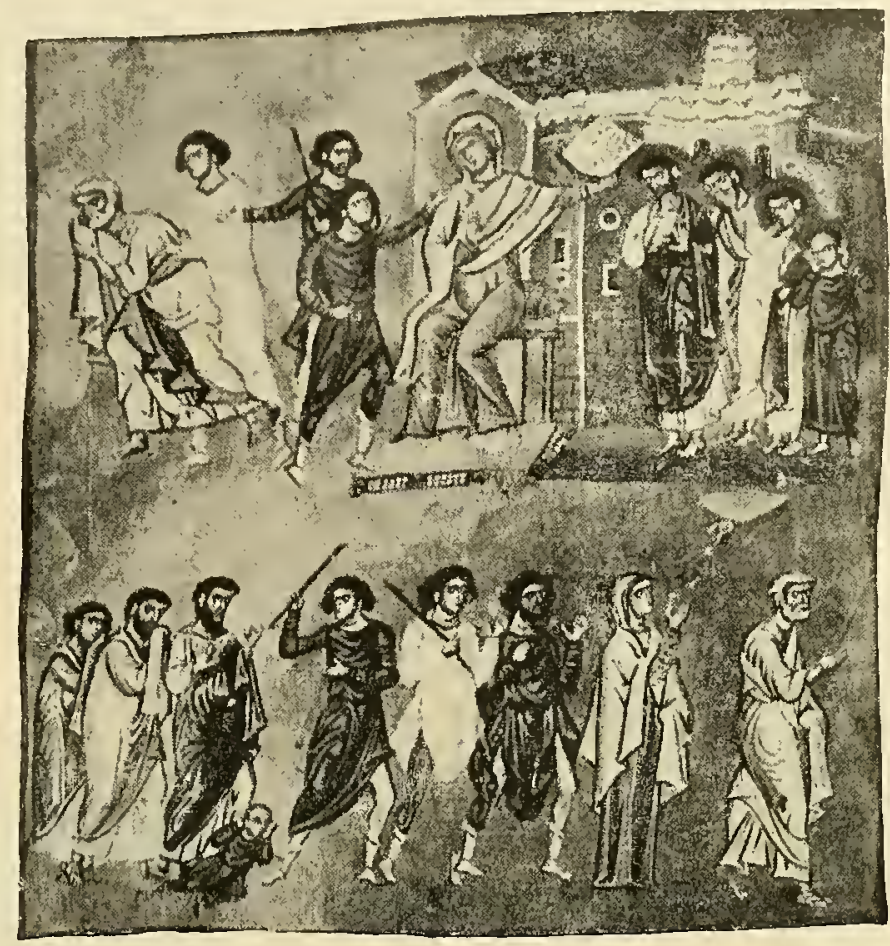

Arresto in Giuseppe e Maria

(Omelie del Monaco Giacomo) gine, che sembra in atto di scolparsi; e, appresso, quegli dorme e un angelo gli appare nel sonno. Na questa, si può dire, è una delle ultime forme della rappresentazione. La gentilezza dell'arte nuova occidentale non ammise la scena bizantina. Nel xir secolo ancora si svolge stentatamente nell'altare della cattedrale di Città di Castello. Essa è destinata a scomparire nel fuoco purificatore dell'arte. Le idealità nuove della fede, la nobiltà, la freschezza del sentimento di generazioni rinnovate da miscele etniche, non potevano tollerare una rappresentazione grossolana, ove si rivelava il medio evo nella sua materialità, nella sua curiosità strana, ne’ suoi sospetti. Il pettegolezzo dei Bizantini tacque sul nostro suolo. Giotto, nella cappella degli Scrovegni a Padova, non se ne curò, e dalla Visitazione trascorse alla Natività. 



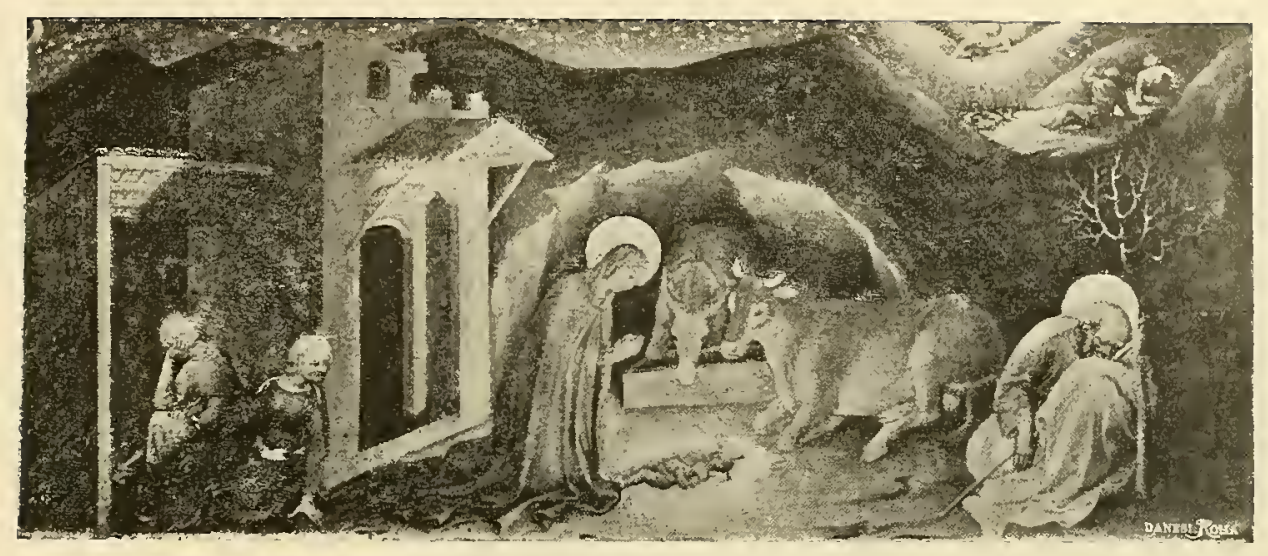

R. Galleria antica e moderna in Firenze

(Gentile da Fabriano)

\section{Presepe.}

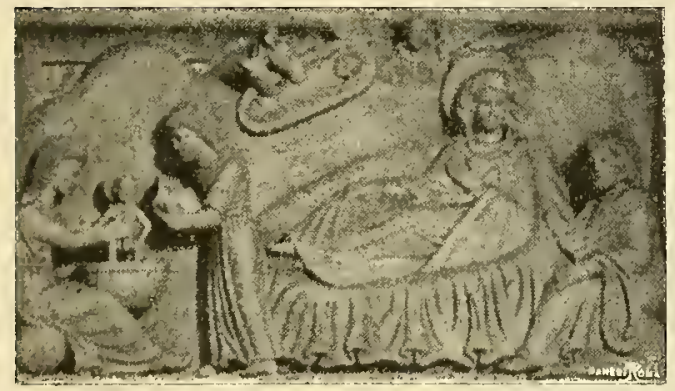

Pulpito di San Bart. in Pantano a Pistoia

(Guido DA CoMo)

Nell'arcosolio di una delle gallerie oscure della necropoli circostanti alla basilica di San Sebastiano sulla via Appia, ${ }^{(x)}$ è dipinta una panca di legno e sovr'essa disteso il divin Bambino in fasce coi due rustici animali accanto. Da quella forma della rappresentazione d'un rozzo frescante nel secolo $\mathrm{IV}$ alla "Notte" del Correggio, quale lungo cammino percorse l'arte, quante fatiche durate, che lunga elaborazione!

Seguire passo per passo il variare dei tipi e delle composizioni finchè fioriscono nella civiltà animati dal soffio del loro creatore, è far viaggio nel mondo degl'ideali umani. Oggi lo storico dell'arte, intento a scrutare e analizzare lo stile di un'opera, a definirla e a classificarla, ben di rado tien conto di ciò che in essa vi è di mutato, di aggiunto alle opere precedenti. Eppure l'arte crebbe a somiglianza del corallo che spunta a fior d'acqua e si erge cone scoglio sulle onde, di mano in mano che le gemme dei polipi si aggiungono alle spoglie dei loro generatori. Il nuovo nell'arte non

(i) D) Rossi, Bullettino di archcol. crist. I 877 , pag. I 4 I ; I 878, pag. 58 . 


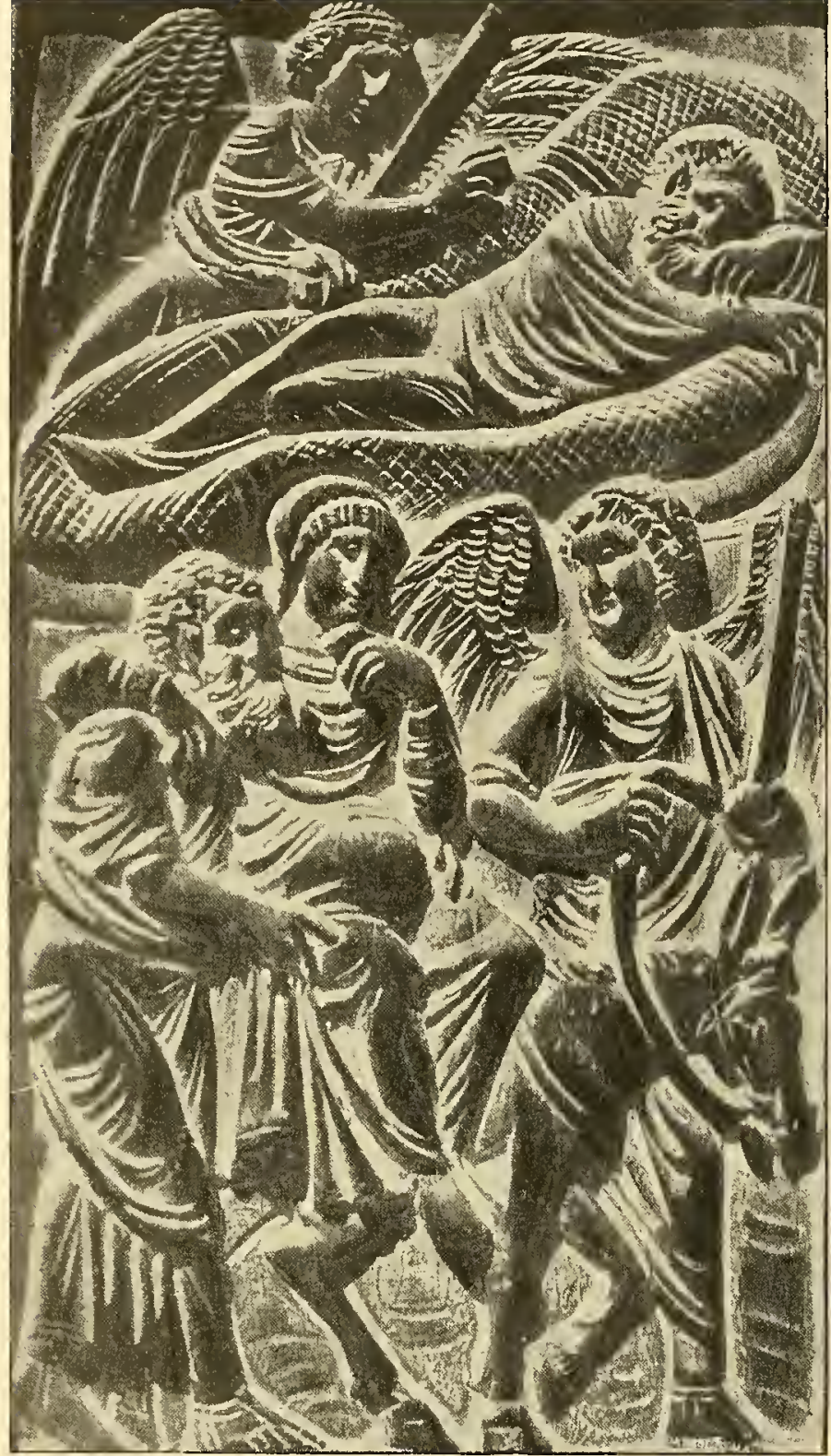

Avorio della cattedra di Massimiano. Duomo di Ravenna è mai altro che una modificazione del vecchio. Così almeno intendevano la novità molto quietamente gli antichi, lavorando concordi al trionfo dell' arte nazionale, sopra una stessa trama di tradizioni e d'idee. A comprendere però come quella trana si compose, bisogna seguire il corso delle rappresentazioni a traverso il tempo, non già col metodo degli iconografi, che, in generale, invece d'avere di mira lo svolgimento artistico d' una forma ricercano il significato delle immagini. Oltre che talora si fa dire alle figure certe cose ch' esse smentirebbero risolutamente se non avessero solo l'apparenza della realtà, gl'iconografi sono come quei commentatori de' poeti,

i quali spiegano tutte le virgole e l'arte no. Importa loro di notare che la mano di una figura è aperta o chiusa, le braccia in alto o in basso, le gambe piegate o diritte; e intanto, nel considerare e misurare i particolari anche più insignificanti, perdon di vista il movimento della composizione, l'affannosa ricerca della bellezza. E ciò anche perchè essi tengono fissi gli occhi sopra periodi limitati di tempo; mentre l'iconografia non può essere 
ausiliaria allo studio dell'arte, se non stende lo sguardo dalla cellula o dalle forme prime, alle più rigogliose e complete, dalla genesi di un soggetto nei primi tempi cristiani, al suo sviluppo lungo il tempo, fino alla sua piena determinazione. Tali idee possono volgersi nella mente a chi esamini, ad esempio, lo studio dello Schmid sulla * Natività di Cristo ${ }^{(x)}$ o a chi scorra i volumi sulla "Sainte Fierge" di Rohault de Fleury, ${ }^{(2)}$ tanto più che le indagini di quegli autori e d'altri con essi si soffermano prima che tutta l'opera assidua rinnovatrice del medio evo produca fiori e frutti. Sembra quasi che gl'iconografi si sieno messi a ricercare più i documenti religiosi che gli artistici. A ogni modo, per esser giusti, i loro lavori recano utilità maggiore

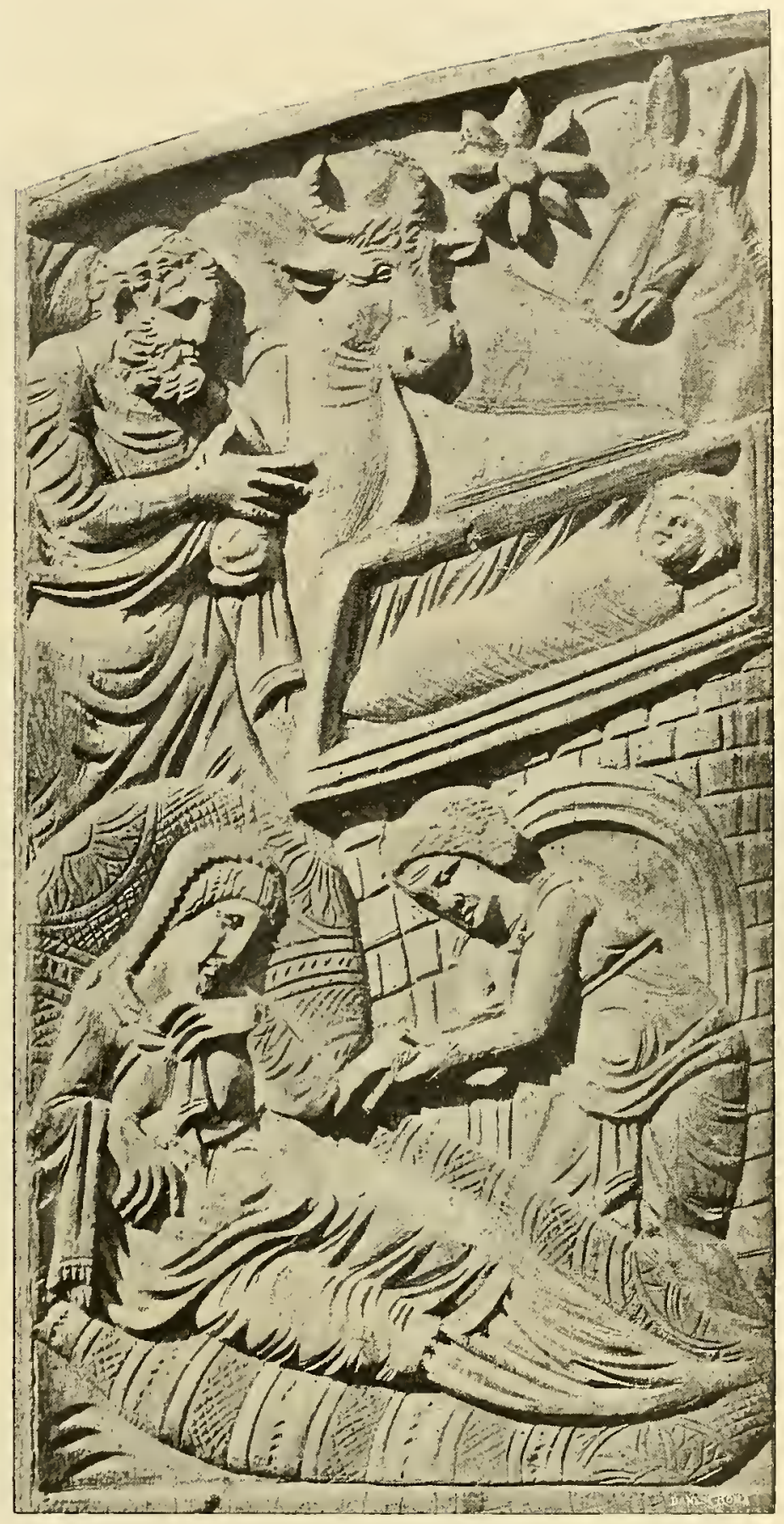

Cattedra di Massimiano. Duomo di Ravenna

(1) Die Darstellung der Geburt Christi in der bildenden Kunst. Entwickiungsgeschichtliche studie von Dr. Max Schnib. Mit 63 Illustrationen. Stuttgart, Julius Hoffinann, I 890.

(2) La Sainte Vierge. Pari;, I878. Cfr. anche sul soggetto: N. Baldorta, Liz nascita ali Cristo nell'arte figurativa (L'Italia artistica illustrata, V, I 886). 
degli altri più comuni dei critici, che per discorrere di un'opera d'arte si sbizzarriscono intorno al suo soggetto, e volano come Icaro a traverso gli

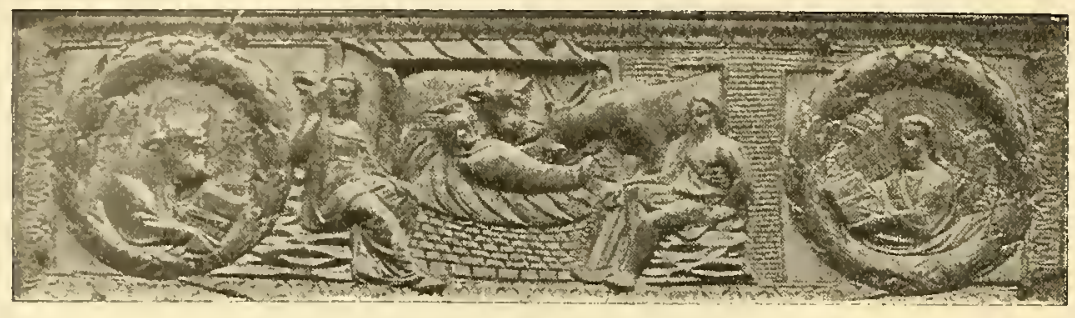

Dalla coperta d'avorio nella Cattedrale di Milano

spazî con ali appiccicate sul dorso da molle cera. Quei primi hanno anguste limitazioni nello studio, i secondi non ne hanno alcuna. Altrettanto non sia detto di noi!

Dagli Evangeli di San Luca e di San Matteo hanno origine le prime rappresentazioni della "Natività »: in questo si parla di Gesù nato in Be-

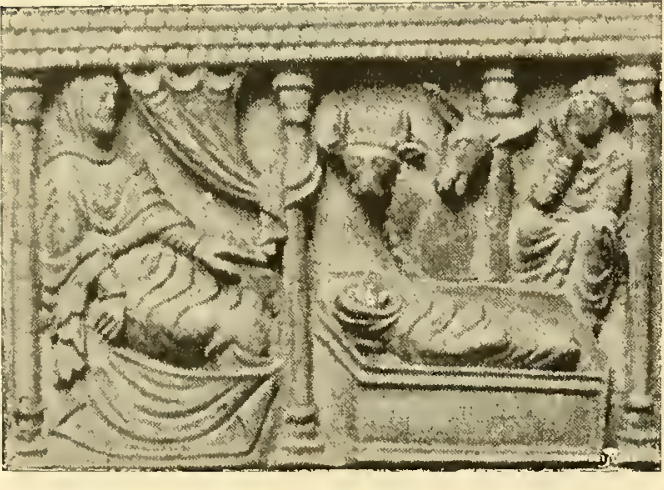

Da cofano d'avorio del Museo del Louvre tlemme di Giuda, regnante Erode, e dei Magi che, veduta la loro stella in Oriente, andarono a rendergli omaggio; in quello si descrive la nascita di Gesù, Maria in atto di avvolgerlo in fasce e di collocarlo in una greppia, i pastori veglianti attorno alle mandre, allorchè sopraggiunge cinto di splendore l'Angelo di Dio, il quale, annunciata loro la lieta novella, rivolò al cielo con una schiera di compagni, tutti inneggiando al Signore. L'Evangelo di San Luca non discorre de' Magi; ma ben presto i due sacri testi si fusero insieme nelle menti dei fedeli. che tuttavia non li tradussero nei marmi dei sarcofagi o nei freschi delle catacombe prima del Iv secolo. Rifuggivano i primitivi cristiani dal raffigurare fatti concreti, quelli specialmente che toglievano il velo alla figura sublime del Redentore, mostrandolo a traverso le sofferenze dell'uomo, giacente nell'umile presepio, morto sul legno infame del Calvario. L'arte loro, semplice, astratta, tutta volta all' ideale, erede del simbolismo profondo della razza semitica, non ricercava il godimento degli occhi, bensì immagini indeterminate, lontane dalla vita 


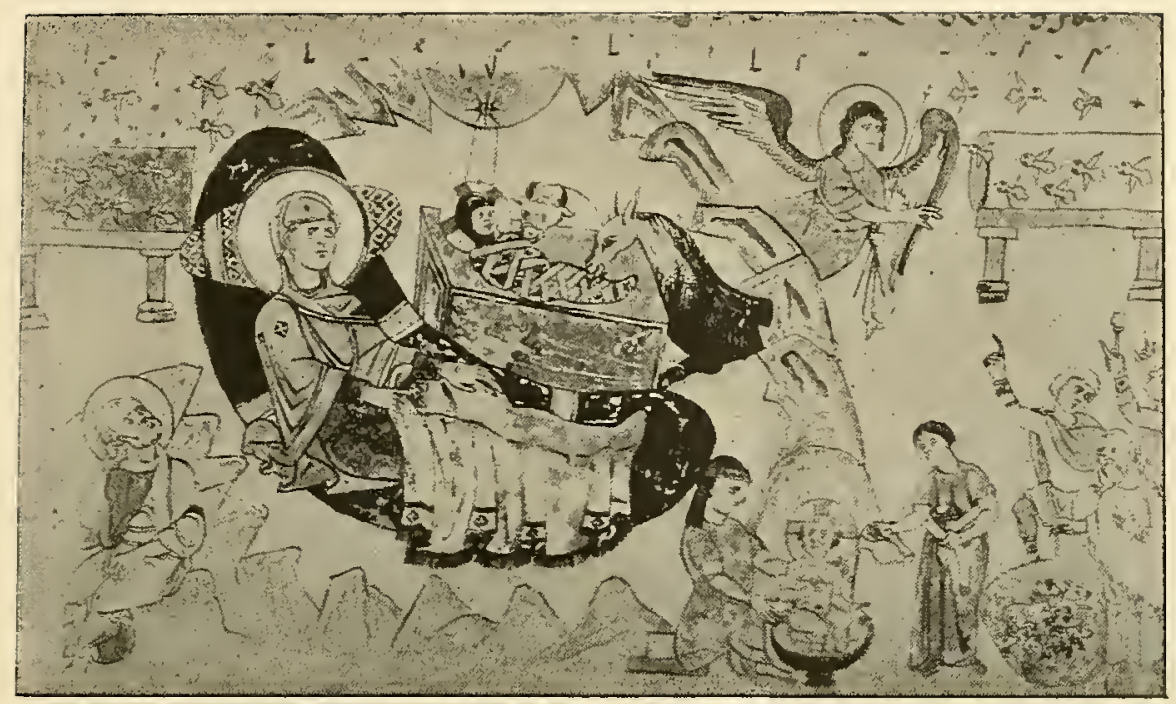

Dal frammento di « Exultet» di San Lorenzo nel Piceno

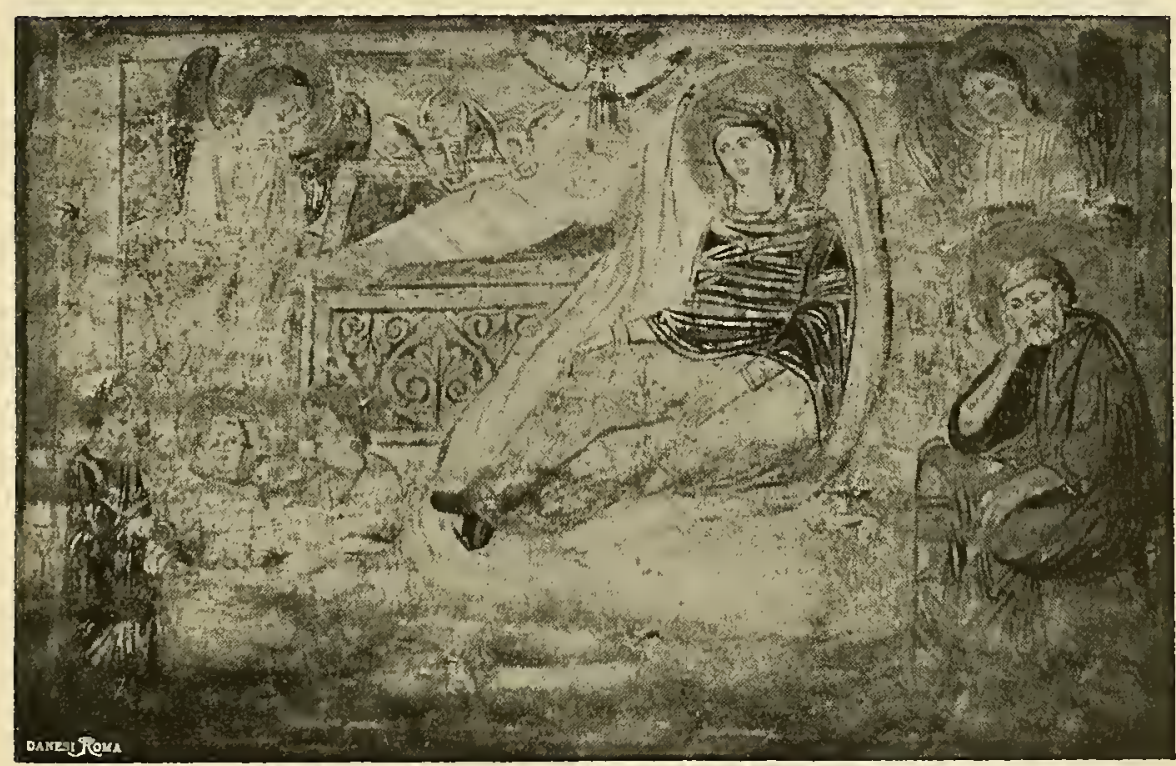

Affresco. Chiesa di Sant' Urbano alla Caffarella

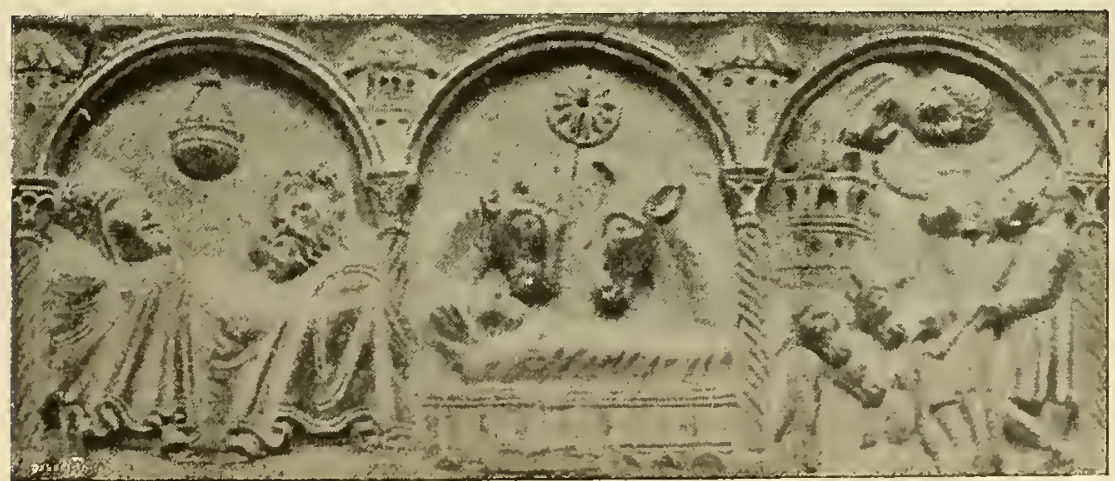

Passorilievo romanico. Cattedrale di Piacenza 
e dalla realtà, riproducenti le visioni dell'anima che aspirava al cielo. Nel raffigurarsi la scena della "Natività ", i primitivi cristiani collegarono il

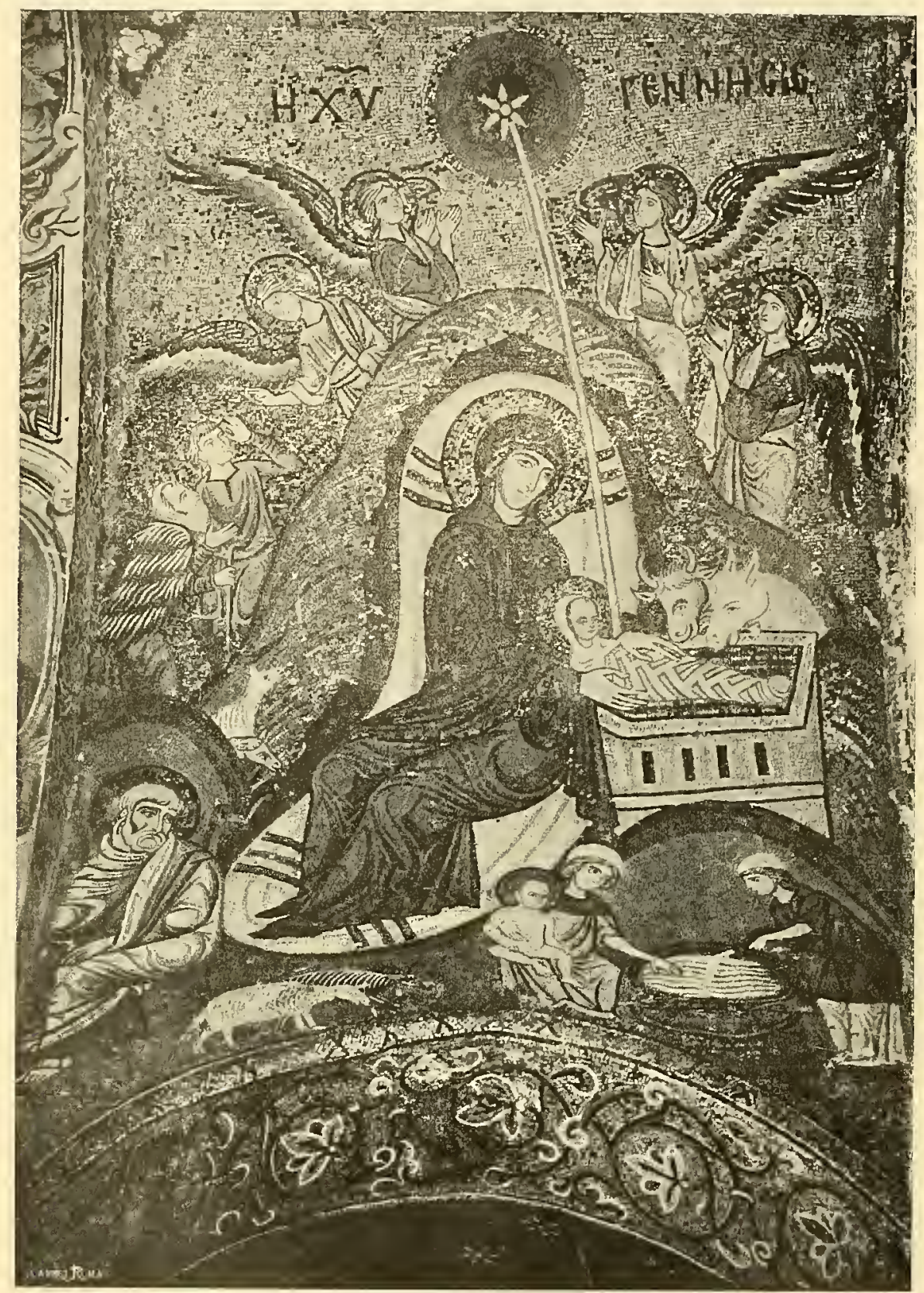

Musaico del xi secolo. Chiesa della Martorana in Palermo

racconto degli Evangeli alle profezie bibliche. Alla loro mente accesa dalla fede ricorse la visione d'Isaia, predicente la venuta di un pargoletto, del Principe della pace in mezzo al popolo che si trascinava nelle tenebre o 
giaceva nell'oscura regione della morte. E ricordarono ad un tempo le parole del profeta che annuncia ai cieli e alla terra l'ira di Dio tonante su Gerusalemme: "Il bue distingue il suo padrone e l'asino la greppia del suo Signore, ma Israele non mi riconobbe e il popolo mio non intende». Per questo ricordo del profeta, $\mathrm{i}$ due rustici animali furono congiunti alla rappresentazione della nascita del Redentore; e nulla vi era, del resto, che rendesse inverosimile la loro presenza. Pure, ogni forma dell'arte dovendo essere un

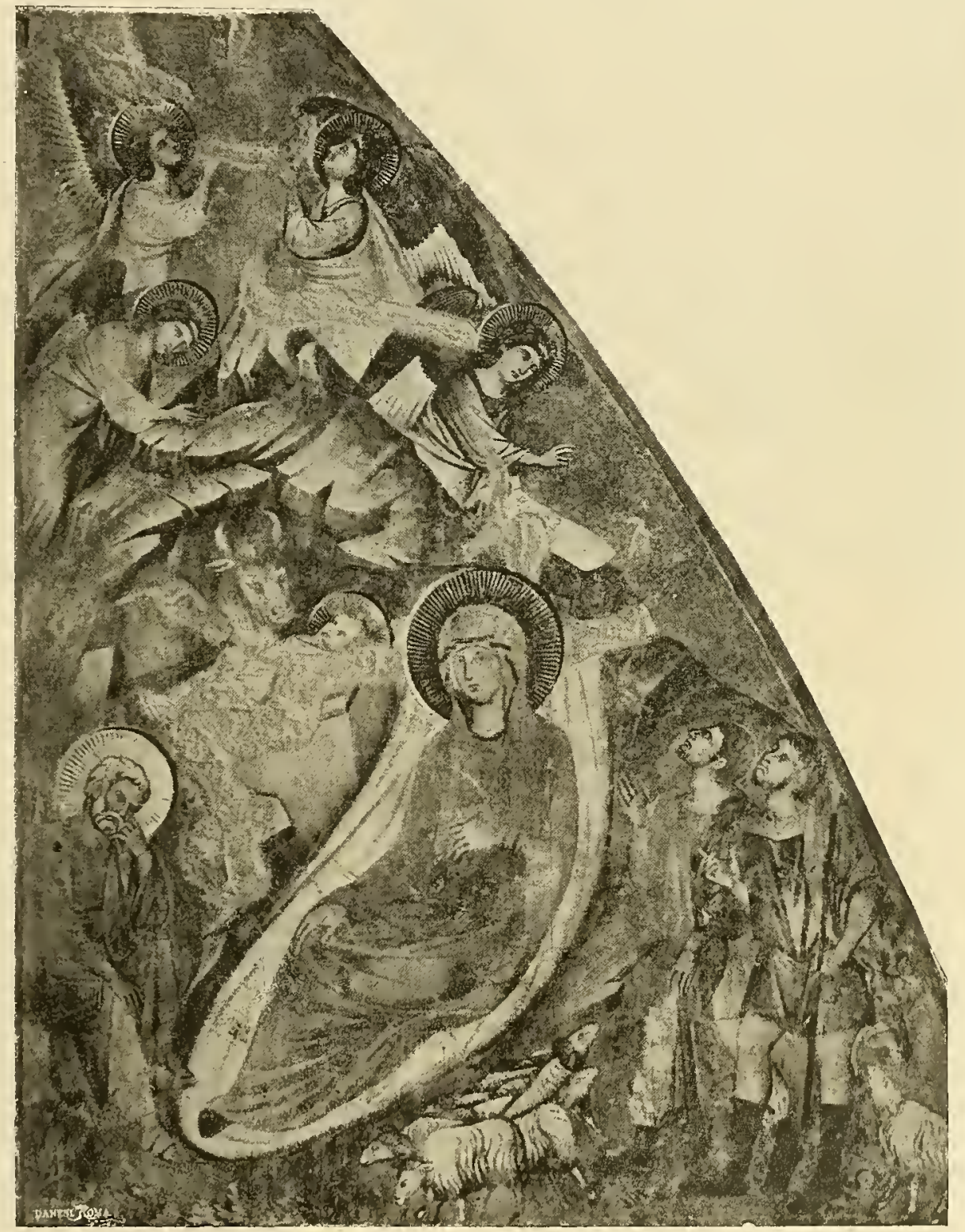

Chiesa superiore di San Francesco in Assisi

(Scuola di Cimabue) 


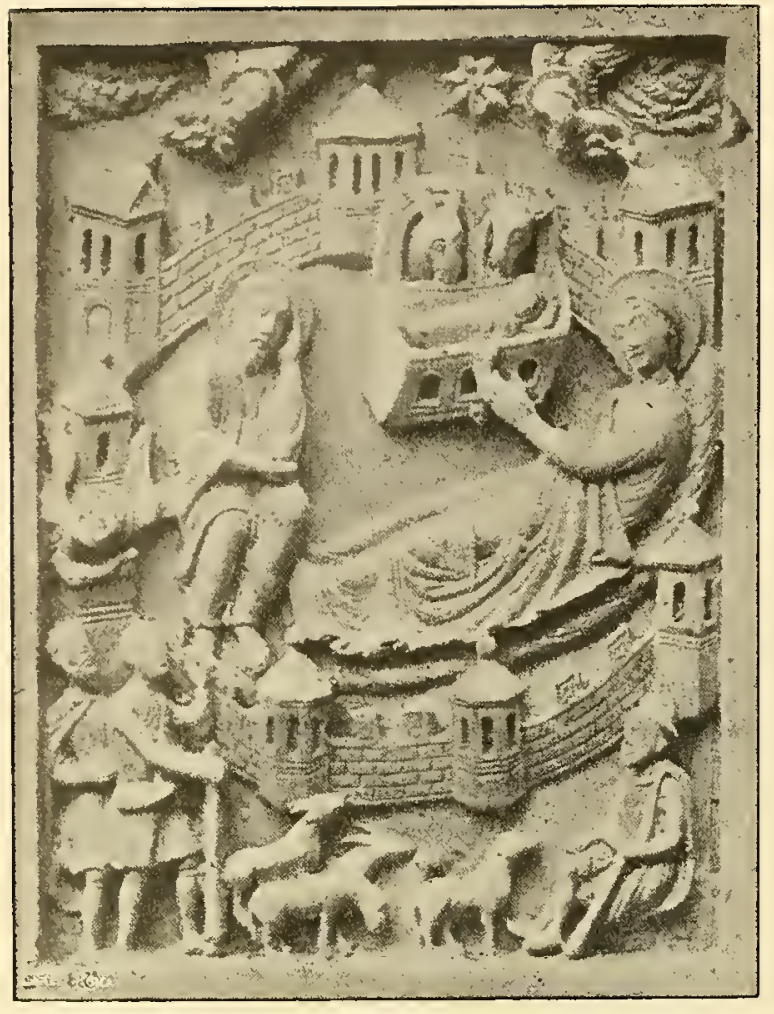

Avorio del Museo di Cologna (arte renana, sec. xII)

simbolo, un segno convenzionale del pensiero, un modello ideografico, i Padri della Chiesa adombrarono nelle figure del bue e dell'asino l'umanità giudaica e la pagana. Sant'Ambrogio medesimo riconobbe nell'asino la figura dei Gentili; e San Gregorio di Nysse, nel bue, il Giudeo incatenato dalla legge; nell'asino, colui che portava la soma dell' idolatria. Tale simbolismo ecclesiastico non poteva esser proprio agli artisti; poichè i Padri della Chiesa allontanavano dalla realtà e dalla vita, mentre questi a esse le avvicinavano; quelli si sforzavano a coprire d'un mistico velo i fattistorici, questi a comporre leggende pel popolo. E così il bue e l'asino, con' ebbero abbandonata un po' per volta l'allusione quasi satirica, divennero parte naturale, necessaria della rappresentazione. Dapprima il simbolo e la realtà non furono ben separati ; anzi perchè il simbolo splendesse di evidenza non si mancò, ad esempio, di figurare innanti alla Vergine il profeta Isaia in atto di additare la stella misteriosa. Poi di mano in mano il simbolo andò dimenticato, e la forma materiale, l'involucro, rimase nell'arte; onde nell'Evangelo dello pseudo Matteo, verso il vi secolo, compilato anche su fonti greche (quali il Proto-Evangelo di San Jacopo e i racconti di Tommaso l'Israelita), si descrive addirittura il divino Fanciullo nella mangiatoia adorato dal bue e dall'asino. Invano poi il Proto-Evangelo dello pseudo Matteo fu condannato da papa Gelasio, chè la leggenda della nascita dell'Emanuele era nella fede popolare. ${ }^{\left({ }^{(1)}\right.}$

Altrettanto avvenne d'altri elementi della rappresentazione della * Natività », determinatisi al tempo del trionfo della Chiesa, allorchè Costantino

(1) René Grousset, Le bauf et l'âne à la nativité du Christ (Mélanges d'archéologie et d'histoire, IV, 1884). 
ebbe edificata una basilica cristiana a Betlemme, e si cominciò a celebrare ai 25 di dicembre il Natale, ${ }^{(\mathrm{r})}$ festa sconosciuta in Occidente nei primi tre secoli. Al puro simbolismo dell' èra dei martiri succede la rappresentazione dei fatti biblici, la glorificazione della Chiesa; l'arte esce dalle catacombe, e si spande nelle basiliche splendenti di marmi e di musaici, e declama ad alta voce i racconti degli evangeli con le parole

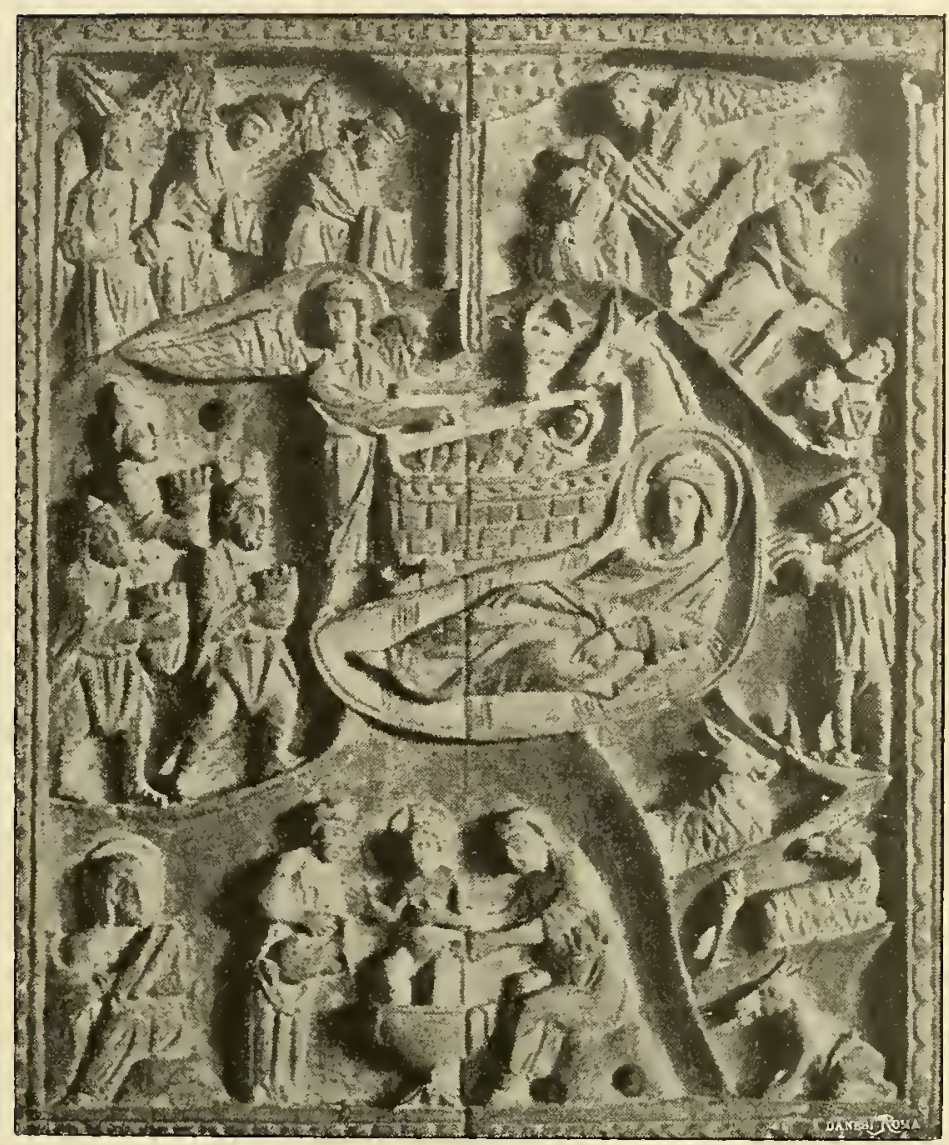

Avorio. Museo Nazionale in Ravenna dei gentili. "Un giorno sereno e limpido s scrive Eusebio, "un giorno che alcuna nube non oscurerà più mai, illuminerà di luce divina le chiese del Cristo sparse sulla terra».(2) Animata da questo entusiasmo, l'arte si mani-

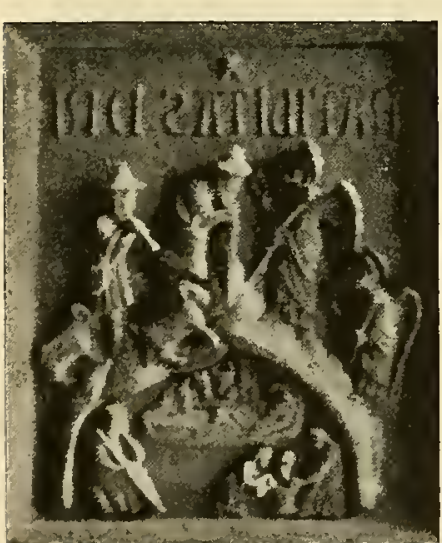

Porta della Cattedrale di Pisa (Bonanno Da PISA) festa in un nuovo rigoglio di forme.

La scena della "Natività * si ebbe dall' arte pagana le figure dei pastori, create dall'amore della vita campestre diffuso da tanti poeti nelle egloghe pastorali. Già i cristiani nell'oscurità delle catacombe avevano disegnata la figura del Buon Pastore in una forma agreste e umile di villico semplice e decoroso; bastava dunque togliergli l'agnello dalle spalle per unirlo a' compagni intorno

(r) Piper, Dor christl. Bilderkreis. Berlin, i 852 .

(2) Eusebio, Hist. eccl., I. X, c. I. 
a la stalla, ove Dio riluceva nella mangiatoia. Questi portano la tunica ad esomide, il bastone ricurvo, come i fauni e i centauri delle pitture di Pompei; appaiono tra gli alberi, come gli dèi rustici, ma sono buoni, onesti e semplici.

La Vergine, principalmente nelle sculture, prende il tipo giunonio, quasi che, secondo il racconto forse di un audace gnostico, ${ }^{(x)}$ sotto le spoglie di Maria fosse comparsa sulla terra Giunone. Quel racconto ne insegna tuttavia come l'atmosfera impregnata di paganesimo avvolgesse la nuova fede e l'arte. "Vi era in Persia un tempio di Giunone de' più splendidi, edifi-

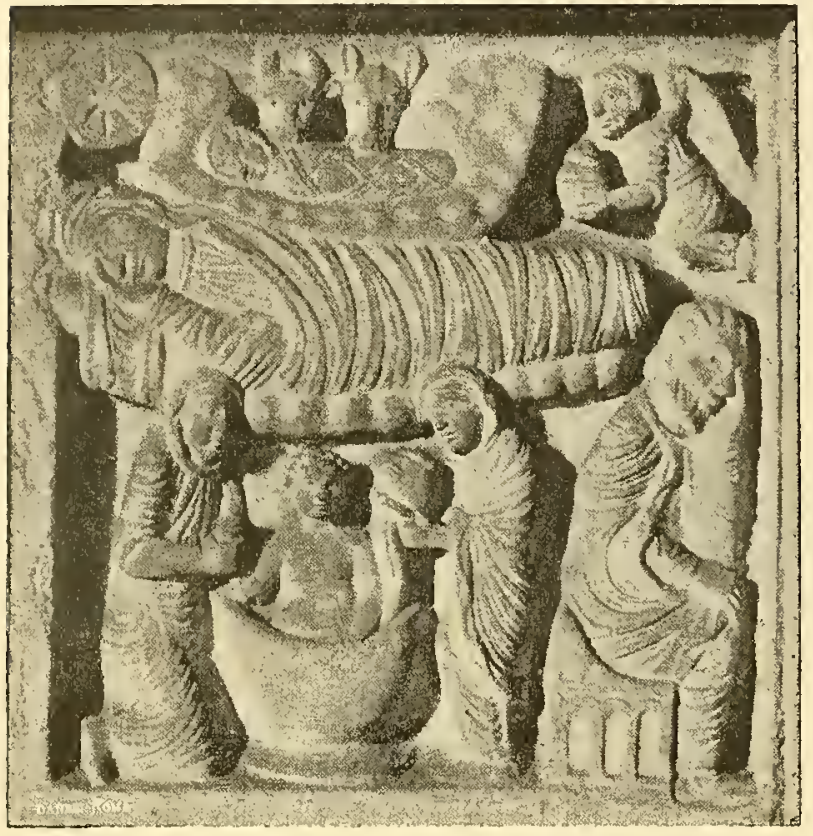

Dal pulpito di Groppoli (anno II94) cato da Ciro e da lui adorno di statue di numi in oro e argento », i quali (ci sia permesso d'abbreviare il lungo racconto), conversando tra loro, rivelarono al sacerdote del tempio che Giunone non era morta, ma aveva preso il nome di Maria e sposato un operaio, dalla cui unione era nato il principe degli operai, quegli che con infinita sapienza architettò il trono del cielo. Ciro ascoltava il racconto del sacerdote, quando le statue sonarono i loro strumenti, uccelli d'argento e d'oro volarono per il tempio, e il re guardava spaventato ogni cosa. "Il tetto del tempio si squarcia e una stella splendida filante dal cielo s'arresta sulla colonna della sorgente" e ad essa annuncia la nascita d'un fanciullo "che sarà il principio e la fine, il principio della salute, la fine della morte». Allora tutte le statue si prostrano, e il re convoca tutti i savî del regno, che vedendo chine le statue e commessa di pietre preziose la stalla, gli dicono: "La sorgente è Maria, figlia della sorgente di Betlemme; manda a Gerusalemme, e vi troverai il figlio di Dio onnipotente, sotto umane spoglie, nelle braccia di una donna». La 

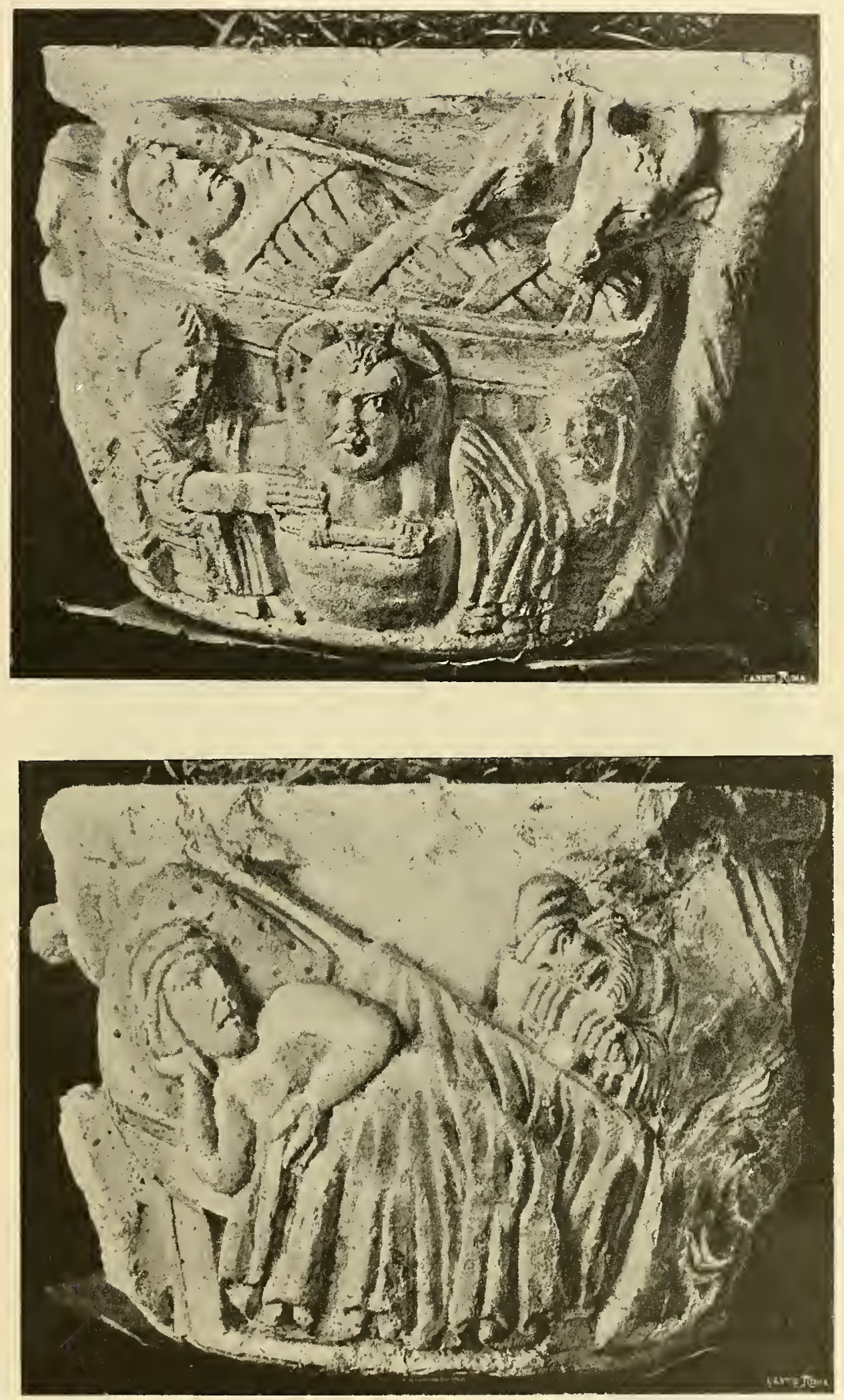

Capitello romanico, giả nella chiesa di San Vitale alle Carpineti (Reggio Emilia) 
stella rimase immota sulla celeste sorgente sino alla partenza dei Magi, e con essi si allontanò. Tale è in parte il racconto attribuito a Sesto Giulio Africano, del In secolo, traduzione degli Evangeli in una forma pagana. Meno fantastici, anzi con linguaggio che riflette quello di Seneca e di Platone, i Padri della Chiesa cantano la maternità di Maria e la gloria del Figlio divino. Ambrogio canta il presepio fulgente e la notte rischiarata da

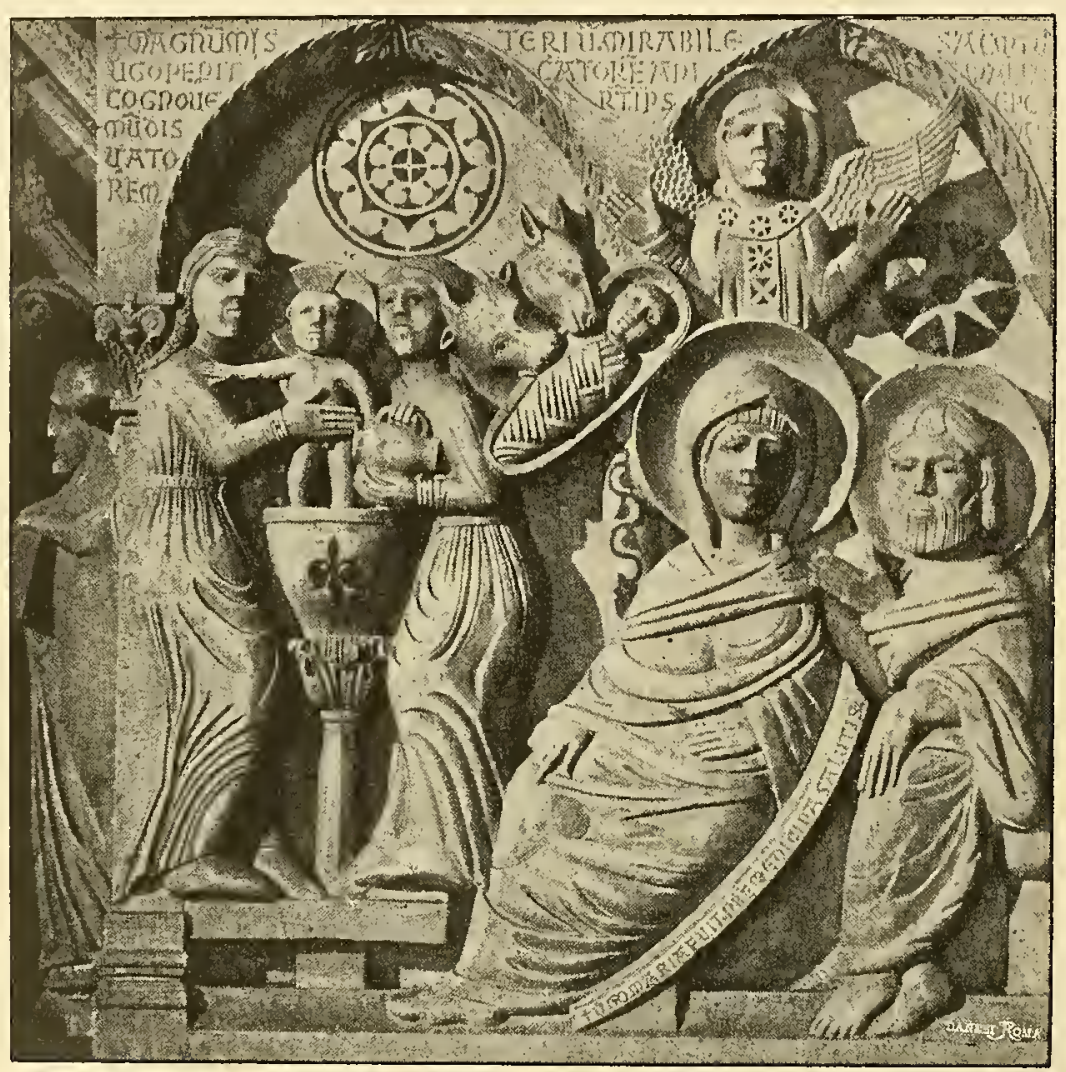

Dal pulpito del Duomo di Barga nella provincia di Lucca

nuova luce: Vittorino fa sorridere la terra al ricevere la santa semenza, gioire il mare, le nubi e i venti.

Gli scultori cristiani, come i sacri poeti, come i Padri della Chiesa, si attenevano allo stile dei pagani nell'affermare a colpi di scalpello la vittoria della nuova religione, e raccoglievano gli strumenti, i materiali, i tipi che il vecchio mondo caduto aveva gettato loro. Ed ecco anche le Vittorie alate staccarsi dagli archi di trionfo, per annunciare ai pastori nel presepio la lieta novella, e, in lunga veste candida, col volto maschile di giovanetti, in attitudine ieratica, librarsi sul Re, cui un giorno saranno retaggio i popoli; 


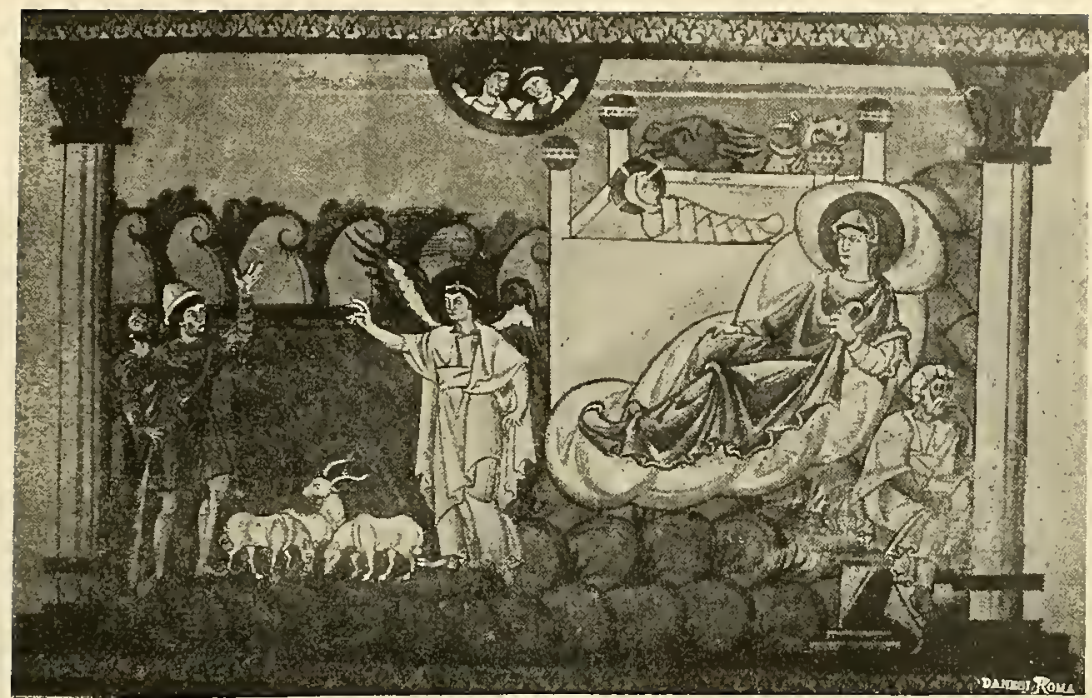

Dall' «Orationale» di Fulda (avanti il I054). Ms. vaticano, latino 3548

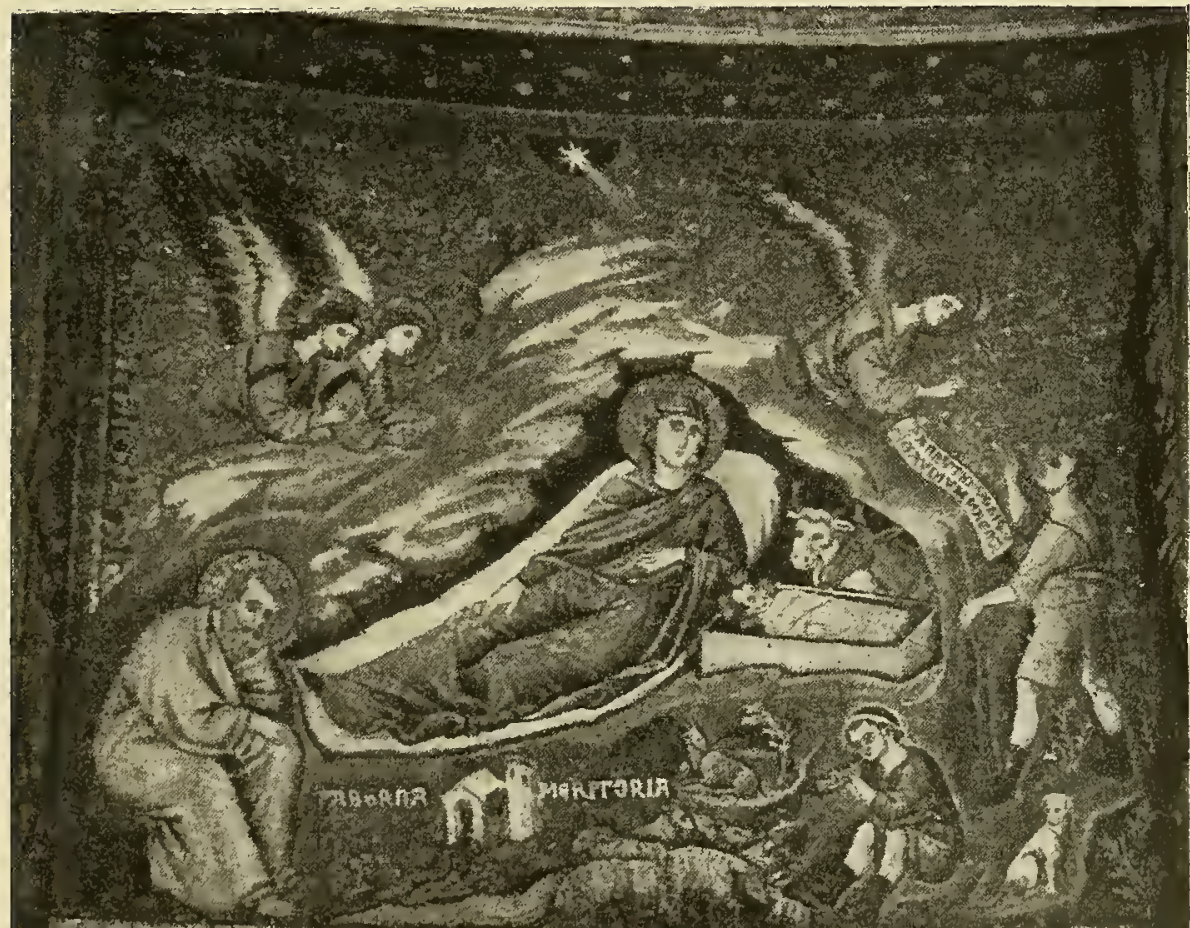

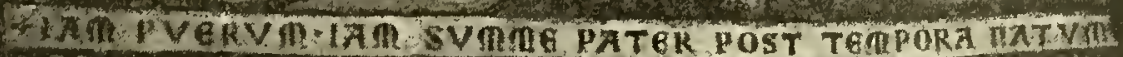

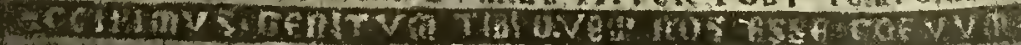

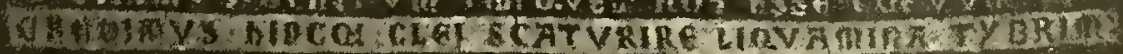


ed ecco Maria, come una statua della Pudicizia, sedersi presso la greppia, in attitudine di abbandono e di contemplazione; e i Magi, col costume che

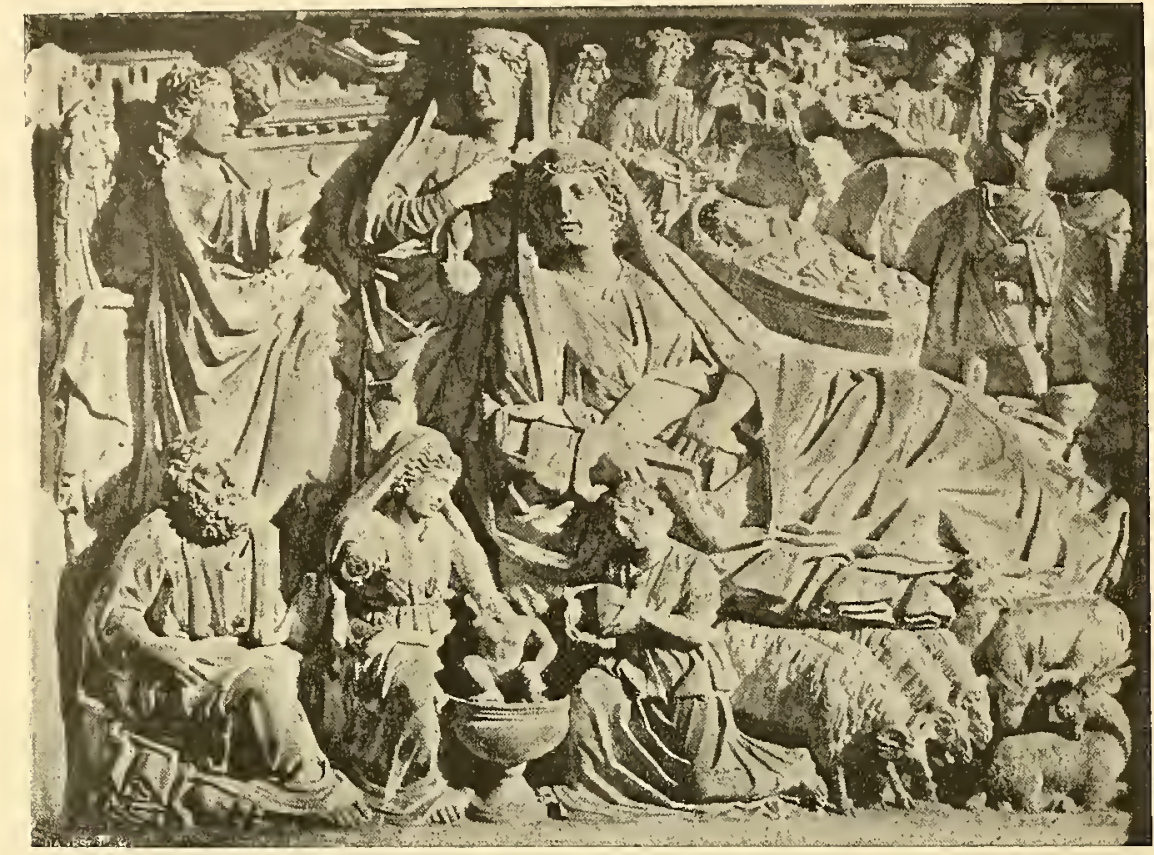

Dal pulpito nel Battistero di Pisa

(Nicoló Pisani)

si riscontra nei monumenti mitriaci e nelle figure dei Paridi, recare cornucopie e corbe di frutta, invece dell'oro e dell'incenso dei Sabei, ne' quali Origene vedeva adombrato il Re e Dio, e invece della mirra, segno, secondo l'autore stesso, del sepolcro e della fine del Dio. ${ }^{\left({ }^{(}\right)}$

Questi ed altri sensi simbolici si sforzano tuttavia di penetrare nelle prime rappresentazioni: la stella, guida dei Magi, è spesso sostituita da un monogramma inscritto in un cerchio, indicante ai fedeli che l'astro era Cristo, guida degli uomini smarriti nelle tenebre; e i Re Magi, secondo i Padri della Chiesa, significano il contrasto dei Gentili illuminati dalla verità coi Grudei persistenti nell'errore; e Maria stessa rappresenta l'umanità di Cristo. Il penetrare delle forme ellenistiche nell'arte occidentale si rileva anche in un particolare della rappresentazione del luogo della nascita, segnato sui sarcofagi dagli scultori romani come una semplice tettoia sostenuta da pali 
o da tronchi d'albero, mentre la tradizione greco-orientale collocava in una grotta la culla del Redentore, chè tale era il luogo sacro innanzi a cui pie-

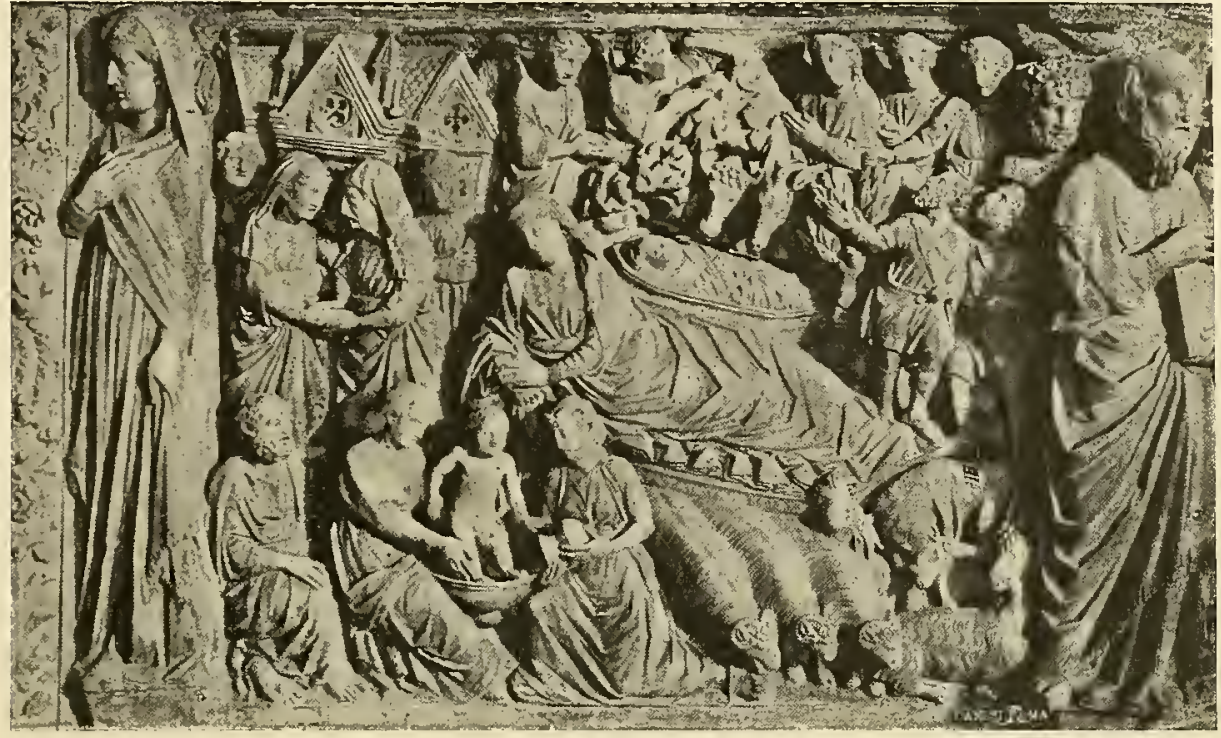

Particolare del pulpito della Cattedrale di Siena

(Nicola Pisano e seguaci)

gavano le ginocchia i pellegrini a Betlemme. E la grotta sostituì in molti casi l'edificio primitivo scolpito nei sarcofagi, tanto più che nulla contraddiceva

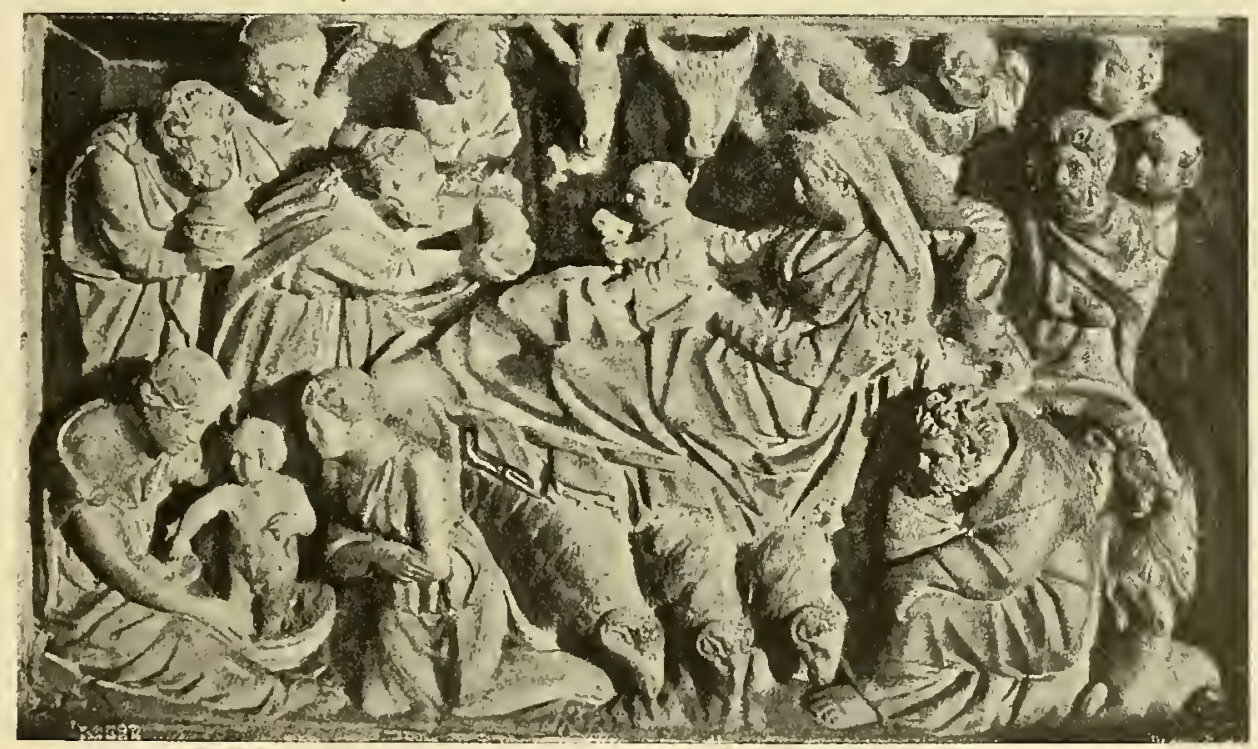

Chiesa di San Giovanni fuori civitas in Pistoia (Fra Guglielio da Pisa) 
all' Evangelio di San Luca, per essere le caverne nella Palestina rifugio alle mandre. Lo pseudo-Matteo però confonde e mesce la tradizione latina con la greca, discorrendo della stalla come della spelonca illuminata da un misterioso chiarore.

Mentre si diffondeva quell' Evangelo apocrifo, verso il vi secolo, la scena della "Natività " tendeva a farsi più reale e spogliarsi d'ogni mistico velo.

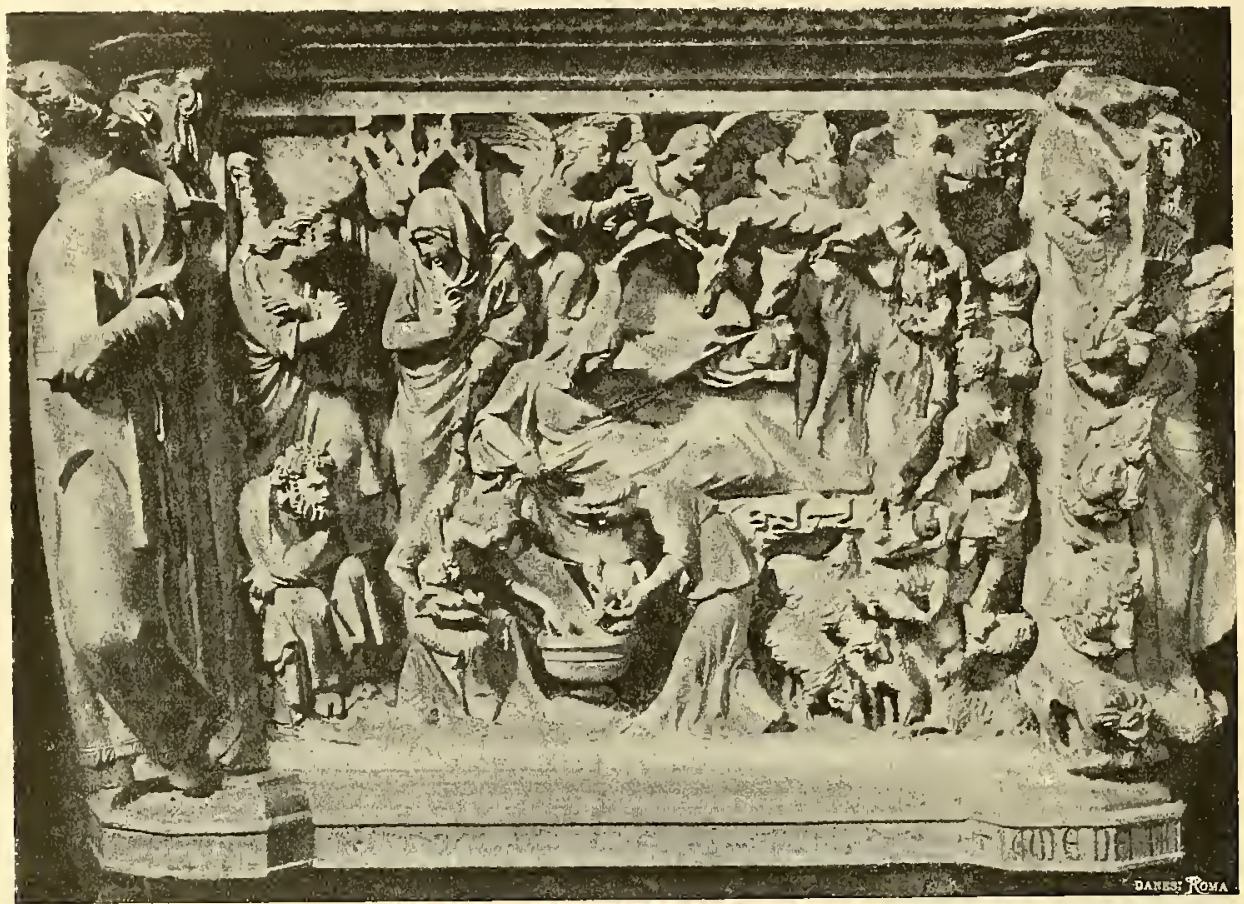

Chiesa di Sant'Andrea in Pistoia

(Giovanni Pisano)

Lo stesso pseudo-Matteo discorre di Zelomi e Salome, assistenti la Vergine; e la figura di San Giuseppe, custode della divina creatura, trova il suo posto nella composizione. Il volgo non può seguire a lungo nei mistici rapimenti i suoi maestri; ha bisogno di dar corpo alle fantasie, di mirare gli avvenimenti svolgersi nello specchio dell'arte come nella sua propria casa; le sottigliezze non fanno per lui. I Padri della Chiesa nel cielo, i volghi sulla terra ricercavano il raggio degli splendori divini; e benchè l'arte, docile a' consigli dei savî, avesse determinato sin dall'epoca costantiniana $i$ contorni generali della scena cristiana, ora, serva di mecenati barbari o di plebi ignoranti, doveva modificare quei contorni, alterarli per negligenze, 


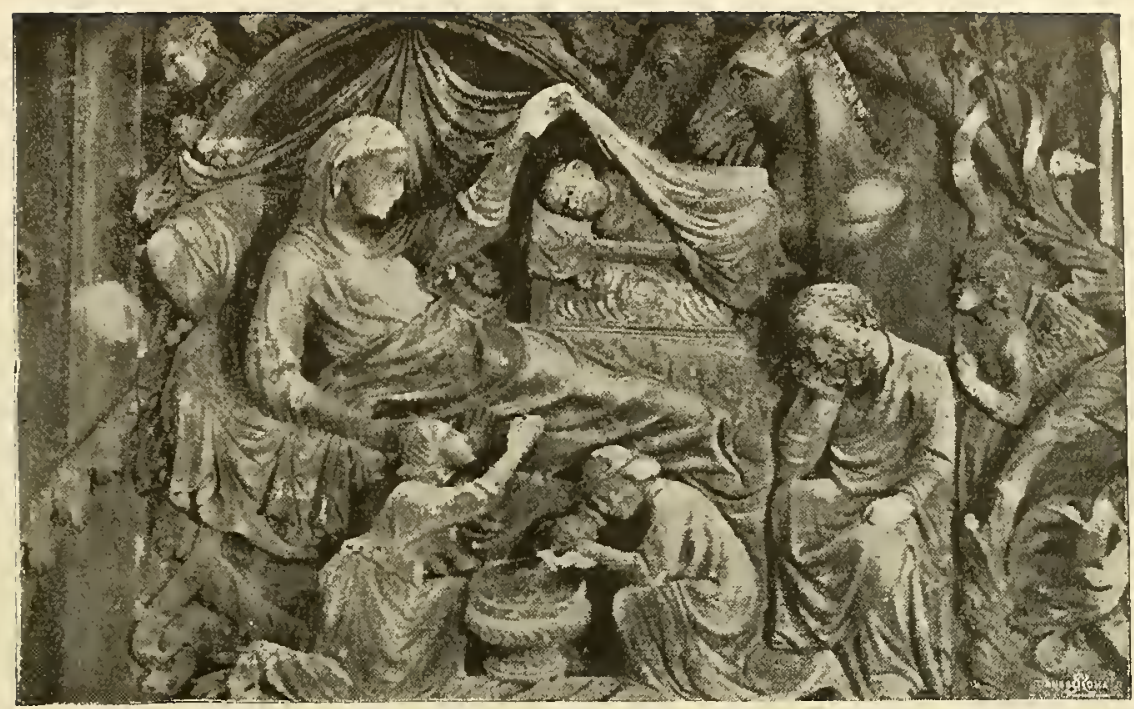

Bassorilievo nella facciata della Cattedrale d'Orvieto

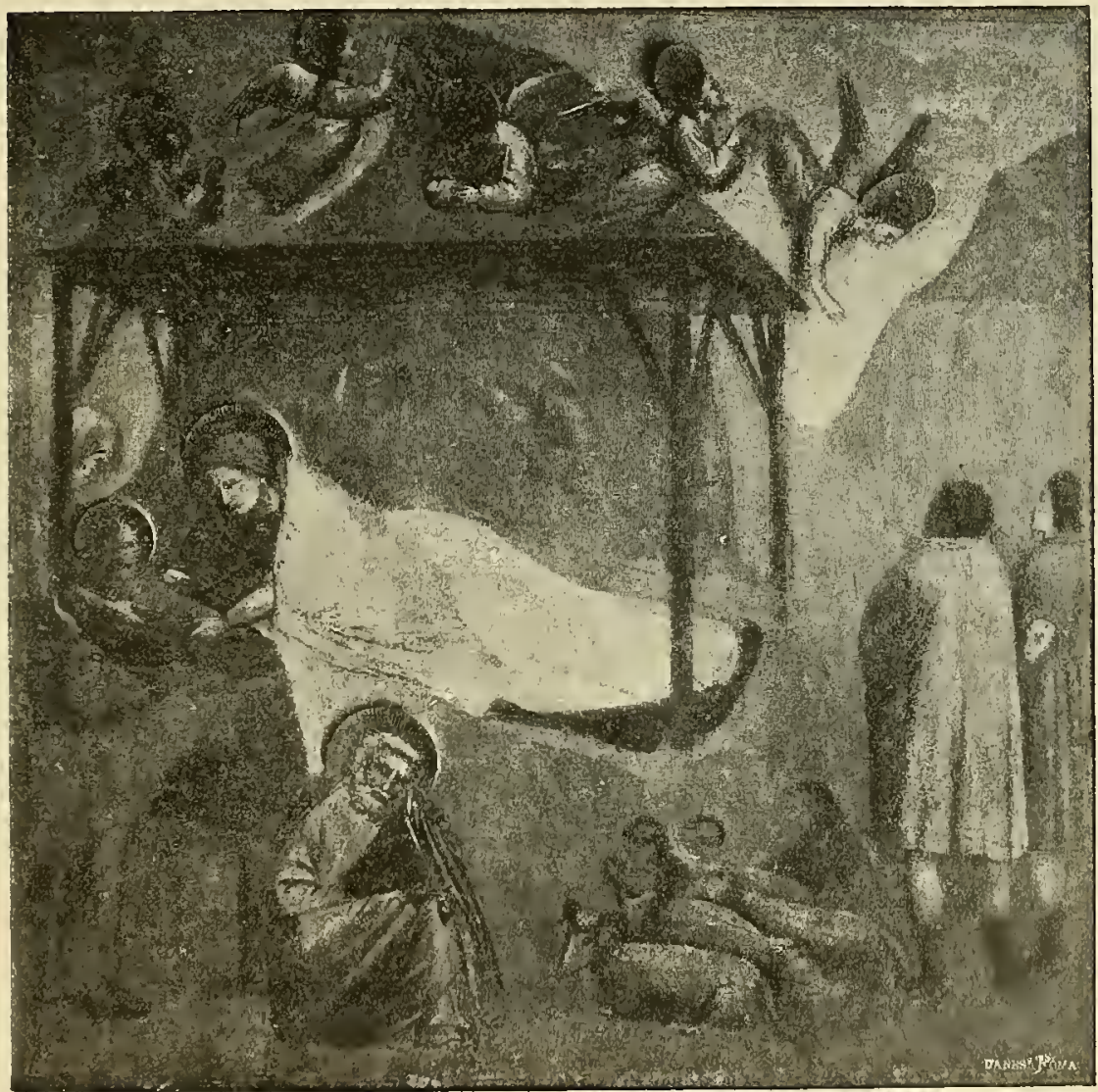

Chiesa dell'Arena in Padova

(Grotto) 
puerilità, materialità, rozzezza. Fin dal vi secolo la "Natività " è divenuta una scena reale: Maria giace sopra un materasso, Zelomi e Salome l'assi-

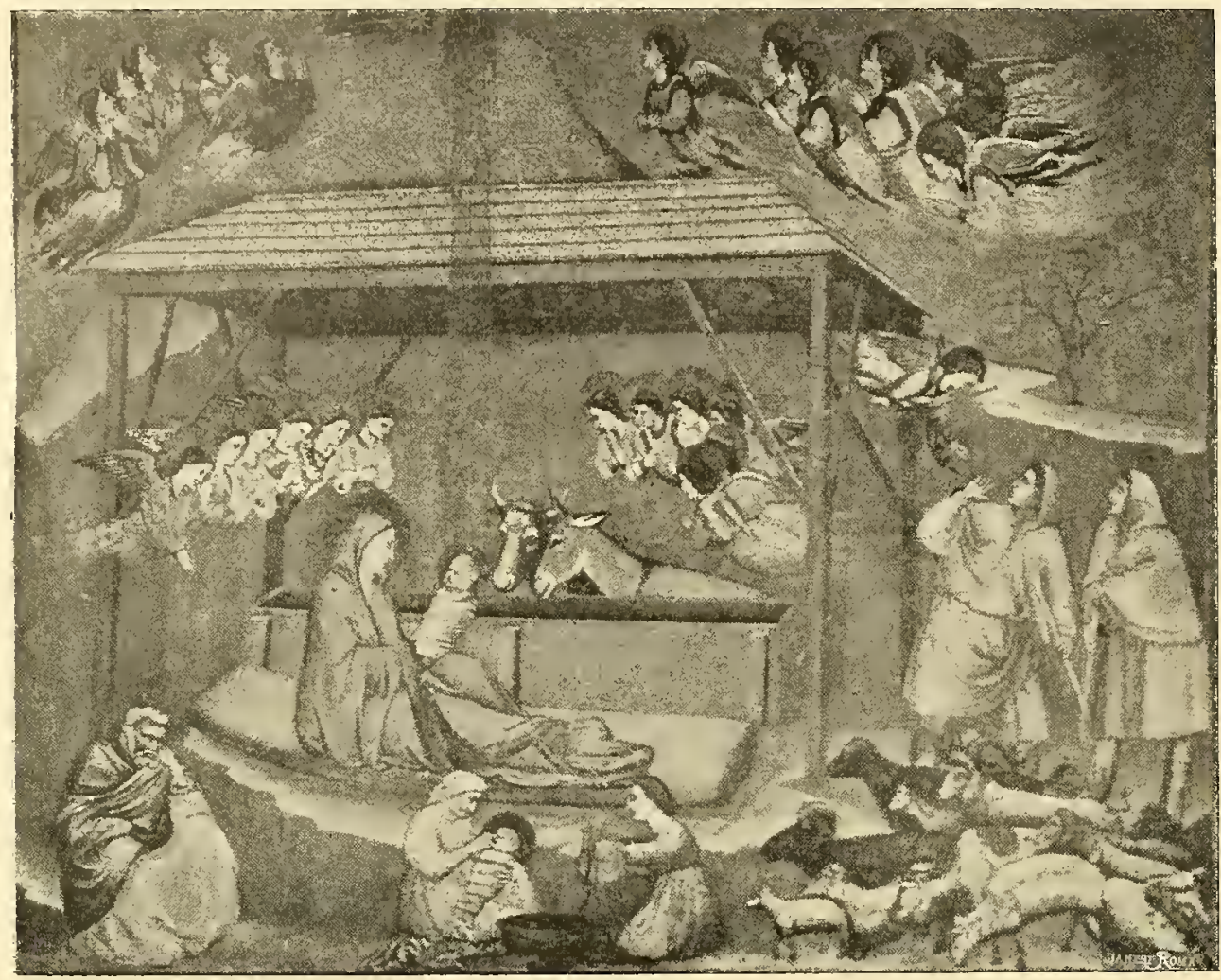

Basilica di Assisi

(Giotтo e suoi seguaci)

stono e lavano il Bambino; Salome ha il braccio inaridito per aver dubitato della verginità della Madre di Dio, indi, per intercessione di lei, guarisce. In uno degli avorî della cattedra di Massimiano a Ravenna si vede il divin Fanciullo dormente nella greppia, corteggiato dai due rustici animali, guardato da Giuseppe, vecchio di forme erculee, mentre la Vergine sta adagiata sur un materasso bizantino, e tutta pensosa ascolta Salome che le mostra la mano cadente. E la leggenda di Salome, derivata dal Proto-Evangelo di San Giacomo, si riflette nei musaici della cappella di Giovanni VII, in San Pietro, e negli avorî, in quello, ad esempio, del Museo Civico di Bologna. Per lunghi secoli la rappresentazione rimase inalterata; l'arte ripetè la scena meravigliosa per il popolo, quasi col timore di non esser fedele, di non dire a dovere ciò che si sapeva a memoria da tutti. Il manoscritto greco dell'vin secolo 
a Venezia, il menologio greco della Biblioteca di Berlino (x secolo), l'altro della Vaticana, che appartenne probabilmente a Basilio Porfirogenito, il sal-

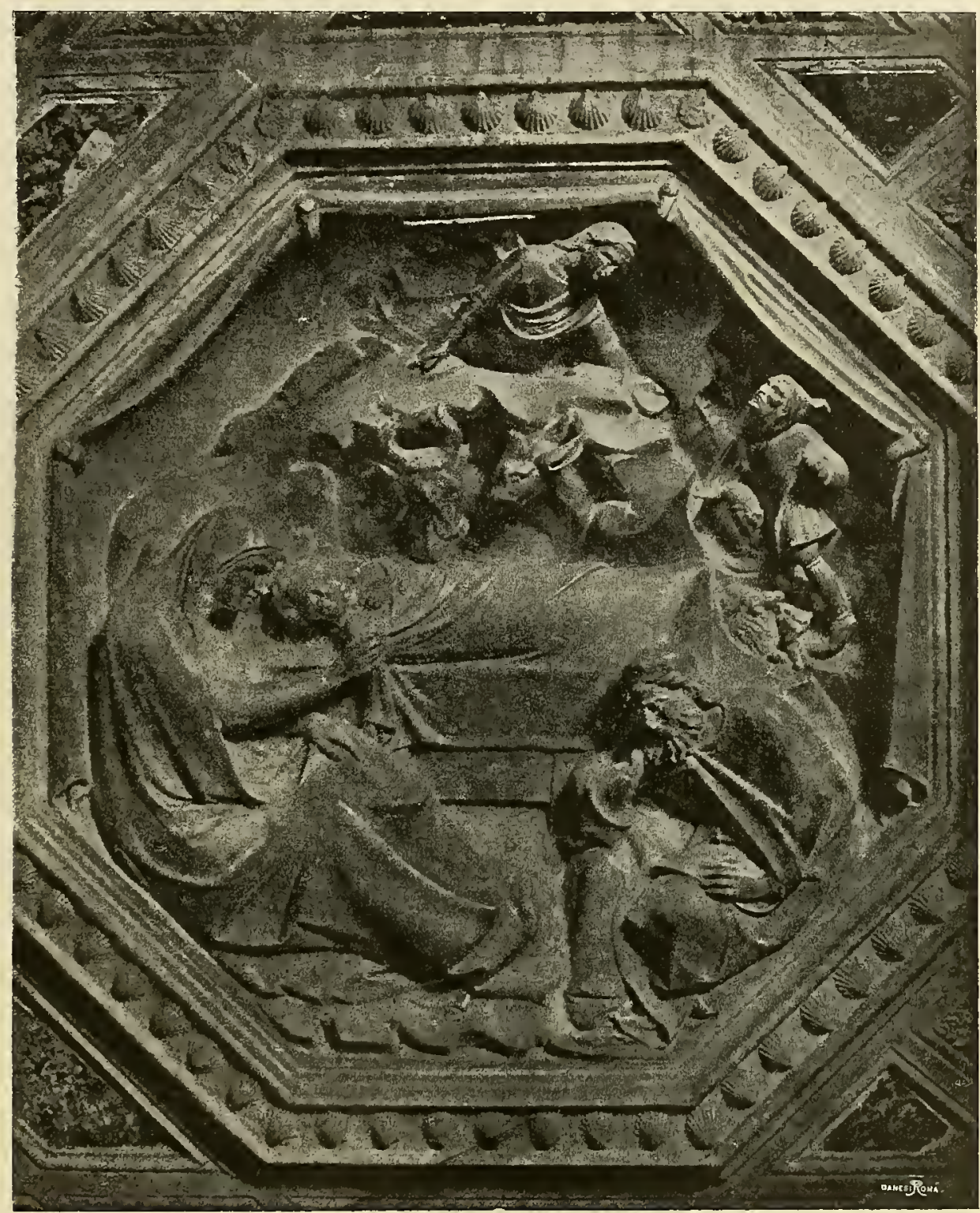

Tabernacolo in Or' San Michele in Firenze

(ORCAGNA)

terio bizantino del dottor Comarmont di Lione (XI-XIr secolo), un musaico del battistero di Firenze, traducono tutti all'incirca il medesimo soggetto. In tutti la stella irradia la culla riscaldata dagli animali, la Vergine è distesa o seduta in attitudine pensosa, San Giuseppe medita profondamente o dorme, 
i pastori son guidati dall'angelo, Salome e Zelomi lavano in una vasca il neonato. Appena si può notare la scomparsa della rappresentazione del castigo o della guarigione di Salome: ella non si vede più se non perdonata da Dio, in atto di offrir la mano al Fanciullo, secondo gli ordini dell'angiolo. E, del resto, lo spirito del Proto-Evangelo di San Giacomo perdura: nella sacra scena sembra di vedere ogni moto sospeso, e l'aria immobile, come nel Proto-Evangelo stesso sono descritti, al momento dell'arrivo del Redentore, i dintorni di Betlemme: "Gli agnelli si fermavano nel cammino, il pastore alzava il bastone per incitarli al corso, ma la sua mano restava ferma nell'aria; e alla riva d'un torrente le capre tenevano aperta la bocca e non bevevano *. Un musaico che adornava la cripta della chiesa della Natività in Betlemme,

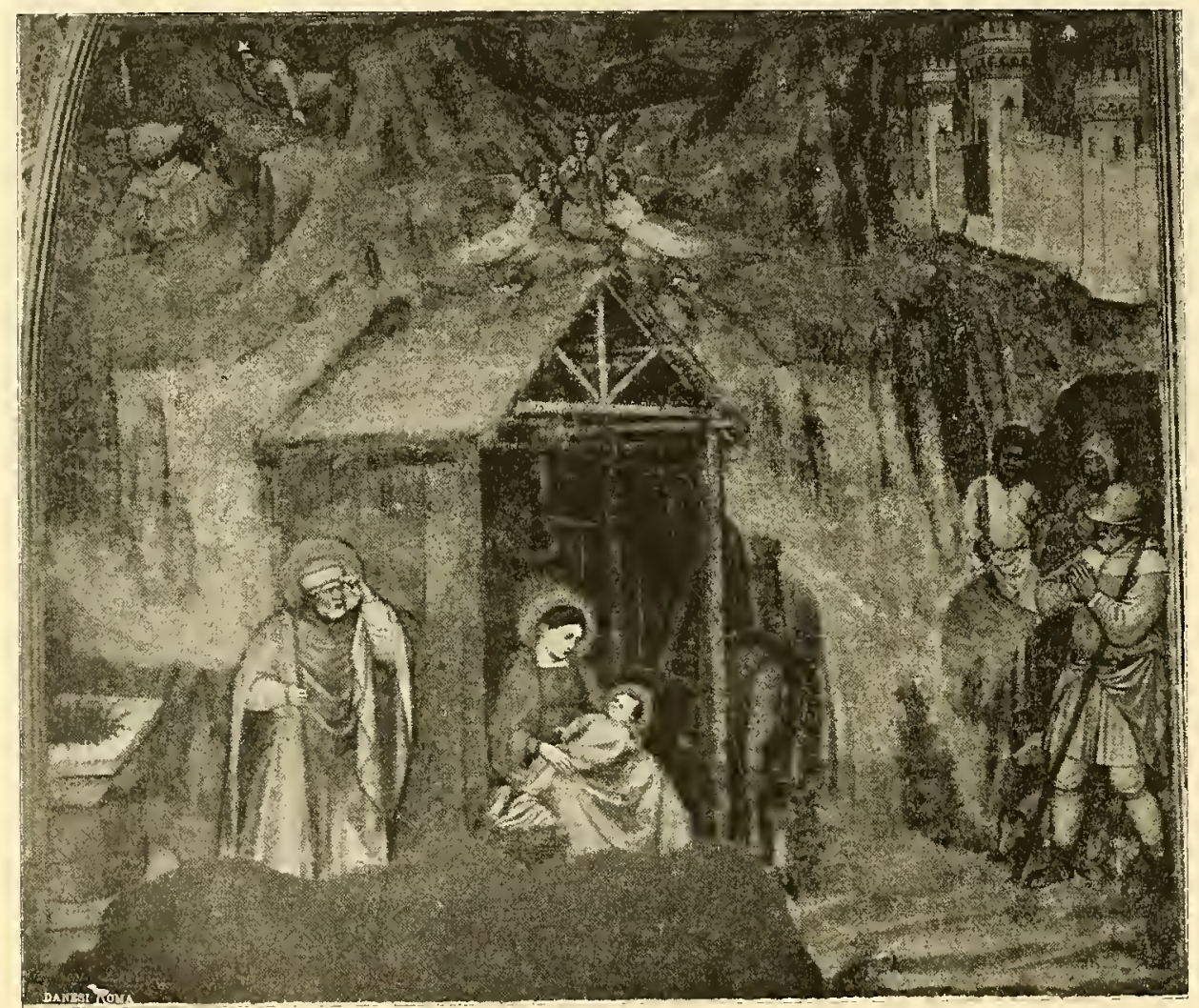

Oratorio di San Giorgio in Padova

(Jacopo Avanzi)

già eseguito nel 1 I 69 da Efrem per ordine di Emanuele Comneno Porfirogenito, fu descritto del $I_{1} \delta_{5}$ da Focas, monaco cretese, visitatore della 
Palestina; ${ }^{\left({ }^{2}\right)}$ eppure la descrizione del monaco, benchè rifletta cose da lui vedute, è tutta simile a quella che il retore Coricio Gazeo diede nel secolo vi

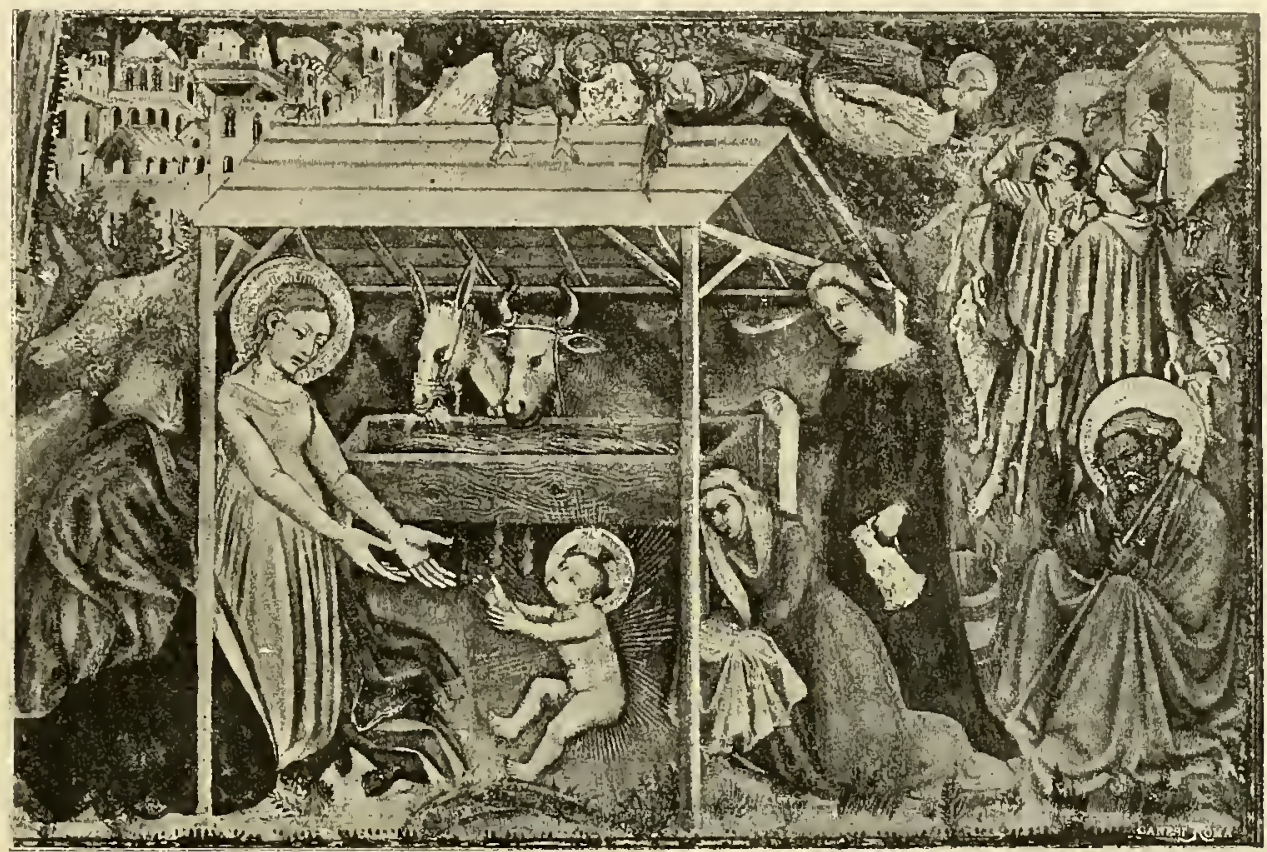

Palazzo de' Trinci in Foligno

(Ottaviano Nelli)

di un'altra composizione esaminata coi proprî occhi. Ciò lascia pensare che le immagini e le composizioni cristiane migrassero lungo il medio evo, sino al secolo xirI, come in un lungo viaggio su carovane attraverso al deserto.

Nicola Pisano trasportò la rappresentazione della "Natività " nel campo della bellezza plastica; non però nel pulpito di Pisa, ove le figure assumono una classica grandiosità, e la Vergine sembra una giunonica matrona romana o un' imperatrice diademata assisa in un triclinio; bensì nel pulpito di Siena, cui sgorga dall'arte spontaneo e vivo il sentimento. Quivi Giunone, Ercole, i Paridi, le Vittorie si fanno cristiani; gli angioli non sono i satelliti della divinità, ma anime oranti; i pastori, colpiti dalla luce della stella, esprimono il loro incanto; le ostetriche curano rispettose, divote, il Bambino; e la Vergine non alza fieramente il capo di dominatrice, come a Pisa, ma lo piega sulla spalla destra e medita, con le mani sovrapposte, in dolce abbandono materno. Un seguace di Nicola, Fra Guglielmo, che ripete le forme del

(1) Metch. de Vogüte, Les églises de la Tare-Sainte. Paris, I 860. 
maestro, quelle sole però del pulpito di Pisa, sa tuttavia animare d'entusiasmo le figure grandiose che gli servirono di modello; e nel suo pulpito di Pistoia, a San Giovanni fuori civitas, spira alla Vergine, al Bambino, ai Re Magi il fervore, il sussulto della vita. E Giovanni Pisano ad un tempo, pure in Pistoia, mentre s'attiene devoto alle forme paterne, fa sollevare delicatamente dalla Vergine la coltre che copre parte della tonda testina del neonato: motivo artistico il quale trovò poi nell'arte tante applicazioni, a cominciare dal più bello de' bassorilievi della facciata della cattedrale di Orvieto, sino alla Madonna dal Velo di Raffaello.

Il sentimento della maternità traluce meglio nell'opera di Giotto ad Assisi, il quale figurò la Vergine in atto di guardare amorosamente il Figliuolo in

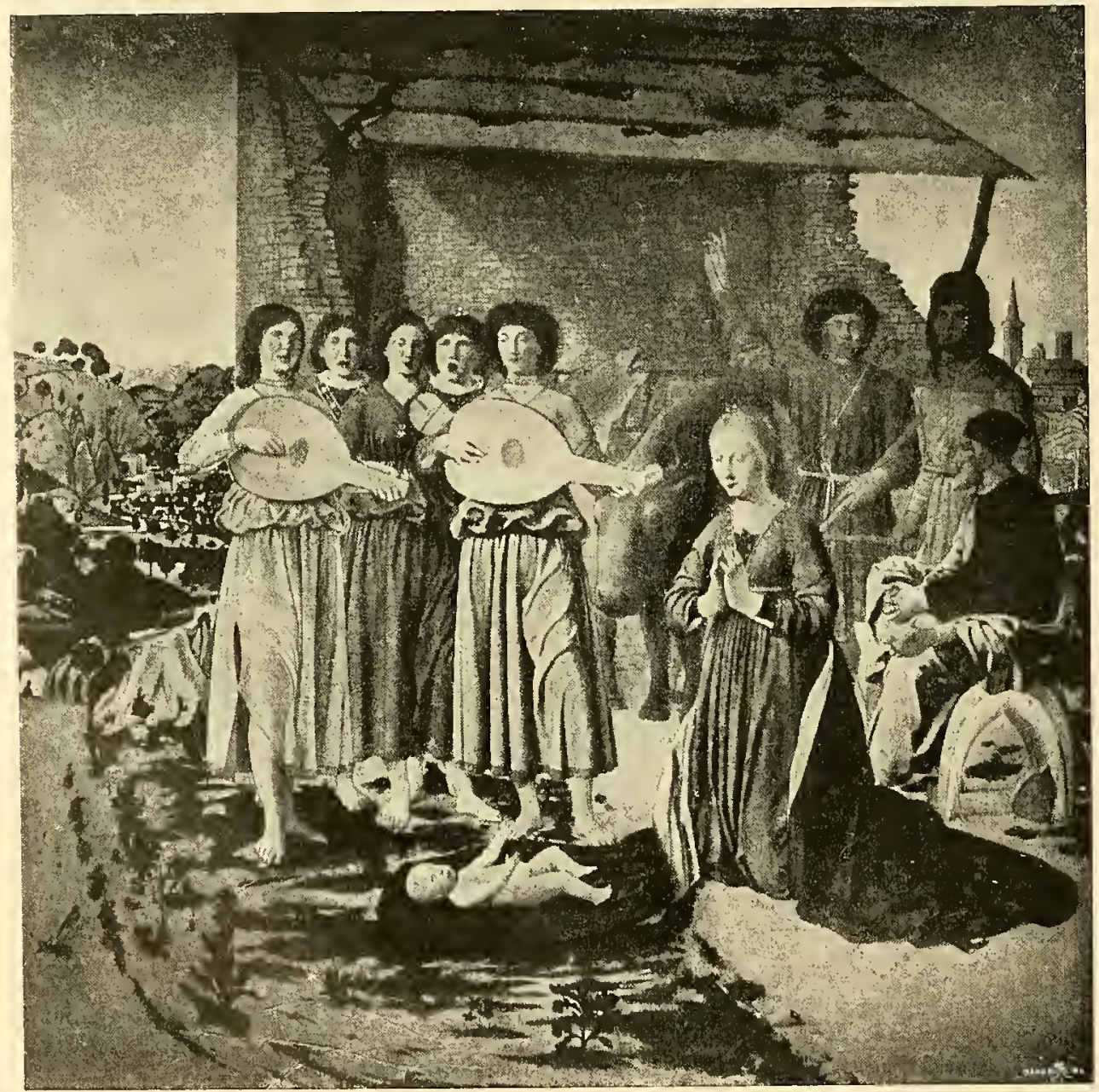

Galleria Nazionale di Londra

(Pier della Francesca) 
fasce, sollevato dalle sue mani, mentre l'asino e il bue girano gli occhi sul Bambino, quasi con senso divoto, e a schiere a schiere scendono gli angioli, sotto la tettoia, con le mani giunte o conserte sul petto, accesi di sacro entusiasmo; mentre sopra la tettoia, con gli sguardi e le mani e i corpi vòlti alla luce che fende l'aria e cade sulla culla divina, altri angioli a destra e a sinistra esultano. I pastori dietro al gregge, che annusa e guata, si arrestano meravigliati all'annuncio dell'angiolo; San Giuseppe medita; una delle oste-

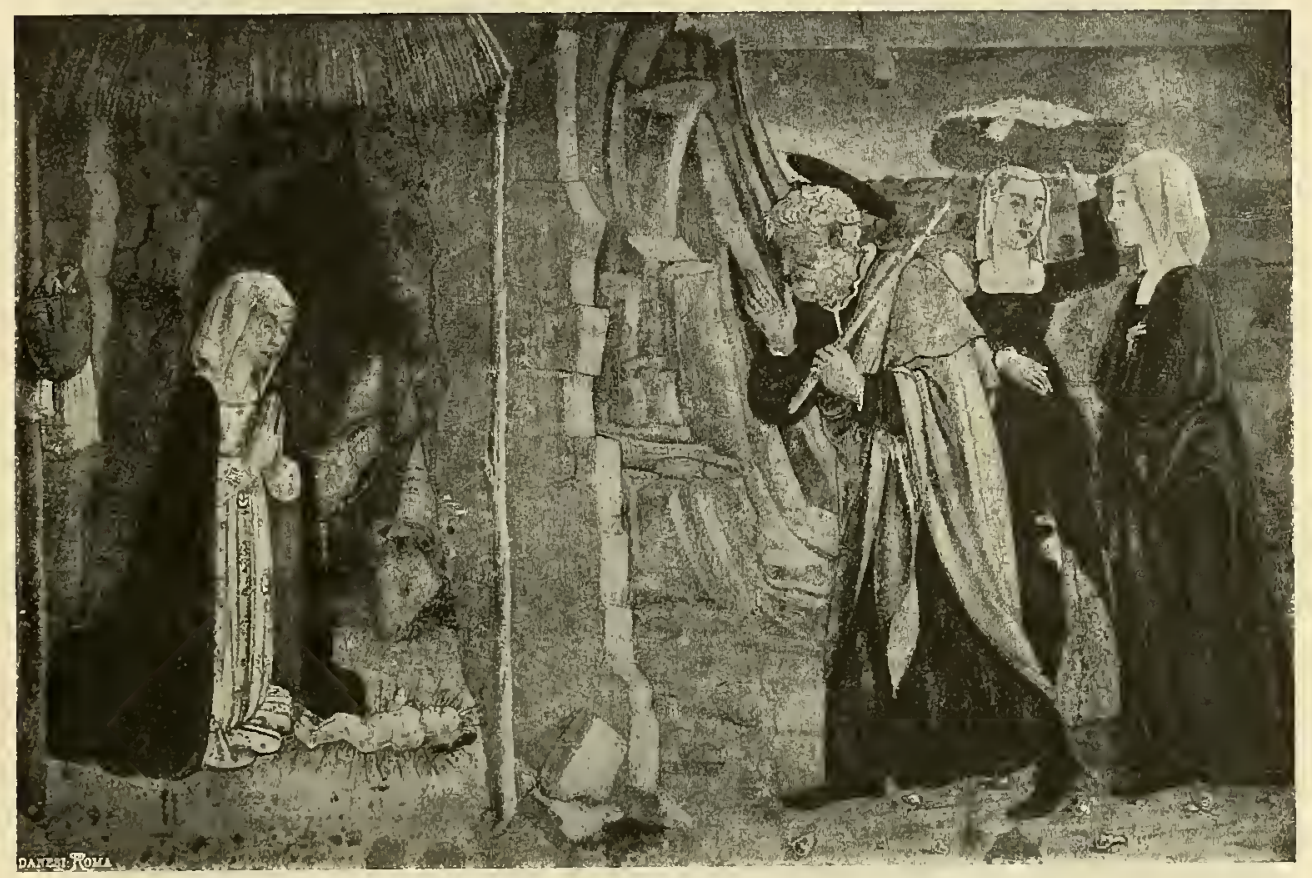

Chiesa di Santa Maria della Verita in Viterbo

(LORENZO DA VITERBO)

triche prende scherzando il Bambino pel naso, e l'altra gli appresta i pannolini. Con questa composizione di Giotto la scena della "Natività " si svolge nel campo dell'ideale, come semplice e solenne preludio all'epopea cristiana. Ma perchè il preludio acquistasse sempre maggiore varietà, rispecchiando le menti e i cuori degli uomini, conveniva associarvi i ricordi, le predilezioni, le speranze dei fedeli, permettere che il divoto prendesse parte alla scena religiosa. Già il Cavallini, disegnando il Presepe nei musaici di Santa Maria in Trastevere (1291), rappresenta la taberna meritoria, cioè una casetta situata sulle falde del monte, donde scaturiva una fonte d'olio, per indicare l'origine della basilica o il luogo ove $\mathrm{i}$ fedeli perseguitati da Alessandro 


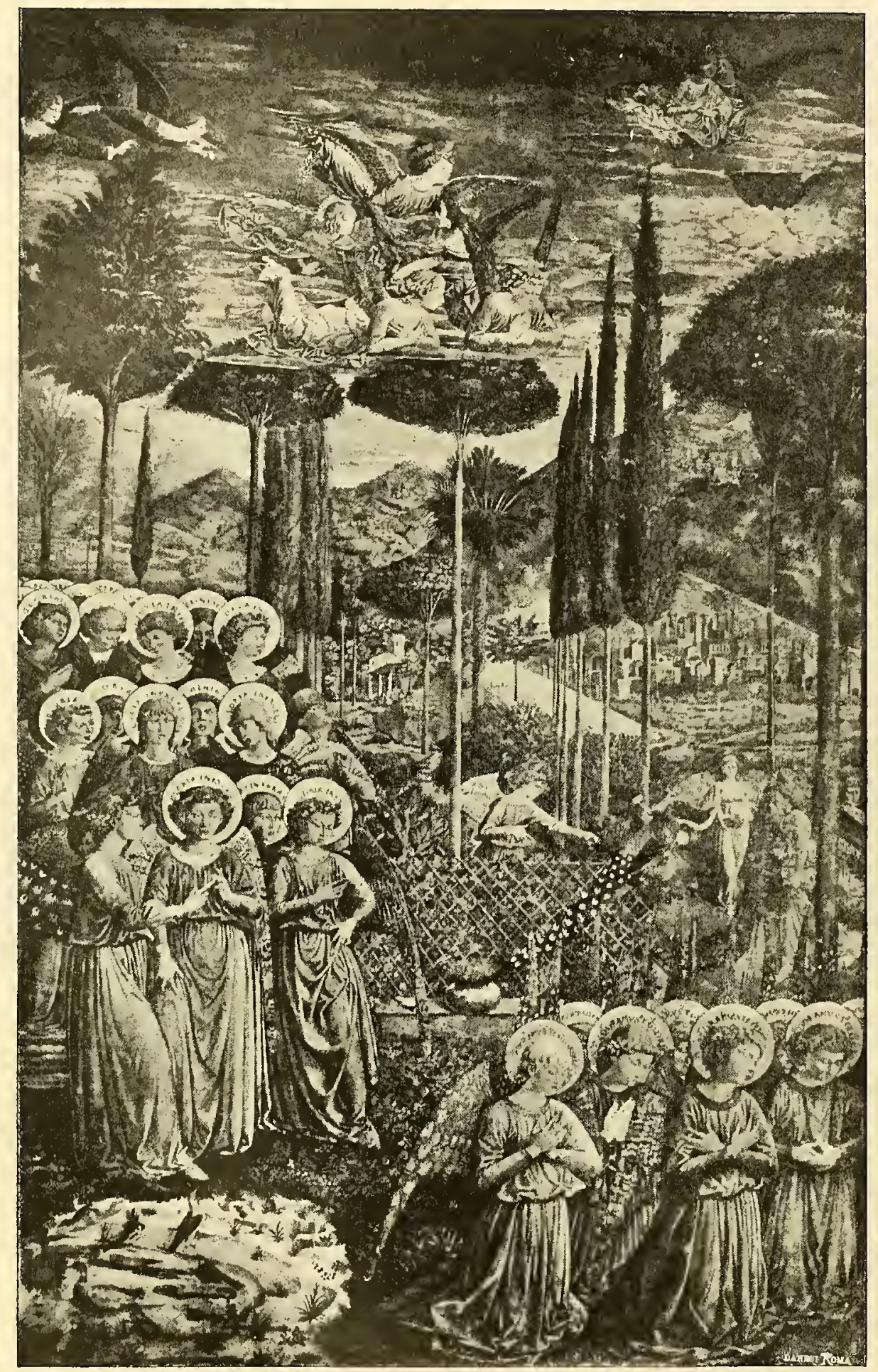

Cappella del palazzo Riccardi in Firenze

(Benozzo Gozzoli) 


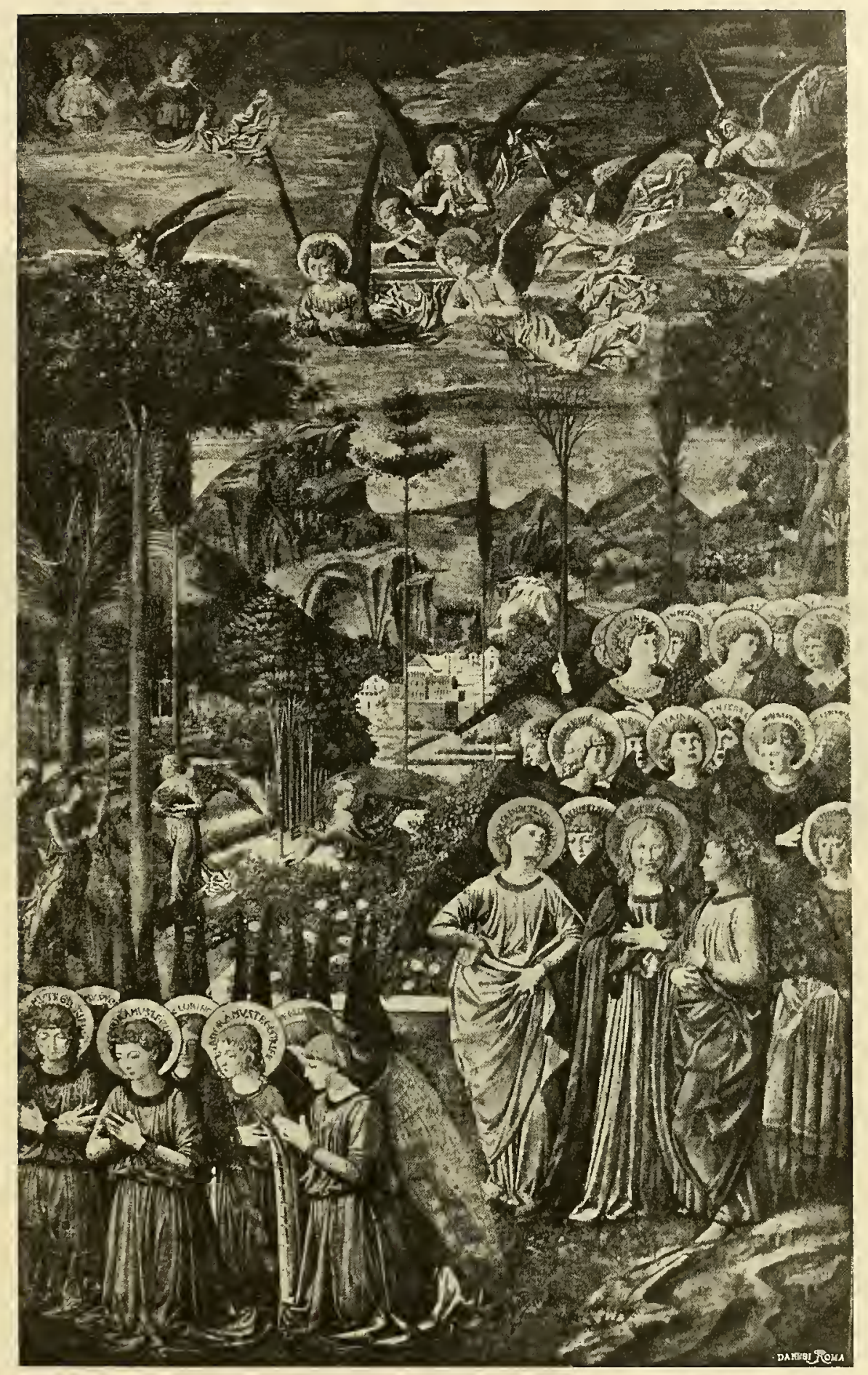

Cappella del palazzo Riccardi in Firenze

(Benozzo Gozzoli) 
Severo si raccolsero. ${ }^{(1)}$ Questo ci mostra la tendenza artistica di connettere alla scena della "Natività i ricordi speciali del luogo in cui essa è rappresentata, per trasformarla di mano in mano nelle Sacre Conversazioni. Spoglia di tutti i particolari realistici, senza i rustici animali, senza pastori, senza stalle e mangiatoie, la scena si svolgerà in aperta campagna, o entro mirabili

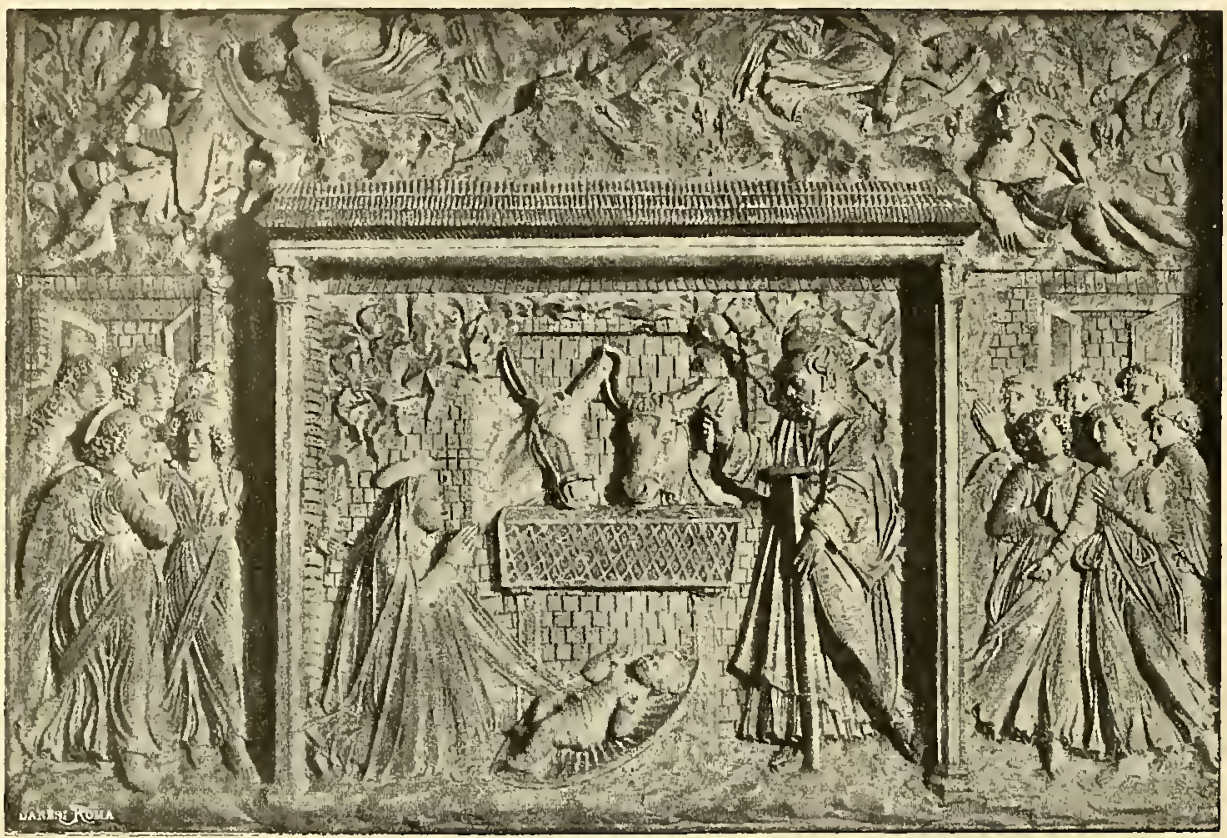

Basilica di Santa Maria Maggiore in Roma

(Mino DA Fiesole)

edificî, o sotto archi di trionfo; e i fedeli coi loro padroni faranno corona al Figlio di Dio.

Tanto nella pittura, come nella scultura, al principio del secolo xiv, la composizione traduce gli affetti più dolci del cuore umano: la madre ammira la sua creatura, la stringe fra le braccia, la cura amorosamente: così come San Bonaventura descrive Maria, che con grande dolcezza abbraccia il Pargoletto, se lo pone in grembo e sta col volto sopra la mangiatoia, con gli occhi fissi e con tutto l'affetto sul soavissimo Figliuolo. ${ }^{(2)}$ Nell'arte dei seguaci del Pisano le teste delle Madonne, che guardano fissamente il Bambino, a poco a poco si piegano dolcemente sugli omeri, e, come vinte da tenerezza, si chinano sulla testina del neonato. Le ostetriche scompaiono dalla

(r) De Rossi, Musaici cristiani di Roma.

(2) V. D'Ancona, Origini del teatro italiano, I. Torino, Loscher, I 89 г. 
scena quasi da per tutto. Ma quella vita nuova, quell'onda di sentimento, sembra allentarsi con l'arte gotica, la cuale cinse di corone feudali il capo della Vergine e del Bambino, e parve tendere a trasformare in simboli ciò che dal simbolo era uscito. Fortunatamente per l'arte, e per la più bella delle arti neo-latine, I'italiana, lo stile gotico non allignò gran fatto tra noi.

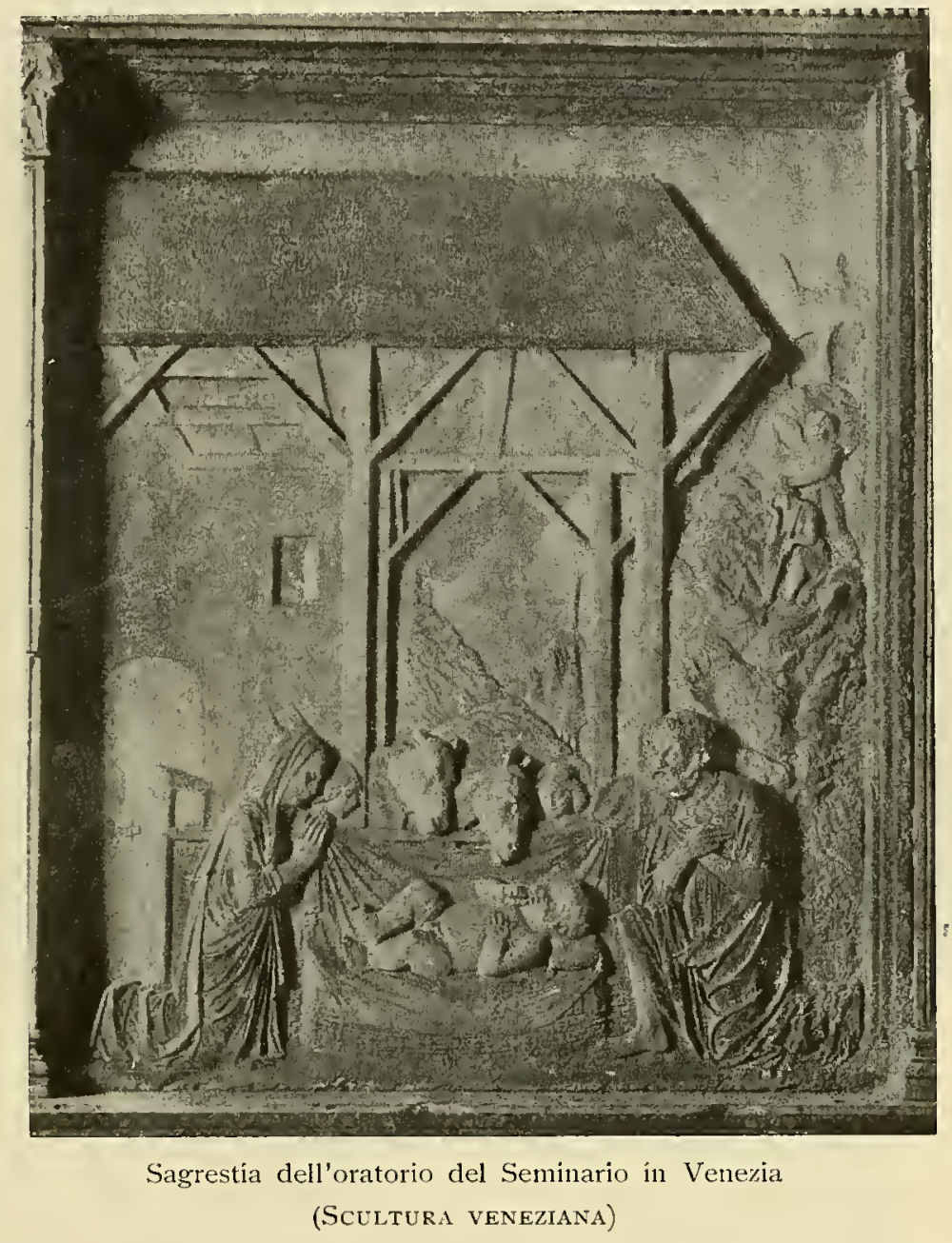

Nel dramma religioso della Natività, che intanto si venne determinando, "le anime ingenue de' compositori, scrive il D'Ancona, provano una tenerezza quasi infantile per il divin Fanciullo; e i più graziosi diminutivi, i versi più dolcemente sonanti, gli affetti più soavi, volgono ad inusata armonia l'ispida lingua e la rima disadorna, quasi rose che spuntino di mezzo ai roveti e spirino la selvaggia fragranza nativa ". Al modo stesso l'arte figurativa prodigava tutte le carezze al nascente Redentore. Nel secolo xv la 
Vergine, non più siede in atto di abbandono sul sacconcello tolto dalla sella dell'asino, ma cade in ginocchio innanzi al Figliuolo, lo adora beata, e come nella pastorale drammatica pubblicata dall'abbate Carnel, ${ }^{(\mathrm{r})}$ sembra dirgli: - Sii benvenuto in questa valle di lagrime, fiore di Jesse sbocciato nei giardini del cielo. O Re, sii il benvenuto in questa stalla... Inginocchiata, t'adoro, io madre tua. Vedo le tue piccole guance rosseggiare più belle delle più

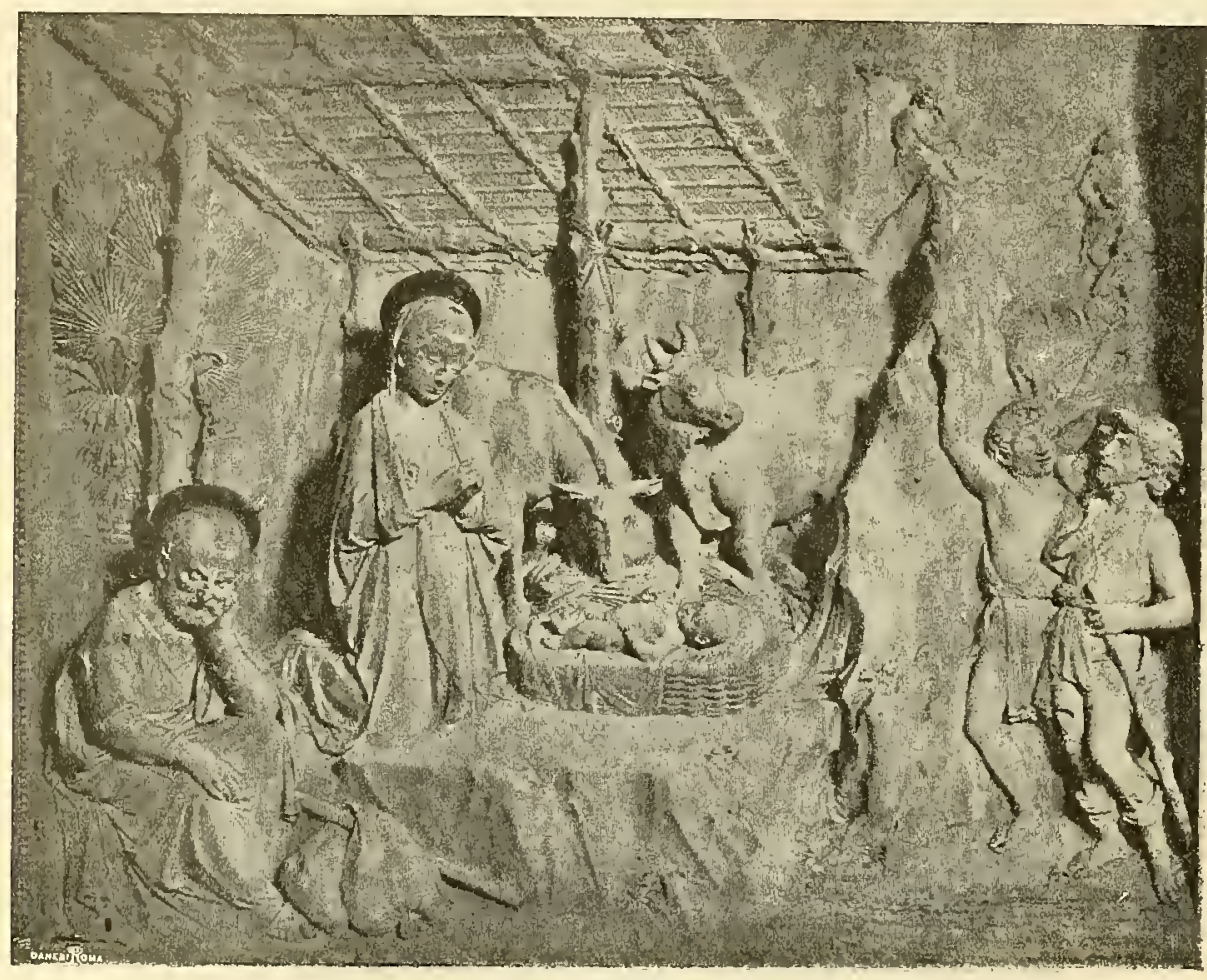

Chiesa di Monteoliveto in Napoli

(Antonio Rossellino)

belle rose. Lasciami cogliere il latte e il miele dalle tue guance! - In tale atteggiamento il Beato Angelico figura la Vergine, mentre lo stuolo degli angioli cantano gloria a Dio "come si canta in cielo». E San Giuseppe non è più il «vecchierello addormentato * della sacra laude, nè pieno di tristezza, secondo lo descrisse San Bonaventura, "perchè non poteva apparecchiare quelle cose che si convenivano»; ma con le braccia conserte

(x) T. Krineetje, Le mystìe de la nativité du Christ chez les Flanands de France. Pastorale dramatique, recueillie par l'abbé D. Caknel. Per altre rappresentazioni della natività cor. De Coussemsker, Drames liturgiques du mojen âge; e nel Du Méril, La fastorale sur la naissance de Jésus-Christ. 


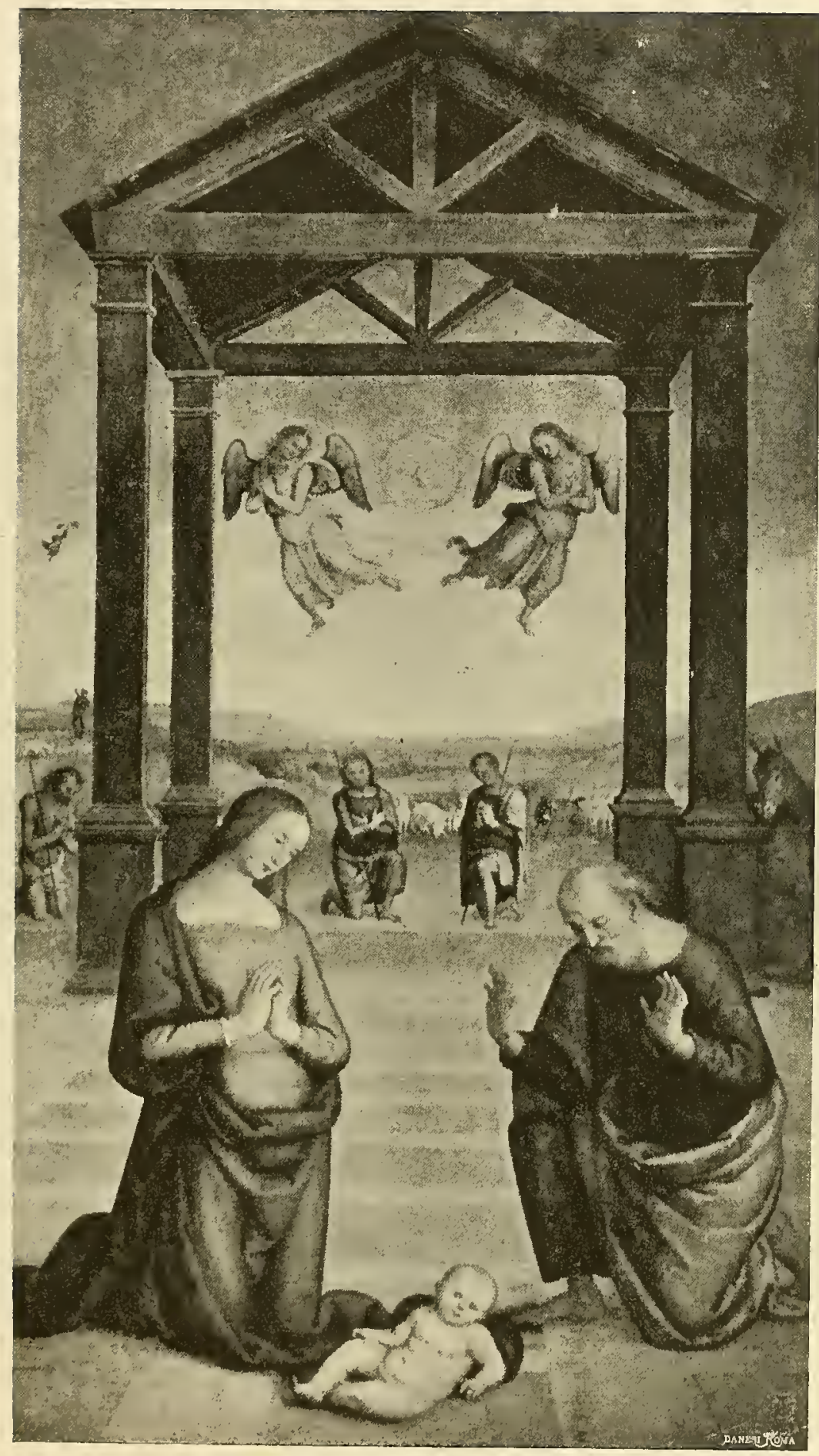

Pinacoteca Vannucci in Perugia

(Perugino) 
adora profondamente. Al Beato Angelico doveva sembrar naturale che intorno al Fanciullo rilucente tutti cadessero ginocchioni. I raggi di luce che si diffondono, non più a mo' d'aureola sul capo del Bambino, ma da tutto il corpicciuolo, sono un altro particolare notevole di quel dipinto e di altri dello stesso tempo. Già Jacopo Avanzi, nel collocare la destra mano di San Giuseppe distesa innanzi alle sopracciglia, aveva tentato di esprimere l'abbagliante splendore che emanava dalla culla; ma il Beato Angelico determina

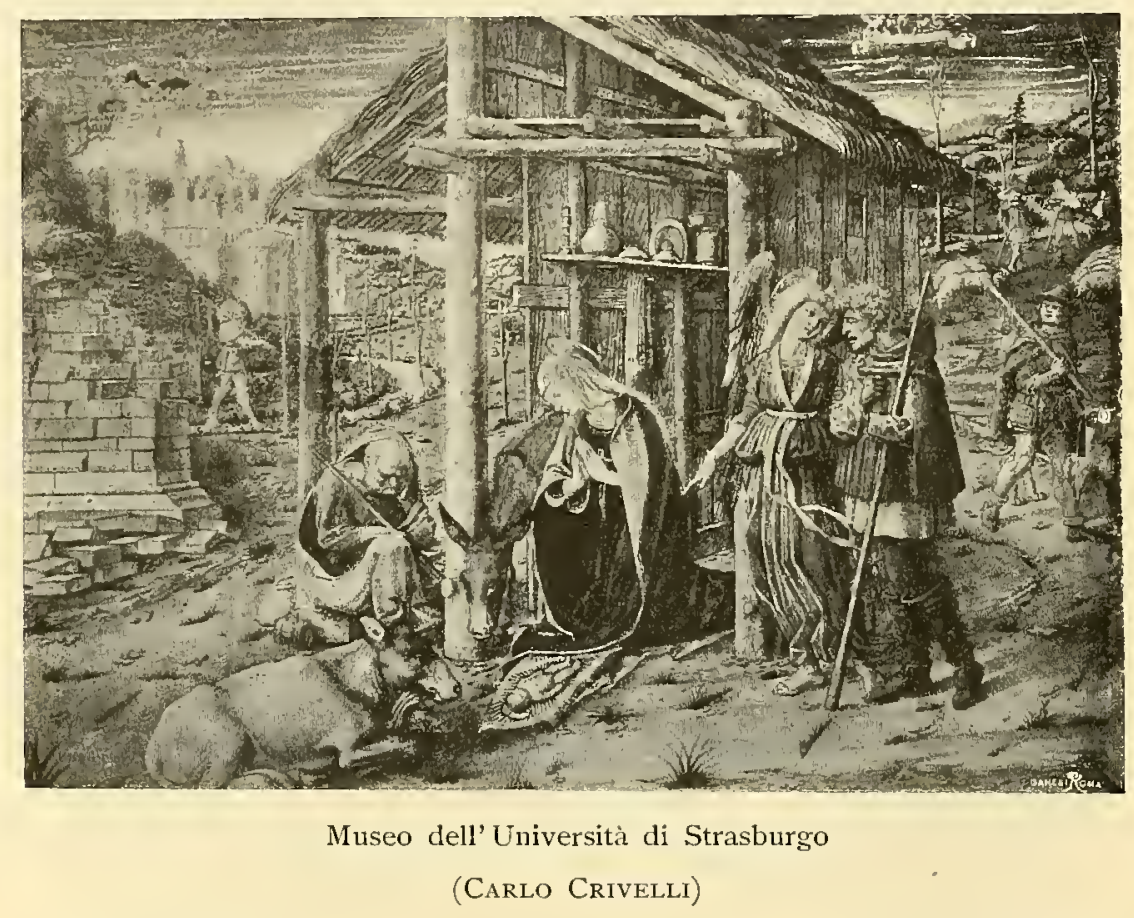

meglio il concetto di rappresentare l'autore della luce, e mostra quasi il desiderio di tradurre le strofe di San Fortunato, che cantava la nascita della luce al nascere di Gesù. L'idea rappresentativa non verrà più meno, si perfezionerà di mano in mano, finchè il Correggio nel quadro della "Notte * avvolgerà tutto e tutti nei raggi del divino Fanciullo.

Nel quadretto ora citato dell'Accademia di belle arti di Firenze, l'Angelico rivela la sua anima pia nella divozione che domina Maria e Giuseppe, i pastori che di lontano avanzano come timidi fraticelli, e gli angioli disposti sulle nubi intorno alla luce celeste come intorno a un ostensorio. In questo quadretto e in tutta l'arte toscana la rappresentazione si mostra semplificata, purificata d'ogni traccia del realismo medievale: non più pastori, 


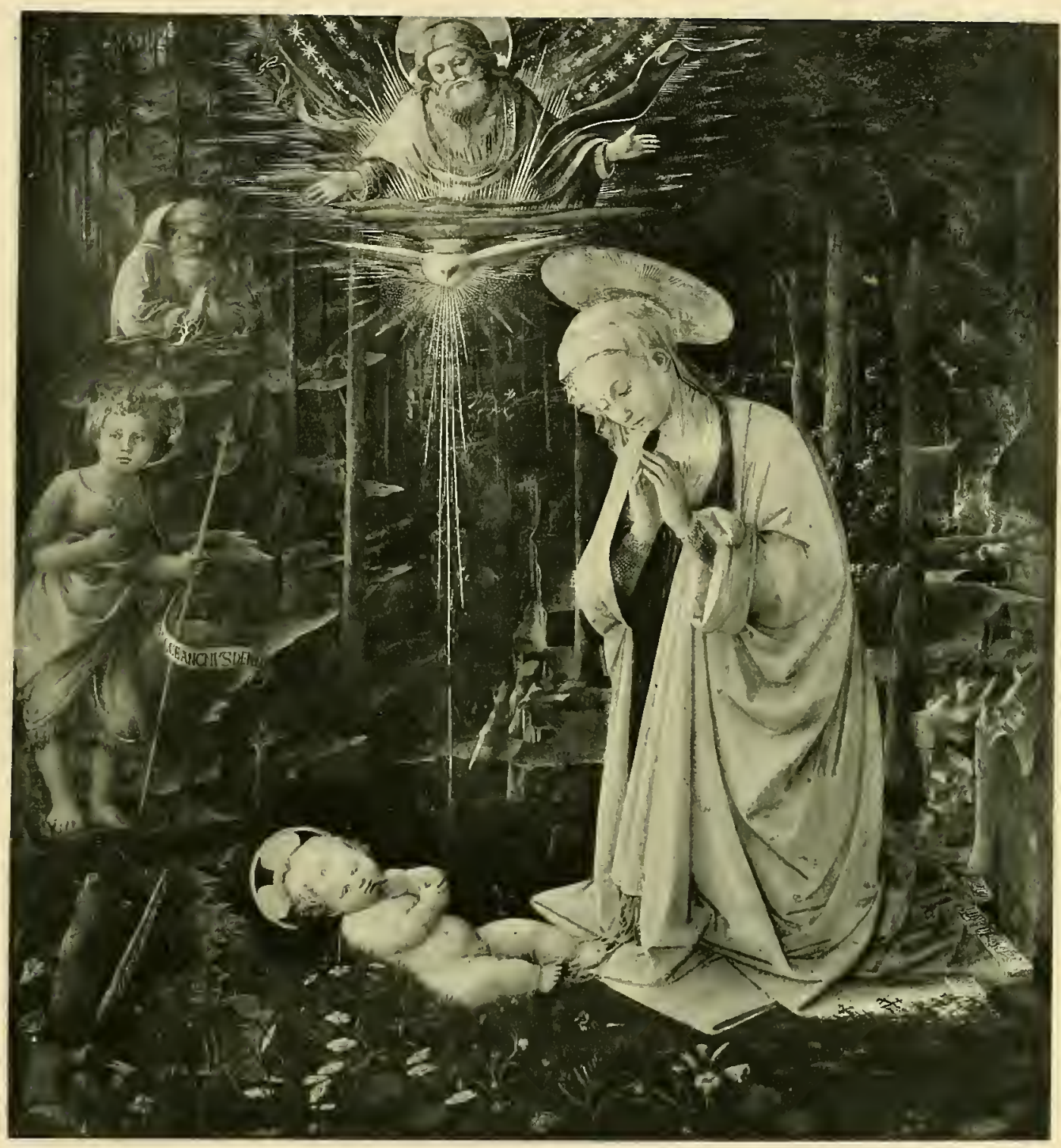

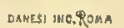

MUSEO REALE DI BERLINO

FILIPPO LIPPI 

asini e buoi, mangiatoie, materassi, sacconcelli, Zelomi e Salome; o almeno i pastori si lasciano nel lontano, l'asino e il bue non riscaldano più col loro fiato il Fanciullo, le mangiatoie restano nel fondo del quadro messe in

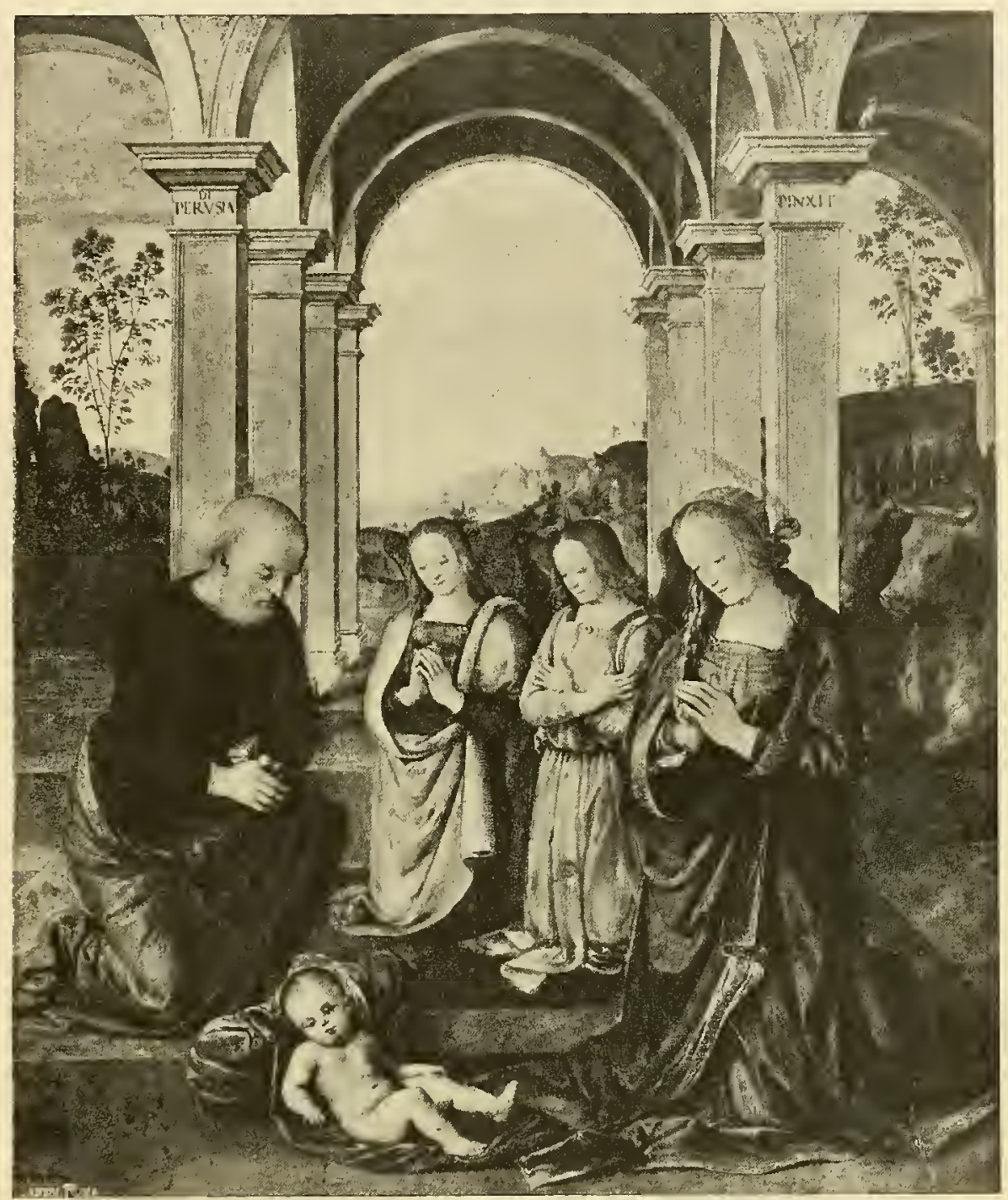

Particolare del polittico nella villa Albani in Roma

(Perugino)

un canto, quasi materiale disusato. Pier della Francesca, che conservò alcuno degrli elementi tradizionali nel quadro che ora si vede nella National Gallery di Londra, li usò in modo tutto nuovo; conservò i pastori, ma diede loro atteggiamento drammatico, nel rappresentarli in atto di spiegar la ragione delia loro venuta a San Giuseppe, il quale siede sopra una sella con le 
mani incrocicchiate sulle gambe a cavalcioni. Essi additano la stella, e l'asino guarda pure in alto verso la stella ragliando; la Vergine, vestita come una gentildonna del secolo xv, adora il Bambino, che stende a lei ambe le braccia; intanto cinque angioli in fila, come cinque menestrelli, due in atto di cantare e tre in atto di sonare il liuto e la viola, intonano laudi al Signore.

Gli angioli, che non si librano solo nei cieli, ma prendono parte alla rappresentazione della "Natività , entrano nella capanna e s'accostano al

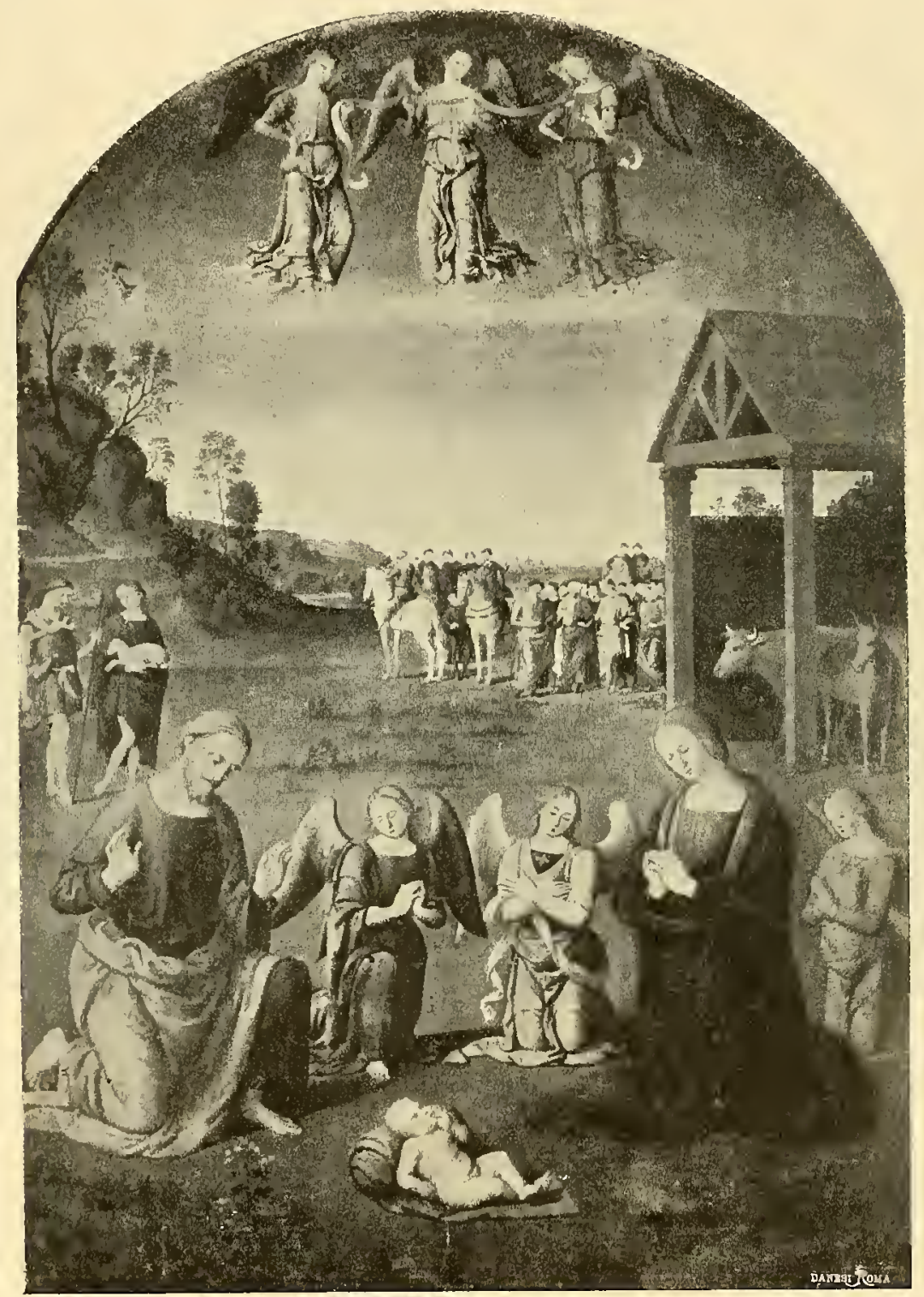

Galleria Vaticana in Roma

(Giovanni Sisgna) 


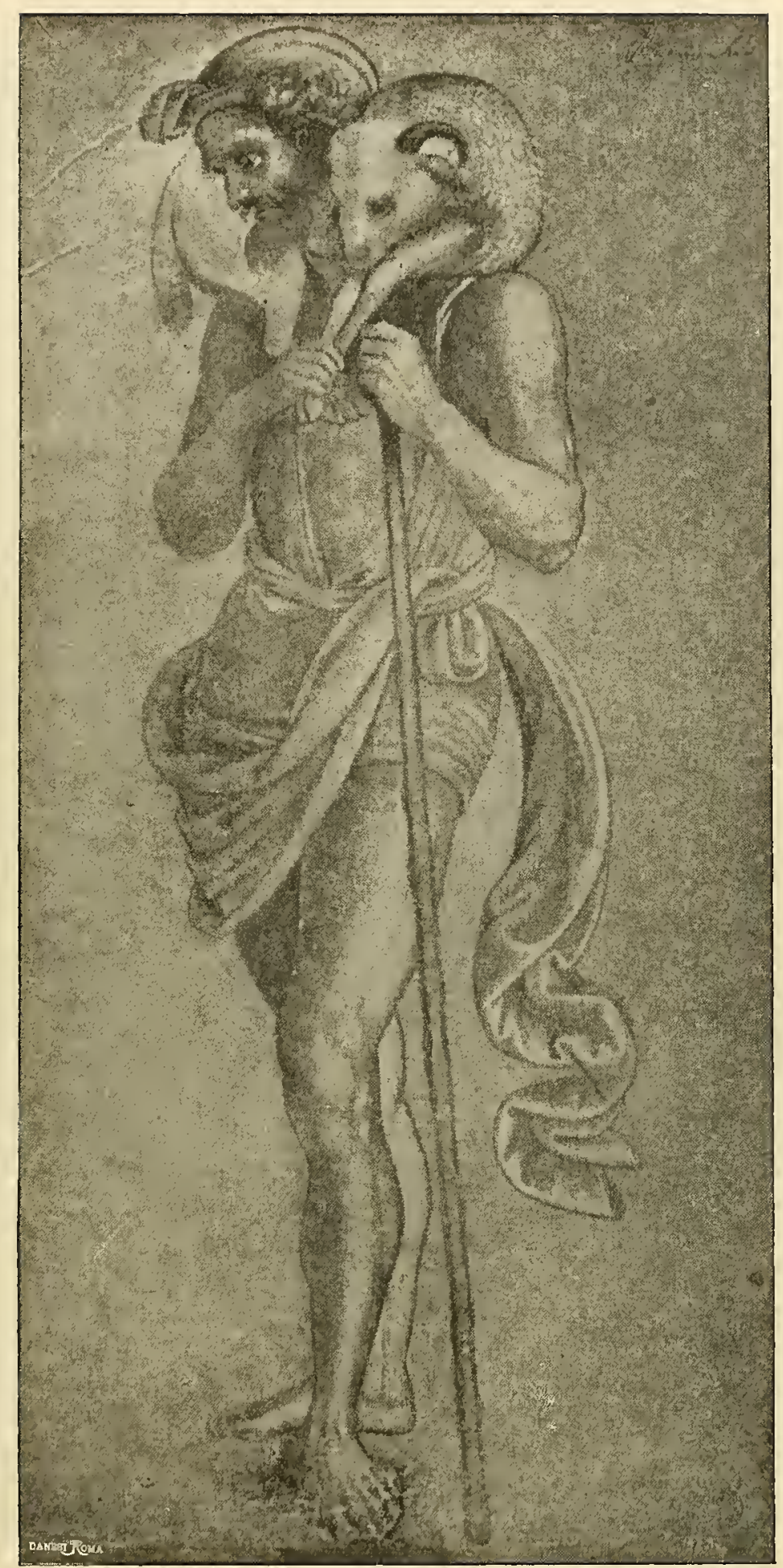

Disegno nella R. Galleria degli Uffizi in Firenze (Scuola Peruginesca) 
Dio, son figurati in forme sublimi dall'arte toscana del Quattrocento. Ricordisi Benozzo Gozzoli, ad esempio, che nel palazzo Riccardi a Firenze dipinse un giardino fantastico con aiuole forite e siepi di rose, tra gli alti fusti di abeti, cipressi e palme. Dall'alto gli angioli fendono le nubi; nel

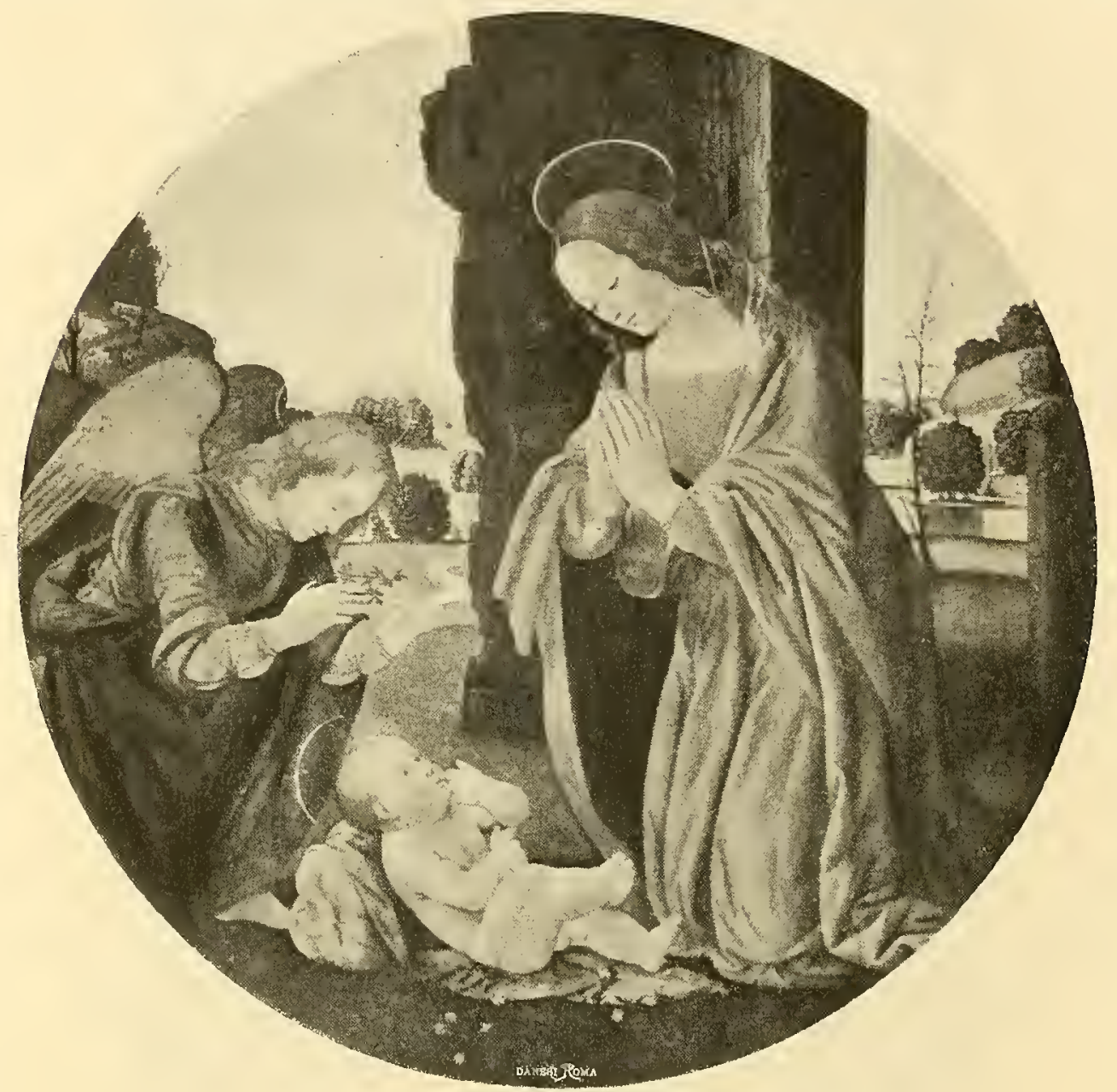

R. Galleria degli Uffizi in Firenze (LORENZO di CREDI)

piano s'avanzano pei giardini, a destra e a sinistra, le celesti coorti con le ali gemmate de' pavoni, cantando in coro; altre due schiere genuflesse, prone, adorano umilmente il Bambino, e pei giardini alate fanciulle, in candide vesti, recano fiori nel grembo o li spiccano dalle siepi odorose. È questo il sogno di Natale dell'arte fiorentina del Rinascimento. Fra quei due affreschi, evocazioni del paradiso, stava una tavola di Filippino Lippi, ora a Berlino, ${ }^{(x)}$

(r) V. Ulmann, Fra F. Lippi und Fra Diamante als Lehrer Sandro Botticelli. Breslau, I 890. 


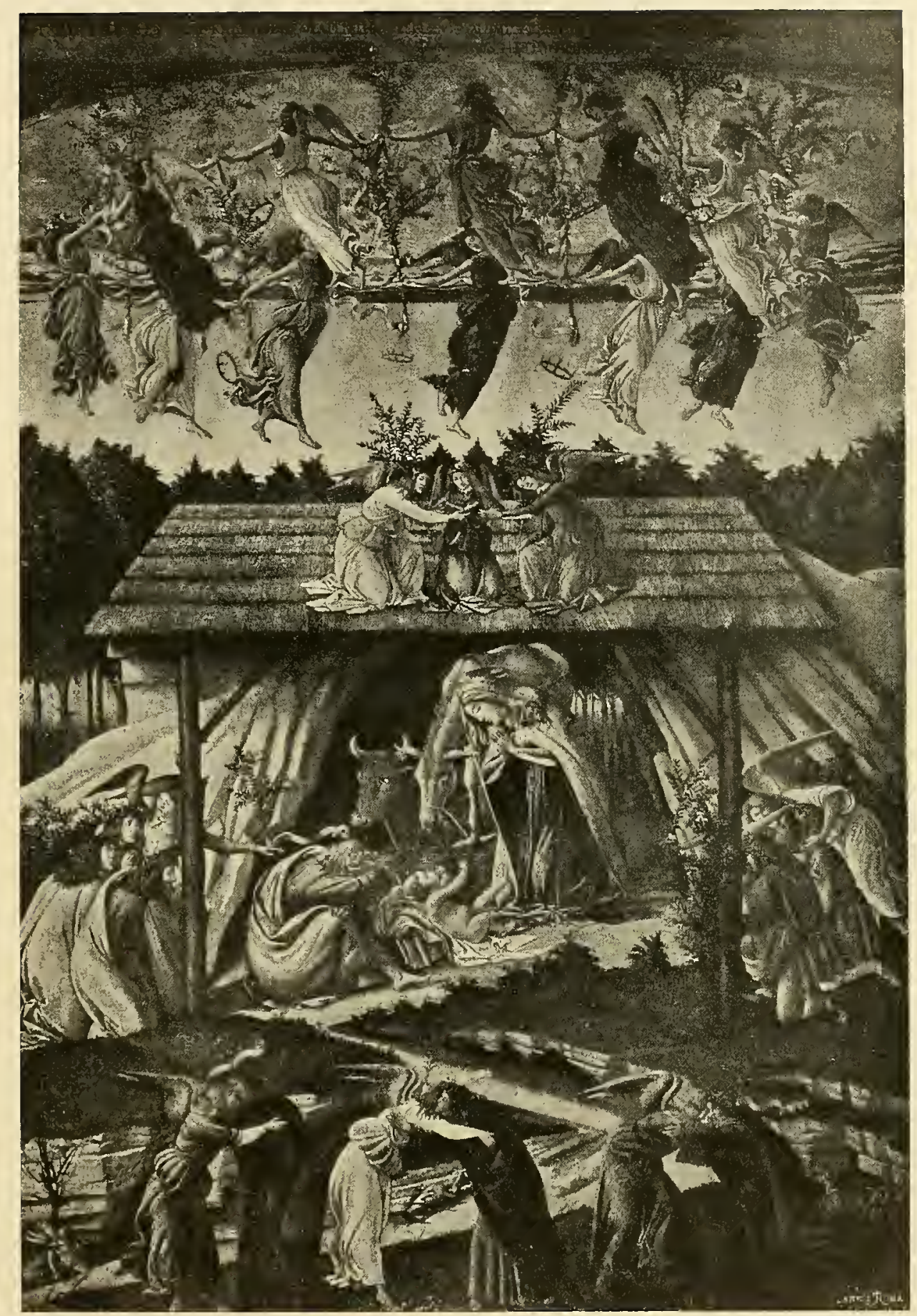

National Gallery di Londra

(BotTicelli) 
simile ad altre due dell'Accademia di belle arti di Firenze, tutte con la Vergine adorante il frutto delle sue viscere, con espressione di soave candore;

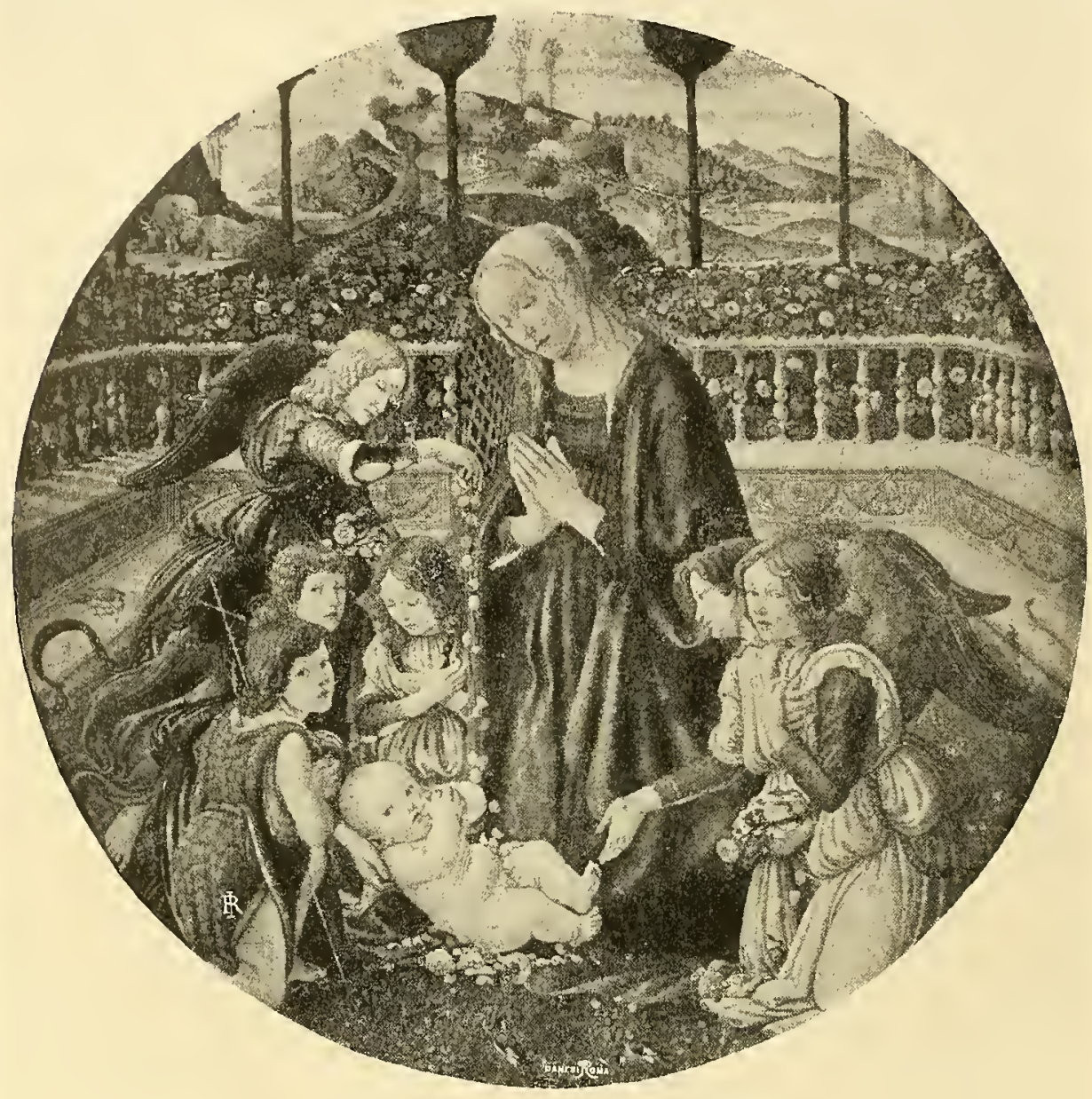

R. Galleria Pitti in Firenze

(SCUOLA DI FILTPPINO LIPPI)

tutte semplicissime, senza l'apparato scenico medievale, solo con qualche figuretta di santi anacoreti tra le rocce del fondo. La riduzione di mano in mano giunse sino a rappresentare semplicemente la Vergine in forma di vaghissima fanciulla, adorante il Bambino figurato coi vezzi proprî dell' età sua, tra gigli e rose. Così Andrea della Robbia, così Francesco Francia nella Madonna del Roseto a Monaco. Questa riduzione ai minimi termini rese più comuni delle "Natività " le "Sacre Famiglie"; e quando, in sul finire del Quattrocento, sembra correr sulla terra il soffio di un nuovo misticismo, e lo spirito di Savonarola attraversa i campi dell'arte, nelle scene del Natale solo gli angioli si accostano al Messia recandogli l'omaggio dell' umanità. 
Per cui Lorenzo di Credi spira l'ardore della fede ne' suoi angioli estasiati; Mariotto Albertinelli fa tendere da un angiolo al Bambino la croce coronata di spine; un seguace di Filippino Lippi fa spargere dalle mani degli angioli petali di rose sul Fanciullo divino, ${ }^{(1)}$ come poi Raffaello nella "Sacra Famiglia * detta di Francesco I. E il Botticelli, fattosi seguace del Savonarola, piagnone, non dimenticò tuttavia le sue immagini fiorenti di giovinezza nel colorire sotto il cielo luminoso, in alto del suo Presepe (che si vede a Londra nella Gal-

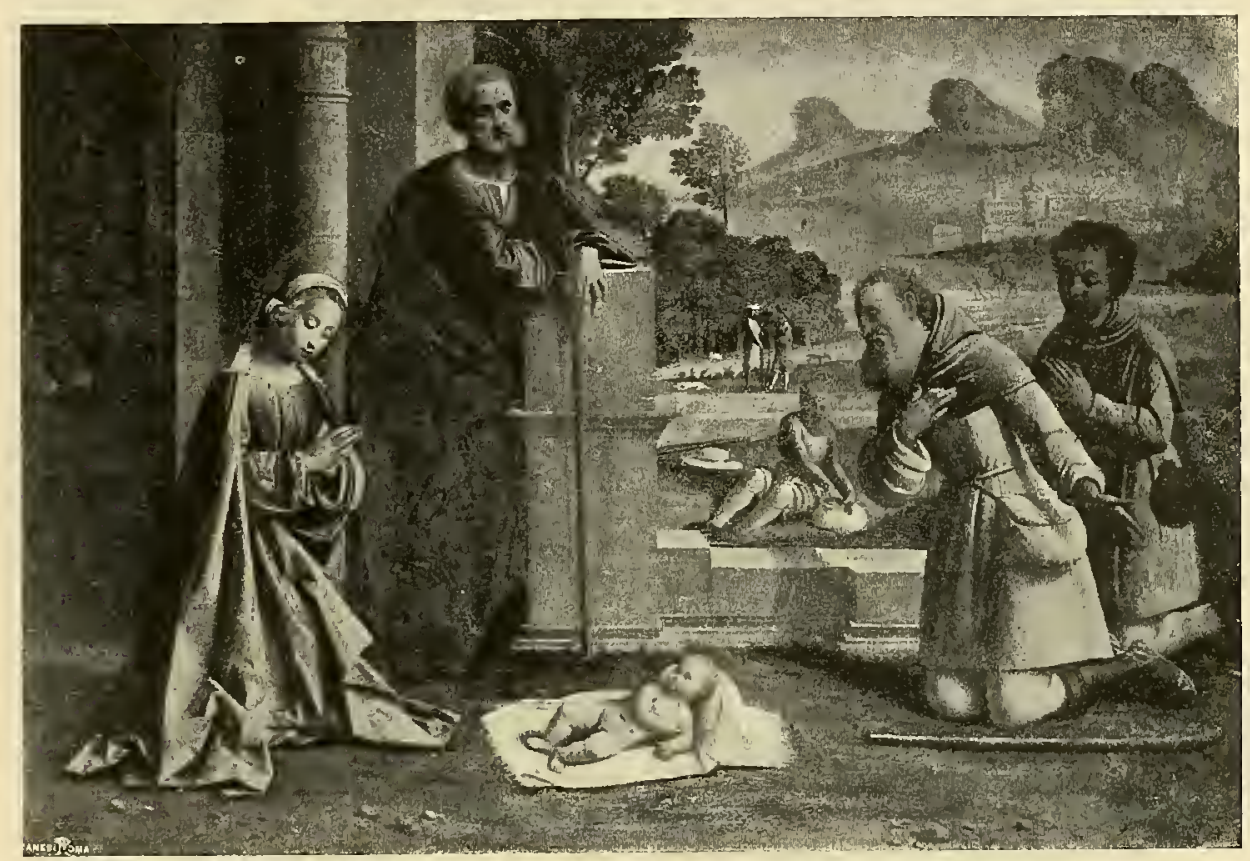

Collezione privata in America

(Gio. Benvenuti detto Ortolano)

leria Nazionale) dodici angioli, come le dodici ore antiche, intessenti carole, con ramoscelli di olivo in ciascuna mano; e verdeggiano di olivi il tetto di paglia, la terra, il capo dei pastori che gli angioli, intermediarî fra la divinità e l'uomo, abbracciano e guidano alla grotta meravigliosa. ${ }^{(2)}$ Memore dell'Apocalisse, il piagnone dipinse anche spiritelli diabolici uscenti dalle rocce, così come nel mistero della natività rappresentato nel $\mathrm{I}_{507},{ }^{(3)}$ mentre gli

(1) Si accenna a quadri di Lorenzo di Credi nell'Accademia di belle arti di Firenze, all'altro di Mariotto e a quello attríluito a Fílippino Lippi nella galleria Pitti.

(2) Il Colvin nella The Academy ( 5 febbraio i 87 I, pag. I30) spiega l'iscrizione apposta al quadro.

(3) V. De Jullevilie, Les Mysteres. Paris, I 880. 
angioli salutavano cantando il neonato, e la madre ginocchioni l'adorava, gl'idoli cadevano nei templi pagani, l'inferno sia priva e lasciava scorgere la rabbia dei demoni. Queste idee mistiche non attecchirono a lungo, e solo restò il simbolo, determinatosi nel Rinascimento, del vecchio mondo cadente

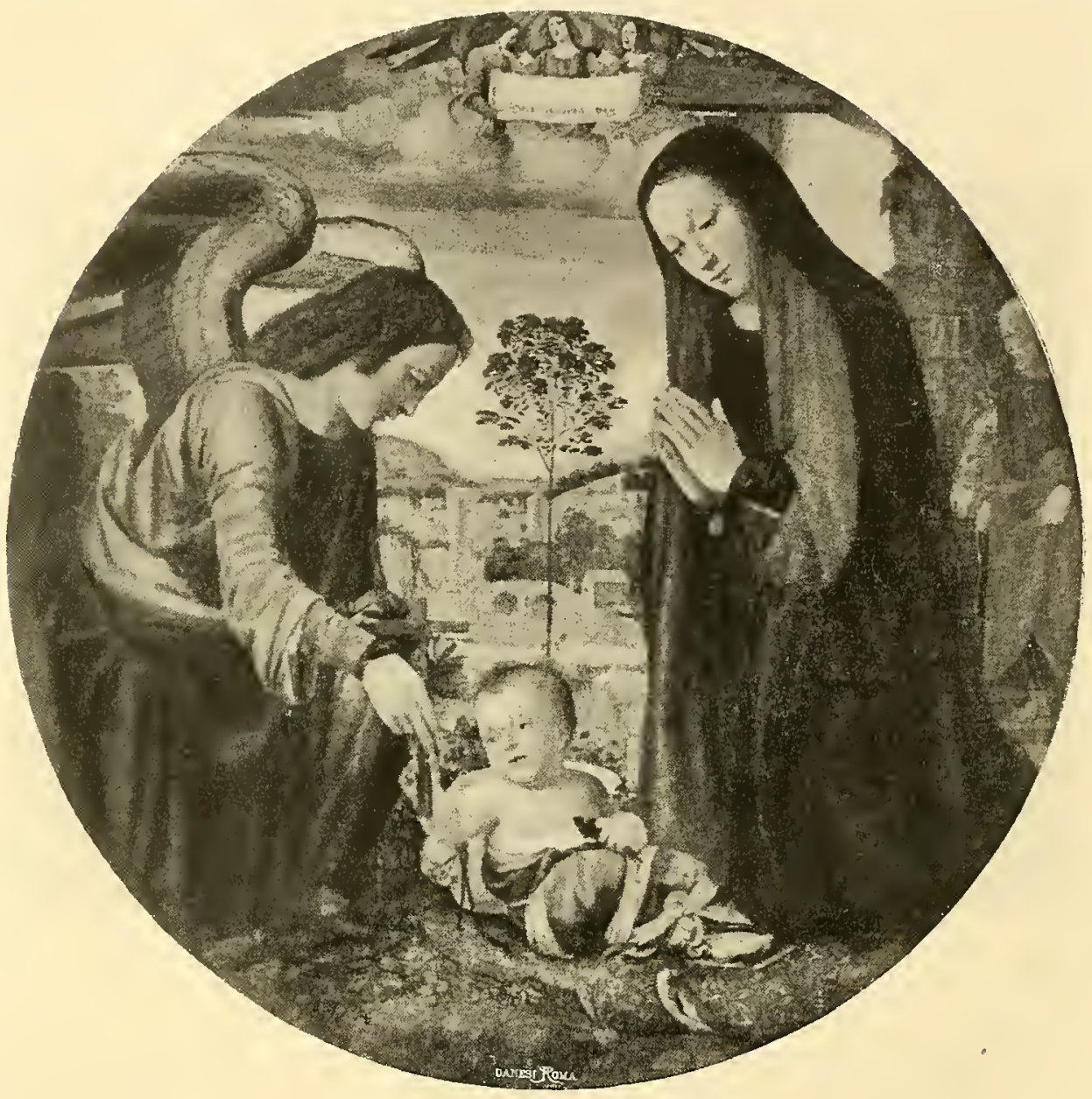

R. Galleria degli Uffizi in Firenze (Mariotto Albertinelli)

rappresentato da archi e palazzi in rovina, presso l'umile albergo del Redentore. In conchiusione, l'arte toscana nel figurare il Natale ebbe freschezza d'ispirazione e varietà di motivi, quali potevano trovarsi in luoghi ove il mistero era rappresentato solennemente; cosi che a Firenze, a detta del Machiavelli, nell'anno I466, uno ne fu eseguito "di tanta pompa e sì magnifico, che in ordinarlo e farlo tenne più mesi occupata tutta la città " . La rappresentazione non ebbe altrettanta fortuna nell' Umbria, ove pure 
il sacro dramma volgare aveva avuto il nascimento, e cadde in forme monotone, sinmetriche, perdendo libertà e vita. Il Bambino è steso su drappi, la Madonna, San Giuseppe, i pastori, gli angioli adorano: la Madonna e

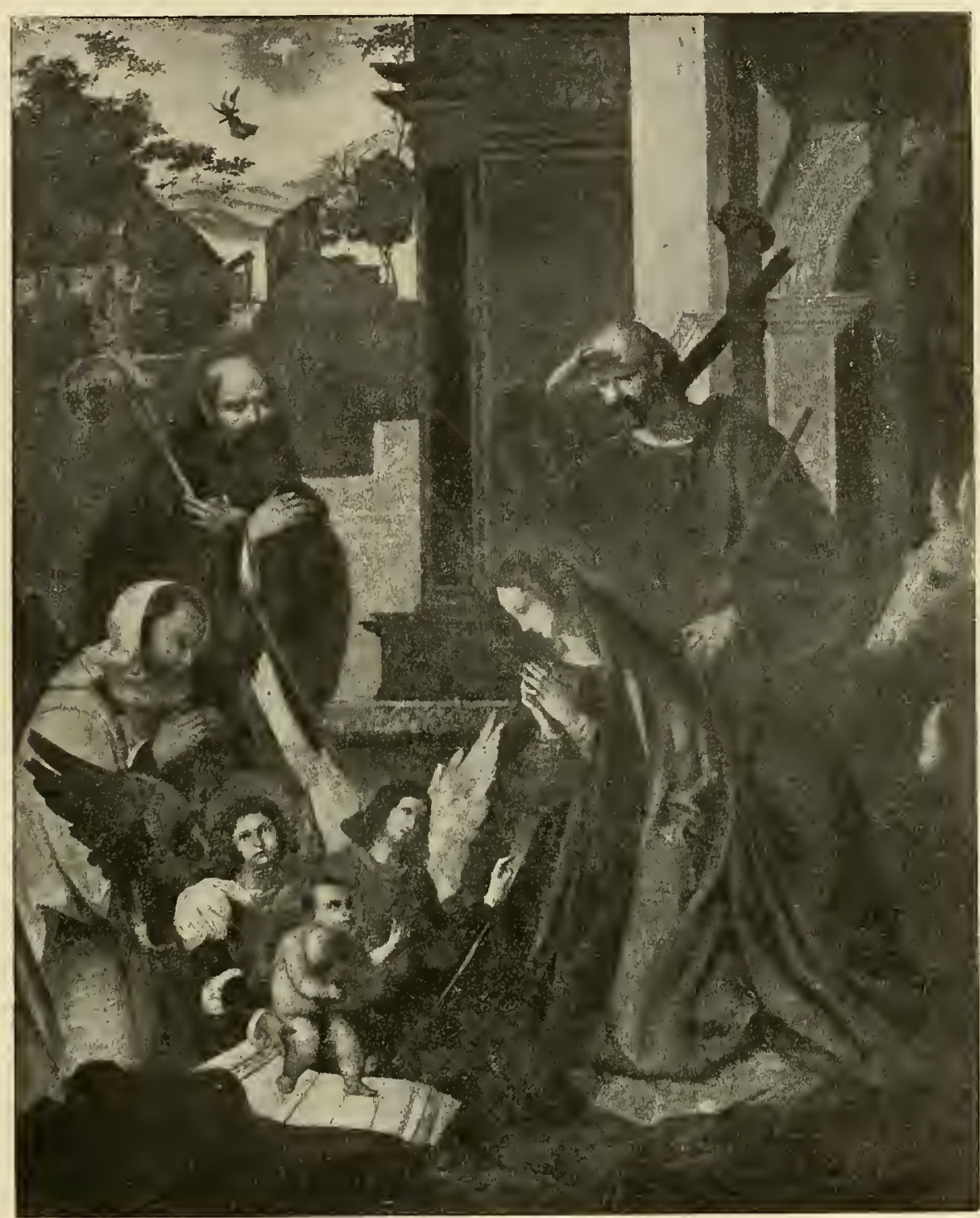

Galleria dell'Ateneo in Ferrara

(Ludovico Mazzolino)

San Giuseppe nel primo piano, i pastori nel secondo, e gli angioli in alto o nel secondo piano pur essi invece dei pastori. Cosìnel Perugino e ne'suoi seguaci. $^{(1)}$ I vecchi Umbri erano però ben più animati, a giudicare dal dipinto

(1) V., ad es., la Natività del Perugino nella Pinacoteca di Perugia, nel Cambio, a Montefalco; dello Spagna nella Galleria del Vaticano. 
di Ottaviano Nelli nel palazzo governativo dei Trinci in Foligno, ove la Madonna in ginocchio stende le mani al Bambino raggiante, $e$ in un atteggia-

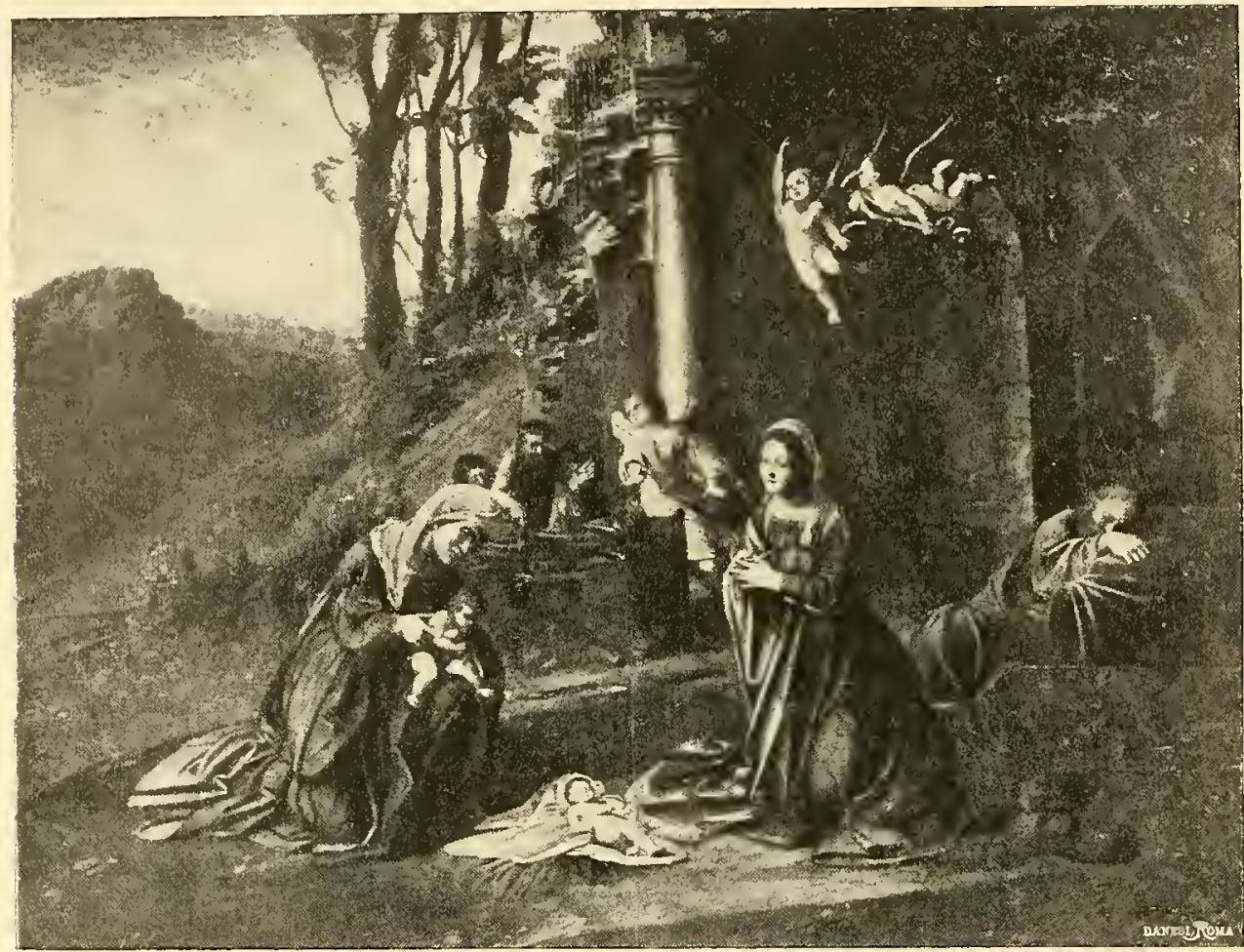

Galleria Crespi in Milano

(CORREGGIO)

mento repentino, quasi scomposto. Quanto lontani sempre, prima nel taglio sgarbato delle figure, poi nelle compassate forme, dal rigoglio toscano! Forse nell' Umbria riuscirono d'ostacolo al movimento e al rinnovamento della rappresentazione $\mathrm{i}$ sensi divoti e il tenace spirito di conservazione delle forme tradizionali. Un seguace del Perugino ne fornisce un esempio col disegno del Buon Pastore, ${ }^{(1)}$ eseguito per una Natività, cioè con la copia del simbolo di Dio stesso, quale si usò dai Cristiani nel periodo evangelico, e in genere prima dell'apparizione del Crocifisso nell'arte. Ora il Buon Pastore ritorna per mezzo di quel peruginesco, ma come un proprio e vero pastore, così come a Venezia, in una delle arcate della porta principale di San Marco, si vede scolpito quale agreste simbolo di un mese.

(s) Si vede nella R. Galieria degli Uffizi a Firenze. 
Nell'Italia settentrionale, in Ferrara specialmente, al principio del secolo xvi, si elaborò la composizione della Natività. Gli elementi secondarî

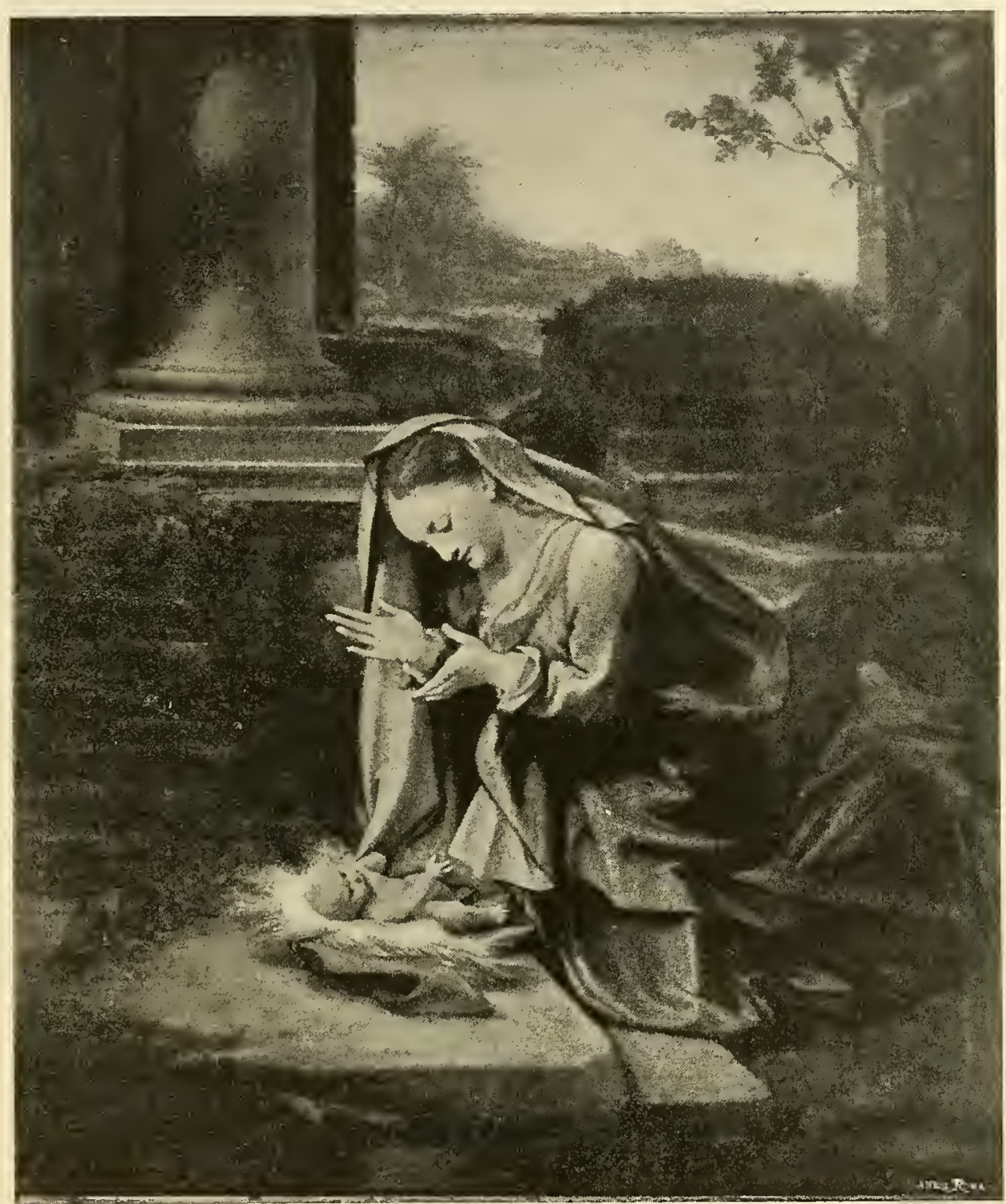

R. Galleria degli Uffizi in Firenze

(CORREGgio)

sono messi in disparte dall'Ortolano; ${ }^{(\mathrm{r})}$ la luce si riflette viva, accende $\mathrm{i}$ volti dei personaggi nel Presepio del Mazzolino; una grazia delicatissima adorna

(x) Ci riferiamo alle due Natività dipinte dall'Ortolano, la prima nella galleria Doria, la seconda già nella Galleria Borghese in Roma ora in America. 


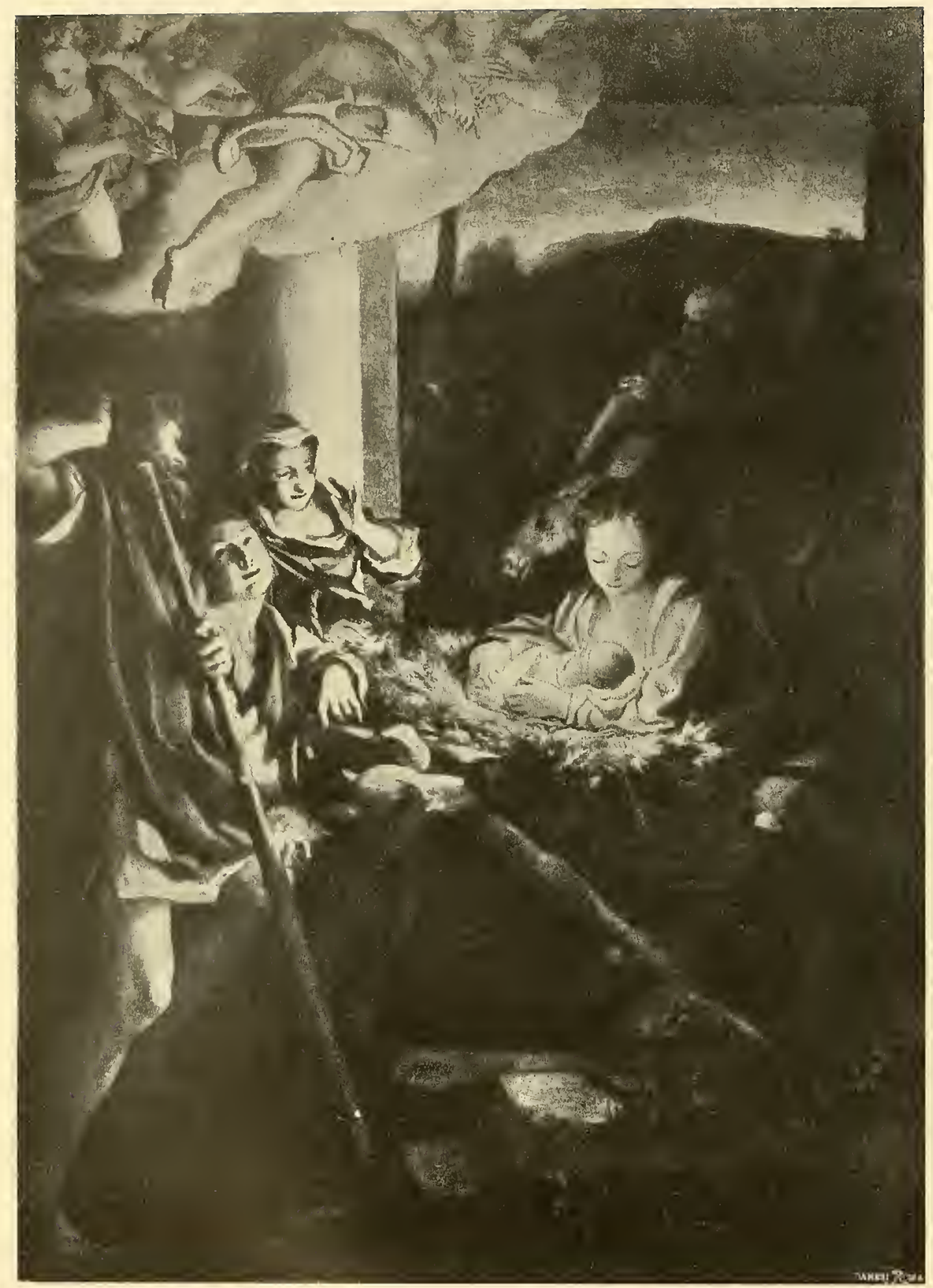

Galleria di Dresda

(Correggro) 
le figurette del Natale di Ercole Grandi, ${ }^{(x)}$ ed ecco il pittor delle Grazie che trae suo pro dal lungo lavorio dei secoli, sentendo nell'anima il murmure dei canti dei Padri della Chiesa, delle sacre laudi, dei cori dei misteri religiosi, vedendo come in un baleno innanzi agli occhi le visioni de' profeti, i contrasti dei simboli con la realtà, gl'ideali cristiani prender forma sensibile dalla natura. E crea una prima "Natività "(2) ove la Madonna adorante si copre la destra col manto, quasi a indicare il freddo della notte invernale; e la luna, nascente dietro le antiche rovine, manda luce argentina sulle nuvole vaganti nell'azzurro della notte; e gli aíberi, coi rami piegati dal vento, accrescono l'impressione del freddo. Un angiolo librato sulle ali addita ai pastori il Fanciullo dormente sur un bianco drappo, mentre Sant'Elisabetta lo mostra al piccolo San Giovanni, che con infantile curiosità protende il capo e guarda. Su questa prima forma della "Natività " il Correggio ne vagheggiò una seconda affatto semplice, e l'espresse con la Vergine che adora beata il Bambino e sembra a un tempo invitarlo ai baci e alle carezze. ${ }^{(3)}$ Infine nella "Notte" la composizione del Correggio raggiunge il più completo svolgimento. La luce che nasce dal Fanciullo si spande tutt'intorno, schiara il volto della Madre soavissima, si riflette sui pastori e si diffonde sugli angioli in gloria. Il quadro meraviglioso, ora a Dresda, può dirsi la sintesi delle rappresentazioni della Natività; e come Leonardo nella * Cena degli Apostoli », Tiziano nella "Presentazione della Vergine al tempio » e nella "Assunzione", così il Correggio segnò nella "Notte * il termine d'una lunga via battuta dall'arte, coronò il lavoro assiduo iniziato nelle tenebre delle catacombe, continuato nelle basiliche della religione triofante e poi nelle cattedrali dei Comuni italiani, vivificato dagli affetti e dalla fede del popolo.

(r) La Natività del Mazzolino e di Ercole Grandi nella Galleria dell'Ateneo di Ferrara.

(2) $\dot{\mathrm{E}}$ conservata dal signor Crespi in Milano.

(3) Ł̇ nella Tribuna a Firenze. 



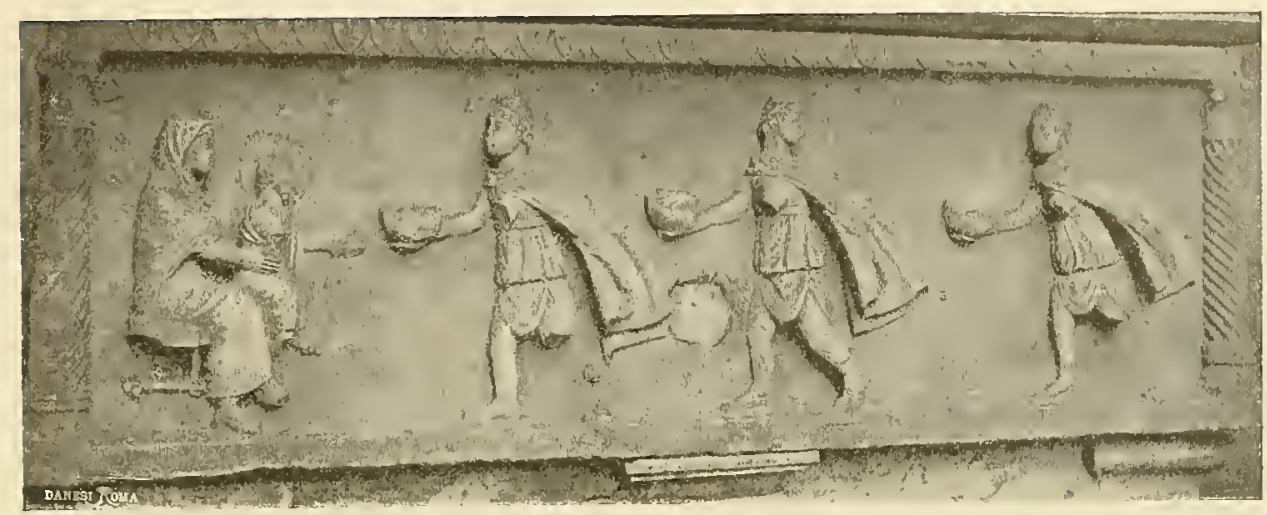

Dall'urna di Isaaccio VIII. Chiesa di San Vitale in Ravenna

\section{L'Adorazione de' Magi.}

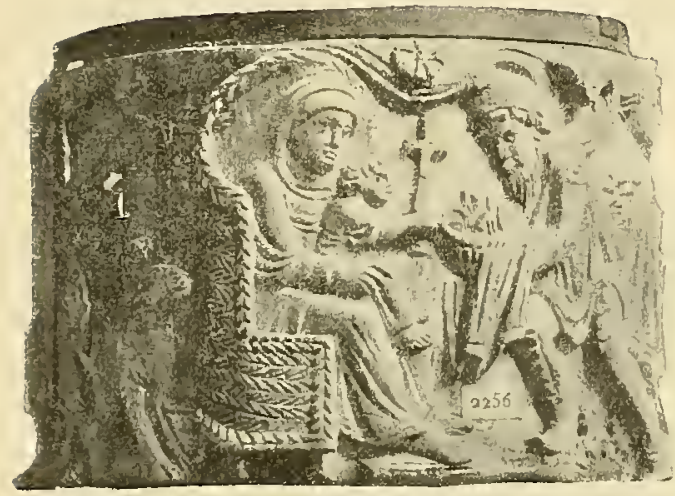

Pisside d'avorio. Museo di Pesaro

"Sulle rive del golfo Persico, dove nasce il sole ", così cantava nel suo Cathemericon il poeta Prudenzo, « i Magi, esperti interpreti, scorgono il vessillo regale. Dacchè rifulge, gli altri astri si oscurano, nè lo stesso Lucifero osa contrapporre a quello la bella sua forma. Ma chi è, domandano essi, il sovrano tanto potente che domina gli astri? Colui per cui tremano le cose celesti, e a cui servono la luce e l'etra?... E il re delle genti, il re del popolo de' Giudei, che fu promesso al padre Abramo e alla sua stirpe... Già spunta il fiore davidico dalla radice di Jesse; pieno di vigoria, brandisce lo scettro e governa il mondo dall'alto. Animati da questi pensieri, con lo sguardo fiso al cielo i Magi seguono il solco luminoso della stella che li guida nella via. Essa si arrresta sopra il capo del fanciullo divino e lo disvela con la sua luce. E i Magi, vedutolo, schiudono i tesori apportati dall'Oriente, e si prostrano, offrendo incenso e mirra e l'oro regale *. Così nel secolo iv l'Evangelo di San Matteo aveva ispirata la fantasia del poeta Prudenzo, come già quella dei pittori delle necropoli. Nelle catacombe dei Santi Marcellino e Pietro sulla via Labicana, in quelle di Callisto e di Domitilla, la rappresentazione si 


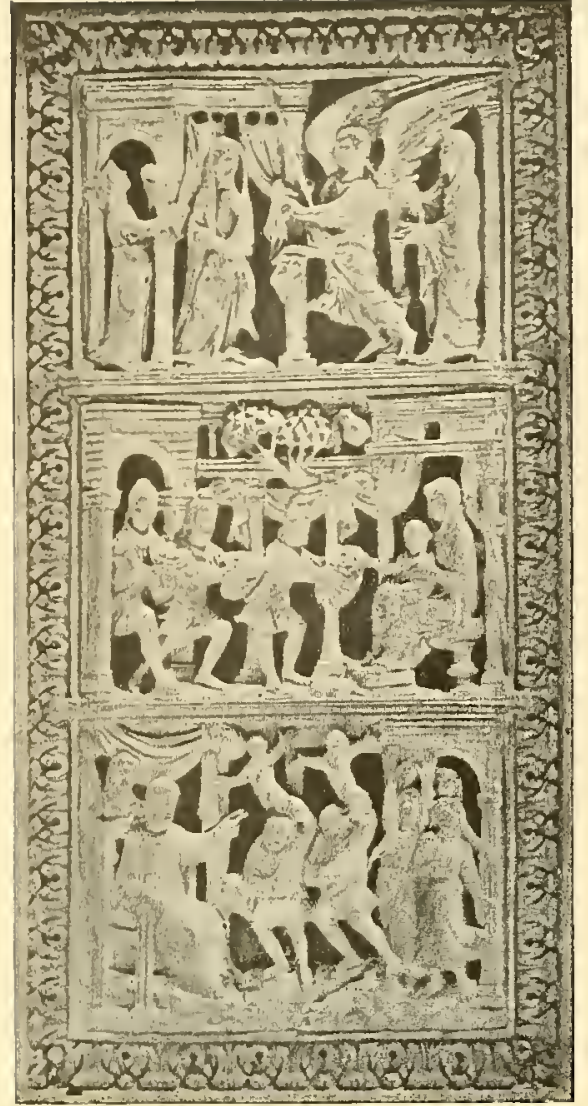

Avorio. Tesoro della Cattedrate di Milano

era determinata: la Vergine seduta in cattedra, con la tunica listata di porpora, tiene il Bambino in grembo, mentre i Magi s'avanzano in atto di offrire i doni all'aspettato dalle genti. La Vergine, non appartata quasi dalla scena, come talvolta vedesi nel Presepe, è compresa clella sua dignità materna; i Magi vestiti di corta tunica tagliata a liste, con calzoni a quadriglia chiamati saraballa dai Persiani, col berretto frigio o pileo persiano comune a vedersi nelle rappresentazioni mitriache, recano ansiosamente $\mathrm{i}$ doni nelle patere. Dalle rappresentazioni dei popoli dell'Asia e dell'Africa o delle provincie recanti a Roma e all' Impero i tributi, l'arte cristiana ricavò quel tipo de' Magi, come può ritenersi dall'esame dell'avorio Barberini e da un frammento di un dittico delle cinque parti pubblicato dal Meyer. Sino alla fine del secolo vi, tranne la rappresentazione che si vede nell'arco trionfale di Santa Maria Maggiore, l'Adorazione dei ${ }_{\text {Le }}^{\top}$ Magi rimane all' incirca la stessa, e dappertutto, a Salonicco nell'ambone illustrato dal Bayet, a Roma nei sarcofagi del Laterano, a Ravenna ne' mosaici e ne' sarcofagi pure, la Vergine si mostra come una nobile matrona in cattedra d'onore. Soltanto, col procedere del tempo, ella cresce di maestà, e siede

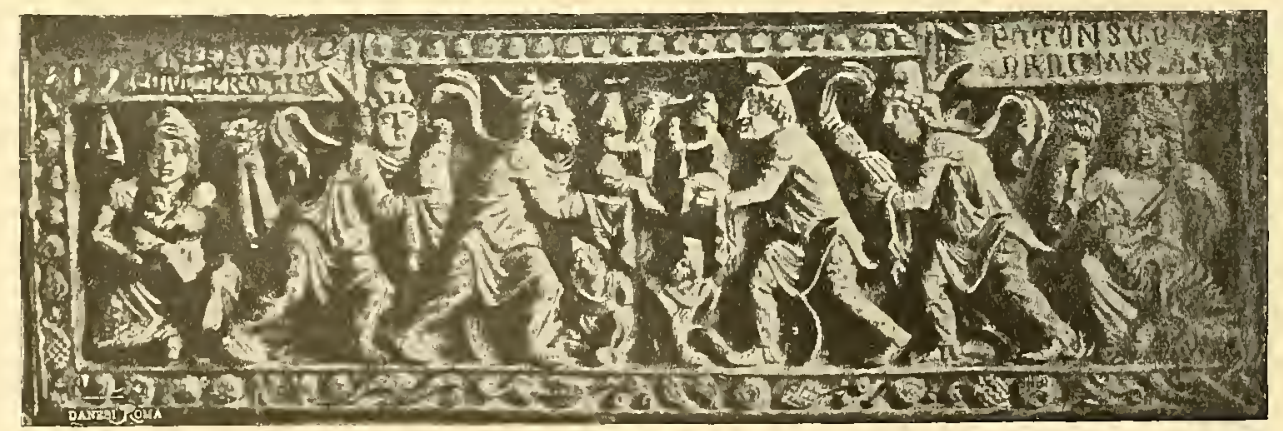

Avorio. Frammento di dittico dalle cinque parti nella raccolta Trivulzio in Milano 


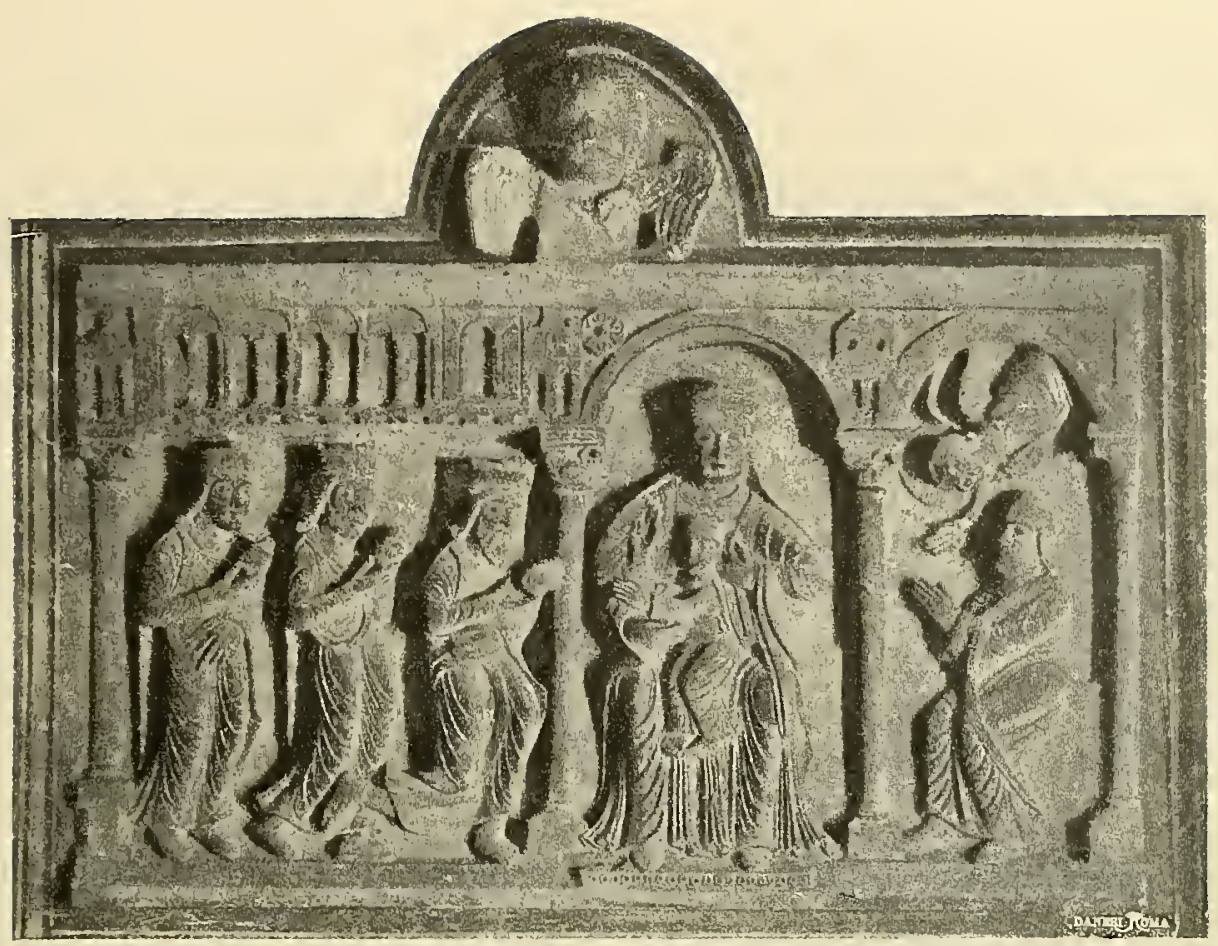

Bassorilievo romanico. Palazzo dell'arcivescovado in Fano

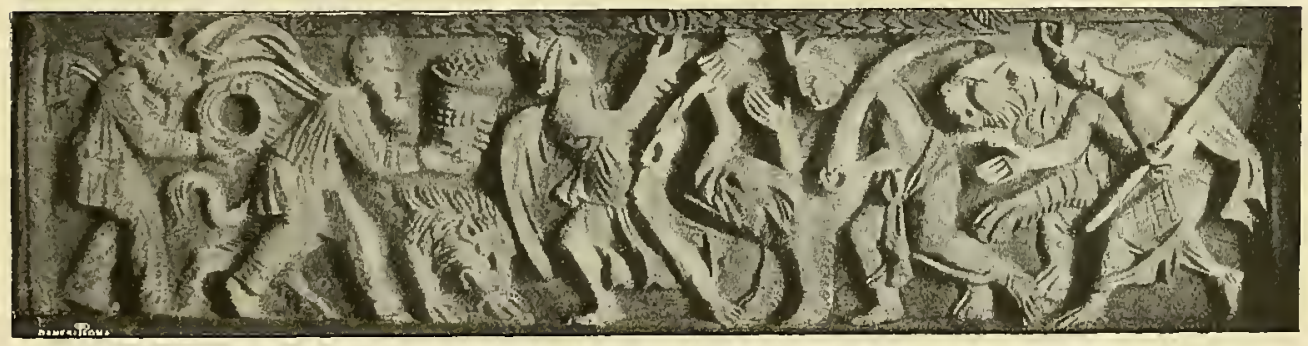

Avorio. Particolare di un dittico delle cinque parti della raccolta Barberini in Roma

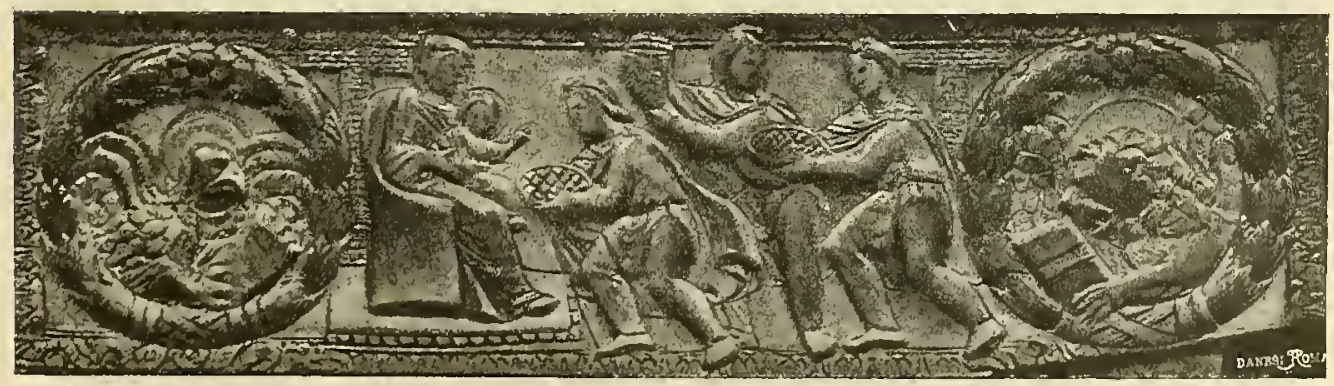

Avorio. Coperta da libro della Cattedrale di Mliano 
avviluppata nel manto imperiosa e immobile. Non più, come nelle catacombe di Pietro e Marcellino, i capelli le forman corona, ma un nimbo

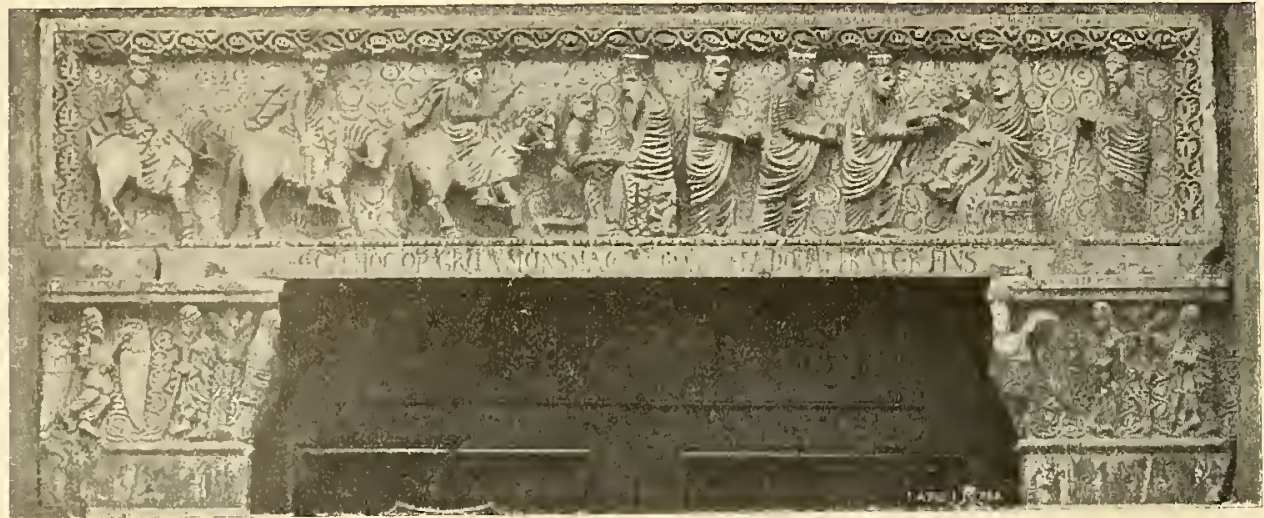

Fregio romanico. Dalla porta di Sant'Andrea di Pistoia

d'oro, nel musaico di Sant'Apollinare Nuovo, a Ravenna, le circonda la testa regale; e tra i Magi e l'augusta Madre stanno gli angioli, intermediarî tra il cielo e la umanità. Ciò basta a classificare come opera di un tempo ben più remoto di quanto fu ritenuto il sarcofago che contenne

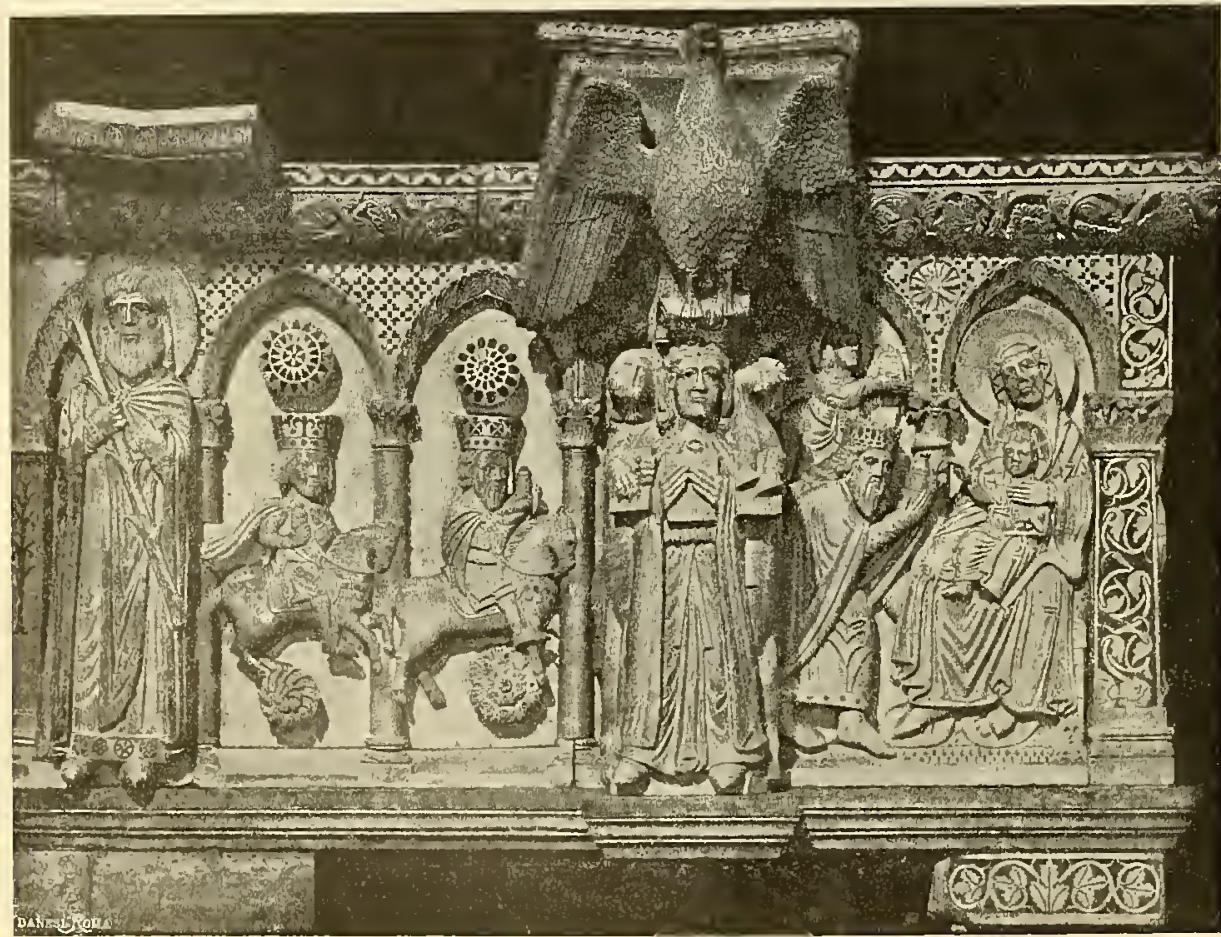

Dal pulpito del secolo xul. Chiesa di Barga in provincia di Lucca 


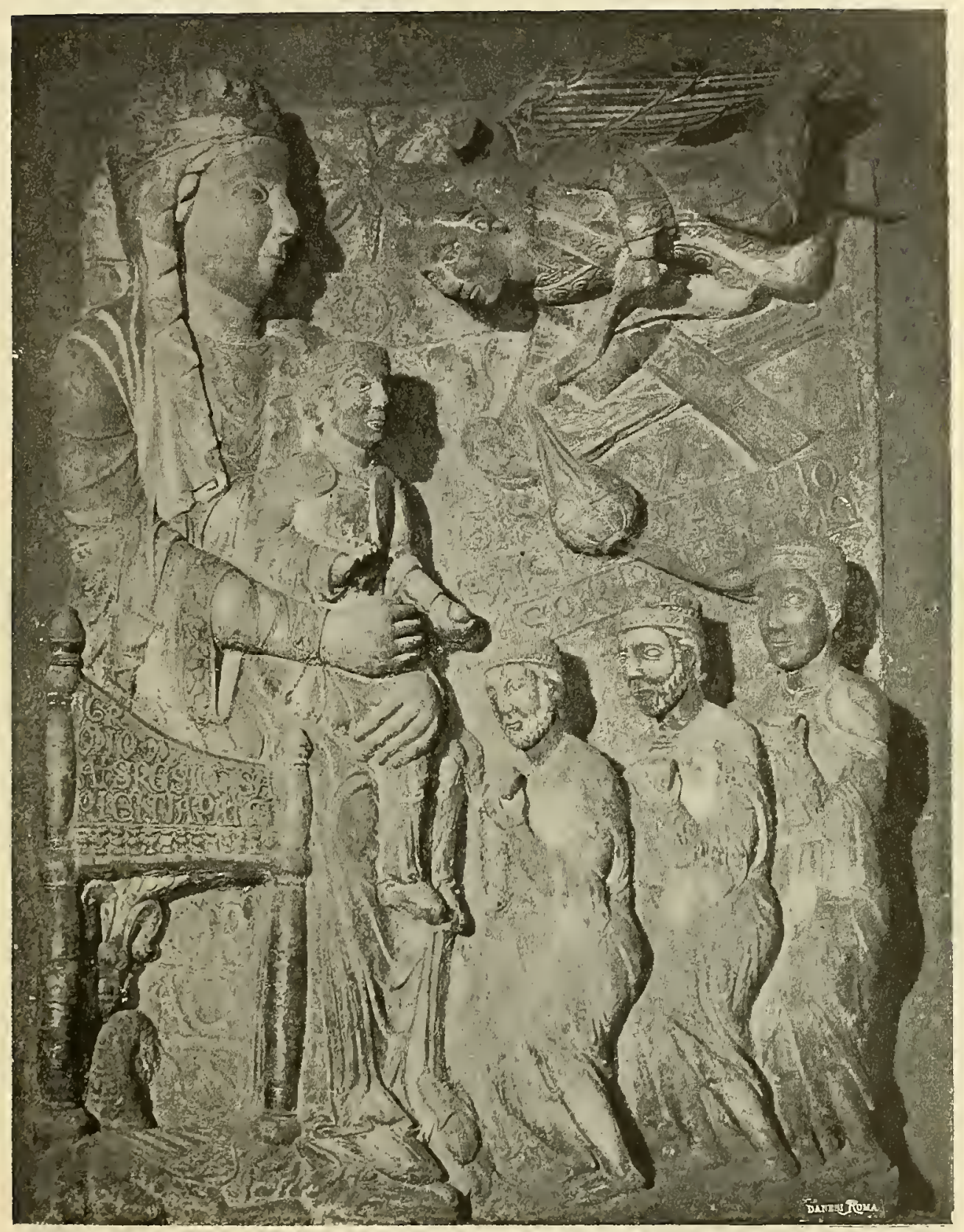

Bassorilievo romanico. Chiesa della Pieve in Arezzo 
le spoglie d'Isaaccio VIII, esarca di Ravenna, morto l'anno 643, perchè la rappresentazione è di una semplicità che più non ha riscontro in quell'epoca.

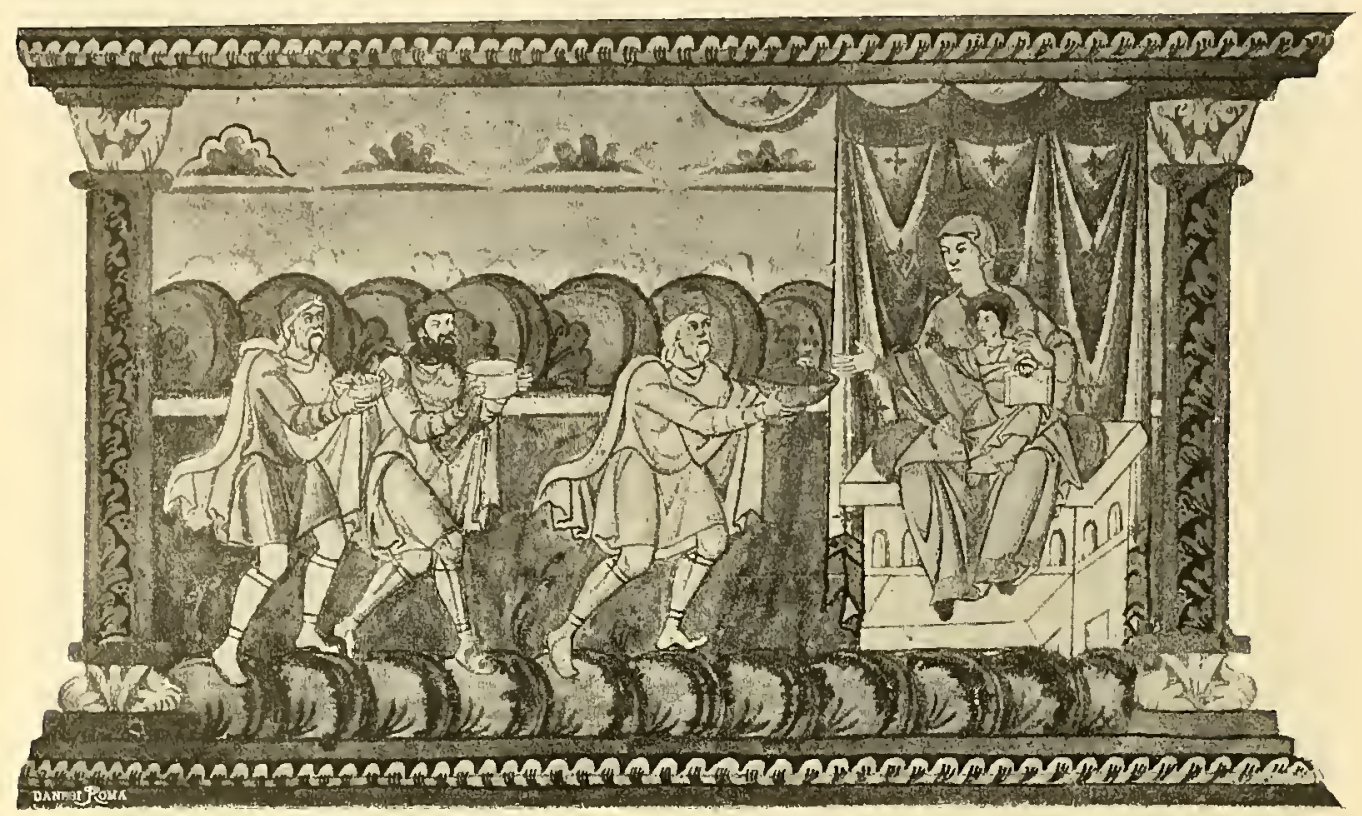

«Orationale» di Fulda nella Biblioteca Vaticana, lat. 3548 (Miniatura, avanti il I054)

Finanche la scena si era complicata nella cattedra di Massimiano a Ravenna, monumento del secolo vi, dove un angelo appare col bastone viatorio presso

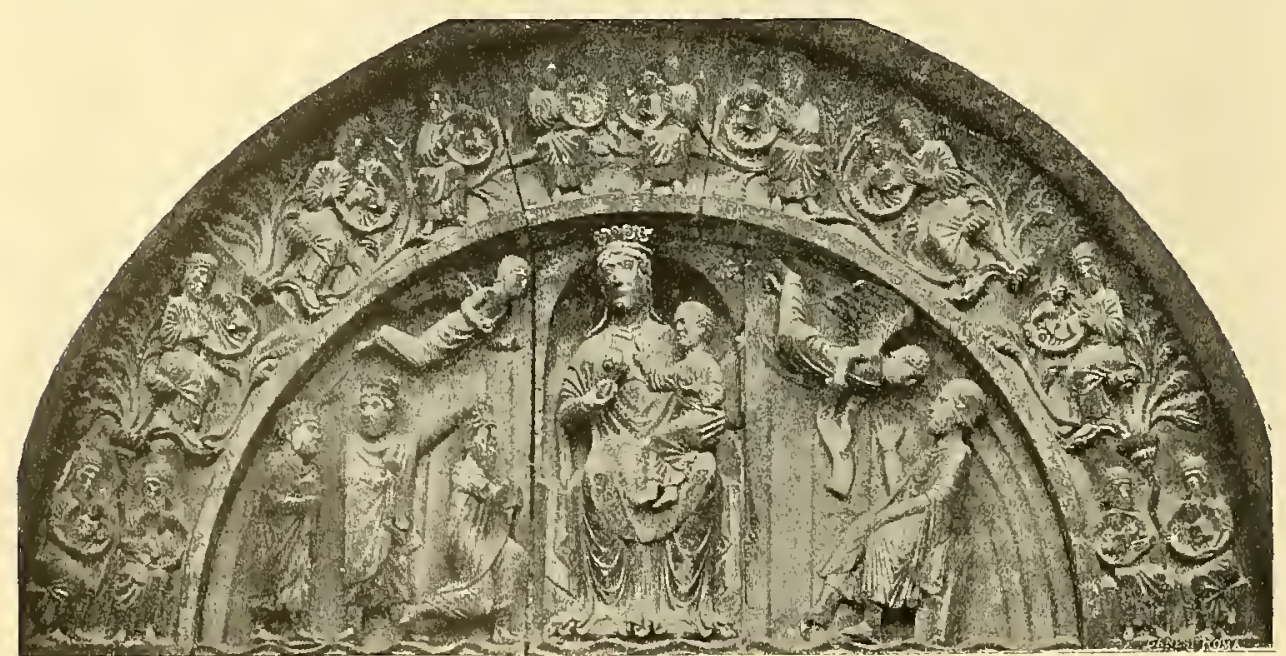

Battistero di Parma

(BENEDETTO ANTELAMI)

la Vergine: e nella pisside del Museo Nazionale di Firenze, ove i Magi si presentano, in segno di venerazione, con le mani velate. 


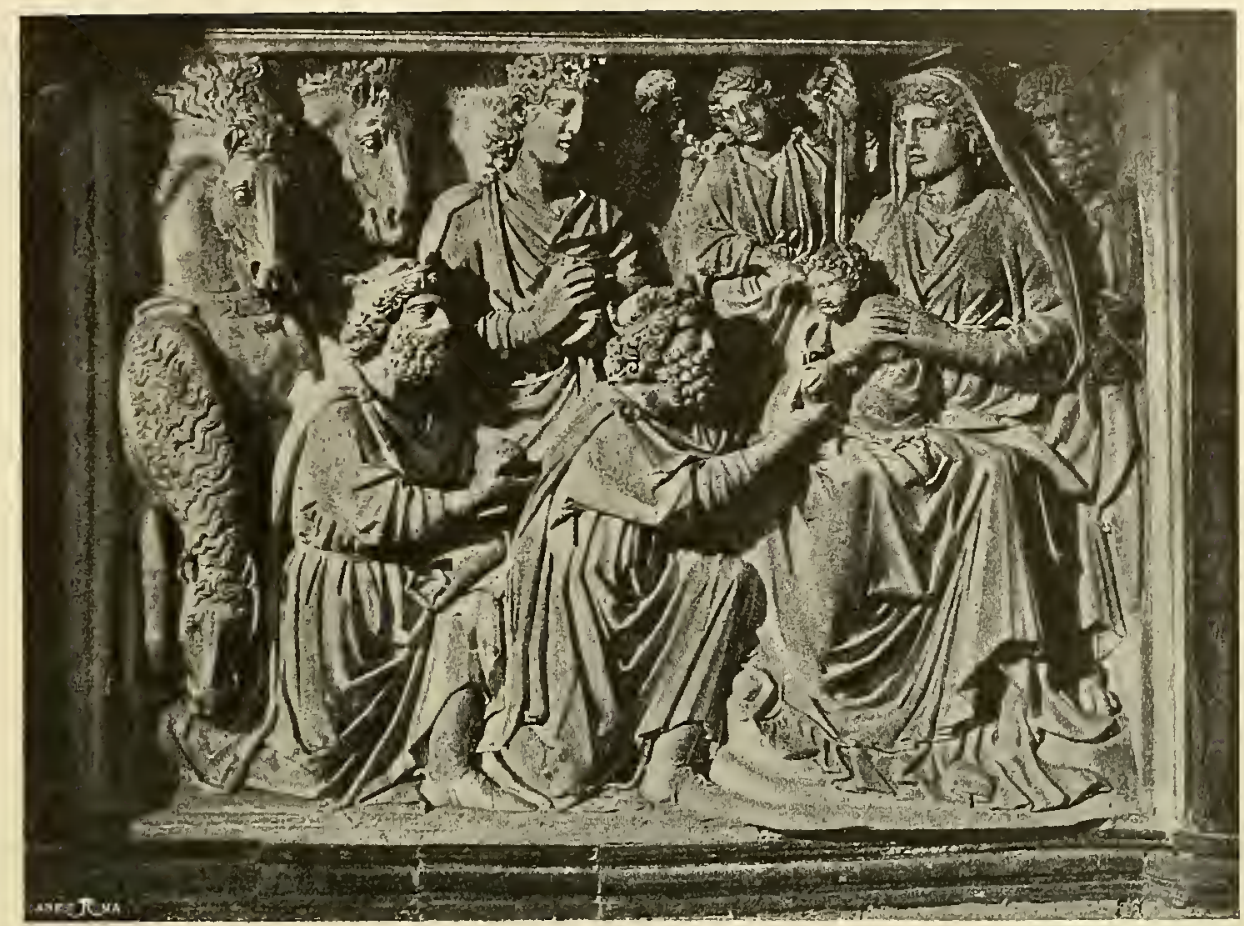

Dal pulpito del Battistero di Pisa (Nicola Pisano)

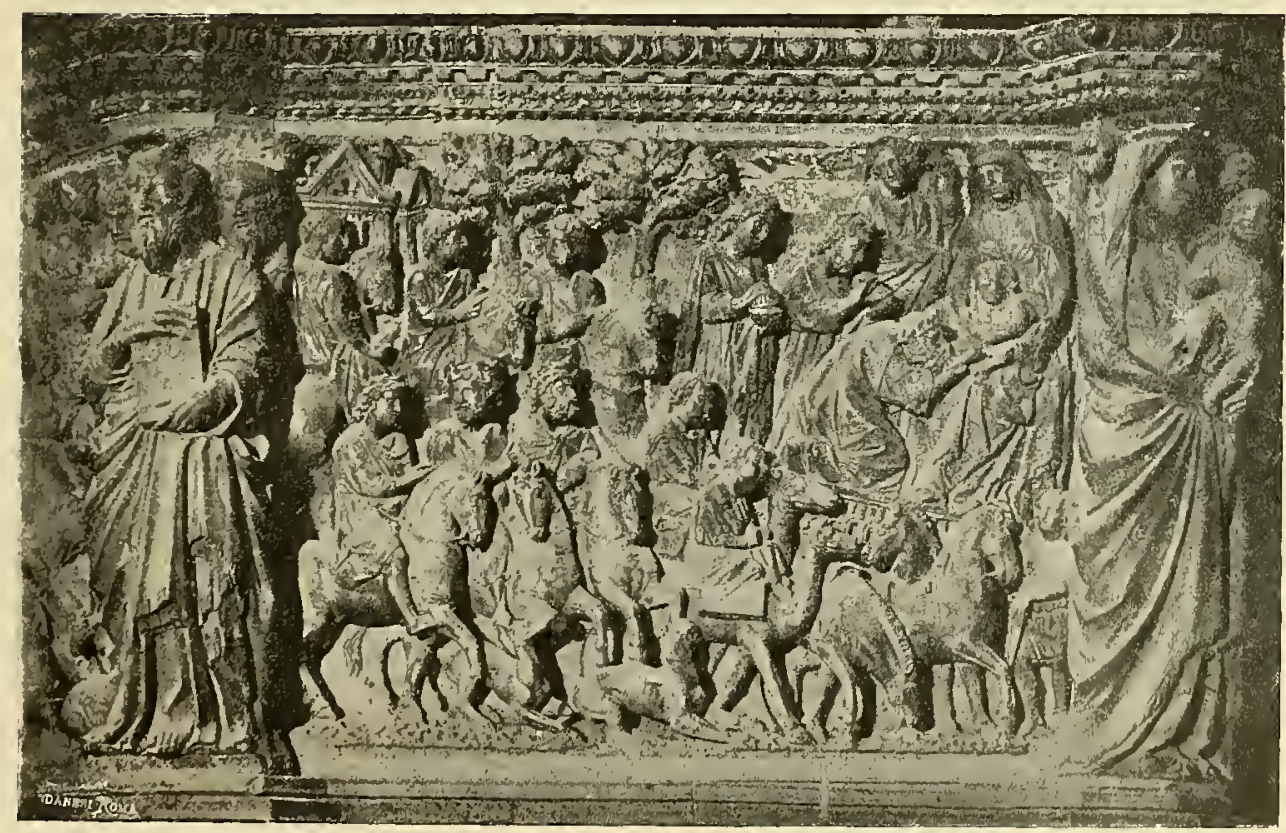

Dal pulpito della Cattedrale di Siena (Nicola Pisano e seguaci) 
L'Adorazione dei Pastori si associò alcune volte con questa de’ Magi nei bassi tempi, benchè in generale gli artefici intendessero di rappresentare scene consecutive della vita del Cristo, figurato in fasce innanzi ai pastori, in tunica innanzi ai Magi. La confusione tuttavia qualche volta avvenne, specialmente per la tirannia dello spazio, in una fiala di Monza, nella pisside citata di Firenze e nelle altre di Werden e di Rouen. Invece a Venezia,

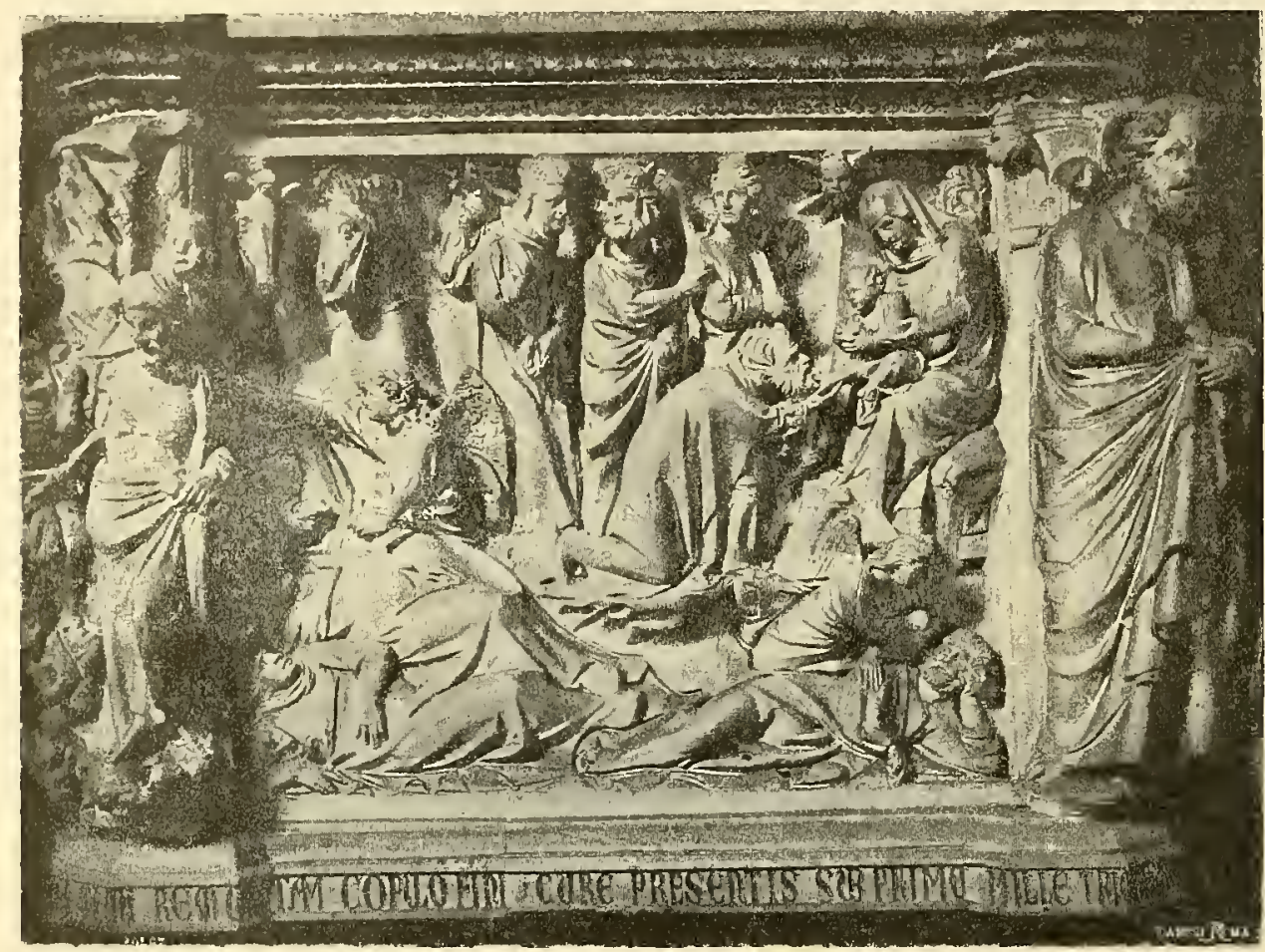

Chiesa di Sant'Andrea in Pistoia

(Giovanni Pisano)

sotto le arcatine delle colonne anteriori del ciborio di San Marco, il racconto evangelico si svolge chiaramente. Dopo l'arrivo de' pastori per adorare Gesù, si vedono $i$ tre Magi, il primo in atto di osservare una sfera, il secondo, di svolgere un rotulo, il terzo, di additare la stella. Mentre Erode sta tutto corrucciato sul trono, i Magi presentano i doni entro coppe, e adorano il Bambino tenuto sulle ginocchia dalla Madre. ricoperta, come di consueto, dal manto che le si stende anche sul capo in modo da formare il velo. Come nei musaici dell'arco di Santa Maria Maggiore, Giuseppe assiste alla cerimonia. Ma in quei musaici il divino fanciullo sta solo in trono, imperiale infante, a ricevere gli omaggi; e la Madre lo guarda compiaciuta, 
benedicendolo. Nel secolo vi la composizione si era dunque ingrandita, nobilitata così che dovevasi figurare la Vergine come un'imperatrice bizantina, il divin Figlio in atto di benedire o di brandire quale scettro la croce.

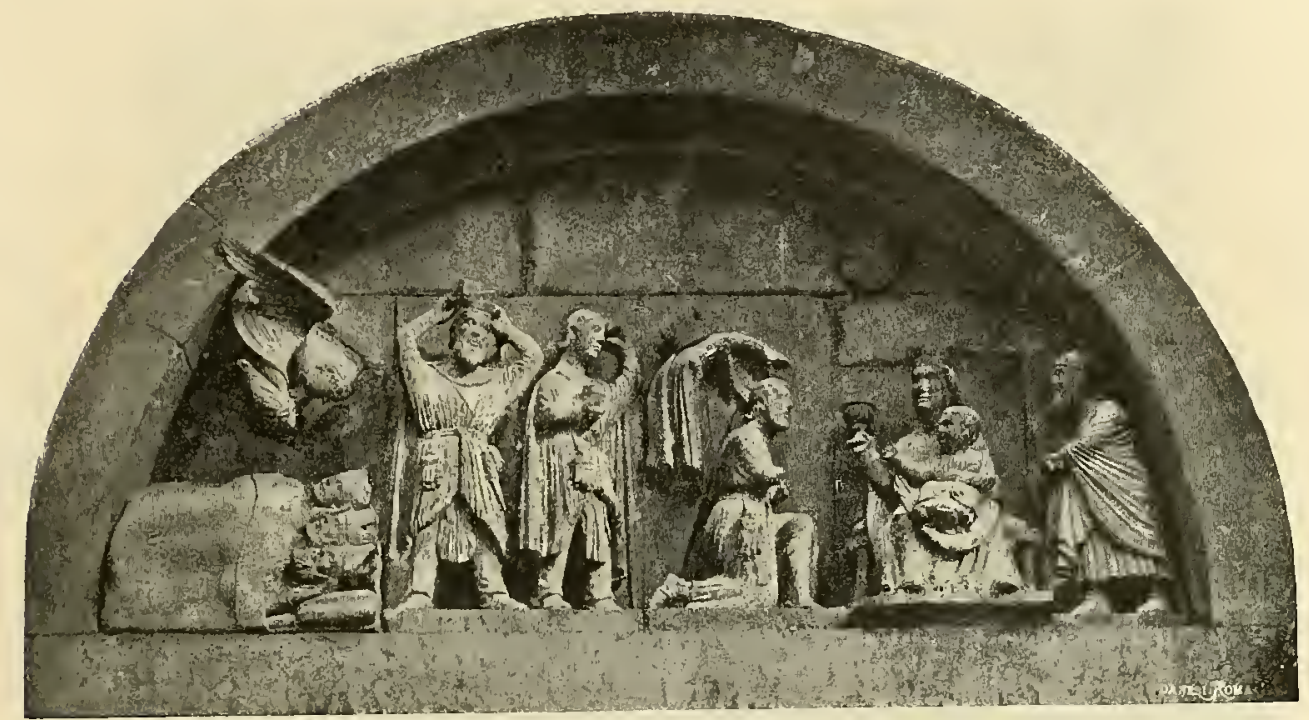

Bassorilievo romanico. Chiesa di San Mercuriale in Forli

Le celesti guardie assistono intorno al trono, che si eleva sopra una gradinata, come già a Santa Sabina, e diviene altare.

Lungo il medio evo la rappresentazione rimane quasi come il mondo classico l'aveva lasciata in eredità ai barbari. A Santa Maria in Cosmedin,

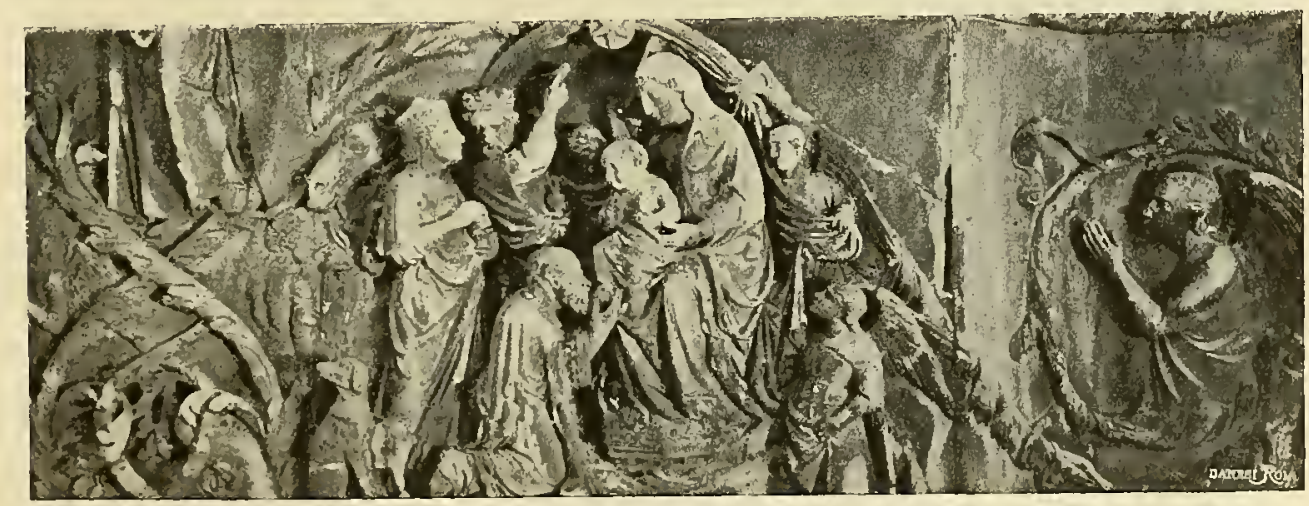

Bassorilievo della facciata della Cattedrale di Orvieto

nel menologio greco dell'imperatore Basilio, si rivede Gesù "sedcutcm in simu Mariae», secondo è descritto nell'apocrifo della Natività deila Vergine, quando si fa parola dei Magi che penetrano nella casa su cui pendeva 
immobile la stella. Ma i Greci arrivarono a rendere co più minuti particolari la scena evangelica, così che, nel canone della Guida dolla pittura pubblicato dal Didron, si era prescritta in questa forma: "Casa: la Vergine

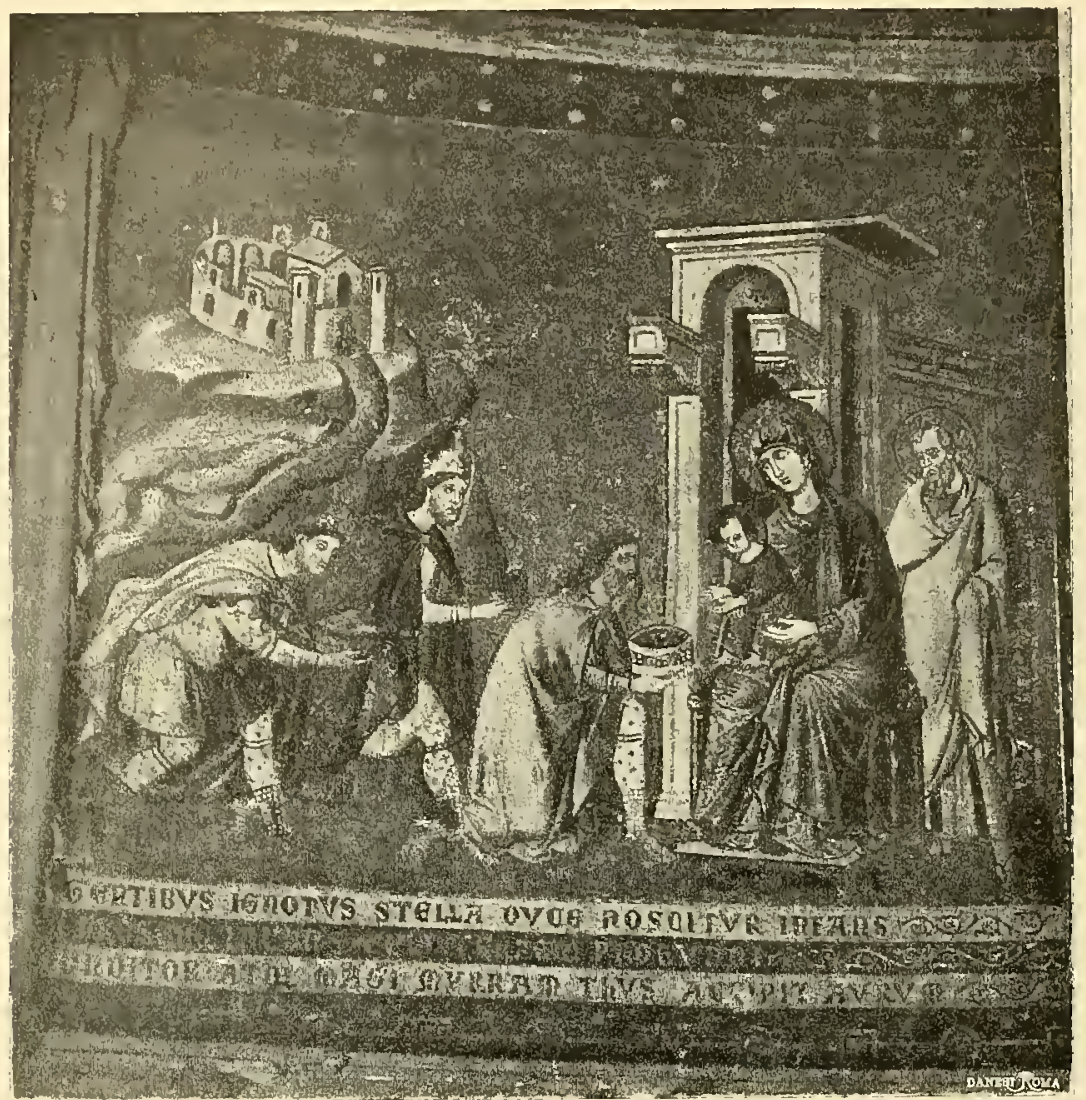

Musaico. Basilica di Santa Maria in Trastevere di Roma

seduta porta Cristo bambino benedicente: i tre Magi offrono i doni in cassettine di oro. L'uno vecchio, barba lunga, testa scoperta, s'inginocchia tenendo gli occhi rivolti al Cristo, e con una mano gli offre il dono, con l'altra tiene la propria corona. Il secondo ha poca barba; il terzo non ne ha, ed è per lo più di razza negra. Si guardano fra loro, mostrandosi Gesù Cristo. Dietro alla Vergine sta San Giuseppe in piedi, in atto d'ammirazione. Fuori della grotta un giovane tiene tre cavalli per la briglia. Di lontano, sopra una montagna, si scorgono i Magi a cavallo, di ritorno alla loro patria, con la scorta d'un angelo». La complicazione della scena cominciò quindi nel mondo orientale, e l'Occidente, passando sulle tracce dell'arte greca, trasformò la semplice rappresentazione in un ricevimento solenne, 
contrapponendo all' idillico Presepe il canto festoso dell'Epifania. Già intorno al 1000 sul capo de' Magi si sostituisce la corona di re alla mitra orientale, e la Vergine, non più avvolta dal manto, ma in vestimenta regali, con diadema gigliato, riceve gli ospiti augusti. Così ci appare la scena nel principio del secolo xir a Fano, e nello stesso secolo ad Arezzo nella chiesa della Pieve: i Magi sono accompagnati da un angiolo a volo, col turibolo. La linea generale della composizione rimane tuttavia invariata, e solo mutano e rimutano $\mathrm{i}$ particolari delle figure. Nel bassorilievo dell'architrave della porta di Sant'Andrea a Pistoia, opera del i I66, la Vergine è vecchia, il Bambino prende

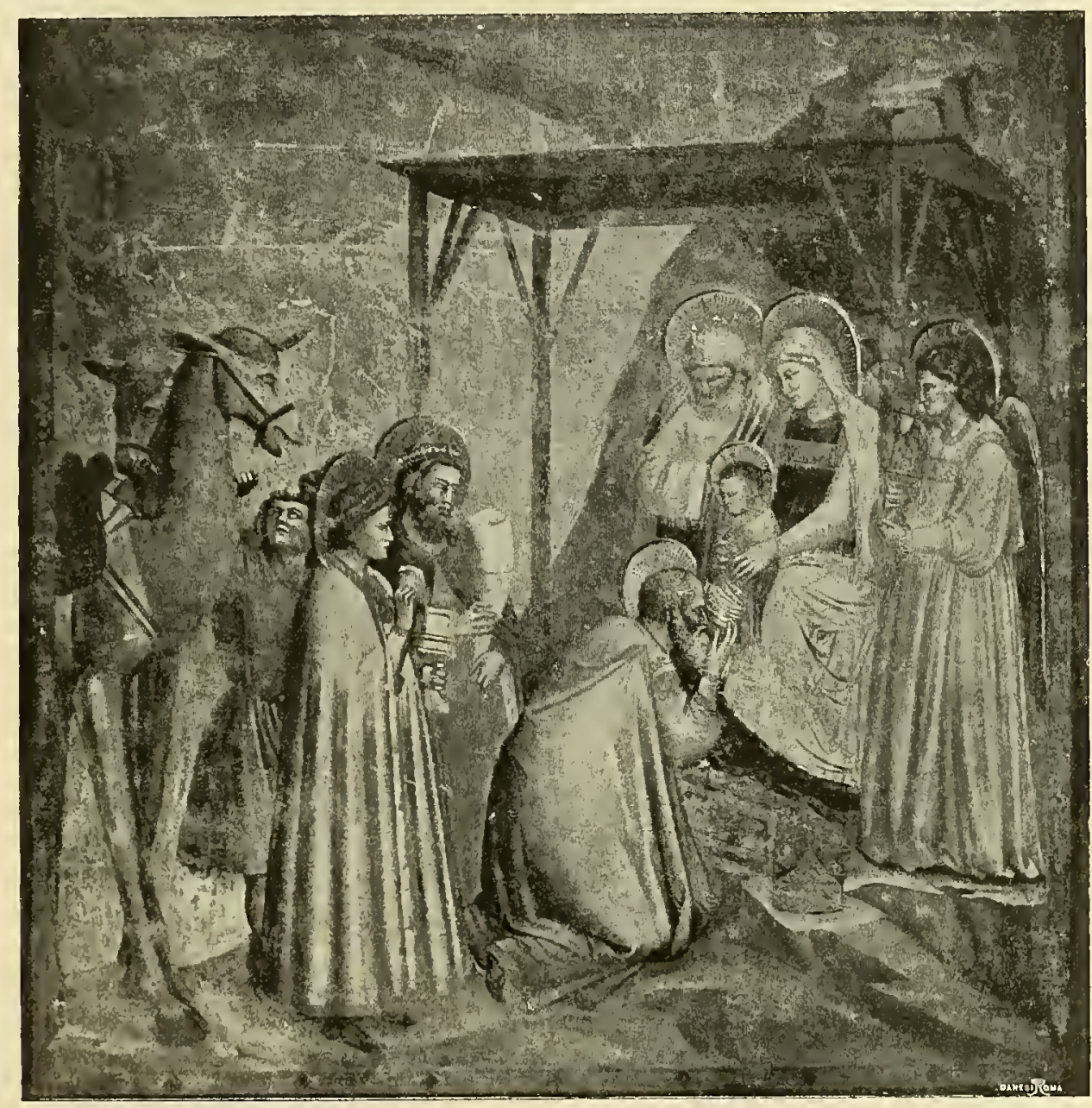

Cappella degli Scrovegni nella chiesa dell'Arena di Padova

(GIoTro)

con ambe le mani i doni del primo e più anziano dei Re, San Giuseppe sta dietro alla cattedra della madre divina. A Barga, nel pulpito, il Bambino 
benedice l'offerente, dietro cui caracollano per l'aria i due compagni, veri nani, tanto più piccoli quanto più si allontanano dalla divinità. Maria tutta pensosa, sembra quasi ritorcere il capo. Forse il rozzo scultore, immaginando come l'animo di lei dovesse essere angustiato per la salvezza della creatura divina,

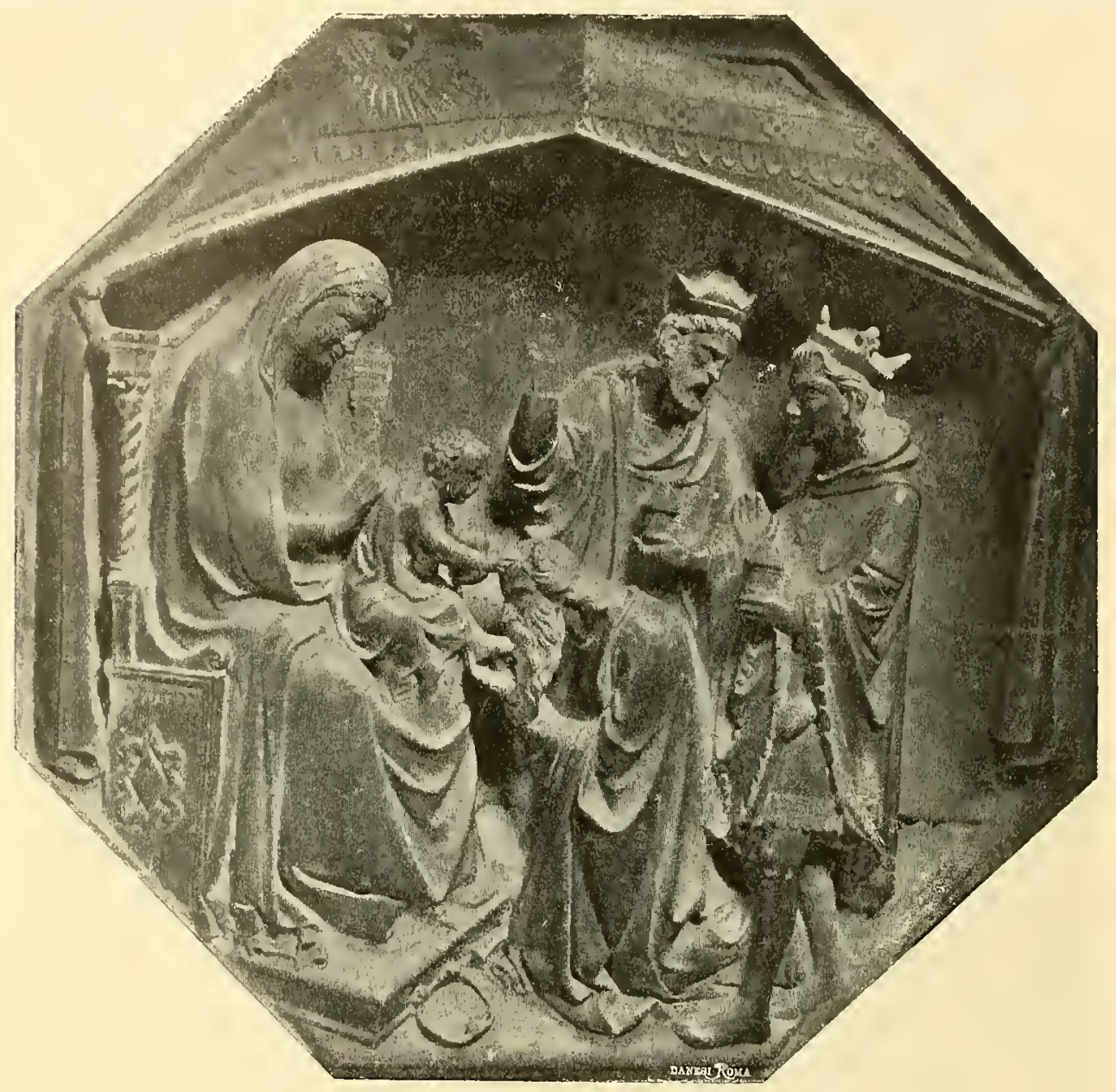

Dal tabernacolo in Or' San Michele di Firenze

(OrCagna)

tentò di rifletterle sul volto l'interna ambascia. Così si fece sin dai tempi antichi dall' arte, e così Sant'Efrem spiegò nella cantica in cui ci mostra Maria tremante che Erode tragga la spada per recidere il dolce grappolo prima che fosse maturo. All'arrivo dei Re, ella chiese loro perchè avessero abbandonato la patria per recar tesori al Fanciullo; e rispondendo essi di prestare omaggio al Re dei Re, Sant'Efrem le fa dire: "Quando mai una povera donna ha dato in luce un Re? Io sono priva di tutto, la mia casa 


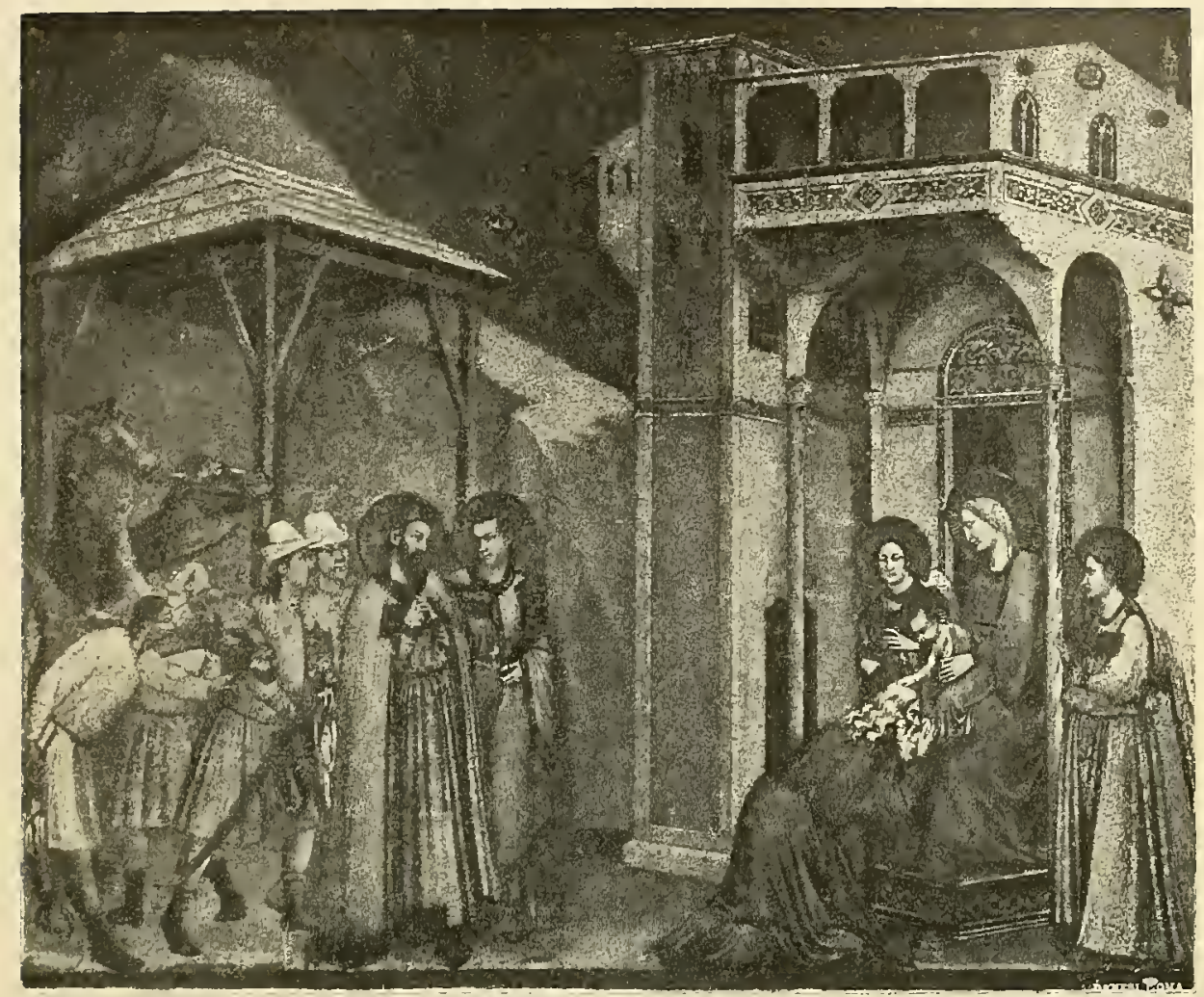

Basilica di Assisi

(TADDEO GADDI)

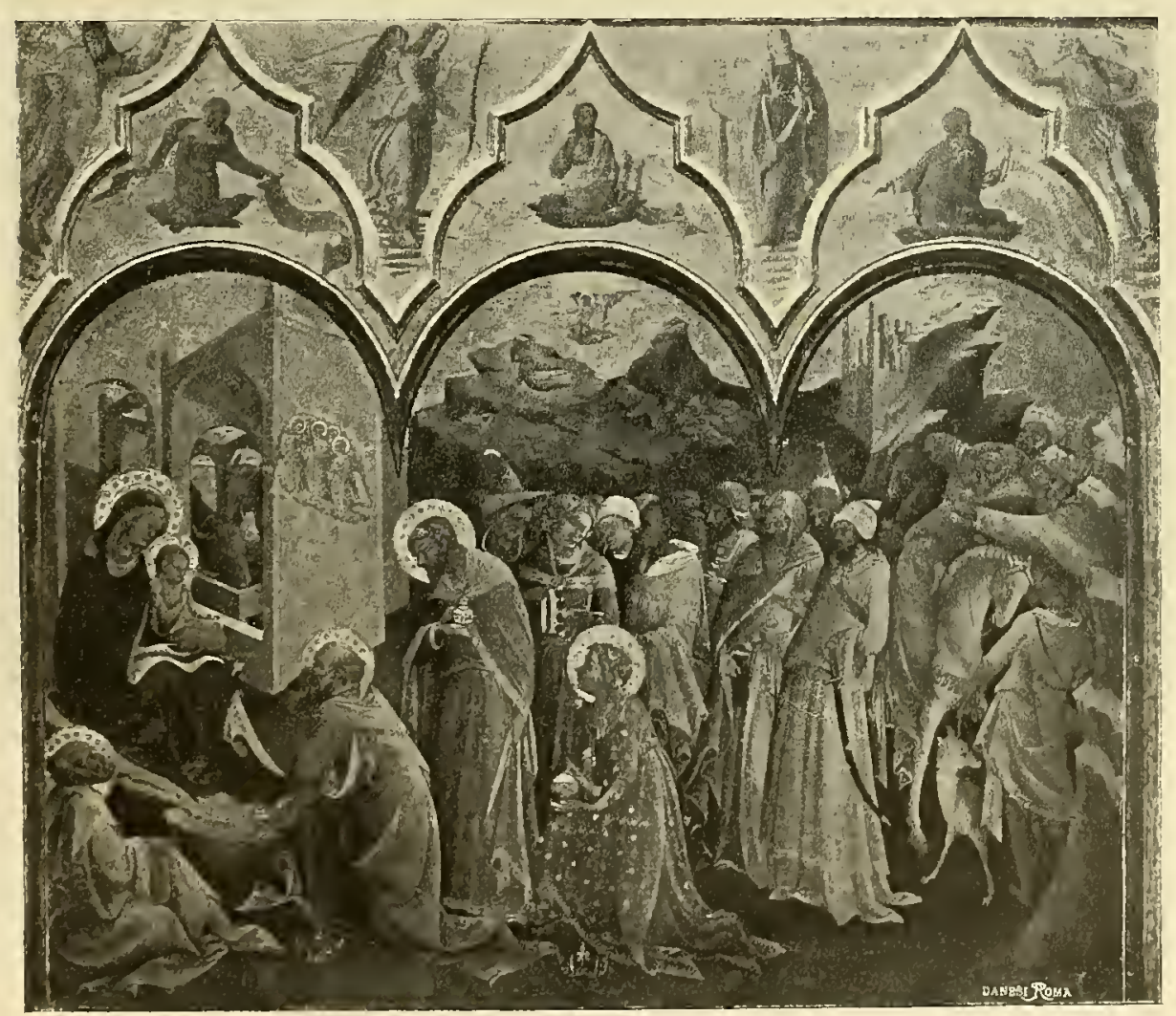

R. Galleria degli Uffizi in Firenze

(Lorenzo Monaco) 
è povera e vuota. Il mio Bambino non ha nè diademi, nè troni, nè coorti, ed è coricato tutt'avvolto nella povertà della madre sua " .

La titubanza, il sospetto di Maria si rivela ne' monumenti del secolo xıı, in cui cessa il parallelismo nelle figure de' tre Re Magi, e in generale tutta la scena prende libero movimento. A Forli, nella chiesa di San Mercuriale, nella lunetta soprastante alla porta, la Vergine guarda austeramente i Re, uno dei quali, entrando nella casa del Dio, si toglie la corona; il secondo

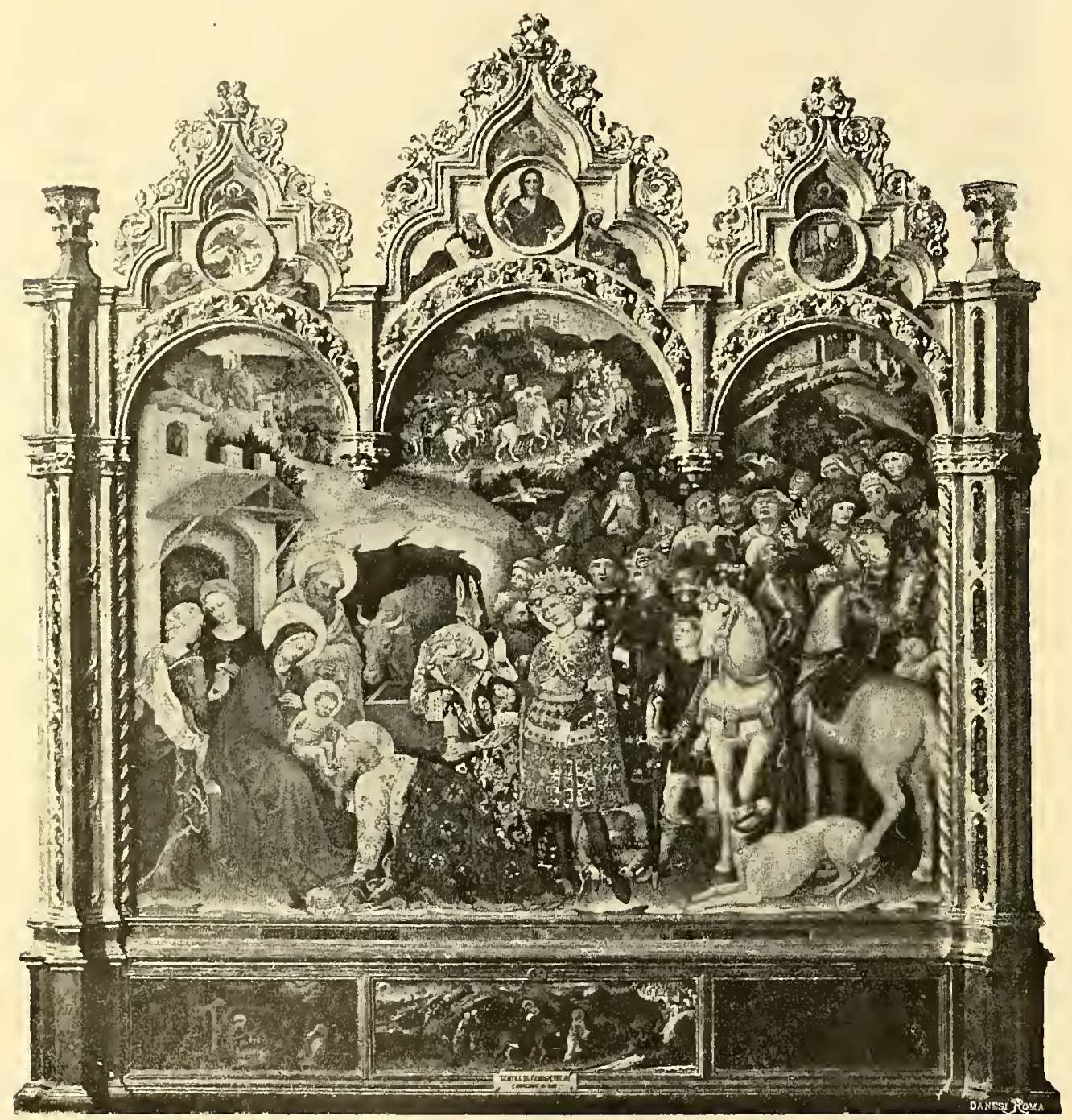

Galleria antica e moderna in Firenze

(Gentile da Fabriano)

l'ha già tolta; il terzo, da persona bene educata, ha già messo il manto e la corona all'attaccapanni. Avanzano invece come di corsa, al modo antico, 
anelanti d'offrire i loro tributi al Fanciullo divino, i tre Magi, nel musaico di Santa. Maria in Trastevere; e la Vergine guarda dubitosa nel presentar loro

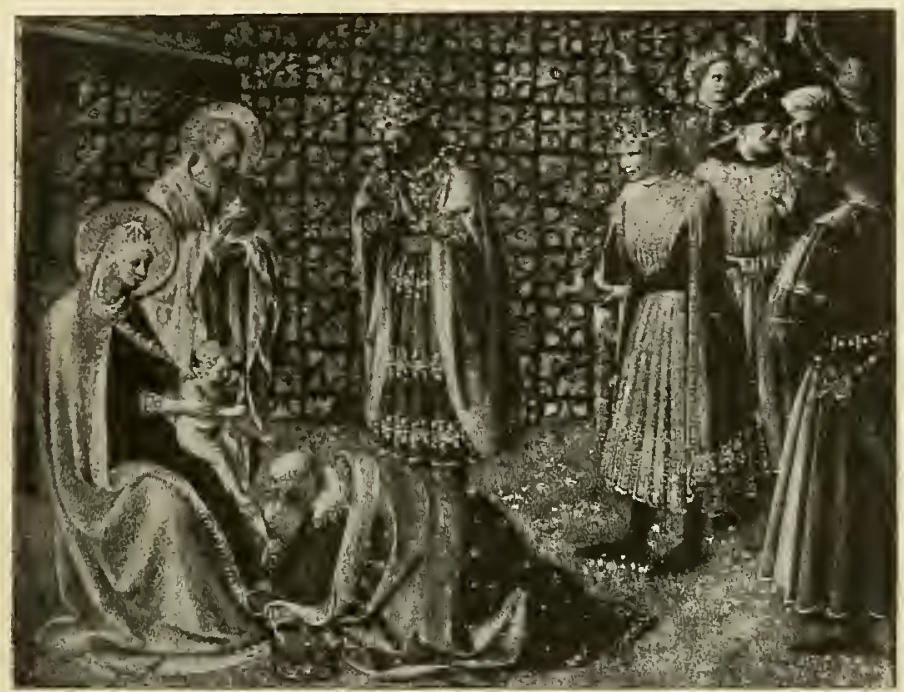

Firenze. Museo di San Marco

(Beato Angelico)

il Figlio. Ella si è ravvolta nel manto, i regali visitatori riprendono le clamidi affibbiate e le calze a scacchi, San Giuseppe indossa di nuovo il pallio. Questo ritorno all'antico, si vede anche nel pulpito del Battistero di Pisa ( 1260 ), opera di Nicola Pisano. Maria è coperta dal manto, e il diadema gira pure

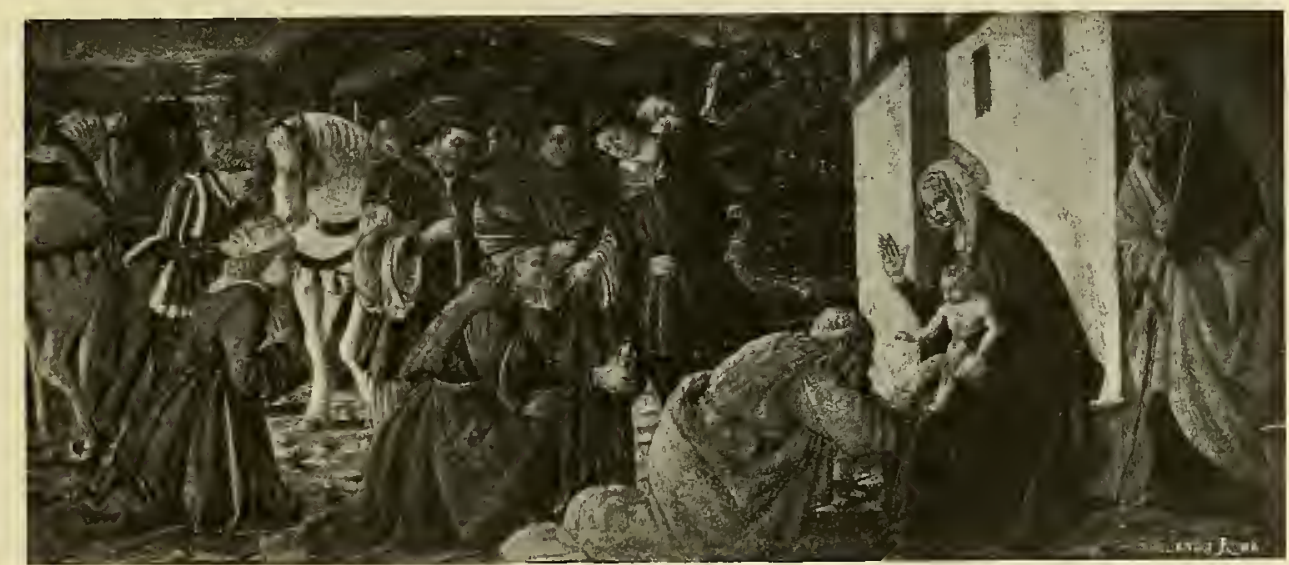

Prato. Galleria municipale

(SCUOLA DI FILIPPO LIPPI)

sulla testa giunonica; riappare l'angelo col bastone viatorio, e, invece dei camelli, che, per segno del viaggio dei Magi si trovano nei sarcofagi 
lateranensi, qui si vedono i cavalli tratti dalla rappresentazione di un carro trionfale. La natura prese poi il sopravvento sull'antico nell'altro pulpito di Nicola Pisano, quello in Siena (1266-68), ove la Vergine piega il capo, meravigliata degli omaggi dei Re, ed invece del classico diadema ha la

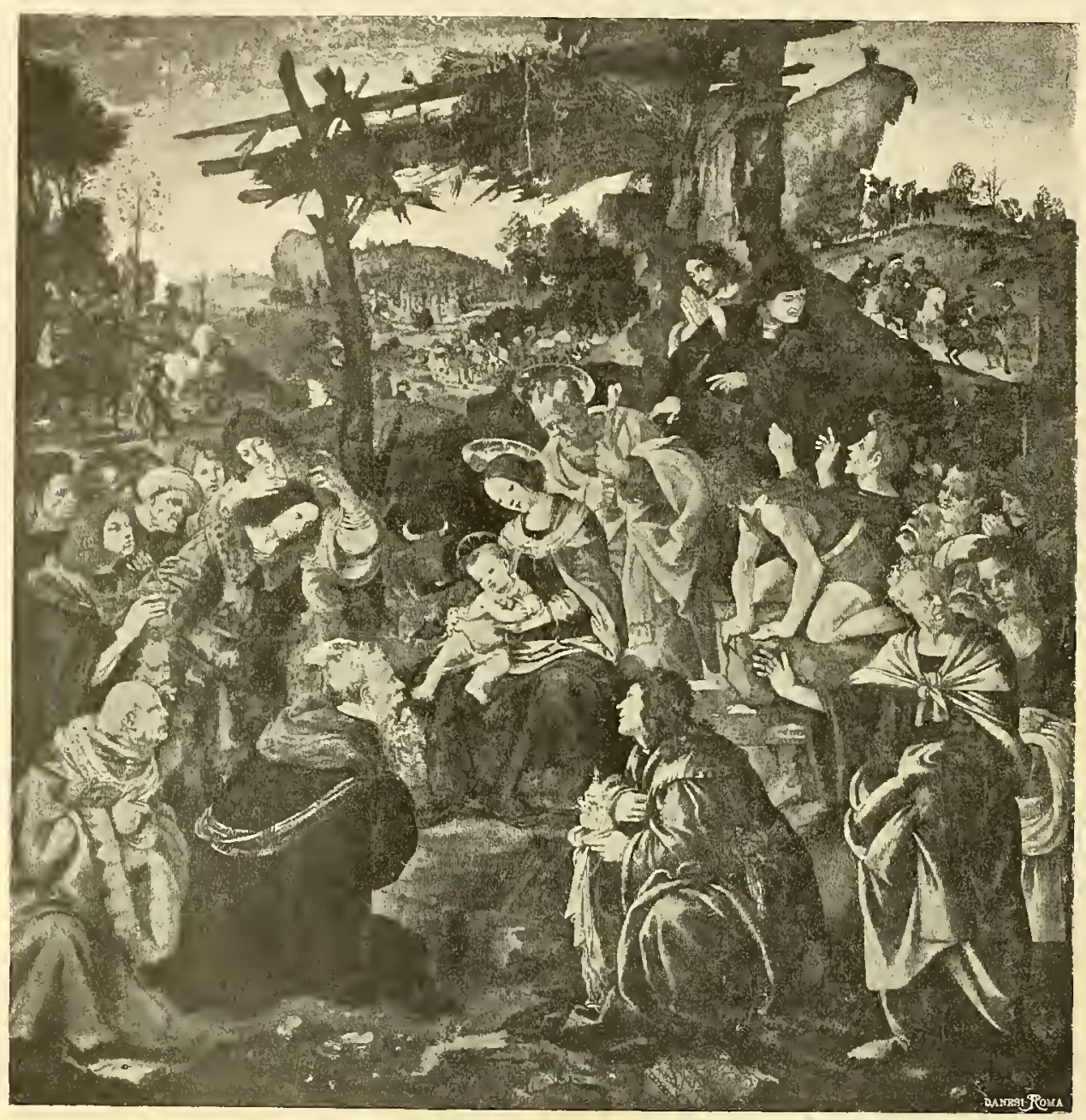

Regia Galleria degli Uffizi in Firenze

(FILIPPINo LippI)

corona medievale. Uno dei Re accosta alle labbra un piede del Bambino per baciarlo: non è più il principe d'una provincia romana che rechi il tributo a Cesare, è un fedele che si prostra nella polvere; e gli altri due, sollevando leggermente il coperchio dei vasi che portano, stanno con la testa china, quasi, per soggezione alla vista del Re dei Re, vogliano mostrare i doni avanti d'esprimere i sensi divoti. 


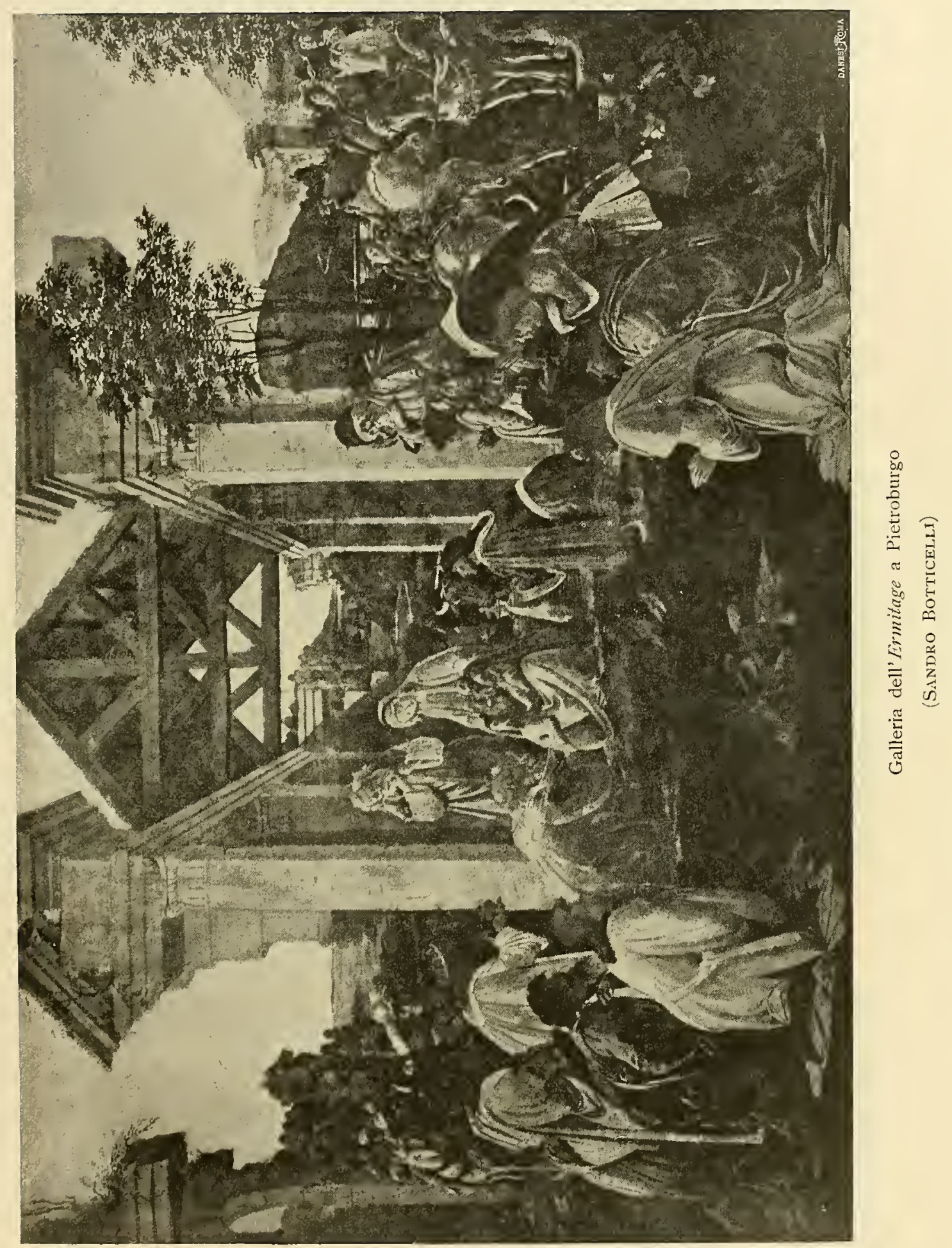


Questa composizione potentemente espressiva fu imitata da Giovanni Pisano nel pulpito di Sant'Andrea a Pistoia; ma la scena perdè di grandezza e festività, e $\mathrm{i}$ corpi perdettero la loro forte struttura e le sicure proporzioni.

Giotto diede l'antica austerità alla Vergine pensosa che presenta il Bambino a uno dei Re. Sotto la povera tettoia, che sembra stendersi come un baldacchino sopra il sacro gruppo, ella si asside quale regina; San Giu-

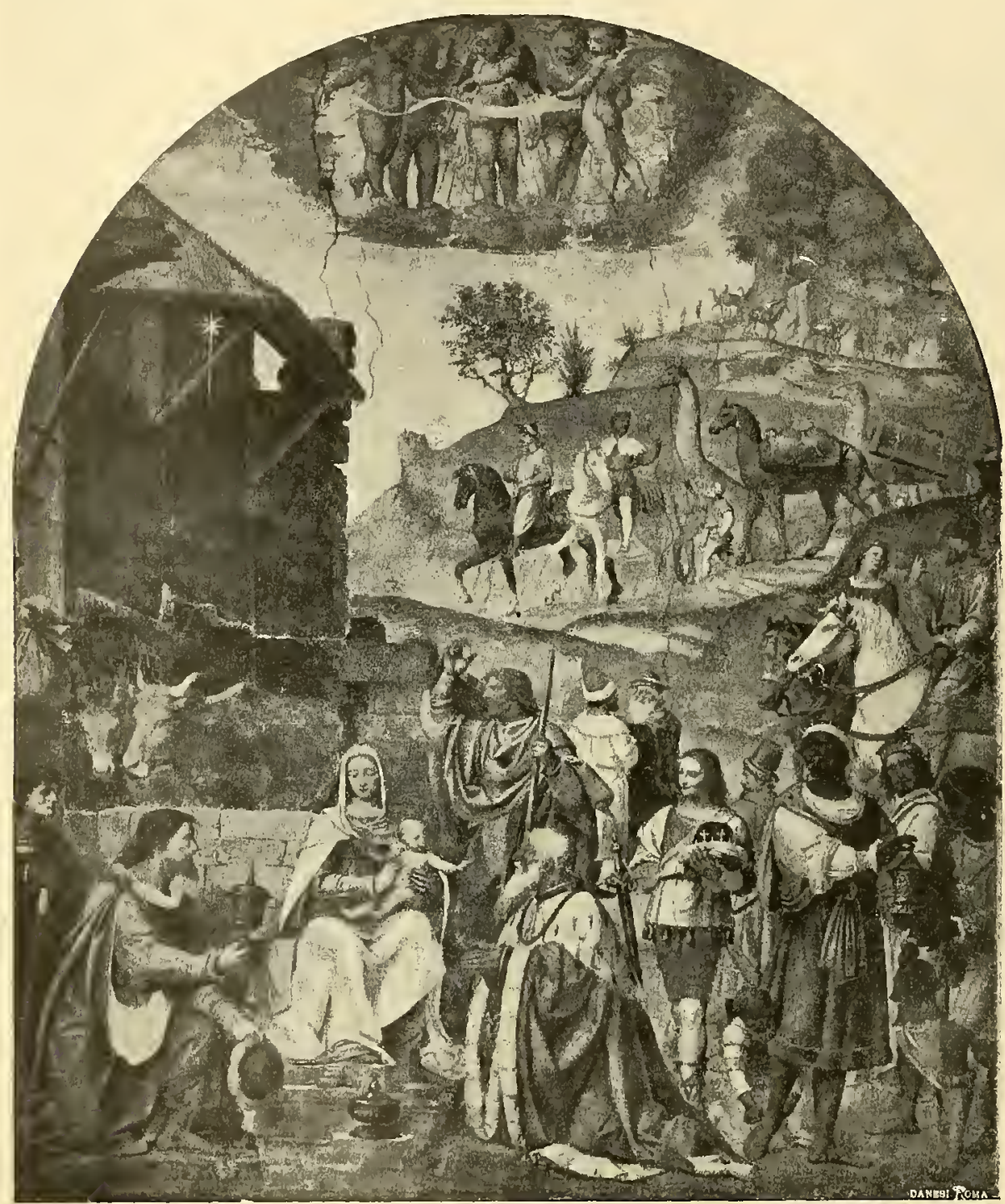

Santuario di Saronno

(BERNARDINO L UINI)

seppe e un angelo, nimbati, assistono al trono; il Bambino, con la clamidetta che ne copre il corpo in fasce, ha quasi una severità regale, mentre 


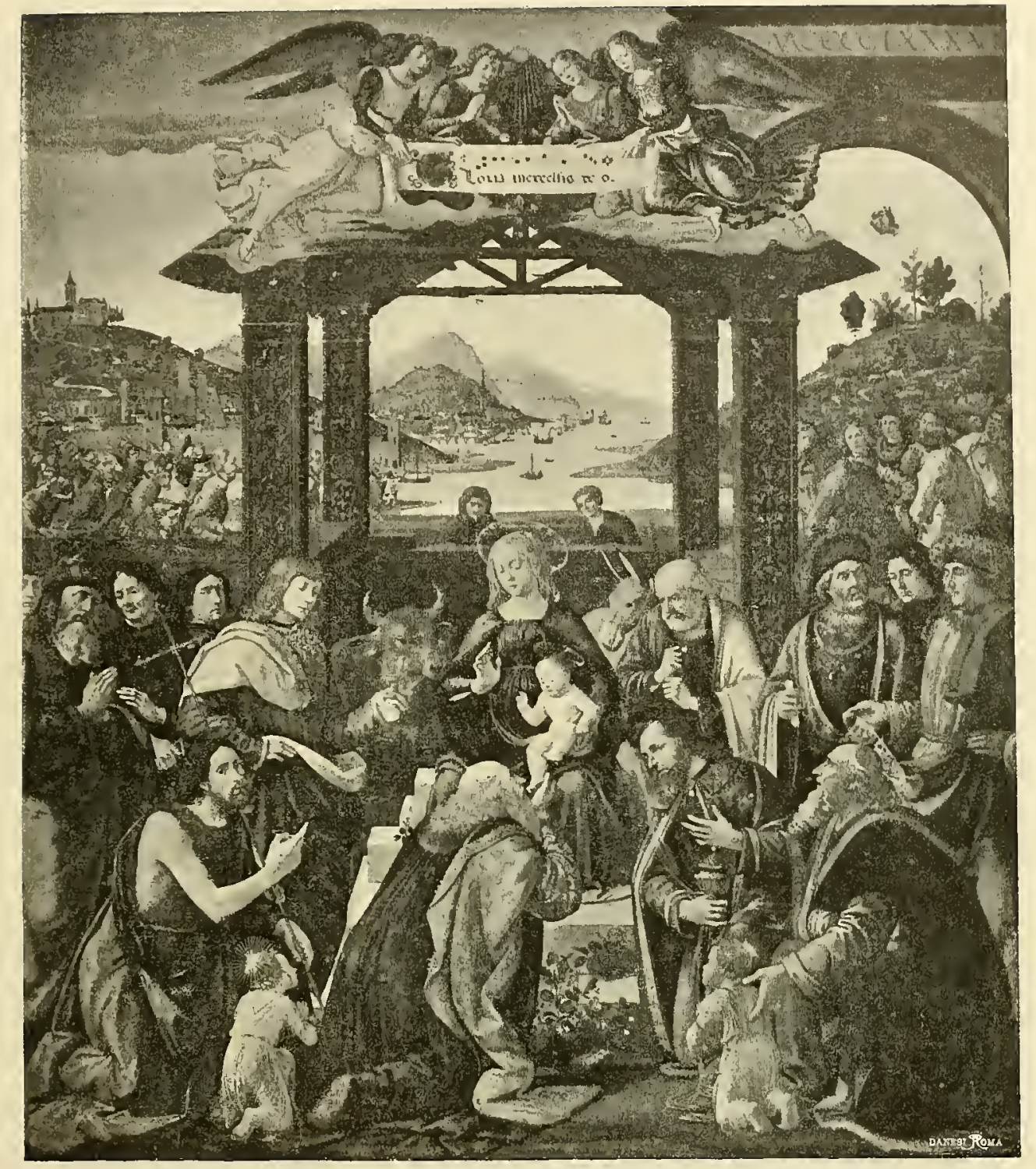

Cappella dell' Ospizio degli Innocenti in Firenze

(Domenico Ghirlandalo)

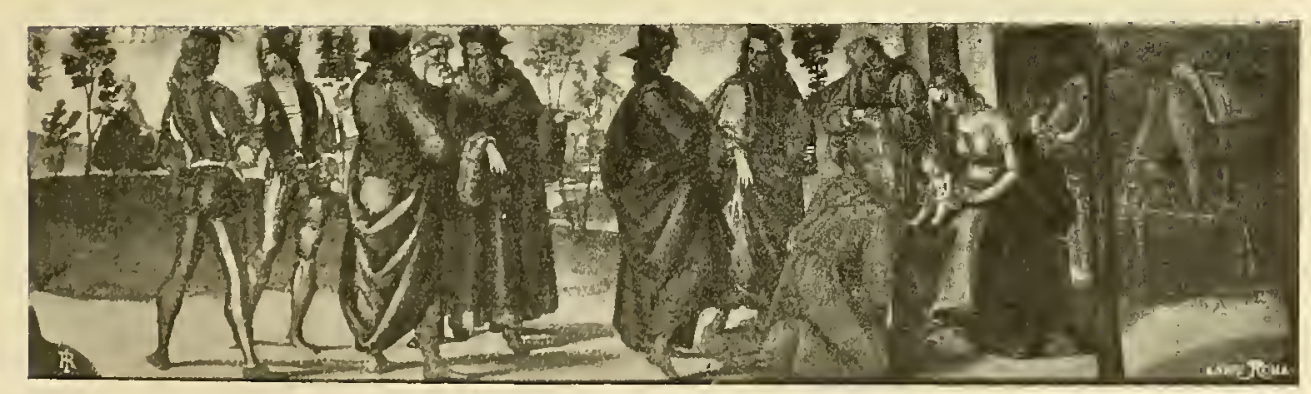

Firenze. Galleria degli Uffizi

(Lica Signorelli) 
uno dei Nagi sembra accostarsi carezzerole per baciarlo, e gli altri due. come sacerdoti, in nobile atteggiamento, ossequiosi, merarigliati, aspettano

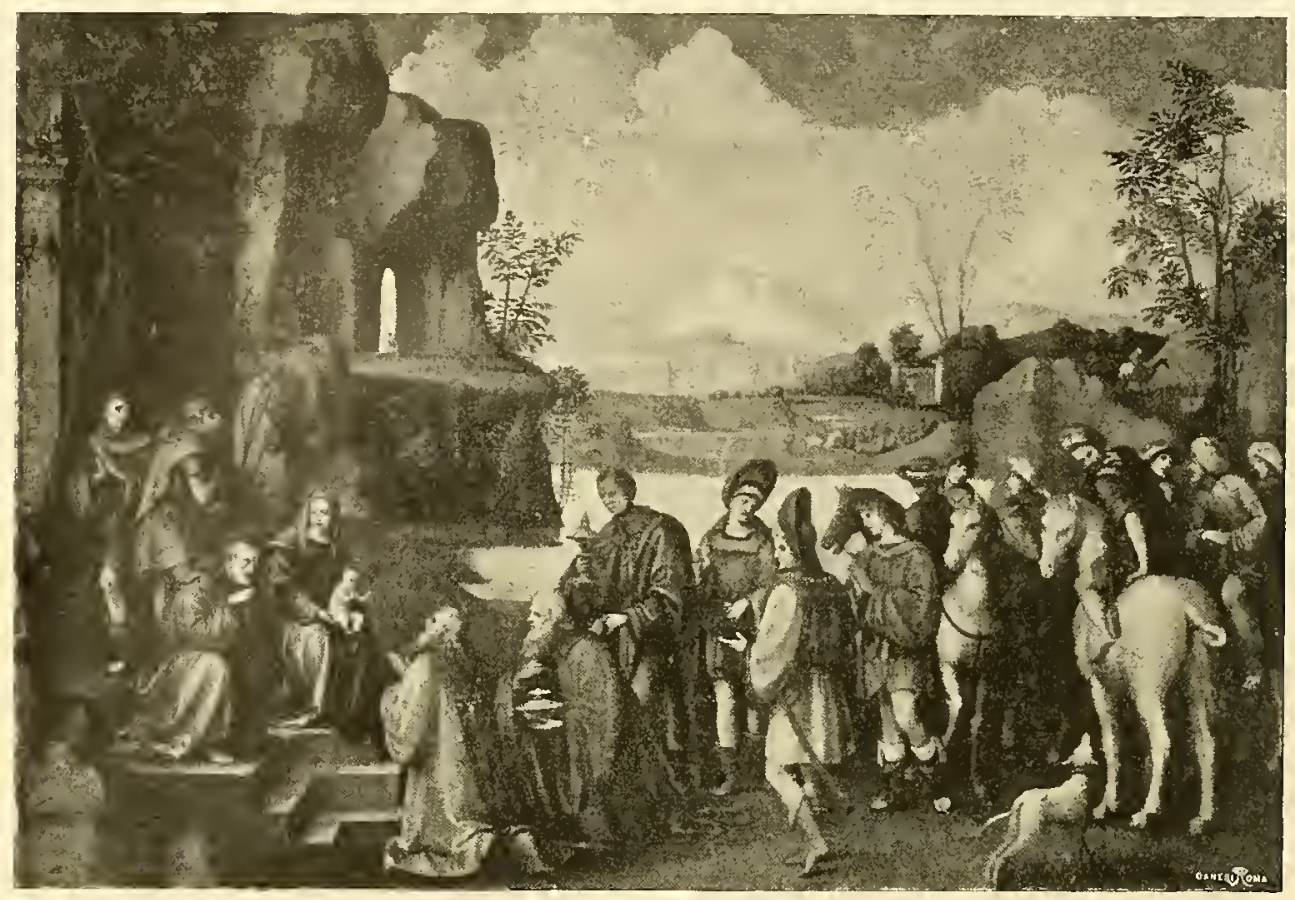

Galleria di Dresda

(Fraxcesco Raibolini, detto il liraxcia)

di porgere gli omaggi al Divin fanciullo. Uno de' camelli, su cui sono arrivati $\mathrm{i}$ Re. con l'aperta bocca e le orecchie tese e gli occhi fissi al Bambino, prende pure parte alla scena.

Ad Assisi, un seguace di Giotto, Taddeo Gaddi, in simile ma più ornato modo, raccontò il sacro avvenimento, pur senza ottenere l'austerità dellił rappresentazione padovana, la quale sembra svolgersi in una cattedrale, sotto l'ala del mistero, nel raccoglimento delle anime.

La Vergine è sempre in cattedra, come ne tempi primitivi; ma già gli angioli ad Orvieto, ne' bassorilievi del Duomo, le stendono dietro un baldacchino: e nel tabernacolo dell'Orcagna ad Or' San Michele la cattedra diventa uno scanno con colonne tortili ai lati, una sedia episcopale del xirn secolo. Mutano i particolari, non l'atteggiamento della Madre, nell" Adorazione dei Nagi». Ella anzi riveste il manto semplice, e non ha corona, mentre i Re, lasciati i saraballa, indossano il costume elegante de' Fiorentini del tempo. Nel secolo di spariscono dal volto della V'ergine l'austerità, la sorpresa, il 
timore. Ella prende parte alla festa, adorando, insieme coi Re, la creatura divina, su cui china gli occhi pieni di materno amore. Mentre Lorenzo Monaco mostrava la T'ergine col Bambino apparire, come in una visione, a Giuseppe e

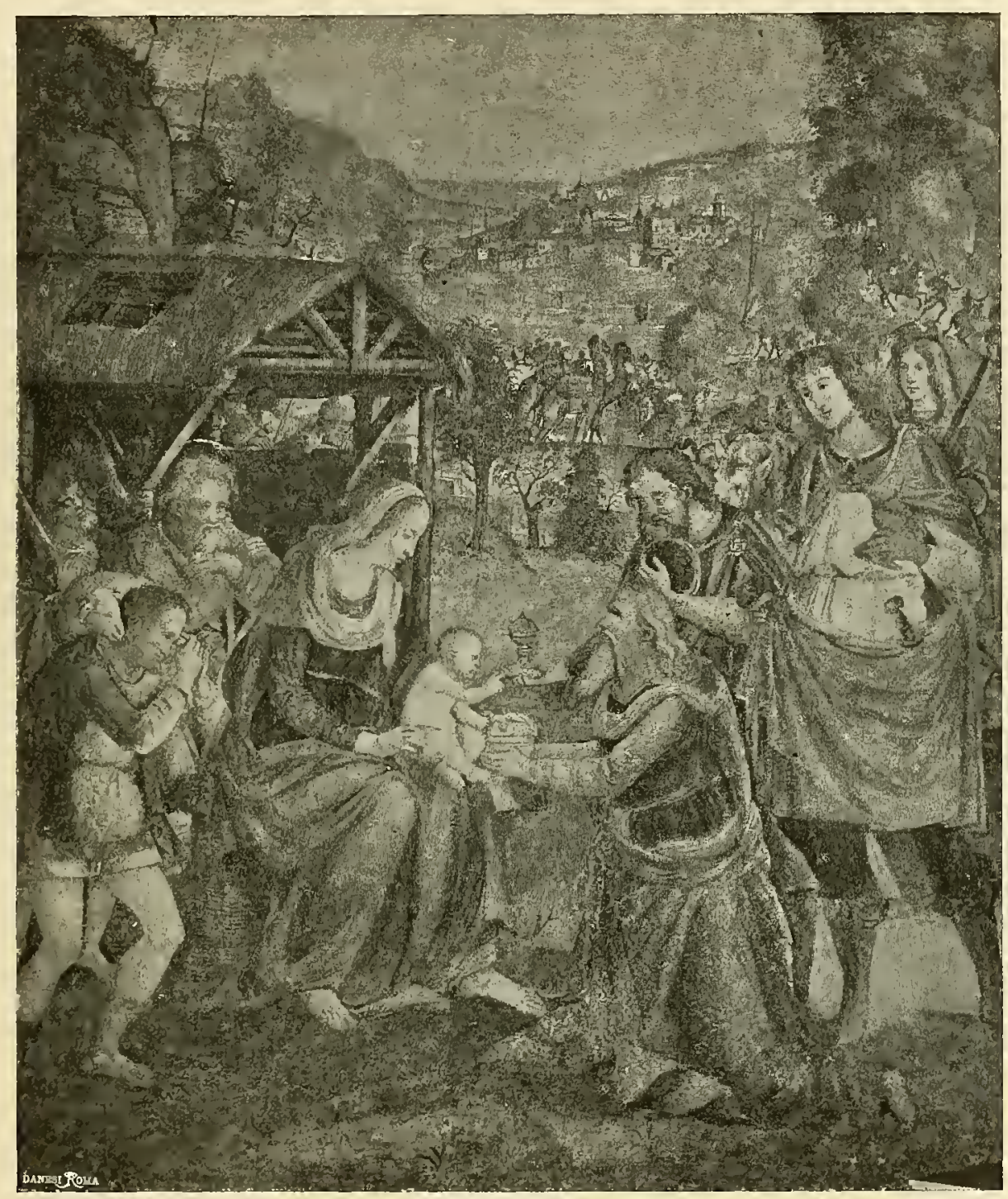

Chiesa di Sant'Onofrio in Roma

(Baldassare Peruzzi)

ai Re, Gentile da Fabriano faceva assumere alla scena un grandioso carattere sociale. Passano i Magi di contrada in contrada, scendono e salgono i monti, varcano i ponti levatoi dei castelli, seguiti dai cortigiani coi falchi in pugno, dai cacciatori coi liopardi. Il più vecchio dei Re si prostra e bacia un piede al Bambino, che gli pone la manina sulla calva testa: e gli altri due 
compagni offirono riverenti i loro doni chiusi in gotici reliquiari. Tra quello splendor di broccati e di costumi pomposi. tra il profuvio de' fiori che si riversano sui piccoli campi delle cornici gotiche, tra lo scintillio dell'oro, la Vergine china la testa gentile e porta una mano clirotamente sul petto.

Ancora Filippo Lippi a Prato fa che la divina Madre, mentre uno dei Re

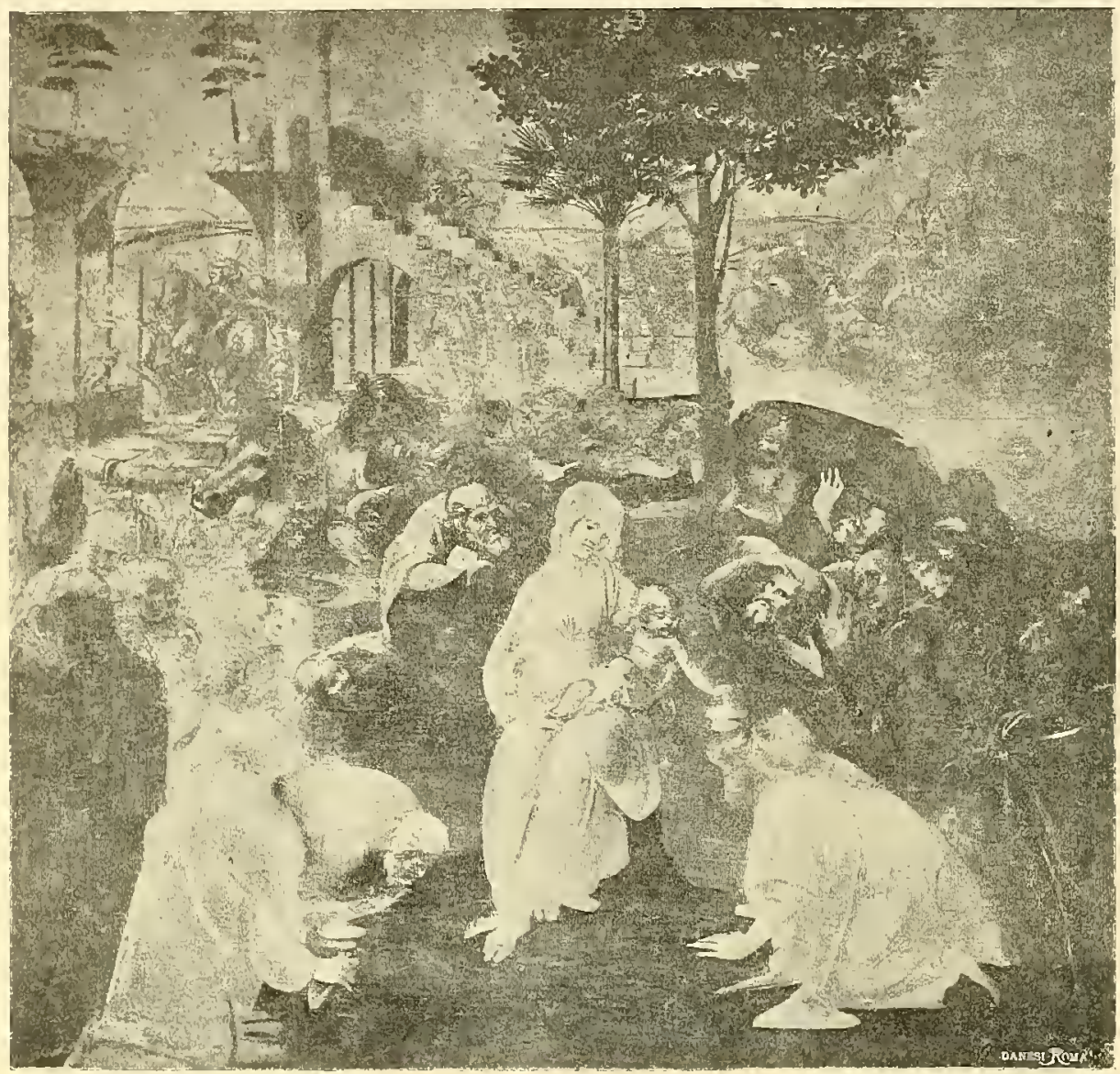

R. Galleria degii Uffizi in lirenze

(LEONARDO DA VINCI)

prende un piedino di Gesì. si chini e con la destra aperta esprima l'ansia timorosa: ma il Ghirlandaio, pure morendo similmente quella mano. ne fece poi ripiegar le dita graziosamente come in dolce atto di sorpresa. Il Beato Angelico e il Signorelli, ligi alle antiche forme iconografiche, continuarono invece a figurar la Mladonna che presenta la creatura divina all'adorazione dei Magi.

In generale l'arte del Quattrocento schiude agli occhi dei Nagi la visione della Sacra Famiglia: e cosi l'intese principalmente Leonardo da Vinci, 
disponendo tutt intorno al gruppo della Vergine col Bambino la corona degli uomini meravigliati, inginocchiati, come offesi dalla luce del Dio. Il gruppo pare abbia una nicchia in quel formicolio di esseri. La Madonna non è più di profilo. come ne' tempi antichi, bensì nel mezzo della scena, col bambinetto ignudo, nell umiltà trionfante sulle grandezze umane. Così il Botticelli, il Ghirlandaio e Filippino Lippi disposero le superbe composizioni, traendo

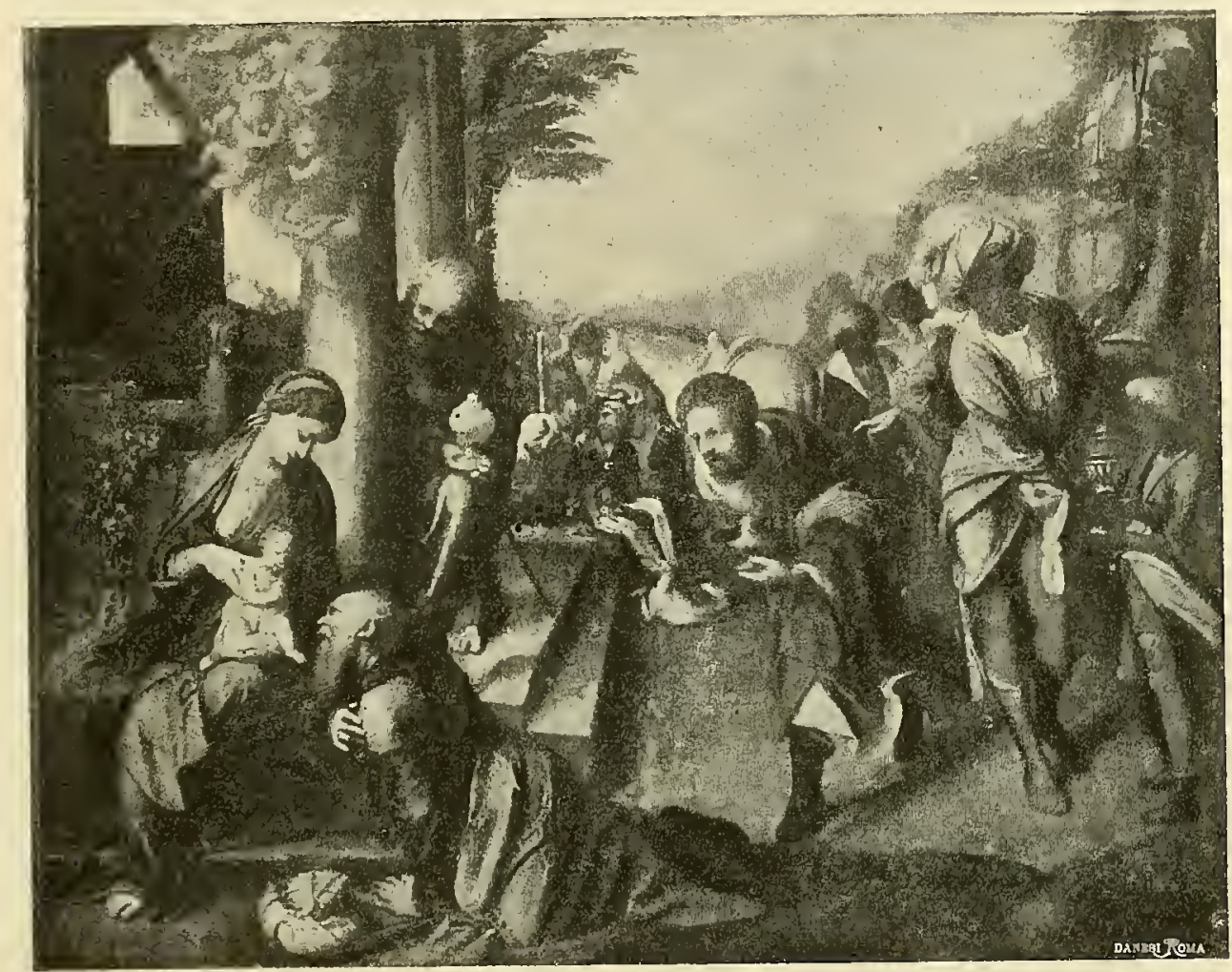

R. Galleria di Brera in Milano

(CorregGio)

i costumi dalle Corti italiane, dai ricevimenti dei magnifici signori. La cattedra d'onore era divenuta un semplice gradino, perchè gli artisti, tutti intensi a dar verità alla composizione, non compresero pì̀ il simbolo e lo tolsero davanti alla capanna. Na i gradini si moltiplicarono, come già nella primitiva rappresentazione di Santa Sabina, e sopra essi sedette la Madre, guardando in basso alla turba divota. La capanna diviene un oratorio diruto nel Ghirlandaio e in altri maestri; sulle rovine troneggia la Madonna.

L'arte, poi ch'ebbe conquistata la sua libertà, ruppe nel secolo xv le lince della composizione, associò di nuovo i pastori ai Re. la stalla fu lasciata nella 
composizione, gli angioli volarono, cantarono in alto, come già nel Presepe. Anche Raffaello, nel purissimo quadro giovanile, nella predella della Galleria Vaticana, accostò timidamente i suoi ingenui personaggi al gruppo divino, ma a destra i pastori e a sinistra i Re: e così fece il Peruzzi in Sant'Onofrio. Il Signorelli e il Luini non esclusero il bue e l'asino dalla scena; e come il Luini, il Correggio, nel gemmeo dipinto della Galleria di Brera in Milano, fece apparire in alto gli angioli nel gaudio. La Vergine gode degli onori tributati al Figlio, dignitosa osserva gli atti divoti e presenta il Bambino, il suo sacro tesoro.

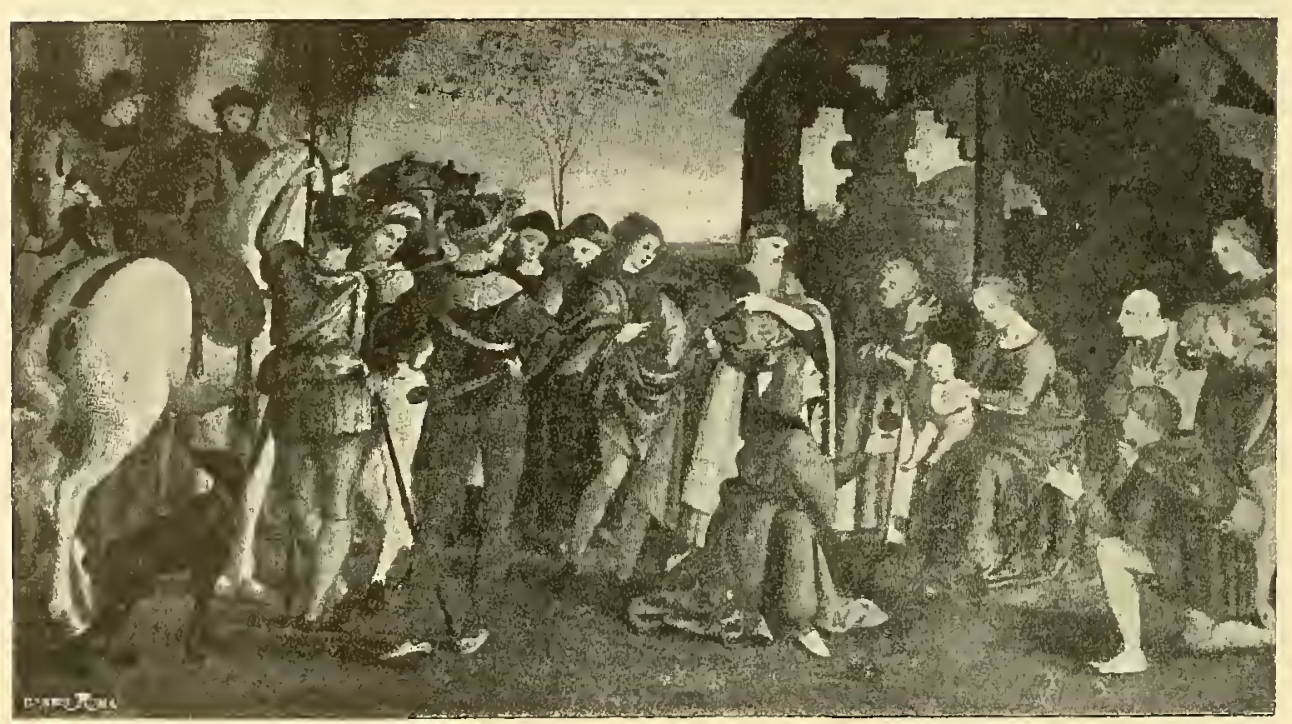

Dalla predella nella Galleria Vaticana

(Raffaello) 


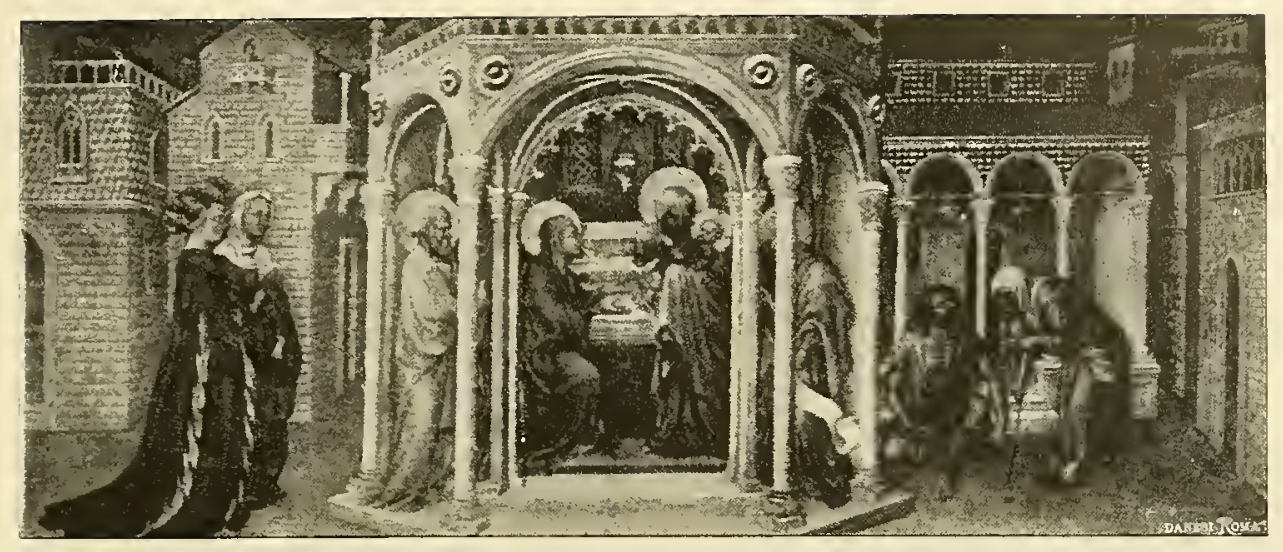

Museo del Lourre a Parigi

(Gentule da Fabriano)

\section{La Purificazione.}

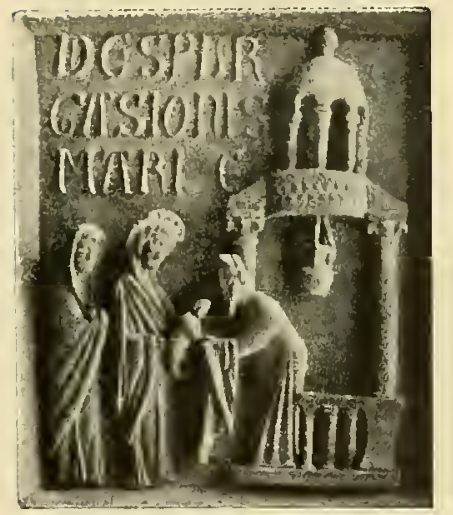

Porta della Cattedrale di Pisa (Boxanxo di PISA)
Leggesi nell evangelo che, compiuto il tempo della purificazione della V'ergine, ella e Giuseppe portarono il fanciullo a Gerusalemme per consacrarlo al Signore, secondo la legge di Mosè, che prescrive anche l'offerta d'una coppia di tortore o di piccioni. Ora a Gerusalemme viveva un uomo giusto chiamato Simeone, il quale era stato avvertito che non avrebbe chiusi gli occhi alla vita senza aver veduto il Cristo. Egli arrivò nel tempio quando i genitori di Gesù giunsero per adempiere il dovere prescritto dalla legge, e si prese nelle braccia il Fanciullo benedicendo Dio, chiedendo di morire in pace, perchè i suoi occhi avevano veduto la luce che illuminerà le nazioni e la gloria d'Israele. I genitori di Gesù si meravigliarono, e Simeone li benedisse, predicendo a Maria i dolori che avrebbe sofferto per il bene degli uomini. Intanto Anna, vecchia profetessa addetta al servizio di Dio nel tempio. presente alla cerimonia, lodava il Signore e parlava del Fanciullo divino a chiunque attendeva la redenzione d'Israele.

Gli evangeli apocrifi aggiungono colori al racconto. Quello dell'infanzia ci mostra il vecchio Simeone che vede Gesù come una colonna di luce, e 
intorno a Maria, recante tutta giuliva il Fanciullo in braccio, una folla di angeli formare un cerchio, come satelliti al seguito del loro Re. L'altro

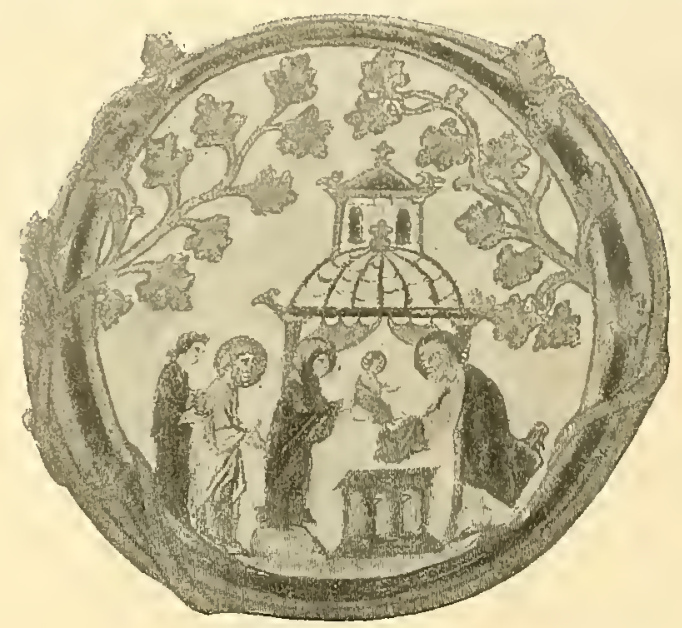

Sacramentario di Drogon. Bibl. Nazionale di Parigi

evangelo della natività di Maria descrive Simeone che adora il Fanciullo, lo prende nel suo mantello, gli bacia le piante de'piedi, gridando: Dio ha visitato il suo popolo! Nellarco trionfale di Santa Maria Maggiore, sin dal secolo v il fatto sacro riceve la sua deteminazione. Maria, come una impe-

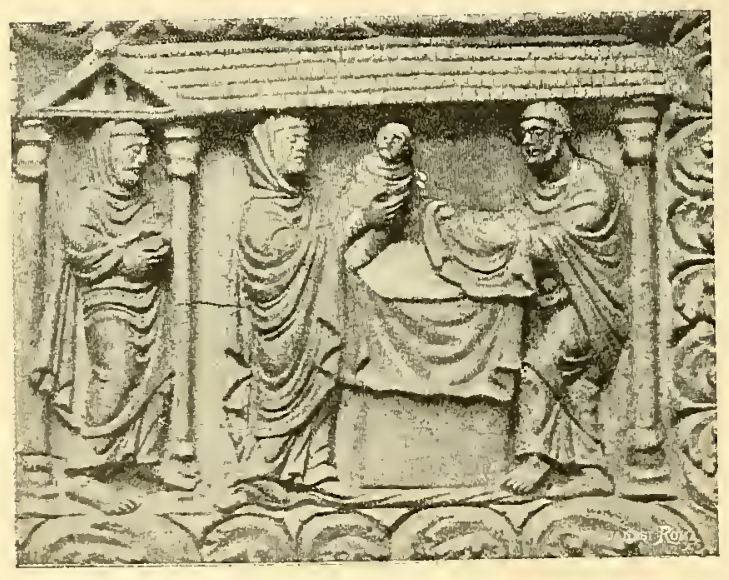

Cofano d'avorio. Biblioteca Nazionale di Parigi

ratrice, si avanza col Bambino, preceduta da Giuseppe e circondata da celesti guardie, verso Simeone che protende le mani velate, mentre la profetessa Anna fa segni di meraviglia. Ma la classica scena grandiosa ben presto si rimpicciolisce, e, quando più tardi si ritrova, non ha più la solennità 


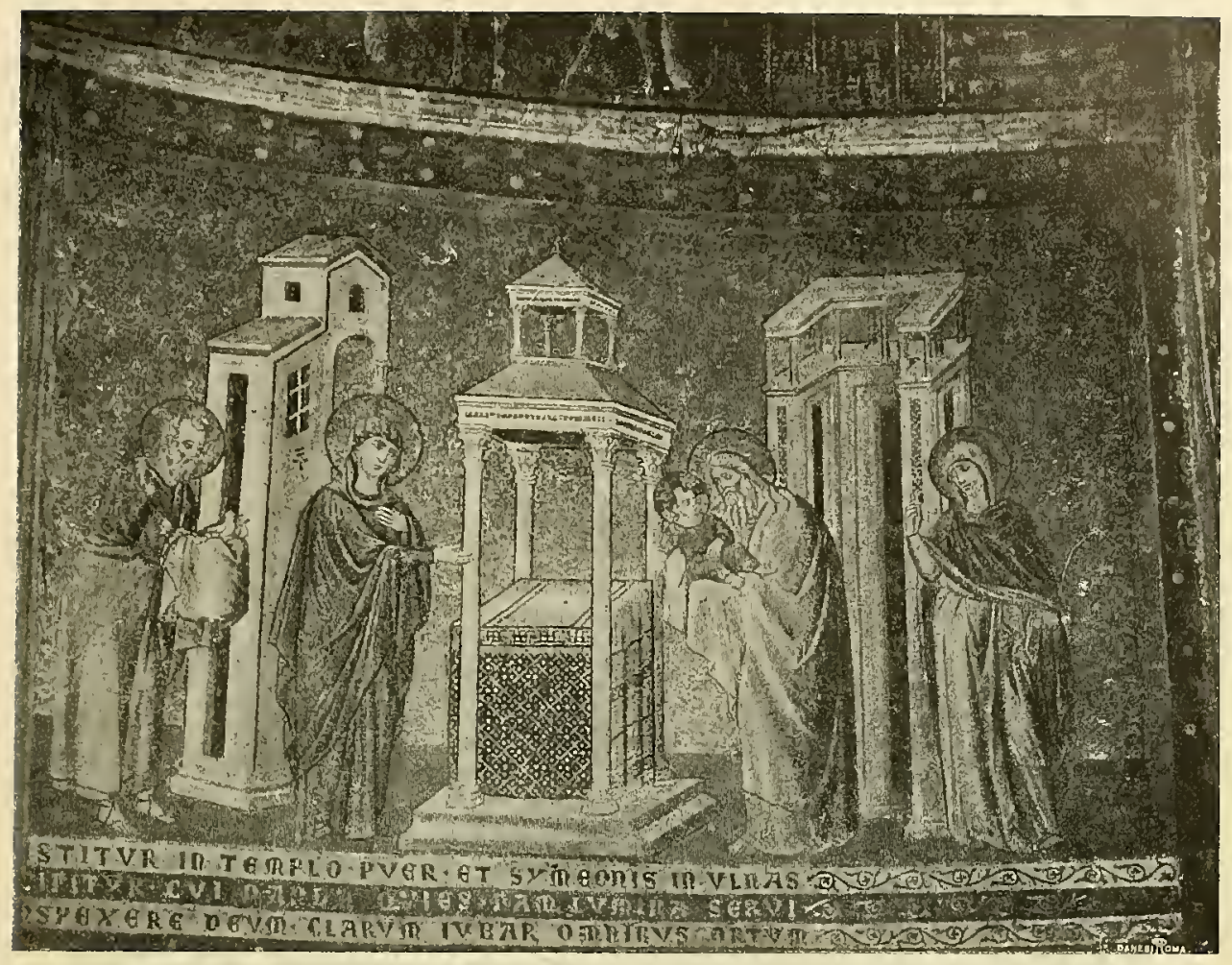

Musaico. Santa Maria in Trastevere in Roma

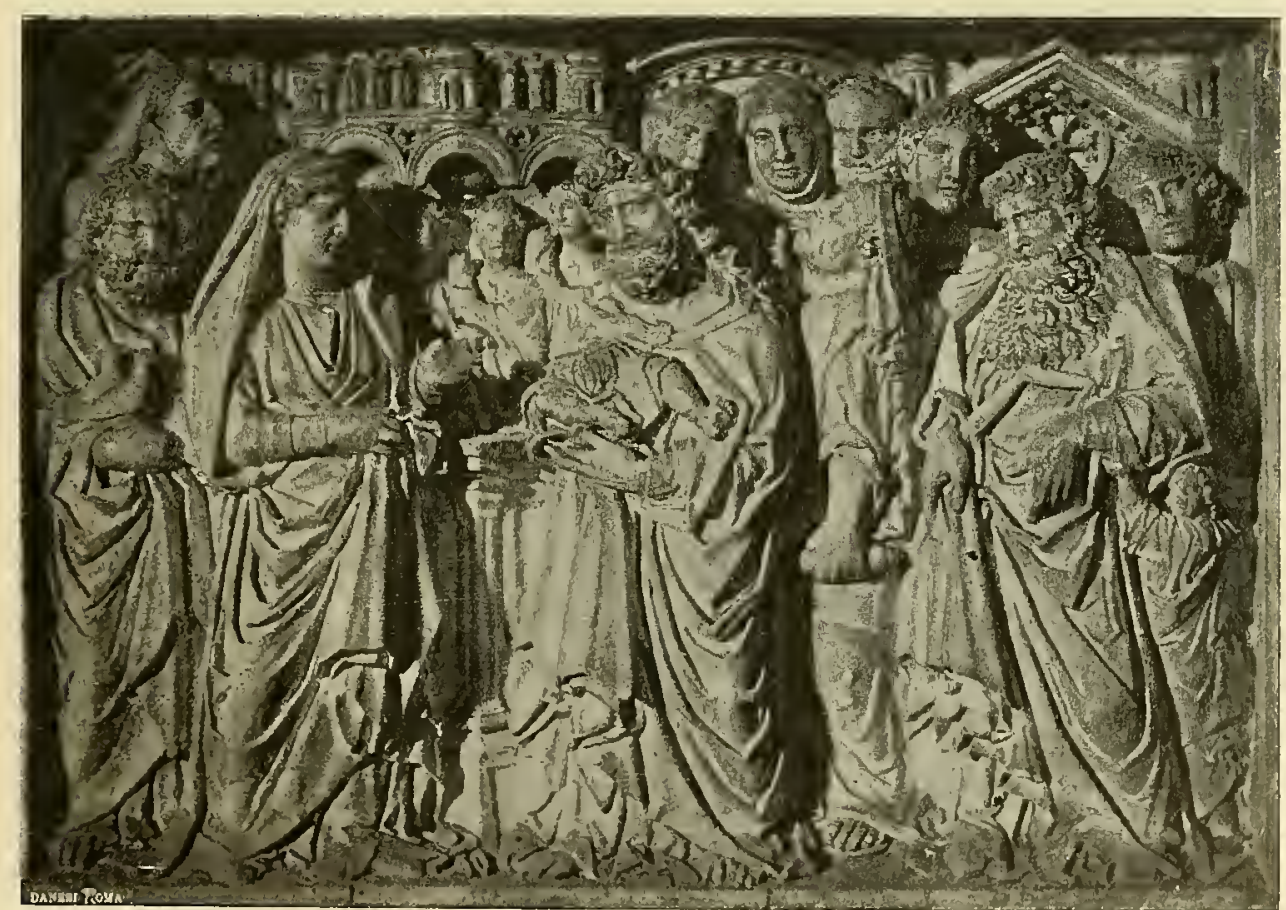

Battistero di Pisa

(NICOLA PISANO) 
storica de'musaici di Santa Maria Maggiore. Nella miniatura del menologio della Vaticana, come nella porta del duomo di Spalato, redonsi i quattro

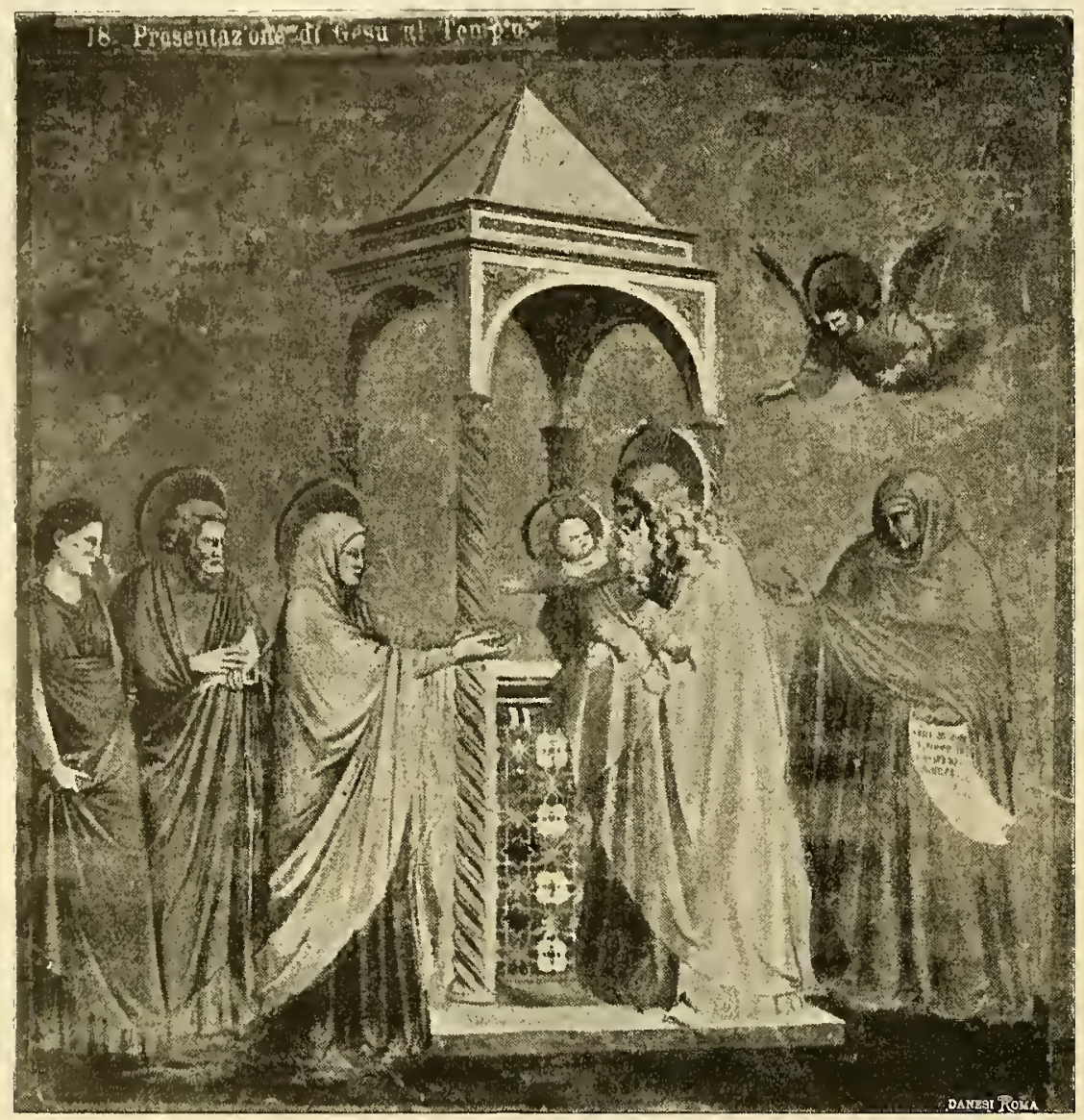

Chiesa dell'Arena in Padova

(Grotto)

personaggi di cui parla l'evangelo, accanto ad un ciborio: Simeone con le mani velate, curvo, in attesa di ricevere il Figlio di Dio dalla Tergine:

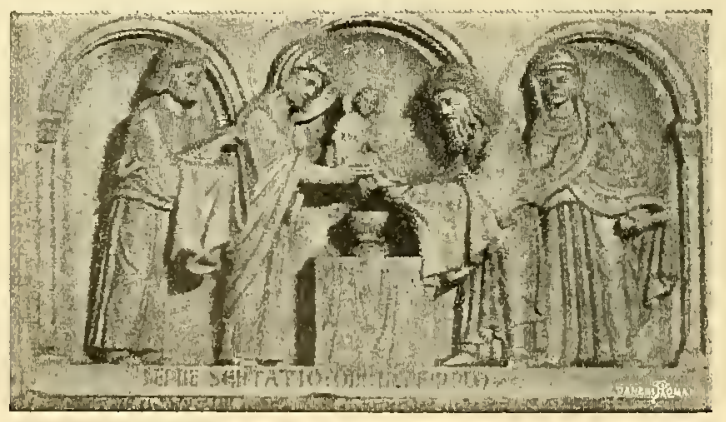

Dal pulpito di San Bartolomeo in Pantano a Pistoia (Guido DA Como) 


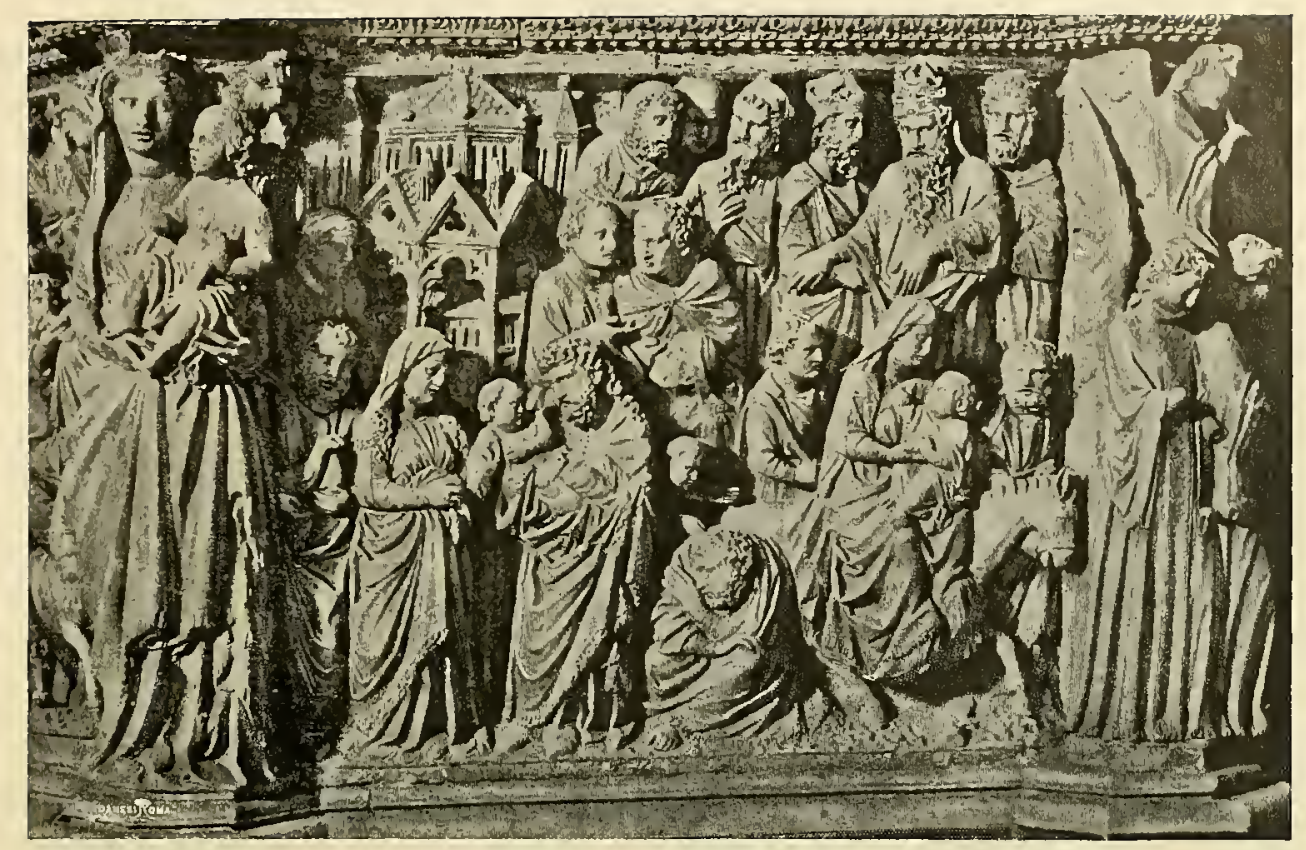

Cattedrale di Siena

( NICOLA PISANO)

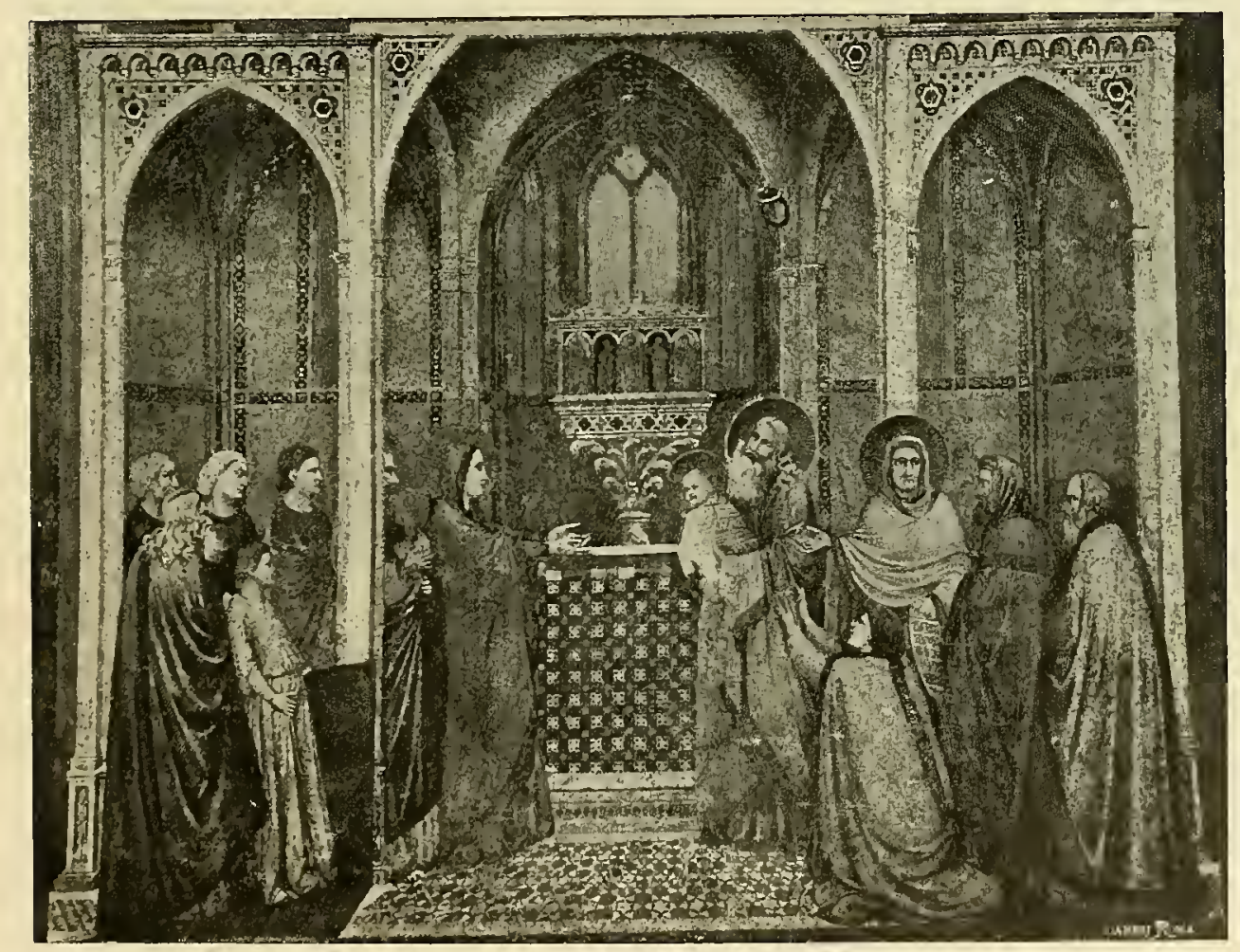

Chiesa inferiore di San Francesco d'Assisi

Giotro) 
San Giuseppe, dietro. con la coppia di tortorelle, e Anna profetessa in atteggiamento ispirato. Cosi per molto tempo rimane distribuita la composizione: solo in seguito il ciborio bizantino terminato a cupola, da cui pendono lampade. si trasforma in un tempio aperto, con corone e lampade appese, e finanche con labari a destra e a sinistra della mensa dell'altare: su questo

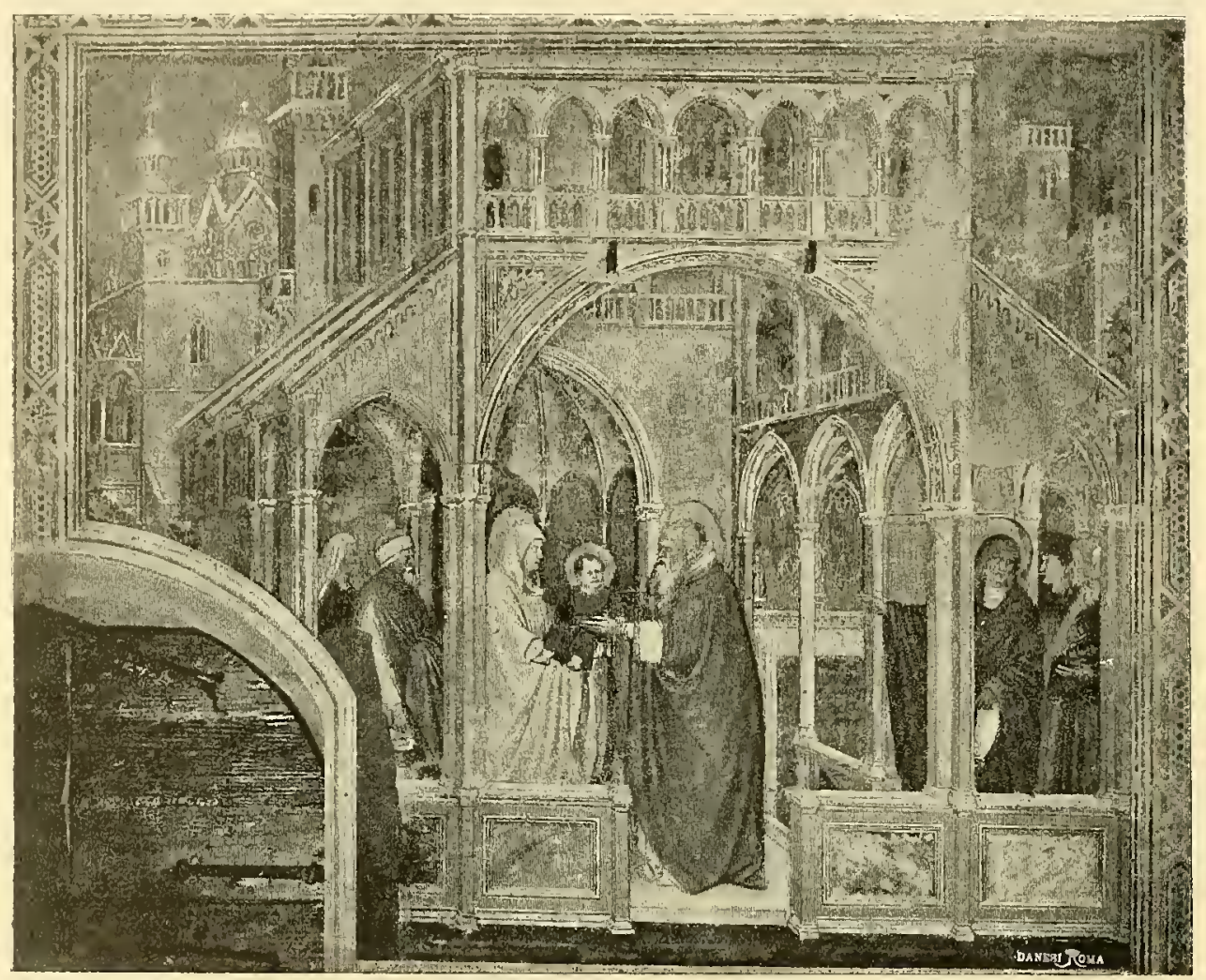

Oratorio di San Giorgio in Padora

(J.ACOPO ArANZI)

redesi un calice, che a poco a poco vien meno; anzi, nel bassorilievo dell Orcagna in Or' San Nichele, invece dell'altare si vede un'ara ardente, indicante il fuoco purificatore. La V'ergine serba un'espressione d'umiltà e di cordoglio; San Simeone abbandona il drappo che gli copriva le mani, e riceve e abbraccia e bacia teneramente il sacro Fanciullo: San Giuseppe, vecchissimo, meditabondo, segue la V'ergine con le tortorelle; la profetessa, con un rotulo, leva gli occhi al cielo, in attitudine di declamare o come incantata. Ma il corteo di Maria e Giuseppe si va rifacendo: ora le ancelle seguono la Vergine e una di esse, inrece di Giuseppe, reca le tortorelle: ora la turba dei parenti 


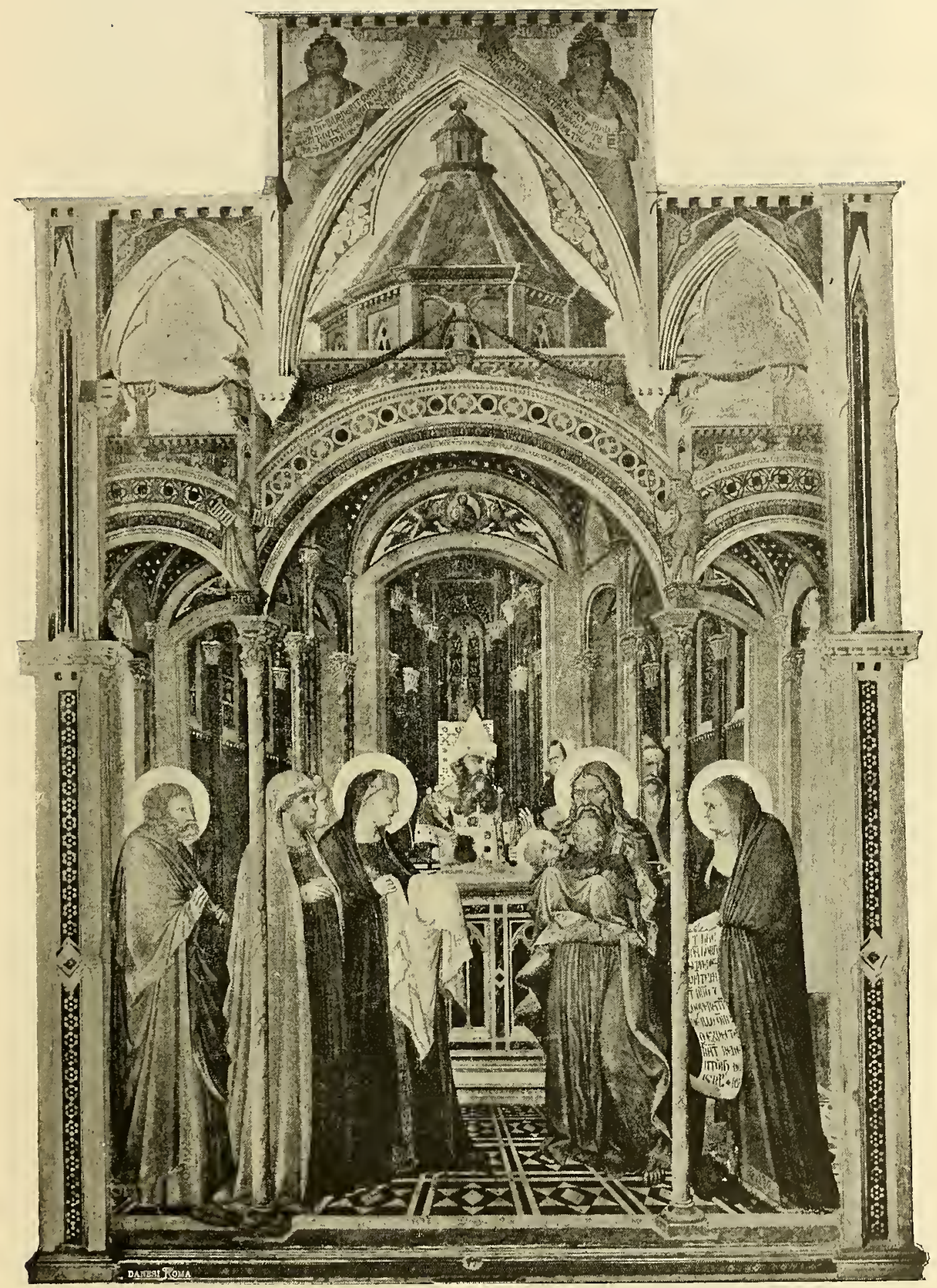

Galleria antica e moderna in Firenze

(AMB. LORENZETTI) 
circonda i personaggi sacri. Nicola Pisano, nel battistero di Pisa, collocò sacerdoti, profeti e angioli nella scena: Naria qui ha il tipo giunonico, meno

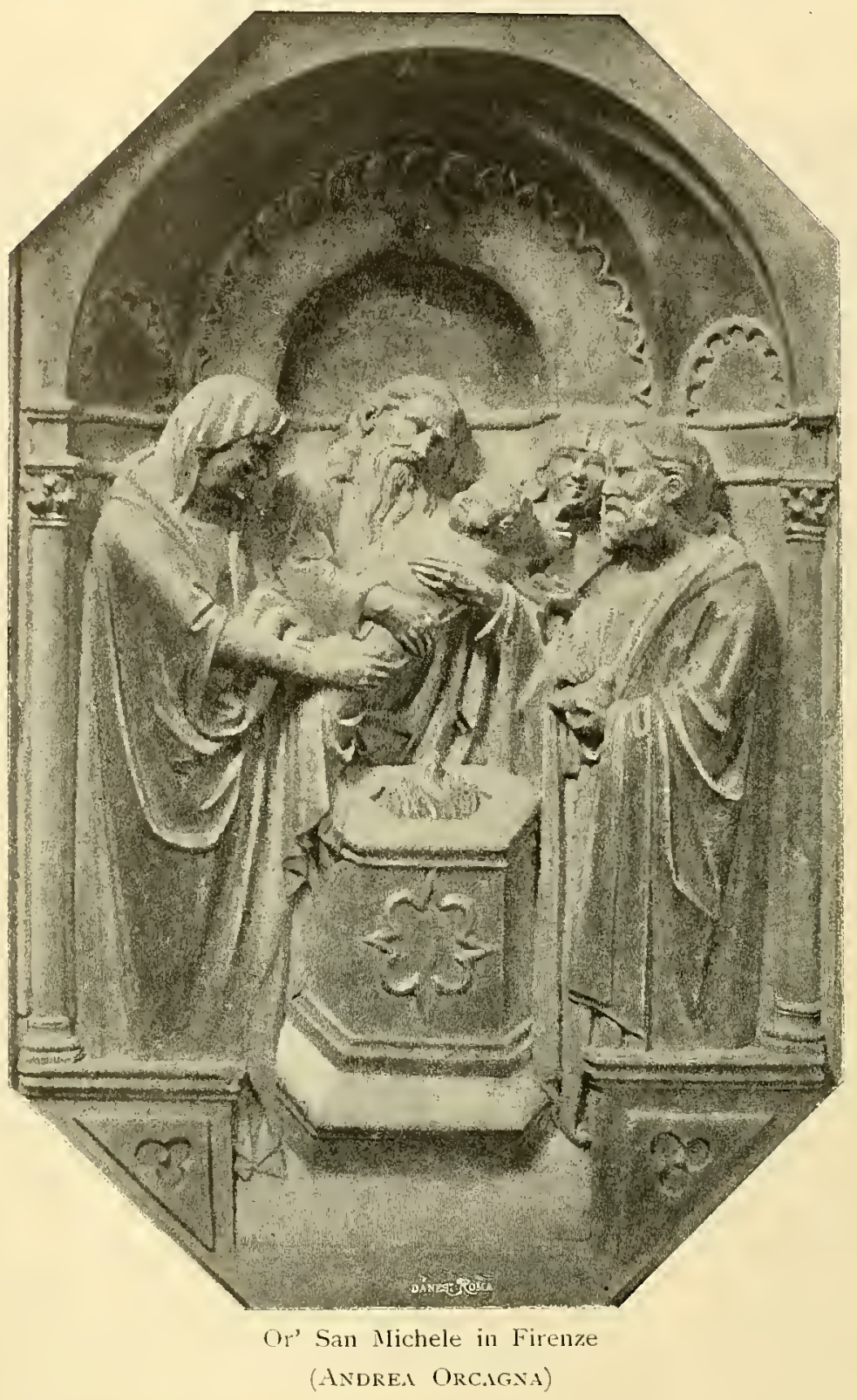

espressivo del tipo che assunse nel pulpito di Siena, ove si mostra animata di timore materno per il Fanciullo che cerca le sue braccia, ritraendosi da quelle del solenne Vegliardo, mentre la profetessa, dietro a San Giuseppe, lo addita con energia a párecchi personaggi meditanti o discutenti fra loro. Giotto, a Padova, attenendosi a questa forma più progredita della 


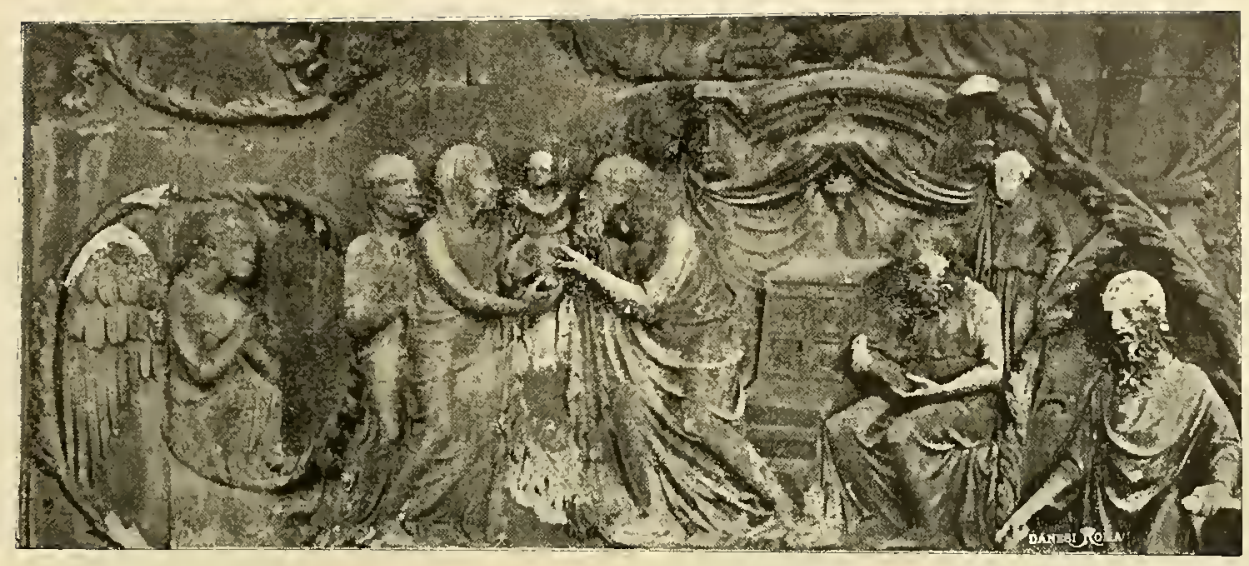

Rilievo della facciata della Cattedrale di Orvieto

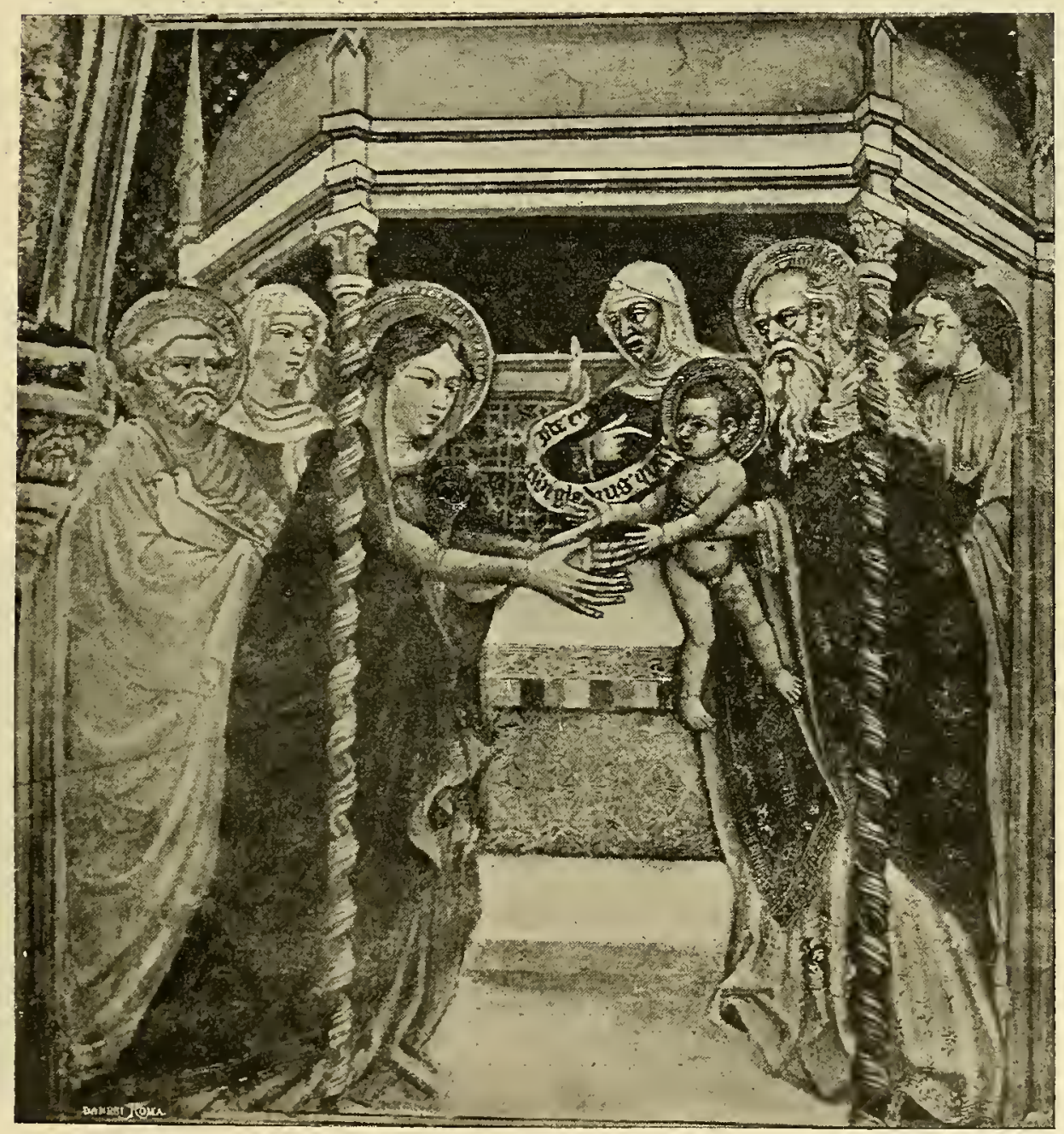

Palazzo de' Trinci in Foligno

(OtTAYlino NeLLI) 
composizione collocò nelle braccia di Simeone il Bambino, il quale accenna con la destra verso la Madre. che gli tende amorosamente le mani. Qui la composizione trovò una grandezza tutta nuova. Simeone, come Giove, con lunga barba e lunghi capelli ricadenti inanellati sugli omeri, fissa intensa-

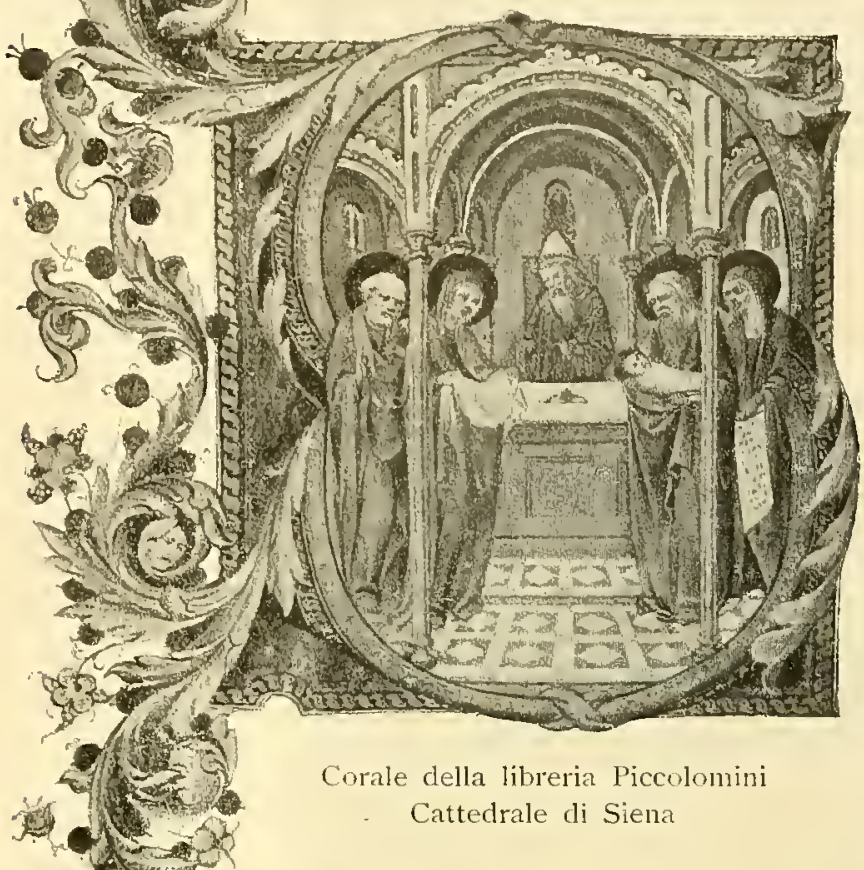
mente il Bambino, quasi gli occhi suoi, prima di chiudersi alla luce, rolessero ben vedere il Figlio di Dio. Questi, nella forza dello syuardo e nel gesto energico, palesa la propria grandezza: la Madre, Giuseppe e una giovane, Salome forse, sono compresi d'ammirazione per le cose dette del Fanciullo da Simeone, e cioè ch egli sarà luce delle nazioni e gloria d'Israele: Maria protende le mani ansiosa per riavere il Bambino: intanto Anna, tutta ravrolta nel manto, tiene dispiegato il rotulo della profezia, e inchinando la testa saluta l'aspettato dalle genti, quasi seguendo il moto che un angelo fa in alto sopra il suo capo.

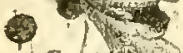

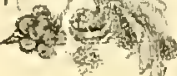

Giotto riassume così le composizioni dei maestri che lo precedettero: il Dante della pittura cristiana fece vibrare tutti i sentimenti umani nell'opera sua. Guido da Como, nel pulpito di Pistoia, sa esprimere la venerazione di Simeone e l'estro profetico di Anna; lo scultore de' bassorilievi della facciata d'Orvieto rende la maestà regale del Bambino e l'ansietà di Simeone; Nicola P'isano, nel pulpito di Siena, dà al Pargolo la sua istintiva timidezza; ma Giotto coordina tutto ed anima tutte le figure.

La scena rimase per gran tempo inalterata o quasi, cosi che Jacopo Avanzi nell'oratorio di San Giorgio a Padova non vi aggiunse di suo altro che la magnifica architettura di un tempio. Il Bambino ha l'aspetto di un dominatore nell'energia della

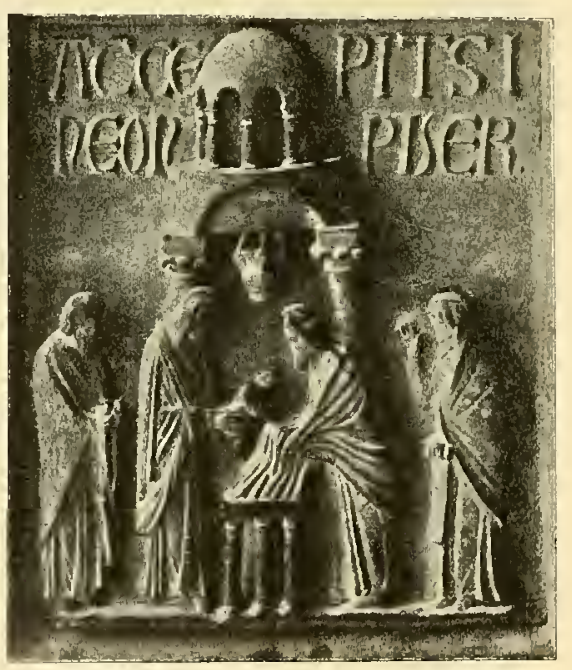

Porta della Cattedrale di Pisa (Boninxo DA P1SA) 
testolina; Anna ha il rotulo nella destra, e con l'altra addita al popolo il Redentore; Simeone stringe con le mani il corpicciuolo di lui: San Giuseppe vien dietro con le tortore in un canestrino. Gentile da Fabriano poi, nel frammento di predella ora nella Galleria del Louvre, si prova a raccoglier meglio la composizione, la quale si svolge come nell' interno di un battistero eretto

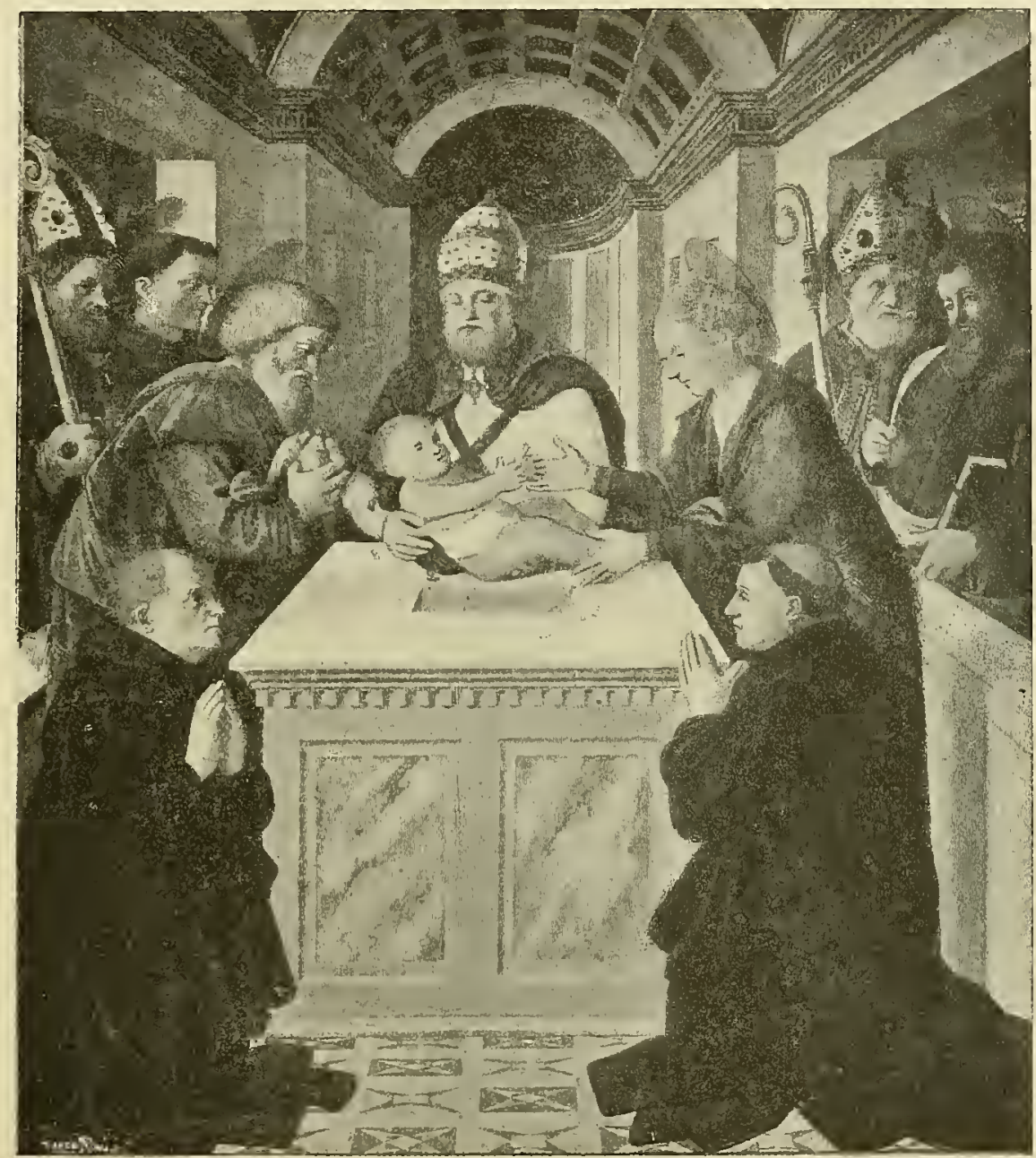

Chiesa dello Spirito Santo in Prato

(Fri Fllippo Lippi)

nel mezzo d'una piazza circondata da case gotiche e da portici. La Vergine, con un ginocchio piegato, presso l'altare, tende le mani al Figlio che cerca le sue braccia, mentre Simeone tiene il corpicciuolo divino nelle ampie pieghe del manto. Due donne fiorentine s'appressano curiose al battistero; dall'altra parte un mendicante e una vecchia cadente, curva sul bastoncello, sembrano ascoltare avidamente le parole che escono dal sacro luogo. 


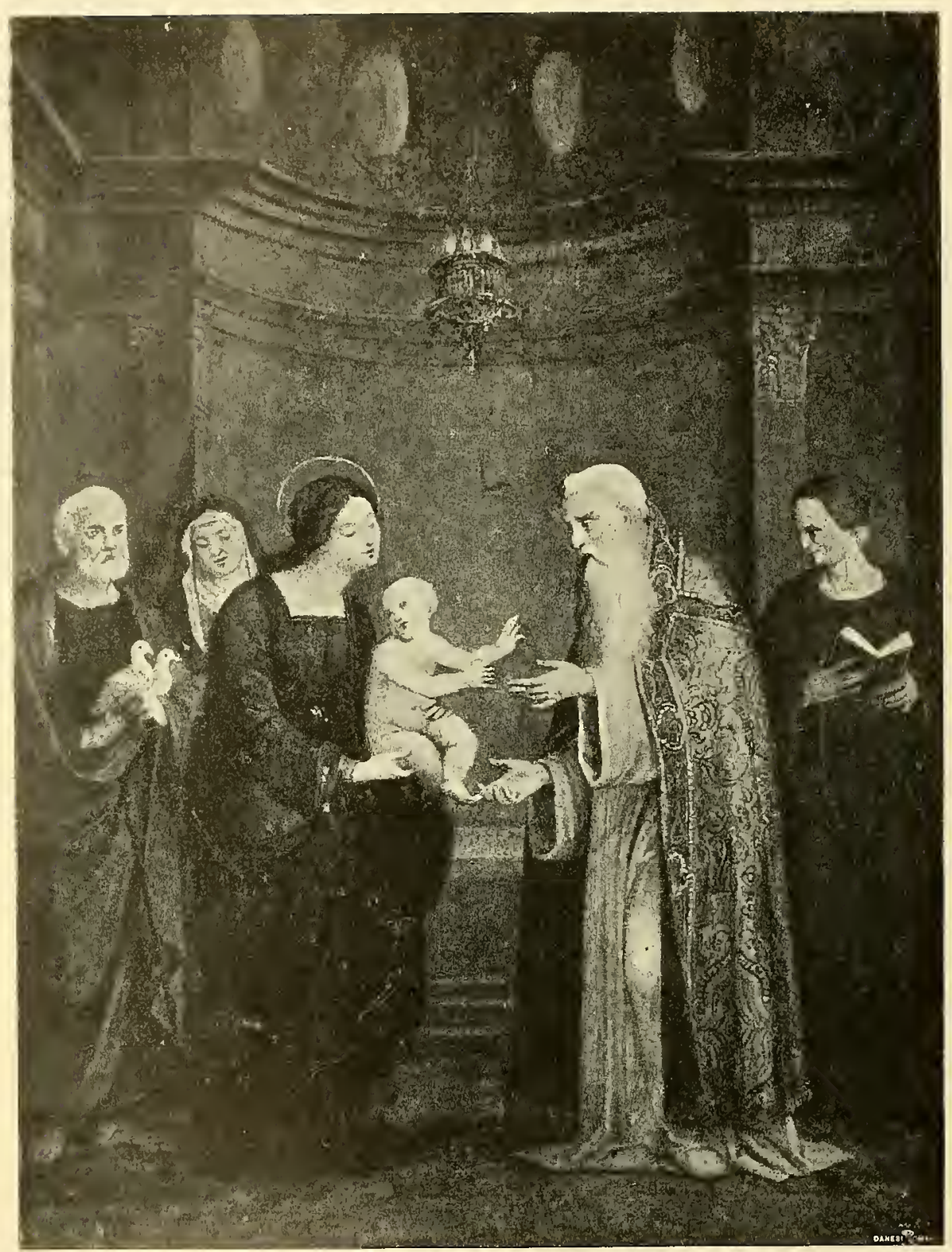

Galleria comunale di Cesena

(FraNCIA) 


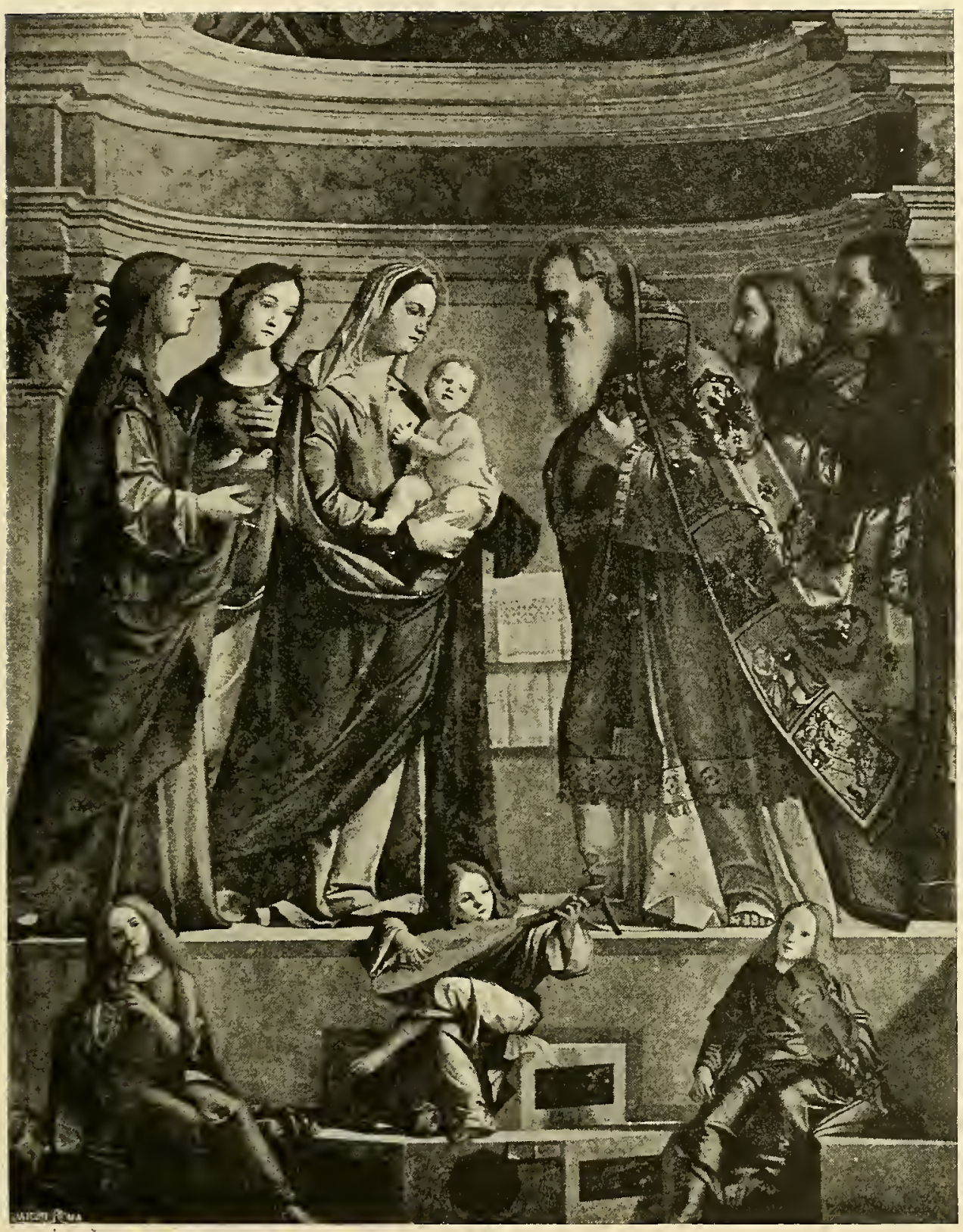

Galleria di Venezia

(VITTORE CARPACCIO) 
Verso la fine del Quattrocento e al principio del secolo successivo la scena si popola di Santi nel quadro del Francia nel Campidoglio e in quello del

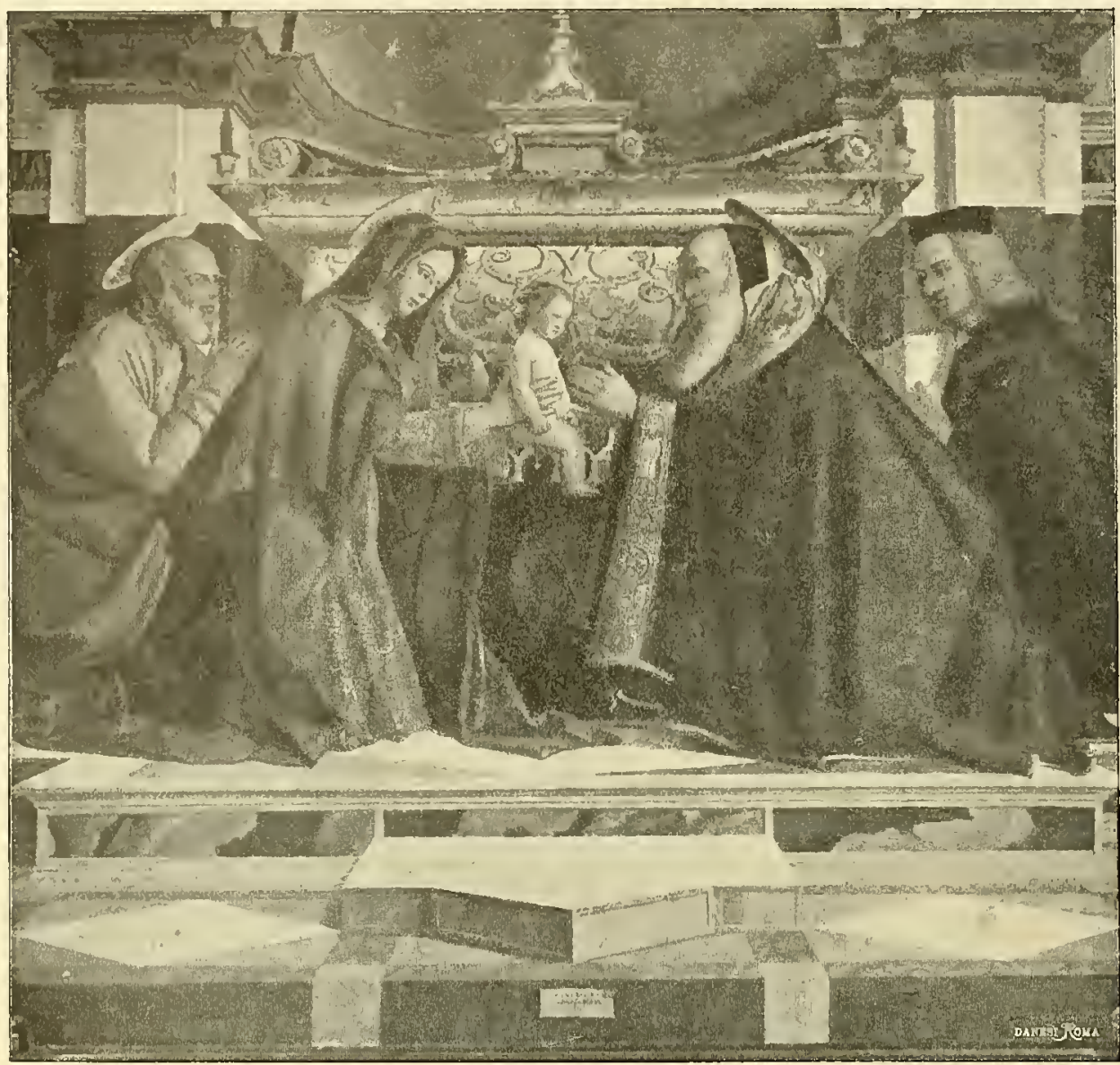

Museo Civico di Vicenza

( BARTOLOMEO MONTAGNA)

Carpaccio dell'Accademia di Venezia; l'uno e l'altro artista rendono la scena divotissima, tutta piena di sacra unzione, benchè il Carpaccio, di natura più vivace, faccia anche intervenirvi tre angioletti musicanti, orchestra graziosissima innanzi al palco della cerimonia. Simeone è divenuto un vescovo col piviale ricamato a fiorami, e i Santi adorano con lui il Redentore. Qualche volta, come nella predella dell'Albertinelli a Firenze, San Giuseppe ed altri tengono i ceri divotamente. Dall'uso antico di una processione con ceri, nella festa della Purificazione, entrava così un ricordo nella scena; il racconto dell' evangelo si traduceva in una cerimonia religiosa co' riti cattolici. Non manca nel quadro dell'Albertinelli il chierico col turibolo, e Simeone 
porta una tiara papale. Il Carpaccio, il Francia e l'Albertinelli dimenticano la profetessa Anna, o meglio questa perde il rotulo, l'estro profetico, e semplicemente, con le mani giunte, adora. Non la dimenticò il Luini a Saronno,

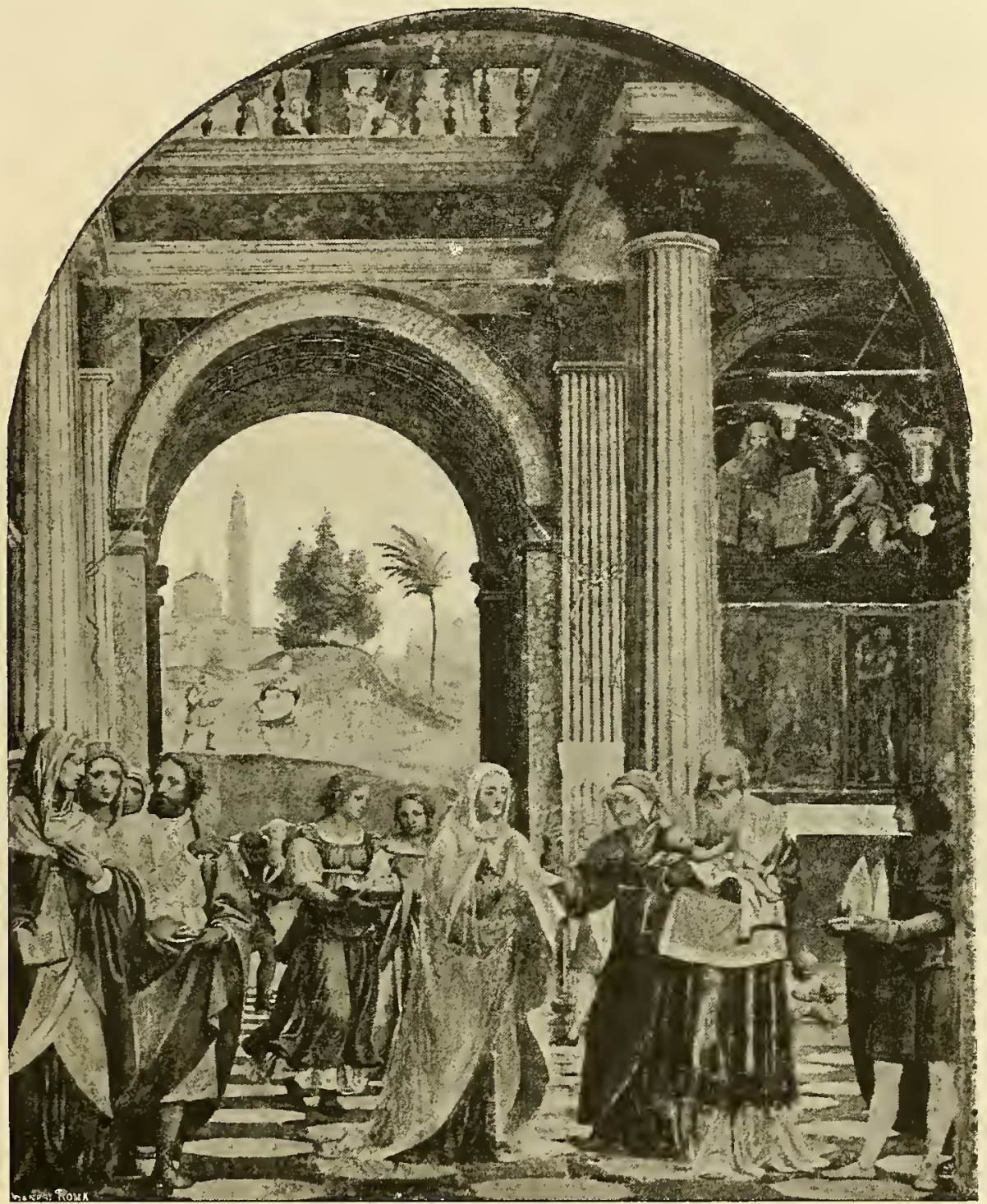

Santuario di Saromno

(BERN. LUINI)

ove svolse popolarmente la scena con nobiltà tutta sua, nel dipingere la profetessa come una vecchia comare lombarda. Ma quella è una delle ultime forme in cui l'arte si avvince ancora all'antica tradizione e la ravviva col sentimento del vero. La Vergine adora a mani giunte avanzandosi verso il Bambino, che volge la testa e $\mathrm{i}$ lucenti occhietti e sembra aspettarla desideroso. 
Un giovane in figura di elegante paggio tiene la nitra vescovile in un vassoio: alcune fanciulle inoltrano con le tortorelle, e un contadino le segue con una pecora sulle spalle, come un Buon Pastore antico; Giuseppe parla a parecchie donne meravigliate, belle e divote. È una commedia sacra che si rappresenta in un tempio marmoreo: la vecchia profetessa in cuffia contrasta con Maria, la quale sembra una sposa che vada all'altare: il bel paggio ricorda quelli delle corti magnifiche dei signori italiani. È una commedia religiosa, quale realmente poteva rappresentarsi a Milano nelle feste, e il Luini la tradusse con sincerità, col buon sorriso che traluce da ogni opera sua.

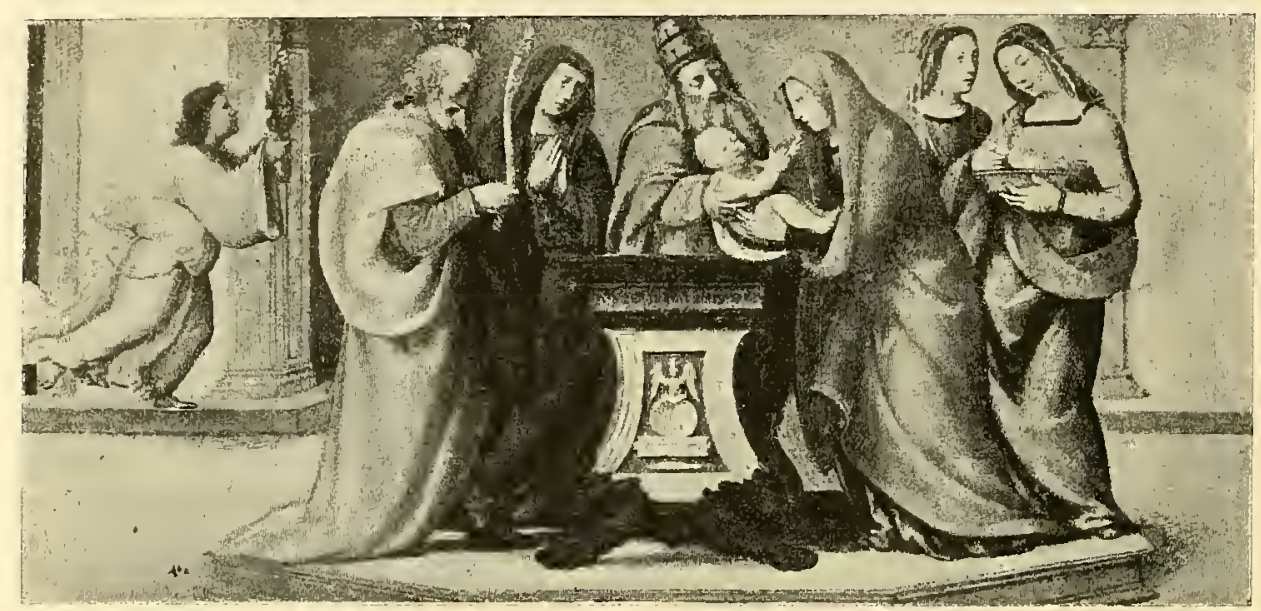

Galleria degli Ufizizi in Firenze

(Mariotto Albertinelli) 


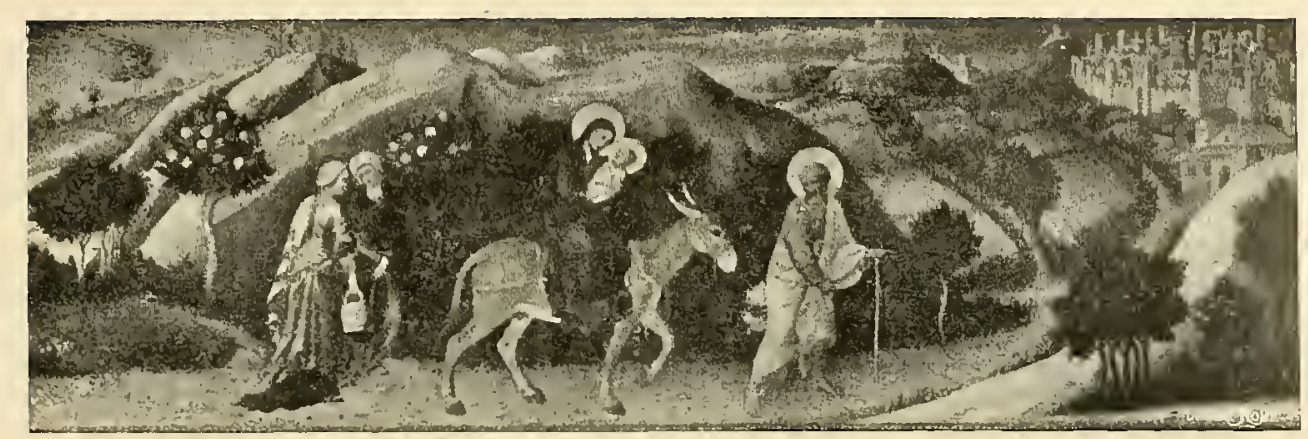

Galleria antica e moderna in Firenze

(Gentile da Fabriano)

\section{La fuga in Egitto.}

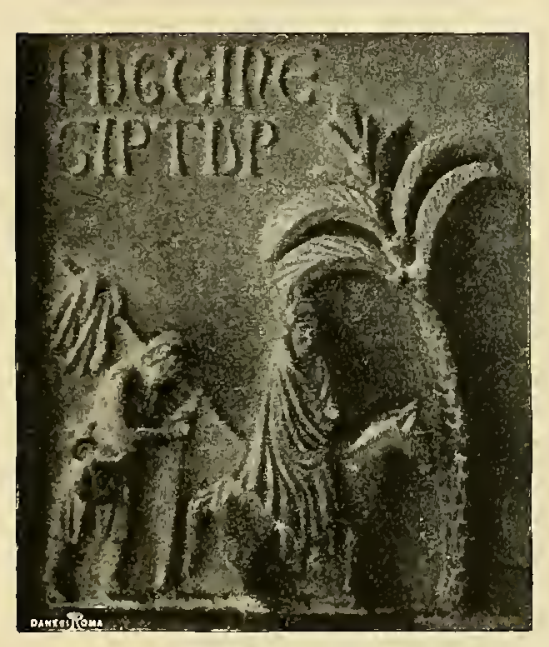

Dalla Porta di bronzo di Bonanno a Pisa
Nell' istoria di Giuseppe il falegname, Gesì stesso racconta che il pio vegliardo fu ayvertito in sogno de truci pensieri di Erode, " e alzandosi prese mia madre Maria, che mi portò nelle braccia. E Salome li seguì per accompagnarli nel viaggio, in Egitto, ove. lasciata la sua casa, stette un anno intero * Meno semplicemente nell' evangelo dell' Infanzia, noto per la traduzione francese fatta verso il xirn secolo, è narrata la leggenda. Cadono gl'idoli al passaggio del Figlio di Dio, suonano per l'aria strumenti musicali come innanzi al corteggio di un re, sgorgano nuove fonti sotto a un sicomoro. dileguano mostri, fuggono banditi, guariscono infermi e produce balsamo la terra. L'immaginazione orientale aggiunse i più strani particolari al racconto: metamorfosi umane, sogni, miracoli, meraviglie: i venti pronti alle vendette del Dio fanciullo, le belve obbedienti a' suoi cenni. In un'altra "Istoria della natività di Maria e dell'infanzia del Redentore ", questi è adorato da draghi, leoni, leopardi e lupi. Nel terzo giorno del cammino Maria era stanca nel deserto per l'ardore troppo vivo del sole e, vedendo un albero, disse a Giuseppe: Riposiamoci alquanto sotto la sua ombra. Giuseppé si affrettò a condurla presso l'albero, e la fece discendere di sella. 
Sedutasi, Maria alzò gli occhi alla vetta della palnna, e nel vederla coperta di frutta, disse a Giuseppe: Desidererei uno di quei datteri, se fosse possibile. E questi a lei: Mi stupisco della tua dimanda: perchè tu vedi quanto

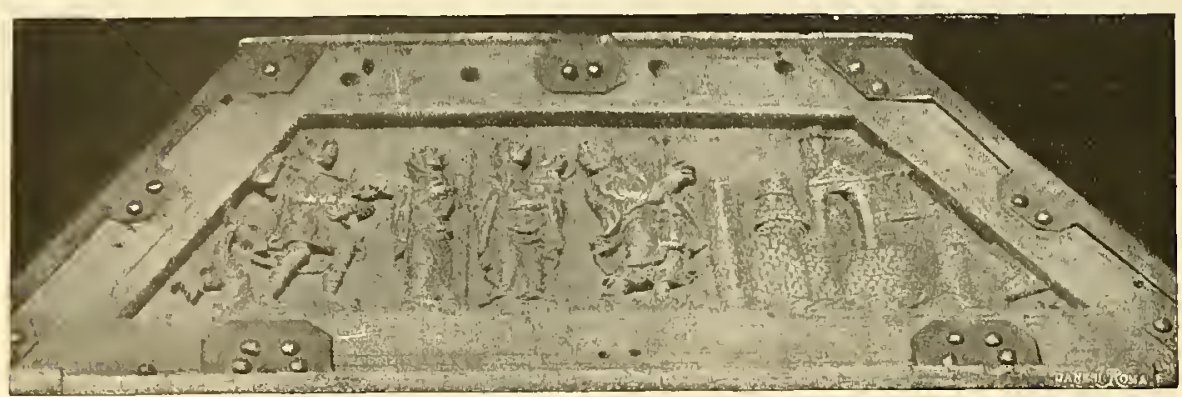

Coperchio di cassettina d'avorio al Louvre. Secolo $x$

sieno elevati i rami della palma. Allora il fanciullo Gesù, che era nelle braccia della Vergine, disse alla palma: Albero, piega i tuoi rami e nutriscila de' tuoi frutti. Tosto la palma chinò la cima sino ai piedi di Maria.

La rappresentazione cominciò a svolgersi nel $x$ secolo. Nel menologio della Vaticana non vi è Salome dietro la Vergine, ma un servo con un

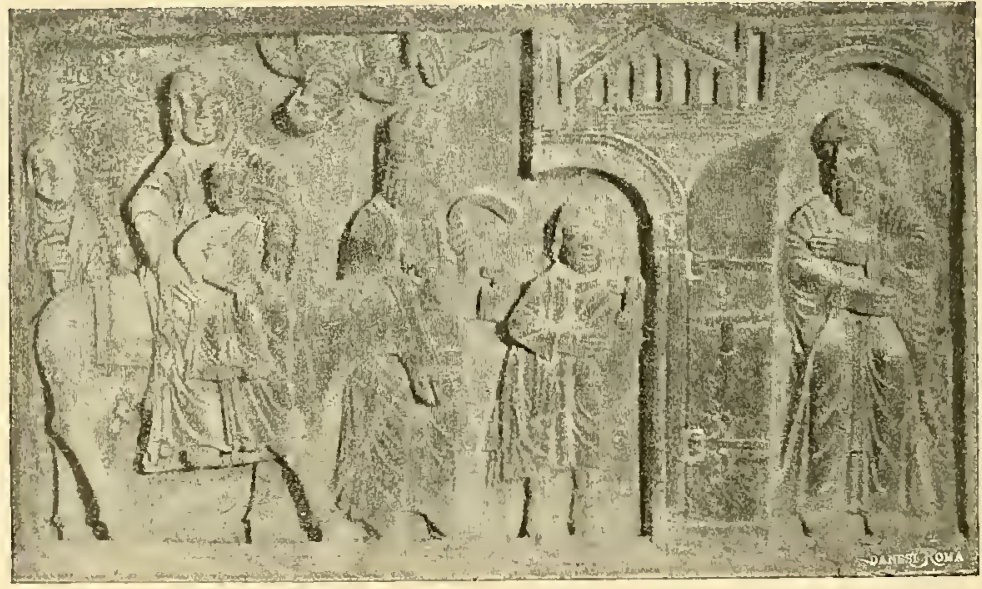

Bassorilievo romanico. Palazzo arcivescovile di Fano

cesto appiccato a un bastone, simile al pastore che si vede dietro Anna e Gioacchino, di ritorno dai campi. Maria, sopra un asinello guidato per la cavezza da Giuseppe, è rappresentata come nelle immagini sacre, col Bambino visto di faccia, benedicente lo spettatore quasi da sull altare. Il gruppo della Vergine col Figlio è come staccato dalla sua cornice. Innanzi a loro si apre la porta merlata d'una città, personificata, secondo gli antichi criterî 
dell'arte, in una donna con diadema turrito, protendente le braccia coperte da un drappo, in segno di devozione.

È un riflesso d'arte classica in questa figura rappresentante la città dell' Egitto, Alessandria forse, ove erano vòlti i fuggenti; come nella porta socchiusa della città medesima ci sembra vedere un ricordo delle porte rappresentate sulle arche de' defunti dall'arte tuscanica e dalla romana. Nella cassetta del Louvre, attribuita allo stesso secolo, le reminiscenze classiche

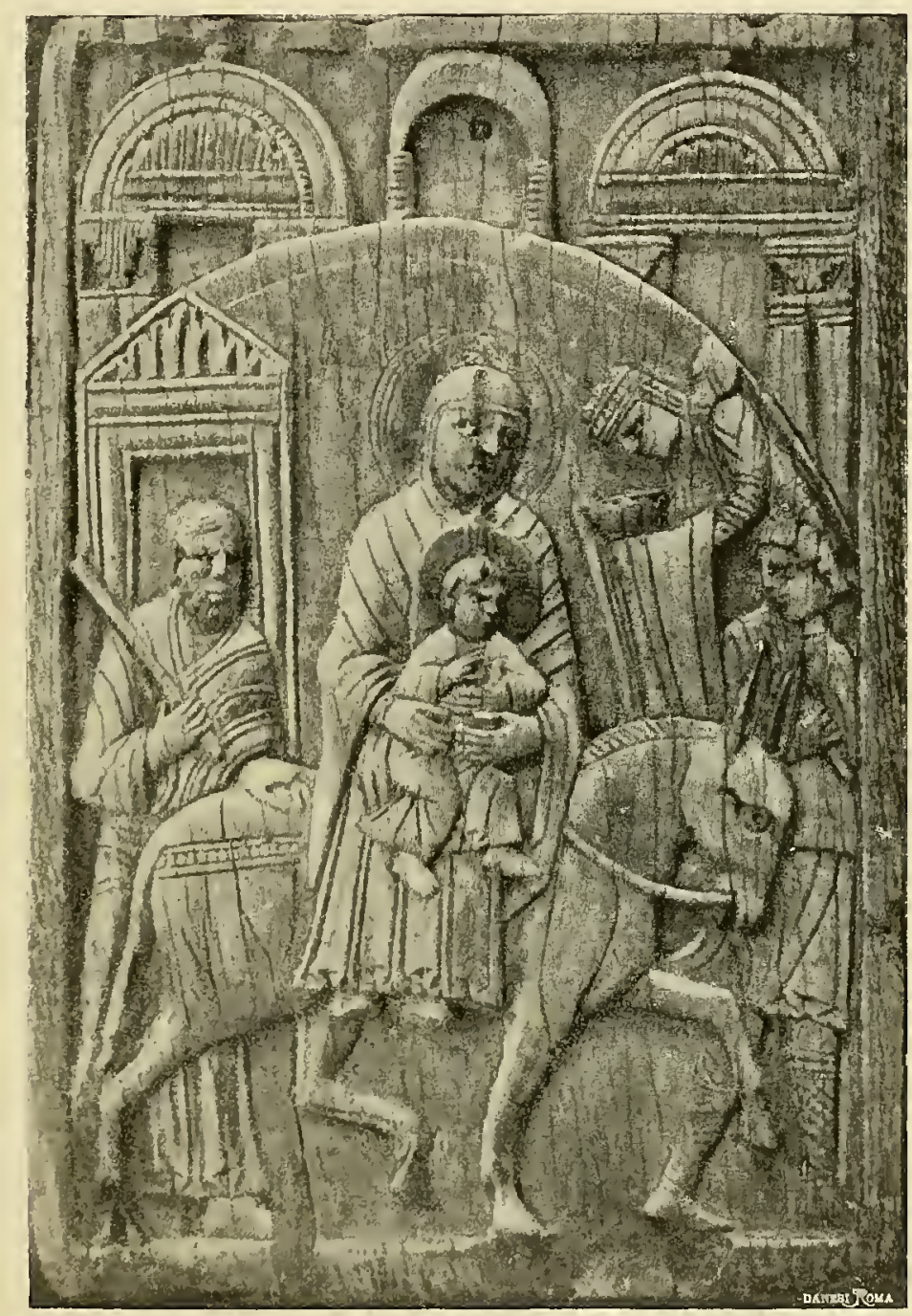

Avorio del Museo Civico di Bologna

spariscono: la Vergine, perduto l'aspetto sacro, è una povera donna che porta il suo bambino in fasce sul grembo, non il Redentore benedicente 
come nel menologio. Ella s'avanza a piedi preceduta da Giuseppe, che nella sinistra tiene un gran bastone viatorio e con la destra addita una

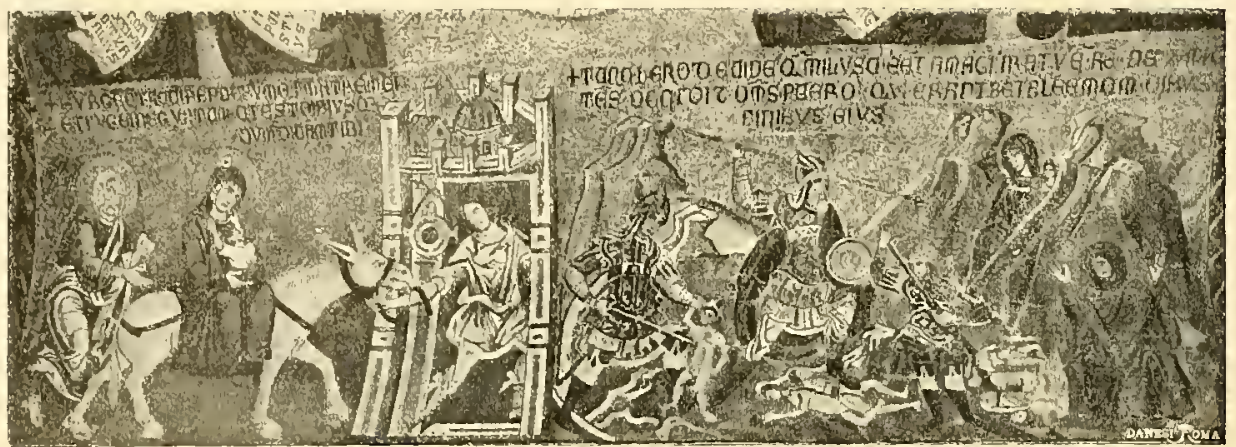

Mlusaico del San Marco in Venezia

città murata, fiancheggiata da torri, con una chiesa, un battistero e un campanile. Salone, avvolta come la Vergine nello scialle, la segue, munita di

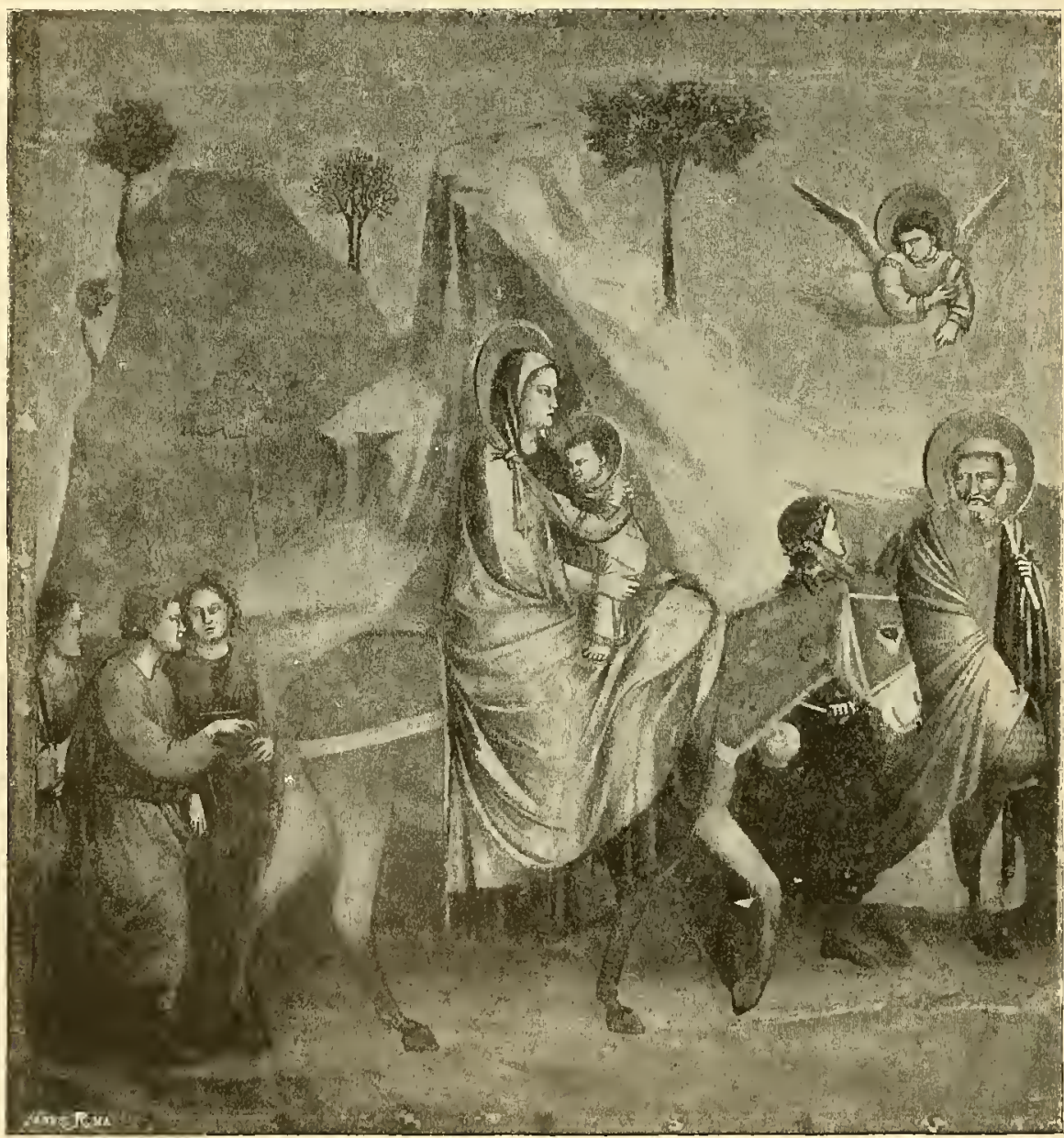

Cappella degli Scrovegni in Padova

(Giotтo) 


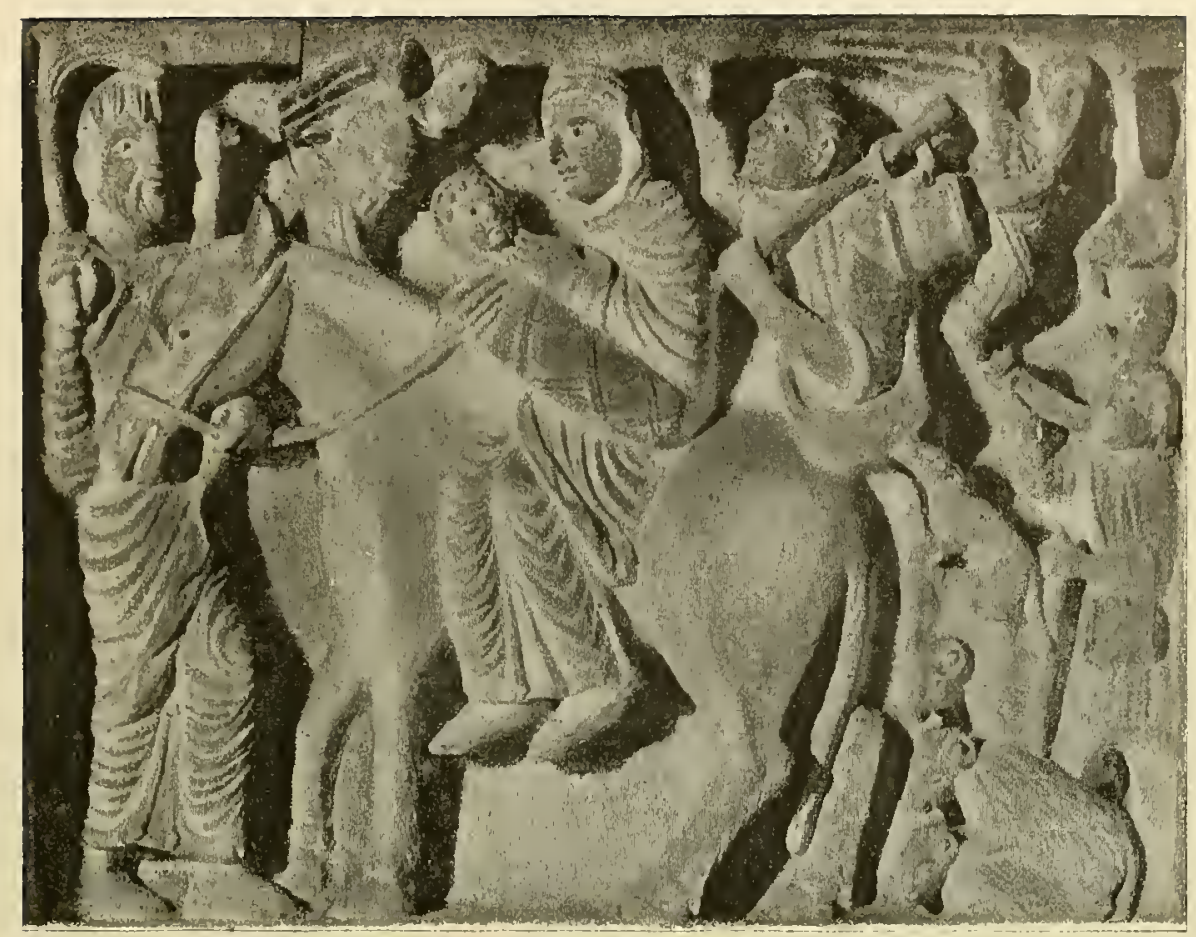

Pulpito di Groppoli presso Pistoia. Anno Ir9.t

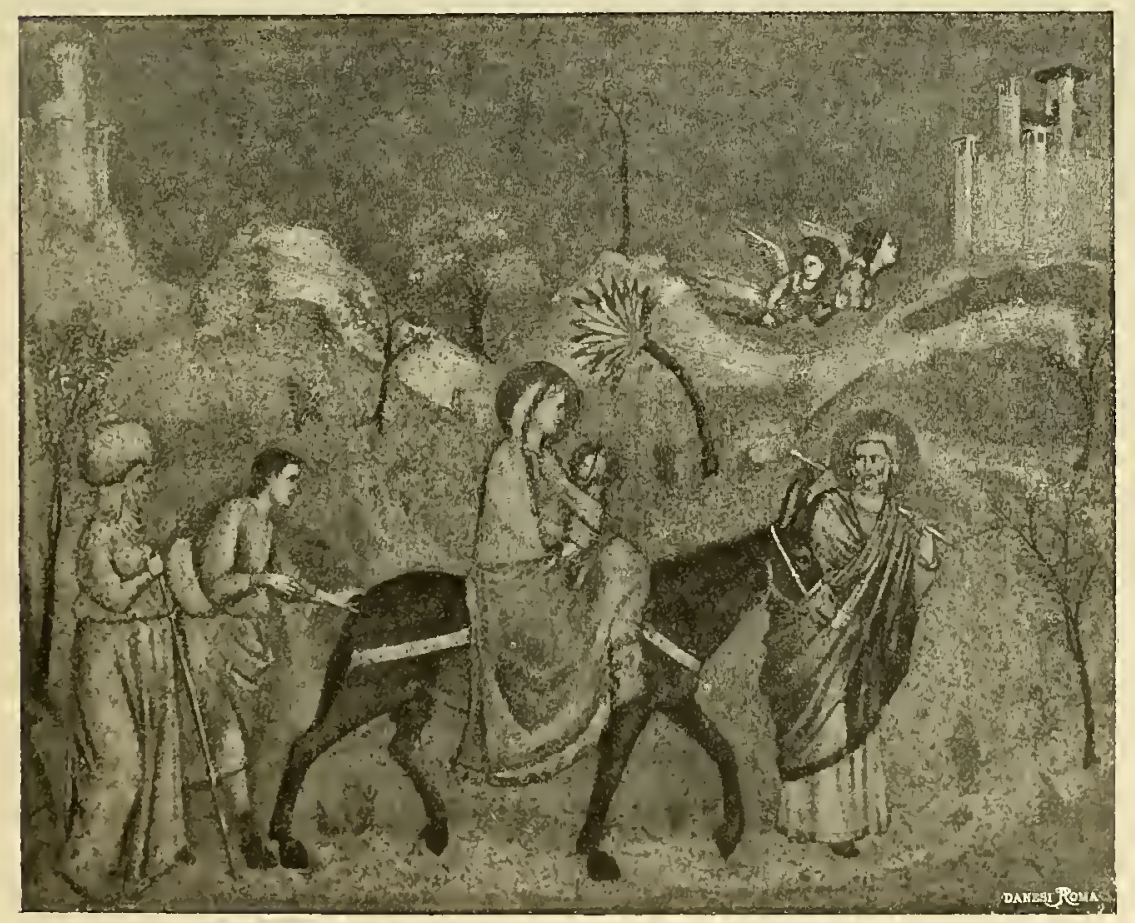

Chiesa inferiore di San Francesco in Assisi

(Grotto e seguaci) 
un lungo bastone da pellegrino, e un villico cammina dietro a lei, recando cibi per il viaggio. Questa rappresentazione è tutta occidentale, perchè i

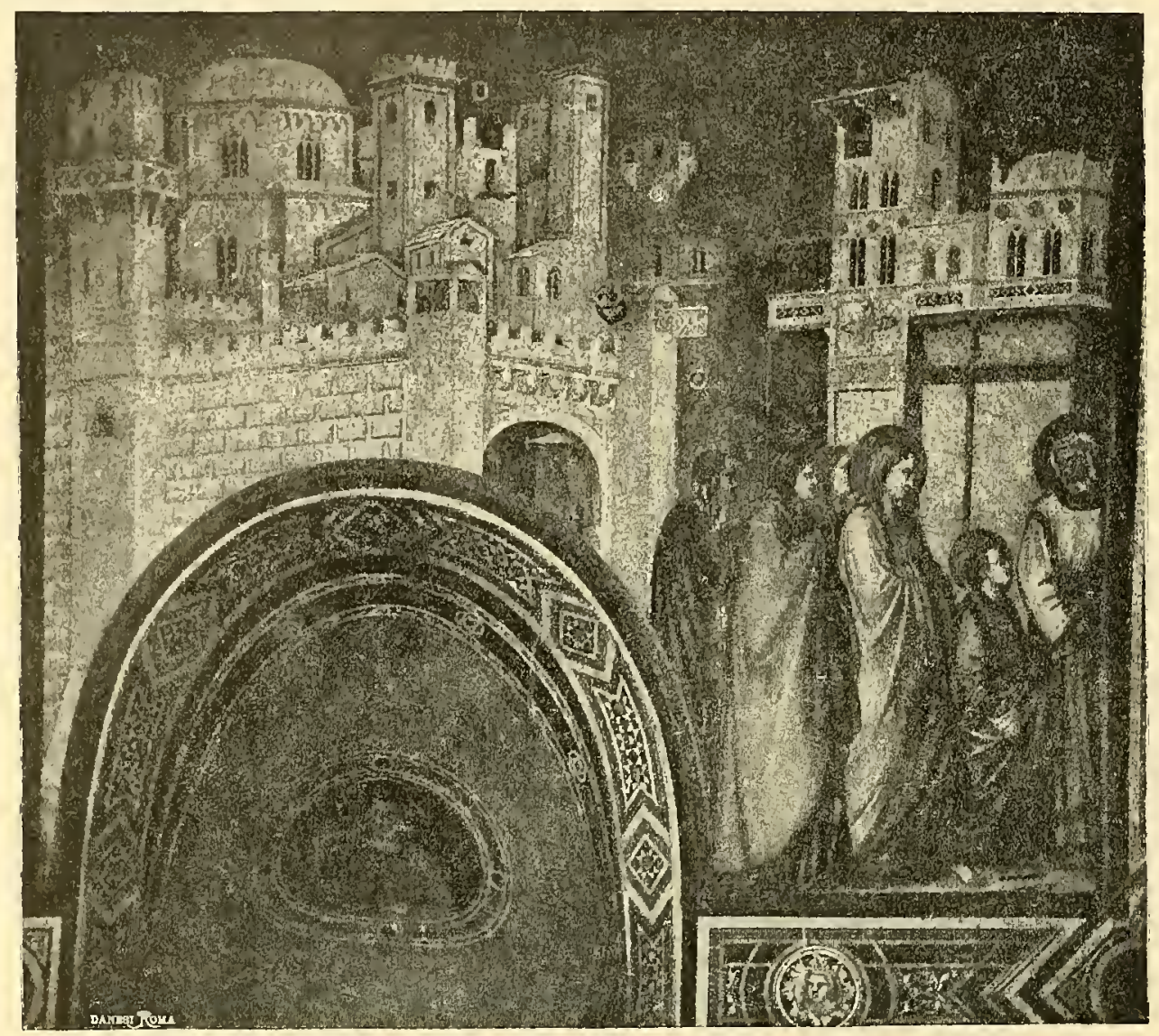

Ritorno da Nazaret. Affresco della chiesa inferiore di San Francesco in Assisi

(Grotro)

Bizantini non dimenticarono di segnare innanzi alla porta della città, verso cui son diretti i profughi, la figura simbolica della città medesima genuflessa . o china. Così si vede nella Biblioteca Nazionale di Parigi, nel manoscritto greco (n. 74), ove la scena corrisponde pienamente a quella del menologio, e la Vergine sembra in cattedra, piuttosto che sul dorso di un asino, e il Bambino sembra che benedica i fedeli; così pure nel manoscritto greco della Vaticana (n. 1156), ove la donna personificante la città cade quasi bocconi sotto l'arco della loggia d'una torre. La scena è più famigliare e scevra di simbolismo presso gli Qcciclentali. Nella porta di Pisa si vede in un compartimento la Vergine sull'asino presso la palma piegata, e San Giuseppe che vien dietro con un cesto sulle spalle, appoggiato al bastone; non 
altro. A Benevento e nel paliotto di Città di Castello, San Giuseppe porta sulle spalle il Fanciullo e guida per la cavezza l'asinello su cui sta Maria. Nella porta del duomo di Spoleto San Giuseppe è innanzi al somiero con una cesta infilzata in un bastone, e Salome sospinge con una mano lanimale. Nel pulpito di Groppoli (a. I 194), presso Pistoia, Giuseppe, trae dietro l'asino, tenendo uno staffile. Sulla porta di bronzo di San Zeno in Verona, il beato Vecchio tiene una ferula; ma a Groppoli, come a Città di Castello, si aggiungono gli angioli a guidar la sacra comitiva e pro-

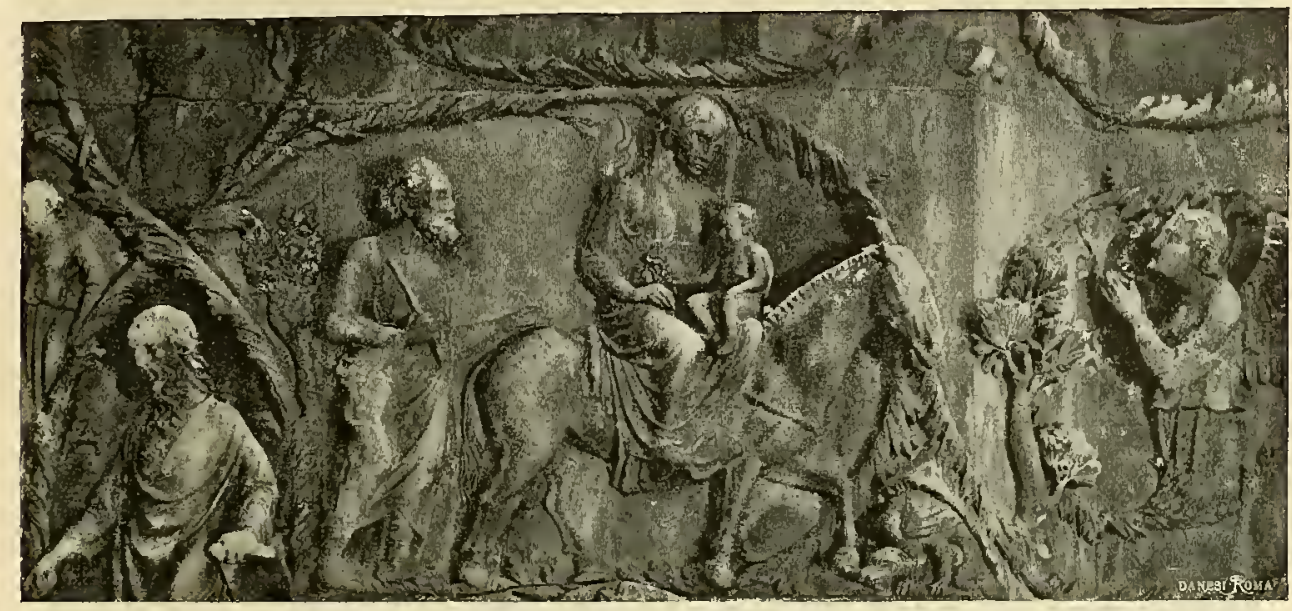

Dalla facciata della Cattedrale di Orvieto. Secolo XIV

teggerla. Più ci allontanianı dai tipi e dagii influssi bizantini, più la Madonna, invece d'essere rappresentata di faccia e col Bambino pure di faccia, si volge di profilo; anzichè nella clamide si avvolge in uno scialle, e il Bambino si vede tutto fasciato. Se si confronta la rozza ma espressiva scultura nell'Arcivescovado di Fano con quella del pulpito di Groppoli, si vedrà chiara la differenza. Giotto ad Assisi e a Padova raccoglie tutti gli elementi elaborati dal medio evo e li vivifica. Sembra essersi ispirato a due versioni della leggenda; e a Padova, secondo l'istoria della natività di Maria e della fanciullezza del Salvatore, mette nel seguito della Sacra Famiglia tre giovanetti e una fanciulla; ad Assisi, Salome e il contadino che porta vivande. A Padova il divin Fanciullo, benchè si stringa affettuosamente al seno della Madre, veste come un piccolo sacerdote; ad Assisi è involto in fasce ed ha la testina coperta di un cappuccetto; lì la Vergine passa tra le alte scogliere, diritta, silenziosa, meditabonda, guardando 
innanzi a sè, quasi mirasse it proprio clestino: qui la sua testa si inchina con espressione di dolcezza, e l'albero della palma si piega verso di lei.

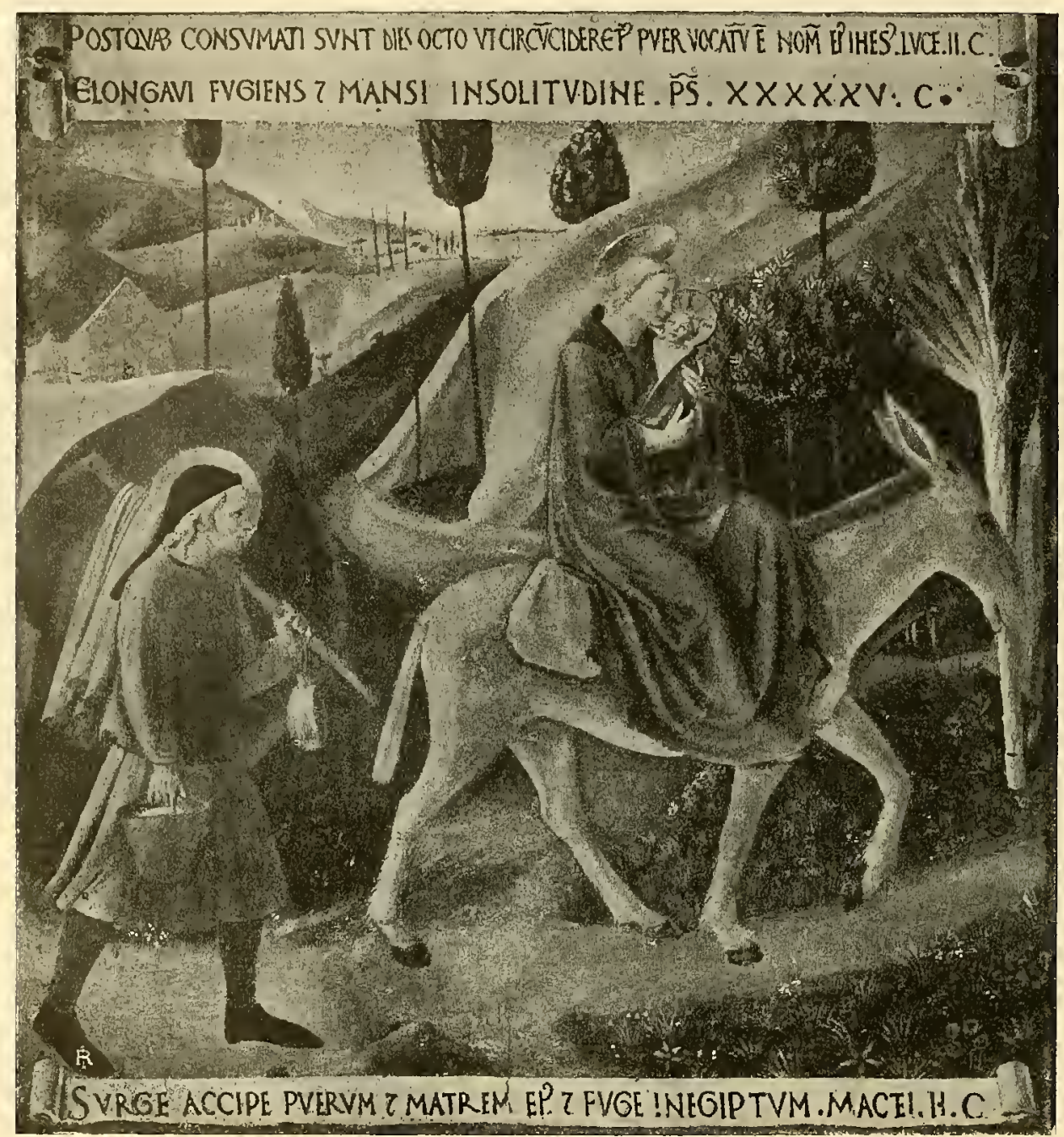

Galleria antica e moderna in Firenze

(BeAto Angelico)

In Padova un angiolo, fermo il vólo sulla comitiva, addita la strada; in Assisi due alati messaggieri fendono l'aria, volano verso una città che sta sulla vetta d'un monte, e uno di essi volando accenna al luogo. Vi è ad Assisi una varietà di motivi, una vivezza, una naturalezza tutta nuova. Anche San Giuseppe, similmente vòlto nell uno e nell'altro affresco, a Padova, non si curva, nè per il peso delle robe portate sulla spalla, nè per la fatica del`•viaggio; e le figure de' giovanetti che conversan tra loro là non hanno la 
semplicità della figura di Salome, che sembra un'alpigiana, nè dell'elegante contadino che spinge innanzi lasinello. La composizione così fu pienamente

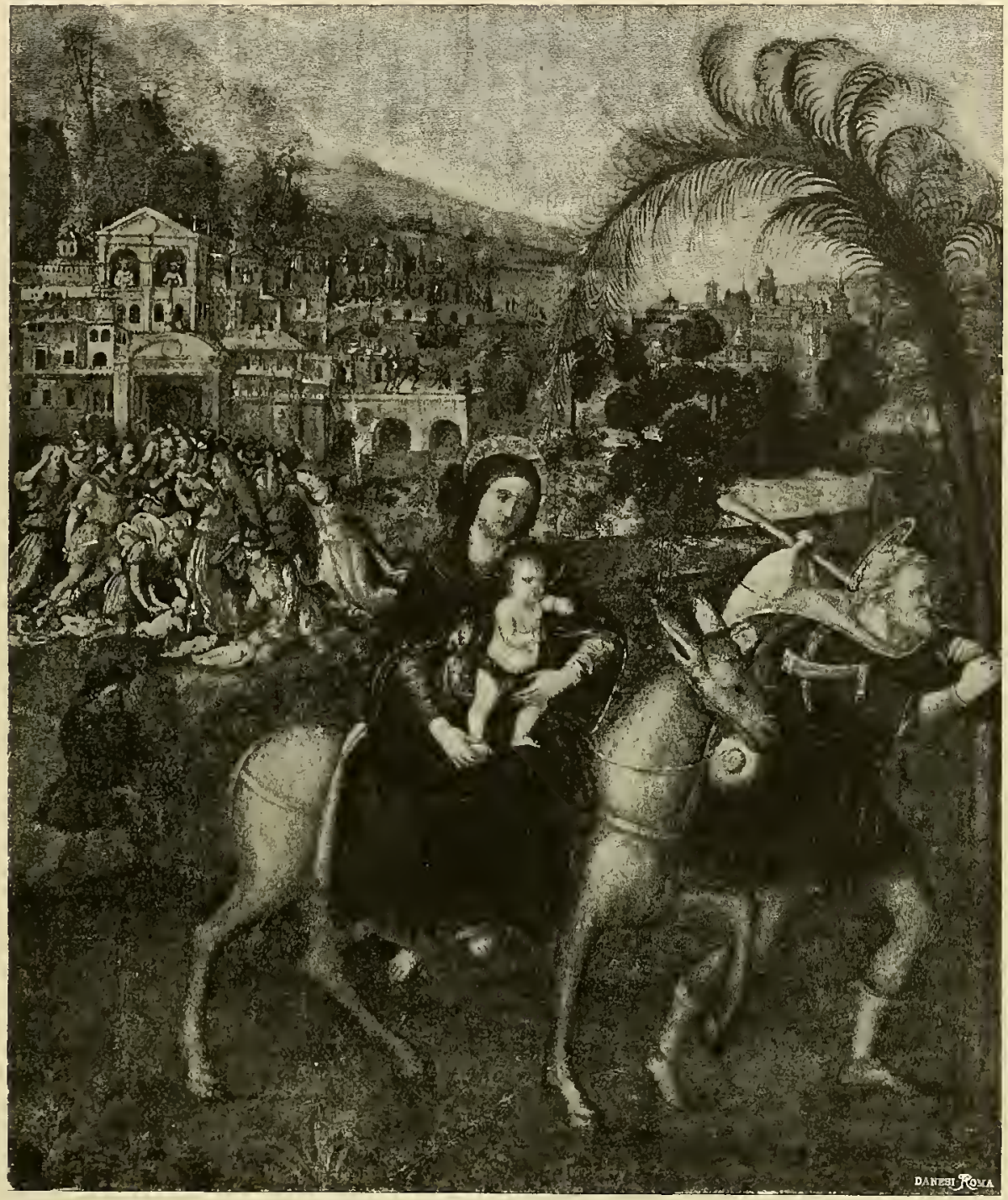

Chiesa di Sant' Onofrio in Roma

(Baldassare Peruzzi)

determinata in vario modo; e di rado poi spuntarono fuori gli elementi messi in disparte da Giotto. Nelle sculture della scuola dei Pisani, sulla facciata della cattedrale d'Orvieto, la Vergine, coperta il capo da un velo, siede sull'asinello col Bambino ignudo, e dietro cammina Giuseppe con un bastoncello; la zampa dell'asino tocca le fauci d'un drago, che, come lumaca nel guscio, si rincasa nella grotta; e ciò richiama il tratto della leggenda, 
ov'è parola di draghi usciti da una caverna, i quali, adorato Dio, si rintanarono,

Gentile da Fabriano, nel secolo xv, si attiene alla forma più semplice della rappresentazione, nella predella del suo gran quadro all'Accademia di belle arti in Firenze. L'asinello è preceduto da Giuseppe che s'appoggia a

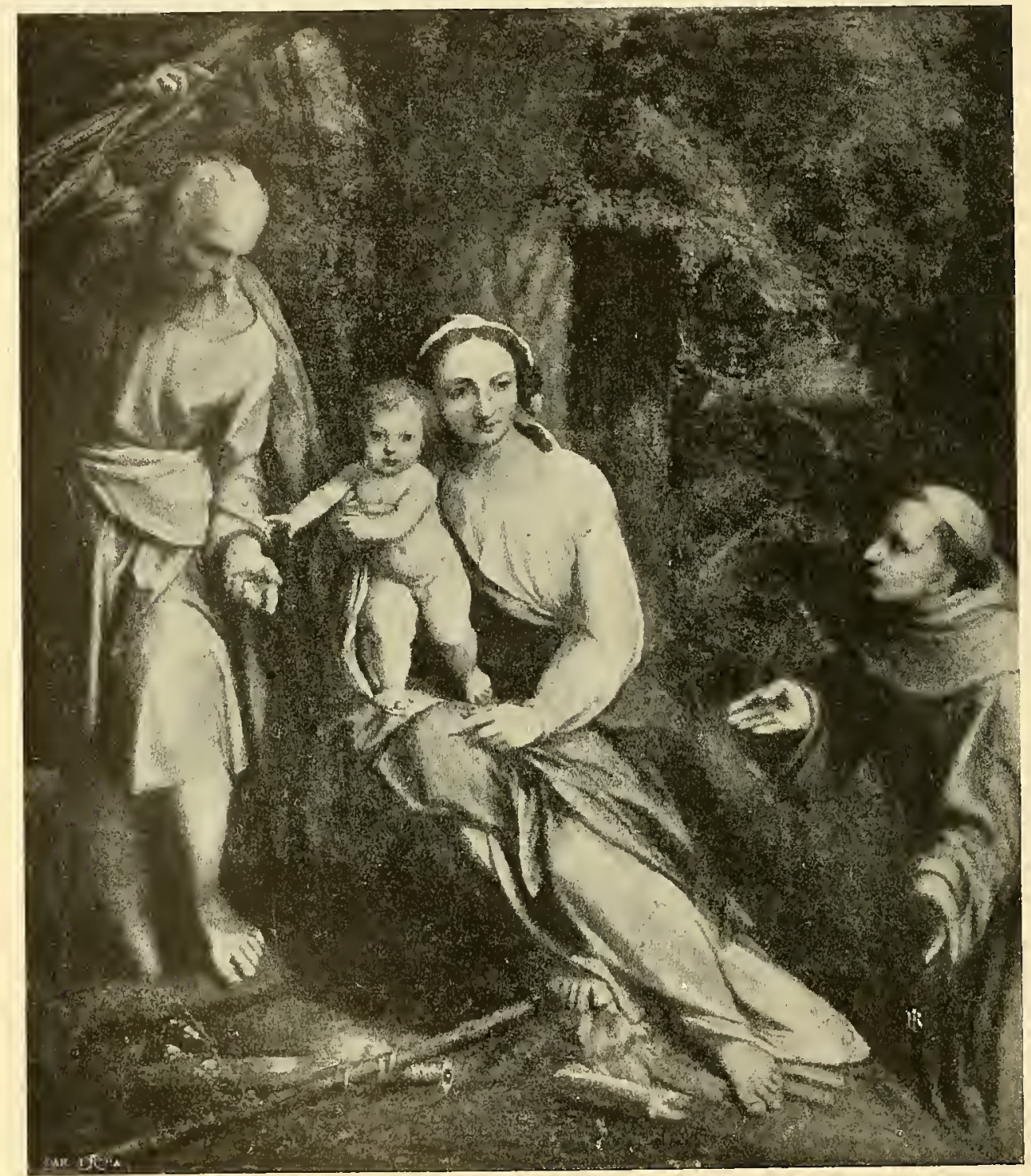

Galleria degli Uffizi in Firenze (CORREGGIO)

una ferula e tiene con l'altra mano la cavezza; la Vergine guarda il Bambino in fasce, e due donne, di cui l'una con la sporta. li seguono per la via 
sassosa, a' piedi d'un monte spàrso di alberi fruttiferi, verso una città con mura merlate, torri, chiese, battisteri. La scena è trasportata a traverso i colli toscani, abbellita di toscana gentilezza. Similmente il Beato Angelico

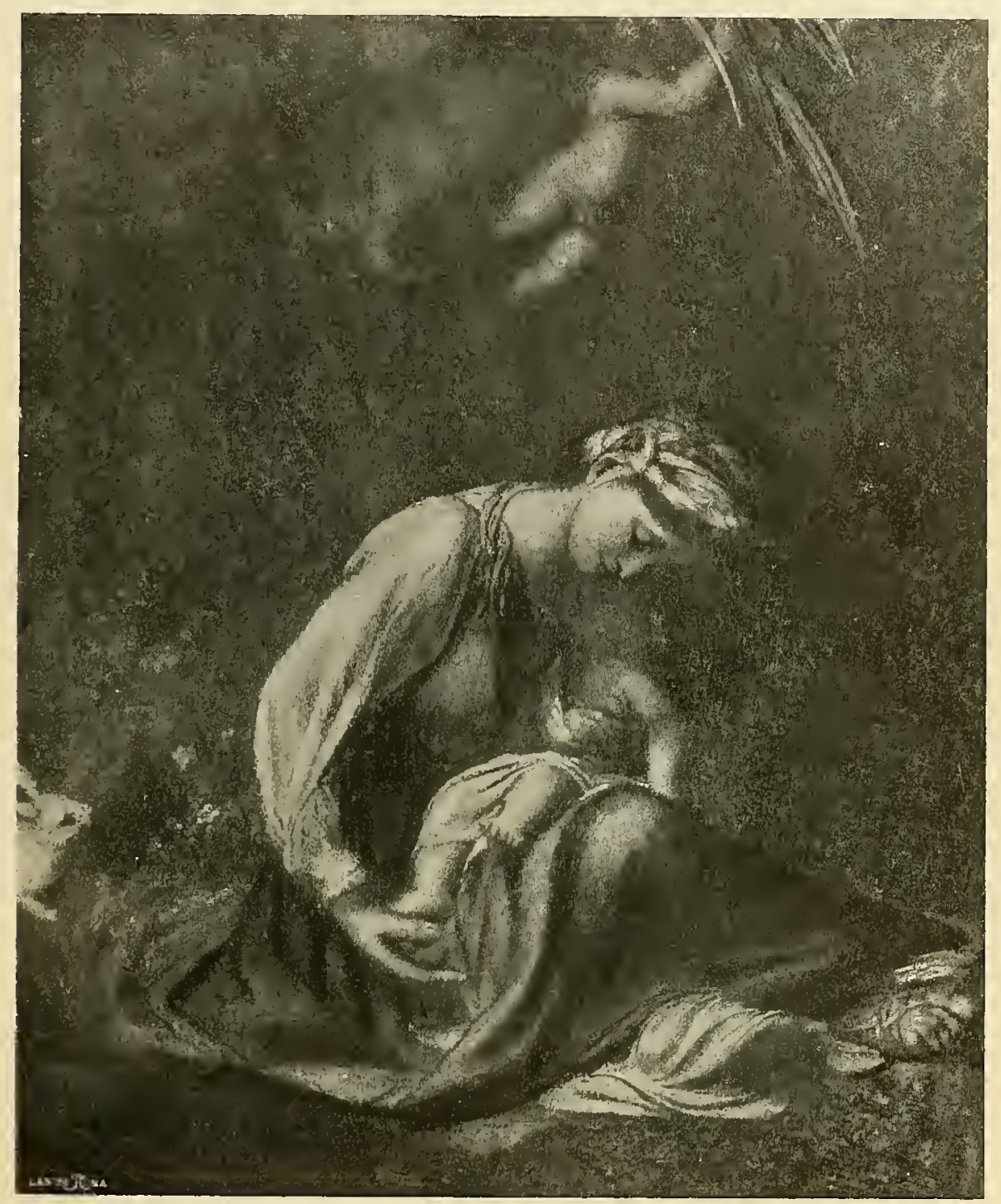

Galleria Nazionale di Napoli

(CORREGGIO)

figurò la via che s'apre tra zolle fiorite, su per una collina sparsa di ulivi e cipressi ; e la Vergine si stringe al petto, come la sua più cara cosa, il Bambino, e l’asinello avanza, verso la palma piegata, portando il gruppo gentile.

Nel florido Rinascimento parve poco dignitosa la scena, e piuttosto che in cammino si rappresentò in riposo la Sacra Famiglia. Il Correggio, nella 
Madonna della Scodella, trovò la forma perfetta, equilibrata, completando in un idillio la composizione della Madonna della Palma, nella Tribuna degli Uffizî. La leggenda rappresentò la Vergine affaticata dal viaggio, discendere di sella e sedersi all'ombra della palma, da cui per miracolo del Bambino si

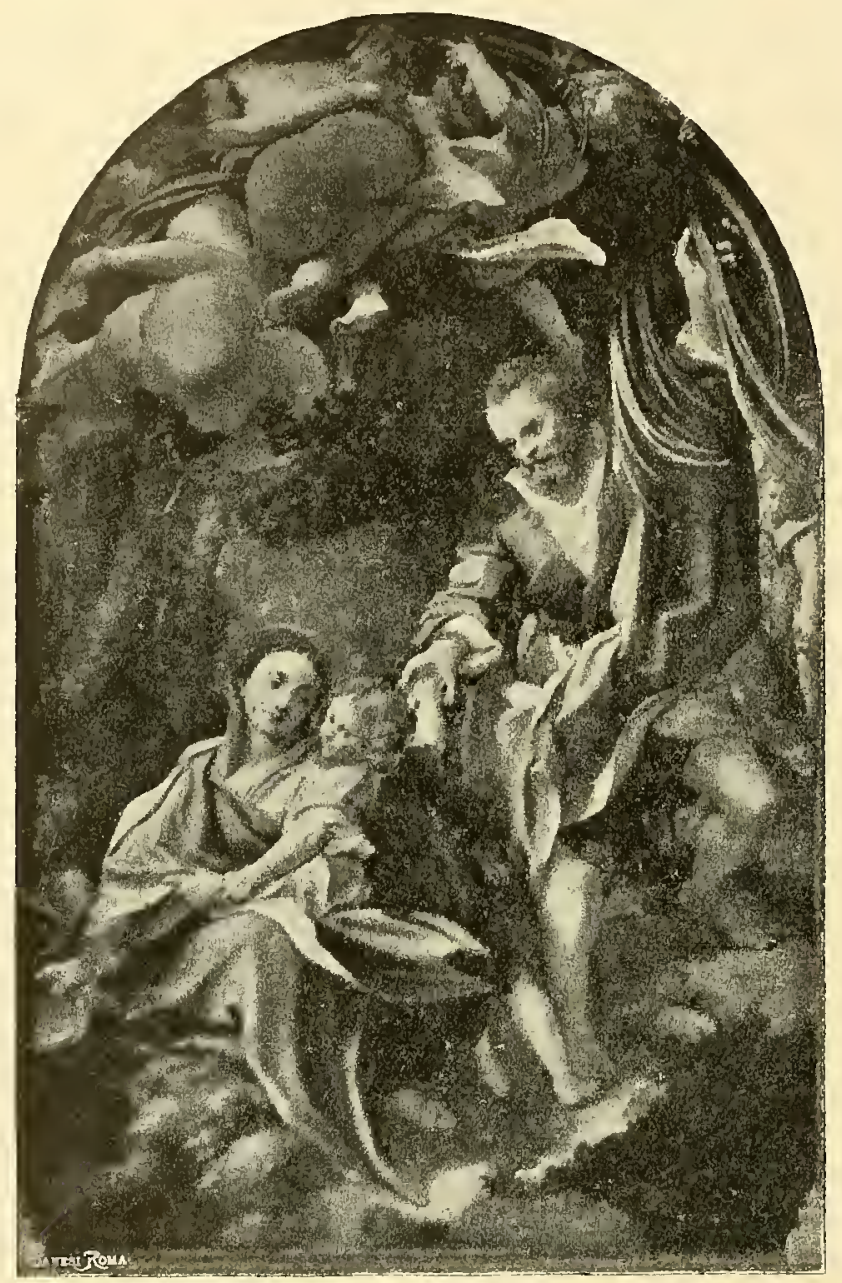

R. Galleria di Parma

(CORREGGIO)

raccolsero le frutta della cima; e in seguito, per comando del Dio fanciullo, vedesi rilevarsi la palma, e dalla sua radice sgorgare una fonte di fresca acqua limpidissima. Quasi che il Correggio ricordasse confusamente la leggenda, nella Madonna della Scodella sono uniti i diversi momenti: l'acqua scorre sotto la pianta che protegge con l'ombra la Madonna e il Bambino, e intanto gli angioli sembrano arrampicarsi e curvare i rami della palma, da cui San Giuseppe coglie i datteri. In quella frescura la Vergine sorride al 
vispo Fanciullino, che riceve dalla destra paterna le frutta, e, con l'altra mano, accenna ad aspettar la scodelia dalla mano della Madre. Nel fondo. l'angelo che li ha guidati lega il somaro. Presso alla fonte vi è un putto con un vaso che la personifica, particolarità che ci fa pensare alle classiche reminiscenze durate nell'arte medioevale. Il Correggio ebbe forse innanzi a sè qualche antica miniatura, da cui trasse l'ispirazione della tavola che il Vasari chiamò "pittura divina "? Certo è che il Cinquecento, per raccoglier le figure e coordinarle, preferì rappresentare il riposo sulla via dell'Egitto, anzichè la fuga da Betlemme: l'asinello ha un posto secondario, nel fondo $o$ in secondo piano; la Sacra Famiglia è riunita all'ombra degli alberi; talora la Vergine, stanca dal viaggio, dorme con la testa china sul Figlio adorato. Un maestro del Seicento, il Saraceni, nel quadro della Galleria Doria, fece anche intervenire un angiolo musicante, quasi che la sua melodia dovesse rallegrare i dormienti, e San Giuseppe gli tiene innanzi la carta da musica, e l'asinello s'avanza come se godesse a quei suoni. Il Saraceni però svolgeva così un altro motivo correggesco, quello della Zingarella, nel Museo di Napoli, che può dirsi un frammento della scena del riposo in Egitto. Ivi pure gli angioli si stringono ai rami della palma, che copre di ombre trasparenti il gruppo divino, e il Fanciullo dorme sul seno della Madre: Dio riposa tra il verde delle piante, vegliato da una fata e dagli angioli azzurrini. L'arte infine tradusse così la scena come una fantasia notturna. 



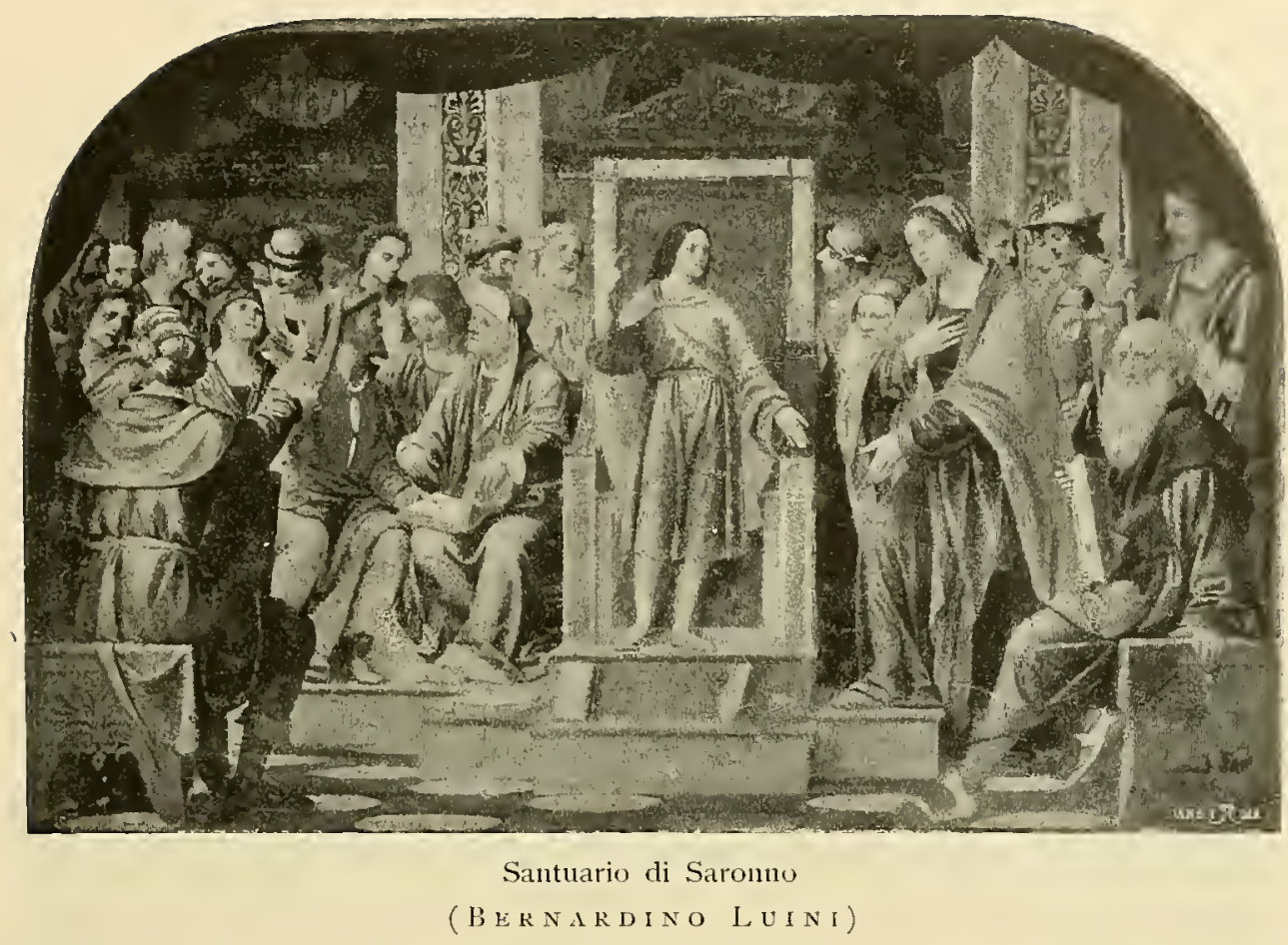

\section{Disputa di Gesù nel tempio.}

Cristo già siede in cattedra nel tempio, nel mezzo delle nobili figure dei vecchi in ascolto, stupefatti della sua sapienza. La figura dell'adolescente assume severità dottorale, gli occhi mandano lampi, la destra si solleva lenta e grave. Intanto i genitori sopravvengono: Giuseppe, come un villico stupito di udire argomenti superiori al suo intelletto, pende dalle labbra di Gesì sedente sull'angusto scamno, e Maria è lieta di rivedere il figliuolo e confusa ad un tempo.

Così rappresentò Giotto la disputa di Gesù. Padrone dei moti dell'anima, espresse nelle figure de' sacerdoti i sentimenti più variati; e chi si ritrae meravigliato, chi tende l'orecchio, chi medita sulle parole udite stringendo la barba fluente, chi porta alcune dita al collo, quasi che quelle parole lo infastidissero. Pare che Giotto con l'affresco dell'Arena tracciasse nei secoli avvenire la via al pittore della "Cena Domini", al divino Leonardo. Mai più la composizione della "Disputa " trovò tanta solennità come tra le navate del gotico tempio di Giotto; ma rimase nell'arte il carattere di Maria, 
tenera donna, semplice popolana innanzi alla grandezza del fanciullo sapiente. Generalmente ella è figurata da un lato, come se arrivasse spettatrice del trionfo dell'eloquenza del Figlio innanzi all'assemblea dei dotti; e così si vede

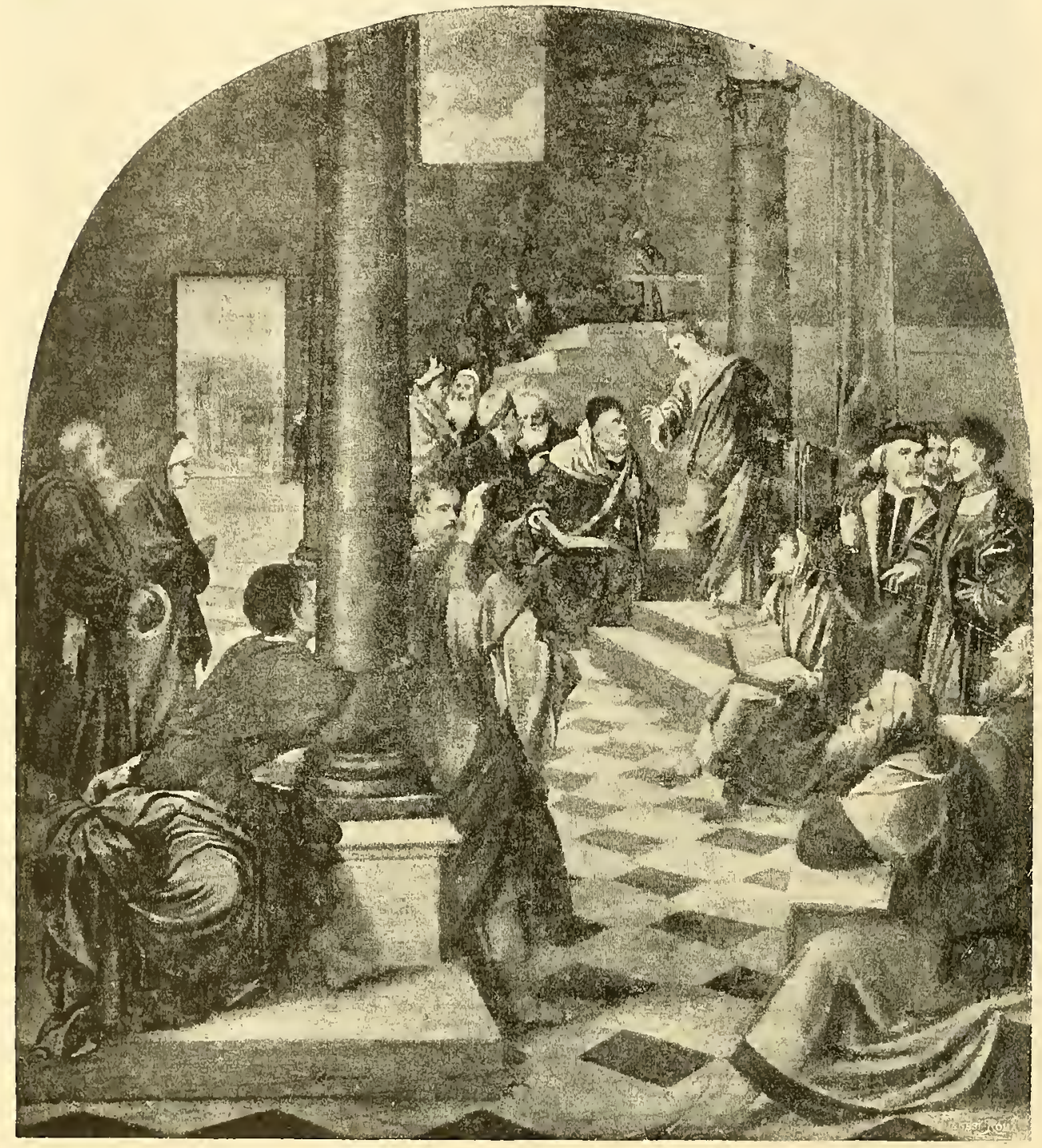

R. Galleria Pitti in Firenze

(Bonifacio Veneziano)

ne' quadri del Mazzolino, che ripetè tante volte il soggetto, e nel vago dipinto di Bonifacio Veneziano nella Galleria Pitti.

Il Mazzolino poco seppe esprimere nella faccia tonda della Vergine, e l'atteggiò a divozione facendole congiunger le mani, mentre il divin Figlio non mostra di accorgersi del sopravvenire de' genitori. Ella ode il verbo di 


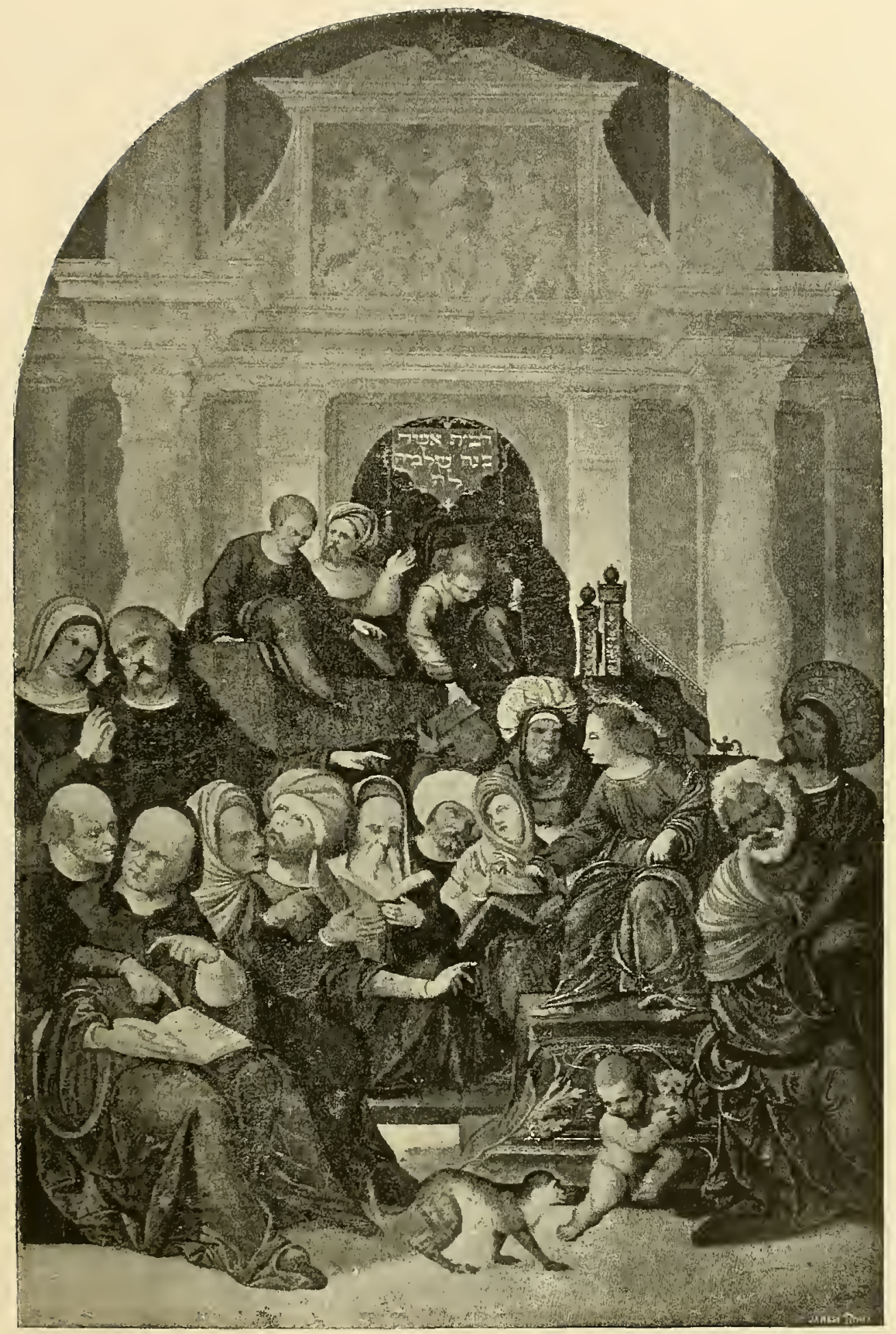

R. Museo di Berlino

(LuDovico Mazzolino) 
Dio, e adora. Similmente è figurata da Bonifacio: umile e pia ella avanza nel tempio, mentre l'Adolescente spiega la legge del Padre.

Bernardino Luini, a Saronno, figurò la Vergine che, tra la folla dei dottori, si approssima al Figlio; ed egli che doveva rispondere duramente, secondo il testo evangelico, accenna all'alto sì, ma col visino dolce guarda la madre, che esprime l'ansia delle sue ricerche e timida venerazione. L'arte ingentiliva tutto, e tra $\mathrm{i}$ dottori del tempio si rivedono le soavi figure che il Luini diede altra volta ai compagni del Cristo: spunta tra la folla degli ebrei la graziosa testa giovanile dell'apostolo Giovanni; Maria è ancora la umile ancella dell" "Amunciazione»; e Giuseppe ringiovanito prende l'aspetto che poi assunse il Nazzareno. Spariva così in quella dolcezza molle il carattere della composizione; e i profeti, in colloquio tra loro o non rivolti al Cristo, non subivano quel fascino che nell'opera di Giotto avvince potentemente tutti.

Lì la voce sola di Gesì rintrona solenne nel tempio: Maria e Giuseppe arrivano, ma non chiedono ragione al Figlio del suo essersi allontanato da loro; tutti ascoltano: Iddio parla!

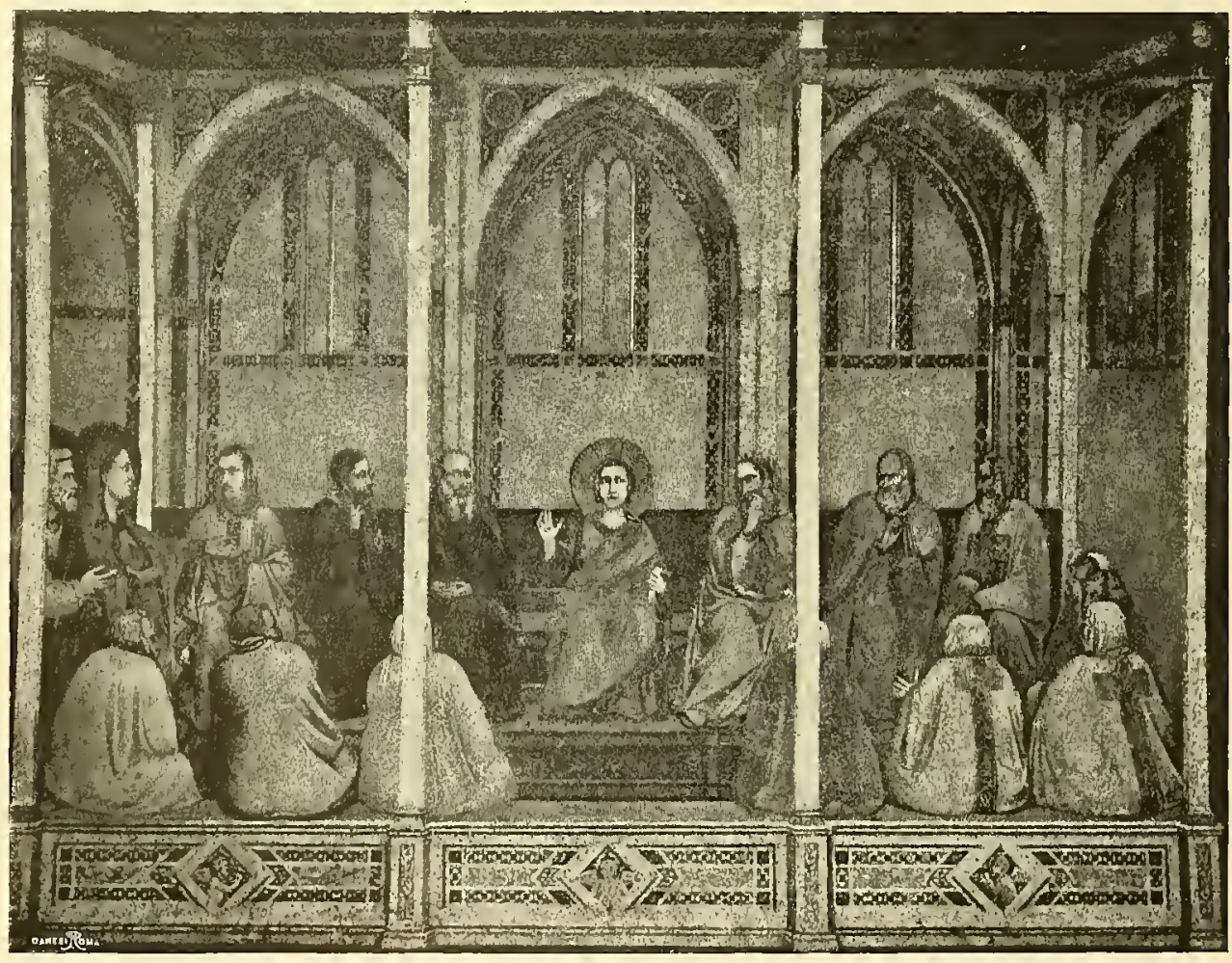

Tasilica d'Assisi

(Giotto e seguaci) 


\section{La Passione del Cristo.}

Nelle scene della Passione Maria prende parte soltanto ne'tempi del maggiore sviluppo dell'arte, e vi si mostra accasciata, svenuta nelle braccia delle pie donne. Vi è però una scena che, quantunque tratta dagli Evangeli apocrifi, ebbe nel secolo $x i$ la più bella forma, cioè quella che raffigurava il Cristo in atto di dire addio alla Madre prima di partire per il Calvario. Il Correggio rappresentò la scena pietosa alla fioca luce della sera, con quattro figure le cui ombre si disegnano lunghe sul suolo, mentre, nel lontano, l'ultima striscia di barlume crepuscolare sembra svanire riflettendosi nelle ombre e nei vapori azzurri del piano. In questo quadro del Benson, a Londra, il genio dell'Allegri si rivela in tutta la sua potenza. Cristo ginocchioni innanzi alla Madre, con la testa china, le braccia conserte, sembra aspettare la benedizione materna, mormorando in tono di preghiera l'addio; San Giovanni, che gli sta presso, lo fisa col capo ripiegato e le dita incrociate, profondamente triste, vicino a scoppiare in pianto. E la Vergine, che più non si regge dal dolore e non riesce ad accostarsi al Figlio, con gli occhi senza luce più, con le labbra socchiuse, come se il grido dell' anima vi si fosse spento, pallida, esangue, è sorretta dalla gentile Maddalena, sulle cui braccia lascia ricader la mano forse sollevata a benedire o a trattenere o a supplicare il Figliuolo.

Il quadro, al confronto dell'altro dello stesso soggetto, opera di Lorenzo Lotto nella Galleria di Berlino, ci dimostra quanto si sia lontani dal vero nell'associare il nome del Correggio a quello del Lotto. Nel quadro di lierlino si vede San Pietro accigliato, una vecchia che torce la bocca, un 
cagnolino che scherza con la veste della committente del dipinto, un gatto con occhi fosforescenti, un pergolato nel fondo, una rama di ciliege e una arancia in primo piano. Il Correggio creò un dramma, il Lotto fece una con-

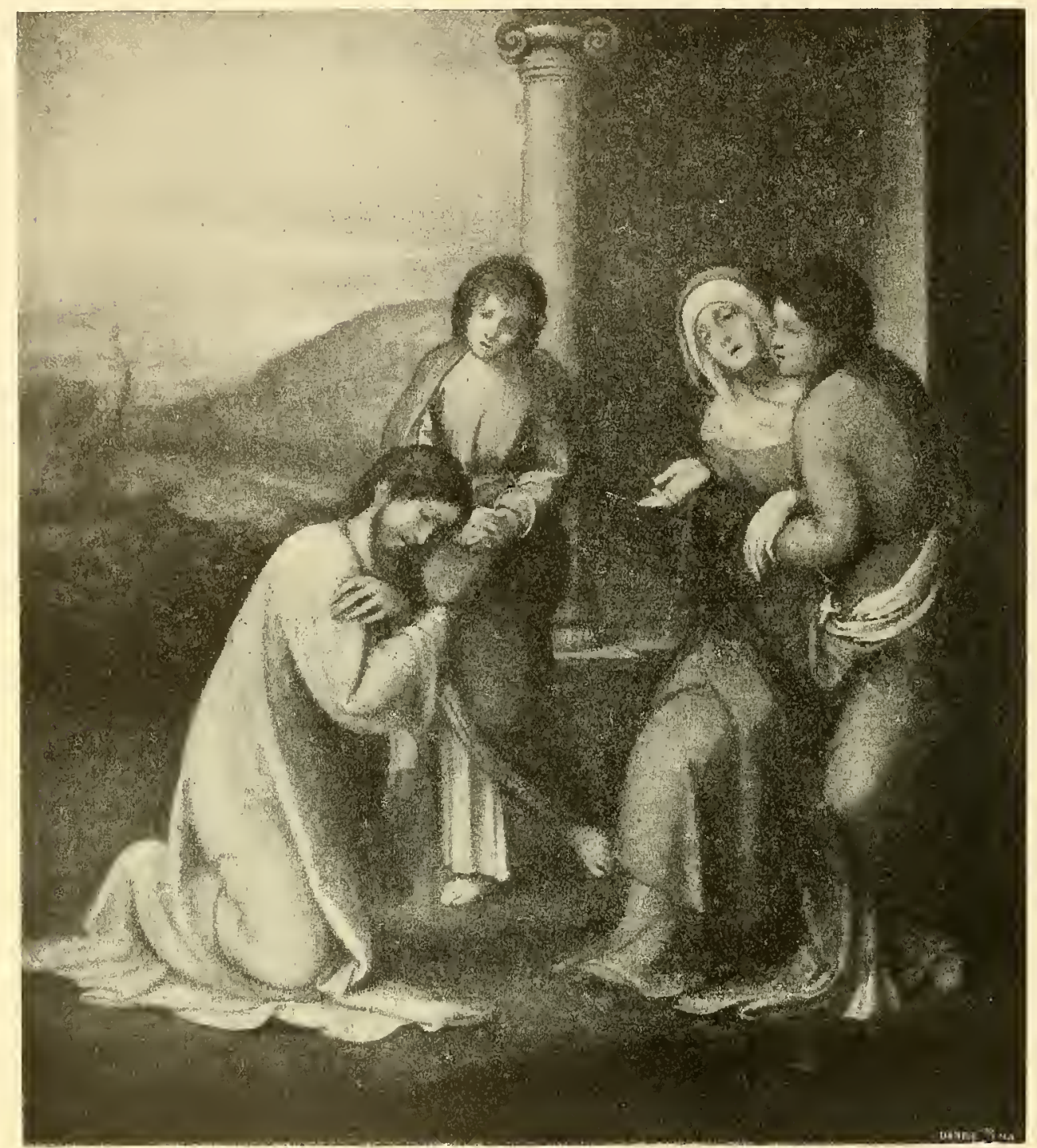

Collezione R. Benson a Londra

(CORREGGIO)

posizione coi primi materiali di bottega che gli capitarono tra le mani; cosi come, nel colorire, si attenne al suo metodo d'impastare ugualmente di rosa le carni, di rendere le ombre terree e verdognole e segnare gli ornamenti negli orli delle vesti a rete, a rombi, a puntolini. Antonio Allegri cerca invece l'idea, con islancio, nell'estasi di amore o nell'ardore della voluttà. Lorenzo 
Lotto è un maestro sapiente, Correggio è il genio; il primo trova aggraziate e semplici movenze nelle sue familiari figure, il secondo le anima di vita eterea; Lorenzo Lotto continua la tradizione, Antonio Allegri la corona.

La iconografia del Cristo che prende congedo dalla madre prima di partire per la Passione, sembra avere particolarmente nel Veneto il suo svolgimento, a giudicare anche da un altro quadro della Galleria dell'Accademia delle belle arti di Vienna, attribuito alla scuola lombarda (n. 530) e che appartiene invece alla veneta. Certe forme si svilupparono in una regione meglio che in altre, e qua crebbero rigogliose, là appena germogliarono o non attecchirono neppure, così come $\mathrm{i}$ fiori, secondo la natura del suolo e del clima, qua rallegrano di loro bellezza, là chiudono nella terra il seme infecondo. 



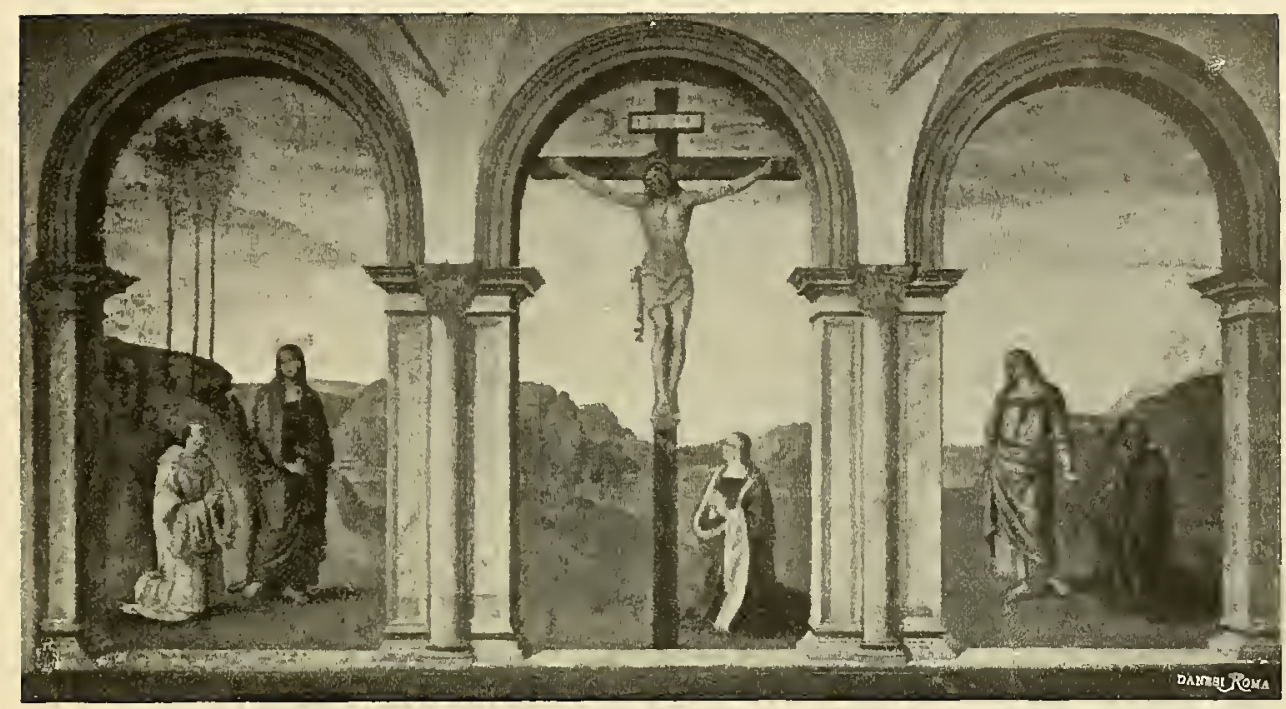

Santa Maddalena dei Pazzi in Firenze

(Perugino)

\section{La Crocifissione.}

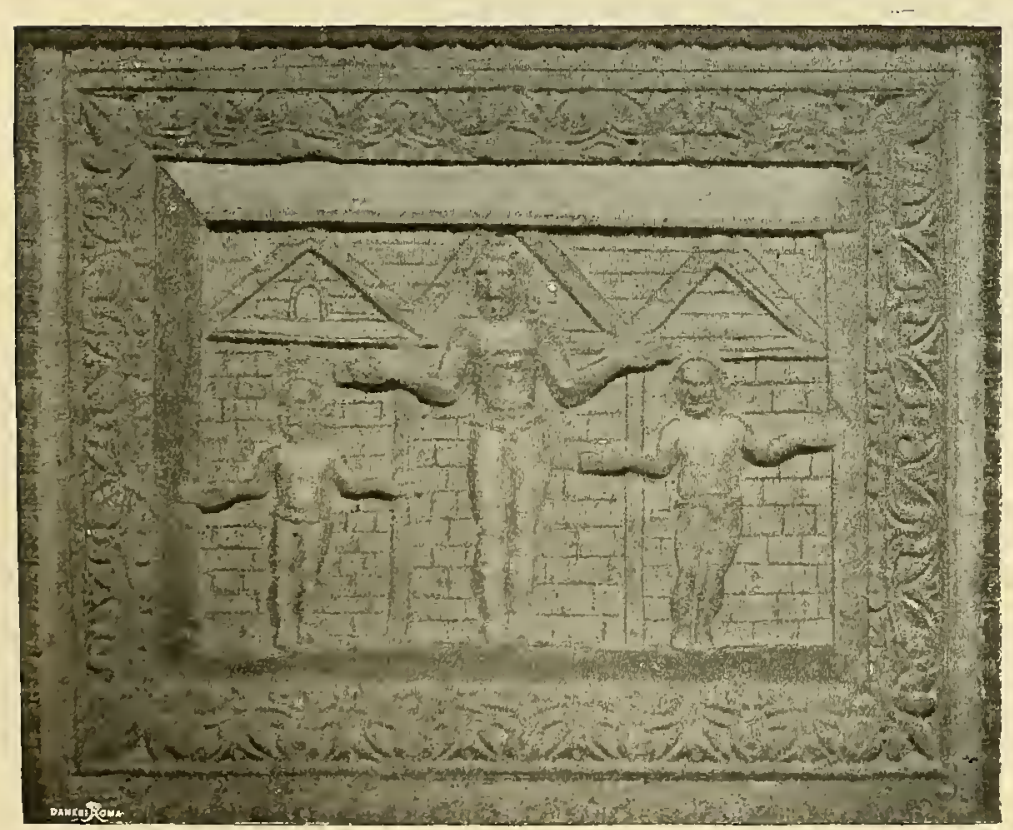

Dalla porta intagliata di Santa Sabina. Secolo v
Nella scuola dei giovani schiavi al Palatino, un adolescente, al principio del sec. IIt, si fece beffe di un compagno, segnando a graffito sul muro un crocefisso con la testad'asino, poi un uomo volto all'immagine e una scritta greca che può tradursi così : "Alexamene ado-

ra il suo Dio". In quegli sgorbi, in quello scherzo del ragazzo pagano, si riconobbe la più antica forma del crocefisso, l'accusa lanciata sin dal secolo terzo ai cristiani di adorare un Dio con lá testa di somaro. Minucio Felice, 


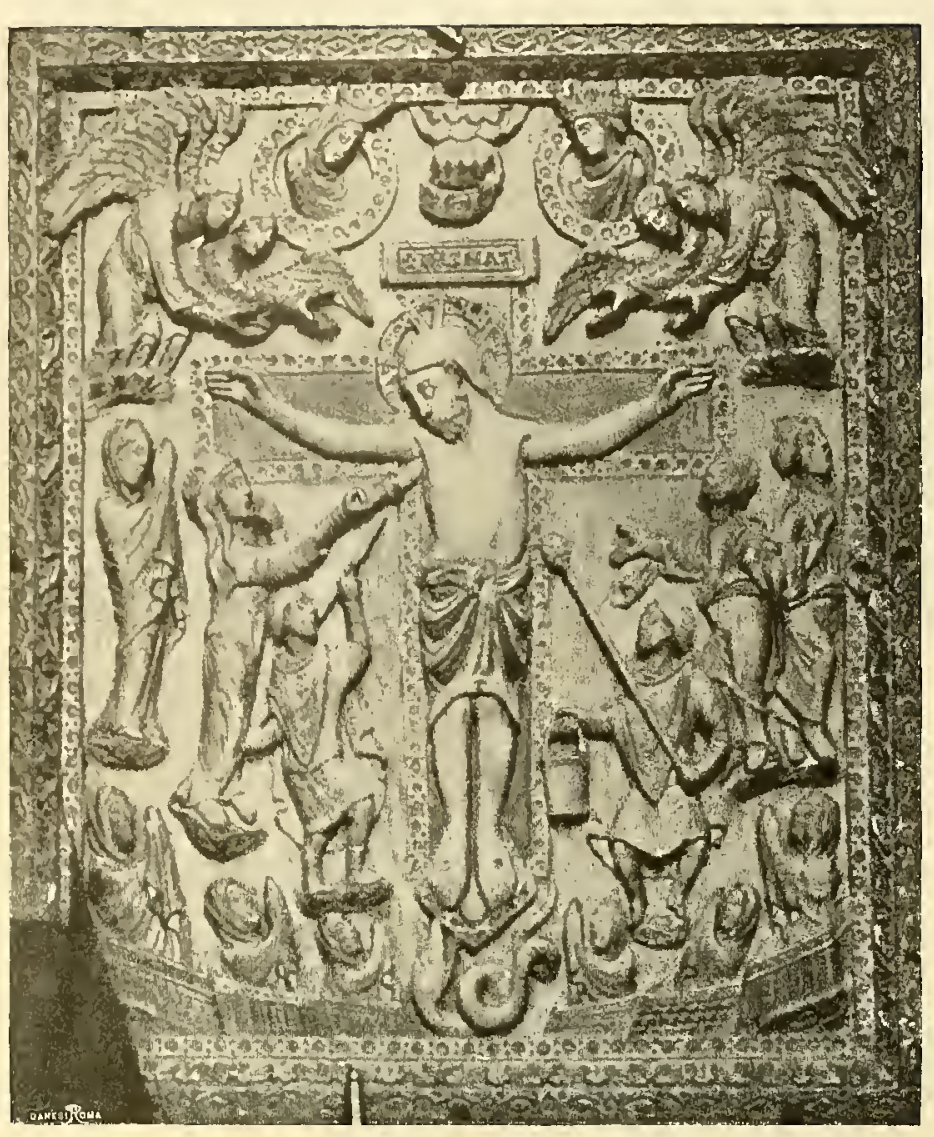

Museo Nazionale di Firenze. Avorio del secolo x

che ricorda la bestem mia, esclama: "A che dovrei farmi un simulacro di Dio, se in verità l'uomo stesso è di Dio simulacro ?... Meglio è consacrare albergo a Dio nel nostro spirito e nel profondo del cuore ». Così il cristiano primitivo rifuggiva dalle immagini che riducevano entro limiti, racchiudevano in angusti contorni la Divinità. Piuttosto nei simboli del Buon Pastore, del delfino, dell'agnello, celava segretamente il suo

Dio; e mai lo avrebbe raffigurato appeso al legno infame della croce sul Golgota. La realtà non attraeva gli occhi della fede fissi nel cielo, nè poteva vincere l'arte cristiana uscita avvolta nel peplo dalla tramontata scuola dell'arte classica. Invece dei tormenti del corpo, larte si compiaceva a rendere $\mathrm{i}$ gaudì dell'anima, la fede nella celeste pace e nella vita immortale. Ma quando la Chiesa emerse dalle catacombe alla luce, volle esprimere il suo trionfo coi bagliori della croce, che apparve coronata sul labaro delle legioni romane e sui sarcofagi, splendente di gemme nelle absidi costellate, come il firmamento, ne' mausolei e nelle basiliche. Sui sarcofagi è sculto il Cristo, non affisso alla croce, ma glorioso sulla roccia da cui sgorgano i quattro fiumi dell'Eden; e nelle absidi delle basiliche il Cristo assume la forma d'un agnello ai piedi della croce luminosa. Paolino da Nola, che verso la fine del secolo iv descrive le pitture di cui erano adorne le chiese, dice che il mistero della Trinità si rivelava per mezzo di segni: un'aureola circondava la croce; stavano 
gli Apostoli intorno al globo luminoso in forma di colombe, l'agnello mistico e la croce sulla rupe da cui fluivano le sorgenti della vita, i quattro Evangeli; il Padre tuonava nel cielo, e sporgeva tra le nubi una mano con una corona; la colomba, segno dello Spirito Santo, volava dall'alto; e le palme s'innalzavano dietro la mistica rupe, quale segno del giardino di delizie,

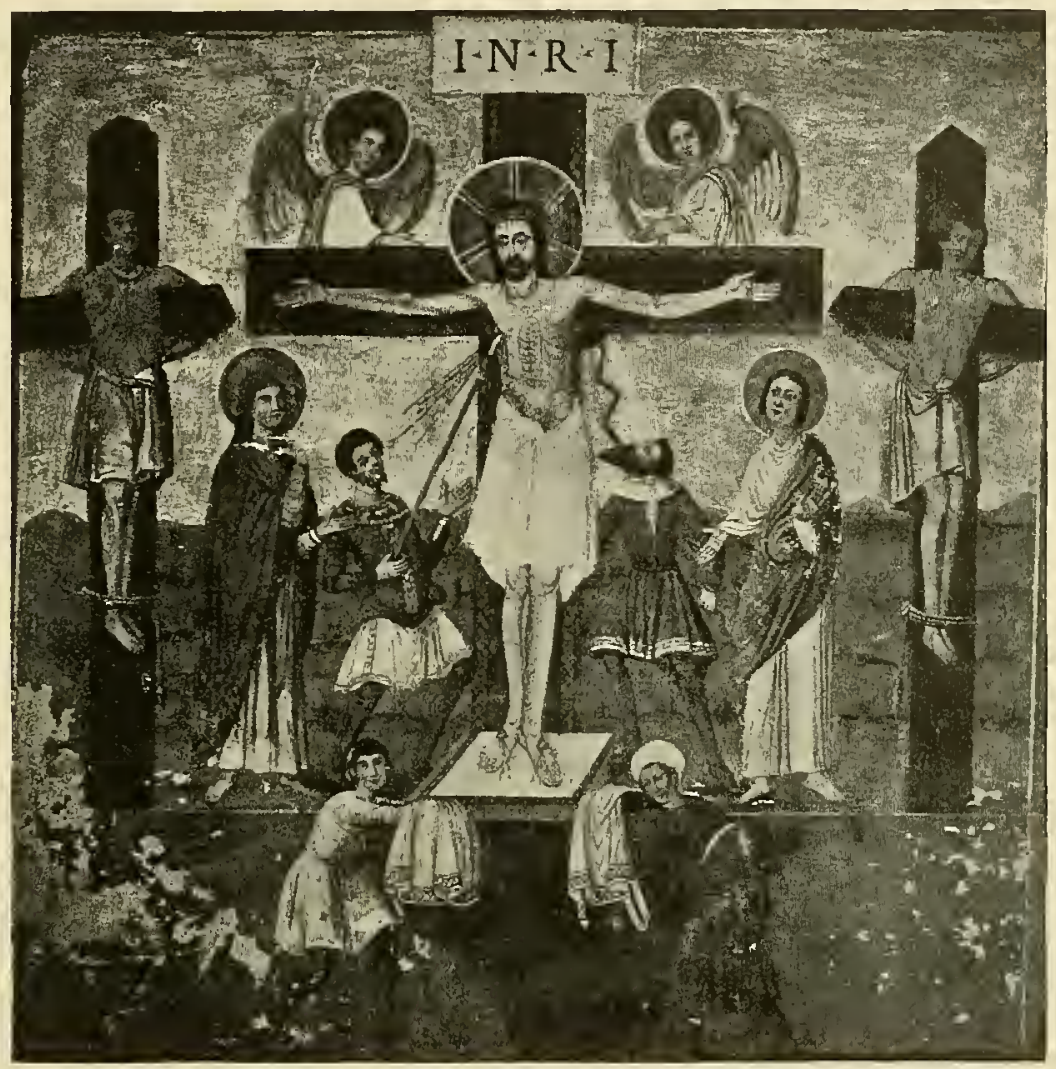

Affresco del secolo $x i$

Sant' Urbano alla Caffarella presso Roma

premio dei combattenti per la fede. Nelle onde della vita, scorrenti come ruscelli nei prati, le anime in forma d'augelli, o di occhiuti pavoni, o di cervi sitibondi, accorrevano a dissetarsi.

A questo puro simbolismo, più complesso e più ampio che non quello delle necropoli, doveva succedere il racconto della storia della Chiesa: la ricerca della forma reale, popolare. che desse corpo alle parole sacre degli Erangeli e alle -leggende.

Sulla porta di cipresso di Santa Sabina sull'Aventino, basilica che Pietro d'lliria, prete romano, fondò a sue spese, nel secolo $v$, sopra le fondanenta 


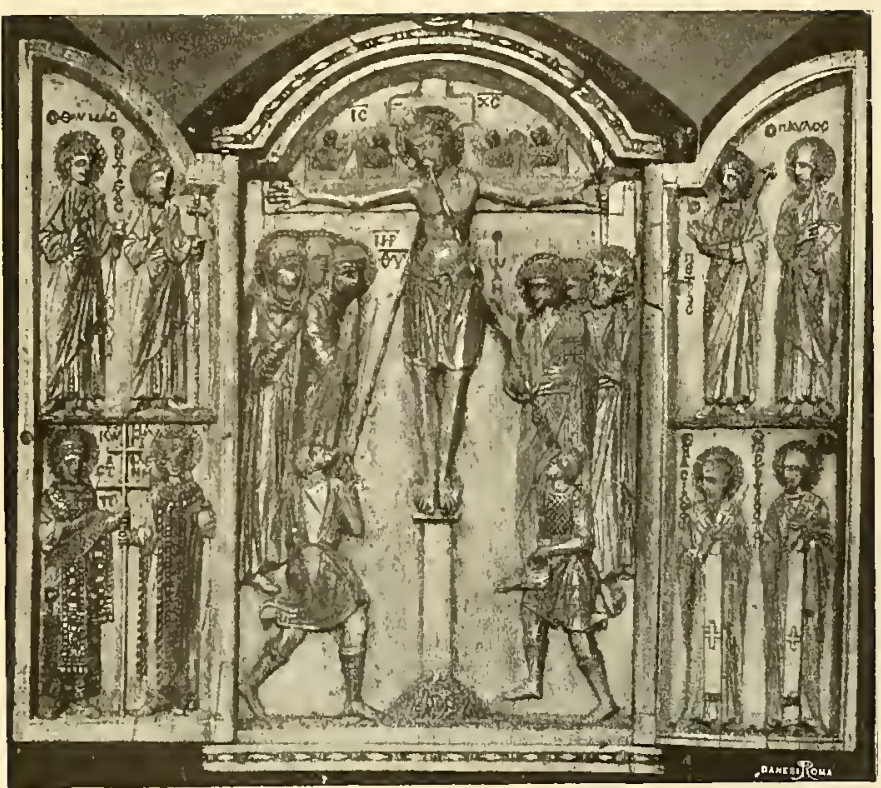

Avorio del Museo di Berlino

Arte bizantina, sec. xiI

dei templi di Diana e di Giunone Regina, è intagliato il Crocefisso tra i due ladroni. Egli ha capelli lunghi, ricadenti sugli omeri, secondo il modo con cui nei monumenti cristiani sono figurati gli Orientali; ha gli occhi aperti; stende le braccia quasi nell'attitudine di orante, e tiene una cintura breve a mezzo il corpo. Questo bassorilievo, il più antico che rappresenti il Crocefisso, ha il fare indeciso, confuso, stanco dei contemporanei scultori di sarcofagi; e vedesi tra gli altri scompartimenti intagliati, ove sono espressi la gloria di Cristo e i sacri misteri. Pietro d'Illiria, come il Zaccaria di uno dei bassorilievi, affacciandosi alla porta, alzando il velo ornato di seta e oro che la copriva, doveva additare ai leviti e al popolo il catechismo figurato della religione predominante ormai sulla terra. Mentre però quell'abbozzata rappresentazione del Crocefisso, in cui non si distinguono neppure i bracci della croce, era intagliata nel cipresso, l'arte cristiana pareva non ardisse ripeterne l'inmagine, e collocava al posto del Croce. fisso il mistico agnello,

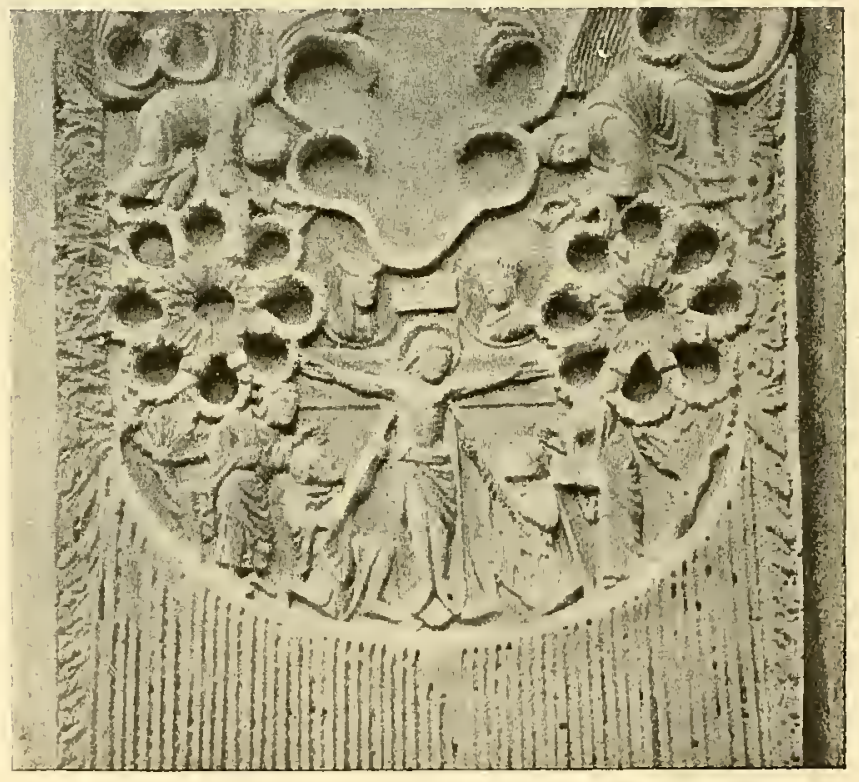

Petine liturgico in avorio detto di S. Ereherto Nuseo di Colomia 
come si vede in un medaglione all' intersecazione dei bracci della croce, sopra una delle colonne del ciborio di San Marco in Venezia, opera del secolo rr,

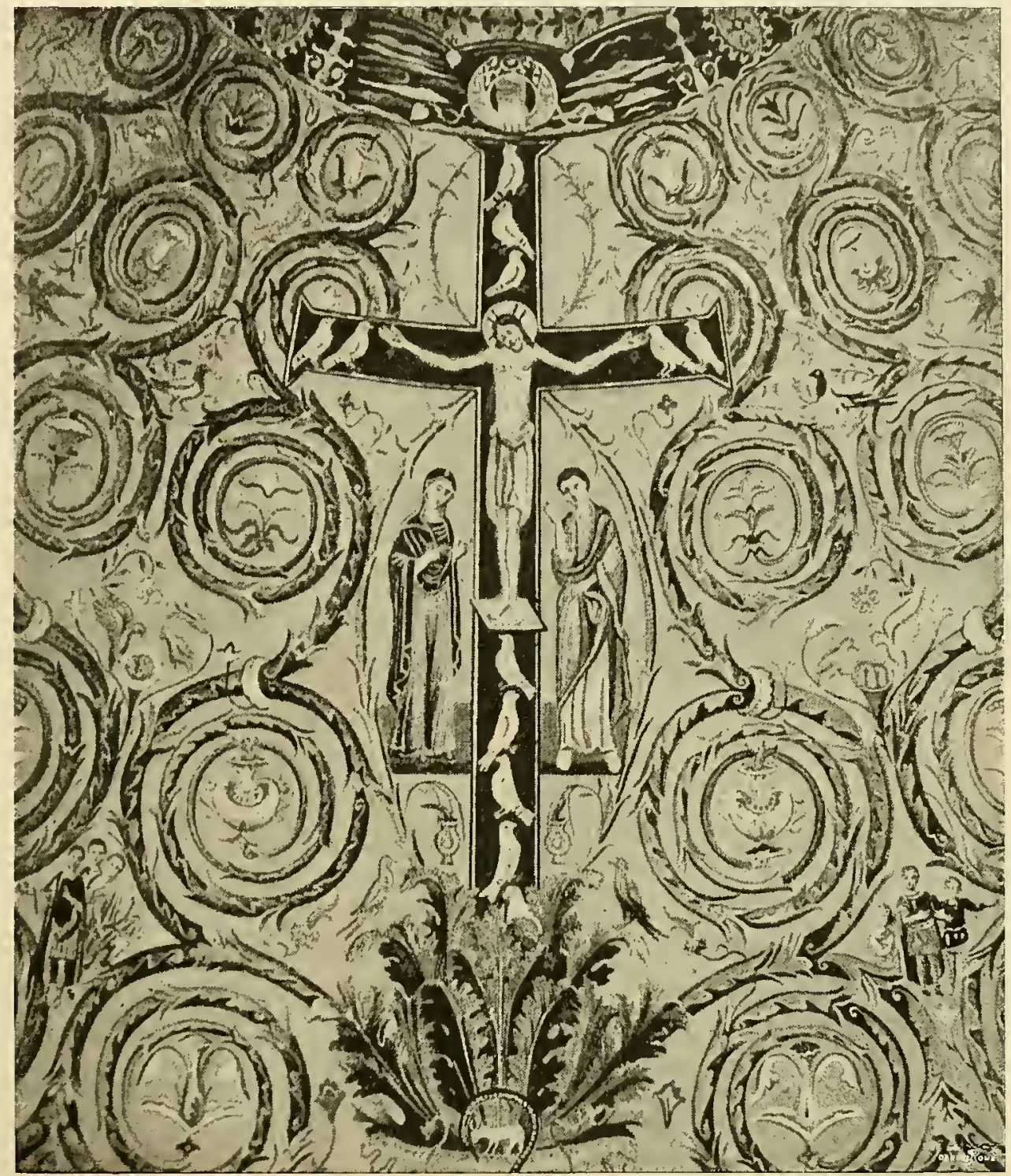

Musaico dell'abside della basilica di San Clemente in Roma

Principio del secolo xir

e nella croce imperiale della basilica vaticana, dono di Giustino IJ e di Sofia, sua consorte. La rappresentazione della figura umana diveniva sempre più ardua all'arte che rendeva l'ombra della realtà nelle sue forme irrigidite, allungate, spaventevoli; e con fori e solchi e strie più non riesce a sprigionar figure dal marmo. Pure, mentre s'intagliava la porta di Santa Sabina e si 


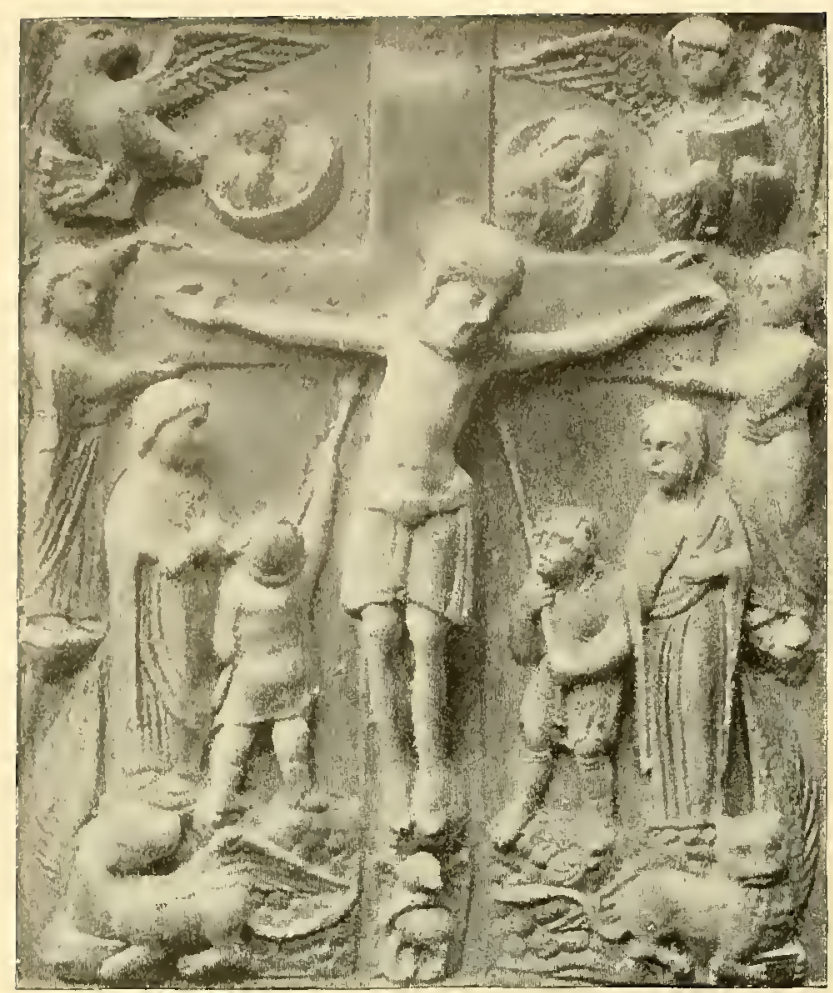

Coperta di libro in avorio. Secolo xir Santa Maria in Lyskirchen

scolpivano le colonne del ciborio ora in San Marco, un intagliatore nella teca d'avorio del British Museum rappresentava il Cristo crocefisso e alla destra della croce, secondo gli Evangeli, Maria e Giovanni: Maria, tutta avvolta nel manto; segue l'A postolo.

L'assemblea dei vescovi greci in Trullo» (anno 692), richiamando l'uso di rappresentare il Redentore sotto forma d'agnello, decretava che al simbolo si sostituisse il Cristo *in alcune delle sante immagini." Cosi si esprime il decreto: "... si dipinge, additato dal Precursore, l'agnello, simbolo della grazia divina, e che significa, secondo la legge, il vero agnello, Cristo nostro Dio. Tali antichi tipi, tali allegorie trasmesse alla Chiesa, noi le onoriamo come abbozzi della realtà; ma preferiamo la realtà stessa, che ci dà l'evidenza della legge. E perchè tale perfezione sia espressa sui quadri agli occhi di chiunque, ordiniamo che, in luogo dell'agnello redentore del mondo, si rappresenti il Cristo nella sua forma umana . Quando tale decreto fu emanato, l'arte già di frequente aveva messo in abbandono il simbolo, o i simboli sostituiti alla figura di Gesì; e non solo il Crocefisso, ma anche la scena della Crocifissione aveva ricevuto una forma. Nel codice siriaco del monaco Rabula, alla Laurenziana (anno 586), la scena della Crocifissione si trova così grandemente svolta, che già Crowe e Cavalcaselle dubitarono dell'autenticità del foglio miniato, sostenuta poi con buone ragioni dal Bayet c da altri. Il Cristo vestito di una tunica senza maniche, il sole e la luna sopra la croce, i due ladroni crocefissi ai lati, Longino che ferisce il fianco alla vittima divina e il soldato che le tende la spugna intrisa di ficle, la 
Vergine, San Giovanni, le pie donne, i soldati che giuocano le vesti del Salvatore, - tali gli elementi, verso la fine del secolo vi, aggiunti alla sacra rappresentazione. La Vergine nimbata solleva il manto, come se volesse portarlo al volto, secondo il modo antico di esprimere il dolore; ma ella non sembra agitata da passione umana, il gesto non corrisponde al sentimento della figura.

Era troppo presto ancora, anzi i molti elementi cresciuti d’improvviso sulla scena religiosa, si trovano di rado in altri monumenti contemporanei. Ad esempio, nelle ampolle, dono della pia regina Teodolinda alla basilica di Monza, provenienti in gran parte da Gerusalemme, pare che l'artista ancora tremi in raffigurar Cristo, di cui si vede in un'ampolla la testa nimbata, in alto sulla croce; $e$ in un'altra tutta la persona con le braccia stese, come a Santa Sabina, senza che si discerna la croce, e però la figura sembra campata in aria. Il sole e la luna, la Vergine e San Giovanni, i due ladroni, gli adoratori ai lati della croce, si rivedono in quei reliquiari trasportati dai Luoghi Santi; ma l'azione delle figure non è ben determinata a causa della piccolezza dei vasetti metallici, e perchè, quando questi si distribuivano come ricordo ai pellegrini, la croce era ancora tenuta simbolo glorioso, vessillo dei cristiani, più che segno di martirio e di morte. Ad ogni modo, verso la fine del sesto secolo, il Crocefisso si disegnava nelle chiese, nelle case, nei fòri, dovunque: nelle chiese, tra $\mathrm{i}$ vasi sacri di smalto e lapislazzuli e le cortine ricamate di Bisanzio e di Rodi, o sui tappeti di Tiro splendeva la croce d'oro gemmata: nei fòri s' innalzava tra statue imperiali; e i vinti e i vincitori s'inchinavano ad essa, e la portavano sulle vestimenta come amuleto contro il

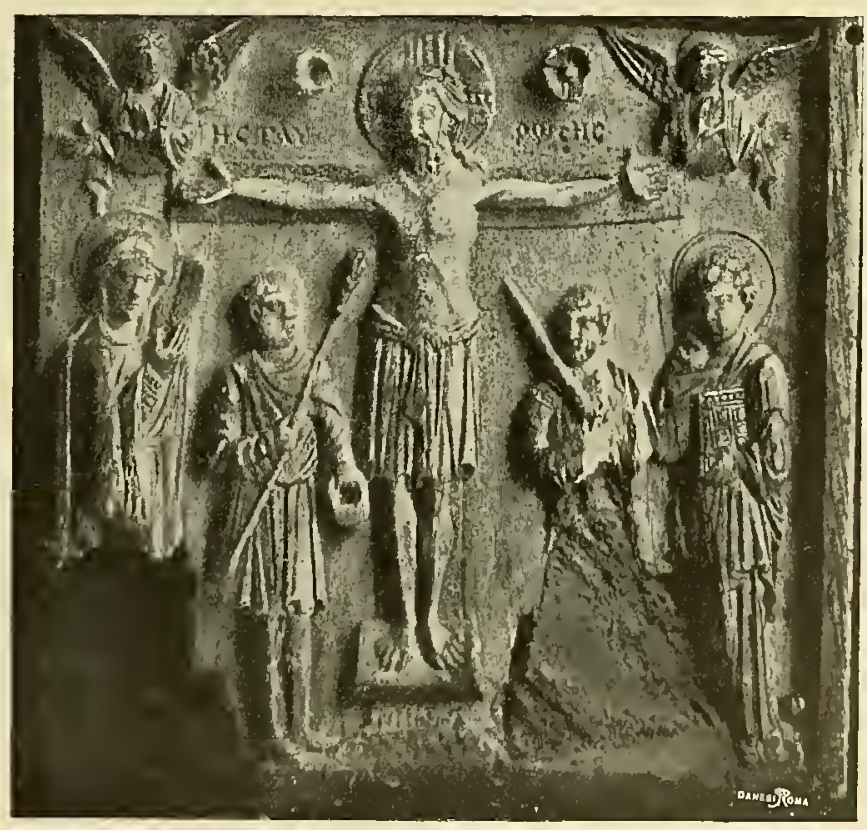

Avorio del secolo xin Raccolta del conte Stroganoff in Roma 
male. I vincitori barbari munivano i defunti di crocette con viluppi di nastri, con mostri, con teste dagli occhi sbarrati, dalla barba irta, orride. I vinti

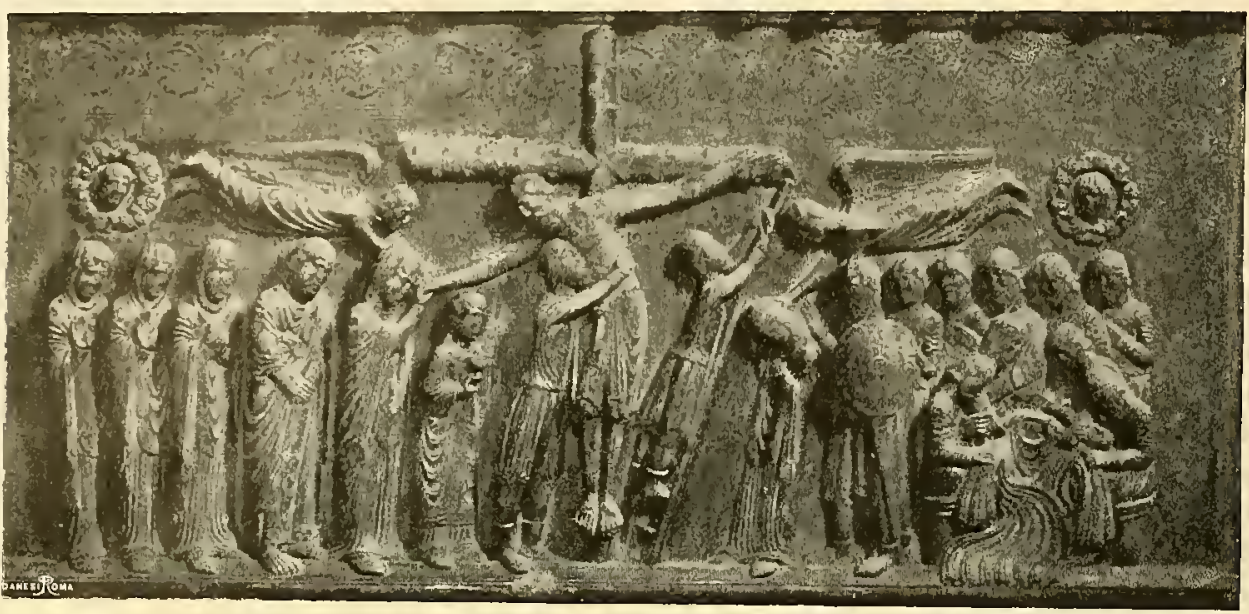

Cattedrale di Parma

(BENEDETTO ANTELAMI)

tentavano, ritentavano di rendere il Cristo, e, nel loro ebete stordimento, concepivano sfigurate, atterrite immagini umane.

Intanto alle effigie del Dio altre figure si associavano, create dalle leggende, dagli Actr Pilati, dall'Evangelo di Nicodemo. Giunto il momento

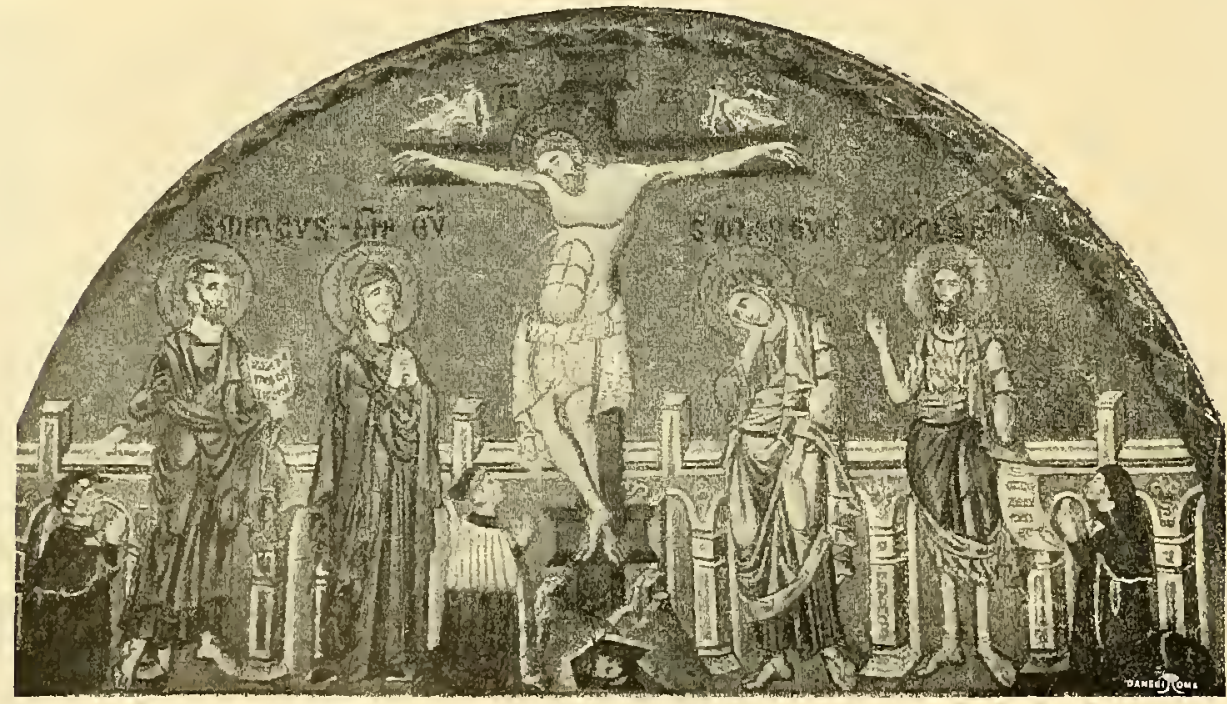

Basilica di San Marco in Venezia. Musaico del secolo xul

in cui la scena si elabora faticosamente, senza tregua, e ogni suo particolare si studia, si discute, si amplifica, si scinde, si dispone nello spazio, 


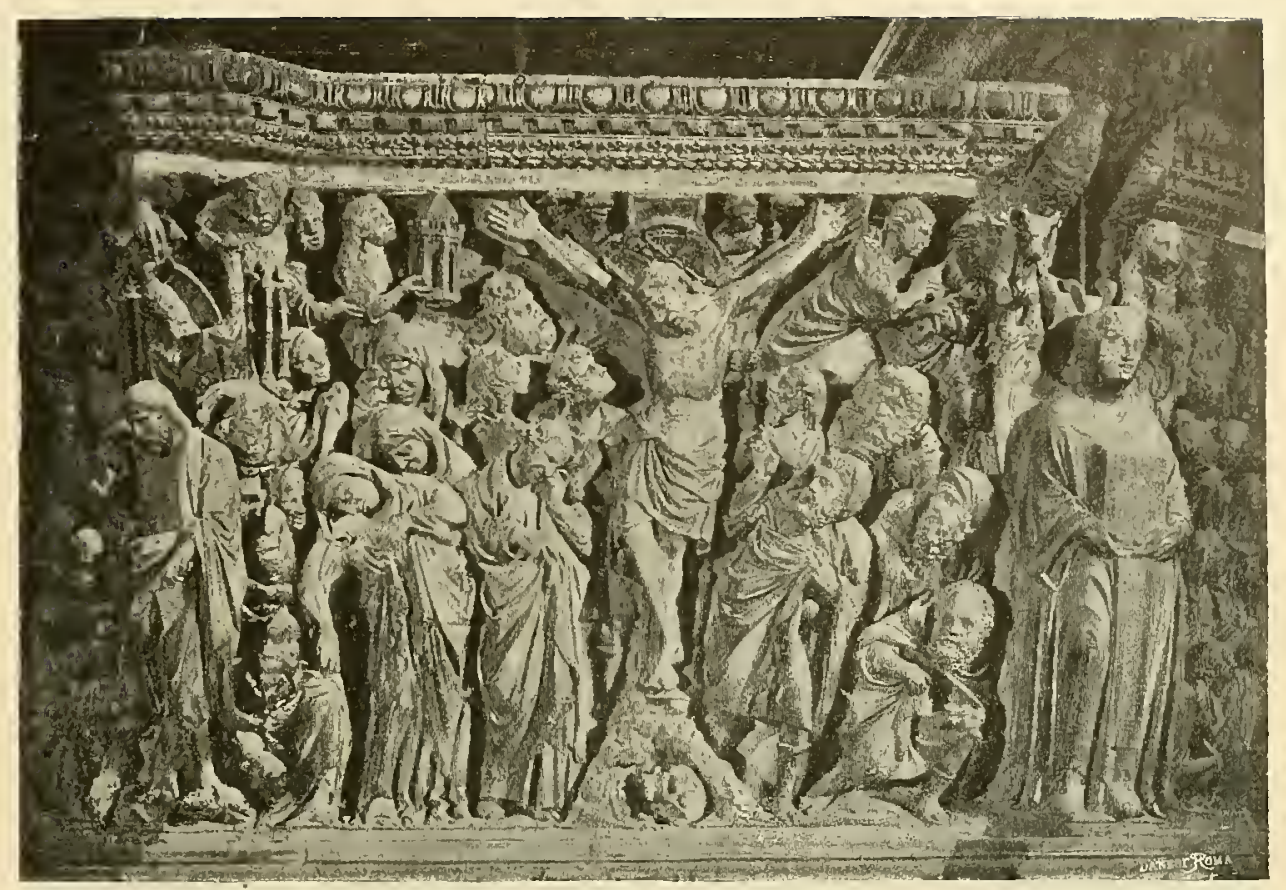

Pulpito della Cattedrale di Siena

(Nicola Pisano)

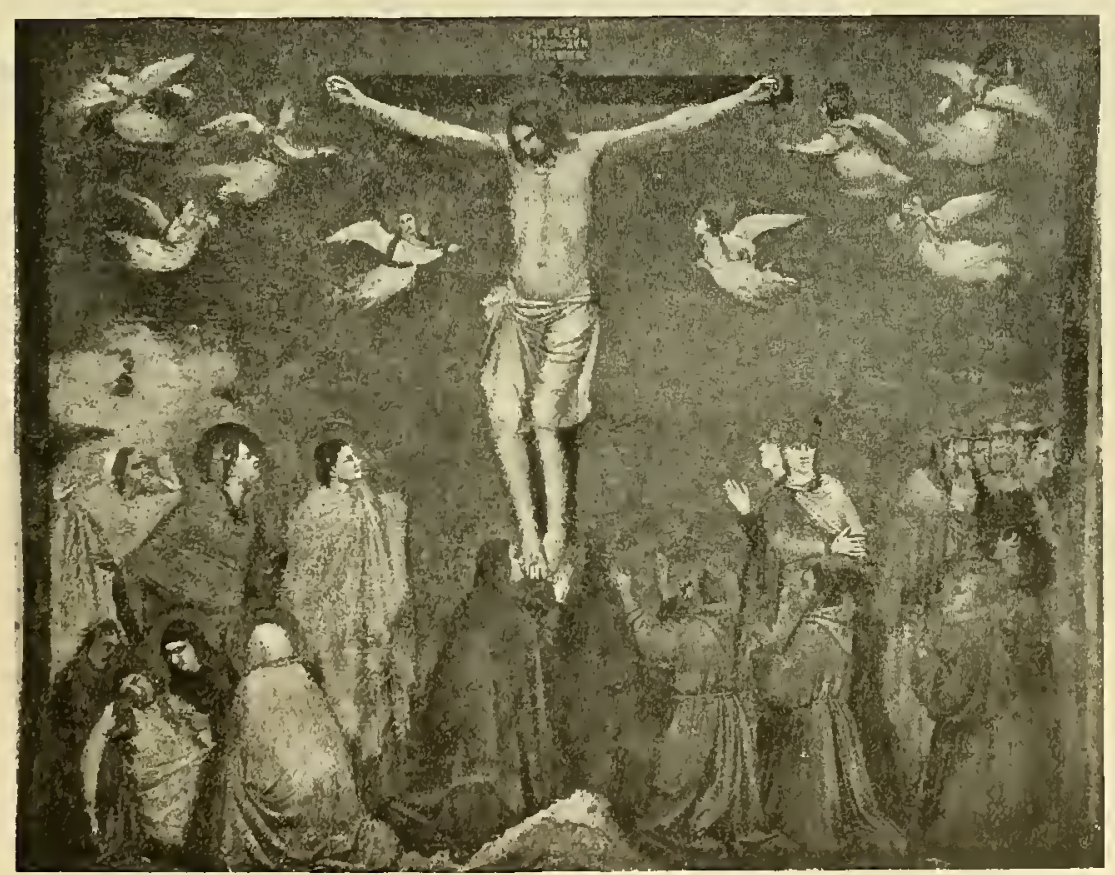

Basilica inferiore di San Francesco in Assisi (GIOT"To) 
secondo il grado d'importanza, e logiche e artistiche corrispondenze. Verso la fine del secolo vi e nel rı, la traduzione degli Evangeli diviene quasi letterale nell'arte rappresentativa. Matteo e Luca, evangelisti, avevano parlato dell'oscurarsi del sole alla morte del Redentore; e gli artisti figurarono in alto il sole e la luna: il sole a destra, come astro raggiante, o giovine

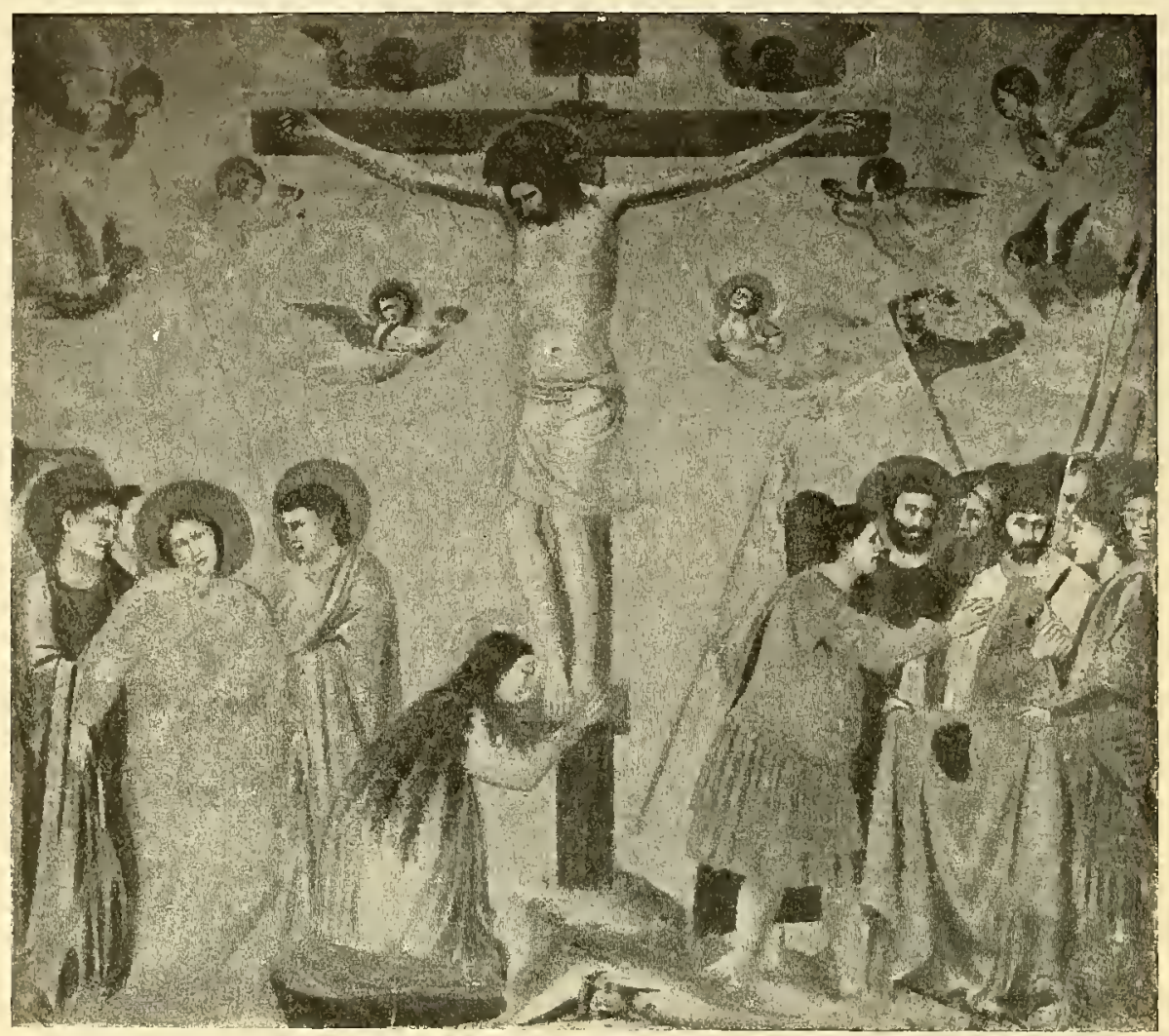

Oratorio degli Scrovegni in Padova

(GiotTo)

incoronato, o Apollo; la luna a sinistra, non tonda ma falcata, oppure in forma di fanciulla o di Diana con la mezzaluna sul capo. Gli evangelisti parlano di Gesù, che, dalla croce, vedendo il discepolo amato presso alla Madre, disse a lei: "Donna, ecco tuo figlio"; e al discepolo: "Ecco tua madre ". E, fedelmente, l'arte rappresentativa dispose ai lati della croce la Vergine e Giovanni: poi raggruppò vicino alla Vergine le pie donne, ricordate dall' Evangelo; di qua e di là eresse le croci dei due ladroni, i quali si studiò di distinguere in qualche modo, rappresentando, ad esempio, nelle ampolle di Monza, l'uno con lo sguardo vòlto verso il Salvatore, l'altro 
all'opposto. Tutte queste figure, i ladroni, la Vergine e Giovanni, la luna e il sole, gli angioli, i simboli evangelici, si fanno riscontro, secondo le più

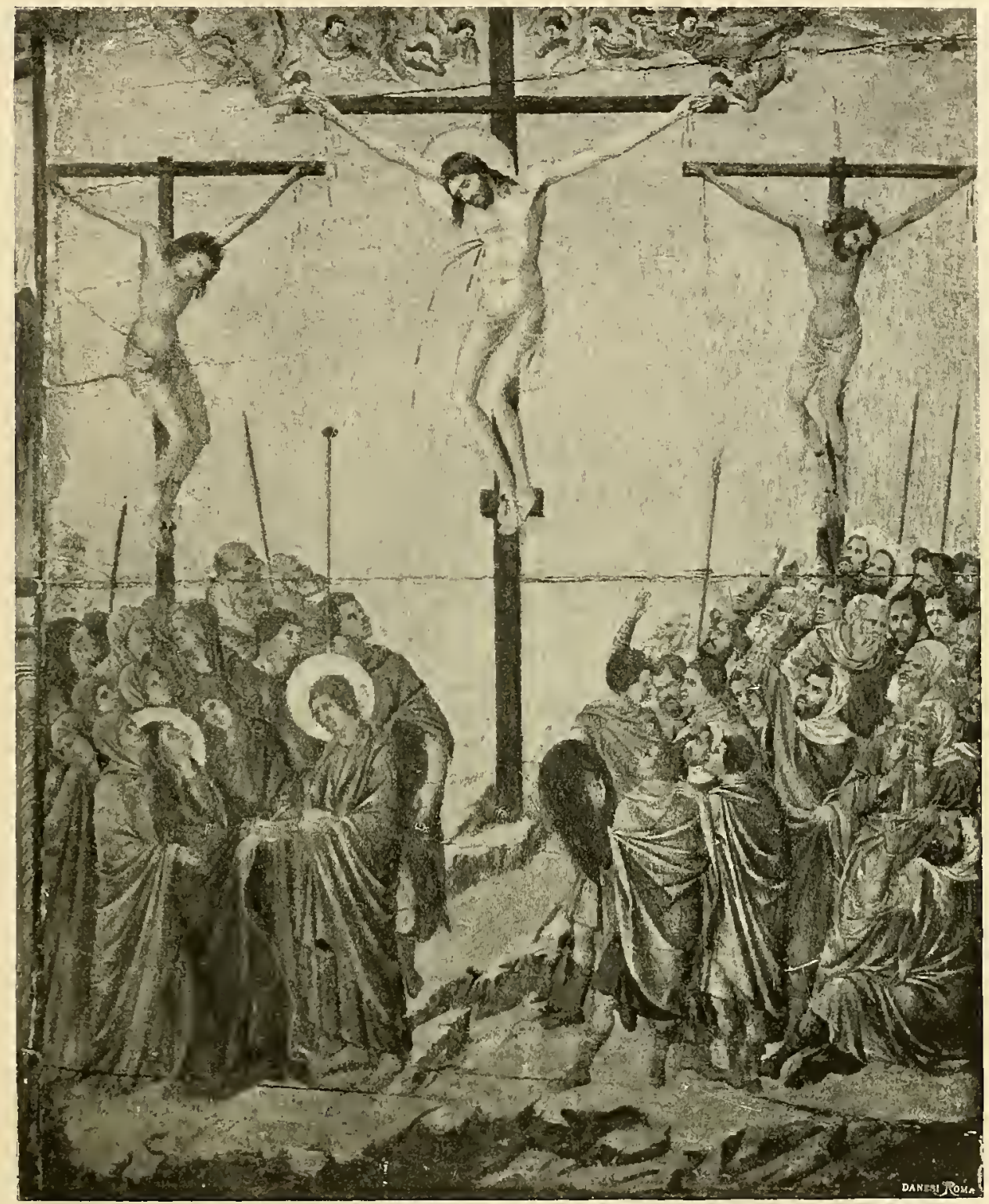

Museo dell'Opera della Cattedrale di Siena

(Duccio di Boninsegna)

risude leggi della simmetria; e cosi, prossimi alla croce, in proporzioni minori delle figure di Maria e Ciovanni, si corrispondono Longino il portalancia, rappresentante la gentiliti convertita, e il portaspugna, che ricorda il giuclaismo ostinato. 
Cristo è calmo, con gli occhi aperti, impassibile, come se $\mathrm{i}$ chiodi non gli perforassero le mani e i piedi; stende orizzontali, senza sforzo, le braccia, e poggia i piedi su una mensola o uno sgabelletto, senza che le gambe si ripieghino o si storcano. È il Dio insensibile al dolore delle membra che lo vestono, è il trionfatore della morte. La croce stessa su cui è inchiodato verdeggia talora come albero della vita, secondo la leggenda della sua origine adombrata nell'Evangelo di Nicodemo così : Il padre Adamo disse a suo figlio Seth di raccontare a' suoi figli, ai patriarchi, ai profeti, le cose udite dall'arcangelo Michele, allorchè si recò alle porte del Paradiso per supplicare il Signore che gli largisse l'olio dell'albero della misericordia, a fine di ungere il corpo malato del padre. E Seth, avvicina-

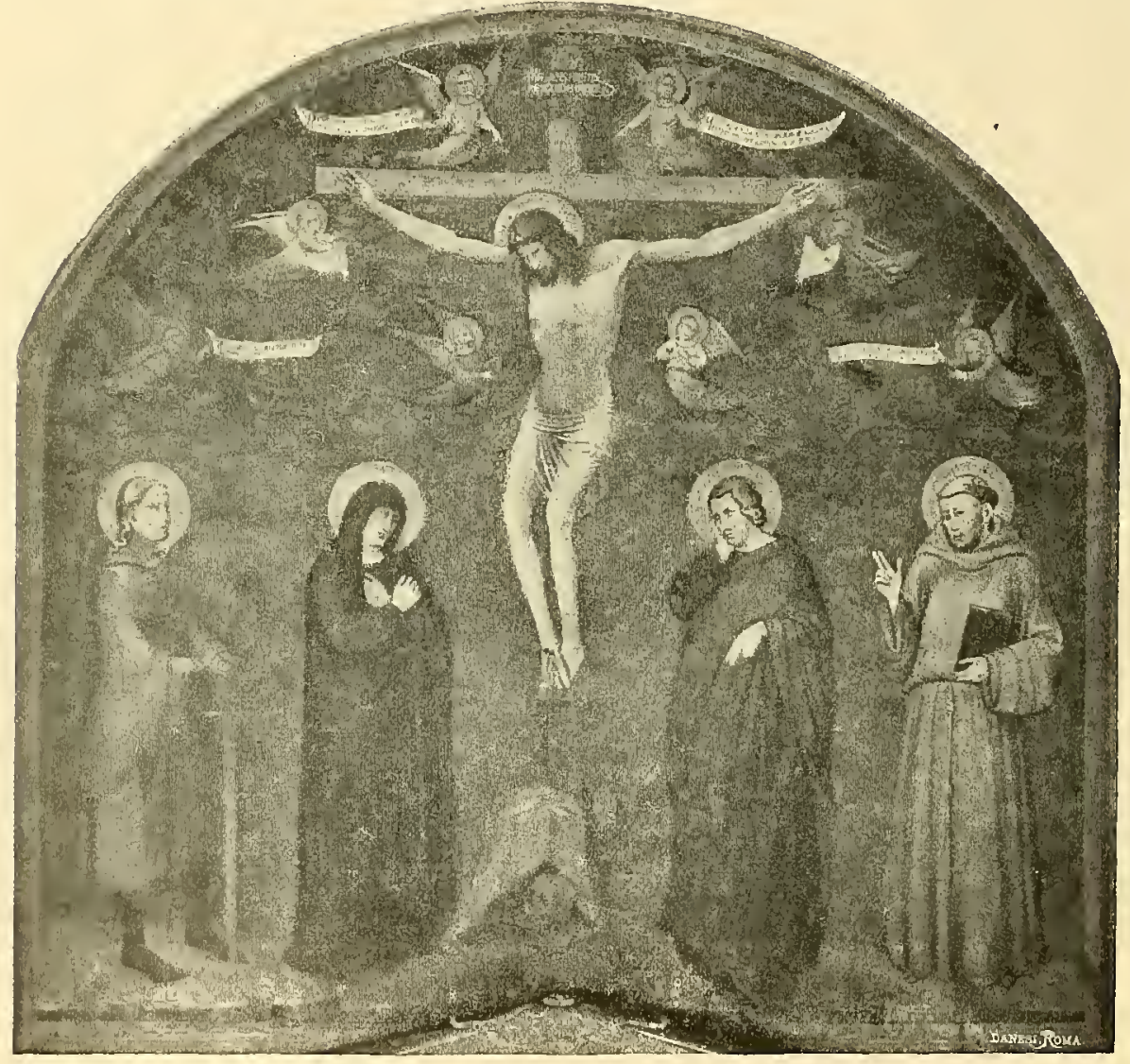

Calledrale di Arezzo

(Berna Senfese)

tosi ai santi patriarchi e ai profeti, disse: Io pregavo il Signore, innanzi alle porte del Paradiso, quando l'angelo del Signore, Michele, mi apparve, 
dicendomi: Dio m'ha inviato a te; non chiedere l'olio dell'albero della misericordia per ungere l'egro corpo di tuo padre Adamo, perchè in alcun modo

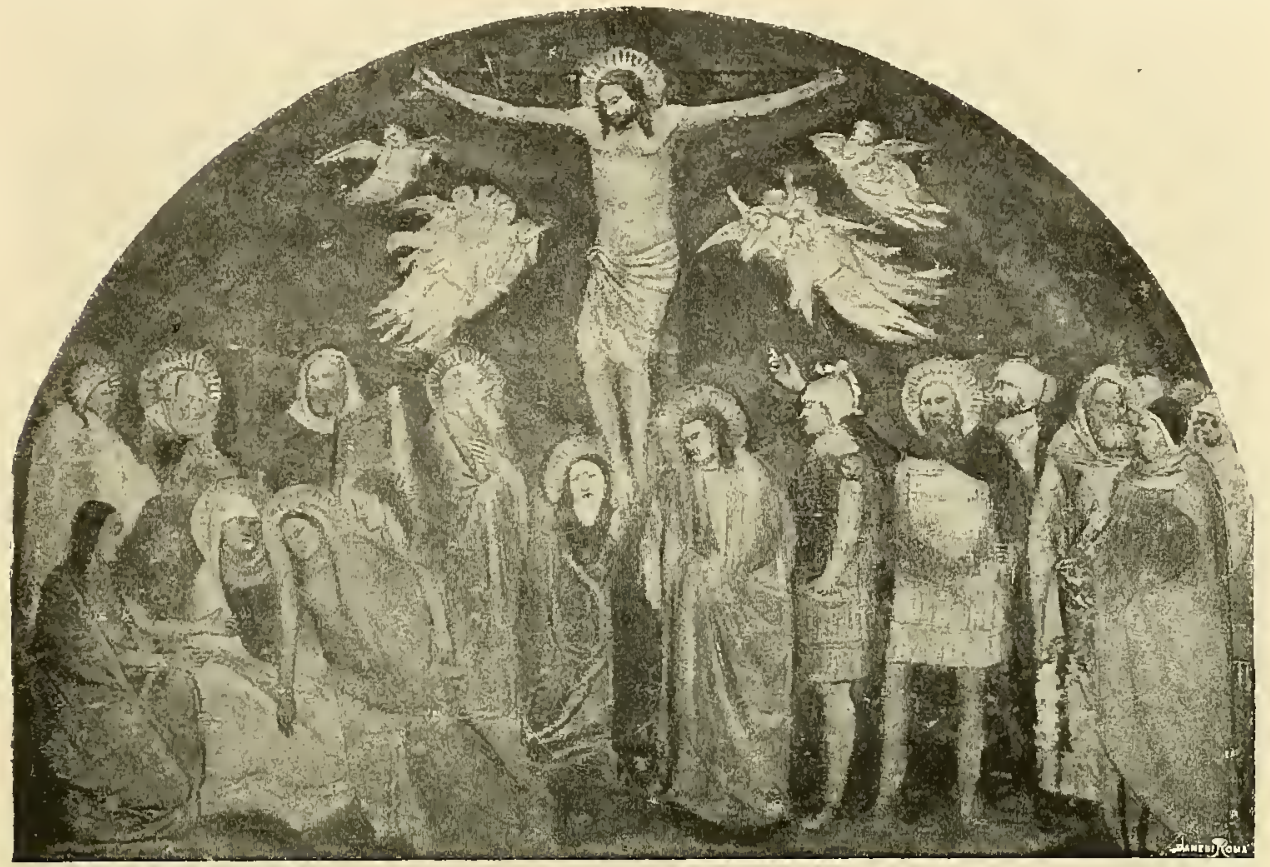

Chiesa di Santa Maria Novella in Firenze

(GiotTino)

non ne potrai ricevere, se non tra mille e cinquecento anni, allora che il Figlio di Dio, ardente d'amore, verrà sulla terra e resusciterà il corpo di Adamo e dei morti ». La leggenda si svolge più ampia, più ricca in seguito. Seth, Abramo o un figlio di Noè pianta un seme o un germoglio portato dal Paradiso terrestre, e ne spunta un albero che fornisce ad Aronne e a Mosè le magiche verghe. Tagliato per servire alla costruzione del tempio di Salomone, non fu usato però dagli architetti, e allora fu posto come ponte su di un fiume, ove rimase, benchè la regina di Saba, che leggeva nell'avvenire, intravedesse il destino del legno meraviglioso. Più tardi, gettato in una piscina, ove andavano ad abbeverarsi gli armenti, comunicava alle acque virtù salutari, e, rimasto di nuovo inutile per il disseccarsi della piscina, fu messo in opera per il supplizio di Dio. Sotterrato insieme con le croci dei due ladroni, dopo la morte del Redentore (e qui incomincia un'altra leggenda), Elena, madre di Costantino, lo ritirò sul monte Calvario, su cui già si ergeva un tempio di Venere, e grazie alle indicazioni di un 
ebreo erudito, che avera fatto tesoro d'ogni notizia, d'ogni tradizione relativa al luogo. Na le tre croci non si distinguevano l'una dall'altra, perchè il cartello di quella del Salvatore si era staccato dal tronco. Allora Macario, vescovo di Gerusalemme, suggeri di mettere sulle croci a giacere tre malati,

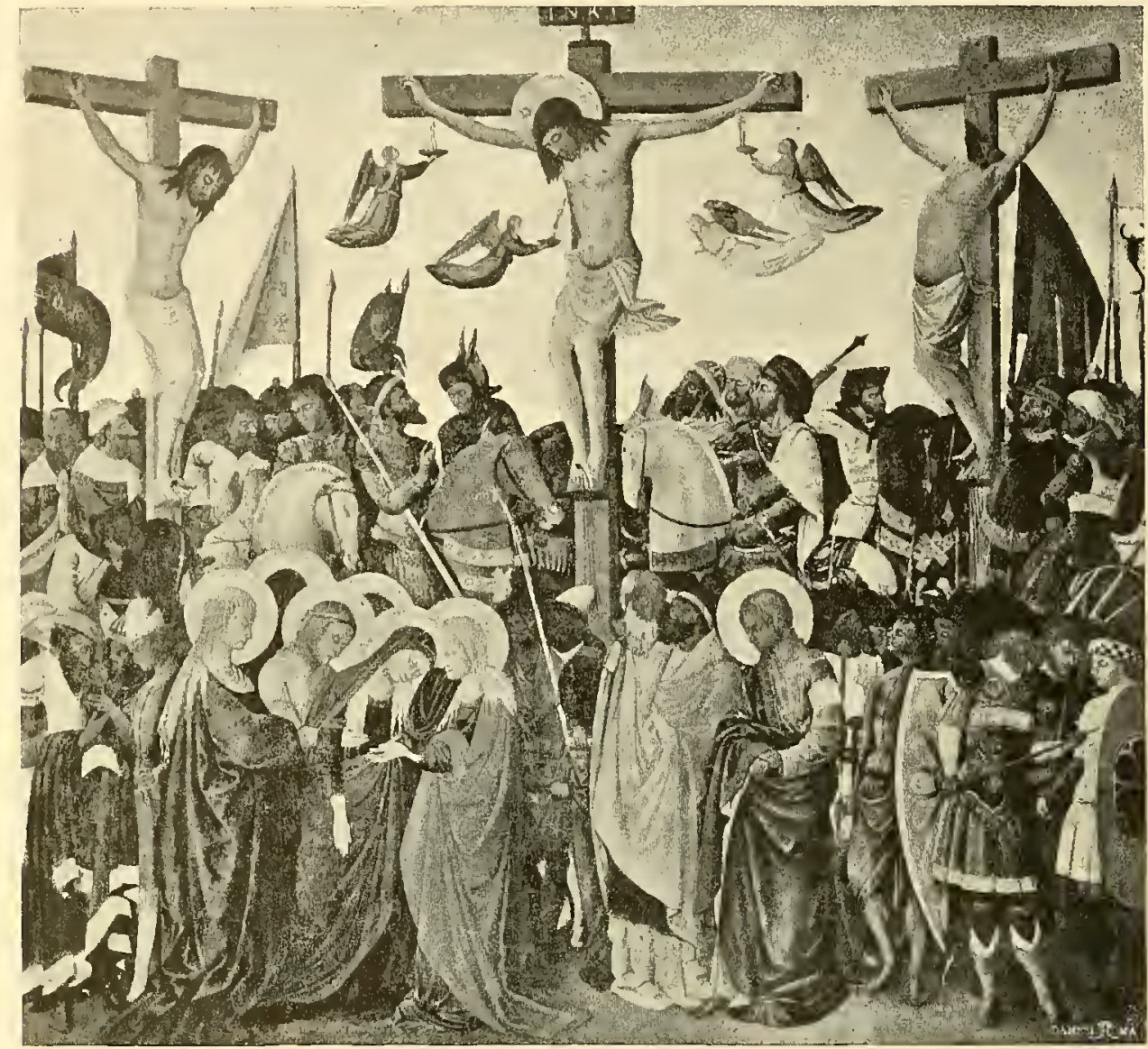

Galleria antica e moderna in Firenze

(Pittore de! principio del secolo xv)

per riconoscere quale fosse la sacra; e cosi fattosi, l'una, che si designò per quella del Cristo, operò la guarigione del misero. Elena allora adorò il Re che fu sospeso al legno, non il legno, scrive Sant'Ambrogio. Ed è il Re, tra gli emblemi della vittoria, colui che l'arte orientale specialmente rappresentò sulla croce: ad esempio, nel Cristo di Nicodemo, o Volto Santo di Lucca, non posteriore al secolo vir, ov' Ei si mostra nello splendore della regalità o del sacerdozio. Inclossa una tunica con maniche, veste che cloveva divenire meno comune, per la diffusione dell'Evangelo apocrifo Actr. Pilati, 
in cui leggesi che il Cristo, spogliato delle vesti, ebbe cinti i fianchi da un drappo di lino; o per la leggenda, formatasi su questo passo dell'Evan-

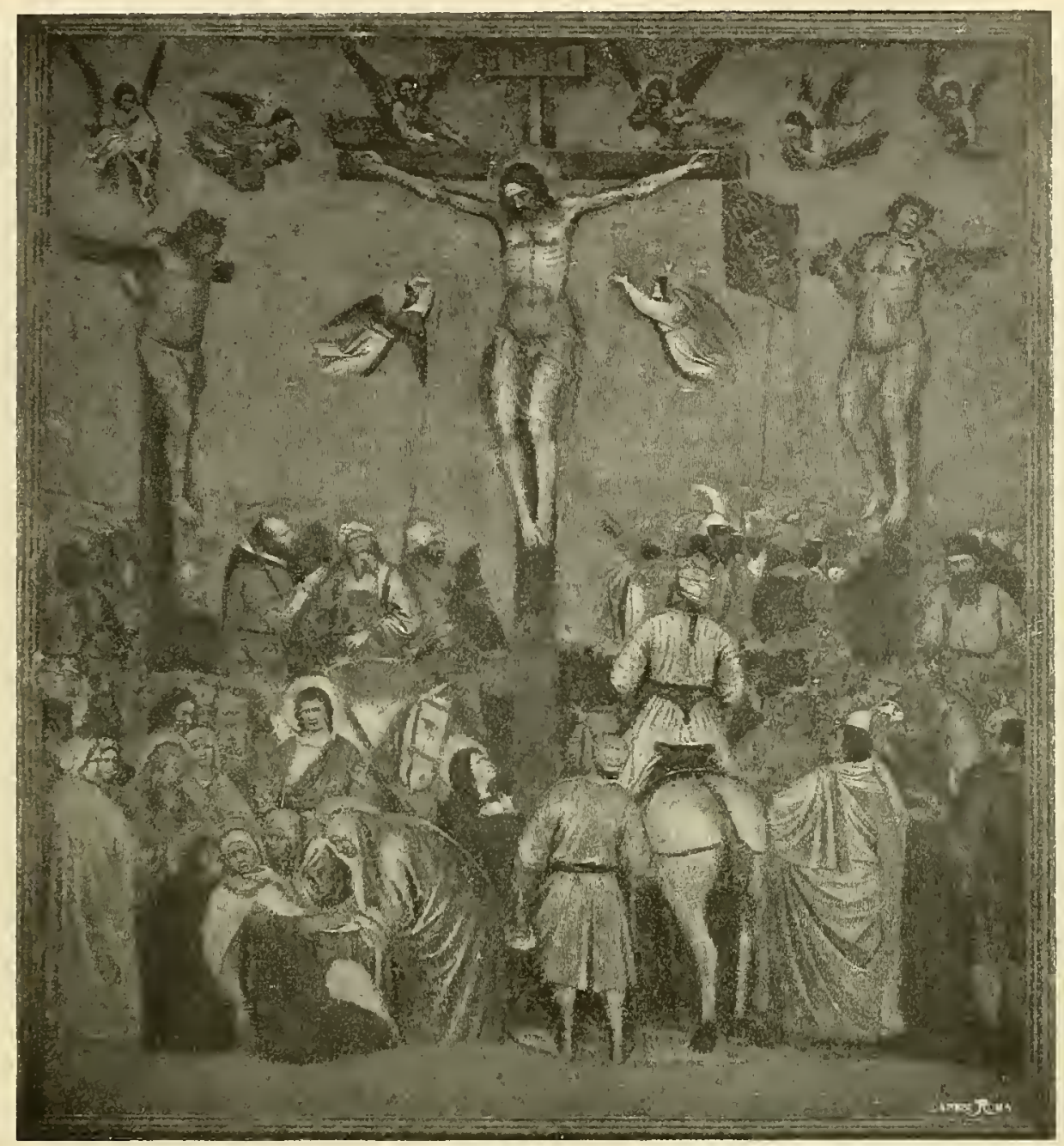

Oratorio di San Giorgio in Padova

(JACOPo AvanzI)

gelo apocrifo, che rappresenta la Vergine in atto di levarsi il velo dal capo per coprire la nudità del Figlio martire.

Mentre l'arte si provava a rispecchiare le pie leggende, infierì la contesa degl'Iconoclasti, e l'immagine del Crocefisso fu presa principalmente di mira dai persecutori. Consacrata dalla persecuzione, nel periodo carolingio essa si presenta con gli elementi antichi e con altri nuovi. Nonostante la povertà delle forme, le idee penetrano, traspariscono sotto la materia 
indocile, sia pure a mo' di geroglifici, e la pietà umana move dal rigido corpo del Martire e fa nascondere nel manto i volti piangenti al sole e alla luna, sul Crocefisso d'oro di Lotario, ad Aix-la-Chapelle. La mano celeste

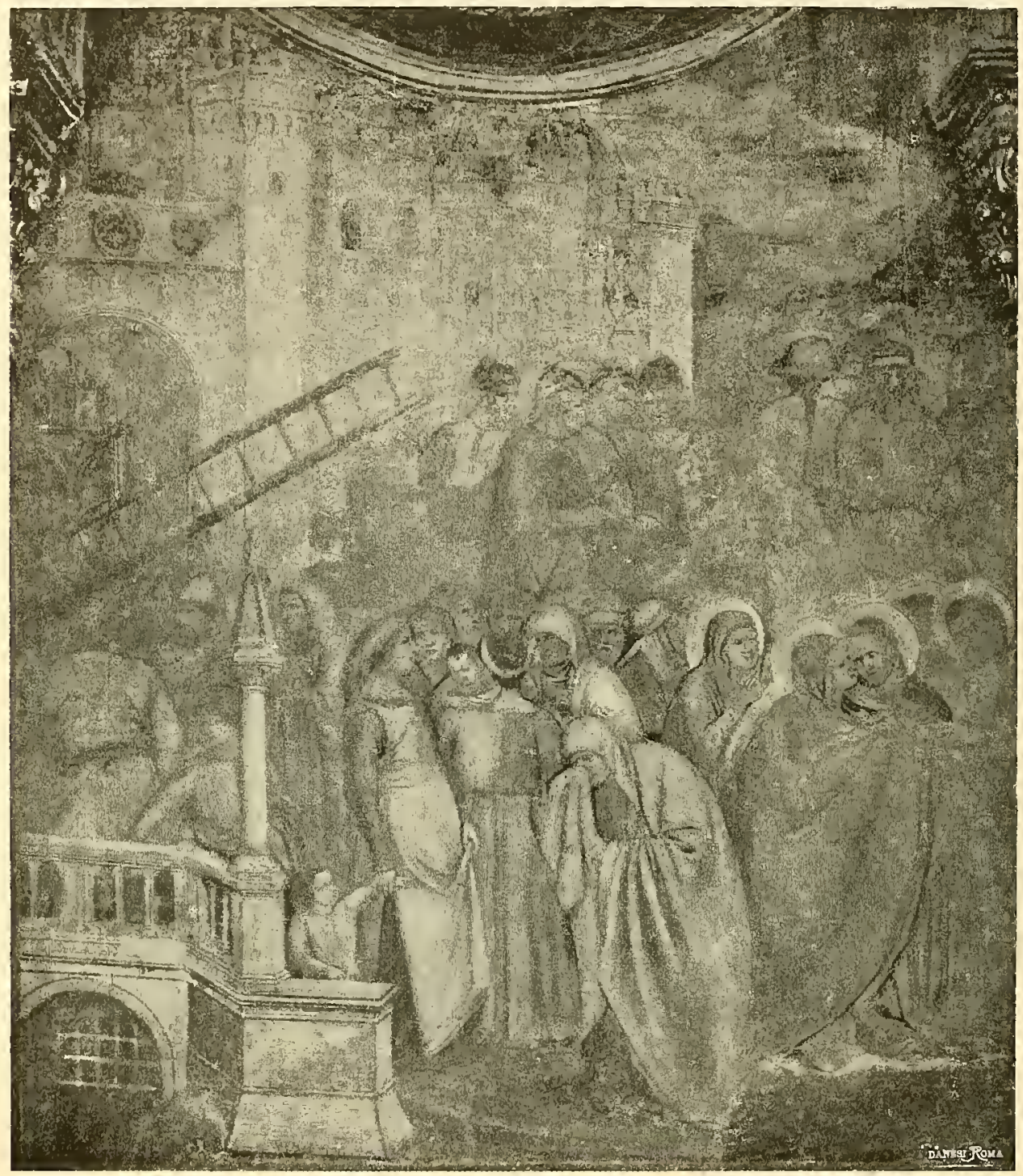

Basilica di Sant'Antonio in Padova

(JaCOPO Avanzi)

si sporge dal cielo, come nelle primitive rappresentazioni, ma tra lingue di fuoco, quali di un roveto ardente, e stende la corona sul capo del Figlio; la colomba, simbolo dello Spirito Santo, sta dentro il serto, e appiè della croce si torce un serpente cornuto, il quale allude alla lotta del male contro 
l'uomo, del principe delle tenebre contro il Cristo. Questi piega il capo sulla spalla destra, contrae alquanto il busto e curva le gambe, come se un tremito assalga il corpo percosso dalla lancia, mentre sta per rendere l'anima al cielo. Così il dolore dell'universo, significato dagli astri che sembrano tergersi il pianto, corrisponde all'espressione del dolore nel Cristo. La Vergine è sempre calma, o almeno sembra una pietosa visitatrice del Dio martire. Nel poema di remota antichità, attribuito a torto a Gregorio Nazianzeno (Patrologia di Migne, XXXVIII, pag. 309), la Vergine, vicina alla croce, riceve lode dal Figlio e invito a non piangere, perchè tutto ciò che fu annunciato si compie; e Maria, ammirando la generosità, la santità dell'anima del Cristo che perdona sulla croce, dice che aspetterà il sole per tre giorni, perchè si verifichi la promessa divina. Solo quando il Figlio non le risponde, la Madre esclama: "Fosse piaciuto a Dio che io avessi data per la tua anima la mia, che non ha più valore per me! Già

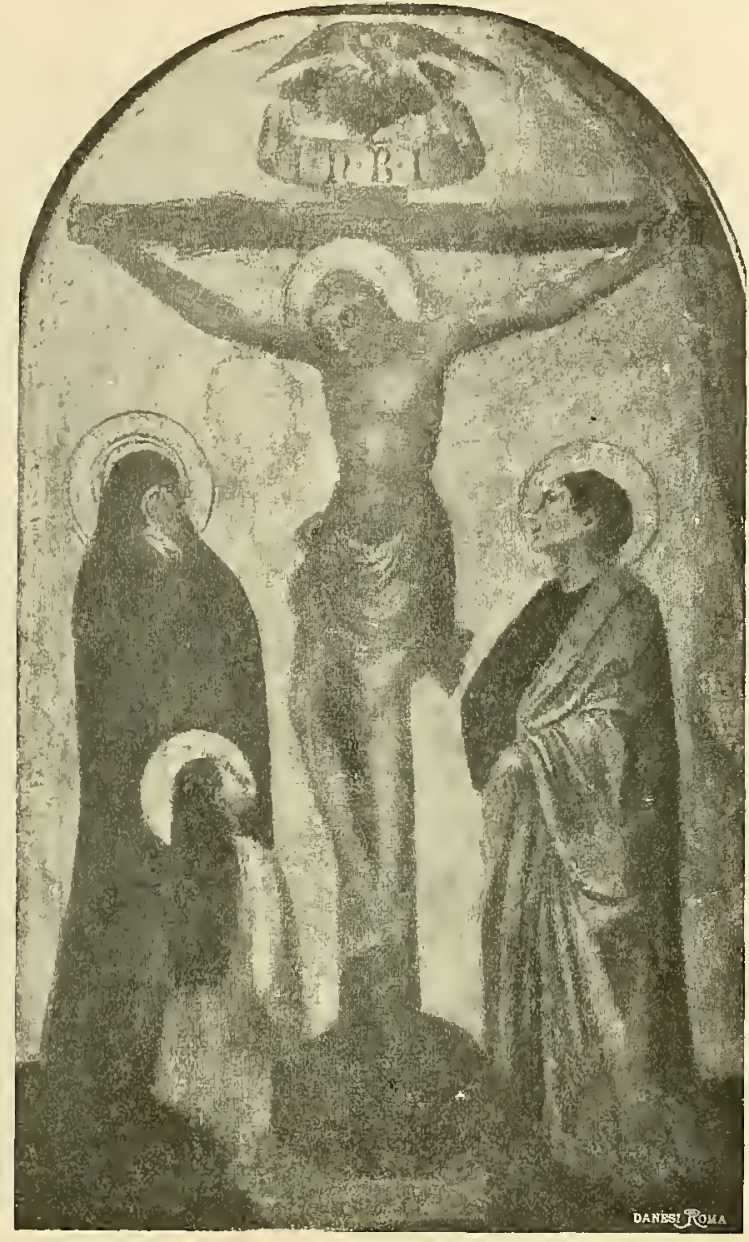

Galleria Colonna in Roma (Jacopo Avanzi bolognese) le tenebre velano i miei occhi; senza di te desidero di essere nascosta sotterra. Invano dunque ti ho nutrito, o figlio mio... Io non posso più reggere a guardarti; perchè sei tu silenzioso? Perchè non apri le labbra? Parla un po' a tua madre, o mio figlio! E in quest'ultima espressione si vede Maria in alcuni avorî carolingi delle Biblioteche nazionali di Parigi, di Monaco e di Firenze, con le mani stese, in atto d'invocare, di raccomandarsi.

In altre rappresentazioni del Ix secolo, oltre la mano celeste, il sole e la luna, Maria e Giovanni, il portalancia e il portaspugna, il rettile appiè 
della croce, vediamo la Chiesa e la Sinagoga, con le bandiere spiegate, farsi riscontro: la Chiesa raccoglie nel calice il sangue che sgorga dalla ferita del costato di Gesù ; la Sinagoga si allontana dalla croce. Nel basso, in un piano sottostante alla croce, sorge Adamo, sorgono i morti, fasciati come mummie, dalle tombe scoperchiate, dalle porte dei mausolei, e seggono, guardando la scena, la Terra altrice di rettili e di fanciulli, l'Oceano in aspetto di Nettuno, su delfini o su mostri del mare. Ronna stessa, la capitale della cristianità, sotto la croce, nel dittico di Rambona appare in forma di lupa lattante Romolo e Remo, e indica l'Occidente, a cui il Cristo, secondo

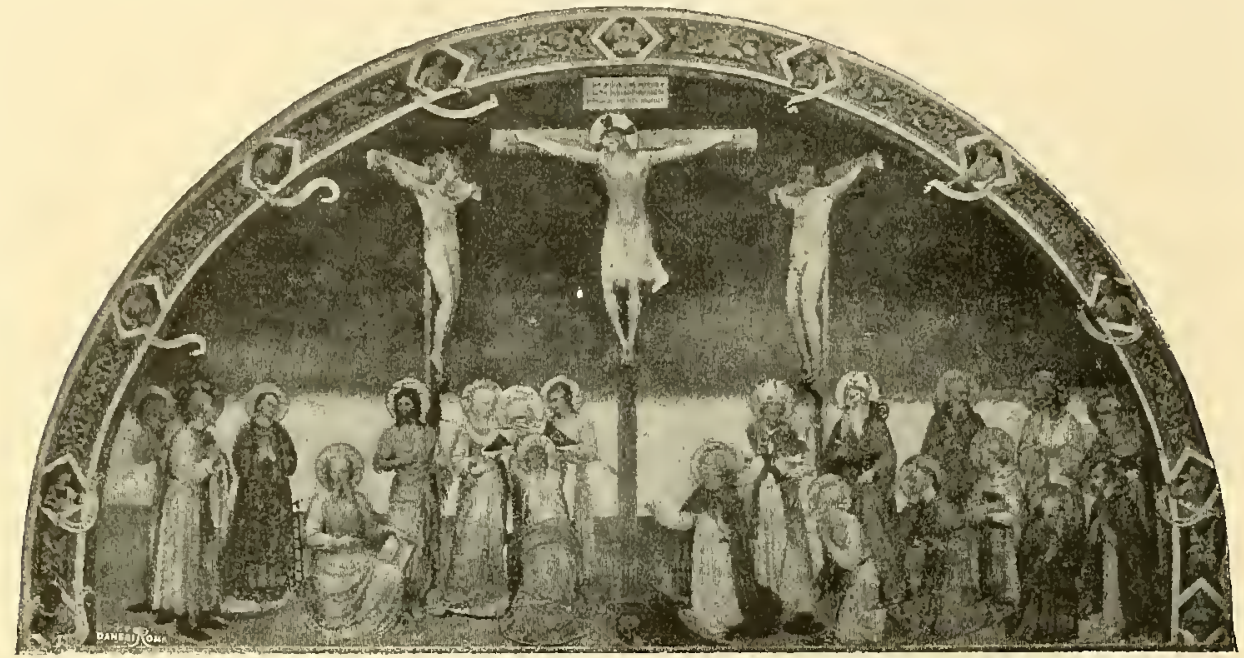

Museo di San Marco in Firenze

(Beato Angelico)

una credenza popolare, volse la faccia esalando lo spirito. Tutto il mondo geme per la morte del Dio, e la croce si eleva, non più albero della vita sulla mistica rupe, ma funebre insegna tra i popoli, alta sulla terra e sul mare; non più a' suoi piedi le azzurre acque dei fiumi del Paradiso, ma cranî e ossa sul Calvario, cimitero de’ rei.

In questa desolazione, la Madre del Cristo s'appressa alla croce, reg. gendosi con una mano la testa, come Giovanni che le fa riscontro, e stendendo l'altra verso il figlio. La figura si conserva calma nel dolore, non si dispera, non leva strida, non sviene, sì come è detto negli Acta Pilati, non cade con la faccia a terra, come il Venerabile Beda la descrive nelle sue Meditazioni. Non era dato all'arte co'suoi scarsi mezzi, co'suoi segni stentati, di mostrare la profondità del dolore di Maria. Solo facendole 
portare il manto al volto o la sinistra alla guancia, secondo l'antico modo classico di rendere l'afflizione, si sforzava a rappresentare lo strazio, e facendole stender le mani invocanti, s' industriava di rivelar la tenerezza materna. Dall'alto, ad attestare il lutto del cielo, arrivano intanto i puri spiriti, gli alati messaggeri, con la testa piegata sulle spalle, con le mani protese

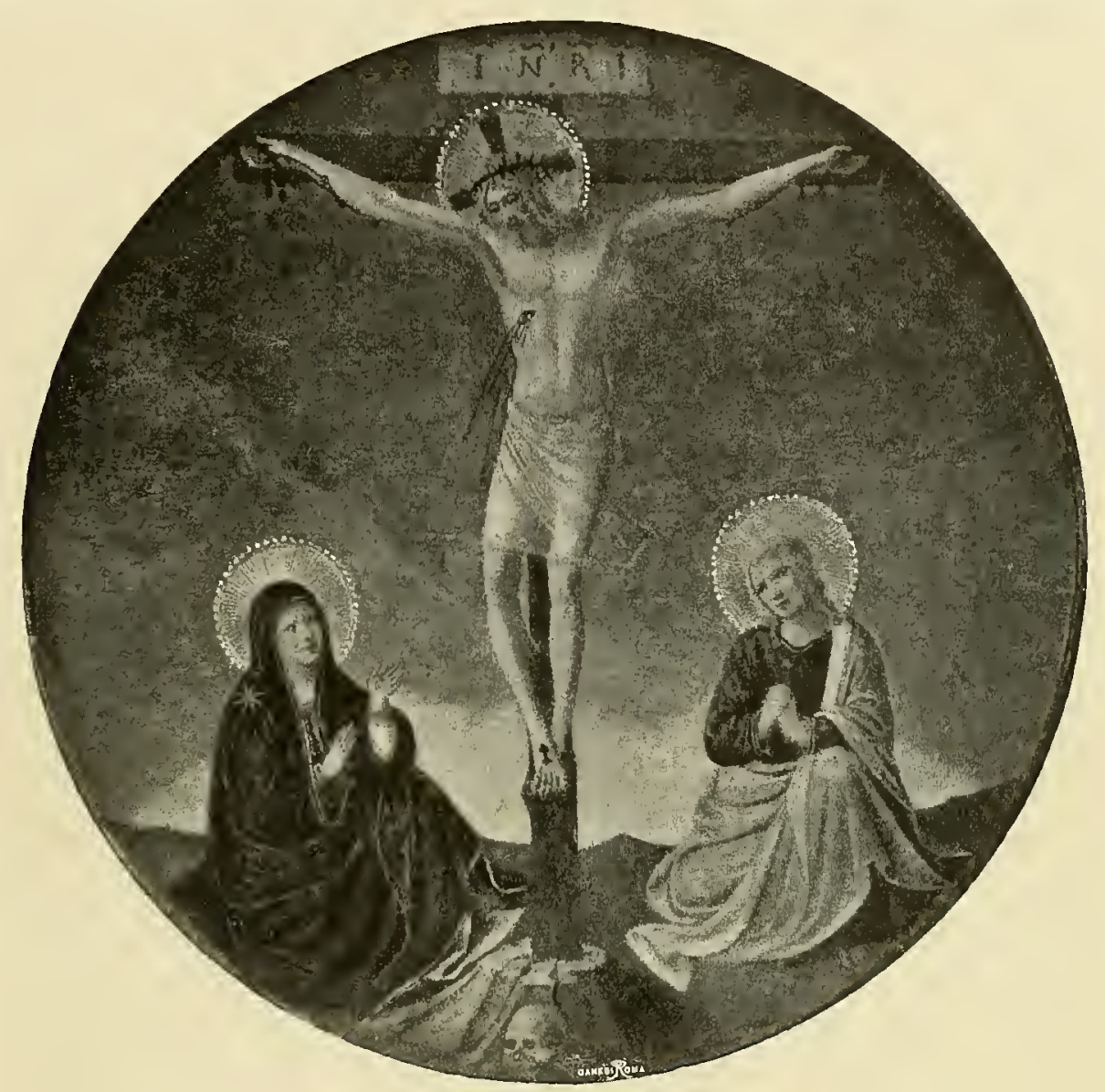

Galleria antica e moderna in Firenze

(Bento Angelico)

verso il Cristo, a coronare la croce. Più tardi si riceverà nei calici e nelle coppe il sangue divino, che ora la Chiesa raccoglie, ora il padre Adamo, o anche Giuseppe d'Arimatea, custode del San Graal, secondo la leggenda che annodò alle avventure dei cavalieri della Tavola Rotonda l'avvenimento della morte del Redentore.

Trascorso il periodo carolingio, l'arte, sino al secolo xin, mescolò gli elementi già ragunati. lasciandone in disparte or più, or meno, richiamando 
in voga rappresentazioni cadute in disuso o ripetendole con poche varianti. Vediamo quindi al principio del secolo xis, in Roma, nella basilica di San Clemente, il Salvatore confitto alla croce, lungo i bracci della quale volano

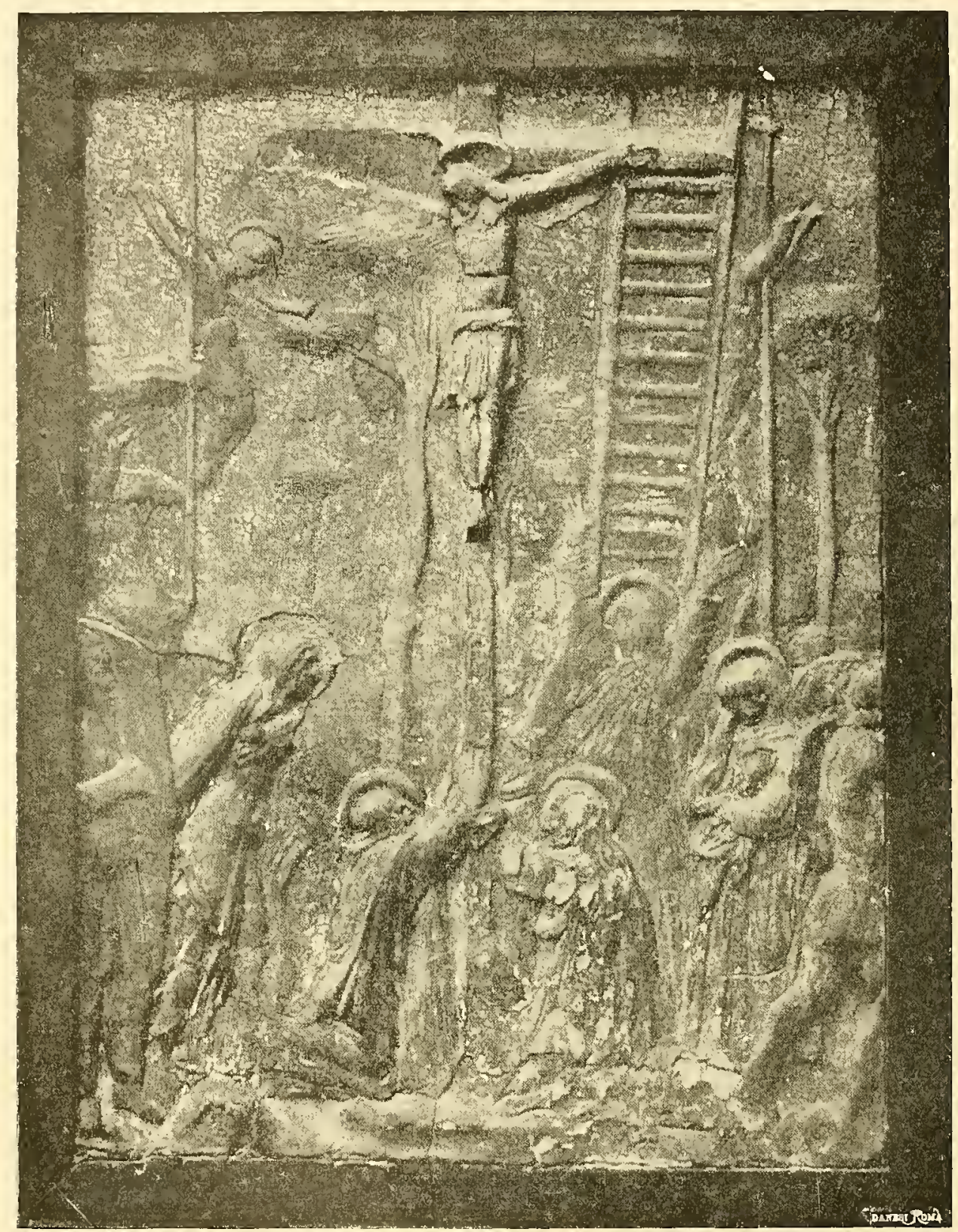

Stucco nel Mfuseo di Berlino

(Donatello)

dodici colombe, simbolo degli evangelisti; in alto, la mano sporgente dalle nubi; in basso, a piè della rupe da cui si estolle la croce, i quattro fiumi 
dell'Eden, che irrigano i pascoli del gregge di Cristo e a cui corrono a dissetarsi pellicani, cigni, pavoni e cervi. Dal cespo donde esce la croce si dipartono verdi rami che si svolgono per tutta l'abside e racchiudono entro le spire uccelli, fiori e santi, per dare l'idea del giardino della feli-

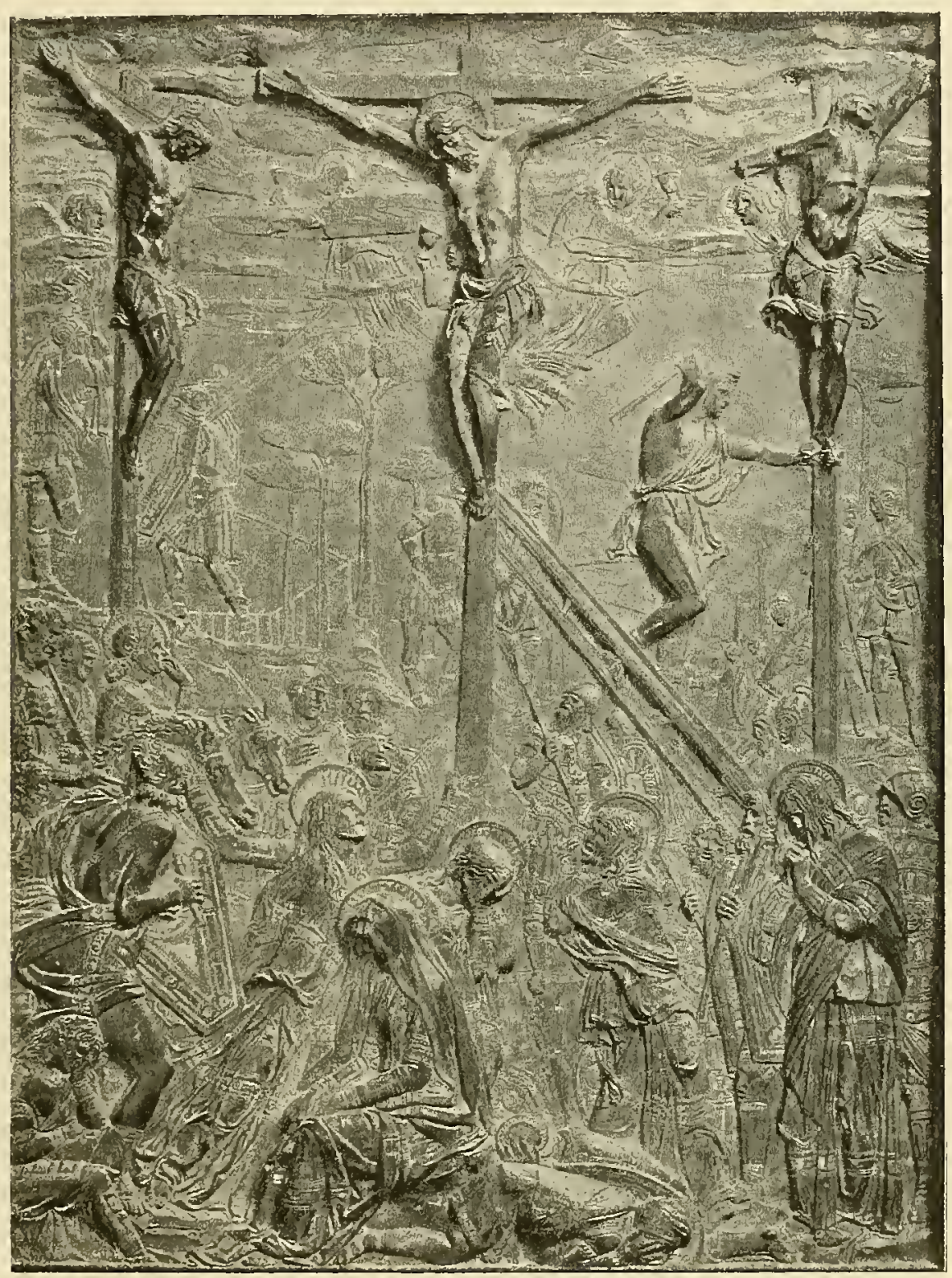

Nuseo Nazionale di Firenze

(DONATELLO)

cità. In tal modo, nel secolo xir, si tornava ad illustrare $\mathrm{i}$ versi di Paolino da Nola, come nel candelabro di San Paolo fuori le mura, il Cristo in 
croce che vi è scolpito veste alla guisa dei Crocefissi del secolo vı, con una tunica o colobio senza maniche, e, come il Crocefisso di Santa Sabina, serba le proporzioni, tanto maggiori dei due ladroni che gli stanno ai lati. E mentre gli artisti s'ispiravano da una parte alla primitiva semplicità del Crocefisso, dall'altra tornavano all' arcaismo siriaco, forse per la celebrità goduta da alcune immagini, quale ad esempio il Volto Santo di Lucca, nel cui nome giurava volentieri il normanno re d'Inghilterra Guglielmo il Rosso; e, certamente, anche per l'impotenza dell'arte a creare staccanclosi dai vecchi tipi.

Il Crocefisso di Robert Curzon, di cui tenne parola Lady Eastlake, e quello analogo pubblicato da Grimouard de Saint-Laurent, sembrano idoli. La corona, già di fiori e di fronde, cambiatasi in corona regale, non più vien protesa dalla mano dell' Eterno o dagli angioli sul capo del Cristo, ma ne cinge la fronte: una tunica orlata di pietre pieziose, con la cintura pure gemmata e splendente, riveste la figura del Re e del Pontefice, che, con gli occhi spalancati, la chioma ricadente sugli omeri, le braccia orizzontali, sta a perpendicolo sulla croce. In queste forme risorte dall'antico pare che lo spirito umano abbia quasi rinunciato a lasciare la sua impronta nel tempo, anzi abbia dimenticato in gran parte il cammino affannosamente percorso lungo i secoli per rintracciare forme nuove. Eppure la vita continuava a fluire tra quei fantasmi d'altri tempi e luoghi, e qualche leggero moto si vede nell'arte romanica.

L'Eterno sin dal secolo xir non sporge più la mano tra le nubi, ma si mostra su esse a mezzo busto, come nelle scene della Creazione e nelle altre ove occorreva indicare l'intervento divino. Dal costato del Cristo ferito di lancia sprillano acqua e sangue a raggi sul volto di Longino, che retrocede e sembra cadere riverso. Così nella Crocefissione della chiesa di Sant' Urbano alla Caffarella, affresco del secolo xis, ove il Cristo ha la fronte cinta d'una corona non più di fiori, non più di gemme, non più di gloria, ma di spine che la insanguinano. Non in quel monumento, bensì in altri contemporanei appare la figura del Centurione, che, vedendo la Natura conmossa per la morte del Cristo, lo glorifica e lo proclama giusto. Il Centurione, che poi prende tanta parte nella rappresentazione, non prima del secolo $x$ si fa largo tra le figure che popolano la vetta del Golgota, forse perchè l'arte sino allora aveva raffigurato il Cristo vivo. Nell'arte romanica 


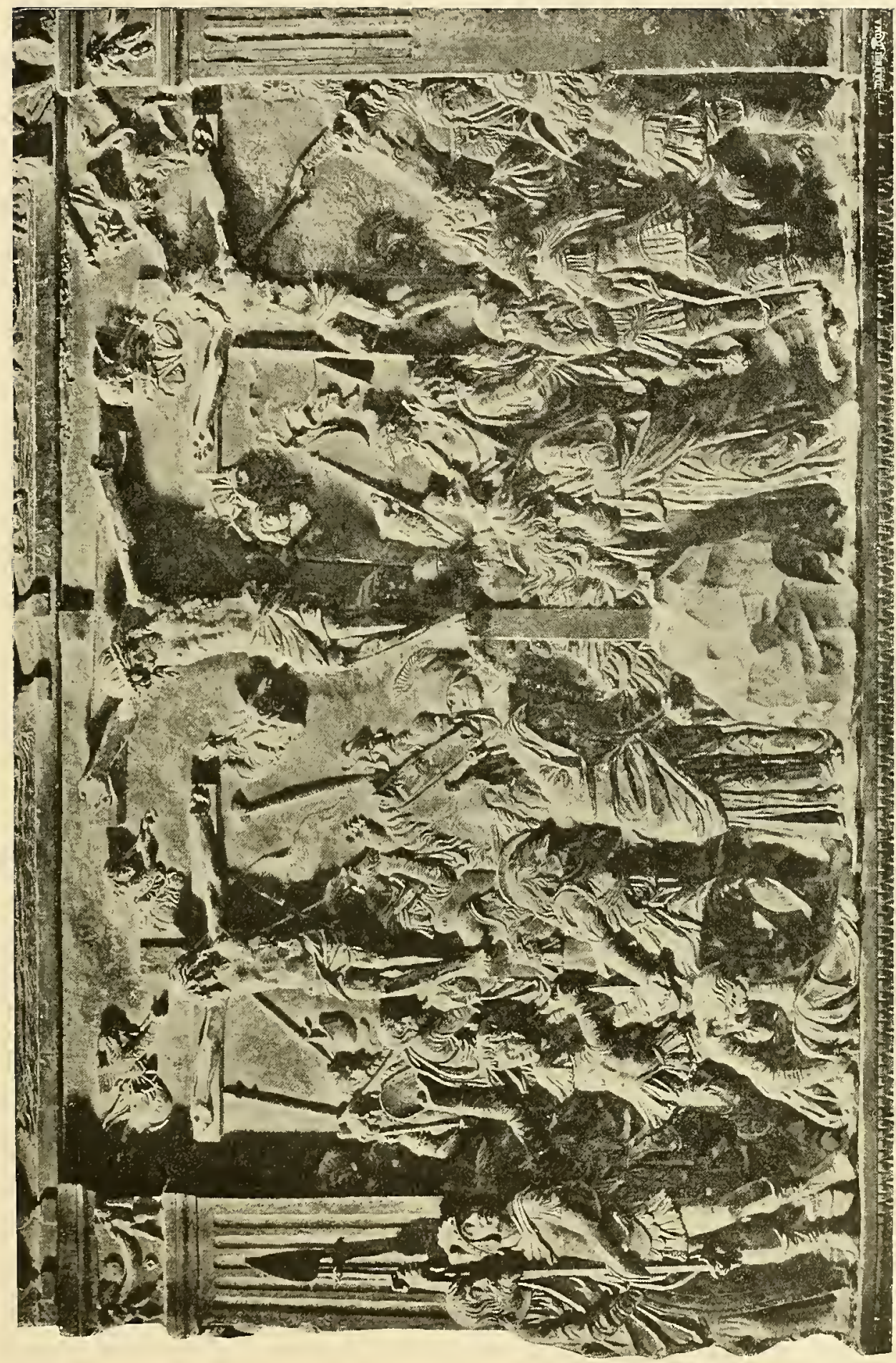


Gesù pende dalla croce spesso con gli occhi chiusi (esémpio il Crocefisso scolpito del Museo di Arezzo); e il Centurione doveva quindi intervenire per additare con la destra sollevata la vittima innocente.

Tutti questi elementi sembrano turbinare intorno all anima dell'arte, finchè non compongono il dramma. E il clramma prorompe nell'opera di Giunta ad Assisi, ove San Francesco ginocchioni stringe teneramente il piede della croce. Maddalena alza le braccia disperata, e uno stormo d'angeli in lagrime batte le ali intorno al Cristo e raccoglie nelle coppe il sangue che gli sgorga dalle piaghe.

I simboli precedenti si nascondono nella realtà della rappresentazione del secolo xilı, o almeno prendono sangue e moto, lasciando la tranquillità ereditata clall'arte classica. La Chiesa, ad esempio, nelle opere di Nicola Pisano e della scuola, a P'isa, a Siena, a Pistoia, si avanza verso il Cristo con un vaso o un modello di battistero, accompagnata o trasportata da un angiolo; mentre la Sinagoga, non vaga fanciulla o giovane sposa come la Chiesa, ma vecchia strega, in odio alle genti, da un altro angiolo è respinta lontano. Queste ed altre personificazioni dovevano presto scomparire, quasi che, non create nei tempi primitivi del cristianesimo, mancassero, come altre di differenti soggetti sacri, della consecrazione religiosa e del suggello di tradizioni tenaci. Anche nel secolo xul l'attenzione sembra rivolgersi di preferenza alla figura del Cristo, che ricasca col peso del corpo sulle braccia, ed ha le dita delle mani contratte, la fronte solcata da rughe, i muscoli e il ventre gonfi, il corpo contorto, i piedi (l'un l'altro sovrapposti e confitti da un solo chiodo) irrigiditi sullo sgabello del legno infame. Innumerevoli i Crocefissi giganteschi di quel tempo, che sui bracci della croce e in riquadri sulla croce stessa, o intorno a mo' di cornice, rappresentano i personaggi principali del dramma della Passione e della Morte del Cristo. Lo spirito di San Francesco che si strugge di soffrire come il Crocefisso e riceve le stimmate qual ricompensa di amore, sveglia e innova da per tutto il culto dell'immagine. La rappresentazione prima della Redenzione, mutatasi poi in quella del trionfo della Divinità, sta per trasformarsi in una scena di tenerezza. Il Cristo non sarà più l'eroe, fra i trofei, nei paludamenti sacerdotali, con regali insegne, ma l'uomo che si sacrifica per l'uomo, il pellicano che dà cibo di sè a'suoi nati, unico simbolo questo aggiuntosi nel Trecento agli antichi. Nella chiesa inferiore di San Francesco in Assisi, Giotto crea il dramma 
del Golgota, congiunge con l'ardore del sentimento i personaggi rimasti quasi sempre isolati. Volano nell affresco gli angioli intorno al Cristo morente, bat-

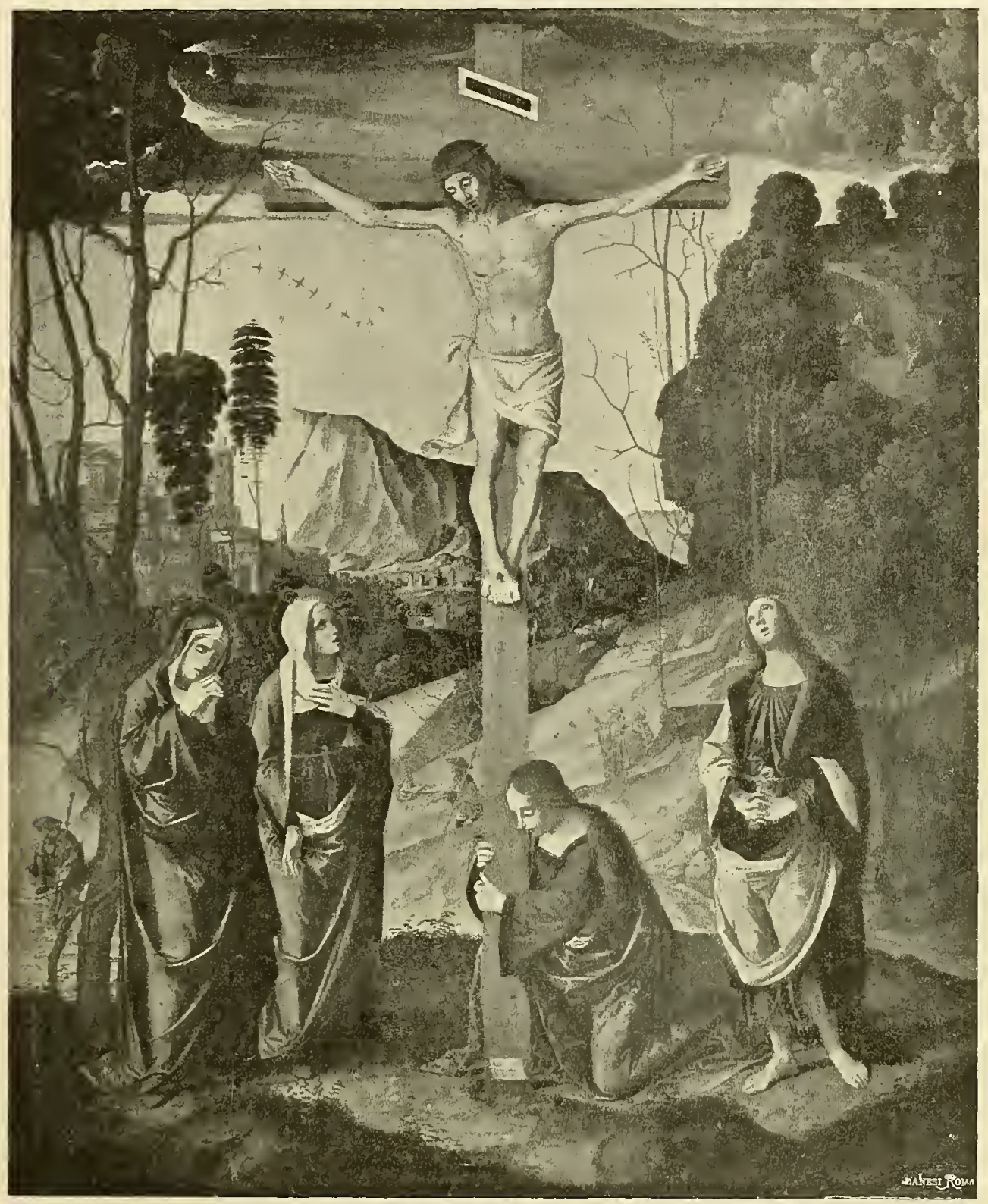

Galleria degli Utizi in Firenze

(Marco Palmezzano)

tendosi le guance, strappandosi le vesti, disperati; Maddalena s'appressa riverente e pietosa ai piedi dell' Uomo-Dio; s'avanza Giovanni con le mani congiunte, strette sotto al mento, e lo seguono due pie donne che scoppiano in moti di dolore, mentre altre, accasciate, soccorrono, sostengono la Vergine 
Syenuta, cui la mano ricade in abbandono senza forza e la testa si piega sulla spalla destra, velata dall'ombra della morte. Dall'altra parte San Francesco adora e pare si sollevi con le braccia, col corpo verso il Dio; e dietro a lui, inginocchiati a due a due, altri fraticelli d'Assisi pregano divotamente. E prega Longino in piedi con le mani giunte, mentre il Centurione, vòlto alla turba de' Giudei, con piglio soldatesco par che proclami la divinità di Gesù, e la turba si ritrae pensosa. L'umanità si strugge di dolore innanzi alla salma del Cristo, sospesa sulla croce, col capo chino, come

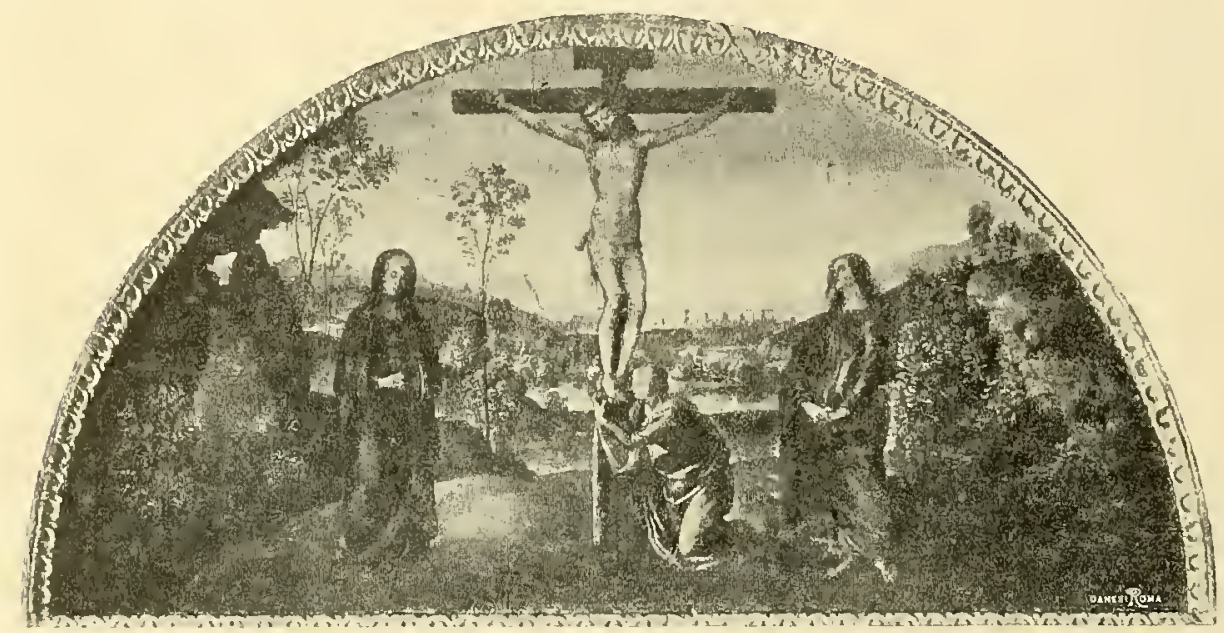

Lunetta del quadro esistente nella Villa Albani

(Perugino)

in ascolto delle preghiere e dello strazio dei cuori. D'un tratto il genio di Giotto soppresse tutte le materialità medioevali, gli astrusi simboli, e creò il dramma con insuperata potenza. Cimabue ad Assisi aveva fatto avanzare a stento la divina Madre verso la croce; Nicola Pisano, nel pulpito di Pisa, l'aveva fatta cadere nelle braccia delle pie donne, all' indietro, con gli occhi aperti e con una mano sul petto, in segno dell' interna ambascia. Giotto espresse a Padova il subito venir meno della Vergine, il vacillare delle membra disfatte dal dolore, il capo ricadente sulla spalla destra, le braccia ciondoloni, gli occhi chiusi come per sonno; il bell'ovale del volto di donna ancora nel fiore degli anıi è rischiarato dal nimbo luminoso, e il corpo, benchè si pieghi, conserva ancora la matronale grandezza. Più drammatico il Cavallini ad Assisi, e poi Duccio di Boninsegna a Siena, fecero che la Madre, sorretta dalle pie donne, si avanzi e fissi disperata l'ultima volta 


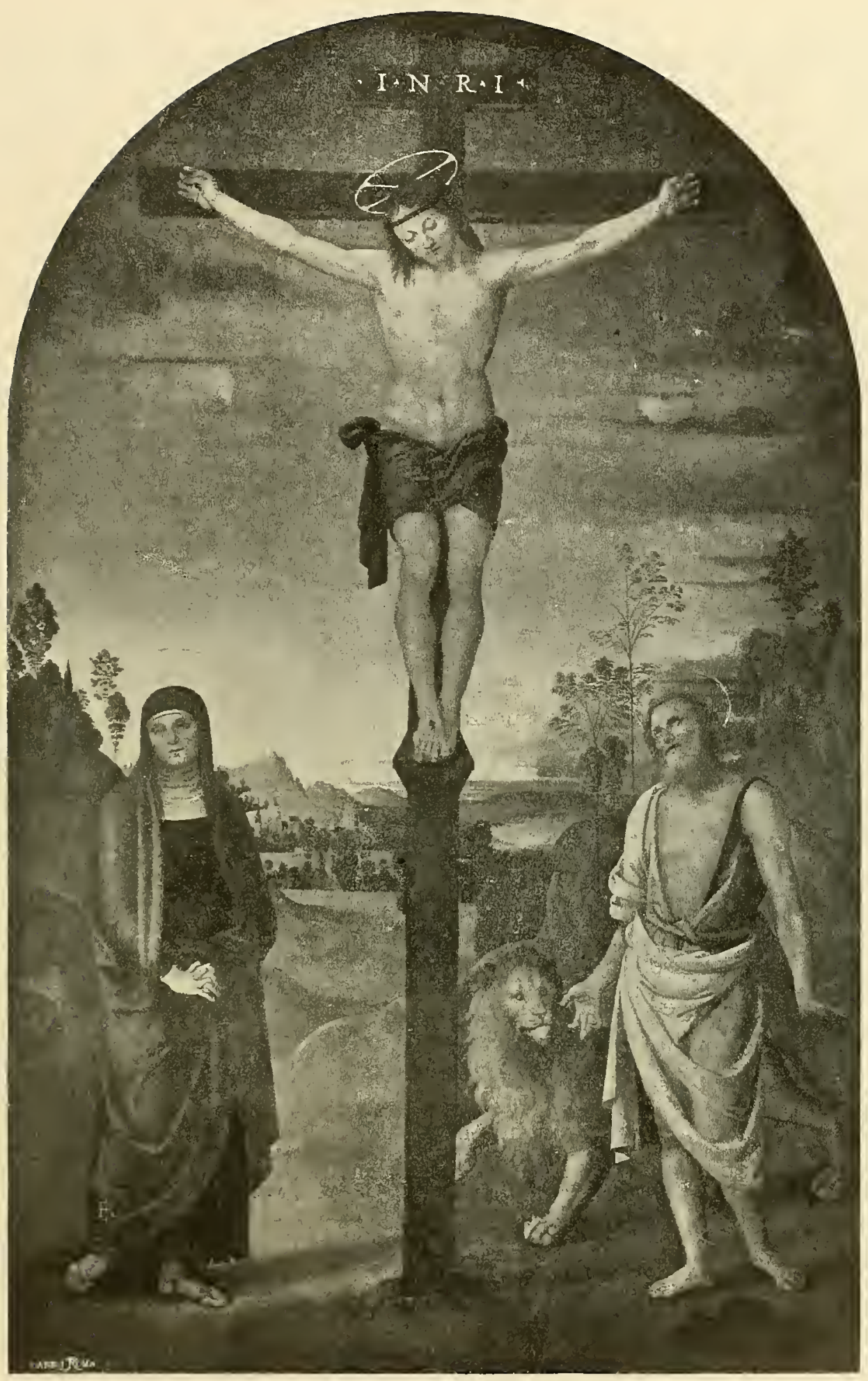

Galleria antica e moderna in Firenze (Perugino) 
l'immagine del Figlio morente; e Giovanni Pisano, nel pulpito di Pistoia, svolgendo questo motivo, fa cadere Maria esanime, all' indietro, tra braccia pietose, col volto in aria, come se la visione del dolore del Figlio l'avesse priva dei sensi. Ma Giotto, anche nella realtà del dolore, non dimenticò la divinità della V'ergine.

1 seguaci di Giotto, pure attenendosi alle forme del maestro, affollarono di popolo la vetta del Golgota; così che tra i fanti e $\mathrm{i}$ cavalieri passano le pie donne e pregano i beati; sui pennoni. le lance e le lunghe tube, volano gli angioli. Duccio di Boninsegna a Siena raccoglie in due gruppi, a destra e a sinistra della croce, la folla del Golgota; e vi riuscì alquanto, benchè le figure si assiepino, facendo drizzare gli sguardi di tutti verso il Cristo, mentre a destra la Vergine chiude gli occhi rivolti al Figlio, a sinistra il Centurione, in mezzo a' Giudei, con un gesto oratorio accenna la vittima innocente.

In queste composizioni $\mathrm{e}$ in altre contemporanee potrebbero distinguersi tra i soldati il portalancia e il portaspugna; ma essi non toccano più il Cristo. La ressa della moltitudine ha spezzato la simmetria. Dalla ferita del costato di Cristo zampillano acqua e sangue, che nè la Chiesa, nè Giuseppe d'Arimatea, nè Adlamo raccolgono più, bensì gli angioli in preda alla disperazione, mentre altri di essi portano al cielo l'anima uscita dal corpo del buon ladrone. e $\mathrm{i}$ demoni afferrano quella del ladrone cattivo.

Il dramma non più si svolge chiaramente, come nell'opera di Giotto, in quelle grandiose rassegne di popolo di Pietro Lorenzetti ad Assisi, di Simone Martini a Firenze, nel chiostro di Santa Maria Novella, e altrove. Chi piange, chi prega, chi discute, chi fugge: nugoli di cavalieri nelle più strane fogge si avanzano coi vessilli ondeggianti al vento, gli araldi dànno fiato alle trombe, i soldati giuocano ai dadi le vesti del Cristo e si azzuffano, le pie donne si agitano, santi e fedeli pregano. Da Simone Martini a Bernardino Luini in Saronno la Crocifissione sembra l'ultima scena d'un grande spettacolo teatrale; e la teatralità deriva dai sacri misteri eseguiti nelle chiese, nell'atrio dei palazzi, sui palchi e tribunali nelle piazze. Rimangono nel Trecento ad un tempo parecchie forme della rappresentazione della Vergine, che ora si vede, come a Santa Maria Novella nellopera di Simone Martini, tra le pie donne, fissi gli sguardi nell' immagine che si estolle sul Calvario, ora nelle scene più anguste è in piedi, col volto contratto dal dolore, con la 
testa piegata sulle mani giunte; ora, e il più delle volte, cade senza spiriti di vita.

Nel Quattrocento il dramma perdette, col Beato Angelico, la gagliardia di Giotto, si affiochirono le voci dei personaggi della Crocifissione. Essi levano gli occhi chiari e dolci, che sotto l'arco lieve delle sopracciglia si affissano

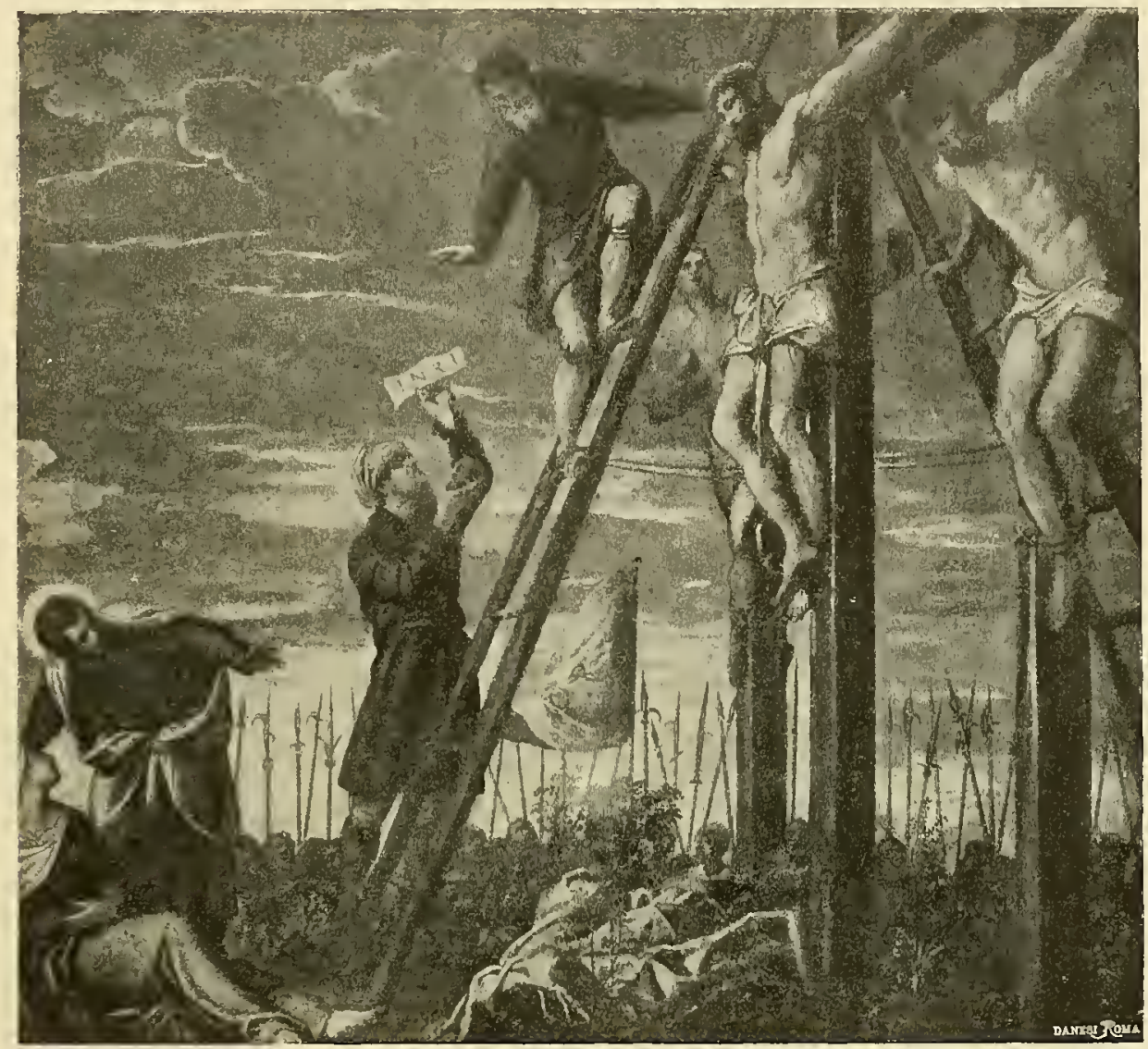

Chiesa di San Cassiano in Venezia

(TIN'SORETTO)

senza l'intensità dello sguardo e del pensiero di Giotto. Non prorompono in atti di disperazione; e gli angioli non si strappano le vesti, ma mormorano litanie o si dolgono a bassa voce. Una dolce pietà penetra negli animi, e si esprime sui volti degli assistenti al supplizio: non strida, non gesti violenti, ma geniti, preghiere al Cielo e carezze alla salma del Cristo, che dorme, chino il capo tra $\mathrm{i}$ riccioli biondi, placidamente.

La scena storica scompare col Beato Angelico nel convento di San Marco e in Benozzo Crozzoli a San Domenico di Pisa, e in altri artisti del Quattrocento, 
che fanno assistere al sacrificio divino anacoreti, martiri, padri della Chiesa, fondatori di Ordini monacali, anime erranti nel giardino di delizie, frutti dell'albero della misericordia, che ne' secoli primitivi appaiono in forma di pavoni e di cervi. Così il dramma di Giotto si è diviso in due parti : il coro dei santi e dei monaci, che interrompe con l'inno e la preghiera i gemiti del Golgota, innalza ora da solo a Dio le voci della gratitudine e dell'amore. D'altra parte la scena, specialmente in luoghi lontani da Firenze, capitale artistica d'Italia, si svolge. con tutta l'evidenza della realtà, come sul sagrato di una cattedrale. Fu celebre a Bologna l'affresco della Crocifissione di Ercole Roberti da Ferrara, in San Pietro, purtroppo caduto nel nostro secolo tra le macerie, intorno al quale scrisse il Vasari una vivissima descrizione, una delle pagine sue più belle: "Oltre il Cristo che vi si vede già morto, vi è benissimo espresso il tumulto dei Giudei venuti a vedere il Messia in croce: e tra essi è una diversità di teste maravigliosa: nel che si vede che Ercole con grandissimo studio cercò di farle tanto differenti l'una dall'altra, che non somigliassero in cosa alcuna. Sonovi anche alcune figure

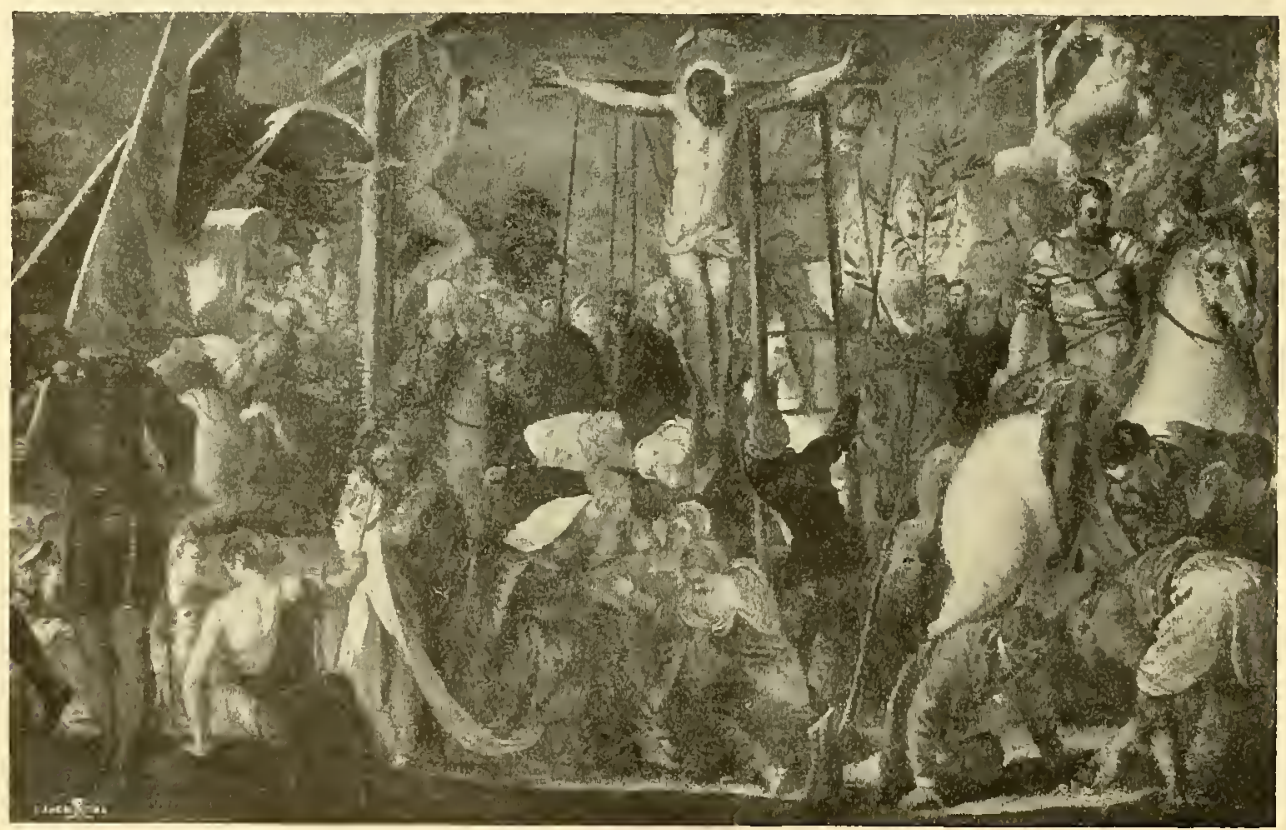

R. Galleria di Venezia

(Tintoretto)

che, scoppiando di dolore nel pianto, assai chiaramente dimostrano quanto egli cercasse d'imitare il vero. Evvi lo smarrimento della Madonna, ch'̀̀ 
pietosissimo: ma molto più sono le Marie verso di lei: perchè si veggiono tutte compassionevoli e nell'aspetto tanto piene di dolore, quanto appena è

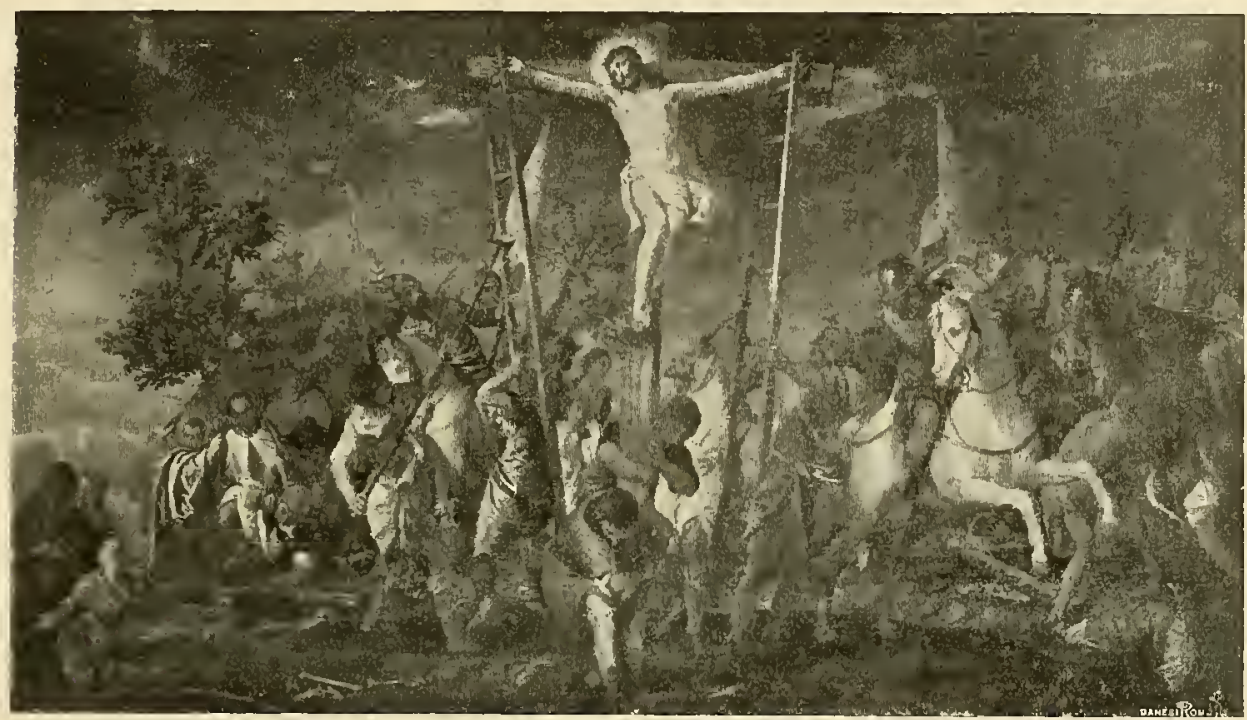

R. Galleria degli Uffizi

(Paolo Veronese)

possibile immaginarsi, nel vedersi morte innanzi le più care cose che altri abbia, e stare in perdita delle seconde. Tra l'altre cose notabili, ancora, che vi sono, vi è un Longino a cavallo sopra una bestia secca, in iscorto, che ha rilievo grandissimo: e in lui si conosce l'impietà nell'avere aperto il costato di Cristo, e la penitenza e conversione nel trovarsi ralluminato. Similmente in strana attitudine figurò alcuni soldati che si giuocavano la veste di Cristo, con modi bizzarri di volti ed abbigliamenti di vestiti. Sono anco ben fatti e con belle invenzioni i ladroni che sono in croce: e perchè si dilettò Ercole assai di fare scorti, i quali, quando sono bene intesi, sono bellissimi; egli fece in quell'opera un soldato a cavallo che, levate le gambe dinanzi in alto, viene in fuori di maniera che pare di rilievo; e perchè il vento fa piegare una bandiera che egli tiene in mano, per sostenerla fa una forza bellissima. Fecer'i anche un San Giovanni che, rinvolto in un lenzuolo, si fugge».

Per comprendere tale descrizione, resta un disegno del Gabinetto delle stampe in Berlino, e restano le opere dei seguaci del Roberti nell' Emilia, tra le quali una tavola nella Galleria Estense di Modena, opera giovanile di Francesco Bianchi-Ferrari. L'arte godeva così a rappresentare armigeri crudeli, feroci nel ghigno, tra le lance, le alabarde, gli scudi, le bandiere 
recanti l'insegna infernale dello scorpione: e Giudei quasi grotteschi, cuori impietriti : e bambini curiosi dietro alla madre o sulle spalle del padre, e gentili giovinetti intenti allo spettacolo, sulla vetta, dove sembra appena terminato lo scoppio d'una battaglia. Per tutto il Quattrocento a questé composizioni rombanti si contrappongono le altre rappresentazioni, i beneficî del sacrifizio divino, e come in San Clemente di Roma nel secolo xir, così dall'albero della croce ancora si volvono rami con le istorie del Cristo, con versetti di salmi, con le immagini degli eletti. È il contrasto che dura per tutto il Quattrocento, la lotta delle tradizioni con la realtà.

La lotta si palesa anche nella forma dei particolari della composizione, e pure nel rappresentare il Cristo. E noto che Donatello fece con straordinaria fatica un Crocefisso per Santa Croce, pel quale il Brunellesco gli disse "che gli pareva che egli avesse messo in croce un contadino, e non un corpo simile a Gesù Cristo, il quale fu delicatissimo ed in tutte le parti il più perfetto uomo che nascesse giammai». E l'esempio datogli poi dal Brunelleschi non andò perduto, chè nel Crocefisso di Padova il Donatello sembra ricordare la forma di quello che per Santa Maria Novella intagliò il suo giudice severo. Ma Donatello trovò nel bassorilievo del Museo Nazionale di Firenze, con la figura della Vergine seduta appiè della Croce, in profilo, con le mani cadenti sulle ginocchia, immobile, la figura terribile del dolore. Intorno chi piange, o si dispera, o stende alte le braccia, o si batte le guance; dietro, armi ed armati; in alto, tra le nuvole, angioli che gridano angosciati. Ella sola, nel primo piano, tra guerrieri caduti, sta assorta nel dolore che sembra ricoprirla tutta di un manto luttuoso. Tra le urla e i gemiti e la morte, rinane, impietrita.

Alla fine del Quattrocento l'ideale si congiunse alla realtà, come bellissima vite che al tronco si attorcigli e l'adorni. La composizione si semplifica, le turbe della vetta del Golgota si diradano, e lasciano sfogo al dolore, a un dolore tranquillo di chi ad un tempo piange l'womo e venera il Dio. Il Perugino a Santa Maria Maddalena dei Pazzi, per esempio, dimentica le umbre scene elegiache, i suoi precursori che cercarono la violenza, la contrazione dei muscoli nei volti spaventevoli delle donne urlanti, quasi furie, sul Calvario, e dipinge assorta nella preghiera la Maddalena, San Giovanni con le braccia cadenti e le mani aperte come in atto d'invocare il dolce Maestro, e la Vergine in piedi, calma nel dolore. 
Ritorna così nell'arte la forma della Vergine, quale si disegnò in antico nella mente di Sant'Ambrogio, e si rivedono pure sulle croci del Perugino il sole e la luna nell'eclissi. Ma ciò che importa si è che l'espressione piana, la tranquillità dei movimenti, dànno alla composizione una solennità religiosa, un sacro silenzio sotto l'ala della morte. L'arte evitò l'espressione degli affetti violenti, che alterano, contorcono, contraggono le linee dei volti; e sollevò sospiri da giovani cuori contriti d'amore, redenti dall'amore. L'immagine del Crocefisso sembrò anzi troppo lugubre nei giorni in cui l'arte italiana fioriva di giovinezza eterna, e confe ai primi tempi cristiani si rifuggi dal rappresentarlo. Solo dopo la Contro-Riforma, col Crocifisso livido, insanguinato, convulso, si pensò di trarre a divozione il popolo; ma l'arte cadde, precipitò in un eccessivo naturalismo materiale, perdette la sua ispirazione cristiana, non seppe quasi più renderci l'olocausto dell'Uo.no-Dio e la grandezza morale della Madre martire.

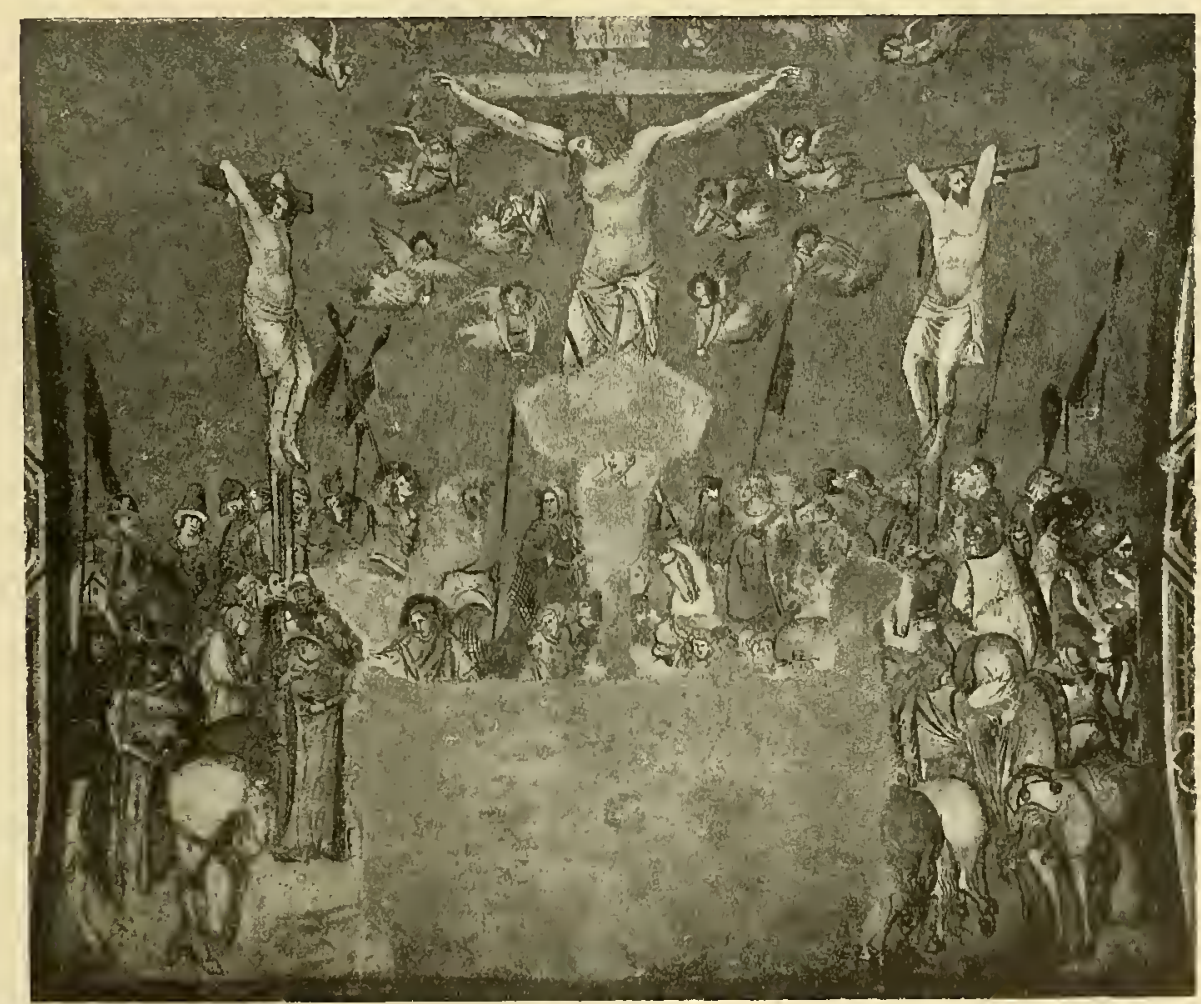

Affresco nella Basilica di Assisi

(Cavallini) 



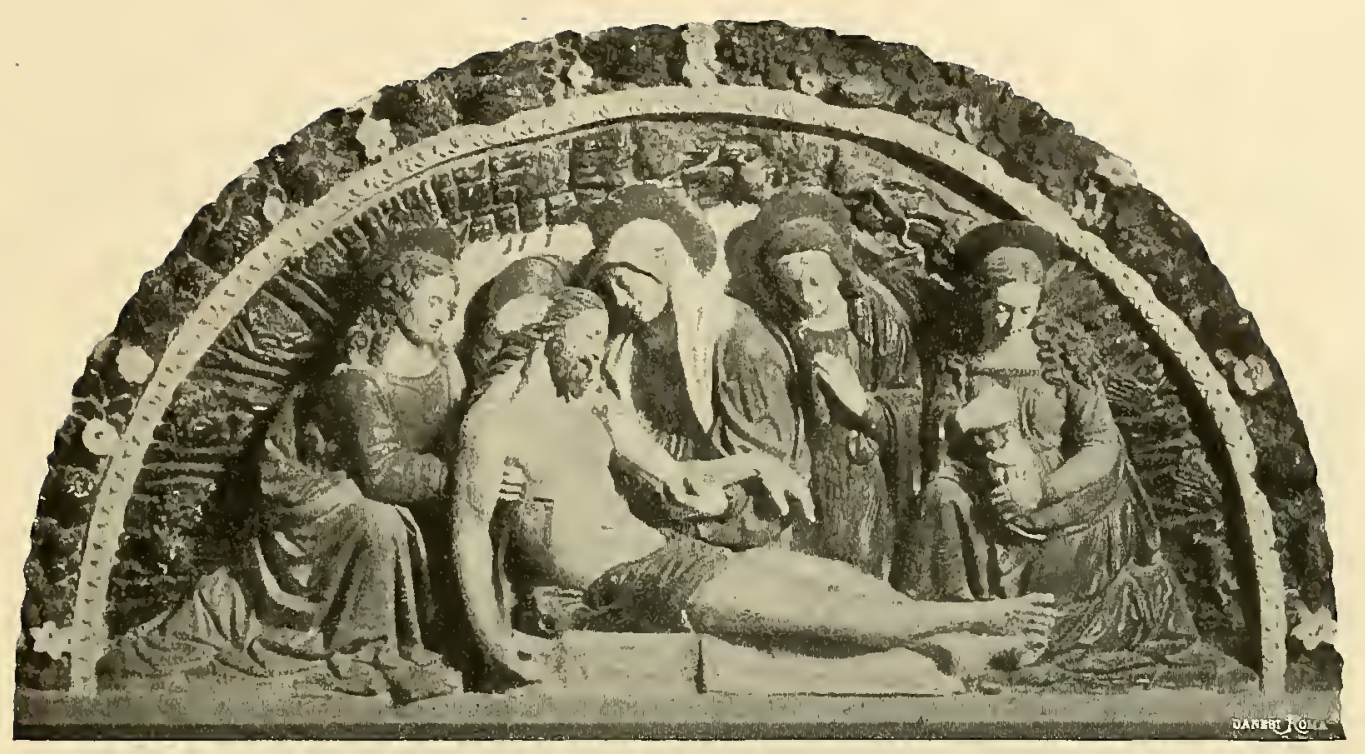

Museo Nazionale di Firenze

(GIO. DELLA RobBia)

\section{La Deposizione dalla Croce e la "Pietà ".}

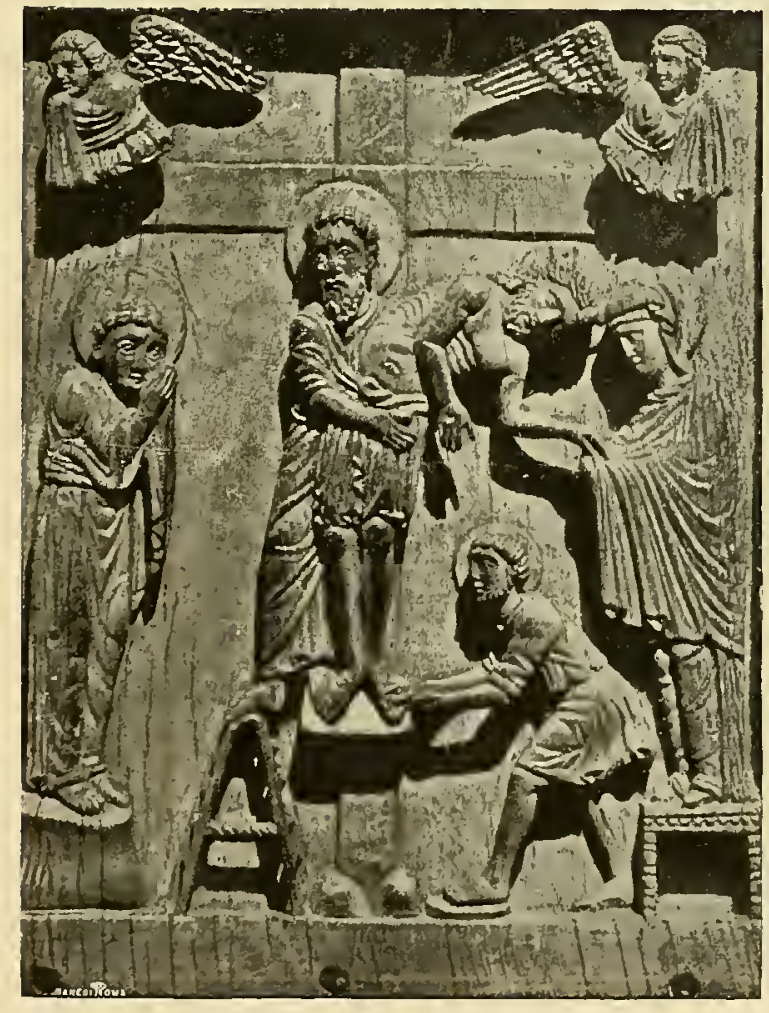

Avorio del secoln xur. Mluseo Art. Ind. di Milano
L'arte bizantina diede alla Vergine addolorata un' eroica grandezza, rappresentandola sul Calvario vegliante sulla salma e sulla tomba del Cristo. Metafrasto l'addita in cerca del discepolo, padrone del nuovo sepolcro, ove, per le sue preghiere, fu rinchiuso il corpo del Salvatore; e la figura in atto di dare aiuto a calarlo giù dalla croce, raccoglierne i chiodi nel suo grembo, dare il lenzuolo a Giuseppe di Arimatea, invitandolo ad aviolgerne le care spoglie e a deporlo con onore nella tomba odorata di mirra. Una leggenda riportata dall' abbate Darras $(1,237)$ fa 
ch'Ella stacchi dapprima la mano destra, e ne sostenga il corpo, mentre Nicodemo ne toglie $\mathrm{i}$ chiodi dal braccio sinistro e dai piedi. Ed Ella prese,

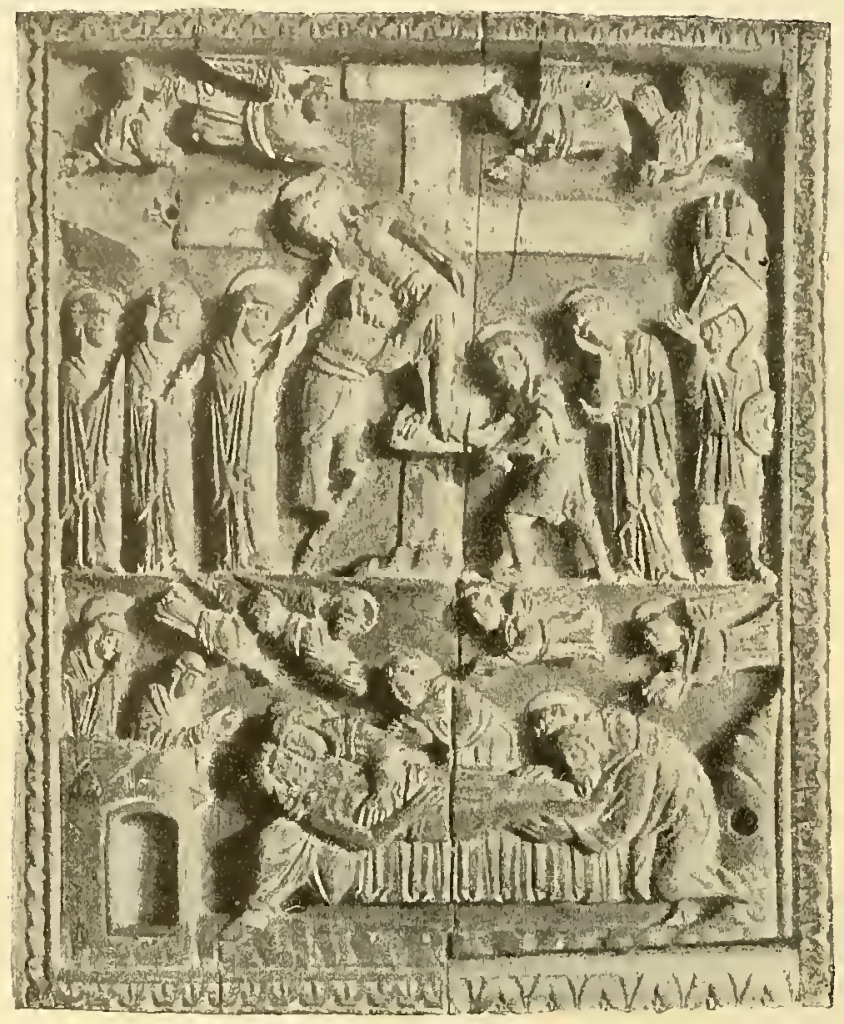

Copertina d'avorio. Museo Nazionale in Ravenna

dice la leggenda, una delle mani che cadeva in giù senza vita, e la baciò, versando un torrente di lagrime. Così vedesi Maria raffigurata negli avorî

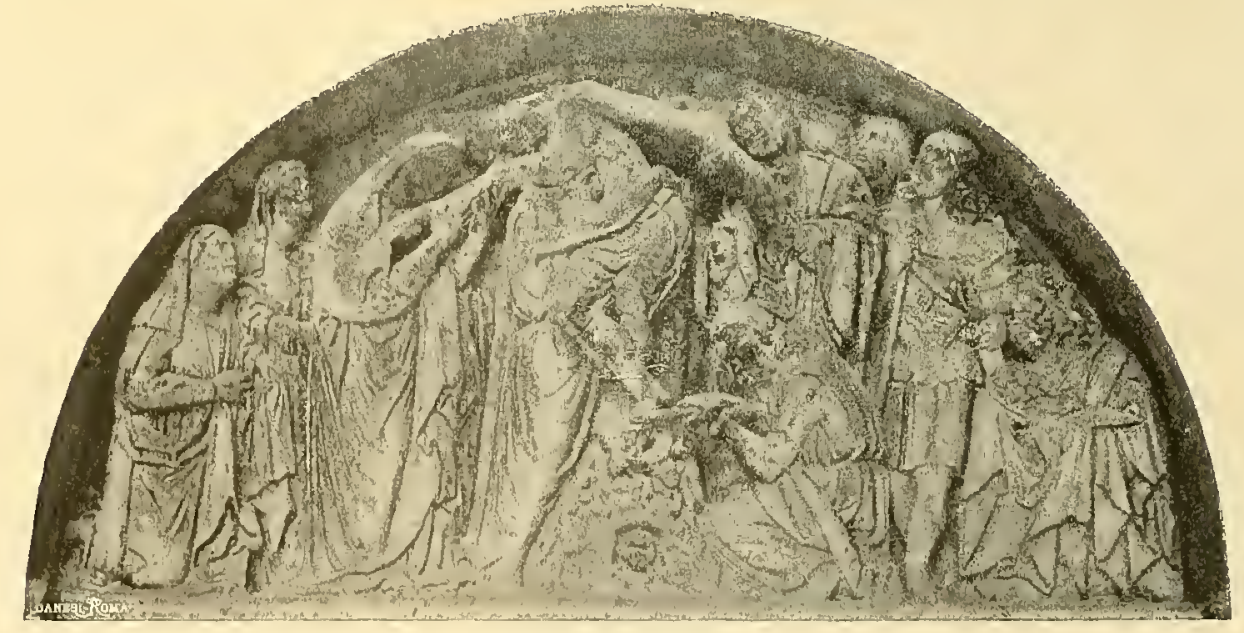

Cattedrale di Lucca

(NICOLA PISANO) 
del secolo xir alla fine del xiı, esempio quello del Museo Nazionale di Ravenna, e gli altri dell'esposizione retrospettiva in Milano e del medagliere estense in Modena. La rappresentazione continua nel bassorilievo dell'A-n telami a Parma e trova il suo più completo sviluppo in quello della Catte-

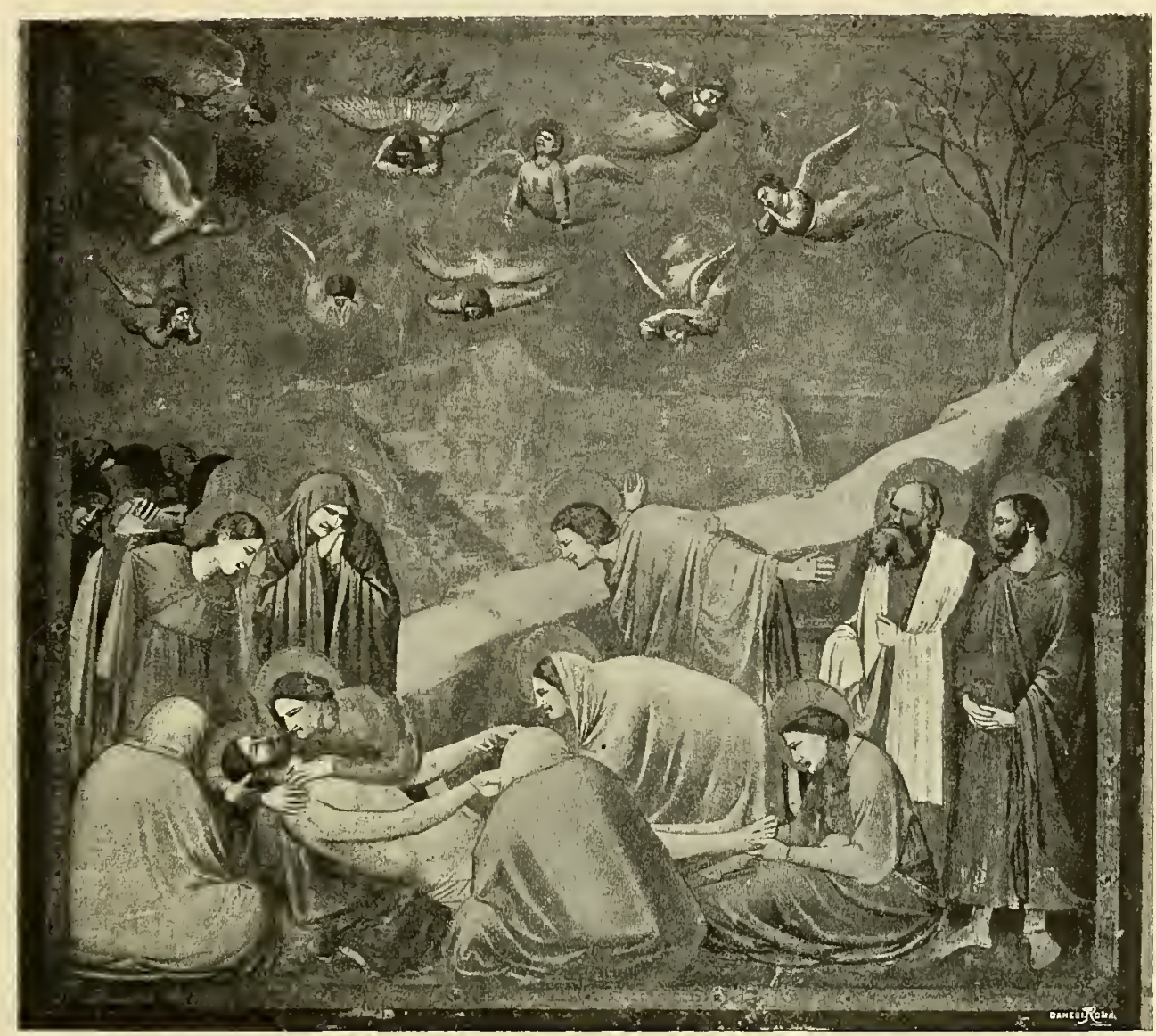

Oratorio degli Scrovegni in Padova

(GIотTо)

drale di Lucca, opera di Nicola Pisano, in cui Maria e Giovanni sorreggono le care braccia del Cristo morto e piangono; Giuseppe d'Arimatea, nobile e poderoso vecchio, gli cinge il corpo cadente e lo regge sopra una spalla; Maria tiene teneramente la sacra destra, che su di lei si abbandona, vi appressa le labbra che gemono di dolore, vi fissa gli occhi ingranditi.

Questa scena della "Deposizione dalla Croce" non ebbe fortuna, e perdette ben presto l'impeto del sentimento che la formò. L'arte, che si andava facendo logica, non riusciva a trovar modo di accostare la Vergine alla destra 
del Figliuolo ancora attaccato in parte all'alta croce, nè di far sostenere da lei, distrutta dall'ambascia, il peso delle morte membra. La logica cancellò la poesia; ed ecco la Vergine nel gran quadro del Perugino, nella Galleria antica e moderna in Firenze, avanzarsi sorretta dalle pie donne, vacillante, con le ginocchia piegate, cadente in deliquio, mentre i seguaci del Cristo su per le scale, con lenzuola tagliate a strisce, reggono il corpo

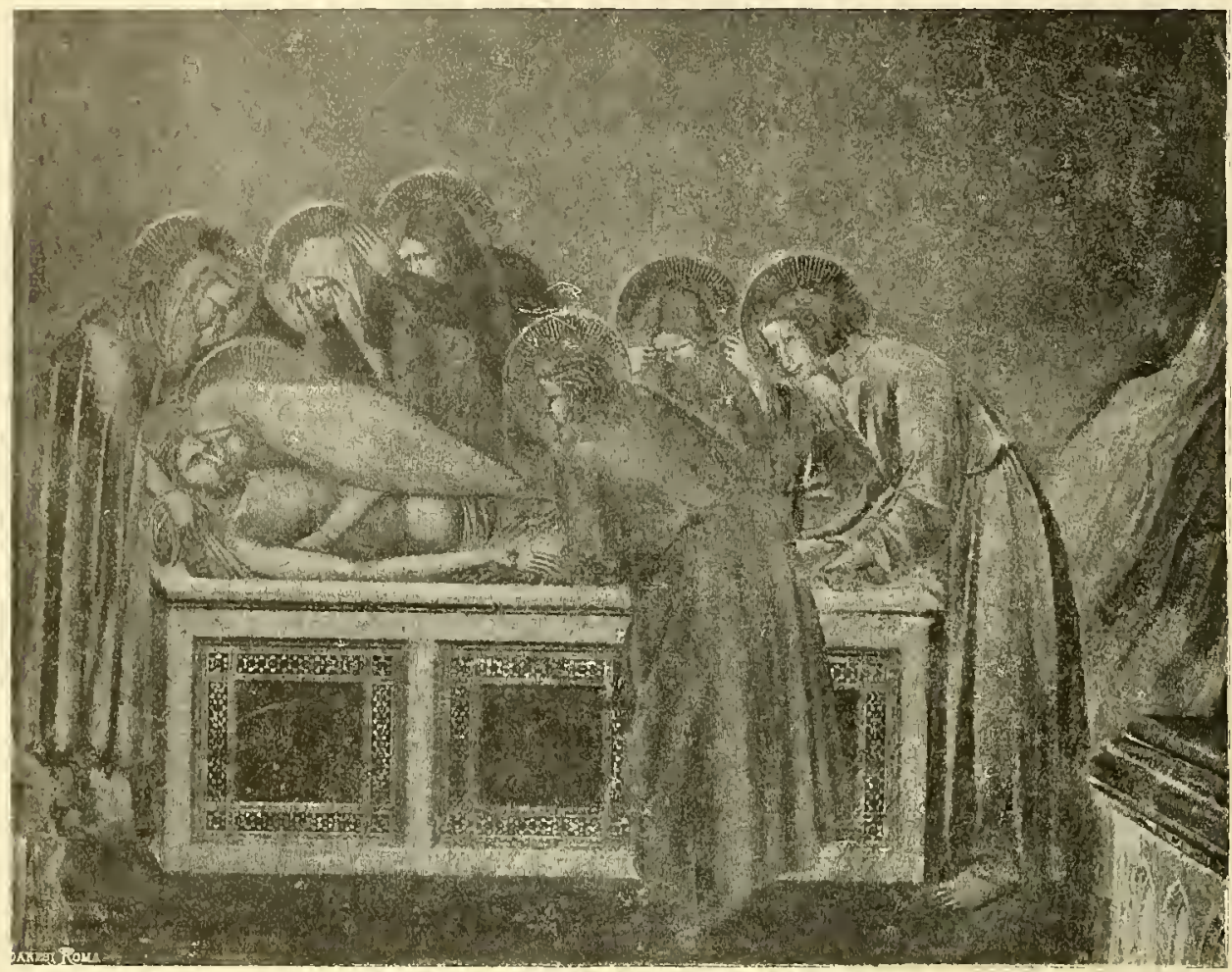

Basilica inferiore di San Francesco in Assisi (Attribuilo a GгтTо)

distaccato dalla croce. E il Signorelli nel solenne quadro d'Umbertide, il Begarelli nel San Francesco di Modena, nella grande equilibrata composizione, rappresentarono la Vergine già svenuta ai piedi della croce tra le pie donne che le fanno corona. Intanto, nel gruppo del Begarelli, cala dall'alto, stretta come in un abbraccio da Giovanni e sorretta pure da robusti nomini, la salma divina. Ma se la «Deposizione dalla Croce» perdette di bellezza, in tutto quel complicarsi di scale, di strumenti, di leve umane, la rappresentazione consecutiva della "Pietà " toccò il sublime.

Già nell'avorio del Museo di Ravenna si vedono nella zona inferiore alla "Deposizione dalla Croce "Naria, gli angioli e i seguaci del Cristo struggersi 


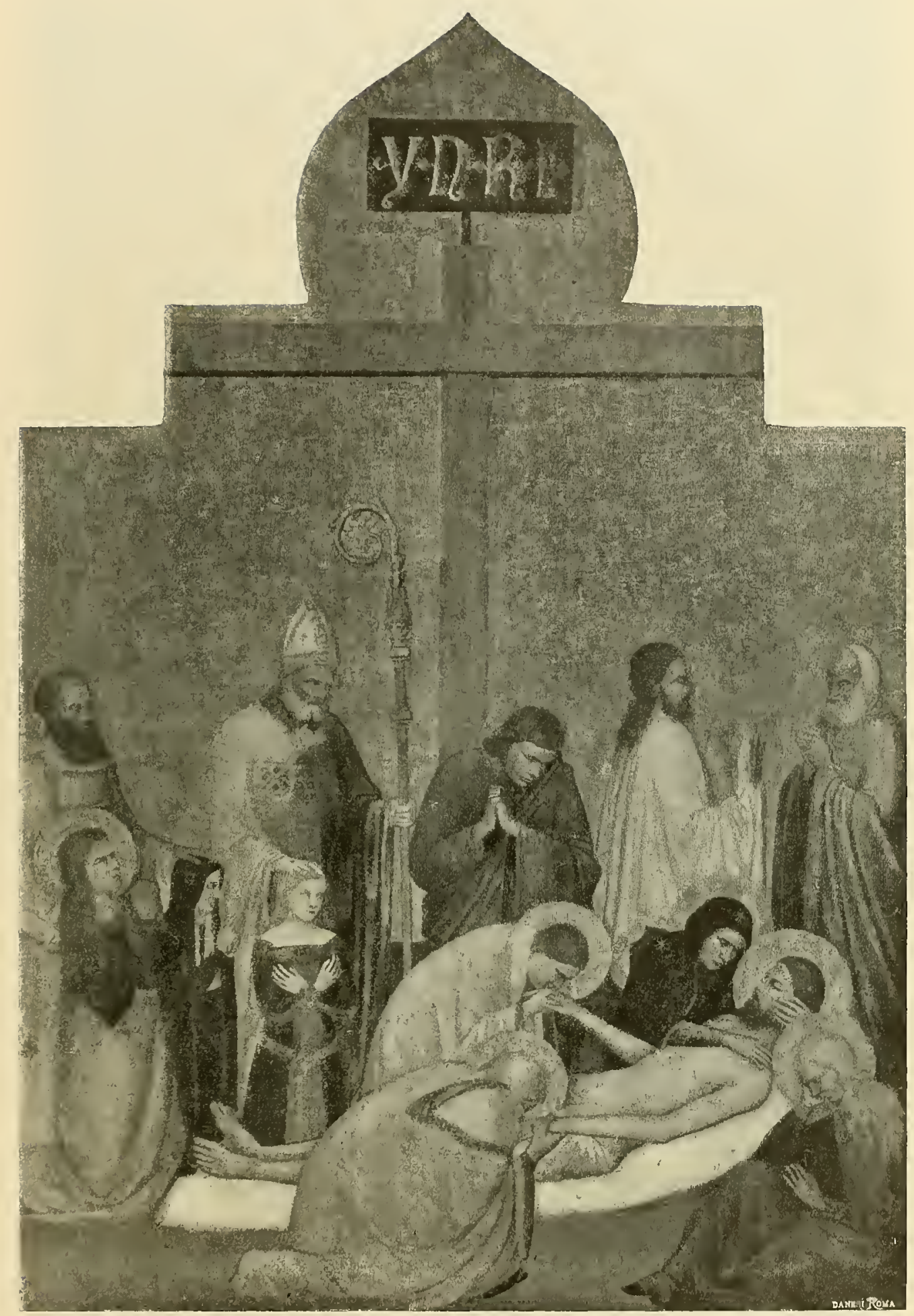

R. Galleria degli Uffizi in Firenze

(Giottino) 
di dolore sulla sua salma: Maria ne solleva la testa per stringerla al suo rolto, e la guarda fissamente e la bacia: tutti, con impeto di passione, attorniano il corpo esanime. È quello l'abbozzo che resterà nei secoli, esemplare dell'arte, compiuto da Giotto nella forma più drammatica. Egli dipinse la Vergine che cinge con le braccia la testa del Figlio, scrutando un segno di vita ne' lineamenti chiusi dalla morte, e geme e sta per iscoppiare in un pianto disperato. Le pie donne gli prendono le mani, la testa e i piedi, e

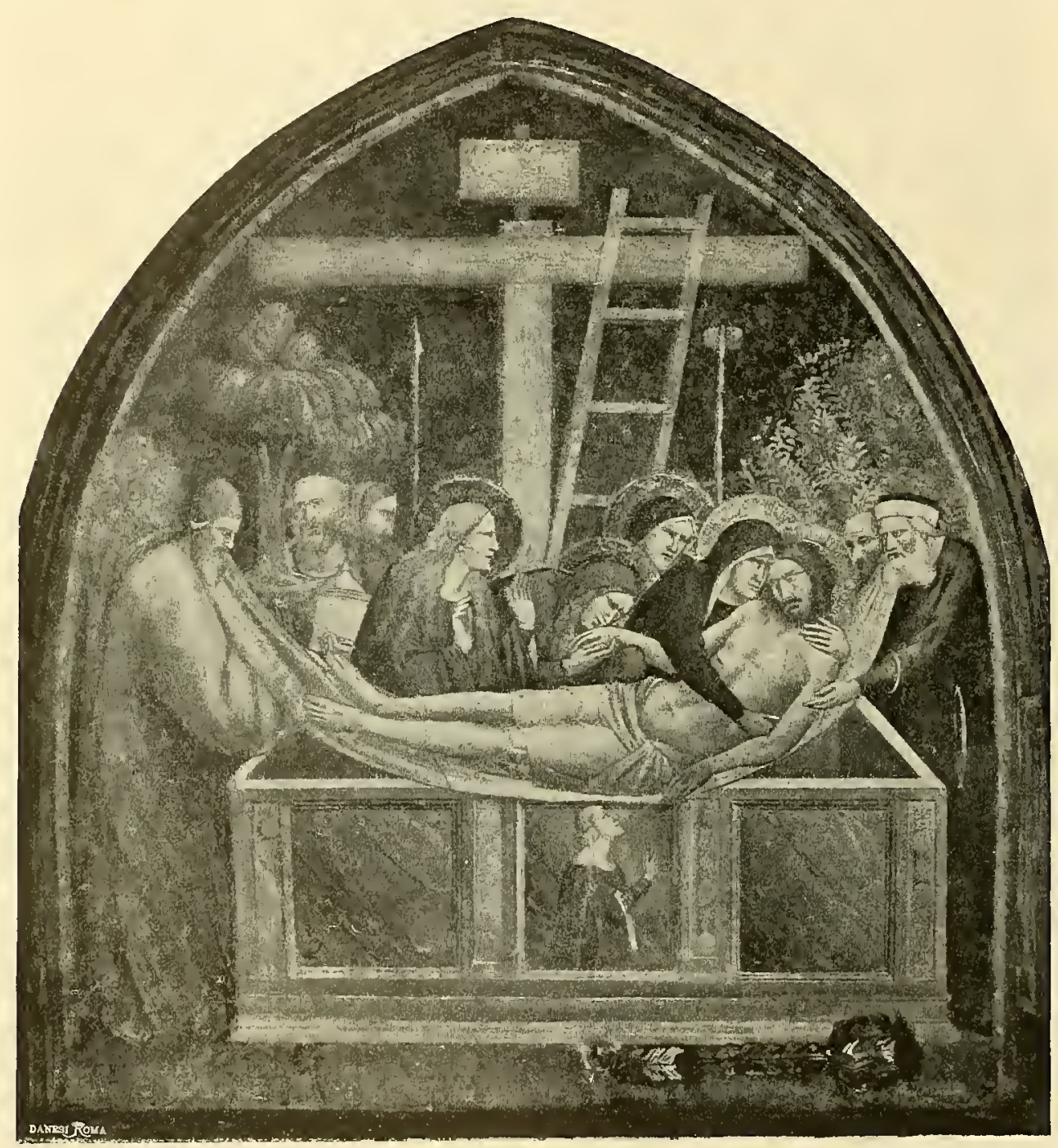

Santa Croce in Firenze

(Grottino?)

par che diano nuovo moto alla salma, mentre altre in piedi fanno eco allo strazio di tanti cuori. In quella costernazione tragica s'ode un altissimo urlo: 


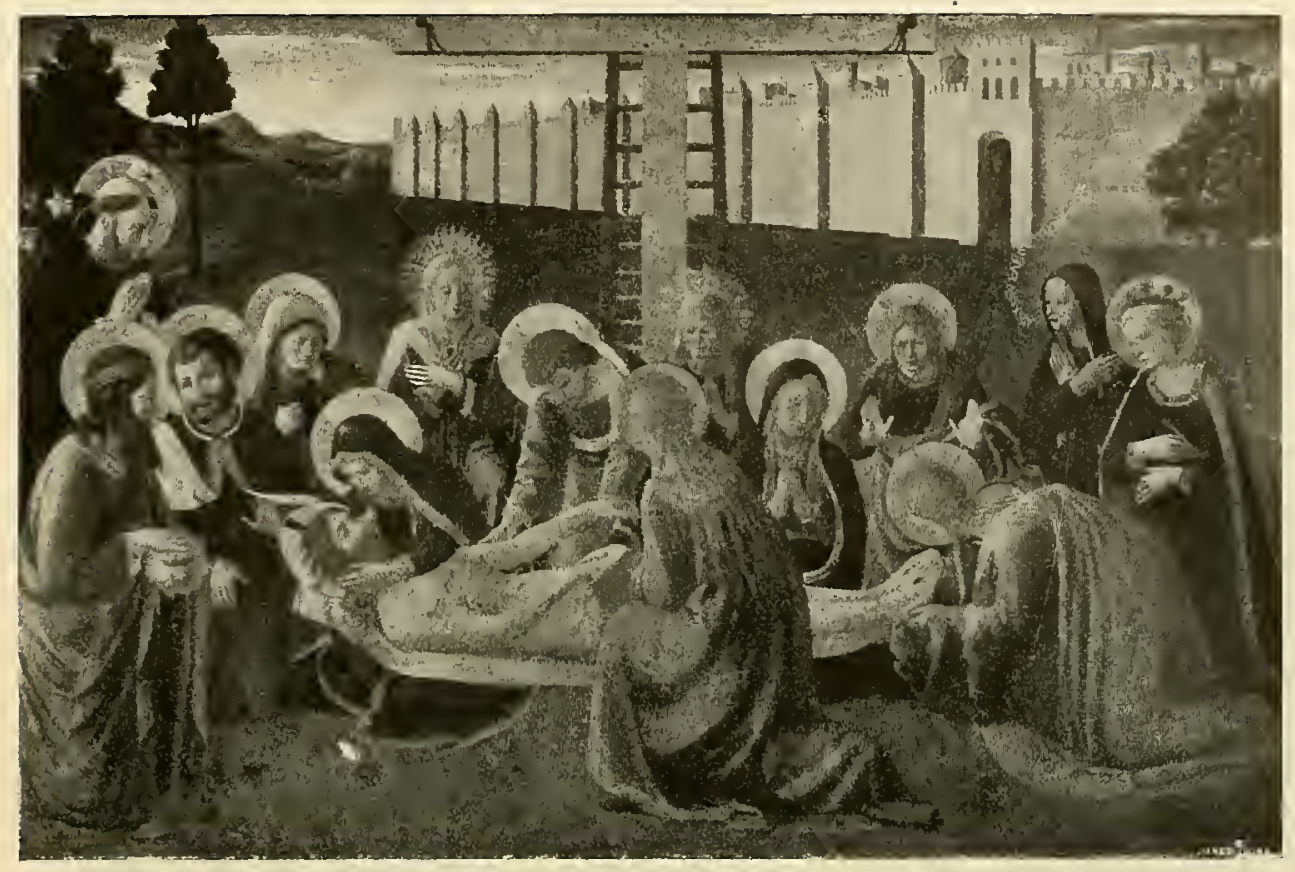

Galleria antica e moderna in Firenze

(Beato Angelico)

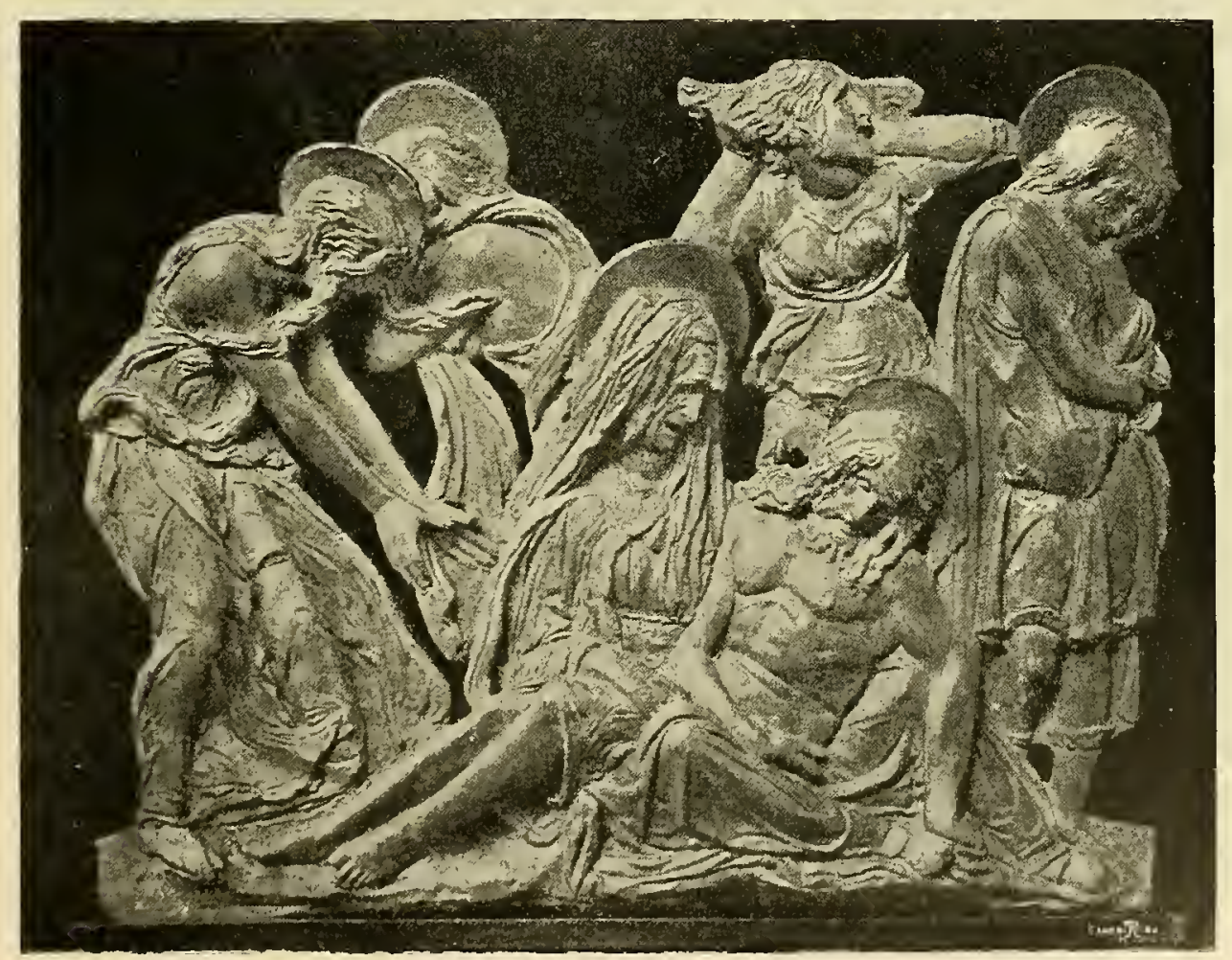

South Kensington Museum di Londra.

(DONATELLO) 


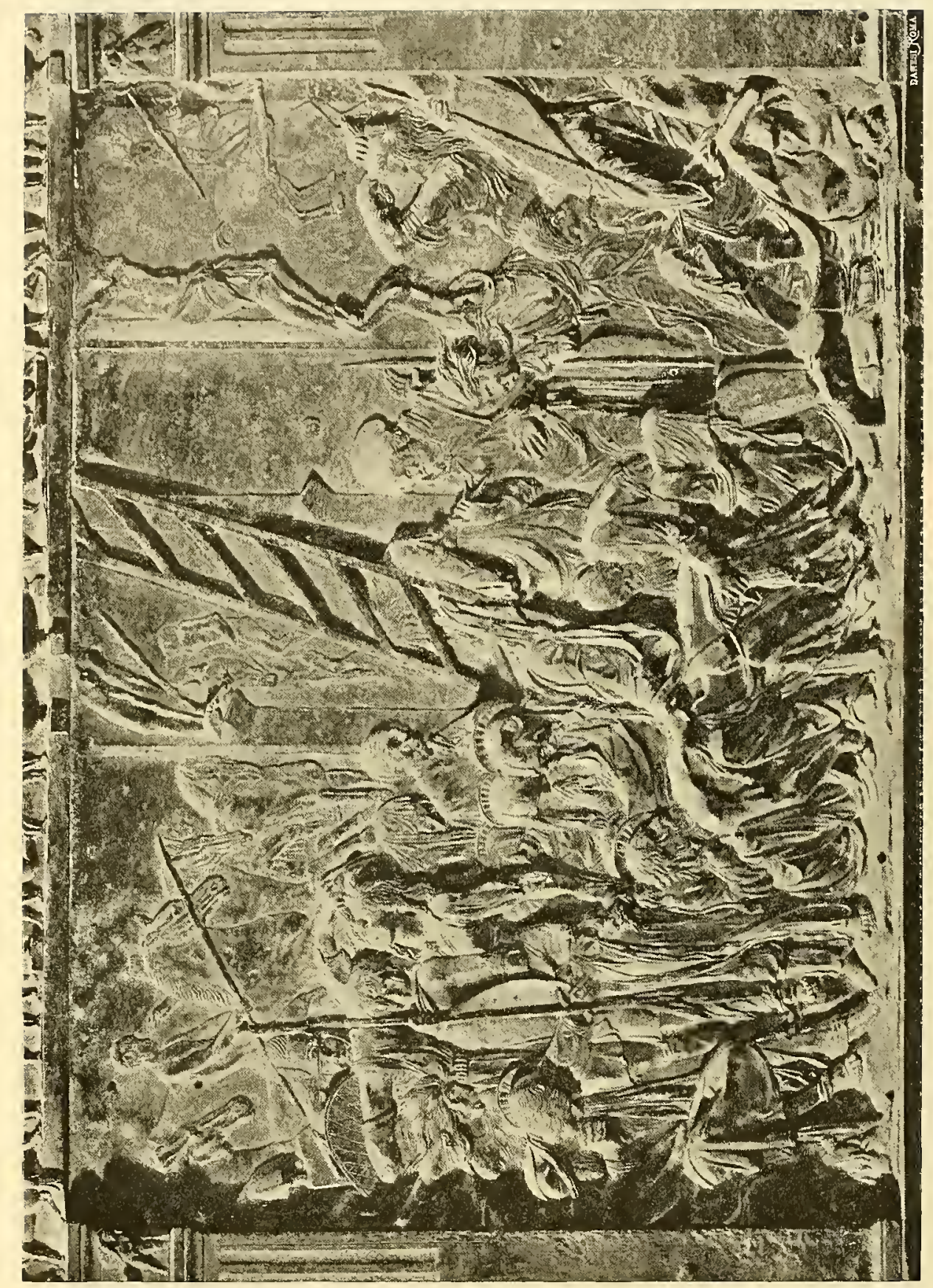




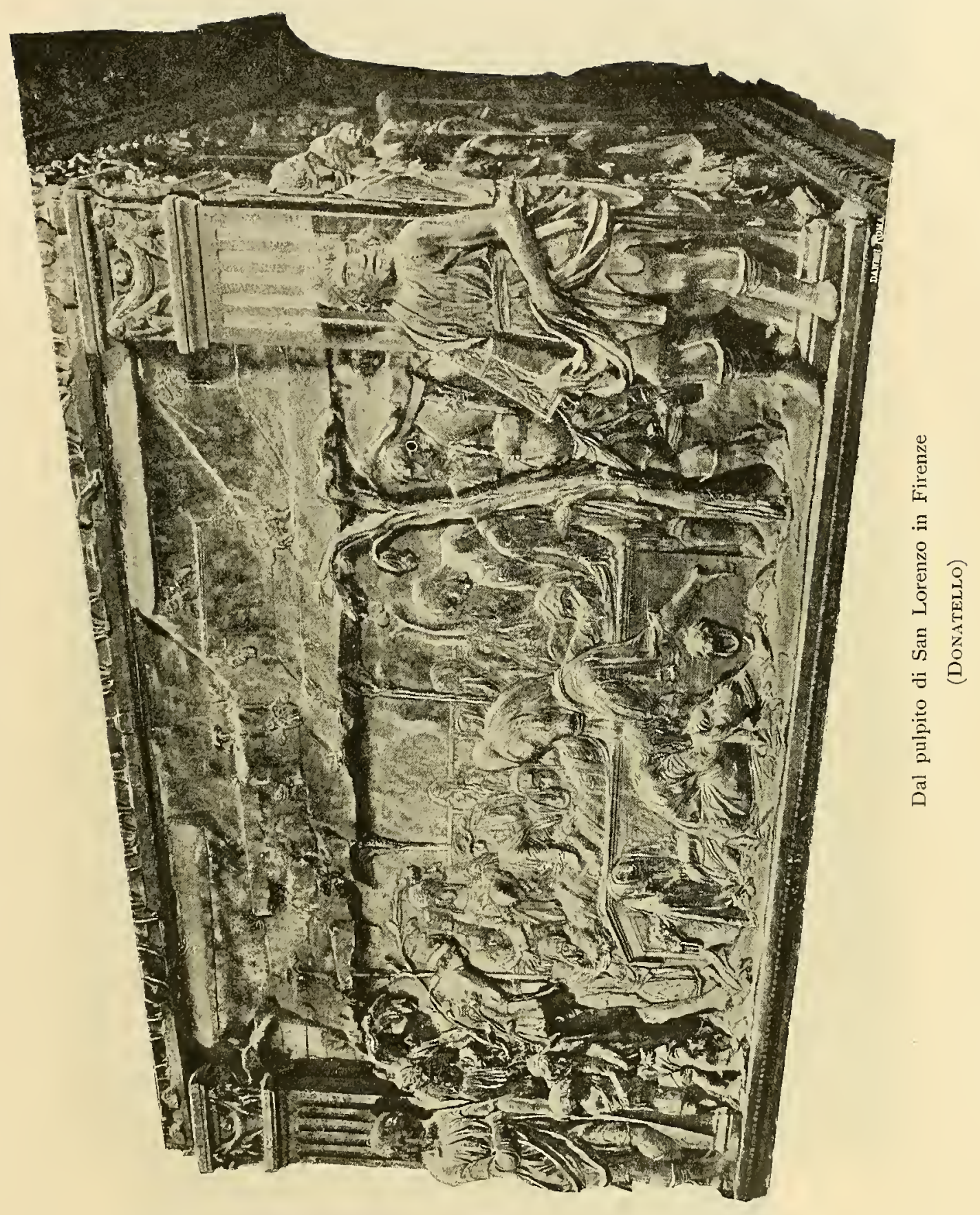


è Giovanni che avanza, con le braccia indietro tese e s'arresta fulminato alla vista del cadavere. Gli angelici spiriti intanto fendono l'aria e s'aggirano come tormentati.

La scena non ha più il tragico effetto che aveva nel Trecento: un dolore più tranquillo, uno spirito di divozione anima i pietosi che circondano la salma. L'umanità sua scompare, e ne resta la divinità, la reliquia. Così nella

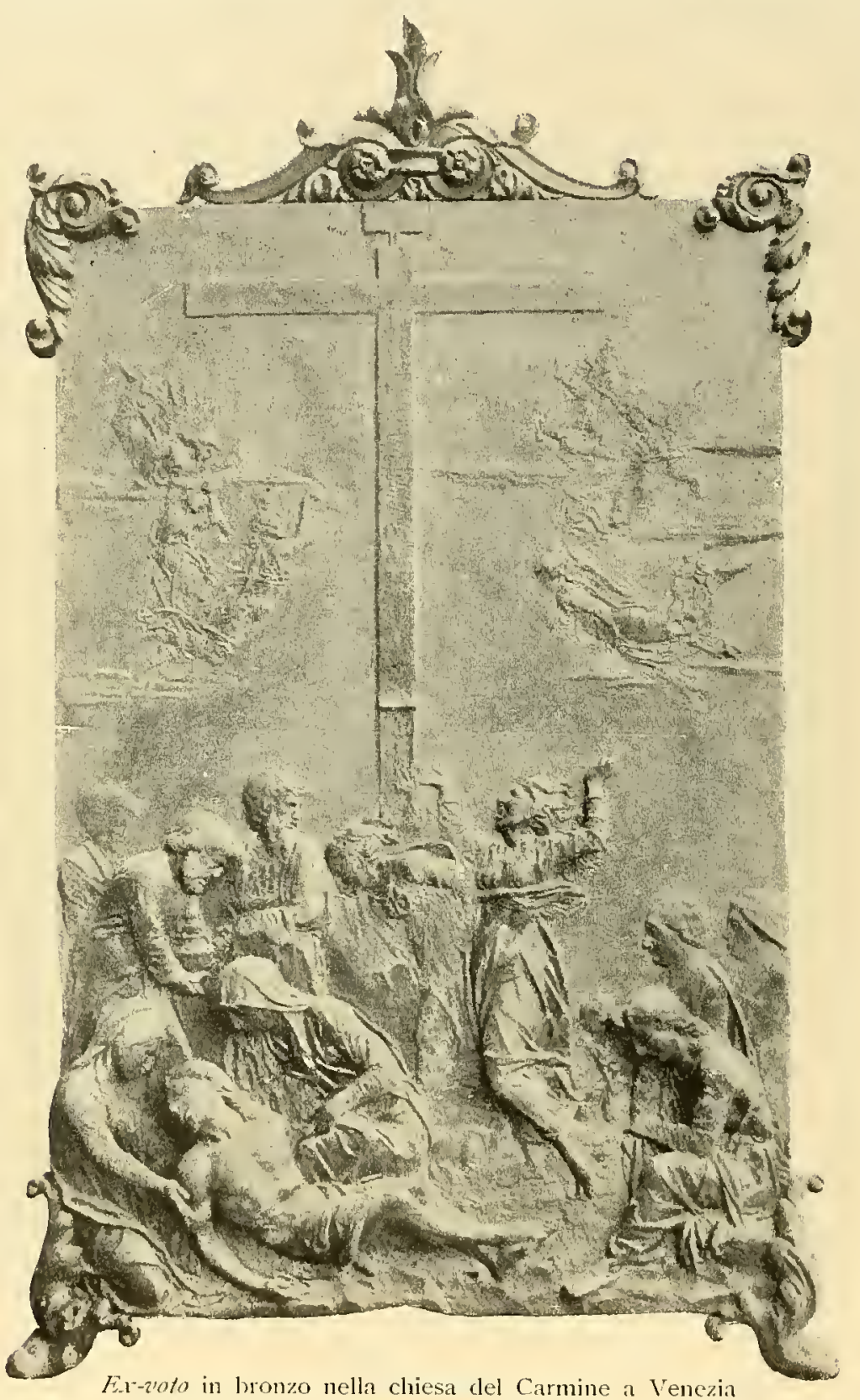

(VERROCCHIO) 


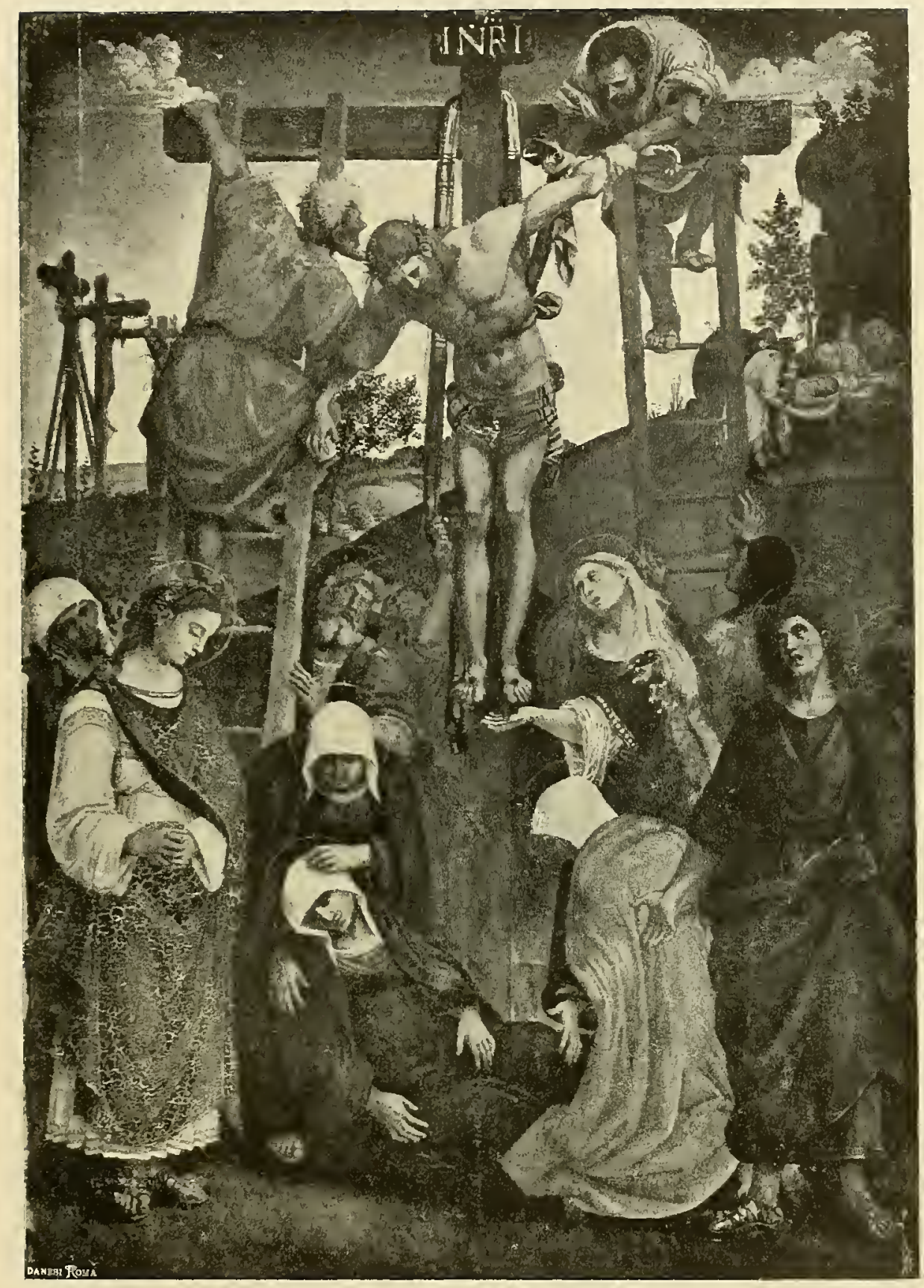

Chiesa di Santa Croce in Umbertide

(SigNoRelLI) 
"Pietà del cosiddetto Giottino, agli Uffizi in Firenze. Ma il realistico Quattrocento tornò all'antico, senza ricordare mai l'elegia giottesca. Beato Angelico fa cingere dalla Vergine il collo del Cristo, rialzargli le braceia e toceargli i piedi, come già fece Giotto, ma il silenzio del chiostro regna nella rappresentazione.

Donatello nei pergami della ehiesa medicea a Firenze evoca Giotto: il dolore prorompe in acutissime strida, e diviene delirio. La fantasia del genio,

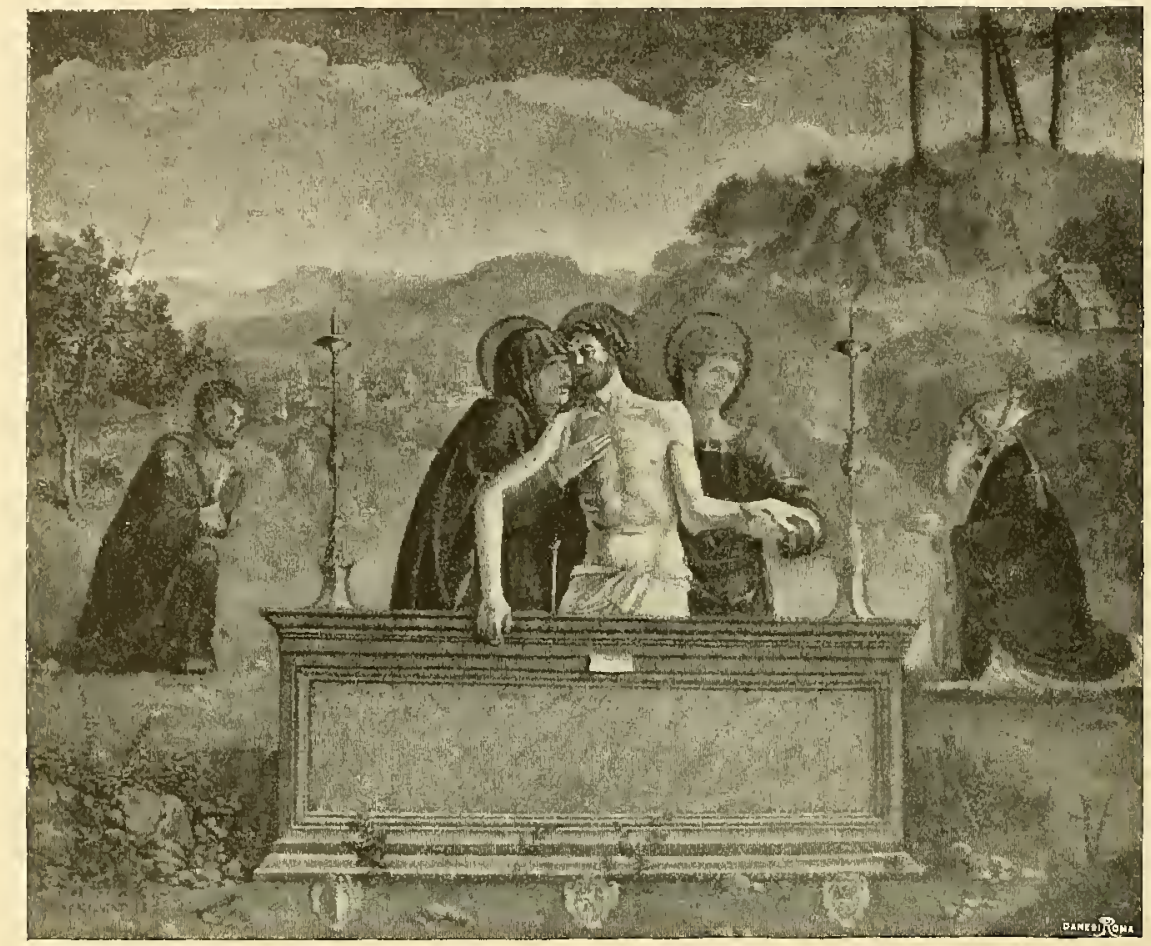

Vestibolo della chiesetta nel Palazzo Ducale a V'enezia

(Giambelino)

prima di chiudersi al sonno eterno, penetra negli abissi del dolore umano, fa cadere intorno alla salma del Cristo i corpi viventi come drappi funebri. La febbre s'impadronisce dell'arte, e il Verrocchio, nell'Ex-roto per Federigo da Montefeltro, spira ancora la disperazione sulla terra e nel cielo.

Lo spirito più mite riprende il sopravvento con Giovanni della Robbia, il Perugino, il Francia ed altri. Il Perugino, dice il Vasari, pose "Cristo in grembo alla nostra Donna, con quattro figure intorno non men buone che l'altre della maniera sua; e, fra le altre cose, fece il detto Cristo morto così intirizzito, come se e' fusse stato tanto in croce, che lo spazio ed it 


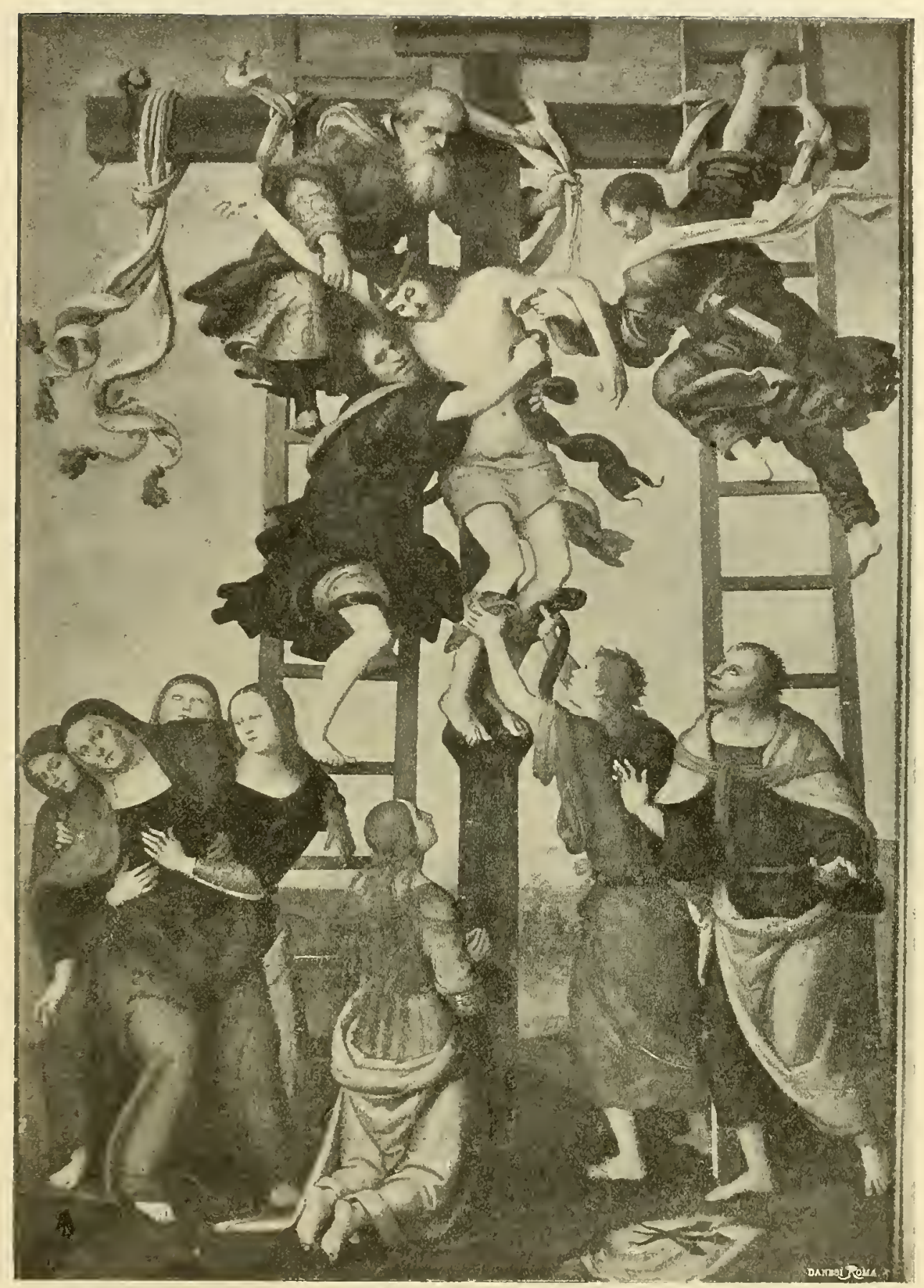

Galleria antica e moderna in Firenze

(Perugino) 
freddo l'avessino ridotto così onde lo fece reggere a Giovanni e alla Maddalena, tutti afflitti e piangenti». Cadono le lagrime come perle luccicanti sulle guance, dagli occhi umidi e rossi di San Giovanni, della Vergine e della

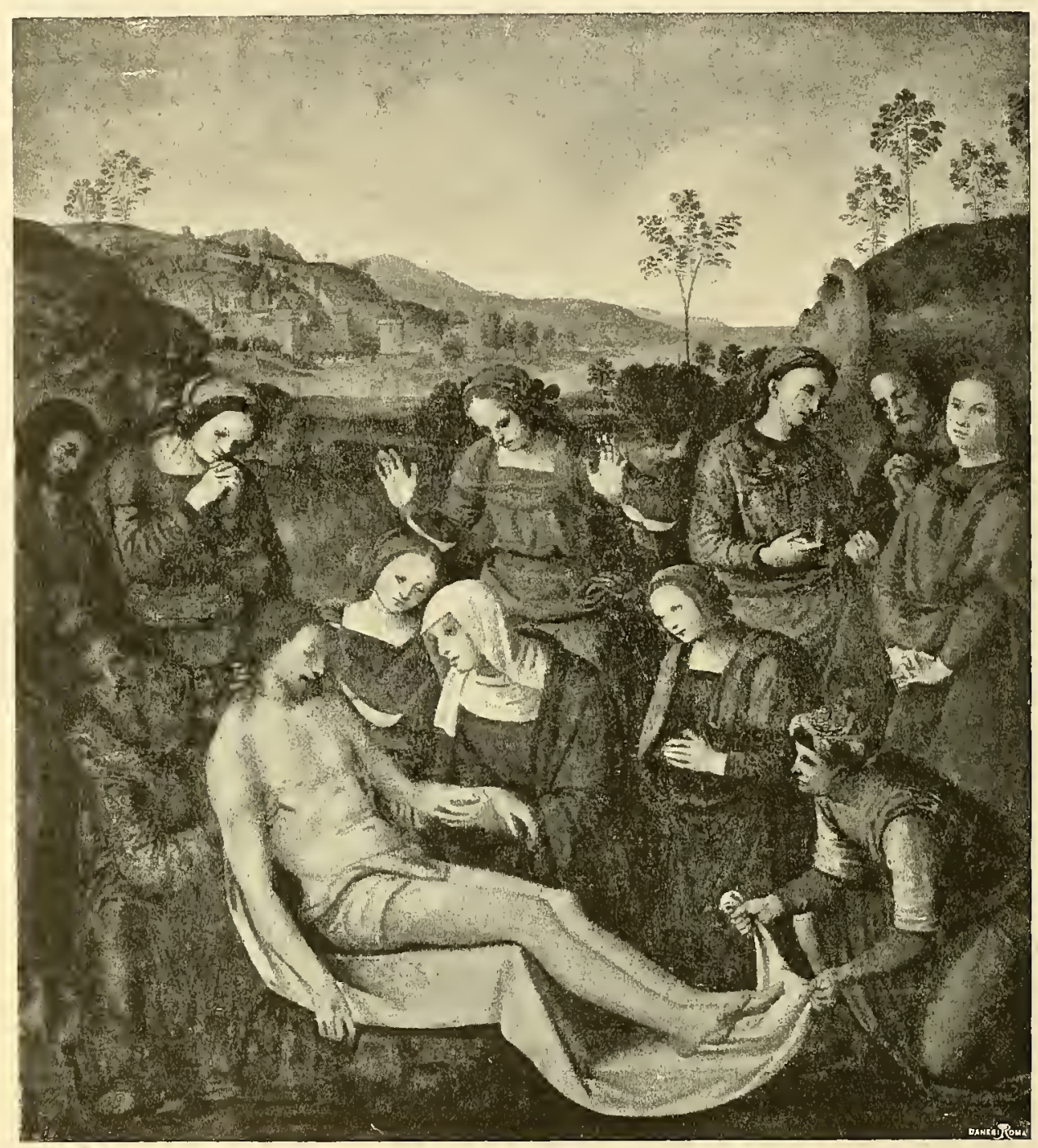

R. Galleria Pitti in Firenze

(Perugino)

Maddalena. Le labbra semiaperte di Maria esprimono il materno affanno; e le mani di tutte le figure traducono il commovimento degli animi, tanto quelle di Nicodemo che si serrano fortemente, quanto le altre, strette, supplici della Maddalena, e la sinistra cadente della divina Madre, alla quale fanno contrasto le aggranchiate del Cristo. In un'altra tavola, pure 


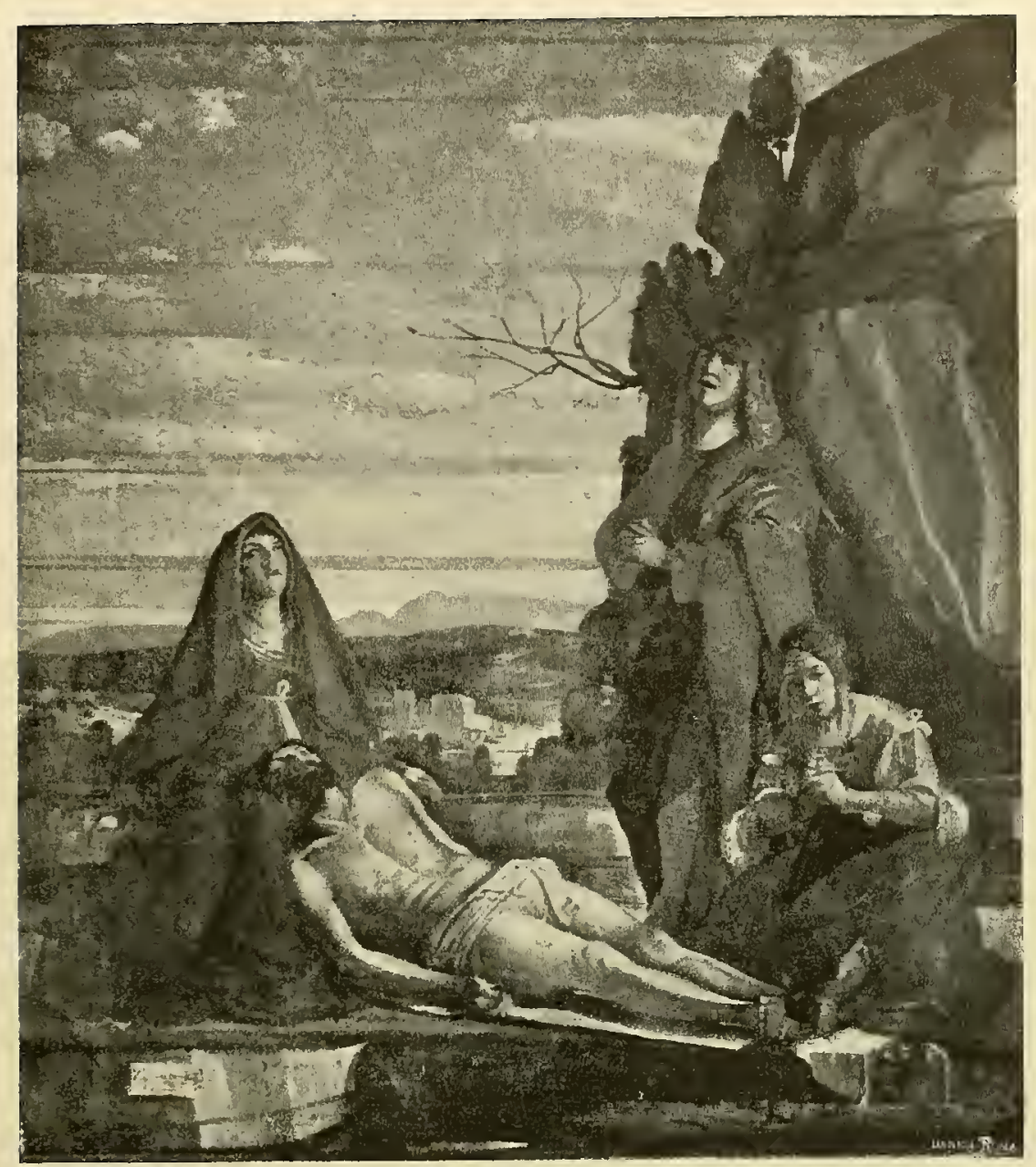

Galleria di Vicenza

(MAREsCalco)

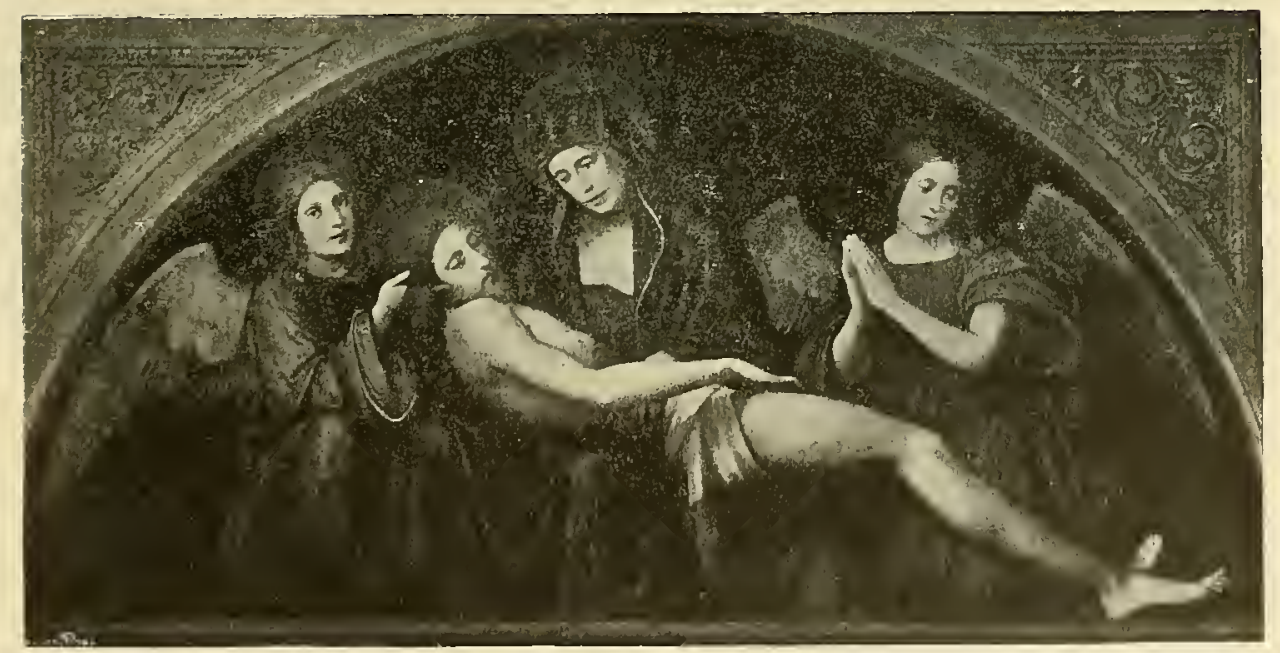

National Gallery di Londra

(Francia) 
a Firenze, il Perugino lavorò, così scrive il Vasari, "un Cristo morto con sì vago colorito e nuovo, che fece credere agli artefici d'avere a essere mara-

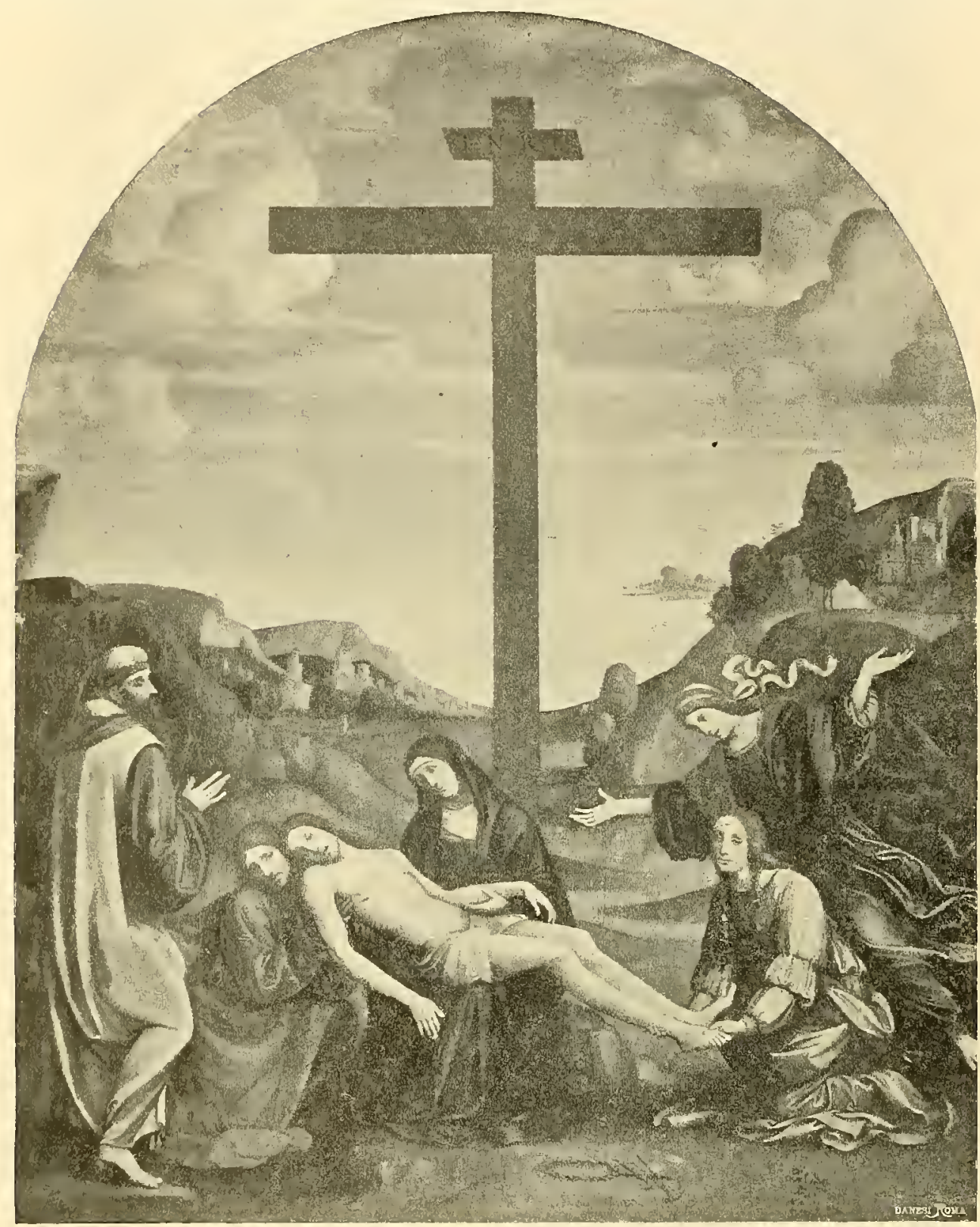

R. Galleria di Parma

( FR N N ESCO FR N C I A )

viglioso ed eccellente. Veggonsi in quest'opera alcune bellissime teste di vecchi; e similmente certe Marie, che, restate di piangere, considerano il morto con ammirazione ed amore straordinario: oltrechè vi fece un paese, 
che fu tenuto allora bellissimo». E certo un'opera eseguita dal Perugino nel pieno vigore del suo intelletto artistico (I 495). Quivi bella disposizione di gruppi in un insieme bene equilibrato; e forza di dolorosa espressione

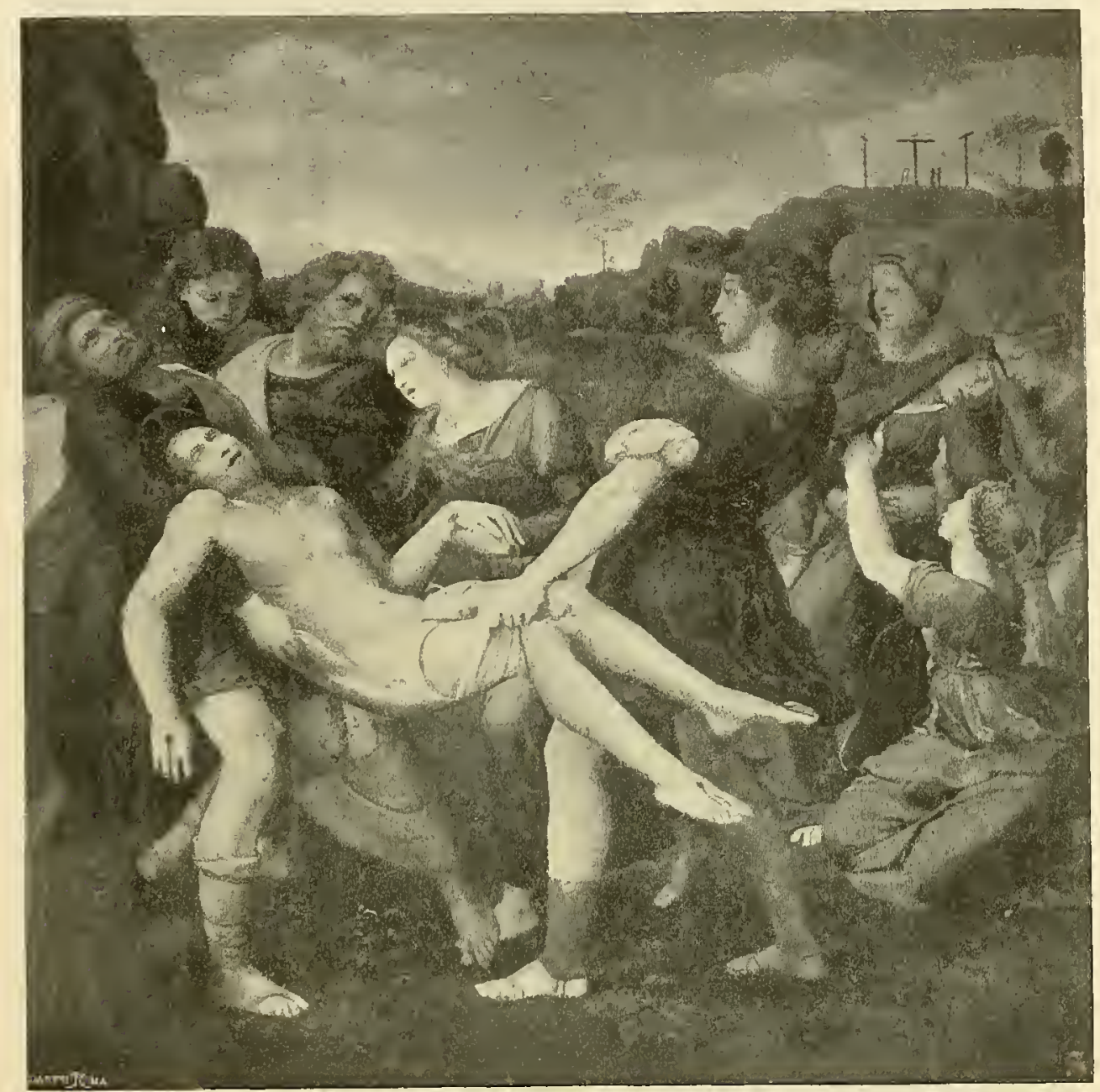

Galleria Borghese in Roma

(RAFFAELLO)

nei volti, specialmente in quelli della Vergine che fissa con intensità d'affetto e di cordoglio gli occhi immobili sul volto dell'amato Figliuolo; e finezza estrema di disegno, di colorito, di forme rappresentate in tutti i loro particolari; e vaghezza incantevole nel paesaggio variato e luminoso.

Ma non un atteggiamento violento, tragico nelle figure della sacra rappresentazione; il dolore non iscompone, non frange i puri contorni della bellezza. Anche nelle "Pietà " del Francia, a Parma e a Londra, il Cristo sembra 
riposare, e la Madre che lo tiene sulle ginocchia non ha una contrazione. non una ruga solca il volto atteggiato a mestizia. Nel quadro di Londra, un

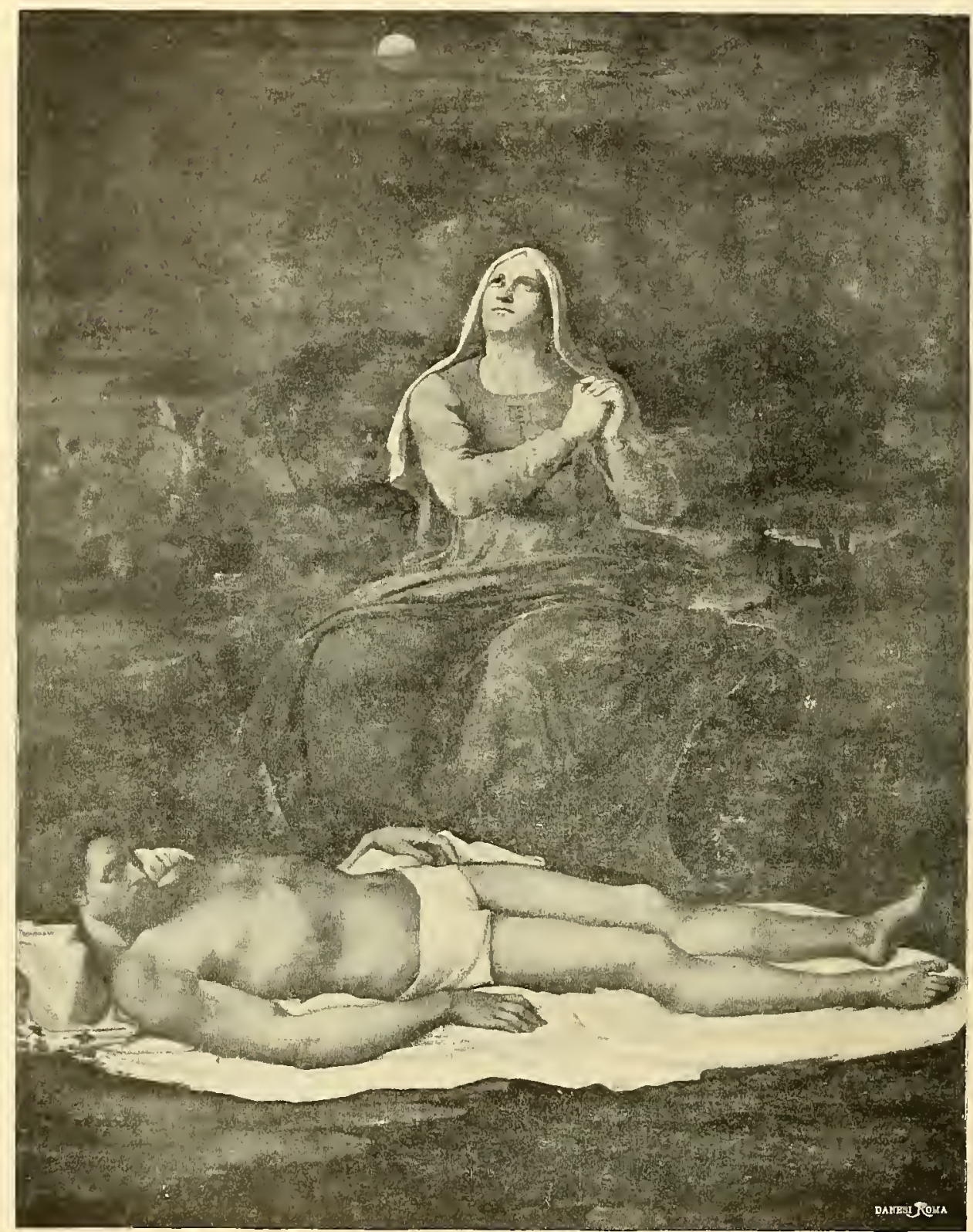

Museo Comunale di Viterbo

(Sebastiano del Piomo)

angiolo ginocchioni congiunge le mani, ma il suo sguardo non esprime intensità di preghiera: l'altro che gli fa riscontro sostiene il capo del Cristo, mettendogli la mano tra i lunghi capelli ricadenti, e volge graziosamente la testina allo 
spettatore. Nel Cinquecento Michelangelo trovò l'espressione più solenne del dolore della Madre di Dio. Cadono le ombre leggère diafane sulla augusta fronte, sugli occhi chiusi della donna assorta nella sua angoscia. Il pensiero, la luce s'affondano nel petto: e solo la mano sinistra, che sta per aprirsi, per stendersi desolata, segue l'interno moto dell'anima che ha perduto il suo

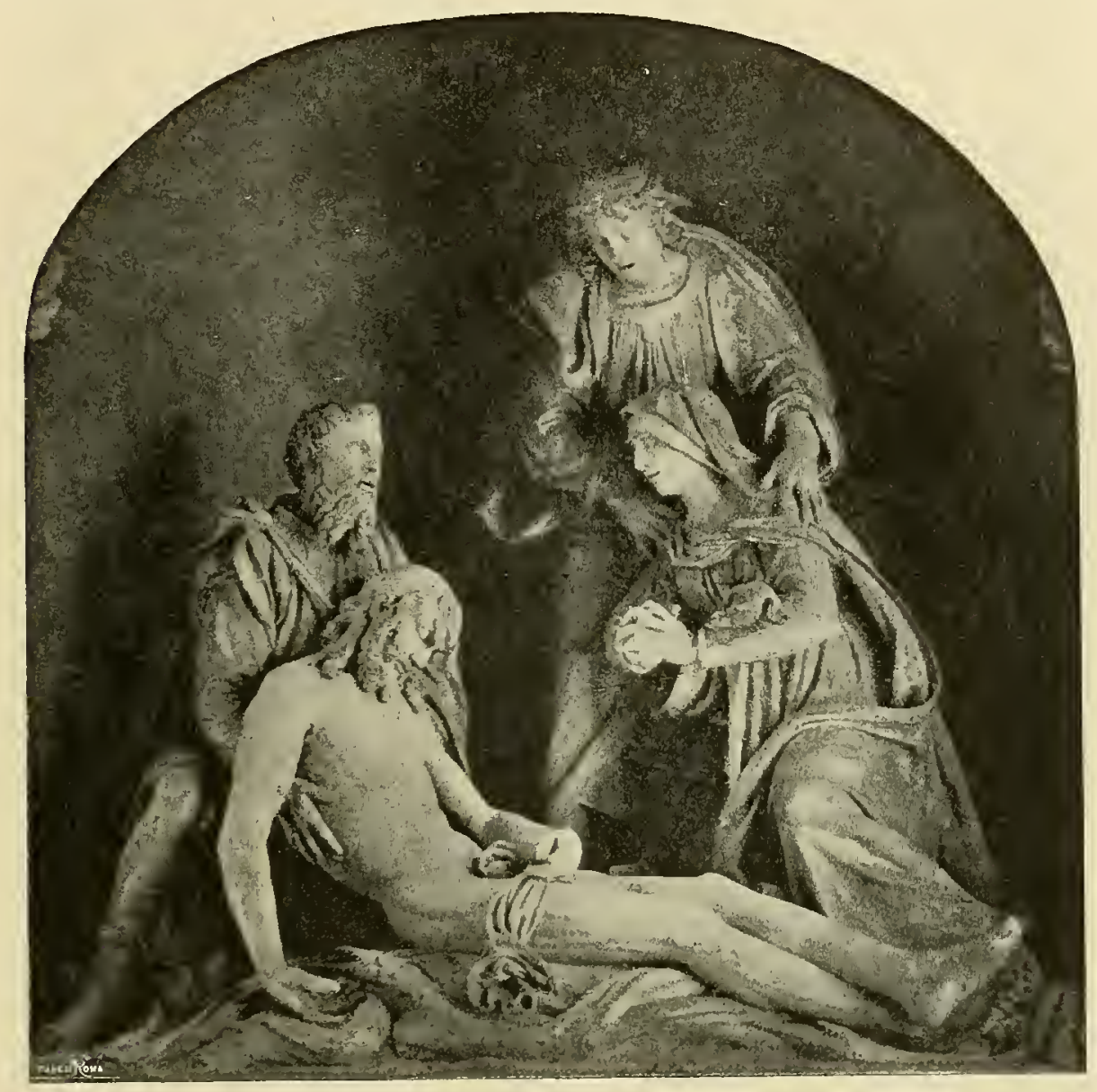

Chiesa di San Pietro in Modena

(Lud. Piegarelli)

bene e sente la immensità del sacrificio del Cristo. La bocca chiusa non geme, appena la tunica si agita, per l'affanno che solleva il cuore e lo fa battere contro la prigione del corpo. La donna nobile e forte sente venir meno, con la vita del Figlio, la ragione dell'esser suo; sente però ancora il mistero della redenzione umana, che le profezie e il volere di Dio si compiono.

Con michelangiolesca grandezza, ma col senso veneziano vivissimo della realtà, Sebastiano del Piombo raffigurò nel crepuscolo, tra le tenebre che 
invadono giù la terra, la Madre, non nobile, ma nobilitata dal dolore, pregante innanzi alla salma e rivolta al cielo, sola col dolore che ricopre ogni cosa. Ella prega pure, accompagnata e sorretta affettuosamente da Giovanni, nel gruppo del Begarelli, in San Pietro di Modena.

La composizione nel Cinquecento si è ristretta, si è fatta più sculturale, e all'artista basta rappresentare il gruppo di Gesù morto in grembo alla Vergine. Nel quarto quadro del Sodoma, nella Galleria Borghese, il fondo

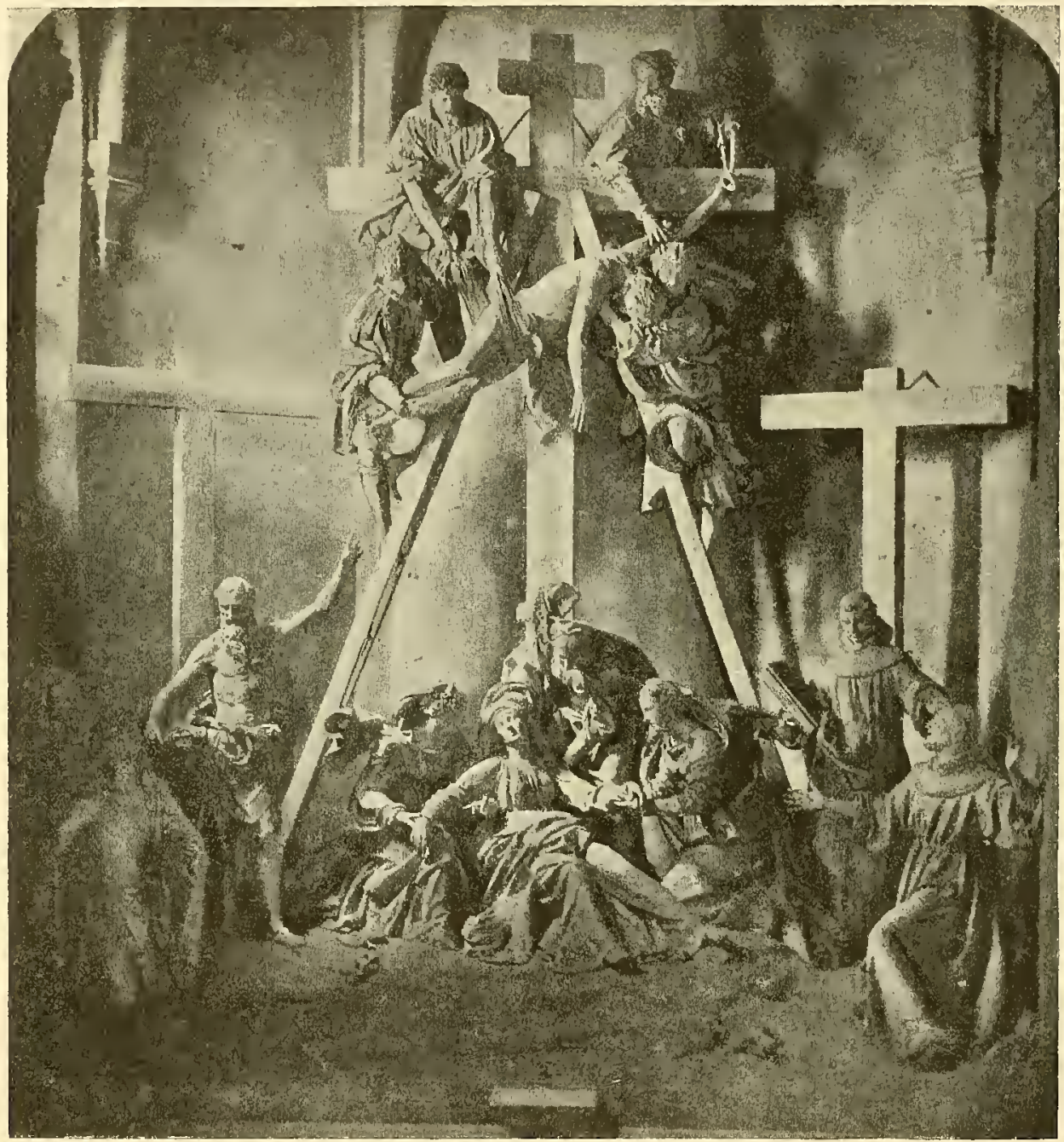

Chiesa di San Pietro in Modena

(L_UD, BEgARELLi)

del gruppo è freddo, tetro, con alberi spinosi, dispogliati, c una luce bianca dietro le rupi del Calvario che nereggiano come esseri squallidi e tormentati. 
Qualche volta, come abbiano veduto, col farsi sempre più logica, l'arte staccò dal grembo di Maria la salma del Cristo, distesavi sopra; ma, senza

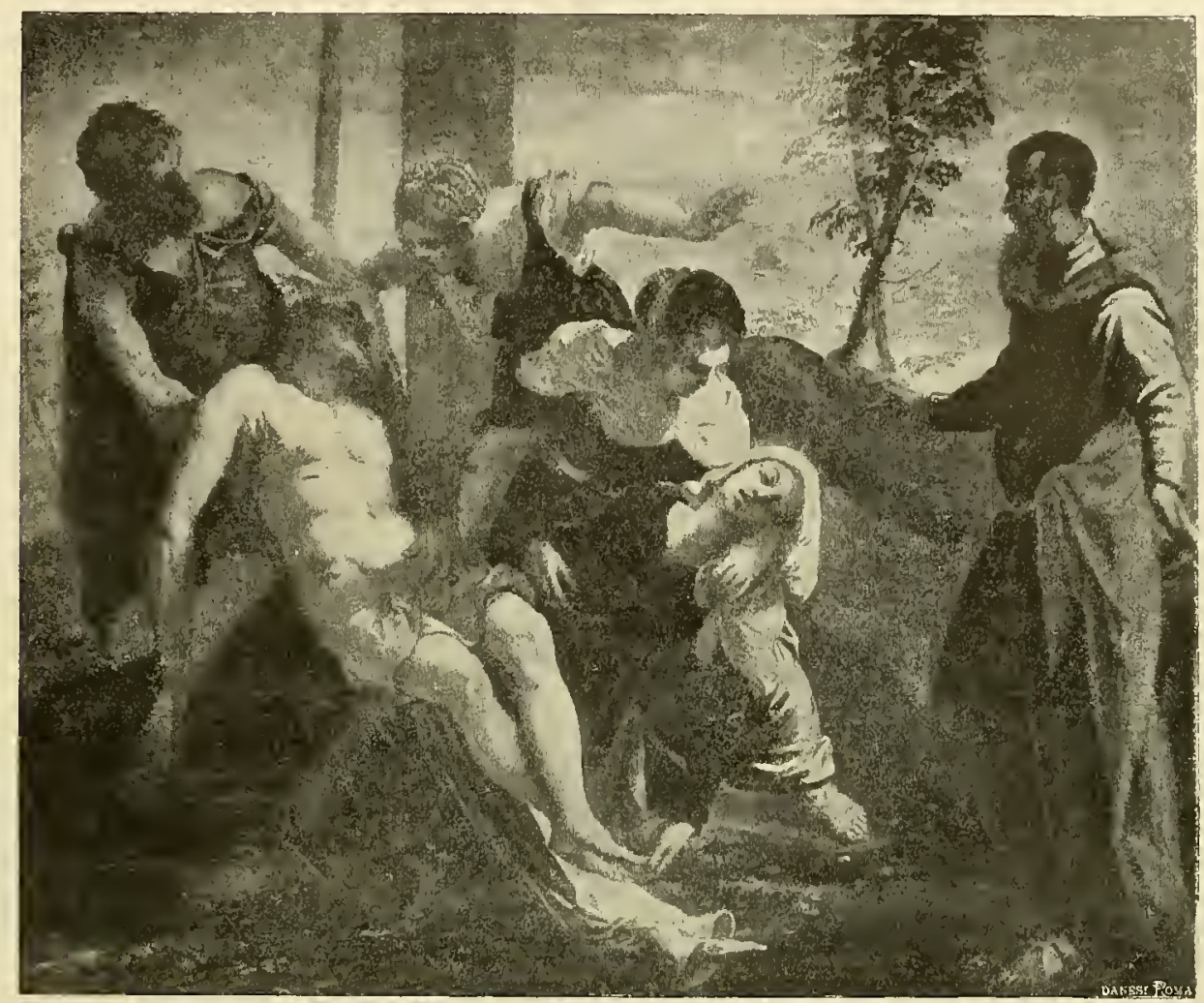

Galleria Pitti in Firenze

(Tintoretto)

ricorrere al motivo comune, il Buonconsigli conservò la grandezza tragica della Donna la cui testa spicca nel cielo sanguigno; Ella apre le braccia desolata, mentre sul suo grembo riposa l'adorato capo del Figlio.

A Venezia però, ove nel Cinquecento la pittura non fu ligia alla scultura e non cercò forme a rilievo, continua la tradizione dell' antica e più complessa composizione, da Cima da Conegliano al Tintoretto. Entrambi dipinsero la Vergine cadente all' indietro nelle braccia delle pie donne, mentre il suo volto è velato dalle ombre della morte. Ma Tiziano, prima di chiudere gli occhi che avevano seguito gl'ideali dell'arte del grande secolo, diede gigantesca grandezza alla scena, ponendo nell'ombra i lugubri personaggi innanzi a un nicchione su cui sembrano cadere faville dalle fiaccole ardenti. Pare che la terra tremi sotto le figure disposte in linea traversale, e sotto 
i piedi vacillanti di Maddalena. La Madre divina con la destra tesa solleva il capo del Cristo, e lo guarda muta. Nell'ombra, sopra piedistalli a teste leonine, ai lati dell'edificio marmoreo, il profeta Mosè con le tavole della legge e la Fede incoronata che addita la croce. La "Pietà sta così tra la legge mosaica e la legge del Cristo, tra l'antico e il nuovo Testamento personi-

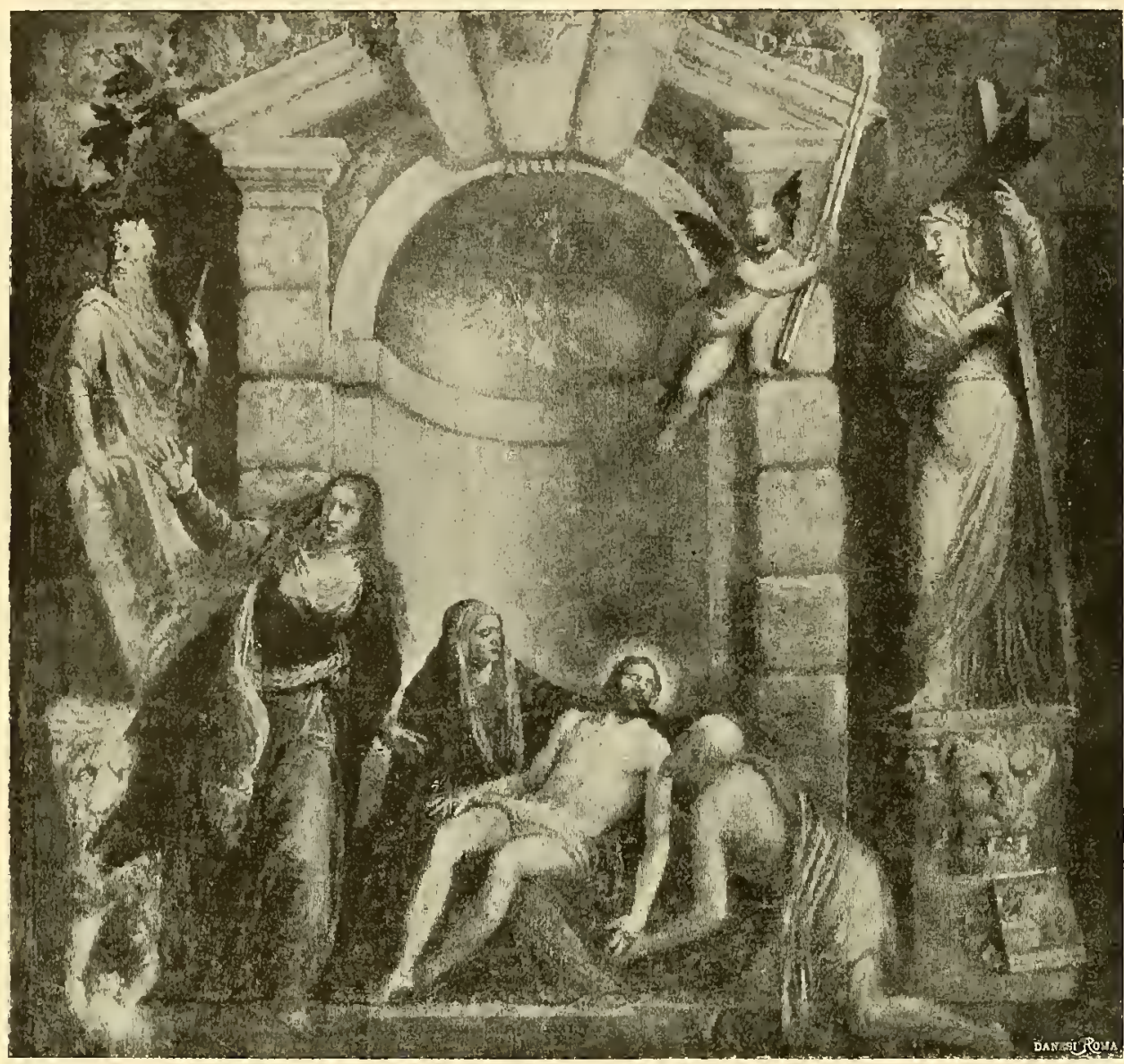

Galleria di Venezia

( TIziAno e seguaci)

ficati, tra le tavole del Sinai e la croce. Maria non lacrima; conscia del sacrificio del Figlio, lo guarda ancora una volta; e la grandezza del Martire le spira maestà nella persona e nel volto. Così il Tiziano compose il quadro, come se prima di morire, a novantanove anni, avesse dovuto edificare il mausoleo del Cristo.

Un'altra composizione che di frequente viene intitolata la "Deposizione dalla Croce " o la "Pietà ", è il trasporto della salma del Cristo nel sepolcro. 
Sembra che la scena siasi formata nel Quattrocento con lo studio dell'antico, e particolarmente de' sarcofagi figuranti la morte di Meleagro. Rappresentando la deposizione del Cristo nel sepolcro, Donatello s'ispirò certamente agli antichi sarcofagi figuranti Meleagro ucciso dal cignale calidonio, cosi come, alla fine del secolo Iv, l’intagliatore della teca eburnea di Brescia, nel rappresentare Anania morto, portato via dal cospetto di San Pietro, ricavò il motivo artistico da quei marmi. Raffaello, nell'eseguire per Atalanta Baglioni e collocare nel San Francesco di Perugia il quadro del trasporto della salma

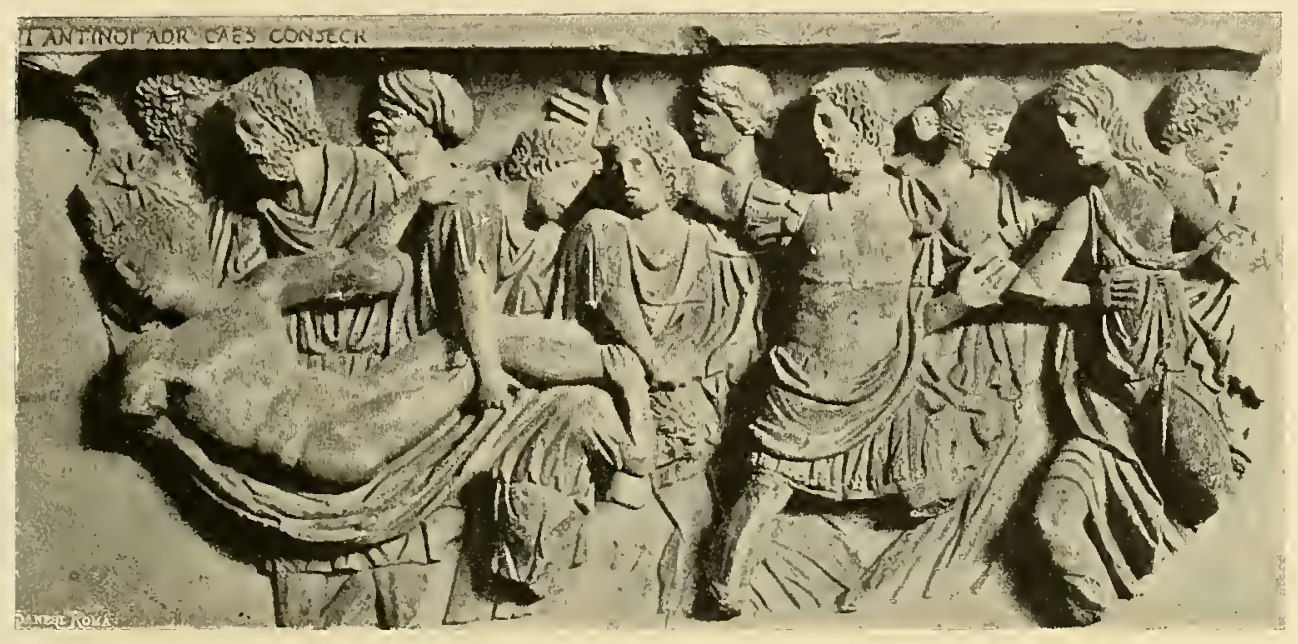

Frammento di sarcofago romano. Museo Vaticano

di Gesù, portò il soggetto a insuperata altezza. Solo in un tempo in cui regnava la più raffinata civiltà potevasi creare un'opera così nobile e pura. Traverso la luminosa chiarezza delle carni e i più dolci colori, appare il Cristo che sembra chiudere le palpebre offese dalla luce e immergersi nel sonno sulle braccia dei fedeli. Ma ammirabile sopratutto è il gruppo delle giovani candide e pietose che sostengono la Vergine svenuta, la quale si piega come giglio falciato.

La deposizione del Cristo nel sarcofago è l'ultimo atto della tragedia. Mentre il rigido corpo steso sulla coltre funerale cala nella tomba, le pie donne, strappandosi i capelli e urlando, la Madre abbracciando e baciando la salma, vogliono ritardare il momento in cui non la vedranno più. Così rappresentò la scena un seguace di Giotto ad Assisi e, più mitemente, un altro in Santa Croce. 
Il Quattrocento in generale mostrò il Cristo morto in piedi, ritto clentro al sarcofago, sporgente dalle anche in su, e sostenuto da Maria e da Giovanni. E tra $i$ tanti esempî di questa semplificata rappresentazione ci sembra degno d'essere additato quello di Giambellino, nel vestibolo della chiesetta del palazzo ducale, in cui la testa del Cristo s'appoggia alla sinistra guancia della Madre, e le socchiuse bocche d'entrambi sembrano mormorare, confidarsi un lamento. La scena era fuori del verosimile; la deposizione del Cristo si era così riassunta in un gruppo simbolico per la pietà dei fedeli. Il Redentore si mostra ancora al popolo, chinsi gli occhi, coronato di spine, coperto di lividure e di piaghe: non ha vita più, ma Maria e l'apostolo Giovanni lo reggono sul sarcolago, dal mezzo in su, perchè il mondo lo pianga e lo adori. 


\section{L'Ascensione.}

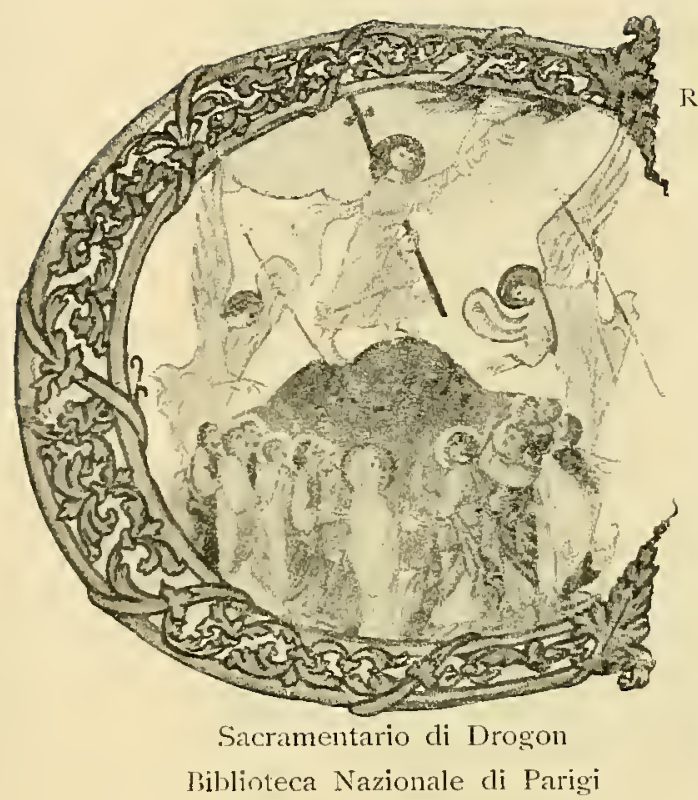

RISTO glorioso appare tra i bassorilievi a destra della porta della basilica di Santa Sabina in Roma, monumento del secolo $\mathrm{v}$. Il datore della nuova legge, dalla testa apollinea, vestito di pallio, sta sull universo in un clipeo circondato da lauro; tiene, quasi fosse una cetra, un rotulo in cui è scritto in lettere greche il suo nome, e stende la destra protettrice alla terra. L'入 e l' $(\boldsymbol{D})$ intagliate ai lati della figura, lo designano il Cristo dell'Apocalisse, il primo e l'ultimo, il Principio e la Fine. Ne' triangoli mistilinei formati dal medaglione con lo scompartimento rettangolare, sono intagliati i simboli evangelici; e sotto la volta del cielo (ove raggia il sole e splendono la luna e le stelle) stanno sul piano, due apostoli, Pjetro e Paolo, stendenti in alto una corona crociforme, e una donna, la Chiesa lasciata nella terra, che contempla ammirata la gloria del Dio.

É questa la prima forma della rappresentazione, e Maria, che, nell'inizio dell' arte cristiana è personificata dalla Chiesa madre de’ fedeli, si mostra poi nel suo chiaro aspetto di Madre del Dio. Così vedesi già nel codice siriaco del monaco Rabula, nella Laurenziana di Firenze: mentre gli angioli additano agli apostoli il Cristo in un'aureola sostenuta dai cherubi, sui quattro simboli apocalittici coperti dalle ali occhiute dell'angiolo che si congiunge arl essi: intorno alla mandorla che s'innalza sulle vette dei monti, girano le 
ruote dei troni, e due alati spiriti recano sulle mani velate la corona al trionfatore. Maria, a guisa delle Oranti delle Catacombe, solleva ed apre le

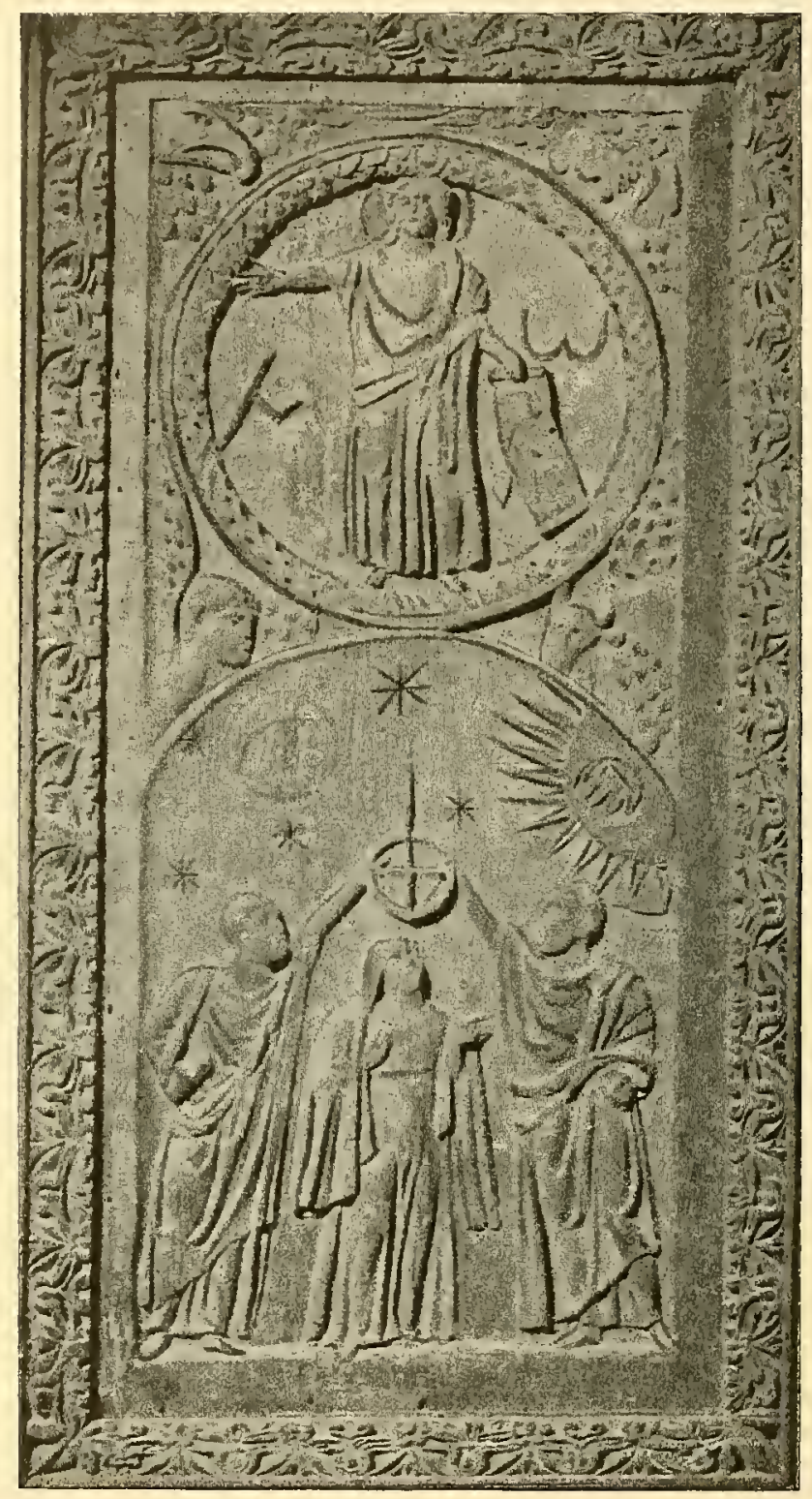

Dalla porta intagliata di Santa Sabina. Secolo v

braccia: ma il nimbo la corona, e veste il manto che le copre il capo, a mo' di velo, come una Madonna bizantina.

La composizione nel secolo vi era quindi definita ne suoi contorni; e tale si rivede nel Sacramentario carolingio di Drogon, in un avorio della 


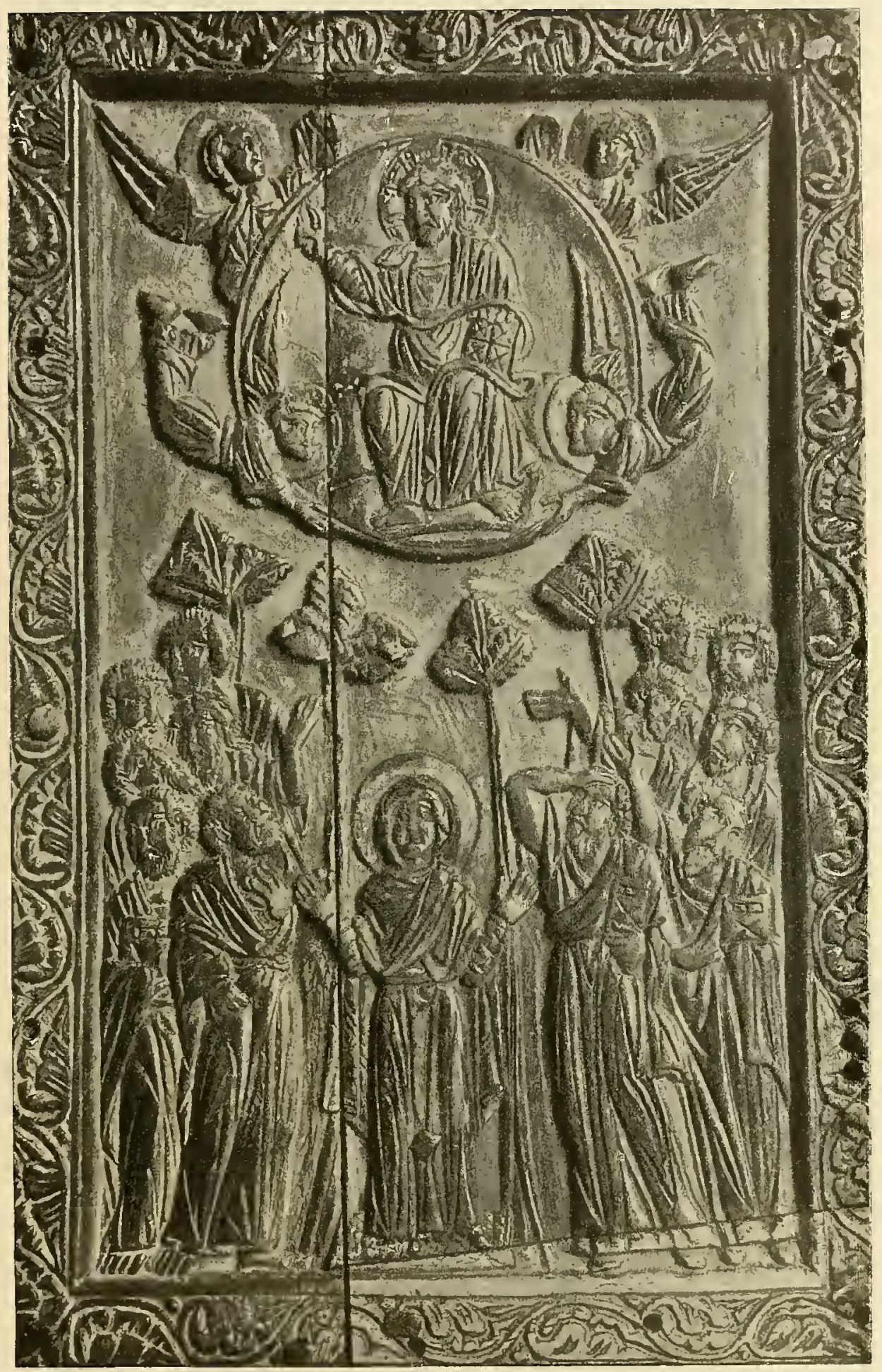

Coperta d'avorio carolingia. Biblioteca Barberini 
Biblioteca Barberini (sec. Ix), e con poche varianti nell'età bizantina: esempio il frontispizio delle onelie del monaco Giacomo e l'avorio della raccolta

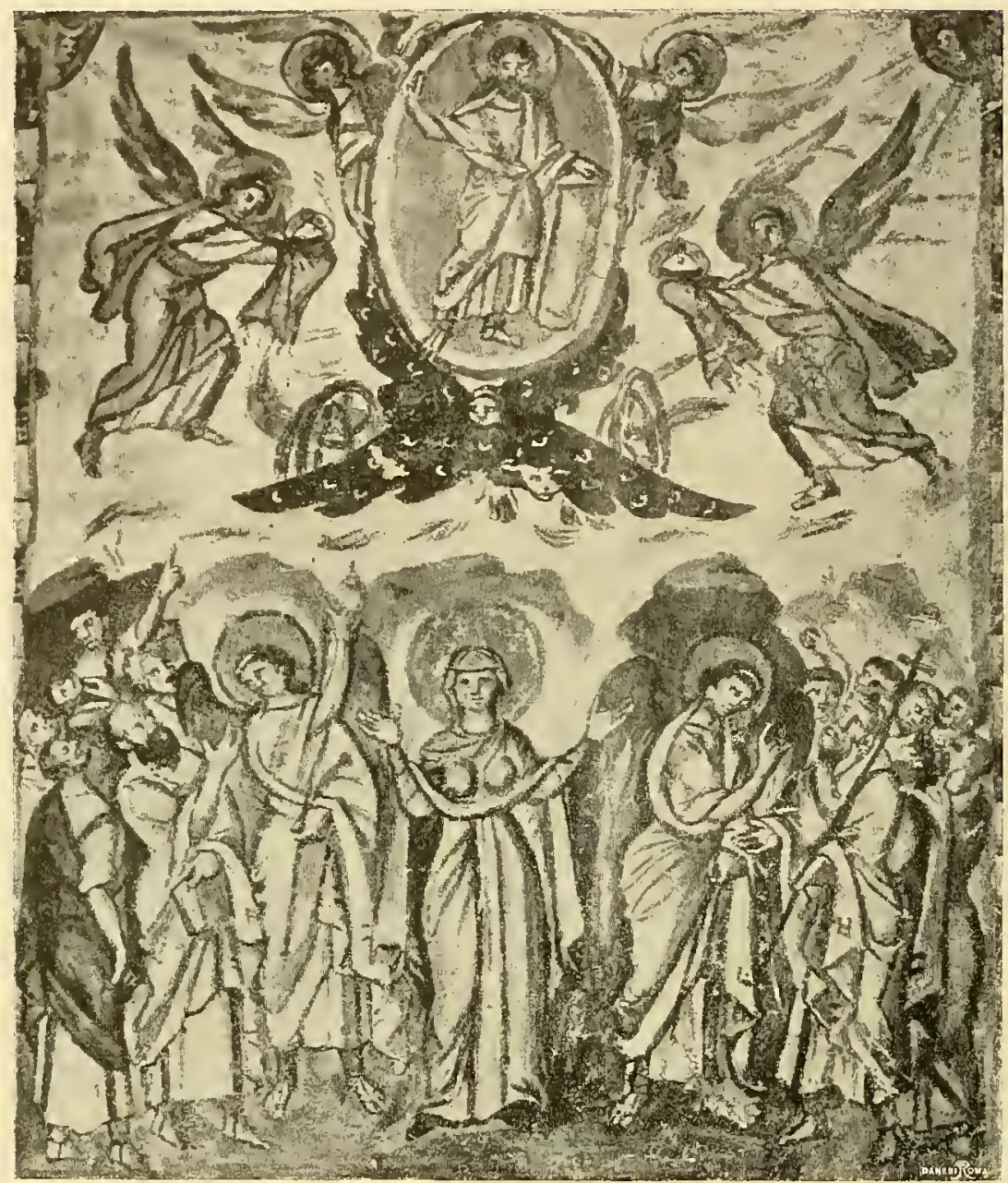

Piblioteca Laurenziana di Firenze

(Codice deljionaco Rabula)

Carrand in Firenze della fine del secolo xI, con la scritta che significa: "Uomini di Galilea, perchè tenete gli occhi rivolti in cielo?"

L'arte italiana, pur conservando gli elementi antichi della composizione, la perfezionò nel Trecento: il Cristo par che prenda lo slancio dalla terra, come nel Sacramentario di Drogon; i due angioli additano la visione agli apostoli, come nel codice siriaco, ma essi sembrano portati quai fuscelli dolcemente dall'aria tranquilla, e gli apostoli caduti in ginocchio recano le mani a difesa delle intente pupille abbagliate dalla luce, mentre Maria estasiata 


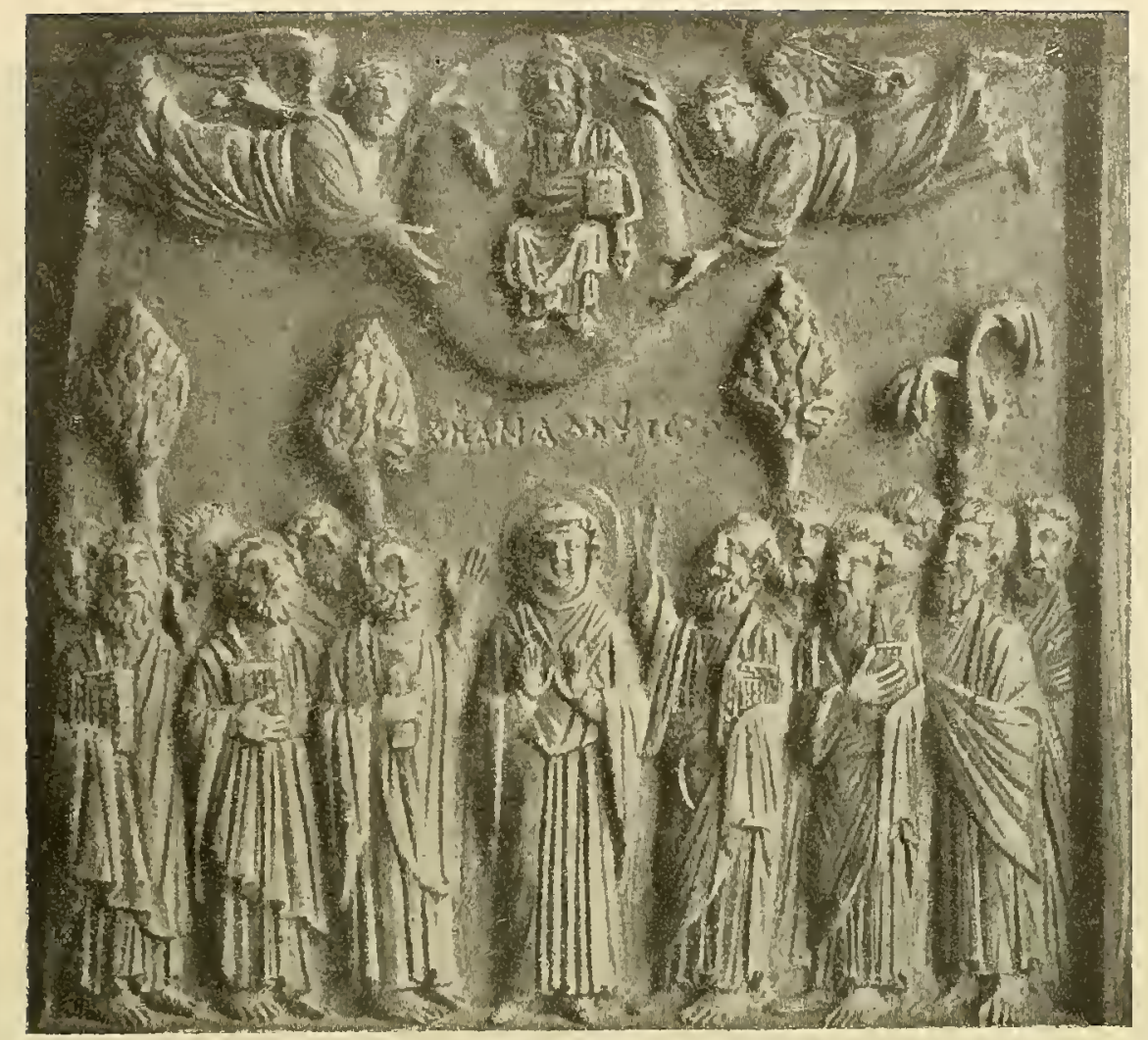

Avorio del secolo xir. Collezione Stroganoff in Roma

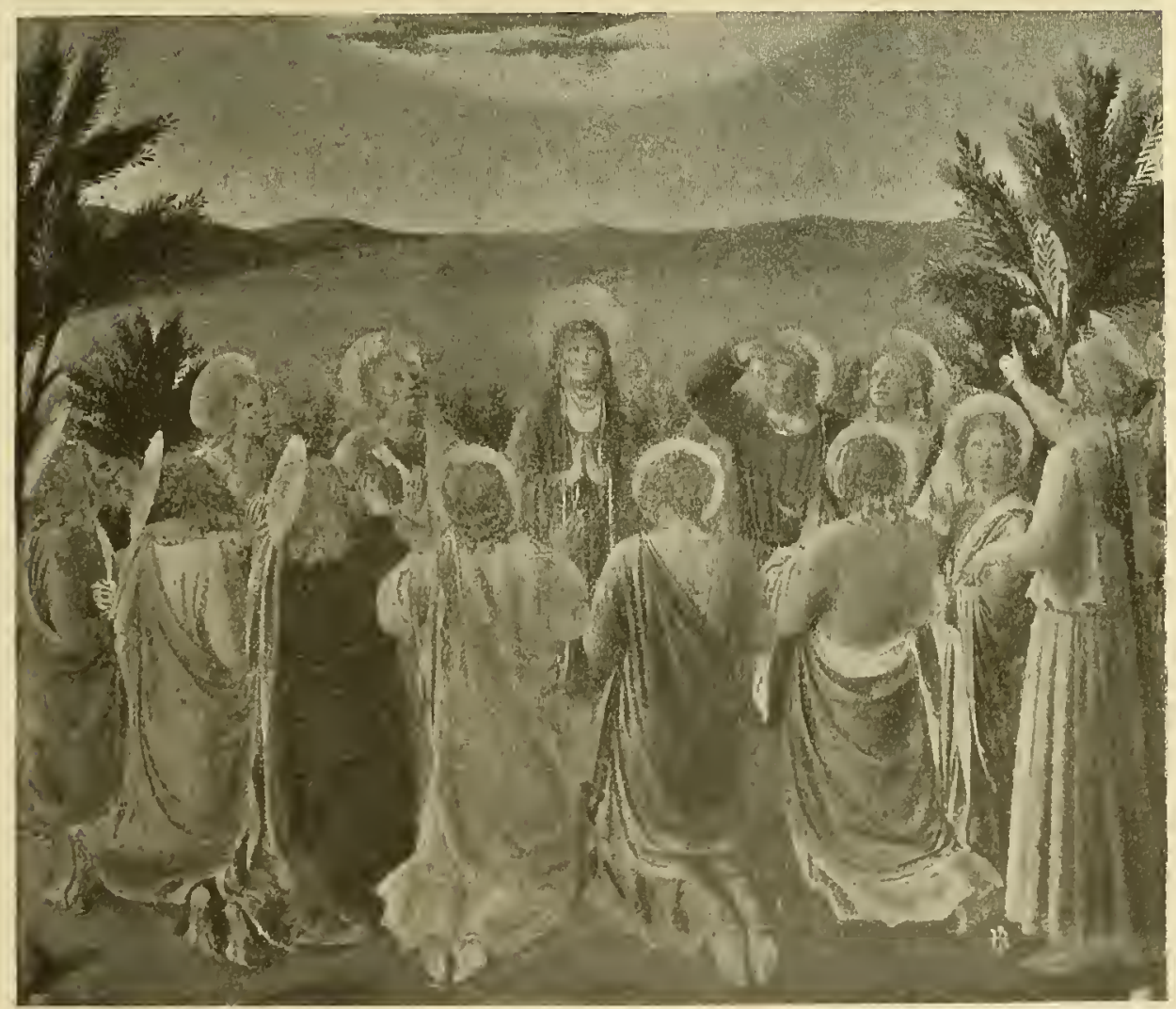

Galleria antica e moderna in Firenze

(Beato Angelico) 


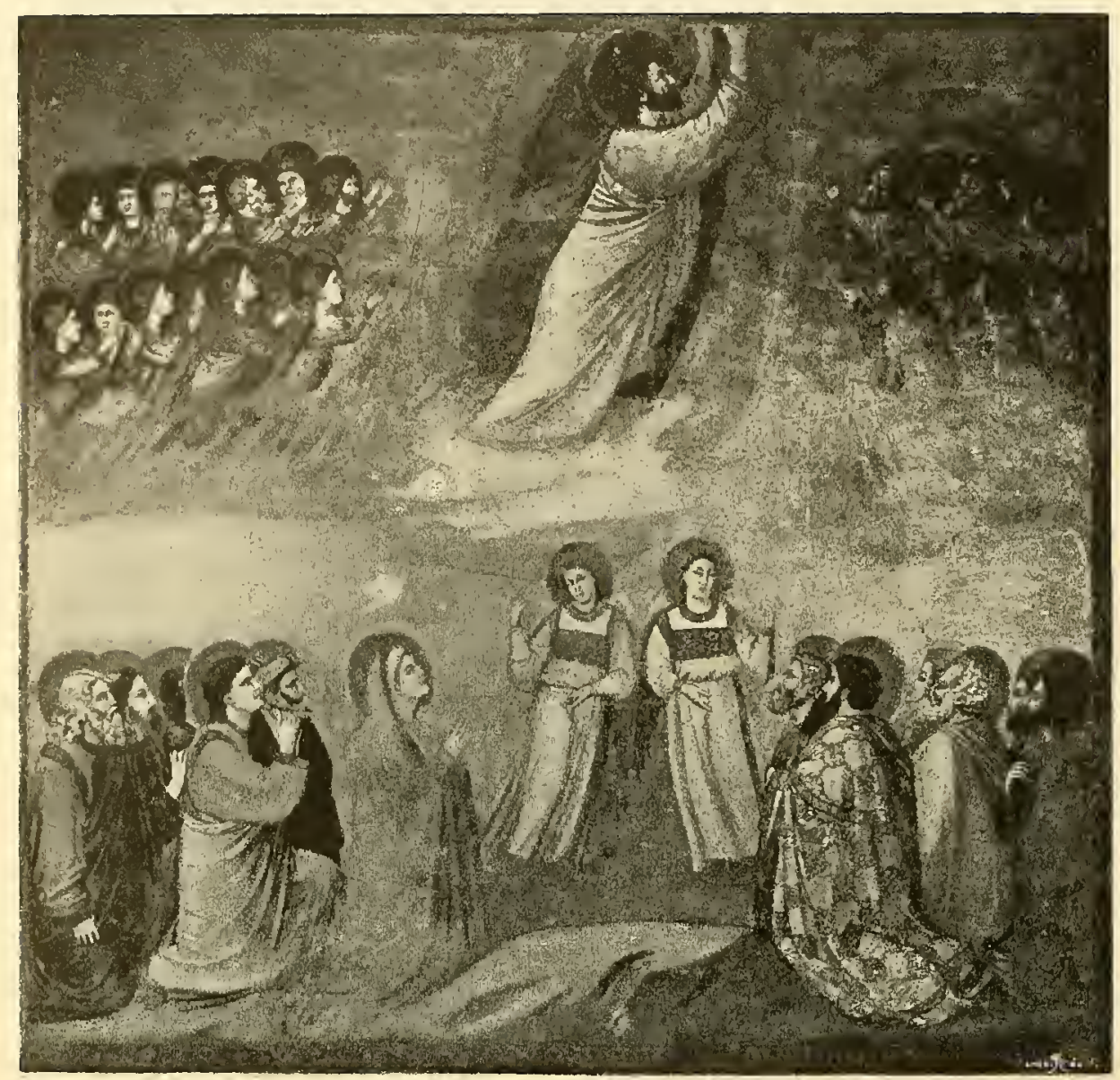

Oratorio degli Scrovegni in Padova (Grotto)

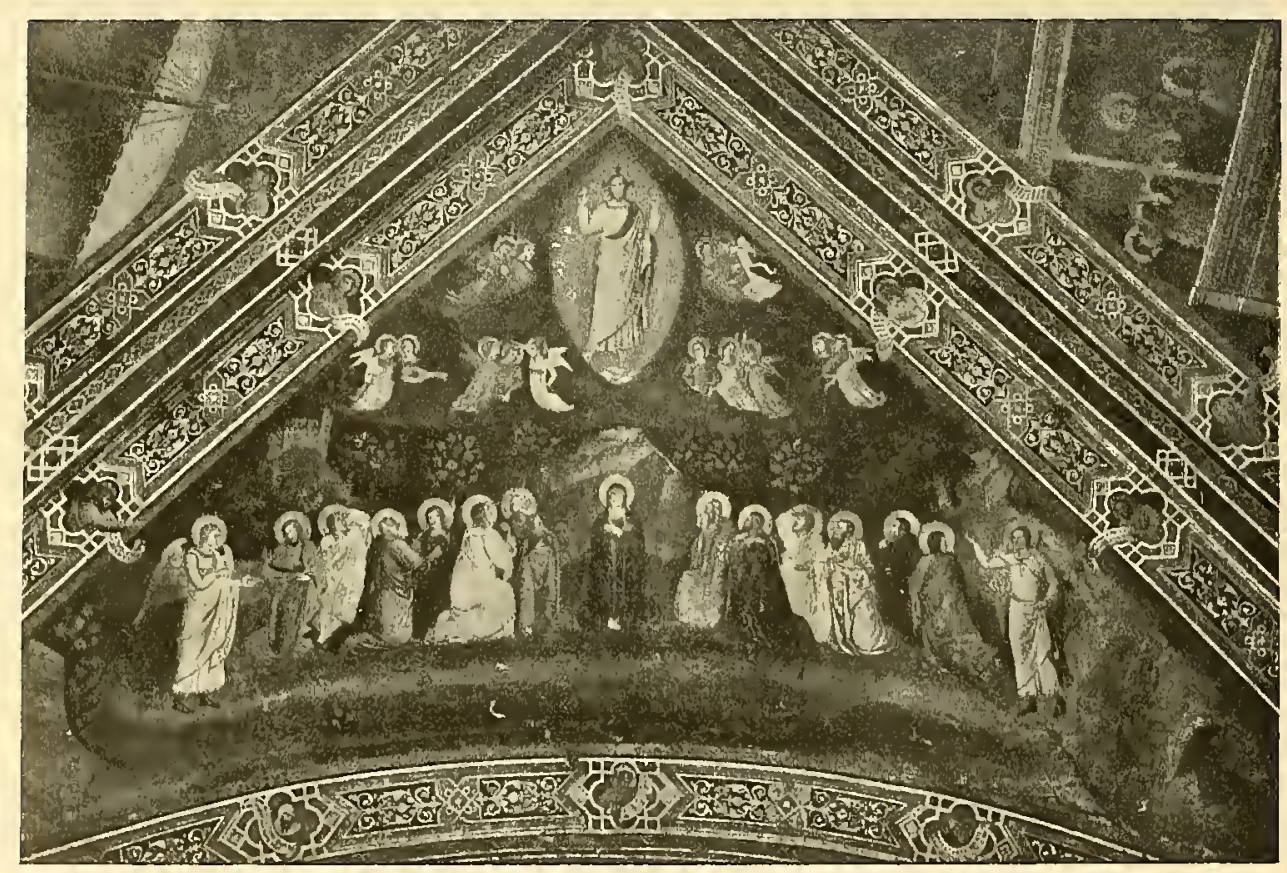

Cappellone degli Spagnuoli in Firenze a Santa Maria Novella

(TADDEI GADDI?) 


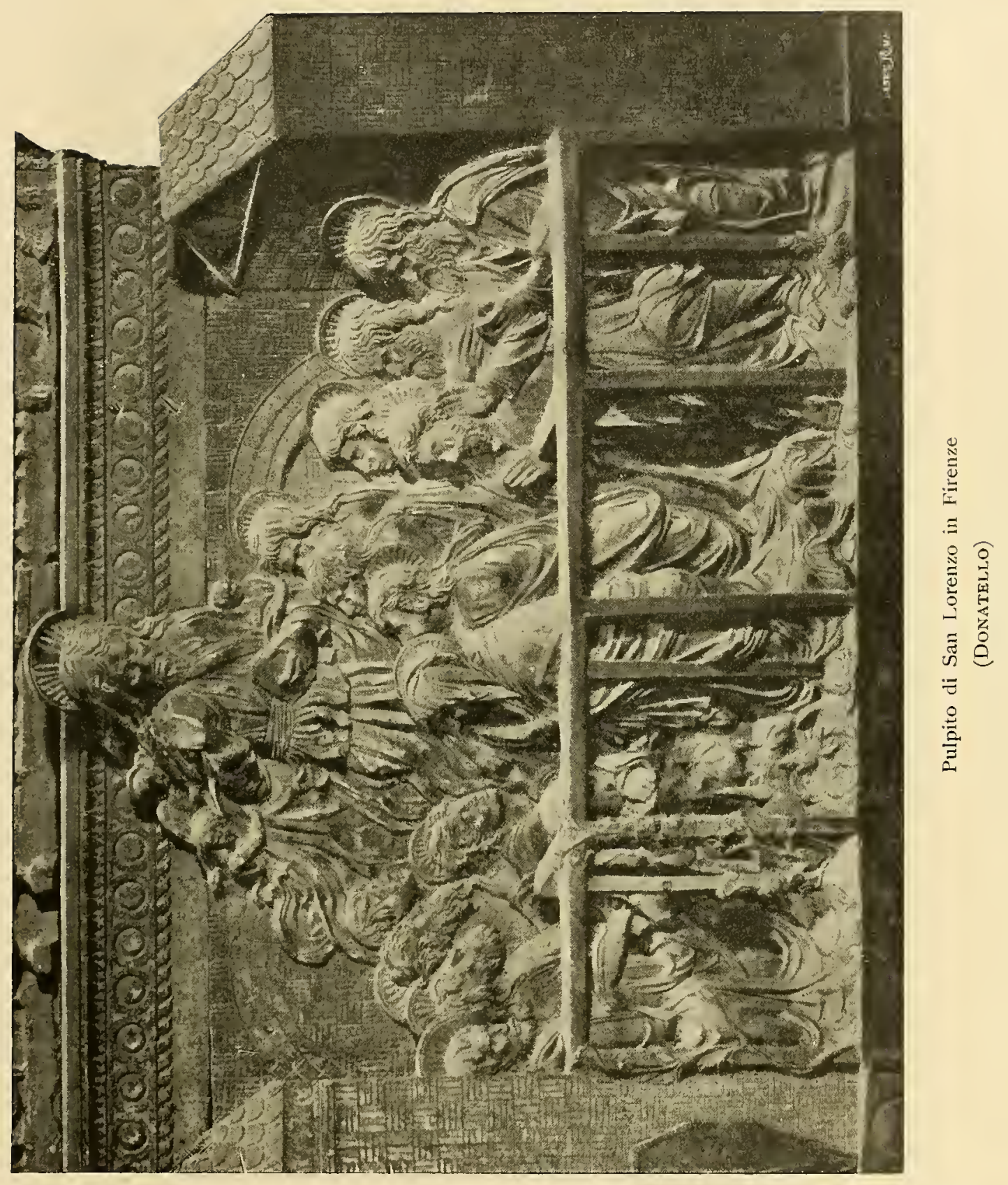


prega con le mani congiunte. Cosi Giotto insuperato nell'Arena di Padova. Nè può contrapporglisi la simmetrica composizione di Taddeo Gaddi (?). nel cappellone degli Spagnuoli in Firenze. Il Beato Angelico, che più tardi figurò

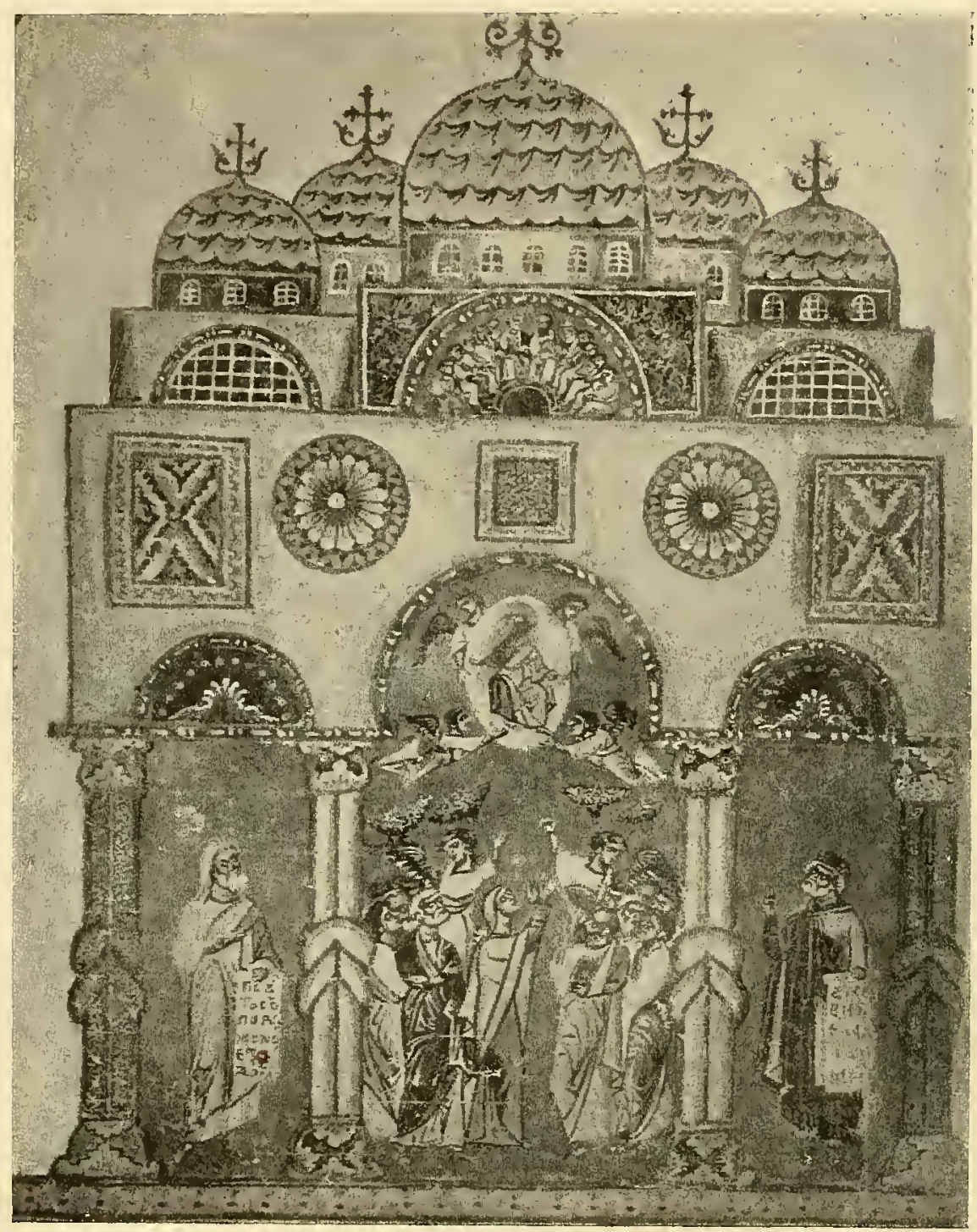

Biblioteca Nazionale di Parigi

(Omelie del Monaco Giscomo)

la scena stessa trovando una bella linea ondulata di montagne sull'orizzonte. conservando $\mathrm{j}$ due angioli e finanche $\mathrm{i}$ due olivi che abbiamo veduto nell'avorio e che si ripetono di consueto nelle rappresentazioni bizantine: ma quella sua corona di apostoli incantati, che guardano disparire nelle nubi del tramonto, in un grande alone, il Cristo, non ha la vita, la commozione profonda 


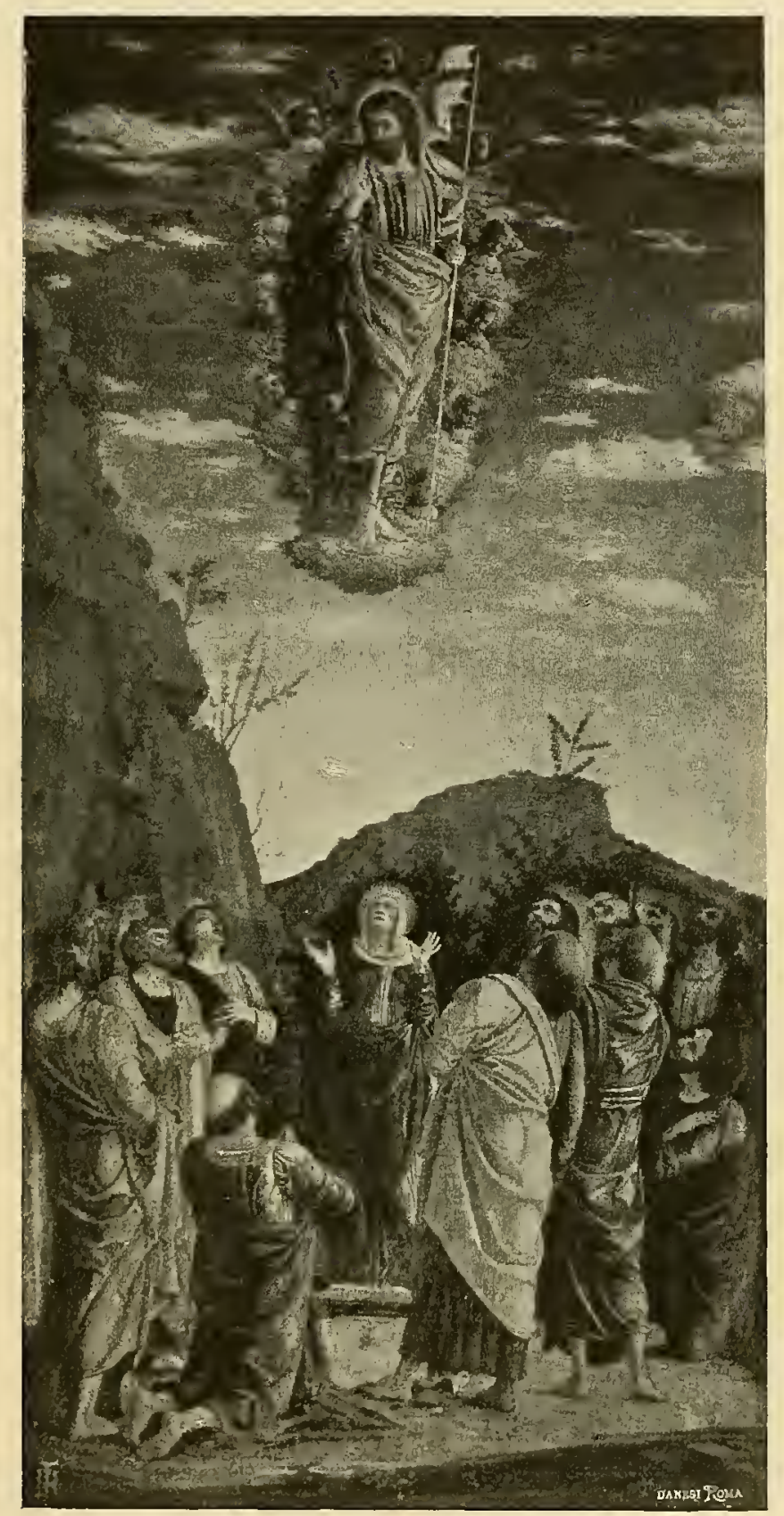

Galleria degli Uffizi in Firenze

(MANTEGNA) 
degli apostoli variamente raggruppati da Giotto, davanti e alle spalle di Maria, in cui Giovanni da Fiesole non esprime nè il tenero amore, nè il gaudio. E non li esprime il Mantegna, nell' "Ascensione" degli Uffizi, nel ben calcolato quadro, ove si rivede Maria in attitudine d'orante: pittura mirabile, dalla finezza di un cameo antico; ma il sentimento non sgorga come nell'opera di Giotto. C'è troppo in evidenza l'allestimento scenico!

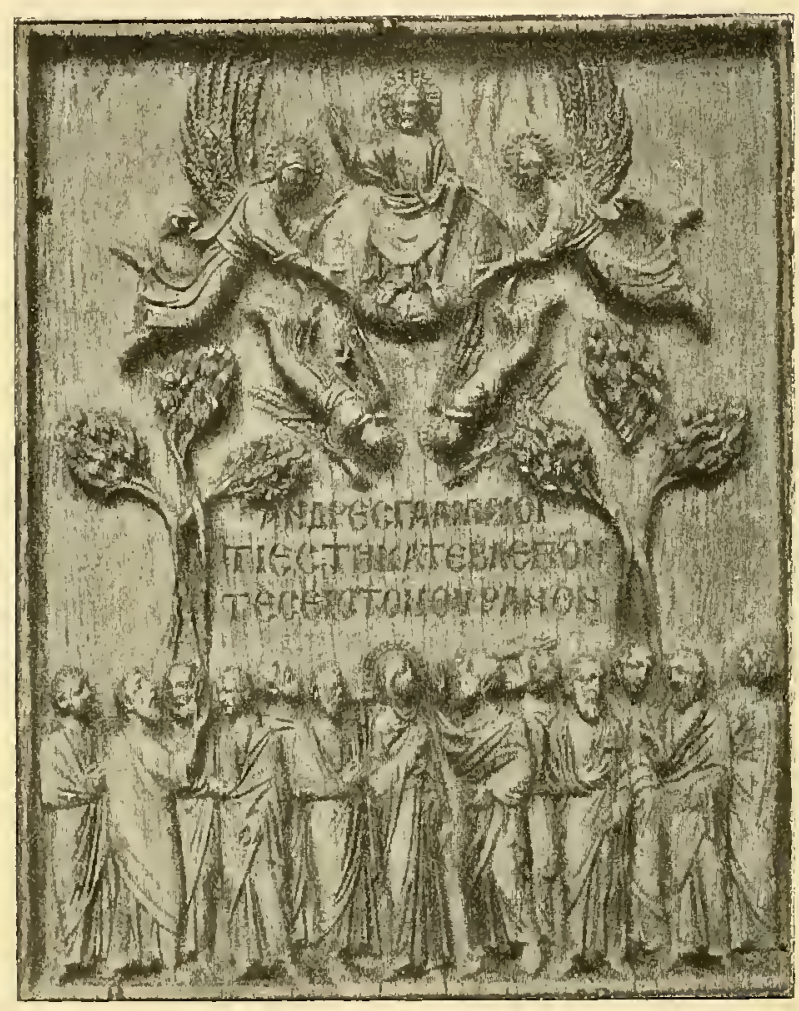

Avorio bizantino.

Raccolta Carrand nel Museo Nazionale di Firenze 


\section{La Pentecoste.}

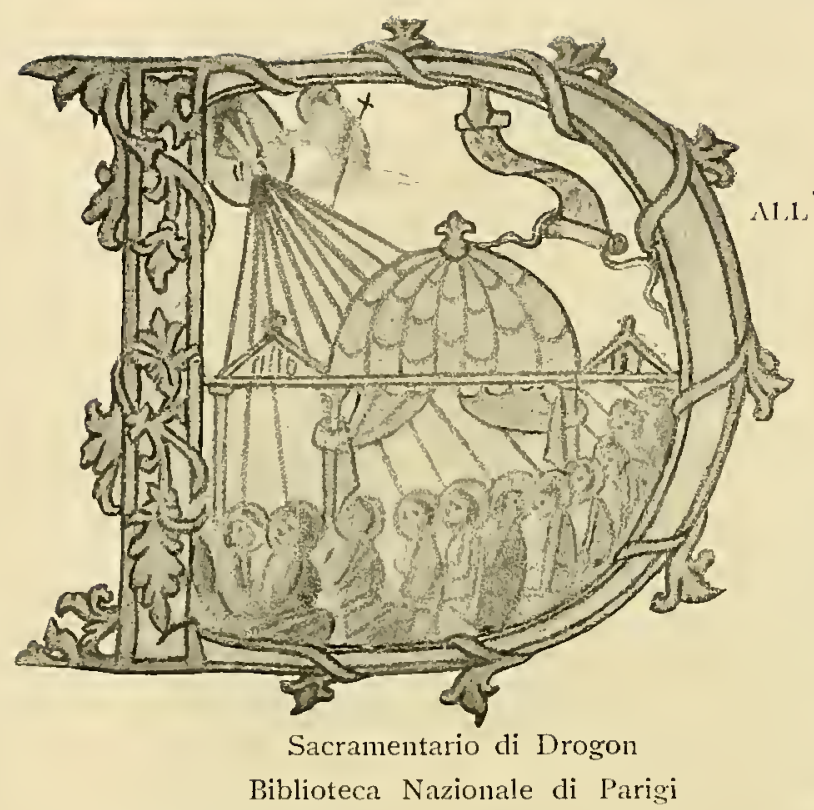

Ascrnsione alla Pentecoste. Nel codice siriaco del monaco Rabula, la Vergine sta in mezzo agli apostoli; tutti in piedi, in un coro trionfale. guardano innanzi a sè, mentre ardono nei loro nimbi le fiammelle dello Spirito Santo che, in forma di colomba dal becco raggiante, sembra piombare sul capo della Vergine. Cadono invece i raggi come lunghe lance sulle teste degli apostoli seduti nel Sacramentario di Drogon, e nell'avorio carolingio della Biblioteca Barberini; ma la Vergine non si trova nel consesso, come non si vede, più tardi, a Padova, nell'affresco di Giotto. Taddeo Gaddi riprese le tradizioni, interpretò di nuovo i testi, moltiplicò i seguaci del Cristo raccolti intorno alla Vergine e pose anche innanzi alla porta del luogo, sotto la casa, ove quelli siedono e pregano in due schiere a destra e a sinistra di Maria, i pellegrini giunti da lontane regioni al convegno. Maria, divota monaca intenta alla preghiera, guarda con le assorte pupille al cielo. Il testo sacro fu interpretato bene dall' erudito pittore del cappellone degli Spagnuoli, ma l'arte non fece un gran passo, così come non lo fece poi con Beato Angelico, che più volte rappresentò ridotta quella scena. Il Cinquecento col Tiziano a Venezia, nella Chiesa della Salute, e Paris Bordone a Milano, nel quadro della Pinacoteca di Brera, trovò modo di rappresentare l'adunanza 


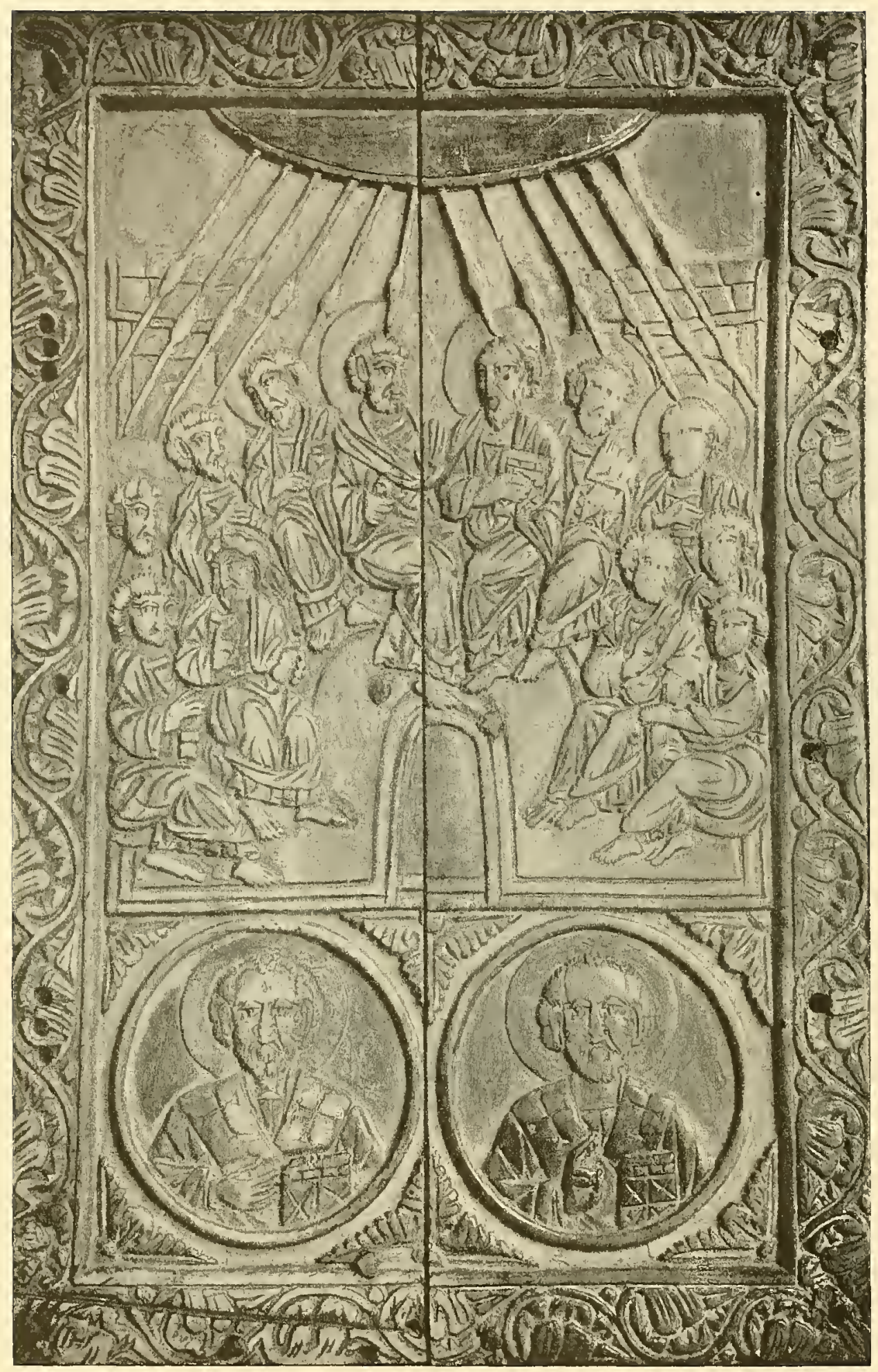

Coperta d'avorio carolingia. Biblioteca Barberini in Roma 


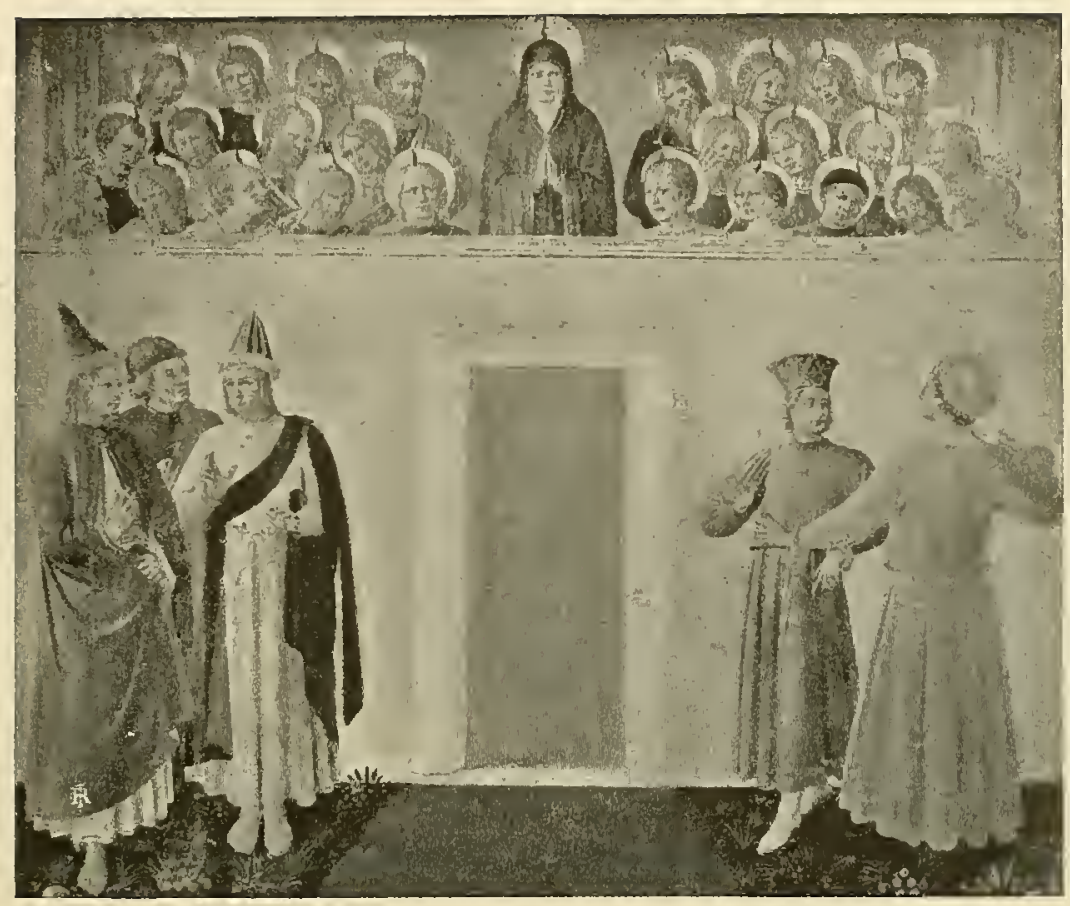

Galleria antica e moderna in Firenze (Besto Angelico)

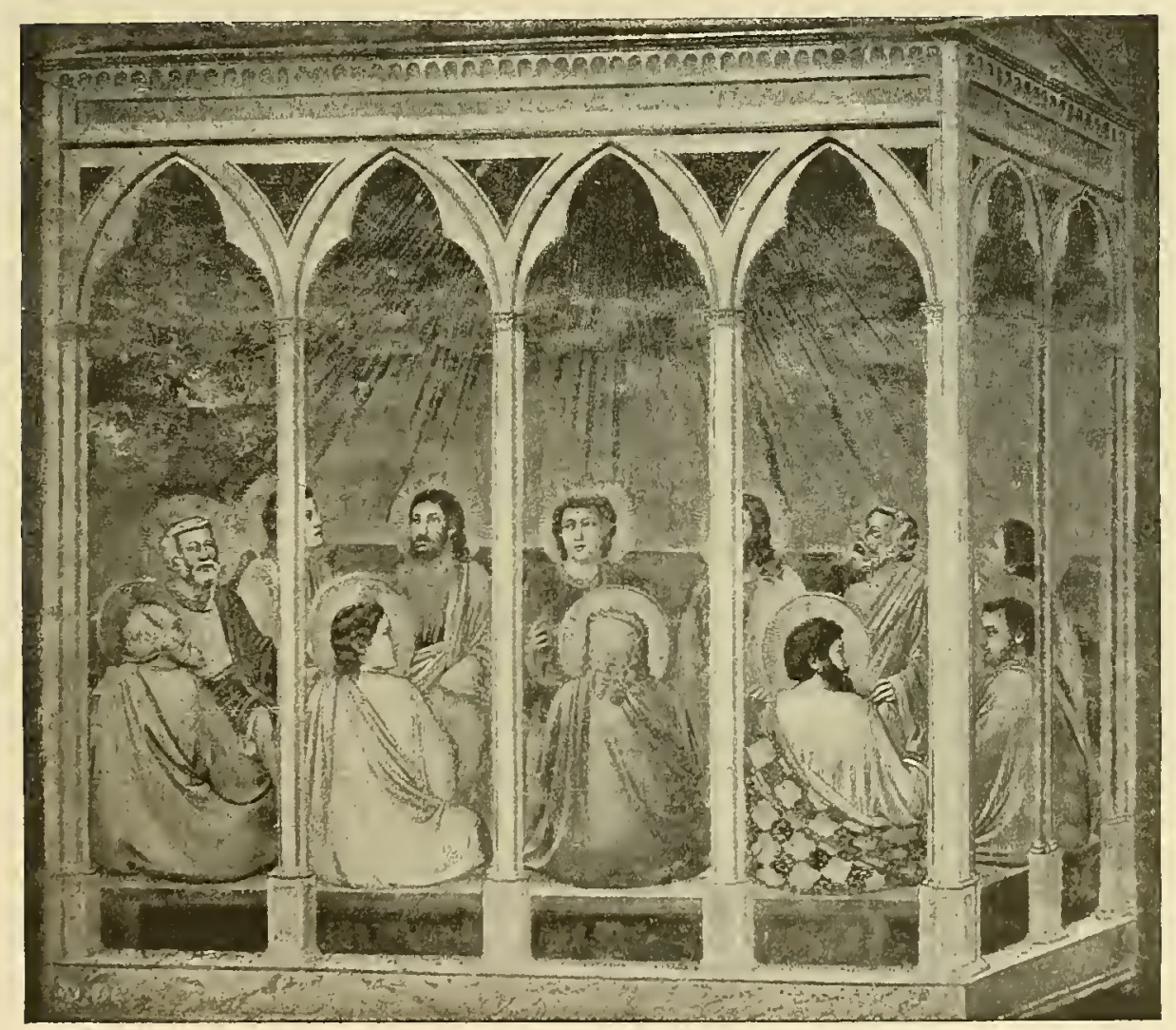

Oratorio degli Scrovegni in Padova (Giotto) 


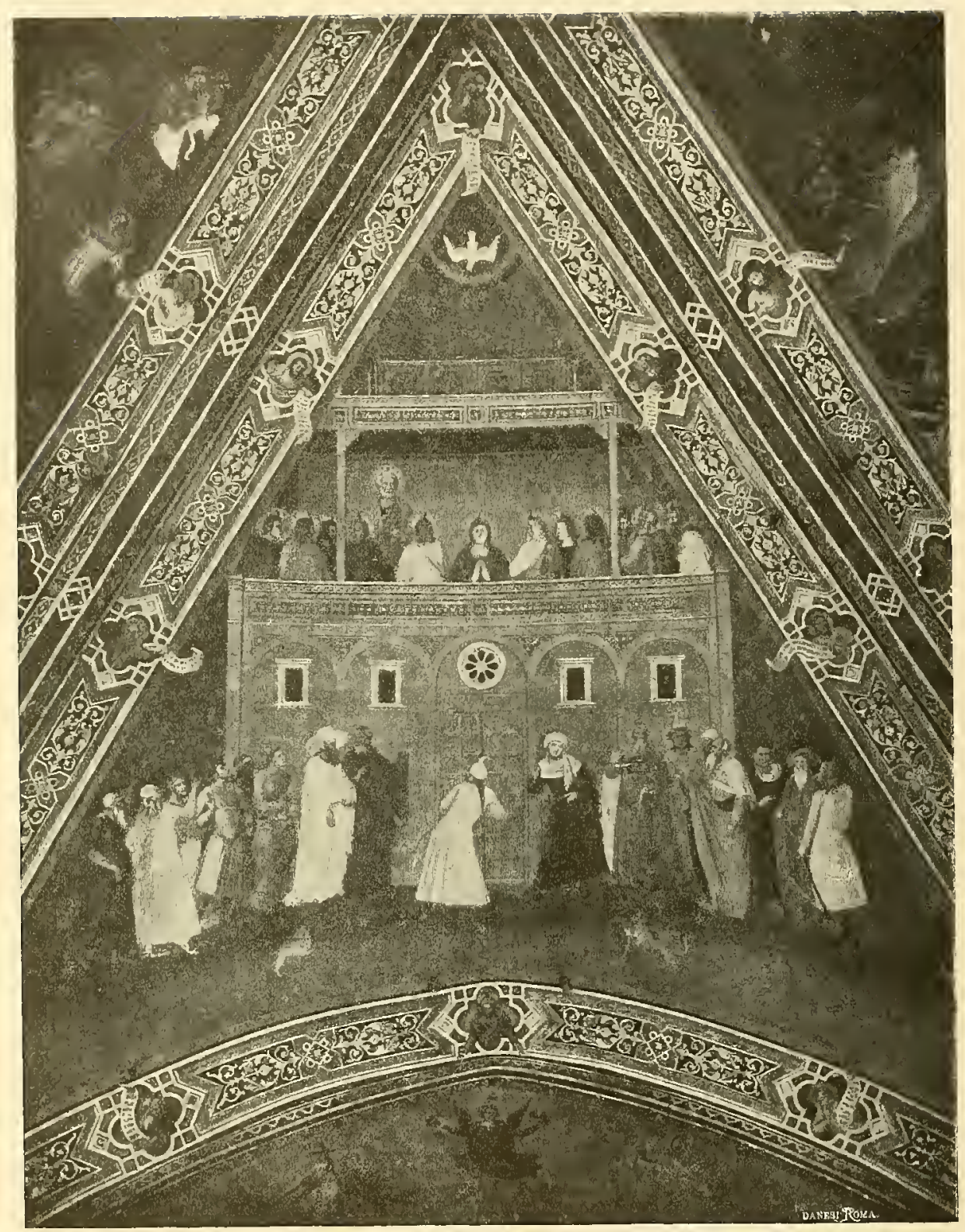

Cappellone degli Spagnuoli in Firenze a Santa Marla Novella (TADDEO GADDI?) 


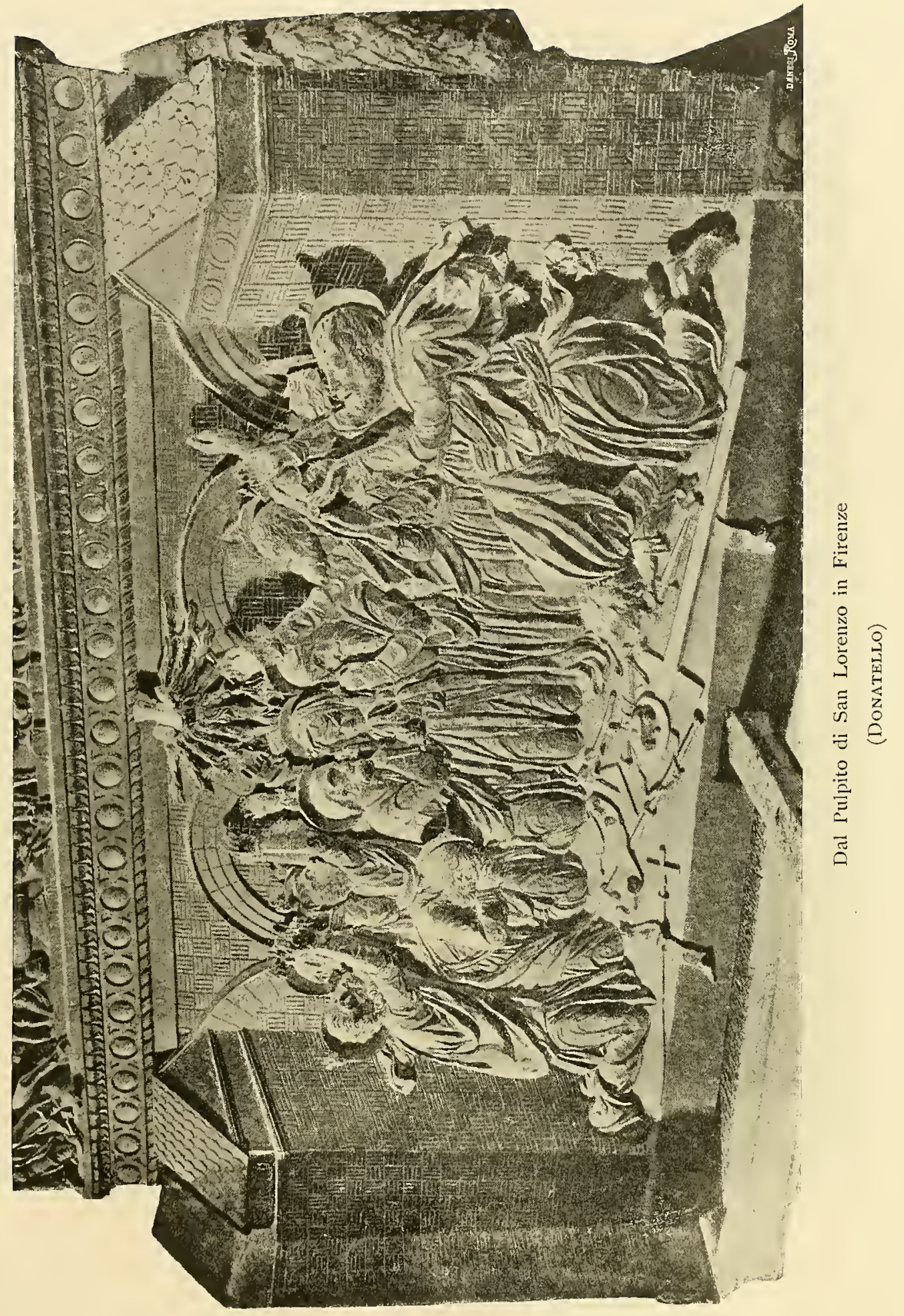




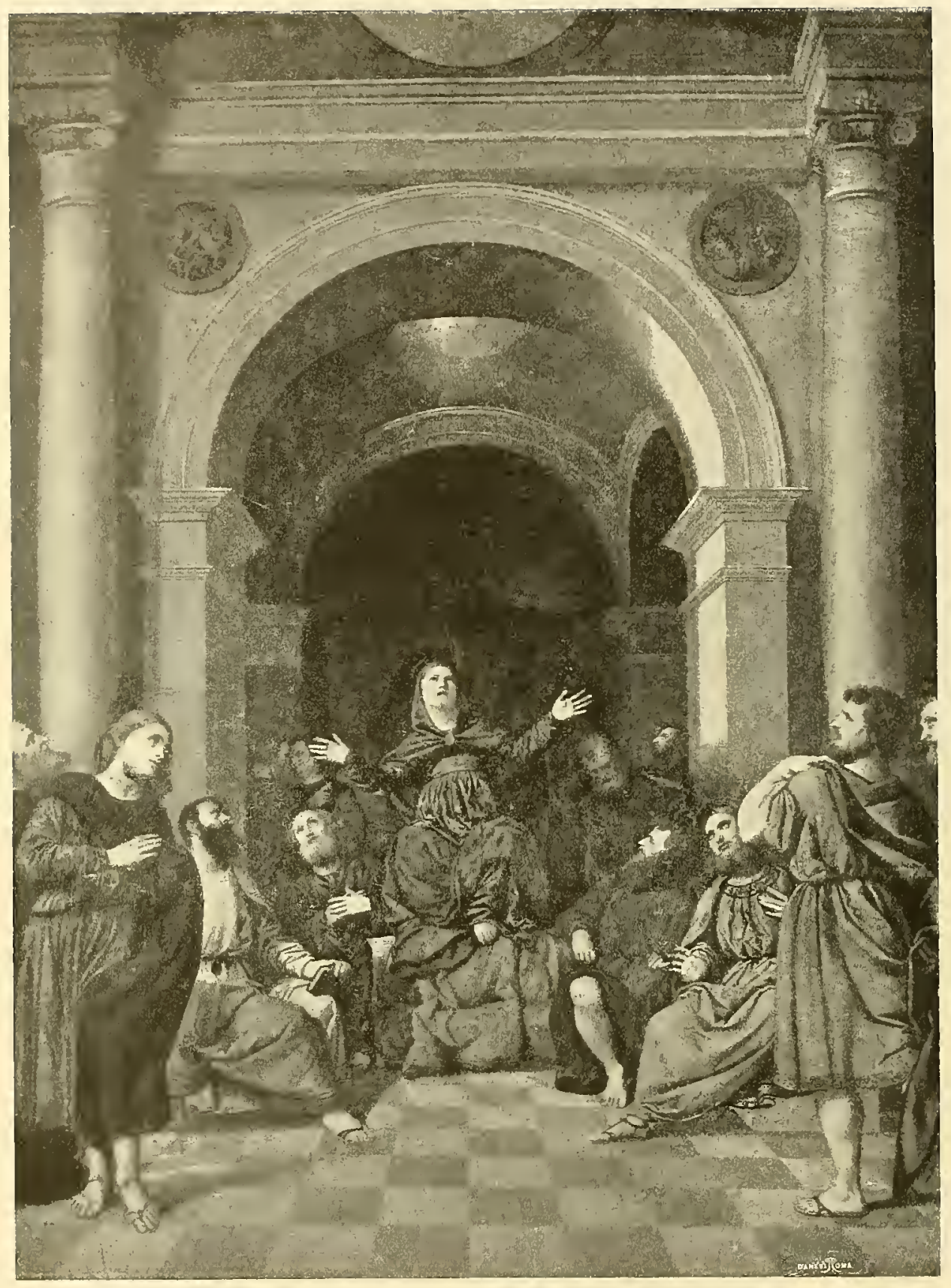

R. Galleria di Brera in Milano

(PARIS Bordone) 
de' ferventi apostoli, uniti nell'amore di Dio, e tra essi si erge la Madonna con le braccia aperte di orante, con lo spirito anelante al cielo. La luce cade sull'eletta tra le donne, e si diffonde sul capo de suoi nobili compagni: Ella sembra assorgere in alto, alla fonte stessa della luce.

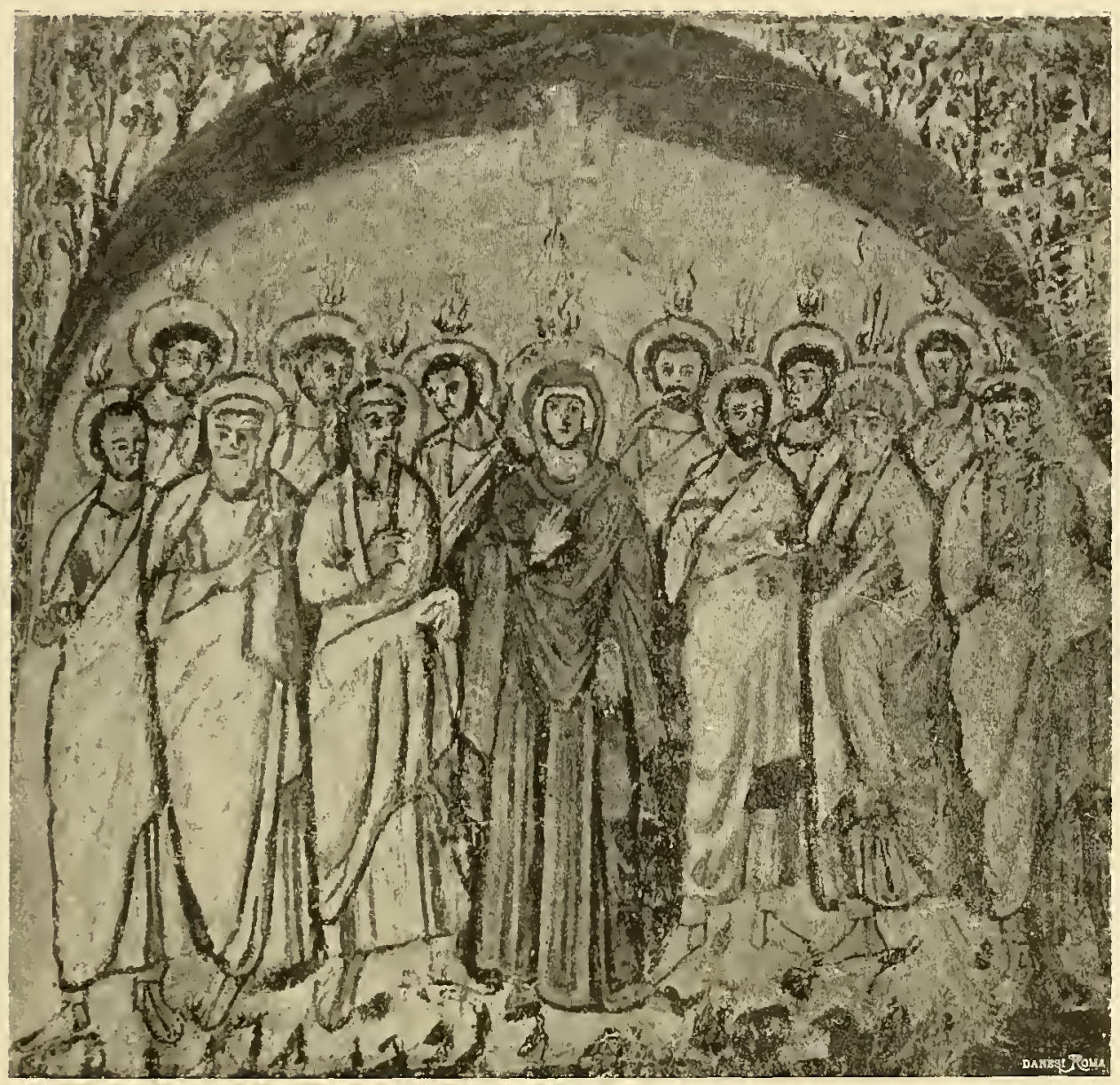

Biblioteca Laurenziana di Firenze

(Codice del Monaco Rabula) 



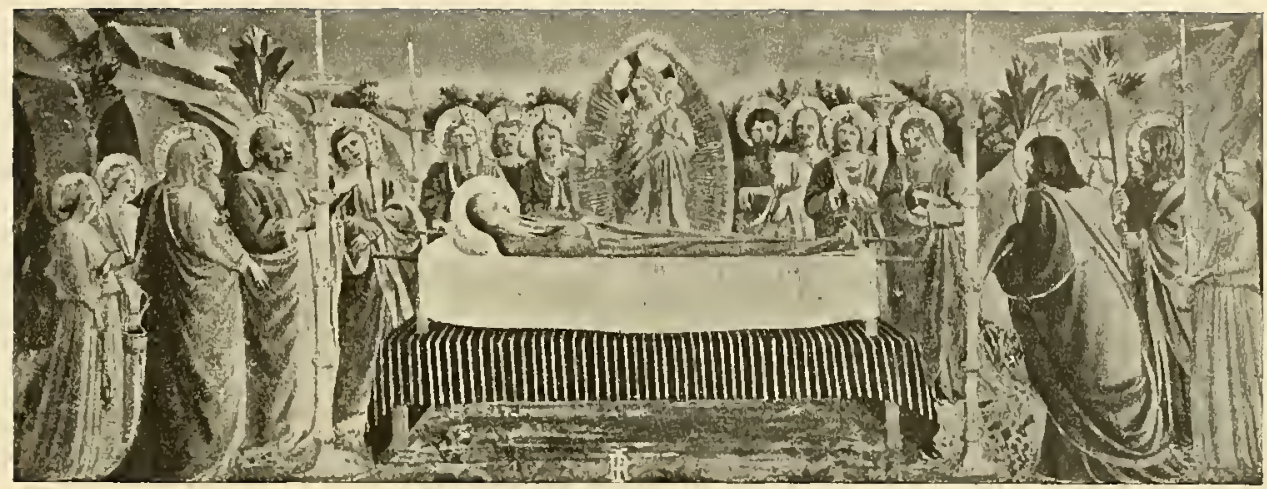

R. Galleria degli Uffizi in Firenze

(Beato Angelico)

\section{L'Assunzione.}

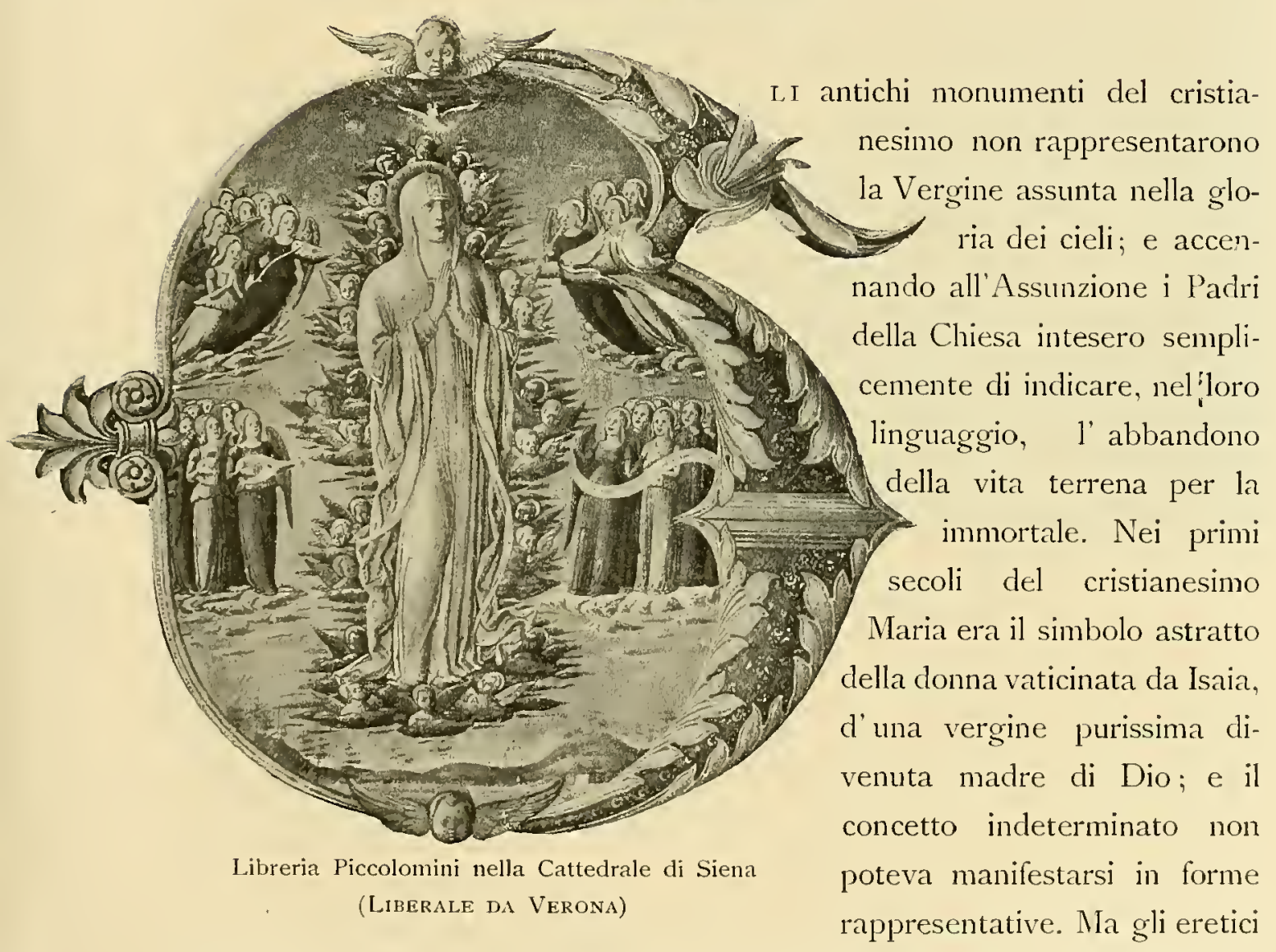

gnostici nel III e nel IV secolo tentarono audacemente animare di affetti umani la venerabile Vergine, e composero quella poetica istoria del suo Transito, che fu condannata poi come ereticale da papa Gelasio alla fine del secolo v. 


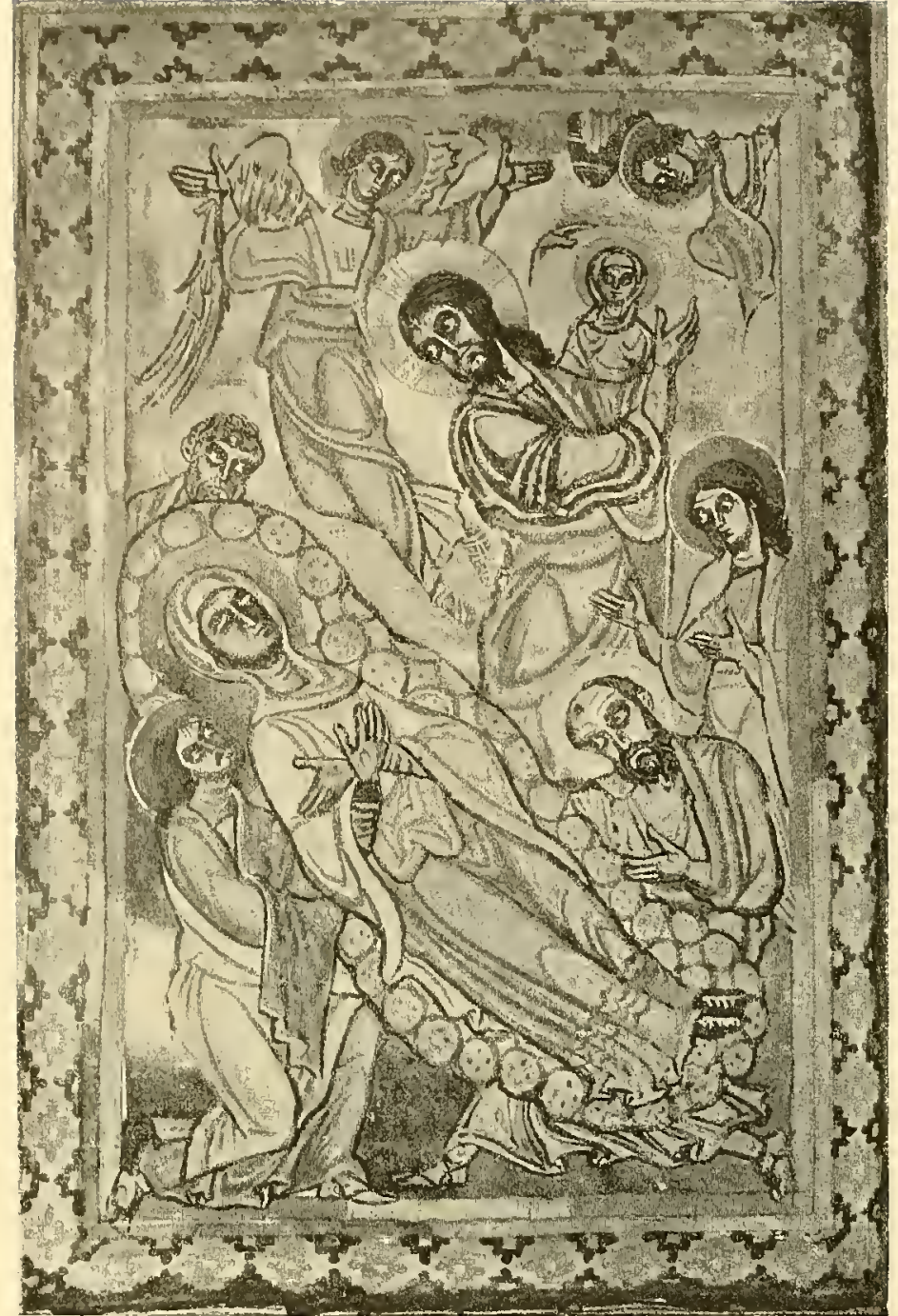

Miniatura del ms, latino r $5903_{3}$ c. Sr v. Sec. Xir, scuola di Salzburg Biblioteca Reale di Monaco

Nonostante che la leggenda gnostica si divulgasse, i cristiani dei primi secoli furono restii a tradurla, desiderosi com erano di coprire di un velo $\mathrm{i}$ sacri avvenimenti e di attenersi ai libri del Nuovo Testamento e agli Atti degli Apostoli, in cui si fa parola dell'Assunzione; onde sembra non possa ritenersi rappresentata l'Assunta nell' antico sarcofago di Saragozza, nel quale si vede la mano divina stendersi giù dal cielo e stringere un braccio a una donna orante tra gli apostoli Pietro e Paolo.

Solo nel secolo vi, e più nel vir, le leggende del Transito presero voga, entrarono nella coscienza dei cristiani, tanto che a scrittori ortodossi fu attribuito il libro gnostico, rispecchiantesi allora nelle cantiche dei poeti e nei sermoni dei vescovi, e ascritto da alcuni a San Giovanni apostolo, da altri a Melitone vescovo, vissuto nel tempo di Marc'Aurelio.

Un giorno, così suona la leggenda, che la Vergine era in lagrime per i] desiderio di rivedere il Figlio divino, un angelo circonfuso di luce le apparve e le porse un ramo di palma, perchè fosse portato innanzi alla bara di lei, quando, dopo tre giorni, sarebbe avvenuta la morte e l'assunzione. Maria 
allora desiderò gli Apostoli le fossero vicini, la seppellissero; e domandò che la sua anima all'uscire dal corpo non incontrasse alcun maligno spirito. L'angelo le disse: Colui che di Giudea in Babilonia trasportò il profeta per un capello, potrà ora condurre a te gli Apostoli dispersi nel mondo; e tu non temerai il maligno spirito, tu che gli hai schiacciata la testa e riverso il trono. Così detto, l'angelo rivolò al cielo in un'onda di luce; e la palma che aveva lasciata in terra brillava: essa era verde come un ramo naturale, ma le sue foglie scintillavano come la stella del mattino. Maria si pose in letto per rimanervi sino alla sepoltura. Intanto, mentre Giovanni

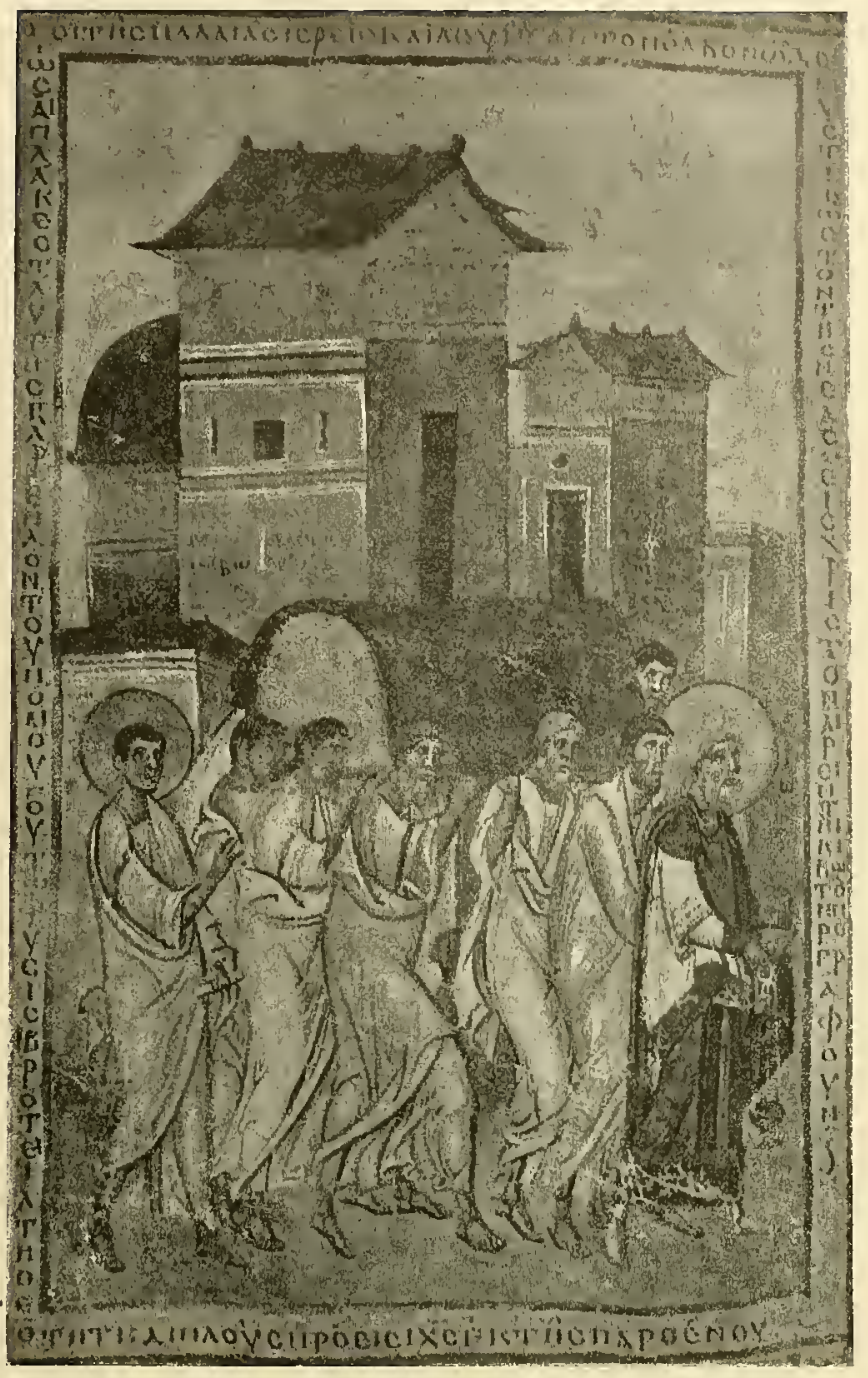

Miniaturádel secolo xil Biblioteca Vaticana predicava a Efeso, il cielo subitamente tonò, una bianca nube avvolse l'apostolo e lo depose innanzi alla casa di Maria. Egli bussò alla porta, entrò e salutò sua madre, che pianse di gioia al rivederlo, gli ricordò le parole dette sulla croce dal Maestro, che a lui l'affidava, e gli raccomandò le proprie spoglie terrestri, affinchè gli Ebrei non potessero, come avevano tramato, rapire e gettare alle fiamme il suo corpo che aveva concepito Gesù. Nello stesso tempo il tuono rombò, e tutti gli apostoli trasportati dalle nubi fuori dalle contrade ove predicavano, caddero come pioggia innanzi alla casa di Maria. Giovanni annunciò loro che la Vergine era vicina a morte, e 
tergendosi le lagrime raccomandò loro di non piangere, perchè il popolo non si turbasse. Quando Maria vide tutti gli apostoli radunati, benedisse Iddio;

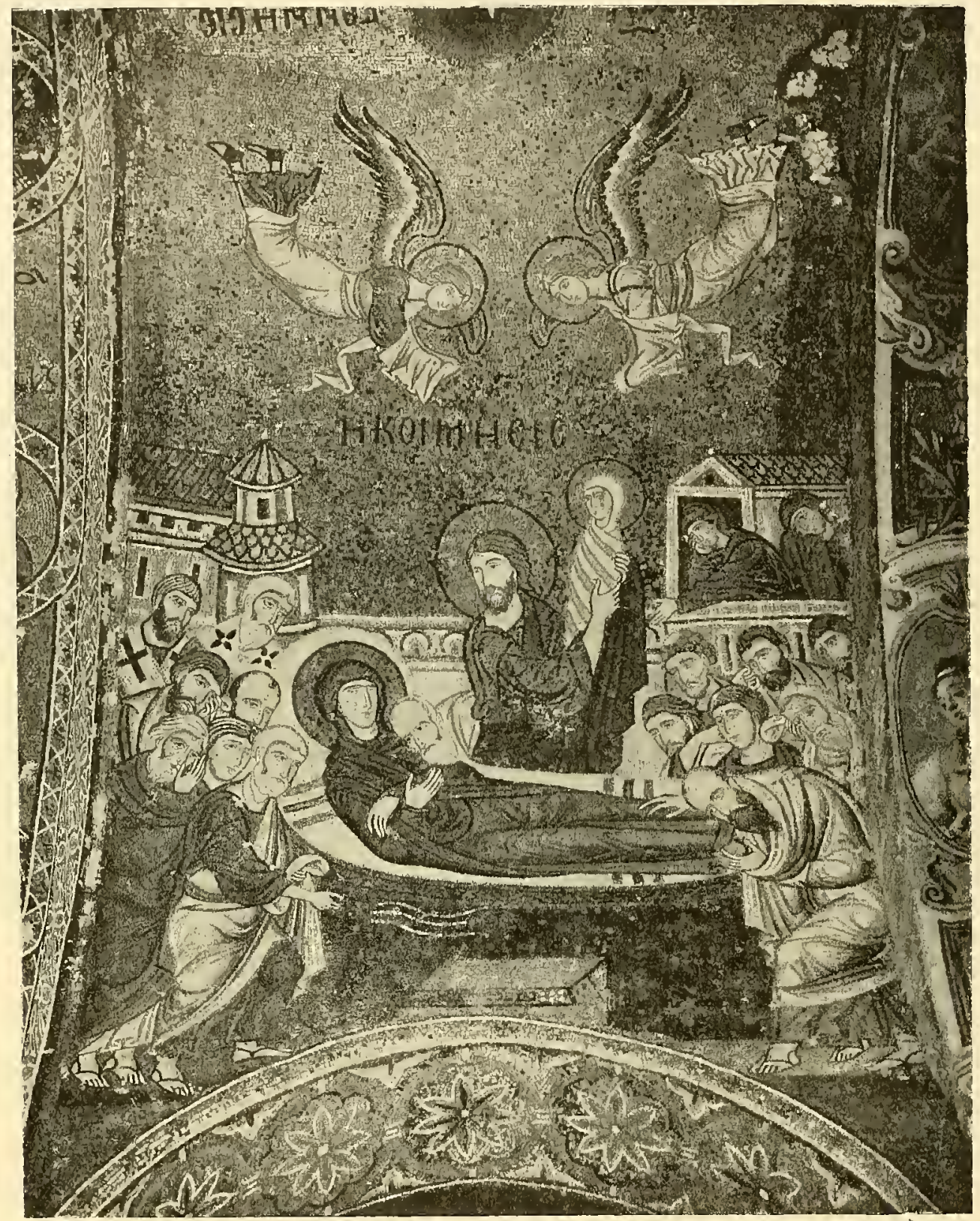

Chiesa della Martorana in Palermo. IIusajco del secolo xII

li fece sedere tra le lampade e le lucerne ardenti, mostrò il ramo luminoso di palma e si stese nel letto in aspettazione della morte. Pietro stava all'origliere, Giovanni ai piedi, gli altri apostoli intorno, celebrando le lodi della 


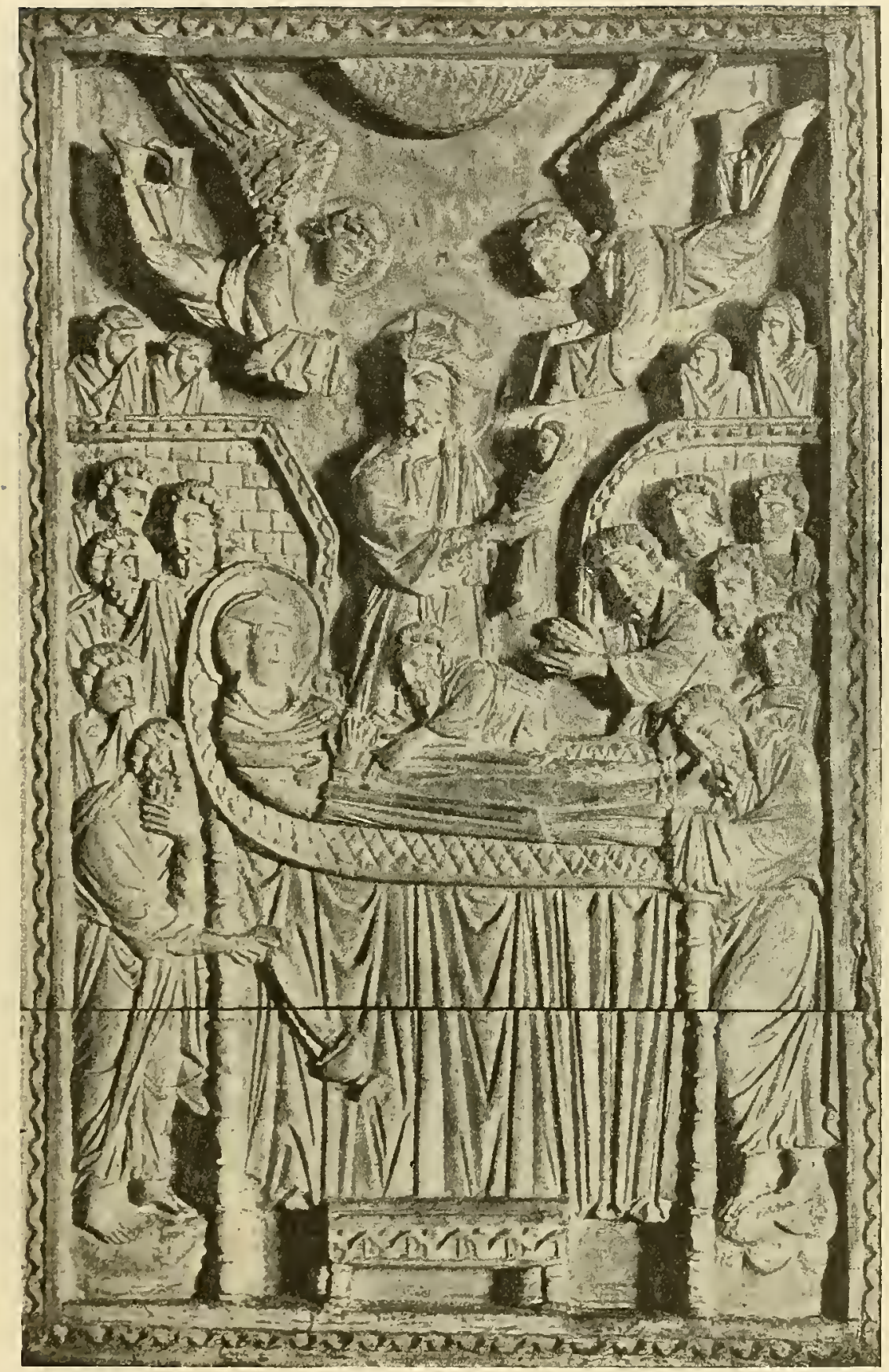

Coperta d'avorio. Museo di Classe in Ravenna 
Vergine. Verso la terza ora di notte un tuono fece tremare la casa, e si sparse nella stanza un profumo così delizioso, che tutti, meno gli apostoli e le tre vergini, le quali tenevano le fiaccole, si assopirono. Allora Gesù arrivò con gli angioli, i patriarchi, i martiri, i confessori e i cori delle vergini. Tutti si raccolsero intorno al letto di Maria salmodiando. Gesù disse alla Madre:

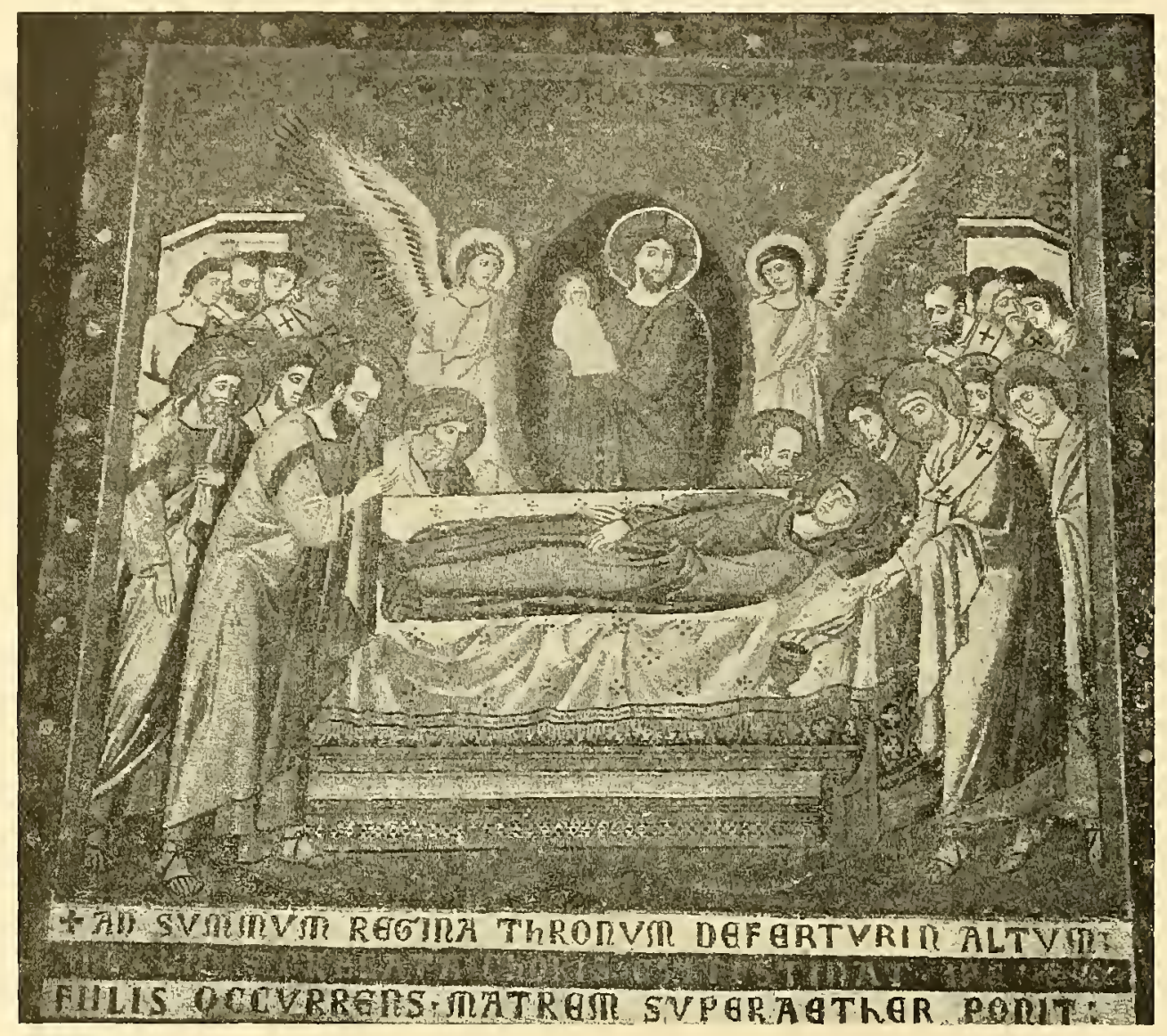

Santa Maria in Trastevere in Roma. Musaico del secolo xu

Vieni, eletta fra le donne, io ti porrò sul mio trono. Signore, rispose Naria, il mio cuore è pronto. Allora tutti quelli che accompagnavano il Cristo soavemente cantarono; e Maria pure così cantò: Tutte le generazioni mi proclamano felice, perchè l'Onnipotente ha fatto grandi cose per me. E Dio intonò le parole: Mia donna, vieni dal Libano a ricevere la corona. Ed eccomi, disse Maria, perchè voi siete la mia gioia. In quel momento l'anima della Vergine usci senza dolore dal corpo, e s'involò nelle braccia del Figlio, che invitò gli apostoli a portare la salna della Madre nella valle di Giosafatte e 
a restarvi tre giorni, sino che egli giungesse. Tosto le rose e i gigli delle valli, cioè i celesti spiriti e i beati, circondarono l'anima, più che latte candida,

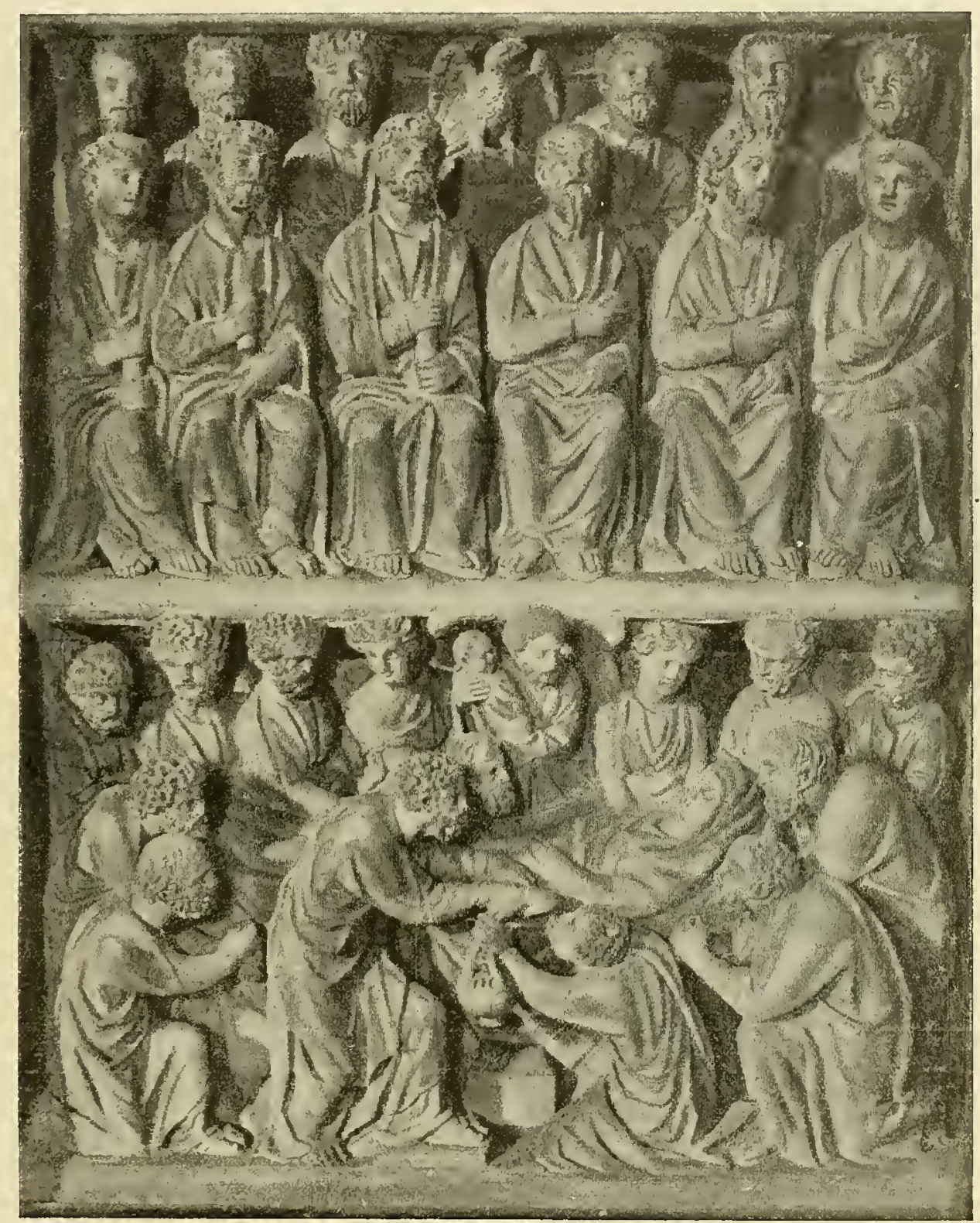

Pulpito della Chiesa di San Giovanni fuori civitas

(Guglielao da PisA)

portata da Gesù, e con essa salirono al cielo, mentre gli apostoli dalla terra pregavano la Vergine di ricordarli; e $\mathrm{i}$ santi rimasti in cielo, attratti dalle melodie di quelli che vi facevano ritorno, vedendo il loro Re con l'anima di 
una donna nelle braccia, si domandavano: Chi è colei che sale dal deserto, piena di grazie, stretta al suo sposo? Ella è, rispose il corteo della Vergine, la

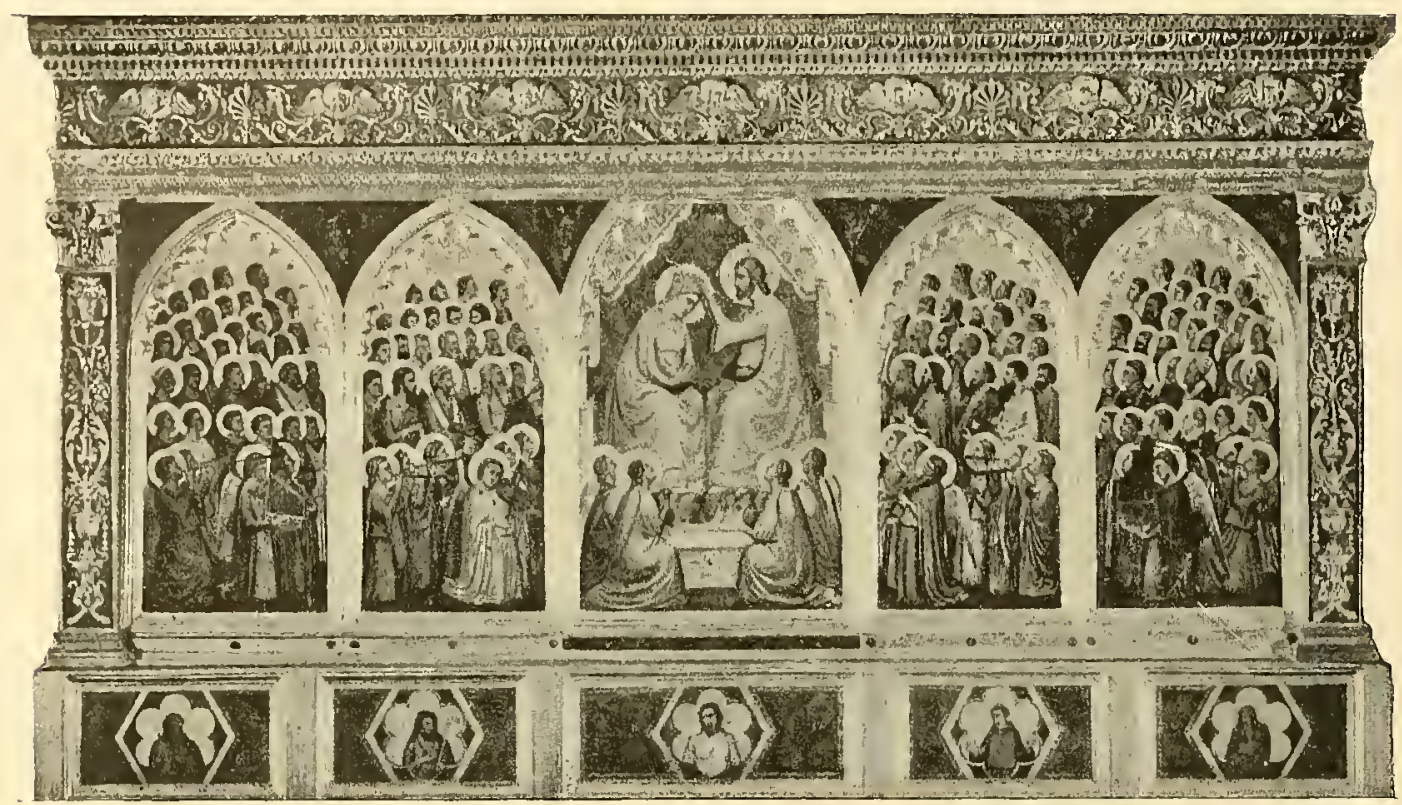

Chiesa di Santa Croce in Firenze

(G1отто)

bellissima tra le figlie di Gerusalenme, e come voi la vedeste piena di carità e d'amore, vedetela ora sul trono di gloria alla destra del Figlio suo. Intanto,

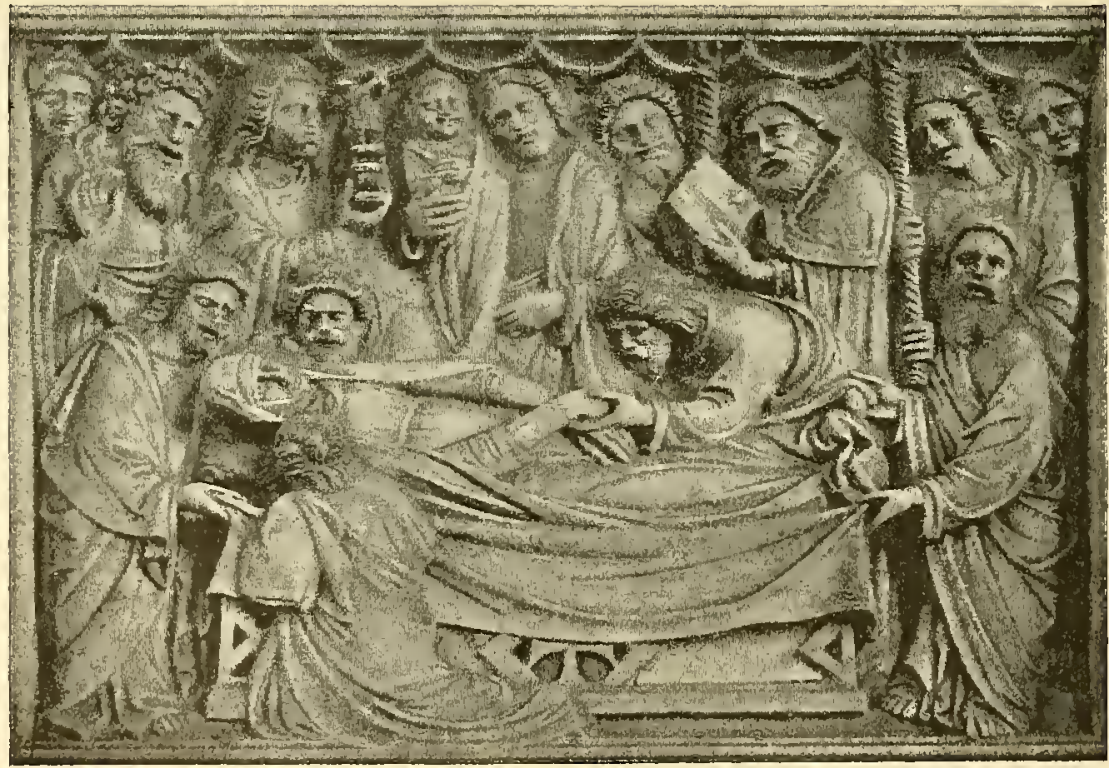

Caltedrale di Arezzo. Dai rilievi dell'altar maggiore

Opera di Gio. Francesco d'Arezzo e Betto di Francesco da Firenze 

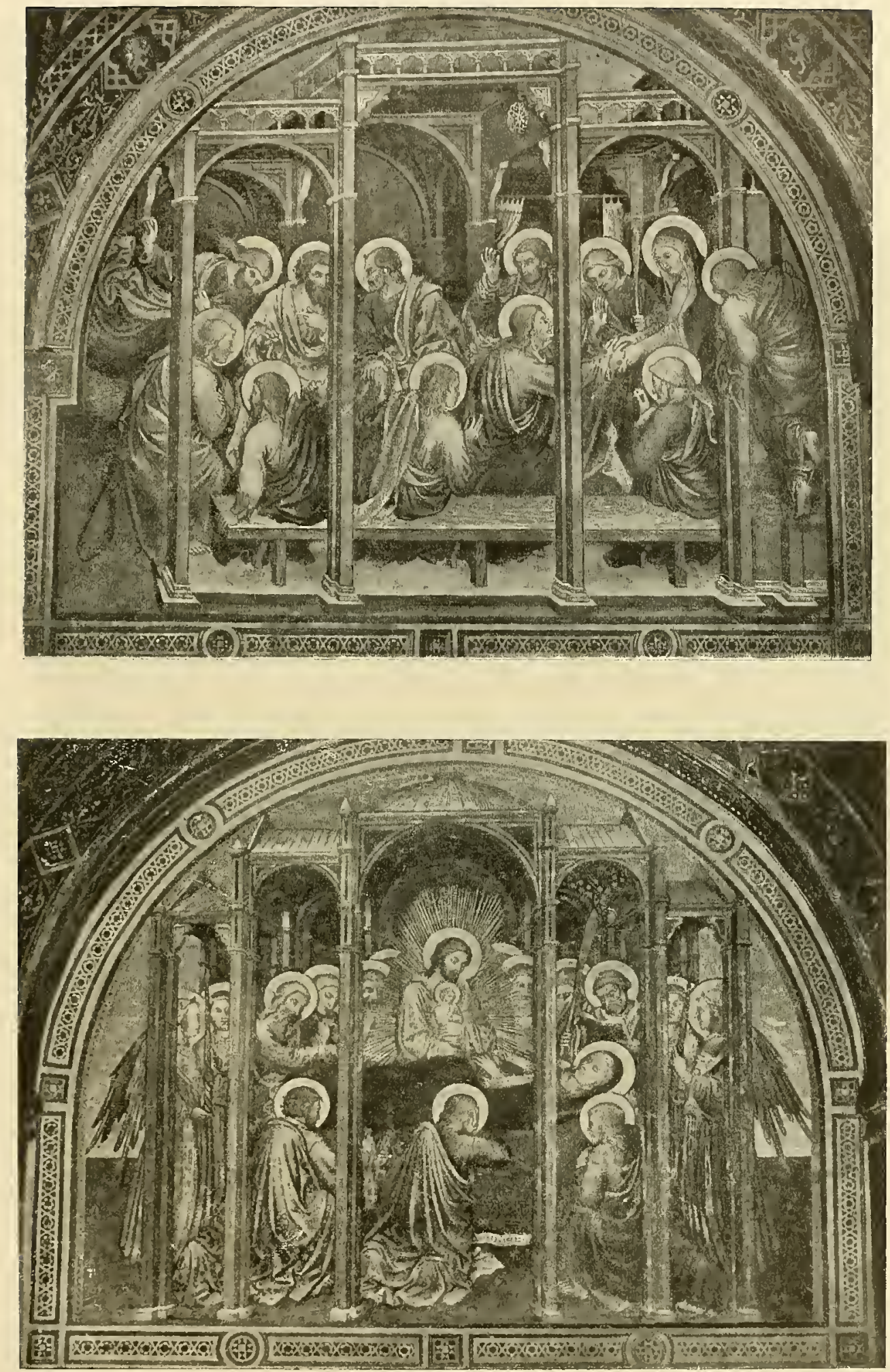

Palazzo Comunale di Siena

52

(TADDeo di Bartolo) 
giù sulla terra, si svegliarono coloro che erano stati vinti dal sonno presso il letto della Vergine, e ruppero in pianto al vederne il corpo esanime. Le tre fanciulle che già portavano le fiaccole, fecero per levarne il corpo, il quale s'illuminò di tanto splendore che esse potevano toccarlo, ma non guardarlo. Avvolta in un sudario la salna, e messa dagli apostoli in un feretro, Giovanni

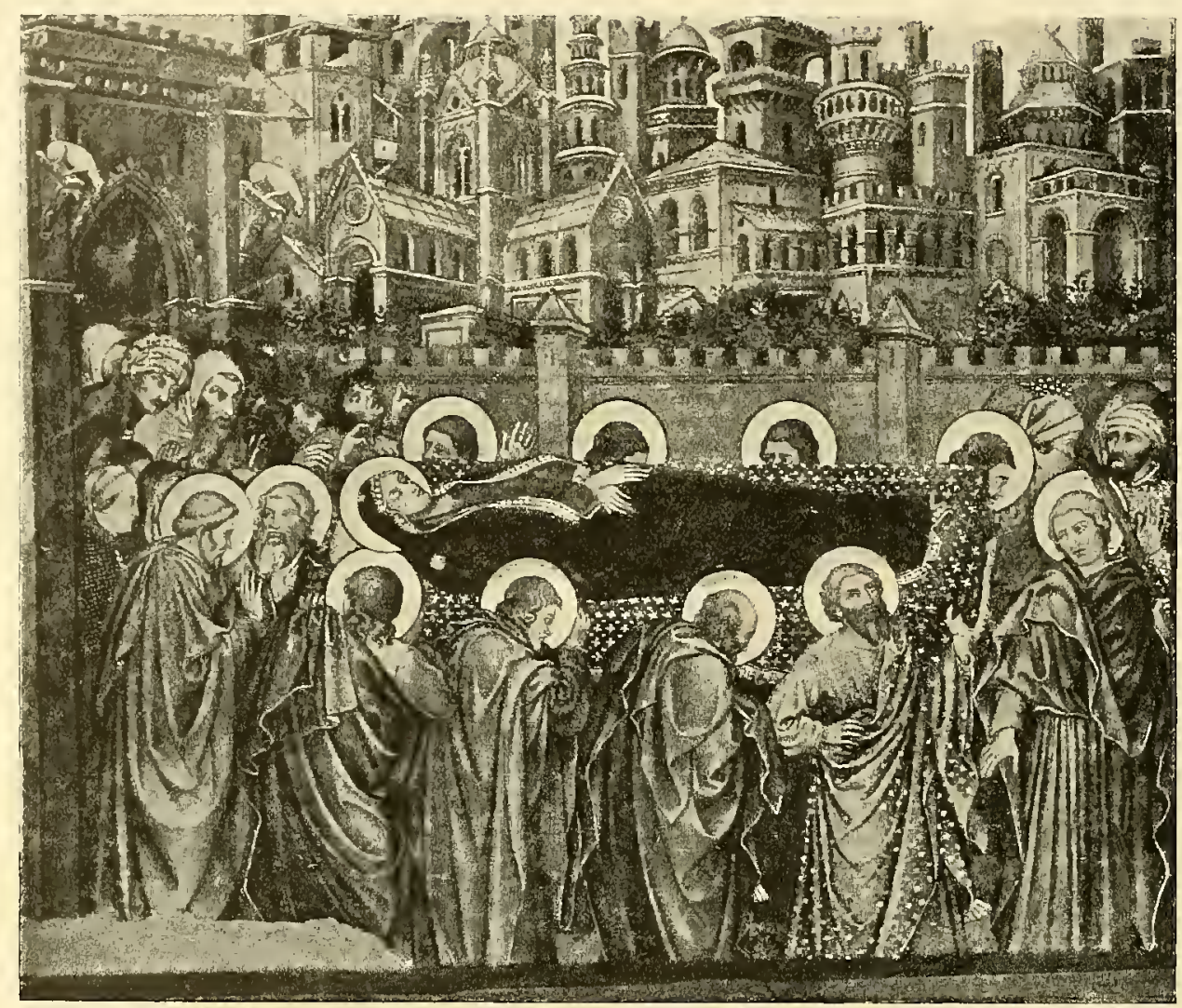

Palazzo Comunale di Siena

(TADdeo di BARTOLO)

prese la palma radiante, Pietro e Paolo si caricarono il feretro sulle spalle e s'incamminarono cantando a bassa voce. Dio li coprì d'una nube, così che si udivano i loro canti senza che si vedessero i cantori, e gli angioli, in ischiera, a due a due, accompagnavano col canto gli apostoli, e sulla terra si diffondeva un suono d'ineffabile dolcezza. Tutto il popolo di Gerusalemme ne fu commosso; ma, saputo che $\mathrm{i}$ discepoli di Gesù portavano Maria al sepolcro, corsero alle armi per ucciderli e dare alle fiamme il corpo di colei che generò il Salvatore. Il maggior sacerdote degli Ebrei mise rabbiosanente le mani sul feretro per farlo cadere; ma le sue braccia di subito si disseccarono e vi 
restarono inchiodate, e il popolo fu accecato dagli angioli. Poi il gran sacerdote si ravvide, e gli si ricomposero le braccia; preso anzi il ramo di palma datogli dall'apostolo Pietro, toccò il popolo accecato, e tornò la luce alle pupille dei ravveduti. Arrivati intanto gli apostoli nella valle, composero la salma della Vergine nel sepolcro, e inginocchiati pregarono e cantarono. Al terzo giorno

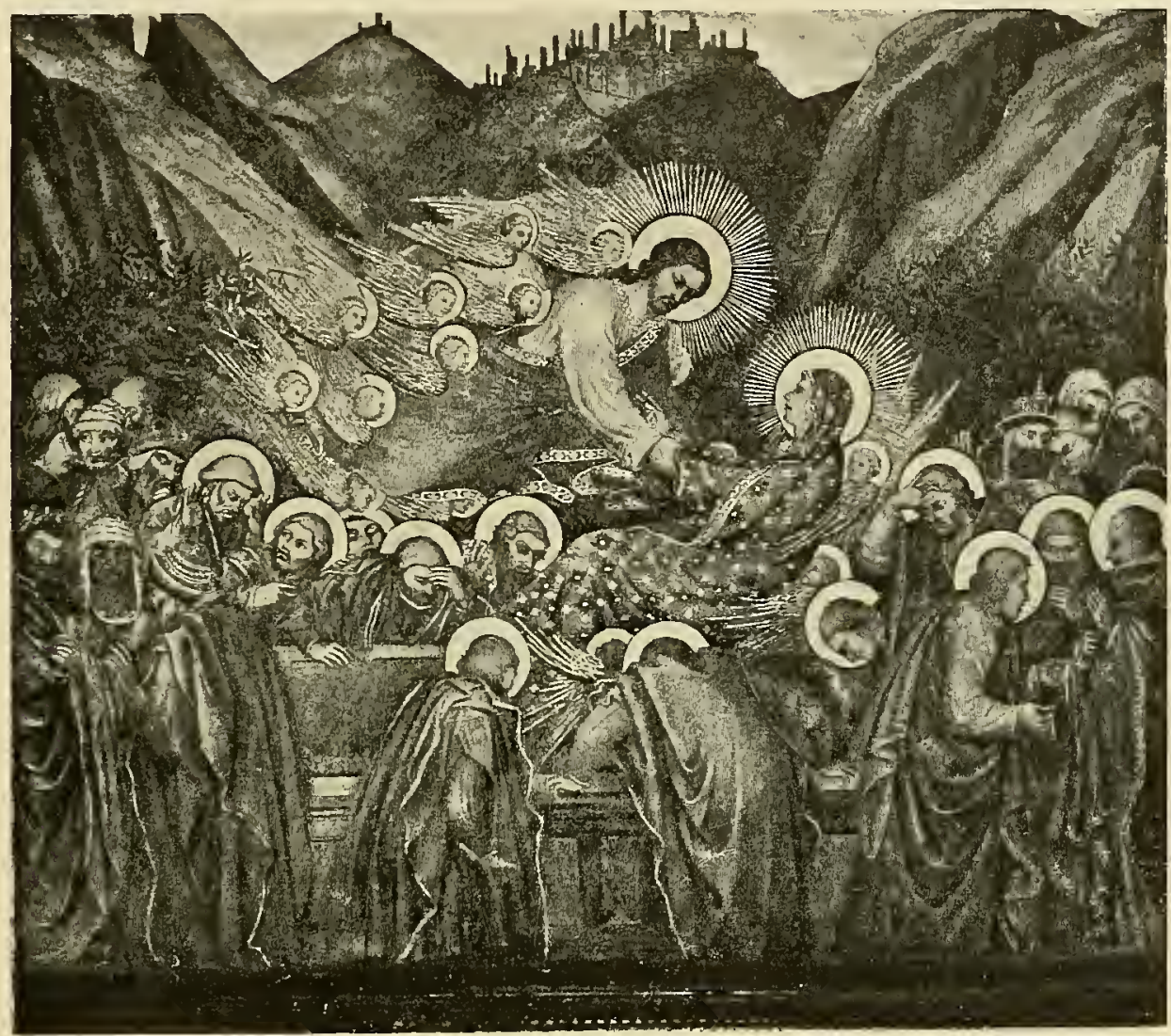

Palazzo Comunale di Siena

(TADDEO DI BARTOLO)

una nube splendente circondò la tomba, un profumo soave si sparse, celesti voci risonarono intorno, e Cristo, disceso in terra con una moltitudine d'angioli, salutò i discepoli, dicendo: La pace sia con voi. Essi risposero: Con voi la gloria! San Michele venne allora, presentò al Signore l'anima di Maria che, resa al corpo, col corpo uscì dalla tomba, e s'innalzò tra gli angioli al cielo, ove fu ricevuta dal Figlio che l'abbracciò e la vestì tutta di luce.

Tale è per sommi capi il racconto che si diffuse in Oriente, fu riprodotto ne' suoi lineamenti principali dagli artisti greci e ispirò nell'Occidente tante opere d'arte nel medio evo. 
Mentre infieriva la persecuzione iconoclasta, nel secolo vill, Sant'Adriano donava alla basilica di Santa Maria Maggiore un paramento d'altare tessuto

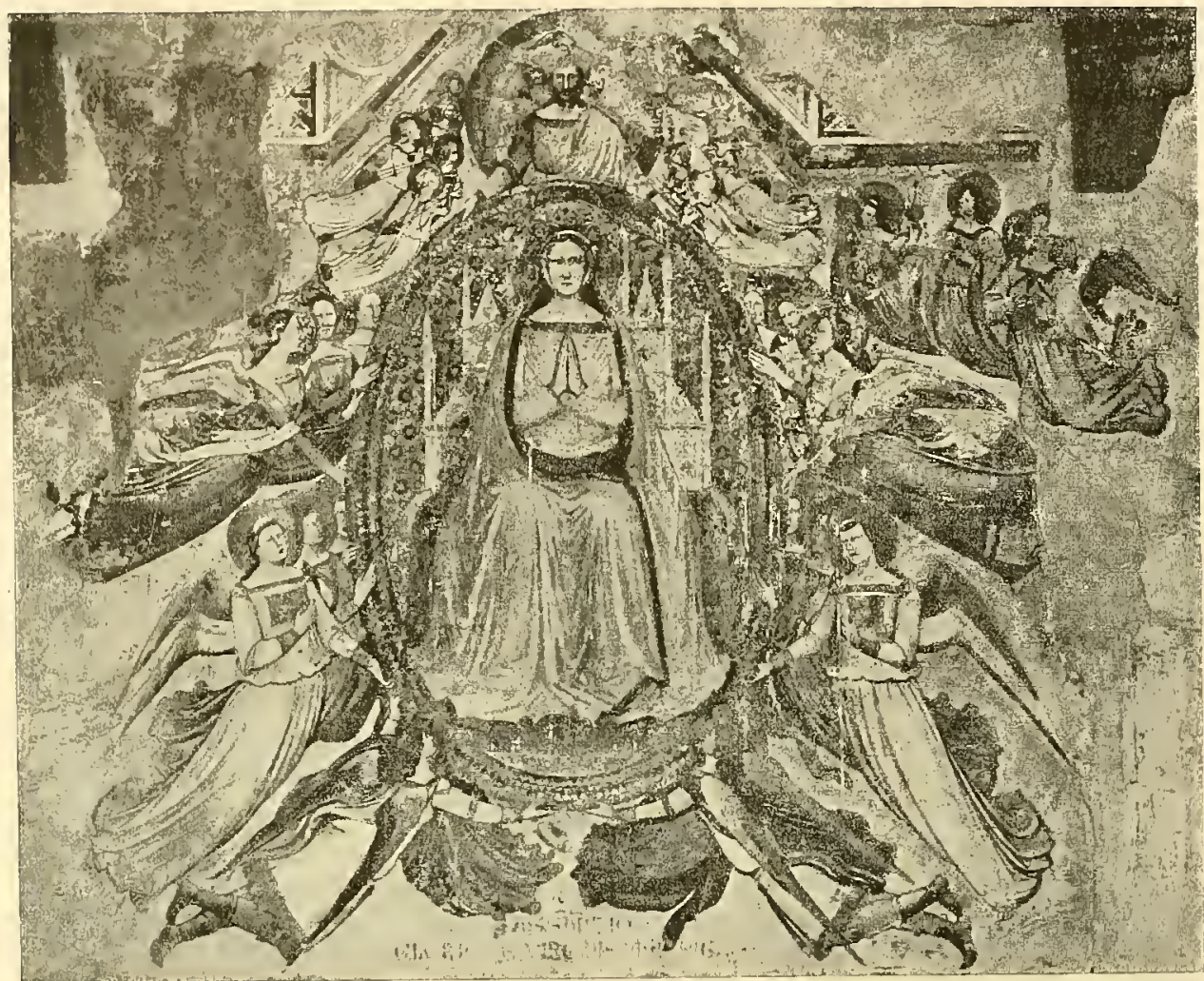

Camposanto di Pisa

(Simone- Memmi)

d'oro, ornato di gemme, ricamato con la immagine dell'Assunzione. Tanto afferma Anastasio nel Liber Pontificalis, ove pure si legge la notizia di un paludamento con la istoria del Transito della Vergine, eseguito al tempo di Leone III, e d'un altro parato sacro di Pasquale I (So $7-823)$, in cui si vedeva l'assunzione del corpo di Maria. Di tali opere, probabilmente di mano degli artisti greci fuggiaschi da Costantinopoli, non si ha più traccia: e conviene giungere al tempo di Leone IV, quando già la festa dell'Assunzione era celebrata per tutto l'Occidente in forza delle deliberazioni imperiali di Carlo Nagno e di Ludovico suo figilo, per trovare una rappresentazione della Vergine assunta. E fu un vescovo di Carlo Magno quei che, interrogato sul soggetto dell'Assunzione, gli mandava un trattato, attribuito poi a Sant'Agostino, nel quale descriveva Maria nel regno dei cieli, fra i cori delle vergini da 
lei guidate tra gigli e rose alle fonti eterne della vita, passare sui prati d'oro e sulle erbe rugiadose, cogliere le viole che non avvizziscono mai e, ornata di perle e di gemme, assidersi sul trono apprestatole dagli angioli nella corte dell' Eterno.

Nell'anno 847, il papa aggiunse un'ottava alla festa dell'Assunzione; e intanto la forma della rappresentazione nell'Occidente si distingue singolar-

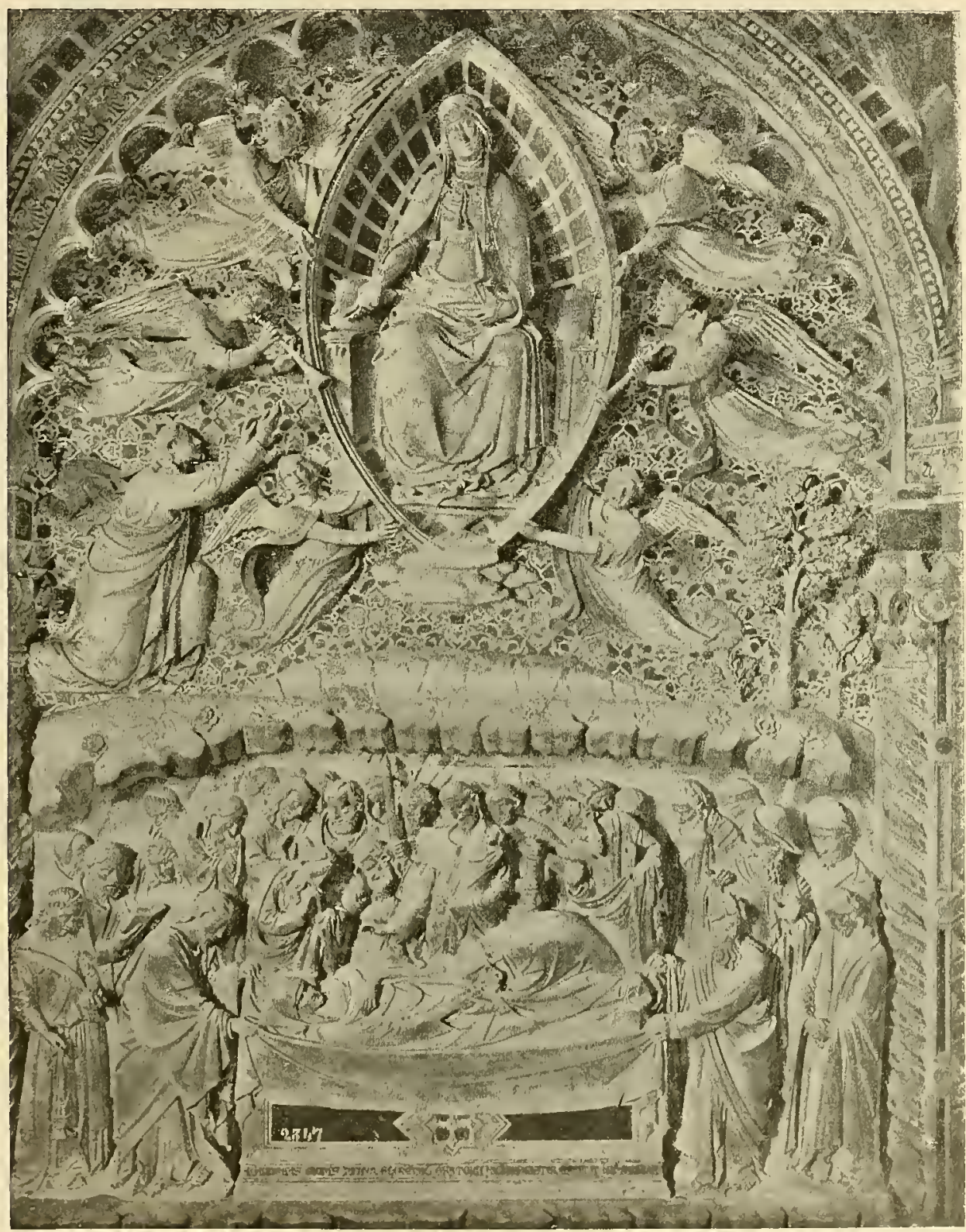

Chiesa di Or' San Michele in Firenze

(ORCAGNA) 


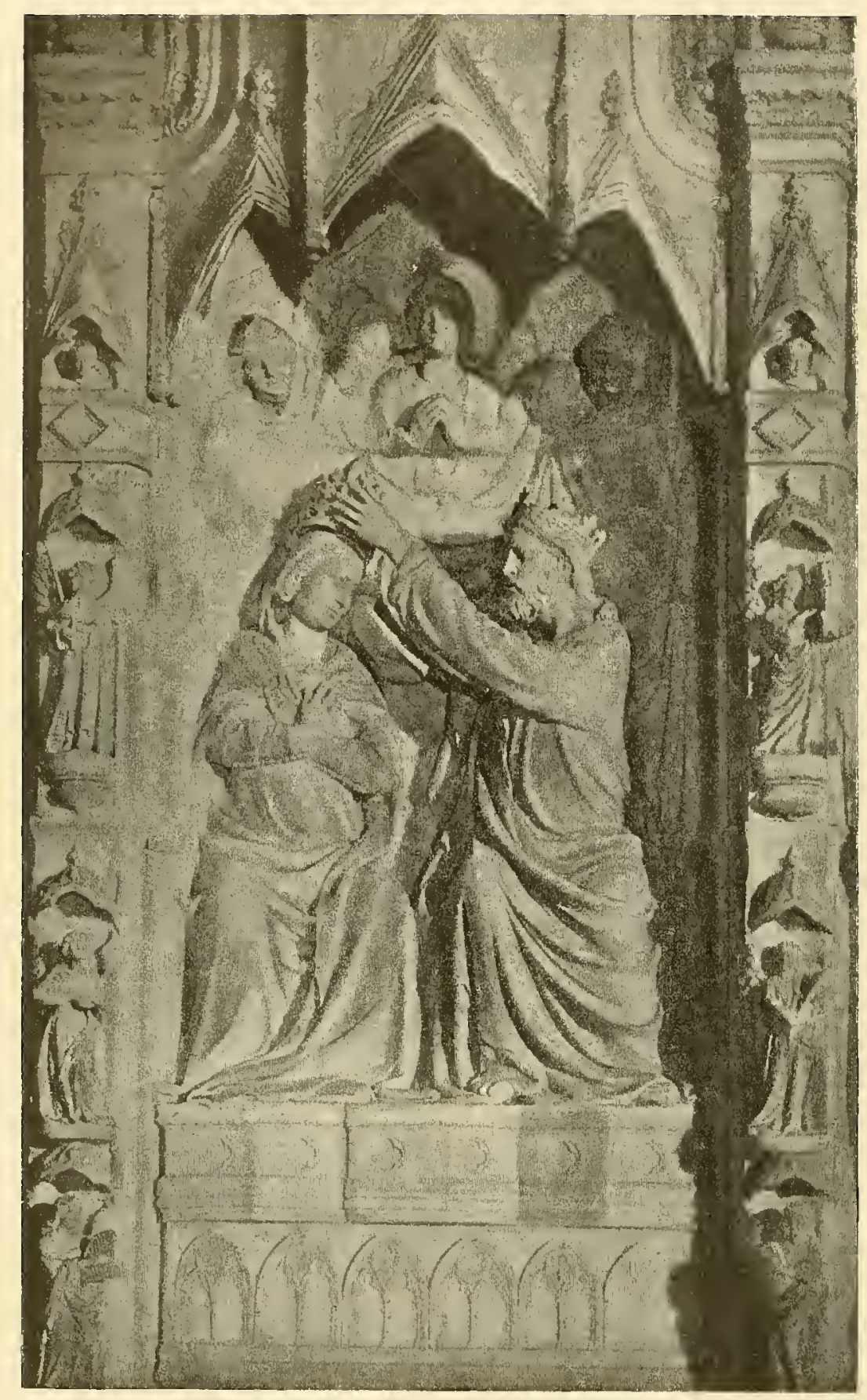

Chiesa di San Francesco in Bologna

(GIACOMO E PIERPAOLO DI VENEZIA) 


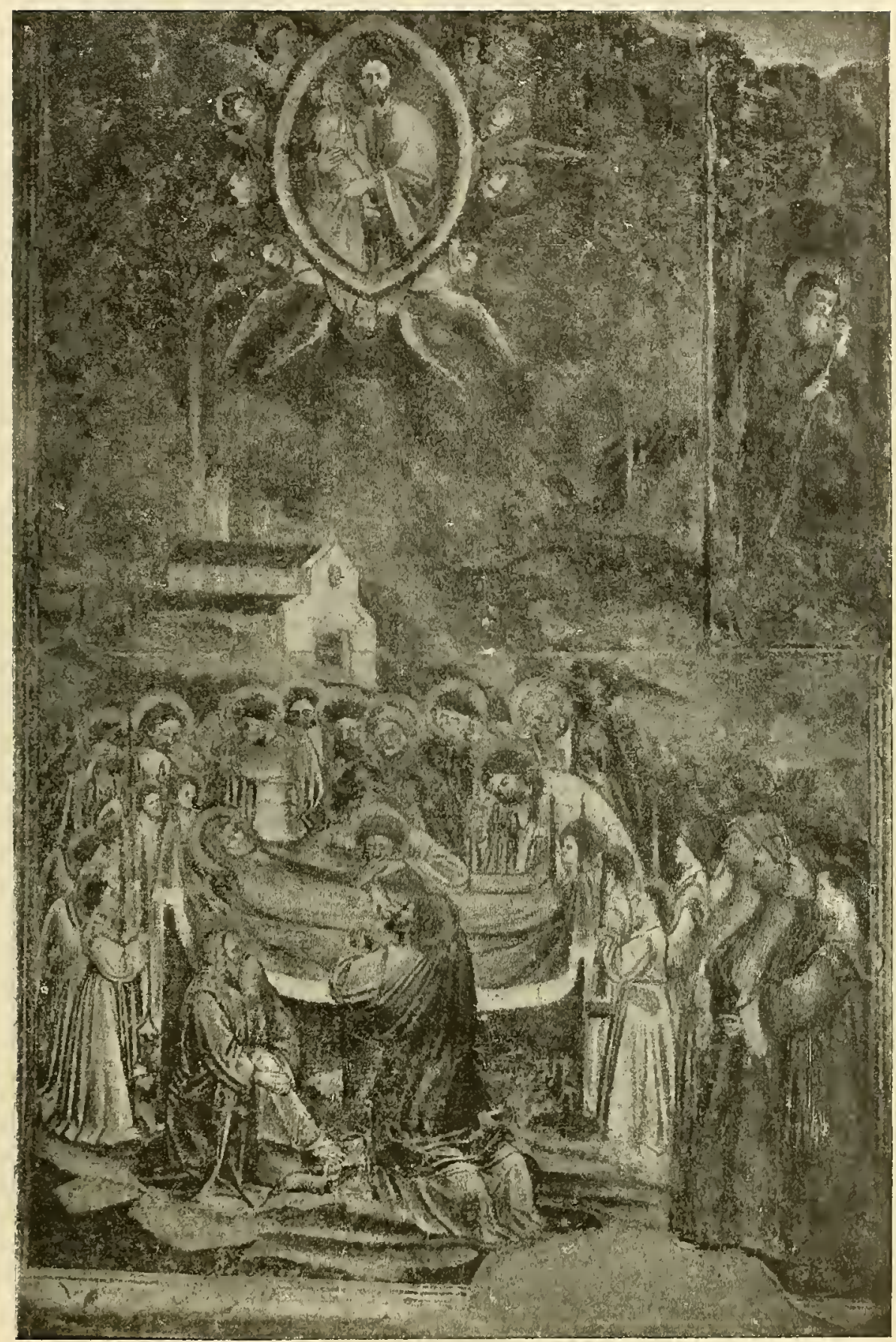

Chiesa di San Michele in Padova (JACOPo AvaNzI) 
mente da quella presso i Greci, i quali spiegavano come sonno, riposo, migrazione, transito l'Assunzione e raffigurarono quindi la Vergine con gli occhi

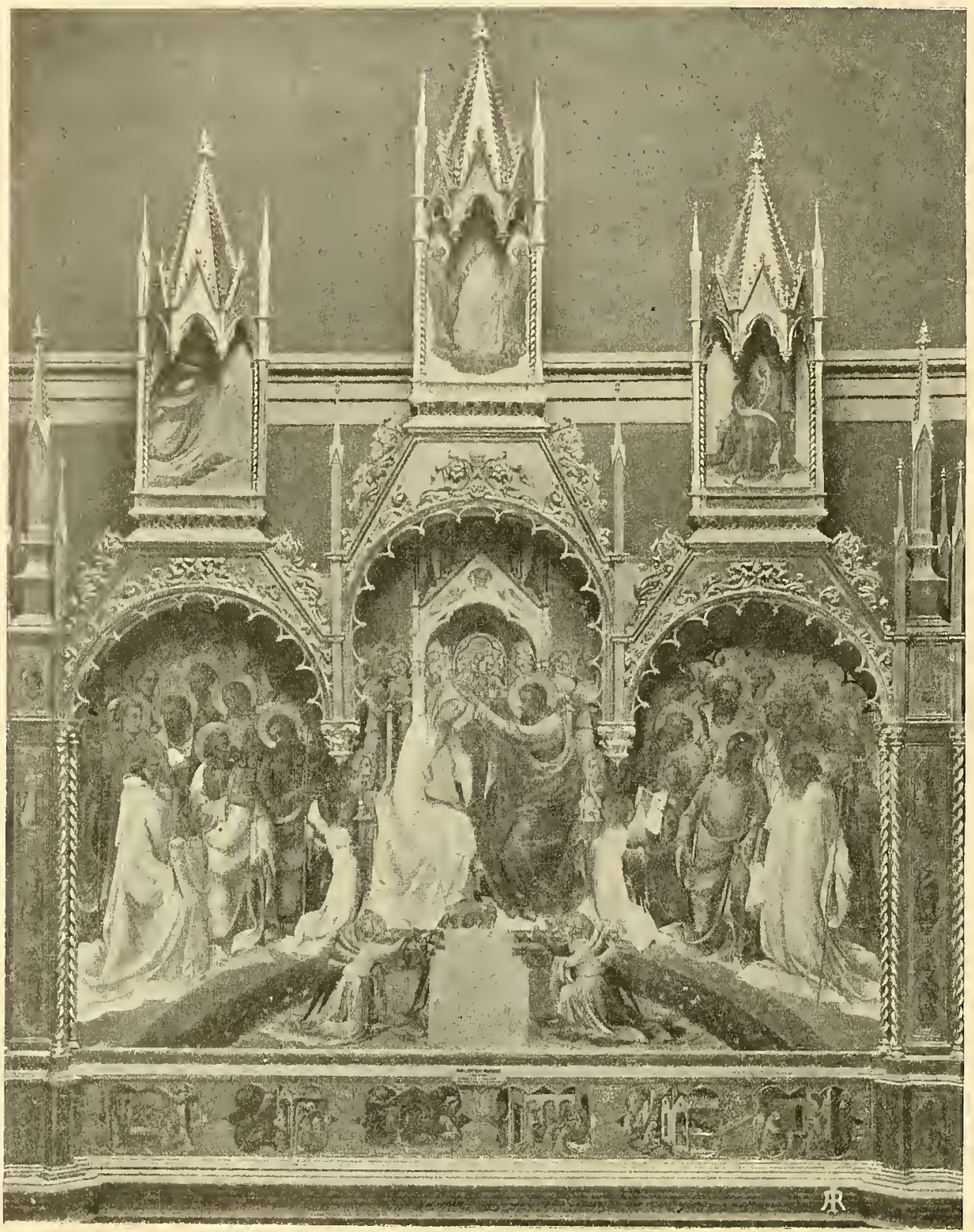

R. Galleria degli Uffizi in Firenze

(Lorenzo Monaco)

chiusi, distesa sul letto funebre. In Occidente volle vedersi la resurrezione, in Oriente la morte del corpo; qua si adombrò il mistero dell' emigrazione dell'anima, là si spiegò con estrema evidenza. E per spiegare il ritorno della 


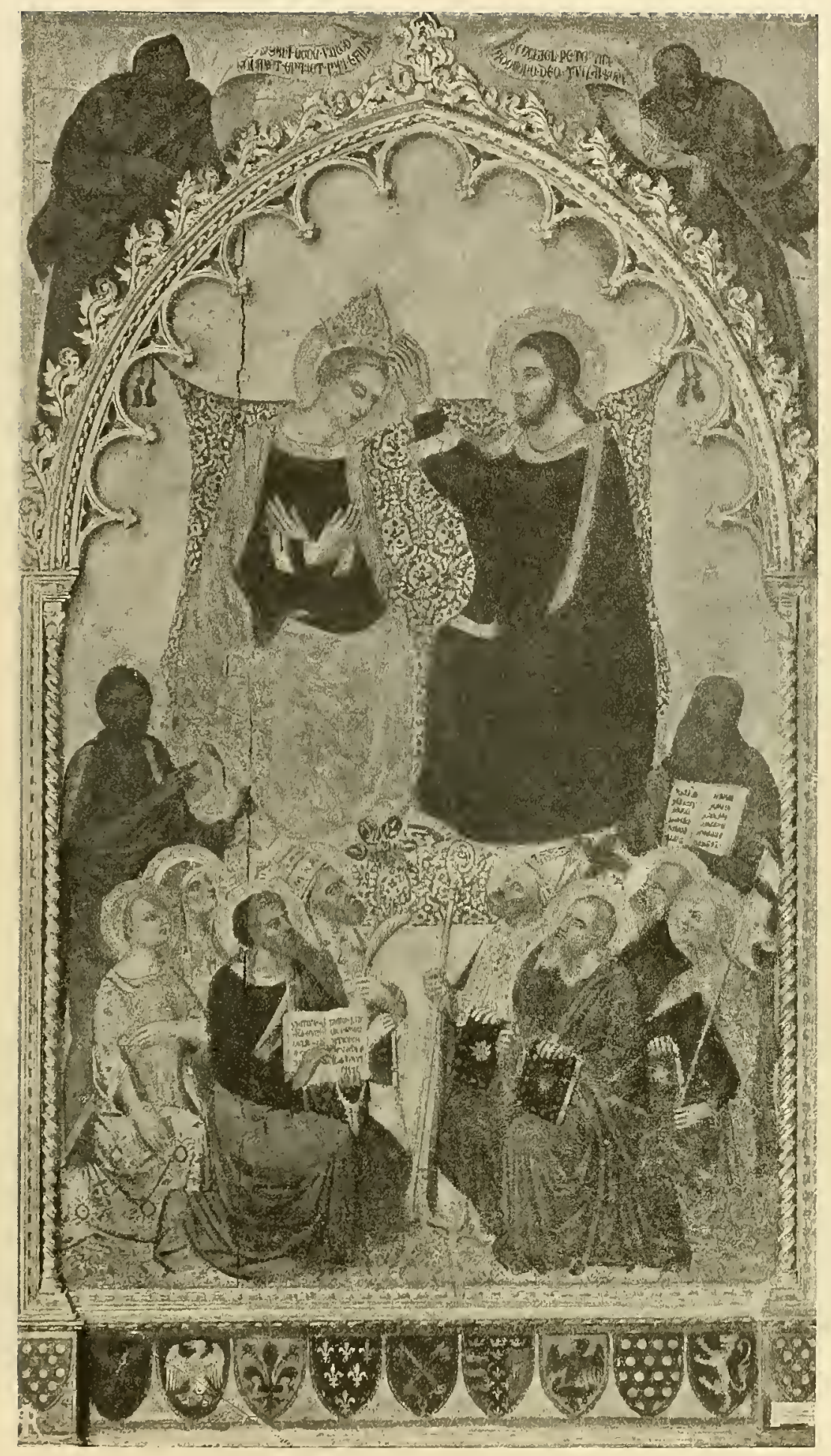

R. Galleria degli Uffizi in Firenze

(N. GERINI) 
Vergine a vita e a vita immortale, o il suo ingresso nei superni regni, l'arte occidentale tolse a prestito le forme con cui già si era rappresentata l'Ascen-

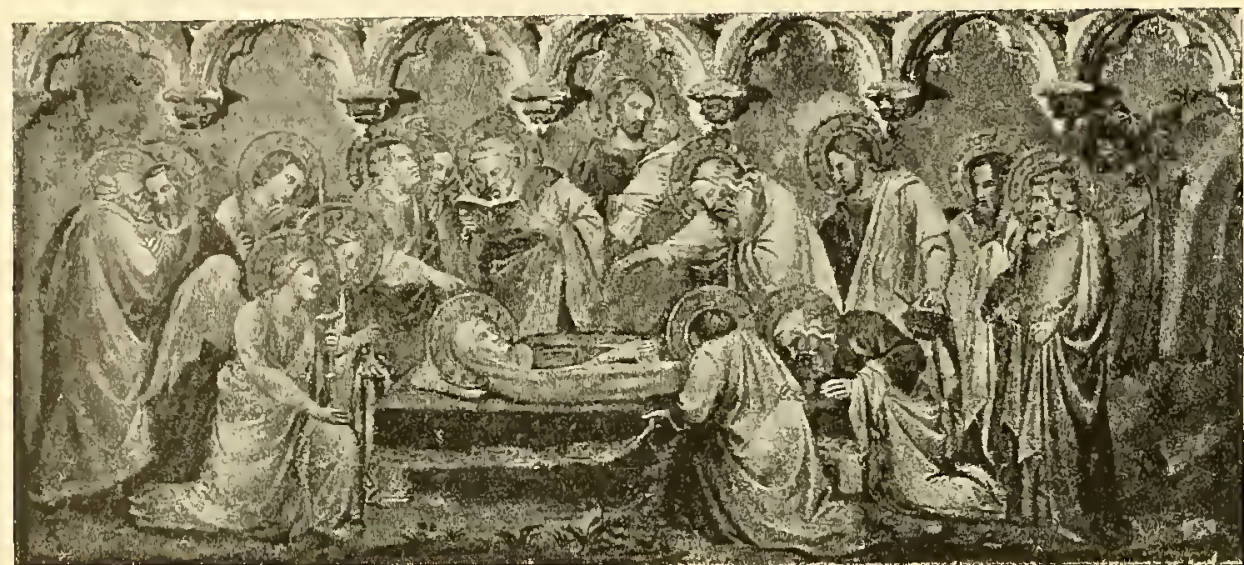

Accademia di Belle Arti in Siena

(Spinello Aretino)

sione del Cristo, quale si vede, già appieno determinata, ad esempio nella Bibbia siriaca del monaco Rabula nella Biblioteca Laurenziana in Firenze, e nella basilica inferiore di San Clemente in Roma.

La grandiosa semplicità della scena doveva venire alterata per molto tempo dagl'influssi bizantini. In tre avorî, uno del Museo di Ravenna, il

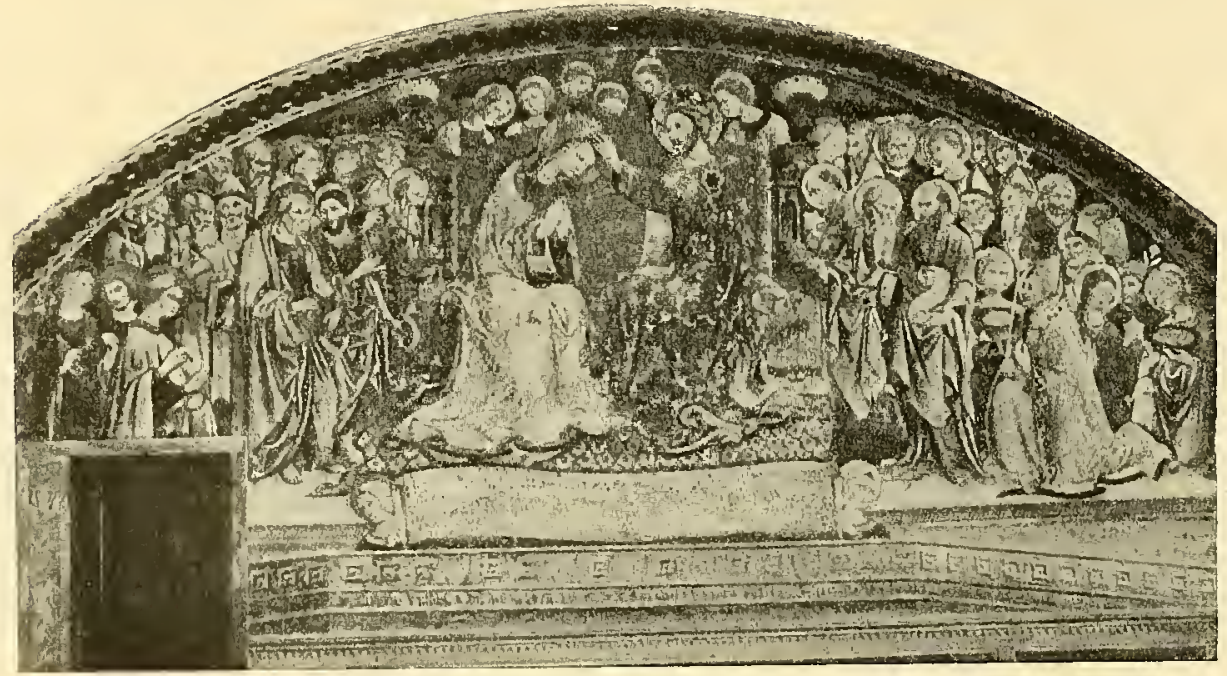

Palazzo comunale di Siena

(SAno di Pietro)

secondo della reale Biblioteca di Monaco, il terzo a Darmstadt, come nelle miniature di un evangelario della chiesa di Devenser e del ms. 11. $944 \mathrm{~S}$ 
della Biblioteca di Parigi, tutti eseguiti intorno al $\mathrm{x}$ secolo, troviamo la composizione bizantina appieno determinata. La Vergine è adagiata nel curvo letto, con le braccia conserte al seno, assorta nel sonno; la circondano un turiferario e gli apostoli, alcuni dei quali portano le mani alla bocca, o il manto al volto, come per coprirsi, secondo l'uso classico di esprimere il dolore. Il Redentore, in piedi, prende l'anima della Vergine sotto le sembianze di una fanciullina, e la innalza verso due angioli, che con le mani coperte dal manto si apprestano divotamente a raccoglierla. E così appare la scena ne' musaici della Martorana in $\mathrm{Pa}-$ lermo. Non era nuovo il modo di rappresentare l'anima come un bambino lattante in fasce; già $\mathrm{i}$ Greci diedero una forma infantile alle anime separate dai corpi; vedasi nei bassorilievi del monumento di Xanto, antichissini, ove $\mathrm{i}$ morti, in aspetto di fanciullini, sono tra. sportati dalle Arpie.

Al letto mortuario l'arte sostituì il sarcofago col rimosso coperchio, nella porta bizantina di San Paolo fuori le

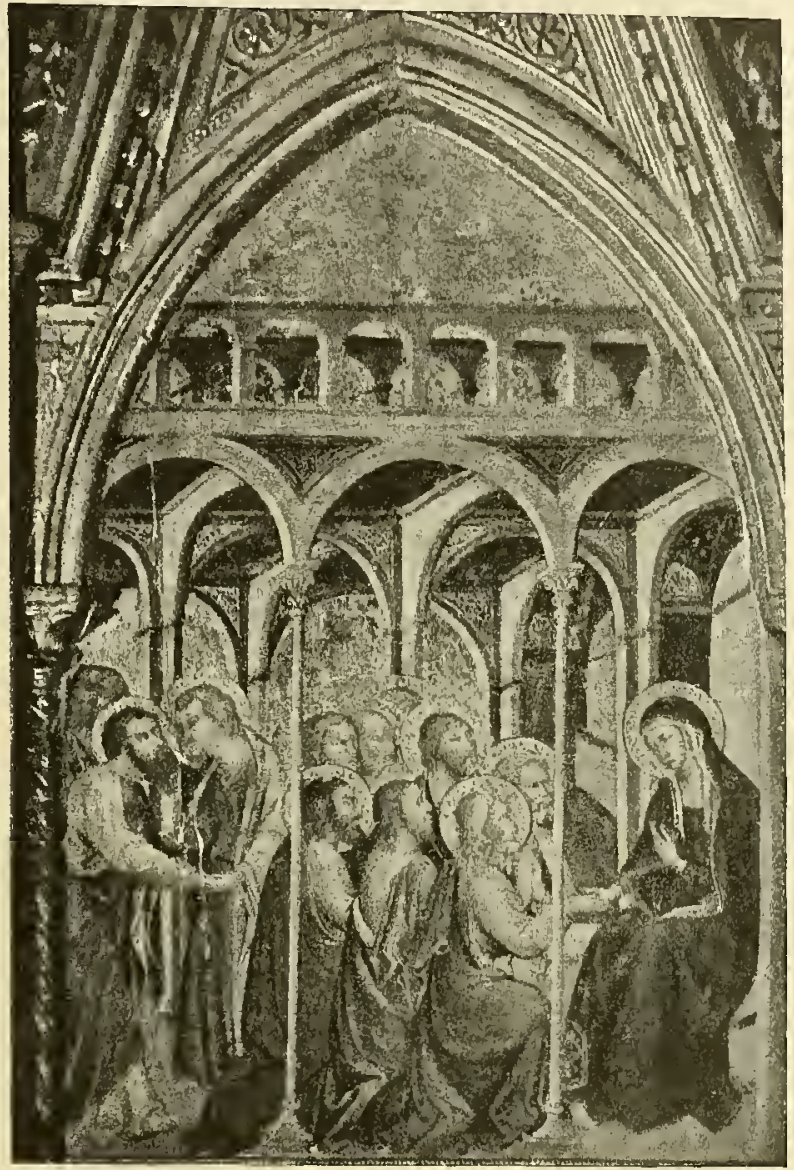

Accademia di Belle Arti di Siena

(T.IDUEO DI B.AR'TOLO) mura, dell'xi secolo; e si studiò anche di collegare alla rappresentazione un motivo dell'ascensione di Elia profeta al cielo, prescrivendo nei canoni della scuola pittorica del monte Athos che fosse dipinta la Vergine in atto di far dono della cintura a Tommaso apostolo. Come già Elia gettò ad Eliseo il mantello, Maria, pure trionfante sulla morte, diede a Tommaso quel segno della propria risurrezione. Dicono le leggende, che quell' apostolo essendo giunto da luogo più lontano degli altri e troppo tardi per assistere 
alla morte di Maria, desiderò di contemplarla ancora una volta; scopertasi la tomba, non si trovò il corpo di lei, ma solo le tele che l'avvolgevano odoranti; allora gli apostoli giudicarono che la Vergine fosse risorta, $\epsilon$ Tommaso poi ne forni la prova, raccontando che l'augusta Donna gli era apparsa, e mostrando anche la cintura da lei ricevuta, qual pegno della

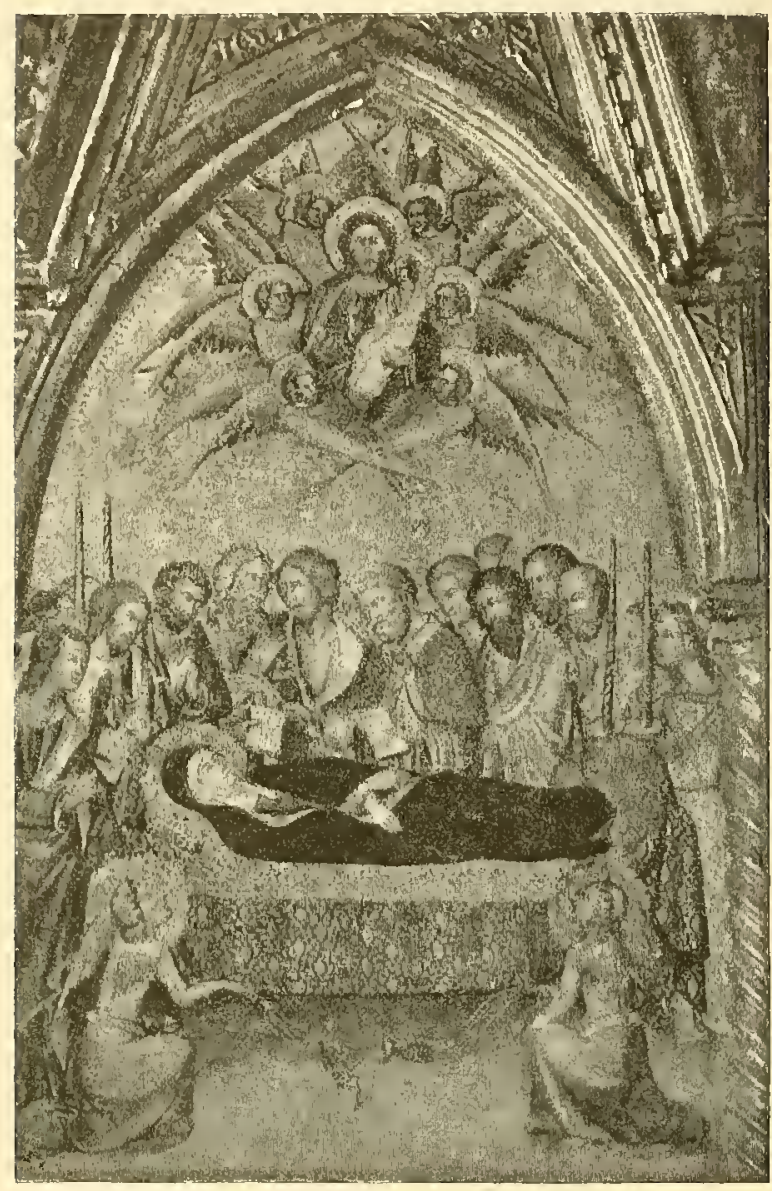

Accadenia di Belle Arti di Siena

(TADDEO Di Baetolo) verità della visione.

Gli artisti dell' Occidente latino tennero conto di tutti questi elementi, più per glorificare la Vergine che per raccontarne le pie leggende; e l'Incoronazione di Maria, soggetto che nell' iconografia cristiana comincia soltanto al xir secolo, sostituisce di frequente la rappresentazione dell'Assunta. Non più i soli apostoli mirano elevata nel cielo l'umile figlia di Nazareth; ma anche i patriarchi, i profeti, i cori dei beati. Vediamo, ad esempio, nella grande composizione del nartice dell'abbazia di Vezzolano, presso Albugnano d'Asti. rappresentata in una fascia superiore, a sinistra, Maria deposta nel sarcofago e circondata dagli apostoli piangenti; a destra, la Vergine portata in cielo da alcuni angioli, mentre altri le dànno gl'incensi; nel mezzo, il Redentore e Maria incoronati sul trono; nella fascia sottoposta $i$ patriarchi in lunga schiera assistono al trionfo della Vergine coi rotuli spiegati, chi meditando col capo appoggiato alla destra, chi ragionando col compagno, chi spingendo lontano lo sguardo di veggente. L'artista, probabilmente un comacino del principio del secolo xirr, ha dato alle figure i loro caratteri essenziali, una spontaneità tutta nuova e una varietà di movimenti 
grandissima; ma ha soppresso dalla composizione l'elemento bizantino dell'anima in forma di fanciullo. La Vergine siede nella gloria, con lo scettro

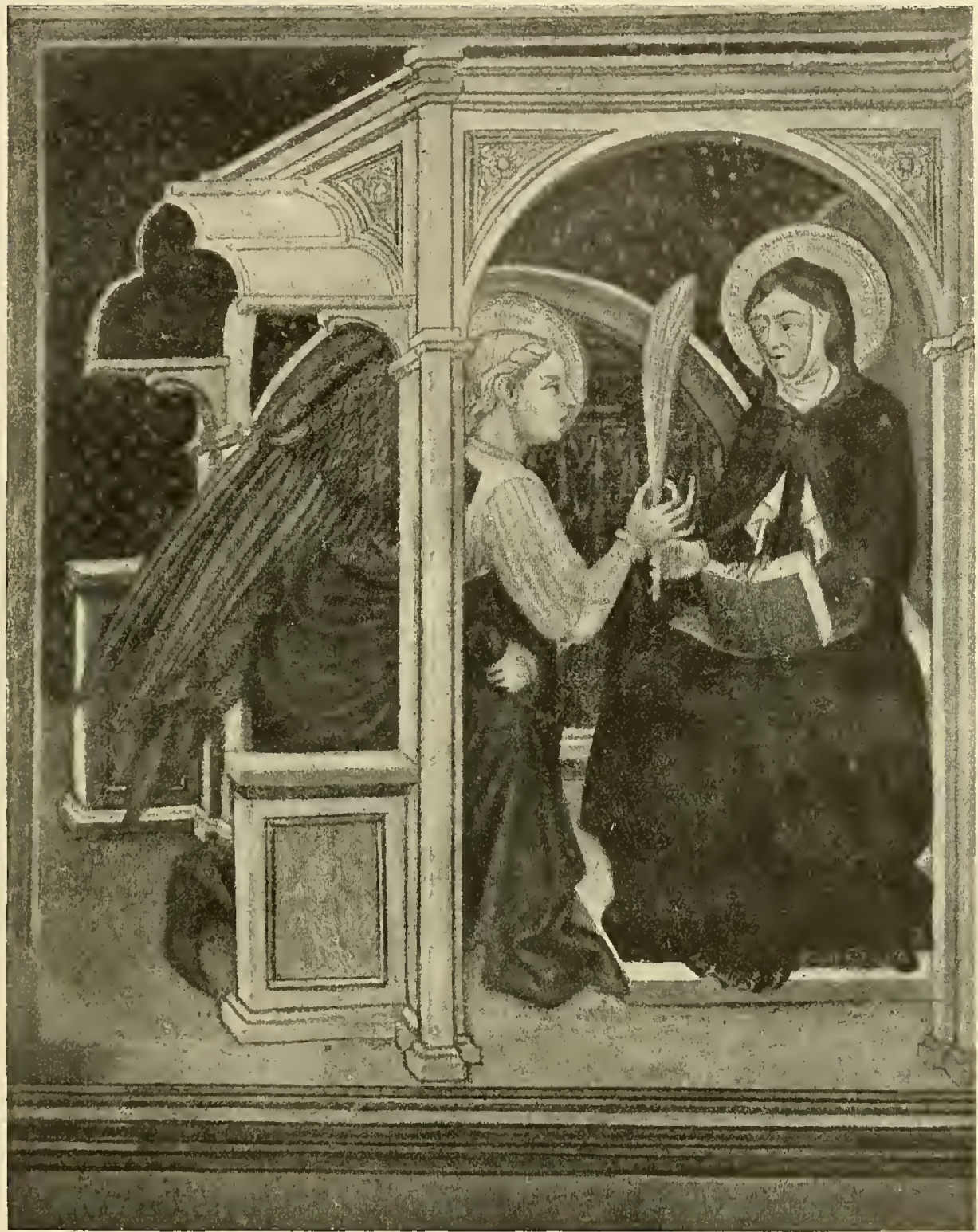

Palazzo dej Trinci in Foligno

(Ottaviano Nelli)

yigliato nelle mani e il serto di regina, a destra del Re dei cieli, mentre i biblici vegliardi, i profeti incoronati si adunano, ricordando i vaticinì e le visioni loro. Come già nelle Omelie del monaco Giacomo dal $x$ all'xi secolo si vedono i profeti contemplare la Vergine col divin Figlio in trono, così il 
comacino scultore dispose ai piedi della Vergine assunta la corte dei profeti, i quali sembrano udire le parole che il monaco bizantino scrisse ne' suoi sermoni: "Al convito magnifico e lieto partecipiamo tutti. Le generazioni si successero, le profezie si diffusero, i patriarchi e tutti gli uomini giusti vissero nella speranza. Abramo passò, e dopo lui i suoi nipoti sospirarono gli avvenimenti del futuro, a loro noti. Mosè, spingendo lo sguardo chiaroveggente nel mistero e considerando i segni del vero, pensò che le predizioni si avve-

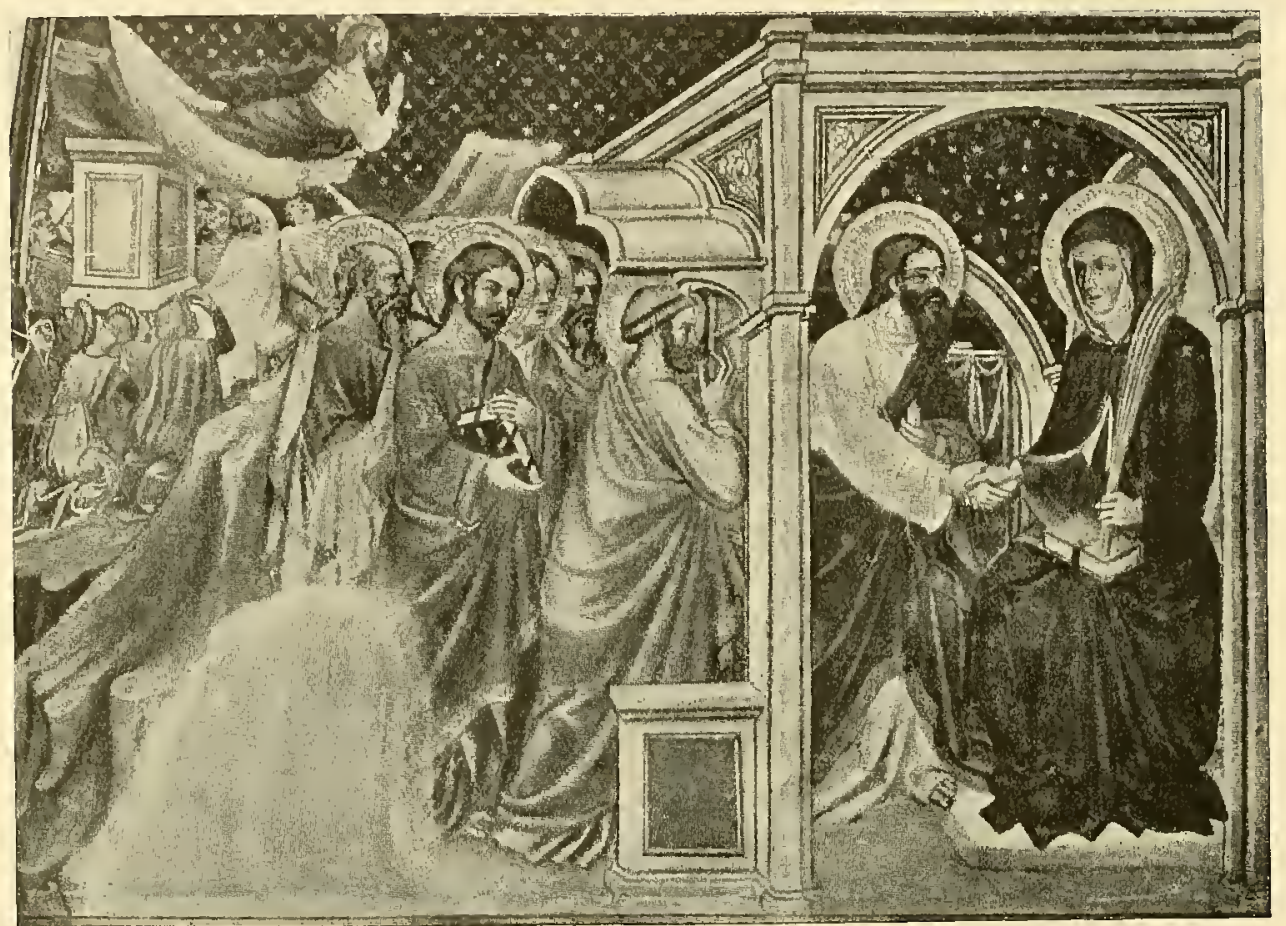

Palazzo dei Trinci in Foligno

(OtTaviano Nelli)

rassero al suo tempo; e la speranza alitò nel deserto, e i padri del popolo stettero in attesa. Samuele ebbe segni del nuovo che si apprestava, David non cessò di bandire che il giorno era vicino, $i$ profeti annunciarono in coro che il Cristo era alla porta; ma tutti passarono senza vedere avverate le speranze... . Il miniato:e delle Omelie dispose pure in due piani la rappresentazione e fece che i profeti si volgessero verso l'alto di tra le piante fiorite; mentre lo scultore comacino li schierò in una tribuna del cielo, quali principi assistenti al trono del loro Re. La Vergine appare incoronata, come a Santa Maria in Trastevere nel musaico dell'abside: ma l'arte, in 

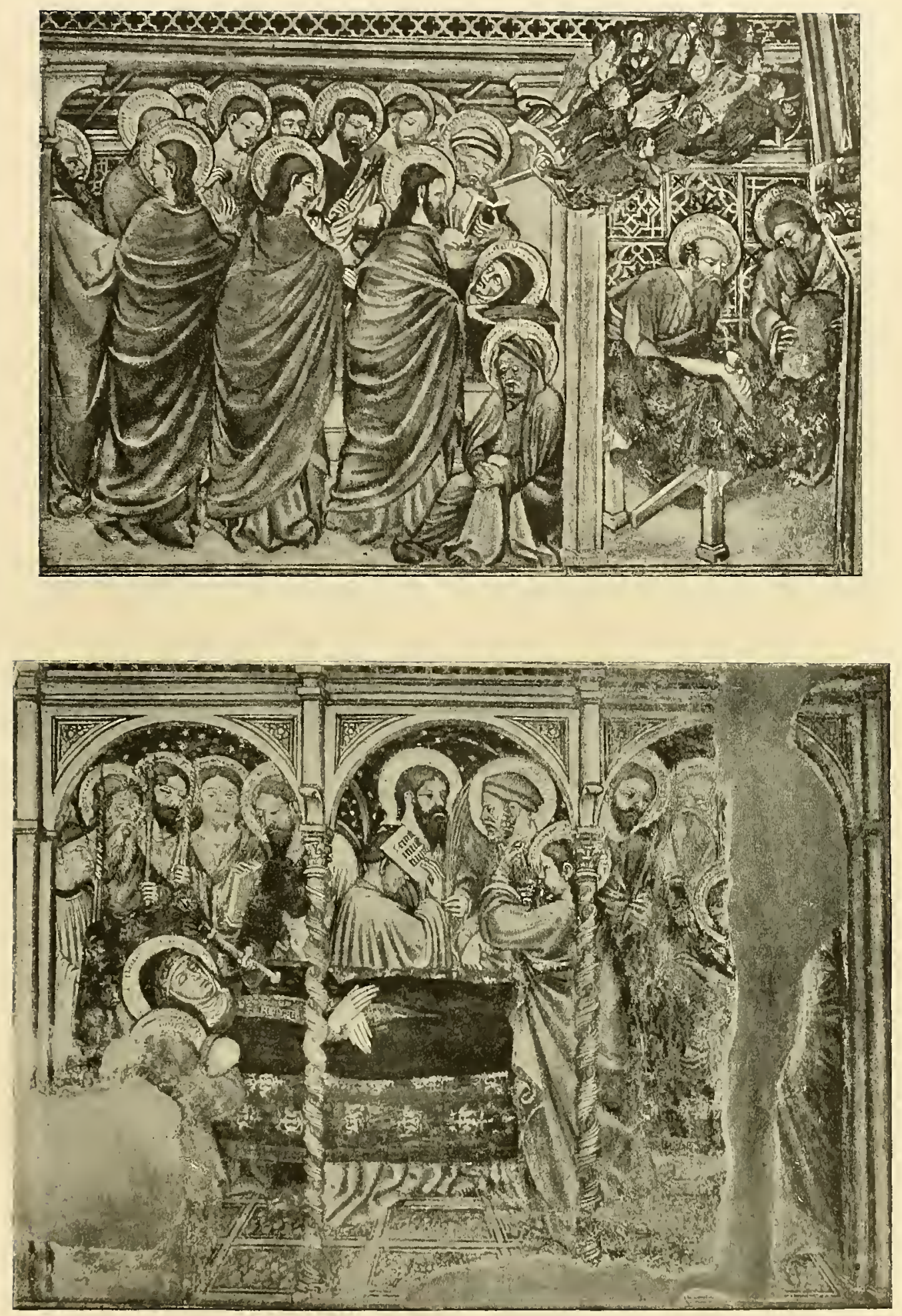

Palazzo dei Trinci in Foligno

(Ottaviano Nelis) 


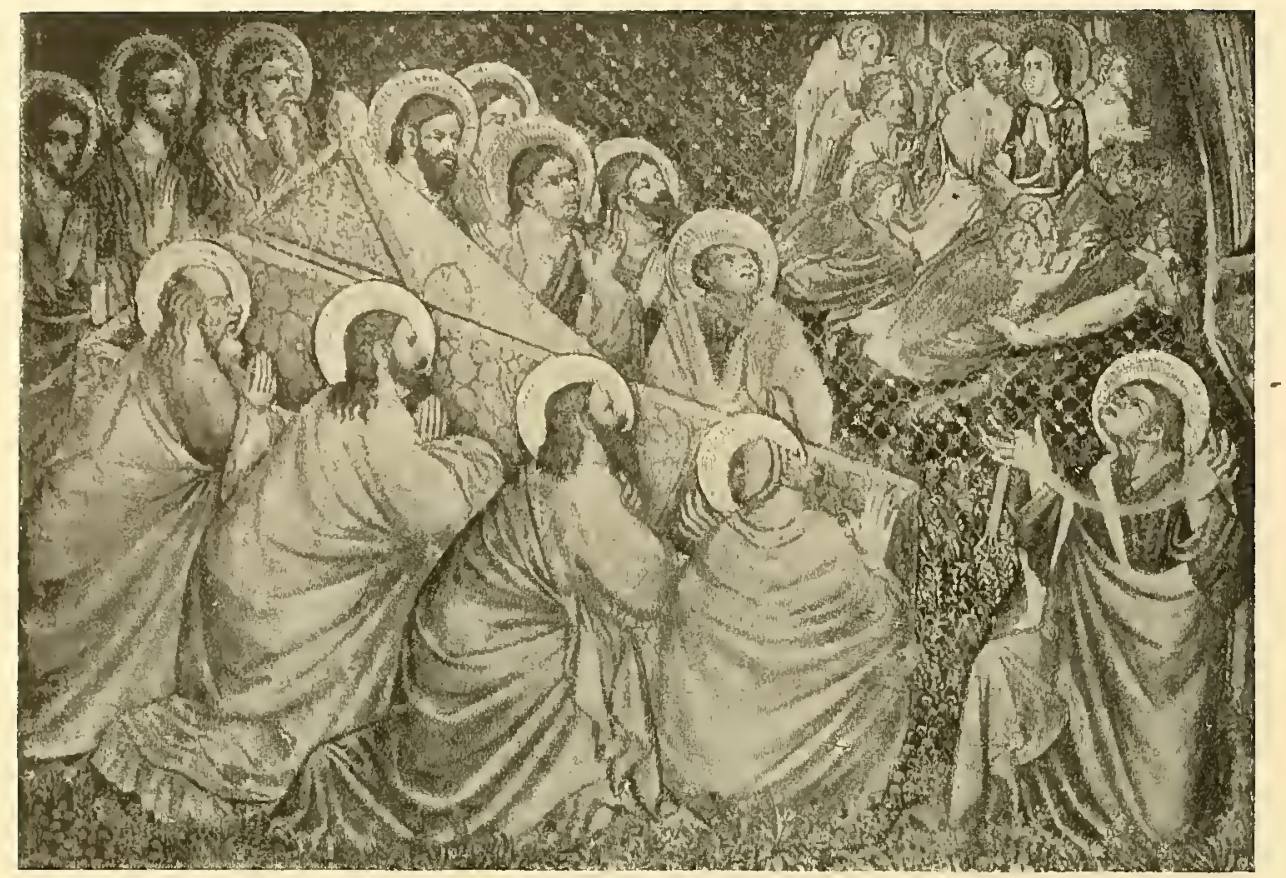

Palazzo dej Trinci in Foligno

(Ottaviano Nelli)

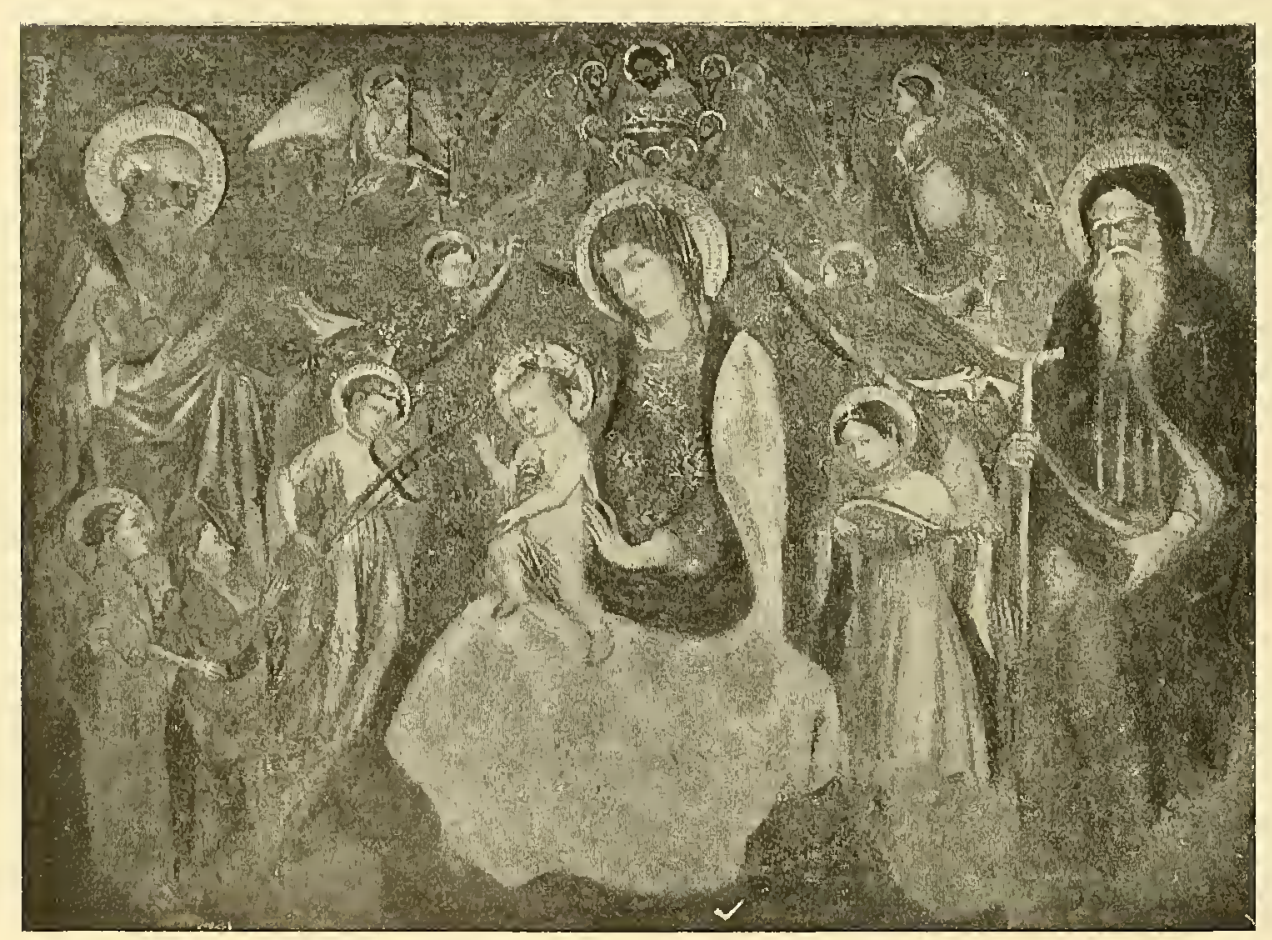

Chiesa di Santa Maria Nuova in Gubbio (Ottaviano Nelli) 


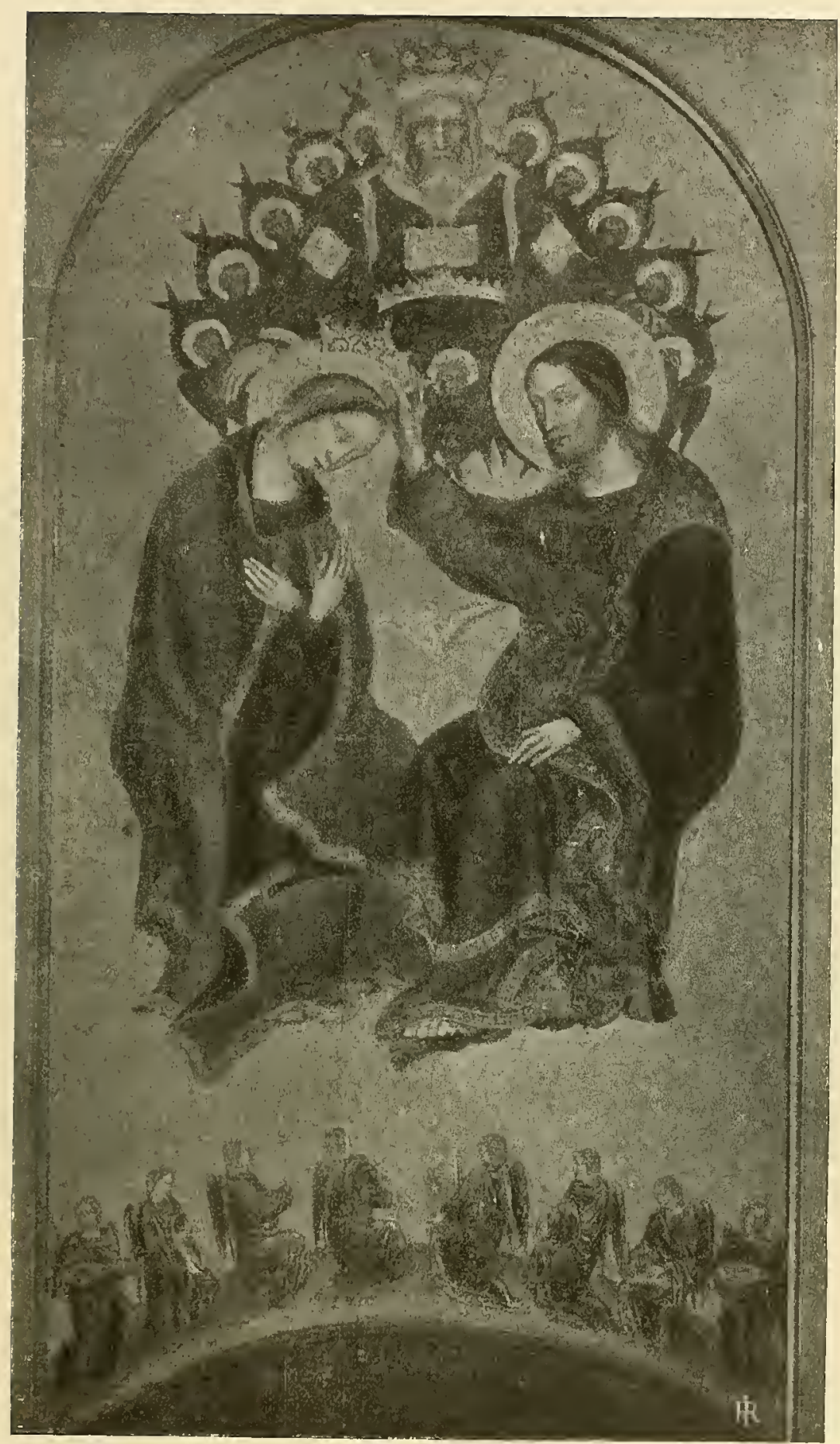

Galleria di Brera in Milano

(Gentire da Fabrinno) 
seguito, per curare i passaggi della rappresentazione e per far sì che ogni parte di essa continuasse ogni forma precedente, senza sottintesi e senza strappi, mosse il Redentore a porre la corona regale sul capo della Vergine, che la riceve china con le mani giunte sul petto. Più tardi, per coordinare

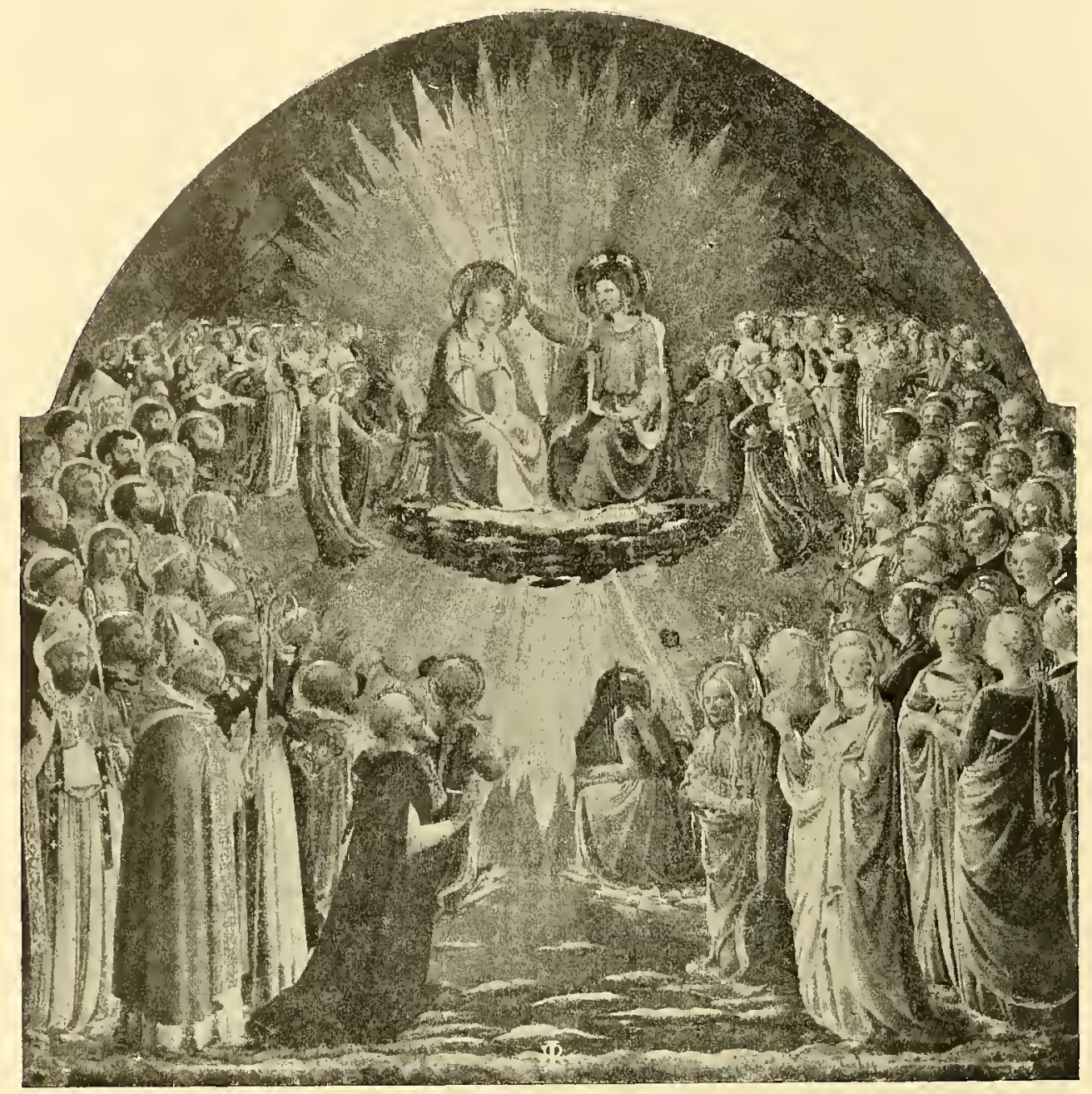

R. Galleria degli Uffizi

(Bento Angelico)

i diversi momenti della rappresentazione con più stretta logica, Tiziano rappresentò gli angioli in atto di apprestare la corona all'Eterno, che mira assurgere in cielo Maria.

Verso il Trecento adunque l'arte nostra rappresentava, più che la Vergine assunta, la glorificazione della Regina dei cieli, sempre vestita di umiltà, ma tutta avvolta nella luce e sollevata sublime, mentre i cori degli angeli 
intonano alleluia, e i patriarchi benedicono a lei. e le vergini beate le tendono le braccia, e i santi l'adorano Non è più la donna che lascia le spoglie terrene e si stringe come fantolina nelle braccia del Redentore; è la Sovrana cui Dio cinge di corona la fronte, la tenera Madre nellapoteosi. Dante, nel

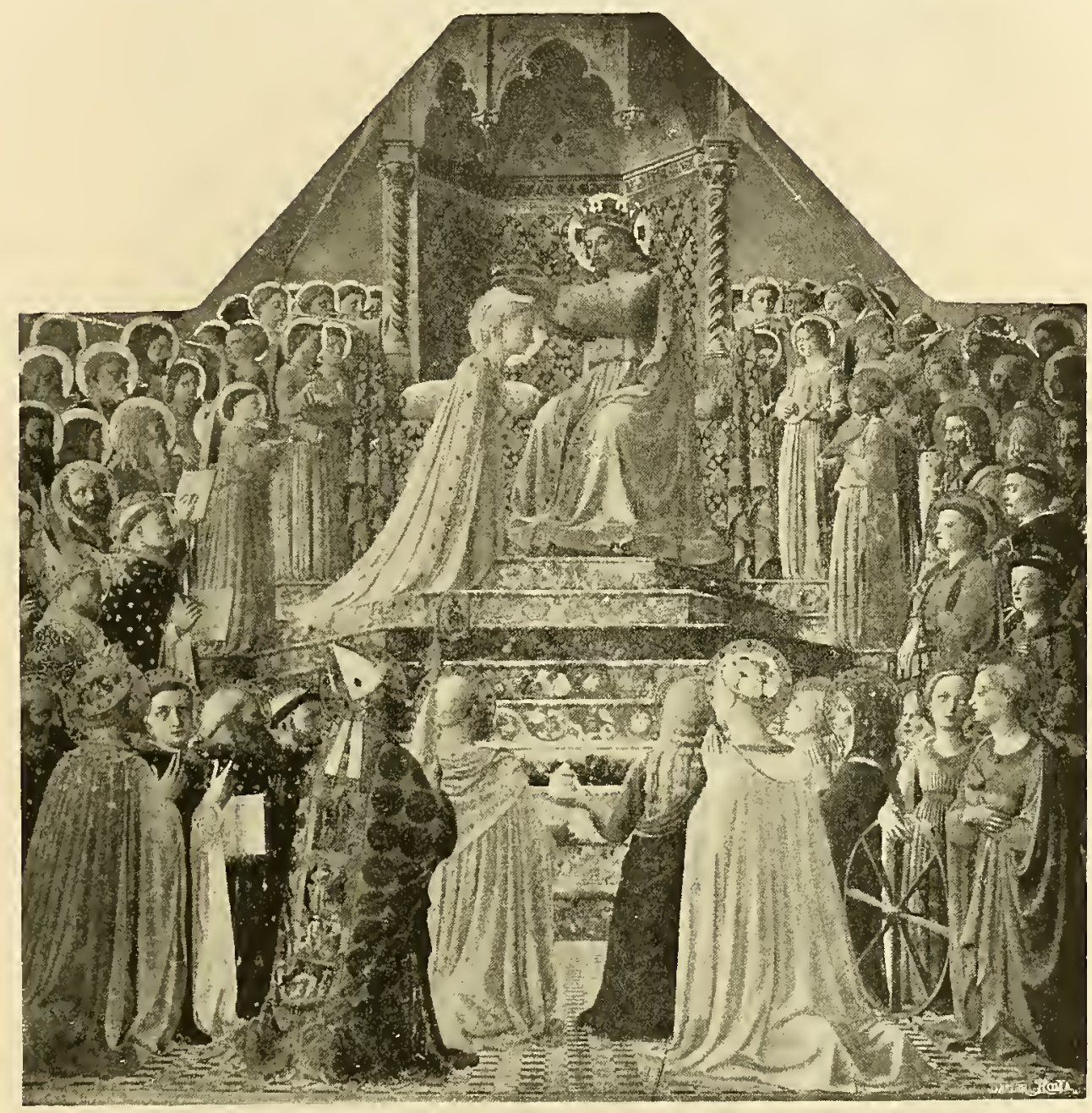

Museo del Lowre

(BEATO ANGELICO)

canto XXXI del Paradiso, descrive la Vergine nel trionfo, in mezzo a una pacifica orifiamma, ovvero a un'aureola splendente, e intorno più di mille angeli festanti:

Vicli quindi ai lor giochi ed ai lor canti ridere una bellezza, che letizia era negli occhi a tutti gli altri santi. 
Pare che Dante descriva cosi il dipinto di Giotto in Santa Croce a Firenze, che rappresenta gli angioli e $\mathrm{i}$ santi tutti assorti in Maria, con le labbra socchiuse come per meraviglia e le pupille intente alla divina Madre. A Pisa nel camposanto, come a Firenze nel tabernacolo dell' Orcagna in Or' San Michele, la Vergine sta avvolta da un' aureola elissoidale, che corrisponde alla pacifica orifiamma della Dizina Commedia, e tutto attorno ad

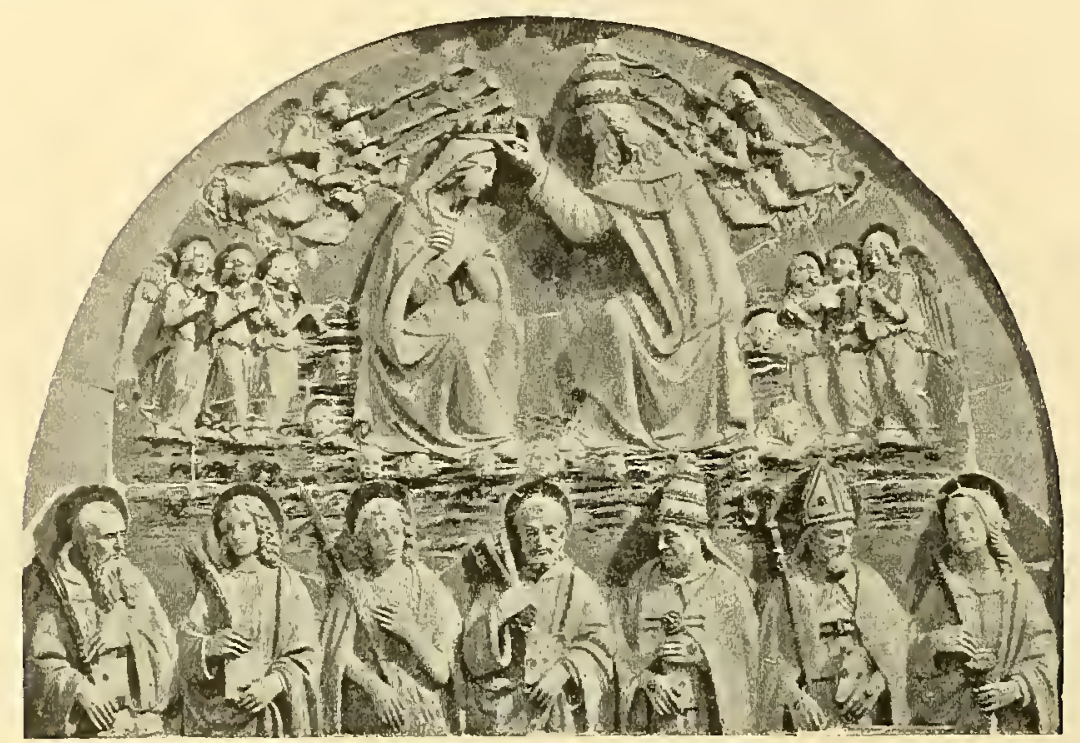

Chiesa d'Ognissanti in Firenze

(LUCA DELLA ROBBIA)

essa, "ed a quel mezzo con le penne sparte ", come canta il poeta, stanno gli angeli beati.

Io vidi sopra lei tanta allegrezza piover...

soggiunge Dante e addita quindi $\mathrm{i}$ santi intorno e Anna fra grli altri che non move occhi per cantare usanna.

e Gabriele che

guarda negli ucchi la nostra Regina innamorato si che par di foco.

Interpretando gl'inni di trionfo alla Vergine, l'arte non tralasciava di elaborare le leggende che avevano condotto a quelle forme trionfali. La 


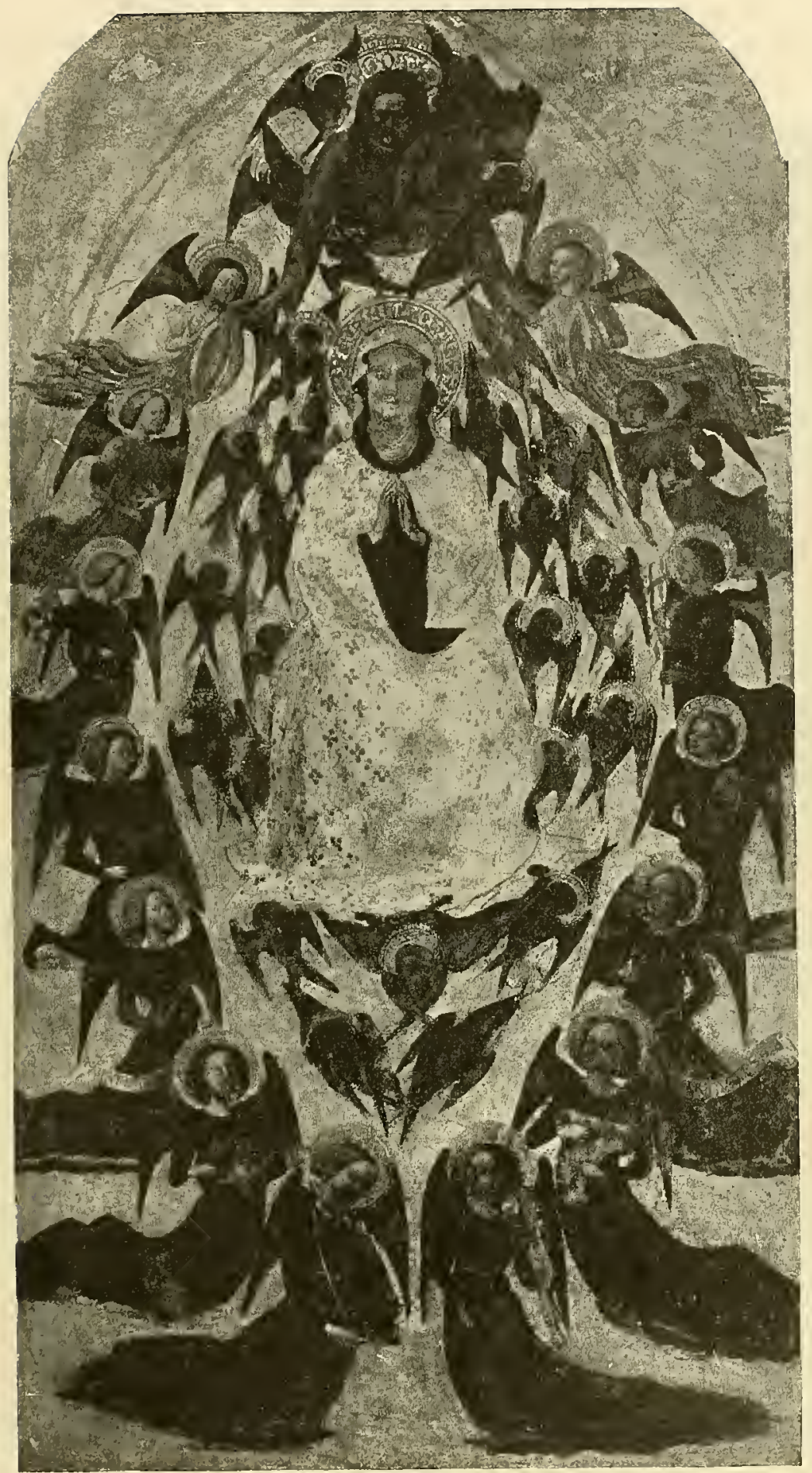

Galleria Nazionale di Napoli

(MASOlino) 
scena della morte di Maria è resa con un senso di realtà vivissimo: la Vergine è stesa nel cataletto con le braccia conserte, e gli apostoli attorno

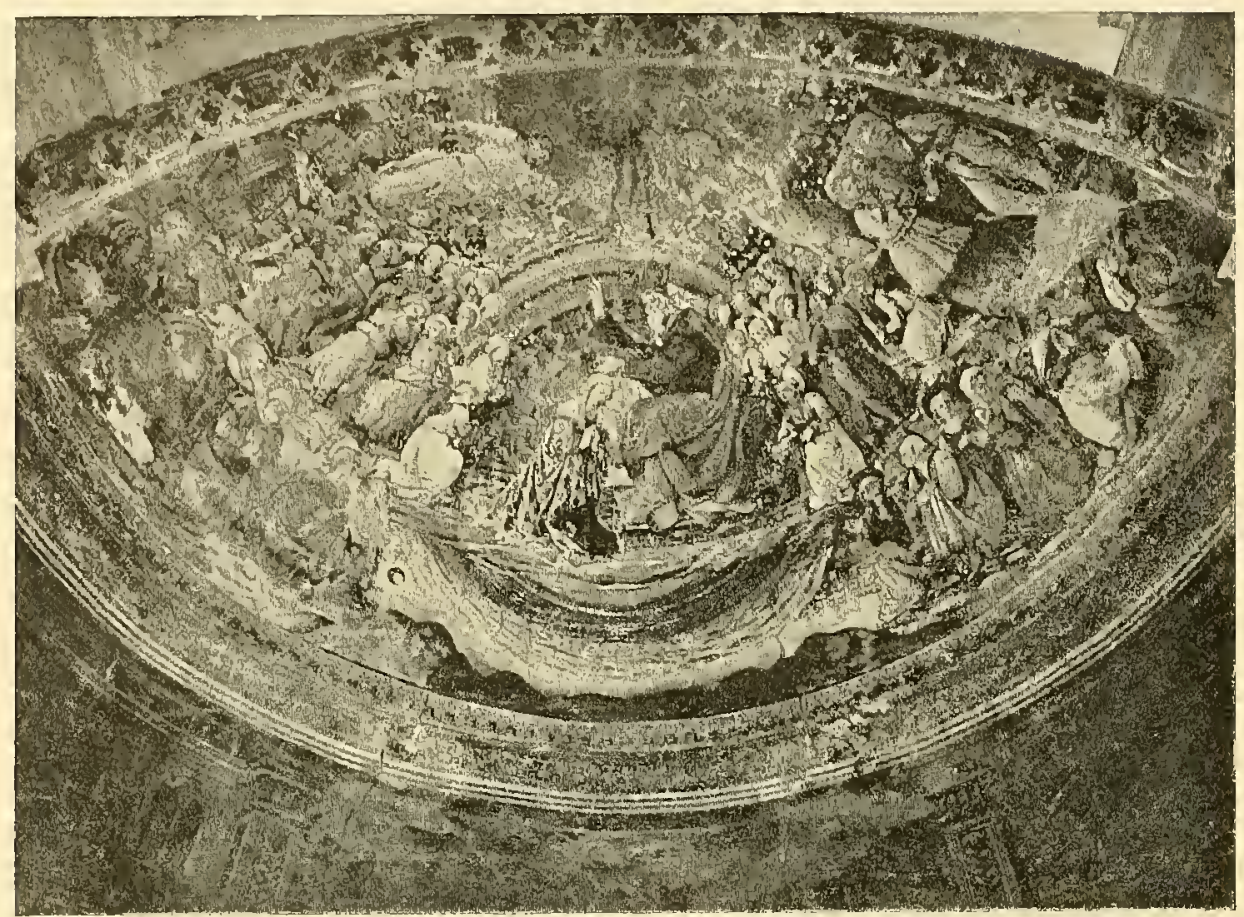

Caltedrale di Spoleto

(FILIPPO LIPPI)

pregano: San Pietro, vestito come un sacerdote, legge le orazioni dei defunti, un altro apostolo tiene l'aspersorio, un terzo il secchiello dell'acqua santa, un quarto il turibolo, gli altri mormorano le preci, e uno di essi, mentre si solleva la coltre mortuaria, disperato bacia la destra della benedetta tra le genti. Gli angioli stanno tra i dodici discepoli del Cristo con torce, e v'e pure il Redentore col bambinello simbolico tra le braccia. Così la scena legsgrendaria prese forma dalla realtà, dai riti religiosi, dalle costumanze nostre; e dalla realtà ricavò espressioni di dolore, accenti di pietà che composero il dramma. Vecchi apostoli curvi, angosciati raffigurò l'Orcagna in Or' San Michele; e Spinello Aretino a Siena espresse sentimenti di venerazione e pietà presso la salma, mentre Pietro a stento legge nel libro, Giovanni fisa gli occhi disperato al cielo, e due angioli con un ginocchio a terra tengono i candelabri, con le candele accese, dietro al capo dell'esanime. Una corona di teste addolorate cinge il feretro della Vergine pure in 


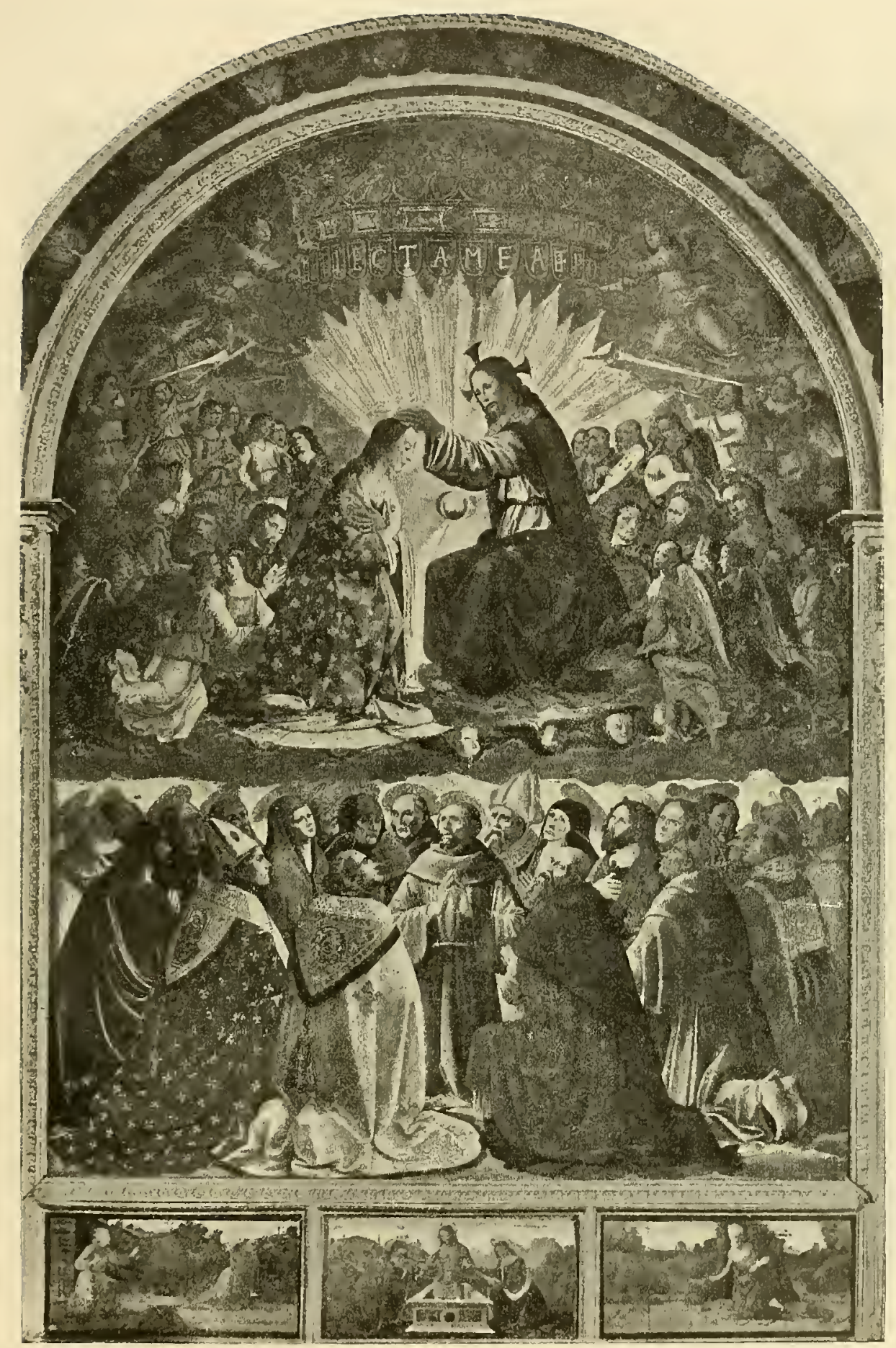

Palazzo comunale di Narni

(1) ONENICO GHIRLANDAIO) 
Siena, al palazzo della Signoria, nella pittura di Taddeo di Bartolo, che rappresentò i diversi momenti della leggenda del Transito. Si vedono gli

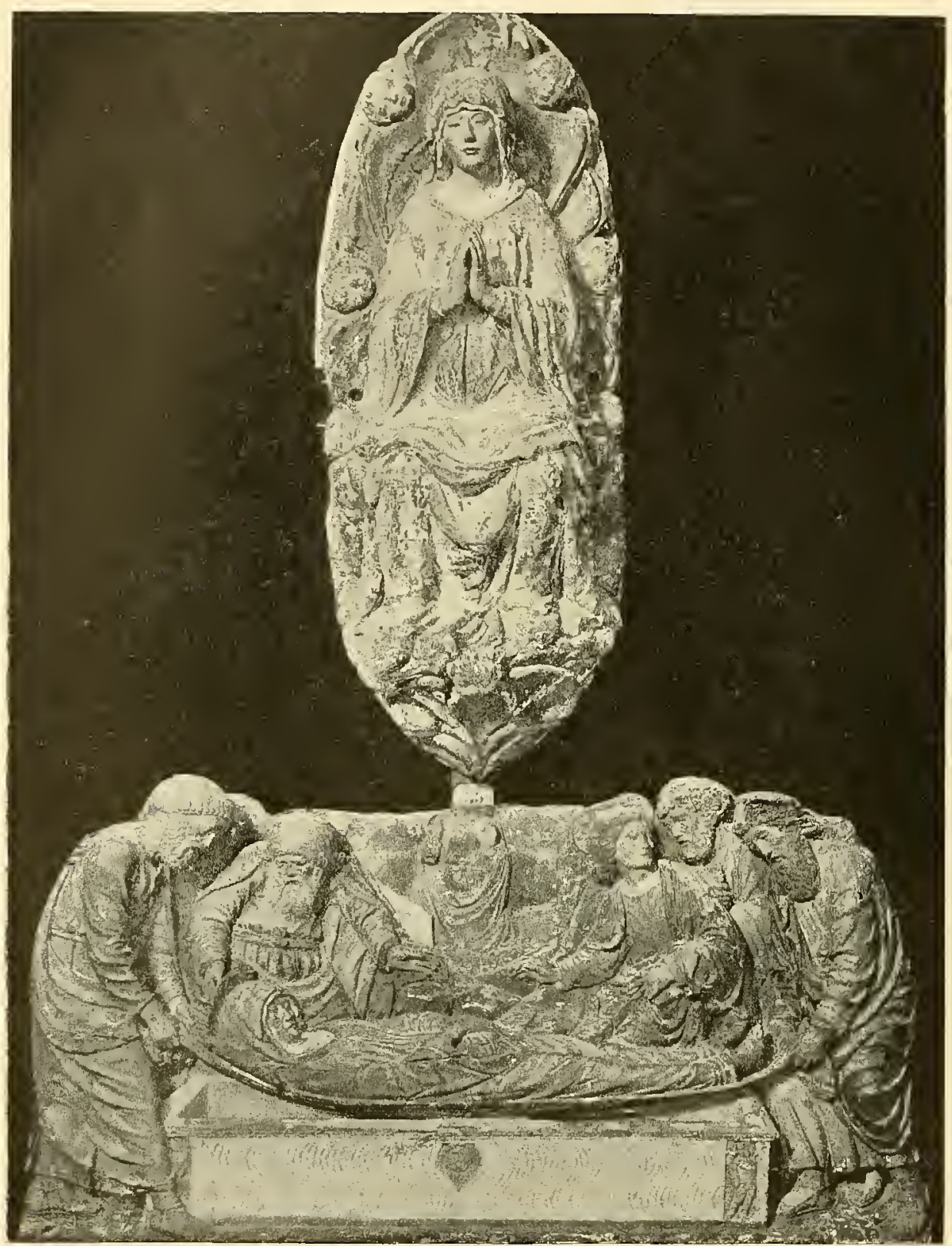

Pinacoleca di Lucca

(altribuito al Civitali e ad Ambrogio Pucci)

apostoli arrivare a volo e stringere le mani a Maria; in un altro riquadro la morte di lei e il Redentore che ne prende l'anima; in un terzo il trasporto alla sepoltura sotto le mura di Gerusalemme; nel quarto gli apostoli intorno 
al vuoto sepolcro e la visione di San 'Tommaso, il quale mostra ai compagni la cintura ricevuta in dono. Per mettere d'accordo le leggende, Taddeo Bartoli figurò soltanto nell'ultima scena il numero completo degli apostoli, mentre altrove nella rappresentazione della morte di Maria dodici sono gli assistenti. Si provò anche Taddeo a figurare il braccio del sacrilego troncato è attaccato al feretro, ma non ottenne l'evidenza così come fu ottenuta

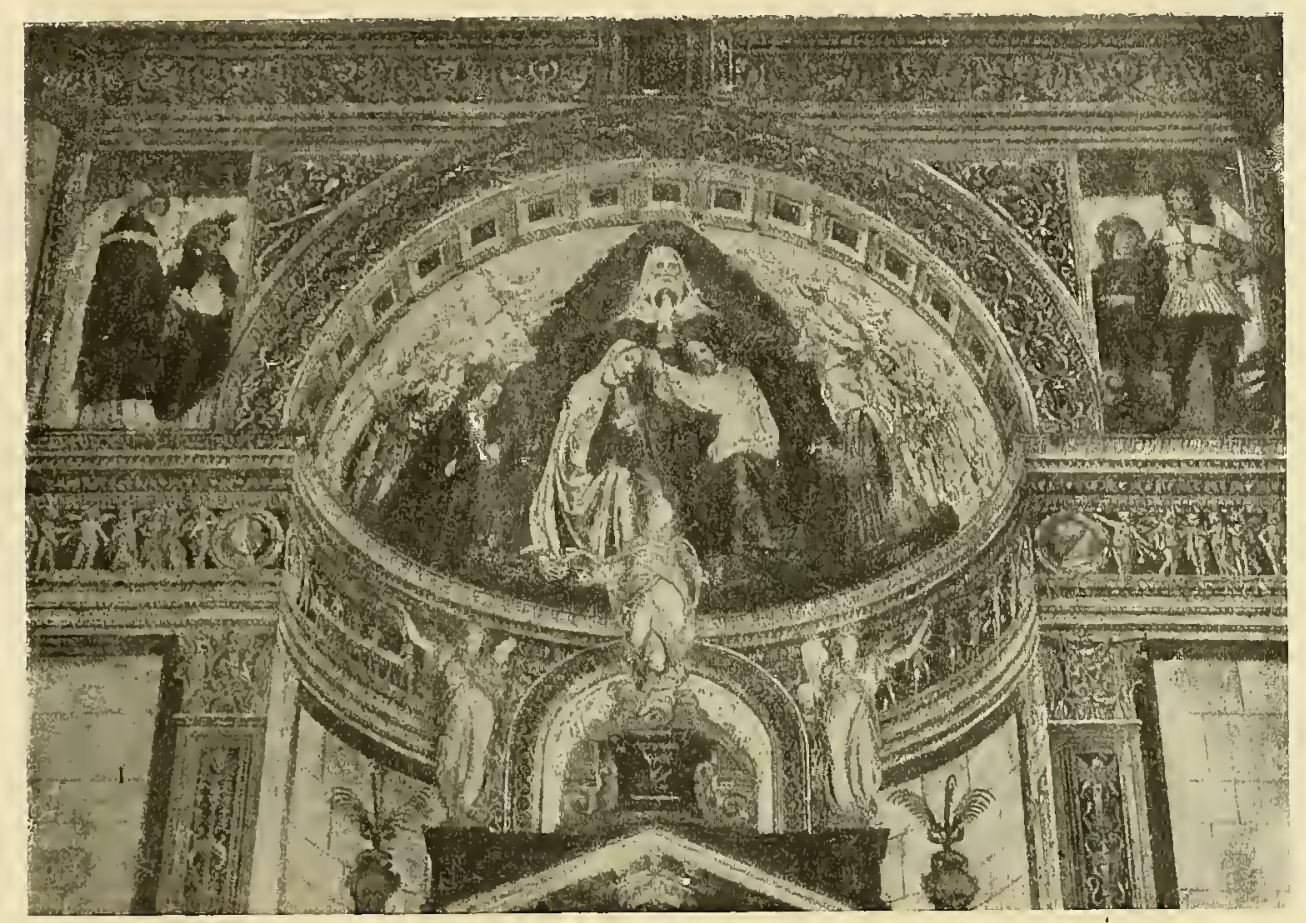

Affresco in San Simpliciano in Milano

(A. BORGOGNONE)

in un quadro di tempo posteriore, posseduto da B. W. Currie in Londra, ove si vede prostrato l'uomo col moncherino, l'angelo che ne taglia con la spada le mani, e queste attaccate al feretro.

L'arte che si provava a significare il racconto della morte di Maria clovette sentire anche il bisogno di separare gli elementi soprannaturali dalla scena; ed ecco che il Redentore con l'anima della Vergine nelle braccia non appare in mezzo agli apostoli intorno al feretro e senza che essi mostrino di accorgersi della sua presenza, bensì in alto, tra una corona di serafini alati o in un'aureola di gloria. Così in Siena nel quadro di Bartolo di Fredi, e così pure nell affresco di Jacopo Avanzi nella chiesa di San Michele in 
Padova, in quella pietosa, naturalistica rappresentazione a cui intervengono come spettatori anche $\mathrm{i}$ mortali. Al dramma, che aveva ricevuto il suo pieno

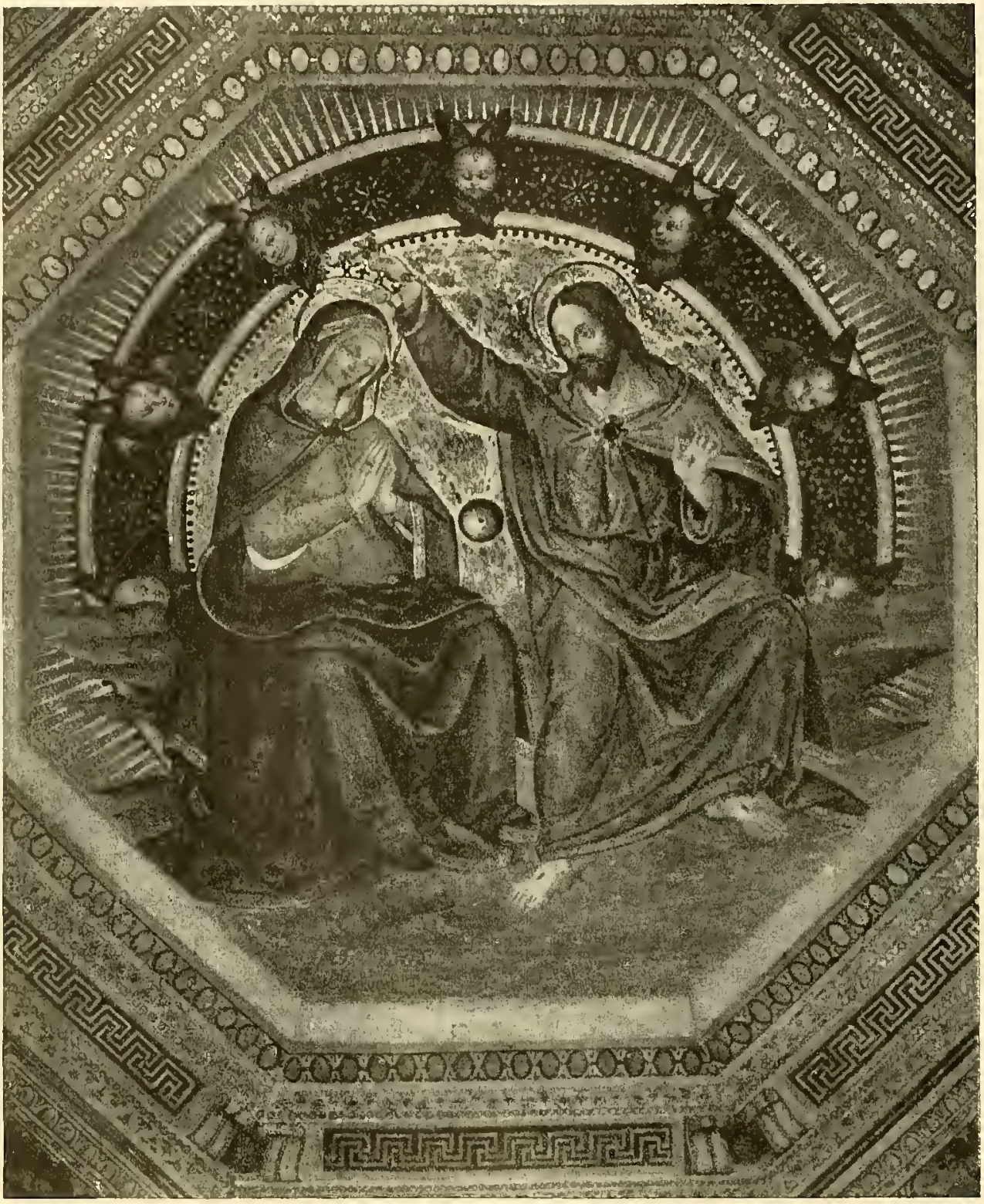

Chiesa di Santa Maria del Popolo

(Pinturicchio)

sviluppo, assistono commossi $\mathrm{i}$ fedeli, che vogliono essere ritratti quasi ne fossero il coro. Ma è quella una delle ultime forme con cui si rappresenta la morte della Vergine, perchè i quattrocentisti, secondo il genio latino, 


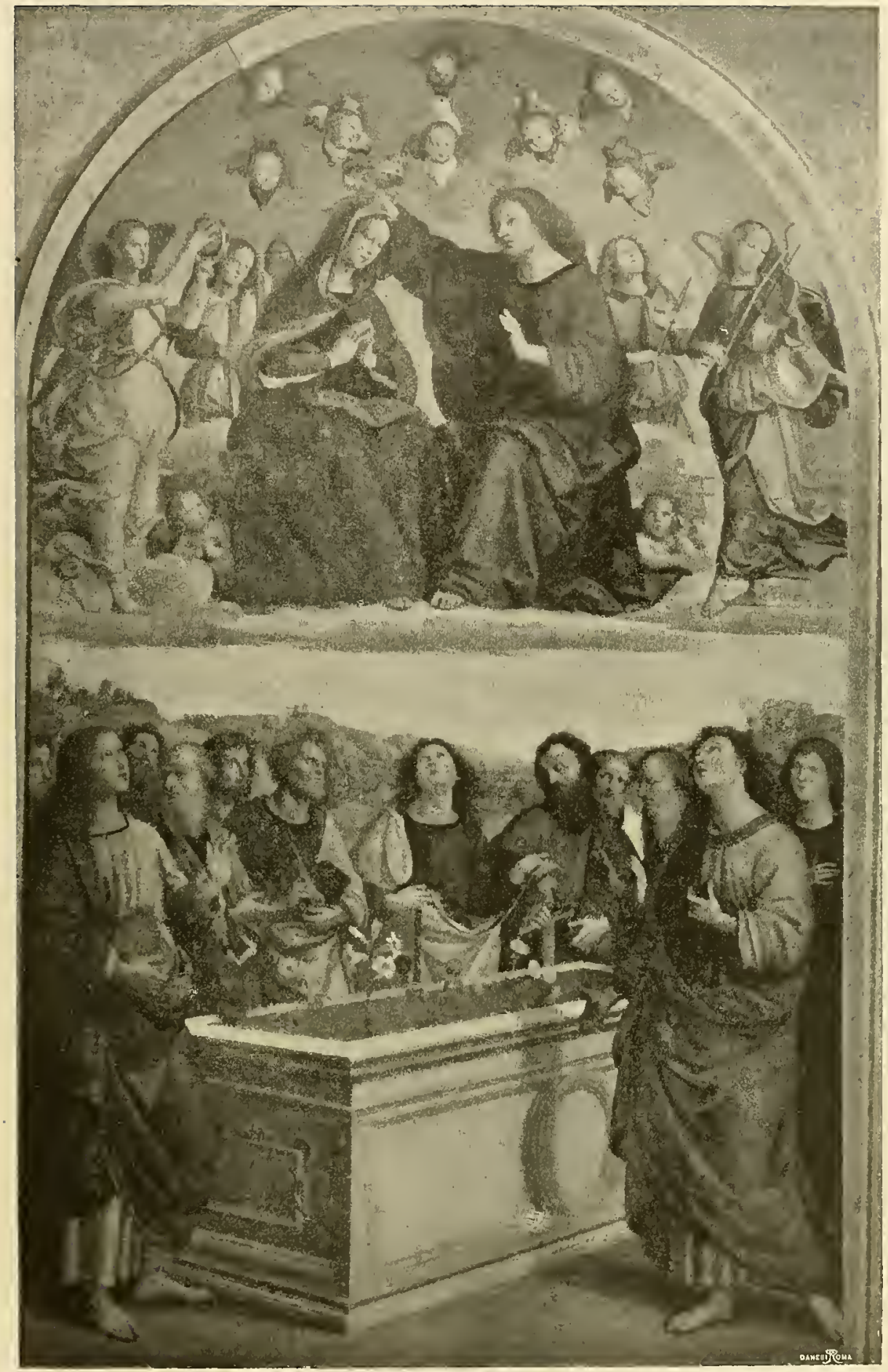

Galleria Vaticana

(R.AFFAELLO) 
preferirono di rendere l'Assunzione e l'Incoronazione anche approssimando e confondendo le due scene.

Al principio del Quattrocento il Beato Angelico, in un quadro ora agli Uffizi, dipinse il Transito della Vergine secondo le tradizioni bizantine; ma in altri quadri, separando nettamente l'Incoronazione dalla Morte di Maria, creò

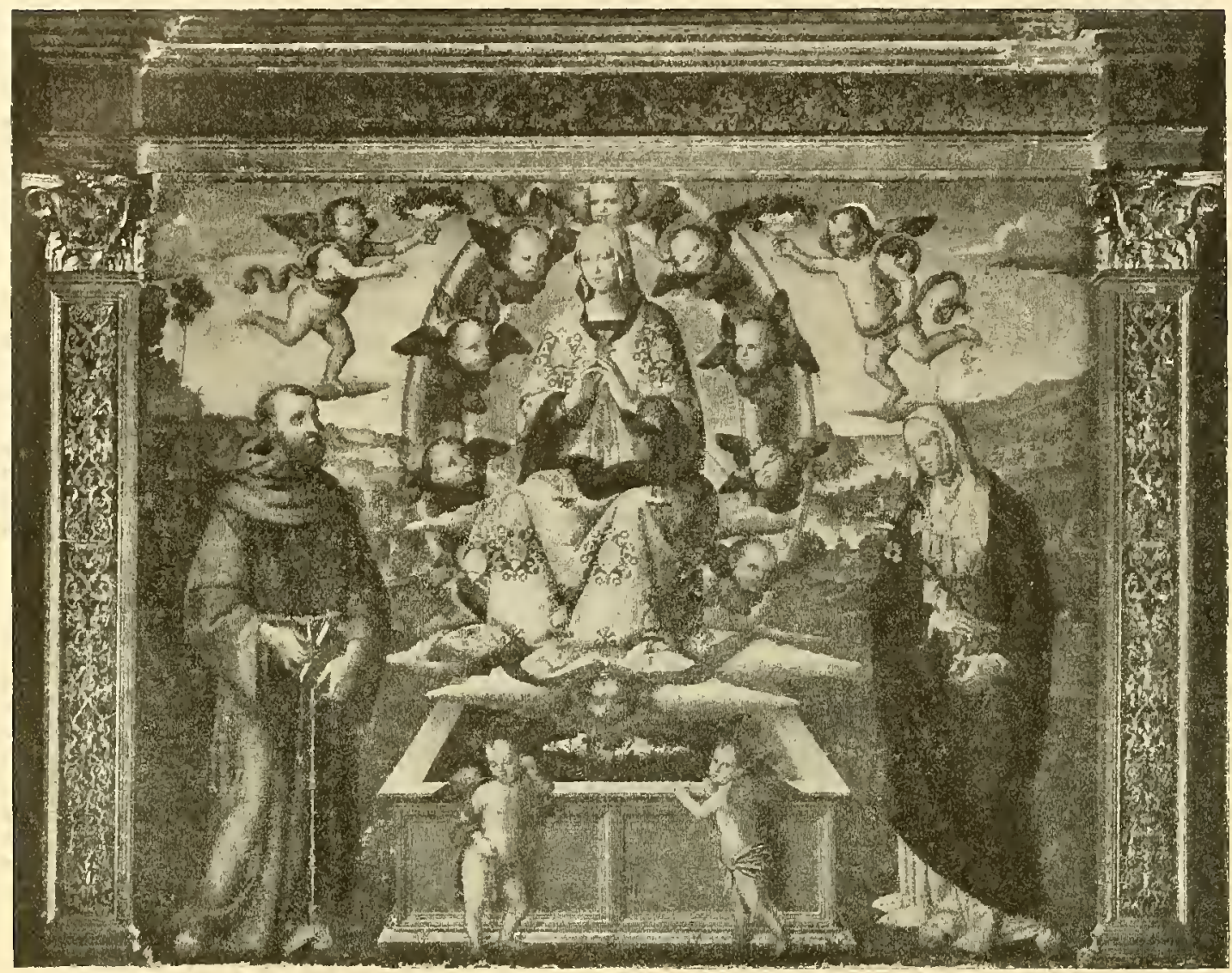

Chiesa di Santo Spirito in Siena

(MATTEO BALDUCCI)

capilavori d'arte cristiana. Alla stessa Galleria degli Uffizi si vede la sublime. Incoronazione coi santi in estasi, alabastrini. con occhi chiari e dolcissini. Pare che l'anima tremi di affetto a quelle soavi figure dell'Angelico, e splenda come in terso cristallo nei felici che si muovono lievemente tra le nubi intorno a Maria, per formarle una ghirlanda di rose. Gli angioli o fanno squillare le lunghe tube, o cantano e suonano variati strumenti, o innalzano $\mathrm{i}$ turiboli; le generazioni dei beati ascoltano e ammirano, e l'occhio dell'Eterno, come sole, saetta raggi d'oro intorno all' Incoronata. Come Giotto, il Beato Angelico 


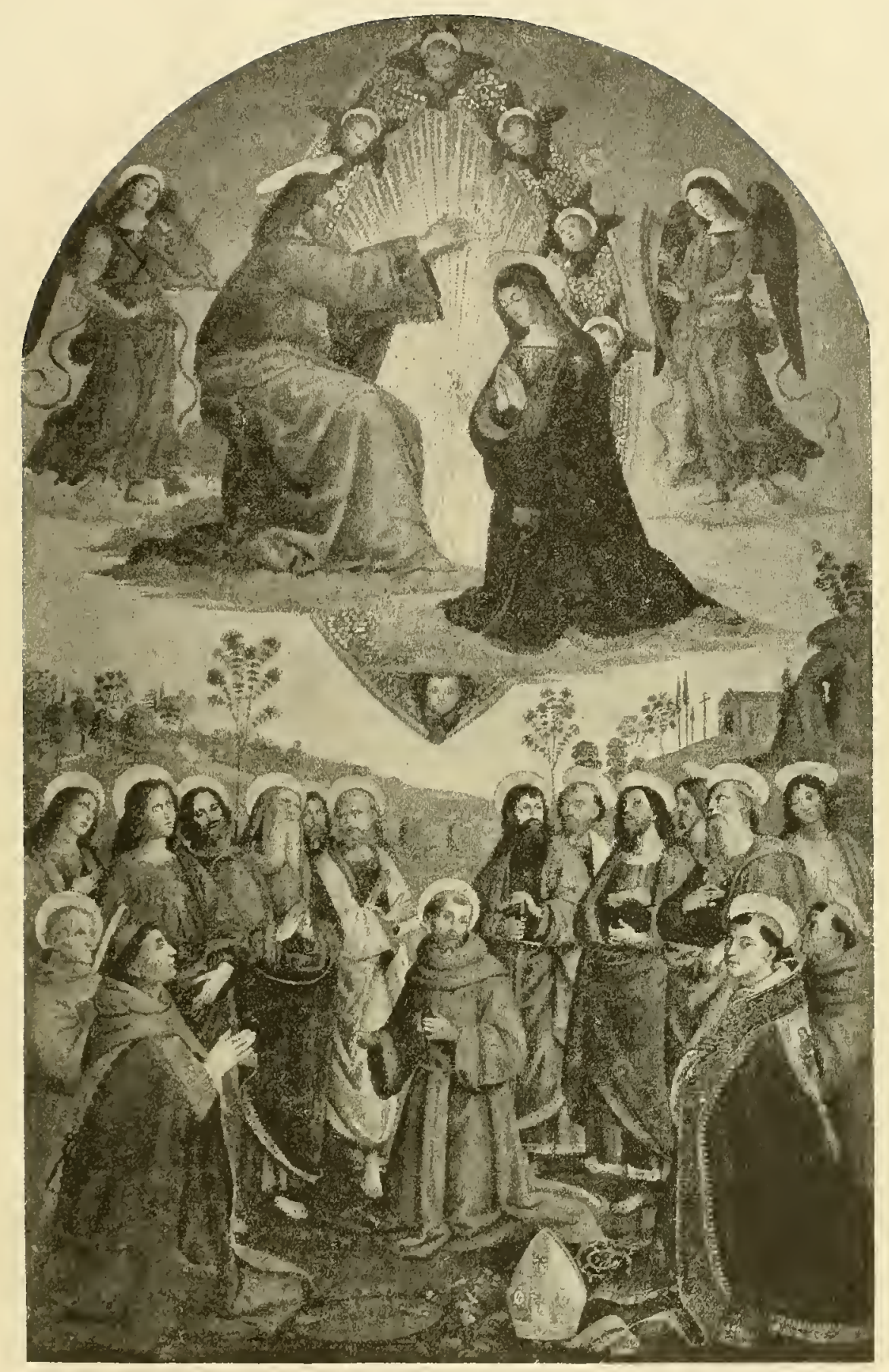

Galleria Vaticana

(PINTURIC CHIO) 
rappresentò la Vergine in età giovanile, e diede anche a tutto il corteo celeste le rose di gioventù, per quella tendenza propria dell' arte che si approssima alla perfezione, di rappresentar l'uomo nel fiore degli anni, senza tracce della caducità della vita.

Per tutto il Quattrocento l'Incoronazione è uno spettacolo grandioso, a cui prendono parte i cori degli spiriti e degli eletti: la cerimonia celeste che nel Trecento si svolgeva sui troni, sotto baldacchini o ciborî, si svolge poi sulle nubi sparse d'ali di serafini e di fiori. Filippo Lippi, nella cattedrale di Spoleto, sotto quelle nuvole e l'iride divina, disegnò gli astri, il

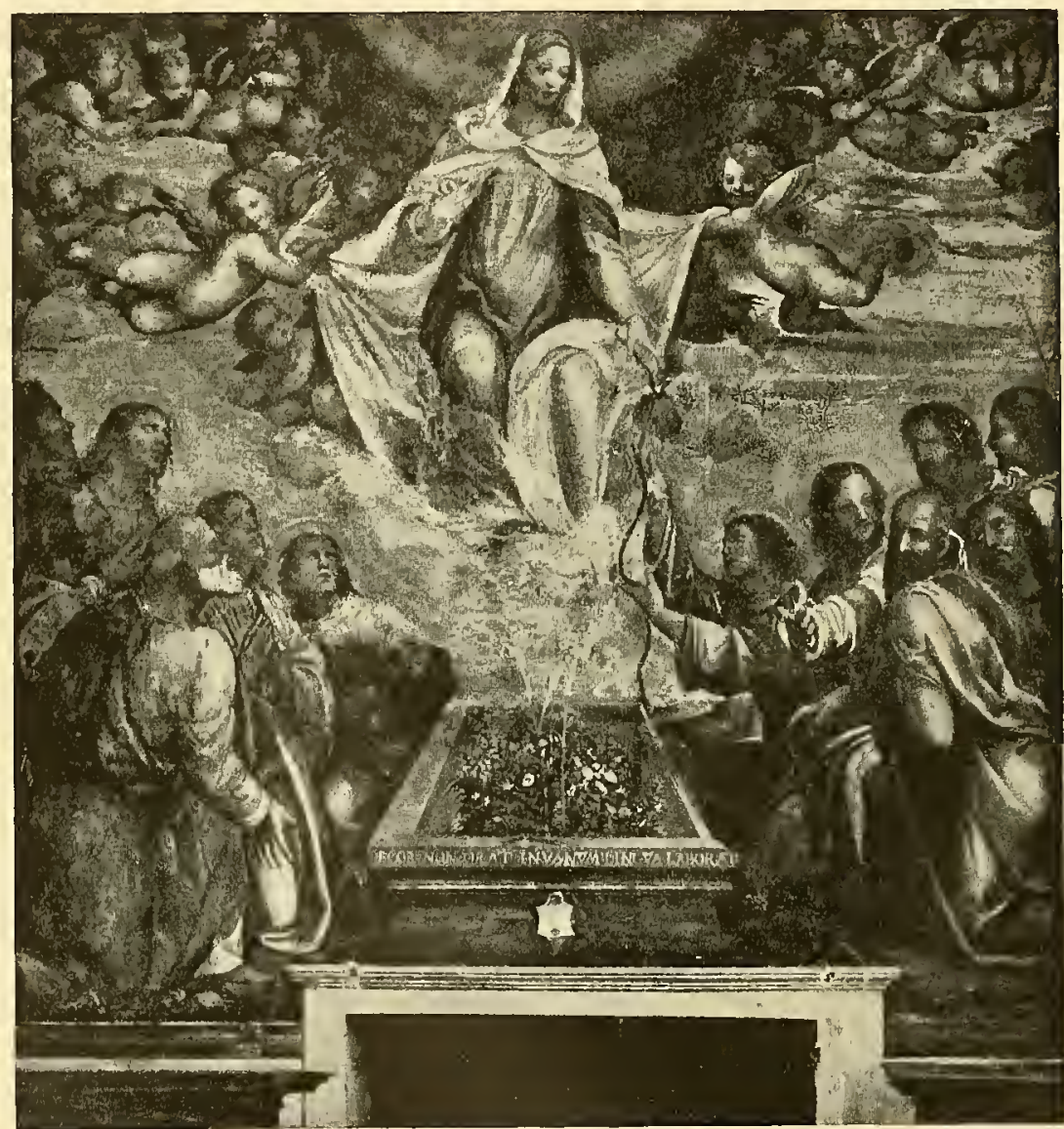

Oratorio di San Bernardino in Siena

(SODOMA)

mare popolato di pesci e i monti della terra; il Botticelli, nel quadro dell'Accademia di Firenze, fece intessere carole agli angioli intorno le nuvole sparse di rose; Domenico Ghirlandaio, in Narni, sopra la stella di luce che 


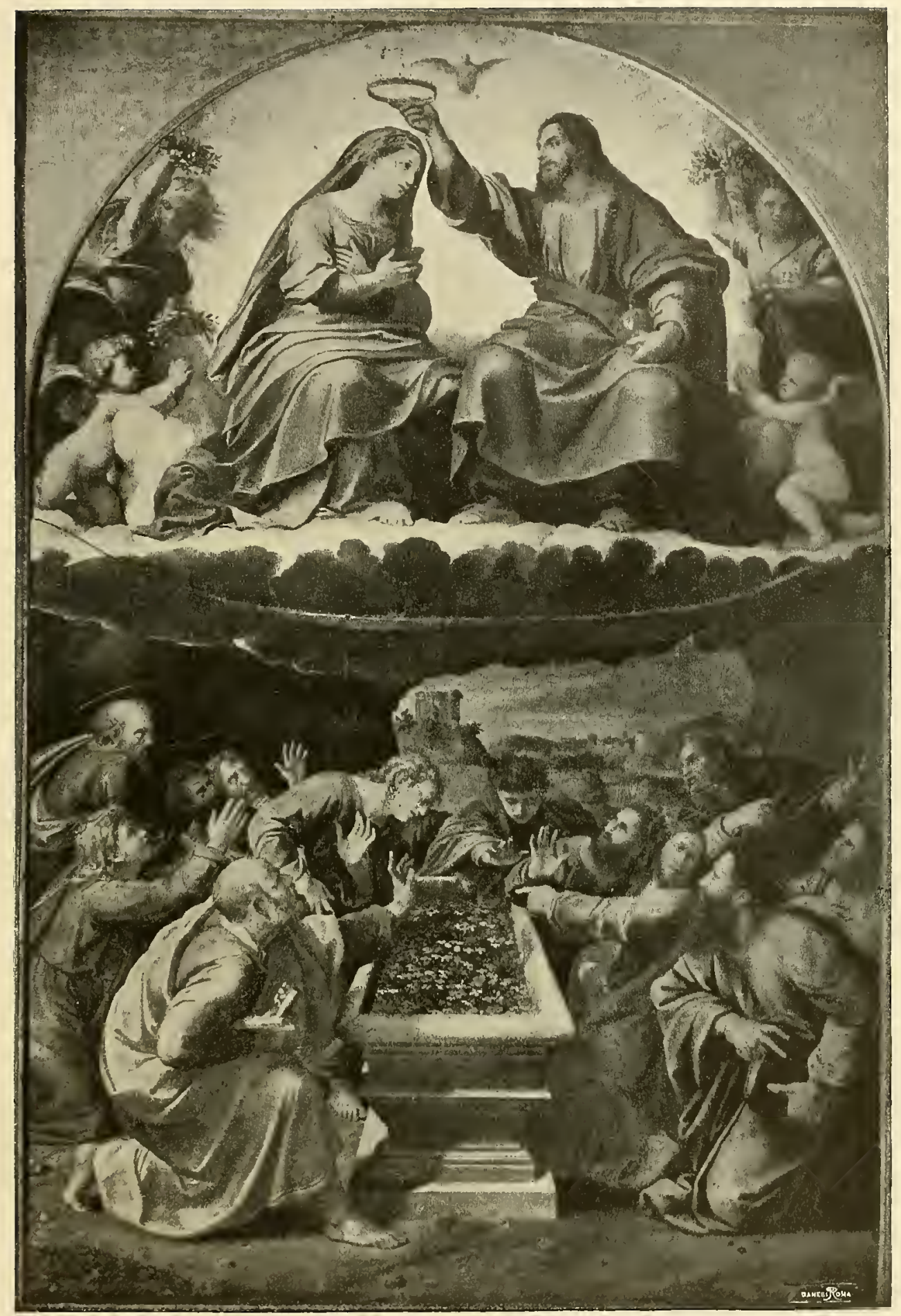

Madonna di Monteluce nella Galleria Vaticana

(Gillio Romano e il. Fattore) 
brilla dietro alla Divinità, fece tenere da due angioli un baldacchino in cui si leggrono le parole: ELECTA. MEA. ecc. Ma le turbe dei beati a poco a

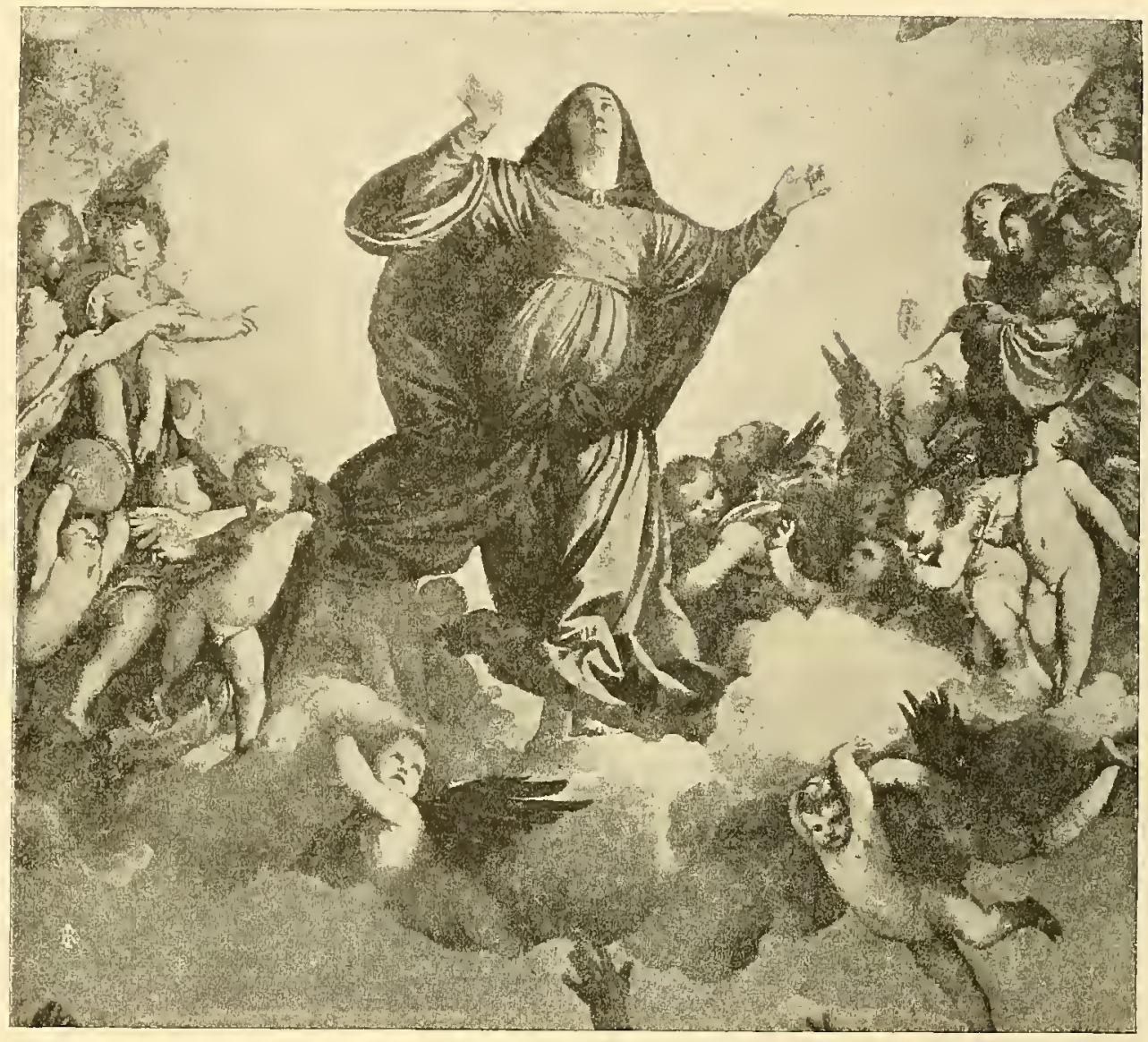

R. Galleria di Venezia

(Tiziano)

poco diradano all'approssimarsi della fine del Quattrocento, e soltanto i quattro dottori della Chiesa si veggono nell' Incoronazione del Botticelli, in Firenze, e sei santi in quella del Pollaiuolo, in San Gemignano.

Anche le semplici rappresentazioni dell'Assunta non mostrano quasi più nel piano gli apostoli intorno al vuoto sepolcro; e la Vergine non si vede in trono entro la mandorla luminosa, come nel Trecento, ma seduta sulle nubi o eretta tra raggi e lingue serpentine di fuoco. La mandorla stessa si modifica e financo vien meno nel quadro di Masolino, nella Galleria di Napoli, ove gli angioli alati si dispongono in forma elissoide intorno alla Vergine.

L'Incoronazione e l'Assunzione si fondono in un componimento solo nel quadro del Pinturicchio, in Vaticano, ove assistono all'Incoronazione i dodici 
apostoli e parecchi beati: e nel quadro di Raffaello, pure al Vaticano, ove agli apostoli appare la Vergine incoronata dal Figlio. In questo ultimo dipinto, dallo scoperchiato sepolcro spuntano fuori gigli e rose: motivo che è una libera traduzione di un passo attribuito a San Giovanni Damasceno, in cui è detto che San Tommaso, aperta la tomba, non trovò se non i drappi avvolgenti Maria, i quali spandevano intorno un celeste profumo.

L'eco delle antiche leggende non taceva mai, anzi diffondeva le sue onde sonore sull'opera del genio. Anche quando, al principio del Cinquecento, quell'eco sembra spegnersi, l'arte non distingue tutte le voci e $\mathrm{i}$ suoni che le erano familiari in antico, ma riconosce tuttavia gli accenti più belli e $\mathrm{i}$

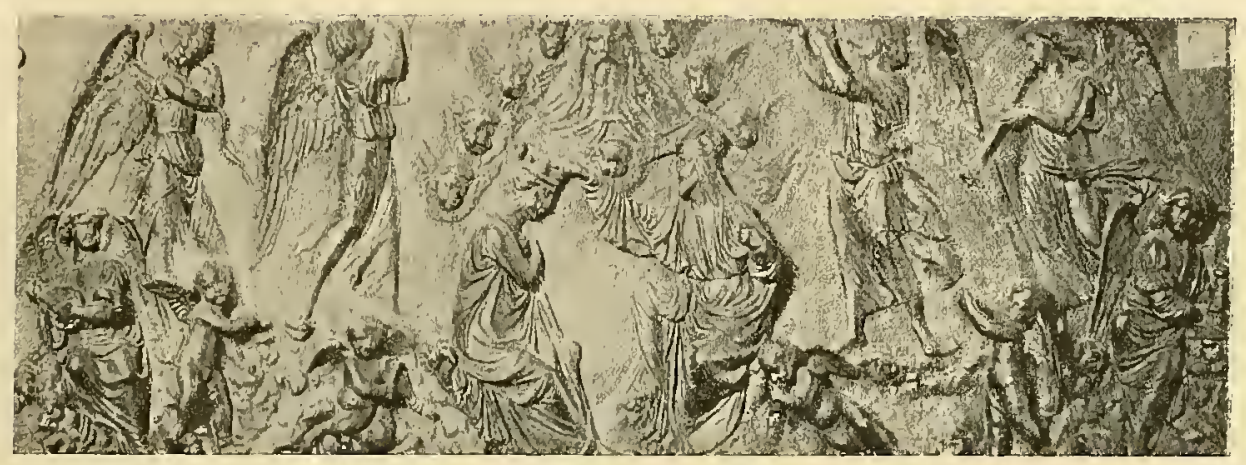

Museo archeologico di Venezia

(SCUOLA DEI LOMBARDI)

suoni più gentili, e con essi compone l'opera nuova. È nel Rinascimento tıtto un lavoro di riduzione, di semplificazione, di scelta degli elementi antichi, contrario a quello medioevale di moltiplicazione e d'ingrandimento. Dopo questa elaborazione il genio italiano stampò la sua orma immortale.

Tiziano raffigurò Maria che s'innalza al cielo, sulle lucenti nubi sorrette da innumerevoli angioletti, uno dei quali le solleva il lembo del manto, un altro suona il cembalo, un terzo la zampogna, altri cantano in coro; e chi compreso di stupore guarda la Regina dei cieli, e chi l'adora a mani giunte, mentre, più indietro, altri angioli si allontanano pel cielo, quasi eco di quell'inno di gloria. Ancora altri fanciulli sani, rosei, vivi, aleggiano sulla figura dell'Eterno e nuotano nella luce a cui tende la Vergine; e l'Eterno in gaudio la mira, e un angelo attende impaziente di cleporre sul capo della Vergine la corona regale. Sulla terra, gli apostoli in ombra, agitati, in atto di meraviglia e di devozione, o con il volto levato verso la 
Donna del cielo, e nell'alto angioli innocenti che cantano, suonano, scherzano, ammirano, pregano, affollati intorno alla Vergine, che rolge gli occhi e le braccia in su come un'orante; ma non è la mistica orante delle catacombe, nè la sacerdotessa dei Bizantini, bensì la donna ricca di salute e di forze, rischiarata dal sole estivo, madre gloriosa della sua prole, felice tra $\mathrm{i}$ pargoli, nella festa della luce. Mentre questo canto d'uomo poderoso risonava potente sulla laguna veneta, a Parma il canto diverso dell'Allegri, tutto di voci argentine, s’innalzava su per la cupola della cattedrale. La Vergine in dolcissimo abbandono sulle nubi stendeva assorta le braccia; e tutt'intorno volavano angioli occhieggianti fra le nubi stesse, sospingendole per trasportare il fiore della grazia nei cieli. 





$$
\text { - }
$$




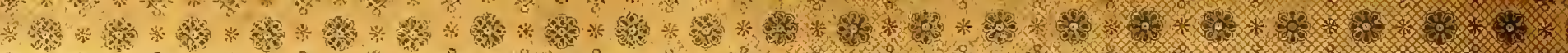

H.

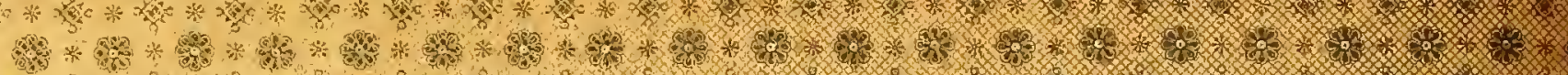

9.

月. $\%$ \%

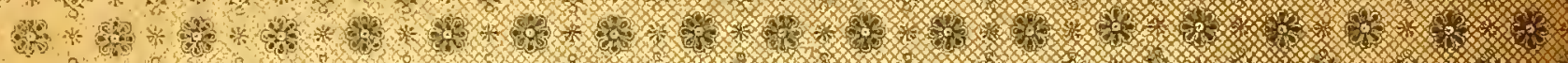

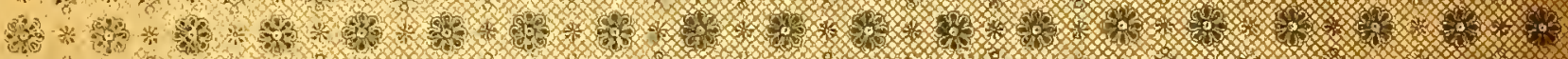

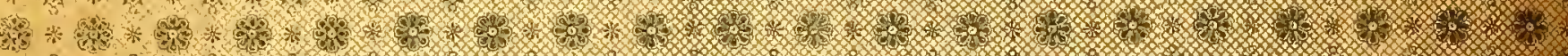

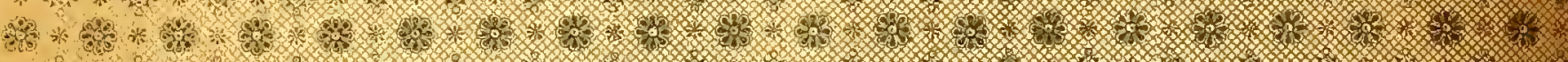

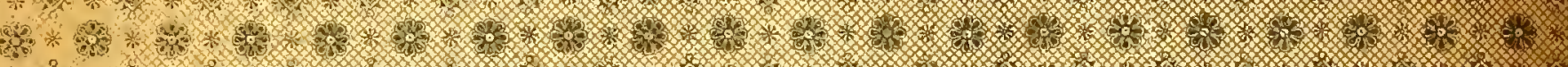

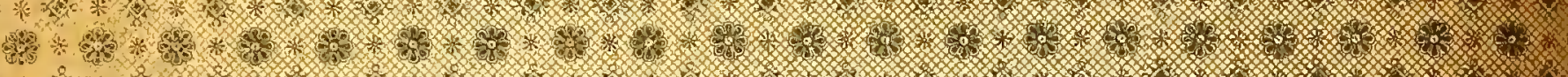

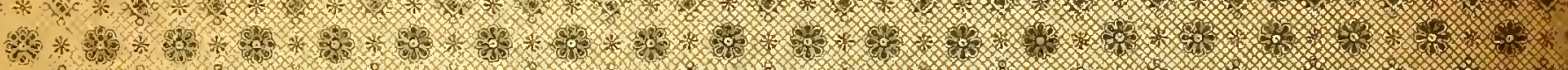

母.

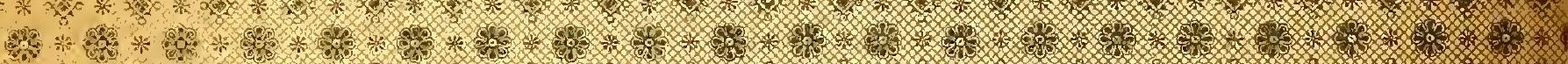

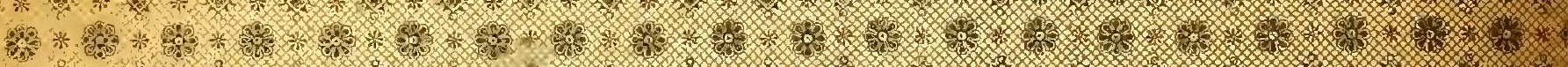

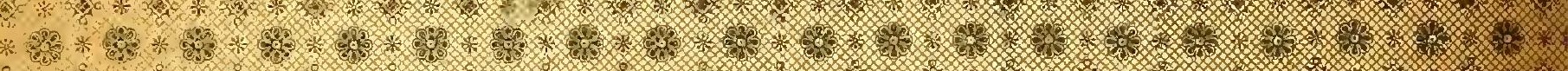

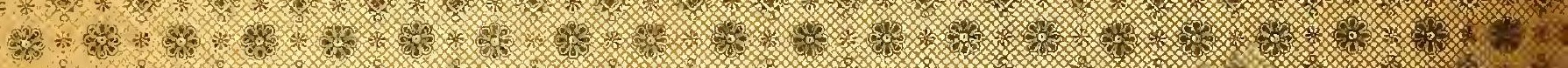

8.

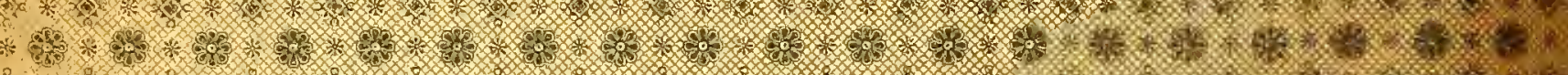

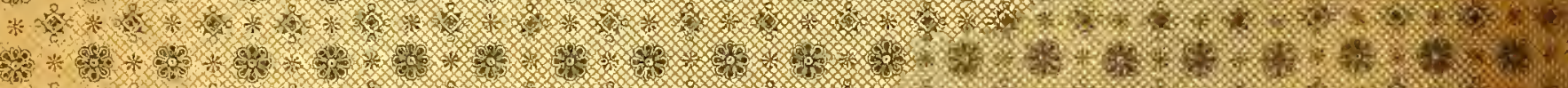

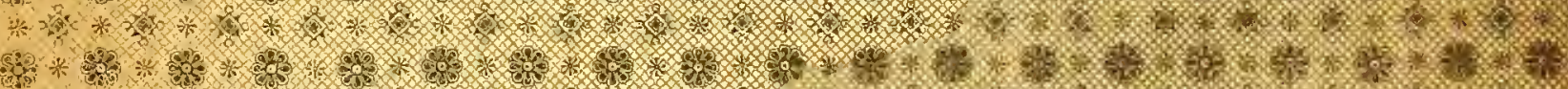

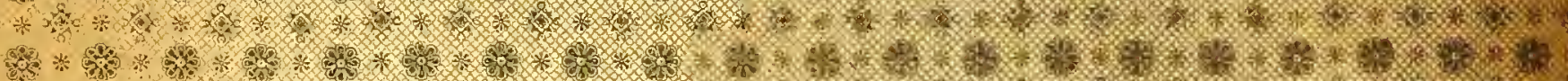

.

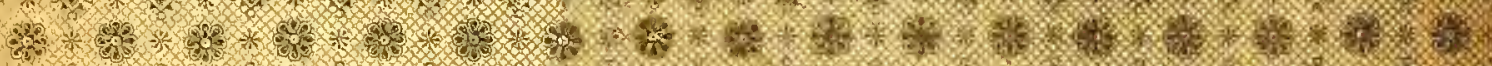

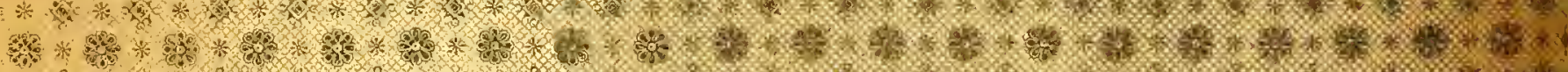

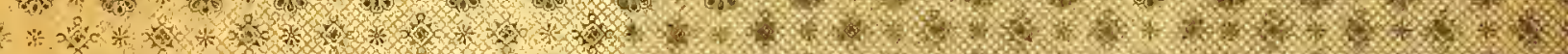

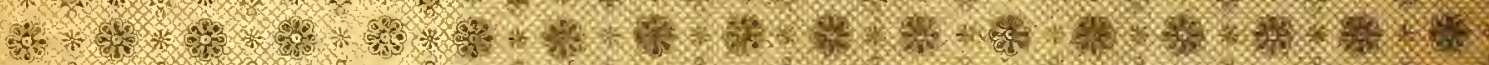

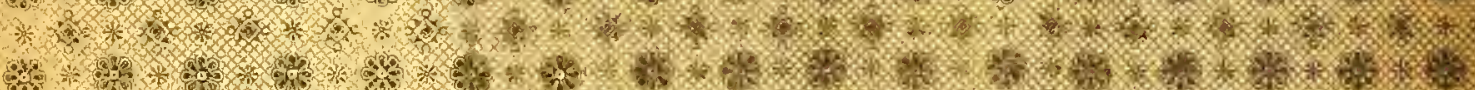

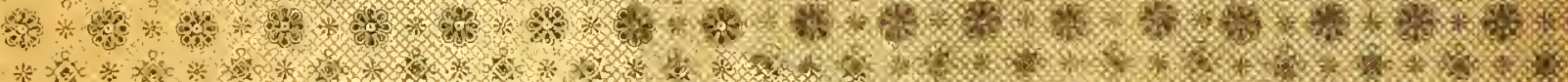

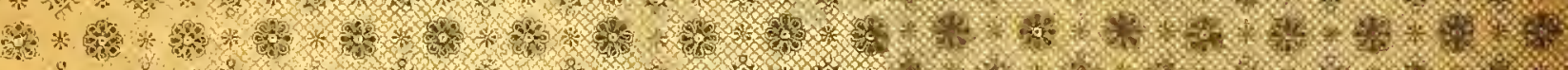

3.

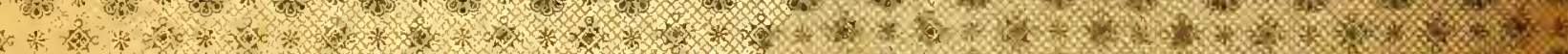

6月

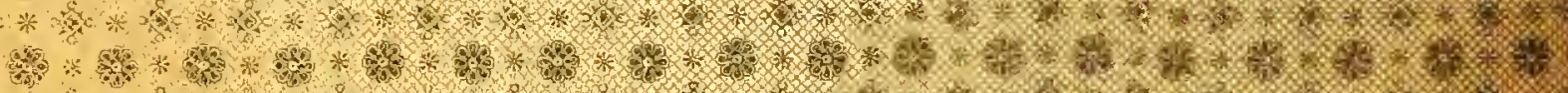

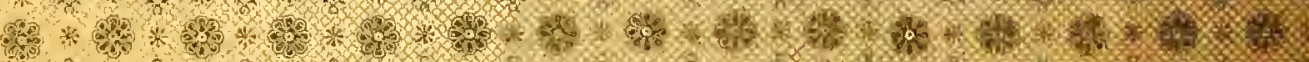

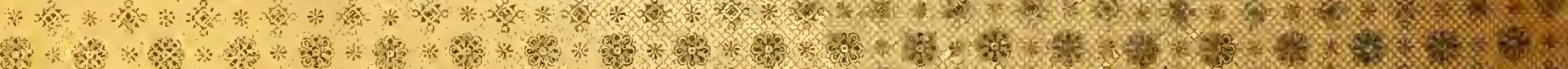



